
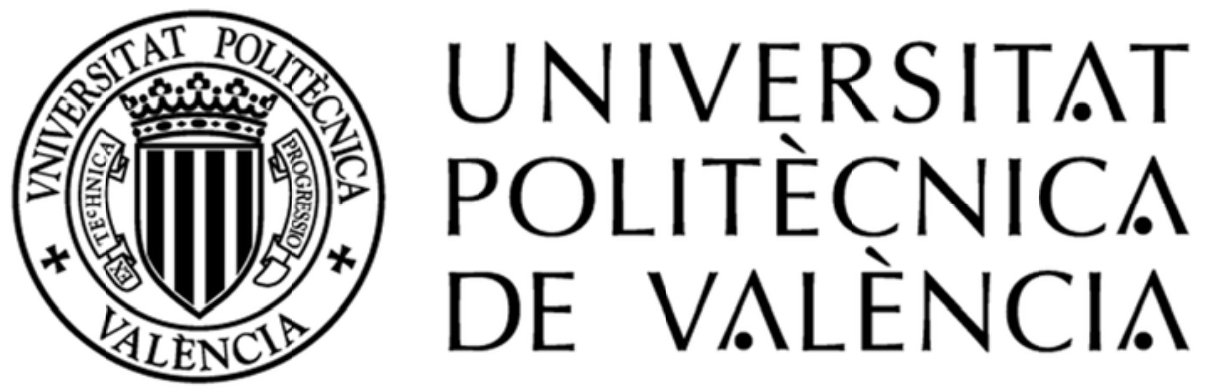

\title{
ESTUDIO EXPERIMENTAL Y NUMÉRICO DE LA CAPACIDAD DE DEFORMACIÓN DE SOPORTES ESBELTOS DE HORMIGÓN ARMADO
}

\section{TESIS DOCTORAL}

Presentada por:

ÁNGELA CELMIRA BARRERA PUERTO

Dirigida por:

Dr. JOSÉ LUIS BONET SENACH

Dr. MANUEL LUIS ROMERO GARCÍA

Valencia, julio de 2012 



\section{Agradecimientos}

En el momento de culminar mi tesis doctoral, siento el sincero deseo de agradecer a las muchas personas que han estado conmigo en los buenos y los no tan buenos momentos. Por ello, me gustaría mostrar mi agradecimiento:

En primer lugar, a mis directores de tesis, los doctores José Luis Bonet Senach y Manuel Luis Romero García, por su dedicada labor de supervisión y apoyo al trabajo llevado a cabo en la presente investigación, y por lo mucho que he aprendido de ellos.

A los profesores del Departamento de Ingeniería de la Construcción y de Proyectos de Ingeniería Civil de la Universidad Politécnica de Valencia, en especial al profesor Pedro Calderón García por su gran apoyo tanto profesional como personal. A los profesores Miguel Ángel Fernández Prada y Pedro Miguel Sosa, que colaboraron estrechamente conmigo en el proyecto de investigación en el cual se enmarca esta tesis. Al profesor Pedro Serna Ros por su asesoramiento en el trabajo de laboratorio. Y también al profesor Joaquín Catalá Alís, cuya gestión hizo posible mi traslado a Valencia para cursar estudios de Doctorado. Hago extensivo mi agradecimiento a todos los profesores del departamento, por su siempre amable disposición: Juan José, Amalia, Juan, Nacho, Luis, Carmen, María José, Teresa, Eugenio, Esther, Jordi y Pepe.

A dos instituciones que han resultado cruciales en mi vida académica: a la Generalitat Valenciana, por haberme concedido una beca de formación en investigación, así como al Ministerio de Economía y Competitividad de España, por la financiación del Proyecto de Investigación BIA 2009-10207 (dentro del Plan E), en el cual se ha desarrollado parte del trabajo que ha dado lugar a esta tesis.

A los técnicos del laboratorio, Pascual, Javier, Juan M., Juan F., Lino, Paco y Vicente, porque su colaboración siempre hizo el trabajo más agradable y en el merecido descanso me enseñaron a jugar a los chinos.

A los compañeros de Doctorado con los que inicié este camino y a los compañeros de despacho en el Departamento, Johnson, César (in memóriam), Patricia, David, Cristina, Lorena, Luiz... porque de todos ellos aprendí y con todos compartí momentos e ilusiones académicas.

Al personal de administración del Departamento, que han resultado ser la ayuda perfecta para superar los trámites y papeleos.

A mis amigos y amigas, Marga, Fina, Rafa, Pepe, Sonia, Rodrigo, por haber sabido comprender mis largos momentos de ausencia, y por agotar la pregunta ¿cómo va la tesis? con la mejor de sus intenciones. En verdad han logrado que no todo fuera un trabajo solitario y que la distracción, en el mejor de sus sentidos, apareciera de cuando en cuando en mi vida. 
A quienes me cuidaron en los momentos más difíciles: la familia Doménech, Amalia, Felipe, Isabel, Bárbara, Aris, Fina, David, Lorena y Rafa, que me hicieron comprender que nunca hay que rendirse y que la vida vale la pena. A la familia Rodríguez Ibáñez, por los entrañables momentos que he pasado en su hogar.

A Rafa, que ha sido un soporte tan resistente como el hormigón armado y con quien es una dicha contar.

A mi familia: a mi madre, porque se ha empeñado en darme la mejor educación que ha podido, y se ha sacrificado para que yo pudiera llegar a mi destino; a mi hermana Isabel, Víctor, Lina y David, por la maravillosa alegría que me dan cada día, y porque sin su apoyo esta tesis no habría visto la luz; a mi padre, a mis hermanos Edgar y Luis y a mis sobrinos, porque todos ellos siempre me han apoyado en la distancia; a todo el resto de mi familia, que vive a muchos kilómetros de distancia, pero ha estado en todo momento muy cerca de mí.

A todos y todas, muchas gracias: sin vuestro apoyo, este trabajo, tal y como es, no hubiera sido posible. 


\section{Resumen}

La evaluación de la capacidad de deformación en elementos de hormigón armado es de gran importancia para garantizar un comportamiento estructural adecuado ante la combinación de acciones gravitatorias y laterales. Las actuales normas europeas (Eurocódigo 8, 2004) han adoptado algunos métodos analíticos y empíricos para evaluar la capacidad de deformación en elementos de hormigón armado. Dichos métodos se han desarrollado a partir de una gran base de datos de ensayos experimentales con características geométricas y mecánicas que cubren un amplio rango de parámetros. A pesar de ello, existe todavía una escasa o nula comprobación experimental para determinados tipos de elementos, como los soportes de esbeltez de cortante mayor que 6, y los soportes de hormigón de alta resistencia ( $f_{c}$ mayor que $50 \mathrm{MPa}$ ). Por otra parte, algunos estudios han demostrado que los resultados obtenidos son muy diferentes según se adopten los métodos analíticos o los métodos empíricos propuestos en la misma norma (Eurocódigo 8).

Por ello, en esta tesis doctoral se ha llevado a cabo un estudio de la capacidad de deformación de soportes esbeltos de hormigón convencional y de alta resistencia, con los siguientes propósitos: (1) identificar los parámetros que más influyen en la capacidad de deformación; (2) comprobar si los actuales métodos pueden ser aplicados en soportes esbeltos de hormigón armado, y, en caso de no ser así, (3) proponer métodos generales cuya aplicación sea factible en este tipo de elementos.

Este estudio de la capacidad de deformación de elementos de hormigón se ha realizado en base a una serie de 44 ensayos experimentales de elementos de hormigón armado sujetos a compresión constante y flexión monotónica. Adicionalmente, se ha desarrollado una serie de 250 simulaciones numéricas para elementos bajo las mismas condiciones estructurales y de carga, utilizando el programa de análisis no lineal "ATENA-2D".

A partir de los resultados obtenidos experimental y numéricamente, se ha llevado a cabo un estudio de los parámetros que más influyen en el comportamiento deformacional de elementos de hormigón armado. Finalmente, esto ha permitido desarrollar una propuesta de métodos simplificados para la evaluación de la capacidad de deformación de elementos de hormigón armado, para el estado elástico y último.

Dichos métodos se han desarrollado tanto para la comprobación como para el dimensionamiento de elementos de hormigón armado. Y, a partir de ellos, es posible evaluar de forma muy sencilla las siguientes variables: la rigidez elástica efectiva y última, el desplazamiento elástico efectivo y último, y, por consiguiente, la ductilidad en desplazamientos.

Los métodos propuestos son válidos en elementos con características dentro de los siguientes rangos: axil reducido entre 0.1 y 0.6 , esbeltez de cortante entre 3.5 y 10.5, resistencia del hormigón entre $30 \mathrm{MPa}$ y $90 \mathrm{MPa}$, cuantía de armadura longitudinal entre $1 \%$ y $4 \%$ y cuantía de armadura transversal entre 1 y $4 \%$. 



\section{Resum}

L'avaluació de la capacitat de deformació en elements de formigó armat és de gran importància per a garantir un comportament estructural adequat davant de la combinació d'accions gravitatòries i laterals. Les actuals normes europees (Eurocodi 8,2004 ) han adoptat alguns mètodes analítics i empírics per a avaluar la capacitat de deformació en elements de formigó armat. Aquests mètodes s'han desenvolupat a partir d'una gran base de dades d'assaigs experimentals amb característiques geomètriques i mecàniques que cobreixen un ampli rang de paràmetres. Tot i això, existeix encara una escassa o nul-la comprovació experimental per a determinats tipus d'elements, com ara les columnes d'esveltesa de tallant més gran que 6 , i les columnes de formigó d'alta resistència $\left(f_{c}\right.$ superior $a$ $50 \mathrm{MPa}$ ). D'altra banda, alguns estudis han demostrat que els resultats obtinguts són molt diferents segons s'adopten els mètodes analítics o els mètodes empírics proposats en la mateixa norma (Eurocodi 8).

Per això, en aquesta tesi doctoral s'ha dut a terme un estudi de la capacitat de deformació de columnes esveltes de formigó convencional i d'alta resistència, amb els següents propòsits: (1) identificar els paràmetres que més influeixen en la capacitat de deformació; (2) comprovar si els actuals mètodes poden ser aplicats en columnes esveltes de formigó armat, i, en cas de no ser així, (3) proposar mètodes generals l'aplicació del quals siga factible en aquest tipus d'elements.

Aquest estudi de la capacitat de deformació d'elements de formigó s'ha realitzat en base a una sèrie de 44 assaigs experimentals d'elements de formigó armat subjectes a compressió constant i flexió monotònica. Addicionalment, s'han desenvolupat una sèrie de 250 simulacions numèriques per a elements sota les mateixes condicions estructurals $i$ de càrrega, utilitzant el programa d'anàlisi no lineal "ATENA-2D".

A partir dels resultats obtinguts experimentalment i numèricament, s'ha dut a terme un estudi dels paràmetres que més influeixen en el comportament deformacional d'elements de formigó armat. Finalment, això ha permés desenvolupar una proposta de mètodes simplificats per a l'avaluació de la capacitat de deformació d'elements de formigó armat, per a l'estat elàstic i últim.

Aquests mètodes s'han desenvolupat tant per a la comprovació com per al dimensionament d'elements de formigó armat. I, a partir d'aquests, és possible avaluar de forma molt senzilla les següents variables: la rigidesa elàstica efectiva $i$ última, el desplaçament elàstic efectiu i últim, i, per tant, la ductilitat en desplaçaments.

Els mètodes proposats són vàlids en elements amb característiques dins dels rangs següents: axil reduït entre 0.1 i 0.6 , esveltesa de tallant entre 3.5 i 10.5 , resistència del formigó entre $30 \mathrm{MPa}$ i $90 \mathrm{MPa}$, quantia d'armadura longitudinal entre 1\% i 4\% i quantia d'armadura transversal entre $1 \%$ i $4 \%$. 



\section{Summary}

The assessment of deformation capacity in reinforced concrete members is very important to ensure an adequate structural behaviour when subject to a combination of gravitational and lateral loads. Current European regulations (Eurocode 8, 2004) have adopted certain analytical and empirical methods in order to assess the deformation capacity of reinforced concrete members. These methods have been developed on the basis of a large database of experimental tests with geometric and mechanical characteristics that cover a wide range of parameters. Nevertheless, there is still scarcity or lack of experimental testing for certain types of members, such as columns with a shear slenderness higher than 6, and High Strength Concrete columns $\left(f_{c}\right.$ higher than $\left.50 \mathrm{MPa}\right)$. On the other hand, some studies have shown that the results obtained vary to a great extent depending on whether the analytical methods or the empirical methods proposed in the same code (Eurocode 8) are adopted.

Therefore, in this thesis a study on the deformation capacity of Normal Strength and High Strength Concrete slender columns has been carried out with the following purposes: (1) identifying the parameters with the strongest influence on deformation capacity; (2) checking whether the current methods can be applied to slender reinforced concrete columns, and, in case they cannot, (3) proposing general methods whose application to this type of members is feasible.

This study on the deformation capacity of concrete members has been carried out based on an experimental series of 44 tests on reinforced concrete members subject to constant axial load and monotonic bending. Additionally, a series of 250 numerical simulations has been developed, under the same structural and load conditions, by using the non-linear analysis program "ATENA-2D".

Building on the results obtained experimentally and numerically, a study of the parameters that have the strongest influence on the deformational behaviour of reinforced concrete members has been carried out. Finally, this has made it possible to develop a proposal of simplified methods for the assessment of the deformation capacity of reinforced concrete members, for the elastic and ultimate state.

These methods have been developed both for the verifying and for the cross-section design of reinforced concrete members. Based on the methods, it is posible to assess in a very straightforward manner the following variables: effective elastic and ultímate stiffness, effective elastic and ultimate displacement, and, consequently, the displacement ductility factor.

The proposed methods are valid in members having characteristics within the following ranges: axial load between 0.1 and 0.6 , shear slenderness between 3.5 and 10.5, concrete strength between $30 \mathrm{MPa}$ and $90 \mathrm{MPa}$, longitudinal reinforcement ratio between $1 \%$ and $4 \%$ and confinement volumetric geometric reinforcement ratio between $1 \%$ and $4 \%$. 



\section{ÍNDICE}

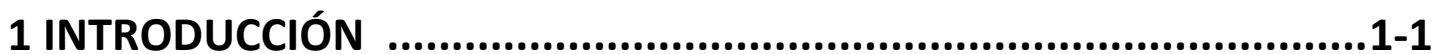

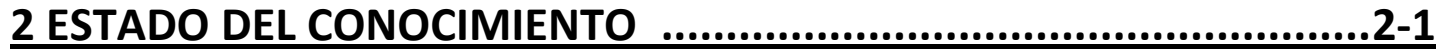

2.1 FUNDAMENTOS TEÓRICOS DE LA CAPACIDAD DE DEFORMACIÓN .................... 2-2

2.1.1 ÍNDICES DE DEFORMABILIDAD A NIVEL DEL ELEMENTO .................................. 2-3

2.1.2 ÍNDICES DE DEFORMABILIDAD A NIVEL DE LA SECCIÓN ................................... 2-3

2.1.3 ÍNDICES DE DEFORMABILIDAD DE LA RÓTULA PLÁSTICA ................................. 2-4

2.1.4 INTERACCIÓN ENTRE LOS DIFERENTES FACTORES DE DUCTILIDAD ..................2-4

2.2 MÉTODOS TEÓRICOS QUE EVALÚAN LA CAPACIDAD DE DEFORMACIÓN EN

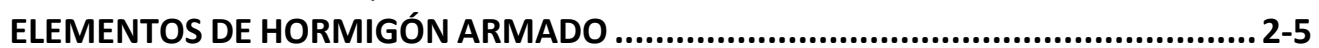

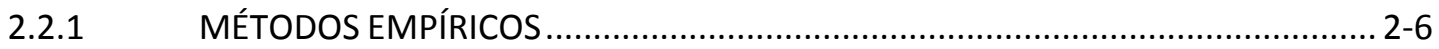

2.2.1.1 Método empírico propuesto por Panagiotakos y Fardis (2001) ................2-6

2.2.1.2 Método empírico propuesto por Lam, Wu, Wong, Wang, Li (2003) ....... 2-10

2.2.2 MÉTODOS ANALÍTICOS SIMPLIFICADOS.................................................... 2-11

2.2.2.1 Método análitico de Priestley y Park (1996) ......................................... 2-12

2.2.2.2 Método de Lehman y Moehle (1998) .............................................. 2-15

2.2.2.3 Método analítico de Fardis et al. (2001) ............................................... 2-16

2.2.3 LONGITUD DE RÓTULA PLÁSTICA ........................................................... 2-20

2.2.3.1 Expresiones de $L_{p}$ obtenidas a partir de la integración de la curvatura inelástica .............................................................................................. 2-21

2.2.3.2 Expresiones de $L_{p}$ obtenidas a partir del análisis del soporte en

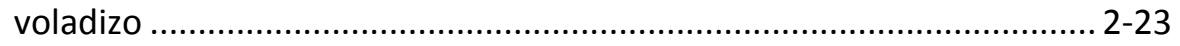

2.2.4 MÉTODOS ANALÍTICOS MÁS COMPLEJOS ….......................................... 2-26

2.2.4.1 Método para elementos en flexión sin carga axial ................................ 2-26

2.2.4.2 Método para elementos en flexión con carga axial ............................... 2-29

2.3 ANTECEDENTES DE LA INVESTIGACIÓN EXPERIMENTAL................................ 2-34

2.3.1 CARACTERÍSTICAS DE LA BASE DE DATOS DE FARDIS ET AL. (2001).................. 2-34

2.3.2 DESCRIPCIÓN DE LA BASE DE DATOS DE ESTE ESTUDIO …............................ 2-35

2.3.2.1 Descripción de los modelos de ensayo que componen la base de

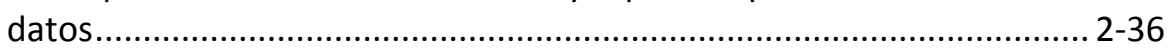

2.3.2.2 Análisis de las características de los ensayos que componen la base

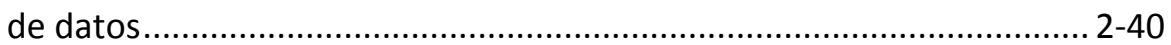

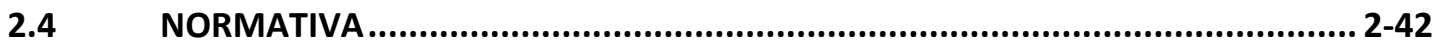

2.4.1 MÉTODOS PROPUESTOS PARA EVALUAR O PREDECIR LA CAPACIDAD DE

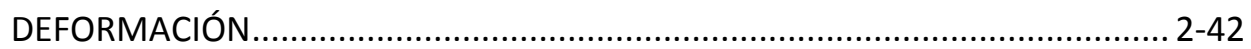

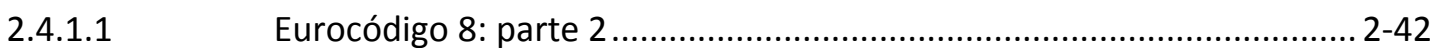

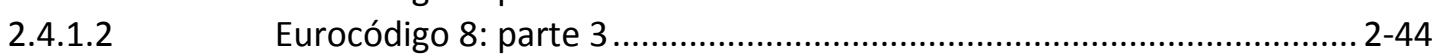


3.2 ANÁLISIS DEL ESTADO ACTUAL DEL CONOCIMIENTO ....................................... 3-2

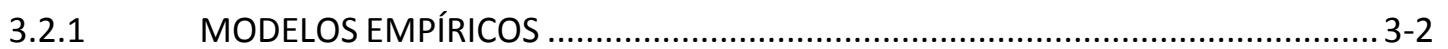

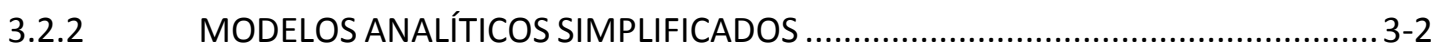

3.2.3 MÉTODOS ANALÍTICOS MÁS COMPLEJOS ..................................................... 3-5

3.2.4 ESTUDIOS EXPERIMENTALES ......................................................................

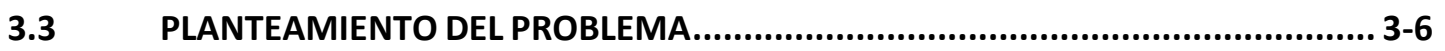

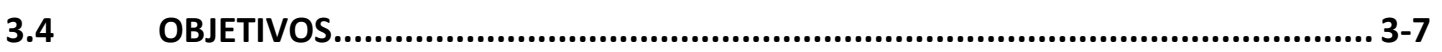

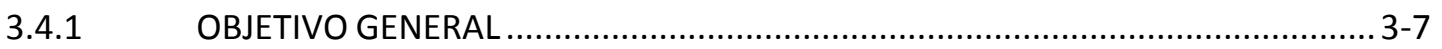

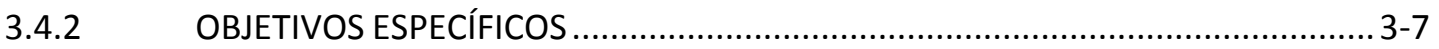

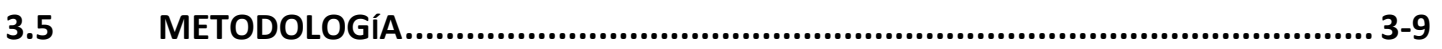

\section{MODELO DE ENSAYO Y DESARROLLO DEL PROGRAMA}

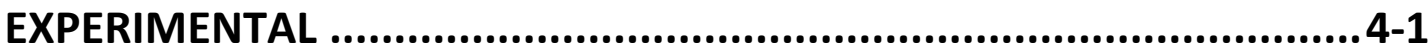

4.1 OBJETIVO DEL PROGRAMA EXPERIMENTAL ................................................ 4-2

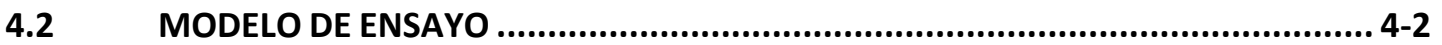

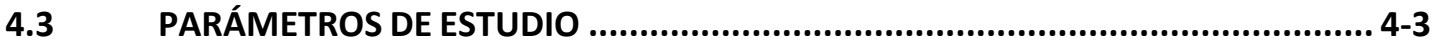

4.4 DESCRIPCIÓN GEOMÉTRICA DEL SOPORTE ................................................. 4-4

4.5 CARACTERÍSTICAS DE LOS SOPORTES ENSAYADOS ..................................... 4-6

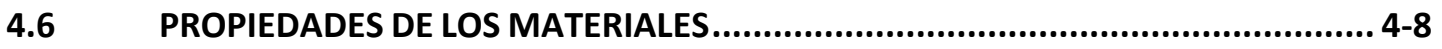

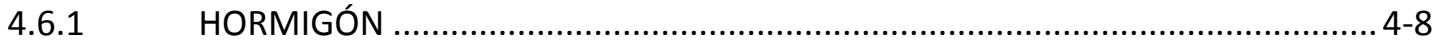

4.6.1.1 Materiales utilizados en la fabricación del hormigón ................................ 4-9

4.6.1.2 Resultados de los ensayos de compresión simple ................................... 4-9

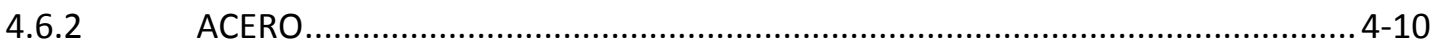

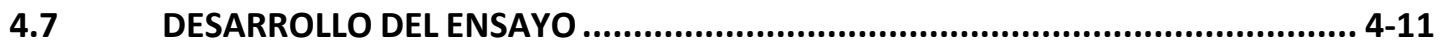

4.7.1 DESCRIPCIÓN DEL PÓRTICO DE CARGA …............................................ 4-11

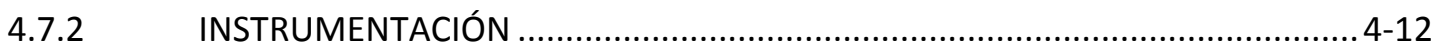

4.7.2.1 Deformación dentro de la zona de rótula plástica .................................. 4-12

4.7.2.2 Deformada del soporte .............................................................. 4-13

4.7.2.3 Carga de flexión y carga axial ...................................................................... 4-14

4.7.2.4 Control en la ejecución del ensayo ....................................................... 4-15

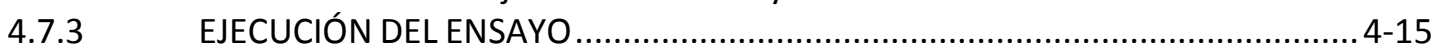


5 RESULTADOS DIRECTOS Y OBSERVACIONES EXPERIMENTALES .....5-1

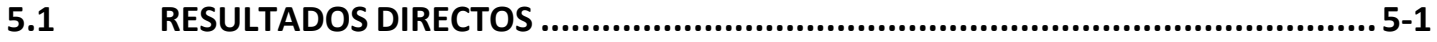

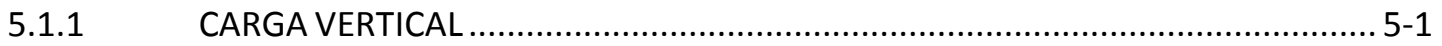

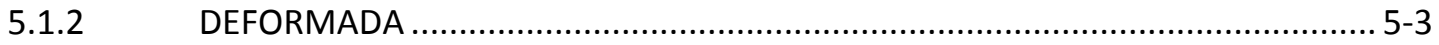

5.1.3 DEFORMACIÓN DE LA ARMADURA EN COMPRESIÓN Y TRACCIÓN.................... 5-3

5.2 EFECTOS OBSERVADOS DURANTE EL ENSAYO

5.2.1 DEFORMACIONES DE LA ARMADURA EN LA RÓTULA PUNTO …..................... 5-5

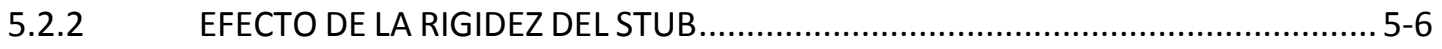

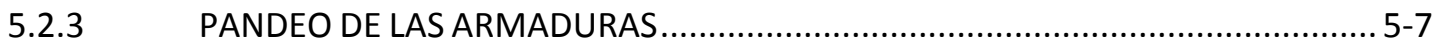

$5.3 \quad$ NIVELES DE DAÑO Y APARIENCIA FINAL DE LOS SOPORTES …........................ 5-7

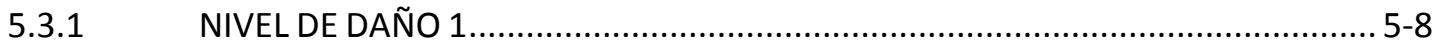

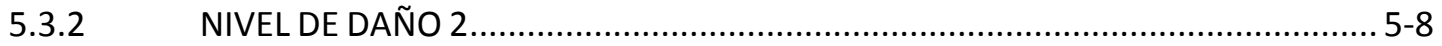

5.3.3 NIVEL DE DAÑO 3

5.3.4 NIVEL DE DAÑO 4

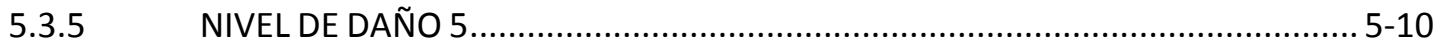

5.4 RESUMEN GENERAL DEL PROCESO DE DEFORMACIÓN DE LOS MATERIALES, DE LOS EFECTOS Y ESTADOS DE DAÑO .................................................... 5-10

6 ANÁLISIS DE LOS RESULTADOS EXPERIMENTALES _...................6-1

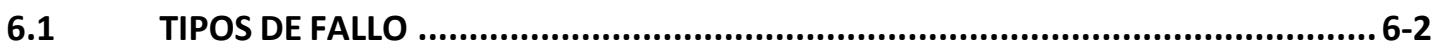

6.1.1 MÉTODO APLICADO EN LA IDENTIFICACIÓN DEL MODO DE FALLO DE LOS

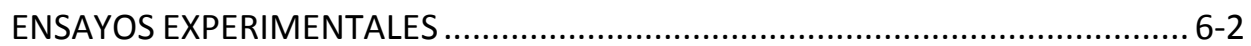

6.1.2 RESULTADOS EXPERIMENTALES DE TIPO DE FALLO ...................................... 6-4

6.1.2.1 Agotamiento por tracción ....................................................................... 6-4

6.1.2.2 Agotamiento por compresión .............................................................. 6-4

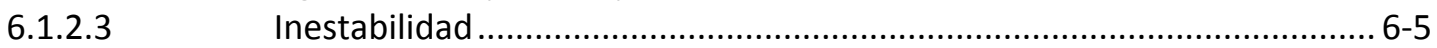

6.2 COMPARACIÓN DEL MOMENTO MÁXIMO EXPERIMENTAL Y TEÓRICO............... 6-9

6.2.1 DESCRIPCIÓN DE LOS MÉTODOS IMPLEMENTADOS PARA EL CÁLCULO DEL

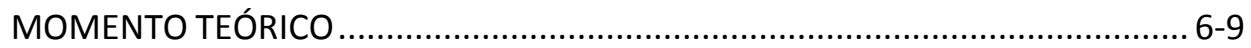

6.2.2 RESULTADOS DEL MOMENTO MÁXIMO EXPERIMENTAL Y TEÓRICO ............... 6-11

6.2.3 COMPARACIÓN ENTRE EL MOMENTO MÁXIMO EXPERIMENTAL Y EL TEÓRICO RESPECTO A LOS PARÁMETROS ANALIZADOS................................ 6-14

6.3 COMPARACIÓN DE LA CARGA MÁXIMA EXPERIMENTAL Y TEÓRICA ................ 6-15

6.3.1 DESCRIPCIÓN DE LOS MÉTODOS IMPLEMENTADOS PARA EL CÁLCULO DE LA CARGA MÁXIMA TEÓRICA ........................................................................... 6-15

6.3.2 RESULTADOS DE LA CARGA MÁXIMA EXPERIMENTAL Y TEÓRICA....................6-16

6.3.3 COMPARACIÓN ENTRE LA CARGA MÁXIMA EXPERIMENTAL Y TEÓRICA RESPECTO A LOS PARÁMETROS ANALIZADOS............................................. 6-19

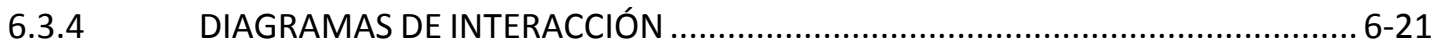




\begin{tabular}{|c|c|}
\hline \multirow[t]{2}{*}{6.4} & DEALIZACIÓN DE LOS DIAGRAMAS CARGA FLECHA Y MOMENTO \\
\hline & URVATURA \\
\hline .4 .1 & ADO ................ 6-23 \\
\hline & \\
\hline 4 & ..................6-24 \\
\hline .4.1.3 & o aproximad \\
\hline 4.2 & VTO DE FALLO O ESTADO ÚLTIMO.... \\
\hline
\end{tabular}

\subsection{APLICACIÓN DE LOS MÉTODOS DE IDEALIZACIÓN A LOS RESULTADOS

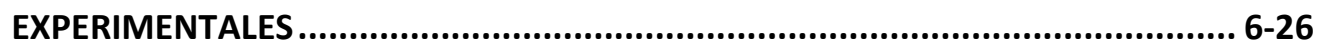 \\ 6.5.1 DEFORMACIONES DEL HORMIGÓN Y DEL ACERO EN EL PUNTO DE}

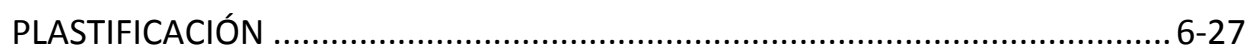

6.5.1.1 Comparación de las deformaciones en los puntos de plastificación .......6-27

6.5.2 RESULTADOS DE LA IDEALIZACIÓN DEL DIAGRAMA MOMENTO-CURVATURA

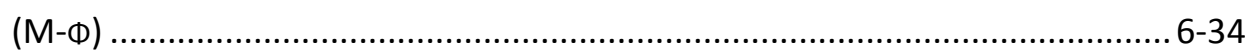

6.5.2.1 Influencia de la esbeltez de cortante ................................................ 6-34

6.5.2.2 Influencia del nivel de carga axil ...................................................6-36

6.5.2.3 Influencia de la cuantía de armadura longitudinal .................................6-38

6.5.2.4 Influencia de la cuantía de armadura transversal...................................6-41

6.5.3 RESULTADOS DE LA IDEALIZACIÓN A NIVEL DEL ELEMENTO (P- $\Delta$ ) ...................6-44

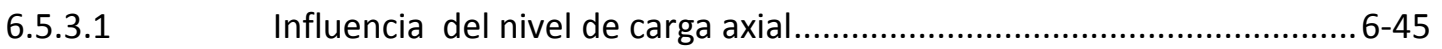

6.5.3.2 Influencia de la esbeltez de cortante ..................................................6-47

6.5.3.3 Influencia de la cuantía de armadura longitudinal ................................ 6-48

6.5.3.4 Influencia de la cuantía de armadura transversal................................. 6-51

6.6 LONGITUD DE RÓTULA PLÁSTICA ............................................................. 6-55

6.6.1 CÁLCULO DEL DESPLAZAMIENTO ELÁSTICO TEÓRICO TENIENDO EN CUENTA

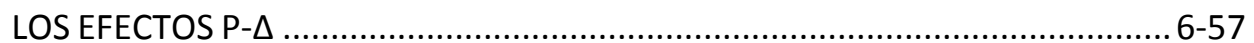

6.6.2 LONGITUD DE RÓTULA PLÁSTICA EQUIVALENTE........................................6-59

6.6.3 COMPARACIÓN ENTRE LA LONGITUD DE RÓTULA PLÁSTICA EXPERIMENTAL Y LA CALCULADA MEDIANTE EXPRESIONES EMPÍRICAS ................................ 6-63

6.6.4 COMPARACIÓN ENTRE LAS LONGITUDES DE ROTÚLA EXPERIMENTALES Y LAS OBTENIDAS EN OTROS ESTUDIOS ................................................................ 6-69

6.7 COMPARACIÓN DE LOS RESULTADOS EXPERIMENTALES CON LA

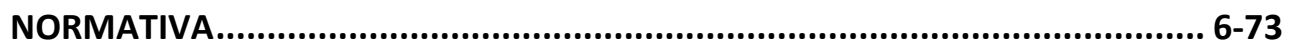

6.7.1 ANÁLISIS DE LOS FACTORES DE DUCTILIDAD EXPERIMENTAL RESPECTO A LA

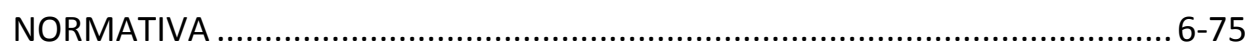

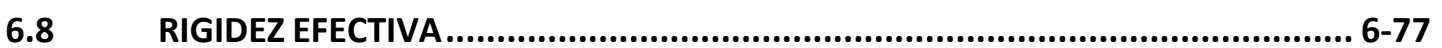

7 CALIBRACIÓN DE UN MODELO NUMÉRICO PARA SIMULAR EL COMPORTAMIENTO DE SOPORTES DE HORMIGÓN ARMADO ...........7-1

7.1 DESCRIPCIÓN DEL PROGRAMA ATENA …........................................................ 7-2

7.1.1 EL MODELO CONSTITUTIVO BASADO EN UNA APROXIMACIÓN DE FISURACIÓN DISTRIBUIDA ("SMEARED CRACK MODEL") 


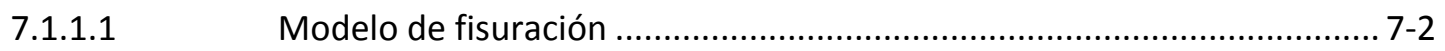

7.1.1.2 Curva tensión-deformación equivalente ................................................ 7-3

7.1.1.3 Parámetros del modelo del hormigón ........................................................ 7-5

7.1.2 CURVA TENSIÓN-DEFORMACIÓN DEL ACERO PARA LA ARMADURA ................. 7-6

7.2 DESCRIPCIÓN DEL MODELO NUMÉRICO _........................................................

7.2.1 RESULTADOS OBTENIDOS DEL MODELO ................................................ 7-7

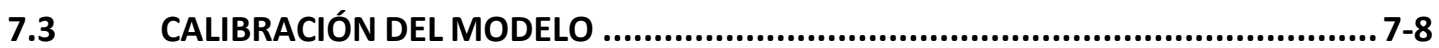

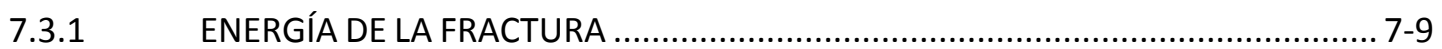

7.3.2 RAMA DE REBLANDECIMIENTO PARA EL HORMIGÓN EN COMPRESIÓN .........7-10

7.3.3 MODELO DE CONFINAMIENTO ................................................................. 7-11

7.3.4 INCORPORACIÓN DEL MODELO DE ADHERENCIA ...................................... 7-12

7.4 COMPARACIÓN ENTRE LOS RESULTADOS NUMÉRICOS Y EXPERIMENTALES... 7-13

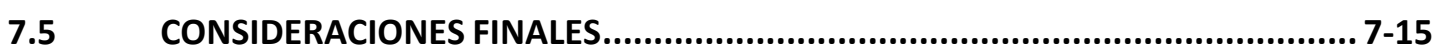

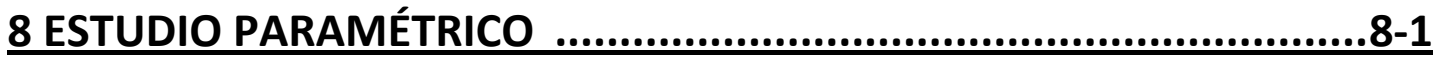

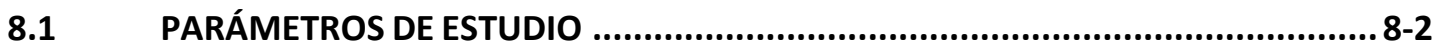

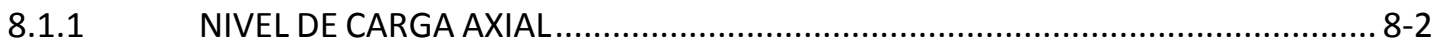

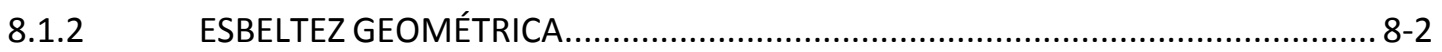

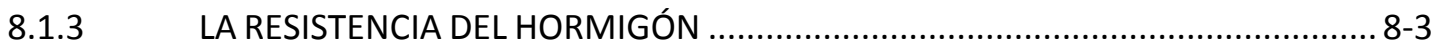

8.1.4 CUANTÍA DE ARMADURA LONGITUDINAL.......................................................

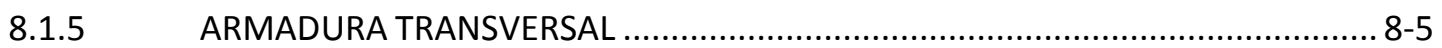

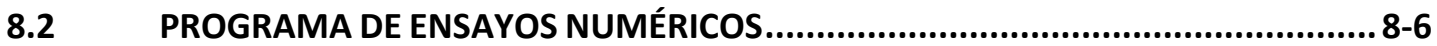

8.3 ANÁLISIS PARAMÉTRICO

8.3.1 DESPLAZAMIENTO ELÁSTICO EFECTIVO ................................................ 8-10

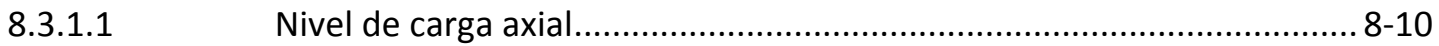

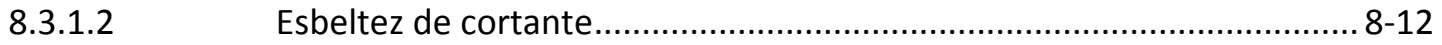

8.3.1.3 Cuantía de armadura longitudinal .................................................. 8-14

8.3.1.4 Cuantía de armadura transversal ..................................................... 8-16

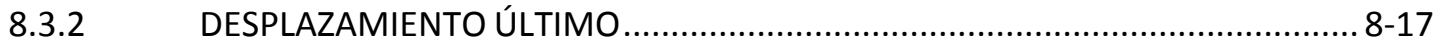

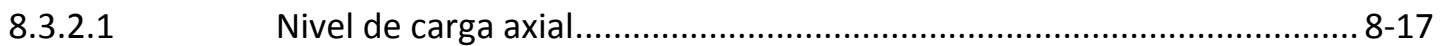

8.3.2.2 Esbeltez de cortante....................................................................... 8-18

8.3.2.3 Cuantía de armadura longitudinal ................................................... 8-20

8.3.2.4 Cuantía de armadura transversal....................................................... 8-23

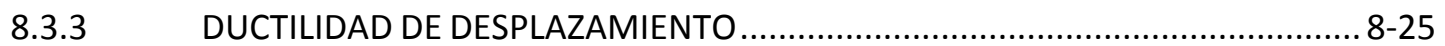

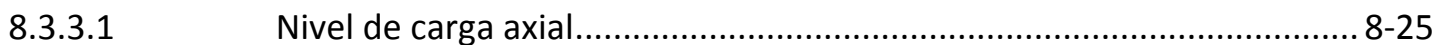

8.3.3.2 Esbeltez de cortante........................................................... 8-27

8.3.3.3 Cuantía de armadura longitudinal .................................................... 8-30

8.3.3.4 Cuantía de armadura transversal......................................................... 8-32

8.4 RESUMEN GENERAL DEL ESTUDIO PARAMÉTRICO ...................................... 8-33 


\section{EVALUACIÓN DE LA CAPACIDAD DE DEFORMACIÓN MEDIANTE} MÉTODOS EXISTENTES ..............................................................9-1
9.1 COMPARACIÓN ENTRE LOS MÉTODOS EXISTENTES Y LOS RESULTADOS
EXPERIMENTALES, PARA LA CAPACIDAD DE DEFORMACIÓN ............................9-2
9.1.1 MÉTODO ANALÍTICO DE PANAGIOTAKOS Y FARDIS .......................................... 9-2
9.1.1.1 Descripción del método .........................................................................9-2
9.1.1.2 Comparación entre resultados experimentales y teóricos obtenidos mediante el método analítico de Panagiotakos y Fardis ...........................9-9
9.1.2 MÉTODO ANALÍTICO DEL EUROCÓDIGO 8 ...................................................... 9-12
9.1.2.1 Descripción del método ................................................................... 9-12
9.1.2.2 Comparación entre resultados experimentales y teóricos obtenidos mediante el método analítico del Eurocódigo 8 .................................... 9-14
9.1.3 MÉTODOS EMPÍRICOS ........................................................................... 9-17
9.1.4 CONSIDERACIONES DE LA COMPARACIÓN ENTRE LOS MÉTODOS TEÓRICOS Y LOS RESULTADOS EXPERIMENTALES ……………….................................9-20

9.2 COMPARACIÓN DE LOS MÉTODOS TEÓRICOS Y LOS RESULTADOS DE LA SIMULACIÓN NUMÉRICA, PARA LA CAPACIDAD DE DEFORMACIÓN................... 9-21

9.2.1.1 Comparación de los métodos respecto a la esbeltez de cortante ...........9-23

9.2.1.2 Comparación de los métodos respecto al nivel de carga axial ................9-24

9.2.1.3 Comparación de los métodos respecto a la resistencia del hormigón ...9-27

9.2.1.4 Comparación de los métodos respecto a la cuantía de armadura longitudinal...................................................................................... 9-29

9.2.1.5 Comparación de los métodos respecto a la cuantía de armadura

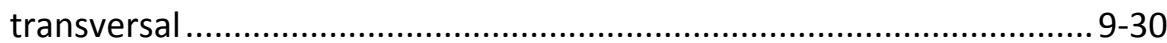

9.2.2 CONSIDERACIONES DE LA COMPARACIÓN ENTRE LOS MÉTODOSTEÓRICOS Y LOS RESULTADOS NUMÉRICOS .............................................................. 9-32

10 PROPUESTA DE MÉTODO SIMPLIFICADO .............................10-1

10.1 EVALUACIÓN DE LA RIGIDEZ ELÁSTICA EFECTIVA DE SOPORTES DE

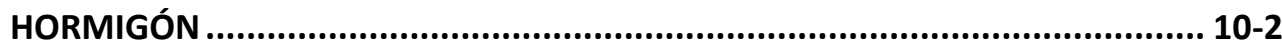

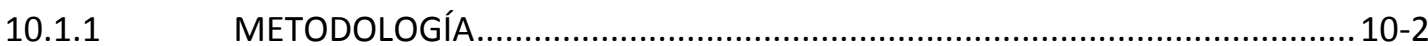

10.1.2 FACTOR DE RIGIDEZ ELÁSTICO EFECTIVO DE DISEÑO $\alpha_{e}^{*} \ldots \ldots \ldots \ldots \ldots \ldots \ldots \ldots . . . . . . . . . . .10-3$

10.1.3 FACTOR DE RIGIDEZ ELÁSTICO EFECTIVO DE COMPROBACIÓN $\alpha_{e} \ldots \ldots \ldots \ldots . . . .10-6$

10.2 EVALUACIÓN DE LA RIGIDEZ ÚLTIMA DE SOPORTES DE HORMIGÓN ............... 10-8

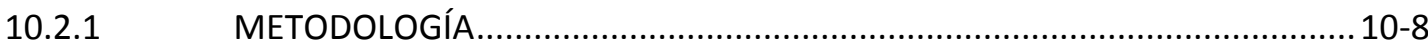

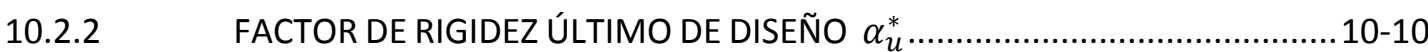

10.2.3 FACTOR DE RIGIDEZ ÚLTIMO DE COMPROBACIÓN $\boldsymbol{\alpha}_{\boldsymbol{u}} \ldots \ldots \ldots \ldots \ldots \ldots \ldots \ldots . . . . . . . . . .10-11$

10.2.4 VARIABLES QUE PUEDEN SER EVALUADAS MEDIANTE LOS METODOS SIMPLIFICADOS PROPUESTOS ............................................................. 10-13

$10.3 \quad$ EVALUACIÓN DEL ERROR .............................................................................. 10-14

10.3.1 COMPARACIÓN DE LOS MODELOS PROPUESTOS CON LOS RESULTADOS OBTENIDOS EN LA SIMULACIÓN NUMÉRICA .........................................10-14 
10.3.2 COMPROBACIÓN DE LOS MÉTODOS PROPUESTOS Y LOS RESULTADOS EXPERIMENTALES.

10.4 COMPARACIÓN ENTRE LOS MÉTODOS PROPUESTOS Y LOS MÉTODOS EXISTENTES.

11.1 CONCLUSIONES 11-1

11.2 FUTURAS LÍNEAS DE INVESTIGACIÓN $11-9$

REFERENCIAS BIBLIOGRÁFICAS R-1

\section{ANEJOS}

ANEJO A: RESUMEN DE LOS ESTUDIOS EXPERIMENTALES INCLUIDOS EN LA BASE DE DATOS

ANEJO B: RESULTADOS DE LA RESISTENCIA DEL HORMIGÓN EN COMPRESIÓN EN PROBETAS CILÍNDRICAS

ANEJO C: DESCRIPCIÓN DEL PÓRTICO DE CARGA Y PROCESO CONSTRUCTIVO DE SOPORTES

ANEJO D: FOTOS DEL ESTADO DE DAÑO AL FINALIZAR EL ENSAYO. D1

ANEJO E: RESULTADOS DIRECTOS DE LOS ENSAYOS EXPERIMENTALES.....................E1

ANEJO F: IDENTIFICACIÓN DEL TIPO DE FALLO. F1

ANEJO G: DEFORMACIONES DEL ACERO Y DEL HORMIGÓN EN EL PUNTO DE PLASTIFICACIÓN APLICANDO DIFERENTES MÉTODOS.

ANEJO H: IDEALIZACIÓN DE LOS DIAGRAMAS MOMENTO CURVATURA EXPERIMENTAL. 
ANEJO J: RESULTADOS DE LA IDEALIZACIÓN MOMENTO-CURVATURA Y

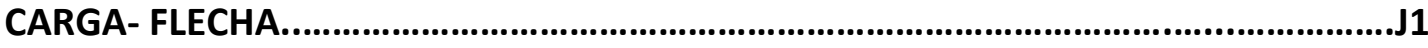

ANEJO K: DESPLAZAMIENTOS ELÁSTICO TEÓRICOS Y LONGITUDES DE

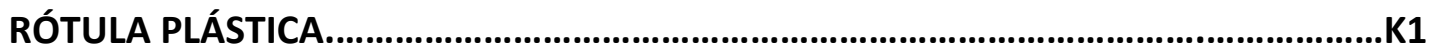

ANEJO L: COMPARACIÓN DE LOS RESULTADOS CARGA-DESPLAZAMIENTO EXPERIMENTALES Y NUMÉRICOS.

ANEJO M: RESPUESTA CARGA FLECHA E IDEALIZACIÓN DE LOS ENSAYOS NUMÉRICOS. M1

ANEJO N: LISTADO DE LAS CARACTERÍSTICAS DE LOS ENSAYOS NUMÉRICO........N1 


\section{CAPÍTULO 1}

\section{INTRODUCCIÓN}

La deformación de elementos de hormigón armado es de gran importancia para determinar el comportamiento de estructuras de hormigón, sujetas a la combinación de acciones gravitatorias y laterales. La capacidad de deformación en elementos de hormigón armado ha despertado un gran interés en los últimos años debido a que aparecen novedosos procesos y métodos para la evaluación sísmica de estructuras, nuevas y existentes, que requieren la verificación de la capacidad de deformación (Eurocódigo 8 (2004) [59], NEHRP ${ }^{1}$, informes FEMA ${ }^{2} 273$ [98]). Adicionalmente, en las normas aplicadas al diseño de nuevas estructuras (Eurocódigo 8 (2004) [59]), se establecen las bases para el análisis no lineal ("Analysis Pushover") aplicado al cálculo de estructuras, lo que implica la comprobación de las deformaciones del elemento.

\footnotetext{
${ }^{1}$ NEHRP (National Earthquake Hazards Reduction Program, Guidelines for the Seismic Rehabilitation of Buildings)

${ }^{2}$ FEMA (Federal Emergency Management Agency)
} 
Estos antecedentes han motivado el desarrollo de importantes investigaciones con el objetivo de proponer métodos capaces de predecir la capacidad de deformación de elementos de hormigón armado, tanto en nuevas estructuras como en las ya existentes. Por consiguiente, aparecen en la bibliografía diferentes tipos de métodos con diversos grados de complejidad en su aplicación y en su concepción. Los más comunes son los métodos simplificados y los analíticos basados en el análisis de la sección y en la evaluación de la longitud de rótula plástica de forma empírica.

Algunos de los métodos empíricos y analíticos se han introducido en las actuales normas europeas (Eurocódigo 8 (2004) [59]); sin embargo, se ha demostrado que existen diferencias significativas en los resultados obtenidos mediante la aplicación de estos dos tipos de métodos (Inel M. et al. (2007) [67], Ceroni (2003) [37]), dejando en entredicho la fiabilidad de dichos métodos.

Los métodos propuestos en el Eurocódigo 8 para evaluar la capacidad de deformación se han desarrollado a partir de una base de datos de ensayos experimentales en elementos de hormigón armado sometidos a compresión y flexión monotónica y cíclica. La primera referencia de la base de datos (Panagiotakos y Fardis (2001) [100]) incluía más de 1100 ensayos; más tarde, aparecen otras publicaciones (CEB-FIB Bulletin 25 (2003) [35] y Fardis y Biskinis (2003) [60]) que llegan a reunir más de 1700 ensayos.

Aunque la base de datos conformada es extensa, en ella se muestra que, para determinados rangos de parámetros, la evidencia experimental es muy baja o nula, como por ejemplo para elementos con esbeltez de cortante $\left(\lambda=L_{s} / h\right)^{3}$ mayor que 6.0. En consecuencia, resulta destacable el hecho de que ninguno de los métodos propuestos en la normativa hasta la fecha ha considerado la influencia de los efectos de segundo orden en la capacidad de deformación. Sin embargo, cada vez es más frecuente el uso del hormigón de alta resistencia en soportes para obtener una reducción de la sección transversal, manteniendo la misma longitud y carga axial, lo que implica un aumento de la esbeltez $y$, por consiguiente, un incremento de los efectos de segundo orden. Además, teniendo en cuenta que el comportamiento de los elementos de hormigón de alta resistencia es más frágil que en elementos de hormigón convencional, se debería revisar y comprobar experimentalmente si los actuales modelos pueden ser válidos para determinado tipo de elementos, como son los soportes esbeltos de hormigón armado. En caso de no ser así, sería necesario desarrollar métodos generales cuya aplicación sea factible en este tipo de elementos.

En este contexto, el presente estudio tiene el objetivo de evaluar la capacidad de deformación de soportes esbeltos de hormigón armado, prestando especial atención a los efectos de segundo orden. Para ello se ha planteado llevar a cabo un programa experimental de ensayos en soportes esbeltos sometidos a compresión y flexión monotónica, el cual, además de ser una metodología de comprobación real de la capacidad de deformación, se ha usado en el desarrollo y la calibración de una herramienta de simulación numérica para el comportamiento de soportes de hormigón, de tal manera que el estudio es extensivo a una amplio rango de parámetros que afectan al comportamiento estructural de los soportes. Este estudio

\footnotetext{
${ }^{3}\left(\lambda=L_{s} / h\right.$, siendo $L_{s}$ la distancia del elemento entre el momento máximo y el momento nulo, y $h$ el canto de la sección)
} 
ha permitido analizar y valorar los parámetros que más influyen en la capacidad resistente y de deformación, como son: el nivel de carga axial, la esbeltez de cortante, la resistencia del hormigón y las cuantías de armadura longitudinal y transversal. De este modo, es posible, por un lado, comprobar los métodos existentes para evaluar la capacidad de deformación en este tipo de elementos, y, por otra parte, proponer nuevos métodos simplificados para evaluar la capacidad de deformación en el estado elástico y último. Los métodos propuestos permiten evaluar las variables de rigidez elástica efectiva, desplazamiento elástico efectivo, rigidez última, desplazamiento último y ductilidad en desplazamientos, en función de las características geométricas y mecánicas de los elementos. En el Capítulo 3 se explican de forma detallada los objetivos específicos de este estudio, incluyendo información sobre su desarrollo.

La estructura de esta tesis doctoral consta de diez capítulos principales.

En el Capítulo 2, "Estado del Conocimiento", se lleva a cabo un análisis del estado del conocimiento que abarca la revisión, por un lado, de los métodos existentes para la evaluación de la capacidad de deformación, y, por otro lado, de la bibliografía relacionada con la comprobación experimental del comportamiento resistente y deformacional de elementos de hormigón armado. La información relacionada con los ensayos experimentales existentes ha sido organizada en una base de datos. Esto ha resultado fundamental para identificar y complementar los vacíos existentes encontrados también en otras bases de datos. Finalmente, se han revisado los métodos propuestos en las normas.

Tras la evaluación del estado del conocimiento, en el Capítulo 3, "Planteamiento de la tesis", se plantea, justifica y delimita el estudio. Se exponen los objetivos generales y específicos, así como la metodología a partir de la cual se alcanzan dichos objetivos.

En el Capítulo 4, "Modelo de ensayo y desarrollo del programa experimental", se incluyen las siguientes secciones, que describen el desarrollo de un programa experimental de 44 ensayos en soportes esbeltos de hormigón armado sometidos a compresión y flexión monotónica: (1) diseño y construcción de un pórtico de carga; (2) definición de los parámetros más influyentes y delimitación de los rangos de estudio; (3) descripción geométrica del soporte; (4) caracterización de los materiales; (5) localización de la instrumentación; y (6) ejecución de los ensayos hasta la rotura.

En el Capítulo 5, "Resultados directos y observaciones experimentales", se presentan los resultados directos obtenidos en el programa experimental, se incluyen los efectos observados durante los ensayos, y se lleva a cabo una descripción del nivel de daño al finalizar el ensayo.

En el Capítulo 6, "Análisis de los resultados experimentales", se incluye un completo análisis de los resultados de la resistencia y capacidad de deformación obtenida en los ensayos experimentales de soportes esbeltos de hormigón armado, lo cual incluye los siguientes aspectos: (1) identificación del tipo de fallo que presentó cada uno de los soportes; (2) comparación de los resultados experimentales de carga y momentos máximos resistentes y los resultados calculados a partir de los modelos descritos en las normas de diseño; (3) análisis de 

hormigón armado

la capacidad de deformación a nivel de la sección y del elemento completo; (4) evaluación de la longitud de rótula plástica experimental; y (5) evaluación de la rigidez elástica efectiva. En cada uno de los análisis mencionados, se ha realizado el estudio de la influencia de los parámetros considerados en esta investigación.

En el Capítulo 7, "Calibración de un modelo numérico para simular el comportamiento de soportes de hormigón armado", se incluye la descripción del proceso seguido en la calibración de un modelo numérico que permite simular el comportamiento estructural de soportes esbeltos de hormigón sometidos a flexocompresión. En la simulación numérica se ha utilizado el programa de análisis no lineal “ATENA 2D", versión V3, desarrollado por CERVENKA CONSULTING.

En el Capítulo 8, "Estudio paramétrico", se desarrolla un estudio del comportamiento deformacional de elementos de hormigón sometidos a compresión y flexión monotónica, con el propósito de evaluar la influencia de los principales parámetros que afectan al comportamiento deformacional. Los parámetros estudiados se corresponden con los ya tratados en el estudio experimental, llevándose a cabo una ampliación de los rangos de estudio.

En el Capítulo 9, "Evaluación de la capacidad de deformación mediante métodos existentes", en primer lugar, se lleva a cabo la comparación entre la capacidad de deformación medida en los ensayos experimentales y la calculada mediante los métodos teóricos existentes (empíricos y analíticos). En segundo lugar, se realiza una comparación (en términos de la deriva última, $\theta_{u}$ ) entre los diferentes métodos empíricos y analíticos utilizados en la evaluación de la capacidad de deformación última. Esta comparación también se realiza con respecto a los resultados obtenidos del modelo numérico y los resultados experimentales.

En el Capítulo 10, "Propuesta de métodos simplificados", en base al estudio paramétrico llevado a cabo en el Capítulo 8 , se proponen métodos simplificados para medir la capacidad de deformación de elementos de hormigón armado sujetos a compresión y flexión monotónica. Mediante los métodos propuestos, es posible predecir las siguientes variables relacionadas con la capacidad de deformación: desplazamiento elástico efectivo $\left(\delta_{\mathrm{y}}^{\prime}\right)$, desplazamiento último $\left(\delta_{\mathrm{u}}\right)$, ductilidad de desplazamiento $\left(\mu_{\delta}\right)$, rigidez elástica efectiva $\left(E l_{e}\right)$ y rigidez última $\left(E I_{u}\right)$. Dichos métodos son comprobados con los resultados obtenidos en la simulación numérica y con los resultados experimentales de 40 soportes ensayados en este estudio.

En el Capítulo 11, "Conclusiones y propuestas para futuras investigaciones", se presenta un resumen de las principales conclusiones derivadas a lo largo del presente estudio, mediante las cuales se comprueba la consecución de los objetivos propuestos. Además, a partir de esta tesis doctoral se proponen algunas recomendaciones para futuras líneas de investigación.

\footnotetext{
${ }^{4}\left(\theta_{u}=\delta_{u} / L_{s}\right.$, siendo $\delta_{u}$ el desplazamiento último del elemento, y $L_{s}$ la distancia del elemento entre el momento máximo y el momento nulo)
} 


\section{CAPÍTULO 2}

\section{ESTADO DEL CONOCIMIENTO}

En la literatura técnica se encuentran tres tipos de métodos para evaluar la capacidad de deformación en elementos de hormigón armado. El primer tipo corresponde a métodos empíricos, obtenidos a partir de resultados experimentales, como los propuestos por Panagiotakos y Fardis (2001) [100] y Fardis y Biskinis (2003) [60], que han sido adoptados por el Eurocódigo 8 (2004) [59], así como también el desarrollado por Lam et al. (2003) [77], con menor aplicación.

El segundo tipo corresponde a los métodos analíticos simplificados, donde el desplazamiento último de un elemento de hormigón armado se obtiene a partir de la integración de la curvatura en una longitud equivalente de rótula plástica, como por ejemplo el método analítico de Panagiotakos y Fardis (2001) [100], el de Priestley et al. (1996) [110] y el método de Lehman (2000) [80]. Sin embargo, la correcta aproximación en este tipo de métodos no sólo depende de una adecuada evaluación de las curvaturas, sino también del cálculo de la longitud de rótula plástica, obtenida a partir de expresiones empíricas. Por consiguiente, una gran parte de los estudios se ha centrado en encontrar expresiones para la evaluación de la longitud de rótula plástica. 
En tercer lugar, existen propuestas relevantes de modelos analíticos más complejos, en los cuales la evaluación de la respuesta del comportamiento de los elementos de hormigón armado, se obtiene a partir de la interacción de modelos más sofisticados que simulan los efectos más influyentes, como pueden ser: la adherencia, el efecto de "tensión stiffening", la fisuración, el pandeo de la armadura longitudinal, y el confinamiento, entre otros. Este tipo de modelos se proponen habitualmente para evaluar la capacidad de rotación plástica en elementos tipo viga, como por ejemplo los modelos de Stuttgar, Nápoles, Darmstadt-Leipzig, Zurich, Delf, etc., la mayoría de los cuales se presentan en el CEB Bulletin 242 [30]. Por otro lado, la propuesta de modelos para elementos sujetos a flexo-compresión (como los soportes de hormigón) es más escasa. Se destaca, sin embargo, el método propuesto por Bae (2005) [12].

En este capítulo, en primer lugar, se hace una revisión bibliográfica de los métodos teóricos para la evaluación de la capacidad de deformación en elementos de hormigón. Esto incluye un resumen de: (1) los modelos empíricos, (2) los modelos analíticos simplificados, (3) las expresiones para el cálculo de la longitud de rótula plástica, (4) modelos analíticos más complejos para evaluar la capacidad de rotación plástica en vigas, y (5) modelos analíticos complejos para evaluar el desplazamiento último de soportes.

En segundo lugar, se ha realizado un estudio bibliográfico referente a ensayos experimentales previos, en donde se han identificado los siguientes aspectos: (1) tipos de elementos ensayados; (2) parámetros de la geometría del elemento y características de los materiales que más influyen en la capacidad de deformación; y (3) parámetros ampliamente estudiados y aquellos que necesitan una mayor comprobación experimental.

Por último, se ha llevado a cabo una revisión de los métodos propuestos en el Eurocódigo 8 (2004) [59], para evaluar la capacidad de deformación de estructuras existentes y para el diseño de nuevas estructuras.

\subsection{FUNDAMENTOS TEÓRICOS DE LA CAPACIDAD DE DEFORMACIÓN}

Para analizar el comportamiento de una estructura es necesario conocer algunos índices que describen su capacidad de deformación. Estos índices pueden estar relacionados con el tipo de elemento. Por una parte, para elementos tipo viga, la capacidad de deformación es evaluada mediante el índice de la rotación plástica $\theta_{p}$ que se acumula dentro de la rótula plástica, con el propósito de garantizar una redistribución de momentos.

Por otra parte, en el diseño sísmico de estructuras el interés se centra en asegurar un buen comportamiento de la rótula plástica que se forma cerca de las conexiones en caso de movimientos sísmicos. Dicho comportamiento depende de la adecuada capacidad de absorber y disipar energía sin una pérdida significativa de resistencia, es decir, de la ductilidad.

Existen varios índices de ductilidad que miden la capacidad de deformación de soportes de hormigón armado. Estos índices son definidos a nivel del elemento 
completo, a nivel de la rótula plástica y a nivel de la sección. Los índices de deformación se determinan a partir de dos puntos característicos que representan el estado elástico y último sobre el diagrama idealizado de respuesta resistenciadeformación (R-X), como se muestra en la Figura 2.1.

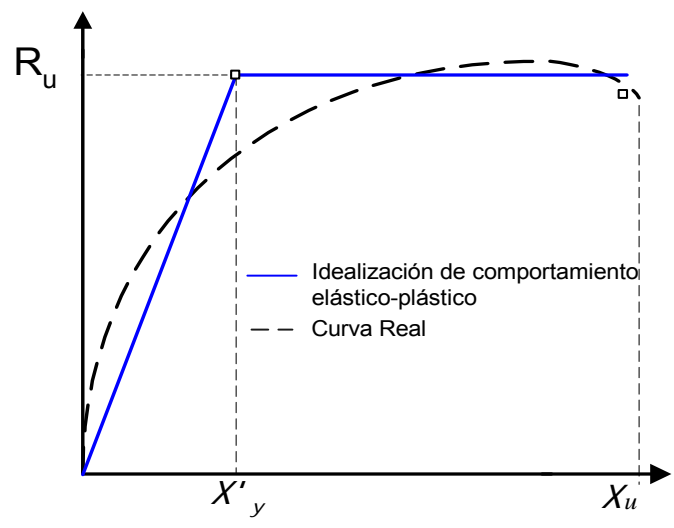

Figura 2.1 Diagrama elástico-plástico idealizado

\subsection{1 ÍNDICES DE DEFORMABILIDAD A NIVEL DEL ELEMENTO}

A nivel del elemento, la capacidad de deformación se mide en términos del desplazamiento elástico efectivo $\left(\delta_{y}^{\prime}\right)$ y último $\left(\delta_{u}\right)$. A partir de estas dos variables es posible definir los siguientes índices de capacidad de deformación:

- Ductilidad de desplazamiento $\left(\mu_{\delta}=\delta_{\mathrm{u}} / \delta_{\mathrm{y}}^{\prime}\right)$ : índice que expresa la demanda de ductilidad en toda la estructura, y es un factor más incorporado habitualmente en las normas de diseño sísmico.

- Deriva o "chord rotation" $\left(\theta=\delta / L_{s}\right)$ : es una medida de la capacidad de deformación de elementos de hormigón armado utilizada en el análisis de estructuras para el diseño sismo-resistente de nuevas estructuras y para la evaluación sísmica de estructuras existentes. La deriva se define como la relación entre el desplazamiento $(\delta)$ y distancia entre las secciones de momento máximo y momento nulo $\left(L_{s}\right)$. La deriva puede estar definida para el estado elástico $\left(\theta_{\mathrm{y}}=\delta_{\mathrm{y}}^{\prime} / \mathrm{L}_{\mathrm{s}}\right)$ y también para el estado último $\left(\theta_{\mathrm{u}}=\delta_{\mathrm{u}} / \mathrm{L}_{\mathrm{s}}\right)$.

\subsection{2 ÍNDICES DE DEFORMABILIDAD A NIVEL DE LA SECCIÓN}

El comportamiento de la sección se describe mediante el diagrama momentocurvatura $(\mathrm{M}-\varphi)$. Por lo tanto, los índices de deformabilidad, a nivel de la sección, son medidos en términos de la curvatura elástica $\left(\varphi_{y}^{\prime}\right)$ y de la curvatura última $\left(\varphi_{u}\right)$. A partir de estos últimos se deducen los siguientes índices:

- Curvatura plástica $\left(\varphi_{\mathrm{p}}=\varphi_{\mathrm{u}}-\varphi_{\mathrm{y}}^{\prime}\right)$ : es la cuantificación de la curvatura no elástica de una sección.

- Ductilidad de curvatura $\left(\mu_{\varphi}=\varphi_{u} / \varphi_{y}^{\prime}\right)$ : también puede utilizarse para expresar la ductilidad local en la zona de rótula plástica. 


\subsection{3 ÍNDICES DE DEFORMABILIDAD DE LA RÓTULA PLÁSTICA}

La rótula plástica en elementos de hormigón armado sometidos a flexión simple o flexo-compresión, ocurre cuando se acumulan grandes curvaturas alrededor de la sección de momento máximo. Además, se desarrolla una concentración de efectos no lineales, como la plastificación de la armadura, la fisuración, el pandeo y/o deslizamiento de la armadura, y la rotura del hormigón, etc. El índice que define el comportamiento deformacional de la rótula plástica es la rotación plástica. La longitud de rótula plástica $\left(L_{p}\right)$ es una longitud equivalente, sobre la cual se acumula toda la curvatura plástica.

- Rotación plástica de la rótula $\left(\theta_{\mathrm{p}}\right)$ : concentración de la deformación inelástica en la zona definida como longitud de rótula plástica, $\theta_{p}=\left(\varphi_{u^{-}}\right.$ $\left.\varphi_{y}^{\prime}\right) L_{p}$.

\subsubsection{INTERACCIÓN ENTRE LOS DIFERENTES FACTORES DE DUCTILIDAD}

Es común relacionar la capacidad de deformación de la sección con la deformación del elemento, a partir de la definición de longitud de plastificación, en donde se concentran y distribuyen uniformemente las deformaciones inelásticas de todo el elemento. Este concepto se ha utilizado tanto en elementos tipo viga como en soportes.

En elementos tipo viga, la rotación plástica puede evaluarse mediante la Ec. 2-1 siendo $\left(\varepsilon_{\mathrm{cu}}\right)$ y $\left(\varepsilon_{\mathrm{ce}}\right)$, las deformaciones última y elástica del hormigón, respectivamente, y $(x)$ la profundidad de la fibra neutra.

$$
\theta_{p} \cong \frac{\varepsilon_{c u}-\varepsilon_{c e}}{x} L_{p}
$$

En elementos tipo soporte, Park y Paulay (1975) [103] proponen calcular el desplazamiento máximo de un soporte en voladizo a partir de la capacidad de deformación de la sección y de la longitud de rótula plástica $\left(L_{p}\right)$, mediante la Ec. 2-2. Esta ecuación puede expresarse en función de la ductilidad en desplazamientos y curvaturas, mediante la Ec. 2-3.

$$
\begin{gathered}
\delta_{u}=\delta_{y}+\delta_{p}=\frac{\varphi_{y} L_{s}^{2}}{3}+\left(\varphi_{u}-\varphi_{y}\right) L_{p}\left(L_{s}-0.5 L_{p}\right) \\
\mu_{\delta}=1+3\left(\mu_{\varphi}-1\right) \frac{L_{p}}{L_{s}}\left(1-0.5 \frac{L_{p}}{L_{s}}\right)
\end{gathered}
$$

Donde

$\delta_{y} \quad$ Desplazamiento elástico efectivo

$\delta_{u} \quad$ Desplazamiento último

$\delta_{p} \quad$ Desplazamiento plástico $\left(\delta_{u}-\delta_{y}^{\prime}\right)$

$L_{s} \quad$ Distancia entre las secciones de momento máximo y momento nulo

$\varphi_{u} \quad$ Curvatura última de la sección crítica

$\varphi_{y} \quad$ Curvatura elástica de la sección crítica

$L_{p} \quad$ Longitud de rótula plástica 


\section{$\mu_{\delta} \quad$ Ductilidad de desplazamiento \\ $\mu_{\varphi} \quad$ Ductilidad de curvatura}

En la Figura 2.2 se muestra la relación que existe entre los factores de ductilidad de curvatura y desplazamiento, según la Ec. 2-3. Esta relación depende de dos factores, que son la esbeltez geométrica $\left(\lambda=L_{s} / h\right.$, siendo $h$ el canto de la sección transversal) y la longitud de la rótula plástica. Sin embargo, según Bayrak (1998) [21], en las Ec. 2-2 y Ec. 2-3 no se han considerado los efectos de segundo orden causados por la carga axial, ni tampoco las no-linealidades geométricas y del material, ya que su consideración podría complicar la relación entre los parámetros de ductilidad.

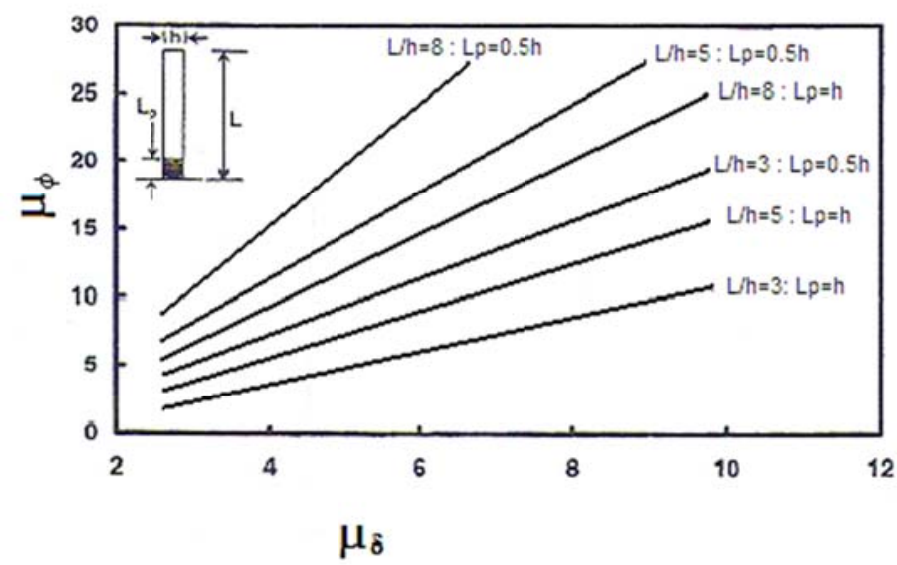

Figura 2.2 Relación entre los índices de ductilidad de curvatura y de desplazamiento, Bayrak (1998) [21]

\subsection{MÉTODOS TEÓRICOS QUE EVALÚAN LA CAPACIDAD DE DEFORMACIÓN EN ELEMENTOS DE HORMIGÓN ARMADO}

En esta sección se presenta un resumen de los modelos existentes desarrollados para predecir la capacidad de deformación en elementos de hormigón armado sometidos a flexo-compresión.

El primer tipo corresponde a modelos totalmente empíricos, obtenidos a partir de resultados de ensayos experimentales. En este tipo de modelos se incluye el de Panagiotakos y Fardis (2001) [100], que, con ciertos ajustes, se ha incluido en la norma europea (Eurocódigo 8) [59]. En este método se proponen expresiones para la estimación de los índices de capacidad de deformación de deriva última $\left(\theta_{u}\right)$ y deriva elástica $\left(\theta_{\mathrm{y}}\right)$. Otro de los modelos empíricos propuesto para el cálculo de $\theta_{\mathrm{u}}$ es el de Lam et al. (2003) [77].

El segundo tipo incluye los modelos analíticos donde el desplazamiento máximo de un elemento de hormigón armado se evalúa a partir del comportamiento de la sección crítica y de la longitud de rótula plástica $\left(L_{p}\right)$. Sin embargo, su correcta aproximación no sólo depende de una evaluación adecuada del diagrama momento-curvatura $(\mathrm{M}-\varphi)$, sino también de la evaluación de la longitud de rótula plástica $\left(L_{p}\right)$, la cual se obtiene a partir de expresiones empíricas. 
Existen en la literatura algunas expresiones que pueden usarse para calcular la longitud de rótula plástica en elementos de hormigón armado. En la sección 2.2.3 se presenta un resumen de dichas expresiones.

El tercer tipo se refiere a modelos analíticos más complejos en los cuales se incorporan otros modelos que interpretan los efectos no lineales, como: la fisuración, el pandeo de la armadura, el confinamiento, la adherencia, etc.

\subsubsection{MÉTODOS EMPÍRICOS}

\subsubsection{MÉTODO EMPÍRICO PROPUESTO POR PANAGIOTAKOS Y FARDIS (2001)}

Panagiotakos y Fardis (2001) [100], han recopilado una base de datos de ensayos experimentales de elementos de hormigón armado. La base de datos incluye los siguientes elementos: vigas y soportes de sección rectangular y circular, muros rectangulares y pilas de sección hueca, sometidos a flexión uniaxial con o sin carga axial, bajo carga monotónica o cíclica.

Esta base de datos se ha utilizado con el propósito de plantear métodos para la evaluación de la capacidad de deformación elástica y última de elementos de hormigón armado, en función de sus características mecánicas y geométricas. Se han planteado dos tipos de métodos, uno de ellos totalmente empírico, que trataremos en esta sección, y el otro analítico, en base al comportamiento de la sección crítica y de la longitud de rótula plástica, que se expondrá en la siguiente sección.

Los métodos propuestos plantean expresiones simples para evaluar la deriva $(\theta)$, es decir, la relación entre el desplazamiento del elemento en la sección de máximo momento $\left(\delta_{u}\right)$ y la longitud de cortante $\left(L_{s}\right.$, la longitud entre la sección de momento nulo y momento máximo).

Un resumen de la base de datos construida por Panagiotakos y Fardis (2001) [100] se presenta en la sección 2.3.1. Cabe destacar que la mayoría de los ensayos recogidos en la base de datos alcanzaron la rotura, identificándose esta para una caída del $15 \%$ de la carga post-pico en la respuesta Carga-desplazamiento, tanto en ensayos bajo carga monotónica como cíclica. Posteriormente, Fardis y Biskinis (2003) [60] modifican la determinación de la situación de rotura en el $20 \%$ de caída en la rama post-pico o de reblandecimiento.

\subsection{Expresiones para el cálculo de la deriva elástica}

La deriva elástica $\left(\theta_{y}=\delta_{y} / L_{s}\right)$ es una variable importante en la evaluación de los índices de deformabilidad. Además, es útil para el cálculo de la rigidez efectiva de elementos de hormigón armado sometido a flexo-compresión, Ec. 2-4.

$$
E I_{e}=\frac{M_{y} L_{s}}{3 \theta_{y}}
$$




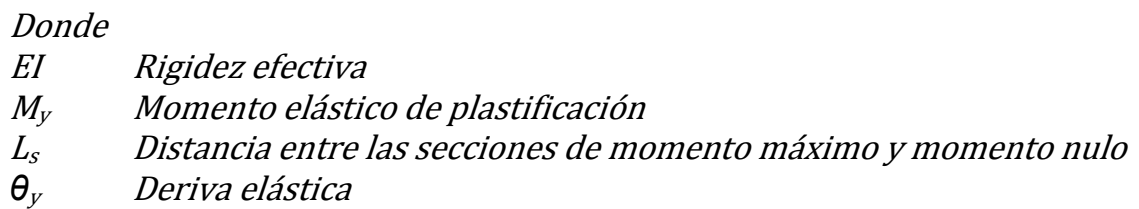

En una primera aproximación, Panagiotakos y Fardis (2001) [100], proponen la Ec. 2-5 (Tabla 2-1) para el cálculo de la deriva elástica $\left(\delta_{y} / L\right)$. Esta expresión se compone de tres términos independientes. El primer término se debe a la deformación por flexión $\left(\varphi_{\mathrm{y}} \mathrm{L}_{\mathrm{s}} / 3\right)$. El segundo término puede ser considerado como la distorsión debida a la fisuración por cortante en el elemento para el estado de flexión elástica, y el tercer término incluye el efecto de la rotación en el extremo fijo debido al deslizamiento de la armadura en la zona de anclaje. El tercer término de la Ec. 2-6 (Tabla 2-1), no debe ser considerado cuando el deslizamiento de la armadura anclada sea físicamente imposible, en cuyo caso $\alpha_{\mathrm{sl}}$ es igual a cero. Fardis y Biskinis (2003) [60] proponen la Ec. 2-6 (Tabla 2-1), que muestra un mejor ajuste con los ensayos experimentales, tal y como se observa en la Tabla 2-2.

Tabla 2-1 Expresiones de deriva elástica

\begin{tabular}{|c|c|c|}
\hline $\begin{array}{c}\text { Panagiotakos y Fardis } \\
\text { (2001) [100] }\end{array}$ & $\theta_{y}=\varphi_{y} \frac{L_{s}}{3}+0.0025+\alpha_{s l} \frac{0.25 \varepsilon_{y} d_{b} f_{y}}{\left(d-d^{\prime}\right) \sqrt{f_{c}}}$ & Ec. 2-5 \\
\hline $\begin{array}{c}\text { Fardis y Biskinis } \\
\text { 2003) [60] }\end{array}$ & $\theta_{y}=\varphi_{y} \frac{L_{s}}{3}+0.00275+\alpha_{s l} \frac{0.2 \varepsilon_{y} d_{b} f_{y}}{\left(d-d^{\prime}\right) \sqrt{f_{c}}}$ & Ec. 2-6 \\
\hline
\end{tabular}

$\begin{array}{ll}\text { Donde: } & \\ \varphi_{y} & \text { Curvatura elástica } \\ L_{s} & \text { Distancia entre las secciones de momento máximo y momento nulo } \\ \alpha_{S l} & 1 \text { si se desliza la armadura longitudinal en la zona de anclaje, de lo contrario } 0 \\ \varepsilon_{y} & \text { Deformación correspondiente al límite elástico del acero } \\ d_{b} & \text { Diámetro de las barras de acero longitudinales } \\ f_{y} & \text { Límite elástico del acero } \\ f_{c} & \text { Resistencia a compresión del hormigón } \\ d & \text { Canto útil de la sección } \\ d^{\prime} & \text { Recubrimiento mecánico de la armadura en compresión }\end{array}$

Las Ec. 2-5 y Ec. 2-6 se han deducido al cuantificar la curvatura elástica $\left(\varphi_{y}\right)$ en función de la geometría de la sección y de las propiedades del material. La curvatura elástica $\left(\varphi_{y}\right)$, será el menor valor entre las dos siguientes situaciones. La primera de ellas se refiere a que se alcance, en la fibra más comprimida de la sección, una deformación límite que corresponde al comienzo de la no-linealidad del hormigón, y la segunda situación se da si se alcanza primero la deformación elástica del acero $\left(\varepsilon_{y}\right)$ en las barras de tracción. En las expresiones Ec. 2-5 y Ec. 2-6 se ha considerado que la no-linealidad del hormigón comienza para un valor del $90 \%$ de la deformación correspondiente a la tensión pico del hormigón $\left(\varepsilon_{\mathrm{co}}\right)$. 
Estudio experimental y numérico de la capacidad de deformación de soportes esbeltos de hormigón armado

Tabla 2-2 Resultados del ajuste de las expresiones Ec. 2-5 y 2-6: Media, mediana, y coeficiente de variación (CV) de la relación entre la deriva elástica calculada y la experimental, Panagiotakos y Fardis (2001) [100]

\begin{tabular}{|c|l|l|l|l|l|}
\hline Referencia & \multicolumn{1}{|c|}{ Ec. } & $\begin{array}{c}\mathbf{N}^{\circ} \\
\text { Ensayos }\end{array}$ & Media & Mediana & $\begin{array}{c}\text { CV } \\
\text { (\%) }\end{array}$ \\
\hline $\begin{array}{c}\text { Panagiotakos y Fardis } \\
(2001)[100]\end{array}$ & Ec. 2-5 & 963 & 1.06 & 0.79 & 40.0 \\
\hline $\begin{array}{c}\text { Fardis y Biskinis (2003) } \\
{[60]}\end{array}$ & Ec. 2-6 & 1349 & 1.05 & 0.995 & 38.6 \\
\hline
\end{tabular}

\subsection{Expresiones para el cálculo de la deriva última}

Panagiotakos y Fardis (2001) [100] propusieron distintas expresiones para el cálculo de la deriva última en soportes y vigas de hormigón armado. Para obtener estas expresiones, realizaron un análisis estadístico de 875 ensayos de la base de datos, en los cuales la rotura del elemento se manifestó por agotamiento en flexión. Las expresiones incluyen las siguientes variables: nivel de axil reducido ( $v=N / A_{g} f_{c}$ ), esbeltez de cortante $\left(\lambda=L_{s} / h\right)$, resistencia del hormigón $\left(f_{c}\right)$, cuantías de armadura longitudinal en compresión y tracción $\left(\rho_{\mathrm{I}}\right.$ y $\left.\rho_{{ }_{\mathrm{l}}}\right)$, cuantía de armadura transversal $\left(\rho_{\mathrm{sx}}\right)$, características mecánicas del acero $\left(\varepsilon_{\mathrm{y}}, \mathrm{f}_{\mathrm{y}}\right)$, efecto de la adherencia y tipo de carga monotónica o cíclica. En este trabajo se presentaron tres expresiones que fueron calibradas según el tipo de carga: la Ec. 2-7 para ensayos con carga monotónica, la Ec. 2-8 para ensayos con caga cíclica y la Ec. 2-9 para ensayos con carga monotónica y cíclica. Cabe destacar que tales expresiones se calibraron asumiendo que la situación de rotura se produce en el $15 \%$ de caída de la rama post-pico del diagrama de respuesta carga-desplazamiento.

Más adelante, la expresión para carga cíclica y monotónica, Ec. 2-9, de Panagiotakos y Fardis (2001) [100], es modificada y presentada en el CEB-FIP Bulletin 24 y 25 (2003) [34] y [35], mediante la Ec. 2-10. Y una última versión (Ec. 2-11) aparece modificada por Fardis y Biskinis (2003) [60]. Específicamente, las dos últimas expresiones se han calibrado asumiendo la rotura del elemento en una caída del $20 \%$ en rama de reblandecimiento.

Se debe tener en cuenta que la base de datos incluye elementos de hormigón armado construidos con una gran variedad de tipos de acero en cuanto a características de ductilidad, las cuales influyen considerablemente en la capacidad de deformación de elementos de hormigón armado. Para tener en cuenta este efecto, en las expresiones se propuso un factor independiente $\left(\alpha_{\mathrm{st}}\right)$ para cada tipo de acero. Los tipos de acero de la armadura fueron clasificados en tres grupos: (1) acero rodado en caliente ("hot-rolled"), con una relación de endurecimiento $\left(\mathrm{f}_{\mathrm{t}} / \mathrm{f}_{\mathrm{y}}\right)$ del orden de 1.5 y una deformación en la tensión máxima $\left(\varepsilon_{\mathrm{su}}\right)$ alrededor del $15 \%$, utilizado en la mayoría de los ensayos; (2) acero con tratamiento térmico ("heattreated"), con un valor de $\mathrm{f}_{\mathrm{t}} / \mathrm{f}_{\mathrm{y}}$ del orden de 1.2 y una $\varepsilon_{\text {su }}$ del orden del $8 \%$; y (3) acero trabajado en frio ("cold-worked"), con un valor de $\mathrm{f}_{\mathrm{t}} / \mathrm{f}_{\mathrm{y}}$ de aproximadamente 1.1 y una $\varepsilon_{\text {su }}$ de alrededor del $4 \%$. En la Tabla 2-4 se muestran los valores asignados al factor $\left(\alpha_{\text {st }}\right)$ correspondiente a cada acero en cada una de las expresiones. Adicionalmente, en la Tabla 2-4 aparece el valor asignado al factor $\alpha_{\text {cyc }}$ que tiene en 
cuenta el tipo de carga (monotónica y cíclica), en aquellas expresiones calibradas para los dos tipos de carga.

Tabla 2-3 Resumen de expresiones para el cálculo de la deriva última $\left(\theta_{u}\right)$, obtenidas a partir de la base de datos realizada por Fardis et al. y presentadas en diferentes publicaciones

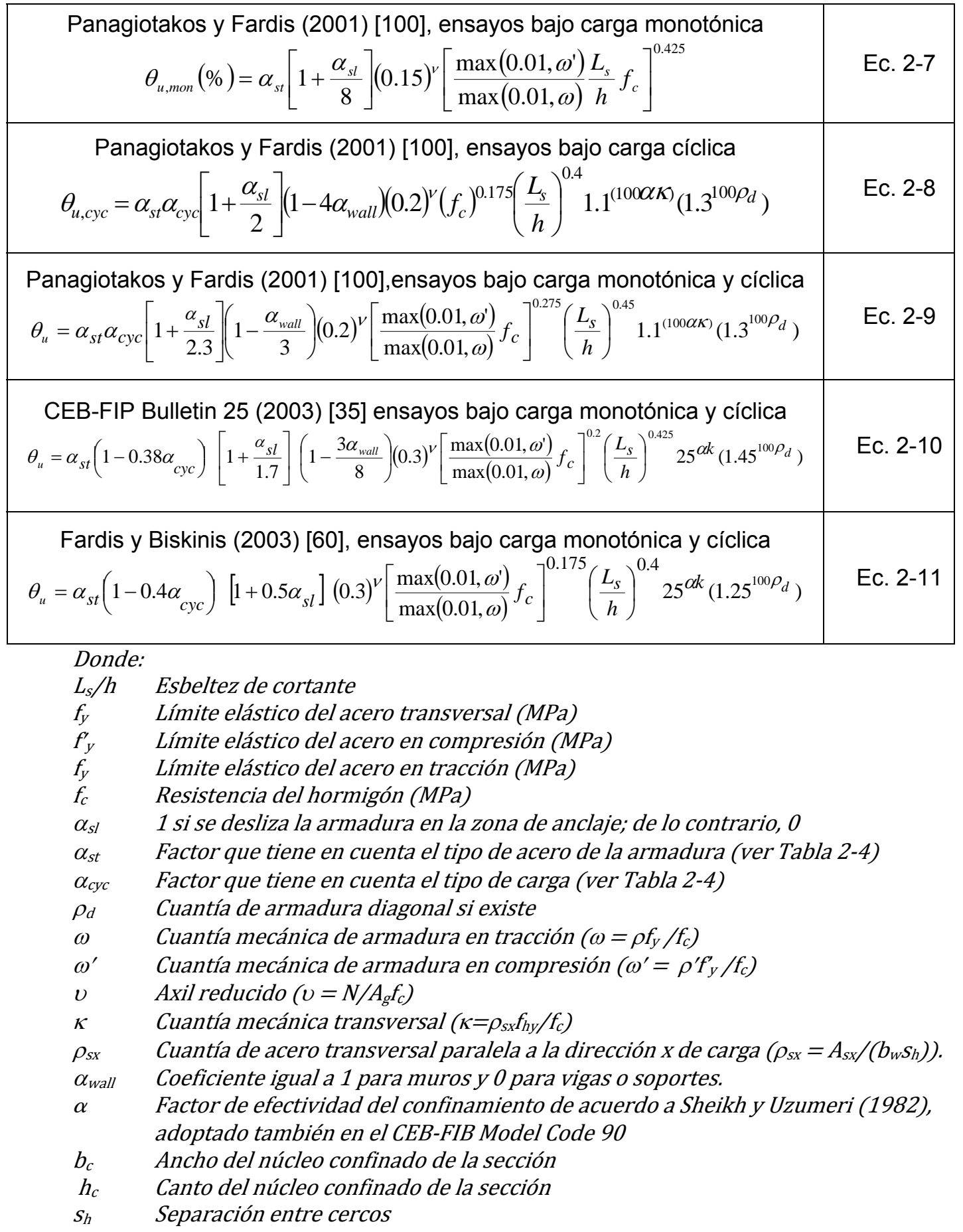

En la Tabla 2-5 se presentan los valores estadísticos del ajuste conseguido para las expresiones Ec. 2-7 a Ec. 2-11 con los resultados de la base de datos. 
Estudio experimental y numérico de la capacidad de deformación de soportes esbeltos de hormigón armado

Tabla 2-4 Factores de $\alpha_{s t}$ y $\alpha_{c y c}$ asignados en los modelos empíricos

\begin{tabular}{|c|c|c|c|c|c|}
\hline \multirow{2}{*}{ Ec. } & \multicolumn{2}{|c|}{$\alpha_{\text {st }}$ Factor Tipo de acero } & \multicolumn{2}{c|}{$\alpha_{\text {cyc }}$} \\
\cline { 2 - 6 } & $\begin{array}{c}\text { Rodado en } \\
\text { caliente }\end{array}$ & $\begin{array}{c}\text { Tratamiento } \\
\text { térmico }\end{array}$ & $\begin{array}{c}\text { Trabajado } \\
\text { en frío }\end{array}$ & $\begin{array}{c}\text { carga } \\
\text { monotónica }\end{array}$ & $\begin{array}{c}\text { Carga } \\
\text { cíclica }\end{array}$ \\
\hline Ec. 2-7 & 1.250 & 1.00 & 0.50 & - & - \\
\hline Ec. 2-8 & 1.125 & 1.00 & 0.80 & - & - \\
\hline Ec. 2-9 & 1.500 & 1.25 & 0.80 & 1.0 & 0.6 \\
\hline Ec. 2-10 & 0.016 & 0.016 & 0.0105 & 0 & 1.0 \\
\hline Ec. 2-11 & 0.0194 & 0.0194 & 0.0125 & 0 & 1.0 \\
\hline
\end{tabular}

Tabla 2-5 Resultados del ajuste de las expresiones Ec. 2-7 a 2-11: Media, mediana, y coeficiente de variación (CV) de la relación entre la deriva última calculada y la experimental

\begin{tabular}{|l|c|c|c|c|c|}
\hline \multicolumn{1}{|c|}{ Referencia } & Ec. & $\begin{array}{c}\mathbf{N}^{\mathbf{0}} \text { de } \\
\text { ensayos }\end{array}$ & Media & Mediana & C.V. (\%) \\
\hline \multirow{2}{*}{$\begin{array}{l}\text { Panagiotakos y Fardis } \\
\text { (2001) [100] }\end{array}$} & Ec. 2-7 & 234 & 1.17 & 1.01 & 57.0 \\
\cline { 2 - 6 } & Ec. 2-8 & 633 & 1.05 & 1.01 & 41.0 \\
\cline { 2 - 6 } & Ec. 2-9 & 875 & 1.06 & 1.00 & 47.0 \\
\hline Fib Bulletín 25 [35] & Ec. 2-10 & 1056 & 1.07 & 1.00 & 47.0 \\
\hline Fardis y Biskinis (2003) [60] & Ec. 2-11 & 1159 & 1.05 & 1.00 & 43.9 \\
\hline
\end{tabular}

\subsubsection{MÉTOdO EMPÍRICO PROPUESTO POR LAM, WU, WONG, WANG, LI (2003)}

Lam et al. (2003) [77] proponen un modelo empírico para el cálculo de la deriva última (Ec. 2-12 y Ec. 2-13). El modelo introduce un parámetro adimensional $\alpha$ para incluir la influencia debida a la esbeltez de cortante $\left(m=L_{s} / h\right)$, el nivel de axil reducido $\left(v=N / A_{g} f_{c}\right)$, la cuantía geométrica transversal $\left(\rho_{s}\right)$ y las propiedades de los materiales (límite elástico del acero y resistencia a la compresión del hormigón). Este modelo es desarrollado a partir de los resultados de 15 ensayos experimentales en soportes de hormigón convencional sometidos a flexocompresión cíclica. Siete de los ensayos han sido realizados por Lam et al. (2003) [77], y los demás se han seleccionado de una base de datos proporcionada por Taylor et al. (1997) [126]. Las características de estos ensayos se resumen en la Tabla 2-6.

En los ensayos experimentales, la carga última y la flecha última es la correspondiente a una caída en la rama post-pico del $20 \%$ de la carga máxima.

$$
\begin{gathered}
\alpha=(1+m)(1-\sqrt{n}) \sqrt{\frac{\rho_{s} f_{y h}}{f_{c}}} \\
\frac{\theta_{u}}{100}=0.564+8.489 \alpha-7.804 \alpha^{2}
\end{gathered}
$$

Donde

$\begin{array}{ll}\alpha & \text { Factor adimensional } \\ m & \text { Esbeltez de cortante }\left(L_{s} / h\right)\end{array}$




$\begin{array}{ll}n & \text { Nivel de axil reducido }\left(N / A_{g} f_{c}\right) \\ \rho_{s} & \text { Cuantía de armadura transversal } \\ f_{y h} & \text { Límite elástico de la armadura transversal } \\ f_{c} & \text { Resistencia del hormigón en compresión }\end{array}$

Tabla 2-6 Características de los ensayos utilizados en la calibración del modelo de Lam et al. [75], para el cálculo de $\theta_{u}$

\begin{tabular}{|l|c|c|}
\hline \multicolumn{1}{|c|}{ Parámetros } & Lam et al. [75] & $\begin{array}{c}\text { Taylor et. al } \\
\text { (1997) [126] }\end{array}$ \\
\hline Resistencia del hormigón, $\mathrm{f}_{\mathrm{c}}{ }_{\mathrm{c}}(\mathrm{MPa})$ & 32 a 36 & 20 a 44 \\
\hline Nivel de carga Axial, $\left(\mathrm{N} / \mathrm{A}_{\mathrm{g}} \mathrm{f}_{\mathrm{c}}\right)$ & 0.4 a 0.65 & $0.3 \mathrm{a} 0.8$ \\
\hline Esbeltez, $\left(\mathrm{L}_{\mathrm{s}} / \mathrm{h}\right)$ & $1.5 \mathrm{a} 3$ & $1 \mathrm{a} 4$ \\
\hline Cuantía longitudinal, $\rho_{\mathrm{l}}(\%)$ & 3 a 3.5 & 1.5 a 3 \\
\hline Cuantía transversal, $\rho_{\mathrm{s}}=\mathrm{A}_{\mathrm{sh}} / \mathrm{s} . \mathrm{h}(\%)$ & 0.1 a 0.3 & 0.25 a 0.7 \\
\hline
\end{tabular}

Los resultados experimentales se encuentran dentro de un rango de error del $20 \%$ respecto a los valores evaluados por el modelo empírico propuesto. El modelo sólo es válido en elementos con características similares a los utilizados en la calibración.

\subsubsection{MÉTODOS ANALÍTICOS SIMPLIFICADOS}

Los modelos analíticos permiten evaluar la capacidad de deformación elástica y última y están basados en la idealización del modelo "soporte en voladizo", tal y como se muestra en la Figura 2.3. Este tipo de métodos son propuestos para evaluar el desplazamiento en el extremo libre del soporte, para los estados de carga elástica y última, a partir de la distribución de curvaturas de flexión, y considerando que la curvatura inelástica se acumula en una longitud equivalente de rótula plástica $\left(L_{p}\right)$, (Figura 2.3). De este modo, el desplazamiento máximo se evalúa a partir de la Ec. 2-14.

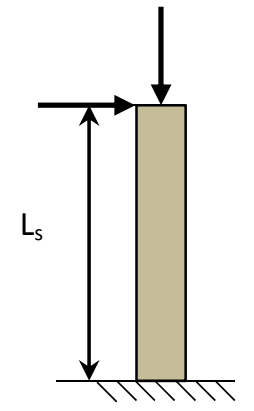

(a)

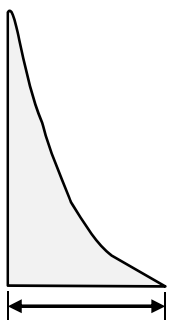

$\varphi_{\mathrm{u}}$

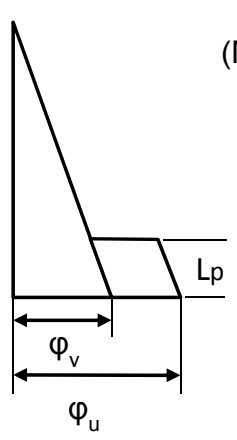

(c)
(M)

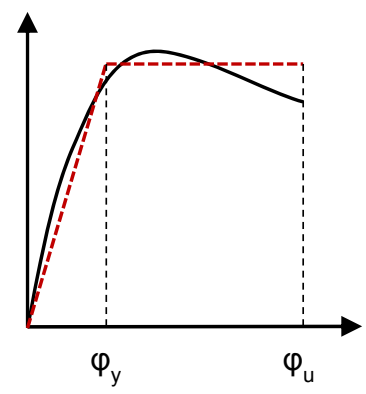

(d)

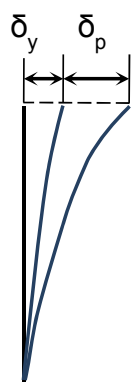

(e)

Figura 2.3 Modelo de soporte en voladizo.

$$
\delta_{u}=\delta_{y}^{\prime}+\delta_{p}=\delta_{y}^{\prime}+\left(\varphi_{u}-\varphi_{y}^{\prime}\right) L_{p}\left(L_{s}-0.5 L_{p}\right)
$$




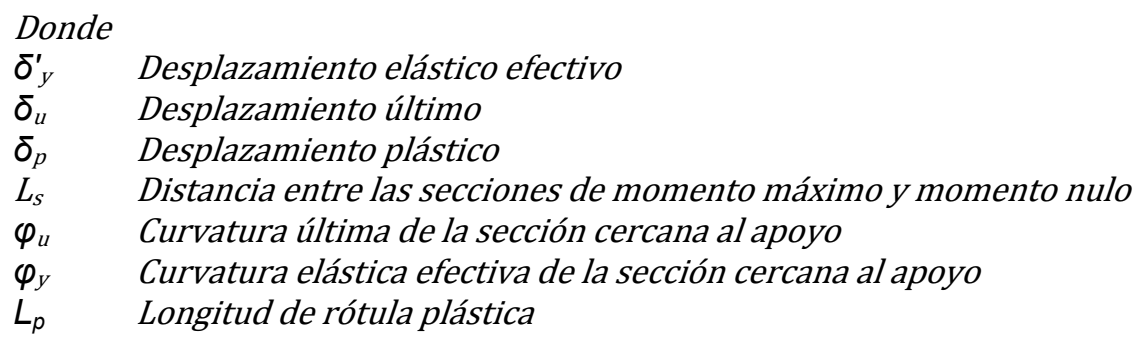

Los principios fundamentales del modelo de "soporte en voladizo" son:

- Se asume una distribución de curvaturas, tal y como aparece en la Figura 2.3c, la cual corresponde al desarrollo de las deformaciones de flexión elástica y post-elástica.

- Se considera que todo el comportamiento inelástico ocurre dentro de una longitud equivalente de rótula plástica $\left(L_{p}\right)$, y se asume un comportamiento elástico fuera de $L_{p}$. Por lo tanto, si la longitud de la rótula plástica es conocida, el desplazamiento en el extremo puede obtenerse mediante la integración de las curvaturas.

Algunos de los métodos utilizados en la evaluación del desplazamiento elástico y último basados en el modelo de soporte en voladizo, son los propuestos por: (a) Priestley et al. (1996) [110], (b) Lehman et al. (1998) [80] y (c) Fardis et al. (2003) [60]. Estos modelos se caracterizan porque, además de considerar la flexión, tienen en cuenta la contribución del cortante y el deslizamiento de la armadura en la zona de anclaje.

A continuación, se presentan los tres métodos analíticos, para los cuales se describe el proceso de evaluación de las siguientes variables: (1) curvatura efectiva elástica y última; (2) desplazamiento elástico; y (3) longitud de plastificación.

\subsubsection{Método analítico de Priestley y PARK (1996)}

El método de Priestley et. al. (1996) [110] fue deducido utilizando los resultados de ensayos experimentales en pilas de gran escala para puentes. El modelo utiliza una idealización de la respuesta monotónica para el elemento y la sección que se muestra en las Figura 2.4.

\section{Curvatura elástica y última}

La curvatura elástica se evalúa en este método sobre la curva idealizada del diagrama $\mathrm{M}-\varphi$ (Figura 2.4), en donde la curvatura elástica efectiva $\left(\varphi_{y}^{\prime}\right)$, no tiene por qué coincidir con el punto de plastificación. Conocido el punto de plastificación $\left(\varphi_{y}\right.$, $\mathrm{M}_{\mathrm{y}}$ ) en el diagrama momento-curvatura, la curvatura elástica efectiva se obtiene como la intersección entre la rama plástica y elástica. La pendiente de la rama elástica $\mathrm{El}_{\mathrm{e}}$ es denominada rigidez elástica efectiva a flexión de la sección y se obtiene como el cociente $M_{y} / \varphi_{y}$. Dicha rama elástica se prolonga hasta el momento nominal $\left(M_{n}\right)$. 


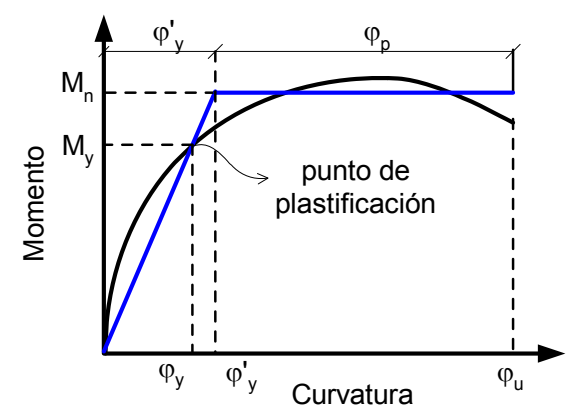

(a) Diagrama momento-curvatura

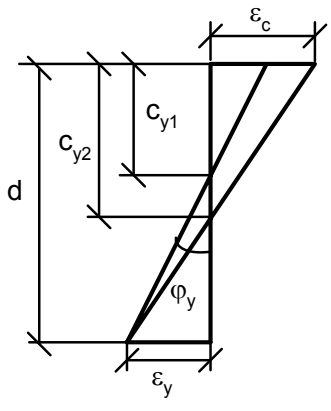

(b) Curvatura elástica

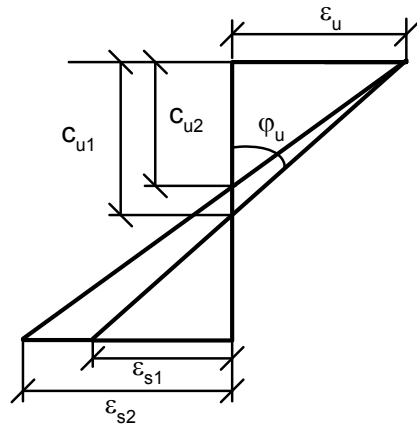

(c) Curvatura última

Figura 2.4 Descripción de la curvatura elástica y última, Método de Priestley et al. (1996) [110]

La curvatura elástica $\left(\varphi_{y}\right)$ correspondiente al punto de plastificación se define a partir de dos posibles situaciones: la armadura longitudinal plastifica o la deformación del hormigón en la fibra más comprimida alcanza el valor $\varepsilon_{c}=0.0015$, (Figura 2.4b). Dicho valor representa el $75 \%$ de la deformación correspondiente a la tensión máxima para hormigones convencionales con resistencia a la compresión menor de $50 \mathrm{MPa}$. Es decir, la curvatura elástica será el menor valor entre las Ec. 2-15, y Ec. 2-16.

Si plastifica la armadura:

$$
\varphi_{y}=\frac{\varepsilon_{Y}}{\left(d-c_{y}\right)}
$$

Donde

$\varepsilon_{y} \quad$ Deformación elástica del acero

$c_{y} \quad$ Profundidad de la fibra neutra para la situación $\varepsilon_{s}=\varepsilon_{y}$

d Canto útil de la sección transversal

En elementos con una alta cuantía de armadura longitudinal o sometidos a niveles altos de carga axial, se puede alcanzar una deformación importante del hormigón, antes que el acero en tracción alcance el límite elástico. En dicho caso, la curvatura elástica se calcula como:

$$
\varphi_{y}=\frac{\varepsilon_{c}}{c_{y}}
$$

Donde

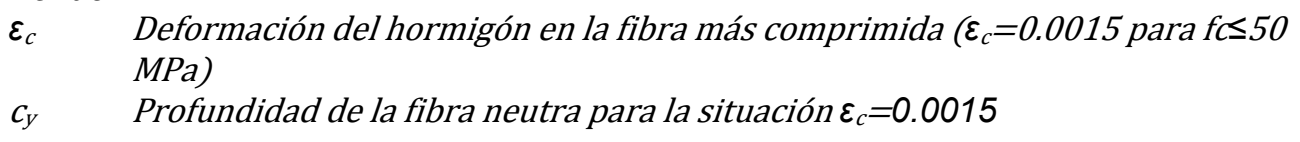

La curvatura elástica efectiva $\left(\varphi_{y}^{\prime}\right)$ se evalúa a partir de la Ec. 2-17 :

$$
\varphi_{y}^{\prime}=\frac{M_{n}}{M_{y}} \varphi_{y}
$$

El momento $\mathrm{M}_{\mathrm{y}}$ se determina en el punto de plastificación y el momento nominal resistente de la sección $\left(\mathrm{M}_{\mathrm{n}}\right)$ se calcula cuando la deformación del hormigón en la fibra más comprimida de la sección alcanza el valor de $\varepsilon_{\mathrm{u}}=0.004$. 
En este método la curvatura última está condicionada por la deformación máxima en la fibra más comprimida de la sección. Originalmente, Paulay y Priestley (1992) [104] proponen que para elementos de hormigón no confinados, la deformación máxima puede adoptar el valor de 0.004 para $\mathrm{f}_{\mathrm{c}} \leq 45 \mathrm{MPa}$. En ese caso, la profundidad de la fibra neutra $\left(\mathrm{c}_{\mathrm{u}}\right)$ se calcula considerando la sección completa.

Posteriormente, Priestley et al. (1996) [110], consideran que para elementos confinados la curvatura última está limitada por la capacidad de deformación del núcleo de hormigón confinado. En este caso, la deformación máxima de compresión del hormigón en el núcleo se calcula de acuerdo a la ecuación de Mander, (Ec. 2-18), y la profundidad de la fibra neutra $\left(\mathrm{c}_{\mathrm{u}}\right)$ se calcula para la sección de núcleo confinado.

$$
\begin{gathered}
\varepsilon_{c u}=0.004+1.4 \varepsilon_{\text {su }} \frac{\rho_{s} f_{y h}}{f_{c c}^{\prime}} \\
\varphi_{u}=\frac{\varepsilon_{c u}}{c_{u}}
\end{gathered}
$$

Donde

$\begin{array}{ll}\varepsilon_{s u} & \text { Deformación del acero en el punto de tensión máxima } \\ \rho_{s} & \text { Cuantía de armadura transversal } \\ f_{y h} & \text { Límite elástico del acero transversal } \\ f_{c c} & \text { Resistencia del hormigón confinado según } f_{c c}=1.7 f_{c}\end{array}$

\section{Desplazamiento elástico}

La expresión Ec. 2-20 permite determinar el desplazamiento elástico $\left(\delta_{\mathrm{y}}\right)$ en el punto de plastificación. Sin embargo, desde la perspectiva del diseño, el punto de interés es el desplazamiento elástico efectivo $\left(\delta_{\mathrm{y}}^{\prime}\right)$ evaluado sobre la curva de respuesta idealizada; entonces, $\delta_{y}^{\prime}$ se obtiene a partir de la Ec. 2-21.

$$
\begin{aligned}
& \delta_{y}=\frac{\varphi_{y} L_{s}^{2}}{3} \\
& \delta_{y}^{\prime}=\frac{M_{n}}{M_{y}} \delta_{y}
\end{aligned}
$$

\footnotetext{
Donde

$\varphi_{y} \quad$ Curvatura elástica

$L_{s} \quad$ Distancia entre la secciones de momento máximo y momento nulo

$M_{n} \quad$ Momento nominal calculado cuando la deformación del hormigón en la fibra más comprimida de la sección alcanza el valor de $\varepsilon_{u}=0.004$.

$M_{y} \quad$ Momento elástico, calculado para la menor de las dos condiciones Ec. 2-15 y Ec. 2-16.
}

\section{Longitud de plastificación}

La longitud de rótula plástica se calcula con la expresión Ec. 2-22. El primer término se relaciona con el comportamiento a flexión del soporte, y el segundo incluye principalmente el efecto de deslizamiento de la armadura en la zona de anclaje.

$$
L_{p}=0.08 L_{s}+0.022 f_{y} \Phi \quad\left(f_{y} \text { en } M P a\right)
$$


Donde

$L_{s} \quad$ Distancia entre las secciones de momento máximo y momento nulo

$f_{y} \quad$ Límite elástico del acero longitudinal

$\Phi \quad$ Diámetro de la armadura longitudinal

\subsubsection{MÉtodo de Lehman y MoEhLe (1998)}

El método propuesto por Lehman y Moehle (1998) [80], al igual que el método de Priestley y Park (1996) [110], asume un comportamiento bilineal para la idealización del diagrama de respuesta de la sección $(M-\varphi)$.

\section{Curvatura elástica y última}

La curvatura elástica $\left(\varphi_{y}\right)$ se calcula a partir de la plastificación de la armadura o del inicio del comportamiento no lineal del hormigón para $\varepsilon_{\mathrm{c}}=0.002$. El momento nominal $\left(\mathrm{M}_{\mathrm{n}}\right)$ se calcula conforme a la Norma ACl-318 [1] y la curvatura elástica efectiva se evalúa de acuerdo a la Ec. 2-24.

$$
\begin{gathered}
\varphi_{y}=\frac{\varepsilon_{c}}{C_{y}} \\
\varphi_{y}^{\prime}=\frac{M_{n}}{M_{y}} \varphi_{y}
\end{gathered}
$$

Ec. 2-24

En este método la curvatura máxima $\left(\varphi_{\max }\right)$ se obtiene para un límite de deformación del acero en tracción, igual a la mitad de la deformación en la carga última $\left(0.5 \varepsilon_{\mathrm{su}}\right)$. Este límite de deformación se asume para tener en cuenta implícitamente los efectos de la carga cíclica en ensayos con desplazamiento impuesto.

$$
\varphi_{\max }=\frac{0.5 \varepsilon_{\text {su }}}{c_{u}}
$$

\section{Desplazamiento elástico}

El desplazamiento elástico $\left(\delta_{y}\right)$ se obtiene como la suma de tres componentes: flexión $\left(\delta_{y-f}\right)$, deslizamiento de la armadura en el extremo del apoyo $\left(\delta_{y-v}\right)$, y cortante $\left(\delta_{y-s}\right)$. El deslizamiento elástico efectivo $\left(\delta_{y y}^{\prime}\right)$, se calcula a partir de $\delta_{y}$ nuevamente amplificado por la relación $\mathrm{M}_{\mathrm{n}} / \mathrm{M}_{\mathrm{y}}$.

$$
\begin{gathered}
\delta_{y}^{\prime}=\frac{M_{n}}{M_{y}} \delta_{y} ; \quad \delta_{y}=\delta_{y-f}+\delta_{y-v}+\delta_{y-s} \\
\delta_{y-f}=\frac{\varphi_{y} L_{s}^{2}}{3} \\
\delta_{y-v}=\frac{V_{y} L_{s}}{0.4 \cdot E_{c s} 0.8 A_{g}}
\end{gathered}
$$




$$
\delta_{y-s}=\varphi_{y} L_{s} \frac{d_{b} f_{y}}{8 \sqrt{f_{c}}}
$$

Donde

$\varphi_{y} \quad$ Curvatura elástica

$L_{s} \quad$ Distancia entre las secciones de momento máximo y momento nulo

$V_{y} \quad$ Carga de cortante en el punto de plastificación

$E_{c s} \quad$ Módulo del hormigón secante $E_{c s}=f_{c} / 0.002$ para $f_{c} \leq 50$

$A_{g} \quad$ Área bruta de la sección transversal

$d_{b} \quad$ Diámetro de la armadura longitudinal

$f_{y} \quad$ Límite elástico del acero

$f_{c} \quad$ Resistencia del hormigón a compresión

\section{Longitud de rótula plástica}

Lehman y Moehle (2000) [80] proponen la Ec. 2-30 para evaluar la longitud de rótula plástica.

$$
L_{p}=0.5 L_{s} \frac{\left(M_{u}-M_{y}\right)}{M_{n}}+\frac{1.2\left(f_{u}-f_{y}\right) d_{b}}{\left(4 \sqrt{f_{c}}\right)}
$$

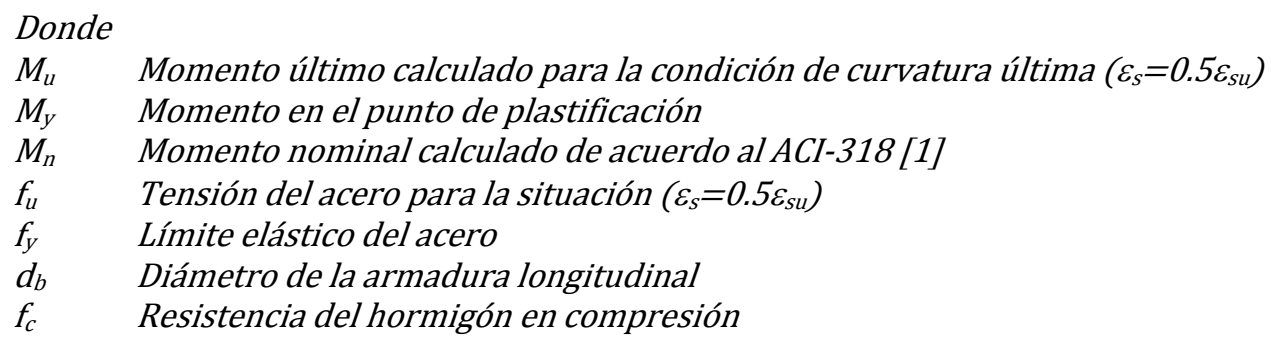

\subsubsection{MÉtodo ANALítico de FARdis et AL. (2001)}

El modelo analítico de Panagiotakos y Fardis (2001) [100], presentado posteriormente por Fardis y Biskinis (2003) [60], ha sido desarrollado en base a los principios del análisis teórico de elementos de hormigón armado. Este método se ha calibrado con una amplia base de datos compuesta por más de 1200 ensayos en elementos tipo viga y soportes de hormigón armado, en los cuales la rotura del elemento se ha debido al agotamiento por flexión. Los rangos y parámetros para los cuales el método ha sido ajustado se indican en la Tabla 2-7.

\begin{tabular}{|c|c|}
\hline Parámetro & Rango \\
\hline Resistencia del hormigón, $f_{c}(\mathrm{MPa})$ & 15 a 90 \\
\hline Axil reducido, $\left(N / A_{g} f_{c}\right)$ & 0 a 0.85 \\
\hline Esbeltez, (L/h) & 1 a 6,5 \\
\hline Cuantía longitudinal, $\rho_{1}(\%)$ & 0.1 a 4 \\
\hline Cuantía transversal, $\rho_{\mathrm{s}}=\mathrm{A}_{\mathrm{sh}} / \mathrm{s} . \mathrm{h}(\%)$ & 0.1 a 2 \\
\hline \multicolumn{2}{|c|}{$\begin{array}{l}\text { Acero trabajado en frio, con tratamiento térmico y rodado en } \\
\text { caliente }\end{array}$} \\
\hline
\end{tabular}

Tabla 2-7 Rangos y parámetros incluidos en la base de datos de Fardis et al. 
Este método propone un proceso analítico para determinar la deformación elástica y última de elementos de hormigón armado en términos de la deriva $\left(\theta=\delta / L_{s}\right)$, basado en el modelo de soporte en voladizo, Ec. 2-31.

$$
\theta_{u}=\theta_{y}+\theta_{p}=\theta_{y}+\left(\varphi_{u}-\varphi_{y}\right) L_{p}\left(1-\frac{0.5 L_{p}}{L_{s}}\right)
$$

\section{Donde}

$\theta_{y} \quad$ Deriva elástica

$\theta_{p} \quad$ Deriva plástica

$L_{s} \quad$ Distancia entre el punto de momento máximo y momento nulo

$L_{p} \quad$ Longitud de rótula plástica

$\varphi_{u} \quad$ Curvatura última de la sección cercana al apoyo

$\varphi_{y} \quad$ Curvatura elástica de la sección cercana al apoyo

\section{Curvaturas elástica y última}

La curvatura elástica $\left(\varphi_{y}\right)$ es evaluada para el punto que marca el comienzo de la no-linealidad en el diagrama $M-\varphi$, (Ec. 2-32). En este caso el punto de plastificación se refiere a la primera situación que ocurre entre las dos siguientes: o bien cuando plastifica la armadura longitudinal o bien cuando la deformación del hormigón en la fibra más comprimida de la sección es igual al $90 \%$ de la deformación correspondiente a la tensión máxima $\left(\varepsilon_{\mathrm{co}}\right)$.

$$
\varphi_{y}=\min \left\{\frac{f_{y}}{E_{s}} \cdot \frac{1}{d-x_{y}}, \frac{\varepsilon_{c, y}}{x_{y}} \approx \frac{1.8 f_{c}}{E_{c} k_{y} d}\right\}
$$

El momento elástico, $\mathrm{M}_{\mathrm{y}}$, se estima aplicando la Ec. 2-33.

$$
\frac{M_{y}}{b d^{3}}=\phi_{y}\left\{E_{c} \frac{k_{y}^{2}}{2}\left(0.5\left(1+\delta^{\prime}\right)-\frac{k_{y}}{3}\right)+\frac{E_{s}}{2}\left[\left(1-k_{y}\right) \rho+\left(\kappa_{y}-\delta^{\prime}\right) \rho^{\prime}+\frac{\rho_{v}}{6}\left(1-\delta^{\prime}\right)\right]\left(1-\delta^{\prime}\right)\right\} \quad \text { Ec. 2-33 }
$$

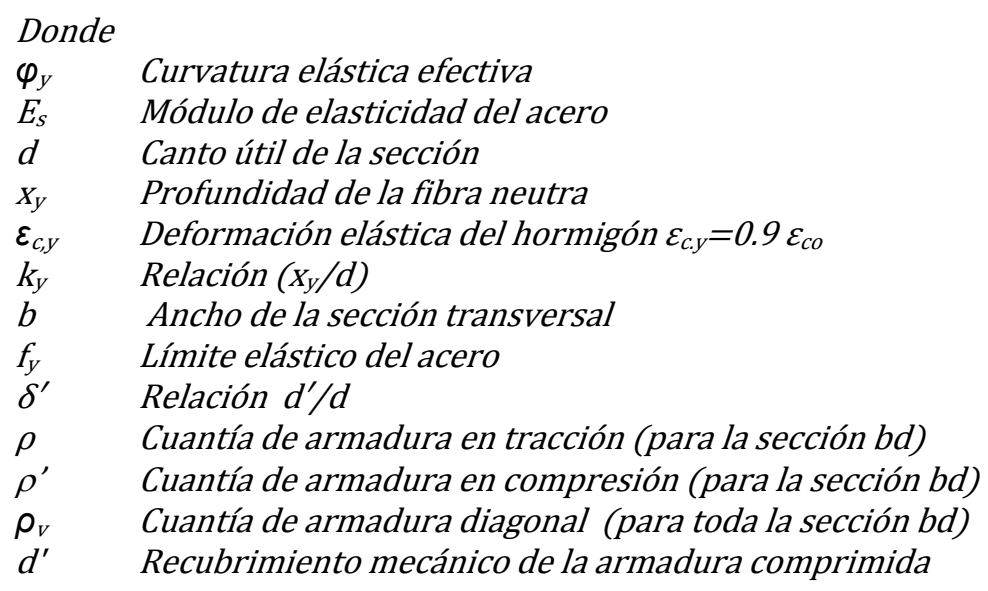

Panagiotakos y Fardis (2001) [100], proponen un procedimiento analítico para evaluar la curvatura última, en el cual se tiene en cuenta el modo de fallo de la sección, si se produce la rotura de la armadura en tracción o si el fallo se presenta en la zona de compresión. Adicionalmente, este método considera que los dos 
modos de fallo pueden ocurrir o bien con la sección completa o bien con el núcleo confinado de hormigón.

Si el fallo se debe a la rotura del acero, la curvatura última se calcula como:

$$
\varphi_{s u}=\frac{\varepsilon_{s u}}{\left(1-k_{s u}\right) d}
$$

Donde

$\mathcal{E}_{S u} \quad$ Deformación última del acero

$k_{s u} \quad$ Relación entre la profundidad de la fibra neutra $(x)$ y el canto útil de la sección (d), cuando el fallo ocurre por agotamiento del acero

d Canto útil de la sección

Cuando falla la zona de compresión, la curvatura última se calcula como:

$$
\varphi_{c u}=\frac{\varepsilon_{c u}}{k_{c u} d}
$$

Donde

$\mathcal{E}_{s u} \quad$ Deformación última del hormigón compresión

$k_{c u} \quad$ Relación entre la profundidad de la fibra neutra $(x)$ y el canto útil de la sección (d), cuando el fallo ocurre en la zona en compresión.

Si la rotura ocurre en el núcleo confinado, las variables de las Ec. 2-34 y Ec. 2-35 deben ser remplazadas por las correspondientes a la sección del núcleo confinado.

La deformación última del hormigón confinado se calcula de acuerdo con el modelo de Mander, Ec. 2-36, mientras que la resistencia máxima para el hormigón confinado se calcula con la Ec. 2-37.

$$
\begin{gathered}
\varepsilon_{\text {su }}=0.004+1.4 \varepsilon_{\text {su }} \frac{\rho_{s} f_{y h}}{f_{c c}} \\
f_{c c}=f_{c}\left(1+3.7\left(\frac{0.5 \alpha \rho_{s} f_{y h}}{f_{c}}\right)^{0.87}\right)
\end{gathered}
$$

Donde

$\rho_{s} \quad$ Cuantía de armadura transversal

$f_{y h} \quad$ Límite elástico del acero transversal

$f_{c} \quad$ Resistencia del hormigón en compresión

El coeficiente $\alpha$ de la Ec 2-37 tiene en cuenta el efecto de la distribución de la armadura transversal. Este coeficiente se calcula de acuerdo a Sheikh y Uzumeri (1980) [119], adoptado más tarde por el CEB-FIP 1990 Código Modelo [33] y el Eurocódigo (2004) [58], a partir de la siguiente expresión (para secciones rectangulares):

$$
\alpha=\left(1-\frac{s_{h}}{2 b_{c}}\right)\left(1-\frac{s_{h}}{2 h_{c}}\right)\left(1-\frac{\Sigma b_{i}^{2}}{6 b_{c} h_{c}}\right)
$$


Donde

$s_{h} \quad$ Separación entre cercos

$b_{c} \quad$ Ancho del núcleo confinado

$h_{c} \quad$ Canto del núcleo confinado

bi Distancia entre sucesivas armaduras longitudinales atadas mediante ganchos

\section{Desplazamiento elástico}

Panagiotakos y Fardis (2001) [100] proponen utilizar la Ec. 2-39 para el cálculo del desplazamiento elástico efectivo $\left(\delta_{\mathrm{y}}^{\prime}\right)$. Al igual que el modelo de Lehman et al. [80], existe una componente de flexión (Ec. 2-40), de cortante (Ec. 2-41) y de deslizamiento (Ec. 2-42). Cabe destacar que las expresiones de Panagiotakos y Fardis (2001) [100], permiten evaluar directamente el desplazamiento efectivo de la curva idealizada.

$$
\begin{gathered}
\delta_{y}^{\prime}=\delta_{y-f}+\delta_{y-v}+\delta_{y-s} \\
\delta_{y-f}=\frac{\varphi_{y} L_{s}^{2}}{3} \\
\delta_{y-v}=0.00275 L_{s} \\
\delta_{y-s}=a_{s l} \frac{0.2 \varepsilon_{y} d_{b} f_{y} L_{s}}{\left(d-d^{\prime}\right) \sqrt{f_{c}}}
\end{gathered}
$$

\footnotetext{
Donde

$\delta_{y-f} \quad$ Desplazamiento elástico debido a la flexión

$\delta_{y-v} \quad$ Desplazamiento elástico debido al cortante

$\delta_{y-s} \quad$ Desplazamiento elástico debido al deslizamiento de la armadura anclada en el apoyo

$\varphi_{y} \quad$ Curvatura elástica calculada de acuerdo con Panagiotakos y Fardis (2001) (2001) [100]

$L_{s} \quad$ Longitud del elemento de hormigón entre el punto de momento máximo y momento nulo

$\varepsilon_{y} \quad$ Deformación correspondiente al límite elástico del acero

$d_{b} \quad$ diámetro de la armadura longitudinal

$F_{y} \quad$ Límite elástico del acero

d Canto útil de la sección

$d^{\prime} \quad$ Recubrimiento mecánico de la armadura comprimida

$f_{c} \quad$ Resistencia del hormigón en compresión

$a_{s l} \quad$ Coeficiente igual a 1 si se desliza la armadura longitudinal en la zona de anclaje en las secciones cercanas al apoyo, y 0 si esto no es posible
}

\section{Longitud de la rótula plástica}

En las siguientes expresiones los efectos de fisuración por cortante y el deslizamiento de la armadura por pérdida de adherencia están incluidos en la longitud de plastificación $\left(L_{p}\right)$. 
Para carga cíclica

$$
\begin{array}{ll}
L_{p l_{c y, L s}}=0.08 L_{s}+\frac{1}{60} a_{s l} d_{b} f_{y} & \text { Ec. } 2-43 \\
L_{p l_{, c y, h}}=0.225 h+\frac{1}{60} a_{s l} d_{b} f_{y} & \text { Ec. } 2-44
\end{array}
$$

Para carga monotónica

$$
\begin{gathered}
L_{p l_{\text {mon }, L s}}=0.18 L_{s}+0.025 a_{s l} d_{b} f_{y} \\
L_{p l_{c y, h}}=0.8 h+0.025 a_{s l} d_{b} f_{y}
\end{gathered}
$$

Panagiotakos et al. (2001) [100] y Fardis et al. (2003) [60], presentan los valores estadísticos del ajuste conseguido para cada una de las expresiones desarrolladas en el método analítico. El error se evalúa como la relación entre los valores calculados y los valores experimentales. Los resultados del error y el número de ensayos utilizados en la comparación se presentan en la Tabla 2-8.

\begin{tabular}{|c|c|c|c|c|c|}
\hline & Ec. & $\begin{array}{c}N^{\circ} \text { de } \\
\text { ensayos }\end{array}$ & Media & Mediana & $\begin{array}{l}\text { C.V. } \\
\text { (\%) }\end{array}$ \\
\hline$\varphi_{y-\exp } / \varphi_{y, \text { cal }}$ & Ec. 2-32 & 296 & 1.22 & 1.16 & 32 \\
\hline $\mathrm{M}_{\mathrm{y} \text {-exp }} / \mathrm{M}_{\mathrm{y}, \mathrm{cal}}$ & Ec. 2-33 & 1008 & 1.06 & 1.02 & 20 \\
\hline$\varphi_{\text {u-exp } /} \varphi_{u, \text { cal }}$ & Ec. 2-34 a Ec. 2-38 & 261 & 1.26 & 1.0 & 70 \\
\hline$\theta_{\mathrm{y} \text {-exp/ } /} \theta_{\mathrm{y}, \text { cal }}$ & Ec. 2-39 a Ec. 2-42 & 963 & 1.06 & 1.0 & 36 \\
\hline $\begin{array}{c}\theta_{\mathrm{u} \text {-exp/ }} \theta_{\mathrm{u}, \mathrm{cal}} \\
\text { (monotónico) }\end{array}$ & Ec. 2-32 a Ec. 2-42+ Ec. 2-43 & 242 & 1.37 & 1.01 & 94 \\
\hline $\begin{array}{c}\theta_{\mathrm{u} \text { exp/ } /} \theta_{\mathrm{u}, \text { cal }} \\
\text { (ciclico) }\end{array}$ & Ec. $2-32$ a Ec. $2-42+$ Ec. $2-45$ & 633 & 1.23 & 0.99 & 83 \\
\hline
\end{tabular}

Tabla 2-8 Resultados de la Media, mediana, y coeficiente de variación (CV) obtenidos para cada una de las expresiones desarrolladas en el método analítico según Panagiotakos et al. (2001) [100]

\subsubsection{LONGITUD DE RÓTULA PLÁSTICA}

En los métodos simplificados propuestos que predicen el desplazamiento elástico y último de soportes de hormigón armado, la estimación de la longitud de rótula plástica resulta ser la variable con mayor incertidumbre en el cálculo. Por consiguiente, algunas investigaciones, como Baker y Amarakone (1964) [14], Corley (1966) [45], Sheikh et al. (1989-1998) [17] [18] [121] [122], Park et al. (1982) [102], entre otros. se han dedicado exclusivamente al estudio de los parámetros que afectan la longitud de rótula plástica y su implicación dentro del cálculo de $L_{p}$. Por ello, se considera de gran importancia realizar un resumen de las investigaciones realizadas para la evaluación de la rótula plástica.

La longitud de rótula plástica se ha estudiado a partir de dos posibles aplicaciones. Una de ellas tiene que ver con las primeras expresiones de $L_{p}$ que aparecen en la bibliografía, las cuales se propusieron con el propósito de evaluar la rotación plástica que ocurre en vigas hiperestáticas y que permiten una redistribución de los momentos. Esto ha sido considerado dentro del análisis no lineal, el análisis lineal con distribución de momentos y en el análisis plástico. La segunda aplicación de $L_{p}$ 
que ha dado origen a una importante cantidad de propuestas, tiene que ver con la evaluación del desplazamiento último en modelos de "soporte en voladizo".

\subsubsection{EXPRESIONES DE $L_{P}$ OBTENIDAS A PARTIR DE LA INTEGRACIÓN DE LA CURVATURA INELÁSTICA}

En esta sección, se presenta un resumen de las propuestas más importantes para el cálculo de la $L_{\mathrm{p}}$, desarrolladas a partir de la integración de la curvatura inelástica a lo largo de $L_{s}$, longitud entre el momento máximo y el momento nulo, Figura 2.5.

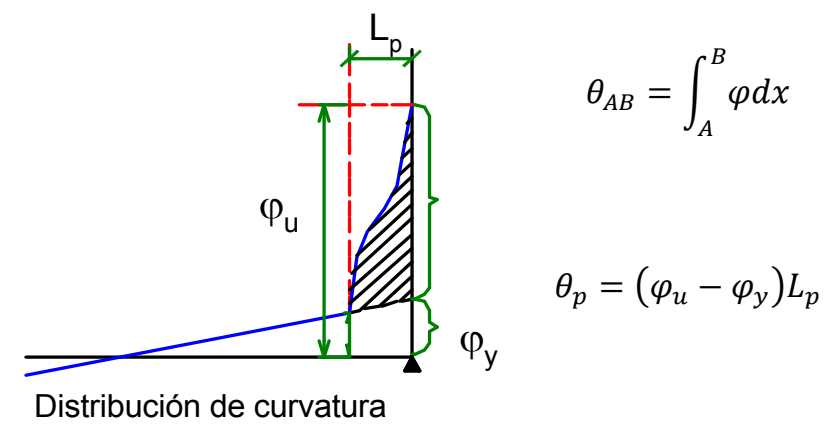

Figura 2.5 Planteamiento teórico, para el cálculo de rotación plástica en vigas hiperestáticas

A comienzos de los años 60 el Comité Europeo del Hormigón (CEB) coordinó un amplio estudio del comportamiento inelástico de estructuras de hormigón armado. Se llevaron a cabo 90 ensayos experimentales en elementos de hormigón en 18 laboratorios de 13 países (citado en Baker y Amarakone (1964) [14]), y los resultados fueron presentados mediante la relación momento-curvatura y capacidad de rotación. A partir de esta iniciativa, se demostró la influencia de varios parámetros en la deformación plástica en elementos de hormigón armado que fueron atribuidos a la longitud de la rótula plástica $\left(L_{\mathrm{p}}\right)$. Basándose en estos resultados, Baker y Amarakone (1964) [14], propusieron una primera expresión para $L_{\mathrm{p}}$ :

$$
L_{p}=k_{1} k_{2} k_{3}\left(\frac{L_{s}}{d}\right)^{1 / 4} d
$$

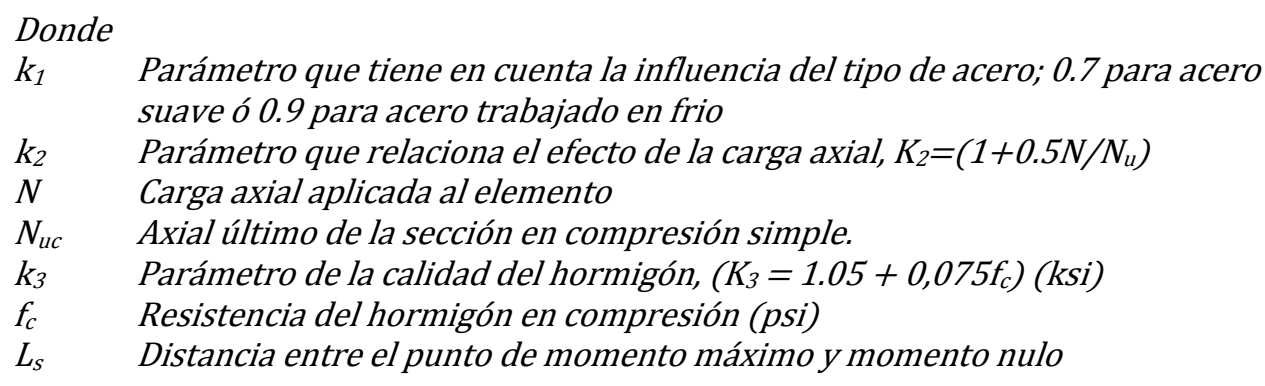

En el "International Symposium on the Flexural Mechanics of Reinforced Concrete" (1964) [14] se presentó una revisión conjunta de este trabajo. En esta publicación aparecen algunas propuestas para $L_{\mathrm{p}}$. Por un lado, Baker y Amerakone (1964) [14] proponen la Ec. 2-48 para simplificar la expresión inicial de Baker. 


$$
L_{p}=0.8 k_{1} k_{3}\left(\frac{L_{s}}{d}\right) x
$$

Donde:

X $\quad$ Altura de la fibra neutra para el estado último

Ls Distancia del elemento desde el momento máximo hasta el momento nulo

d Canto útil de la sección

k1 y k2 Como en Ec. 2-47

Por otra lado, Mattock (1965) [87], basándose en los ensayos de 37 vigas sometidas a flexión, propone un método de cálculo para evaluar la rotación de la rótula plástica en vigas de hormigón armado, a partir del cual se deduce la Ec. 2-49 para $L_{\mathrm{p}}$.

$$
L_{p}=\frac{d}{2}\left\{1+\left(1.14 \sqrt{\frac{L_{s}}{d}}-1\right)\left[1-\left(\frac{q-q^{*}}{q_{b}}\right) \sqrt{\frac{d}{16.2}}\right]\right\}
$$

Donde:

$q \quad$ Cuantía mecánica de armadura de tracción $\left(q=\rho f_{y} / f_{c}\right)$

$q^{*} \quad$ Cuantía mecánica de armadura de compresión $\left(q^{\prime}=\rho^{\prime} f_{y} / f_{c}\right)$

$q_{b}: \quad$ Cuantía mecánica de la armadura en tracción, para la condición de balanceo,

$\left(q_{b}=\rho_{b} f_{y} / f_{c}, \rho_{b}\right.$ es calculada asumiendo $\left.\varepsilon_{u}=0.003\right)$

$f_{y} \quad$ Límite elástico del acero

$f_{c} \quad$ Resistencia del hormigón en compresión

Otras propuestas realizadas durante los años sesenta son las de Corley (1966) [45], y Mattock (1965) [87]. En el desarrollo de estos trabajos se consideraron los efectos de la rama de endurecimiento del acero en la resistencia última de elementos de hormigón armado.

Corley (1966) [45] estudió el efecto de las variables no consideradas por Mattock (1965) [87], el tamaño de las vigas y el confinamiento transversal. Para ello realizó 40 ensayos en vigas simplemente apoyadas y sometidas a flexión con una carga puntual en el centro de la luz, proponiendo la siguiente expresión:

$$
L_{p}=\frac{d}{2}+\frac{0.2 L_{s}}{\sqrt{d}}
$$

Mattock (1967) [89] posteriormente sugirió ajustar la ecuación propuesta por Corley (Ec. 2-50).

$$
L_{p}=0.5 d+0.05 L_{s}
$$

Donde

d $\quad$ Canto útil de la sección

$L_{s} \quad$ Distancia entre las secciones de momento máximo y momento nulo

Cabe destacar que la única expresión que ha sido obtenida considerando el nivel de carga axial, es la primera expresión de Baker (1964) [14]. Baker y Amarakone (1964) [14] desestiman la influencia del nivel de carga axil. Corley (1966) [45] y Mattock (1965) [87], obtienen las expresiones sólo utilizando elementos vigas 
sometidas a flexión. Adicionalmente, se destaca la importante diferencia entre las propuestas de Mattock, Baker-Amarakone y Corley respecto a la expresión de deformación última del hormigón en compresión, lo que implica que existen notables discrepancias en la concepción y calibración entre dichas expresiones.

\subsubsection{EXPRESIONES DE $L_{P}$ OBTENIDAS A PARTIR DEL ANÁLISIS DEL SOPORTE EN VOLADIZO}

En general, las expresiones propuestas para el cálculo de la longitud de rótula plástica son obtenidas a partir de resultados de ensayos experimentales en los cuales se conoce tanto el comportamiento de la sección como el comportamiento del elemento $y$, por consiguiente, la $L_{p}$ se puede deducir de la ya conocida Ec. 2-14.

En el proceso de análisis para obtener una expresión de $L_{p}$, algunos investigadores, como Priestley (1996) [111], Lehman (1998) [81], Panagiotakos y Fardis (2001) [100], o Lehman y Moehle (2000) [80] basan el análisis en la Ec. 2-52.

$$
L_{p}=\frac{M_{\max }-M_{y}}{M_{\max }} \cdot L_{s}+C_{t}=\alpha L_{S}+C_{t}
$$

Donde

$M_{\max } \quad$ Momento máximo de la sección transversal

$M_{y} \quad$ Momento elástico

$L_{s} \quad$ Distancia entre las secciones de momento máximo y momento nulo

El primer término representa la longitud plástica debida a los efectos de flexión, y en el segundo término $\left(\mathrm{C}_{\mathrm{t}}\right)$ se incorpora el efecto del deslizamiento de la armadura en el extremo fijo del soporte (Figura 2.6).

Priestley (1996) [111] asume el valor de $\alpha=0,08$, Panagiotakos y Fardis (2001) [100] asumen $\alpha=0,12$, mientras que Lehman y Moehle (2000) [80] usan la expresión general para $\alpha=\left(M_{\max }-M_{y}\right) / M_{\max }$.

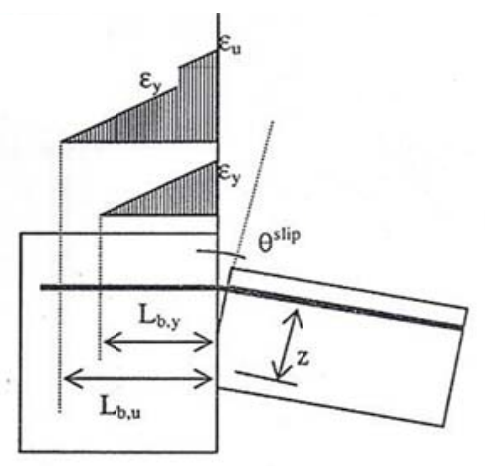

Figura 2.6 Rotación debida al deslizamiento de la armadura

En la Tabla 2-9 se presenta un resumen de las principales expresiones propuestas para $L_{p}$. Dichas expresiones tienen dos términos en los que se tiene en cuenta la flexión y el deslizamiento de la armadura en el extremo del apoyo. Estas expresiones han sido obtenidas a partir de ensayos experimentales y en especial para soportes de hormigón armado. 
Estudio experimental y numérico de la capacidad de deformación de soportes esbeltos de hormigón armado

Tabla 2-9 Resumen de expresiones para la longitud de rótula plástica obtenidas a partir de la experimentación de soportes de hormigón armado, $L_{p_{-} \text {exp }}$ ha sido medida a partir de la relación entre las curvaturas y los desplazamientos

\begin{tabular}{|c|c|c|}
\hline $\begin{array}{c}\text { Priestley y Park } \\
(1987) \text { [110] }\end{array}$ & $L_{p}=0.08 L_{s}+6 \Phi$ & Ec. 2-53 \\
\hline $\begin{array}{c}\text { Zahn F. A. (1986) } \\
\text { [138] }\end{array}$ & $L_{p}=\left(0.08 L+6 d_{b}\right)\left(0.5+1.67 \frac{P}{f_{c} A_{g}}\right)$ para $\frac{P}{f_{c} A_{g}}<0.3$ & Ec. 2-54 \\
\cline { 2 - 4 } & $L_{p}=0.08 L+6 d_{b} \quad$ para $\frac{P}{f_{c} A_{g}} \geq 0.3$ & Ec. 2-55 \\
\hline $\begin{array}{c}\text { Mander J.B. } \\
\text { (1984) [84] }\end{array}$ & $L_{p}=32 \sqrt{d_{b}}+0.06 L$ & Ec. 2-56 \\
\hline $\begin{array}{c}\text { Paulay y Priestley } \\
\text { (1992) [104] }\end{array}$ & $L_{p}=0.08 L_{s}+0.022 f_{y} \Phi$ & Ec. 2-57 \\
\hline $\begin{array}{c}\text { Lehman (1998) } \\
\text { [81] }\end{array}$ & $L_{p}=0.5 \alpha L_{s}+1.2 \alpha f_{u} \frac{\Phi}{4 f_{b, y}}$ & Ec. 2-58 \\
\hline $\begin{array}{c}\text { Panagiotakos y } \\
\text { Fardis (2001) } \\
\text { [100] }\end{array}$ & $L_{p}=0.12 L_{s}+0.014 f_{y} \phi$ & Ec. 2-59 \\
\hline $\begin{array}{c}\text { Lehman y Moehle } \\
\text { (2000) [80] }\end{array}$ & $L_{p}=\frac{l_{y}}{2}+\frac{\left(f_{u}-f_{y}\right) \phi}{40 \sqrt{f_{c}}} ; l_{y}=\frac{M_{u}-M_{y}}{M_{u}}($ en $p s i)$ & Ec. 2-60 \\
\hline
\end{tabular}

Ceroni, Manfredi y Pecce (2003) [36], llevaron a cabo un amplio programa de ensayos numéricos, con el propósito de evaluar la rotación plástica desarrollada en soportes de hormigón armado. Los ensayos se realizaron utilizando un modelo de fibras donde, además de incluir las características geométricas de los materiales, se introdujo un modelo de adherencia entre el hormigón y la armadura. El modelo ha sido desarrollado para elementos sujetos a carga axial y flexión monotónica.

En estos ensayos, la rotación del elemento se evalúa mediante dos contribuciones, siendo una de ellas la de la flexión y la otra la rotación en el extremo del apoyo. La primera rotación, debida a la flexión, se calcula integrando la distribución de curvatura a lo largo del soporte.

Para calcular la rotación en la base del soporte, debida al efecto del deslizamiento de la armadura anclada, se calcula la longitud de transferencia de tensión del acero al hormigón dentro de la zona de anclaje y, por consiguiente, el deslizamiento.

$$
\theta_{p, f f x}=\frac{s_{b}}{\left(d-x_{c}\right)}
$$

Donde

$S_{b} \quad$ Deslizamiento de la armadura

$x_{c} \quad$ Profundidad de la fibra neutra de la sección en la base del soporte 


\section{$\theta_{p, \text { fix }} \quad$ Rotación plástica en la base del soporte, debida al efecto del deslizamiento de la armadura anclada}

Para cada una de las contribuciones de rotación plástica (Ec. 2-62) es posible obtener una expresión para la longitud de rótula plástica, al dividir cada una de las contribuciones de rotación plástica por la curvatura plástica de la sección en la base del elemento. La rotación plástica para cada contribución en los ensayos de Ceroni, Manfredi y Pecce (2003) [36] fue evaluada como la diferencia entre la rotación en el momento máximo $\left(\theta_{\mathrm{u}}\right)$ y la rotación elástica definida para cuando ocurre la plastificación del acero $\left(\theta_{y}\right)$ :

$$
\begin{gathered}
\theta_{p}=\theta_{p, c}+\theta_{p, f i x} \\
\theta_{p}=\theta_{u}-\theta_{y}=\left(\varphi_{u}-\varphi_{y}\right) L_{p} \\
L_{p}=L_{p}^{I}+L_{p}^{I I}
\end{gathered}
$$

Donde

$\theta_{p} \quad$ Rotación plástica total

$\theta_{p, c} \quad$ Rotación plástica de flexión

$\theta_{p, f i x} \quad$ Rotación plástica en la base del soporte, debida al efecto del deslizamiento de la armadura anclada

$L_{p}^{I} \quad$ Longitud de rotula plástica, $\theta_{p, c} /\left(\varphi_{u}-\varphi_{y}\right)$

$L^{I I} \quad$ longitud de rotula plástica, $\theta_{p, f i x} /\left(\varphi_{u}-\varphi_{y}\right)$

Las expresiones para $L_{p}^{\prime}$ y $L_{p}^{\prime \prime}$ (Ec. 2-65 y Ec. 2-66) han sido obtenidas a partir de 3780 simulaciones numéricas, y realizando un análisis estadístico sobre los resultados numéricos con respecto a los parámetros más importantes.

$$
\begin{gathered}
L_{p}^{I}=6.1\left(\frac{L}{h}\right)^{0.43} \cdot\left(\frac{f_{t}}{f_{y}}-1\right)^{0.65} \cdot \varepsilon^{-0.32}\left(1+\frac{N}{N_{0}}\right)^{-1.83} \\
L_{p}^{I I}=5 \cdot d_{b} \cdot\left(\frac{f_{t}}{f_{y}}-1\right)
\end{gathered}
$$

Donde

L Longitud del elemento

h $\quad$ Altura de la sección

$f_{t} \quad$ Carga de rotura del acero

$f_{y} \quad$ Límite elástico del acero

$\mathcal{E} \quad$ Deformación correspondiente a la carga de rotura del acero

$N \quad$ Axil aplicado

$N_{o} \quad$ Axil reducido $\left(A_{g} f_{c}\right)$

$d_{b} \quad$ Diámetro de la armadura longitudinal

Por último, Bae (2005) [12] propone una nueva expresión para la longitud de rótula plástica. Esta propuesta sugiere un método no convencional para medir $L_{p}$, llamado "Método de deformación de compresión del hormigón".

El método consiste en obtener la distribución de deformación de la fibra exterior del núcleo confinado a lo largo del soporte, la cual es igual a la deformación de la armadura en compresión. La longitud del tramo de soporte en el cual la 

hormigón armado

deformación de la armadura comprimida está plastificada se denomina $L_{\mathrm{p}}$. Bae considera que utilizar la distribución de deformaciones del hormigón en compresión para evaluar $L_{p}$, permite identificar de una forma más clara los parámetros que la afectan. Adicionalmente, la rotura del hormigón está más relacionada con las deformaciones del hormigón que con las curvaturas. Por consiguiente, las deformaciones de compresión del hormigón desarrolladas en el núcleo de hormigón cuando se alcanza la capacidad de momento máximo en la sección crítica del soporte, pueden ser una buena indicación de la formación de la rótula plástica.

Para precisar los factores que más influyen en $L_{\mathrm{p}}$, Bae, lleva a cabo un análisis paramétrico. Para ello realiza una serie de ensayos numéricos con el propósito de obtener la respuesta de soportes de hormigón, mediante la utilización de un programa numérico propio. En estos ensayos, $L_{\mathrm{p}}$ es medida de acuerdo con la metodología descrita en el "método de deformaciones de compresión del hormigón".

Los parámetros claves que influyen en la longitud de la rótula plástica son identificados mediante un análisis de sensibilidad. Estos parámetros son: la carga axial $\left(N / N_{u}\right)$, la esbeltez $\left(L_{s} / h\right)$, y la cuantía de armadura $\left(\rho_{l}=A_{s} / A_{g}\right)$. Basándose en los resultados numéricos observa una relación lineal entre estos parámetros $\left(\mathrm{N} / \mathrm{N}_{\mathrm{u}}\right.$, $\mathrm{L}_{\mathrm{s}} / \mathrm{h}$, y $\mathrm{A}_{\mathrm{s}} / \mathrm{A}_{\mathrm{g}}$ ). Bae (2005) [12] propuso la expresión (Ec. 2-67) obtenida a partir del análisis de mínimos cuadrados, utilizando la base de datos del UW/PEER ${ }^{1}$. Esta expresión puede ser utilizada para el cálculo del desplazamiento máximo en modelos de soporte en voladizo.

$$
\frac{L_{p}}{h}=\left[0.3\left(\frac{N}{N u}\right)+3\left(\frac{A_{s}}{A_{g}}\right)-0.1\right]\left(\frac{L}{h}\right)+0.25 \geq 0.25 \quad \text { Ec. } 2-67
$$

$\begin{array}{ll}\text { Donde } & \\ N & \text { Carga Axial aplicada } \\ N_{u} & \text { Capacidad de carga axial de acuerdo al ACI 318-08 }\left(0.85 f_{c^{*}}\left(A_{g}-A_{s}\right)+A_{s} f_{y}\right) \\ A_{s} & \text { Área total de armadura longitudinal } \\ A_{g} & \text { Área de la sección transversal } \\ L & \text { Altura del soporte completo } \\ h & \text { Canto de la sección transversal }\end{array}$

\footnotetext{
1 Se trata de una base de datos desarrollada por el centro de investigación UW/PEER (Pacific Earthquake Engineering Research Center) de la Universidad de Washington. http://nisee.berkeley.edu/spd/
} 


\subsubsection{MÉTODOS ANALÍTICOS MÁS COMPLEJOS}

\subsubsection{MÉTOdO PARA ELEMENTOS EN FLEXIÓN SIN CARGA AXIAL}

En esta sección se presenta un resumen de los modelos existentes más importantes para el cálculo de la rotación plástica. Este resumen se hace fundamentalmente en base al Bulletin del CEB 242 (1998) [30], donde se describe la mayor parte de los modelos. Sin embargo, otros modelos descritos se encuentran en Bigaj (1999) [25] y Shakir y Rogowski (2000) [118]. En estos tres documentos, se presenta una amplia propuesta de modelos analíticos dedicados esencialmente a la simulación del comportamiento deformacional en elementos tipo viga, cuyo principal objetivo es evaluar la capacidad de rotación plástica que se desarrolla en los apoyos internos en vigas continuas, con el propósito de permitir una adecuada redistribución de momentos. Dentro de este grupo se incluyen los siguientes modelos: (1) Stuttgart, (2) Nápoles, (3) Zúrich, (4) Darmsradt-Leipzig, (5) Delft, (6) Shakir y Rogoswsky.

En la Tabla 2-10 se presenta un resumen de los modelos analíticos complejos propuestos en la modelización de elementos sometidos a flexión sin carga axial. En dichas tablas se incluye una comparación de cómo se han considerado los siguientes aspectos en la simulación.

- Influencia de la fisuración de cortante

- Efectos del plato de carga

- Discretización de la fisuración

- Modelos de adherencia

- Modelo constitutivo del hormigón

- Modelo constitutivo del acero de la armadura

- Evaluación de la rotación plástica 
Tabla 2-10 Resumen de métodos analíticos complejos propuestos para la estimación de la capacidad de rotación en elementos tipo viga

\begin{tabular}{|c|c|c|c|}
\hline MODELO & STUTTGART & NAPOLES & DARMSTADT-LEIPZIG \\
\hline Autores & $\begin{array}{l}\text { Langer P. ; Li L. (1987, } \\
\text { 1995) }\end{array}$ & $\begin{array}{l}\text { Cosensa E.; Greco C.; } \\
\text { Manfredi G. (1991) }\end{array}$ & $\begin{array}{l}\text { Pommerening D.; Tue N.; } \\
\text { Quian L. (1996) }\end{array}$ \\
\hline $\begin{array}{l}\text { Cálculo de la } \\
\text { rotación }\end{array}$ & 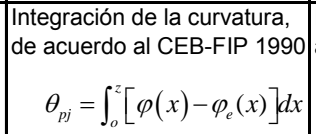 & $\begin{array}{l}\text { Integración de la curvatura, de } \\
\text { acuerdo al CEB-FIP } 1990 \\
\theta_{p j}=\int_{o}^{z}\left[\varphi(x)-\varphi_{e}(x)\right] d x\end{array}$ & $\begin{array}{l}\text { Dilger (1966): } \\
\theta_{p l, t o t}=\theta_{p l, f l e x}+\theta_{p l, \text { cort }}\end{array}$ \\
\hline Plato de carga & $\begin{array}{l}\text { Distribución de la carga } \\
\text { formando un ángulo de } 45^{\circ} \\
\text { hasta el eje de la viga }\end{array}$ & $\begin{array}{l}\text { Distribución de la carga } \\
\text { formando un ángulo de } 45^{\circ} \\
\text { hasta el eje de la viga }\end{array}$ & No se tiene en cuenta \\
\hline $\begin{array}{l}\text { Fisuración debido } \\
\text { al cortante }\end{array}$ & $\begin{array}{l}\text { Criterio de Dilger (1966), } \\
\text { mediante la translación del } \\
\text { diagrama de fuerza de } \\
\text { tracción } \\
\quad d_{s}=\frac{d}{2}(\cot \alpha-\cot \beta)\end{array}$ & $\begin{array}{l}\text { Modificación del diagrama de } \\
\text { momento flector, con una } \\
\text { translación definida por la } \\
\text { intersección de las fisuras de } \\
\text { cortante y flexión }\end{array}$ & $\begin{array}{l}\text { Translación del diagrama de } \\
\text { fuerza de tracción, criterio } \\
\text { de Dilger (1966) } \\
a_{l}=\frac{d^{\prime}}{2} \cdot(\cot \beta-\cot \alpha)\end{array}$ \\
\hline $\begin{array}{l}\text { Modelo de } \\
\text { discretización de } \\
\text { la fisuración }\end{array}$ & $\begin{array}{l}\text { Martí (1978) Y Kreller } \\
\text { (1989) }\end{array}$ & $\begin{array}{l}\text { La separación entre fisuras } \\
\text { esta marcada por la } \\
\text { localización de los cercos }\end{array}$ & \\
\hline Adherencia & $\begin{array}{l}\text { Eligehausen, Popov y } \\
\text { Bertero (1983) }\end{array}$ & $\begin{array}{l}\text { Eligehausen, Popov y Bertero } \\
\text { (1983) }\end{array}$ & \begin{tabular}{|l|} 
Tensiones stiffening, \\
Código modelo CEB - FIP \\
1990 (sección 3.2.3). \\
\end{tabular} \\
\hline Hormigón & $\begin{array}{l}\text { Sheik y Uzumeri (1982), la } \\
\text { ley considera el efecto del } \\
\text { confinamiento }\end{array}$ & $\begin{array}{l}\text { Hillerborg (1989), incluye el } \\
\text { efecto de la altura de la } \\
\text { sección }\end{array}$ & $\begin{array}{l}\text { Código modelo CEB - FIP } \\
1990 \text { (sección 2.1.4.3) }\end{array}$ \\
\hline Acero & $\begin{array}{l}\text { Descripción polígono hasta } \\
30 \text { puntos, se acerca a la } \\
\text { forma real de la curva }\end{array}$ & $\begin{array}{l}\text { La no linealidad puede ser } \\
\text { incorporada por una } \\
\text { aproximación teórica y/o } \\
\text { empírica }\end{array}$ & $\begin{array}{l}\text { Relación bilineal con } \\
\text { endurecimiento }\end{array}$ \\
\hline MODELO & DELF & ZÜRICH & SHAKIR Y ROGOWSKY \\
\hline Autores & $\begin{array}{l}\text { Bigaj A.J. y Walraven, J.C. } \\
\text { (1999) }\end{array}$ & Sigrist V.; Martí P. (1994) & $\begin{array}{l}\text { Adnan Shakir y David M. } \\
\text { Rogowsky, (2000) }\end{array}$ \\
\hline $\begin{array}{l}\text { Cálculo de la } \\
\text { rotación }\end{array}$ & $\begin{array}{l}\text { Definición de Bachmann } \\
\theta_{\text {tot }}=\sum_{\mathrm{i}=1}^{\mathrm{n}} \theta_{\mathrm{el}}^{\mathrm{i}}\end{array}$ & $\begin{array}{l}\text { Definición de Bachmann } \\
\theta_{T}=\int_{0}^{L} \frac{\varepsilon_{s} d x}{(d-x)}=\sum_{i=1}^{n} \frac{w_{m}}{d-x}\end{array}$ & $\begin{array}{l}\text { Integración de la curvatura, } \\
\text { sobre una longitud plástica, } \\
\text { generalmente } \mathrm{Ip}=\mathrm{d} \\
\qquad \theta_{u}=\frac{1}{d-c} \int_{0}^{L_{p}} \varepsilon_{s x} d x\end{array}$ \\
\hline Plato de carga & No se tiene en cuenta & No se tiene en cuenta & No se tiene encuenta \\
\hline $\begin{array}{l}\text { Fisuración debido } \\
\text { al cortante }\end{array}$ & No se tiene en cuenta & $\begin{array}{l}\text { Variación en la fuerza de } \\
\text { tracción } \\
\qquad \mathrm{F}_{\mathrm{t}}=-\frac{\mathrm{M}}{\mathrm{d}_{\mathrm{v}}}+\frac{\mathrm{V} \cdot \cot \alpha}{2}\end{array}$ & $\begin{array}{l}\text { Variación en la fuerza de } \\
\text { tracción } \\
\mathrm{F}_{\mathrm{t}}=-\frac{\mathrm{M}}{\mathrm{d}_{\mathrm{v}}}+\frac{\mathrm{V} \cdot \cot \alpha}{2}\end{array}$ \\
\hline $\begin{array}{l}\text { Modelo de } \\
\text { discretización de } \\
\text { la fisuración }\end{array}$ & \begin{tabular}{|l} 
separación de fisuras es \\
deducido como 1.3 veces la \\
longitud de transmisión
\end{tabular} & $\begin{array}{c}\text { Sheikh y Uzumeri (1982), } \\
s_{r m}=\lambda s_{r m o}\end{array}$ & $\begin{array}{l}\text { La separación entre fisuras } \\
\text { esta marcada por la } \\
\text { localización de los cercos }\end{array}$ \\
\hline Adherencia & Den Uijl and Bigaj 1996 & $\begin{array}{l}\text { Modelo escalonado de Sigrist } \\
\text { y Martí (1994) }\end{array}$ & $\begin{array}{l}\text { Modelo escalonado de } \\
\text { Sigrist y Martí (1994) }\end{array}$ \\
\hline Hormigón & $\begin{array}{l}\text { Hormigón en tracción } \\
\text { “Fictitious Crack Model" } \\
\text { (FCM), Hillerborg 1983; } \\
\text { hormigón en compresión } \\
\text { "Compressive Damage } \\
\text { Zone Model” (CDZ) } \\
\text { Merkeset (1993) }\end{array}$ & & $\begin{array}{l}\text { Modelo modificado de Park } \\
(1982) \text {, incorpora I efectos } \\
\text { de confinamiento, y se ha } \\
\text { asumido } \varepsilon_{\mathrm{cu}}=0,005\end{array}$ \\
\hline Acero & $\begin{array}{l}\text { Un polígono de seis puntos, } \\
\text { que describe con bastante } \\
\text { aproximación la forma } \\
\text { característica para cada tipo } \\
\text { de acero }\end{array}$ & $\begin{array}{l}\text { Relación bilineal, con } \\
\text { endurecimiento }\end{array}$ & $\begin{array}{l}\text { Relación de tensión- } \\
\text { deformación bilineal con } \\
\text { endurecimiento }\end{array}$ \\
\hline
\end{tabular}




\subsubsection{MÉTODO PARA ELEMENTOS EN FLEXIÓN CON CARGA AXIAL}

En elementos con carga axial se ha encontrado un menor número de propuestas de métodos analíticos. Cabe destacar el modelo de Bae (2005) [12], en el cual se plantea una solución para determinar el desplazamiento máximo de un soporte en voladizo. Bae (2005) [12] desarrolló un proceso analítico que puede ser usado para evaluar la relación del momento-curvatura y el desplazamiento lateral. En la Figura 2.7 se presenta el esquema de diseño del modelo.

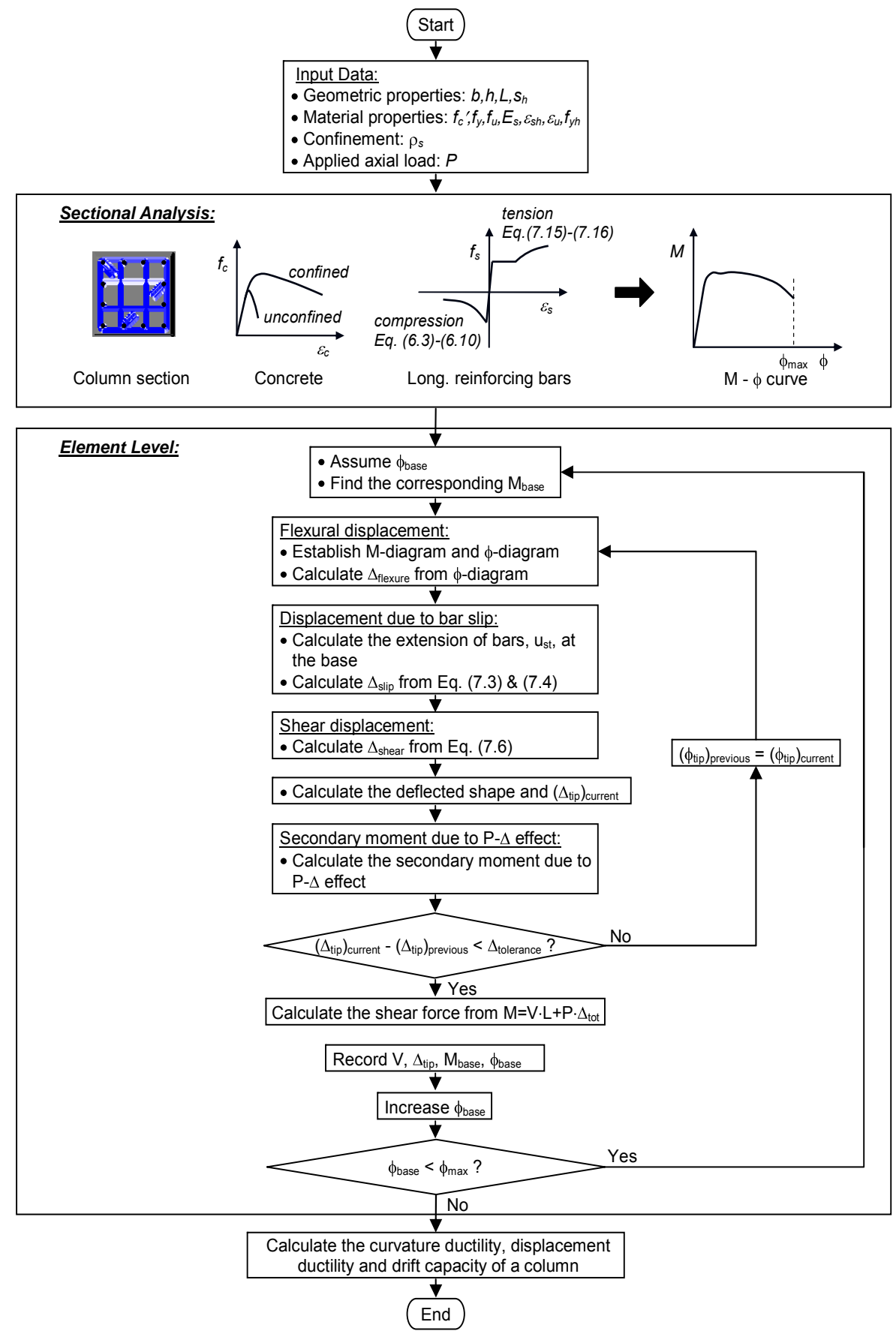

Figura 2.7 Esquema del modelo analítico, tomado de Bae (2005) [12] 
Dentro del proceso del método analítico de Bae (2005) [12], se incluyen los modelos para el hormigón confinado y el pandeo de la armadura longitudinal. En el modelo se considera que en el desplazamiento total de un soporte en voladizo intervienen tres componentes de deformación, como son: (1) la deformación de flexión, (2) la rotación en el extremo fijo, resultante del deslizamiento de las barras longitudinales, y (3) la deformación debida al cortante.

$$
\delta=\delta_{f}+\delta_{s}+\delta_{v}
$$

El modelo, además, considera los efectos P- $\Delta$, en la evaluación de las tres componentes de desplazamiento, puesto que los momentos de segundo orden generados incrementan el desplazamiento lateral medido en el extremo superior de un soporte en voladizo.

\section{Cálculo del desplazamiento por flexión}

La contribución de la deformación de flexión $\left(\delta_{f}\right)$ puede ser calculada integrando las curvaturas a lo largo del soporte (Ec. 2-69).

$$
\delta_{f}=\int_{0}^{L} \varphi(x) x d x
$$

Esta ecuación es utilizada para calcular la rama ascendente del diagrama de respuesta carga-desplazamiento. Sin embargo, surgen dificultades teóricas cuando se utiliza esta ecuación en el análisis para estimar la rama de descenso en la respuesta carga-flecha (P-ס). Por consiguiente, se introduce el concepto de longitud de rótula plástica $\left(L_{p}\right)$ y se asume que las curvaturas inelásticas están concentradas dentro de la zona de rótula plástica. Bae (2005) [12] propone su propia expresión para $L_{p}$, mostrada en la Ec. 2-67.

\section{Cálculo del desplazamiento debido al deslizamiento de las barras longitudinales}

La flexión en la interfaz de un soporte (unión con otro elemento de la estructura tipo viga o cimentación), conlleva una deformación de las barras longitudinales cerca de la fisura. El desarrollo y el crecimiento de las fisuras produce deformaciones inelásticas en las barras de la armadura longitudinal. Esto da como resultado la plastificación de la armadura dentro de la zona de anclaje, causando una extensión de la barra. De ahí que los soportes de hormigón armado experimenten una rotación del elemento rígido adicional en la base debida al deslizamiento de las barras.

En el método analítico de Bae (2005) [12], dicho desplazamiento de la barra es calculado utilizando el modelo analítico propuesto por Alsiwat y Saatcioglu ${ }^{2}$. Este modelo incorpora la plastificación y el comportamiento no elástico asociado a la armadura anclada, así como la posibilidad de deslizamiento. Una vez se ha

\footnotetext{
${ }^{2}$ Citado por Bae (2005) [12]
} 
calculado el deslizamiento de la barra en el apoyo del soporte, la rotación en el extremo y el correspondiente desplazamiento en el extremo libre de un soporte en voladizo puede determinarse de la siguiente manera.

$$
\begin{aligned}
& \theta_{s}=\frac{u_{s t}}{d-c} \\
& \delta_{s}=\theta_{s} \times L
\end{aligned}
$$

Donde

$\mu_{s t} \quad$ Deslizamiento de las barras cerca del apoyo

d $\quad$ Canto útil de la sección

C Profundidad de la fibra neutra

$L \quad$ Longitud del soporte en voladizo

\section{Cálculo del desplazamiento por cortante}

Aunque las deformaciones por cortante son pequeñas en el rango elástico lineal, estas son incluidas en todas las etapas del cálculo de la respuesta cargadesplazamiento. En el rango elástico lineal el desplazamiento debido al cortante puede ser calculado a partir de la siguiente expresión.

$$
\delta_{v}=\frac{V \cdot L}{A \cdot G} ; \quad G=\frac{E_{c}}{2(1+v)}
$$

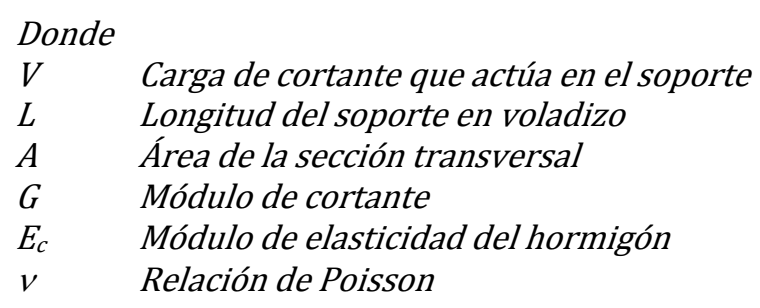

La componente de desplazamiento lateral debida al cortante, en el extremo superior del soporte, es calculada mediante el modelo de Lehman y Moehle (2000) [80], de la siguiente manera.

$$
\begin{gathered}
\delta_{v}=\int_{0}^{L} \frac{V(x)}{A_{e f f}(x) \cdot G_{e f f}(x)} d x=V \cdot \int_{0}^{L} \frac{d x}{A_{e f f}(x) \cdot G_{e f f}(x)} \\
G_{e f f}(x)=\frac{E_{c, \text { sec }}(x)}{2(1+v)}
\end{gathered}
$$

Donde

$A_{\text {eff }} \quad$ Área efectiva de cortante $\approx$ área del hormigón sujeto a deformaciones de compresión

$E_{c, \text { sec }} \quad$ Módulo secante del núcleo de hormigón

$v \quad$ Relación de Poisson $(\approx 0.3)$

\section{Deformaciones adicionales debidas al efecto P- $\Delta$}

Cuando los soportes están sometidos a importantes cargas axiales, y experimentan desplazamientos laterales, los momentos de segundo orden no pueden ser 
ignorados. Puesto que la distribución de dichos momentos depende de la deformada del soporte, se requiere de un proceso iterativo.

\section{Hormigón confinado}

El modelo analítico de Bae (2005) [12] tiene en cuenta el aumento de la ductilidad debido a la armadura transversal. Aunque es posible usar diferentes modelos constitutivos para el hormigón confinado, se ha utilizado el modelo de Razvi y Saatcioglu (1994) [113]. Este modelo fue elegido ya que, por una parte, su incorporación ofrecía mejores estimaciones que otros modelos de confinamiento, y por otra parte, este puede ser aplicable a soportes tanto de hormigón convencional como de alta resistencia.

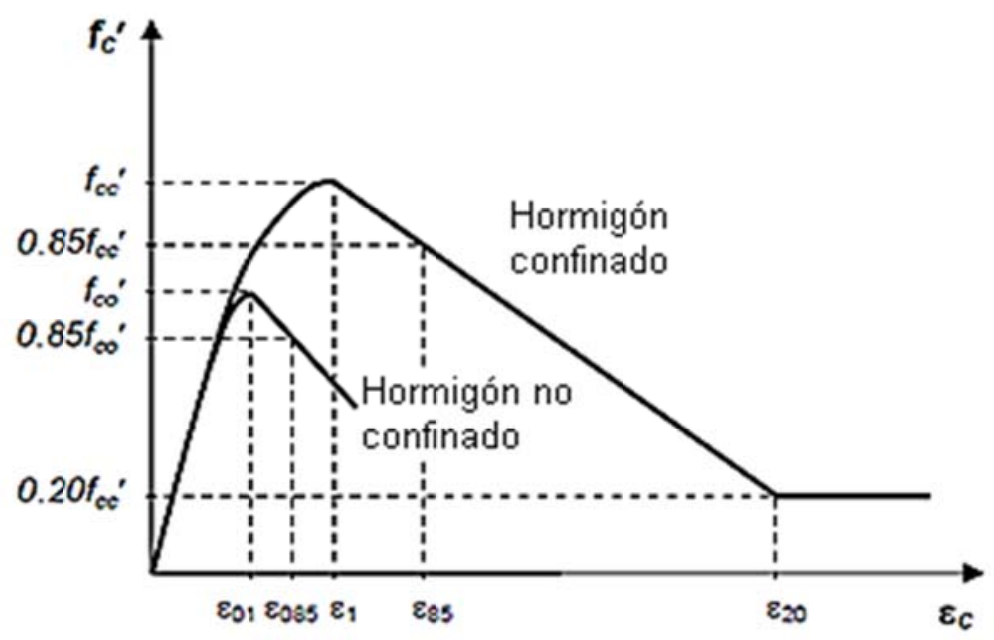

Figura 2.8 Modelo para el hormigón confinado de Razvi y Saatcioglu (1994)

\section{Relación constitutiva del acero}

La repuesta tensión-deformación de las barras de la armadura en tracción es modelizada simplemente utilizando una relación bilineal hasta el inicio de la deformación de endurecimiento. El modelo tensión-deformación propuesto por Mander et al. (1984) [84] es usado para simular el comportamiento de las barras de armadura. De acuerdo con Mander et al.(1984) [84], la relación entre la tensión $\left(\mathrm{f}_{\mathrm{s}}\right)$ y la deformación $\left(\varepsilon_{\mathrm{s}}\right)$ en la región de endurecimiento se puede expresar con las siguientes ecuaciones.

$$
\begin{gathered}
f_{s}=f_{u}+\left(f_{y}-f_{u}\right)\left(\frac{\varepsilon_{u}-\varepsilon_{s}}{\varepsilon_{u}-\varepsilon_{s h}}\right)^{p} \\
p=E_{s h}\left(\begin{array}{c}
\varepsilon_{u}-\varepsilon_{s h} \\
f_{u}-f_{y}
\end{array}\right)
\end{gathered}
$$

\footnotetext{
${ }^{3}$ Tomado de Bae (2005) [12]
} 
Donde

$f_{y} \quad$ Límite elástico del acero

$f_{u} \quad$ Carga de rotura del acero

$\varepsilon_{s h} \quad$ Deformación en el inicio del endurecimiento

$\varepsilon_{u} \quad$ Deformación correspondiente a la carga última

$E_{s h} \quad$ Módulo de elasticidad en el inicio de la deformación de endurecimiento

\section{Modelo de pandeo}

El modelo de pandeo de las barras longitudinales, desarrollado también por Bae (2005) [12], se basa en la propuesta original de Mau y El-Mabsout ${ }^{4}$, los cuales sugieren que el desplazamiento axial total y la deformación axial promedio de las barras de armadura pueden ser calculadas a partir de las expresiones Ec. 2-78 y Ec. 2-79. Estas ecuaciones muestran que el desplazamiento axial total (o la deformación axial promedio) puede dividirse en dos componentes: (1) el desplazamiento axial (o deformación axial) debido al acortamiento y (2) el desplazamiento axial (o deformación axial) inducido por la deformación transversal.

$$
\begin{gathered}
\mu=\mu_{a}+\mu_{b} \\
\varepsilon_{\text {med }}=\frac{d \mu_{a}}{d x}-z \frac{d^{2} w}{d x^{2}}
\end{gathered}
$$

Donde

$\mu \quad$ Desplazamiento axial total

$\mu_{a} \quad$ Desplazamiento axial debido al acortamiento

$\mu_{b} \quad$ Desplazamiento axial inducido por el desplazamiento transversal

$\varepsilon_{\text {med }} \quad$ Deformación axial promedio

$x \quad$ Distancia medida en dirección longitudinal a partir del extremo de la barra

$z \quad$ Distancia medida en dirección transversal

w Desplazamiento transversal de la barra.

La Ec. 2-78, se aplica en la simulación del pandeo inelástico de las barras. La deformación axial promedio se asume como el sumatorio de la deformación axial debida a la carga axial y la deformación axial resultante de la deformación transversal de la barra que experimenta el pandeo inelástico, como se indica en la Ec. 2-79.

$$
\varepsilon_{\text {med }}=\varepsilon_{\mathrm{s}}+\varepsilon_{\text {tra }}
$$

Donde

$\mathcal{E}_{\text {med }} \quad$ Deformación axial promedio

$\varepsilon_{s} \quad$ Deformación axial debido a la compresión

$\varepsilon_{\text {tra }} \quad$ Deformación axial resultante del desplazamiento transversal

El trabajo analítico desarrollado por Bae puede considerarse una simplificación del proceso de análisis de rótula plástica propuesto por Bayrak y Sheikh (2001) [19].

\footnotetext{
${ }^{4}$ Citado por Bae (2005) [12]
} 


\subsection{ANTECEDENTES DE LA INVESTIGACIÓN EXPERIMENTAL}

Durante la revisión de la bibliografía se ha podido comprobar que existe un amplio estudio experimental de la capacidad de deformación en elementos de hormigón armado. Esto se confirma, teniendo en cuenta que los modelos descritos anteriormente en este estudio se han propuesto a partir de los resultados de ensayos experimentales en elementos de hormigón armado. Cabe destacar que existen importantes bases de datos de ensayos experimentales constituidas específicamente para ser utilizadas en la calibración, validación y desarrollo de modelos propuestos para la evaluación de la capacidad de deformación, como es el caso de la base de datos realizada por Panagiotakos y Fardis (2001) [100].

A partir de la revisión bibliográfica se ha elaborado una base de datos de ensayos existentes en elementos de hormigón convencional $(\mathrm{HC})$ y de alta resistencia (HAR) sujetos a cargas de flexión o cargas combinadas de compresión y flexión monotónica o cíclica. De cada uno de los ensayos se ha obtenido información respecto a las características geométricas del elemento y características mecánicas de los materiales, así como también de los índices de deformabilidad obtenidos en los ensayos.

La base de datos de Panagiotakos y Fardis (2001) [100], junto con la desarrollada en este estudio, han permitido identificar algunos parámetros claves en el estudio de la capacidad de deformación, así como los respectivos rangos en los cuales es necesario desarrollar una mayor comprobación experimental.

Esta sección incorpora, en primer lugar, una descripción general de la base de datos de Panagiotakos y Fardis (2001) [100] y de la realizada en este estudio. En segundo lugar, se lleva a cabo un resumen de los principales elementos de la estructura utilizados como modelos de experimentación. Esto es útil para realizar una clasificación del modelo de ensayo utilizado en cada una de las referencias bibliográficas que conforman la base de datos. A continuación, se presenta un análisis de las bases de datos con respecto a las variables geométricas y mecánicas estudiadas en los ensayos experimentales, con el propósito de detectar las variables y rangos en los cuales existen vacíos. Todo este análisis permite fundamentar la selección de los parámetros y rangos que han sido estudiados en la presente investigación.

Finalmente en el anejo A se presenta un resumen de cada una de las referencias a partir de las cuales se ha obtenido la información necesaria para elaborar la base de datos de este estudio. En este resumen se destaca el objetivo, el programa experimental, los parámetros de estudio y las conclusiones obtenidas.

\subsubsection{CARACTERÍSTICAS DE LA BASE DE DATOS DE FARDIS ET AL. (2001)}

Inicialmente, la base de datos fue presentada por Panagiotakos y Fardis (2001) [100], conformada con un total de casi 1000 ensayos en elementos de hormigón armado. Esta base ha sido continuamente actualizada. Fardis y Biskinis (2003) [60] logran reunir en una última versión un total de 1802 ensayos. Sin embargo, una 
versión intermedia publicada en el "CEB-FIB Bulletin" 25 (2003) [35] ha sido utilizada en este estudio para hacer la revisión de las características y composición de la base de datos de Panagiotakos y Fardis (2001) [100].

La base de datos descrita en "CEB-FIB Bulletin" 25, se compone de 1282 ensayos en elementos de hormigón armado bajo flexión uniaxial, con y sin carga axial; 299 de los ensayos han sido llevados a cabo en elementos tipo viga, ya que se considera la asimetría de la armadura longitudinal y han sido ensayados con carga de flexión sin carga axial. Todas las vigas tienen una sección transversal rectangular, a excepción de dos vigas con sección $\mathrm{T} ; 863$ ensayos son considerados como soportes con armadura simétrica, y sección cuadrada 0 rectangular, ensayados con o sin carga axial; 99 ensayos fueron realizados en muros rectangulares; 37 ensayos en soportes con armadura diagonal; y 21 ensayos con armadura asimétrica ensayados bajo carga axial.

\subsubsection{DESCRIPCIÓN DE LA BASE DE DATOS DE ESTE ESTUDIO}

Tras la revisión de la bibliografía experimental, se ha logrado recopilar una base de datos de ensayos en elementos de hormigón convencional $(\mathrm{HC})$ y hormigón de alta resistencia (HAR), sometidos a flexión y flexo-compresión, con incremento de carga monotónica y cíclica.

La base de datos está conformada por un total de 442 ensayos experimentales, que se encuentran en 30 referencias bibliográficas. La base de datos incorpora información relativa a las siguientes características.

\section{Las características geométricas de los elementos, como son:}

- El canto total (h)

- El ancho (b)

- La longitud total (L)

- La esbeltez geométrica $\left(\lambda=\mathrm{L}_{s} / \mathrm{h}\right)$

- El canto útil (d)

- La altura del recubrimiento (c)

Las características mecánicas de los elementos:

- La cuantía de armadura en tracción $(\rho)$

- La cuantía de armadura en compresión ( $\left.\rho^{\prime}\right)$

- La cuantía de armadura transversal $\left(\rho_{\mathrm{s}}\right)$

Las características mecánicas de los materiales:

- La resistencia del hormigón $\left(\mathrm{f}_{\mathrm{c}}\right)$

- El límite elástico del acero $\left(f_{\mathrm{y}}\right)$

Por otra parte, la base de datos también recoge la información disponible respecto a los resultados experimentales obtenidos en cada uno de los ensayos. Generalmente, la información experimental recogida se refiere a los valores de resistencia que pueden ser cargas y/o momentos. También puede encontrarse información correspondiente a los parámetros de deformación del elemento, de la sección o de la rótula plástica, como son: desplazamientos, curvaturas, rotación total, rotación plástica, longitud de plastificación, deriva plástica y deriva última. Los 
resultados de la experimentación han sido medidos en diferentes estados de su comportamiento, como son: la rotura del hormigón, la plastificación de la armadura, la carga máxima y la carga última. Por consiguiente, la información disponible es muy variada, y resulta ser bastante compleja para poder llevar a cabo un análisis de los resultados en cuanto a la capacidad de deformación, debido además a que existen notables diferencias en relación a los siguientes aspectos:

- Tipos y tamaños de ensayo

- Variabilidad en los sistemas de instrumentación y formas de medida

- Diferencias en los parámetros medidos

- Tipos de acero

- Diferencias en la definición de los puntos característicos de rotura y plastificación

- Diferencias en los tipos de carga: cíclica o monotónica

- Diferencias en el detalle de la armadura transversal puesto que esto condiciona la efectividad del confinamiento

\subsubsection{DESCRIPCIÓN DE LOS MODELOS DE ENSAYO QUE COMPONEN LA BASE DE DATOS}

En la documentación estudiada se ha comprobado que existen diferentes modelos de ensayo, los cuales representan partes específicas de la estructura, como por ejemplo varios tipos de conexiones entre vigas y soportes (Figura 2.9), mientras que otros, aunque no representan físicamente una parte de la estructura, pueden ser idealizados para representar, de forma indirecta, un estado de esfuerzos (Figura 2.10).

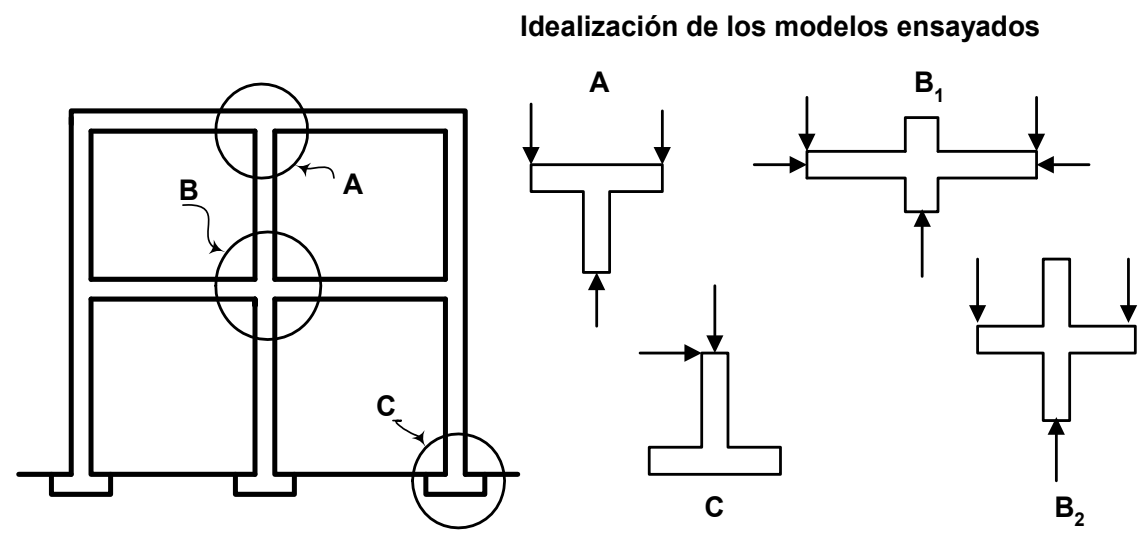

Figura 2.9 Modelización de conexiones viga soporte

La capacidad de deformación de pórticos de hormigón armado sujetos a cargas o deformaciones laterales depende principalmente de la capacidad de deformación de las conexiones, puesto que es en la conexión donde más deformación se concentra, y es donde se puede desarrollar la rótula plástica. En estructuras de entramados existen diferentes tipos de conexiones ( $A, B$ y $C$ ), tal y como se muestra en la Figura 2.9.

Las conexiones tipo $\mathrm{B}$ y $\mathrm{C}$ son las que suelen aparecer más frecuentemente en la bibliografía, sometidas a esfuerzos combinados de flexo-compresión. La conexión 
tipo B se representa mediante un elemento rígido en el centro de la luz ("stub"), el cual reproduce la unión viga-columna. La conexión tipo $\mathrm{C}$, es un modelo utilizado para simular la conexión soporte-cimentación, tanto en soportes de edificación como de pilas de puentes de gran tamaño.

Ernest, en 1957 [57], fue el primero en realizar ensayos basados en el modelo de conexión viga-soporte, en elementos sometidos a flexo-compresión, con el objeto de estudiar la rotación disponible de la rótula que se desarrolla cerca de la conexión. Más adelante, en los años 60, Burns N. H. y Siess C. P. (1962) [29] y Yamasiro R. y Siess C. P. (1962) [135] realizan ensayos sobre elementos tipo A y $B$, con el propósito de obtener información de las conexiones, especialmente en la zona de rótula plástica.

En los años 70 y comienzos de los 80 , da comienzo un extenso programa de ensayos en la Universidad de Canterbury (Nueva Zelanda) adoptando el modelo de ensayo B. Potangaroa R. T. et al.(1979) [109], Park R. et al. (1982) [102], Ang B. G. et al. (1981) [5], Zahn F. A.et al. (1986) [138], y Tanaka H. et al. (1990) [125] bajo la dirección de Park R. y Priestley M. J. N., llevan a cabo ensayos a gran escala con el fin de estudiar la capacidad de deformación de soportes de hormigón convencional bajo carga axial constante y flexión cíclica. Otra serie importante de ensayos en elementos tipo $C$ bajo carga cíclica es la realizada por Sheikh S. A. y colaboradores a partir de los años 90 (Sakai K. y Sheikh S. A. (1989) [116], Sheikh S. A. y Khoury S. S.(1993) [121], Sheikh S. A. et al. (1994) [121], Bayrak O. y Sheikh S. A. (1997 y 1998) [18] [16], Bae S. y Bayrak O. (2006) [8]). Este programa continuo de experimentación ha permitido estudiar la influencia de la mayoría de los parámetros que afectan la capacidad de deformación, como son: el efecto del confinamiento del hormigón, el nivel de carga axil, la resistencia del hormigón y la esbeltez de cortante. Los ensayos han sido realizados en elementos de hormigón convencional y de alta resistencia.

Una gran parte de la investigación experimental de la capacidad de deformación se ha centrado en el estudio de la rotación plástica necesaria para permitir una determinada distribución de los momentos en vigas hiperestáticas. Estos estudios se han realizado considerando el modelo de ensayo que aparece en las Figura 2.10; este modelo consiste en representar aproximadamente el estado de esfuerzos correspondiente a la parte de una viga hiperestática entre el momento nulo y el momento máximo en el apoyo central, mediante una viga simplemente apoyada con una carga puntual en el centro del vano.

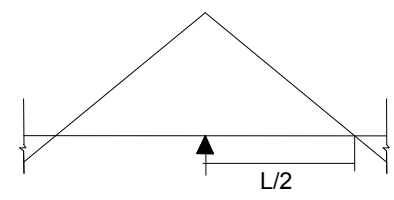

Diagrama de momentos en el apoyo central de una viga continua.

(a)

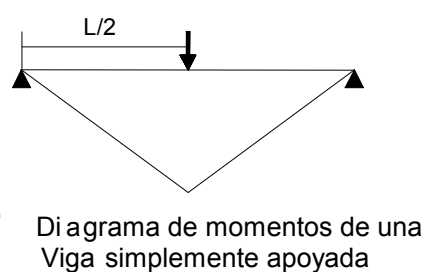

(b)

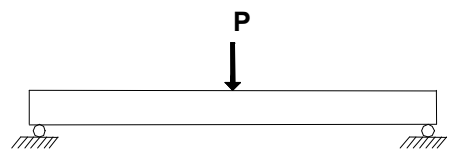

Viga de ensayo

(c)

Figura 2.10 Idealización de un modelo para el estudio de la rotación plástica disponible en vigas hiperestáticas

Existen algunas variaciones de este modelo, en las cuales la viga de hormigón puede estar sujeta a dos o tres cargas puntuales, al considerar que la aplicación de 
tres cargas sobre el vano se acerca más a una distribución de cargas real. En la Tabla 2-11 se presenta una clasificación del tipo de modelo de ensayo utilizado para cada una de las referencias bibliográficas consultadas.

Tabla 2-11 Tipos de modelos de ensayo utilizados en los proyectos de investigación que conforman la base de datos

\begin{tabular}{|l|}
\hline Tipo 1. Flexión simple con una carga puntual \\
Burns N. H., Siess C (1962) [29] \\
Mattock A. H. (1965) [87] \\
Corley G. (1866) [45] \\
Tadros Gamil S. (1970) [124] \\
Bosco C., Debernardi P. G. (1992) [27] \\
Beedy A. W. (1997) [22] \\
Tholen M. L., Darwin D (1998) [127] \\
Pecce M., Fabrocino G. (1999) [105] \\
Bigag A. J. (1999) [25] \\
Ko M. Y., Kim S. W., Kim J. K (2001) [73] \\
Mendis P. et al. (2001) [92] \\
Ventotini L. A. (2003) [129] \\
\hline Tipo 2. Flexión simple con dos cargas puntuales \\
Ko, M.Y. et al. (1997) [73] \\
Almeida Bernardo L. F.(1998-2003) [4] - [3] \\
Mendis P. et al. (2001) [92] \\
\hline Tipo 3. Flexión simple con tres cargas puntuales \\
Bosco C., Debernardi P.G. (1992) [27] \\
Mendis P. et al. (2001) [92] \\
\hline Tipo 4. Flexión en un elemento tipo conexión \\
viga- soporte \\
Ernest G. C. (1957) [57] \\
Burns N. H., Siess, C. P. (1962) [29] \\
Tipo 5. Flexo-Compresión sin "stub" \\
W W L Chan (1955) [41] \\
Burns N. H., Siess, C. P. (1962) [29] \\
Nawy E. G. et al. (1968) [96] \\
Tadros G. S. (1970) [124] \\
Mendis P. et al. (2001) [92] \\
\hline Yamashiro R. y Siess C. P. (1962) [135] \\
conexión viga- soporte \\
\hline
\end{tabular}




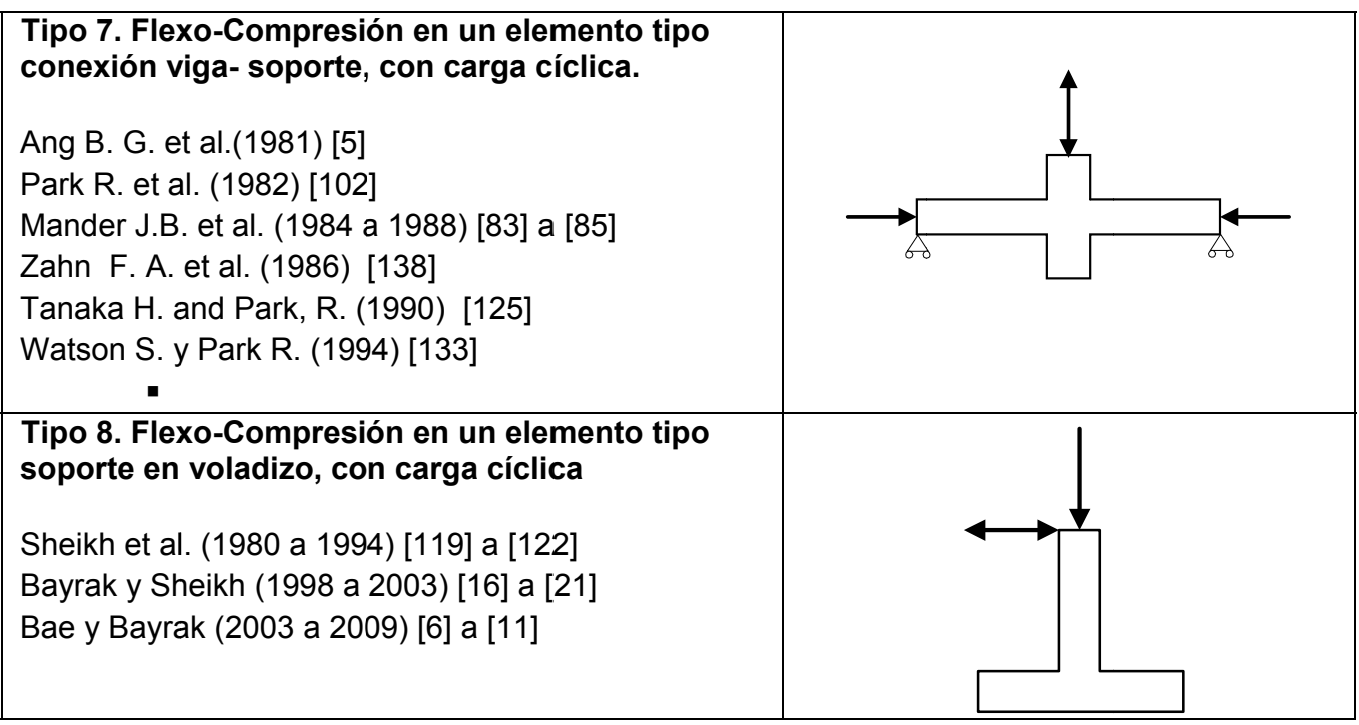

En la Figura 2.11 se muestra el número de elementos ensayados para cada tipo de modelo de ensayo relacionado en la Tabla $2-11$, de acuerdo con la información clasificada en la base de datos.

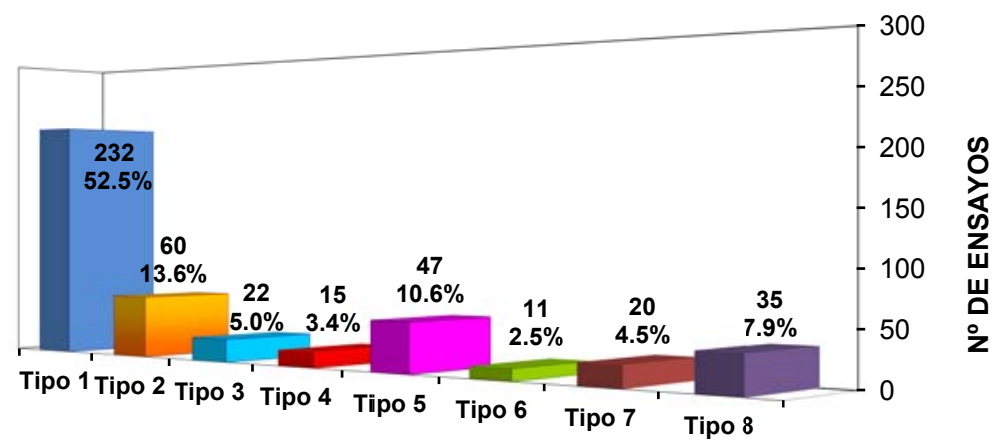

Figura 2.11 Número de ensayos para cada tipo de modelo de ensayo

La base de datos está conformada por 442 ensayos, de los cuales la mayor parte corresponde a ensayos bajo carga monotónica (387 ensayos), y 55 ensayos bajo carga cíclica.

De los ensayos bajo carga cíclica, se han realizado 20 ensayos correspondientes al tipo de modelo 7, y 35 ensayos con el tipo de modelo 8 . De los ensayos bajo carga monotónica, 329 ensayos se han llevado a cabo en elementos sometidos a flexión sin carga axial (modelos de ensayo tipo 1, 2, 3 y 4), y tan sólo 58 ensayos se han desarrollado en elementos sometidos a esfuerzos combinados de flexión y carga axial (modelos de ensayo tipo 5 y 6). Como se puede comprobar, existe una escasa experimentación referida al modelo de ensayo tipo 6 , es decir, ensayos de compresión y flexión monotónica en soportes con conexión intermedia (tan sólo 11 ensayos en nuestra base de datos). 


\subsubsection{ANÁLISIS DE LAS CARACTERÍSTICAS DE LOS ENSAYOS QUE COMPONEN LA BASE DE DATOS}

La información de la base de datos de Panagiotakos et al. (2001) [100] y la base de datos de este estudio han sido utilizadas de forma conjunta para poder determinar los posibles vacíos existentes en la comprobación experimental de la capacidad de deformación de elementos de hormigón armado. Para ello se ha realizado un análisis estadístico para los siguientes parámetros: nivel de carga axial, resistencia del hormigón, esbeltez de cortante, y cuantía transversal. De esta forma se ha podido comprobar que existe una escasa comprobación experimental en algunos rangos de dichos parámetros, como se expone a continuación.

\subsection{Nivel de carga axial}

A partir de la base de datos de Panagiotakos et al. (2001) [100] y la de este estudio (Figura 2.12), se puede observar que existe una escasa experimentación en elementos con moderados y altos niveles de compresión, a partir de 0.4 del axil reducido. En la base de datos recopilada se ha comprobado que tan sólo 23 ensayos se han realizado con un axil reducido superior a 0.35 .

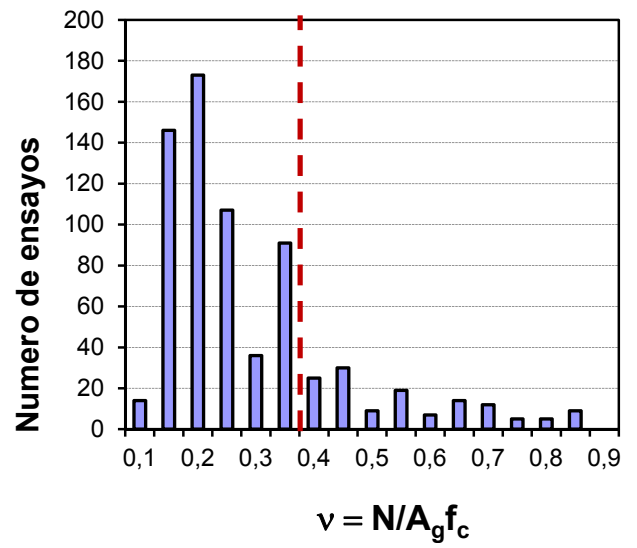

(a)

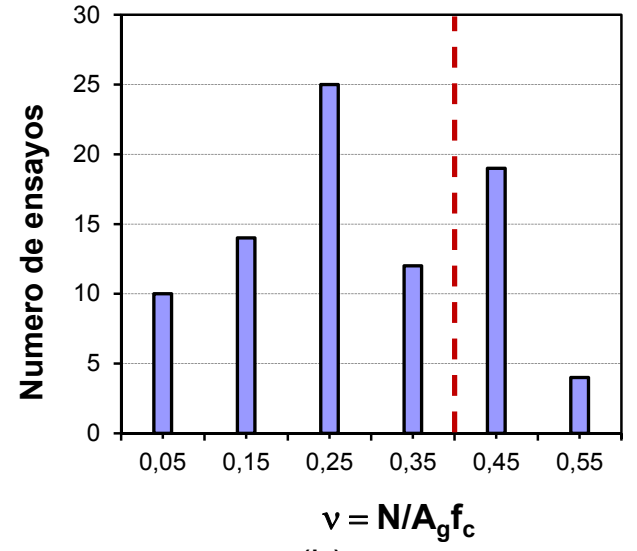

(b)

Figura 2.12 Número de ensayos según el nivel de carga axial: (a) base de datos de Panagiotakos et al. (2001) [100]; (b) base de datos propia

\subsection{Resistencia del hormigón}

En las Figura 2.13 se muestra claramente que la mayor parte de los ensayos realizados en la investigación de la capacidad de deformación de elementos de hormigón armado han sido llevados a cabo en elementos fabricados con hormigón convencional ( $\left.f_{c} \leq 50 \mathrm{MPa}\right)$. Tan sólo el $25 \%$ de los ensayos han sido realizados en elementos de hormigón de alta resistencia $\left(\mathrm{f}_{\mathrm{c}}>50 \mathrm{MPa}\right)$.

Por otro lado, si se tiene en cuenta que la base de datos elaborada por Panagiotakos et al. (2001) [100] se ha utilizado para proponer y validar métodos que puedan predecir la capacidad de deformación en elementos de hormigón armado, incorporados por el Eurocódigo 8 [59], puede considerarse que, para validar y comprobar dichos métodos en un amplio rango de resistencia del 
hormigón, sería conveniente una mayor experimentación en elementos con hormigón de alta resistencia.

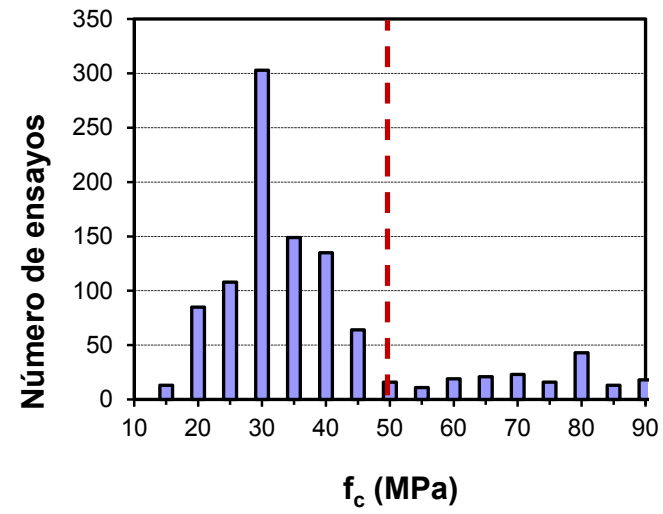

(a)

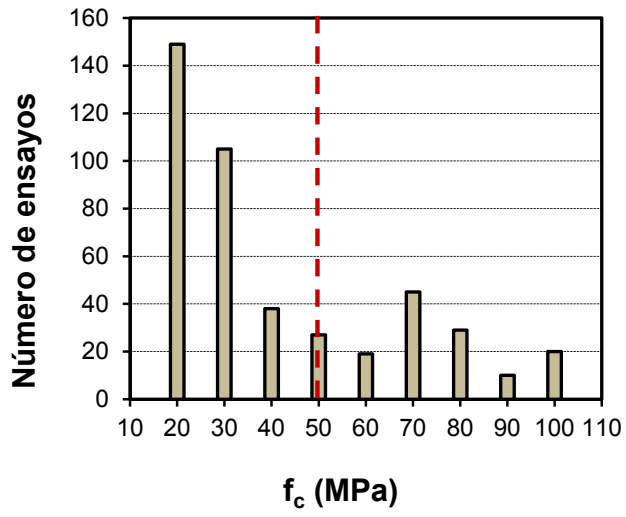

(b)

Figura 2.13 Número de ensayos según la resistencia del hormigón: (a) base de datos de Panagiotakos et al. (2001) [100]; (b) base de datos propia

\subsection{Esbeltez Geométrica}

En las Figura 2.14 se puede comprobar que la experimentación en elementos de hormigón armado con una esbeltez de cortante superior a 6 es casi inexistente. Por consiguiente, los métodos simplificados para evaluar la capacidad de deformación, expuestos en las secciones anteriores, tan sólo se han comprobado y calibrado en elementos con esbelteces inferiores a 6.

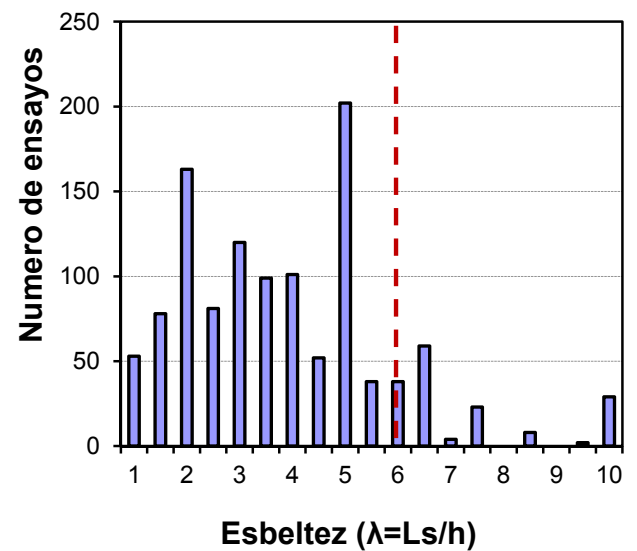

(a)

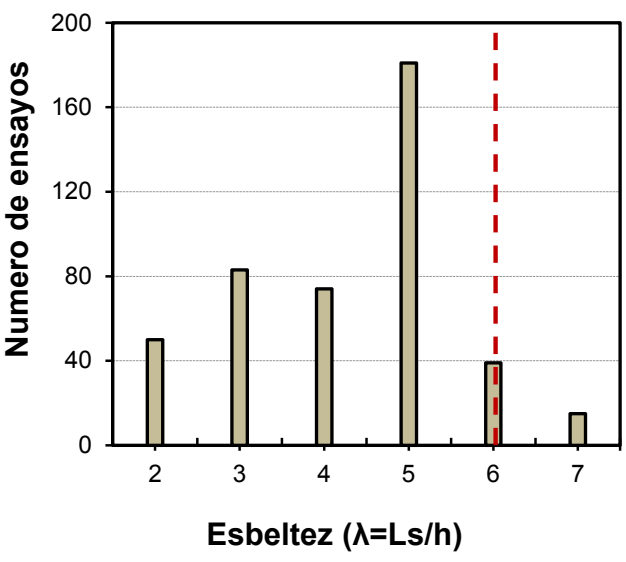

(b)

Figura 2.14 Número de ensayos según la resistencia del hormigón: (a) base de datos de Panagiotakos et al. (2001) [100]; (b) base de datos propia

\subsection{Cuantía de armadura transversal}

Durante la revisión de la bibliografía experimental, se ha podido comprobar que en la mayoría de los estudios el efecto del confinamiento es normalmente considerado como una variable con especial importancia en el comportamiento deformacional de elementos de hormigón (Figura 2.15). Por dicha razón, pueden encontrarse 
ensayos para un amplio rango de cuantía de armadura transversal. Aun así, la mayor parte de los ensayos han sido realizados para cuantías de armadura transversal menores que el $2 \%$, por lo que resultaría conveniente incrementar el número de ensayos con cuantía transversal entre un $2 \%$ y un $3 \%$, para poder considerar también el efecto del confinamiento.

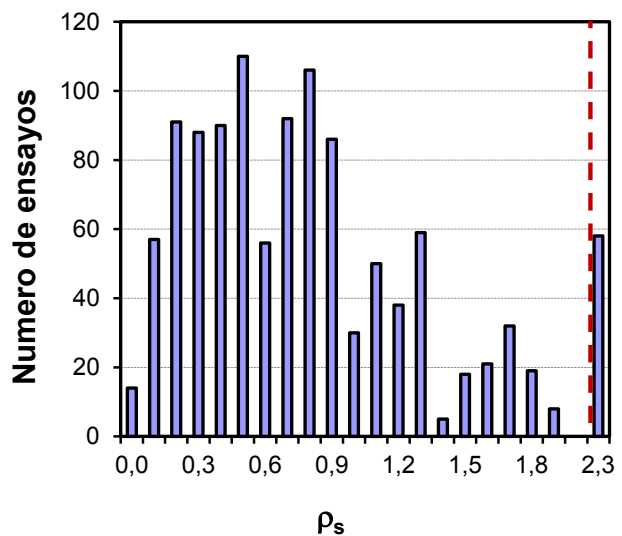

(a)

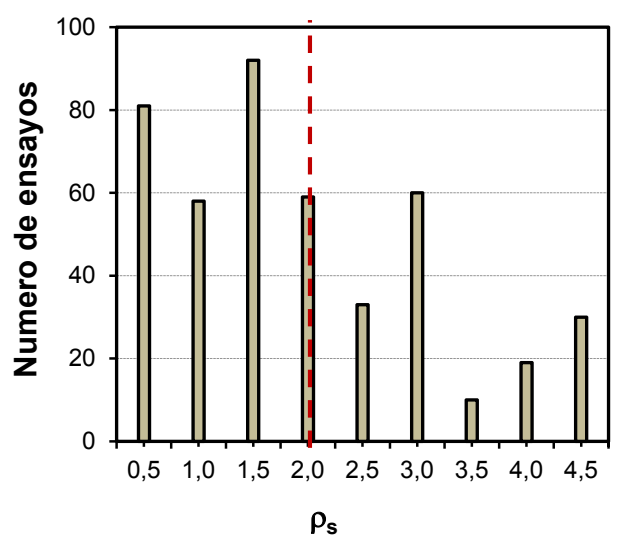

(b)

Figura 2.15 Número de ensayos según la cuantía de armadura transversal: (a) base de datos de Panagiotakos et al. (2001) [100]; (b) base de datos propia

\subsection{NORMATIVA}

\subsubsection{MÉTODOS PROPUESTOS PARA EVALUAR O PREDECIR LA CAPACIDAD DE DEFORMACIÓN}

\subsubsection{EUROCÓDIGO 8: PARTE 2}

En el Eurocódigo 8 (Diseño de estructuras sismorresistentes, parte 2: Puentes) [59], se plantea un método analítico simplificado para evaluar la capacidad de deriva plástica $\left(\theta_{\mathrm{pu}}\right)$ y la deriva total $\left(\theta_{\mathrm{u}}\right)$ de la rótula plástica (Ec. 2-80). Este método se basa en la estimación del diagrama momento-curvatura $(M-\varphi)$ y de la longitud de rótula plástica $\left(L_{p}\right)$.

$$
\begin{gathered}
\theta_{u}=\theta_{y}+\theta_{p u} \\
\theta_{p u}=\left(\varphi_{u}-\varphi^{\prime}{ }_{y}\right) L_{p}\left(1-\frac{L_{P}}{2 L}\right)
\end{gathered}
$$

Donde:

$\theta_{y} \quad$ Deriva elástica evaluada con la Ec. 2-82

$\varphi_{y}^{\prime} \quad$ Curvatura elástica efectiva

$\varphi_{u} \quad$ Curvatura última

L $\quad$ Distancia entre la sección de momento máximo y la sección de momento nulo

Si el momento flector tiene una variación lineal, la deriva elástica se puede calcular según la siguiente expresión: 


$$
\theta_{y}=\frac{\varphi^{\prime}{ }_{y} L}{3}
$$

La curvatura elástica y la curvatura última se calculan a partir de un análisis de la sección $(M-\varphi)$. El diagrama $M-\varphi$ teórico se idealiza mediante un diagrama bilineal (elástico-plástico perfecto). Para ello se determina previamente el punto de plastificación, el cual se identifica cuando la armadura alcanza el límite elástico. La curvatura elástica efectiva $\left(\varphi_{y}^{\prime}\right)$ se deduce conforme a las Figura 2.16. En la Sección 6.4 se presenta una descripción más detallada del proceso de idealización del diagrama $\mathrm{M}-\varphi$.

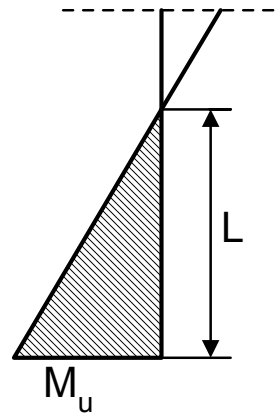

(a)
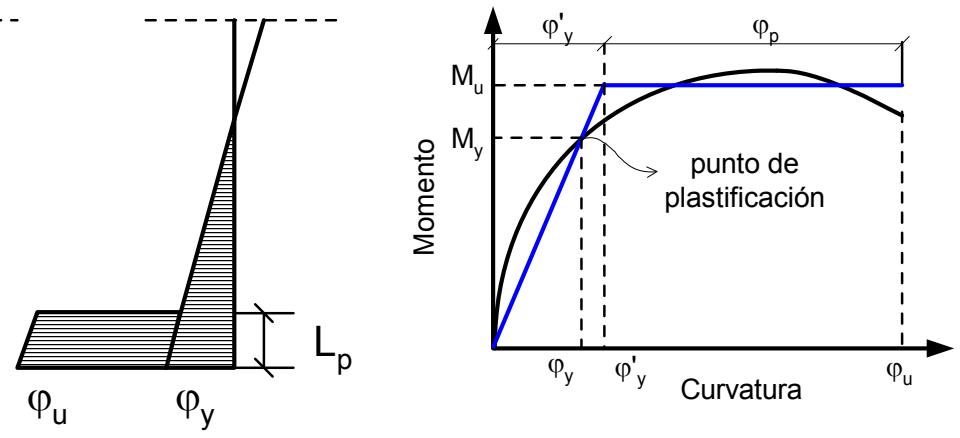

(b)

Figura 2.16 (a) definición de rotula plástica, ( b) definición de curvatura elástica a partir de la idealización del diagrama $M-\varphi$

La curvatura última $\varphi_{u}$ en la rótula plástica se evalúa a partir de la Ec. 2-83, para el estado último. Este estado se define para cuando uno de los dos materiales (hormigón y/o acero) o los dos han alcanzado los valores de deformación última. Sin embargo, hay que aclarar que cuando la deformación en la fibra más comprimida de la sección completa es mayor o igual que la deformación última del hormigón no confinado $\left(\varepsilon_{\mathrm{cu}, 1}\right)$, se deberá tener en cuenta sólo la sección del núcleo confinado. Por consiguiente, el estado último está dado por la condición $\varepsilon_{\mathrm{c}}=\varepsilon_{\mathrm{cu}, \mathrm{c}}, \mathrm{y}$ el canto útil es el de la sección confinada $\left(\mathrm{d}=\mathrm{d}_{\mathrm{c}}\right)$.

$$
\varphi_{u}=\frac{\varepsilon_{s}-\varepsilon_{c}}{d}
$$

Donde:

$\begin{array}{ll}\varepsilon_{S} & \text { Deformación de la armadura en tracción para el estado último } \\ \varepsilon_{c} & \text { Deformación del hormigón para el estado último } \\ \varepsilon_{c u 1} & \begin{array}{l}\text { Deformación de compresión del hormigón no confinado, según Eurocódigo } 2 \\ \text { (2004) [58] }\end{array} \\ \varepsilon_{c u, c} & \begin{array}{l}\text { Deformación de compresión del hormigón confinado, de acuerdo al Eurocódigo } \\ \text { 2(2004) [58] }\end{array} \\ \varepsilon_{S u} & \begin{array}{l}\text { Deformación del acero correspondiente a la tensión máxima } \\ d\end{array} \\ \text { Canto útil de la sección }\end{array}$

La longitud de rótula plástica se evalúa mediante la siguiente expresión:

$$
L_{p}=0.115 L+0.0085 f_{y k} d_{s}
$$




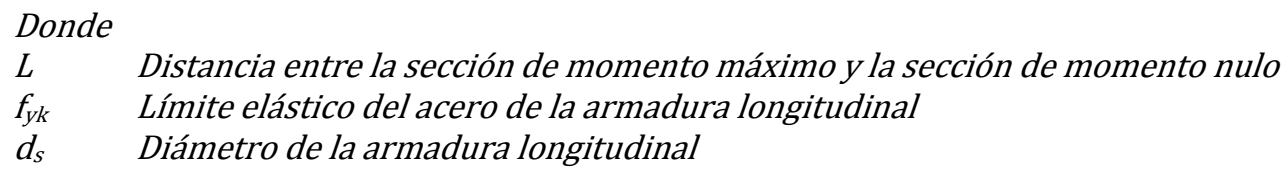

La expresión para el cálculo de la rotación plástica es válida para elementos con esbeltez de cortante $\lambda_{s}=\mathrm{L} / \mathrm{d} \geq 3$, para valores de $1 \leq \lambda_{s}<3$, la capacidad de deriva plástica debe ser multiplicada por un factor de reducción $\lambda\left(\alpha_{\mathrm{s}}\right)$.

$$
\lambda\left(\alpha_{s}\right)=\sqrt{\frac{\alpha_{s}}{3}}
$$

\subsubsection{EUROCÓDIGO 8: PARTE 3}

En la evaluación y revisión de estructuras existentes, la capacidad de deformación de elementos de hormigón (vigas, soportes y muros), se verifica en términos de la deriva última. El Eurocódigo 8 (parte 3), fija la evaluación de la deriva a partir de expresiones simples referidas al estado de daño de la estructura, para el cual se definen tres estados límites (LS): cerca del colapso (NC), daño significativo (SD), y daño limitado (DL). Estos tres estados límite se caracterizan de la siguiente manera:

- Estado límite cerca del colapso (NC): La estructura está altamente dañada, con baja resistencia residual en sentido lateral y baja rigidez, aunque los elementos verticales son todavía capaces de aguantar cargas verticales. La mayoría de los elementos no estructurales han colapsado. Hay presencia de grandes derivas permanentes. La estructura está cerca del colapso y probablemente no resistiría otros sismos, incluso de moderada intensidad.

- Estado límite de daño significativo (SD): La estructura está significativamente dañada, con alguna resistencia y rigidez residual lateral, y los elementos verticales son capaces de aguantar cargas verticales. Los componentes no estructurales están dañados, aunque las particiones no han fallado. Hay presencia de derivas permanentes moderadas. La estructura puede aguantar réplicas sísmicas de moderada intensidad. Es posible que no sea económicamente factible reparar la estructura.

- Estado límite de daño limitado (DL): La estructura está ligeramente dañada. Se ha evitado una significativa plastificación de los elementos estructurales, manteniéndose sus propiedades de resistencia y rigidez. Los elementos no estructurales, tales como muros de partición y divisiones, pueden mostrar cierta distribución de fisuras, pero la reparación del daño puede ser económicamente viable. La deriva permanente es despreciable. La estructura no necesita ninguna medida de reparación.

\section{Evaluación de la capacidad de deriva última para el estado límite NC}

El valor de la capacidad de deriva última $\left(\theta_{\mathrm{u}}\right)$, puede ser calculado a partir de la siguiente expresión: 


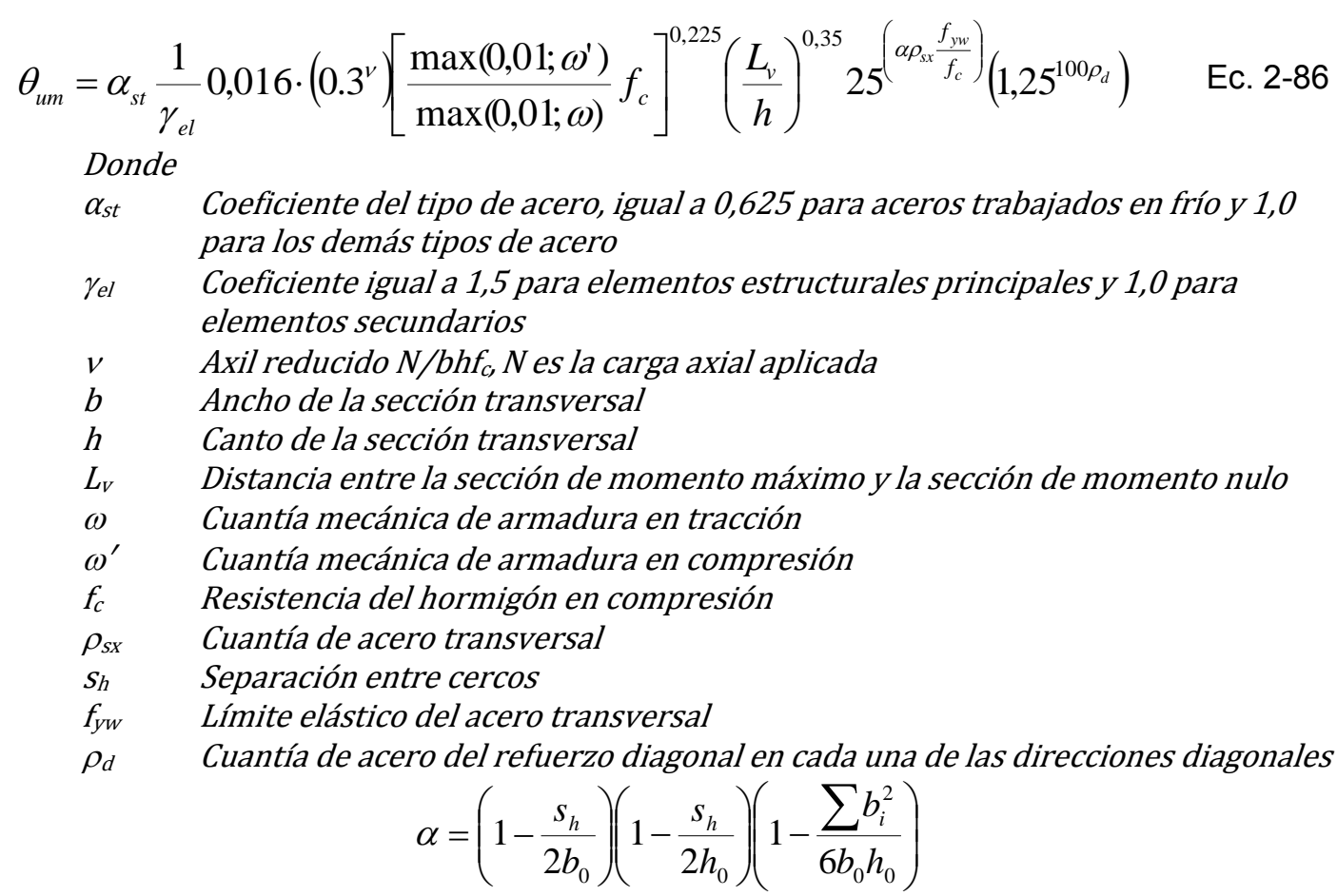

$\alpha \quad$ Factor de efectividad del confinamiento

$b_{0}, h_{0}$ Ancho y canto del núcleo confinado de la sección

$b_{i} \quad$ Distancia entre barras lateralmente atadas con cercos o ganchos

Por otra parte, la deriva plástica puede calcularse de la siguiente manera:

$$
\left.\theta_{u m}^{p l}=\theta_{u m}-\theta_{y}=\alpha_{s} \frac{1}{\gamma_{e l}} 0,0145 \cdot\left(0.25^{v}\right)\left[\frac{\max \left(0,01 ; \omega^{\prime}\right)}{\max (0,01 ; \omega)}\right]^{0,3}\left(f_{c}\right)^{0,2}\left(\frac{L_{v}}{h}\right)^{0,35} 25^{\left(\alpha \rho_{s x} \frac{f_{y w}}{f_{c}}\right.}\right)\left(1,275^{100 \rho_{d}}\right) \quad \text { Ec. } 2-87
$$

Donde

$\alpha_{s} \quad$ Coeficiente del tipo de acero igual a 0.5 para aceros trabajados en frío y 1,0 para los demás tipos de acero

rel Coeficiente igual a 1,8 para elementos estructurales principales y 1,0 para elementos secundarios

$\theta_{y} \quad$ Deriva elástica, calculada a partir de Ec. 2-98 Ec. 2-99

En elementos sin detalles sismorresistentes los valores de la Ec. 2-86 y Ec. 2-87 son multiplicados por 0,825 .

Método alternativo para evaluar la capacidad de deriva última para el estado límite NC

$$
\theta_{u m}=\frac{1}{\gamma_{e l}}\left(\theta_{y}+\left(\varphi_{u}-\varphi_{y}\right) L_{p 1}\left(1-\frac{0,5 L_{p}}{L v}\right)\right)
$$

Donde

$\theta_{y} \quad$ Deriva elástica evaluada con la Ec. 2-98 o Ec. 2-99

$\varphi_{u} \quad$ Curvatura última de la sección cercana al apoyo

$\varphi_{y} \quad$ Curvatura elástica de la sección cercana al apoyo 
El valor de la longitud de rótula plástica $\left(L_{p 1}\right)$ depende de cómo se tienen en cuenta, en el cálculo de la curvatura última de la sección, el aumento de la resistencia y la capacidad de deformación del hormigón debido al confinamiento. Por consiguiente, se establecen dos alternativas para evaluar la curvatura última y, con esta, la $L_{p 1}$, que se explican a continuación:

1. Si la curvatura última de la sección $\varphi_{u}$, bajo cargas cíclicas es calculada con:

(a) La deformación última de la armadura longitudinal, $\varepsilon_{\text {su }}$, siendo esta igual a:

- El mínimo valor dado en el Eurocódigo 2 (2004) [58], para la deformación característica en la tensión máxima en aceros clase A o B.

- $6 \%$ para el acero clase $\mathrm{C}$

(b) El modelo de confinamiento en Eurocódigo 2 (sección 3.1.9) [58], asumiendo la tensión de confinamiento lateral efectiva $\sigma_{2}$ igual a $\alpha \rho_{s x} f_{y w}$.

$$
\begin{array}{cc}
f_{c k, c}=f_{c k}\left(1+5 \frac{\sigma_{2}}{f_{c k}}\right) \text { para } \sigma_{2} \leq 0.05 f_{c k} & \text { Ec. 2-89 } \\
f_{c k, c}=f_{c k}\left(1.125+2.5 \frac{\sigma_{2}}{f_{c k}}\right) \text { para } \sigma_{2}>0.05 f_{c k} & \text { Ec. 2-90 } \\
\varepsilon_{c 2, c}=\varepsilon_{c 2}\left(f_{c k, c} / f_{c k}\right)^{2} & \text { Ec. } 2-91 \\
\varepsilon_{c u 2, c}=\varepsilon_{c u 2}+0.2 \sigma_{2} / f_{c k} & \text { Ec. } 2-92
\end{array}
$$

Donde

$f_{y w} \quad$ Límite elástico del acero transversal

$\alpha \quad$ Factor de efectividad del confinamiento

$f_{c k, c} \quad$ Resistencia característica del hormigón confinado en compresión

$f_{c k} \quad$ Resistencia característica del hormigón en compresión

$\varepsilon_{c 2, c} \quad$ Deformación última del hormigón confinado

$\varepsilon_{c 2} \quad$ Deformación del hormigón cuando se alcanza la tensión máxima de compresión, Modelo parábola-rectángulo Eurocódigo 2 (2004) [58]

$\varepsilon_{c u 2}$ Deformación última del hormigón, Modelo parábola-rectángulo Eurocódigo 2 (2004) [58]

$\rho_{S X} \quad$ Cuantía de acero transversal paralela a la dirección de carga $\left(A_{S X} / b_{W} S_{h}\right)$

$A_{S X} \quad$ Área de armadura transversal paralela a la dirección de carga

$s_{h} \quad$ Separación entre cercos

$b_{w} \quad$ Ancho del núcleo confinado

entonces, para elementos con detalles sismorresistentes y sin solapes de las barras longitudinales cerca de la sección donde se espera la plastificación, la $L_{p 1}$ puede ser calculada a partir de la siguiente expresión:

$$
L_{P 1}=0.1 L_{v}+0.17 h+0.24 \frac{d_{b l} f_{y}}{\sqrt{f_{c}}}
$$

Donde

$L_{V} \quad$ Distancia entre la sección de momento máximo y la sección de momento nulo

$h \quad$ Canto de la sección transversal

$d_{b l} \quad$ Diámetro medio de la armadura en tracción 
$f_{y} \quad$ Límite elástico del acero

$f_{c} \quad$ Resistencia del hormigón en compresión

2. Si la curvatura última de la sección, $\varphi_{u}$, bajo carga cíclica se calcula con:

La deformación última de la armadura longitudinal, $\varepsilon_{\text {su }}$, calculada como en la sección anterior (a), y se utiliza un modelo de confinamiento más adecuado que el modelo del Eurocódigo 2 (Sección 3.1.9) [58]; es decir un modelo donde:

La resistencia del hormigón confinado se evalúa a partir de:

$$
f_{c c}=f_{c}\left(1+3.7\left(\frac{\alpha \rho_{s x} f_{y w}}{f_{c}}\right)^{0.86}\right)
$$

La deformación en la tensión máxima del hormigón confinado, se calcula con:

$$
\varepsilon_{c c}=\varepsilon_{c 2}\left(1+5\left(\frac{f_{c c}}{f_{c}}-1\right)\right)
$$

Y la deformación última en el extremo de la fibra más comprimida se evalúa a partir de:

$$
\varepsilon_{c u}=0.004+0.5 \frac{\alpha \rho_{s x} f_{y w}}{f_{c c}}
$$

Donde

$\alpha \quad$ Factor de efectividad del confinamiento, definido en el método anterior

$\rho_{S x} \quad$ Cuantía de acero transversal paralela a la dirección $x$ de carga $A_{s x} /\left(b_{w} S_{h}\right)$

$f_{y W} \quad$ Límite elástico del acero transversal

$f_{c c} \quad$ Resistencia del hormigón confinado en compresión

entonces, para elementos con detalles sismorresistentes y sin solapes de las barras longitudinales cerca de la sección donde se espera la plastificación, la $L_{p 1}$ puede calcularse a partir de la siguiente expresión.

$$
L_{P 1}=\frac{L_{v}}{30}+0.2 h+0.11 \frac{d_{b l} f_{y}}{\sqrt{f_{c}}}
$$

Donde

$L_{V} \quad$ Distancia entre la sección de momento máximo y la sección de momento nulo

h $\quad$ Canto de la sección transversal

$d_{b l} \quad$ Diámetro medio de la armadura en tracción

$f_{y} \quad$ Límite elástico del acero

$f_{c} \quad$ Resistencia del hormigón en compresión

Si el modelo de confinamiento del Eurocódigo 2 (2004) [58] es adoptado en el cálculo de la curvatura última de la sección, $\varphi_{u}$, y el valor de $L_{p 1}$ a partir de la expresión Ec. 2-93 es usado en la expresión Ec. 2-88, entonces el factor $\gamma_{\mathrm{el}}$ es igual a 2 para elementos sismorresistentes principales, y 1,0 para elementos sismorresistentes secundarios. Si, por el contrario, se utiliza el modelo de 
confinamiento dado por las expresiones Ec. 2-94 a Ec. 2-96, junto con la expresión Ec. 2-97, entonces el valor del factor $\gamma_{e l}$ es igual a 1.7 para elementos sismorresintentes principales y 1,0 para elementos sismorresistentes secundarios.

\section{Evaluación de la capacidad de deriva última para el estado límite SD}

La capacidad de deriva correspondiente a un nivel de daño significativo (SD), puede calcularse como el $75 \%$ de la deriva última evaluada para el nivel de daño cerca del colapso (NC), es decir, aplicando cualquiera de los dos métodos anteriores.

\section{Evaluación de la capacidad de deriva última para el estado límite DL}

La capacidad de este estado límite significa la verificación de la deformación para el momento elástico de flexión $\left(\mathrm{M}_{\mathrm{y}}\right)$. De modo que se requiere de la evaluación de la deriva elástica $\theta_{y}$, que puede ser efectuada a partir de cualquiera de las dos siguientes alternativas para vigas y soportes:

$$
\begin{gathered}
\theta_{y}=\varphi_{Y} \frac{L_{V}+a_{v} z}{3}+0.00135\left(1+1.5 \frac{h}{L_{v}}\right)+\frac{\varepsilon_{y}}{d-d^{\prime}} \frac{d_{b} f_{y}}{6 \sqrt{f_{c}}} \\
\theta_{y}=\varphi_{Y} \frac{L_{V}+a_{v} z}{3}+0.0013\left(1+1.5 \frac{h}{L_{v}}\right)+0.13 \varphi_{y} \frac{d_{b} f_{y}}{\sqrt{f_{c}}}
\end{gathered}
$$

Donde

$\varphi_{y} \quad$ Curvatura elástica de la sección

$a_{v} Z \quad$ Cambio del diagrama de momentos debido a la fisuras inclinadas (Eurocódigo 2 sección 9.2.1.3.) [58]

$z \quad$ Brazo mecánico de la sección

$L_{V} \quad$ Distancia entre la sección de momento máximo y la sección de momento nulo

$a_{V} \quad$ Es igual a 1,0 si se espera que la fisuración de cortante preceda a la flexión elástica en la sección. Cuando el momento elástico de la sección exceda $L_{V}$ veces la resistencia de cortante del elemento, sin considerar la armadura de cortante $V_{R, c}$. Es decir si $\left.M y<L_{V} V_{R, c}\right) \alpha_{V}=0$.

$V_{R c} \quad$ Resistencia a cortante sin considerar la armadura, calculada conforme al Eurocódigo 2 (sección 6.2.2) [58]

$f_{y} \quad$ Límite elástico del acero

$f_{c} \quad$ Resistencia del hormigón en compresión

$\varepsilon_{y} \quad$ Deformación elástica del acero $\varepsilon_{y}=f_{y} / E_{s}$

d $\quad$ Canto útil de la sección

d' Recubrimiento mecánico de la armadura en compresión.

$d_{b l} \quad$ Diámetro medio de la armadura de tracción. 


\section{CAPÍTULO 3}

\section{PLANTEAMIENTO DE LA TESIS}

\subsection{JUSTIFICACIÓN}

La capacidad de deformación en soportes de hormigón armado es de particular interés, ya que es en estos elementos donde se localiza originalmente el comportamiento inelástico de un sistema estructural sismorresistente. En este trabajo de investigación se pretende realizar un estudio de la capacidad de deformación en soportes esbeltos de hormigón convencional y de alta resistencia, con el propósito de, por una parte, determinar cuáles son los parámetros que mayor influencia tienen en la capacidad de deformación de los soportes de hormigón armado, y, por otra parte, comprobar si esta capacidad de deformación puede ser evaluada con los métodos existentes en la literatura (Paulay y Priestley (1992) [104]; Priestley et. al (1996) [111]; Lehman y Moehle (2000) [80], Elwood (2009) [56], Panagiotakos y Fardis (2001) [100] y en actuales normas y recomendaciones Europeas (Eurocódigo 8 (2004) [59], CEB-Fib Bulletin TG7.2 (2003) [35]), ya que se sabe que todos estos métodos han sido realizados en base a investigaciones numéricas $y / 0$ experimentales preferiblemente en soportes de hormigón convencional con bajos valores de esbeltez de cortante entre $2<L_{s} / h<6$, por lo que 
resulta imprescindible conocer si la aplicación de dichos métodos pueden extrapolarse a soportes con otras características, como son hormigón de alta resistencia y una mayor esbeltez de cortante. De no ser así, se debería o bien proponer nuevos métodos o bien adaptar los métodos existentes.

\subsection{ANÁLISIS DEL ESTADO ACTUAL DEL CONOCIMIENTO}

En el capítulo 2 del "estado del conocimiento" se ha realizado una recopilación de los métodos encontrados en la literatura existente y en las actuales normas de diseño sísmico, utilizados para valorar la capacidad de deformación en elementos de hormigón armado. Estos métodos han sido clasificados en tres tipos: empíricos, analíticos simplificados y analíticos más complejos.

\subsubsection{MODELOS EMPÍRICOS}

Dentro de este grupo destaca el modelo simplificado de Panagiotakos y Fardis (2001) [100], para el cálculo de la deriva última. Posteriormente, Fardis y Biskinis (2003) [60] modifican esta propuesta. Finalmente, la norma europea Eurocódigo 8 (2004) [59] ha adoptado este modelo con algunos ajustes. El modelo de Fardis et al. ha sido obtenido a partir del análisis de regresión de una amplia base de datos de ensayos existentes (Panagiotakos y Fardis (2001) [100] y Fardis y Biskinis (2003) [60]). Sin embargo, los diferentes modelos empíricos para el cálculo de la deriva última propuestos por Fardis et al. muestran una amplia dispersión con los resultados experimentales, obteniéndose un coeficiente de variación superior al $40 \%$.

Esto muestra que, aunque la base de datos comprende un gran número de ensayos experimentales, existen algunos aspectos que hacen difícil conseguir un modelo general para el cálculo de la deformación última. Estos aspectos pueden ser: la amplia dispersión en el tipo de acero de la armadura, los detalles de la armadura transversal, y el hecho de que algunos de los elementos cumplen con especificaciones de normas de diseño sismorresistentes mientras que otros no. Por otra parte, en la base de datos de Fardis et al. ([100] y [60]) se ha identificado también que existen vacíos experimentales en cuanto a elementos con esbeltez de cortante superiores a 6 y elementos con hormigón de alta resistencia.

Otros modelos simplificados con menor trascendencia han sido propuestos para el cálculo de la deriva última, como el de Lam et al. (2003) [75]. Este modelo presenta una limitada aplicación, ya que sólo es válido para elementos de hormigón con esbelteces inferiores a 3, de hormigón convencional, y bajos niveles de carga axial.

\subsubsection{MODELOS ANALÍTICOS SIMPLIFICADOS}

En este grupo se encuentran los modelos de Priestley y Park (1996) [111], Lehman y Moehle (2000) [80], Panagiotakos y Fardis (2001) [100]. La principal característica de los modelos analíticos es que el estudio del mecanismo de deformación inelástica está basado en el modelo "soporte en voladizo". En estos métodos la distribución de curvaturas es ajustada de tal manera que la componente plástica se concentra dentro de la longitud equivalente de rótula plástica $\left(L_{p}\right)$, y se adopta un 
comportamiento elástico fuera de $L_{p}$. Por consiguiente, la capacidad de deformación del elemento depende de la adecuada evaluación de la curvatura elástica y última para la sección crítica, y especialmente de la evaluación de la longitud equivalente de rótula plástica.

Los métodos analíticos simplificados presentan algunos inconvenientes para evaluar la capacidad de deformación de elementos de hormigón, debido a los siguientes aspectos:

1. La respuesta del diagrama momento curvatura depende del modelo de confinamiento del hormigón adoptado en el cálculo. Aunque obtener teóricamente el diagrama momento curvatura es un proceso sencillo, la respuesta real depende de una gran variedad de factores y, entre ellos, del efecto del confinamiento. Sin embargo, adoptar un modelo de confinamiento no siempre conduce a la obtención de una respuesta más acertada del diagrama momento-curvatura $(M-\varphi)$, ya que efectos como la pérdida del recubrimiento y el pandeo de la armadura longitudinal, pueden llegar a cambiar el comportamiento de la sección.

2. No sólo surgen inconvenientes a la hora de calcular el diagrama de momento-curvatura, sino que existen importantes diferencias en los criterios para identificar los puntos claves de curvatura elástica efectiva $\left(\varphi_{y}^{\prime}\right)$ y última $\left(\varphi_{\mathrm{u}}\right)$, como ya se ha explicado en el capítulo 2 , en la descripción de cada uno de los métodos analíticos simples.

3. La longitud equivalente de la rótula plástica $\left(L_{p}\right)$ es obtenida a partir de expresiones empíricas. Este es un aspecto ampliamente estudiado en la literatura. En la Tabla 3-1 se resumen los estudios llevados a cabo para proponer expresiones de la longitud de rótula plástica $\left(L_{p}\right)$ obtenidas a partir de diferentes métodos. Esto hace que existan grandes variaciones entre las expresiones propuestas para $L_{p}$. Las razones que pueden explicar dicha variación son:

- Muchas de las expresiones han sido obtenidas a partir de la calibración de ensayos experimentales con diferentes características en cuanto al tipo de elemento (vigas en flexión simple, soportes en flexo-compresión) y al tipo de carga (monotónica o cíclica).

- Los conceptos que sirven de base para la obtención de la expresión de la $L_{p}$ son distintos. En algunos casos, la expresión es totalmente empírica, mientras que en otros casos se intenta analizar de manera independiente algunos efectos locales dentro de la $L_{p}$, como son la flexión, el deslizamiento de la armadura y el efecto de la fisuración inclinada por cortante.

- Es interesante destacar que la mayoría de las expresiones de $L_{p}$ no consideran la carga axial como un parámetro, a excepción de las expresiones propuestas por Baker (1956) [15] y Baker y Amarakone (1964) [14]. Esto se debe a que el comportamiento de las vigas de hormigón fue el principal objetivo al estudiar la longitud de rótula plástica $\left(L_{p}\right)$ en las investigaciones previas. Posteriormente, el comportamiento 
de los soportes de hormigón ha despertado un mayor interés. Por consiguiente, se ha dado gran importancia al estudio de la influencia del nivel de carga axial. Pero en algunos casos, los resultados obtenidos pueden considerarse contradictorios. Por ejemplo, Park y Priestley (1982) [102] y Mendis (1992) [92] concluyeron que la $L_{p}$ es independiente del nivel de carga axial basándose en los resultados de sus ensayos; por el contrario, Tanaka y Park (1990) [125] llegaron a la conclusión de que la $L_{p}$ aumentaba de $0.46 \mathrm{~h}$ a $0.75 \mathrm{~h}$ a medida que aumentaba el axil reducido aplicado desde $0.1 \mathrm{f}_{c} \mathrm{~A}_{\mathrm{g}}$ a $0.30 \mathrm{f}_{c} \mathrm{~A}_{\mathrm{g}}$. Los resultados de los ensayos de Légeron y Paultre (2000) [78] indicaron que el incremento de $L_{p}$ con la carga axial podía también ser observado para soportes de hormigón de alta resistencia.

- Por último, aunque recientemente las expresiones propuestas para el cálculo de la $L_{p}$ son obtenidas a partir del análisis de amplias bases de datos experimentales o numéricas, se siguen detectando vacíos en la comprobación experimental para validar estas expresiones, como se pudo comprobar en el capítulo anterior (apartado 2.3).

En vista de lo anterior, se concluye que los métodos analíticos simplificados existentes carecen de una comprobación experimental más allá de los rangos y parámetros a partir de los cuales han sido calibrados. Y las expresiones de longitud de rótula se refieren a una variable en la que se acumula el ajuste de los métodos hasta ahora propuestos.

Tabla 3-1 Resumen de estudios llevados a cabo para obtener expresiones de $L_{p}$

\begin{tabular}{|c|c|}
\hline Autor & Resumen de Observaciones en el estudio de $L_{p}$ \\
\hline Baker A.L.L. (1964) [14] & \multirow{5}{*}{$\begin{array}{l}\text { Proponen expresiones de } L_{p} \text {, calibradas a partir de ensayos } \\
\text { experimentales en elementos tipo viga sometidos a flexión simple. Estas } \\
\text { expresiones son utilizadas en el cálculo de capacidad de rotación plástica } \\
\text { requerida para el desarrollo de la distribución de momentos en vigas } \\
\text { continuas. }\end{array}$} \\
\hline Baker A.L.L. et al. (1964) [14] & \\
\hline Mattock A.H (1964) [89] & \\
\hline Sawyer H.A.(1964) [117] & \\
\hline Corley W.G. (1966) [45] & \\
\hline Mattock A.H. (1967) [87] & Incluye ensayos de flexo compresión monotónica. \\
\hline Mendis P.A. (2001) [92] & $\begin{array}{l}\text { Realiza ensayos en } 13 \text { vigas y } 4 \text { soportes bajo carga monotónica con } \\
\text { esbeltez inferior a } 5 \text {. Concluye que la } L_{p} \text { incrementa con } L / h \text {, disminuye con } \\
\text { el incremento de cuantía de confinamiento y es insensible al nivel de carga } \\
\text { axial. }\end{array}$ \\
\hline Park R. et al. (1982) [102] & Ensayos en soportes poco esbeltos ( $(\mathrm{L} / \mathrm{h}=2)$ bajo carga cíclica. $\mathrm{L}_{\mathrm{p}}$ es $0.4 \mathrm{~h}$ \\
\hline Pristley M.J.N. y Park R. (1987) [110] & \multirow{3}{*}{$\begin{array}{l}\text { Realizan ensayos en soportes poco esbeltos }(\mathrm{L} / \mathrm{h}<3) \text {, bajo carga cíclica. } \\
\text { Tienen en cuenta en su expresión dos términos } L_{p}=\alpha L_{s}+C_{t} \text { en el primer } \\
\text { término se considera el efecto del incremento de resistencia del acero de } \\
\text { la armadura, a partir del límite elástico a la carga última } \alpha=(\text { fu-fy)/fu, } \alpha \\
\text { puede variar desde } 0.08 \text { a } 0.18 \text { en las expresiones. El segundo término } \\
\text { tiene que ver con el deslizamiento de la armadura en la zona de anclaje, } C_{t} \\
\text { depende del diámetro de la armadura y del límite elástico. }\end{array}$} \\
\hline $\begin{array}{l}\text { Paulay T. y Priestley M.J.N. (1992) } \\
\text { [104] }\end{array}$ & \\
\hline Lehman D.E. (1998) [81] & \\
\hline Sakai K. y Sheikh S.A. (1989) [116] & \multirow{2}{*}{$\begin{array}{l}\text { Realizan un amplio estudio experimental en soportes de hormigón } \\
\text { convencional y de alta resistencia, con valores de esbeltez } 6 \text { y altos niveles } \\
\text { de carga axial, sujetos a carga cíclica. Obtienen que } L_{p}=h \text {. Se han } \\
\text { encontrado contradicciones sobre la influencia de las variables a lo largo } \\
\text { de la investigación. }\end{array}$} \\
\hline Sheikh S.A. y Khoury S.S. (1993) [121] & \\
\hline Panagiotakos T.B. et al. (2001) [100] & \multirow{4}{*}{$\begin{array}{l}\text { Estas expresiones son similares, la } L_{p} \text { está en función de dos variables } L_{s} \text { y } \\
d_{\mathrm{d}} f_{\mathrm{y}} \text {. Estas expresiones son obtenidas a partir de la calibración de una } \\
\text { amplia base de datos de alrededor de } 1000 \text { ensayos en vigas y soportes } \\
\text { de hormigón. Algunas de estas expresiones han sido diferenciadas para el } \\
\text { tipo de carga monotónica o cíclica. }\end{array}$} \\
\hline Fardis M.N. y Biskinis D.E. (2003) [60] & \\
\hline CEB-FIB Bulletin 25 (2003) [35] & \\
\hline Eurocódigo 8 (2003) [59] & \\
\hline Ceroni F. et al. (2005) [36] & $\begin{array}{l}\text { Obtenida a partir de una regresión de una base de datos de } 3780 \text { ensayos } \\
\text { numéricos }\end{array}$ \\
\hline Bae S. y Bayrak O. (2008) [8] & $\begin{array}{l}\text { Obtiene una expresión para la } L_{p} \text {, en base a la implementación de un } \\
\text { método analítico para obtener la distribución de deformaciones de } \\
\text { compresión del hormigón. }\end{array}$ \\
\hline
\end{tabular}




\subsubsection{MÉTODOS ANALÍTICOS MÁS COMPLEJOS}

Los métodos simplificados complejos han sido en su mayor parte propuestos para elementos de hormigón sin carga axial, es decir, elementos tipo viga. Sólo el modelo de Bae (2005) [12], el cual ha sido desarrollado para llevar a cabo una simulación más completa del comportamiento deformacional en elementos de hormigón armado, incluye los efectos de segundo orden debidos a la carga axial. Otros efectos considerados en el modelo de Bae (2005) [12] son el deslizamiento de la armadura, la deformación por cortante, el confinamiento del hormigón y efectos locales del pandeo de la armadura longitudinal. Este modelo fue calibrado con una serie de 5 ensayos experimentales, y los resultados de capacidad de deformación obtenidos del modelo fueron comparados con los resultados obtenidos en ensayos experimentales tomados de la base de datos del UW/PEER [139]. Por último el modelo fue utilizado como herramienta de simulación para obtener un modelo más simplificado.

En realidad, este tipo de modelos son complejos en la práctica y su aplicación más directa es la simulación para obtener modelos más simplificados. Sin embargo, en el caso del modelo analítico complejo de Bae (2005) [12], es necesaria una mayor comprobación experimental, puesto que el rango de variables utilizadas es muy escaso, ya que en su calibración se consideran sólo ensayos experimentales en los que la máxima esbeltez es 7 y la resistencia del hormigón es menor de $50 \mathrm{MPa}$. Por consiguiente, su aplicación puede estar limitada a elementos con dichas características.

\subsubsection{ESTUDIOS EXPERIMENTALES}

Tomando como referencia la base de datos de ensayos experimentales efectuados en elementos de hormigón (soportes y vigas) bajo carga cíclica y monotónica desarrollada por Panagiotakos et al. (2001) [100], y la base de datos realizada en el presente estudio para ensayos bajo carga monotónica, las cuales han sido presentadas en el Capítulo 2 (sección 2.3), se puede concluir que existen evidentes vacíos en la experimentación de elementos de hormigón de alta resistencia (superior a $50 \mathrm{MPa}$ ), con valores de esbeltez mayores que 6, y con niveles entre moderados y altos de carga axial (superiores al $30 \% \mathrm{~N} / \mathrm{N}_{\mathrm{u}}$ ).

Como es sabido, algunos modelos analíticos y empíricos para el cálculo de la capacidad de deformación en elementos de hormigón, como por ejemplo los de Panagiotakos y Fardis (2001) [100], Eurocódigo 8 (2004) [59], Fardis y Biskinis (2003) [60], han sido obtenidos a partir del análisis de la base de datos de ensayos experimentales construida por Fardis et al. ([100] y [60]). Por lo tanto, existe incertidumbre acerca de la validez de dichos modelos en aquellos rangos en los que existen vacíos experimentales. 


\subsection{PLANTEAMIENTO DEL PROBLEMA}

El comportamiento de la capacidad de deformación de elementos de hormigón armado ha sido ampliamente estudiado. A partir de los años 60, se despertó un gran interés por estudiar la capacidad de rotación de las rótulas plásticas en elementos tipo viga, con el propósito de analizar la redistribución de momentos en vigas continuas. A partir de los años 80 , el interés se ha centrado en el estudio de la capacidad de deformación y de ductilidad de elementos de hormigón armado. Este interés se debe al surgimiento de conceptos basados en el desplazamiento para el diseño sísmico de nuevas estructuras y la evaluación sísmica de las ya existentes. Esta amplia investigación previa ha permitido que se desarrollen métodos para evaluar la deformación última en elementos de hormigón armado. Sin embargo, surge el problema de la incertidumbre a la hora de aplicar estos métodos, ya que los resultados obtenidos pueden presentar grandes diferencias dependiendo de las características geométricas, mecánicas y de niveles de carga axil de los soportes.

A partir del análisis del estado actual del conocimiento, se ha observado que algunos investigadores (Inel et al. (2007) [67], Ceroni et al. (2003) [37]) han comparado diferentes métodos existentes, obteniéndose notables diferencias en lo que respecta al cálculo de la capacidad de deformación de soportes, en términos de la deriva última. Tras analizar estas comparaciones, y teniendo en cuenta el análisis que se ha llevado a cabo sobre la bibliografía existente, se podría concluir que las grandes diferencias observadas se deben a los siguientes factores:

1. La gran dispersión existente en los valores de la longitud de rótula plástica equivalente obtenidos de forma empírica y aplicada a modelos analíticos.

2. Los diferentes criterios utilizados para definir los puntos de plastificación y último en la idealización de los diagramas de momento-curvatura o cargaflecha.

3. Algunos de los modelos han sido obtenidos en base a una escasa comprobación experimental, por lo cual los parámetros y rangos de estudio son mínimos. Esto hace que, al ser aplicados a rangos diferentes, su validez disminuya considerablemente.

4. A pesar de que algunos métodos han sido obtenidos utilizando una amplia base de datos de ensayos experimentales existentes, se han identificado una serie de vacíos en relación con algunos rangos dentro de los parámetros claves en el comportamiento deformacional de los soportes, como son la esbeltez, el nivel de carga axil y la resistencia del hormigón.

5. Aunque los métodos Panagiotakos y Fardis (2001) [100] (analítico y empírico) utilizan una amplia base experimental, estos métodos han sido calibrados con una dispersión muy amplia. Hasta tal punto que algunos autores han encontrado diferencias de hasta el $100 \%$ en la aplicación de estos dos métodos (Inel et al. (2007) [67], Ceroni et al. (2003) [37]). 


\subsection{OBJETIVOS}

\subsubsection{OBJETIVO GENERAL}

Una vez identificados en la investigación previa los problemas y carencias que acabamos de exponer, se plantea como objetivo general el estudio de la capacidad de deformación en soportes esbeltos de hormigón convencional y de alta resistencia sometidos a flexo compresión recta. Dicho estudio se realiza en base a un programa de ensayos experimentales y mediante la utilización de una herramienta numérica sofisticada para la simulación del comportamiento de soportes de hormigón armado. El estudio pretende proponer modelos simplificados para la evaluación de la capacidad de deformación de elementos de hormigón armado que puedan ser aplicados dentro de un amplio rango de parámetros de esbeltez, resistencia del hormigón y niveles de carga axial, y con diferentes grados de confinamiento.

\subsubsection{OBJETIVOS ESPECÍFICOS}

Los objetivos específicos que se derivan a partir de tal objetivo general son:

1. Identificar los parámetros clave en el comportamiento deformacional de soportes de hormigón, a partir del análisis de estudios previos en la bibliografía y de los resultados obtenidos en ensayos experimentales existentes.

2. Diseñar un programa experimental específico para el ensayo de soportes de hormigón armado sometidos a compresión y flexión monotónica, que reproduzca la condición real de un soporte esbelto típico de edificación. Esto permitirá estudiar los efectos no lineales concentrados dentro de la rótula plástica que se forma en este tipo de elementos en particular.

3. Realizar un programa experimental en soportes esbeltos de hormigón convencional y de alta resistencia con el propósito de completar los vacíos encontrados en las bases de datos de ensayos experimentales existentes. Los parámetros de estudio se presentan en la Tabla 3-2:

Tabla 3-2 Parámetros de estudio en el programa experimental

\begin{tabular}{|l|l|}
\hline Resistencia del hormigón, $\mathrm{f}_{\mathrm{c}}(\mathrm{MPa})$ & $30,60,90$ \\
\hline Tipo de acero de la armadura & B $500 \mathrm{~S}$ \\
\hline Esbeltez de cortante, $\boldsymbol{\lambda}$ & $7.5,10.5$ y 15 \\
\hline Nivel de carga axial, $\mathrm{N} / \mathrm{N}_{\mathrm{u}}(\%)$ & $0,15,30,45$ y 60 \\
\hline Cuantía de armadura longitudinal, $\rho_{\mathrm{l}}(\%)$ & $1.4,2.2$ y 3.2 \\
\hline Cuantía de armadura transversal, $\rho_{\mathrm{s}}(\%)$ & 1,2, y 3 \\
\hline
\end{tabular}


4. A partir de los resultados experimentales se realizará un estudio de:

- La capacidad resistente del elemento y de la sección.

- La deformación de los materiales, de la sección y del elemento en la situación de punto de plastificación y rotura.

- Identificación de tipos de fallos, en base a la resistencia y deformación de los materiales.

- Evaluación de los índices de capacidad de deformación, las ductilidades de curvatura y de desplazamientos, y la longitud de rótula plástica.

- Análisis de los resultados experimentales de resistencia, de índices de capacidad de deformación, de ductilidades y de longitudes de rótula plástica con respecto a los parámetros de estudio.

5. Calibración de una herramienta numérica de elementos finitos mediante los ensayos experimentales, con el propósito de realizar un amplio programa de ensayos numéricos para lograr dar continuidad al estudio de los parámetros, conforme a la Tabla 3-3.

Tabla 3-3 Parámetros de estudio del programa de simulaciones numéricas

\begin{tabular}{|l|l|}
\hline Resistencia del hormigón, $\mathrm{f}_{\mathrm{c}}(\mathrm{MPa})$ & $30,45^{*}, 60,75^{*}, 90$ \\
\hline Tipo de acero de la armadura & B $500 \mathrm{~S}$ \\
\hline Esbeltez de cortante, $\lambda$ & $3.5^{\star}, 5.0^{*}, 7.5$ y 10.5 \\
\hline Nivel de carga axial, $\mathrm{N} / \mathrm{N}_{\mathrm{u}}(\%)$ & $0,7.5^{*}, 15,22.5^{*}, 30,45$ y 60 \\
\hline Cuantía de armadura longitudinal, $\rho_{\mathrm{I}}(\%)$ & $1.2,2.2,3.2$ y $4.2^{*}$ \\
\hline Cuantía de armadura transversal, $\rho_{\mathrm{s}}(\%)$ & $1,2,3$, y $4^{*}$ \\
\hline
\end{tabular}

* valores de los parámetros de estudio adicionales en el programa de ensayos numérico

6. Estudio paramétrico para identificar y valorar la influencia de los factores que afectan la capacidad de deformación en soportes esbeltos de hormigón convencional y de alta resistencia.

7. Comprobación de la validez de los métodos existentes para predecir la capacidad de deformación y ductilidad en soportes esbeltos de hormigón convencional y de alta resistencia. Ya que se debe tener cuenta que estos métodos tienen escasa comprobación para los rangos y parámetros de estudio propuestos en esta investigación.

8. Propuesta de métodos simplificados para la evaluación de la capacidad de deformación y de la ductilidad de elementos de hormigón armado, en términos de:

$>$ Rigidez elástica efectiva y última.

$>$ Desplazamiento elástico y último.

$>$ Ductilidad de desplazamiento. 


\subsection{METODOLOGÍA}

Previamente se ha llevado a cabo una revisión de la documentación existente relacionada con los siguientes aspectos:

- Identificación de modelos existentes para medir la capacidad de deformación y ductilidad de soportes.

- Revisión de las características de los elementos de hormigón utilizados en la validación de métodos existentes.

- Identificación de los tipos de ensayos realizados con fines similares, para medir la deformación de soportes de hormigón.

Para lograr los objetivos planteados en este estudio se establece la siguiente metodología.

En la primera parte de este trabajo se plantea el desarrollo de un programa experimental que permita obtener, por un lado, información acerca de los efectos locales que se desarrollan dentro de la rótula plástica, y, por otro lado, obtener resultados del comportamiento real de soportes esbeltos de hormigón convencional y de alta resistencia. Dichos resultados son utilizados para caracterizar el comportamiento del soporte a nivel del elemento, a nivel de la rótula plástica y a nivel de la sección, mediante la valoración de los respectivos índices de capacidad de deformación y ductilidad. Esto permitirá analizar de un modo general la influencia de los parámetros de estudio en el comportamiento de los soportes. Adicionalmente, los resultados serán utilizados para comprobar algunos métodos propuestos para evaluar la capacidad de deformación.

En la segunda parte del trabajo, se hará uso de una herramienta numérica de elementos finitos para la simulación de elementos de hormigón armado. El modelo numérico obtenido será calibrado mediante los ensayos experimentales. Esto permitirá la realización de un amplio programa de simulaciones numéricas, a partir del cual se obtendrán los resultados para llevar a cabo un estudio paramétrico completo, que permitirá evaluar la influencia de cada uno de los parámetros en los índices de capacidad de deformación. Finalmente, mediante un análisis estadístico, se plantearán y propondrán modelos simples para la evaluación de la capacidad de deformación y de la ductilidad de elementos de hormigón armado. 
Estudio experimental y numérico de la capacidad de deformación de soportes esbeltos de hormigón armado 


\section{CAPÍTULO 4}

\section{MODELO DE ENSAYO Y DESARROLLO DEL PROGRAMA EXPERIMENTAL}

El conocimiento actual del comportamiento de las estructuras de hormigón armado se ha fundamentado especialmente a partir de la experimentación de elementos aislados de la estructura. A partir de ello se han llegado a deducir modelos teóricos y numéricos utilizados en el análisis y diseño de estructuras de hormigón armado, de modo que sea posible garantizar un correcto comportamiento de la estructura, alcanzándose un satisfactorio nivel de seguridad.

Durante la experimentación, el comportamiento del elemento estructural bajo las acciones específicas es determinado a partir de la observación y la valoración de los fenómenos que se producen. Dichos fenómenos pueden ser explicados mediante la respuesta experimental obtenida en términos de la capacidad resistente y la de capacidad de deformación. Adicionalmente, la observación, tanto de los mecanismos de rotura como del desarrollo del proceso de fisuración, contribuyen a una mejor interpretación de dichos fenómenos. 
Aunque indudablemente la experimentación tiene claras ventajas, se trata de un proceso que también presenta limitaciones que no se pueden ignorar. Generalmente, tales limitaciones están relacionadas con múltiples errores que aparecen a lo largo del proceso de experimentación (errores en las mediciones, imperfecciones geométricas, calibración de la instrumentación, etc.), y, por lo tanto, deberán tenerse en cuenta en el análisis de nuevas propuestas.

\subsection{OBJETIVO DEL PROGRAMA EXPERIMENTAL}

El objetivo principal de este programa de experimentación es estudiar la capacidad de deformación y de ductilidad de soportes esbeltos de hormigón convencional y de alta resistencia. Para ello, se ha llevado a cabo un programa experimental de 44 ensayos de soportes esbeltos sometidos a esfuerzos combinados de carga axial constante y flexión monotónica. Este programa experimental engloba el estudio de la influencia de los parámetros que más influyen en la capacidad de deformación, como son: el nivel de carga axial, la cuantía de armadura longitudinal, la esbeltez geométrica, la cuantía de armadura transversal y la resistencia del hormigón.

\subsection{MODELO DE ENSAYO}

El esquema general del modelo (Figuras 4.1) está basado en la representación de dos pilares conectados a un elemento más rígido, definido en la literatura como "stub", que se refiere a la unión del soporte con una viga, forjado o cimentación.

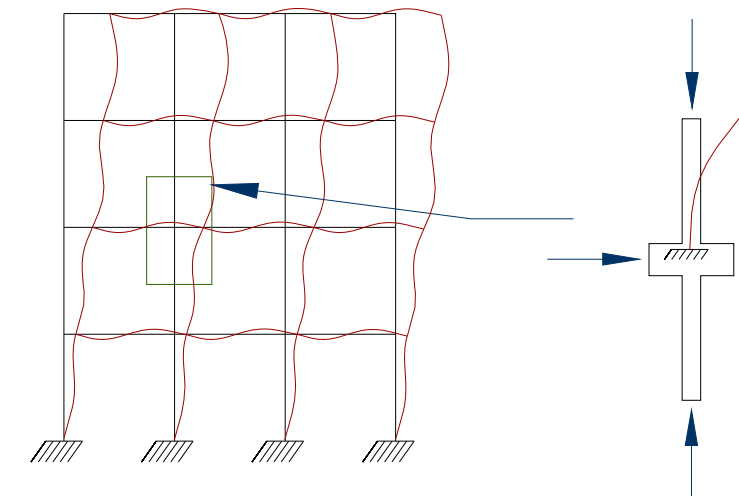

(a) (b)

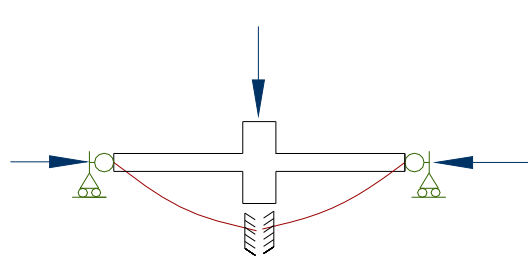

(c)

Figura 4.1 Modelo del ensayo: (a) pórtico estructural, (b) soporte aislado, (c) modelo del ensayo

Este modelo ha sido ya utilizado por varios investigadores, como Park $\mathrm{R}$. et al. (1982) [102], Ang B. G. et al. (1981) [5], Mander J.B. et al. (1984 a 1988) [83] a [85], Zahn F. A. et al. (1986) [138], Tanaka, H. and Park, R. (1990) [125], Watson S. y Park R. (1994) [133], y es comúnmente adoptado en el estudio de la capacidad de deformación de los soportes, ya que esto implica el análisis y caracterización de la rótula plástica. 


\subsection{PARÁMETROS DE ESTUDIO}

La definición de los parámetros y la delimitación de los rangos de estudio se han llevado a cabo, en primer lugar, en base a los conceptos teóricos fundamentales del comportamiento estructural de soportes. En segundo lugar, se ha tenido en cuenta la interacción de varios parámetros que influyen en el comportamiento dúctil en soportes de hormigón armado, como son:

- Las propiedades de los materiales (hormigón, acero) y su interacción.

- Las características geométricas (tamaño, esbeltez geométrica, cuantía de armadura longitudinal y transversal).

- Nivel de carga axial.

Por lo tanto, en este trabajo (para el estudio de la capacidad de deformación de elementos sometidos a flexo compresión), se han incluido todos los parámetros enunciados anteriormente, a excepción de las propiedades del acero, puesto que se ha considerado el uso de un acero normalizado (Clasificación B500 SD, de acuerdo a la norma EHE-08 (2008) [53]), solicitado en estructuras de hormigón con determinadas exigencias de ductilidad.

Por otra parte, la delimitación de los rangos de estudio para cada uno de los parámetros se ha realizado teniendo en cuenta los siguientes criterios: (a) los vacíos encontrados en la bibliografía existente, donde aparece una escasa verificación experimental; (b) los requerimientos de las normas existentes, con respecto a rangos de cuantía geométrica normalmente utilizada en elementos de hormigón.

En definitiva, los parámetros y rangos estudiados en el programa experimental son los siguientes:

1. Esbeltez geométrica: Constituye el factor que más influye en el estudio de los efectos se segundo orden, la esbeltez geométrica constituye un factor influyente. De acuerdo a la norma española EHE (1998) [52] vigente en el momento de plantear la propuesta de ensayos, los rangos de esbeltez geométrica se delimitaban entre 10 y 30 . Se han escogido tres valores, 15, 21 y 30 (para los cuales es posible obtener distintos tipos de rotura del soporte: por agotamiento de la armadura y por inestabilidad). Los tres valores de esbeltez geométrica corresponden a los valores de esbeltez de cortante de $7.5,10.5$ y 15 respectivamente, teniendo en cuenta que la esbeltez de cortante se define como la relación entre $L_{s} / h$ (siendo $L_{s}$ la distancia entre las secciones de máximo momento y momento nulo, y h el canto de la sección transversal)

2. Resistencia del hormigón: El estudio se ha realizado tanto en elementos de hormigón convencional como de alta resistencia, y se eligieron tres valores: 30 $\mathrm{MPa}, 60 \mathrm{MPa}$ y $90 \mathrm{MPa}$.

3. Nivel de carga axil: Debido a la gran influencia de este parámetro, se ha considerado que esta variable se estudiará en un rango entre el axil nulo y un $60 \%$ del axil último. En la norma EHE-08 (2008) [53], en el anejo $10^{\circ}$ (Requisitos especiales recomendados para estructuras sometidas a acciones sísmicas) se 

hormigón armado

establece que para soportes el axil de cálculo debe ser inferior al $65 \%$ del axil reducido, para conseguir algún nivel de ductilidad.

4. Cuantía de armadura longitudinal. Los valores adoptados para este estudio están en el rango de $1.44 \%$ a $3.2 \%$, es decir, entre un valor muy cercano a la cuantía mínima (1\%) y una cuantía de armadura elevada, lográndose una distribución simétrica del armado. De acuerdo a la EHE-08 (2008) [53], en el anejo $10^{\circ}$ (Requisitos especiales recomendados para estructuras sometidas a acciones sísmicas) se establece que para soportes la cuantía de armadura longitudinal no debe ser inferior al $1 \%$ ni superior al $6 \%$.

5. Cuantía transversal: El efecto del confinamiento del hormigón provocado por la cuantía transversal es determinante en el comportamiento deformacional de los soportes de hormigón armado. En este estudio se han considerado tanto soportes poco confinados, provistos de una cuantía de armadura transversal alrededor del $1 \%$, como también soportes confinados con cuantías de armadura del $2 \%$ y $3 \%$.

\subsection{DESCRIPCIÓN GEOMÉTRICA DEL SOPORTE}

En la Figura 4.2 se presenta un esquema de la geometría de los soportes ensayados. La longitud total entre apoyos es de $3300 \mathrm{~mm}$. Sin embargo, el elemento de hormigón ocupa $2940 \mathrm{~mm}$, dejando a cada lado un espacio disponible de $180 \mathrm{~mm}$ para la ubicación de elementos metálicos utilizados para sujetar y apoyar el soporte dentro del pórtico de carga (ver Anejo C. Pórtico de carga). La geometría del "stub" es igual en todos los soportes.

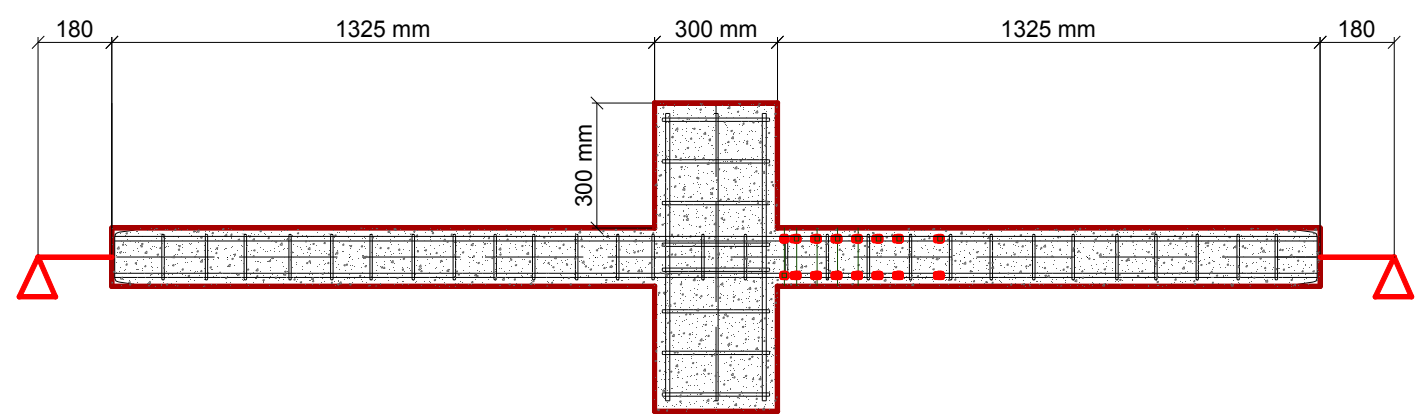

Figura 4.2 Geometría lateral de los soportes ensayados

En la Figura 4.3 se presenta la distribución del armado longitudinal y transversal. Cabe destacar el hecho de que en uno de los lados del soporte se ha dispuesto una barra adicional del mismo diámetro que la definida en la armadura longitudinal descrita en la Tabla 4.1, tanto en la cara superior como inferior. Esto garantiza que el fallo del soporte ocurra siempre en el lado instrumentado.

Los rangos de esbeltez y de cuantías longitudinal y transversal propuestos en el programa experimental han dado lugar a las secciones y combinaciones de armadura que aparecen en la Tabla 4-1. 

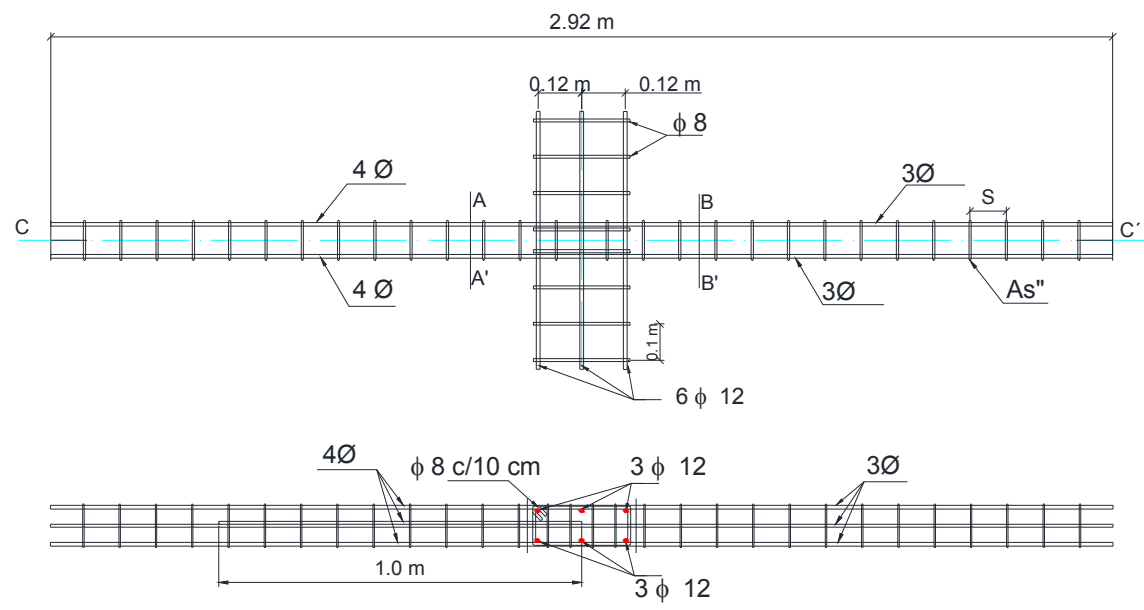

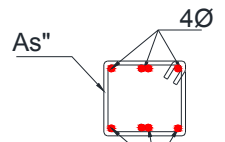

$4 \varnothing$

CORTE A-A

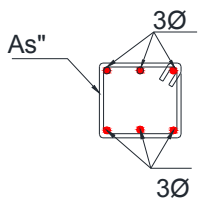

CORTE B-B

Figura 4.3 Esquema general de la distribución de armadura longitudinal y transversal

Tabla 4-1 Características geométricas de los tipos de sección transversal

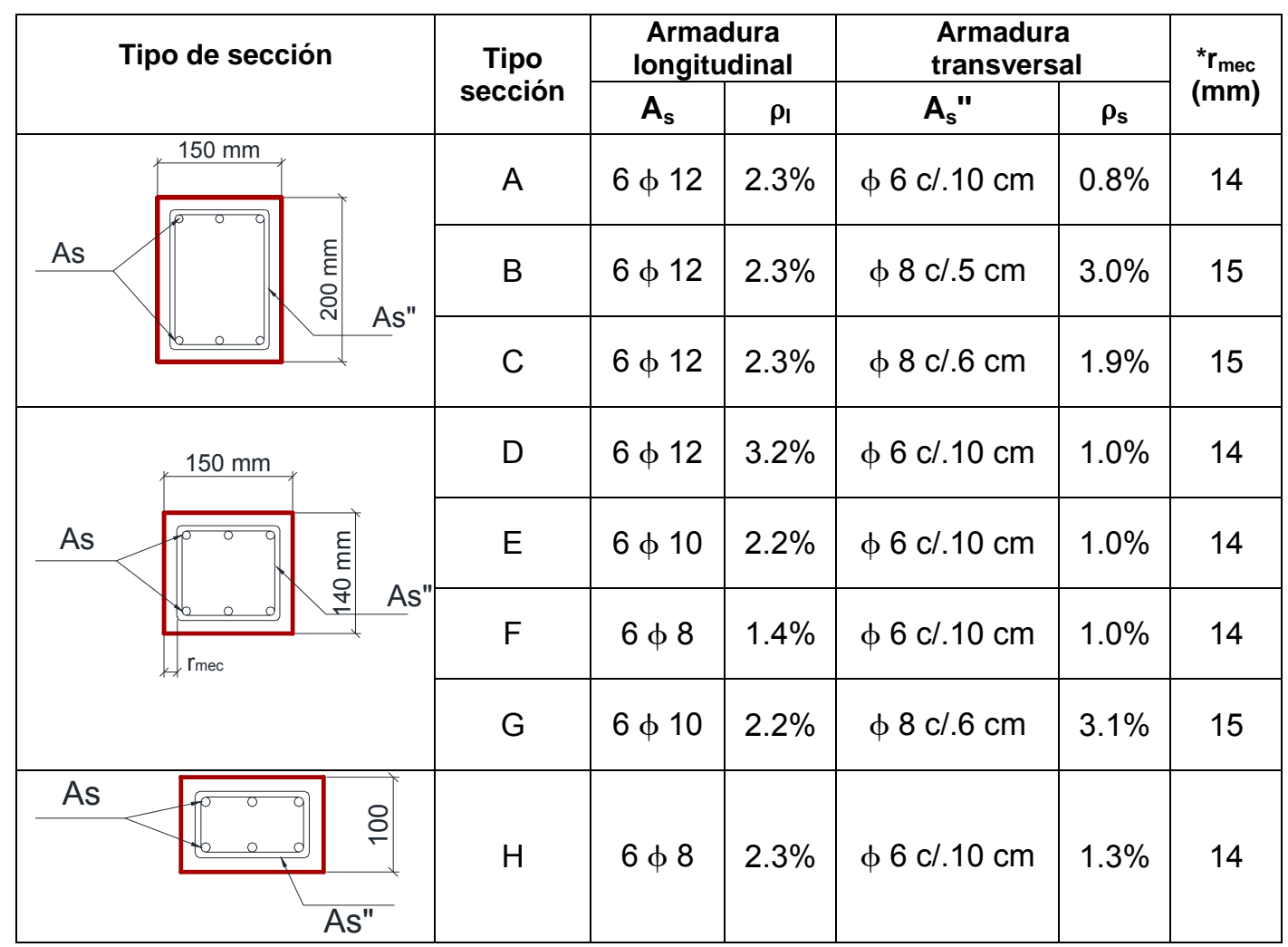

${ }^{*}$ Recubrimiento geométrico medido desde el borde exterior del cerco hasta el extremo de la sección. 


\subsection{CARACTERÍSTICAS DE LOS SOPORTES ENSAYADOS}

En la Tabla 4-2 se presentan detalladamente todas las características de los 44 ensayos que conforman el programa experimental. La referencia que define cada uno de los soportes consta de una codificación alfanumérica que, dividida en bloques separados por guiones, tiene un significado específico. El primer bloque contiene una letra (que puede ser $\mathrm{N}$ para el hormigón convencional, o $\mathrm{H}$ para el hormigón de alta resistencia), seguida de dos números que describen la resistencia especificada del hormigón (30,60 ó $90 \mathrm{MPa}$ ). El segundo bloque se refiere a la esbeltez de cortante $\left(\lambda=L_{s} / h\right)$, es decir, la relación entre la longitud de cortante $\left(L_{s}\right)$, definida en la Figura 4.4 y el canto de la sección transversal $(\mathrm{h})$ cuyo valor puede ser $7.5,10.5$ ó 15 . El tercer bloque señala el tipo de confinamiento $\left(\rho_{s}\right)$, que puede ser C0 (si se trata de la mínima cuantía transversal en este estudio, la cual se encuentra alrededor del 1\%), C2 (si está alrededor del 2\%), o C3 (para una cuantía transversal alrededor del $3 \%$ ). En el cuarto bloque se refleja la cuantía longitudinal $\left(\rho_{1}\right)$. En el bloque quinto, la referencia designa el nivel de carga axial $\left(\mathrm{N} / \mathrm{N}_{\mathrm{u}}\right)$. El axil último ha sido calculado de acuerdo a la Ec. 4-2.

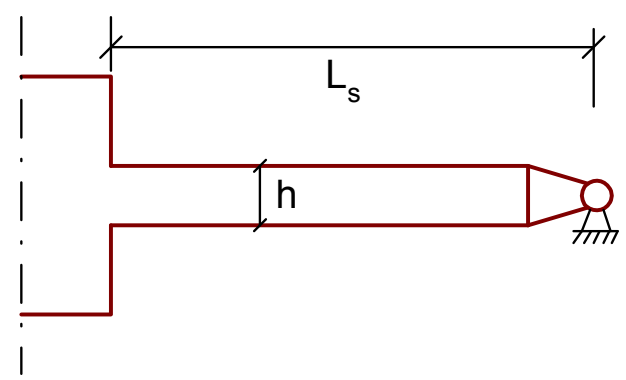

$$
\lambda=\frac{L_{s}}{h}
$$

Figura 4.4 Definición de esbeltez de cortante para los soportes ensayados

$$
N_{u}=b \cdot h \cdot f_{c}+\sigma_{s} \cdot A_{s} \rightarrow \sigma_{s}=\varepsilon_{c 1} \cdot E_{s} \leq f_{y}
$$

Donde:
$b \quad$ Ancho de la sección transversal
$h \quad$ Canto de la sección transversal
$f_{c} \quad$ Resistencia del hormigón en compresión
$A_{s} \quad$ Área de armadura longitudinal
$E_{s} \quad$ Módulo de elasticidad del acero (200.000 MPa)
$f_{y} \quad$ Límite elástico del acero
$\varepsilon_{c 1} \quad$ Deformación para la tensión pico del hormigón, $\varepsilon_{c 1}(\% 0)=0.7 \cdot f_{c}^{0.31}<2.8$ 
Tabla 4-2 Características de los soportes ensayados

\begin{tabular}{|c|c|c|c|c|c|c|c|}
\hline $\mathbf{N}^{\mathbf{O}}$ & REFERENCIA & $\begin{array}{c}f_{\mathrm{c}} \\
(\mathrm{MPa})\end{array}$ & $\begin{array}{l}\text { Tipo } \\
\text { sec. }\end{array}$ & $\lambda$ & $\mathbf{N} / \mathbf{N}_{\mathrm{u}}$ & $\mathrm{N}_{\mathrm{u}}(\mathrm{KN})$ & $\mathrm{N}(\mathrm{kN})$ \\
\hline 1 & N30-10.5-C0-2-00 & 32.2 & $\mathrm{E}$ & 10.5 & 0.00 & 865 & 0 \\
\hline 2 & N30-10.5-C0-2-15 & 31.8 & $\mathrm{E}$ & 10.5 & 0.14 & 855 & 123 \\
\hline 3 & $\mathrm{~N} 30-10.5-\mathrm{C} 0-2-30$ & 31.6 & $\mathrm{E}$ & 10.5 & 0.30 & 852 & 255 \\
\hline 4 & N30-10.5-C0-2-45 & 34.5 & $\mathrm{E}$ & 10.5 & 0.42 & 913 & 381 \\
\hline 5 & N30-7.5-C0-2-30 & 30.1 & A & 7.5 & 0.30 & 1174 & 350 \\
\hline 6 & N30-7.5-C0-2-45 & 33.0 & A & 7.5 & 0.42 & 1261 & 533 \\
\hline 7 & N30-15-C0-2-30 & 32.7 & $\mathrm{H}$ & 15.0 & 0.29 & 611 & 180 \\
\hline 8 & N30-15-C0-2-45 & 32.9 & $\mathrm{H}$ & 15.0 & 0.43 & 614 & 265 \\
\hline 9 & $\mathrm{~N} 30-10.5-\mathrm{C} 0-1-30$ & 42.2 & $\mathrm{~F}$ & 10.5 & 0.23 & 1007 & 228 \\
\hline 10 & N30-10.5-C0-1-45 & 35.2 & $\mathrm{~F}$ & 10.5 & 0.51 & 860 & 440 \\
\hline 11 & N30-10.5-C0-3-15 & 33.5 & $\mathrm{D}$ & 10.5 & 0.15 & 974 & 142 \\
\hline 12 & N30-10.5-C0-3-30 & 29.5 & $\mathrm{D}$ & 10.5 & 0.31 & 891 & 280 \\
\hline 13 & H60-10.5-C0-2-00 & 55.8 & $\mathrm{E}$ & 10.5 & 0.00 & 1389 & 0 \\
\hline 14 & H60-10.5-C0-2-15 & 54.1 & $\mathrm{E}$ & 10.5 & 0.15 & 1353 & 208 \\
\hline 15 & $\mathrm{H} 60-10.5-\mathrm{C} 0-2-30$ & 60.5 & $\mathrm{E}$ & 10.5 & 0.29 & 1486 & 432 \\
\hline 16 & H60-10.5-C0-2-45 & 63.9 & $\mathrm{E}$ & 10.5 & 0.43 & 1559 & 676 \\
\hline 17 & H60-7.5-C0-2-30 & 63.0 & A & 7.5 & 0.29 & 2202 & 637 \\
\hline 18 & $\mathrm{H} 60-7.5-\mathrm{C} 0-2-45$ & 67.7 & $A$ & 7.5 & 0.40 & 2342 & 947 \\
\hline 19 & H60-15-C0-2-30 & 58.2 & $\mathrm{H}$ & 15.0 & 0.30 & 1012 & 300 \\
\hline 20 & H60-15-C0-2-45 & 58.7 & $\mathrm{H}$ & 15.0 & 0.46 & 1018 & 465 \\
\hline 21 & H60-10.5-C0-1-15 & 57.8 & $\mathrm{~F}$ & 10.5 & 0.16 & 1353 & 220 \\
\hline 22 & H60-10.5-C0-1-30 & 58.5 & $\mathrm{~F}$ & 10.5 & 0.30 & 1367 & 412 \\
\hline 23 & H60-10.5-C0-3-15 & 58.3 & $\mathrm{D}$ & 10.5 & 0.15 & 1536 & 238 \\
\hline 24 & H60-10.5-C0-3-30 & 61.6 & $\mathrm{D}$ & 10.5 & 0.29 & 1606 & 470 \\
\hline 25 & $\mathrm{H} 90-10.5-\mathrm{C} 0-2-00$ & 85.7 & $\mathrm{E}$ & 10.5 & 0.00 & 2045 & 0 \\
\hline 26 & H90-10.5-C0-2-15 & 90.5 & $\mathrm{E}$ & 10.5 & 0.15 & 2146 & 329 \\
\hline 27 & $\mathrm{H} 90-10.5-\mathrm{C} 0-2-30$ & 90.1 & $\mathrm{E}$ & 10.5 & 0.30 & 2137 & 636 \\
\hline 28 & H90-10.5-C0-2-45 & 93.2 & $\mathrm{E}$ & 10.5 & 0.44 & 2202 & 972 \\
\hline 29 & H90-7.5-C0-2-30 & 100.4 & A & 7.5 & 0.27 & 3363 & 914 \\
\hline 30 & H90-7.5-C0-2-45 & 94.0 & A & 7.5 & 0.41 & 3173 & 1316 \\
\hline 31 & $\mathrm{H} 90-10.5-\mathrm{C} 0-1-15$ & 90.3 & $\mathrm{~F}$ & 10.5 & 0.15 & 2052 & 314 \\
\hline 32 & H90-10.5-C0-1-30 & 96.2 & $\mathrm{~F}$ & 10.5 & 0.29 & 2177 & 624 \\
\hline 33 & H90-10.5-C0-3-15 & 89.6 & $\mathrm{D}$ & 10.5 & 0.15 & 2234 & 340 \\
\hline 34 & H90-10.5-C0-3-30 & 94.4 & $\mathrm{D}$ & 10.5 & 0.29 & 2334 & 680 \\
\hline 35 & N30-10.5-C3-2-30 & 41.0 & G & 10.5 & 0.25 & 1049 & 258 \\
\hline 36 & N30-10.5-C3-2-45 & 34.2 & $G$ & 10.5 & 0.43 & 907 & 387 \\
\hline 37 & N30-7.5-C3-2-30 & 35.8 & B & 7.5 & 0.27 & 1344 & 364 \\
\hline 38 & N30-7.5-C3-2-45 & 35.0 & B & 7.5 & 0.41 & 1321 & 546 \\
\hline 39 & H90-10.5-C3-2-30 & 93.5 & G & 10.5 & 0.29 & 2179 & 636 \\
\hline 40 & H90-10.5-C3-2-45 & 92.0 & G & 10.5 & 0.44 & 2148 & 961 \\
\hline 41 & H90-7.5-C3-2-30 & 86.4 & $\mathrm{~B}$ & 7.5 & 0.31 & 2903 & 910 \\
\hline 42 & H90-7.5-C3-2-45 & 78.2 & $B$ & 7.5 & 0.50 & 2659 & 1360 \\
\hline 43 & H90-7.5-C2-2-30 & 95.7 & C & 7.5 & 0.28 & 3117 & 910 \\
\hline 44 & H90-7.5-C2-2-45 & 89.2 & $C$ & 7.5 & 0.45 & 2988 & 1354 \\
\hline
\end{tabular}




\subsection{PROPIEDADES DE LOS MATERIALES}

En esta sección se hace referencia a las características y propiedades de los materiales (hormigón y acero) utilizados en los ensayos experimentales. El conocimiento de las propiedades de los materiales de los ensayos es fundamental para delimitar las condiciones de la experimentación realizada, y conseguir así una óptima interpretación de los resultados.

En este estudio se ha adoptado la definición establecida en la norma EHE-08 (2008) [53] para el hormigón de alta resistencia (HAR), definido como aquel cuya resistencia característica a la compresión, en probeta cilíndrica de $15 \times 30 \mathrm{~cm}$, supera los $50 \mathrm{MPa}$ a los 28 días.

La descripción del hormigón como material utilizado en los ensayos de soportes sometidos a flexo-compresión, tiene un especial interés, debido a que, en esta investigación, las características resistentes del hormigón constituyen uno de los parámetros fundamentales en el estudio de la capacidad de deformación y de ductilidad de los soportes.

Por otro lado, las características mecánicas del acero también desempeñan un papel fundamental dentro del estudio de la ductilidad de los soportes de hormigón armado. Sin embargo, en esta investigación se ha considerado conveniente delimitar el estudio a un determinado tipo de acero, designado en la norma EHE (2008) [53] como acero tipo B 500 SD. Además, así se ha conseguido concentrar el análisis en otros parámetros para los que se requiere especial atención, debido a la falta de evidencia experimental.

En el desarrollo de este apartado se describe, en primer lugar, el proceso seguido para la obtención de las dosificaciones óptimas en la fabricación del hormigón convencional y de alta resistencia; en segundo lugar, se indican los materiales empleados en dichas dosificaciones; en tercer lugar, se exponen los resultados obtenidos para la resistencia a la compresión simple del hormigón en cada uno de los soportes ensayados. Finalmente, se definen las características constitutivas del acero utilizado, determinadas mediante ensayos de tracción simple.

\subsubsection{HORMIGÓN}

Dentro del programa experimental se definieron tres tipos de resistencia del hormigón: $30 \mathrm{MPa}, 60 \mathrm{MPa}$ y $90 \mathrm{MPa}$. Adicionalmente, estos hormigones debían cumplir ciertas características especiales de consistencia y de tamaño mínimo del árido.

Por una parte, la consistencia era necesaria para garantizar una buena manejabilidad en el hormigonado del soporte; por lo tanto, se requería obtener una consistencia blanda o plástica del hormigón. Por otra parte, el tamaño máximo del árido tenía que ver con el recubrimiento mínimo, es decir, se debía utilizar un tamaño máximo del árido (TMA) de modo que garantizara el recubrimiento geométrico indicado en la Tabla 4-1. 
Para establecer una dosificación que se ajustara a las características del hormigón anteriormente explicadas, se realizaron algunas pruebas preliminares, especialmente para obtener el hormigón de alta resistencia de $60 \mathrm{MPa}$ y $90 \mathrm{MPa}$.

Los parámetros ajustados en estas pruebas fueron la relación agua-cemento, el porcentaje de áridos y el tipo y cantidad de aditivo. Consecuentemente, se obtuvieron las siguientes dosificaciones, utilizadas en la fabricación de los soportes ensayados (Tabla 4-3).

Tabla 4-3 Dosificaciones del hormigón por $\mathrm{m}^{3}$

\begin{tabular}{|c|c|c|c|c|c|c|}
\hline Hormigón & $\begin{array}{c}\text { Cemento } \\
(\mathbf{k g})\end{array}$ & $\begin{array}{c}\text { Arena } \\
(\mathbf{k g})\end{array}$ & $\begin{array}{c}\text { Grava } \\
(\mathbf{k g})\end{array}$ & $\begin{array}{c}\text { Agua } \\
(\mathbf{L})\end{array}$ & $\begin{array}{c}\text { Fluidificante } \\
(\mathbf{k g})\end{array}$ & $\begin{array}{c}\text { Humo de } \\
\text { Sílice (Kg) }\end{array}$ \\
\hline $30 \mathrm{MPa}$ & 348 & 1065 & 666 & 220 & - & - \\
\hline $60 \mathrm{MPa}$ & 425 & 918 & 918 & 180 & 5 & - \\
\hline $90 \mathrm{MPa}$ & 570 & 705 & 890 & 180 & 12 & 50 \\
\hline
\end{tabular}

\subsubsection{MATERIALES UTILIZADOS EN LA FABRICACIÓN DEL HORMIGÓN}

\section{Tipo de cemento:}

- CEM I 52.5 R.

\section{Características de los áridos:}

- Grava 4/7 caliza machacada, con un tamaño máximo de $7 \mathrm{~mm}$.

- Arena 0/4 caliza, rodada lavada.

Tabla 4-4 Granulometría de los áridos

\begin{tabular}{|c|c|c|}
\hline \multirow{2}{*}{$\begin{array}{c}\text { Abertura de } \\
\text { Tamiz (mm) }\end{array}$} & \multicolumn{2}{|c|}{ \% Acumulado que pasa } \\
\cline { 2 - 3 } & Grava 4/7 & Arena 0/4 \\
\hline 16 & 100 & 100 \\
\hline 8 & 99.41 & 100 \\
\hline 4 & 22.73 & 95.92 \\
\hline 2 & 1.63 & 72.95 \\
\hline 1 & 1.31 & 58.35 \\
\hline 0,5 & & 44.79 \\
\hline 0,25 & & 25.63 \\
\hline 0,125 & & 11.26 \\
\hline 0,063 & & 3.51 \\
\hline
\end{tabular}

\section{Adiciones:}

- Humo de sílice: utilizado en la dosificación de hormigón de 90 MPa.

- Aditivos (superfluidificantes): Sika-Cem para hormigón de $60 \mathrm{MPa}$ y Glenium 300C para el hormigón de 90 MPa.

\subsubsection{RESULTADOS DE LOS ENSAYOS DE COMPRESIÓN SIMPLE}

Para cada uno de los soportes ensayados, se fabricaron en total cuatro probetas cilíndricas estándar de $15 \times 30 \mathrm{~cm}$, dos por cada amasada. Para determinar la resistencia del hormigón utilizada en el análisis, se obtuvo el valor medio de las probetas para la amasada dispuesta en el lado instrumentado del soporte. En el 
Estudio experimental y numérico de la capacidad de deformación de soportes esbeltos de hormigón armado

Anejo B se presentan los valores de la resistencia a la compresión obtenidos de las cuatro probetas, para cada uno de los soportes ensayados.

Tabla 4-5 Valor medio y dispersión de la resistencia del hormigón

\begin{tabular}{|c|c|c|c|}
\hline Hormigón & $\begin{array}{c}\text { Valor medio } \\
\mathbf{f}_{\mathbf{c}} \text { (MPa) }\end{array}$ & $\begin{array}{c}\text { Desviación } \\
\text { estándar }\end{array}$ & $\begin{array}{c}\text { Coeficiente } \\
\text { de variación }\end{array}$ \\
\hline $30 \mathrm{MPa}$ & 34.31 & 3.45 & $10 \%$ \\
\hline $60 \mathrm{MPa}$ & 59.83 & 3.72 & $6.2 \%$ \\
\hline $90 \mathrm{MPa}$ & 91.55 & 4.87 & $5.3 \%$ \\
\hline
\end{tabular}

Los resultados muestran que los valores de resistencia obtenidos son bastante cercanos a los especificados en el programa experimental y, además, que la dispersión se encuentra dentro de un límite razonable.

\subsubsection{ACERO}

El acero utilizado en la fabricación de los soportes ensayados corresponde a un acero tipo B 500 SD. Las barras utilizadas en el armado longitudinal tienen diámetros de 8,10 y $12 \mathrm{~mm}$, mientras que en la armadura transversal se usaron diámetros de 6 y $8 \mathrm{~mm}$.

Con el propósito de obtener las propiedades reales del acero utilizado en los soportes, se realizaron pruebas de tracción simple, de acuerdo con el procedimiento recomendado en las normas UNE-EN 10002-1. Estos ensayos fueron realizados en el laboratorio de materiales de la empresa Grupo de ingeniería y Arquitectura "GIA S.L.", especializado en este tipo de ensayos. Más concretamente, se llevaron a cabo dos ensayos para cada diámetro de barra $(8,10$ y $12 \mathrm{~mm}$ ). En la Tabla 4-6 se presenta el resumen de las propiedades obtenidas en los ensayos a tracción; asimismo, en la Figura 4.5 se representa la curva media característica obtenida para los tres diámetros ensayados.

Tabla 4-6 Propiedades del acero obtenidas a partir del ensayo a tracción simple según procedimiento UNE - EN 10002-1

\begin{tabular}{|c|c|c|c|c|c|c|c|}
\hline Ensayo & $\begin{array}{c}\text { Diámetro } \\
(\mathbf{m m})\end{array}$ & $\begin{array}{c}\text { Fuerza } \\
\text { Máxima } \\
\mathbf{( k N )}\end{array}$ & $\begin{array}{c}\text { Carga } \\
\text { límite } \\
\text { elástico } \\
\mathbf{( k N )}\end{array}$ & $\begin{array}{c}\mathbf{f}_{\mathbf{y}} \\
\left(\mathbf{N} / \mathbf{m m}^{2}\right)\end{array}$ & $\begin{array}{c}\mathbf{f}_{\mathbf{t}} \\
\left(\mathbf{N} / \mathbf{m m}^{2} \mathbf{)}\right.\end{array}$ & $\mathbf{f}_{\mathbf{t}} / \mathbf{f}_{\mathbf{y}}$ & $\begin{array}{c}\left(\mathbf{A}_{\mathbf{g t}} \mathbf{)}\right. \\
\mathbf{( \% )}\end{array}$ \\
\hline $1-1$ & 12 & 72,85 & 60,67 & 536 & 644 & 1,20 & - \\
\hline $1-2$ & 12 & 73,14 & 60,93 & 539 & 647 & 1,20 & 19,8 \\
\hline $2-1$ & 10 & 49,99 & 42,64 & 535 & 637 & 1,19 & - \\
\hline $2-2$ & 10 & 49,20 & 41,71 & 531 & 638 & 1,20 & 19,2 \\
\hline $3-1$ & 8 & 33,52 & 26,79 & 533 & 667 & 1,25 & - \\
\hline $3-2$ & 8 & 33,63 & 26,61 & 529 & 669 & 1,26 & 16,4 \\
\hline
\end{tabular}


Generalmente, las diferentes normas (EHE-08 [53], Eurocódigo 2 [58] y Código Modelo 1990 [33]) establecen que la ductilidad del acero de la armadura puede definirse a partir de dos parámetros; uno de ellos es la relación entre la carga de rotura $\left(f_{t}\right)$ y el límite elástico $\left(f_{y}\right)$, y el otro es el alargamiento en rotura $\left(A_{g t}\right)$. Por consiguiente, a partir de los resultados obtenidos para estos dos parámetros $\left(f_{t} / f_{y}\right.$ y $A_{g t}$ ) en los ensayos de tracción (ver Tabla 4-6), se demuestra que el acero utilizado en la armadura de los soportes corresponde a la clasificación SD (dúctil), según los criterios establecidos en la norma EHE-08 (2008) [53].

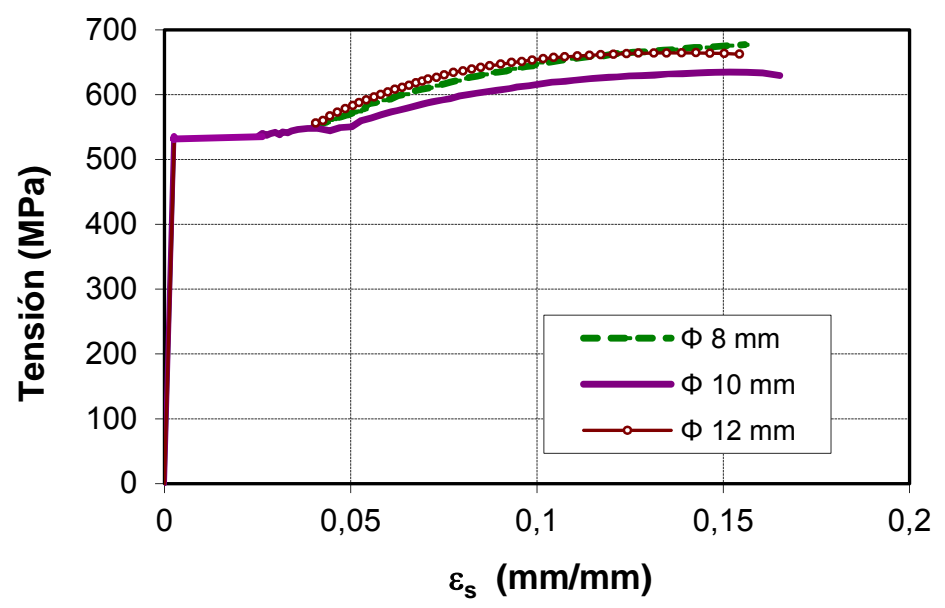

Figura 4.5 Curva media $\sigma-\varepsilon$ del acero utilizado en el armado

\subsection{DESARROLLO DEL ENSAYO}

\subsubsection{DESCRIPCIÓN DEL PÓRTICO DE CARGA}

Para realizar los ensayos de compresión y flexión monotónica en soportes de hormigón armado, se ha diseñado y construido exclusivamente un pórtico de carga. Los aspectos básicos considerados en el diseño del pórtico fueron: el sistema de carga, las condiciones de apoyo y las dimensiones geométricas de los soportes. Otros aspectos tenidos en cuenta fueron la optimización de la instrumentación, la seguridad del ensayo, el ajuste de los elementos y la facilidad de manipulación del ensayo en general.

En la Figura 4.6 se presenta un esquema general de todos los componentes del pórtico de carga, que consta de las siguientes partes fundamentales: (a) bastidor horizontal, dentro del cual se acopla un sistema de carga axial; (b) sistema de carga vertical; (c) condiciones de apoyo; y (d) atado del soporte dentro del pórtico de carga. En el anejo $\mathrm{C}$ se hace una descripción detallada del pórtico de ensayo. 


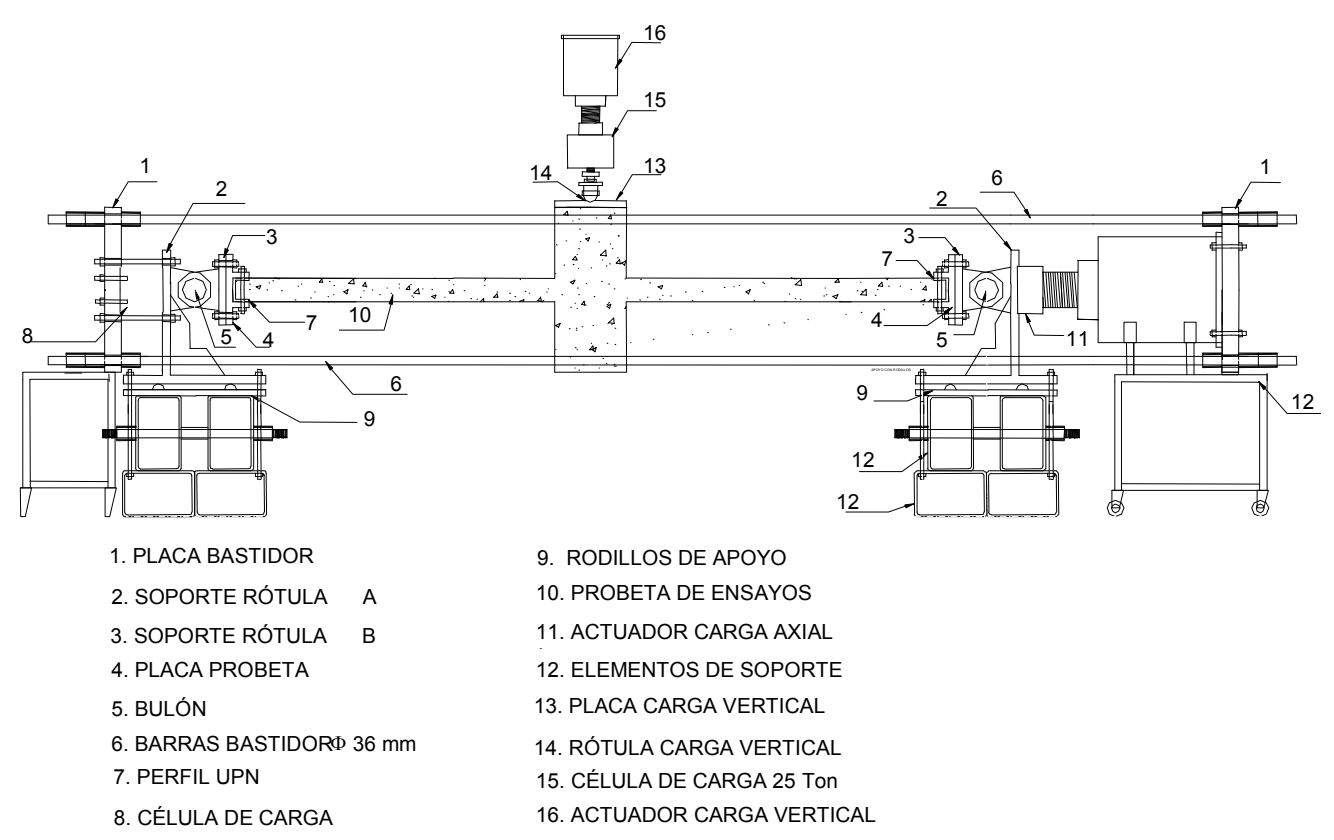

Figura 4.6 Descripción del pórtico de ensayo

\subsubsection{INSTRUMENTACIÓN}

La instrumentación para el ensayo ha sido seleccionada con especial atención, con el fin de obtener la respuesta del comportamiento estructural, tanto a nivel del elemento completo (carga-desplazamiento; deformada), como en las secciones críticas (distribuciones de deformación de la armadura de tracción y de compresión).

En general, la instrumentación se ha dispuesto con el propósito de obtener información relativa a los siguientes cuatro aspectos específicos del ensayo: (1) valorar la deformabilidad dentro de la zona crítica; (2) medir la deformada global del elemento; (3) controlar y medir las condiciones de carga del ensayo; y, por último, (4) desarrollar el control propio en la ejecución del ensayo.

\subsubsection{DEFORMACIÓN DENTRO DE LA ZONA DE RÓtULA PLÁSTICA}

La caracterización de las rótulas plásticas depende directamente de la distribución de curvaturas a lo largo del soporte. En este tipo de ensayo, las curvaturas son obtenidas experimentalmente a partir de las deformaciones en la armadura traccionada y comprimida a lo largo de diferentes secciones, sobre una longitud superior a la zona plástica. Estas deformaciones de la armadura son medidas con bandas extensiométricas, dispuestas sobre una longitud mayor que el doble del canto útil de la sección. La primera banda se localiza a $2 \mathrm{~cm}$ del borde del "stub"; posteriormente, se sitúan seis o siete bandas continuas, con una separación de cinco centímetros, y, seguidamente, otra a $10 \mathrm{~cm}$, y una última banda se localiza a $25 \mathrm{~cm}$ de separación. Esta última banda tiene el objetivo de controlar la deformación dentro de la zona de comportamiento elástico del elemento (Figura 4.7). 
Las bandas extensiométricas se localizan en la barra central, en la armadura de tracción y compresión, y sólo a un lado del soporte. Para garantizar que el lado instrumentado sea el primero en alcanzar el agotamiento en la zona de rótula plástica, el lado no instrumentado ha sido rigidizado, aumentando la cuantía geométrica. Por lo tanto, se ha localizado una barra longitudinal adicional de igual diámetro, tanto en la zona de compresión como de tracción, sobre una distancia que supera la de la rótula plástica (Figura 4.7)
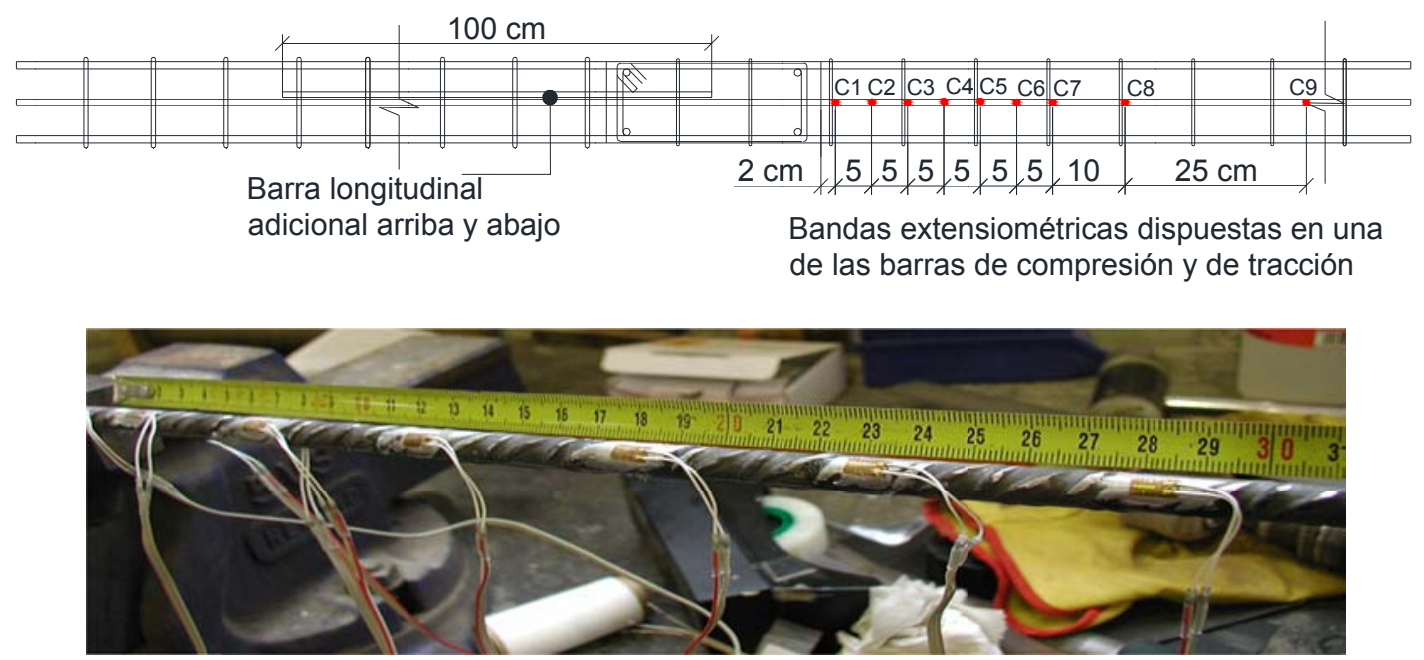

Figura 4.7 Disposición de bandas extensiométricas en la armadura superior e inferior

\subsubsection{DEFORMADA DEL SOPORTE}

A lo largo del soporte, se ha localizado un conjunto de captadores de desplazamiento ("LVDT"), ubicados de forma estratégica, con el propósito de medir los desplazamientos en diferentes puntos del soporte y, además, poder evaluar los efectos de segundo orden ("efecto P- $\Delta$ ").

Como se puede observar en la Figura 4.8, la ubicación de algunos de los captadores dentro de la zona crítica de deformación coincide con la localización de las bandas extensiométricas en las barras longitudinales. En la zona crítica se han localizado cuatro captadores con una separación de $10 \mathrm{~cm}$, el primero de los cuales se ha ubicado a $5 \mathrm{~cm}$ del borde del "stub". Seguidamente, se han localizado otros tres captadores, con separación variable, de 33, 24.5 y $26 \mathrm{~cm}$ respectivamente.

Sobre el lado izquierdo de la Figura 4.8 se puede observar la localización de otros dos captadores, así como también uno a cada lado del "stub", y otro justo en el centro de este elemento. Con esta disposición, es posible obtener la deformada del soporte, tal y como se muestra en la parte inferior de la Figura 4.8. 

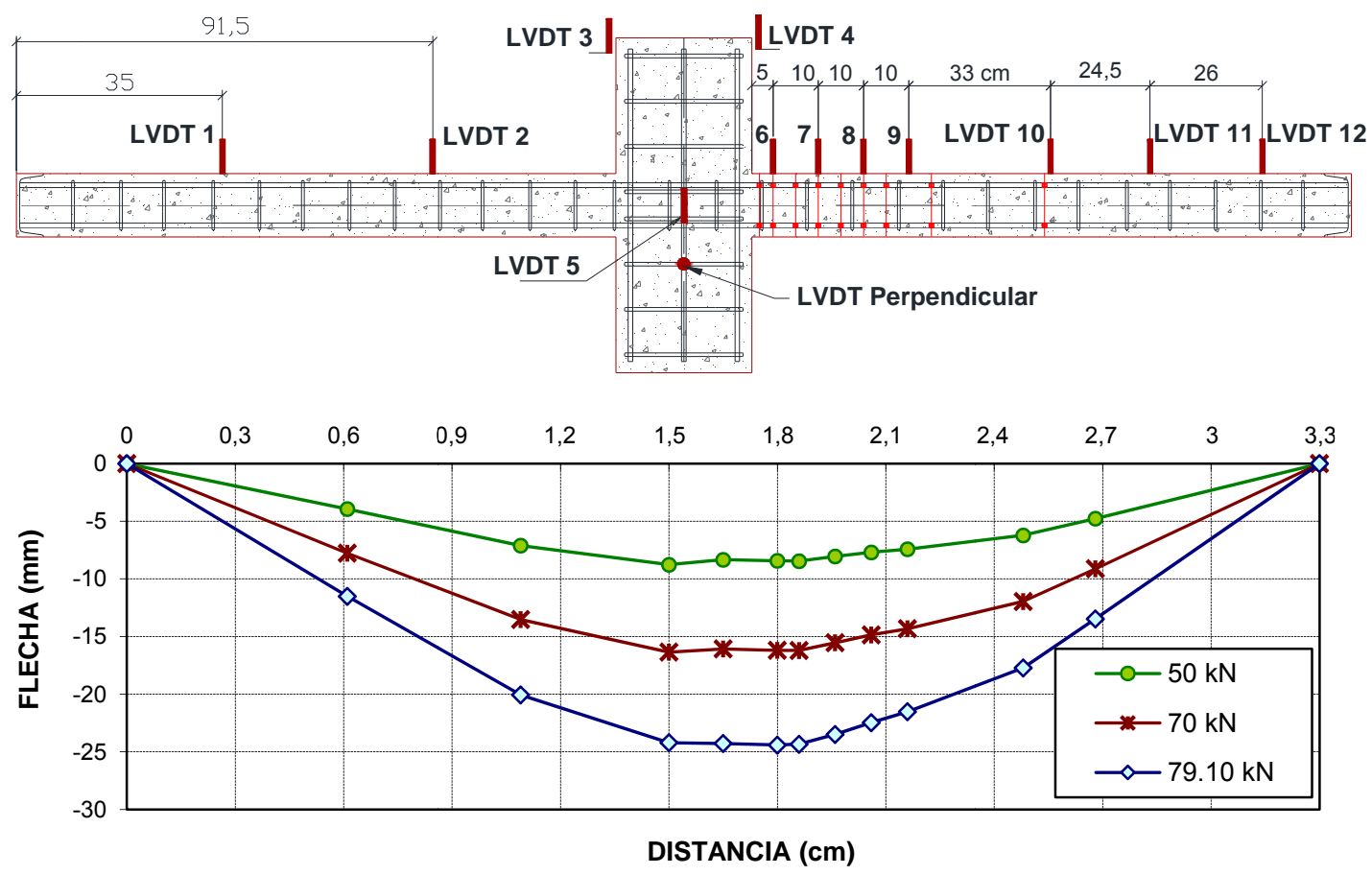

Figura 4.8 Disposición de los captadores de desplazamiento

\subsubsection{CARGA DE FLEXIÓN Y CARGA AXIAL}

Se han dispuesto dos células de carga (Figura 4.9), una de ellas para medir la carga vertical de flexión, y la otra sobre el eje de aplicación de la carga axial, para controlar y medir el comportamiento constante de la carga axial durante todo el ensayo.

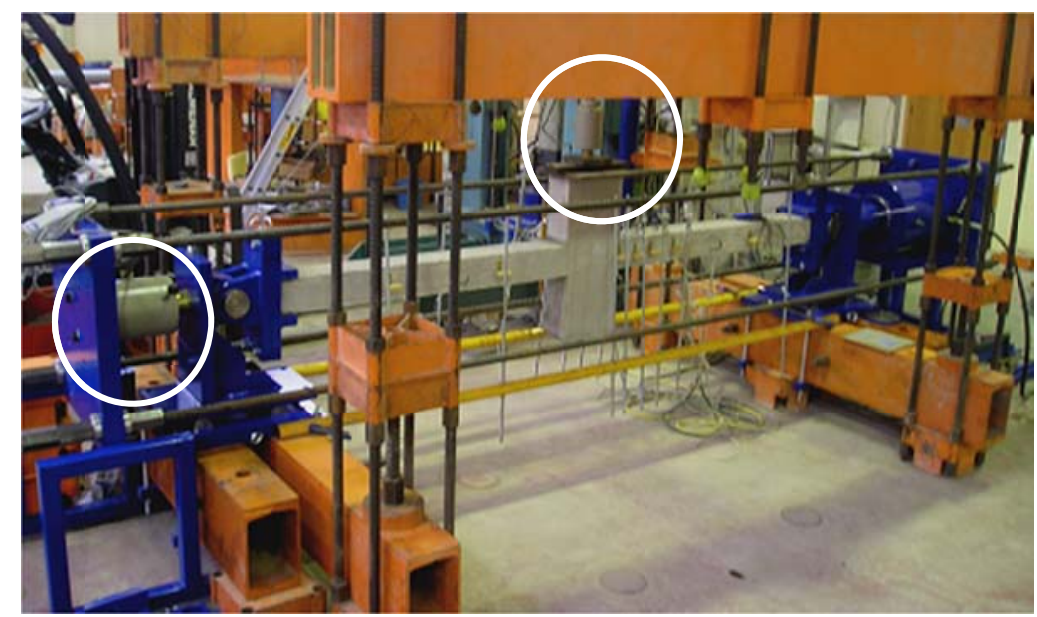

Figura 4.9 Localización de las células de carga 


\subsubsection{CONTROL EN LA EJECUCIÓN DEL ENSAYO}

La deformación en el plano de pandeo del soporte fue controlada durante el ensayo mediante la ubicación de un captador de desplazamiento perpendicular a dicho plano (es decir, perpendicular al plano longitudinal del soporte), y dispuesto en el centro del elemento, Figura 4.8.

\subsubsection{EJECUCIÓN DEL ENSAYO}

Transcurridos 28 días después del hormigonado del soporte (en el anejo C se describe el proceso de fabricación de los soportes ensayados), se realiza el ensayo de compresión y flexión monotónica, siguiendo el proceso que se describe a continuación

1 Configuración de la instrumentación dentro del software de adquisición de datos.

2 Aplicación de la carga axial.

3 Ajuste y aproximación del equipo de carga vertical.

4 Aplicación de la carga vertical hasta el agotamiento del soporte.

5 Registro de información.

6 Descarga del soporte y desconexión de la instrumentación.

A continuación se describen las actividades desarrolladas dentro de cada una de estas fases:

1. Configuración de la instrumentación dentro del software de adquisición de datos

Como actividad preliminar, se realiza la configuración de cada una de las conexiones eléctricas de la instrumentación (bandas extensiométricas, captadores de desplazamiento y células de carga) en el software de adquisición de datos. El ensayo empieza una vez se ha llevado a cabo la "toma de ceros", es decir, cuando todos los parámetros registrados en el ensayo marcan cero.

\section{Aplicación de la carga axial}

La aplicación de la carga axial se realiza mediante un equipo hidráulico de presión con capacidad de $250 \mathrm{~T}$. Este empieza a desplazarse, ejerciendo una presión de compresión a velocidad constante, hasta llegar a un nivel de carga axial predeterminado. Una vez alcanzado este valor, la carga de compresión se mantiene constante durante todo el ensayo.

\section{Ajuste y aproximación del equipo de carga vertical}

Durante la aplicación de la carga axial, el equipo de presión y la célula de carga vertical no están en contacto con el soporte, con el fin de evitar el libre movimiento del soporte. 
Una vez alcanzado el nivel de carga axial, la célula de carga vertical se aproxima manualmente hasta que el cuchillo de carga esté en contacto con la cara superior de la placa que se encuentra sobre el elemento rigidizador.

\section{Aplicación de la carga vertical hasta el agotamiento del soporte}

Seguidamente, el equipo de presión vertical de $50 \mathrm{~T}$ empieza a aplicar la carga a flexión sobre el soporte, hasta que se produce el fallo, e intentando mantener el ensayo hasta que se desarrolle la rama post-pico (Figura 4.10).

\section{Registro de información}

La adquisición de información se obtiene, en primer lugar, a partir del software de adquisición de datos, el cual registra progresivamente, y durante todo el ensayo, los siguientes valores: cargas aplicadas, deformaciones en la armadura y deformada a lo largo del soporte. Estos valores también pueden observarse en la pantalla del ordenador, lo que permite identificar, en algunos casos, situaciones de interés, como la carga de fisuración, el proceso de plastificación de la armadura y la rotura del hormigón. En segundo lugar, directamente en el soporte, se puedle observar el proceso de fisuración y su deformada.

\section{Descarga del soporte y desconexión de la instrumentación}

Una vez finaliza el ensayo, los equipos de presión empiezan a descargar el soporte. Primero se descarga el equipo de presión vertical y luego la carga de compresión. Finalmente, se realiza la desconexión de la instrumentación y se retira del pórtico de carga el elemento ensayado.

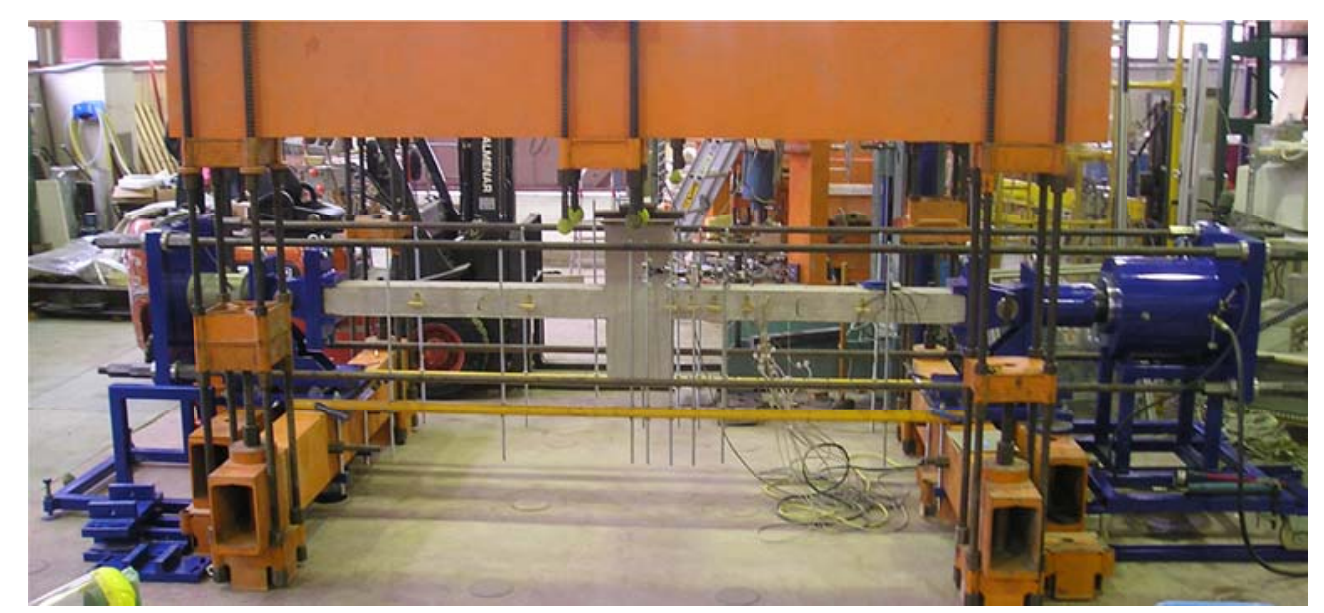

Figura 4.10 Ensayo de compresión y flexión monotónica 


\section{CAPÍTULO 5}

\section{RESULTADOS DIRECTOS Y OBSERVACIONES EXPERIMENTALES}

En este capítulo se presentan los resultados directos obtenidos en los ensayos de compresión y flexión monotónica de los 44 soportes de hormigón (Tabla 4-2). Los resultados directos incluyen las siguientes mediciones: carga de flexión, desplazamientos o flechas a lo largo del soporte, y deformación de la armadura longitudinal de tracción y compresión para diferentes secciones sobre una longitud entre 45 y $50 \mathrm{~cm}$, en el anejo $\mathrm{E}$ se presentan gráficamente estos resultados. Adicionalmente, en este capítulo se presenta un resumen de los efectos locales observados durante el proceso de deformación y de estado de daño final en cada uno de los ensayos.

\subsection{RESULTADOS DIRECTOS}

\subsubsection{CARGA VERTICAL}

En la Tabla 5-1 se presentan los resultados de los 44 ensayos de soportes de esbeltos de hormigón armado sometidos a compresión y flexión monotónica. En dicha tabla se relacionan los resultados de carga máxima $\left(P_{\max }\right)$ y de carga última 

hormigón armado

$\left(\mathrm{P}_{\mathrm{u}}\right)$ medida en el $15 \%$ de caída en la rama post-pico en aquellos casos en los que se ha obtenido una importante prolongación de la rama post-pico, o en su defecto en el último punto de registro después de la carga máxima. Adicionalmente, para los instantes de $P_{\max }$ y $P_{u}$, se presenta el valor del máximo desplazamiento ( $\left.\delta\right)$ a lo largo del elemento, así como las deformaciones de la armadura de compresión $\left(\varepsilon_{s}^{\prime}\right)$ y tracción $\left(\varepsilon_{s}\right)$ en la sección con mayor deformabilidad.

Tabla 5-1 Resultados directos en el ensayo de compresión y flexión monotónica en soportes de hormigón, para el instante de carga máxima y carga última

\begin{tabular}{|c|c|c|c|c|c|c|c|c|c|}
\hline \multirow[b]{2}{*}{$\mathbf{N}^{\circ}$} & \multirow[b]{2}{*}{ REFERENCIA } & \multicolumn{4}{|c|}{ En carga máxima } & \multicolumn{4}{|c|}{ En carga última } \\
\hline & & $\begin{array}{l}\mathbf{V}_{\max } \\
(\mathbf{k N})\end{array}$ & $\begin{array}{c}\delta_{\max } \\
(\mathrm{mm})\end{array}$ & $\begin{array}{c}\varepsilon_{\text {s_max }}^{\prime} \\
\left(x 10^{-3}\right)\end{array}$ & $\begin{array}{c}\varepsilon_{\mathrm{s} \text { max }} \\
\left(\mathrm{x} 10^{-3}\right)\end{array}$ & $\begin{array}{c}V_{u} \\
(k N)\end{array}$ & $\begin{array}{c}\delta_{-u} \\
(\mathrm{~mm})\end{array}$ & $\begin{array}{c}\varepsilon_{s_{-} u^{-3}} \\
\left(x 10^{-3}\right)\end{array}$ & $\begin{array}{c}\varepsilon_{\mathrm{s}} \mathrm{u}^{\mathrm{u}} \\
\left(\mathrm{x} 1 \overline{0}^{3}\right)\end{array}$ \\
\hline 1 & N30-10.5-C0-2-00 & 17,07 & $-74,53$ & 1,00 & $-11,58$ & 17,07 & $-74,53$ & 1,00 & $-11,58$ \\
\hline 2 & N30-10.5-C0-2-15 & 18,63 & $-34,16$ & 1,23 & $-7,72$ & 18,61 & $-34,70$ & 1,24 & $-9,61$ \\
\hline 3 & N30-10.5-C0-2-30 & 16,14 & $-34,18$ & 2,46 & $-2,18$ & 15,23 & $-42,49$ & 3,08 & $-4,26$ \\
\hline 4 & N30-10.5-C0-2-45 & 16,25 & $-25,34$ & 2,19 & $-0,89$ & 14,48 & $-29,05$ & 2,86 & $-1,34$ \\
\hline 5 & $\mathrm{~N} 30-7.5-\mathrm{C} 0-2-30$ & 55,19 & $-31,13$ & 3,75 & $-4,43$ & 54,87 & $-32,37$ & 4,24 & $-7,72$ \\
\hline 6 & $\mathrm{~N} 30-7.5-\mathrm{C} 0-2-45$ & 47,40 & $-21,71$ & 5,42 & $-1,35$ & 45,93 & $-22,84$ & 9,47 & $-1,60$ \\
\hline 7 & N30-15-C0-2-30 & 4,60 & $-10,93$ & 0,80 & 0,00 & 3,68 & $-13,79$ & 0,91 & $-0,16$ \\
\hline 8 & $\mathrm{~N} 30-15-\mathrm{C} 0-2-45$ & 4,17 & $-5,61$ & 1,13 & 0,68 & 3,45 & $-6,49$ & 1,17 & 0,67 \\
\hline 9 & N30-10.5-C0-1-30 & 15,55 & $-27,23$ & 2,14 & $-2,72$ & 15,22 & $-31,99$ & 2,42 & $-11,21$ \\
\hline 10 & N30-10.5-C0-1-45 & 14,74 & $-16,59$ & 2,35 & 0,29 & 13,69 & $-16,96$ & 2,42 & 0,28 \\
\hline 11 & N30-10.5-C0-3-15 & 21,57 & $-48,74$ & 1,64 & $-4,86$ & 19,55 & $-54,40$ & 1,93 & $-9,56$ \\
\hline 12 & N30-10.5-C0-3-30 & 16,57 & $-42,52$ & 3,12 & $-1,81$ & 15,32 & $-45,21$ & 5,06 & $-1,97$ \\
\hline 13 & $\mathrm{H} 60-10.5-\mathrm{C} 0-2-00$ & 18,06 & $-53,87$ & 0,19 & $-11,17$ & 18,06 & $-53,87$ & 0,19 & $-11,17$ \\
\hline 14 & $\mathrm{H} 60-10.5-\mathrm{C} 0-2-15$ & 21,39 & $-38,70$ & 1,47 & $-3,94$ & 20,63 & $-46,63$ & 1,51 & $-8,25$ \\
\hline 15 & $\mathrm{H} 60-10.5-\mathrm{C} 0-2-30$ & 18,43 & $-26,67$ & 2,22 & $-1,20$ & 16,56 & $-34,95$ & 2,69 & $-1,85$ \\
\hline 16 & $\mathrm{H} 60-10.5-\mathrm{C} 0-2-45$ & 20,62 & $-20,89$ & 2,23 & 0,06 & 17,94 & $-33,60$ & 3,21 & $-0,98$ \\
\hline 17 & $\mathrm{H} 60-7.5-\mathrm{C} 0-2-30$ & 65,61 & $-27,09$ & 4,49 & $-2,56$ & 64,00 & $-27,92$ & 6,72 & $-2,75$ \\
\hline 18 & $\mathrm{H} 60-7.5-\mathrm{C} 0-2-45$ & 73,82 & $-21,72$ & 4,37 & $-1,55$ & 73,12 & $-22,59$ & 5,82 & $-1,79$ \\
\hline 19 & $\mathrm{H} 60-15-\mathrm{C} 0-2-30$ & 4,39 & $-9,73$ & 1,20 & 0,56 & 3,76 & $-15,85$ & 1,35 & 0,05 \\
\hline 20 & $\mathrm{H} 60-15-\mathrm{C} 0-2-45$ & 2,92 & $-4,80$ & 1,56 & 1,19 & 2,48 & $-7,98$ & 1,68 & 1,11 \\
\hline 21 & $\mathrm{H} 60-10.5-\mathrm{C} 0-1-15$ & 16,86 & $-30,30$ & 1,40 & $-4,01$ & 15,07 & $-40,49$ & 1,44 & $-7,21$ \\
\hline 22 & $\mathrm{H} 60-10.5-\mathrm{C} 0-1-30$ & 17,23 & $-24,16$ & 2,00 & $-0,62$ & 13,96 & $-40,07$ & 5,69 & $-2,12$ \\
\hline 23 & $\mathrm{H} 60-10.5-\mathrm{C} 0-3-15$ & 24,20 & $-47,17$ & 1,66 & $-3,76$ & 24,09 & $-48,01$ & 1,67 & $-3,93$ \\
\hline 24 & $\mathrm{H} 60-10.5-\mathrm{C} 0-3-30$ & 18,25 & $-28,79$ & 2,10 & $-0,61$ & 14,99 & $-51,64$ & 5,23 & $-2,87$ \\
\hline 25 & $\mathrm{H} 90-10.5-\mathrm{C} 0-2-00$ & 20,09 & $-58,84$ & $-0,97$ & $-11,95$ & 20,09 & $-58,84$ & $-0,97$ & $-11,95$ \\
\hline 26 & $\mathrm{H} 90-10.5-\mathrm{C} 0-2-15$ & 22,14 & $-38,26$ & 1,95 & $-3,72$ & 20,88 & 141,27 & 2,02 & $-6,39$ \\
\hline 27 & $\mathrm{H} 90-10.5-\mathrm{C} 0-2-30$ & 21,90 & $-25,10$ & 1,85 & $-0,94$ & 19,61 & 54,99 & 2,79 & $-2,05$ \\
\hline 28 & $\mathrm{H} 90-10.5-\mathrm{C} 0-2-45$ & 20,24 & $-17,08$ & 2,19 & 0,47 & 39,31 & 39,31 & 3,20 & $-0,26$ \\
\hline 29 & $\mathrm{H} 90-7.5-\mathrm{C} 0-2-30$ & 79,10 & $-25,42$ & 4,50 & $-2,23$ & 78,39 & 54,07 & 5,49 & $-2,40$ \\
\hline 30 & $\mathrm{H} 90-7.5-\mathrm{C} 0-2-45$ & 74,65 & $-19,41$ & 5,40 & $-0,60$ & 73,92 & 55,55 & 7,35 & $-0,76$ \\
\hline 31 & $\mathrm{H} 90-10.5-\mathrm{C} 0-1-15$ & 16,47 & $-26,97$ & 1,77 & $-1,52$ & 13,62 & 76,54 & 2,28 & $-8,29$ \\
\hline 32 & $\mathrm{H} 90-10.5-\mathrm{C} 0-1-30$ & 24,40 & $-22,17$ & 2,16 & $-0,62$ & 21,01 & 74,08 & 5,07 & $-1,59$ \\
\hline 33 & $\mathrm{H} 90-10.5-\mathrm{C} 0-3-15$ & 27,61 & $-48,03$ & 1,34 & $-3,30$ & 27,36 & 80,97 & 1,31 & $-5,65$ \\
\hline 34 & $\mathrm{H} 90-10.5-\mathrm{C} 0-3-30$ & 25,26 & $-26,78$ & 2,06 & $-1,00$ & 23,40 & 53,72 & 2,84 & $-1,78$ \\
\hline 35 & N30-10.5-C3-2-30 & 13,91 & $-31,13$ & 1,98 & $-1,63$ & 13,02 & $-46,51$ & 5,49 & $-3,06$ \\
\hline 36 & N30-10.5-C3-2-45 & 13,34 & $-26,53$ & 2,22 & $-0,79$ & 11,98 & $-34,51$ & 4,28 & $-1,77$ \\
\hline 37 & N30-7.5-C3-2-30 & 47,93 & $-31,88$ & 10,65 & $-3,35$ & 47,78 & $-32,51$ & 11,99 & $-3,57$ \\
\hline 38 & N30-7.5-C3-2-45 & 44,59 & $-24,03$ & 5,58 & $-1,51$ & 44,35 & $-24,73$ & 6,69 & $-1,62$ \\
\hline 39 & $\mathrm{H} 90-10.5-\mathrm{C} 3-2-30$ & 23,90 & $-26,09$ & 1,70 & $-0,92$ & 21,70 & $-38,04$ & 2,00 & $-1,93$ \\
\hline 40 & $\mathrm{H} 90-10.5-\mathrm{C} 3-2-45$ & 16,62 & $-16,53$ & 2,25 & 0,55 & 12,98 & $-27,83$ & 3,65 & $-0,14$ \\
\hline 41 & $\mathrm{H} 90-7.5-\mathrm{C} 3-2-30$ & 75,47 & $-26,21$ & 3,50 & $-1,93$ & 75,47 & $-26,21$ & 3,50 & $-1,93$ \\
\hline 42 & H90-7.5-C3-2-45 & 61,30 & $-20,29$ & 5,48 & $-0,19$ & 60,92 & $-20,72$ & 5,83 & $-0,24$ \\
\hline 43 & $\mathrm{H} 90-7.5-\mathrm{C} 2-2-30$ & 72,72 & $-27,83$ & 3,51 & $-2,04$ & 72,72 & $-27,83$ & 3,51 & $-2,04$ \\
\hline 44 & $\mathrm{H} 90-7.5-\mathrm{C} 2-2-45$ & 61,12 & $-19,11$ & 5,50 & $-0,30$ & 60,93 & $-19,33$ & 5,85 & $-0,34$ \\
\hline
\end{tabular}




\subsubsection{DEFORMADA}

En el programa experimental se han identificado dos distribuciones típicas de la deformada. En la Figura 5.1a se muestra la deformada adoptada para diferentes estados de carga y de rotura cuando se desarrolla una rótula punto. Este tipo de distribución fue observada particularmente en los ensayos de flexión simple sin carga axil. Para los demás ensayos, la deformada adopta una distribución tal y como aparece en la Figura $5.1 \mathrm{~b}$, la cual puede ser ajustada a una función polinómica de tercer o cuarto grado.

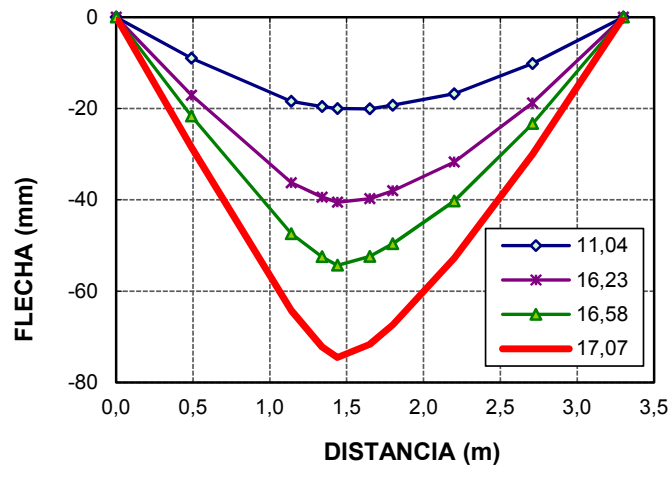

(a)

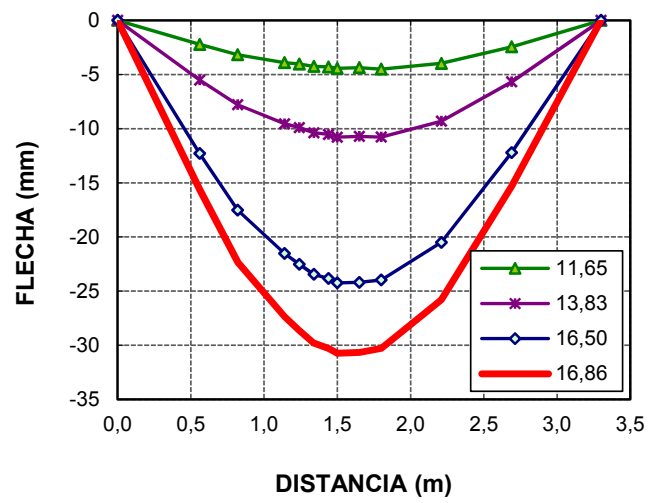

(b)

Figura 5.1 (a) Deformada típica en ensayos con rótula punto, ensayos de flexión sin carga axial (N30-10.5-CO-2-00), (b) Deformada de soportes sometidos a compresión y flexión monotónica (N60-10.5-C0-1-15)

\subsubsection{DEFORMACIÓN DE LA ARMADURA EN COMPRESIÓN Y TRACCIÓN}

Las deformaciones de la armadura de compresión $\left(\varepsilon_{s}^{\prime}\right)$ y tracción $\left(\varepsilon_{s}\right)$ han sido medidas a lo largo de los soportes, sobre una longitud de $50 \mathrm{~cm}$, con una separación de $5 \mathrm{~cm}$ entre las secciones instrumentadas con galgas extensiométricas, tal y como se ha explicado en el capítulo 4. Aunque la respuesta directa de la deformación en la armadura, por sí sola, no es una variable que permita valorar la capacidad de deformación, estos resultados son utilizados para calcular, de forma indirecta, otras variables indispensables en el análisis de la capacidad de deformación de elementos de hormigón, como son la curvatura y la deformación del hormigón en la fibra más comprimida, asumiendo naturalmente la hipótesis de sección plana. Por consiguiente, en este estudio, los resultados obtenidos al medir la deformación en la armadura de compresión y tracción han sido fundamentales para determinar la capacidad de deformación y de ductilidad, en las secciones críticas y también para caracterizar la posible rótula plástica que se forma.

Adicionalmente, la respuesta del proceso de deformación que se desarrolla en la armadura permite conocer el estado de los materiales (acero y hormigón) durante todo el proceso de carga. Esto resulta útil para identificar el inicio de la plastificación de los materiales y para verificar el estado final de los mismos. En la Figura 5.2 se presenta el comportamiento carga-deformación, tanto de la armadura de 
compresión como la de tracción para la sección de mayor deformabilidad, ver sección 5.2.2. El punto $P_{y}$ indica el inicio de la plastificación en la sección, que, en este caso particular se debe al inicio de la no linealidad del hormigón. En la sección 6.4 se presentan los criterios adoptados es esta tesis referentes a la determinación del punto de plastificación. El punto $\mathrm{P}_{\mathrm{u}}$ marca el estado de rotura del ensayo, por lo que se puede comprobar si se ha producido el agotamiento de los materiales.

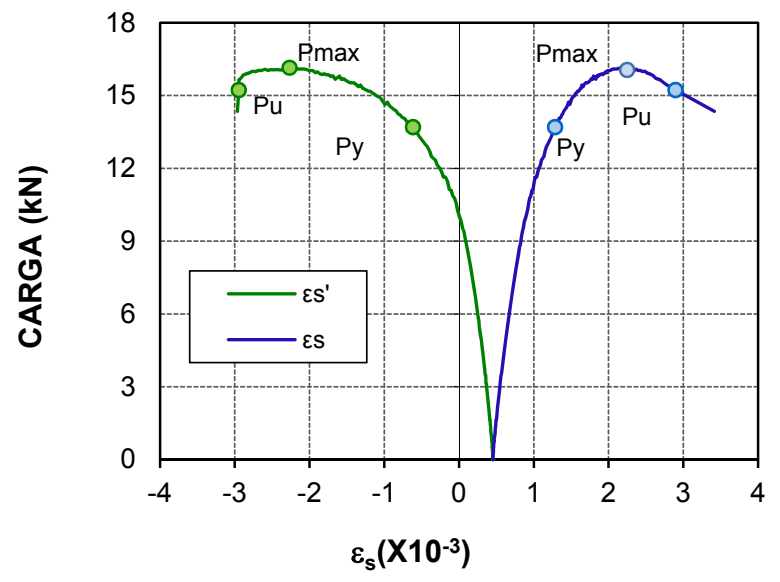

Figura 5.2 Comportamiento carga deformación de la armadura en tracción $\left(\varepsilon_{s}\right)$ y en compresión $\left(\varepsilon_{s}^{\prime}\right)$, (ensayo N30-10.5-CO-2-30)

Por otra parte, a partir de la distribución de las deformaciones, ha sido posible identificar otros efectos que pueden aparecer durante el proceso de carga, como por ejemplo el proceso de concentración de deformación en caso de presentarse la rótula punto, o el efecto de rigidización del "stub", los cuales se explican en los siguientes apartados. En las Figuras 5.3, se presenta la distribución de deformaciones sobre una longitud de $50 \mathrm{~cm}$ del soporte. Esta distribución se presenta para tres estados de carga: de plastificación, máxima y última. Como se puede observar, existen algunas fluctuaciones en la distribución de deformación, lo cual se debe a la presencia de fisuras cerca de o justo en las secciones instrumentadas.

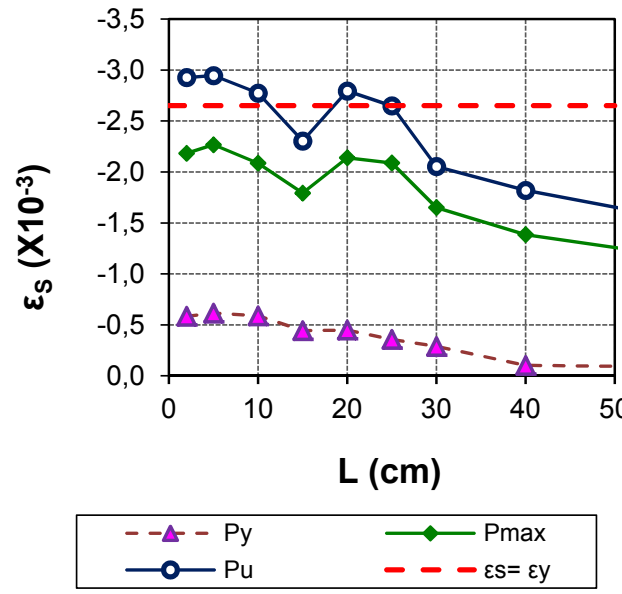

(a)

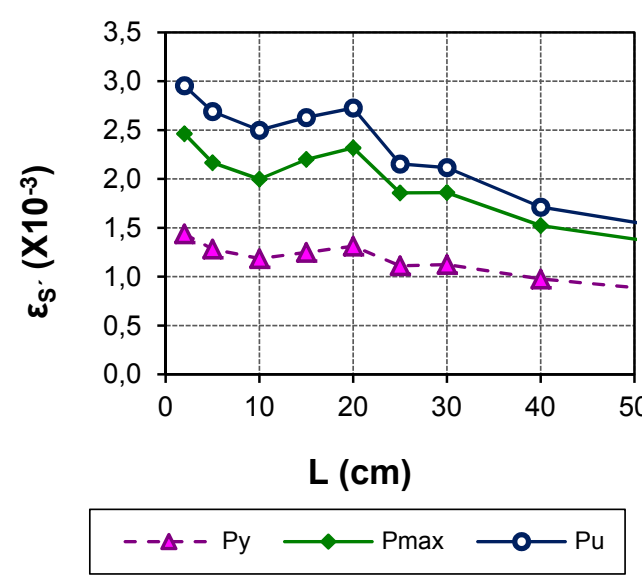

(b)

Figura 5.3 Distribución de deformaciones del ensayo N30-10.5-CO-2-30, para los niveles de carga en el punto de plastificación, carga máxima y carga última 


\subsection{EFECTOS OBSERVADOS DURANTE EL ENSAYO}

\subsubsection{DEFORMACIONES DE LA ARMADURA EN LA RÓTULA PUNTO}

Dentro del programa experimental, la rótula punto tuvo lugar en los tres ensayos de flexión sin carga axial. Estos ensayos mostraron un comportamiento deformacional idéntico y bastante singular respecto a los demás ensayos. En este apartado se hace una descripción de los efectos observados durante el proceso de deformación de la armadura.

Los resultados muestran que, cuando la carga se acerca al máximo valor, se genera una concentración de deformación en la armadura de tracción, en las secciones situadas dentro de la zona de rótula plástica. Inicialmente la deformación plástica se concentra en una sección, cuando alcanza un máximo valor (para cada ensayo es distinto y siempre superior al de plastificación), las secciones más cercanas empiezan a desarrollar grandes deformaciones, concentrándose dichas deformaciones plásticas en una pequeña zona del elemento de unos $15 \mathrm{~cm}$ de longitud, fuera de la cual las deformaciones del acero se encuentran dentro del rango elástico.

En las Figuras 5.4 y 5.5 se puede observar cómo las deformaciones de tracción medidas en las secciones T1, T2 y T3, correspondientes a las primeras tres secciones más cercanas al "stub", plastifican hasta alcanzar la deformación última del acero. Estas tres secciones alcanzan el pico de deformación en diferentes instantes de carga, como se muestra en la Figura 5.4.

Durante el proceso de concentración de la deformación en la armadura de tracción, existe un efecto de relajación de las deformaciones en la armadura de compresión, precisamente en las mismas secciones, aunque luego recupera la trayectoria, y la deformación de compresión aumenta. Este efecto puede ser observado en las Figuras 5.5. Las deformaciones de compresión para las mismas secciones C1, C2 y $\mathrm{C} 3$, presentan una discontinuidad en el proceso de compresión durante un intervalo de carga cercano a la carga máxima. Después, se corrige la trayectoria y aumenta la deformación de compresión.

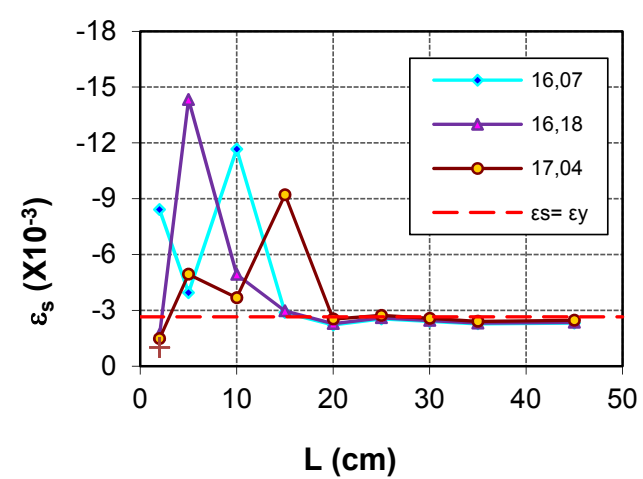

(a)

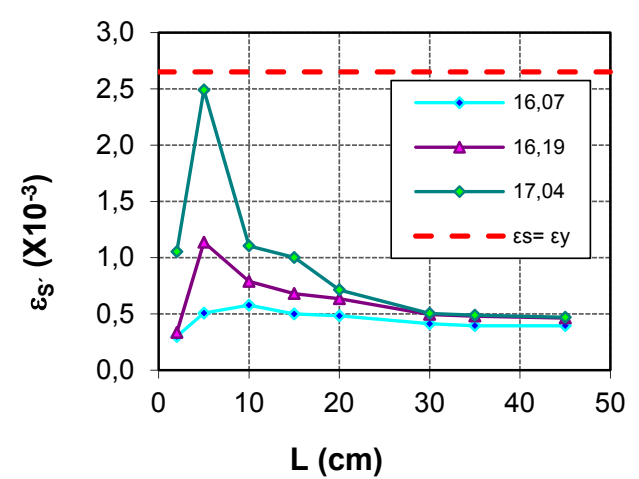

(b)

Figura 5.4 Distribución de deformaciones de la armadura en: (a) tracción $\left(\varepsilon_{s}\right)$ y (b) compresión $\left(\varepsilon_{s}^{\prime}\right)$, (Ensayo N30-10.5-CO-2-00) 

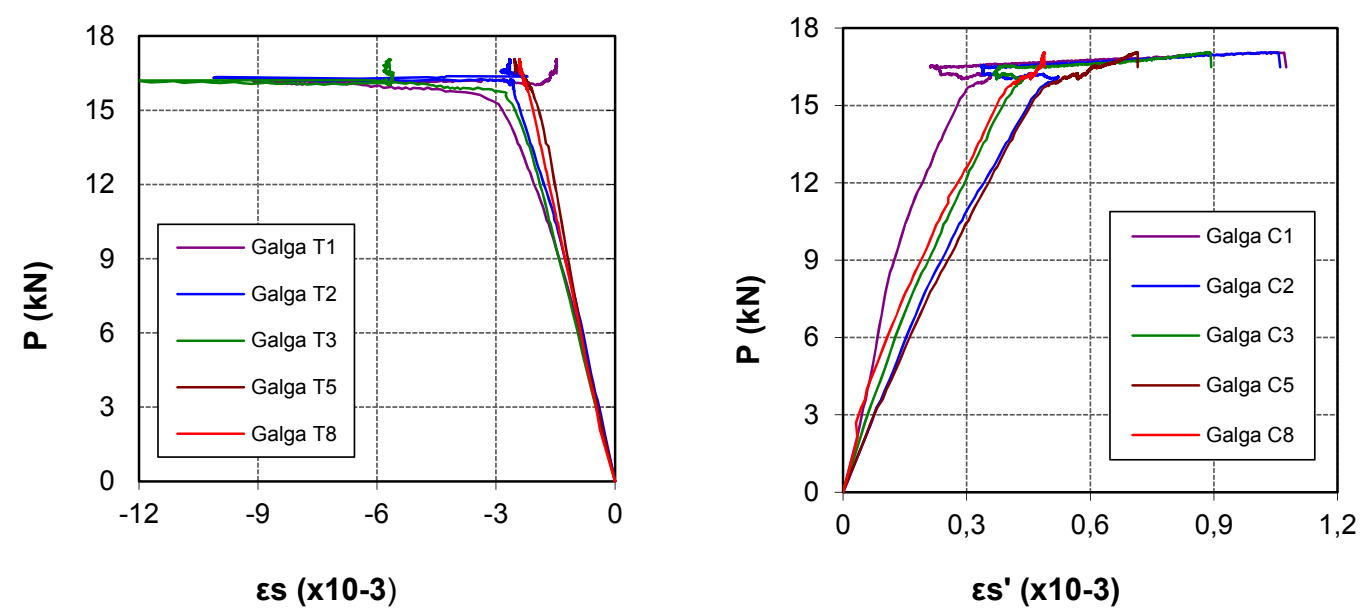

Figura 5.5 Comportamiento carga- deformación de la armadura en tracción $\left(\varepsilon_{s}\right)$ y en compresión $\left(\varepsilon_{s}^{\prime}\right)$, (Ensayo N30-10.5-CO-2-00)

\subsubsection{EFECTO DE LA RIGIDEZ DEL STUB}

En este apartado se explica el efecto que causa el "stub" en la capacidad de deformación y de la resistencia de la conexión. Este efecto es claramente visible en la mayoría de los ensayos, y se manifiesta cuando la zona inmediatamente contigua a la conexión no presenta daño (Figura 5.6a), a pesar de que las secciones de máximo momento se localizan en la conexión soporte-stub, de modo que la sección crítica retrocede y se aleja algunos centímetros de la conexión hacia el soporte. Algunas investigaciones (Sheikh S. A. y Khoury S. S.(1993)[121], Bayrak O. y Sheikh S. A. (1998) [16], Légeron F. y Paultre P (2000)[78], Bae S.(2005) [12]) atribuyen este comportamiento, principalmente, al confinamiento provocado por la mayor rigidez del "stub" en las secciones inmediatamente vecinas. Dicho confinamiento incrementa la capacidad de momento de las secciones inmediatamente contiguas a la cara del "stub", logrando que la sección de momento máximo en la conexión soporte-stub sea más resistente que la sección de fallo. Como resultado, la sección crítica se traslada a una sección cercana.

Otra forma de observar este fenómeno en los ensayos experimentales es mediante la distribución de la curvatura. En la mayoría de los soportes se observó que el máximo valor de curvatura no se producía en la sección más cercana al "stub", sino que los valores pico se localizaban sobre cualquiera de las dos siguientes secciones más cercanas a la conexión a $5 \mathrm{~cm}$ ó $10 \mathrm{~cm}$, como se puede observar en la Figura 5.6b. Esto confirma que las secciones cercanas al "stub" se mantienen no sólo más resistentes, sino más indeformables, debido al efecto del confinamiento que les proporciona la mayor rigidez del "stub". Por último, se ha observado que la zona contigua al "stub" que no presenta daño, coincide con la distancia entre la interfaz soporte-stub y la posición del primer cerco transversal. Este espacio no ha sido constante en todos los ensayos y puede variar entre 2 y $5 \mathrm{~cm}$.

Teniendo en cuenta todo lo anterior, y con vistas al posterior análisis de los resultados, se ha establecido que la sección crítica de fallo se localice a $5 \mathrm{~cm}$ de la cara del "stub", y no en la intersección (Figura 5.6a). Además, esta sección coincide con la localización de galgas extensiométricas sobre la armadura de compresión y 
tracción, y con la ubicación de un captador de desplazamiento para medir la flecha en este punto.

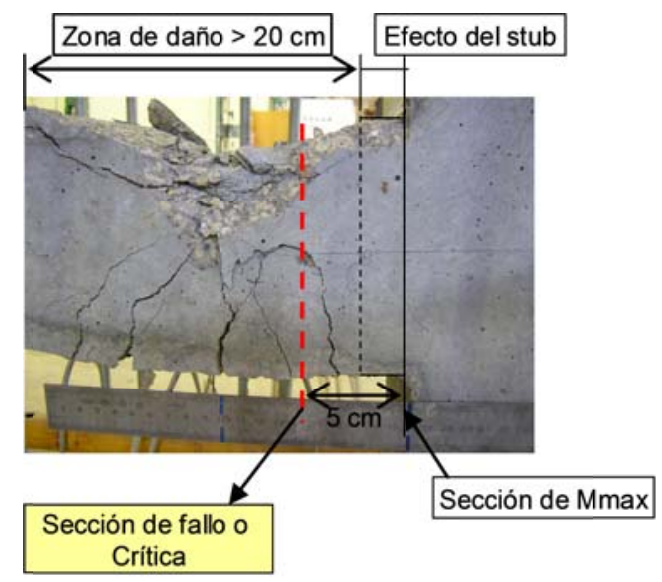

(a)

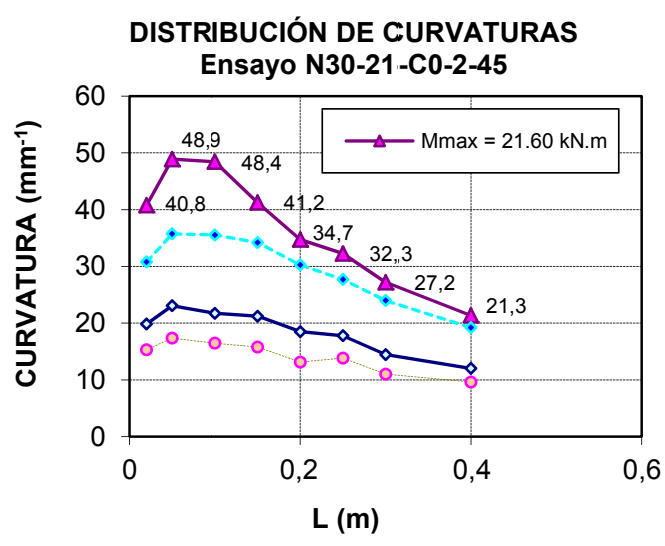

(b)

Figura 5.6 (a) definición de sección crítica (b) efecto del "stub" en la distribución de curvaturas

\subsubsection{PANDEO DE LAS ARMADURAS}

La presencia del pandeo de la armadura en compresión ha sido un efecto constante en casi todos los ensayos de soportes con altos niveles de carga axil (45\%), y, en particular, en los ensayos con una separación de $10 \mathrm{~cm}$ entre cercos. Cabe también destacar que, para ensayos similares con menor separación de la armadura transversal $(5 \mathrm{~cm}$ y $8 \mathrm{~cm}$ ), el efecto del pandeo de la armadura desaparece. Esto confirma, una vez más, los efectos favorables de una adecuada separación entre los cercos, además del incremento de resistencia y deformación del hormigón del núcleo confinado.

El efecto del pandeo de la armadura se produce debido a que el hormigón del núcleo realiza una presión lateral sobre las barras, además esto ocurre generalmente después de que la armadura alcanza el límite elástico, de modo que las barras continúan deformándose en el rango plástico hasta que el acero entra en el rango de endurecimiento. Entre tanto, la resistencia de la capa de recubrimiento disminuye debido al incremento de daño en el hormigón comprimido. Por consiguiente, la presión lateral del núcleo consigue que las barras se deformen hasta que se produce el pandeo, pues el hormigón de recubrimiento se debilita lo suficiente como para que se produzca la pérdida de esta capa.

\subsection{NIVELES DE DAÑO Y APARIENCIA FINAL DE LOS SOPORTES}

Durante el desarrollo del programa experimental se han observado diferencias respecto al estado de daño al finalizar el ensayo. Para visualizar mejor dichas diferencias, se ha llevado a cabo una clasificación teniendo en cuenta el estado de daño en el momento de la rotura del soporte, según los siguientes criterios: tipo de fisuración, rotura del hormigón en la zona comprimida, pérdida del recubrimiento, y pandeo de la armadura. Se ha logrado así identificar cinco niveles de daño en los 
soportes. En el Anejo D se presentan las fotos de cada uno de los soportes al finalizar el ensayo.

\subsubsection{NIVEL DE DAÑO 1}

En este nivel se encuentran los tres ensayos de flexión simple sin carga axial. Estos elementos presentan una zona de daño concentrada aproximadamente en 15 cm a partir de la unión con el "stub". En estos ensayos se ha observado una fisuración vertical, pero con una leve inclinación en la zona comprimida del soporte, y aparece una marcada fisura justo en la unión del soporte y el "stub". Además, se observa un notable daño en la capa de hormigón de recubrimiento, concentrado en una pequeña zona de $10 \mathrm{~cm}$.

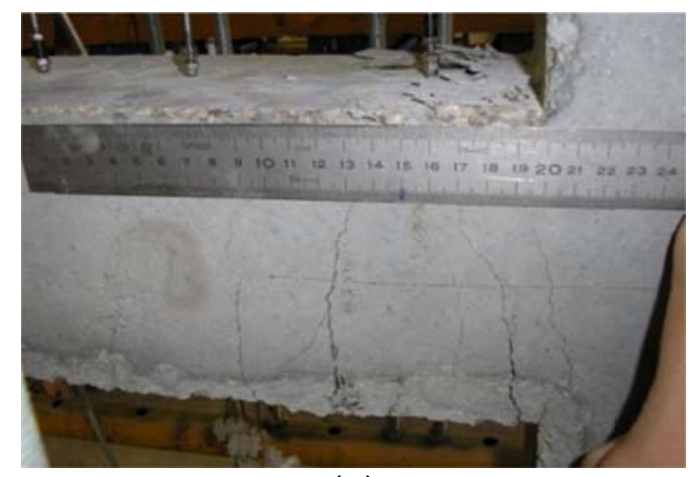

(a)

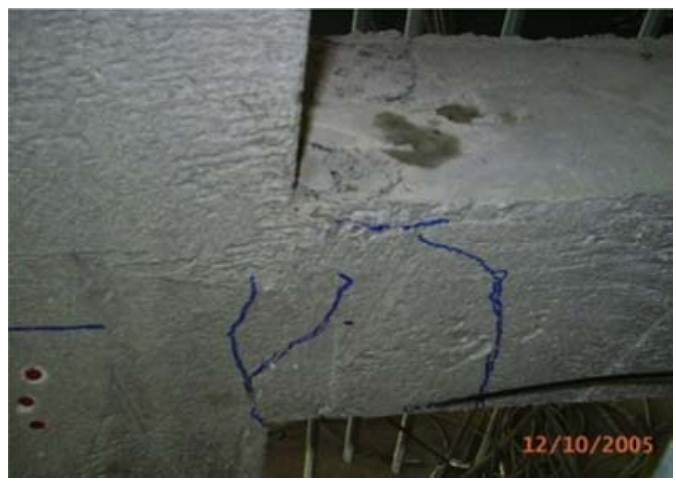

(b)

Figura 5.7 Ensayos con nivel de daño 1 (a) N30-10.5-CO-2-00 y (b) H9O-10.5-CO-2-00

\subsubsection{NIVEL DE DAÑO 2}

En este grupo no se observa una destacada zona de daño cerca del "stub"; esta situación aparece en los soportes que presentan importantes deformaciones en la armadura de tracción. A lo largo del soporte, se presenta una distribución de fisuras casi paralelas, marcadas principalmente por la separación de los cercos. En la mayoría de estos ensayos no se ha presentado rotura del hormigón en la zona de compresión, por lo que se observa un buen aspecto en la capa de hormigón de recubrimiento.

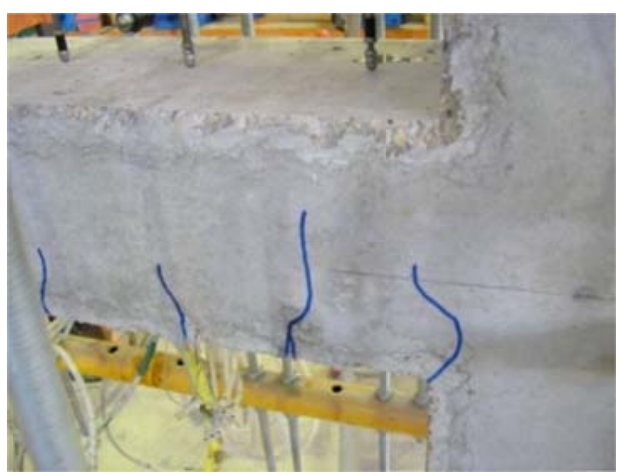

(a)

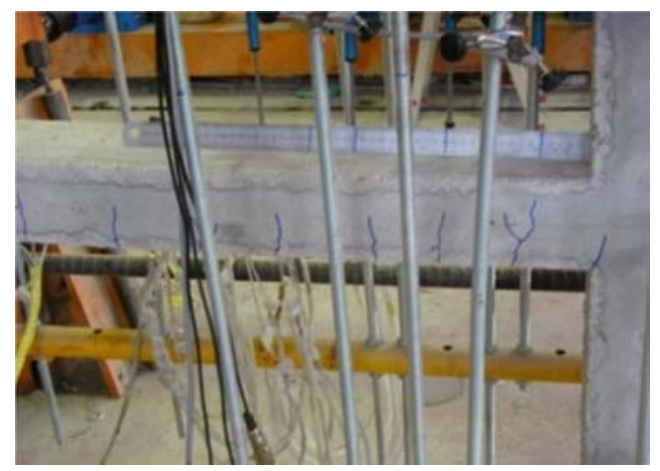

(b)

Figura 5.8 Ensayos con nivel de daño 2 (a) H60-10.5-CO-1-15 y (b) H60-10.5-CO-2-15 


\subsubsection{NIVEL DE DAÑO 3}

Siguiendo con la valoración del daño, en este grupo se han incluido aquellos soportes que muestran un daño considerable en la zona de compresión, hasta la pérdida parcial de la capa de recubrimiento. En estos ensayos, se distinguen aspectos notables de flexión, como la fisuración, aunque algo más inclinada, marcando una tendencia leve de abanico sobre una amplia zona de daño (alrededor de $25 \mathrm{~cm}$ ), y también aparece una mayor abertura de fisura y una menor separación entre fisuras.

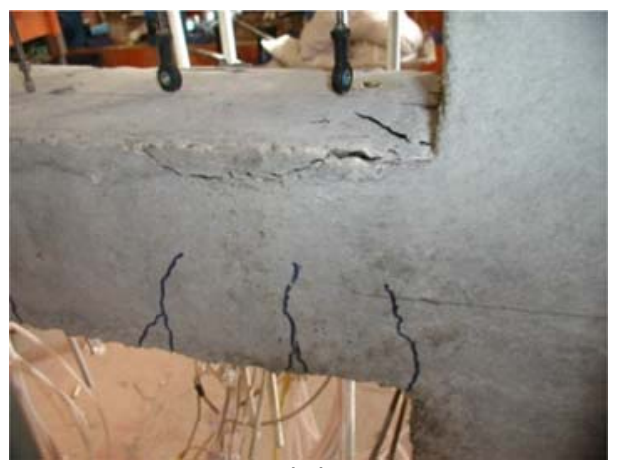

(a)

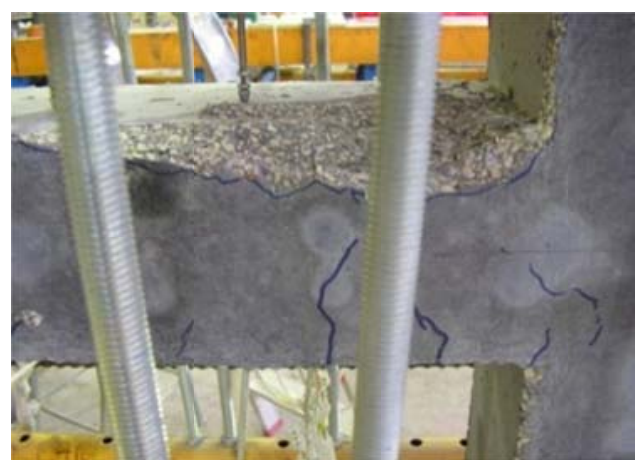

(b)

Figura 5.9 Ensayos con nivel de daño 3 (a) N30-10.5-CO-2-30 y (b) H9O-10.5-CO-2-15

\subsubsection{NIVEL DE DAÑO 4}

El siguiente nivel de daño es típico en elementos en los que la separación de los cercos es menor (entre 5 y $8 \mathrm{~cm}$ ). En estos soportes, el daño se caracteriza por los siguientes aspectos:

- Aunque los ensayos se han realizado para niveles de axil moderados y altos, no existe el pandeo de la armadura.

- Aparece una gran pérdida de la capa de recubrimiento en la zona de compresión, incluso en las zonas laterales, manteniéndose el núcleo de hormigón confinado.

- Se observa una fuerte fisuración inclinada, concentrada en una amplia zona de daño (aproximadamente $30 \mathrm{~cm}$ ).

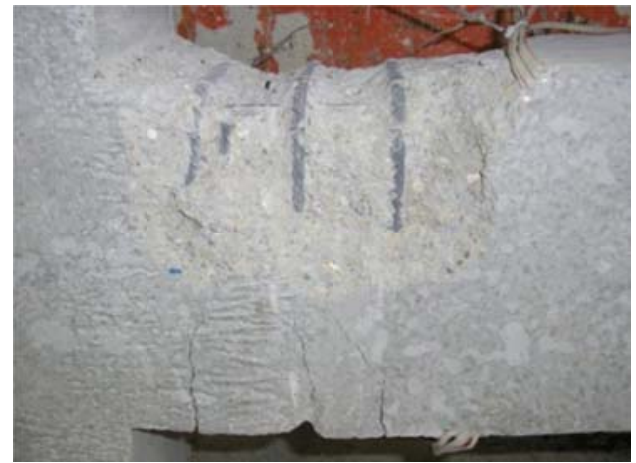

(a)

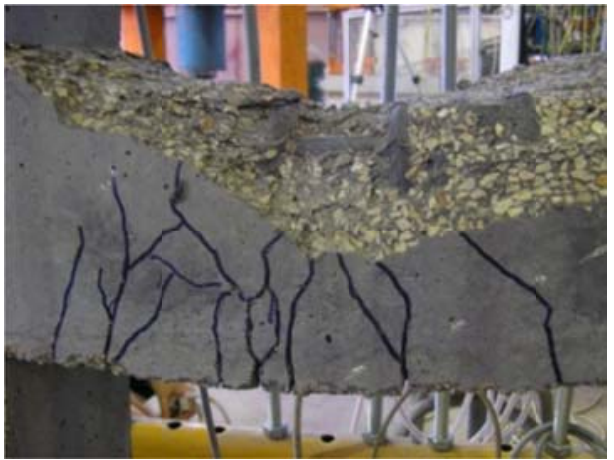

(b)

Figura 5.10 Ensayos con nivel de daño 4 (a) N30-15-C3-2-45 y (b) H9O-10.5-C3-2-30 


\subsubsection{NIVEL DE DAÑO 5}

En este grupo se encuentran los ensayos que han mostrado la peor apariencia de daño. Este nivel ha estado presente en soportes con niveles altos y moderados de carga axil, y una separación de $10 \mathrm{~cm}$ entre los cercos transversalles. En estos soportes se distingue una amplia zona de daño continua en la base del "stub". La longitud de la región de daño aumenta con el nivel de carga axil. Los ensayos con mayores niveles de carga axial $(45 \%)$ no sólo son los que mayor longitud de daño han desarrollado, sino que también en ellos es más evidente la degradación y fractura del hormigón. Adicionalmente, en estos ensayos aparece el efecto del pandeo de las armaduras, de forma más frecuente en los ensayos con mayores niveles de carga axil, provocando que la zona de daño se extienda sobre una mayor longitud.

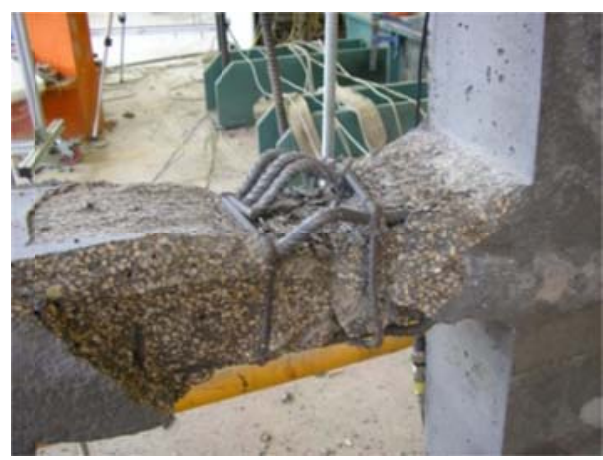

(a)

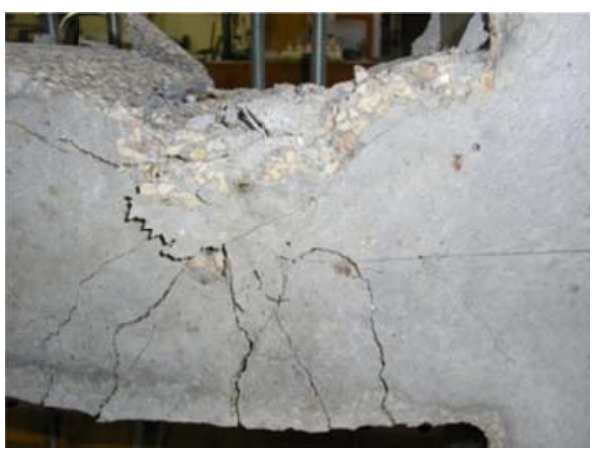

(b)

Figura 5.11 Ensayos con nivel de daño 5 (a) H9O-10.5-CO-2-45 y (b) H60-10.5-CO-2-30

\subsection{RESUMEN GENERAL DEL PROCESO DE DEFORMACIÓN DE LOS MATERIALES, DE LOS EFECTOS Y ESTADOS DE DAÑO}

Los resultados obtenidos de deformación han permitido identificar las condiciones de los materiales en diferentes niveles de carga. Esta información permite confirmar aspectos como el punto de plastificación de los materiales y el tipo de fallo que se analizan en el capítulo 6. En la Tabla 5-2 se han identificado los siguientes aspectos respecto al estado de los materiales, de los efectos y niveles de daño observados.

1. En la sección crítica plastifica primero el acero en tracción $\left(\varepsilon_{s} \geq \varepsilon_{y}\right)$.

2. En la sección crítica plastifica primero el hormigón en compresión $\left(\varepsilon_{C} \geq\right.$ $\left.0.75 \varepsilon_{c 1}\right)$.

3. En estado de carga última, la armadura de tracción alcanza la deformación correspondiente al límite elástico.

4. En estado de carga última, la armadura de compresión alcanza la deformación correspondiente al límite elástico.

5. En estado de carga última, el hormigón comprimido alcanza la deformación de rotura.

6. En estado de carga última, se alcanza la deformación de rotura del acero. Para la armadura comprimida (C), para la armadura traccionada $(T)$.

7. Estado de daño.

8. Se ha observado el pandeo de la armadura.

9. Se ha observado la pérdida del recubrimiento. 
Tabla 5-2 Resumen general del estado de deformación de los materiales y apariencia de daño final en los soportes ensayados

\begin{tabular}{|c|c|c|c|c|c|c|c|c|c|c|}
\hline \multirow{2}{*}{$\begin{array}{c}\mathbf{N}^{\circ} \\
\text { ensayo }\end{array}$} & \multirow[t]{2}{*}{ Referencia } & \multicolumn{2}{|c|}{$\begin{array}{c}\text { Inicio de la } \\
\text { plastificación }\end{array}$} & \multicolumn{4}{|c|}{$\begin{array}{c}\text { Estado final de los } \\
\text { materiales }\end{array}$} & \multicolumn{3}{|c|}{$\begin{array}{l}\text { Estado final } \\
\text { de daño }\end{array}$} \\
\hline & & 1 & 2 & 3 & 4 & 5 & 6 & 7 & 8 & 9 \\
\hline 1 & N30-10.5-C0-2-00 & $\mathrm{x}$ & & $x$ & $x$ & & $T$ & 1 & NO & NO \\
\hline 2 & N30-10.5-C0-2-15 & & $x$ & $x$ & $x$ & & $T$ & 2 & NO & NO \\
\hline 3 & N30-10.5-C0-2-30 & & $\mathrm{x}$ & $\mathrm{X}$ & $x$ & $\mathrm{x}$ & & 3 & NO & $\mathrm{SI}$ \\
\hline 4 & N30-10.5-C0-2-45 & & $x$ & & $x$ & & & 5 & $\mathrm{SI}$ & $\mathrm{SI}$ \\
\hline 5 & N30-7.5-C0-2-30 & & $\mathrm{X}$ & $x$ & $\mathrm{X}$ & $x$ & & 3 & $\mathrm{NO}$ & $\mathrm{NO}$ \\
\hline 6 & N30-7.5-C0-2-45 & & $x$ & & $x$ & $\mathrm{x}$ & $C$ & 5 & $\mathrm{SI}$ & $\mathrm{SI}$ \\
\hline 9 & $\mathrm{~N} 30-10.5-\mathrm{C} 0-1-30$ & & $x$ & $x$ & $x$ & & $T$ & 2 & NO & $\mathrm{NO}$ \\
\hline 10 & N30-10.5-C0-1-45 & & $\mathrm{X}$ & & $x$ & & & 5 & NO & $\mathrm{NO}$ \\
\hline 11 & N30-10.5-C0-3-15 & & $x$ & $x$ & $x$ & & & 2 & NO & $\mathrm{NO}$ \\
\hline 12 & N30-10.5-C0-3-30 & & $\mathrm{x}$ & & $x$ & $x$ & & 5 & NO & $\mathrm{SI}$ \\
\hline 13 & $\mathrm{H} 60-10.5-\mathrm{C} 0-2-00$ & $x$ & & $\mathrm{x}$ & & & $T$ & 1 & NO & $\mathrm{NO}$ \\
\hline 14 & H60-10.5-C0-2-15 & & $\mathrm{X}$ & $x$ & $\mathrm{X}$ & & $T$ & 2 & NO & $\mathrm{NO}$ \\
\hline 15 & $\mathrm{H} 60-10.5-\mathrm{C} 0-2-30$ & & $x$ & & $x$ & & & 5 & NO & $\mathrm{SI}$ \\
\hline 16 & H60-10.5-C0-2-45 & & $x$ & & $x$ & $x$ & & 5 & SI & SI \\
\hline 17 & $\mathrm{H} 60-7.5-\mathrm{C} 0-2-30$ & & $x$ & & $x$ & $x$ & & 3 & NO & $\mathrm{SI}$ \\
\hline 18 & $\mathrm{H} 60-7.5-\mathrm{C} 0-2-45$ & & $x$ & & $x$ & $x$ & & 5 & $\mathrm{SI}$ & $\mathrm{SI}$ \\
\hline 21 & H60-10.5-C0-1-15 & & $x$ & $x$ & $x$ & & & 2 & NO & $\mathrm{NO}$ \\
\hline 22 & $\mathrm{H} 60-10.5-\mathrm{C} 0-1-30$ & & $x$ & & $x$ & $x$ & & 5 & SI & $\mathrm{SI}$ \\
\hline 23 & H60-10.5-C0-3-15 & & $x$ & $x$ & $x$ & & & 2 & NO & $\mathrm{NO}$ \\
\hline 24 & $\mathrm{H} 60-10.5-\mathrm{C} 0-3-30$ & & $x$ & $x$ & $x$ & $x$ & & 5 & SI & SI \\
\hline 25 & $\mathrm{H} 90-10.5-\mathrm{C} 0-2-00$ & $x$ & & $x$ & & & $T$ & 1 & NO & $\mathrm{NO}$ \\
\hline 26 & H90-10.5-C0-2-15 & & $x$ & $x$ & $x$ & & $T$ & 2 & NO & $\mathrm{SI}$ \\
\hline 27 & H90-10.5-C0-2-30 & & $x$ & & $\mathrm{X}$ & $x$ & & 3 & NO & $\mathrm{SI}$ \\
\hline 28 & H90-10.5-C0-2-45 & & $x$ & & $x$ & $x$ & & 5 & $\mathrm{SI}$ & $\mathrm{SI}$ \\
\hline 29 & $\mathrm{H} 90-7.5-\mathrm{C} 0-2-30$ & & $x$ & & $x$ & $x$ & & 3 & NO & $\mathrm{SI}$ \\
\hline 30 & H90-7.5-C0-2-45 & & $x$ & & $x$ & $x$ & & 5 & NO & $\mathrm{SI}$ \\
\hline 31 & H90-10.5-C0-1-15 & & $x$ & $x$ & $x$ & $x$ & & 5 & SI & $\mathrm{SI}$ \\
\hline 32 & $\mathrm{H} 90-10.5-\mathrm{C} 0-1-30$ & & $x$ & & $x$ & $x$ & & 5 & $\mathrm{SI}$ & $\mathrm{SI}$ \\
\hline 33 & H90-10.5-C0-3-15 & & $x$ & $x$ & $x$ & & & 5 & NO & $\mathrm{NO}$ \\
\hline 34 & $\mathrm{H} 90-10.5-\mathrm{C} 0-3-30$ & & $x$ & & $x$ & $x$ & & 5 & $\mathrm{SI}$ & $\mathrm{SI}$ \\
\hline 35 & N30-10.5-C3-2-30 & & $x$ & $x$ & $x$ & $x$ & & 4 & NO & $\mathrm{SI}$ \\
\hline 36 & N30-10.5-C3-2-45 & & $x$ & & $x$ & $x$ & & 4 & NO & $\mathrm{SI}$ \\
\hline 37 & N30-7.5-C3-2-30 & & $x$ & $x$ & $x$ & $x$ & $\mathrm{C}$ & 4 & NO & $\mathrm{SI}$ \\
\hline 38 & N30-7.5-C3-2-45 & & $x$ & & $x$ & $x$ & & 4 & NO & SI \\
\hline 39 & $\mathrm{H} 90-10.5-\mathrm{C} 3-2-30$ & & $x$ & & $x$ & & & 4 & NO & SI \\
\hline 40 & H90-10.5-C3-2-45 & & $x$ & & $\mathrm{X}$ & $x$ & & 4 & SI & $\mathrm{SI}$ \\
\hline 41 & H90-7.5-C3-2-30 & & $x$ & & $x$ & $x$ & & 4 & NO & $\mathrm{SI}$ \\
\hline 42 & $\mathrm{H} 90-7.5-\mathrm{C} 3-2-45$ & & $x$ & & $x$ & $x$ & & 4 & NO & $\mathrm{SI}$ \\
\hline 43 & $\mathrm{H} 90-7.5-\mathrm{C} 2-2-30$ & & $x$ & & $x$ & $x$ & & 4 & NO & $\mathrm{SI}$ \\
\hline 44 & $\mathrm{H} 90-7.5-\mathrm{C} 2-2-45$ & & $x$ & & $x$ & $x$ & & 4 & NO & $\mathrm{SI}$ \\
\hline
\end{tabular}


Estudio experimental y numérico de la capacidad de deformación de soportes esbeltos de hormigón armado 


\section{CAPÍTULO 6}

\section{ANÁLISIS DE LOS RESULTADOS EXPERIMENTALES}

Este capítulo está dedicado al análisis de los resultados experimentales del programa de ensayos de soportes esbeltos de hormigón convencional y de alta resistencia, sometidos a compresión y flexión monotónica. Dicho análisis incluye los siguientes aspectos: (1) identificación del tipo de fallo exhibido en cada uno de los soportes; (2) comparación entre los resultados experimentales de carga y momento máximos resistentes y los resultados calculados a partir de los modelos descritos en las normas de diseño; (3) análisis de la capacidad de deformación a nivel de la fibra, de la sección y del elemento completo; (4) como resultado de la relación entre la capacidad de deformación de la sección y del elemento, se realiza la evaluación de la longitud de rótula plástica experimental; y (5) evaluación de la rigidez efectiva. En cada uno de los análisis mencionados, se ha realizado el estudio de la influencia de los parámetros considerados en esta investigación (nivel de carga axial, esbeltez de cortante, resistencia del hormigón, cuantía de armadura longitudinal y cuantía de armadura transversal). 


\subsection{TIPOS DE FALLO}

En elementos de hormigón sometidos a esfuerzos combinados de flexión y carga axial, la capacidad última depende entre otras de las características mecánicas (relaciones constitutivas $\sigma-\varepsilon$ del hormigón y del acero) y geométricas de la sección transversal (cuantía de armadura longitudinal y transversal), y, por supuesto, de la esbeltez geométrica del elemento; la interacción de estos factores condicionan el tipo de fallo que puede ocurrir en los soportes de hormigón. Un elemento de hormigón armado puede presentar diferentes modos de fallo, los cuales están relacionados directamente con el desarrollo de la ductilidad. Por consiguiente, dentro del análisis previo de la capacidad de deformación, es necesario conocer inicialmente el modo de fallo atribuido a cada uno de los soportes ensayados en el programa experimental.

Concretamente, los soportes esbeltos de hormigón armado pueden dar origen a dos modos de colapso o fallo, el agotamiento de la sección crítica y la inestabilidad del elemento.

El modo de fallo por agotamiento se presenta cuando el soporte de hormigón es capaz de desarrollar las deformaciones de agotamiento en alguno de los materiales (hormigón y/o acero), alcanzando la capacidad de carga máxima del elemento simultáneamente con la de la sección crítica. En este tipo de fallo hay que distinguir si el agotamiento de la sección se presenta en la zona de tracción o en la zona de compresión de la sección crítica. Convencionalmente, si el material que ha alcanzado el agotamiento es el acero en tracción, el fallo se define como agotamiento por tracción. De lo contrario, si para el instante de carga máxima el material que ha agotado primero es el hormigón, el fallo se define como agotamiento por compresión.

El modo de fallo por inestabilidad se produce cuando el soporte no alcanza una situación de equilibrio; bajo esta situación, los materiales no alcanzan en ningún caso las deformaciones de agotamiento.

\subsubsection{MÉTODO APLICADO EN LA IDENTIFICACIÓN DEL MODO DE FALLO DE LOS ENSAYOS EXPERIMENTALES}

Para determinar el modo de fallo en los soportes ensayados, en el análisis se han aplicado dos criterios. El primer criterio se basa en la respuesta del diagrama momento-flecha para la sección crítica. Este criterio sólo permite identificar si el fallo se produce por agotamiento o por inestabilidad. Sin embargo, con el segundo criterio, basado en el estado de deformación de los materiales en el instante del momento máximo, se puede identificar si, en el caso de presentarse el modo de fallo por agotamiento, este se produce por agotamiento de la armadura de tracción o por compresión del hormigón. Adicionalmente, para aquellos soportes que presentan fallo por inestabilidad, la información sobre el estado de deformación de los materiales especifica si hay un predominio de deformación por tracción, compresión, si las deformaciones se sitúan en el dominio elástico de los materiales, o si se presenta una situación de doble pivote. 


\section{Criterio I: Análisis de los diagramas de respuesta Momento-Flecha de la sección crítica}

Esta parte del análisis consiste en comprobar si el máximo momento flector $\left(\mathrm{M}_{\mathrm{T}}\right.$, ver Figura 6.1 y Ec. 6-2) se ha producido en el instante en que se alcanza la máxima capacidad resistente del material. Esto significa que el momento máximo total, que incluye los efectos de segundo orden, coincide con el instante en que se alcanza la carga transversal máxima, o, lo que es lo mismo, cuando se alcanza el máximo momento de primer orden $\left(\mathrm{M}_{1^{\circ}}\right.$, ver Figura 6.1 y Ec. 6-1); de esta manera, se deduce que el elemento ha fallado por agotamiento. Como se puede observar en el diagrama Momento-Flecha de la Figura 6.2a, el instante en el que se alcanza el máximo momento de primer orden $\left(\mathrm{M}_{1{ }^{\circ}-\max }\right)$ coincide con el máximo momento total $\left(\mathrm{M}_{\mathrm{T} \_\max }\right)$. Por otra parte, como se puede observar en la Figura $6.2 \mathrm{~b}$, una vez se ha alcanzado el momento máximo de primer orden, la carga empieza a disminuir, aunque la sección aún no se ha agotado, permitiendo que los efectos de segundo orden sigan aumentando hasta que la sección alcanza su máximo momento total, lo cual significa que el soporte ha fallado por inestabilidad.

En este estudio se debe tener en cuenta que los momentos, y la capacidad de deformación se evalúan en la sección crítica (definida en el capítulo 5), la cual ha sido considerada a una distancia de $5 \mathrm{~cm}$ de la cara del "stub".

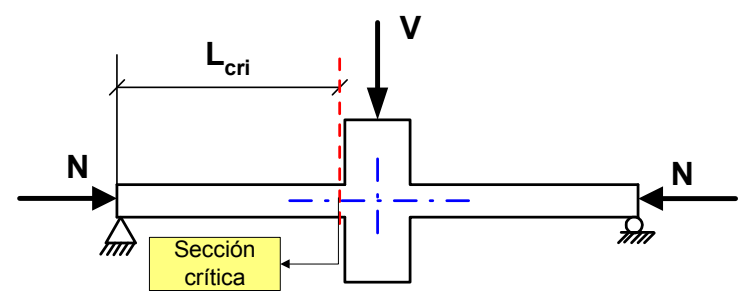

Ec. 6-1

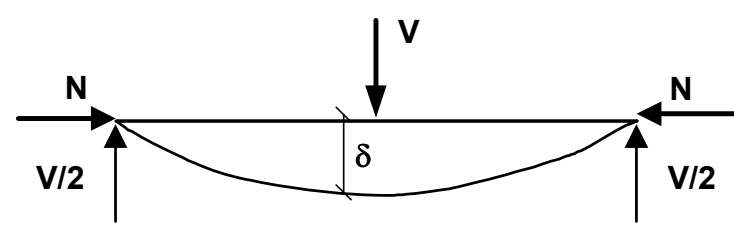

$$
\mathrm{M}_{\mathrm{T}}=\frac{\mathrm{V} \times \mathrm{L}_{\mathrm{cri}}}{2}+\mathrm{N} \times \delta
$$

Figura 6.1 Definición de momento de primer orden (M1은 y momento total (MT)

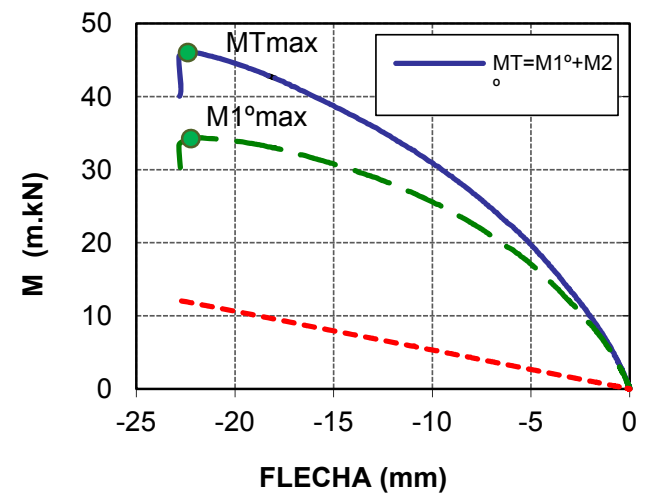

(a)

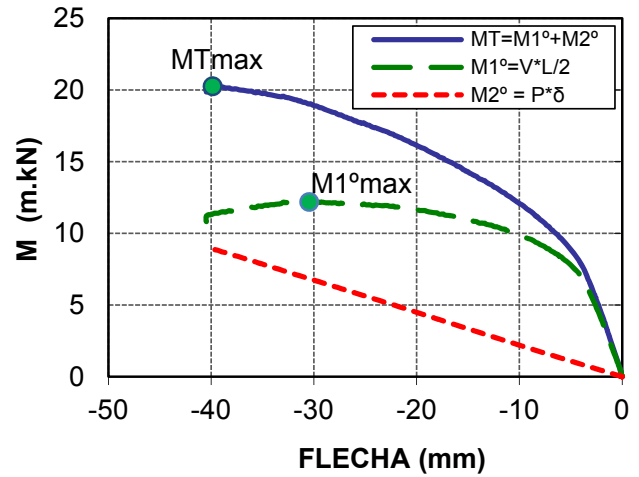

(b)

Figura 6.2 Identificación del tipo de fallo en el diagrama de Momento-Flecha: (a) fallo por agotamiento (N30-7.5-CO-2-45), (b) fallo por inestabilidad (H60-21-CO-1-15) 


\section{Criterio II. Estado de deformación última de los materiales en la sección crítica}

El criterio II del análisis permite esclarecer aún más sobre el tipo de rotura. Como ya se ha dicho, este criterio se basa en verificar el estado de los materiales en la sección crítica, para el instante de momento máximo total. Por consiguiente, los valores de las deformaciones del acero y del hormigón en la sección crítica obtenidos en el ensayo son comparados con los valores de deformación última de los materiales que se definen a continuación.

\section{Acero}

Para la deformación última del acero se ha fijado un valor límite de 10\% conforme a las disposiciones de la norma española EHE-08. Este valor, además, se encuentra dentro de un rango fiable para la medición de deformaciones del acero con galgas extensiométricas.

\section{Hormigón}

Para definir la deformación última del hormigón, se ha empleado el modelo constitutivo según el Eurocódigo-2 (Ec. 6-3 y Ec. 6-4). En este modelo, la deformación última del hormigón $\left(\varepsilon_{\mathrm{cu}}\right)$ alcanza el valor de $3.5 \%$ para el hormigón convencional $\left(\mathrm{f}_{c} \leq 50 \mathrm{MPa}\right)$; para resistencias del hormigón superiores, la deformación última disminuye hasta $3.0 \%$ y $2.8 \%$ para hormigón de $60 \mathrm{MPa}$ y $90 \mathrm{MPa}$, respectivamente.

$$
\begin{array}{cc}
\varepsilon_{c u}=3.5 \% 0\left(f_{c}<50 M P a\right) & \text { Ec. } 6-3 \\
\varepsilon_{c u}=2.8+27\left[\frac{\left(90-f_{c}\right)}{100}\right]^{4}\left(f_{c} \geq 50 M P a\right) & \text { Ec. } 6-4
\end{array}
$$

\subsubsection{RESULTADOS EXPERIMENTALES DE TIPO DE FALLO}

\subsubsection{Agotamiento por tracción}

En los ensayos experimentales, una vez identificado que el tipo de fallo es por agotamiento aplicando el criterio I, se analiza la distribución de deformaciones en la armadura traccionada $\left(\varepsilon_{\mathrm{s}}\right)$ en las secciones cercanas al "stub", para la situación de momento máximo; si una de las secciones alcanza un valor de deformación $\left(\varepsilon_{\mathrm{s}}\right)$ cercano o superior al 10\%, tal y como se muestra en la Figura 6.3a, el fallo se debe a agotamiento por tracción.

\subsubsection{Agotamiento por compresión}

En los soportes, los esfuerzos de compresión son resistidos por el hormigón y por la armadura superior que está comprimida. Por consiguiente, en la identificación del fallo por agotamiento por compresión es imprescindible analizar la deformación última del acero en compresión y la deformación última del hormigón en el extremo de la fibra más comprimida. 
Para este análisis, las deformaciones del hormigón han sido obtenidas para cada instante de carga de forma indirecta, a partir de los valores medidos de deformación de la armadura longitudinal de tracción y compresión calculados con las bandas extensiométricas, y asumiendo la hipótesis de ley plana de deformaciones. En el caso en el que exista un deterioro del hormigón que anteceda el salto del recubrimiento, la deformación del hormigón obtenida por al procedimiento anteriormente descrito no detecta el efecto de dicho salto y en consecuencia tampoco detecta el posible pandeo de la armadura longitudinal.

En la Figura 6.3b se presenta un ejemplo de la distribución de deformaciones de la armadura para el tipo de fallo de agotamiento por compresión. Como se puede observar, la deformación del acero en armadura de compresión $\left(\varepsilon_{\mathrm{s}}^{\prime}\right)$ para algunas secciones puntualmente localizadas es alta. Sin embargo, es evidente que, cuantitativamente, la deformación en el extremo de la fibra más comprimida ya ha alcanzado y superado la capacidad la deformación última, con la posible consecuencia de la aparición de un continuo deterioro del hormigón en la capa de recubrimiento.

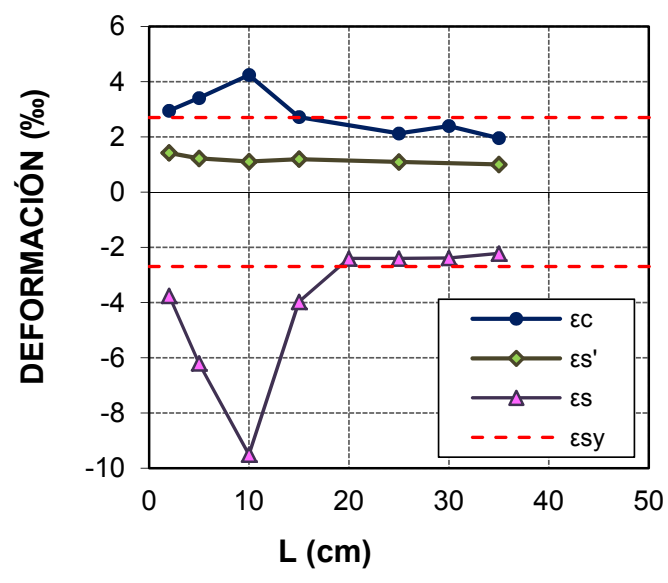

(a)

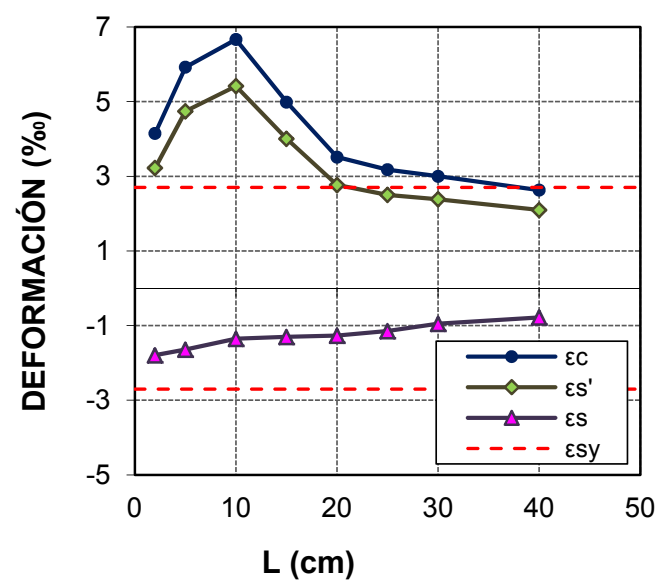

(b)

Figura 6.3 Identificación del tipo de agotamiento en base a la distribución de deformaciones de la armadura: (a) fallo por agotamiento en tracción (N30-10.5-CO-215), (b) fallo por agotamiento en compresión (N30-7.5-CO-2-45)

\subsubsection{Inestabilidad}

Una vez identificado el modo de fallo de inestabilidad, se analiza el estado de deformaciones de los materiales en la zona crítica del soporte para la carga máxima. Se ha observado que se pueden dar tres posibles situaciones:

1. La armadura traccionada y comprimida alcanzan deformaciones prácticamente similares (Figura 6.4a); esta situación de deformación, en este estudio, ha sido definida como "doble pivote", y, en este caso particular, las deformaciones son muy cercanas a la deformación elástica del acero $\left(\varepsilon_{y}=2.7 \%\right)$; en consecuencia, este tipo de elementos presentan un comportamiento poco dúctil. 
2. El valor absoluto de la deformación en la armadura comprimida es mayor que en la armadura traccionada, en este caso la inestabilidad se produce con predominio de la deformación por compresión (Figura 6.4b).

3. Finalmente, si el valor absoluto de la deformación de la armadura de tracción es mayor que la deformación de la armadura de compresión, puede presentarse una importante deformación post-pico, pudiéndose alcanzar una mayor ductilidad, (Figura 6.4c).

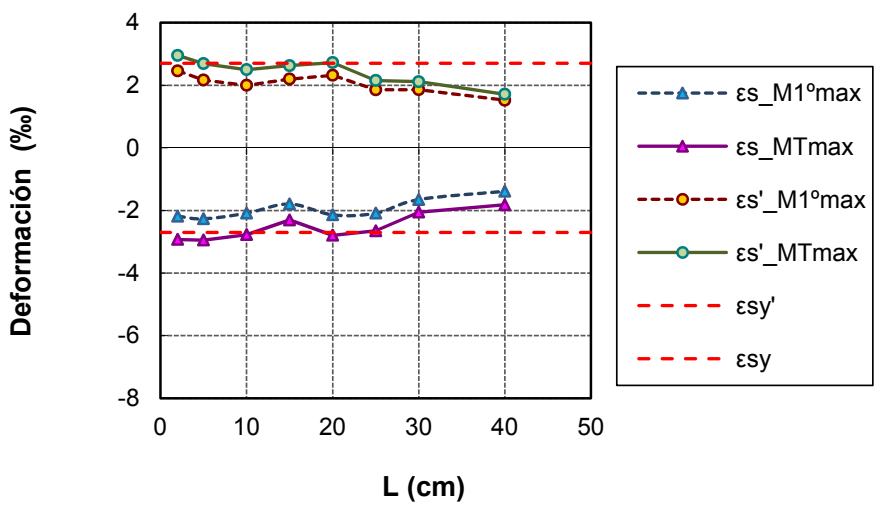

(a)

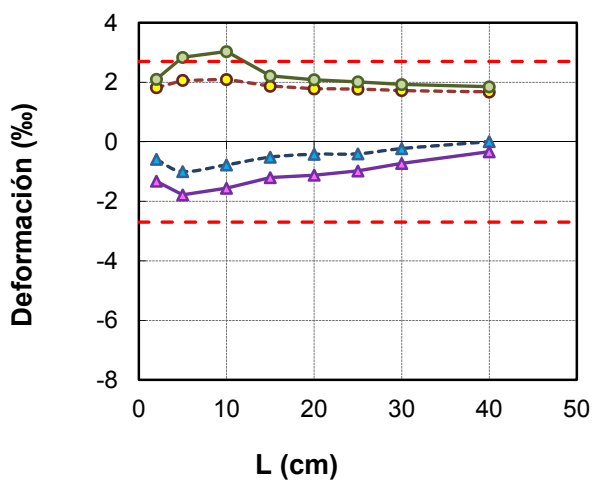

(b)

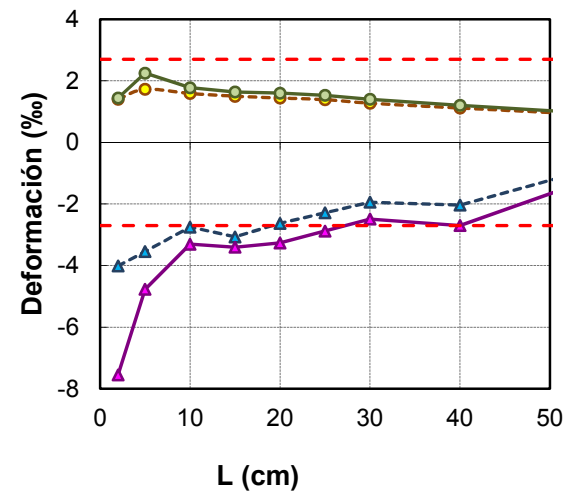

(c)

Figura 6.4 Tipo de fallo por inestabilidad: (a) deformación equivalente en la armadura de tracción y compresión, (b) predominio de deformación en la zona de compresión, (c) predominio de deformación en la zona de tracción

En la Tabla 6-1 se presentan para cada uno de los soportes ensayados los resultados de: el tipo de fallo identificado, las deformaciones de la armadura en compresión $\left(\varepsilon_{\mathrm{s}}\right)$ y en tracción $\left(\varepsilon_{\mathrm{s}}\right)$, y la deformación del hormigón $\left(\varepsilon_{\mathrm{c}}\right)$, para la sección crítica y en el punto de momento máximo. Adicionalmente, en el anejo $F$, se incluyen todos los resultados utilizados en la determinación del modo de fallo, como son: (1) diagramas de respuesta del momento total, momento de primer orden, y momento de segundo orden en función del desplazamiento para la sección crítica; (2) la distribución de deformaciones de la armadura de compresión y tracción, y la distribución de las deformaciones del hormigón en la fibra más comprimida para el instante de momento total máximo, en el caso de elementos que presentan un modo de fallo por agotamiento. En elementos en los que el modo de fallo es la inestabilidad, las distribuciones de deformación se presentan para los instantes de momento total máximo y para el momento máximo de primer orden. 
Tabla 6-1 Resultados de la identificación del tipo de fallo, y deformación de los materiales, en la sección crítica para el instante de momento total máximo

\begin{tabular}{|c|c|c|c|c|c|c|}
\hline \multirow{3}{*}{$\mathbf{N}^{\circ}$} & \multirow{3}{*}{$\begin{array}{l}\text { REFERENCIA } \\
\text { N30-10.5-C0-2-00 }\end{array}$} & \multirow{2}{*}{\multicolumn{2}{|c|}{ Tipo de Fallo }} & \multicolumn{3}{|c|}{ En $\mathbf{M}_{\mathbf{T}_{\text {_max }}}$} \\
\hline & & & & \multirow{2}{*}{$\begin{array}{c}\begin{array}{c}\boldsymbol{\varepsilon}_{\mathbf{s}} \\
(\%)\end{array} \\
-11.58\end{array}$} & \multirow{2}{*}{$\begin{array}{l}\begin{array}{c}\boldsymbol{\varepsilon}_{\mathrm{s}}{ }^{\prime} \\
(\%)\end{array} \\
1.00\end{array}$} & \multirow{2}{*}{$\begin{array}{c}\begin{array}{c}\varepsilon_{\mathrm{c}} \\
(\% \circ)\end{array} \\
4.72 \\
\end{array}$} \\
\hline & & Agotamiento & Tracción & & & \\
\hline 2 & N30-10.5-C0-2-15 & Agotamiento & Tracción & -7.72 & 1.23 & 3.87 \\
\hline 3 & N30-10.5-C0-2-30 & Inestabilidad & Doble pivote & -6.18 & 3.19 & 4.14 \\
\hline 4 & N30-10.5-C0-2-45 & Inestabilidad & Compresión & -0.89 & 2.19 & 3.12 \\
\hline 5 & N30-7.5-C0-2-30 & Agotamiento & Compresión & -4.43 & 3.75 & 5.26 \\
\hline 6 & N30-7.5-C0-2-45 & Agotamiento & Compresión & -1.35 & 5.42 & 6.67 \\
\hline 9 & N30-10.5-C0-1-30 & Agotamiento & Tracción & -11.21 & 2.42 & 6.36 \\
\hline 10 & N30-10.5-C0-1-45 & Agotamiento & Compresión & 0.29 & 2.35 & 2.90 \\
\hline 11 & N30-10.5-C0-3-15 & Agotamiento & Tracción & -4.86 & 1.64 & 3.61 \\
\hline 12 & N30-10.5-C0-3-30 & Agotamiento & Compresión & -1.81 & 3.12 & 4.67 \\
\hline 13 & $\mathrm{H} 60-10$ & Agotamiento & Tracción & -11.17 & 0.19 & 3.55 \\
\hline 14 & H60-10.5-C0-2-15 & Inestabilidad & Tracción & -3.94 & 1.47 & 3.07 \\
\hline 15 & $\mathrm{H} 60-10.5-\mathrm{C} 0-2-30$ & Inestabilidad & Compresión & -1.20 & 2.22 & 3.23 \\
\hline 16 & $\mathrm{H} 60-10.5-\mathrm{C} 0-2-45$ & Inestabilidad & Compresión & 0.06 & 2.23 & 2.87 \\
\hline 17 & $\mathrm{H} 60-7.5-\mathrm{C} 0-2-30$ & Agotamiento & Compresión & -2.56 & 4.49 & 5.79 \\
\hline 18 & $\mathrm{H} 60-$ & Agotamiento & presión & -1.55 & 4.37 & 5.46 \\
\hline 21 & H60-10.5-C0-1-15 & Inestabilidad & Tracción & -4.01 & 1.40 & 2.91 \\
\hline 22 & $\mathrm{H} 60-10.5-\mathrm{C} 0-1-30$ & Inestabilidad & Compresión & -0.62 & 2.00 & 2.72 \\
\hline 23 & $\mathrm{H} 60-10.5-\mathrm{C} 0-3-15$ & Agotamiento & Tracción & -3.76 & 1.66 & 3.36 \\
\hline 24 & $\mathrm{H} 60-10.5-\mathrm{C} 0-3-30$ & Inestabilidad & Compresión & -0.61 & 2.10 & 2.95 \\
\hline 25 & $-\mathrm{C} 0-2-00$ & Agot & Tracción & -11.95 & -0.97 & 2.27 \\
\hline 26 & H90-10.5-C0-2-15 & Inestabilidad & Tracción & -3.72 & 1.95 & 3.50 \\
\hline 27 & H90-10.5-C0-2-30 & Inestabilidad & Compresión & -0.94 & 1.85 & 2.68 \\
\hline 28 & H90-10.5-C0-2-45 & Inestabilidad & Compresión & 0.47 & 2.19 & 2.70 \\
\hline 29 & H90-7.5-C0-2-30 & Agotamiento & Compresión & -2.23 & 4.50 & 5.74 \\
\hline 30 & $\mathrm{H} 90-7.5-\mathrm{C} 0-2-45$ & Agotamiento & Compresión & -0.60 & 5.40 & 6.51 \\
\hline 31 & H90-10.5-C0-1-15 & Inestabilidad & Tracción & -1.52 & 1.77 & 2.74 \\
\hline 32 & H90-10.5-C0-1-30 & Inestabilidad & Compresión & -0.62 & 2.16 & 2.93 \\
\hline 33 & H90-10.5-C0-3-15 & Agotamiento & Tracción & -3.30 & 1.34 & 2.80 \\
\hline 34 & H90-10.5-C0-3-30 & Inestabilidad & Compresión & -1.00 & 2.06 & 3.02 \\
\hline 35 & N30-10.5-C3-2-30 & Inestabilidad & Compresión & -1.63 & 1.98 & 3.10 \\
\hline 36 & N30-10.5-C3-2-45 & Inestabilidad & Compresión & -0.79 & 2.22 & 3.15 \\
\hline 37 & N30-7.5-C3-2-30 & Agotamiento & Compresión & -3.35 & 10.65 & 13.51 \\
\hline 38 & N30-7.5-C3-2-45 & Agotamiento & Compresión & -1.51 & 5.58 & 7.03 \\
\hline 39 & H90-10.5-C3-2-30 & Inestabilidad & Doble pivote & -0.92 & 1.70 & 2.73 \\
\hline 40 & H90-10.5-C3-2-45 & Inestabilidad & Compresión & 0.55 & 2.25 & 2.92 \\
\hline 41 & $\mathrm{H} 90-7.5-\mathrm{C} 3-2-30$ & Agotamiento & Compresión & -1.93 & 3.50 & 4.61 \\
\hline 42 & H90-7.5-C3-2-45 & Agotamiento & Compresión & -0.19 & 5.48 & 6.64 \\
\hline 43 & $\mathrm{H} 90-7.5-\mathrm{C} 2-2-30$ & Agotamiento & Compresión & -2.04 & 3.51 & 4.65 \\
\hline 44 & H90-7.5-C2-2-45 & Agotamiento & Compresión & -0.30 & 5.50 & 6.68 \\
\hline
\end{tabular}

\section{Efecto del nivel de carga axial, esbeltez de cortante y resistencia del hormigón en el modo de fallo}

A continuación se analiza el modo de fallo en relación con los diferentes parámetros de estudio. Se analiza la interacción de los parámetros nivel de carga axial $\left(\mathrm{N} / \mathrm{N}_{\mathrm{u}}\right)$, esbeltez de cortante $\left(\lambda=L_{s} / H\right)$ y resistencia del hormigón $\left(f_{c}\right)$, en el tipo de fallo de los soportes (Tabla 6-2), obteniéndose las siguientes conclusiones: 
- Como cabe esperar, el modo de fallo de agotamiento por tracción ha sido propio de soportes con nulos y bajos niveles de carga axial. Se caracteriza por una deformación excesiva en la armadura en tracción. En consecuencia, este tipo de fallo favorece la ductilidad de curvatura del elemento.

- Para los soportes con esbeltez $\lambda=10.5$, el incremento del nivel de carga axial produce un cambio significativo en el modo de fallo, como se puede observar en la Tabla 6-2, en soportes que pasan de un modo de fallo por agotamiento por tracción a la inestabilidad, con un incremento del $15 \%$ en el $\mathrm{N} / \mathrm{N}_{\mathrm{u}}$. En soportes con moderados y altos niveles de carga axial (30\% y $45 \%$ ), el fallo es en general por inestabilidad, con predominio de deformaciones en compresión.

- Como es de esperar, si la esbeltez es menor, el cambio en el tipo de fallo no es tan brusco. Para los soportes con $\lambda=7.5$ y niveles de carga axial del $30 \%$ y $45 \%$, el fallo siempre se debe al agotamiento por compresión.

- En soportes con $\lambda=10.5$ se muestra que al aumentar la resistencia del hormigón, la deformación de los materiales disminuye, siendo más probable la situación de inestabilidad que de agotamiento. Por otra parte, en soportes con $\lambda=7.5$ el tipo de fallo se muestra indiferente con respecto a la resistencia del hormigón.

Tabla 6-2 Resumen de la influencia de los parámetros $\mathrm{N} / \mathrm{Nu}, \lambda$ y fc en el modo de fallo

\begin{tabular}{|c|c|c|c|c|c|c|}
\hline \multicolumn{3}{|c|}{$\lambda=10.5 ; \rho_{\mathrm{l}}=2 \% ; \rho_{\mathrm{s}}=1 \%$} & \multicolumn{3}{c|}{$\lambda=7.5 ; \rho_{\mathrm{I}}=2 \% ; \rho_{\mathrm{s}}=1 \%$} \\
\hline \multirow{2}{*}{$\mathrm{N} / \mathrm{N}_{\mathrm{U}}$} & \multicolumn{2}{|c|}{ fC (MPa) } & \multicolumn{3}{c|}{ fC (MPa) } \\
\cline { 2 - 7 } & $\mathbf{3 0}$ & $\mathbf{6 0}$ & $\mathbf{9 0}$ & $\mathbf{3 0}$ & $\mathbf{6 0}$ & $\mathbf{9 0}$ \\
\hline 0 & A-T & A-T & A-T & - & - & - \\
\hline 0.15 & A-T & I-T & I-T & - & - & - \\
\hline 0.3 & I-DP & I-C & I-C & A-C & A-C & AC \\
\hline 0.45 & I-C & I-C & I-C & A-C & A-C & A-C \\
\hline
\end{tabular}

\section{Efecto de la cuantía de armadura longitudinal en el modo de fallo}

Se han observado los siguientes aspectos en lo que respecta a la influencia de la cuantía de armadura longitudinal (Tabla 6-3) en el modo de fallo en soportes con $\lambda=10.5$.

- $\quad$ En soportes de hormigón de alta resistencia (60 MPa y $90 \mathrm{MPa}$ ) y niveles de carga axial de $30 \%$, no se produce ninguna modificación en el modo de fallo cuando se incrementa la cuantía de armadura. Si el nivel de carga axil disminuye hasta el $15 \%$, se observa que un incremento de la cuantía de armadura del $2.2 \%$ al $3.2 \%$ modifica el comportamiento del soporte, ya que pasa de un fallo por inestabilidad a un fallo por agotamiento en tracción.

- $\quad$ En soportes de hormigón convencional (30 MPa) y niveles bajos de $N / N_{u}$ $(15 \%)$, el fallo que se produce es de agotamiento por tracción, y es indiferente con $\rho_{\text {I. }}$. Por otra parte, si $\mathrm{N} / \mathrm{N}_{\mathrm{u}}$ aumenta hasta un $30 \%$, y se incrementa la cuantía de armadura longitudinal, se modifica el modo de fallo cambiando de inestable a agotamiento por compresión. 


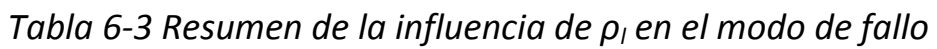

\begin{tabular}{|c|c|c|c|c|c|c|c|}
\cline { 2 - 8 } \multicolumn{1}{c|}{} & \multicolumn{6}{c|}{$\lambda=10.5 ; \rho_{\mathrm{s}}=1 \%$} \\
\hline \multicolumn{2}{|c|}{$\mathbf{f}_{\mathrm{c}}$} & \multicolumn{2}{c|}{$30 \mathrm{MPa}$} & \multicolumn{2}{c|}{$60 \mathrm{MPa}$} & \multicolumn{2}{c|}{$90 \mathrm{MPa}$} \\
\hline \multicolumn{2}{|c|}{$\mathrm{N} / \mathrm{N}_{\mathrm{U}}$} & $\mathbf{0 . 1 5}$ & $\mathbf{0 . 3}$ & $\mathbf{0 . 1 5}$ & $\mathbf{0 . 3}$ & $\mathbf{0 . 1 5}$ & $\mathbf{0 . 3}$ \\
\hline \multirow{2}{*}{$\begin{array}{c}\rho_{\mathrm{I}} \\
(\%)\end{array}$} & 1.4 & - & I-T & I-T & I-C & I-T & I-C \\
\cline { 2 - 9 } & 2.2 & A-T & I-DP & I-T & I-C & I-T & I-C \\
\cline { 2 - 9 } & 3.2 & A-T & A-C & A-T & I-C & A-T & I-C \\
\hline
\end{tabular}

\section{Efecto de la cuantía de armadura transversal en el modo de fallo}

En soportes con $\lambda=7.5$ no se aprecia ninguna influencia de la cuantía de armadura transversal en el tipo de fallo (Tabla 6-4); para dicha esbeltez, todos los soportes presentan un modo de fallo por agotamiento en compresión. Igualmente, en soportes con $\lambda=10.5$, el efecto de la cuantía de armadura transversal no es visible, y todos los soportes fallan por inestabilidad.

Tabla 6-4 Resumen de la influencia de $\rho_{s}$ en el modo de fallo

\begin{tabular}{|c|c|c|c|c|c|c|c|c|c|}
\hline \multirow{2}{*}{\multicolumn{2}{|c|}{10}} & \multicolumn{4}{|c|}{$\lambda=7.5 ; \rho_{1}=2 \%$} & \multicolumn{4}{|c|}{$\lambda=10.5 ; \rho_{1}=2 \%$} \\
\hline & & \multicolumn{2}{|c|}{$30 \mathrm{MPa}$} & \multicolumn{2}{|c|}{$90 \mathrm{MPa}$} & \multicolumn{2}{|c|}{$30 \mathrm{MPa}$} & \multicolumn{2}{|c|}{$90 \mathrm{MPa}$} \\
\hline \multicolumn{2}{|c|}{$\mathrm{N} / \mathrm{N}_{U}$} & 0.3 & 0.45 & 0.3 & 0.45 & 0.3 & 0.45 & 0.3 & 0.45 \\
\hline \multirow{3}{*}{$\begin{array}{c}\rho_{\mathrm{s}} \\
(\%)\end{array}$} & 1 & $A-C$ & $A-C$ & $A-C$ & $\mathrm{~A}-\mathrm{C}$ & I-DP & $\mathrm{I}-\mathrm{C}$ & $\mathrm{I}-\mathrm{C}$ & $\mathrm{I}-\mathrm{C}$ \\
\hline & 2 & - & - & $A-C$ & $A-C$ & - & - & - & - \\
\hline & 3 & $A-C$ & $A-C$ & $A-C$ & $A-C$ & I-C & I-C & I-DP & $\mathrm{I}-\mathrm{C}$ \\
\hline
\end{tabular}

\subsection{COMPARACIÓN DEL MOMENTO MÁXIMO EXPERIMENTAL Y TEÓRICO}

En esta sección se realiza una comparación de los momentos máximos totales obtenidos experimentalmente y los calculados teóricamente. El momento máximo experimental en cada uno de los ensayos ha sido medido en la sección crítica, situada a $5 \mathrm{~cm}$ de la cara del "stub" (apartado 5.2.2), sobre la cual se ha obtenido la respuesta momento-curvatura. Los momentos teóricos (Tabla 6-6) han sido calculados mediante los métodos simplificados descritos en las normas EHE-08 (2008) [53], Eurocódigo 2 (2004) [58] y ACI 318-08 (2008) [1].

\subsubsection{DESCRIPCIÓN DE LOS MÉTODOS IMPLEMENTADOS PARA EL CÁLCULO DEL MOMENTO TEÓRICO}

Se han calculado dos valores de momento máximo para la sección, correspondientes a cada uno de los diagramas de tensión-deformación que señala la EHE-08 (2008) [53], como son el bloque rectangular (EHE_BR), y el diagrama parábola rectángulo (EHE_PR), ver Figuras 6.5. Las ecuaciones que definen los dos modelos para el hormigón en compresión son descritas en el apartado 39.5 de la norma EHE-08 (2008) [53]. Se han tomado los coeficientes de seguridad de los materiales igual a la unidad. 


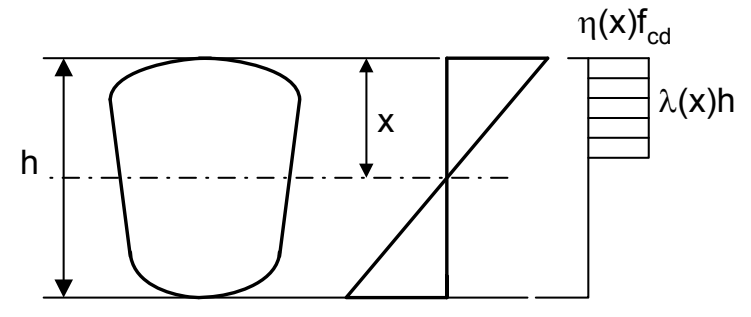

(a)

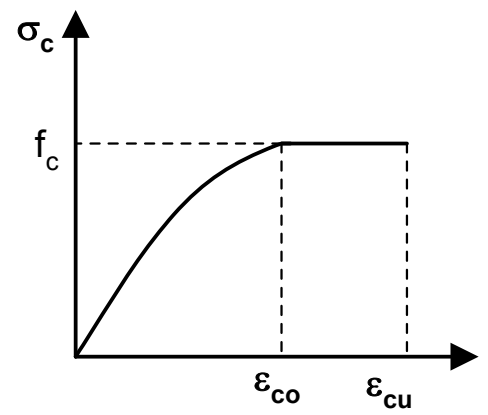

(b)

Figura 6.5 Diagrama de cálculo para el hormigón en compresión, según la EHE-08 (2008) [53]. (a) bloque rectangular y (b) parábola rectángulo

En el caso del Eurocódigo 2 (2004) [58], se ha aplicado el diagrama parábola rectángulo para el hormigón en compresión (EC2_PR).

El método simplificado del ACl-318 (2008) [1] ha sido aplicado de dos formas. En la primera de ellas, los momentos teóricos han sido calculados utilizando el método en su versión original, donde se propone un diagrama rectangular equivalente para el hormigón, cuya resistencia es reducida por un factor de 0.85 y la profundidad del bloque rectangular se obtiene como producto de la fibra neutra (c) y un factor $\beta 1$ dependiente de la resistencia del hormigón (Figura 6.6). En la segunda forma del método, puesto que los ensayos analizados se corresponden con una situación de aplicación de carga de forma instantánea, los momentos teóricos se han obtenido sin tener en cuenta el factor de reducción 0.85 de la resistencia del hormigón $(\beta 1=1)$.
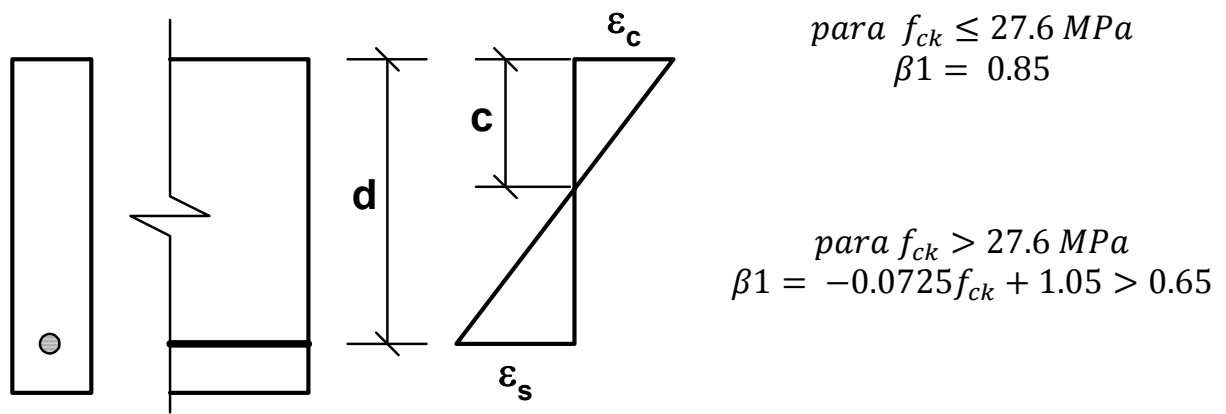

Ec. 6-5

Ec. 6-6

Figura 6.6 Diagrama Rectangular para el hormigón en compresión ACI-318-08

Tabla 6-5 Métodos implementados para el cálculo del momento teórico

\begin{tabular}{|c|c|c|}
\hline Nomenclatura & Norma & Descripción \\
\hline EHE_BR & EHE-08 & Bloque rectangular \\
\hline EHE_PR & EHE-08 & Parábola Rectángulo \\
\hline EC2_PR & Eurocódigo2 (2004) & Parábola Rectángulo \\
\hline ACl & ACl- 318-08 & Bloque rectangular \\
\hline ACl_s & ACl- 318-08 & Bloque rectangular \\
\hline
\end{tabular}




\subsubsection{RESULTADOS DEL MOMENTO MÁXIMO EXPERIMENTAL Y TEÓRICO}

En la Tabla 6-6 se presentan los valores experimentales del momento máximo $\left(\mathrm{M}_{\mathrm{m} \_ \text {exp }}\right)$, así como también los valores de los momentos teóricos $\left(\mathrm{M}_{\mathrm{m} \_ \text {cal }}\right)$ calculados mediante los diferentes métodos. La comparación se realiza para 40 ensayos experimentales. Se han descartado los ensayos 7, 8, 19 y 20 de esbeltez de cortante 15 puesto que no se alcanzó experimentalmente la situación de agotamiento.

Tabla 6-6 Resultados del momento máximo experimental y teórico

\begin{tabular}{|c|c|c|c|c|c|c|c|}
\hline \multirow{2}{*}{$\mathbf{N}^{\circ}$} & \multirow{2}{*}{ REFERENCIA } & \multirow{2}{*}{$\begin{array}{l}M_{m \exp } \\
(\mathrm{kN} \cdot \mathrm{m})\end{array}$} & \multicolumn{5}{|c|}{$M_{m \_c a l}(k N \cdot m)$} \\
\hline & & & EHE_BR & EHE_PR & EC2_PR & $\mathrm{ACl}$ & ACl_s \\
\hline 1 & N30-10.5-C0-2-00 & 12,36 & 12,89 & 12,84 & 12,86 & 12,69 & 12,89 \\
\hline 2 & N30-10.5-C0-2-15 & 17,56 & 18,09 & 18,00 & 18,00 & 17,48 & 17,95 \\
\hline 3 & N30-10.5-C0-2-30 & 22,12 & 20,79 & 20,66 & 20,66 & 17,58 & 19,68 \\
\hline 4 & N30-10.5-C0-2-45 & 21,61 & 20,84 & 20,60 & 20,60 & 17,16 & 19,68 \\
\hline 5 & N30-7.5-C0-2-30 & 49,34 & 47,94 & 47,63 & 47,63 & 40,47 & 45,05 \\
\hline 6 & N30-7.5-C0-2-45 & 45,89 & 46,61 & 46,17 & 46,17 & 38,39 & 43,85 \\
\hline 9 & N30-10.5-C0-1-30 & 18,35 & 18,85 & 18,70 & 18,70 & 17,89 & 18,78 \\
\hline 10 & N30-10.5-C0-1-45 & 17,99 & 17,73 & 17,36 & 17,36 & 14,15 & 17,00 \\
\hline 11 & N30-10.5-C0-3-15 & 22,75 & 23,43 & 23,30 & 23,30 & 22,61 & 23,20 \\
\hline 12 & N30-10.5-C0-3-30 & 24,50 & 23,11 & 22,97 & 22,97 & 19,48 & 21,66 \\
\hline 13 & $\mathrm{H} 60-10.5-\mathrm{C} 0-2-00$ & 12,45 & 13,69 & 13,55 & 13,67 & 13,39 & 13,66 \\
\hline 14 & $\mathrm{H} 60-10.5-\mathrm{C} 0-2-15$ & 24,54 & 22,90 & 22,80 & 22,78 & 22,39 & 23,04 \\
\hline 15 & $\mathrm{H} 60-10.5-\mathrm{C} 0-2-30$ & 28,05 & 28,04 & 27,52 & 26,94 & 24,78 & 27,72 \\
\hline 16 & $\mathrm{H} 60-10.5-\mathrm{C} 0-2-45$ & 35,72 & 27,85 & 27,26 & 26,61 & 25,22 & 29,15 \\
\hline 17 & $\mathrm{H} 60-7.5-\mathrm{CO}-2-30$ & 64,93 & 63,31 & 62,04 & 60,51 & 57,06 & 63,74 \\
\hline 18 & $\mathrm{H} 60-7.5-\mathrm{C} 0-2-45$ & 74,35 & 62,49 & 61,23 & 59,72 & 58,28 & 66,65 \\
\hline 21 & $\mathrm{H} 60-10.5-\mathrm{C} 0-1-15$ & 20,30 & 19,63 & 19,55 & 19,53 & 19,22 & 19,83 \\
\hline 22 & $\mathrm{H} 60-10.5-\mathrm{C} 0-1-30$ & 27,34 & 24,94 & 24,51 & 24,12 & 21,85 & 24,42 \\
\hline 23 & $\mathrm{H} 60-10.5-\mathrm{C} 0-3-15$ & 29,02 & 28,70 & 28,59 & 28,53 & 27,70 & 29,06 \\
\hline 24 & $\mathrm{H} 60-10.5-\mathrm{C} 0-3-30$ & 35,19 & 31,13 & 30,53 & 29,81 & 27,78 & 31,07 \\
\hline 25 & $\mathrm{H} 90-10.5-\mathrm{C} 0-2-00$ & 14,49 & 14,08 & 13,96 & 14,16 & 14,08 & 14,37 \\
\hline 26 & H90-10.5-C0-2-15 & 28,73 & 28,88 & 29,19 & 29,11 & 29,39 & 30,31 \\
\hline 27 & $\mathrm{H} 90-10.5-\mathrm{C} 0-2-30$ & 36,93 & 31,60 & 32,82 & 32,45 & 33,44 & 37,38 \\
\hline 28 & $\mathrm{H} 90-10.5-\mathrm{C} 0-2-45$ & 39,00 & 30,61 & 32,99 & 32,39 & 34,14 & 39,79 \\
\hline 29 & $\mathrm{H} 90-7.5-\mathrm{C} 0-2-30$ & 80,76 & 70,22 & 76,28 & 75,39 & 78,85 & 87,77 \\
\hline 30 & $\mathrm{H} 90-7.5-\mathrm{C} 0-2-45$ & 79,73 & 66,92 & 72,01 & 70,83 & 74,59 & 85,93 \\
\hline 31 & $\mathrm{H} 90-10.5-\mathrm{C} 0-1-15$ & 24,81 & 24,49 & 24,74 & 24,68 & 24,87 & 25,65 \\
\hline 32 & $\mathrm{H} 90-10.5-\mathrm{C} 0-1-30$ & 36,77 & 30,00 & 31,88 & 31,51 & 32,51 & 36,06 \\
\hline 33 & H90-10.5-C0-3-15 & 36,66 & 33,53 & 33,98 & 33,88 & 34,27 & 35,33 \\
\hline 34 & $\mathrm{H} 90-10.5-\mathrm{C} 0-3-30$ & 41,17 & 34,30 & 36,32 & 35,88 & 37,37 & 41,83 \\
\hline 35 & N30-10.5-C3-2-30 & 21,46 & 22,60 & 22,39 & 22,39 & 19,30 & 21,51 \\
\hline 36 & N30-10.5-C3-2-45 & 22,05 & 19,58 & 19,32 & 19,32 & 16,15 & 18,60 \\
\hline 37 & N30-7.5-C3-2-30 & 46,45 & 49,04 & 48,63 & 48,63 & 42,48 & 47,27 \\
\hline 38 & N30-7.5-C3-2-45 & 45,67 & 46,87 & 46,40 & 46,40 & 38,42 & 43,88 \\
\hline 39 & H90-10.5-C3-2-30 & 39,92 & 31,09 & 32,71 & 32,32 & 33,37 & 37,23 \\
\hline 40 & $\mathrm{H} 90-10.5-\mathrm{C} 3-2-45$ & 36,14 & 29,99 & 32,07 & 31,50 & 33,08 & 38,59 \\
\hline 41 & H90-7.5-C3-2-30 & 78,52 & 66,64 & 68,24 & 67,44 & 69,43 & 77,80 \\
\hline 42 & H90-7.5-C3-2-45 & 72,35 & 59,05 & 59,09 & 57,62 & 59,51 & 71,51 \\
\hline 43 & $\mathrm{H} 90-7.5-\mathrm{C} 2-2-30$ & 77,63 & 68,30 & 72,69 & 71,82 & 74,70 & 83,29 \\
\hline 44 & H90-7.5-C2-2-45 & 70,42 & 63,78 & 67,21 & 66,06 & 69,31 & 80,91 \\
\hline
\end{tabular}



hormigón armado

En la Tabla 6-7 y en las Figuras 6.7 se muestran los resultados del análisis estadístico llevado a cabo para comprobar la aproximación entre los resultados experimentales y teóricos para los momentos máximos totales calculados mediante los métodos simplificados descritos en las diferentes nomas. El grado de precisión (E) se ha obtenido como el cociente entre el momento máximo experimental $\left(\mathrm{M}_{\mathrm{m}_{-} \exp }\right)$ y el teórico $\left(\mathrm{M}_{\mathrm{m}_{-} \text {cal }}\right)$. Si este cociente es mayor a la unidad se está del lado de la seguridad.

Las variables estadísticas analizadas son: el error medio $(\bar{E})$, el coeficiente de variación (CV), el percentil del $95 \% \quad\left(P_{95 \%}\right)$ y el percentil del $5 \% \quad\left(P_{5 \%}\right)$. Adicionalmente, se ha realizado un estudio de frecuencias del error $\left(\mathrm{M}_{\mathrm{m}_{-} \text {exp }} / \mathrm{M}_{\mathrm{m}_{\text {_cal }}}\right)$, con el propósito de evaluar la aproximación y dispersión de cada uno de los métodos simplificados con respecto a los resultados experimentales.

Tabla 6-7 Resultados estadísticos del error $\left(M_{m_{-}}\right.$exp $\left./ M_{m_{-} \text {cal }}\right)$

\begin{tabular}{|c|c|c|c|c|c|}
\hline & EHE_BR & EHE_PR & EC2_PR & ACl & ACI_s \\
\hline$\overline{\mathbf{E}}$ & 1.08 & 1.07 & 1.08 & 1.13 & 1.02 \\
\hline $\mathbf{C V}$ (\%) & 9.61 & 8.18 & 8.88 & 10.06 & 7.58 \\
\hline $\mathbf{P}_{95 \%}$ & 1.27 & 1.22 & 1.25 & 1.28 & 1.14 \\
\hline $\mathbf{P}_{5 \%}$ & 0.95 & 0.96 & 0.96 & 0.98 & 0.92 \\
\hline
\end{tabular}

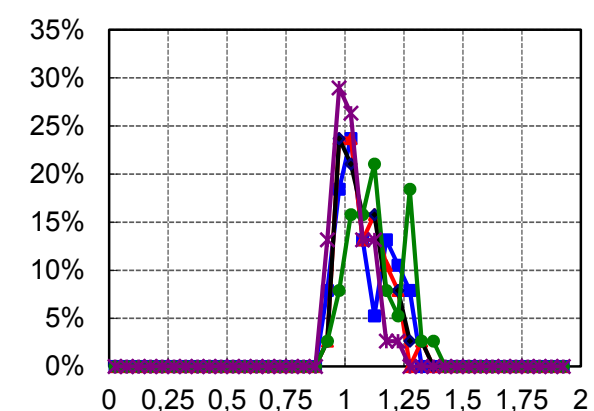

Rango

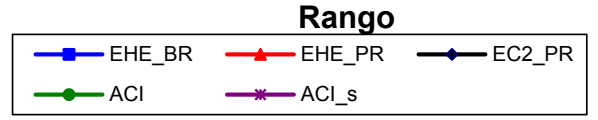

(a)

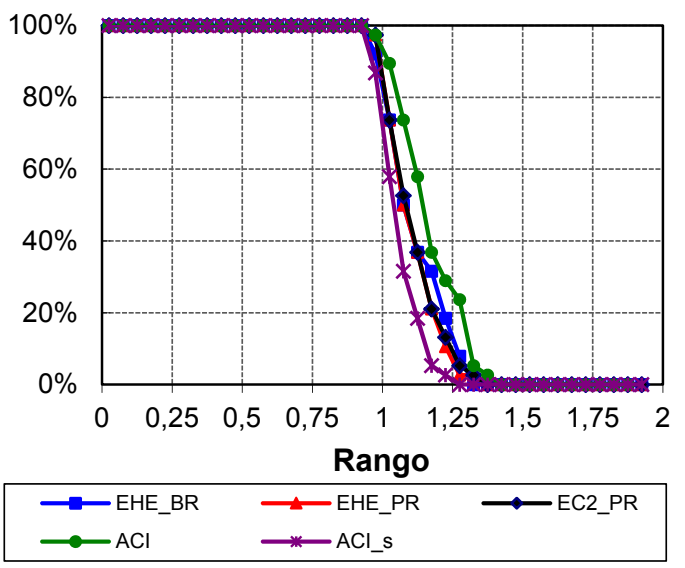

(b)

Figura 6.7 Análisis de dispersión del error mediante: (a) distribución de frecuencias, (b) frecuencias acumuladas

A partir de los resultados de las variables estadísticas que se muestran en la Tabla 6-7 y del análisis de frecuencias (Figuras 6.7) se obtienen las siguientes conclusiones:

- Todos los métodos, en general, predicen con bastante aproximación los valores de momento máximo.

- En el caso del método de la norma EHE-08, existe una mejor aproximación cuando se utiliza el diagrama parábola rectángulo que el bloque rectangular.

- Los resultados de $\mathrm{M}_{\mathrm{m} \text { cal }}$ obtenidos con el método de la EHE-PR y el método del EC2_PR, son similares.

- $\quad$ El método que tiene una mejor aproximación es el propuesto por el $\mathrm{ACl}$ 318 (2008) [1] pero tomando $\beta_{1}=1$ (ACl_s); el error medio es de $\bar{E}=1.02$ y 
el coeficiente de variación de $7,58 \%$, además, tal y como se puede ver en el análisis estadístico de la distribución y la frecuencia acumulada, el método del ACl_s es el que presenta un mejor comportamiento respecto a la dispersión de datos. Sin embargo, hay que tener en cuenta que, si se considera el coeficiente de reducción de resistencia del hormigón de 0.85 contemplado en la norma ACl-318-08 [1], la aplicación de esta normativa se encuentra bastante más del lado de la seguridad $(\bar{E}=1.13)$ y presenta una mayor dispersión (CV=10\%).

En las Figuras 6.8 se muestra gráficamente la comparación de los resultados experimentales y teóricos calculados con los diferentes métodos implementados.

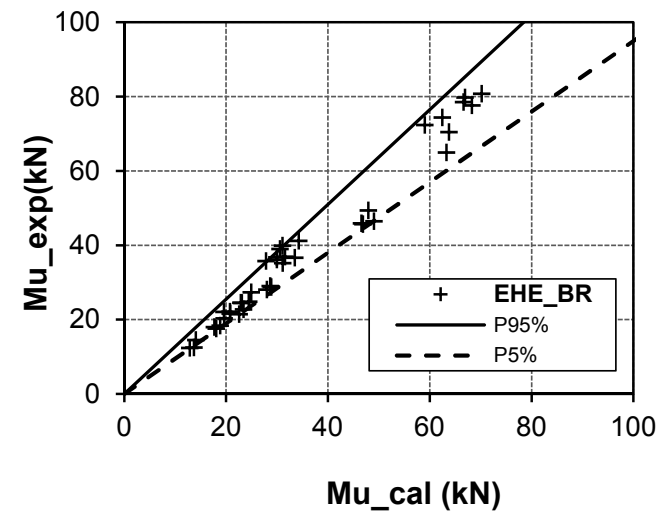

(a)

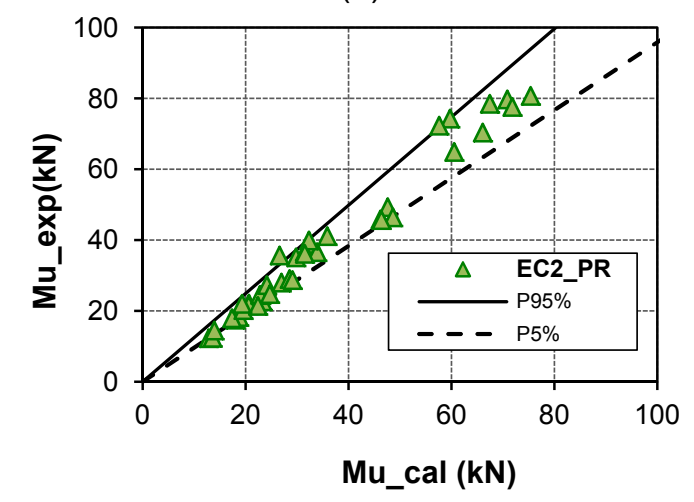

(c)

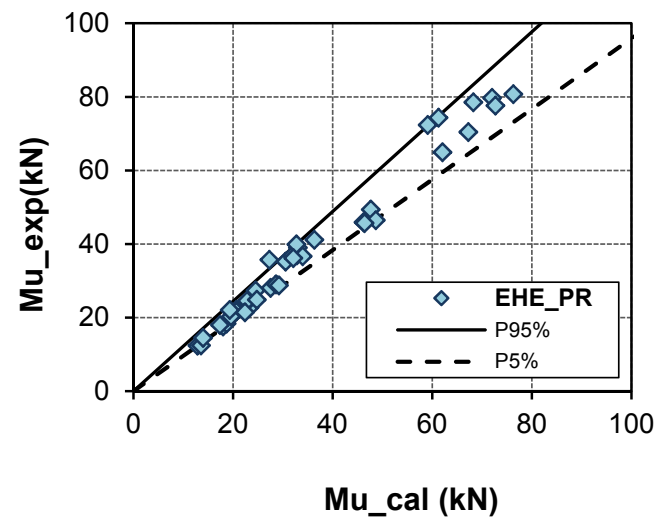

(b)

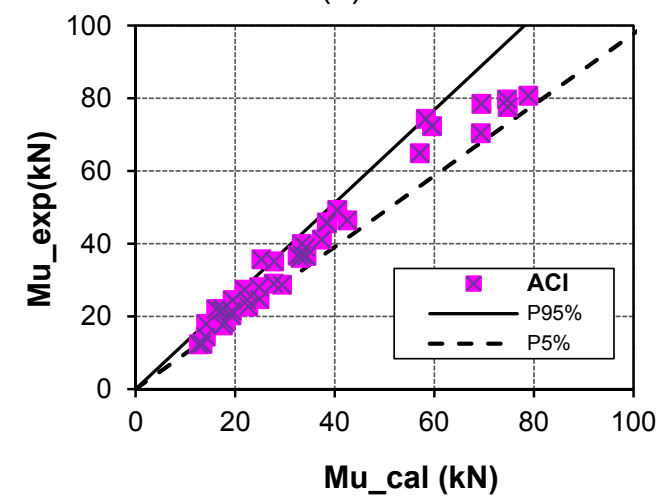

(d)

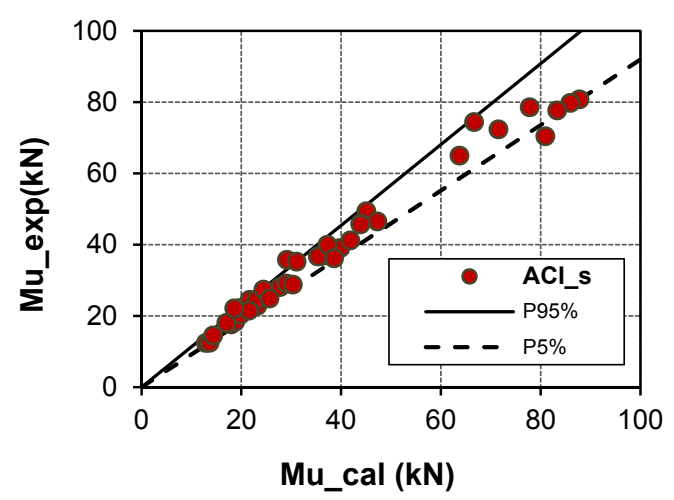

(e)

Figura 6.8 Comparación entre el $M_{m_{-} \text {exp }}$ y el $M_{m_{-} \text {cal }}$ obtenido mediante los métodos:(a) $E H E_{-} B R$, (b)EHE_PR, (c) EC2_PR, (d) $A C l$ (e) $A C l \_s$ 


\subsubsection{COMPARACIÓN ENTRE EL MOMENTO MÁXIMO EXPERIMENTAL Y EL TEÓRICO RESPECTO A LOS PARÁMETROS ANALIZADOS}

En esta sección se pretende determinar si el grado de precisión de los métodos utilizados para calcular los momentos máximos teóricos es dependiente de los parámetros y rangos incluidos en el programa experimental. Para lo cual se ha realizado un análisis de $\overline{\mathrm{E}}$ y $\mathrm{CV}$ con respecto a los parámetros de resistencia del hormigón, nivel de carga axil, esbeltez de cortante, cuantía de armadura longitudinal, y cuantía de armadura transversal.

Tabla 6-8 Resumen de las variables $\bar{E}$ y CV con respecto a los parámetros de estudio, para cada uno de los métodos implementados en el cálculo de $M_{m_{-} \text {cal }}$

\begin{tabular}{|c|c|c|c|c|c|c|c|c|c|c|c|}
\hline \multirow{2}{*}{\multicolumn{2}{|c|}{ Variable }} & \multicolumn{2}{|c|}{ EHE_BR } & \multicolumn{2}{|c|}{ EHE_PR } & \multicolumn{2}{|c|}{ EC2_PR } & \multicolumn{2}{|c|}{$\mathrm{ACl}$} & \multicolumn{2}{|c|}{ ACl_s } \\
\hline & & $\overline{\mathbf{E}}$ & CV & $\overline{\mathbf{E}}$ & CV & $\overline{\mathbf{E}}$ & CV & $\overline{\mathbf{E}}$ & CV & $\overline{\mathbf{E}}$ & CV \\
\hline \multirow{3}{*}{$\begin{array}{c}\text { Fc } \\
(\mathrm{MPa})\end{array}$} & 30 & 1.06 & $5.0 \%$ & 1.06 & $5.2 \%$ & 1.07 & $5.1 \%$ & 1.13 & $10.9 \%$ & 1.03 & $6.9 \%$ \\
\hline & 60 & 1.08 & $9.9 \%$ & 1.09 & $10.3 \%$ & 1.11 & $11.1 \%$ & 1.16 & $12.2 \%$ & 1.06 & $8.3 \%$ \\
\hline & 90 & 1.15 & $7.6 \%$ & 1.11 & $6.5 \%$ & 1.12 & $6.9 \%$ & 1.08 & $6.4 \%$ & 0.98 & $5.3 \%$ \\
\hline \multirow{4}{*}{$\mathrm{N} / \mathrm{Nu}$} & 0.00 & 0.97 & $6.2 \%$ & 0.97 & $6.2 \%$ & 0.97 & $6.3 \%$ & 0.98 & $5.1 \%$ & 0.96 & $5.1 \%$ \\
\hline & 0.15 & 1.01 & $4.4 \%$ & 1.01 & $4.1 \%$ & 1.02 & $4.1 \%$ & 1.03 & $3.8 \%$ & 1.00 & $3.8 \%$ \\
\hline & 0.30 & 1.10 & $8.9 \%$ & 1.08 & $6.7 \%$ & 1.09 & $7.1 \%$ & 1.15 & $6.8 \%$ & 1.03 & $6.8 \%$ \\
\hline & 0.45 & 1.13 & $9.7 \%$ & 1.12 & $9.0 \%$ & 1.13 & $9.9 \%$ & 1.21 & $9.8 \%$ & 1.04 & $10.1 \%$ \\
\hline \multirow{2}{*}{$\lambda$} & 7.5 & 1.09 & $8.9 \%$ & 1.07 & $8.0 \%$ & 1.09 & $8.8 \%$ & 1.13 & $7.6 \%$ & 1.00 & $7.4 \%$ \\
\hline & 10.5 & 1.08 & $10.0 \%$ & 1.07 & $8.4 \%$ & 1.08 & $9.1 \%$ & 1.13 & $11.1 \%$ & 1.03 & $7.5 \%$ \\
\hline \multirow{3}{*}{$\begin{array}{c}\text { pl } \\
(\%)\end{array}$} & 1.4 & 1.06 & $8.6 \%$ & 1.05 & $6.3 \%$ & 1.06 & $6.9 \%$ & 1.12 & $10.4 \%$ & 1.03 & $5.4 \%$ \\
\hline & 2.2 & 1.09 & $10.4 \%$ & 1.07 & $9.0 \%$ & 1.08 & $9.7 \%$ & 1.13 & $10.4 \%$ & 1.02 & $8.2 \%$ \\
\hline & 3.2 & 1.08 & $7.7 \%$ & 1.07 & $6.3 \%$ & 1.08 & $7.1 \%$ & 1.12 & $9.8 \%$ & 1.04 & $6.8 \%$ \\
\hline \multirow{3}{*}{$\begin{array}{c}\rho s \\
(\%)\end{array}$} & 1.0 & 1.07 & $9.2 \%$ & 1.06 & $7.9 \%$ & 1.07 & $8.6 \%$ & 1.12 & $10.5 \%$ & 1.03 & $7.3 \%$ \\
\hline & 2.0 & 1.12 & $2.1 \%$ & 1.06 & $1.4 \%$ & 1.07 & $1.0 \%$ & 1.03 & $1.6 \%$ & 0.90 & $4.8 \%$ \\
\hline & 3.0 & 1.11 & $12.2 \%$ & 1.10 & $10.3 \%$ & 1.11 & $11.1 \%$ & 1.17 & $7.8 \%$ & 1.03 & $7.2 \%$ \\
\hline
\end{tabular}

Respecto a la resistencia del hormigón. No existe una variación clara de los resultados con respecto a este parámetro; es decir, todos los métodos mantienen la misma fiabilidad para los rangos de resistencia propuestos en este estudio. Sin embargo, los métodos EHE_BR, EHE_PR y EC2_PR son más seguros a medida que aumenta la resistencia del hormigón. La norma ACl-318 (ACl y ACl_s) presenta una disminución del error medio a medida que aumenta la resistencia del hormigón.

Respecto al nivel de carga Axial. Este parámetro presenta algunas variaciones evidentes en los resultados. En todos los métodos se aprecia un leve incremento del error y el CV conforme aumenta el nivel de carga axial.

Respecto a la esbeltez de cortante. Aunque no se aprecia un cambio en el error medio respecto a este parámetro, sí que se muestra un leve incremento en el coeficiente de variación cuando aumenta la esbeltez de un valor de 7.5 a un valor de 10.5 .

Respecto a la cuantía de armadura longitudinal. No existe una clara variación de los resultados con respecto a esta variable. 
Respecto a la cuantía de armadura transversal. Los resultados muestran una buena aproximación de esta variable, aunque en los métodos no se ha tenido en cuenta el efecto del confinamiento. Esto significa que el confinamiento no afecta la resistencia máxima de la sección.

\subsection{COMPARACIÓN DE LA CARGA MÁXIMA EXPERIMENTAL Y TEÓRICA}

Se ha realizado una comparación entre los valores de carga máxima obtenidos en los ensayos y los valores de carga calculados mediante algunos de los métodos simplificados especificados en las normas: EHE-08 (2008) [53], Eurocódigo 2 (2004) [58] y ACl 318-08 (2008) [1].

\subsubsection{DESCRIPCIÓN DE LOS MÉTODOS IMPLEMENTADOS PARA EL CÁLCULO DE LA CARGA MÁXIMA TEÓRICA}

Para la evaluación de la carga máxima teórica se han aplicado distintos métodos simplificados que consideran los efectos de segundo orden en soportes esbeltos. Las normas en general se refieren a dos posibles métodos; por una parte, en la norma ACl-318 08 (2008) [1] y Eurocódigo 2 (2004) [58] se propone el método de amplificación de momentos, y por otra parte, la norma EHE 08 (2008) [53] y el Eurocódigo 2 (2004) [58] sugieren el método de la excentricidad adicional

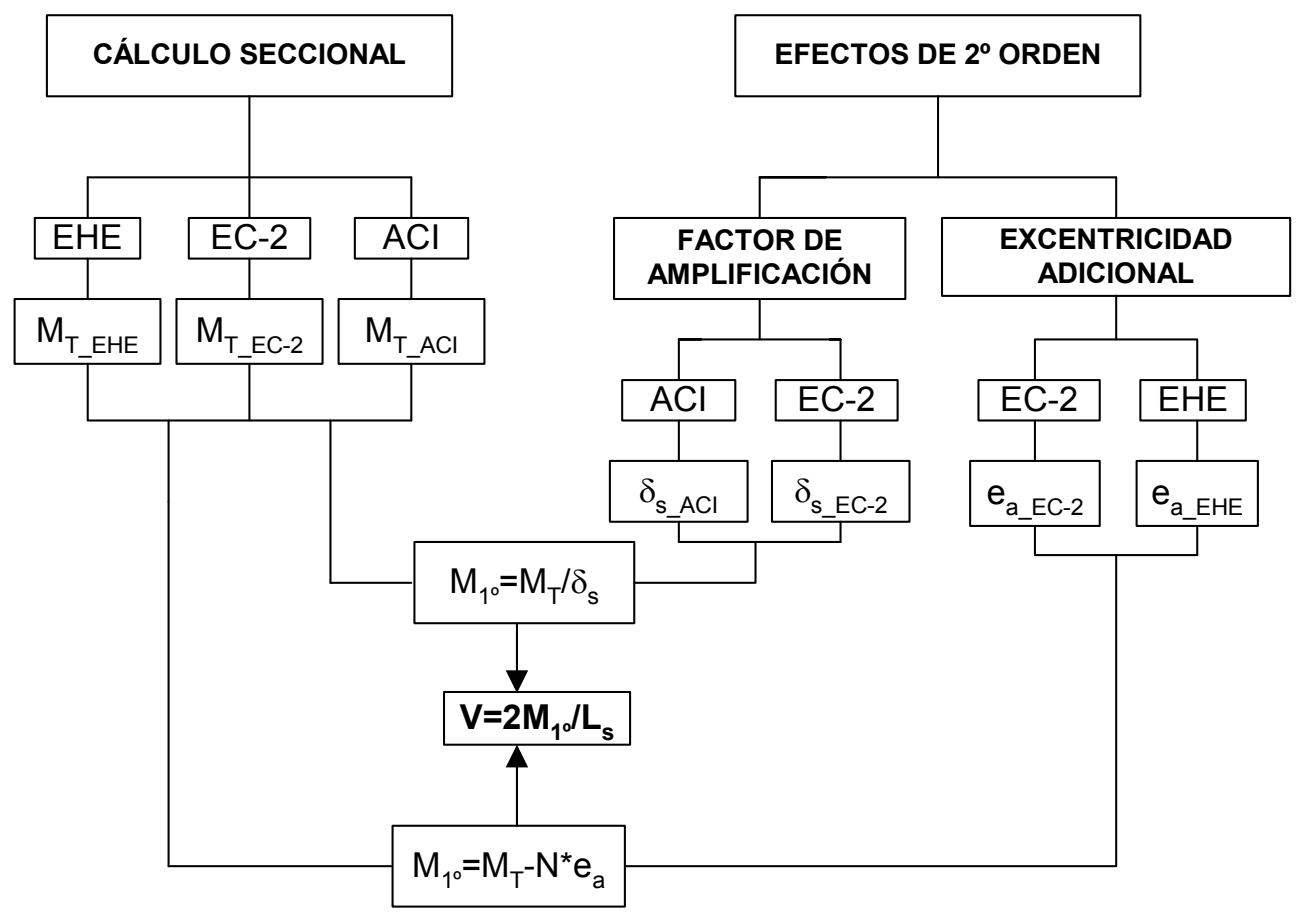

Figura 6.9 Esquema del proceso de cálculo para la carga teórica

El proceso de cálculo desarrollado para evaluar la carga máxima teórica consiste en: (1) evaluar mediante el cálculo seccional el momento flector máximo para una carga axial dada; (2) evaluar los efectos de segundo, es decir el factor de 
amplificación de momentos o la excentricidad adicional; (3) a partir del paso (1) y (2), se obtiene el momento de primer orden; y por último (4), la carga máxima teórica es obtenida a partir de la ley de momentos (tal y como se describe en la Figura 6.9).

En este estudio se han implementado seis posibles formas de obtener la carga máxima teórica, a partir de la combinación de los métodos para el cálculo seccional y para el cálculo de los efectos de segundo orden. En la Tabla 6-9 se lleva a cabo una descripción de la nomenclatura y de los métodos aplicados en el análisis seccional y en el cálculo de los efectos de segundo orden utilizados en la estimación de la carga máxima teórica.

El método del $\mathrm{ACl}$ 318-08 ha sido aplicado de dos formas, en una de ellas (AClsEls) la rigidez del soporte tiene la forma $E I=\alpha^{*} E_{c} I_{c}$, mientras que en el método (ACl-cEls) la rigidez se considera como $E I=\alpha E_{c} I_{c}+E_{s} I_{s}$.

Tabla 6-9 Descripción de los métodos utilizados en el cálculo de la carga máxima teórica

\begin{tabular}{|c|c|c|c|}
\hline $\begin{array}{l}\text { Nomenclatura } \\
\text { del Método } \\
\text { empleado }\end{array}$ & Norma & $\begin{array}{l}\text { Modelo del hormigón } \\
\text { utilizado en el cálculo } \\
\text { seccional }\end{array}$ & $\begin{array}{c}\text { Modelo para el cálculo de } \\
\text { los efectos de segundo } \\
\text { orden }\end{array}$ \\
\hline EHE_BR & EHE-08 (2008) & Bloque rectangular & Excentricidad adicional \\
\hline EHE_PR & EHE-08 (2008) & Parábola Rectángulo & Excentricidad adicional \\
\hline EC2_dns & EC- 2 (2004) & Parábola -Rectángulo & Amplificación de momentos \\
\hline EC2_ea & EC- 2 (2004) & Parábola -Rectángulo & Excentricidad adicional \\
\hline${ }^{*} \mathrm{ACl}$ _sEls & ACI 318-08 (2008) & Bloque rectangular & Amplificación de momentos \\
\hline **ACl_cEls & ACI 318-08 (2008) & Bloque rectangular & Amplificación de momentos \\
\hline
\end{tabular}

\subsubsection{RESULTADOS DE LA CARGA MÁXIMA EXPERIMENTAL Y TEÓRICA}

En la Tabla 6-10 se presentan los valores experimentales de carga máxima $\left(\mathrm{V}_{\mathrm{m} \_ \text {Exp }}\right)$ y los valores teóricos de carga obtenidos con los métodos implementados $\left(V_{m}\right.$ cal $)$. Para algunos ensayos no ha sido posible calcular los valores de carga teóricos. Esto se debe a que los métodos simplificados predicen un axil crítico del soporte inferior al real situándose del lado de la seguridad.

Los ensayos para los cuales no ha sido posible obtener los valores de carga teóricos generalmente corresponden a los ensayos con niveles altos de carga axial (45\%) y esbeltez de cortante 10.5 , lo que corresponde a los ensayos $4,16,28,36$ y 40. Adicionalmente, para los ensayos con una esbeltez alta de cortante (15), tampoco fue posible obtener los valores aproximados de carga teórica (ensayos 7 , 8,19 y 20). Por último, también se encontraron dificultades en el cálculo de la carga máxima teórica en los ensayos con cuantías de armadura del $1 \%$ y niveles de carga axil del 30\% (ensayos 10, 22 y 32). Para los demás ensayos, en la Tabla 6-10 se presentan los valores de carga obtenidos experimentalmente y mediante los métodos simplificados adoptados en este estudio.

El grado de precisión se evalúa como el cociente entre la carga experimental $V_{m \text {,exp }}$ y la obtenida en el método teórico $\mathrm{V}_{\mathrm{m} \_ \text {cal }}$, un valor de este cociente superior a la 
unidad significa que para este ensayo el método simplificado se sitúa del lado de la seguridad.

Tabla 6-10 Resultados de la carga máxima experimental y teórica

\begin{tabular}{|c|c|c|c|c|c|c|c|c|}
\hline \multirow[b]{2}{*}{ No } & \multirow{2}{*}{ Referencia } & \multirow{2}{*}{$\begin{array}{c}\mathbf{V}_{\mathbf{m}_{-} \operatorname{Exp}} \\
(\mathbf{k N})\end{array}$} & \multicolumn{6}{|c|}{$\mathrm{V}_{\mathrm{m}_{-} \text {Cal }}(\mathrm{kN})$} \\
\hline & & & EHE_BR & EHE_PR & EC2_dns & EC2_ea & ACI_sEls & ACI_cEls \\
\hline 1 & N30-10.5-C0-2-00 & 17,07 & 17,19 & 17,11 & 17,11 & 17,11 & 16,91 & 16,91 \\
\hline 2 & N30-10.5-C0-2-15 & 18,63 & 15,89 & 15,77 & 18,96 & 17,61 & 16,11 & 16,29 \\
\hline 3 & N30-10.5-C0-2-30 & 16,14 & 12,07 & 11,95 & 14,93 & 14,96 & 8,40 & 8,79 \\
\hline 5 & N30-10.5-C0-2-45 & 55,19 & 47,81 & 47,40 & 51,91 & 51,48 & 37,26 & 40,28 \\
\hline 6 & N30-7.5-C0-2-30 & 47,40 & 39,01 & 38,42 & 44,77 & 46,32 & 28,15 & 31,80 \\
\hline 9 & N30-7.5-C0-2-45 & 15,55 & 11,25 & 11,05 & 14,98 & 13,33 & 12,01 & 9,14 \\
\hline 11 & N30-10.5-C0-1-30 & 21,57 & 21,64 & 21,46 & 24,70 & 23,61 & 19,68 & 21,46 \\
\hline 12 & N30-10.5-C0-1-45 & 16,57 & 13,55 & 13,42 & 16,97 & 17,83 & 7,04 & 10,83 \\
\hline 13 & N30-10.5-C0-3-15 & 18,06 & 18,25 & 18,07 & 18,07 & 18,07 & 17,86 & 17,86 \\
\hline 14 & N30-10.5-C0-3-30 & 21,39 & 17,04 & 16,94 & 22,05 & 19,59 & 17,91 & 16,62 \\
\hline 15 & $\mathrm{H} 60-10.5-\mathrm{C} 0-2-00$ & 18,43 & 12,54 & 12,00 & 15,54 & 15,61 & 7,08 & 3,56 \\
\hline 17 & $\mathrm{H} 60-10.5-\mathrm{C} 0-2-15$ & 65,61 & 56,22 & 54,61 & 61,37 & 60,43 & 46,46 & 46,41 \\
\hline 18 & $\mathrm{H} 60-10.5-\mathrm{C} 0-2-30$ & 73,82 & 44,54 & 43,01 & 51,71 & 54,83 & 34,31 & 33,45 \\
\hline 21 & $\mathrm{H} 60-10.5-\mathrm{C} 0-2-45$ & 16,86 & 12,57 & 12,47 & 17,88 & 14,85 & 15,15 & 11,84 \\
\hline 22 & $\mathrm{H} 60-7.5-\mathrm{C} 0-2-30$ & 17,23 & 10,28 & 9,89 & 12,26 & 12,44 & 6,94 & 0,00 \\
\hline 23 & $\mathrm{H} 60-7.5-\mathrm{C} 0-2-45$ & 24,20 & 22,63 & 22,48 & 27,78 & 25,56 & 20,65 & 21,18 \\
\hline 24 & $\mathrm{H} 60-10.5-\mathrm{C} 0-1-15$ & 18,25 & 14,25 & 13,61 & 17,98 & 18,45 & 5,67 & 6,26 \\
\hline 25 & $\mathrm{H} 60-10.5-\mathrm{C} 0-1-30$ & 20,09 & 18,77 & 18,61 & 18,59 & 18,59 & 18,77 & 18,77 \\
\hline 26 & $\mathrm{H} 60-10.5-\mathrm{C} 0-3-15$ & 22,14 & 18,04 & 18,35 & 26,20 & 21,74 & 20,02 & 15,56 \\
\hline 27 & $\mathrm{H} 60-10.5-\mathrm{C} 0-3-30$ & 21,90 & 9,43 & 10,39 & 14,09 & 14,95 & 2,34 & 0,00 \\
\hline 29 & $\mathrm{H} 90-10.5-\mathrm{C} 0-2-00$ & 79,10 & 54,90 & 34 & 73,64 & 71,87 & 58,60 &, 12 \\
\hline 30 & H90-10.5-C0-2-15 & 55 & 39,01 & 44,54 & 55,57 & 61,30 & 33,98 & 27,32 \\
\hline 31 & $\mathrm{H} 90-10.5-\mathrm{C} 0-2-30$ & 16,47 & 13,77 & 14,12 & 21,79 & 16,93 & 17,66 & 11,28 \\
\hline 33 & H90-10.5-C0-2-45 & 27,61 & 22,98 & 23,58 & 31,20 & 27,34 & 22,48 & 20,75 \\
\hline 34 & H90-7.5-C0-2-30 & 25,26 & 10,46 & 12,05 & 17,16 & 17,79 & 0,50 & 0,00 \\
\hline 35 & H90-7.5-C0-2-45 & 13,91 & 14,08 & 13,80 & 17,14 & 16,10 & 11,07 & 9,49 \\
\hline 37 & H90-10.5-C0-1-15 & 47,93 & 48,67 & 48,14 & 52,94 & 52,12 & 39,92 & 41,56 \\
\hline 38 & $\mathrm{H} 90-10.5-\mathrm{C} 0-1-30$ & 44,59 & 38,89 & 38,25 & 44,31 & 45,89 & 28,30 & 30,66 \\
\hline 39 & H90-10.5-C0-3-15 & 23,90 & 8,98 & 10,46 & 13,78 & 13,94 & 3,10 & 0,00 \\
\hline 41 & $\mathrm{H} 90-10.5-\mathrm{C} 0-3-30$ & 75,47 & 50,61 & 52,53 & 63,03 & 62,63 & 48,60 & 43,26 \\
\hline 42 & N30-10.5-C3-2-30 & 61,30 & 29,28 & 29,33 & 39,10 & 47,62 & 20,17 & 14,42 \\
\hline 43 & N30-10.5-C3-2-45 & 72,72 & 52,61 & 58,07 & 68,89 & 67,39 & 54,66 & 48,06 \\
\hline 44 & N30-7.5-C3-2-30 & 61,12 & 34,50 & 38,31 & 48,44 & 55,58 & 28,15 & 19,82 \\
\hline
\end{tabular}

En la Tabla 6-11 se presenta el resumen del valor medio (E), el coeficiente de variación $(\mathrm{CV})$, y los valores del percentil del $95 \%\left(\mathrm{P}_{95 \%}\right)$ y percentil $5 \%\left(\mathrm{P}_{5 \%}\right)$ para el error $\left(V_{\mathrm{m} \_ \text {exp }} / V_{\mathrm{m} \_ \text {cal }}\right)$, en cada uno de los métodos analizados. Los métodos que muestran una aproximación más centrada entre los resultados de carga máxima experimental y teórica, son los métodos propuestos por del Eurocódigo 2 (2004) [58]. 
Tabla 6-11 Resultados estadísticos del error $\left(V_{m_{-} \text {exp }} / V_{m_{-}}\right.$cal $)$

\begin{tabular}{|c|c|c|c|c|c|c|}
\cline { 2 - 7 } \multicolumn{1}{c|}{} & EHE_BR & EHE_PR & EC2_dns & EC2_ea & ACl_sEls & ACI_cEls \\
\hline$\overline{\mathbf{E}}$ & 1.41 & 1.38 & 1.11 & 1.12 & 1.61 & 1.79 \\
\hline CV & $31 \%$ & $26 \%$ & $22 \%$ & $17 \%$ & $39 \%$ & $55 \%$ \\
\hline P95\% & 2.36 & 2.10 & 1.56 & 1.44 & 2.84 & 3.78 \\
\hline P5\% & 0.99 & 1.00 & 0.83 & 0.92 & 1.01 & 1.01 \\
\hline
\end{tabular}

Para el EC2_dns el error medio obtenido es $\bar{E}=1.11$, mientras que para el EC2_ea el error es de $\bar{E}=1.12$. Sin embargo, el coeficiente de variación en el método EC2_dns es del 22\%, algo mayor que el obtenido en el método EC2_ea ( $C V=17 \%)$. A la vista de estas variables, se considera que el método EC2-ea, utilizado para el cálculo de la carga máxima teórica, presenta una adecuada aproximación a los resultados experimentales. Adicionalmente, la Figura 6.10 muestra que los dos métodos del EC2 son los que presentan una menor dispersión del error; en especial, el método EC2_ea presenta un ajuste más cercano a la unidad.

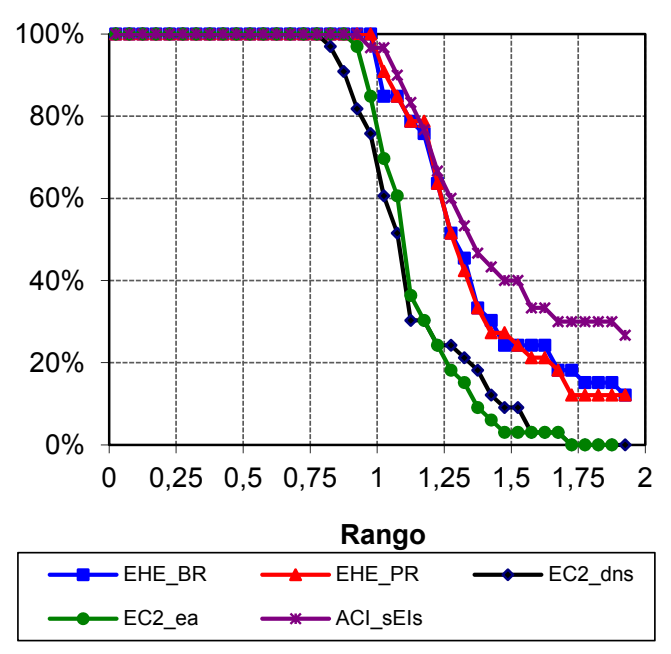

Figura 6.10 Análisis de dispersión del error mediante las frecuencias acumuladas

Con respecto a los dos métodos de la norma EHE-08, ambos se encuentran del lado de la seguridad, como confirma el percentil del $5 \%$, puesto que su valor se aproxima o es igual a la unidad. Los resultados del error al adoptar el diagrama parábola-rectángulo para el hormigón muestran una mínima diferencia respecto al bloque rectangular.

Por otra parte, como se puede apreciar en la Tabla 6-11, los métodos que muestran un mayor error son los propuestos por la norma $\mathrm{ACl} 318-08$, puesto que se encuentran ampliamente del lado de la seguridad, mostrando además una considerable dispersión al efectuarse la comparación con los resultados experimentales.

En las Figuras 6.11a-f, se muestra gráficamente la comparación de los resultados experimentales y los teóricos calculados con los diferentes métodos implementados. Además, se muestran los percentiles del $95 \%$ y $5 \%$ obtenidos para cada uno de los métodos. 


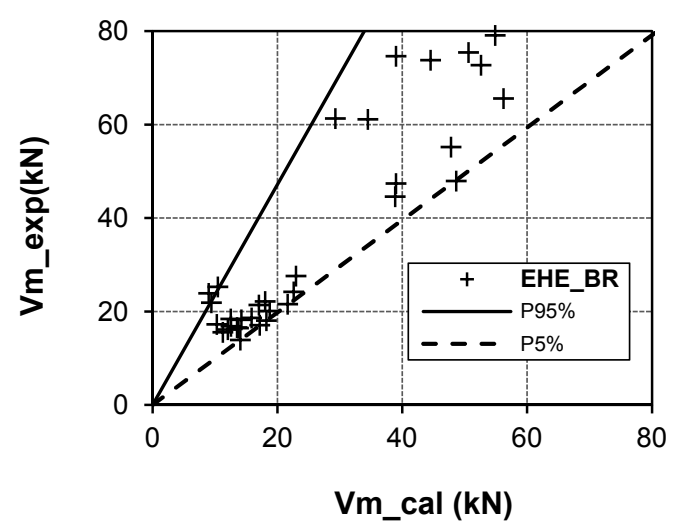

(a)

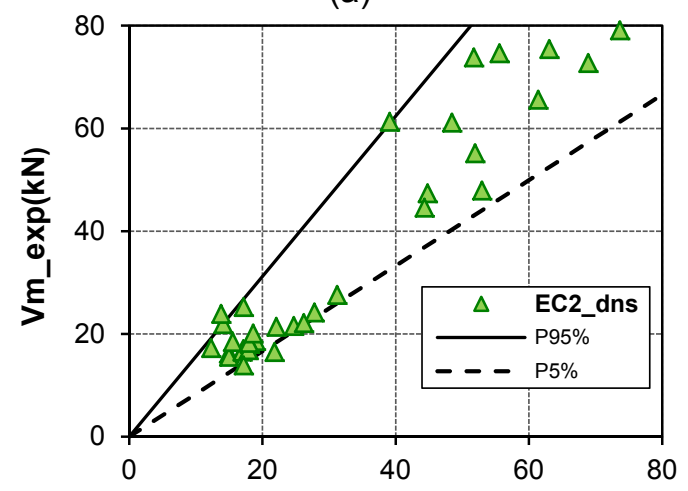

Vm_cal (kN)

(c)

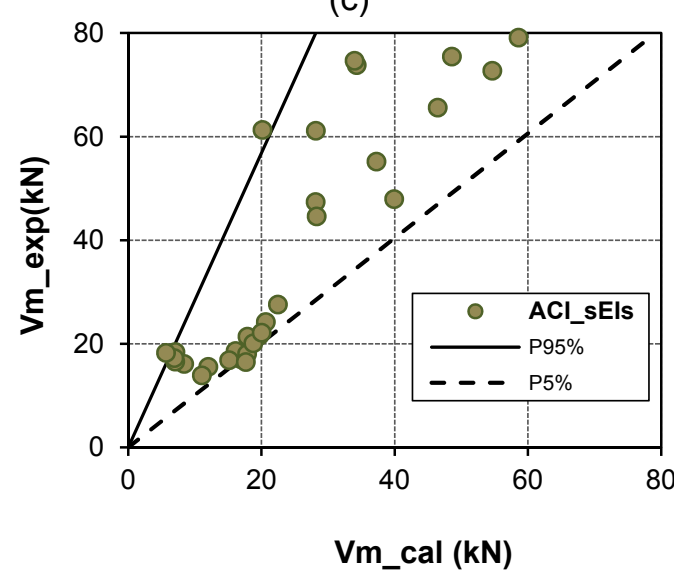

(e)

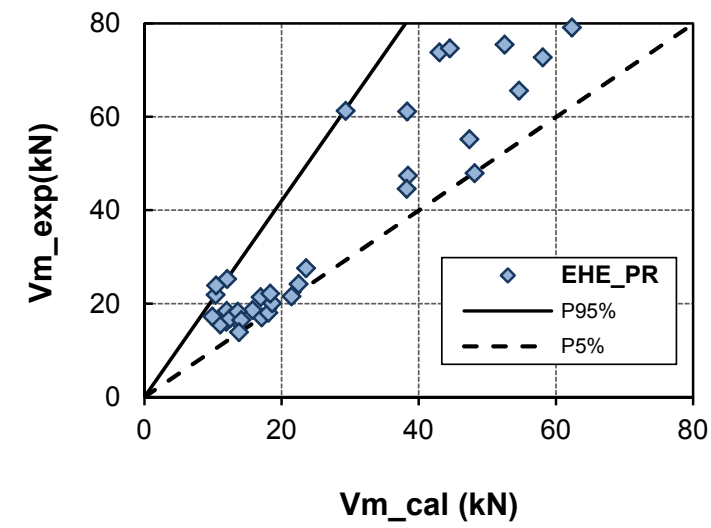

(b)

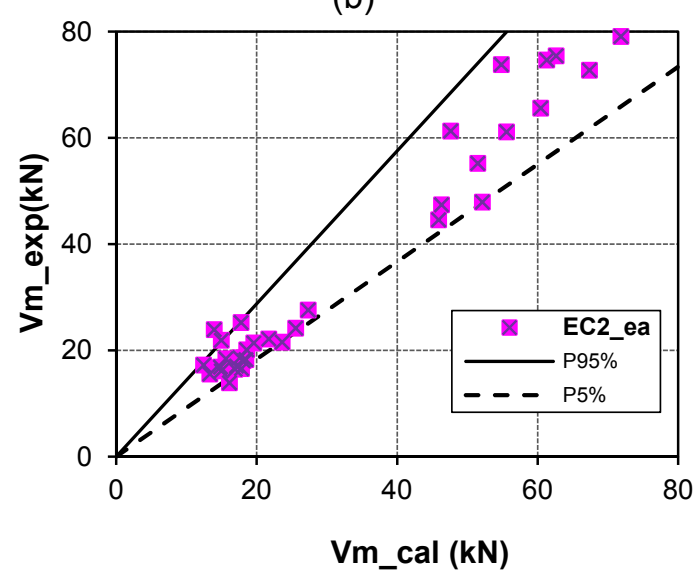

(d)

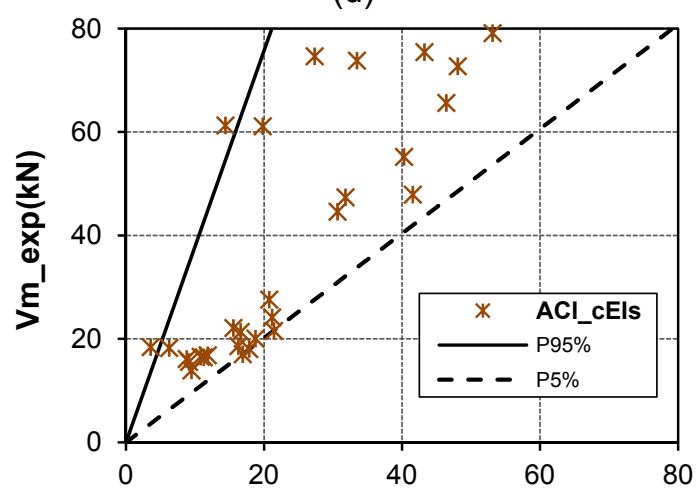

Vm_cal (kN)

(f)

Figura 6.11 Comparación entre la Vm_exp y la Vm_cal obtenida mediante los métodos:(a) EHE_BR, (b) EHE_PR;(c) EC2_dns; (d) EC2_ea, (e) ACI_sEIs, (f) ACl_cEI

\subsubsection{COMPARACIÓN ENTRE LA CARGA MÁXIMA EXPERIMENTAL Y TEÓRICA RESPECTO A LOS PARÁMETROS ANALIZADOS}

En la Tabla 6-12 se presenta un resumen del error medio (E) y del coeficiente de variación (CV) para todos los métodos utilizados en la predicción de la carga máxima teórica, con respecto a las variables de resistencia del hormigón $\left(f_{c}\right)$, nivel 
Estudio experimental y numérico de la capacidad de deformación de soportes esbeltos de hormigón armado

de carga axial $\left(\mathrm{N} / \mathrm{N}_{\mathrm{u}}\right)$, esbeltez de cortante $(\lambda)$, cuantía de armadura longitudinal $\left(\rho_{\mathrm{l}}\right)$, y cuantía de armadura transversal $\left(\rho_{\mathrm{s}}\right)$. Con el propósito de revisar la tendencia de la aproximación entre los resultados teóricos y experimentales con respecto a las variables de estudio.

Tabla 6-12 Resumen de las variables $\bar{E}$ y CV con respecto a los parámetros de estudio, para cada uno de los métodos implementados en el cálculo de Vm_cal

\begin{tabular}{|c|c|c|c|c|c|c|c|c|c|c|c|c|c|}
\hline \multirow{2}{*}{\multicolumn{2}{|c|}{ Variable }} & \multicolumn{2}{|c|}{ EHE_BR } & \multicolumn{2}{|c|}{ EHE_PR } & \multicolumn{2}{|c|}{ EC2_dns } & \multicolumn{2}{|c|}{ EC2_ea } & \multicolumn{2}{|c|}{ ACI_sEls } & \multicolumn{2}{|c|}{ ACl_cEls } \\
\hline & & $\overline{\mathbf{E}}$ & CV & $\overline{\mathbf{E}}$ & CV & $\overline{\mathbf{E}}$ & CV & $\overline{\mathbf{E}}$ & CV & $\overline{\mathbf{E}}$ & CV & $\overline{\mathbf{E}}$ & CV \\
\hline \multirow{3}{*}{$\begin{array}{c}\mathbf{f}_{\mathrm{c}} \\
(\mathrm{MPa})\end{array}$} & 30 & 1.14 & $12 \%$ & 1.16 & $13 \%$ & 0.98 & $9 \%$ & 1.00 & $9 \%$ & 1.46 & $28 \%$ & 1.38 & $20 \%$ \\
\hline & 60 & 1.32 & $18 \%$ & 1.36 & $19 \%$ & 1.10 & $18 \%$ & 1.13 & $14 \%$ & 1.82 & $45 \%$ & 2.07 & $68 \%$ \\
\hline & 90 & 1.71 & $31 \%$ & 1.57 & $28 \%$ & 1.22 & $25 \%$ & 1.21 & $18 \%$ & 1.60 & $42 \%$ & 2.01 & $51 \%$ \\
\hline \multirow{4}{*}{$\mathbf{N} / \mathbf{N}_{\mathbf{u}}$} & 0.00 & 0.99 & $0 \%$ & 1.00 & $0 \%$ & 1.00 & $0 \%$ & 1.00 & $0 \%$ & 1.01 & $0 \%$ & 1.01 & $0 \%$ \\
\hline & 0.15 & 1.18 & $9 \%$ & 1.18 & $9 \%$ & 0.89 & $8 \%$ & 1.02 & $7 \%$ & 1.12 & $8 \%$ & 1.28 & $13 \%$ \\
\hline & 0.30 & 1.52 & $33 \%$ & 1.46 & $27 \%$ & 1.16 & $22 \%$ & 1.17 & $20 \%$ & 1.47 & $64 \%$ & 1.46 & $88 \%$ \\
\hline & 0.45 & 1.63 & $23 \%$ & 1.58 & $22 \%$ & 1.28 & $17 \%$ & 1.16 & $13 \%$ & 2.14 & $24 \%$ & 2.54 & $42 \%$ \\
\hline \multirow[t]{2}{*}{$\lambda$} & 7.5 & 1.45 & $24 \%$ & 1.40 & $22 \%$ & 1.17 & $17 \%$ & 1.12 & $11 \%$ & 1.76 & $30 \%$ & 1.99 & $46 \%$ \\
\hline & 10.5 & 1.39 & $35 \%$ & 1.36 & $28 \%$ & 1.07 & $24 \%$ & 1.12 & $19 \%$ & 1.51 & $45 \%$ & 1.64 & $62 \%$ \\
\hline \multirow{3}{*}{$\rho_{I}(\%)$} & 1.4 & 1.40 & $14 \%$ & 1.42 & $17 \%$ & 1.04 & $26 \%$ & 1.17 & $15 \%$ & 1.46 & $48 \%$ & 1.53 & $10 \%$ \\
\hline & 2.2 & 1.43 & $32 \%$ & 1.38 & $27 \%$ & 1.14 & $21 \%$ & 1.13 & $16 \%$ & 1.59 & $35 \%$ & 1.87 & $58 \%$ \\
\hline & 3.2 & 1.36 & $39 \%$ & 1.32 & $30 \%$ & 1.02 & $23 \%$ & 1.03 & $19 \%$ & 1.81 & $52 \%$ & 1.58 & $49 \%$ \\
\hline \multirow{3}{*}{$\rho_{s}(\%)$} & 1.0 & 1.37 & $27 \%$ & 1.34 & $23 \%$ & 1.08 & $19 \%$ & 1.11 & $14 \%$ & 1.58 & $40 \%$ & 1.69 & $55 \%$ \\
\hline & 2.0 & 1.58 & $17 \%$ & 1.42 & $17 \%$ & 1.16 & $13 \%$ & 1.09 & $1 \%$ & 1.75 & $34 \%$ & 2.30 & $48 \%$ \\
\hline & 3.0 & 1.56 & $44 \%$ & 1.50 & $38 \%$ & 1.20 & $31 \%$ & 1.16 & $27 \%$ & 1.73 & $44 \%$ & 2.01 & $63 \%$ \\
\hline
\end{tabular}

Respecto a la resistencia del hormigón. Los resultados de la Tabla 6-12 indican que E y CV varían con respecto a la resistencia del hormigón. Se ha encontrado que los resultados teóricos se alejan de los valores experimentales y presentan mayor dispersión a medida que aumenta la resistencia del hormigón para todos los métodos.

Respecto al nivel de carga axial. Como ya se ha mencionado, los modelos presentan algunos problemas cuando analizan esbelteces altas $(\lambda=15)$ y niveles altos de carga axial, de manera que no se obtienen resultados para este tipo de elementos. Adicionalmente, se ha podido comprobar que tanto el error medio como el coeficiente de variación aumentan con el nivel de carga axial en todos los métodos.

Respecto a la esbeltez de cortante. Para los dos valores de esbeltez estudiados (7.5 y 10.5) no existe ninguna tendencia significativa del error, aunque en todos los métodos el coeficiente de variación es mayor para la esbeltez de 10.5.

Respecto al parámetro de cuantía longitudinal, no es posible obtener ninguna tendencia del error y del parámetro $\mathrm{CV}$, puesto que el comportamiento de estos dos parámetros estadísticos no es concluyente en todos los métodos, e incluso existen variaciones de la tendencia de $\bar{E}$ y $\mathrm{CV}$ en los distintos métodos con respecto a los tres niveles de cuantía de armadura estudiados (1\%, $2 \%$ y $3 \%)$.

Respecto a la cuantía transversal. Los resultados muestran que el error y el CV aumentan especialmente cuando la cuantía de armadura transversal es del $3 \%$, lo 
cual se cumple para todos métodos. Sin embrago, no se puede concluir que existe una relación general con respecto a los tres valores de $\rho_{s}$ considerados en el estudio que afecte a la precisión en todos los métodos.

\subsubsection{DIAGRAMAS DE INTERACCIÓN}

En las Figuras 6.12 y $6-13$ se presentan los diagramas de interacción calculados a partir del método del Eurocódigo-2 (parábola rectángulo) para el cálculo de la sección transversal $(\lambda=0)$. Además, se presenta la curva de esfuerzos flectores de primer orden (obtenida para el soporte $\lambda \neq 0$ ), obtenida teóricamente a partir de los momentos totales, dividido por el factor de amplificación $\left(\delta_{\mathrm{s}}\right)$. En las mismas gráficas se presentan los puntos correspondientes a los valores experimentales de momento máximo total y momento de primer orden, para el correspondiente valor de carga axil aplicado al soporte. Los valores de $v$ (Ec. 6-7) y $\mu$ (Ec. 6-8) son los valores adimensionales de la carga $(\mathrm{V})$ y del momento $(\mathrm{M})$.

$$
\begin{gathered}
v=\frac{V}{b \cdot h \cdot f_{c}} \\
\mu=\frac{M}{b \cdot h^{2} \cdot f_{c}}
\end{gathered}
$$

Donde

$\begin{array}{ll}h & \text { Canto de la sección transversal } \\ b & \text { Ancho de la sección transversal } \\ f_{c} & \text { Resistencia del hormigón a compresión }\end{array}$

Las Figuras 6.12a, b, y c presentan los diagramas de interacción de los soportes de esbeltez de cortante 10.5 (la esbeltez geométrica utilizada en los cálculos en este estudio es dos veces la esbeltez de cortante), para resistencias medias del hormigón de $30 \mathrm{MPa}, 60 \mathrm{MPa}, 90 \mathrm{MPa}$; cada una de las gráficas está compuesta de tres valores de cuantía de armadura longitudinal, $1.4 \%, 2.2 \%$ y $3.2 \%$. Las Figuras $6.12 \mathrm{e}, \mathrm{f}, \mathrm{y} \mathrm{d}$, representan las curvas de interacción de los soportes con esbeltez de cortante 7.5 , y valores de resistencia del hormigón de $30 \mathrm{MPa}, 60 \mathrm{MPa}, 90 \mathrm{MPa}$, siendo la cuantía de armadura longitudinal del $2.2 \%$. Un último grupo de diagramas de interacción son presentados en las Figuras 6.13a y b; en ellos se presentan las dos esbelteces, 10.5 y 7.5 , y en cada una de ellas se representa el comportamiento para dos tipos de hormigón, $30 \mathrm{MPa}$ y $90 \mathrm{MPa}$, siendo la cuantía de armadura del $2.2 \%$; sin embargo, hay que tener en cuenta que en estas curvas los valores experimentales son los correspondientes a valores de cuantías de armadura transversal del $2 \%$ y $3 \%$ según el caso.

La estimación del error del método de EC-2, tanto en el comportamiento seccional como en el comportamiento de primer orden, ya se ha evaluado en la sección anterior. Como se puede ver gráficamente, el método del EC-2 es más aproximado en el comportamiento seccional que en el comportamiento del elemento, demostrándose así que el método del EC-2 se encuentra ampliamente del lado de la seguridad, especialmente en este último caso. 


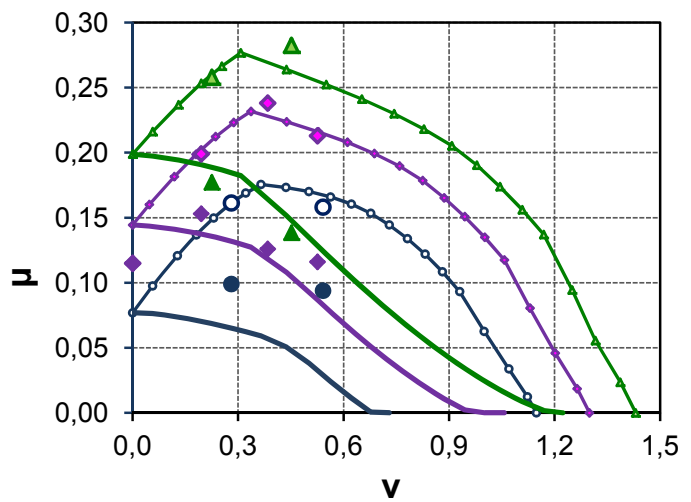

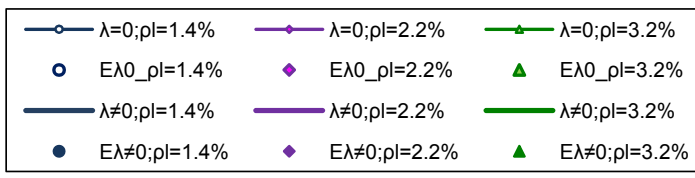

(a) $\lambda=10.5 ; \mathrm{f}_{\mathrm{c}}=30 \mathrm{MPa} ; \rho_{\mathrm{s}}=1 \%$
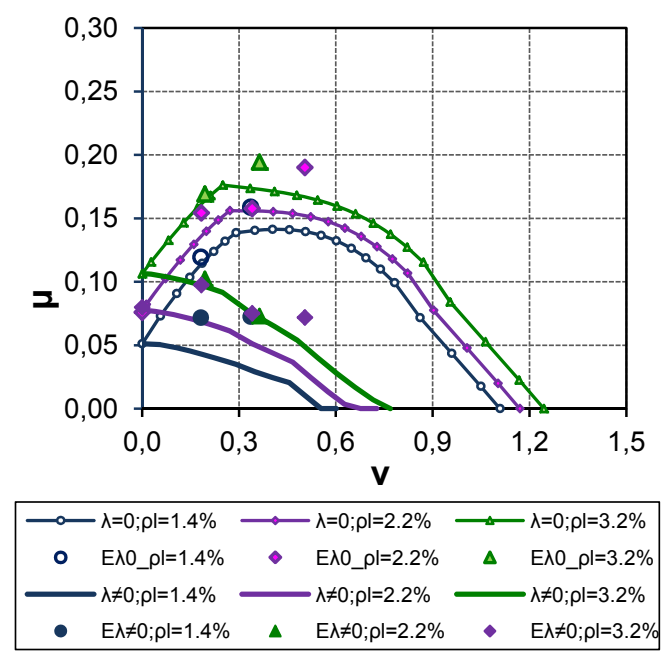

(b) $\lambda=10.5 ; f_{c}=60 M P a ; \rho_{s}=1 \%$
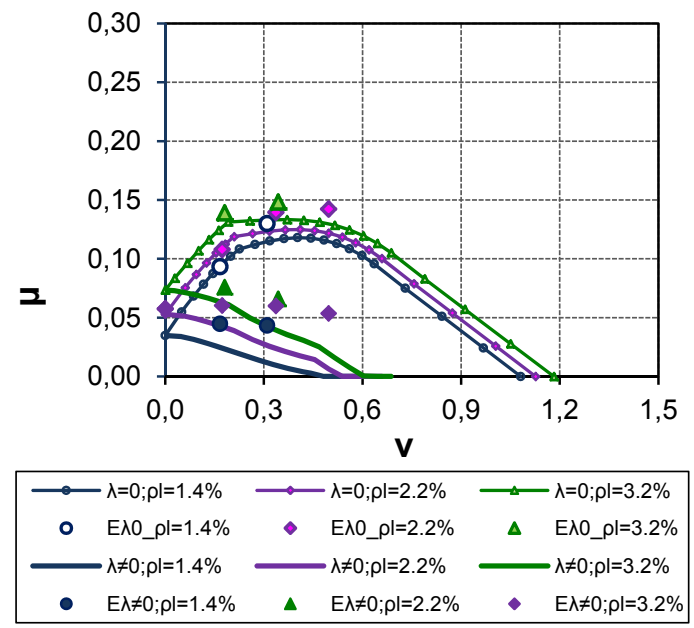

(c) $\lambda=10.5 ; f_{c}=90 \mathrm{MPa} ; \rho_{\mathrm{s}}=1 \%$

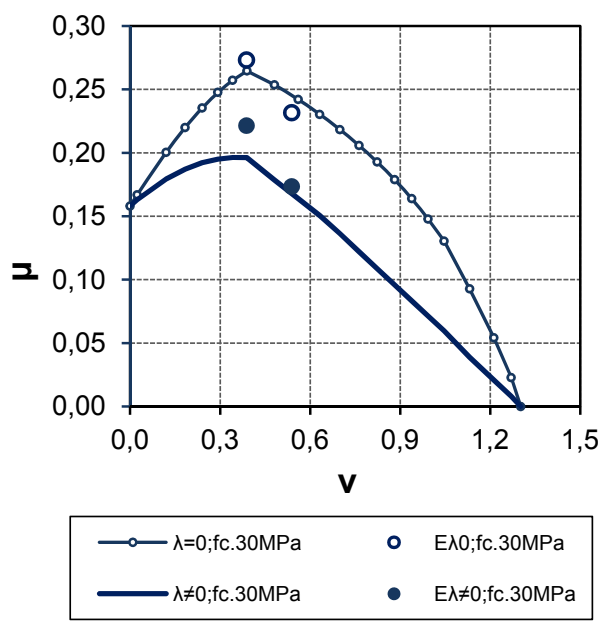

(d) $\lambda=7.5 ; \rho_{1}=2.2 \% ; \rho_{s}=1 \%$

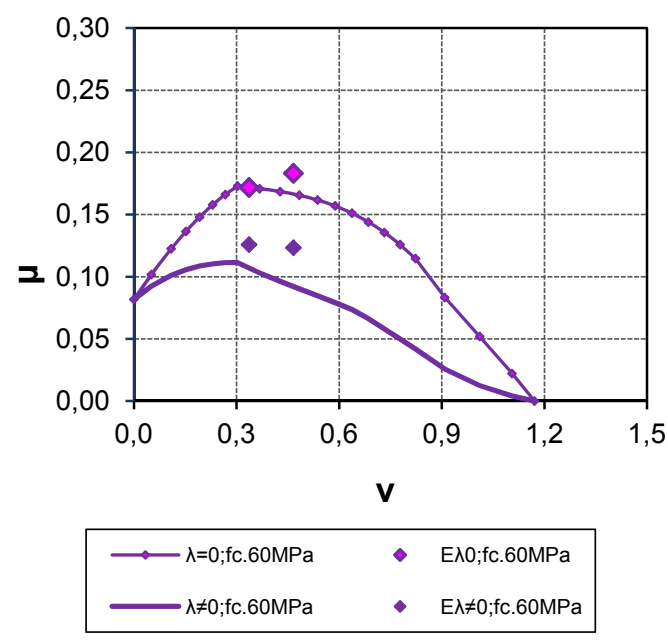

(e) $\lambda=7.5 ; \rho_{1}=2.2 \% ; \rho_{s}=1 \%$
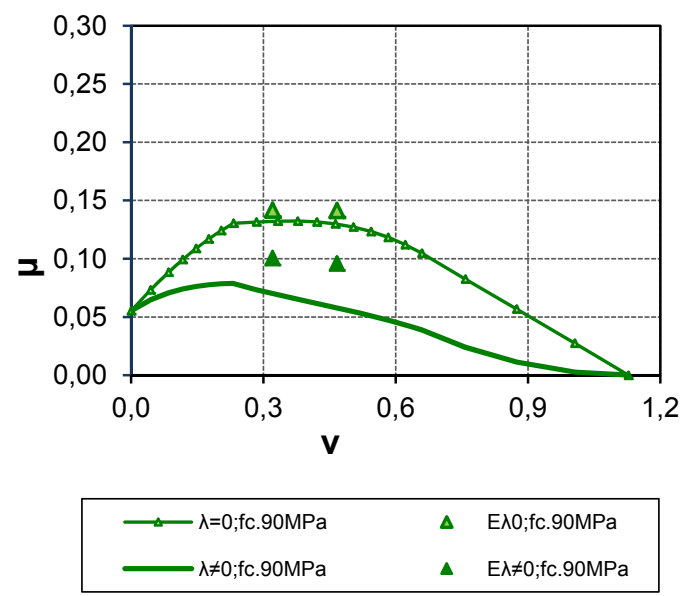

(f) $\lambda=7.5 ; \rho_{1}=2.2 \% ; \rho_{\mathrm{s}}=1 \%$

Figura 6.12 Diagramas de interacción de acuerdo a los métodos del EC-2 y comparación con resultados experimentales 


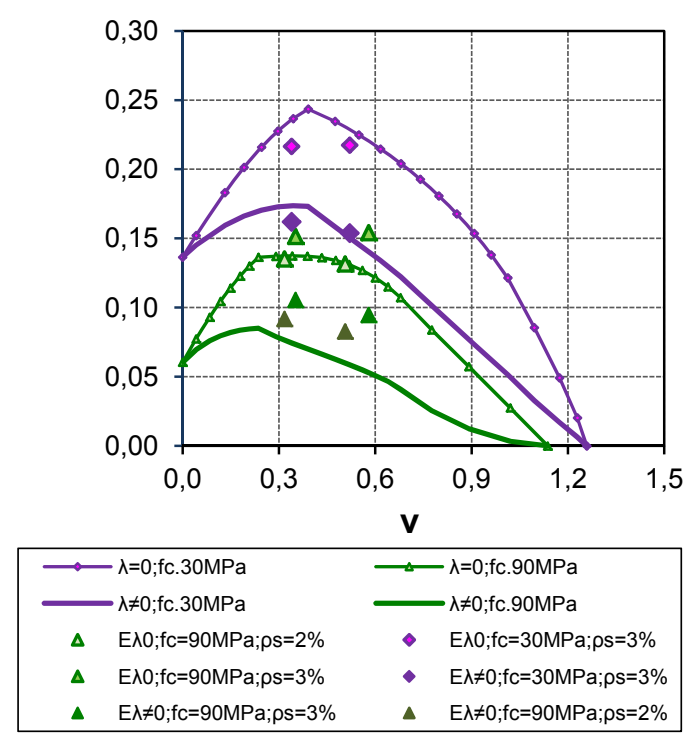

(a) $\lambda=7.5 ; \rho_{1}=2.2 \%$

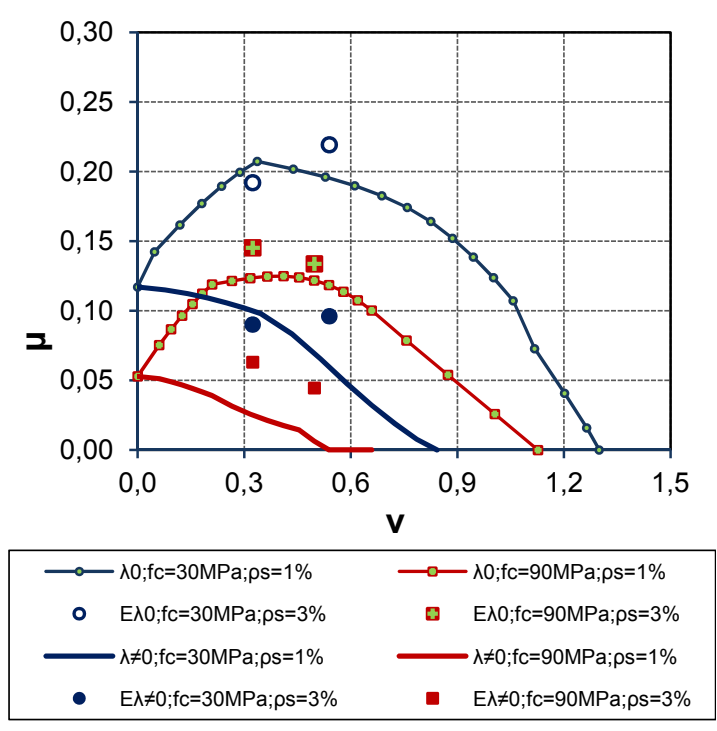

(b) $\lambda=10.5 ; \rho_{1}=2.2 \%$

Figura 6.13 Diagramas de interacción de acuerdo a los métodos del EC-2 y comparación con resultados experimentales

\subsection{IDEALIZACIÓN DE LOS DIAGRAMAS CARGA FLECHA Y MOMENTO CURVATURA}

El comportamiento de la sección y del elemento completo de hormigón armado, en casi todos los casos, no es elasto-plástico perfecto. Sin embargo, para poder llevar a cabo un análisis de la respuesta estructural, tanto a nivel de la sección como a nivel del elemento, es necesario asumir una idealización elasto-plástica de su comportamiento. Este diagrama bilineal idealizado se define a partir de dos puntos característicos; el primero de ellos es el "punto de plastificación efectiva", el cual marca el cambio entre el comportamiento elástico y plástico, y el segundo punto es el que define el "punto de fallo o de rotura".

\subsubsection{PUNTO DE PLASTIFICACIÓN EFECTIVA DEL DIAGRAMA IDEALIZADO}

En este estudio, el "punto de plastificación efectiva", tanto del diagrama idealizado Momento-Curvatura (M- $\varphi$ ) como del diagrama Carga-Flecha (P- $\delta)$, ha sido obtenido aplicando diferentes métodos utilizados en la literatura, los cuales se explican a continuación.

\subsubsection{Método utilizado en el Eurocódigo 8}

El Eurocódigo 8 (2004) [59], en el anexo E, propone la idealización del diagrama M$\varphi$ mediante un balance de energía entre la curva real y la idealizada. En este método, la rigidez secante efectiva de la sección o del elemento pasa por el primer punto en el que se produce la plastificación de la armadura longitudinal. Y el diagrama bilineal se obtiene igualando el área de la curva idealizada y la real, a partir del primer punto de plastificación (ver Tabla 6-13). En esta norma no se 
especifica la definición de punto de plastificación, debido al inicio de la no linealidad del hormigón. Sin embargo, algunas investigaciones, como Priestley et al. (1996) [111] y Priestley y Park.(1997) [110], Panagiotakos y Fardis (2001) [100], Fardis y Biskinis (2003) [60], Watson y Park (1994) [133], definen como punto de plastificación, en ensayos bajo carga monotónica o cíclica, el primer punto en el cual se alcanza la deformación del acero correspondiente al límite elástico o cuando se inicia la no linealidad del hormigón en la fibra más comprimida.

Respecto al valor de deformación que indica el inicio de la no linealidad del hormigón, existe una gran variedad de criterios. Priestley et al. (1996) [111], por ejemplo, utilizaron una deformación $\varepsilon_{\mathrm{cy}}=0.002$ como punto de referencia del inicio de la plastificación en ensayos de hormigón convencional. Sin embargo, Priestley y Park (1997) [110] utilizan una deformación $\varepsilon_{\mathrm{cy}}=0.0015$, también para hormigón convencional. Por otra parte, Panagiotakos y Fardis (2001) [100] y Fardis y Biskinis (2003) [60], han definido como inicio de la no linealidad del hormigón la deformación de $0.9 \varepsilon_{\text {co. }}$. En relación con esto, el Fib Bulletin 25 (2003) [35] aclara que, aunque, Panagiotakos y Fardis haya utilizado como definición el valor de $0.9 \varepsilon_{\text {co }}$ para obtener una mejor calibración en sus métodos para el cálculo teórico de la curvatura y la deriva elástica, en realidad la no linealidad del hormigón se inicia en el $0.75 \varepsilon_{\mathrm{co}}$. En este trabajo, el punto de plastificación sobre la curva experimental ha sido identificado utilizando dos posibles criterios:

- $\quad$ En el punto en el que ocurre la primera de las dos posibles situaciones: o plastifica el acero de la armadura longitudinal $\left(\varepsilon_{\mathrm{s}}=\varepsilon_{\mathrm{y}}\right)$, o la deformación del hormigón en la fibra más comprimida alcanza el valor $\varepsilon_{\mathrm{cy}}=0.90 \varepsilon_{\mathrm{co}}$.

- $\quad$ En el punto en el que ocurre la primera de las dos posibles situaciones: o plastifica el acero de la armadura longitudinal $\left(\varepsilon_{\mathrm{s}}=\varepsilon_{\mathrm{y}}\right)$, o la deformación del hormigón en la fibra más comprimida es $\varepsilon_{\mathrm{cy}}=0.75 \varepsilon_{\mathrm{co}}$.

La deformación correspondiente al límite elástico del acero de la armadura en los ensayos experimentales es $\varepsilon_{y}=2.65 \%$. La deformación correspondiente a la tensión pico del hormigón en compresión $\left(\varepsilon_{\mathrm{co}}\right)$ ha sido calculada conforme al modelo del Eurocódigo 2 (2004) [58] $\left(\varepsilon_{c o}(\% 0)=0.7 f_{c}^{0.31} \leq 2.8\right)$.

\subsubsection{Método basado en el Balance de Energía}

En este método, la idealización de los diagramas de respuesta (M- $\varphi$ y $\mathrm{P}-\delta$ ) se efectúa mediante un balance de energía entre la curva de respuesta experimental y el diagrama idealizado (ver Tabla 6-13). Es decir, el área bajo la curva experimental (área $\mathrm{OCD}$ ) es igual al área de la curva idealizada (OBCD). Como se puede comprobar, en este método no se utiliza ningún criterio para la plastificación de los materiales. Este método se utiliza cuando no existe suficiente información con respecto a la deformación del acero y del hormigón para determinar el primer punto de plastificación.

\subsubsection{Método aproximado}

En este método, la rama elástica está definida por la rigidez secante que pasa por el $75 \%$ de la resistencia máxima $\left(\mathrm{M}_{\max } \circ \mathrm{P}_{\max }\right)$, y la rama plástica es tangente en el punto de resistencia máximo. De igual modo que el anterior, este método es 
utilizado normalmente cuando no existe suficiente información sobre el punto de plastificación en la curva experimental.

En la Tabla 6-13 se presenta gráficamente la definición del diagrama idealizado de los tres métodos utilizados para obtener el punto de plastificación efectiva en los ensayos experimentales. En la parte inferior de cada figura se presentan algunas referencias bibliográficas que han utilizado cada uno de los métodos.

Tabla 6-13 Esquema de métodos utilizados en la idealización de los diagramas de respuesta $P-\delta$ y $M-\varphi$

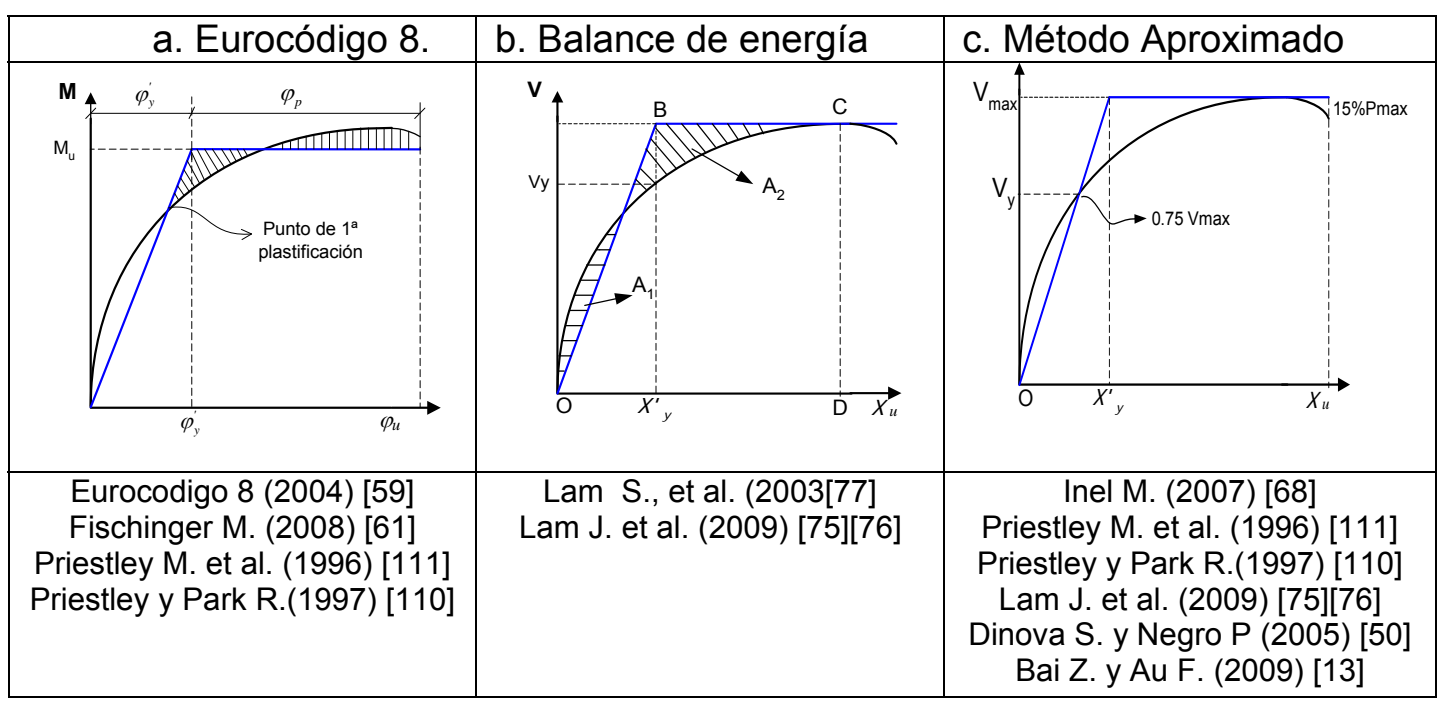

\subsubsection{PUNTO DE FALLO O ESTADO ÚLTIMO}

Generalmente, las normativas como el Eurocódigo-2 (2004) [58] y el Eurocódigo-8 (2004) [59] definen el estado último en el $20 \%$ de caída de la rama post-pico. Esto se debe a que la comprobación experimental en la que se basan dichas normas es realizada en ensayos bajo carga cíclica en donde la rama de descarga puede estar controlada por el desplazamiento impuesto o por el número de ciclos. Sin embargo, en algunas investigaciones en las que se utilizan resultados de ensayos bajo carga monotónica (Panagiotakos y Fardis (2001) [100], Priestley y Park (1997) [110]), es normal asumir una caída del $15 \%$ de la rama post-pico, debido a la dificultad de obtener la rama de descenso, especialmente si se trata de elementos esbeltos de hormigón.

Para definir el punto de fallo o deformación última en los ensayos experimentales, se ha utilizado el criterio del $15 \%$ de caída en la rama post-pico en los diagramas $\mathrm{M}-\varphi$ y $\mathrm{P}-\delta$. Sin embargo, su aplicación no es completamente sistemática en todos los ensayos experimentales, ya que en algunos de estos ensayos no se obtiene una prolongada rama de descenso en la curva de respuesta. Por consiguiente, el punto de fallo en los ensayos experimentales depende exclusivamente del último punto obtenido en la rama de descenso. En los ensayos en los que existe una prolongada rama de descenso, el estado último se obtiene para el $85 \%$ de la carga máxima (Figura 6.14a); si no se desarrolla una suficiente rama de descenso para llegar al $85 \%$ de la resistencia máxima, se toma como punto de fallo el último de los puntos registrados en el ensayo (Figuras 6.14). Finalmente, para algunos ensayos 
experimentales en los que el fallo se debe a la inestabilidad geométrica del elemento, no existe rama de descenso $\mathrm{y}$, por lo tanto, la deformación última coincide con la deformación para la carga máxima (Figuras 6.14).

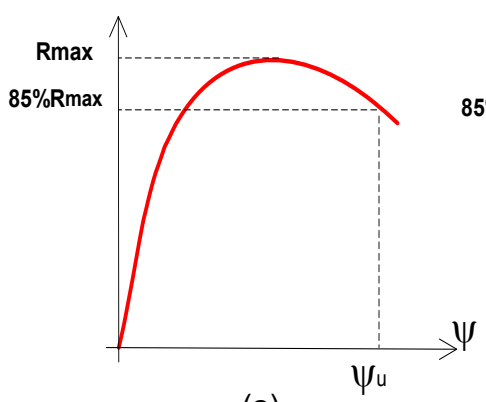

(a)

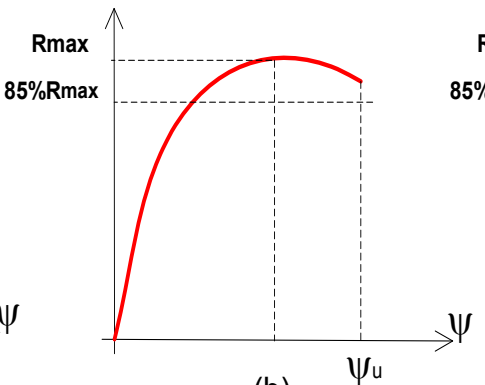

(b)

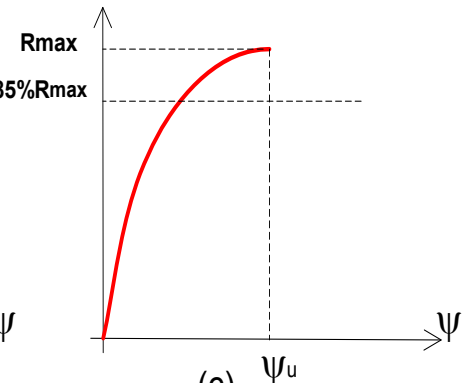

(c) $\psi u$

Figura 6.14 Punto de fallo o estado último en los ensayos experimentales

\subsection{APLICACIÓN DE LOS MÉTODOS DE IDEALIZACIÓN A LOS RESULTADOS EXPERIMENTALES}

Los métodos descritos anteriormente han sido aplicados a los diagramas momentocurvatura $(\mathrm{M}-\varphi)$ y carga-flecha $(\mathrm{P}-\delta)$ obtenidos experimentalmente para la sección crítica definida en el capítulo 5. Los métodos aplicados en este estudio se relacionan en la Tabla 6-14. Se ha de tener en cuenta que el método definido por el Eurocódigo-8 ha sido utilizado tomando en consideración dos versiones distintas para definir el punto en el cual se inicia la no linealidad del hormigón, tal y como se muestra en la Tabla 6-14.

La nomenclatura correspondiente a cada método es utilizada como subíndice para identificar los parámetros obtenidos a partir de la aplicación del método correspondiente.

Tabla 6-14 Relación de métodos utilizados en la idealización de los diagramas experimentales $M-\varphi$ y $P$ - $\delta$

\begin{tabular}{|c|c|c|}
\hline Nomenclatura & MÉTODO & $\begin{array}{c}\text { Criterio punto de } \\
\text { plastificación }\end{array}$ \\
\hline 1A & Eurocódigo 8 & $\varepsilon_{\mathrm{y}} ; \varepsilon_{\mathrm{c}}=0.9 \varepsilon_{\mathrm{co}}$ \\
\hline 1B & Eurocódigo 8 & $\varepsilon_{\mathrm{y}} ; \varepsilon_{\mathrm{c}}=0.75 \varepsilon_{\mathrm{co}}$ \\
\hline $\mathbf{2}$ & Balance de energía & Sin criterio \\
\hline $\mathbf{3}$ & Aproximado & Sin criterio \\
\hline
\end{tabular}

A partir de la idealización de los diagramas $M-\varphi$ y $\mathrm{P}-\delta$ experimentales, se ha realizado un análisis de las variables que intervienen y describen el diagrama idealizado. Dichas variables son las siguientes:

\section{A nivel de la fibra:}

- Deformaciones del hormigón y del acero en el punto de plastificación

A nivel de la sección:

- Curvatura elástica efectiva

- Curvatura plástica

- Curvatura última 
- Ductilidad de curvatura

A nivel del elemento:

- Desplazamiento elástico efectivo

- Desplazamiento último

- Desplazamiento plástico

- Ductilidad en desplazamientos

\subsubsection{DEFORMACIONES DEL HORMIGÓN Y DEL ACERO EN EL PUNTO DE PLASTIFICACIÓN}

En este apartado se ha realizado un análisis comparativo de los valores correspondientes a las deformaciones del hormigón y del acero en el punto de plastificación real sobre la curva experimental $M-\varphi$ y $\mathrm{P}-\delta$. Este análisis ha sido llevado a cabo para verificar el estado de los materiales en dicho punto, ya que la rigidez secante de la sección o del elemento es evaluada pasando por este punto. Es necesario comprobar que, por lo menos hasta el punto de plastificación, el estado de los materiales se encuentre bajo un comportamiento elástico.

En realidad, los valores de las deformaciones del hormigón en la fibra más comprimida y del acero en tracción para la sección crítica, son comparados para seis posibles puntos de plastificación. Estos puntos corresponden a las idealizaciones del diagrama $\mathrm{P}-\delta$ utilizando los cuatro métodos descritos anteriormente, y la idealización de los diagramas $M-\varphi$ aplicando los métodos 2 y 3 . Hay que tener en cuenta que, en los métodos $1 \mathrm{~A}$ y $1 \mathrm{~B}$, al ser la deformación del acero o del hormigón la que marca el inicio de la plastificación, los puntos de momento y carga elástica son concomitantes, $y$, por consiguiente, las deformaciones son iguales. Sin embargo, en los métodos 2 y 3 esto no ocurre, debido a la importante magnitud de los efectos de segundo orden presentes en la mayoría de los ensayos experimentales. De modo que, al aplicar los métodos 2 y 3 en cada uno de los diagramas $\mathrm{P}-\delta$ y $\mathrm{M}-\varphi$, resulta un punto de carga elástica y momento elástico para diferentes situaciones de carga durante el ensayo. En consecuencia, para dicho momento o carga elástica, es posible determinar el correspondiente estado de deformación de los materiales en la sección crítica, ya que, dada la instrumentación del ensayo, la trayectoria de deformaciones del hormigón en la fibra más comprimida y la del acero es conocida durante todo el proceso de carga. Por otra parte, aunque los métodos 2 y 3 no consideran el punto de plastificación como elemento clave en la idealización, en este caso se ha interpretado como punto de plastificación real el punto de intersección entre la curva real y la idealizada.

La metodología del análisis consiste en realizar una comparación en términos de: (1) la relación entre la deformación del hormigón en el punto de plastificación y la deformación correspondiente a la tensión pico del hormigón en compresión $\left(\varepsilon_{\mathrm{c}} / \varepsilon_{\mathrm{co}}\right)$; $\varepsilon_{\mathrm{co}}$ es calculada a partir del modelo tensión deformación del Eurocódigo-2; (2) la relación entre la deformación del acero en tracción en el punto de plastificación y la deformación del acero correspondiente al límite elástico $\left(\varepsilon_{\mathrm{s}} / \varepsilon_{\mathrm{sy}}\right)$. 


\subsubsection{Comparación de las deformaciones en los puntos de plastificación}

Los resultados de deformación del hormigón y del acero en tracción en los puntos de plastificación para los cuatro métodos aplicados se presentan en el Anejo G.

Comparación de las deformaciones obtenidas en el punto de plastificación al aplicar los métodos de idealización 1A y 1B

Para la sección crítica, en la Figura 6.15 se muestra, en su parte superior, la relación entre deformaciones del hormigón $\left(\varepsilon_{\mathrm{c}} / \varepsilon_{\mathrm{co}}\right)$, y, en su parte inferior, la relación de deformaciones del acero en tracción $\left(\varepsilon_{y} / \varepsilon_{\text {sy }}\right)$, obteniéndose las siguientes consideraciones acerca del estado de deformaciones en el punto de plastificación definido por los métodos $1 \mathrm{~A}$ y $1 \mathrm{~B}$ :

- Se ha observado que, sólo para los ensayos con axil nulo (ensayos 1, 13 y 25), la deformación elástica del acero en tracción ocurre antes que la deformación límite definida para el inicio del comportamiento inelástico del hormigón. Para los demás ensayos ocurre lo contrario.

- Existe una relación casi lineal entre la deformación del acero en tracción y el nivel de carga axil; la deformación del acero disminuye conforme aumenta el nivel de carga axil, independientemente de la resistencia del hormigón.

- En ensayos con un nivel de carga axil cercano al 45\%, la armadura inferior o de tracción aún se encuentra comprimida, siendo la relación $\varepsilon_{\mathrm{y}} / \varepsilon_{\mathrm{sy}}$ mayor que cero.

- En los ensayos con cuantías de armadura de 1\% y $3 \%$ y bajos niveles de carga axil, $\mathrm{N} / \mathrm{Nu}=15 \%$, la deformación en la armadura traccionada se encuentra cerca del límite elástico.

- Las deformaciones del acero son similares para los ensayos en los que sólo varía la cuantía de armadura transversal, puesto que el efecto de confinamiento no es relevante en el punto de plastificación.

En la Tabla 6-15 se muestra el valor medio $(\bar{E})$ y el coeficiente de variación (CV) para la relación $\left(\varepsilon_{\mathrm{d}} / \varepsilon_{\mathrm{co}}\right)$. Los resultados muestran que el punto de plastificación seleccionado efectivamente coincide con los criterios establecidos como límites de la deformación elástica del hormigón $\left(0.9 \varepsilon_{\mathrm{co}}\right.$ y $\left.0.75 \varepsilon_{\mathrm{co}}\right)$, obteniéndose además un coeficiente de variación bastante bajo.

Tabla 6-15 Error medio y coeficiente de variación para el punto de plastificación definido por el hormigón (Aplicando el método del Eurocódigo-8)

\begin{tabular}{|c|c|c|c|c|}
\hline \multirow{2}{*}{ Nomenclatura } & \multirow{2}{*}{ MÉTODO } & $\begin{array}{c}\text { Curva } \\
\text { idealizada }\end{array}$ & $\overline{\mathbf{E}}$ & $\mathbf{C V}$ \\
\cline { 4 - 5 } & & $\boldsymbol{\varepsilon}_{\mathrm{c}} / \boldsymbol{\varepsilon}_{\mathrm{co}}$ & $\boldsymbol{\varepsilon}_{\mathrm{c}} / \boldsymbol{\varepsilon}_{\mathrm{co}}$ \\
\hline 1A & Eurocódigo 8 (criterio 1A) & $\mathrm{M}-\varphi / \mathrm{P}-\delta$ & 0.89 & $2.2 \%$ \\
\hline 1B & Eurocódigo 8 (criterio 2B) & $\mathrm{M}-\varphi / \mathrm{P}-\delta$ & 0.75 & $2.3 \%$ \\
\hline
\end{tabular}

Comparación de las deformaciones obtenidas en el punto de plastificación al aplicar los métodos de idealización 2 y 3 en el diagrama P-ठ

En la Figura 6.16 se muestra cómo las deformaciones en el punto de plastificación para la idealización de la curva $\mathrm{P}-\delta$, aplicando el método de balance de energía (método 2) y el método aproximado (método 3), son bastante parecidas. Por consiguiente, es evidente la similitud que existe entre ambos métodos. 
Por otra parte, con respecto a los valores de deformación del hormigón, se observa que existen algunos valores muy cercanos e incluso superiores a la deformación del hormigón en compresión para la tensión pico $\left(\varepsilon_{\mathrm{co}}\right)$. Estos valores son destacables en ensayos con esbeltez de cortante $\lambda=7.5$. Este resultado evidencia que puede existir un efecto relacionado con el tamaño de la sección en los valores de deformación. En la Tabla 6-16 se muestra que, para los dos métodos, la relación $\varepsilon_{c} \varepsilon_{c o}$ se aproxima a un valor medio de 0.75 ; sin embargo, existe un coeficiente de variación alto en los valores de deformación. Por consiguiente, al aplicar los métodos 2 y 3 en la idealización del diagrama $\mathrm{P}$ - $\delta$, el estado de los materiales en el punto de plastificación puede variar en un amplio rango, y es posible que, para algunos ensayos, los materiales se encuentren actuando en un régimen inelástico.

Tabla 6-16 Error medio y coeficiente de variación para el punto de plastificación definido por el hormigón. (Método de balance de energía y el método aproximado en la idealización de $P$ - $\delta$ )

\begin{tabular}{|c|c|c|c|c|}
\hline \multirow{2}{*}{$\mathbf{N}^{\circ}$ Método } & \multirow{2}{*}{ MÉTODO } & \multirow{2}{*}{ Curva idealizada } & $\overline{\mathbf{E}}$ & CV \\
\cline { 3 - 5 } & & $\boldsymbol{\varepsilon}_{\mathrm{c}} \boldsymbol{\varepsilon}_{\mathrm{co}}$ & $\boldsymbol{\varepsilon}_{\mathrm{c}} \boldsymbol{\varepsilon}_{\mathrm{co}}$ \\
\hline 2 & Balance de energía & $\mathrm{P}-\delta$ & 0.75 & $24.2 \%$ \\
\hline 3 & Aproximado & $\mathrm{P}-\delta$ & 0.74 & $25.6 \%$ \\
\hline
\end{tabular}

\section{Comparación de las deformaciones obtenidas en el punto de plastificación al aplicar los métodos de idealización 2 y 3 en el diagrama $M-\varphi$}

En este caso, si se comparan las deformaciones del hormigón y del acero obtenidas para el punto de plastificación al idealizar el diagrama $\mathrm{M}-\varphi$ mediante los métodos 2 y 3 , se ha encontrado que los resultados de los dos métodos son similares. Sin embargo, los valores de las deformaciones son algo superiores a las obtenidas en la idealización del diagrama $\mathrm{P}-\delta$. En la Tabla 6-17 se muestra que la relación de las deformaciones del hormigón $\varepsilon_{\mathrm{c}} / \varepsilon_{\mathrm{co}}$ es cercana a la unidad, y el coeficiente de variación disminuye hasta un $19 \%$ y $17.7 \%$, siendo estos valores todavía altos. Las diferencias en los valores de deformación entre las idealizaciones de los diagramas $\mathrm{P}-\delta$ y $\mathrm{M}-\varphi$ aplicando los métodos 2 y 3 , se deben a los efectos de segundo orden presentes en la mayoría de los ensayos experimentales.

Además, se puede observar en la Figura 6.17 que las deformaciones del hormigón obtenidas en el diagrama $M-\varphi$, en una gran parte de los ensayos, son superiores a la deformación $\varepsilon_{c o}$; por consiguiente, es posible que el hormigón en el punto de plastificación se encuentre en un estado de deformación post-pico.

Tabla 6-17 Error medio y coeficiente de variación para el punto de plastificación definido por el hormigón. (Método de balance de energía y el método aproximado en la idealización de $M-\varphi$ )

\begin{tabular}{|c|c|c|c|c|}
\hline \multirow{2}{*}{$\mathbf{N}^{\circ}$ Método } & \multirow{2}{*}{ MÉTODO } & \multirow{2}{*}{ Curva idealizada } & $\overline{\mathbf{E}}$ & $\mathbf{C V}$ \\
\cline { 4 - 5 } & & & $\boldsymbol{\varepsilon}_{\mathrm{c}} / \boldsymbol{\varepsilon}_{\mathrm{co}}$ & $\boldsymbol{\varepsilon}_{\mathrm{c}} / \boldsymbol{\varepsilon}_{\mathrm{co}}$ \\
\hline 2-MC & Balance de energía & $\mathrm{M}-\varphi$ & 0.97 & $19.1 \%$ \\
\hline $3-\mathrm{MC}$ & Aproximado & $\mathrm{M}-\varphi$ & 1.00 & $17.7 \%$ \\
\hline
\end{tabular}


Deformaciones en el punto de plastificación aplicando los métodos de idealización 1A y 1B

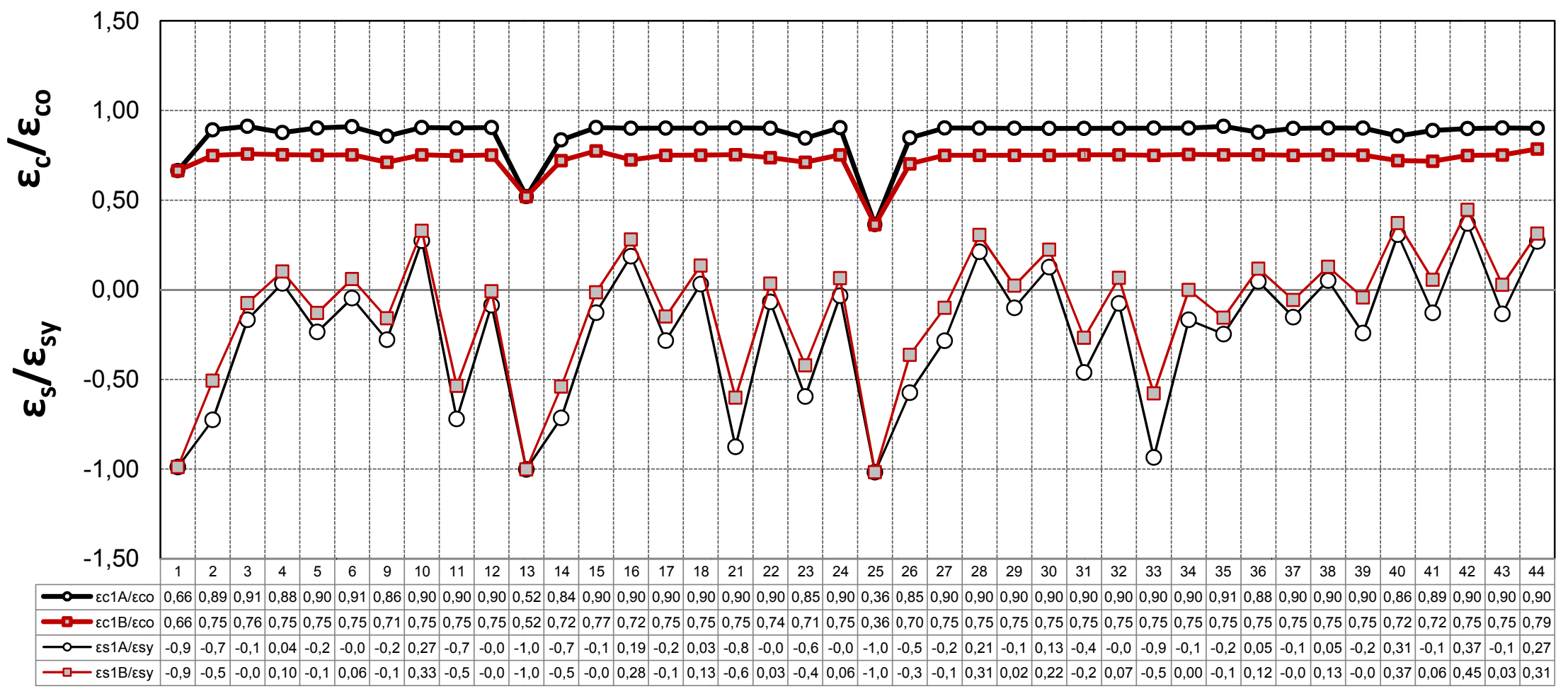

Figura 6.15 Deformaciones en el punto de plastificación aplicando los métodos de idealización $1 A$ y $1 B$ 
Deformaciones en el punto de plastificación aplicando los métodos de idealización 2 y 3 (para P- $\delta$ )

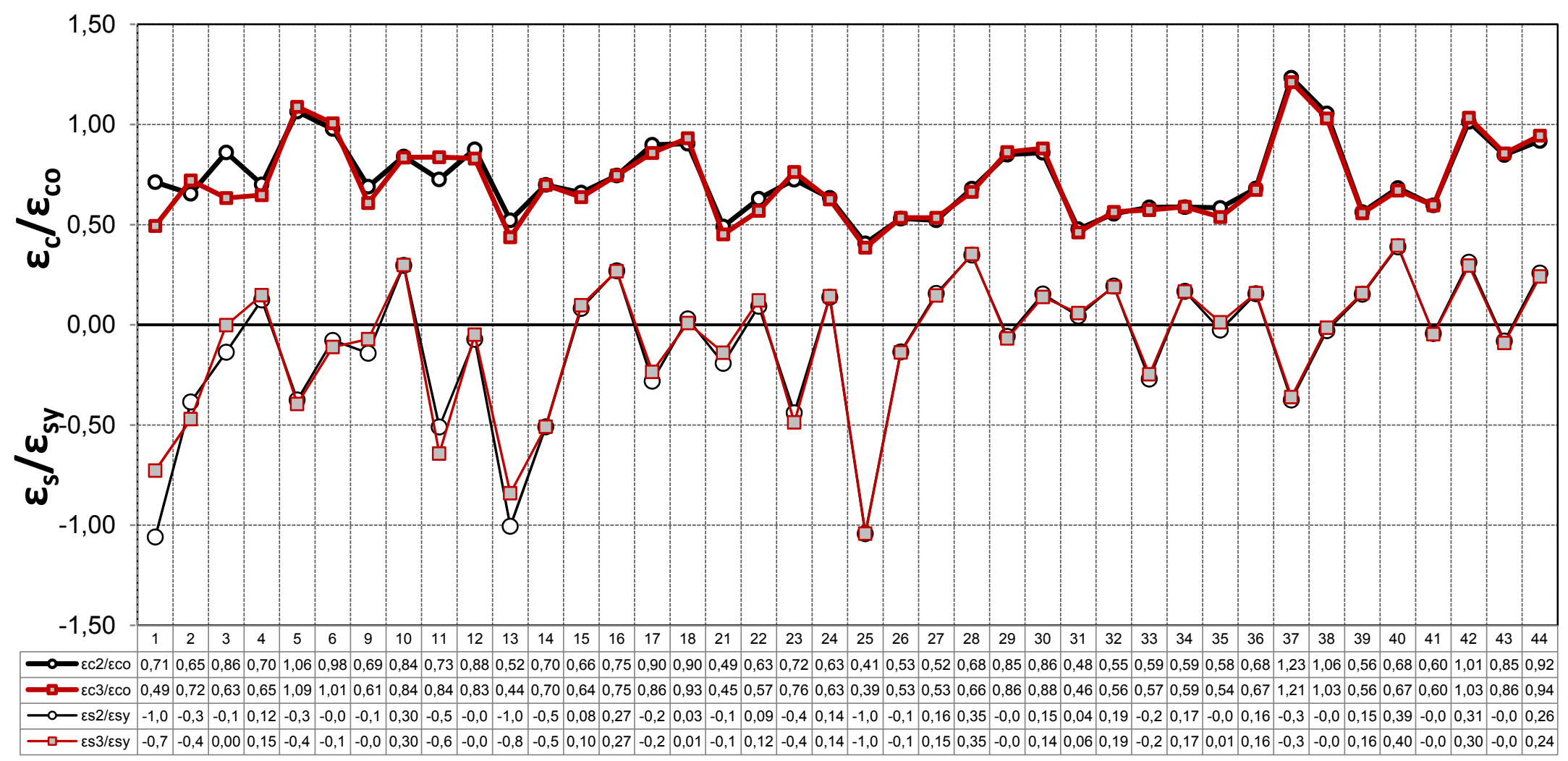

Figura 6.16 Deformaciones en el punto de plastificación aplicando los métodos de idealización 2 y 3 en el diagrama de respuesta P- $\delta$ 
Deformaciones en el punto de plastificación aplicando los métodos de idealización 2 y 3 (para M- $\varphi$ )

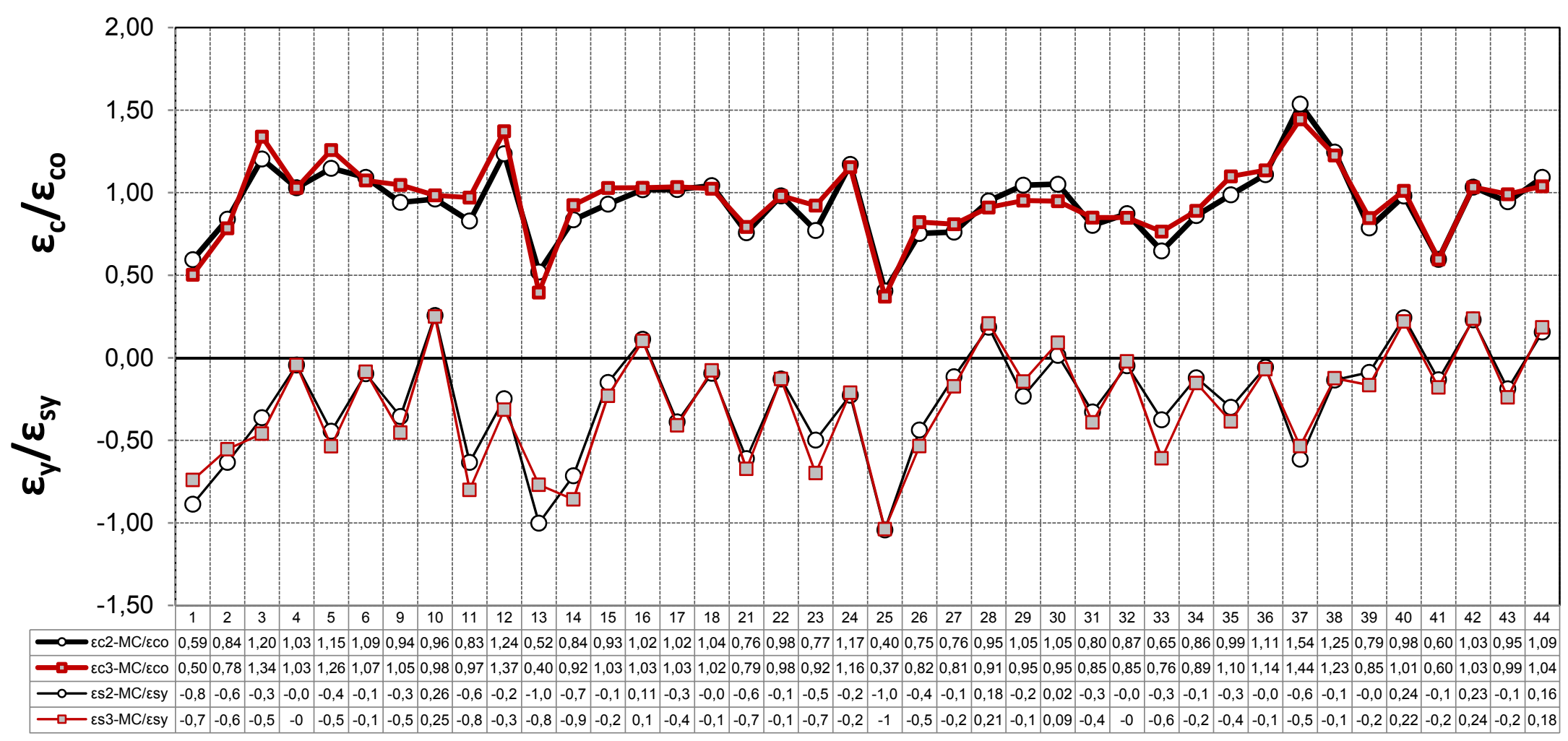

Figura 6.17 Deformaciones en el punto de plastificación aplicando los métodos de idealización 2 y 3 en el diagrama de respuesta M- $\varphi$ 
A partir del análisis de deformaciones en el punto de plastificación se ha llegado a las siguientes conclusiones:

- El punto de plastificación es un punto clave en la evaluación tanto de la rigidez del elemento como de los parámetros de ductilidad. Por consiguiente, es necesario aplicar definiciones precisas para determinar dicho punto. La definición más clara en los métodos aplicados en este estudio es la propuesta en el Eurocódigo-8 [59] y ha sido utilizada en diferentes estudios (Priestley M. et al. (1996) [111] y Priestley M. y Park R. (1997) [110] y Fischinger M. (2008) [61]), ya que condiciona el punto de plastificación a una deformación límite del hormigón o del acero en la que cualquiera de estos dos materiales marca el inicio de su comportamiento inelástico. Una ventaja de la definición de punto de plastificación con el criterio de deformaciones es el efecto de la concomitancia de los diagramas $M-\varphi$ y $P-\delta$, lo cual garantiza también la concomitancia entre el desplazamiento y la curvatura en el punto de plastificación.

- Se ha comprobado que el método del balance de energía (método 2) y el método aproximado (método 3 ) generan resultados bastante similares, tanto si se aplican en la idealización del diagrama $\mathrm{M}-\varphi$ como en el diagrama $\mathrm{P}-\delta$. Adicionalmente, se ha verificado que no existe una relación clara entre el punto de plastificación y el estado de los materiales, al utilizar estos dos métodos en la idealización del comportamiento de $\mathrm{M}-\varphi$ y $\mathrm{P}-\delta$.

- El método de balance de energía y el método aproximado son fácilmente aplicables en la idealización de la respuesta experimental $M-\varphi$ y $\mathrm{P}-\delta$ cuando no se dispone de los valores de deformación de los materiales.

Estos dos métodos son útiles y normalmente han sido utilizados en la idealización del comportamiento $M-\varphi$ y $\mathrm{P}-\delta$ en ensayos poco esbeltos donde los efectos de segundo orden son despreciables y, por consiguiente, la carga elástica coincide con el momento elástico, siendo el desplazamiento elástico concomitante con la curvatura elástica.

En esta investigación, y en base a todo este análisis, se ha considerado que el método más adecuado para la idealización de los diagramas de respuesta experimental $M-\varphi$ y $\mathrm{P}-\delta$ es el método del Eurocódigo-8 [59]. Las razones que han llevado a la elección de este método son las siguientes. En primer lugar, se ha considerado que el criterio para definir un punto de plastificación relacionado con el estado de deformación de los materiales es bastante preciso y permite valorar la rigidez efectiva, la curvatura elástica y el desplazamiento elástico para el mismo punto. En segundo lugar, el criterio de deformación límite para el comportamiento elástico de los materiales garantiza que, por lo menos hasta este punto, los materiales se encuentran actuando bajo un comportamiento elástico. Y, por último, la utilización de este método es factible en este estudio, ya que se dispone de los valores de deformación de los materiales durante todo el ensayo.

En este método se ha considerado que la deformación $0.75 \varepsilon_{\mathrm{co}}$ representa un límite adecuado para el comienzo de la no linealidad del material para todo el rango de resistencias del hormigón en compresión, tal y como lo indica el CEB-FIP Bulletin 25 (2003) [35]. Por consiguiente, para los análisis posteriores en este estudio, se 
utilizarán los resultados de la idealización de los diagramas $\mathrm{M}-\varphi$ y P- $\delta$ obtenidos a partir del método implementado en el Eurocódigo 8 [59], utilizando como criterio para identificar el punto de plastificación un valor de deformación de $0.75 \varepsilon_{\text {co }}$ para el hormigón y la deformación correspondiente al límite elástico del acero $\left(\varepsilon_{\mathrm{sy}}\right)$.

\subsubsection{RESULTADOS DE LA IDEALIZACIÓN DEL DIAGRAMA MOMENTO- CURVATURA (M- $\Phi)$}

En esta sección se presentan los resultados de la idealización del diagrama $\mathrm{M}-\varphi$ empleando el método del Eurocódigo 8 [59], versión 1B. Las variables obtenidas son: la curvatura elástica efectiva $\left(\varphi^{\prime}{ }_{\mathrm{y} 1 \mathrm{~B}}{ }^{*} \mathrm{~d}\right)$, la curvatura última $\left(\varphi_{\mathrm{u}}{ }^{*} \mathrm{~d}\right)$, la curvatura plástica $\left(\varphi_{\mathrm{p} 2}{ }^{*} \mathrm{~d}\right)$ y la ductilidad de curvatura $\left(\mu_{\varphi 1 \mathrm{~B}}\right)$. Las variables de curvatura se presentan en forma adimensional con el canto útil de la sección (d).

Para poder llevar a cabo el análisis, los resultados son presentados en grupos de ensayos que conforman series que permiten evaluar la influencia de cada uno de los parámetros propuestos en el programa experimental. Aunque se pretende determinar de forma independiente la influencia de cada uno de estos parámetros, es necesario que el análisis de los mismos se realice conjuntamente con el análisis de la resistencia del hormigón, puesto que este parámetro, estudiado por sí sólo, no muestra conclusiones claras.

\subsubsection{Influencia de la esbeltez de cortante}

Para evaluar el efecto de la esbeltez de cortante $(\lambda=\mathrm{L} / \mathrm{h})$, se realiza una comparación entre los resultados de la serie de ensayos que incluye los valores de esbeltez ( $\lambda=7.5$ y $\lambda=10.5)$; cada valor de $\lambda$ incorpora tres valores de resistencia del hormigón (alrededor de 30, 60 y $90 \mathrm{MPa}$ ), y dos niveles de carga axil (30\% y 45\%).

Tabla 6-18 Resultados de la idealización del diagrama $M-\varphi$ empleando el método del Eurocódigo 8 (versión 1B), para la serie de ensayos utilizada en el análisis de la influencia del parámetro esbeltez

\begin{tabular}{|c|c|c|c|c|c|c|c|c|c|c|}
\hline $\begin{array}{c}\mathrm{N}^{\circ} \\
\text { ensayo }\end{array}$ & REFERENCIA & $\begin{array}{c}f_{c} \\
(\mathrm{MPa})\end{array}$ & $\mathrm{N} / \mathrm{N}_{\mathrm{u}}$ & $\lambda$ & $\begin{array}{c}\rho_{\mathrm{l}} \\
(\%)\end{array}$ & $\begin{array}{l}\rho_{\mathrm{s}} \\
(\%)\end{array}$ & $\begin{array}{c}\varphi_{\mathrm{y} 1 \mathrm{~B}^{*} \mathrm{~d}}^{\prime} \\
(\% \mathrm{o})\end{array}$ & $\begin{array}{c}\varphi_{p 1 B^{*} d} \\
(\% 0)\end{array}$ & $\begin{array}{l}\varphi_{u}{ }^{*} d \\
(\%)\end{array}$ & $\mu_{\varphi 1 \mathrm{~B}}$ \\
\hline 5 & N30-7.5-C0-2-30 & 30.10 & 0.30 & \multirow{6}{*}{7.5} & \multirow{12}{*}{2.24} & \multirow{12}{*}{1.0} & 3.42 & 10.83 & 14.25 & 4.17 \\
\hline 17 & $\mathrm{H} 60-7.5-\mathrm{C} 0-2-30$ & 58.20 & 0.30 & & & & 3.51 & 7.77 & 11.28 & 3.21 \\
\hline 29 & $\mathrm{H} 90-7.5-\mathrm{CO}-2-30$ & 100.35 & 0.27 & & & & 3.34 & 6.07 & 9.41 & 2.82 \\
\hline 6 & N30-7.5-C0-2-45 & 33.00 & 0.42 & & & & 2.46 & 10.74 & 13.20 & 5.36 \\
\hline 18 & $\mathrm{H} 60-7.5-\mathrm{C} 0-2-45$ & 58.65 & 0.46 & & & & 2.89 & 7.19 & 10.08 & 3.49 \\
\hline 30 & $\mathrm{H} 90-7.5-\mathrm{CO}-2-45$ & 94.00 & 0.41 & & & & 2.67 & 6.99 & 9.67 & 3.62 \\
\hline 3 & N30-10.5-C0-2-30 & 31.60 & 0.30 & \multirow{6}{*}{10.5} & & & 3.46 & 6.13 & 9.59 & 2.77 \\
\hline 15 & $\mathrm{H} 60-10.5-\mathrm{C} 0-2-30$ & 60.45 & 0.29 & & & & 2.68 & 3.25 & 5.93 & 2.21 \\
\hline 27 & $\mathrm{H} 90-10.5-\mathrm{C} 0-2-30$ & 90.10 & 0.30 & & & & 3.14 & 3.18 & 6.32 & 2.01 \\
\hline 4 & N30-10.5-C0-2-45 & 34.50 & 0.42 & & & & 1.93 & 3.70 & 5.62 & 2.92 \\
\hline 16 & $\mathrm{H} 60-10.5-\mathrm{C} 0-2-45$ & 63.90 & 0.43 & & & & 2.09 & 3.38 & 5.47 & 2.61 \\
\hline 28 & H90-10.5-C0-2-45 & 93.20 & 0.44 & & & & 1.91 & 2.61 & 4.52 & 2.36 \\
\hline
\end{tabular}

Como se puede ver en la Figura 6.18a, la tendencia de la curvatura elástica efectiva es aproximadamente lineal e independiente de la resistencia del hormigón, tanto para $\lambda=7.5$ como para $\lambda=10.5$. Sin embargo, los valores del parámetro adimensional 
$\varphi^{\prime}{ }_{y 1 \mathrm{~B}}{ }^{*} \mathrm{~d}$ para $\lambda=7.5$ son algo superiores a los obtenidos para $\lambda=10.5$, debido a que existe un mayor brazo mecánico para la sección de mayor canto $(0.2 \mathrm{~m})$. Adicionalmente, como era de esperar, los valores del parámetro $\varphi^{\prime}{ }_{\mathrm{y} 1 \mathrm{~B}}{ }^{*} \mathrm{~d}$ son algo superiores para niveles de carga axil del $30 \%$ que para el $45 \%$.

En la Figura $6.18 \mathrm{~b}$ se presentan los valores de curvatura última adimensional $\left(\varphi_{u}{ }^{*} \mathrm{~d}\right)$. En ella se observa que los valores de curvatura última son mayores para $\lambda=7.5$ que para $\lambda=10.5$. En este caso, existe una leve tendencia lineal decreciente de los valores de con respecto a la resistencia del hormigón. Además, los valores de $\varphi_{u}{ }^{*} d$ tienden a ser ligeramente mayores para el $30 \%$ de carga axil que para el $45 \%$.

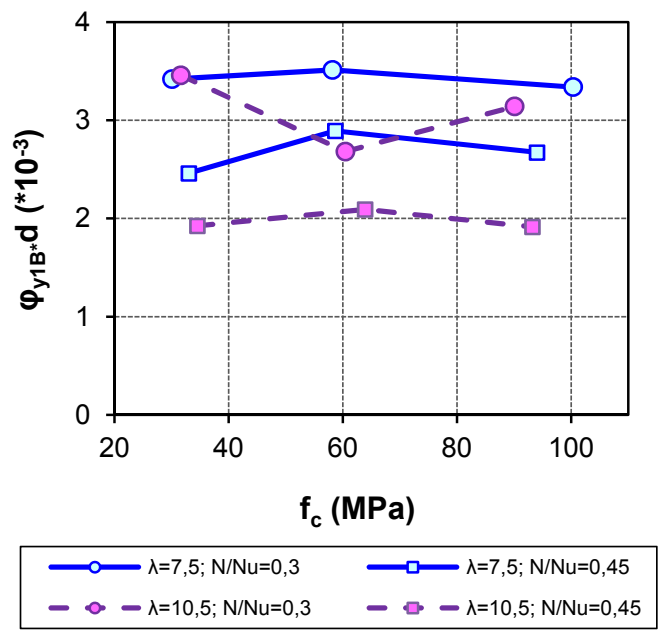

(a)

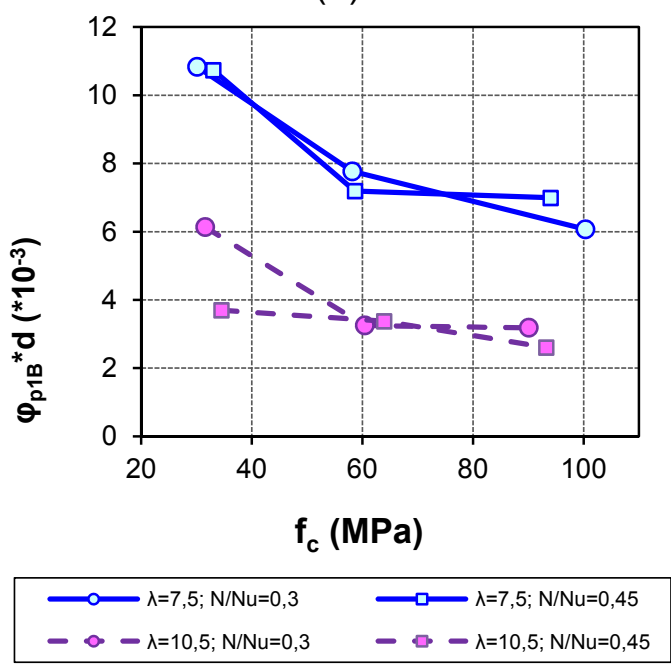

(c)

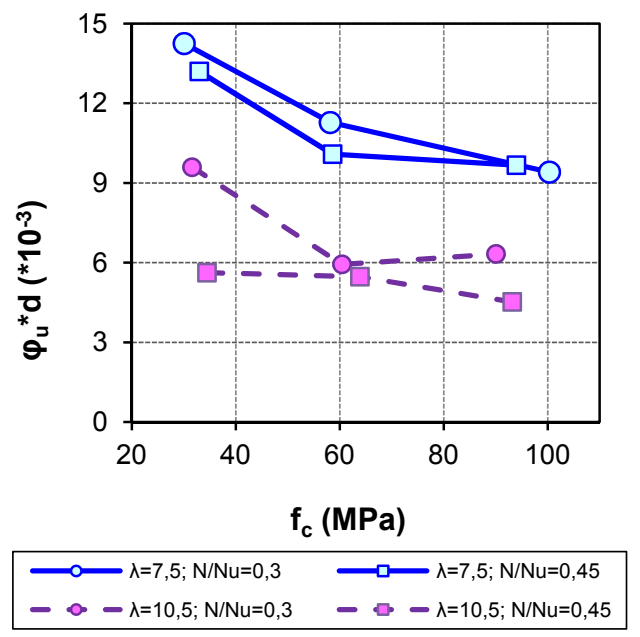

(b)

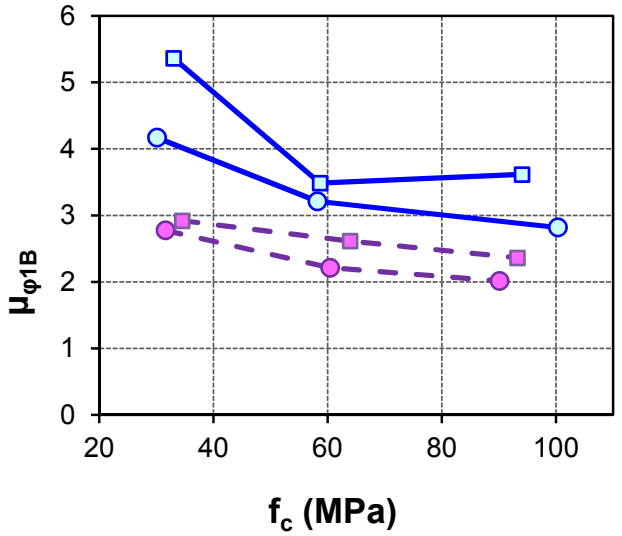

$\begin{array}{ll}\longrightarrow \\ \longrightarrow-\lambda=7,5 ; \mathrm{N} / \mathrm{Nu}=0,3 & \longrightarrow \\ -\lambda=10,5 ; \mathrm{N} / \mathrm{Nu}=0,3 & -\square, 5 ; \mathrm{N} / \mathrm{Nu}=0,45 \\ & -\lambda=10,5 ; \mathrm{N} / \mathrm{Nu}=0,45\end{array}$

(d)

Figura 6.18 Comparación de las variables: (a) curvatura elástica efectiva $\left(\varphi^{\mathbf{y} 1 \mathrm{~B}}{ }^{\prime}\right),(b)$ curvatura última $\left(\varphi_{u}\right),(c)$ curvatura plástica $\left(\varphi_{p 1 B}\right)$ y $(d)$ ductilidad de curvatura $\left(\mu_{\varphi 1 B}\right)$, con respecto a las variables esbeltez, resistencia del hormigón, y nivel de carga axil

La diferencia y el cociente entre las dos variables anteriores $\left(\varphi_{u}\right.$ y $\left.\varphi^{\prime}{ }_{y 1 B}\right)$ dan como resultado la curvatura plástica $\left(\varphi_{\mathrm{p} 1 \mathrm{~B}}\right)$, y la ductilidad de curvatura $\left(\mu_{\varphi 1 \mathrm{~B}}\right)$. Estas dos 
Estudio experimental y numérico de la capacidad de deformación de soportes esbeltos de hormigón armado

variables muestran realmente la capacidad de deformación en el rango inelástico de la sección.

Las Figuras 6.18c y d muestran que la tendencia de la curvatura plástica adimensional $\left(\varphi_{\mathrm{p} 1 \mathrm{~B}}{ }^{*} \mathrm{~d}\right)$ y de la ductilidad de curvatura $\left(\mu_{\varphi 1 \mathrm{~B}}\right)$ son lineales y decrecientes con respecto a la resistencia del hormigón. Además, se indica que para $\lambda=7.5$ las dos variables $\varphi_{\mathrm{p} 2}{ }^{*} \mathrm{~d}$ y $\mu_{\varphi 1 \mathrm{~B}}$ son mayores que para $\lambda=10.5$. Adicionalmente, aunque la variable $\varphi_{\mathrm{p} 2}{ }^{*} \mathrm{~d}$ muestra que para los niveles de carga axil $30 \%$ y $45 \%$ no existen importantes diferencias, para la variable $\mu_{\varphi 1 B}$ se observa que existe un leve incremento de la ductilidad al aumentar el nivel de carga axial de $30 \%$ a $45 \%$. Esto se debe a que el punto de plastificación definido por el límite de deformación del hormigón en compresión se alcanza más rápidamente conforme aumenta el nivel de carga axial, y, en consecuencia, las curvaturas elásticas efectivas serán menores, lo que matemáticamente incrementará la ductilidad dentro de los rangos de esbeltez y nivel de carga axial analizados en este estudio.

\subsubsection{Influencia del nivel de carga axil}

Para comprobar experimentalmente el efecto del nivel de carga axil en soportes esbeltos de hormigón armado, se ha escogido la esbeltez de cortante $\lambda=10.5$, con resistencias a compresión del hormigón de 30,60 y $90 \mathrm{MPa}$, y niveles de carga axil de $0,15,30$ y 45 (Tabla 6-19).

Tabla 6-19 Resultados de la idealización del diagrama $M-\varphi$ empleando el método del Eurocódigo 8 (versión 1B), para la serie de ensayos utilizada en el análisis de la influencia del nivel de carga axil

\begin{tabular}{|c|c|c|c|c|c|c|c|c|c|c|}
\hline $\begin{array}{c}\mathrm{N}^{\circ} \\
\text { ensayo }\end{array}$ & REFERENCIA & $\begin{array}{c}f_{c} \\
(\mathrm{MPa})\end{array}$ & $\mathrm{N} / \mathrm{N}_{\mathrm{u}}$ & $\lambda$ & $\begin{array}{c}\rho_{l} \\
(\%)\end{array}$ & $\begin{array}{l}\rho_{\mathrm{s}} \\
(\%)\end{array}$ & $\begin{array}{c}\varphi_{\text {y1B }}^{\prime}{ }^{*} d \\
(\%)\end{array}$ & $\begin{array}{c}\varphi_{p 1 B^{*}}{ }^{\prime} \\
(\% 0)\end{array}$ & $\begin{array}{l}\varphi_{u}{ }^{*} d \\
(\% 0)\end{array}$ & $\mu_{\varphi 1 B}$ \\
\hline 1 & N30-10.5-C0-2-00 & 36.60 & 0.00 & \multirow{12}{*}{10.5} & \multirow{12}{*}{2.24} & \multirow{12}{*}{1.0} & 4.40 & 12.04 & 16.44 & 3.73 \\
\hline 2 & N30-10.5-C0-2-15 & 31.75 & 0.14 & & & & 3.81 & 11.82 & 15.63 & 4.10 \\
\hline 3 & N30-10.5-C0-2-30 & 31.60 & 0.30 & & & & 3.46 & 6.13 & 9.59 & 2.77 \\
\hline 4 & N30-10.5-C0-2-45 & 34.50 & 0.42 & & & & 1.93 & 3.70 & 5.62 & 2.92 \\
\hline 13 & $\mathrm{H} 60-10.5-\mathrm{C} 0-2-00$ & 55.80 & 0.00 & & & & 4.23 & 10.61 & 14.84 & 3.51 \\
\hline 14 & $\mathrm{H} 60-10.5-\mathrm{C} 0-2-15$ & 54.10 & 0.15 & & & & 3.61 & 9.14 & 12.75 & 3.32 \\
\hline 15 & $\mathrm{H} 60-10.5-\mathrm{C} 0-2-30$ & 60.45 & 0.29 & & & & 2.68 & 3.25 & 5.93 & 2.21 \\
\hline 16 & $\mathrm{H} 60-10.5-\mathrm{C} 0-2-45$ & 63.90 & 0.43 & & & & 2.09 & 3.38 & 5.47 & 2.61 \\
\hline 25 & $\mathrm{H} 90-10.5-\mathrm{C} 0-2-00$ & 91.35 & 0.00 & & & & 5.16 & 9.19 & 14.35 & 2.78 \\
\hline 26 & $\mathrm{H} 90-10.5-\mathrm{C} 0-2-15$ & 90.50 & 0.15 & & & & 4.26 & 9.18 & 13.44 & 3.15 \\
\hline 27 & $\mathrm{H} 90-10.5-\mathrm{C} 0-2-30$ & 90.10 & 0.30 & & & & 3.14 & 3.18 & 6.32 & 2.01 \\
\hline 28 & $\mathrm{H} 90-10.5-\mathrm{C} 0-2-45$ & 93.20 & 0.44 & & & & 1.91 & 2.61 & 4.52 & 2.36 \\
\hline
\end{tabular}

Como se puede observar en la Figura 6.19a, la curvatura elástica efectiva $\left(\varphi^{\prime}{ }^{\prime} 1{ }^{*}{ }^{*} d\right)$ disminuye linealmente cuando aumenta el nivel de carga axial $\left(N / N_{u}\right)$, sin que se observe claramente cuál es efecto con la resistencia del hormigón $\left(f_{c}\right)$. Sin embargo, para niveles de carga axial altos (45\%) se muestra que el $\mathrm{N} / \mathrm{N}_{\mathrm{u}}$ es muy predominante en el comportamiento, Para este nivel de carga axial no existe influencia de la resistencia del hormigón.

Por otra parte, como se observa en la Figura $6.19 \mathrm{~b}$, la curvatura última muestra una tendencia también decreciente con respecto al incremento del nivel de carga axil. 
En esta figura se destaca una diferencia entre los valores de curvatura última para ensayos con hormigón convencional (30 MPa) y ensayos con hormigón de alta resistencia (60 y $90 \mathrm{MPa}$ ), siendo el comportamiento entre estos dos últimos muy similar. Esto se debe a que el hormigón convencional admite por su naturaleza una mayor deformación que el hormigón de alta resistencia. En el caso de la curvatura última, también se observa que, para altos niveles de carga axial, la influencia de la resistencia del hormigón en el comportamiento de la sección es despreciable.

El nivel de carga axial $\left(\mathrm{N} / \mathrm{N}_{\mathrm{u}}\right)$ es el parámetro que mayor efecto causa en el comportamiento deformacional; sin embargo, su influencia no es constante en todo el rango de estudio, ya que el comportamiento de la sección depende más específicamente del modo de fallo, lo cual está condicionado por diferentes factores que interactúan junto con el nivel de axil, como son: la esbeltez, la cuantía de armadura longitudinal, la resistencia del hormigón y la cuantía de armadura transversal.

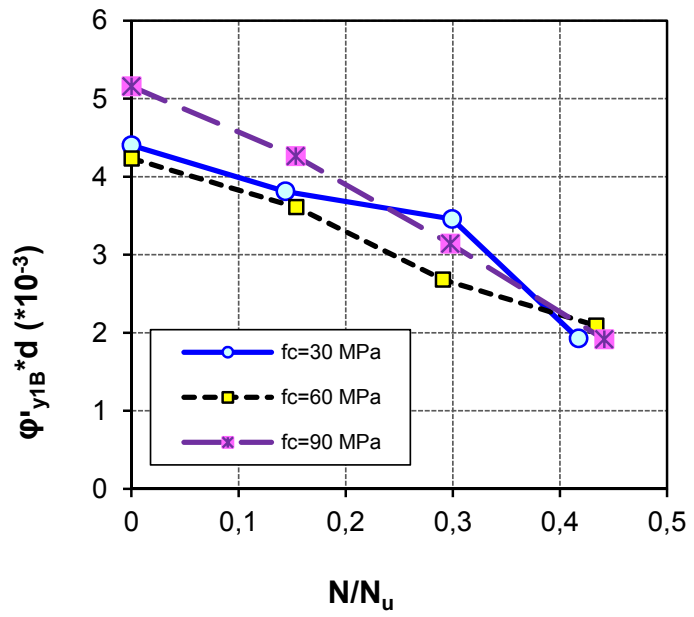

(a)

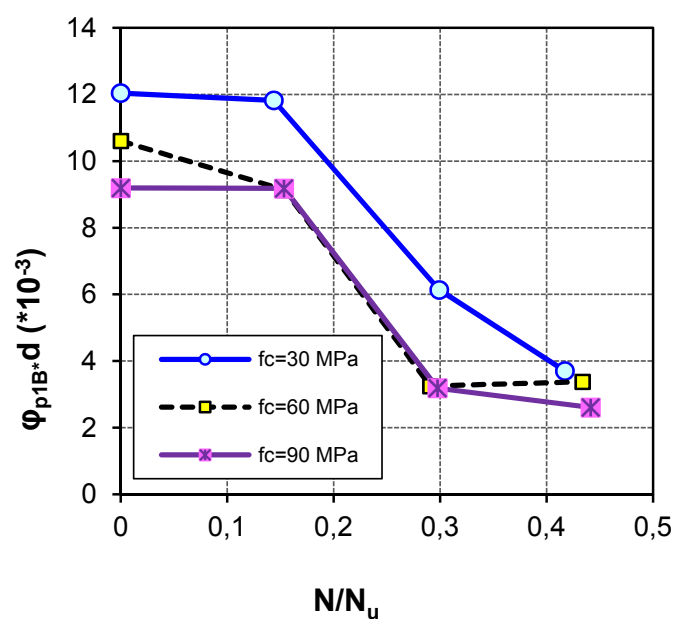

(c)

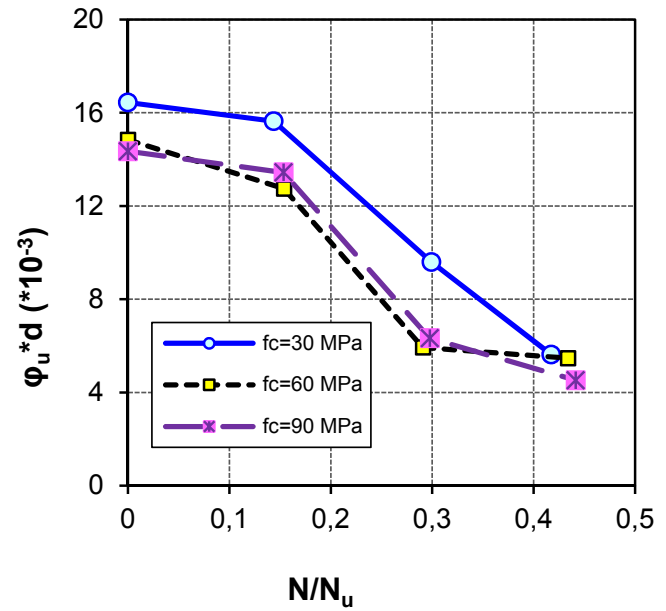

(b)

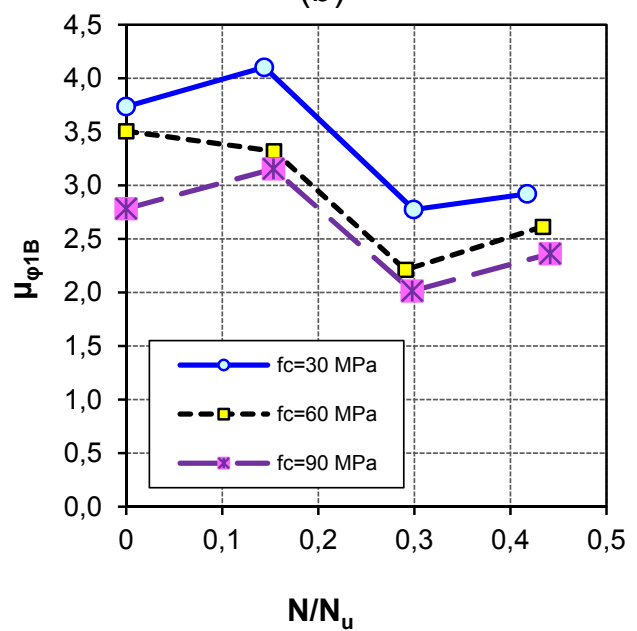

(d)

Figura 6.19 Comparación de las variables: (a) curvatura elástica efectiva $\left(\varphi^{\prime}{ }_{y 1 \mathrm{~B}}\right),(b)$ curvatura última $\left(\varphi_{u}\right),(c)$ curvatura plástica $\left(\varphi_{p 1 B}\right)$ y $(d)$ ductilidad de curvatura $\left(\mu_{\varphi 1 B}\right)$, con respecto a las variables nivel de carga axil y resistencia del hormigón 
En esta investigación no existe un número de ensayos experimentales suficiente como para definir claramente el comportamiento de la deformación inelástica y el efecto de $\mathrm{N} / \mathrm{N}_{\mathrm{u}}$ en un amplio rango. Por consiguiente, para poder interpretar el efecto del nivel de carga axil en los ensayos experimentales, en las Figuras 6.19c y d se representa la curvatura plástica $\left(\varphi_{\mathrm{p} 1 \mathrm{~B}}{ }^{*} \mathrm{~d}\right)$ y la ductilidad de curvatura $\left(\mu_{\varphi 1 \mathrm{~B}}\right)$ respecto al nivel de carga axial $\left(\mathrm{N} / \mathrm{N}_{\mathrm{u}}\right)$, en donde se observan tres posibles zonas en función del comportamiento de la probeta.

- En la parte alta de las curvas, entre un nivel de carga axial de $0 \%$ a $15 \%$, el fallo se debe a la tracción de la armadura, lográndose una alta deformación plástica, debido a la alta deformación de la armadura en tracción. En esta zona se han registrado los mayores valores de las variables $\varphi_{p 1 \mathrm{~B}}{ }^{*} \mathrm{~d}$ y $\mu_{\varphi 1 \mathrm{~B}}$.

- En la parte B de la curva, entre el nivel de carga axil de $15 \%$ a $30 \%$, el fallo se produce por compresión, y se observa que las dos variables $\varphi_{p 1 B}{ }^{*} d$ y $\mu_{\varphi 1 B}$ caen rápidamente conforme aumenta el nivel de carga axil.

- A partir del $30 \%$ hasta el $45 \%$ de carga axil, el fallo de los ensayos de produce por compresión, sin que se presenten diferencias significativas. En la Figura $6.19 \mathrm{c}$ se muestra que la curvatura plástica disminuye levemente con el incremento del nivel de carga axil y tiende a un valor que parece indiferente a la resistencia del hormigón.

- Respecto a la ductilidad de curvatura, en esta parte de la curva se aprecia un leve ascenso de la ductilidad para este rango de carga axial. Este pequeño incremento no es significativo, y, por consiguiente, es necesaria una mayor comprobación experimental en este rango de esbeltez y niveles de carga axial para confirmar este efecto.

Por otra parte, como se puede ver, el efecto de la resistencia del hormigón se puede diferenciar en las dos Figuras 6.19c y d. Para la curvatura plástica existe una diferencia marcada entre el hormigón de $30 \mathrm{MPa}$ y el hormigón de 60 y $90 \mathrm{MPa}$, aunque no se aprecia una importante diferencia entre estos dos últimos. En cuanto a la variable ductilidad, sí se diferencia claramente cómo disminuye ésta con el incremento de la resistencia del hormigón.

\subsubsection{Influencia de la cuantía de armadura longitudinal}

Para evaluar el efecto de la cuantía de armadura longitudinal en la capacidad de deformación de soportes esbeltos de hormigón armado, dentro del programa experimental se ha desarrollado una serie de ensayos en soportes de esbeltez de cortante $\lambda=10.5$. La serie incluye tres valores de resistencia del hormigón (30, 60 y $90 \mathrm{MPa}$ ), dos niveles aproximados de carga axil (15\% y 30\%), y cuantías longitudinales de $1.44 \%, 2.24 \%$ y $3.23 \%$, sin tener en cuenta el efecto del confinamiento. La Tabla 6-20 incluye la relación de ensayos y los resultados obtenidos. 
Tabla 6-20 Resultados de la idealización del diagrama M- $\varphi$ empleando el método del Eurocódigo 8 (versión 1B), para la serie de ensayos utilizada en el análisis de la influencia de la cuantía longitudinal

\begin{tabular}{|c|c|c|c|c|c|c|c|c|c|c|}
\hline $\begin{array}{c}\mathrm{N}^{\circ} \\
\text { ensayo }\end{array}$ & REFERENCIA & $\begin{array}{c}f_{\mathrm{c}} \\
(\mathrm{MPa})\end{array}$ & $\mathrm{N} / \mathrm{N}_{\mathrm{u}}$ & $\begin{array}{c}\rho_{1} \\
(\%)\end{array}$ & $\lambda$ & $\begin{array}{c}\rho_{\mathrm{s}} \\
(\%)\end{array}$ & $\begin{array}{c}\varphi_{\mathrm{y} 1 \mathrm{~B}}^{*} \mathrm{~d} \\
(\% \mathrm{o})\end{array}$ & $\begin{array}{c}\varphi_{p 1 B^{*} d} \\
(\%)\end{array}$ & $\begin{array}{l}\varphi_{u}^{*} d \\
(\%)\end{array}$ & $\mu_{\varphi 1 B}$ \\
\hline 9 & $\mathrm{~N} 30-10.5-\mathrm{C} 0-1-30$ & 42.2 & 0.23 & 1.44 & \multirow{18}{*}{10.5} & \multirow{18}{*}{1.0} & 3.19 & 14.23 & 17.42 & 5.47 \\
\hline 2 & N30-10.5-C0-2-15 & 31.8 & 0.14 & 2.24 & & & 3.81 & 11.82 & 15.63 & 4.10 \\
\hline 11 & N30-10.5-C0-3-15 & 33.0 & 0.15 & 3.23 & & & 4.70 & 10.66 & 15.37 & 3.27 \\
\hline 10 & N30-10.5-C0-1-45 & 35.2 & 0.51 & 1.44 & & & 1.31 & 1.41 & 2.72 & 2.08 \\
\hline 3 & N30-10.5-C0-2-30 & 31.6 & 0.30 & 2.24 & & & 3.46 & 6.13 & 9.59 & 2.77 \\
\hline 12 & N30-10.5-C0-3-30 & 29.5 & 0.31 & 3.23 & & & 2.93 & 6.61 & 9.54 & 3.25 \\
\hline 21 & H60-10.5-C0-1-15 & 57.8 & 0.16 & 1.44 & & & 4.44 & 8.70 & 13.14 & 2.96 \\
\hline 14 & $\mathrm{H} 60-10.5-\mathrm{C} 0-2-15$ & 54.1 & 0.15 & 2.24 & & & 3.84 & 8.91 & 12.75 & 3.32 \\
\hline 23 & H60-10.5-C0-3-15 & 58.3 & 0.15 & 3.23 & & & 4.48 & 3.00 & 7.48 & 1.67 \\
\hline 22 & $\mathrm{H} 60-10.5-\mathrm{C} 0-1-30$ & 58.5 & 0.30 & 1.44 & & & 2.59 & 7.39 & 9.98 & 3.86 \\
\hline 15 & $\mathrm{H} 60-10.5-\mathrm{C} 0-2-30$ & 60.5 & 0.29 & 2.24 & & & 2.68 & 3.71 & 6.39 & 2.21 \\
\hline 24 & $\mathrm{H} 60-10.5-\mathrm{C} 0-3-30$ & 61.6 & 0.29 & 3.23 & & & 3.19 & 7.64 & 10.83 & 3.40 \\
\hline 31 & H90-10.5-C0-1-15 & 90.3 & 0.15 & 1.44 & & & 3.70 & 9.81 & 13.50 & 3.65 \\
\hline 26 & H90-10.5-C0-2-15 & 90.5 & 0.15 & 2.24 & & & 4.26 & 9.18 & 13.44 & 3.15 \\
\hline 33 & H90-10.5-C0-3-15 & 89.6 & 0.15 & 3.23 & & & 4.88 & 4.43 & 9.31 & 1.91 \\
\hline 32 & H90-10.5-C0-1-30 & 96.2 & 0.29 & 1.44 & & & 2.57 & 5.95 & 8.52 & 3.32 \\
\hline 27 & H90-10.5-C0-2-30 & 90.1 & 0.30 & 2.24 & & & 3.14 & 3.18 & 6.32 & 2.01 \\
\hline 34 & H90-10.5-C0-3-30 & 94.4 & 0.29 & 3.23 & & & 3.01 & 3.16 & 6.18 & 2.05 \\
\hline
\end{tabular}

En las Figuras 6.20a y b se observa que la cuantía de armadura longitudinal incrementa la capacidad de deformación en el rango elástico. Este efecto es más evidente en soportes con bajos niveles de carga axil (15\%), donde el fallo es predominantemente por agotamiento por tracción, como se observa en la Figura 6.20a. Sin embargo, el efecto favorable de la cuantía de armadura longitudinal también es visible en el caso de soportes con fallo por agotamiento por compresión (niveles de carga axil de $30 \%$ ), tal y como se observa en la Figura 6.20b.

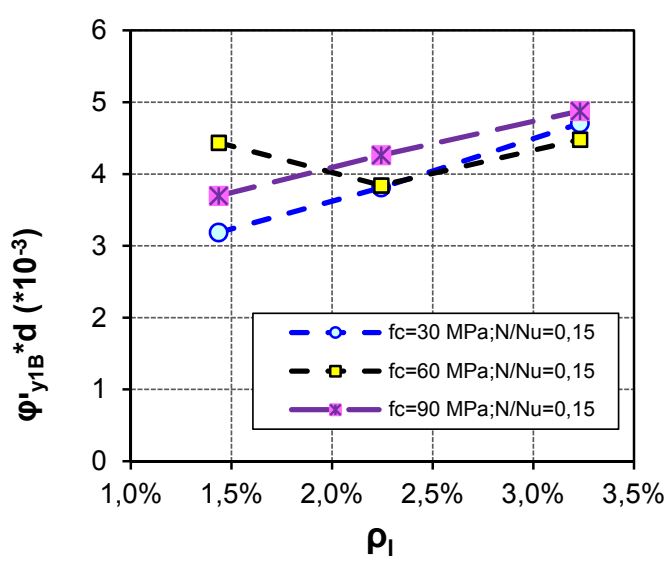

(a)

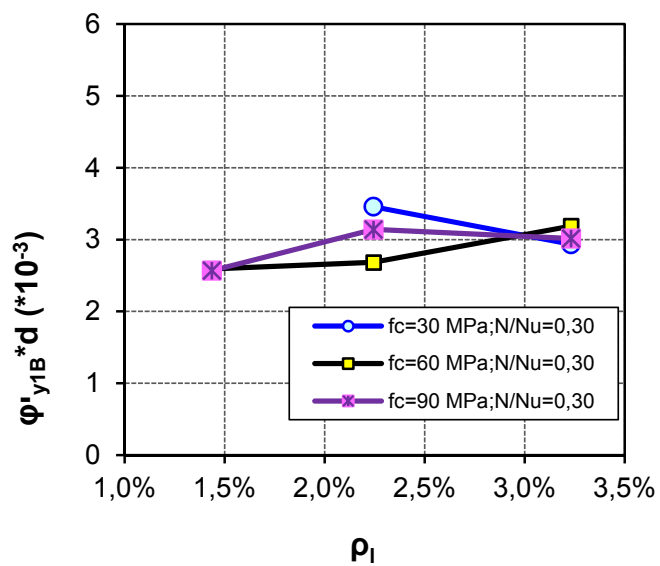

(b)

Figura 6.20 Comparación de la variable curvatura elástica efectiva $\left(\varphi^{\prime}{ }_{y 18}\right)$ con respecto a la cuantía de armadura longitudinal, resistencia del hormigón y niveles de carga axil del (a) $15 \%$ y (b) $30 \%$

En cuanto a la curvatura última, los resultados muestran que, para soportes esbeltos con bajos niveles de carga axial (15\%), cuando el fallo se produce por 
tracción (Figura 6.21a), el aumento en la cuantía de armadura longitudinal disminuye la capacidad de deformación última en términos de $\varphi_{\mathrm{u}}{ }^{*} \mathrm{~d}$. Este efecto puede incluso ser más evidente para hormigón de alta resistencia. Esto se debe a que, para un nivel bajo de carga axial (15\%), la profundidad de la fibra neutra es bastante pequeña de manera que a medida que aumenta la $\rho_{\mathrm{l}}$, las deformaciones en tracción y compresión disminuyen y, en consecuencia, también la $\varphi_{u}{ }^{*} d$.

Por otra parte, cuando el fallo es por compresión, como en el caso de la Figura $6.21 \mathrm{~b}$, la cuantía de armadura longitudinal aparentemente no produce cambios significativos en la curvatura última de la sección. Esto se debe a que probablemente la armadura en tracción no ha plastificado durante el fallo $\mathrm{y}$, por lo tanto, la $\rho_{\mathrm{l}}$ básicamente no produce efecto.

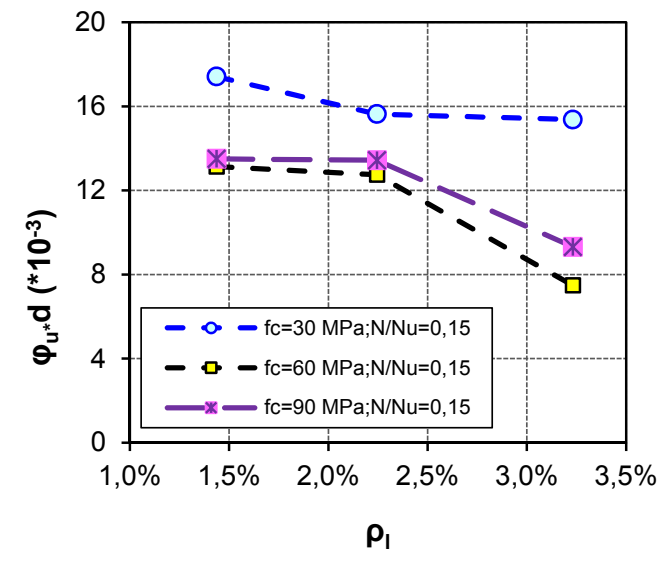

(a)

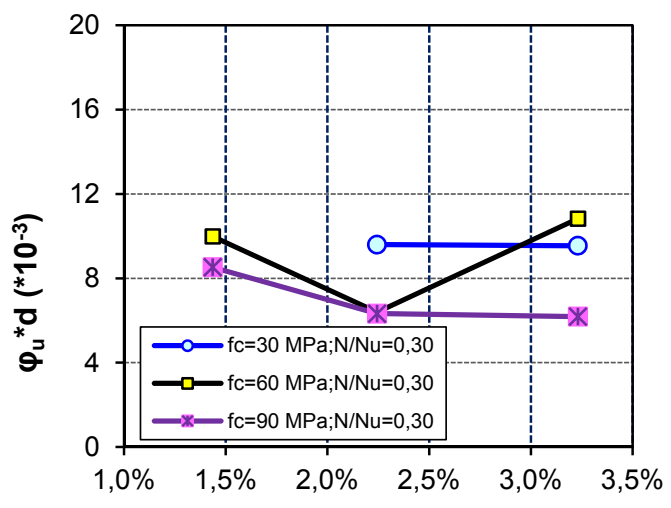

$\rho_{1}$

Figura 6.21 Comparación de la variable curvatura última $\left(\varphi_{u}\right)$ con respecto a la cuantía de armadura longitudinal, resistencia del hormigón y niveles de carga axil del (a) $15 \%$ y (b) $30 \%$

En las Figuras 6.22 y 6.23 se analizarán conjuntamente las dos variables, curvatura plástica adimensional $\left(\varphi_{\mathrm{p} 1 \mathrm{~B}}{ }^{*} \mathrm{~d}\right)$ y ductilidad de curvatura $\left(\mu_{\varphi 1 \mathrm{~B}}\right)$, para estudiar el comportamiento inelástico de la sección frente a la influencia de la cuantía longitudinal en los resultados experimentales, ya que las dos variables muestran un comportamiento similar.

La curvatura plástica y el factor de ductilidad de curvatura se presentan en las Figuras 6.22 y 6.23 en función de la cuantía de armadura longitudinal $\rho_{\mathrm{l}}$, para un nivel de carga axial $\mathrm{N} / \mathrm{N}_{\mathrm{u}}=15 \%$ y $\mathrm{N} / \mathrm{N}_{\mathrm{u}}=30 \%$, respectivamente. Puede verse que, en un nivel bajo de carga axial (Figuras 6.22a y 6.23a), el fallo se produce por tracción, y las dos variables $\varphi_{p 1 B}{ }^{*} d$ y $\mu_{\varphi 1 B}$ disminuyen a medida que la cuantía de armadura longitudinal aumenta. Esto se debe a que, en este nivel de carga axial, el incremento de la cuantía longitudinal $\left(\rho_{\mathrm{I}}\right)$ produce un aumento en la profundidad de la fibra neutra que impide el desarrollo de deformación de la armadura en tracción, $y$, consecuentemente, se observa una disminución en las variables $\varphi_{p 1 B}{ }^{*} d$ y $\mu_{\varphi 1 B}$.

Por otra parte, para un nivel de carga axial del 30\% (Figuras 6.23a y b), el fallo ocurre por compresión y no se aprecia una influencia clara de $\rho_{l}$ en relación con las variables $\left(\varphi_{\mathrm{p} 1 \mathrm{~B}}{ }^{*} \mathrm{~d}\right.$ y $\left.\mu_{\varphi 1 \mathrm{~B}}\right)$. Las razones son las mismas que las que se han dado anteriormente para la curvatura última, puesto que ninguna armadura en tracción 
plastifica durante el fallo y, por lo tanto, el incremento de la cuantía de armadura longitudinal básicamente no tiene efecto.

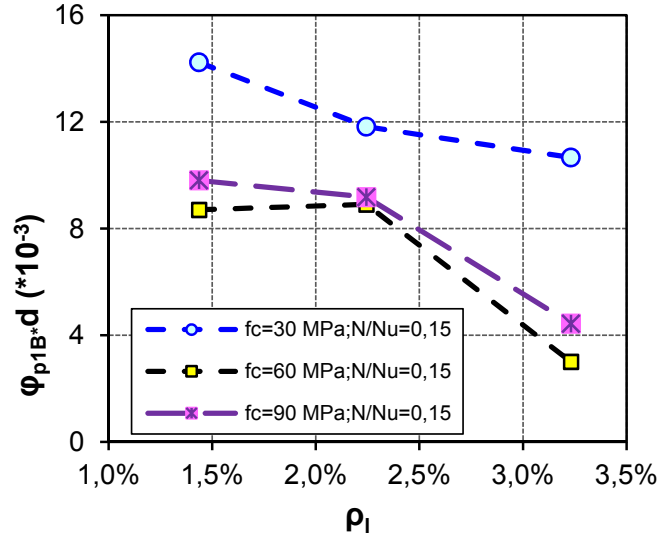

(a)

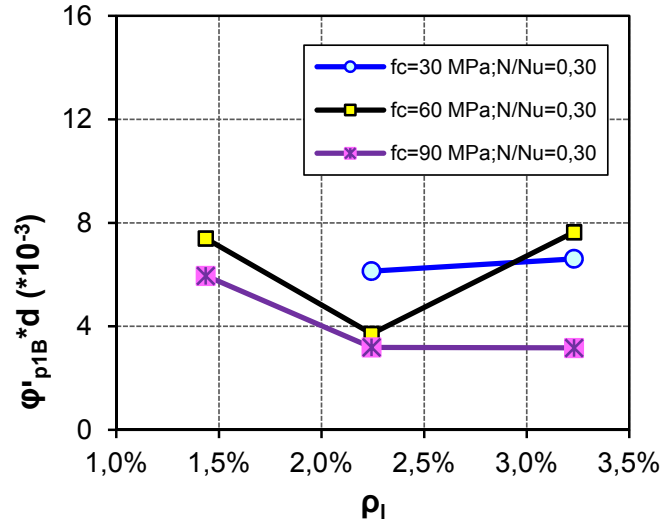

(b)

Figura 6.22 Comparación de la variable curvatura plástica $\left(\varphi_{p 1 B}\right)$ con respecto a la cuantía de armadura longitudinal, resistencia del hormigón y niveles de carga axil del (a) $15 \%$ y (b) $30 \%$

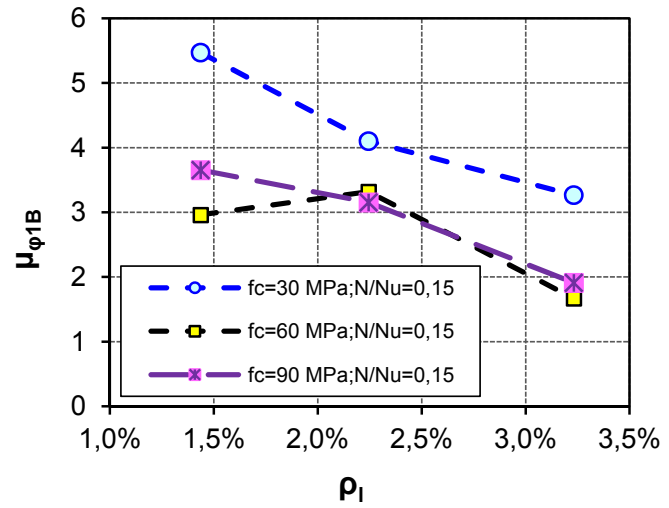

(c)

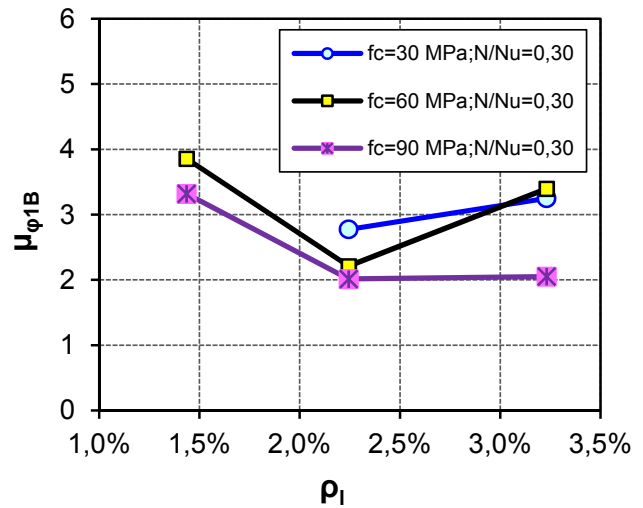

(d)

Figura 6.23 Comparación de la variable ductilidad de curvatura $\left(\mu_{\varphi 1 B}\right)$ con respecto a la cuantía de armadura longitudinal, resistencia del hormigón y niveles de carga axil del (a) $15 \%$ y (b) $30 \%$

\subsubsection{Influencia de la cuantía de armadura transversal}

Para poder estudiar experimentalmente el efecto de la cuantía de armadura transversal en la capacidad de deformación de soportes esbeltos de hormigón armado, se ha seleccionado la relación de ensayos experimentales que aparecen en la Tabla 6-21. La serie comprende las siguientes variables: esbeltez de cortante (10.5 y 7.5), resistencia del hormigón (30 y $90 \mathrm{MPa}$ ), nivel de axil (alrededor de 30\% y $45 \%$ ), cuantía longitudinal (del $2 \%$ ) y cuantía de armadura transversal (del $1 \%$ y $3 \%$, y, excepcionalmente, del $2 \%$ para hormigón de $90 \mathrm{MPa}$ ) y esbeltez (7.5). 
Estudio experimental y numérico de la capacidad de deformación de soportes esbeltos de hormigón armado

Tabla 6-21 Resultados de la idealización del diagrama $M-\varphi$ empleando el método del Eurocódigo 8 (versión 1B), para la serie de ensayos utilizada en el análisis de la influencia de la cuantía transversal

\begin{tabular}{|c|c|c|c|c|c|c|c|c|c|c|}
\hline $\begin{array}{c}\mathrm{N}^{\circ} \\
\text { ensayo }\end{array}$ & REFERENCIA & $\begin{array}{c}\mathrm{f}_{\mathrm{c}} \\
(\mathrm{MPa}) \\
\end{array}$ & $\mathrm{N} / \mathrm{N}_{\mathrm{u}}$ & $\begin{array}{c}\mathrm{pl} \\
(\%) \\
\end{array}$ & $\lambda$ & $\begin{array}{c}\rho_{\mathrm{s}} \\
(\%)\end{array}$ & $\begin{array}{c}\varphi_{y 1 B^{*}}^{*} d \\
(\% 0)\end{array}$ & $\begin{array}{c}\varphi_{p 1 B^{*} d} \\
(\% 0)\end{array}$ & $\begin{array}{l}\varphi_{u}{ }^{*} d \\
(\%)\end{array}$ & $\mu_{\varphi 1 B}$ \\
\hline 3 & N30-10.5-C0-2-30 & 31.60 & 0.30 & \multirow{18}{*}{2.2} & \multirow{8}{*}{10.5} & 1.0 & 3.46 & 6.13 & 9.59 & 2.77 \\
\hline 35 & N30-10.5-C3-2-30 & 41.00 & 0.25 & & & 3.0 & 3.47 & 10.36 & 13.82 & 3.99 \\
\hline 4 & N30-10.5-C0-2-45 & 34.50 & 0.42 & & & 1.0 & 1.93 & 3.70 & 5.62 & 2.92 \\
\hline 36 & N30-10.5-C3-2-45 & 34.20 & 0.43 & & & 3.0 & 2.29 & 6.83 & 9.11 & 3.99 \\
\hline 27 & $\mathrm{H} 90-10.5-\mathrm{C} 0-2-30$ & 90.10 & 0.30 & & & 1.0 & 3.14 & 3.18 & 6.32 & 2.01 \\
\hline 39 & $\mathrm{H} 90-10.5-\mathrm{C} 3-2-30$ & 93.45 & 0.29 & & & 3.0 & 2.91 & 2.76 & 5.66 & 1.95 \\
\hline 28 & $\mathrm{H} 90-10.5-\mathrm{C} 0-2-45$ & 93.20 & 0.44 & & & 1.0 & 1.91 & 2.61 & 4.52 & 2.36 \\
\hline 40 & H90-10.5-C3-2-45 & 91.95 & 0.45 & & & 3.0 & 1.85 & 3.33 & 5.18 & 2.80 \\
\hline 29 & $\mathrm{H} 90-7.5-\mathrm{C} 0-2-30$ & 100.35 & 0.27 & & \multirow{10}{*}{7.5} & 1.0 & 3.34 & 6.07 & 9.41 & 2.82 \\
\hline 43 & $\mathrm{H} 90-7.5-\mathrm{C} 2-2-30$ & 93.50 & 0.29 & & & 2.0 & 3.36 & 6.00 & 9.36 & 2.79 \\
\hline 41 & $\mathrm{H} 90-7.5-\mathrm{C} 3-2-30$ & 86.35 & 0.31 & & & 3.0 & 3.02 & 4.19 & 7.21 & 2.39 \\
\hline 30 & $\mathrm{H} 90-7.5-\mathrm{C} 0-2-45$ & 94.00 & 0.41 & & & 1.0 & 2.67 & 6.99 & 9.67 & 3.62 \\
\hline 44 & $\mathrm{H} 90-7.5-\mathrm{C} 2-2-45$ & 89.20 & 0.45 & & & 2.0 & 2.42 & 5.96 & 8.39 & 3.46 \\
\hline 42 & $\mathrm{H} 90-7.5-\mathrm{C} 3-2-45$ & 78.23 & 0.51 & & & 3.0 & 2.20 & 6.46 & 8.66 & 3.93 \\
\hline 5 & N30-7.5-C0-2-30 & 30.10 & 0.30 & & & 1.0 & 3.42 & 10.83 & 14.25 & 4.17 \\
\hline 37 & N30-7.5-C3-2-30 & 35.75 & 0.27 & & & 3.0 & 3.48 & 15.60 & 19.08 & 5.48 \\
\hline 6 & N30-7.5-C0-2-45 & 33.00 & 0.42 & & & 1.0 & 2.46 & 10.74 & 13.20 & 5.36 \\
\hline 38 & N30-7.5-C3-2-45 & 35.00 & 0.41 & & & 3.0 & 2.55 & 11.06 & 13.61 & 5.34 \\
\hline
\end{tabular}

Como se puede observar en las Figuras 6.24, la cuantía de armadura transversal $\left(\rho_{\mathrm{s}}\right)$ no produce ningún efecto en la curvatura elástica efectiva $\left(\varphi^{\prime}{ }_{\mathrm{y} 1 \mathrm{~B}}{ }^{*} \mathrm{~d}\right)$, para ninguna de las dos esbelteces y niveles de carga axial. En la Figura 6.24a, sin embargo, se pueden apreciar algunos de los efectos mencionados anteriormente, como por ejemplo, la mayor curvatura elástica efectiva presente en hormigón convencional (30 MPa) que en hormigón de alta resistencia (90 MPa), y el hecho que esta diferencia puede ser más apreciable para una esbeltez de 10.5 que para una de 7.5 (Figuras 6.24a y b). Otro efecto visible es el relacionado con el nivel de carga axial, ya que la $\varphi^{\prime}{ }_{y 1 \mathrm{~B}}{ }^{*} \mathrm{~d}$ disminuye cuando el nivel de carga axial aumenta de $30 \%$ a $45 \%$.

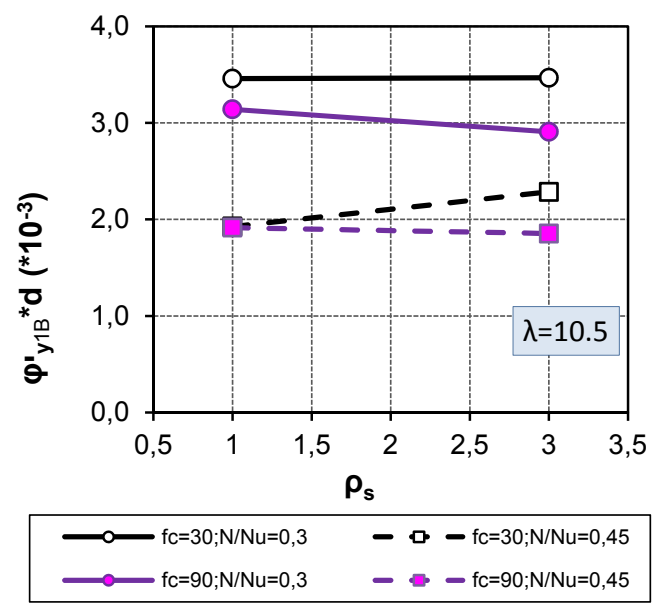

(a)

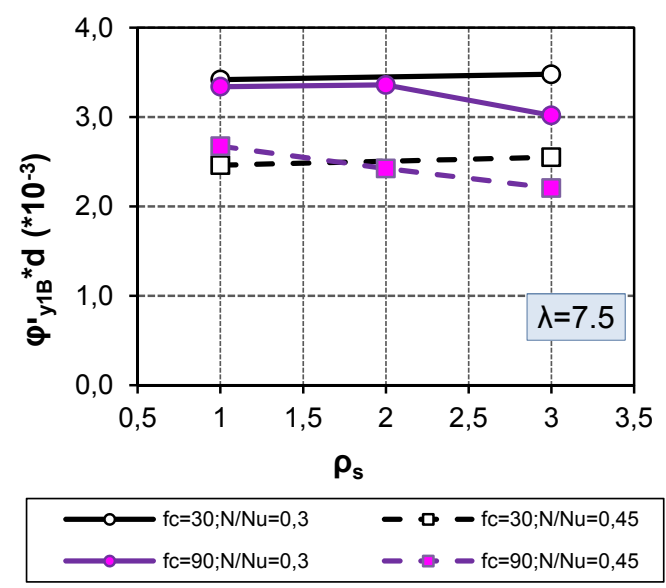

(b)

Figura 6.24 Comparación de la variable curvatura elástica efectiva $\left(\varphi^{\prime}{ }_{11 B}\right)$ con respecto a la cuantía de armadura transversal, resistencia del hormigón, niveles de carga axil y esbeltez (a) $\lambda=10.5$ y (b) $\lambda=7.5$ 
Respecto a la curvatura última $\left(\varphi_{\mathrm{u}}{ }^{*} \mathrm{~d}\right)$, en las Figuras $6.25 \mathrm{a}$ y b se puede observar que el efecto de la cuantía de armadura transversal sólo ocurre para hormigón convencional (30 MPa), independientemente del nivel de carga axial (30\% y $45 \%)$, ya que la $\varphi_{u}{ }^{*} d$ es mayor para $\rho_{s}=3 \%$ que para $\rho_{s}=1 \%$. Por el contrario, en hormigón de alta resistencia (90 $\mathrm{MPa}$ ), no se observa un incremento de la curvatura última con el aumento de $\rho_{\mathrm{s}}$. Esto es consecuencia de las características del comportamiento del hormigón de alta resistencia, puesto que presenta una mayor fragilidad que el hormigón convencional. Sin embargo, en algunos estudios (Bayrak O. y Sheikh S. (1998) [16], Cusson D. y Paultre (1994) [46]) considera que la cuantía de confinamiento puede mejorar el comportamiento del HAR, aunque, en este estudio experimental, no se ha logrado mejorar la deformabilidad última de la sección, es decir, el detalle de la armadura de confinamiento no ha sido eficiente.

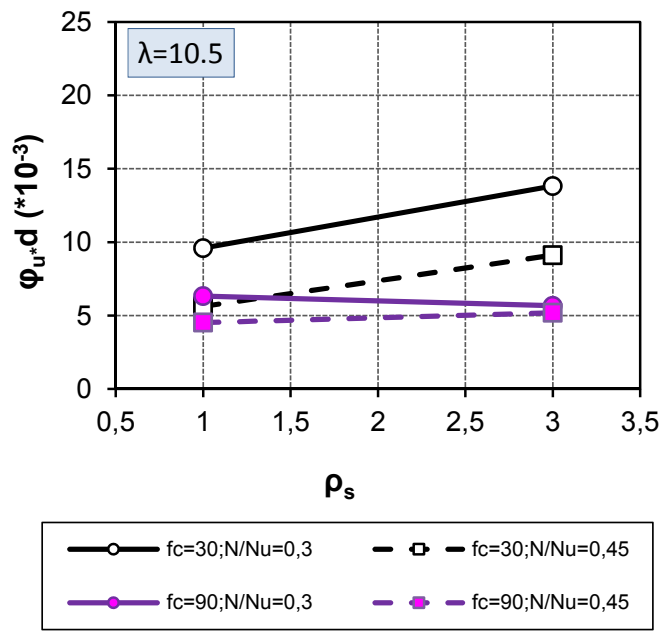

(a)

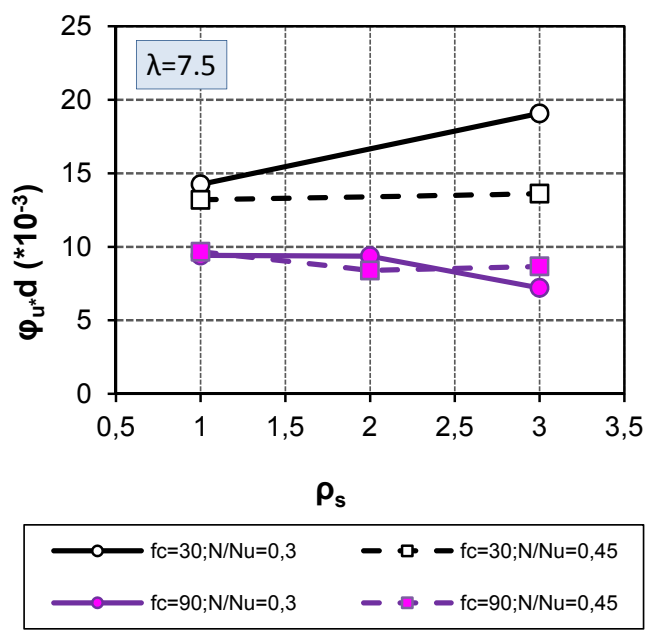

(b)

Figura 6.25 Comparación de la variable curvatura última $\left(\varphi_{u}\right)$ con respecto a la cuantía de armadura transversal, resistencia del hormigón, niveles de carga axil y esbeltez (a) $\lambda=10.5$ y (b) $\lambda=7.5$

Respecto a la curvatura plástica, el comportamiento es similar en el caso del hormigón convencional y de alta resistencia, ya que se comprueba una vez más que la cuantía de armadura transversal afecta favorablemente a la deformación plástica en el caso del HC. Cuando se utiliza HAR en lugar de HC, para condiciones similares, el efecto del confinamiento no logra mejorar el comportamiento inelástico en la variable $\varphi_{\mathrm{p} 1 \mathrm{~B}}{ }^{*} \mathrm{~d}$. Las razones son las mismas que acabamos de explicar en el párrafo anterior.

En lo que respecta a la ductilidad en curvaturas, el efecto sigue siendo el mismo que hemos explicado con respecto a la relación entre la cuantía de armadura transversal y la resistencia del hormigón. La misma diferencia que hemos observado entre la utilización de HAR y HC se cumple también para el parámetro de ductilidad en curvaturas.

De manera similar, como se ha mencionado, la ductilidad medida en soportes de esbeltez 10.5 puede ser ligeramente mayor cuando el nivel de carga axial cambia de $30 \%$ a $45 \%$. Esto también se observa en soportes con esbeltez de 7.5 , pero la diferencia tiende a ser un poco mayor. 


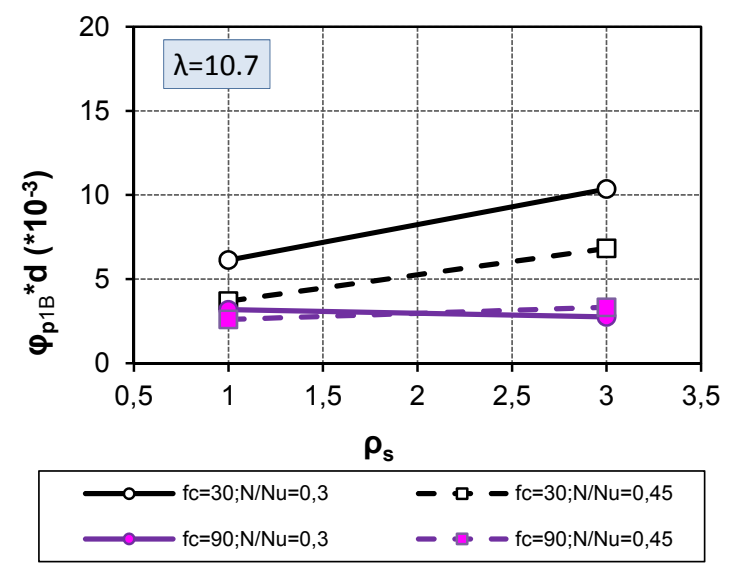

(a)

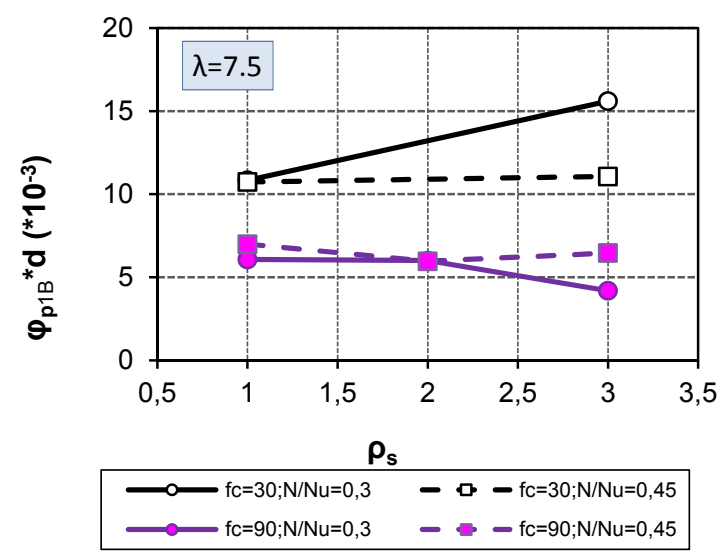

(b)

Figura 6.26 Comparación de la variable curvatura plástica $\left(\varphi_{p 1 B}\right)$ con respecto a la cuantía de armadura transversal, resistencia del hormigón, niveles de carga axil y esbeltez (a) $\lambda=10.5$ y (b) $\lambda=7.5$

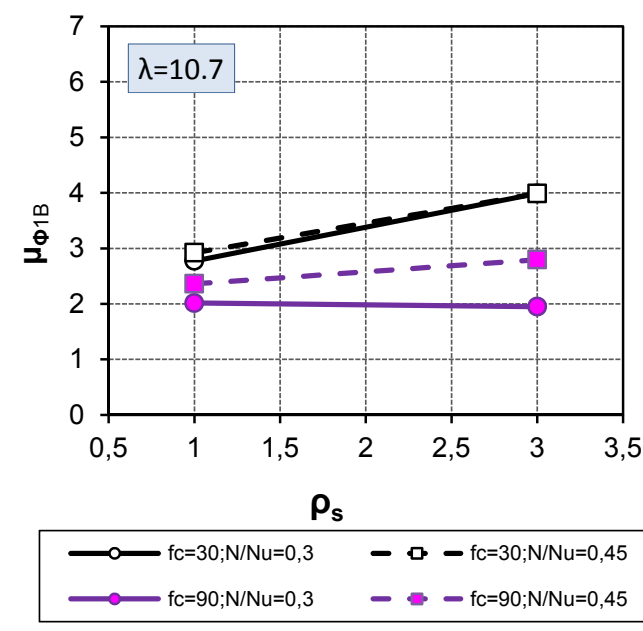

(a)

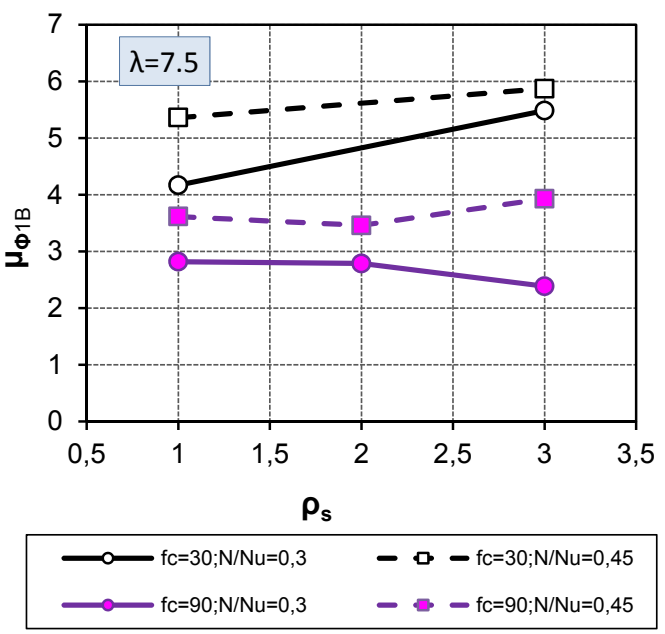

(b)

Figura 6.27 Comparación de la variable ductilidad de curvatura $\left(\mu_{\varphi 1 B}\right)$ con respecto a la cuantía de armadura transversal, resistencia del hormigón, niveles de carga axil y esbeltez (a) $\lambda=10.5$ y (b) $\lambda=7.5$

\subsubsection{RESULTADOS DE LA IDEALIZACIÓN A NIVEL DEL ELEMENTO (P-A)}

A continuación se presentan los resultados correspondientes a la idealización del diagrama carga-desplazamiento $(P-\delta)$. Las variables analizadas en este caso serán el desplazamiento elástico efectivo $\left(\delta^{\prime}{ }_{y 1 B}\right)$, el desplazamiento último $\left(\delta_{u}\right)$, el desplazamiento plástico $\left(\delta_{p 1 B}\right)$ y la ductilidad en desplazamientos $\left(\mu_{\delta 1 \mathrm{~B}}\right)$, obtenidas en la idealización de P- $\delta$ utilizando el método del Eurocódigo 8 [59], versión 1B. Nuevamente, el análisis se realiza siguiendo el mismo esquema de las series de ensayos de la sección anterior, para cada uno de los parámetros objeto de estudio: nivel de carga axial $\left(N / N_{u}\right)$, esbeltez de cortante $(\lambda)$, resistencia del hormigón $\left(f_{c}\right)$, cuantía de armadura longitudinal $\left(\rho_{\mathrm{I}}\right)$ y cuantía de armadura transversal $\left(\rho_{\mathrm{s}}\right)$. 


\subsubsection{Influencia del nivel de carga axial}

Se estima que el parámetro nivel de carga axial es el más determinante en el comportamiento deformacional de los soportes de hormigón. Y su influencia se ve notablemente incrementada si actúa conjuntamente con la esbeltez de cortante. En este apartado se plantea analizar el efecto del nivel de carga axial en elementos de hormigón convencional y de alta resistencia para un valor de esbeltez $(\lambda=10.5)$. Los resultados de la respuesta estructural para dichos elementos se presentan en la Tabla 6-22.

Tabla 6-22 Resultados de la idealización del diagrama $P$ - $\delta$ empleando el método del Eurocódigo 8 (versión 1B), para la serie de ensayos utilizada en el análisis de la influencia del parámetro nivel de carga axial

\begin{tabular}{|c|c|c|c|c|c|c|c|c|c|c|}
\hline $\begin{array}{c}\mathrm{N}^{\circ} \\
\text { ensayo }\end{array}$ & REFERENCIA & $\begin{array}{c}\mathrm{f}_{\mathrm{c}} \\
(\mathrm{MPa})\end{array}$ & $\mathrm{N} / \mathrm{N}_{\mathrm{u}}$ & $\lambda$ & $\begin{array}{c}\rho_{1} \\
(\%)\end{array}$ & $\begin{array}{c}\rho_{\mathrm{s}} \\
(\%)\end{array}$ & $\begin{array}{c}\delta_{\mathrm{y} 1 \mathrm{~B}} \\
(\mathrm{~mm})\end{array}$ & $\begin{array}{c}\delta_{\mathrm{p} 1 \mathrm{~B}} \\
(\mathrm{~mm})\end{array}$ & $\begin{array}{c}\delta_{\mathrm{u}} \\
(\mathrm{mm})\end{array}$ & $\mu_{\delta 1 \mathrm{~B}}$ \\
\hline 1 & N30-10.5-C0-2-00 & 36.60 & 0 & \multirow{12}{*}{10.5} & \multirow{12}{*}{2.2} & \multirow{12}{*}{1.0} & 31.55 & 42.98 & 74.53 & 2.36 \\
\hline 2 & N30-10.5-C0-2-15 & 31.75 & 0.14 & & & & 22.61 & 23.02 & 45.63 & 2.02 \\
\hline 3 & N30-10.5-C0-2-30 & 31.60 & 0.30 & & & & 13.73 & 30.38 & 44.11 & 3.21 \\
\hline 4 & N30-10.5-C0-2-45 & 34.50 & 0.42 & & & & 10.96 & 18.09 & 29.05 & 2.65 \\
\hline 13 & $\mathrm{H} 60-10.5-\mathrm{C} 0-2-00$ & 55.80 & 0.00 & & & & 33.33 & 39.49 & 72.82 & 2.18 \\
\hline 14 & $\mathrm{H} 60-10.5-\mathrm{C} 0-2-15$ & 54.10 & 0.15 & & & & 20.28 & 26.35 & 46.63 & 2.30 \\
\hline 15 & $\mathrm{H} 60-10.5-\mathrm{C} 0-2-30$ & 60.45 & 0.29 & & & & 14.04 & 20.91 & 34.95 & 2.49 \\
\hline 16 & $\mathrm{H} 60-10.5-\mathrm{C} 0-2-45$ & 63.90 & 0.43 & & & & 13.13 & 20.47 & 33.60 & 2.48 \\
\hline 25 & $\mathrm{H} 90-10.5-\mathrm{C} 0-2-00$ & 91.35 & 0.00 & & & & 37.26 & 29.80 & 67.06 & 1.80 \\
\hline 26 & $\mathrm{H} 90-10.5-\mathrm{C} 0-2-15$ & 90.50 & 0.15 & & & & 19.03 & 24.25 & 43.28 & 2.27 \\
\hline 27 & $\mathrm{H} 90-10.5-\mathrm{C} 0-2-30$ & 90.10 & 0.30 & & & & 15.80 & 19.94 & 35.74 & 2.26 \\
\hline 28 & $\mathrm{H} 90-10.5-\mathrm{C} 0-2-45$ & 93.20 & 0.44 & & & & 12.94 & 14.50 & 27.44 & 2.12 \\
\hline
\end{tabular}

En relación al parámetro nivel de carga axial y su influencia en el desplazamiento elástico efectivo $\left(\delta_{\mathrm{y} 1 \mathrm{~B}}^{\prime}\right)$ y el desplazamiento último $\left(\delta_{\mathrm{u}}\right)$, las Figuras 6.28a y b muestran que la capacidad de deformación en el estado elástico y último disminuye conforme aumenta el nivel de carga axil, y es independiente de la resistencia del hormigón. Las gráficas muestran que las variables $\delta_{\mathrm{y} 1 \mathrm{~B}}^{\prime}$ y $\delta_{\mathrm{u}}$ disminuyen más rápidamente para bajos niveles de carga axial, cuando ocurre el fallo por tracción, mientras que cuando el fallo ocurre por compresión, el descenso del desplazamiento es más lento.

La variable del desplazamiento plástico $\left(\delta_{\mathrm{p} 1 \mathrm{~B}}\right)$ presenta un comportamiento similar. Sin embargo, respecto a esta variable se nota una leve influencia de la resistencia del hormigón, de modo que la $\delta_{p 1 B}$ disminuye conforme aumenta la resistencia del hormigón.

Para analizar la variable $\mu_{\delta}$ es necesario tener en cuenta que la serie de ensayos utilizada está compuesta por elementos muy esbeltos $(\lambda=10.5)$, lo cual significa que los resultados están notablemente influenciados por los efectos P- $\Delta$.

Para el valor de esbeltez tratado en este análisis $(\lambda=10.5)$, la influencia de $N / N_{u}$ en la ductilidad en desplazamientos puede ser variable (ver Figura 6.28d). Existe un primer tramo, para bajos niveles de carga axial (entre el $0 \%$ y el $30 \%$ ), en que la ductilidad experimenta un ligero incremento a medida que aumenta el nivel de carga axial hasta alcanzar un punto de inflexión. En un segundo tramo, la ductilidad 
desciende conforme aumenta el nivel de carga axial (entre $30 \%$ y $45 \%$ ). Estos resultados difieren de los obtenidos por otros autores (Légeron et al. (2009); Kim et al. (2007) [72]; Wang et al. (1995); Lam et al. (2003) [77], entre otros) en donde concluyeron que la ductilidad en desplazamientos $\left(\mu_{\delta}\right)$ disminuye con el aumento del nivel de carga axial, puesto que, en tales estudios, los ensayos experimentales han sido llevados a cabo con valores de esbeltez de cortante inferiores a 6 . Sin embargo, no existe evidencia experimental que confirme que esto sea así para valores mayores de esbeltez de cortante, en donde los efectos de segundo orden son mayores.

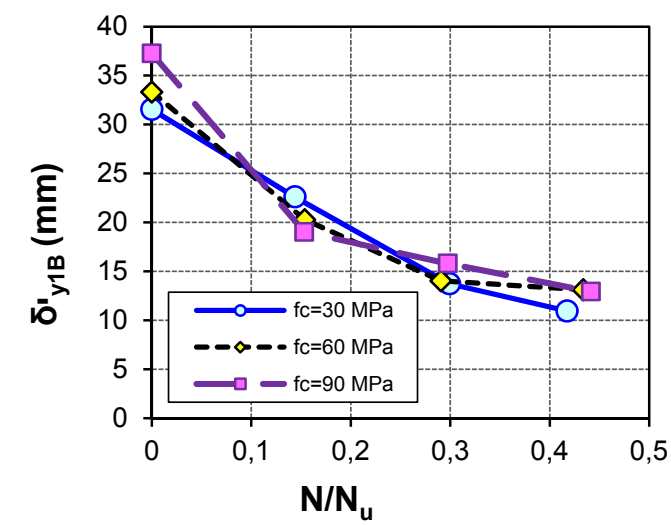

(a)

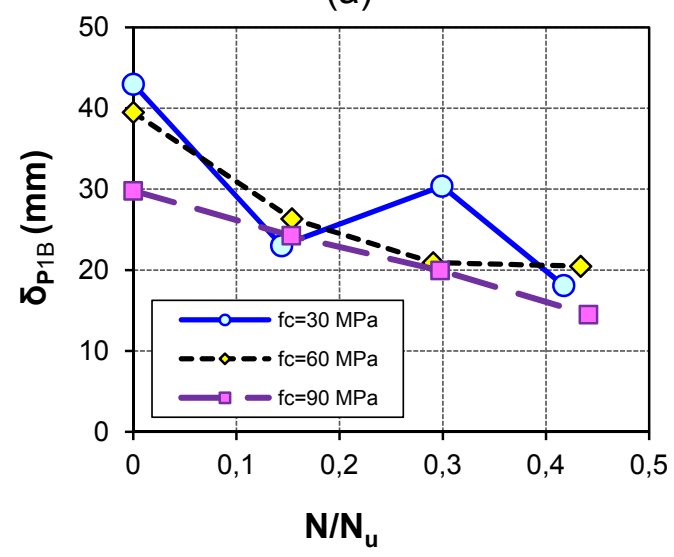

(c)

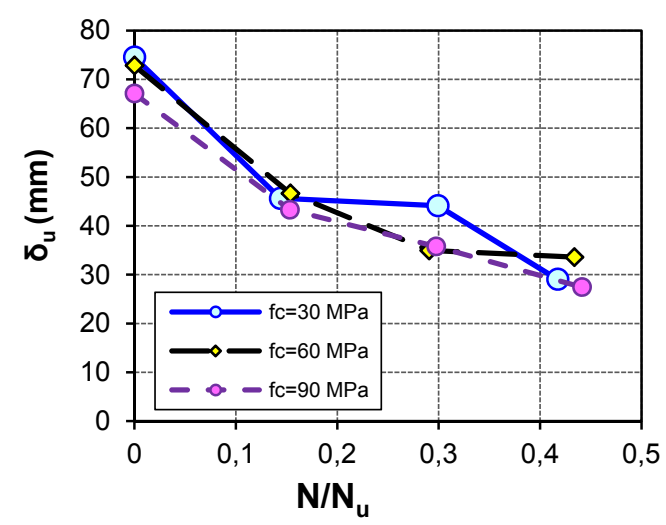

(b)

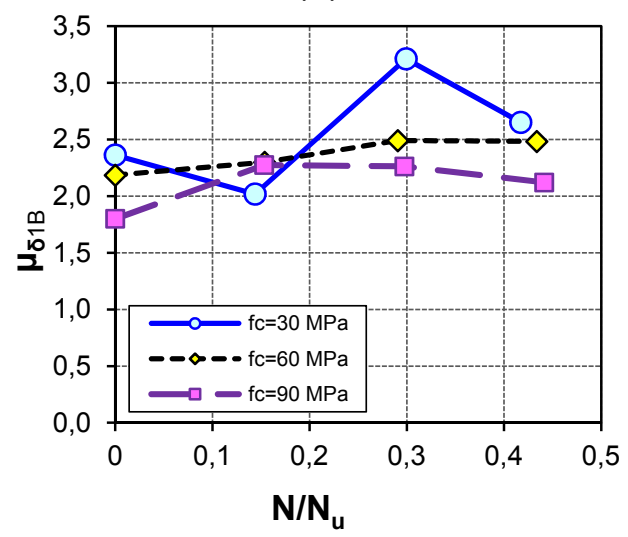

(d)

Figura 6.28 Comparación de las variables: (a) desplazamiento elástico efectivo $\left(\delta_{y 1 B}^{\prime}\right)$, (b) desplazamiento último $\left(\delta_{u}\right)$, (c) desplazamiento plástico $\left(\delta_{p 1 B}\right)$ y $(d)$ ductilidad en desplazamientos $\left(\mu_{\delta 1 B}\right)$, con respecto a las variables nivel de carga axil y resistencia del hormigón

A partir de lo anterior se ha podido comprobar que el efecto del nivel de carga axial en el comportamiento dúctil de soportes esbeltos todavía no está suficientemente estudiado, ya que existe un amplio rango de valores de esbeltez con escasa comprobación experimental. Hay un amplio rango, comprendido entre los valores de 6 y 10.5, donde existe un vacío que hace necesaria una mayor comprobación experimental para entender mejor la influencia del nivel de carga axial en la ductilidad en desplazamientos. 


\subsubsection{Influencia de la esbeltez de cortante}

Para evaluar el efecto de la esbeltez en el comportamiento de soportes de hormigón convencional y de alta resistencia se han seleccionado elementos con dos valores de esbeltez (7.5 y 10.5), y moderados y altos valores de carga axial $\left(30 \%\right.$ y $45 \%$ de $\mathrm{N}_{\mathrm{u}}$ ). El resumen de los resultados del comportamiento deformacional es presentado en la Tabla 6-23.

Tabla 6-23 Resultados de la idealización del diagrama P- $\delta$ empleando el método del Eurocódigo 8 (versión 1B), para la serie de ensayos utilizada en el análisis de la influencia del parámetro esbeltez

\begin{tabular}{|c|c|c|c|c|c|c|c|c|c|c|}
\hline $\begin{array}{c}\mathrm{N}^{\circ} \\
\text { ensayo }\end{array}$ & REFERENCIA & $\begin{array}{c}\mathrm{f}_{\mathrm{c}} \\
(\mathrm{MPa})\end{array}$ & $\left(\mathrm{N} / \mathrm{N}_{\mathrm{u}}\right)$ & $\lambda$ & $\begin{array}{c}\rho_{\mathrm{l}} \\
(\%)\end{array}$ & $\begin{array}{c}\rho_{\mathrm{s}} \\
(\%)\end{array}$ & $\begin{array}{c}\delta_{\mathrm{y} 1 \mathrm{~B}}^{\prime} \\
(\mathrm{mm})\end{array}$ & $\begin{array}{c}\delta_{\mathrm{p} 1 \mathrm{~B}} \\
(\mathrm{~mm})\end{array}$ & $\begin{array}{c}\delta_{u} \\
(\mathrm{~mm})\end{array}$ & $\mu_{\delta 1 B}$ \\
\hline 5 & N30-7.5-C0-2-30 & 30.10 & 0.30 & \multirow{6}{*}{7.5} & \multirow{12}{*}{2.24} & \multirow{12}{*}{1.0} & 12.13 & 21.17 & 33.30 & 2.75 \\
\hline 17 & $\mathrm{H} 60-7.5-\mathrm{C} 0-2-30$ & 58.20 & 0.30 & & & & 13.35 & 14.56 & 27.92 & 2.09 \\
\hline 29 & $\mathrm{H} 90-7.5-\mathrm{C} 0-2-30$ & 100.35 & 0.27 & & & & 13.72 & 12.13 & 25.85 & 1.88 \\
\hline 6 & N30-7.5-C0-2-45 & 33.00 & 0.42 & & & & 9.70 & 13.15 & 22.84 & 2.36 \\
\hline 18 & $\mathrm{H} 60-7.5-\mathrm{C} 0-2-45$ & 58.65 & 0.46 & & & & 11.84 & 10.74 & 22.59 & 1.91 \\
\hline 30 & $\mathrm{H} 90-7.5-\mathrm{C} 0-2-45$ & 94.00 & 0.41 & & & & 11.54 & 8.26 & 19.81 & 1.72 \\
\hline 3 & N30-10.5-C0-2-30 & 31.60 & 0.30 & \multirow{6}{*}{10.5} & & & 13.73 & 30.38 & 44.11 & 3.21 \\
\hline 15 & $\mathrm{H} 60-10.5-\mathrm{C} 0-2-30$ & 60.45 & 0.29 & & & & 14.04 & 20.91 & 34.95 & 2.49 \\
\hline 27 & $\mathrm{H} 90-10.5-\mathrm{C} 0-2-30$ & 90.10 & 0.30 & & & & 15.80 & 19.94 & 35.74 & 2.26 \\
\hline 4 & N30-10.5-C0-2-45 & 34.50 & 0.42 & & & & 10.96 & 18.09 & 29.05 & 2.65 \\
\hline 16 & $\mathrm{H} 60-10.5-\mathrm{C} 0-2-45$ & 63.90 & 0.43 & & & & 13.13 & 20.47 & 33.60 & 2.48 \\
\hline 28 & $\mathrm{H} 90-10.5-\mathrm{C} 0-2-45$ & 93.20 & 0.44 & & & & 12.94 & 14.50 & 27.44 & 2.12 \\
\hline
\end{tabular}

Los resultados del desplazamiento elástico, que se presentan en la Figura 6.29a muestran que el desplazamiento elástico efectivo $\left(\delta^{\prime}{ }_{\mathrm{y} 1 \mathrm{~B}}\right)$ es ligeramente mayor para valores de esbeltez de 10.5 que para valores de 7.5. Además, para estos dos valores de esbeltez, el $\delta_{y 1 B}^{\prime}$ disminuye conforme aumenta el nivel de carga axial de $30 \%$ a $45 \%$. En lo que respecta a la resistencia del hormigón $\left(f_{c}\right)$, los valores de $\delta_{y 1 B}^{\prime}$ aumentan discretamente a medida que aumenta la $\mathrm{f}_{\mathrm{c}}$, siendo más notable el cambio cuando la resistencia $\left(f_{c}\right)$ se incrementa de $30 \mathrm{MPa}$ a $60 \mathrm{MPa}$, que cuando pasa de $60 \mathrm{MPa}$ a $90 \mathrm{MPa}$.

Por otro lado, para elementos comprimidos, el punto de plastificación normalmente se alcanza más rápidamente cuanto más comprimido se encuentra el soporte, lo que explica que el desplazamiento elástico disminuya cuando aumenta el nivel de carga axial.

Respecto al desplazamiento último $\left(\delta_{u}\right)$, la Figura $6.29 \mathrm{~b}$ muestra que, evidentemente, los soportes esbeltos son más deformables, y, adicionalmente, si se encuentran menos comprimidos, el desplazamiento último aún será mayor. Por otra parte, los soportes son ligeramente menos deformables a medida que aumenta la resistencia del hormigón.

El desplazamiento plástico y la ductilidad en desplazamientos permiten confirmar el efecto de los parámetros de esbeltez, nivel de carga axial y resistencia del hormigón, que hemos mencionado anteriormente, es decir, que el desplazamiento inelástico y la ductilidad son mayores cuando aumenta la esbeltez de cortante de 7.5 a 10.5. Adicionalmente, el desplazamiento disminuye cuando aumenta la carga 
axial de $30 \%$ a $45 \%$. Por último, las variables $\delta_{\mathrm{P} 1 \mathrm{~B}}$ y $\mu_{\delta 1 \mathrm{~B}}$ disminuyen ligeramente con la resistencia del hormigón. En algunos estudios (Bayrak O. y Sheikh S. (1997) [18], Razvi S. y Saatcioglu M (1994) [113], Légeron F. y Paultre P. 2000 [78], Mendis P.(2003) [91]) se sugiere que la pérdida de capacidad de deformación de los soportes de hormigón de alta resistencia puede ser mejorada si los elementos son dotados de un adecuado detalle de la armadura de confinamiento. Las comparaciones llevadas a cabo en este apartado se realizan para soportes con un bajo nivel de confinamiento.

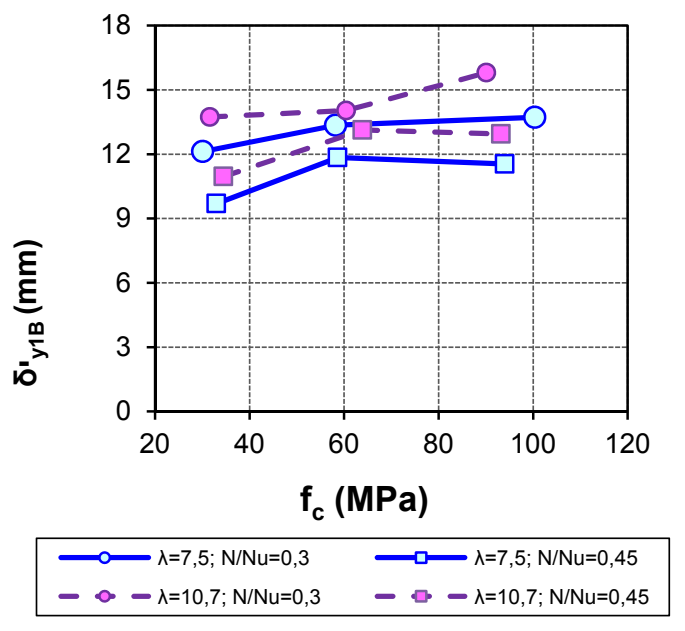

(a)

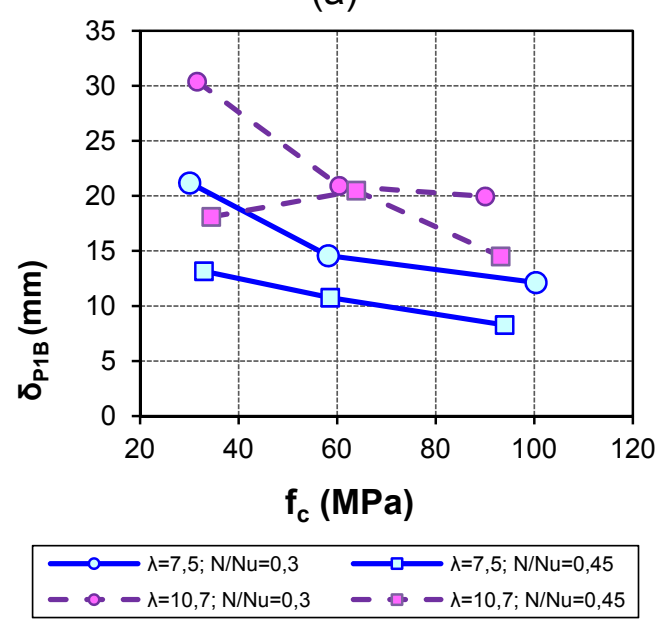

(c)

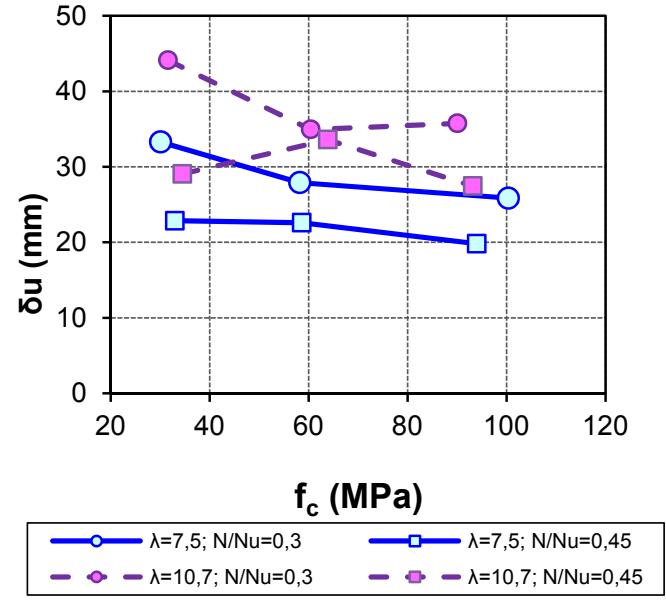

(b)

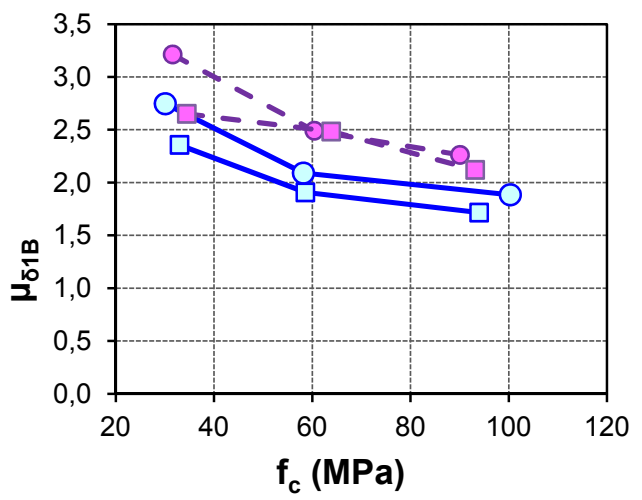

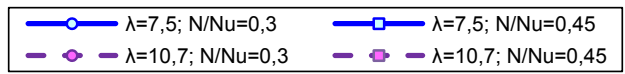

(d)

Figura 6.29 Comparación de las variables: (a) desplazamiento elástico efectivo ( $\left.\bar{\delta}_{{ }_{y 1 B}}\right)$, (b) desplazamiento último $\left(\delta_{u}\right)$, (c) desplazamiento plástico $\left(\delta_{p 1 B}\right)$ y $(d)$ ductilidad en desplazamientos $\left(\mu_{\delta 1 B}\right)$, con respecto a las variables esbeltez, resistencia del hormigón, y nivel de carga axil

\subsubsection{Influencia de la cuantía de armadura longitudinal}

Para estudiar la influencia de la cuantía de armadura longitudinal, se ha seleccionado un conjunto de soportes esbeltos $(\lambda=10.5)$ con resistencia del hormigón de $30 \mathrm{MPa}, 60 \mathrm{MPa}$ y $90 \mathrm{MPa}$, utilizando bajos y moderados niveles de 
carga axial. La cuantía longitudinal varía entre $1.4 \%$ y $3.23 \%$. La respuesta del comportamiento deformacional de los soportes se presenta en la Tabla 6-24.

Tabla 6-24 Resultados de la idealización del diagrama P- $\delta$ empleando el método del Eurocódigo 8 (versión 1B), para la serie de ensayos utilizada en el análisis de la influencia de la cuantía de armadura longitudinal

\begin{tabular}{|c|c|c|c|c|c|c|c|c|c|c|}
\hline $\begin{array}{c}\mathrm{N}^{\circ} \\
\text { ensayo }\end{array}$ & REFERENCIA & $\begin{array}{c}\mathrm{f}_{\mathrm{c}} \\
(\mathrm{MPa})\end{array}$ & $\mathrm{N} / \mathrm{N}_{\mathrm{u}}$ & $\rho_{\mathrm{I}}(\%)$ & $\lambda$ & $\begin{array}{c}\rho_{\mathrm{s}} \\
(\%)\end{array}$ & $\begin{array}{l}\delta_{\mathrm{y} 1 \mathrm{~B}}^{\prime} \\
(\mathrm{mm})\end{array}$ & $\begin{array}{c}\delta_{\mathrm{p} 1 \mathrm{~B}} \\
(\mathrm{~mm})\end{array}$ & $\begin{array}{c}\delta_{\mathrm{u}} \\
(\mathrm{mm})\end{array}$ & $\mu_{\delta 1 B}$ \\
\hline 9 & N30-10.5-C0-1-30 & 42.2 & 0.23 & 1.44 & \multirow{18}{*}{10.5} & \multirow{18}{*}{1.0} & 10.68 & 23.42 & 34.10 & 3.19 \\
\hline 2 & N30-10.5-C0-2-15 & 31.8 & 0.14 & 2.24 & & & 22.61 & 23.02 & 45.63 & 2.02 \\
\hline 11 & N30-10.5-C0-3-15 & 33.0 & 0.15 & 3.23 & & & 26.38 & 41.12 & 67.50 & 2.56 \\
\hline 10 & N30-10.5-C0-1-45 & 35.2 & 0.51 & 1.44 & & & 6.16 & 10.80 & 16.96 & 2.75 \\
\hline 3 & N30-10.5-C0-2-30 & 31.6 & 0.30 & 2.24 & & & 13.73 & 30.38 & 44.11 & 3.21 \\
\hline 12 & N30-10.5-C0-3-30 & 29.5 & 0.31 & 3.23 & & & 14.71 & 30.50 & 45.21 & 3.07 \\
\hline 21 & $\mathrm{H} 60-10.5-\mathrm{C} 0-1-15$ & 57.8 & 0.16 & 1.44 & & & 17.27 & 23.23 & 40.49 & 2.34 \\
\hline 14 & $\mathrm{H} 60-10.5-\mathrm{C} 0-2-15$ & 54.1 & 0.15 & 2.24 & & & 20.28 & 26.35 & 46.63 & 2.30 \\
\hline 23 & $\mathrm{H} 60-10.5-\mathrm{C} 0-3-15$ & 58.3 & 0.15 & 3.23 & & & 24.34 & 31.06 & 55.40 & 2.28 \\
\hline 22 & $\mathrm{H} 60-10.5-\mathrm{C} 0-1-30$ & 58.5 & 0.30 & 1.44 & & & 14.82 & 26.80 & 41.62 & 2.81 \\
\hline 15 & $\mathrm{H} 60-10.5-\mathrm{C} 0-2-30$ & 60.5 & 0.29 & 2.24 & & & 14.04 & 20.91 & 34.95 & 2.49 \\
\hline 24 & $\mathrm{H} 60-10.5-\mathrm{C} 0-3-30$ & 61.6 & 0.29 & 3.23 & & & 15.95 & 33.96 & 49.90 & 3.13 \\
\hline 31 & $\mathrm{H} 90-10.5-\mathrm{C} 0-1-15$ & 90.3 & 0.15 & 1.44 & & & 18.18 & 29.89 & 48.08 & 2.64 \\
\hline 26 & $\mathrm{H} 90-10.5-\mathrm{C} 0-2-15$ & 90.5 & 0.15 & 2.24 & & & 19.03 & 24.25 & 43.28 & 2.27 \\
\hline 33 & $\mathrm{H} 90-10.5-\mathrm{C} 0-3-15$ & 89.6 & 0.15 & 3.23 & & & 25.85 & 23.72 & 49.57 & 1.92 \\
\hline 32 & $\mathrm{H} 90-10.5-\mathrm{C} 0-1-30$ & 96.2 & 0.29 & 1.44 & & & 13.92 & 20.38 & 34.30 & 2.46 \\
\hline 27 & $\mathrm{H} 90-10.5-\mathrm{C} 0-2-30$ & 90.1 & 0.30 & 2.24 & & & 15.80 & 19.94 & 35.74 & 2.26 \\
\hline 34 & $\mathrm{H} 90-10.5-\mathrm{CO}-3-30$ & 94.4 & 0.29 & 3.23 & & & 15.87 & 19.81 & 35.67 & 2.25 \\
\hline
\end{tabular}

La Figura 6.30a muestra que el desplazamiento elástico efectivo $\left(\delta_{\mathrm{y} 1 \mathrm{~B}}^{\prime}\right)$ aumenta con la cuantía de armadura longitudinal para bajos niveles de carga axil (15\%), y no varía con la resistencia a compresión del hormigón, a pesar de que el ensayo $n^{\circ} 9$ se encuentra alejado del comportamiento que acabamos de describir. Esto se debe a que el soporte se encuentra en un nivel de compresión axial algo superior que otros ensayos de similares características. Por otra parte, en la Figura 6.30b, cuando el nivel de carga axil es del orden del $30 \%$, el $\delta_{y 1 \mathrm{~B}}^{\prime}$ no experimenta variación en relación con la cuantía de armadura longitudinal para ninguna de las resistencias del hormigón. Los valores obtenidos para el $\delta_{y 1 \mathrm{~B}}^{\prime}$ son superiores en los ensayos con niveles de axil del $15 \%$ a los ensayos con niveles del 30\%, diferencia que todavía es más amplia si se incrementa la cuantía de armadura longitudinal.

El comportamiento mostrado en la Figura $6.30 \mathrm{a}$ es el esperado cuando los elementos de hormigón desarrollan una notable deformación en la armadura de tracción, y ello sucede sólo si están sujetos a bajos niveles de carga axial, como es el caso. En elementos moderadamente comprimidos, como sucede en los mostrados en la Figura 6.30b, cabe esperar que la resistencia del hormigón, junto con la cuantía longitudinal, presenten un efecto más visible. Sin embargo, esto no ha ocurrido, quizás porque el efecto de la esbeltez de cortante y el nivel de axil destacan sobre el efecto de $f_{c}$ y $\rho_{l}$. 


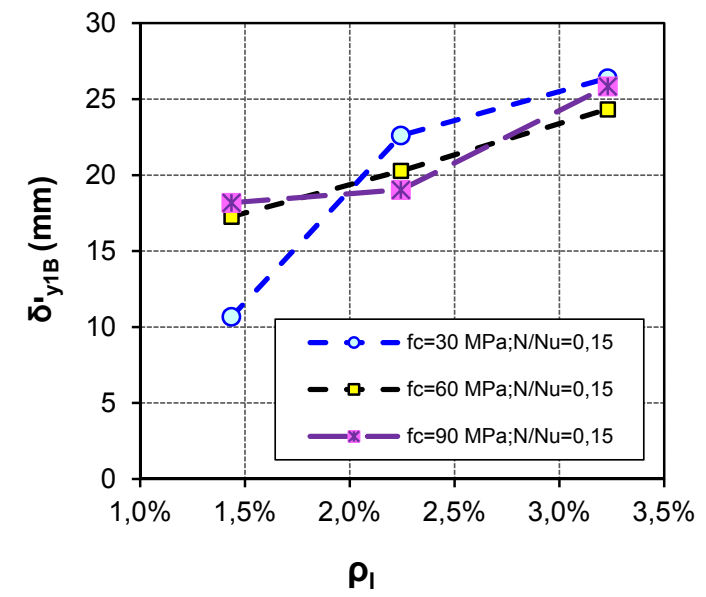

(a)

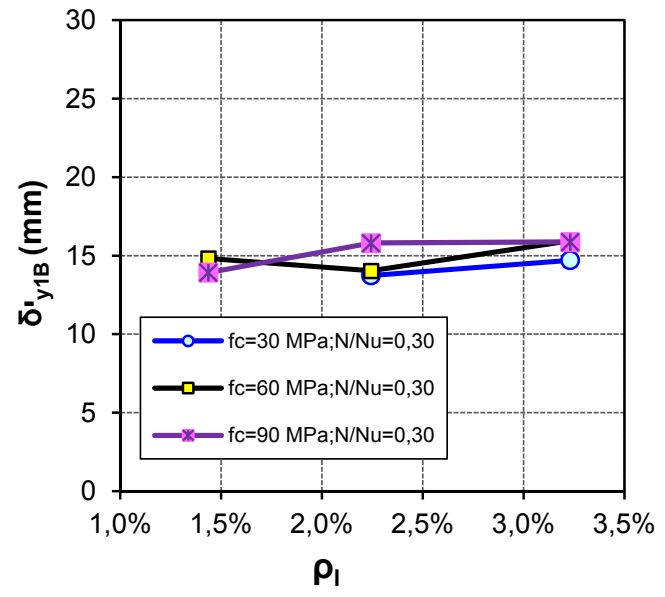

(b)

Figura 6.30 Comparación de la variable desplazamiento elástico efectivo $\left(\delta_{{ }{ }_{11 B}}\right)$ con respecto a la cuantía de armadura longitudinal, resistencia del hormigón y niveles de carga axil del (a) $15 \%$ y (b) $30 \%$

Con respecto al desplazamiento último (Figuras 6.31), el comportamiento y la influencia de la cuantía longitudinal puede considerarse similar al estado elástico, por las mismas razones anteriormente expuestas, aunque aparece una mayor dispersión de los resultados, lo que puede ser atribuido a la influencia de otras variables difícilmente controlables, como, por ejemplo, pequeños movimientos de la armadura que afectan al espesor de la capa de recubrimiento o la dispersión de los valores de resistencia del hormigón.

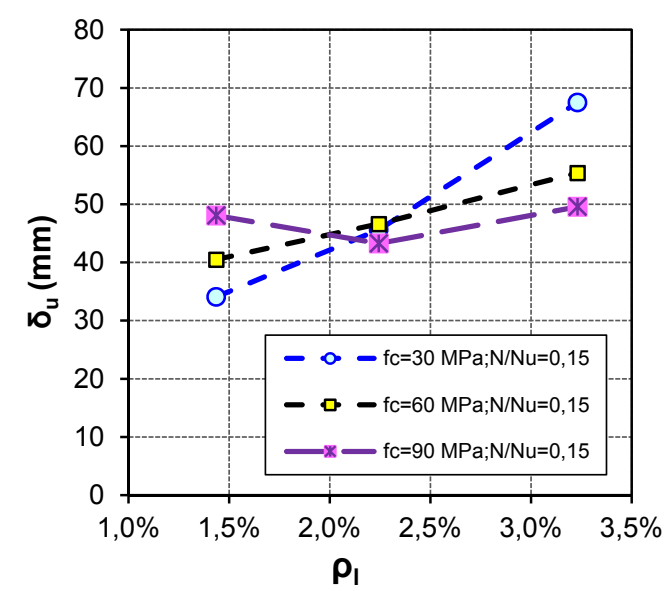

(a)

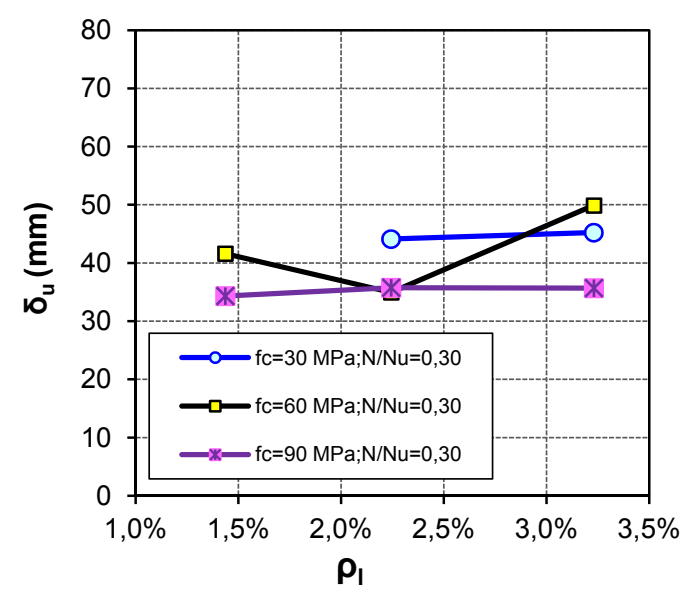

(b)

Figura 6.31 Comparación de la variable desplazamiento último $\left(\delta_{u}\right)$, con respecto a la cuantía de armadura longitudinal, resistencia del hormigón y niveles de carga axil del (c) $15 \%$ y (d) $30 \%$

Como resultado de los dos parámetros anteriores, se encuentra el desplazamiento plástico y la ductilidad en desplazamientos (Figuras 6.32 y 6.33). En realidad, la interpretación de estos parámetros se complica, y no es posible encontrar una clara influencia del parámetro de armadura longitudinal, aunque para la ductilidad en 
desplazamientos se podría interpretar que el efecto de la armadura longitudinal no es esclarecedor para las dos condiciones de carga axial.

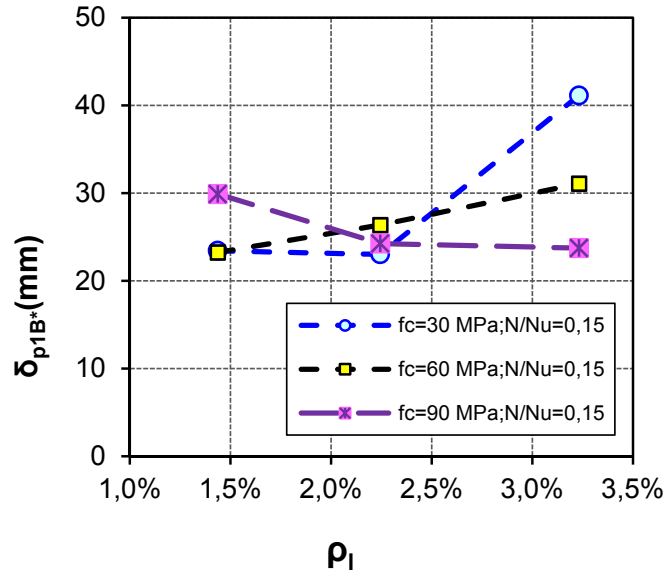

(a)

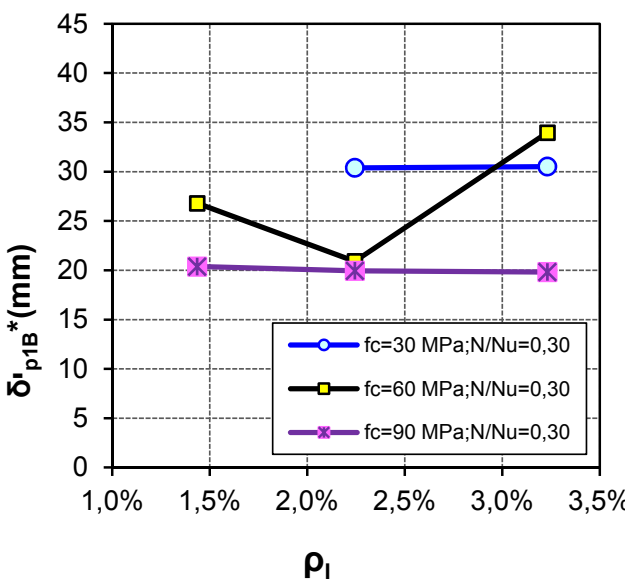

(b)

Figura 6.32 Comparación de la variable desplazamiento plástico $\left(\delta_{p 1 B}\right)$ con respecto a la cuantía de armadura longitudinal, resistencia del hormigón y niveles de carga axil del (a) $15 \%$ y (b) $30 \%$

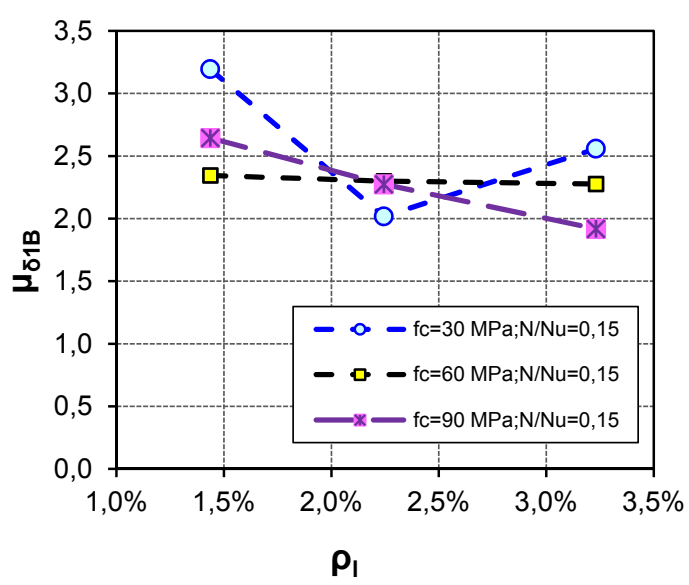

(a)

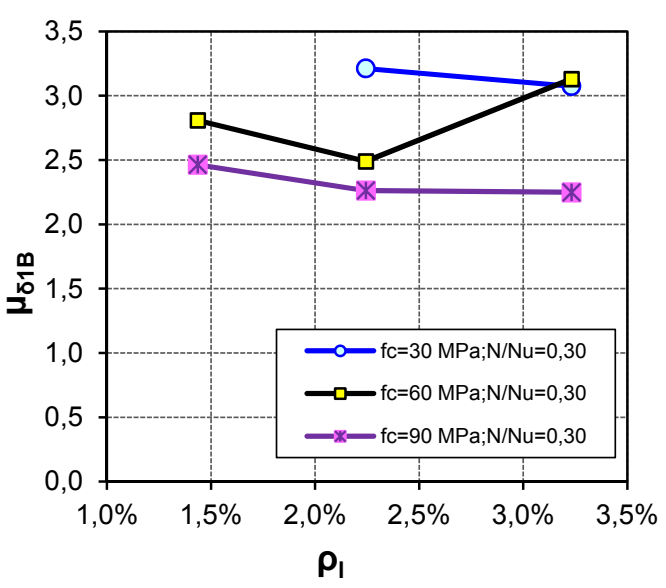

(b)

Figura 6.33 Comparación de la variable ductilidad en desplazamientos $\left(\mu_{\delta 1 B}\right)$ con respecto a la cuantía de armadura longitudinal, resistencia del hormigón y niveles de carga axil del (a) $15 \%$ y (b) $30 \%$

\subsubsection{Influencia de la cuantía de armadura transversal}

El parámetro de la cuantía de armadura transversal juega un importante papel en el proceso de capacidad de deformación. Es bien sabido que, en soportes de hormigón sujetos a flexo-compresión, si la cuantía de armadura transversal es capaz de resistir las tensiones transversales producidas por la armadura longitudinal y por el núcleo de hormigón confinado, y si además se desprende la capa de recubrimiento sin pérdida de la capacidad de carga axial del soporte, es 
Estudio experimental y numérico de la capacidad de deformación de soportes esbeltos de hormigón armado

posible asegurar un cambio favorable en el comportamiento deformacional del soporte.

En este apartado se estudia el efecto de la armadura transversal en el comportamiento carga-desplazamiento de soportes esbeltos de hormigón convencional y de alta resistencia. Los resultados experimentales de la serie de ensayos seleccionada para estudiar este efecto se presentan en la Tabla 6-25.

Durante el desarrollo del comportamiento elástico en el proceso de deformación de los soportes sometidos a flexo-compresión, la armadura transversal no provoca efectos favorables en la capacidad de deformación, ya que el efecto del confinamiento es efectivo cerca de la carga máxima y en la rama de descenso, puesto que la armadura transversal empieza a actuar justo cuando el hormigón de la capa de recubrimiento alcanza la deformación última, y, en consecuencia ocurre la rotura del hormigón, seguida del desprendimiento de la capa de recubrimiento. Como se puede observar en las Figuras 6.34a y b, el aumento en la cuantía de armadura transversal no ocasiona un cambio significativo en el desplazamiento elástico efectivo, a pesar de que, en dos de los ensayos, los resultados no se acomodan a la afirmación anterior.

Tabla 6-25 Resultados de la idealización del diagrama $P$ - $\delta$ empleando el método del Eurocódigo 8 (versión 1B), para la serie de ensayos utilizada en el análisis de la influencia de la cuantía de armadura transversal

\begin{tabular}{|c|c|c|c|c|c|c|c|c|c|c|}
\hline $\begin{array}{c}\mathrm{N}^{\circ} \\
\text { ensayo }\end{array}$ & REFERENCIA & $\mathrm{f}_{\mathrm{c}}(\mathrm{MPa})$ & $\mathrm{N} / \mathrm{N}_{\mathrm{u}}$ & $\begin{array}{c}\rho_{1} \\
(\%)\end{array}$ & $\lambda$ & $\begin{array}{c}\rho_{\mathrm{s}} \\
(\%) \\
\end{array}$ & $\begin{array}{l}\delta_{y 1 B}^{\prime} \\
(\mathrm{mm}) \\
\end{array}$ & $\begin{array}{c}\delta_{\mathrm{p} 1 \mathrm{~B}} \\
(\mathrm{~mm}) \\
\end{array}$ & $\begin{array}{c}\delta_{\mathrm{u}} \\
(\mathrm{mm}) \\
\end{array}$ & $\mu_{\delta 1 \mathrm{~B}}$ \\
\hline 3 & $\mathrm{~N} 30-10.5-\mathrm{C} 0-2-30$ & 31.60 & 0.30 & \multirow{18}{*}{2.2} & \multirow{8}{*}{10.5} & 1.0 & 13.73 & 30.38 & 44.11 & 3.21 \\
\hline 35 & $\mathrm{~N} 30-10.5-\mathrm{C} 3-2-30$ & 41.00 & 0.25 & & & 3.0 & 15.54 & 31.33 & 46.86 & 3.02 \\
\hline 4 & $\mathrm{~N} 30-10.5-\mathrm{C} 0-2-45$ & 34.50 & 0.42 & & & 1.0 & 10.96 & 18.09 & 29.05 & 2.65 \\
\hline 36 & N30-10.5-C3-2-45 & 34.20 & 0.43 & & & 3.0 & 11.19 & 23.57 & 34.75 & 3.11 \\
\hline 27 & $\mathrm{H} 90-10.5-\mathrm{C} 0-2-30$ & 90.10 & 0.30 & & & 1.0 & 15.80 & 19.94 & 35.74 & 2.26 \\
\hline 39 & H90-10.5-C3-2-30 & 93.45 & 0.29 & & & 3.0 & 17.28 & 20.95 & 38.23 & 2.21 \\
\hline 28 & H90-10.5-C0-2-45 & 93.20 & 0.44 & & & 1.0 & 12.94 & 14.50 & 27.44 & 2.12 \\
\hline 40 & $\mathrm{H} 90-10.5-\mathrm{C} 3-2-45$ & 91.95 & 0.45 & & & 3.0 & 8.74 & 19.10 & 27.83 & 3.19 \\
\hline 29 & $\mathrm{H} 90-7.5-\mathrm{C} 0-2-30$ & 100.35 & 0.27 & & \multirow{10}{*}{7.5} & 1.0 & 13.72 & 12.13 & 25.85 & 1.88 \\
\hline 43 & $\mathrm{H} 90-7.5-\mathrm{C} 2-2-30$ & 93.50 & 0.29 & & & 3.0 & 14.14 & 14.63 & 28.77 & 2.03 \\
\hline 41 & $\mathrm{H} 90-7.5-\mathrm{C} 3-2-30$ & 86.35 & 0.31 & & & 1.0 & 13.87 & 12.51 & 26.38 & 1.90 \\
\hline 30 & $\mathrm{H} 90-7.5-\mathrm{C} 0-2-45$ & 94.00 & 0.41 & & & 3.0 & 11.54 & 8.26 & 19.81 & 1.72 \\
\hline 44 & $\mathrm{H} 90-7.5-\mathrm{C} 2-2-45$ & 89.20 & 0.45 & & & 1.0 & 9.16 & 10.41 & 19.57 & 2.14 \\
\hline 42 & $\mathrm{H} 90-7.5-\mathrm{C} 3-2-45$ & 78.23 & 0.51 & & & 3.0 & 8.98 & 12.41 & 21.39 & 2.38 \\
\hline 5 & $\mathrm{~N} 30-7.5-\mathrm{C} 0-2-30$ & 30.10 & 0.30 & & & 1.0 & 12.13 & 21.17 & 33.30 & 2.75 \\
\hline 37 & N30-7.5-C3-2-30 & 35.75 & 0.27 & & & 3.0 & 11.95 & 27.54 & 39.49 & 3.30 \\
\hline 6 & $\mathrm{~N} 30-7.5-\mathrm{C} 0-2-45$ & 33.00 & 0.42 & & & 1.0 & 9.70 & 13.15 & 22.84 & 2.36 \\
\hline 38 & $\mathrm{~N} 30-7.5-\mathrm{C} 3-2-45$ & 35.00 & 0.41 & & & 3.0 & 9.73 & 15.42 & 25.15 & 2.58 \\
\hline
\end{tabular}




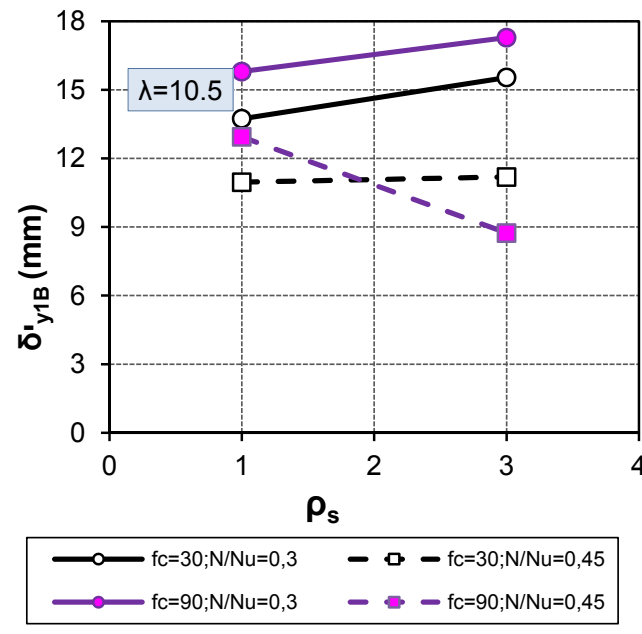

(a)

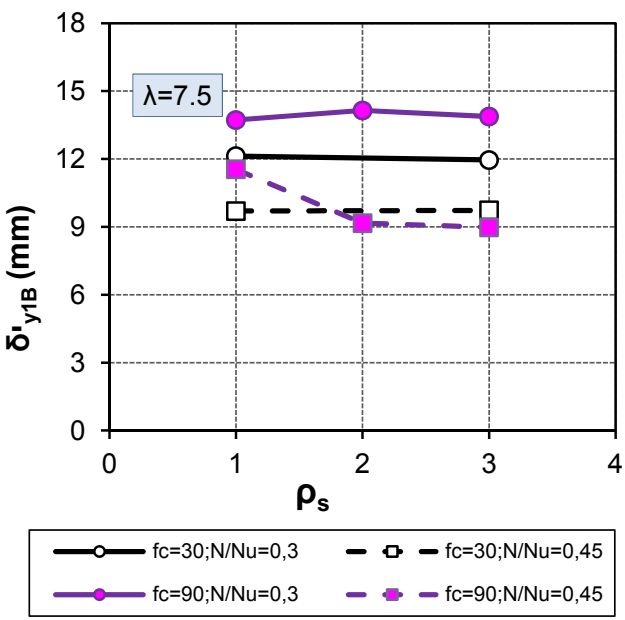

(b)

Figura 6.34 Comparación de las variables desplazamiento elástico efectivo $\left(\delta_{y 1 B}^{\prime}\right)$ con respecto a la cuantía de armadura transversal, resistencia del hormigón, y esbeltez (a) $\lambda=10.5$ y (b) 7.5

En las Figuras 6.35a y $\mathrm{b}$, se ha podido confirmar la influencia del nivel de carga axial, ya que, para los dos valores de esbeltez, la variable $\delta_{\mathrm{y} 1 \mathrm{~B}}^{\prime}$ disminuye al aumentar el nivel de carga axil de $30 \%$ a $45 \%$. También se muestra, por una parte, que para el nivel de carga axial $30 \%$, el $\delta_{y 1 \mathrm{~B}}^{\prime}$ es menor cuando se utiliza hormigón convencional $\left(f_{c}=30 \mathrm{MPa}\right)$ que cuando se utiliza hormigón de alta resistencia (90 $\mathrm{MPa}$ ); por otra parte, si el nivel de carga axial es de $45 \%$, no existe una clara relación respecto al cambio de la resistencia del hormigón. Por último, se puede observar que, en general, el $\delta_{y 1 \mathrm{~B}}^{\prime}$ es mayor para $\lambda=10.5$ que para $\lambda=7.5$.

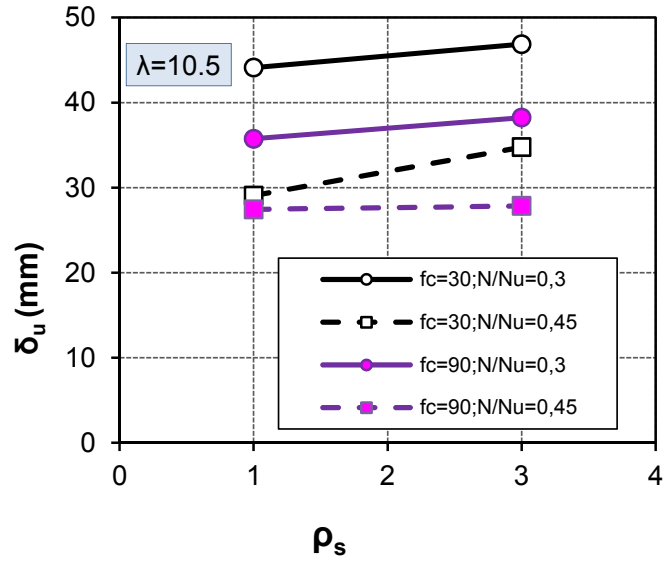

(a)

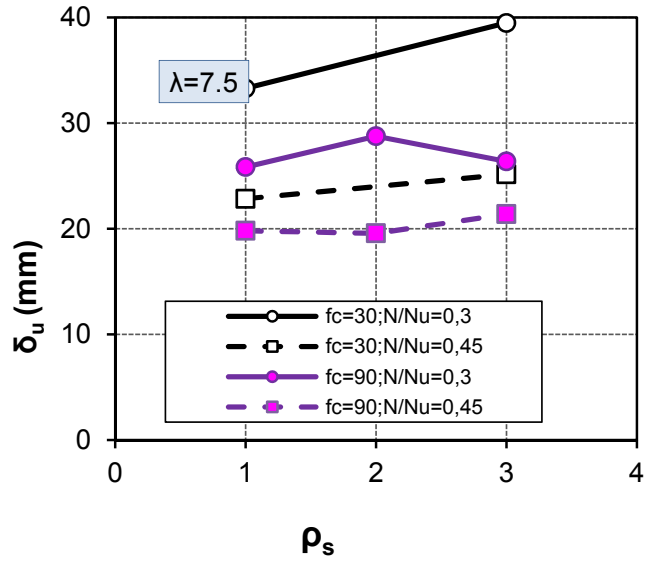

(b)

Figura 6.35 Comparación de la variable desplazamiento último $\left(\delta_{u}\right)$, con respecto a la cuantía de armadura transversal, resistencia del hormigón, y esbeltez (a) $\lambda=10.5$ y (b) 7.5

Al realizar la comparación entre los soportes poco confinados $\left(\rho_{s}=1 \%\right)$ y los confinados $\left(\rho_{\mathrm{s}}=2 \%\right.$ y $\left.3 \%\right)$, para la variable de desplazamiento último $\left(\delta_{\mathrm{u}}\right)$, se puede apreciar, en los resultados de la Tabla 6-25 y de las Figuras 6.35a y b, que, en general, existe un leve aumento del desplazamiento último. El aumento de $\delta_{u}$ es 
apenas visible gráficamente, y podría interpretarse que, en realidad, el aumento de $\rho_{\mathrm{s}}$ en los ensayos experimentales no ha sido del todo eficiente, ya que, a pesar de que se ha controlado el pandeo de la armadura longitudinal en los soportes con cuantías de armadura transversal del $2 \%$ y del $3 \%$, no se ha conseguido que el efecto del confinamiento sea efectivo, de modo que, al producirse el salto del recubrimiento, el núcleo confinado no ha sido capaz de soportar por si solo toda la carga de compresión. Algunos de los factores que pueden haber intervenido en la eficiencia de la armadura de confinamiento son los siguientes:

a. La armadura transversal puede también favorecer el salto del recubrimiento prematuramente, cuando la separación entre cercos es muy pequeña y no existe el suficiente espesor de recubrimiento, lo que puede generar una superficie de rotura débil. Saatcioglu y Razvi (2002) [114] mencionan que la efectividad de la armadura transversal en el confinamiento también depende de la relación entre el área del núcleo confinado y el área de recubrimiento.

b. Estudios realizados por Lam et al. (2003) [77], Lukkunaprasit y Sittipunt (2003) [82], Bayrak y Sheikh [18]), han demostrado experimentalmente, que, si el cierre de los cercos se realiza girando las barras $135^{\circ}$, el efecto del confinamiento en la capacidad de deformación de los soportes es más efectivo que si el cierre de los cercos se realiza girando las barras $90^{\circ}$. Incluso en algunas normas sismo resistentes (ACl-318-08 (2008) [1]) se especifica el giro de $135^{\circ}$ y la longitud mínima del cierre. En este estudio, los ensayos se han realizado con cercos cerrados a $90^{\circ}$, puesto que este es un detalle constructivo habitual en España.

Estas son algunas de las razones por las que no se ha podido establecer una relación general entre la capacidad de deformación de los soportes y la cuantía de armadura transversal. Sin embargo, es posible encontrar algunos efectos específicos producidos por el aumento de la armadura transversal en las variables de desplazamiento plástico $\left(\delta_{p 1 B}\right)$ y ductilidad en desplazamientos $\left(\mu_{\delta}\right)$; dichos efectos se explican a continuación.

En primer lugar, los resultados muestran que el efecto de la armadura transversal en la capacidad de deformación medida a partir de $\delta_{p 1 B}$ y de $\mu_{\delta}$, es más notable para altos niveles de carga axial $\left(\mathrm{N} / \mathrm{N}_{\mathrm{u}}=45 \%\right)$, que para niveles moderados $\left(\mathrm{N} / \mathrm{N}_{\mathrm{u}}=\right.$ $30 \%)$; este efecto se ha demostrado tanto en hormigón convencional como en hormigón de alta resistencia, (ver Figura 6.36 y Figura 6.37). Esto ya ha sido mencionado en la literatura para elementos de hormigón convencional (Sheikh et al.(1994) [122], Watson y Park (1994) [133]) y de alta resistencia (Bae y Bayrak (2006) [10]).

En segundo lugar, se obtiene un mayor valor de $\delta_{\mathrm{p} 1 \mathrm{~B}}$ y $\mu_{\delta}$ (ver Figura 6.36 y Figura 6.37), en soportes de hormigón convencional que en soportes de hormigón de alta resistencia. Estudios como los realizados por Bae y Bayrak (2006) [7], Bayrak y Sheikh (1997) [18], Saatcioglu y Razvi (2002) [114], Ho y Pam (2002) [99], etc., han planteado que, como consecuencia del comportamiento frágil del hormigón de alta resistencia (HAR), la capacidad de deformación de elementos de HAR es menor que la de elementos de hormigón convencional $(\mathrm{HC})$. Estos estudios sugieren incluso que, para alcanzar similares índices de capacidad de desplazamiento $\left(\delta_{\mathrm{u}}\right.$, 
$\left.\mu_{\delta}\right)$, es necesario disponer de altos valores de cuantías de armadura transversal en elementos de HAR.

Finalmente, se muestra una vez más que el comportamiento deformacional en los soportes con esbeltez de 10.5 es mayor que en soportes con esbeltez de 7.5.

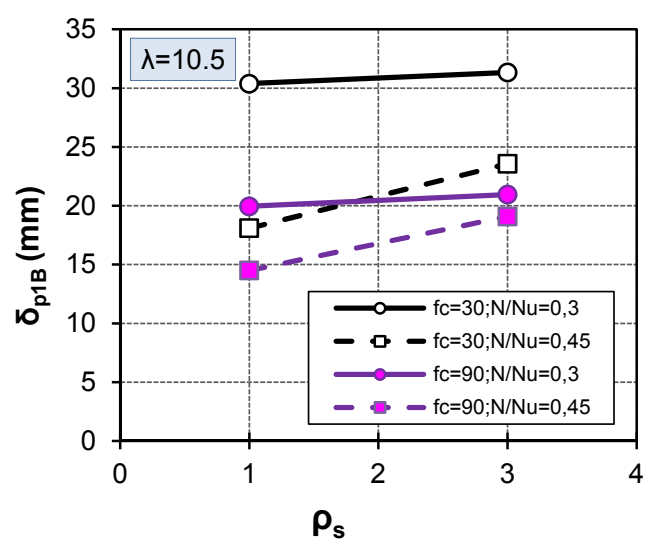

(a)

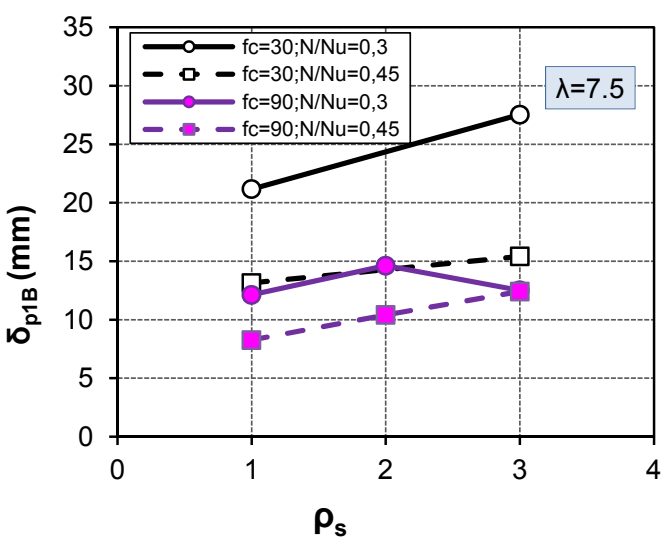

(b)

Figura 6.36 Comparación de la variable desplazamiento plástico $\left(\delta_{p 1 B}\right)$ con respecto a la cuantía de armadura transversal, resistencia del hormigón, y esbeltez (a) $\lambda=10.5$ y (b) 7.5

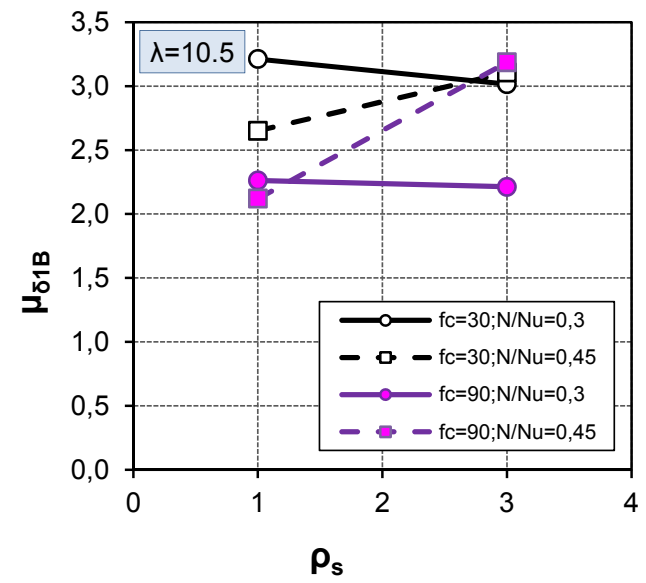

(a)

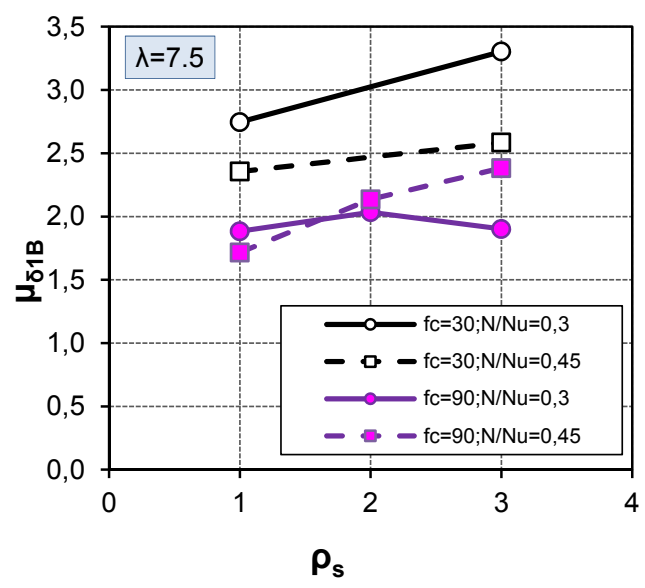

(b)

Figura 6.37 Comparación de la variable ductilidad en desplazamientos $\left(\mu_{\delta 1 B}\right)$ con respecto a la cuantía de armadura transversal, resistencia del hormigón, y esbeltez (c) $\lambda=10.5$ y (d) 7.5

\subsection{LONGITUD DE RÓTULA PLÁSTICA}

Algunos modelos simples utilizan la longitud de rótula plástica $\left(L_{p}\right)$ como paso intermedio para evaluar el desplazamiento en el extremo de un soporte en voladizo, si se conoce de forma fiable su comportamiento seccional (Figura 6.38). Una evaluación precisa de $L_{p}$ es importante para relacionar la respuesta a nivel de sección con la respuesta a nivel de elemento de un soporte de hormigón. A partir de 
este razonamiento, Park y Paulay (1975) [103] propusieron la Ec. 6-9, para evaluar la $L_{p}$ en ensayos experimentales en los que se ha medido el comportamiento tanto de la sección como del elemento.
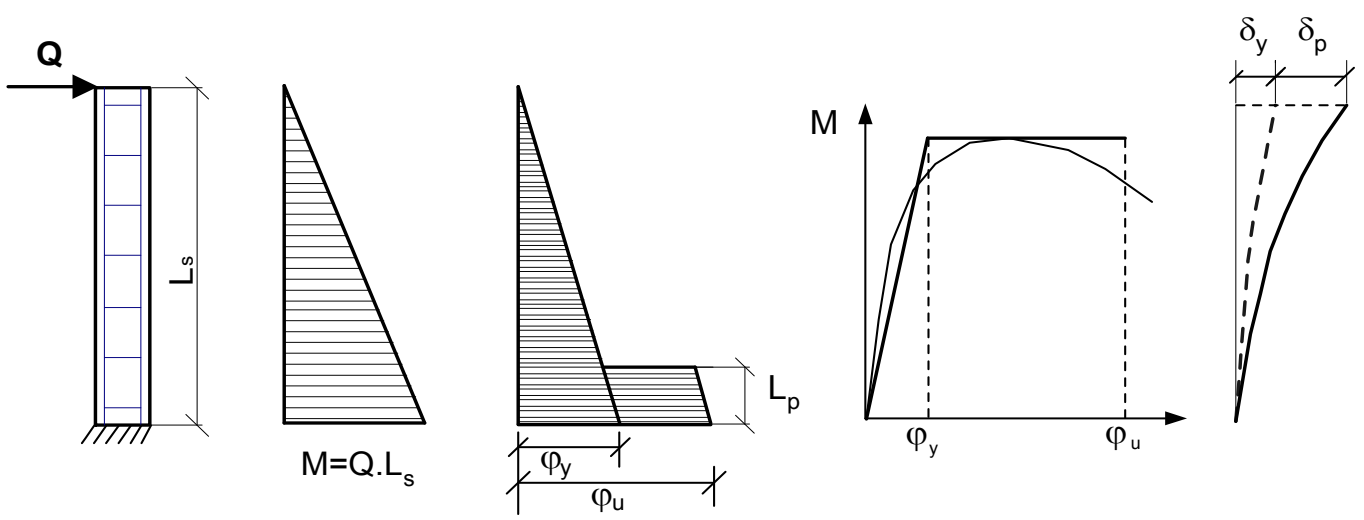

Figura 6.38 Definición de longitud de rotula plástica en soportes de hormigón utilizando un modelo de ménsula

$$
\delta_{\mathrm{u}}=\frac{\varphi_{y} L_{s}^{2}}{3}+\left(\varphi_{u}-\varphi^{\prime}{ }_{y}\right) L_{p}\left(L_{s}-0.5 L_{p}\right) \quad \text { Ec. } 6-9
$$

Donde:

$\delta_{u} \quad$ Desplazamiento máximo para la carga última.

$\varphi^{\prime}{ }_{y} \quad$ Curvatura elástica efectiva del diagrama idealizado $M$ - $\varphi$ para la sección crítica.

$\varphi_{u} \quad$ Curvatura última

$L_{s} \quad$ Distancia desde el momento máximo hasta el momento nulo.

A partir de la Ec. 6-9, Park y Paulay (1975) [103] relacionan los factores de ductilidad en desplazamientos y curvatura, mediante la longitud de rótula plástica, como aparece en la Ec. 6-10.

$$
\mu_{\delta}=1+3\left(\mu_{\varphi}-1\right) \frac{L_{p}}{L_{s}}\left(1-0.5 \frac{L_{p}}{L_{s}}\right)
$$

Las Ec. 6-9 y Ec. 6-10 se han usado comúnmente en otras investigaciones para estimar la $L_{p}$ en soportes de hormigón (Sheikh et al. (1993) y (1994) [121] y [122], Paulay y Priestley (1992) [104], Bayrak (1998) [21], Legerón y Paultre ( 2000) [78]). En estos estudios, el desplazamiento medido en el extremo del soporte incluye las componentes por flexión, el deslizamiento de la armadura que puede producirse en las secciones cercanas a la zona de empotramiento y el desplazamiento que se produce en la zona de la rótula debido a la fisuración inclinada por cortante. Así, la $L_{p}$ estimada utilizando las expresiones Ec. 6-9 y Ec. 6-10 incluyen dichos efectos. Además, es evidente que las dos ecuaciones presentadas son válidas cuando el comportamiento del soporte no es dominado por los efectos $P-\Delta$.

En este estudio, es importante destacar los siguientes aspectos con respecto al cálculo de la longitud de rótula plástica.

a. En las Ec. 6-9 y Ec. 6-10, el desplazamiento elástico teórico $\left(\delta_{y_{-} \text {teo }}=\right.$ $\left.\varphi_{y} L_{s}^{2} / 3\right)$, se calcula para un elemento en ménsula, tal y como se muestra en la Figura 6.38 , sin tener en cuenta los efectos P- $\Delta$. Dado que en este estudio existe una amplia combinación de soportes esbeltos ensayados con moderados y altos niveles de carga axil, es evidente que los efectos 
de segundo orden no pueden despreciarse, en una gran parte de los ensayos. Por dicha razón, en este estudio el término que define el desplazamiento elástico teórico $\left(\delta_{y_{-} \text {teo }}\right)$ se evaluará para las condiciones reales de la deformada elástica teniendo en cuenta los efectos P- $\Delta$, redefiniéndose su expresión.

b. Además, respecto al desplazamiento que se produce debido al deslizamiento de la armadura en la zona de empotramiento soporte"stub", es preciso aclarar que, de acuerdo con la disposición y detalles de la armadura (Figura 4.3), donde la armadura longitudinal es continua a lo largo del elemento, es improbable que se produzca dicho efecto. El efecto del cortante en la zona de rótula plástica, es importante para bajos valores de esbeltez. Además, el efecto del cortante disminuye debido a la presencia del nivel de carga axial, lo cual mejora la resistencia a cortante del hormigón y reduce la deformación de cortante. En este estudio se considera que debido a que los valores de esbeltez utilizados en el programa experimental son altos ( $\lambda=7.5$ y 10.5), el efecto de la deformabilidad por cortante puede ser despreciado. En consecuencia, la $L_{p}$ medida estará influida principalmente por los desplazamientos de flexión, sin tener en cuenta el deslizamiento de las barras en la zona de anclaje, ni las deformaciones por cortante.

\subsubsection{CÁLCULO DEL DESPLAZAMIENTO ELÁSTICO TEÓRICO TENIENDO EN CUENTA LOS EFECTOS P-A}

Para llevar a cabo el cálculo de $\delta_{y_{-} \text {teo }}$ se han utilizado dos posibles aproximaciones. En la primera aproximación, para el cálculo $\left(\delta_{y_{-} \text {teo1 } 1}\right)$ se ha aplicado el método de la "columna modelo". Este método considera que el desplazamiento en el extremo libre de un elemento tipo ménsula depende de la longitud del elemento y de la curvatura en el empotramiento de la ménsula. En este método se plantea la Ec. 6-11 para describir la deformada a lo largo del elemento, derivando dos veces y, considerando las condiciones de contorno $y=0$ en la Ec. 6-13 y de $y=L_{s}$ en la Ec. 6-11, se obtiene la hipótesis básica de la Ec. 6-15 para el cálculo de $\delta_{y_{-} \text {teo1. }}$.

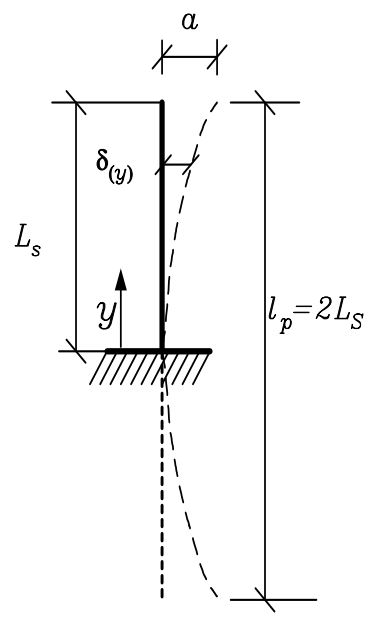

$$
\begin{gathered}
\text { Deformada: } \quad \delta_{(y)}=a \cdot\left(1-\cos \left(\frac{\pi \cdot y}{l_{p}}\right)\right) \\
\delta^{\prime}(y)=a \cdot \frac{\pi}{l_{p}} \operatorname{sen}\left(\frac{\pi \cdot y}{l_{p}}\right) \\
\delta^{\prime \prime}{ }_{(y)}=a \cdot \frac{\pi^{2}}{l_{p}^{2}} \cos \left(\frac{\pi \cdot y}{l_{p}}\right)=\varphi_{(y)} \\
y=0 \Rightarrow \cos \left(\frac{\pi \cdot y}{l_{p}}\right)=1 \Rightarrow a=\frac{l_{p}^{2}}{\pi^{2}} \cdot \varphi_{o}=\frac{4 L_{s}^{2}}{\pi^{2}} \varphi_{o} \\
y_{\left(L_{s}\right)} \approx 0.4 \cdot L_{s}^{2} \cdot \varphi_{o}
\end{gathered}
$$

Figura 6.39 Cálculo del desplazamiento elástico utilizando el método de la columna modelo 
Donde:

$I_{p} \quad$ Longitud de pandeo, que para el caso de los soportes ensayados es 2.

$\varphi_{o} \quad$ Curvatura elástica efectiva en la sección de empotramiento.

$L_{s} \quad$ Distancia entre las secciones de momento nulo y máximo.

La segunda aproximación utilizada para el cálculo del desplazamiento elástico teórico $\left(\delta_{y_{\_}}\right.$teo2$)$, consiste en plantear la ecuación de equilibrio con la posición deformada del soporte, como se muestra en la Figura 6.40.
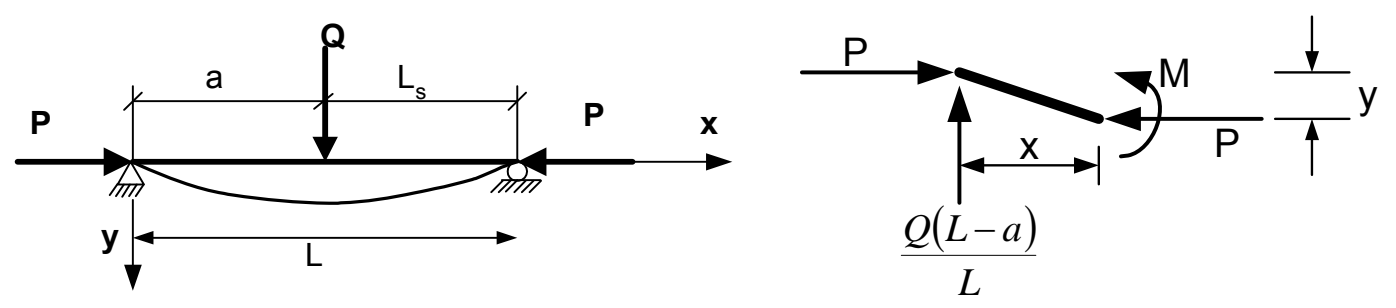

Figura 6.40 Esquema de soporte sometido a una carga axil y carga de flexión

Las ecuaciones diferenciales que definen el equilibrio para el elemento son las siguientes:

$$
\begin{array}{ll}
-E I y^{\prime \prime}=\frac{Q(L-a)}{L} x+P y & \text { para } 0 \leq x \leq a \\
-E I y^{\prime \prime}=Q a\left(\frac{L-x}{L}\right)+P y & \text { para } a \leq x \leq L
\end{array}
$$

Ec. 6-17

Si se considera el caso especial de la Figura 6.40, en que la carga concentrada se encuentra en el centro del vano, es decir $a=L / 2$ y $x=L / 2$, el desplazamiento elástico teórico puede ser calculado a partir de la Ec. 6-18.

$$
\begin{gathered}
y_{\max }=\frac{Q L^{3}}{48 E I}\left[\frac{3(\tan u-u)}{u^{3}}\right]=y_{o}\left[\frac{3(\tan u-u)}{u^{3}}\right] \\
u=\frac{k L}{2}=\frac{\pi}{2} \sqrt{\frac{P}{P_{c}}} \\
P_{c}=\frac{\pi^{2} E I}{l_{p}} \\
\tan u=u+\frac{1}{3} u^{3}+\frac{2}{15} u^{5}+\frac{17}{315} u^{7}+. .
\end{gathered}
$$

Para simplificar la expresión se utiliza la serie exponencial de la Ec. 6-21, cuyo desarrollo matemático conduce a la aproximación de la Ec. 6-22, la cual es utilizada para determinar el desplazamiento elástico teórico $\left(\delta_{y_{-} \text {teo2 }}\right)$ de los ensayos experimentales. Como se demuestra en la Ec. 6-25, la componente yo es 
nuevamente el desplazamiento elástico teórico para la condición estructural de un soporte en ménsula, pero que se encuentra afectada por un segundo término factor de amplificación, que incrementa el desplazamiento elástico debido a los efectos de segundo orden $(\mathrm{P}-\Delta)$. Para la consideración de esta expresión, se ha tenido en cuenta que, al evaluar la carga axial crítica $\left(P_{c}\right)$, la rigidez efectiva (EI) utilizada en el cálculo es la corresponde a la obtenida en el diagrama de respuesta $M-\varphi$ utilizando el proceso de idealización del Eurocódigo 8- versión 1B.

$$
\begin{gathered}
y_{\text {max }} \approx y_{o}\left[\frac{1}{1-\frac{\mathrm{P}}{\mathrm{P}_{\mathrm{c}}}}\right] \\
y_{o}=\frac{Q L^{3}}{48 E I}=\frac{Q L_{s}^{3}}{6 E I} \\
\varphi_{y}=\frac{M_{y}}{E I} \Rightarrow E I=\frac{Q L_{2}}{2} \times \frac{1}{\varphi_{y}} \\
y_{o}=\frac{\varphi_{y} L_{s}^{3}}{3}
\end{gathered}
$$

\subsubsection{LONGITUD DE RÓTULA PLÁSTICA EQUIVALENTE}

En esta sección se presentan los resultados de la longitud de rótula plástica equivalente medida en los ensayos experimentales ( $\left.L_{p_{\_} \text {exp }}\right)$. Para calcular la longitud de rótula plástica experimental $\left(L_{p_{-} \exp }\right)$, se siguen utilizando los mismos conceptos de Park y Paulay (1975) [103], Ec. 6-26, aunque el desplazamiento elástico teórico se calcula mediante las dos aproximaciones anteriormente descritas. Por consiguiente, se obtienen dos posibles valores para la longitud de rótula plástica, $L_{p_{-} \text {exp1 }}$ cuando el desplazamiento elástico teórico $\delta_{y_{-} \text {teo1 }}$ se calcula mediante el método de la columna modelo (Ec. 6-14), y $L_{p_{\text {pexp2} 2}}$ cuando el $\delta_{y_{-} \text {teo2 }}$ se evalúa teniendo en cuenta el factor de amplificación (Ec. 6-21). Los valores de curvatura elástica efectiva corresponden al proceso de idealización (versión 1B - Eurocódigo 8). Igualmente, los valores de curvatura y desplazamiento últimos son los referidos al punto de fallo descrito en la sección 6.4 .2 y ya presentados en el desarrollo de la sección 6.5.2 y 6.5.3.

$$
\delta_{u}=\delta_{\mathrm{yteo}}+\left(\varphi_{u}-\varphi^{\prime}{ }_{y}\right) L_{p}\left(L_{s}-0.5 L_{p}\right) \quad \text { Ec. } 6-26
$$

En la Figura 6.41 y Figura 6.42 se presentan los valores de los desplazamientos elásticos teóricos $\left(\delta_{y_{-} \text {teo1 }}\right.$ y $\left.\delta_{y_{\text {_teo }}}\right)$, y los respectivos valores de la relación entre longitud de rótula plástica experimental y el canto de la sección $h$, ( $L_{p_{-} \exp 1} / \mathrm{h}$ y $\mathrm{L}_{p_{\_} \text {exp2 }} / \mathrm{h}$ ). La comparación entre los valores $\delta_{y_{-} \text {teo1 }}$ y $\delta_{y_{-} \text {teo2 }}$ muestra que existe una buena aproximación entre los dos métodos aplicados. Los valores de $\delta_{y_{-} \text {teo } 1}$ son, en promedio, un $8 \%$ mayores que los valores de $\delta_{y_{-} \text {teo2 }}$. En consecuencia, la longitud de rótula plástica $\left(L_{p_{-} \text {exp }} / h\right)$ es en promedio un $11 \%$ menor que la $L_{p_{-} \text {exp2 }} / h$. Los valores de los ensayos 23 y 39 han sido descartados del análisis de la longitud de rótula plástica, puesto que dichos valores son considerados extremos, ya que son 
superiores a 4, lo que indica que, probablemente en estos soportes, no se ha formado la rótula plástica.

Como se puede ver en la Figura 6.42, en 15 ensayos los valores de longitud de rótula plástica están dentro del rango $0.35 \mathrm{~h} \leq L_{p_{\text {_exp }}} \leq 1.0 \mathrm{~h}$, de los cuales 10 corresponden a los ensayos de esbeltez 7.5, existiendo sólo 2 ensayos para este tipo de esbeltez, donde la $L_{p_{-} \text {exp }}$ es mayor que 1.0h. Los 5 ensayos restantes que se encuentran dentro de este rango de $L_{p}<1.0 \mathrm{~h}$ corresponden a los ensayos de esbeltez 10.5 , con niveles de carga axil del $15 \%$, cuantías de armadura $1.44 \%$ y $2.26 \%$, y resistencias del hormigón alrededor de $30 \mathrm{MPa}, 60 \mathrm{MPa}$ y $90 \mathrm{MPa}$, a excepción del ensayo 31, cuya resistencia del hormigón está alrededor de $90 \mathrm{MPa}$.

Llaman la atención los valores de longitud de rótula plástica obtenidos para los ensayos de flexión sin carga axial, ensayos 1,13 , y 25 , cuyos valores de $L_{p_{-} \text {exp } 2} / \mathrm{h}$ son $2.34,2.67$ y 2.22 respectivamente. Estos valores son relativamente altos en comparación con ensayos llevados a cabo bajo similares características de carga, realizados por Mendis P. (2001) [92] y Pendyala et al. (1994) [106], en los cuales la $L_{p} / h$ es medida experimentalmente obteniéndose un valor de alrededor de 0.5 . Esto se debe a que la curvatura medida experimentalmente en las secciones ha sido limitada por la medición de las galgas extensiométricas en las barras, ya que éstas sólo son capaces de medir valores de hasta el 10\%. Sin embargo, las deformaciones reales de la armadura pueden llegar a valores mucho mayores. Por lo tanto, la curvatura última medida en estos ensayos es inferior a la realmente alcanzada, y en consecuencia los valores de $L_{p}$ se ven seriamente afectados.

A pesar de que la longitud de plastificación $L_{p}$, en ensayos con niveles de carga axil nula está fuera del rango esperado, en los ensayos con esbeltez 10.5 en los que la carga axil aumenta gradualmente a partir del $15 \%$ hasta cerca del $45 \%$, cabe destacar que la longitud de rótula plástica aumenta con el nivel de carga axial. El efecto es contrario en ensayos con esbeltez 7.5, en los que la longitud de rótula plástica disminuye cuando hay un incremento de carga axial del $30 \%$ al $45 \%$. Esto demuestra, una vez más, que el comportamiento puede ser contradictorio para ciertos intervalos de esbeltez.

Los valores más altos de la longitud de plastificación $L_{p}$ se presentan en los ensayos en los que se combina el más alto valor de esbeltez (10.5) con niveles de carga axial superiores al $40 \%$.

Otro de los fenómenos observados está relacionado con cuantías de armadura longitudinal del $3 \%$, para las cuales la $L_{p}$ aumenta con el incremento del nivel de carga axial. En cuanto a la resistencia del hormigón, no se observa un efecto claro de la influencia de este parámetro en la $L_{p}$. 


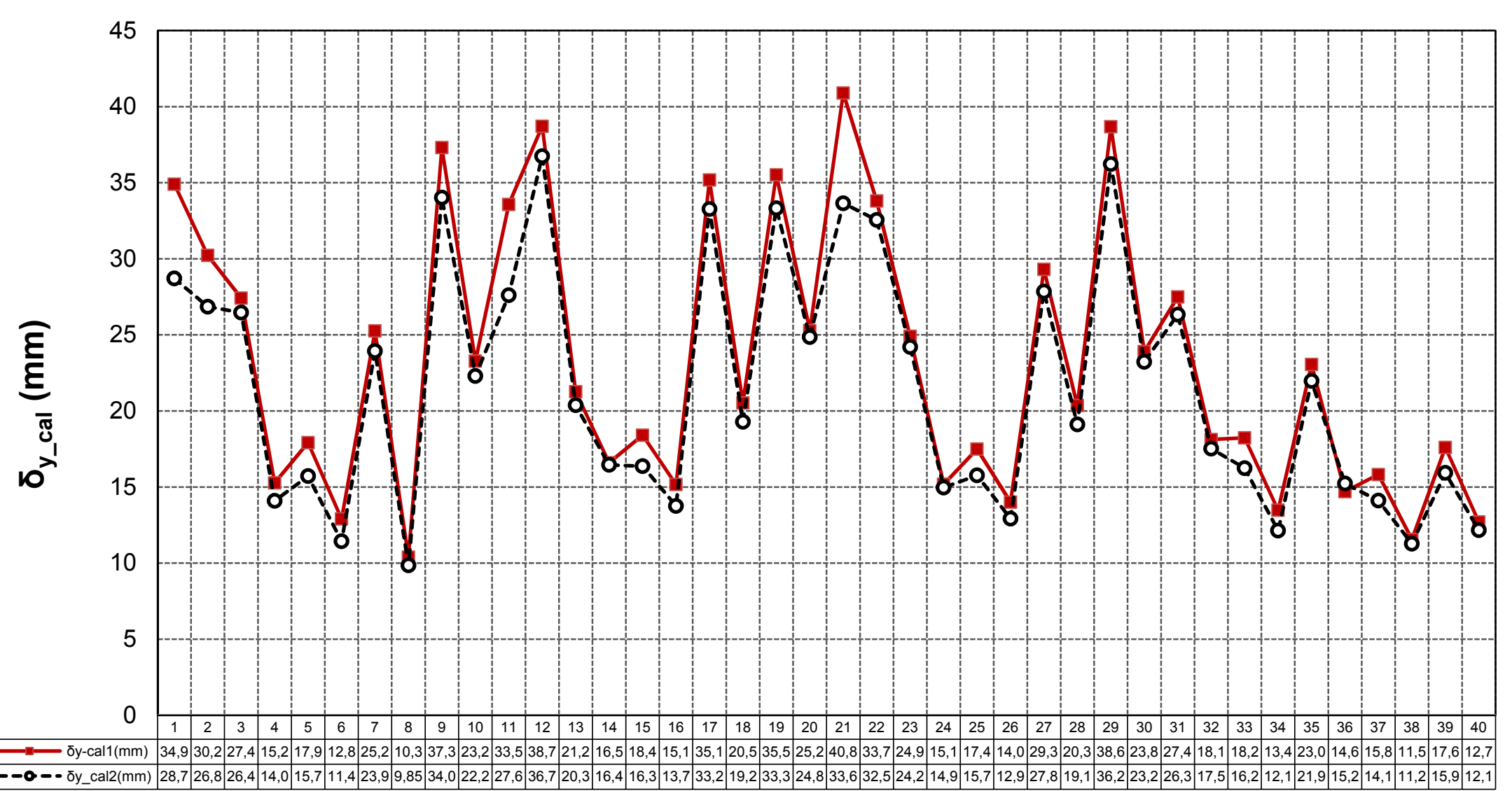

Figura 6.41 Desplazamiento elástico teórico. $\delta_{y \_t e o 1}$ obtenido mediante el método de la columna modelo, $\delta_{y \_t e o 2}$ calculado teniendo en cuenta el factor de amplificación 


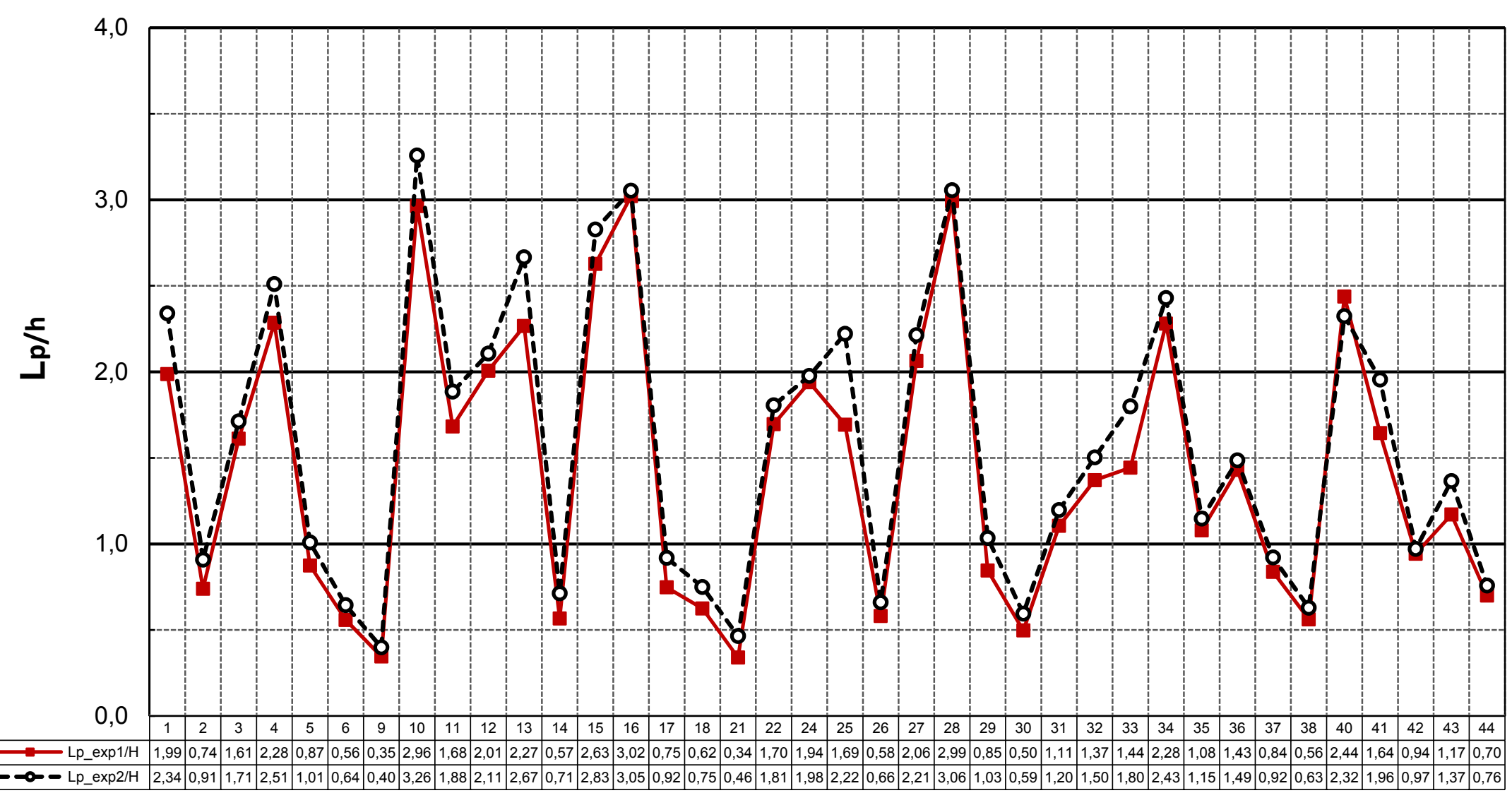

Figura 6.42 Longitud de rotula plástica experimental. $L_{p \_ \text {exp } 1}$ (cuando $\delta_{y \text { teo1 }}$ es obtenido a partir del método de la columna modelo), $L_{p \text { exp2 }}$ (cuando el $\delta_{y_{-} \text {teo }}$ es calculado utilizando el factor de amplificación 


\subsubsection{COMPARACIÓN ENTRE LA LONGITUD DE RÓTULA PLÁSTICA EXPERIMENTAL $Y$ LA CALCULADA MEDIANTE EXPRESIONES EMPÍRICAS}

Los valores de la longitud de rótula plástica experimental $\left(L_{p_{-} \text {exp2 } 2}\right)$ son comparados con los valores calculados $L_{p_{-} \text {cal }} / \mathrm{h}$ mediante algunas expresiones empíricas propuestas en la bibliografía y especificaciones de normas, como por ejemplo el Eurocódigo 8 (2004) [59].

Para poder realizar la comparación entre los valores de la longitud de rótula plástica experimental y la calculada, hay que tomar en consideración que los valores de $L_{\text {p_exp }}$ medidos en ensayos de elementos de hormigón armado bajo carga monotónica son mayores que los que se obtendrían en ensayos con las mismas características bajo carga cíclica, hasta el punto que Fardis et al. (2003) [60] sugieren que la $L_{p}$ en ensayos bajo carga monotónica es 1.5 veces mayor que la $L_{p}$ en ensayos bajo carga cíclica. Teniendo en cuenta lo anterior, todas las expresiones empíricas seleccionadas en este estudio han sido obtenidas a partir del análisis en ensayos bajo carga monotónica. La excepción la constituye la expresión propuesta por Bae S. (2005) [12], que se ha obtenido en base a ensayos cíclicos, pero que, para facilitar la comparación, se ha visto afectada por el factor de 1.5 propuesto por Fardis M. y Biskinis D. (2003) [60] y que aparece también en el CEBFIP Bulletin 25 (2003) [35].

En la Tabla 6-26 se presenta la relación de expresiones utilizadas en la comparación. La expresión propuesta por Pristley y Park (1987) [110], Ec. 6-27, está compuesta por dos términos, el primero de los cuales está relacionado con la flexión del soporte, mientras que el segundo tiene que ver con el deslizamiento debido a la elongación de la armadura en la zona de empotramiento, y sólo está en función del diámetro de la barra $\left(\mathrm{d}_{\mathrm{b}}\right)$.

Tabla 6-26 Relación de expresiones utilizadas en el cálculo de $L_{p}$

\begin{tabular}{|c|c|c|}
\hline Referencia & \multicolumn{2}{|c|}{ Expresión de $L_{p}$} \\
\hline $\begin{array}{c}\text { Pristley y Park (1987) } \\
\text { [110] }\end{array}$ & $L_{p}=0.08 L s+6 d_{b}$ & Ec. 6-27 \\
\hline $\begin{array}{c}\text { Eurocódigo 8. Part2 } \\
\text { (2004) [59] }\end{array}$ & $L_{p}=0.10 L s+0.015 f_{y} d_{b}$ & Ec. 6-28 \\
\hline $\begin{array}{c}\text { CEB-FIP Bulletin 25: } \\
\text { (2003) [35] }\end{array}$ & $L_{p}=0.18 L s+0.025 a_{s l} f_{y} d_{b}$ & Ec. 6-29 \\
\hline $\begin{array}{c}\text { Panagiotakos y Fardis } \\
\text { (2001) [100] }\end{array}$ & $L_{p}=0.18 L s+0.021 a_{s l} f_{y} d_{b}$ & Ec. 6-30 \\
\hline $\begin{array}{c}\text { Fardis y Biskinis (2003) } \\
\text { [60] }\end{array}$ & $L_{p}=0.07 L s+0.125+\frac{a_{s l} f_{y} d_{b}}{40}$ & Ec. 6-31 \\
\hline \begin{tabular}{c} 
Bae (2005) [12] \\
\hline Ceroni et al. (2003) [36]
\end{tabular} & $\frac{L_{p}}{h}=\left[0.3\left(\frac{P}{P_{o}}\right)+3\left(\frac{A_{s}}{A_{g}}\right)-0.1\right]\left(\frac{L_{s}}{H}\right)+0.25 \geq 0.25$ & Ec. 6-32 \\
\hline$L_{p}^{I}=6.1\left(\frac{L_{s}}{h}\right)^{0.43} \cdot\left(\frac{f_{t}}{f_{y}}-1\right)^{0.65} \cdot \varepsilon^{-0.32}\left(1+\frac{N}{N_{o}}\right)^{-1.83}$ & Ec. 6-33 \\
\hline
\end{tabular}


Las Ec. 6-28 a Ec. 6-31 son expresiones obtenidas a partir del análisis de una gran base de datos en ensayos bajo carga monotónica. Al igual que la expresión de Pristley y Park (1987) [110], consideran los dos términos debidos a la flexión y al deslizamiento de la armadura en la zona de empotramiento, aunque en este último término se considera la tensión de adherencia en función de $d_{b}$ y el límite elástico del acero de la armadura $\left(f_{y}\right)$.

La expresión de Bae (2005) [12], aunque ha sido propuesta en base al análisis de ensayos experimentales bajo carga cíclica, tiene un gran interés, ya que es de las pocas expresiones que incluyen el efecto del nivel de carga axil $\left(\mathrm{N} / \mathrm{N}_{\mathrm{u}}\right)$, la esbeltez de cortante $\left(L_{s} / h\right)$ y la cuantía de armadura $\left(A_{s} / A_{g}\right)$. Bae (2005) [12] considera que el efecto de la elongación por deslizamiento de la armadura en la zona de anclaje incrementa el desplazamiento en el extremo libre de un modelo en ménsula, pero que esto no debe ser considerado en la $L_{p}$, sino que propone calcular el desplazamiento en el extremo del elemento debido al efecto del deslizamiento mediante un modelo simplificado independiente.

La Ec. 6-33, propuesta por Ceroni et al. (2003) [36], se obtiene a partir de una base de datos de ensayos numéricos realizados también bajo condiciones de carga monotónica. Esta expresión también considera que la longitud de rótula plástica está compuesta por dos términos presentados en forma independiente, pero que representan igualmente la flexión y el deslizamiento de la armadura en la zona de anclaje. Esta expresión, en el primer término, correspondiente a la de flexión $\left(L_{P}^{I}\right)$, incluye los parámetros de nivel de carga axial $\left(\mathrm{N} / \mathrm{N}_{0}\right)$, esbeltez de cortante y las propiedades del acero de la armadura longitudinal.

Como ya se ha mencionado, en los ensayos experimentales realizados en este trabajo se desprecia el efecto del deslizamiento de la armadura longitudinal en la zona de empotramiento, de modo que, en las ecuaciones empíricas utilizadas en la comparación, se ha ignorado el término de la expresión correspondiente a este efecto. Así, los resultados presentados en la Tabla 6-27 y Tabla 6-28 sólo incluyen el término relacionado con la flexión. En consecuencia, la Ec. 6-29 del CEB-FIP Bulletin 25 (2003) [35] y la Ec. 6-30 de Fardis y Biskinis (2003) [60] muestran el mismo valor.

En la Tabla 6-27 se muestra el valor medio $(\bar{E})$ y el coeficiente de variación $(C V)$ de la relación $L_{p_{-} \text {exp }} / L_{p_{-} \text {cal }}$, para las dos aproximaciones experimentales y para todas las expresiones empíricas. Los resultados muestran que el error medio (E) puede ser aceptable para las expresiones Ec. 6-28, Ec. 6-32 y Ec. 6-33, pero existe una importante dispersión de los resultados, alcanzándose un coeficiente de variación de alrededor del $63 \%$. Por consiguiente, en términos generales, las expresiones utilizadas en este estudio no predicen adecuadamente la $L_{p}$.

Tabla 6-27 Error medio y coeficiente de variación para la relación $L_{p_{-} c a l} L_{p_{-} e x p}$

\begin{tabular}{|c|c|c|c|c|c|c|c|}
\hline & & $\begin{array}{l}\text { Priestley et } \\
\text { al. } \\
\text { Ec. } 6-27\end{array}$ & $\begin{array}{c}\text { Eurocodigo 8: } \\
\text { Part } 2 \\
\text { Ec. 6-28 }\end{array}$ & $\begin{array}{c}\text { Fib Bulletin } \\
25 \\
\text { Ec. 6-29 }\end{array}$ & $\begin{array}{c}\text { Fardis et al. } \\
\text { Ec. 6-31 }\end{array}$ & $\begin{array}{c}\text { Bae } \\
\text { et al. } \\
\text { Ec. 6-32 }\end{array}$ & $\begin{array}{l}\text { Ceroni } \\
\text { et al. } \\
\text { Ec. } 6-33\end{array}$ \\
\hline$L_{p_{\text {_cal }}}$ & $\overline{\overline{\mathbf{E}}}$ & 0.752 & 0.940 & 1.691 & 1.441 & 1.170 & 0.962 \\
\hline$\overline{L_{P \_ \text {exp } 1}}$ & CV & 0.699 & 0.699 & 0.699 & 0.699 & 0.645 & 0.954 \\
\hline$L_{p_{\text {_cal }}}$ & $\overline{\bar{E}}$ & 0.652 & 0.815 & 1.467 & 1.250 & 1.039 & 0.825 \\
\hline$\overline{L_{P \_ \text {exp } 2}}$ & CV & 0.637 & 0.637 & 0.637 & 0.637 & 0.631 & 0.873 \\
\hline
\end{tabular}


Tabla 6-28 Resultados de la longitud de rótula plástica experimental y calculada

\begin{tabular}{|c|c|c|c|c|c|c|c|c|c|}
\hline \multirow[b]{2}{*}{ No } & \multirow[b]{2}{*}{ Referencia } & \multicolumn{2}{|c|}{$L_{p_{\text {exp }}} / \mathrm{h}$} & \multicolumn{6}{|c|}{$\mathrm{L}_{p_{\text {cal }} / \mathrm{h}}$} \\
\hline & & $\frac{L_{p_{\text {exp1 }}}}{h}$ & $\frac{L_{P_{\operatorname{exp2} 2}}}{h}$ & $\begin{array}{l}\text { Priestley } \\
\text { Ec. 6-27 }\end{array}$ & $\begin{array}{c}\text { EC } 8 \\
\text { Ec. } 6-28\end{array}$ & $\begin{array}{l}\text { Fib } 25 \\
\text { Ec. } 6-30\end{array}$ & $\begin{array}{c}\text { Fardis et al. } \\
\text { Ec. 6-31 }\end{array}$ & $\begin{array}{c}\text { Bae } \\
\text { Ec. 6-32 }\end{array}$ & $\begin{array}{c}\text { Ceroni } \\
\text { Ec. 6-33 }\end{array}$ \\
\hline 1 & N30-10.5-C0-2-00 & 1.99 & 2.34 & 0.86 & 1.07 & 1.93 & 1.64 & 0.38 & 1.65 \\
\hline 2 & N30-10.5-C0-2-15 & 0.74 & 0.91 & 0.86 & 1.07 & 1.93 & 1.64 & 0.38 & 1.21 \\
\hline 3 & N30-10.5-C0-2-30 & 1.61 & 1.71 & 0.86 & 1.07 & 1.93 & 1.64 & 1.00 & 0.91 \\
\hline 4 & N30-10.5-C0-2-45 & 2.28 & 2.51 & 0.86 & 1.07 & 1.93 & 1.64 & 1.62 & 0.76 \\
\hline 5 & N30-7.5-C0-2-30 & 0.87 & 1.01 & 0.60 & 0.75 & 1.35 & 1.15 & 0.70 & 0.59 \\
\hline 6 & N30-7.5-C0-2-45 & 0.56 & 0.64 & 0.60 & 0.75 & 1.35 & 1.15 & 1.15 & 0.49 \\
\hline 9 & N30-15-C0-2-30 & 0.35 & 0.40 & 0.86 & 1.07 & 1.93 & 1.64 & 0.38 & 1.39 \\
\hline 10 & N30-15-C0-2-45 & 2.96 & 3.26 & 0.86 & 1.07 & 1.93 & 1.64 & 1.80 & 0.90 \\
\hline 11 & N30-10.5-C0-1-30 & 1.68 & 1.88 & 0.86 & 1.07 & 1.93 & 1.64 & 0.68 & 1.28 \\
\hline 12 & N30-10.5-C0-1-45 & 2.01 & 2.11 & 0.86 & 1.07 & 1.93 & 1.64 & .50 & 0.90 \\
\hline 13 & N30-10.5-C0-3-15 & 2.27 & 2.67 & 0.86 & 1.07 & 1.93 & 1.64 & 0.38 & 1.65 \\
\hline 14 & N30-10.5-C0-3-30 & 0.57 & 0.71 & 0.86 & 1.07 & 1.93 & 1.64 & 0.38 & 1.21 \\
\hline 15 & $\mathrm{H} 60-10.5-\mathrm{C} 0-2-00$ & 2.63 & 2.83 & 0.86 & 1.07 & 1.93 & 1.64 & 1.07 & 0.96 \\
\hline 16 & $\mathrm{H} 60-10.5-\mathrm{C} 0-2-15$ & 3.02 & 3.05 & 0.86 & 1.07 & 1.93 & 1.64 & 1.86 & 0.78 \\
\hline 17 & $\mathrm{H} 60-10.5-\mathrm{C} 0-2-30$ & 0.75 & 0.92 & 0.60 & 0.75 & 1.35 & 1.15 & .75 & 0.63 \\
\hline 18 & $5-C 0-2-45$ & 0.62 & 0.75 & 0.60 & 0.75 & 1.35 & 1.15 & .20 & .53 \\
\hline 21 & $-2-30$ & 0.34 & 0.46 & 0.86 & 1.07 & 93 & 1.64 & .38 & .56 \\
\hline 22 & $\mathrm{H} 60-7.5-\mathrm{C} 0-2-45$ & 1.70 & 1.81 & 6 & 1.07 & 93 & 4 & 75 & 1.25 \\
\hline 23 & $\mathrm{H} 60-15-\mathrm{C} 0-2-30$ & 4.62 & 5.38 & 6 & 7 & 93 & 4 & 9 & 1.29 \\
\hline 24 & $\mathrm{H} 60-15-\mathrm{C} 0-2-45$ & 1.94 & 1.98 & 6 & 7 & 93 & 1.64 & 4 & .02 \\
\hline 25 & $\mathrm{H} 60-10.5-\mathrm{C} 0-1-15$ & 1.69 & 2.22 & 0.86 & 1.07 & 1.93 & 1. & 38 & 1.65 \\
\hline 26 & $\mathrm{H} 60-10.5-\mathrm{C} 0-1-30$ & 0.58 & 0.66 & 0.86 & 1.07 & 1.93 & 1.64 & 0.38 & 1.23 \\
\hline 27 & $\mathrm{H} 60-10.5-\mathrm{C} 0-3-15$ & 2.06 & 2.21 & 0.86 & 1.07 & 1.93 & 1.64 & 1.15 & 0.97 \\
\hline 28 & $\mathrm{H} 60-10.5-\mathrm{C} 0-3-30$ & 2.99 & 3.06 & 0.86 & 1.07 & 1.93 & 1.64 & 1.97 & 0.79 \\
\hline 29 & $\mathrm{H} 90-10.5-\mathrm{C} 0-2-00$ & 0.85 & 1.03 & 0.60 & 0.75 & 1.35 & 1.15 & 0.71 & 0.66 \\
\hline 30 & $\mathrm{H} 90-10.5-\mathrm{C} 0-2-15$ & 0.50 & 0.59 & 0.60 & 0.75 & 35 & 1.15 & .28 & .53 \\
\hline 31 & $\mathrm{H} 90-10.5-\mathrm{C} 0-2-30$ & 1.11 & 1.20 & 0.86 & 1.07 & 93 & 1.64 & .38 & .60 \\
\hline 32 & $\mathrm{H} 90-10.5-\mathrm{C} 0-2-45$ & 1.37 & 1.50 & 0.86 & 1.07 & 1.93 & 1.64 & .71 & .30 \\
\hline 33 & H90-7.5-C0-2-30 & 1.44 & 1.80 & 0.86 & 1.07 & 1.93 & 1.64 & .81 & .32 \\
\hline 34 & H90-7.5-C0-2-45 & 2.28 & 2.43 & 0.86 & 1.07 & 1.93 & 1.64 & 1.59 & 1.04 \\
\hline 35 & H90-10.5-C0-1-15 & 1.08 & 1.15 & 0.86 & 1.07 & 1.93 & 1.64 & 0.76 & .02 \\
\hline 36 & $\mathrm{H} 90-10.5-\mathrm{C} 0-1-30$ & 1.43 & 1.49 & 0.86 & 1.07 & 93 & 1.64 & 1.67 & 0.75 \\
\hline 37 & H90-10.5-C0-3-15 & 0.84 & 0.92 & 0.60 & 0.75 & 1.35 & 1.15 & 0.62 & 0.63 \\
\hline 38 & $\mathrm{H} 90-10.5-\mathrm{C} 0-3-30$ & 0.56 & 0.63 & 0.60 & 0.75 & 1.35 & 1.15 & 1.13 & 0.50 \\
\hline 39 & N30-10.5-C3-2-30 & 3.63 & 3.97 & 0.86 & 1.07 & 1.93 & 1.64 & 1.10 & 0.99 \\
\hline 40 & N30-10.5-C3-2-45 & 2.44 & 2.32 & 0.86 & 1.07 & 1.93 & 1.64 & 1.97 & 0.79 \\
\hline 41 & N30-7.5-C3-2-30 & 1.64 & 1.96 & 0.60 & 0.75 & 1.35 & 1.15 & 0.86 & 0.62 \\
\hline 42 & N30-7.5-C3-2-45 & 0.94 & 0.97 & 0.60 & 0.75 & 1.35 & 1.15 & 1.62 & 0.47 \\
\hline 43 & H90-10.5-C3-2-30 & 1.17 & 1.37 & 0.60 & 0.75 & 1.35 & 1.15 & 0.78 & 0.65 \\
\hline 44 & H90-10.5-C3-2-45 & 0.70 & 0.76 & 0.60 & 0.75 & 1.35 & 1.15 & 1.40 & 0.51 \\
\hline
\end{tabular}

Como se ha podido comprobar, la longitud de la rótula plástica es un parámetro bastante complejo de predecir, puesto que depende de la interacción de muchos factores, como son: 1 ) el nivel de carga axil, 2$)$ la esbeltez de cortante $\left.\left(L_{s} / h\right), 3\right)$ la 
resistencia del hormigón, 4) la cuantía de armadura longitudinal, 5) las propiedades mecánicas de la armadura longitudinal y transversal, 6) el confinamiento del núcleo, 7) la fisuración por cortante, y 8) la adherencia. Aunque existe un importante número de ecuaciones propuestas para la $L_{p}$, las expresiones no incluyen la mayoría de los factores enunciados anteriormente. Incluso incluyendo en las expresiones algunos de los factores más importantes, existen contradicciones acerca de cómo influyen dichos factores. Esto hace que exista una gran variación en los valores de longitud de rótula plástica calculados a partir de las diferentes ecuaciones empíricas, como se muestra claramente en la Tabla 6-27.

\section{Influencia de la esbeltez de cortante en la longitud de rótula plástica}

La relación de expresiones (Pristley y Park (1987) [110], Eurocódigo 8 (2004) [59], Panagiotakos y Fardis (2001) [100], Fardis y Biskinis (2003) [60], Bae (2005) [12], Ceroni et al. (2003) [36]) que se han utilizado para predecir la longitud de rótula plástica en la sección anterior, dan cuenta de la influencia de la esbeltez de cortante $(\lambda=L / h)$. En las Figuras 6.43 se observa que en todas las expresiones la $L_{p}$ aumenta con la esbeltez de cortante $(\lambda)$; sin embargo, existe una gran diferencia con respecto a la magnitud del efecto.

Por otra parte, dentro del programa experimental, para investigar la influencia de la $L / h$ sobre la $L_{p}$, se utilizan los resultados de la serie de ensayos que incluye dos valores de $\lambda(7.5$ y 10.5), dos niveles de carga axil (30\% y $45 \%)$, y resistencias del hormigón alrededor de 30,60 y $90 \mathrm{MPa}$, mientras que la cuantía de armadura longitudinal se mantiene constante $\left(\rho_{l}=2.2 \%\right)$, y los soportes se consideran poco confinados $\left(\rho_{s}=1 \%\right)$.

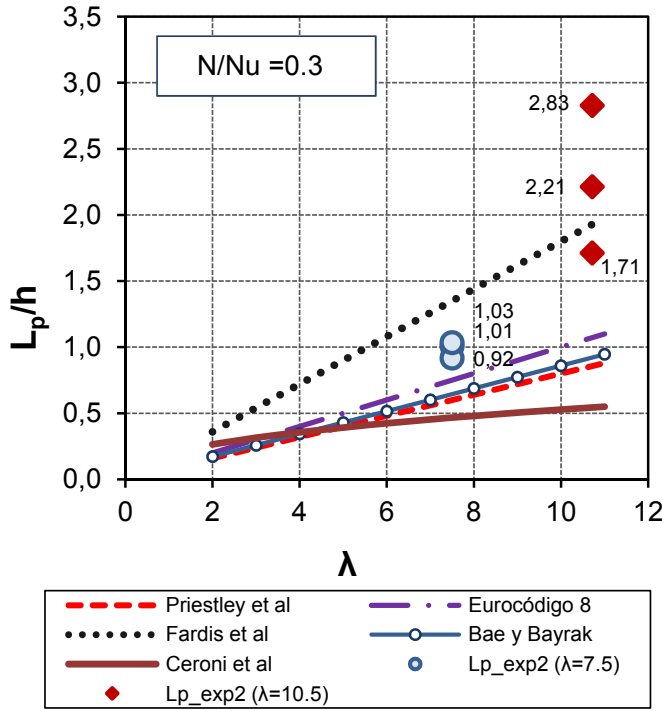

(a)

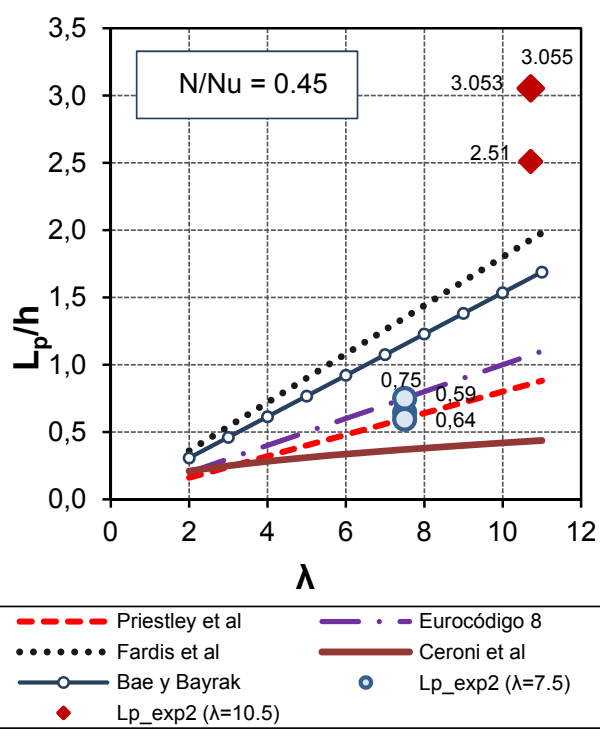

(b)

Figura 6.43 Comparación de las expresiones utilizadas en el cálculo de $L_{p}$ y los resultados experimentales, en función del parámetro esbeltez. (a) para un nivel de carga axil del 30\%, (b) para un nivel de carga axil del $45 \%$

Como puede observarse en las Figuras 6.43 , la $L_{p}$ aumenta considerablemente con el incremento de la esbeltez y el nivel de carga axial. El incremento de $L_{p}$ con respecto a $\lambda$ es menor para el nivel de carga axial del $30 \%$ que para el $45 \%$. 
Los valores experimentales de $L_{p}$ para la esbeltez de 7.5 se encuentran entre $0.5 \mathrm{~h}$ y $1.0 \mathrm{~h}$, mientras que, para $\lambda=10.5$, la $L_{p}$ varía entre $1.7 \mathrm{~h}$ y $3.05 \mathrm{~h}$. Además, si se analiza el efecto de la esbeltez conjuntamente con el nivel de carga axial, la $L_{p}$ para los ensayos con esbeltez 7.5, disminuye con el aumento del nivel de carga axial de $30 \%$ a $45 \%$. Por el contrario, para soportes con esbeltez de 10.5 , la $L_{p}$ aumenta con el incremento del nivel de carga axial. Los resultados se muestran indiferentes con respecto a la resistencia del hormigón, (ver Tabla 6-28)

Por último, si se comparan los resultados experimentales con los calculados, puede verse que, para los soportes de $\lambda=7.5$, los valores de $L_{p}$ se acercan más a las expresiones de Pristley y Park (1987) [110] (Ec. 6-27) y del Eurocódigo 8 (2004) [59] (Ec. 6-28), expresiones que no consideran el efecto del nivel de carga axial.

\section{Influencia del nivel de carga axil en la longitud de rótula plástica}

En las Figuras 6.44 se realiza una comparación de las expresiones de Bae (2005) [12], Ceroni et al. (2003) [36], Panagiotakos y Fardis (2001) [100] y Pristley y Park (1987) [110]. Como se puede apreciar, existen grandes variaciones entre las expresiones para la $L_{p}$. Incluso el efecto del nivel de carga axial es contradictorio entre las expresiones de Bae (2005) [12] y Ceroni et al. (2003) [36].

Además, esto también ha sido confirmado por el resumen realizado por Bae (2005) [12], según el cual "aunque el efecto de la carga axial sobre la $L_{p}$ de los soportes de hormigón ha sido analizado por varios investigadores, los resultados presentados pueden considerarse contradictorios. Park et al. y Mendis concluyeron que la $L_{p}$ era indiferente a los niveles de carga axial basándose en los resultados de sus ensayos; por el contrario, Atalay y Penzien concluyeron que la longitud en la que se extiende la plasticidad o la longitud de la región de daño aumentaba con el aumento de nivel de carga axil. Tanaka y Park concluyeron que la $L_{p}$ aumentaba de $0.46 \mathrm{~h}$ a $0,75 \mathrm{~h}$ a medida que aumentaba el nivel de carga axial aplicado desde $0.1 f_{c} A_{g}$ hasta $0.30 f_{c} A_{g}$. Los resultados de los ensayos de Thomson y Wallace, y los resultados de Légeron y Paultre indicaron que el incremento de $L_{p}$ con la carga axial podía también ser observado para soportes de hormigón de alta resistencia".

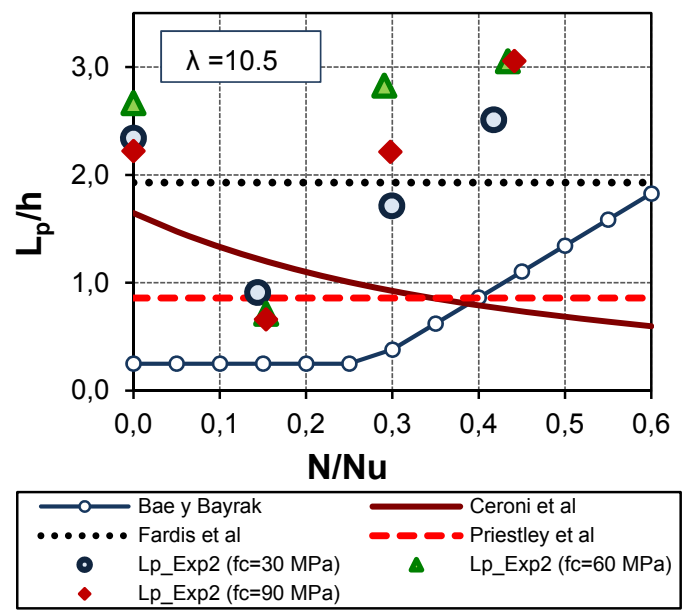

(a)

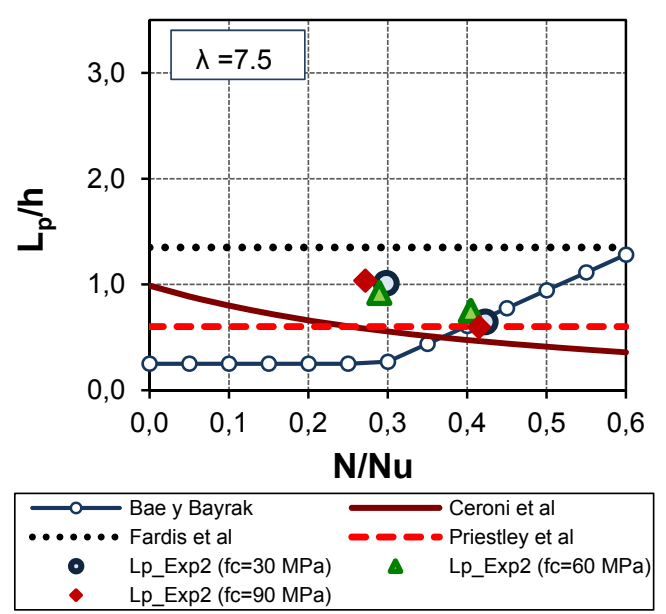

(b)

Figura 6.44 Comparación de las expresiones utilizadas en el cálculo de $L_{p}$ y los resultados experimentales, en función del nivel de carga axil para(a) $\lambda=10.5$, (b) $\lambda=7.5$ 
Por otra parte, en el presente estudio experimental, los resultados muestran nuevamente contradicciones con respecto al nivel de carga axial. En un principio, si sólo consideramos los resultados de $L_{p}$ para los ensayos con niveles de carga axial diferente de cero, podemos observar en las Figuras 6.44, que, para soportes con $\lambda=10.5$, los valores experimentales de $L_{p}$ aumentan considerablemente con el incremento del nivel de carga axial. Contrariamente, la Figura $6.44 \mathrm{~b}$ muestra que, para soportes con $\lambda=7.5$, los valores experimentales de $L_{p}$ sufren una leve disminución con el aumento del nivel de carga axil. A modo de conclusión, lo que se demuestra es que el aumento de la $L_{p}$ se debe más a los efectos conjuntos del nivel de carga axial y esbeltez de cortante causantes de los efectos de segundo orden; naturalmente, si los efectos $\mathrm{P}-\Delta$ son considerables, la rótula plástica no se forma.

\section{Influencia de la cuantía de armadura longitudinal en la longitud de rótula plástica}

De la relación de expresiones utilizadas en este estudio para predecir la $L_{p}$, tan sólo la expresión de Bae (2005) [12] (Ec. 6-32) tiene en cuenta el efecto de la cuantía de armadura longitudinal. Esta expresión considera que, a partir de cierto nivel de carga axial, la $L_{p}$ aumenta con el incremento de cuantía de armadura longitudinal

Los resultados experimentales, en este estudio, muestran que, para soportes esbeltos $\lambda=10.5$ y poco confinados $\rho_{\mathrm{s}}=1 \%$, si se incrementa la cuantía de armadura longitudinal, la $L_{p}$ aumenta. Este efecto se ha observado en elementos con bajos y moderados niveles de carga axial (15\% y $30 \%)$, e independientemente de la resistencia del hormigón. También se ha apreciado que los bajos valores de $\mathrm{L}_{p} \leq 1.0 \mathrm{~h}$ se presentan para bajos niveles de carga axial, y cuantías de armadura del $1.4 \%$ y el $2.2 \%$; si la $\rho_{\text {I }}$ aumenta a $3.2 \%$, la $L_{p}$ se incrementa casi el doble, hasta $\mathrm{L}_{\mathrm{p}} \approx 1.8 \mathrm{~h}$.
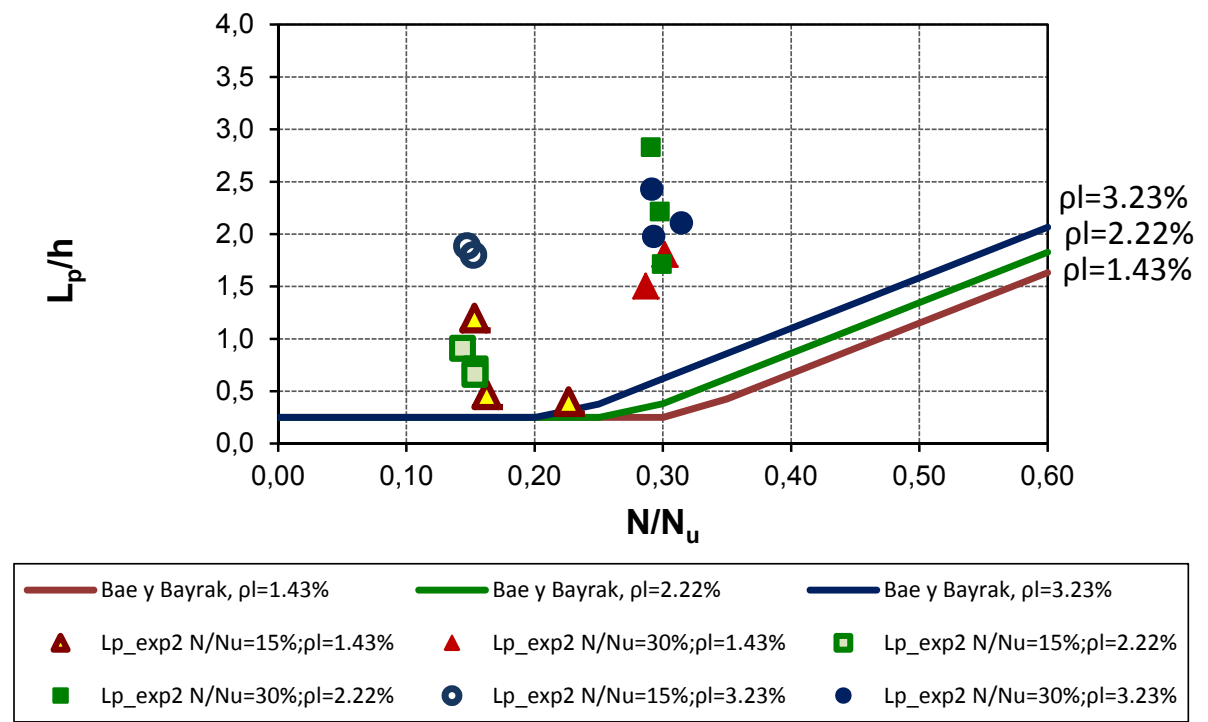

Figura 6.45 Comparación entre la expresión de Bae et al. (Ec. 6-28) y los resultados experimentales de $L_{p}$

Respecto a la cuantía de armadura transversal $\left(\rho_{\mathrm{s}}\right)$, no existen expresiones que consideren directamente los efectos de la $\rho_{\mathrm{s}}$ en el cálculo de la longitud de rótula 
plástica. En este estudio tampoco se ha podido ser concluyente al respecto. Al parecer, efectos como la esbeltez y el nivel de carga axial son predominantes en elementos esbeltos y no es posible determinar claramente cómo influye la $\rho_{\mathrm{s}}$ en el cálculo de la $L_{p}$.

\subsubsection{COMPARACIÓN ENTRE LAS LONGITUDES DE RÓTULA PLÁSTICA EXPERIMENTALES Y LAS OBTENIDAS EN OTROS ESTUDIOS}

Numerosos estudios experimentales han sido realizados para analizar los parámetros que mayor efecto tienen en la longitud de rótula plástica. En la Tabla 6-29 se presenta un resumen de una gran parte de estos estudios. Inicialmente, el estudio de la $L_{p}$ fue relevante para la evaluación de la rotación plástica aplicada al diseño límite. La mayor parte de los estudios bajo carga monotónica fueron realizados en elementos tipo viga, a excepción de algunos ensayos realizados por Baker (1956) [15] y Mendis et al. [91], [92].

Posteriormente, en ensayos de flexo-compresión en soportes bajo carga cíclica, la longitud de la rótula plástica se ha estudiado, por un lado, con el propósito fundamental de ser la variable que relaciona el comportamiento de la sección y del elemento (la longitud de rótula plástica no tiene ningún sentido físico, y es sólo una variable cuantitativa); por otro lado, se ha relacionado de forma indirecta la longitud de rótula plástica con la longitud de las regiones potenciales donde se forma la rótula plástica, de modo que estas regiones deben tratarse para asegurar un adecuado comportamiento dúctil bajo la situación de carga sísmica. Para ello, se debe disponer de una adecuada armadura transversal.

Con respecto a los parámetros que influyen en la $L_{p}$, si nos fijamos en el resumen incluido en la Tabla 6-29, los estudios coinciden en que la esbeltez es el parámetro fundamental en la evaluación de $L_{p}$. Por el contrario, no existe un consenso con respecto al nivel de carga axial. Baker A. L.L. (1964) [15] afirmó que la $L_{p}$ aumentaba con el nivel de carga axial; más adelante Zahn F.A. (1986) [138] dice que la $L_{p}$ disminuye cuando el nivel de carga axial es inferior al $30 \%$; Sheikh et al. [16], [17], [18], [121], [122], en su larga trayectoria de investigación, aseguran inicialmente que la $L_{p}$ puede depender del nivel de carga axial, pero en estudios posteriores concluyen que no depende de este parámetro; por último, Bae (2005) [12] asegura que la $L_{p}$ depende del nivel de carga axial. Contrariamente, Mendis $P$. (2001) [91], Ang et al. (1981) [5] y Mander J.B. (1984)[84] encuentran que la $L_{p}$ no depende del nivel de carga axial.

En estudios previos, la influencia de la cuantía de armadura longitudinal en la longitud de rótula plástica tampoco ha sido claramente definida. Durante los años sesenta, Mattock $A$. (1965) [87] concluyó que la $L_{p}$ aumentaba con la disminución en la armadura de tracción neta $\left[\left(A_{s}-A_{s}^{\prime}\right) / A_{b}\right.$, donde $A_{s}$ es el área de la armadura de tracción, $A_{s}^{\prime}$ es el área de la armadura en compresión, y $A_{b}$ es el área de la armadura de balanceo]. El efecto de la armadura de tracción neta fue estudiado con más detalle por Corley (1966) [45]. Por el contrario, recientemente, Mendis P. (2001) [92] sugirió que la $L_{p}$ aumentaba con un incremento en la cantidad de la armadura de tracción. Es importante destacar que estas conclusiones están basadas fundamentalmente en los resultados de ensayos llevados a cabo en vigas de hormigón armado. Por otra parte, Bae (2005) [12], en base a ensayos de flexo- 
Estudio experimental y numérico de la capacidad de deformación de soportes esbeltos de hormigón convencional y de alta resistencia.

compresión en soportes bajo carga cíclica, demuestra que la $L_{p}$ aumenta con el incremento de la cuantía de armadura longitudinal.

En relación a la cuantía de armadura transversal, sólo existen dos referencias que hacen mención a este parámetro. Mendis P.(2001) [92] asegura que la $L_{p}$ disminuye con el aumento de la cuantía de armadura transversal, mientras que Sheikh et al. (1993 y 1994) [121] y [122] sugieren que no existe relación entre la $L_{p}$ y la cuantía de armadura transversal.

Para finalizar, ninguno de los estudios relacionados en la Tabla 6-29 hace referencia a la influencia del parámetro resistencia del hormigón en la $L_{p}$. Sheikh et al. (1993 y 1994) [121] y [122] muestran que, en ensayos en soportes con hormigón convencional, la $L_{p}$ podría estar en torno a $0.5 \mathrm{~h}$, y en posteriores ensayos con soportes de hormigón de alta resistencia (Sheikh et al.(1997) [18]), la $L_{p}$ obtenida experimentalmente se encuentra cerca de 1.0h. Sin embargo, este cambio no es atribuido al aumento de la resistencia del hormigón, sino a otros parámetros como el nivel de carga axial.

Tabla 6-29 Relación de trabajos de investigación llevados a cabo en el estudio de los parámetros que afectan la $L_{p}$

\begin{tabular}{|c|c|c|}
\hline Referencia & Parámetros estudiados & CONCLUSIONES \\
\hline \multicolumn{3}{|c|}{ CARGA MONOTÓNICA } \\
\hline Baker A. L. L. (1956) [15] & $\begin{array}{l}\text { Resistencia del hormigón, resistencia y } \\
\text { cuantía de armadura longitudinal, carga } \\
\text { axial, cortante, sin confinamiento. }\end{array}$ & $\begin{array}{l}L_{p} \text { depende de la esbeltez y del nivel de } \\
\text { carga axial, } L_{p} \text { varía entre } 0,4 d \text { y } 2,4 d .\end{array}$ \\
\hline $\begin{array}{l}\text { Baker A. L. L. y } \\
\text { Amarakone A.M.N. } \\
(1964)[14]\end{array}$ & $\begin{array}{l}\text { Además de los parámetros anteriores, } \\
\text { tiene en cuenta el confinamiento. }\end{array}$ & $\mathrm{L}_{p}$ depende de la esbeltez. \\
\hline $\begin{array}{l}\text { Mattock Alan H. (1965) } \\
\text { [87] }\end{array}$ & $\begin{array}{l}\text { Cuantía longitudinal, Resistencia de la } \\
\text { armadura, canto útil. }\end{array}$ & $\begin{array}{l}\mathrm{L}_{p} \text { aumenta si la armadura en tracción neta } \\
(\mathrm{As}-\mathrm{A} \text { 's }) /(\mathrm{Ab}) \text { disminuye. }\end{array}$ \\
\hline Sawyer H. (1964) [117] & & $L_{p}$ puede extenderse un poco más $(d / 4)$. \\
\hline $\begin{array}{l}\text { Corley W. Gene (1966) } \\
{[45]}\end{array}$ & $\begin{array}{l}\text { Variables adicionales a Mattock, } \\
\text { (confinamiento y esbeltez). }\end{array}$ & $\begin{array}{l}\text { Nuevas expresiones para } L_{p} \text { en función la } \\
\text { esbeltez. }\end{array}$ \\
\hline \begin{tabular}{|l} 
Mendis Priyan \\
(2001)[92], Pendyala R., \\
Mendis P. y Patnaikuni, \\
(1994) [106], (1996) [107]
\end{tabular} & $\begin{array}{l}\text { Cuantía de armado en compresión y } \\
\text { tracción, cuantía transversal, esbeltez } \\
\text { (entre } 7 \text { y } 8 \text { ), y, bajos Niveles de carga } \\
\text { axial (hasta } 0,3 \text { ). }\end{array}$ & $\begin{array}{l}L_{p} \text { incrementa con: la esbeltez, y la cuantía } \\
\text { longitudinal, pero decrece con la cuantía } \\
\text { transversal, y es indiferente con el nivel de } \\
\text { carga axial. Los valores límites del ACl-ASCE } \\
\text { (428-1968) pueden ser utilizados para } \\
\text { predecir la } L_{p} \text { en elementos con HAR hasta } \\
80 \mathrm{MPa} \text { y bajos niveles de carga axial. }\end{array}$ \\
\hline \multicolumn{3}{|c|}{ CARGA CÍCLICA } \\
\hline Ang Beng Ghee (1981) [5] & $\begin{array}{l}\text { Nivel de carga axial (hasta 0,5), } \\
\text { resistencia del hormigón, } \\
\text { confinamiento. }\end{array}$ & $\begin{array}{l}L_{p} \text { no depende del nivel de carga axial, pero si } \\
\text { de la esbeltez, teóricamente } L_{p}>0,5 d \text {. }\end{array}$ \\
\hline Mander J. B. (1984) [84] & $\begin{array}{l}\text { Nivel de carga axial , resistencia del } \\
\text { hormigón, confinamiento. }\end{array}$ & $\begin{array}{l}\mathrm{L}_{\mathrm{p}} \text {, depende de la longitud de la barra que } \\
\text { plastifica y de la relación de My/Mu, no } \\
\text { depende del nivel de axial. }\end{array}$ \\
\hline 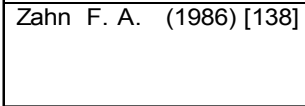 & $\begin{array}{l}\text { Altos niveles de carga axial, resistencia } \\
\text { del hormigón, confinamiento. }\end{array}$ & $\begin{array}{l}\text { Modifica la expresión de Priestley para bajos } \\
\text { niveles de carga axial, } L_{p} \text { disminuye con } \\
\text { niveles de carga axial menores que } 0,3 \text {. }\end{array}$ \\
\hline $\begin{array}{l}\text { Sheikh S. et al. (1989- } \\
\text { 1998) [17], [18], [121], } \\
{[122]}\end{array}$ & $\begin{array}{l}\text { Resistencia del hormigón, resistencia y } \\
\text { cuantía de la armadura longitudinal, } \\
\text { nivel de carga axial, confinamiento. }\end{array}$ & $\begin{array}{l}\text { En 1989, } L_{p} \text { para hormigón convencional es } \\
0.5 \text { d y puede variar con el nivel de carga axial } \\
\text { y la esbeltez; a partir de 1993, para HAR } \\
L_{p}=d \text {, y no hay relación con en nivel de carga } \\
\text { axial y la cuantía de confinamiento. }\end{array}$ \\
\hline $\begin{array}{l}\text { Bae S. y Bayrak O. } \\
(2005-2008)[8]-[12]\end{array}$ & $\begin{array}{l}\text { Nivel de carga axial, altos valores de } \\
\text { esbeltez de cortante. }\end{array}$ & $\begin{array}{l}\mathrm{L}_{p} \text { depende del nivel de carga axial, de la } \\
\text { esbeltez y de la cuantía de armadura } \\
\text { longitudinal. Presenta una nueva expresión. }\end{array}$ \\
\hline
\end{tabular}


A partir de la bibliografía revisada en este estudio, se ha realizado una base de datos con los valores de longitud de rótula plástica incluidos en las diferentes referencias (ver Tabla 6-30). La base de datos está compuesta por ensayos en soportes de hormigón convencional y de alta resistencia, sujetos a flexo-compresión bajo carga cíclica y carga monotónica. En total, se relacionan 68 ensayos; 12 ensayos bajo carga monotónica (Mendis et al. (2001) [92], y Pendyala et al. (1994) [106] y (1996) [107]), y el resto bajo carga cíclica. Treinta y tres ensayos han sido realizados en soportes con hormigón convencional (fc $<50 \mathrm{MPa}$ ) y treinta y cinco ensayos en soportes de hormigón de alta resistencia. Además, sólo cuatro ensayos han sido realizados en soportes con esbeltez superior a 6; Bae (2005) [12] llevó a cabo ensayos en soportes de esbeltez 7.35. En la Tabla 6-31 se presenta un resumen de los valores mínimos y máximos de los parámetros relacionados en la base de datos.

Tabla 6-30 Base de datos de ensayos en soportes de hormigón convencional y de alta resistencia, sujetos a compresión y flexión monotónica o cíclica, en los que se muestran los valores experimentales de $L_{p}$

\begin{tabular}{|c|c|c|c|c|c|c|c|c|c|c|c|c|c|c|c|}
\hline Autor & $\mathbf{N}^{\circ}$ & $\begin{array}{c}\mathrm{fc} \\
(\mathrm{MPa})\end{array}$ & $\begin{array}{c}\rho_{1} \\
(\%)\end{array}$ & $\begin{array}{l}\rho_{\mathrm{s}} \\
(\%)\end{array}$ & $\mathbf{N} / \mathbf{N}_{\mathrm{u}}$ & $\lambda$ & $\mathrm{L}_{\mathrm{p}} / \mathrm{h}$ & Autor & $\mathbf{N}^{\circ}$ & $\begin{array}{c}\mathrm{fc} \\
(\mathrm{MPa})\end{array}$ & $\begin{array}{c}\rho_{1} \\
(\%)\end{array}$ & $\begin{array}{l}\rho_{\mathbf{s}} \\
(\%)\end{array}$ & $N / N_{u}$ & $\lambda_{g}$ & $\mathrm{~L}_{\mathrm{p}} / \mathrm{h}$ \\
\hline \multirow{4}{*}{$\begin{array}{l}\text { Park et al. (1982) } \\
\text { [102] }\end{array}$} & 1 & 23.10 & 1.79 & 1.50 & 0.26 & 2.19 & 0.44 & \multirow{20}{*}{$\begin{array}{l}\text { Bayrak O. et al. } \\
\text { (1998) [16] }\end{array}$} & AS-5HT & 101.80 & 2.58 & 4.02 & 0.45 & 6.00 & 0.86 \\
\hline & 2 & 41.40 & 1.79 & 2.30 & 0.21 & 2.19 & 0.34 & & AS-6HT & 101.90 & 2.58 & 6.74 & 0.46 & 6.00 & 1.05 \\
\hline & 3 & 21.40 & 1.79 & 2.00 & 0.42 & 2.19 & 0.40 & & AS-7HT & 102.00 & 2.58 & 2.72 & 0.45 & 6.00 & 0.88 \\
\hline & 4 & 23.50 & 1.79 & 3.50 & 0.60 & 2.19 & 0.50 & & ES-8HT & 102.20 & 2.58 & 4.29 & 0.47 & 6.00 & 1.26 \\
\hline \multirow{4}{*}{$\begin{array}{l}\text { Ang B. G. (1981) } \\
\text { [15] }\end{array}$} & 1 & 26.00 & 2.43 & 0.70 & 0.20 & 4.00 & 0.54 & & RS-9HT & 71.20 & 2.74 & 3.44 & 0.34 & 5.25 & 1.02 \\
\hline & 2 & 28.50 & 2.43 & 1.52 & 0.56 & 4.00 & 0.61 & & RS-10HT & 71.10 & 2.74 & 3.44 & 0.50 & 5.25 & 1.27 \\
\hline & 3 & 23.60 & 1.51 & 2.83 & 0.38 & 4.00 & 0.73 & & RS-11HT & 70.80 & 2.74 & 5.43 & 0.51 & 5.25 & 1.13 \\
\hline & 4 & 25.00 & 1.51 & 2.21 & 0.21 & 4.00 & 0.55 & & RS-12HT & 70.90 & 2.74 & 1.83 & 0.34 & 5.25 & 1.19 \\
\hline \multirow{4}{*}{$\begin{array}{l}\text { Mander J. B. } \\
\text { (1984) [84] }\end{array}$} & $\mathrm{A}$ & 26.00 & & & 0.10 & 4.27 & 0.37 & & RS-13HT & 112.10 & 2.74 & 3.92 & 0.35 & 5.25 & 0.85 \\
\hline & B & 26.00 & & & 0.50 & 4.27 & 0.38 & & RS-14HT & 112.10 & 2.74 & 3.92 & 0.46 & 5.25 & 1.00 \\
\hline & $C$ & 26.00 & & & 0.30 & 4.27 & 0.40 & & RS-15HT & 56.20 & 2.74 & 2.75 & 0.36 & 5.25 & 0.78 \\
\hline & $\mathrm{D}$ & 26.00 & & & 0.30 & 4.27 & 0.41 & & RS-16HT & 56.20 & 2.74 & 1.83 & 0.37 & 5.25 & 1.08 \\
\hline \multirow{8}{*}{$\begin{array}{l}\text { Zahn F. A. } \\
\text { (1986) [138] }\end{array}$} & 1 & 36.20 & 1.51 & 2.24 & 0.23 & 4.00 & 0.43 & & RS-17HT & 74.10 & 2.74 & 1.83 & 0.34 & 5.25 & 0.85 \\
\hline & 2 & 28.80 & 1.51 & 2.89 & 0.43 & 4.00 & 0.42 & & RS-18HT & 74.10 & 2.74 & 1.83 & 0.50 & 5.25 & 0.91 \\
\hline & 3 & 32.30 & 1.51 & 2.14 & 0.23 & 4.00 & 0.43 & & RS-19HT & 74.20 & 2.74 & 3.54 & 0.53 & 5.25 & 0.98 \\
\hline & 4 & 27.00 & 1.51 & 2.80 & 0.42 & 4.00 & 0.39 & & RS-20HT & 74.20 & 2.74 & 1.90 & 0.34 & 5.25 & 1.00 \\
\hline & 5 & 32.30 & 2.43 & 0.61 & 0.13 & 4.00 & 0.39 & & WRS-21HT & 91.30 & 2.74 & 3.92 & 0.47 & 7.35 & 1.12 \\
\hline & 6 & 27.00 & 2.43 & 1.09 & 0.58 & 4.00 & 0.59 & & WRS-22HT & 91.30 & 2.74 & 3.92 & 0.31 & 7.35 & 1.11 \\
\hline & 7 & 28.30 & 1.51 & 1.56 & 0.23 & 4.00 & 0.55 & & WRS-23HT & 72.20 & 2.74 & 3.44 & 0.33 & 7.35 & 1.03 \\
\hline & 8 & 40.10 & 1.51 & 1.99 & 0.39 & 4.00 & 0.63 & & WRS-24HT & 72.20 & 2.74 & 3.44 & 0.50 & 7.35 & 0.99 \\
\hline \multirow{6}{*}{$\begin{array}{l}\text { Sheikh S. et al. } \\
\text { (1993) [121] }\end{array}$} & FS-9 & 32.40 & 2.44 & 1.68 & 0.76 & 6.00 & 0.85 & \multirow{4}{*}{$\begin{array}{l}\text { Mendis P. } \\
\text { (2001) [92] }\end{array}$} & G1 & 57.90 & 4.61 & & 0.14 & 4.17 & 0.31 \\
\hline & ES-13 & 32.50 & 2.44 & 1.69 & 0.76 & 6.00 & 1.10 & & $\mathrm{G} 2$ & 57.90 & 4.61 & & 0.14 & 4.17 & 0.32 \\
\hline & AS-3 & 33.16 & 2.44 & 1.68 & 0.60 & 6.00 & 0.96 & & $\mathrm{H} 1$ & 57.90 & 4.61 & & 0.07 & 4.17 & 0.30 \\
\hline & AS-17 & 31.30 & 2.44 & 1.68 & 0.77 & 6.00 & 1.05 & & $\mathrm{H} 2$ & 57.90 & 4.61 & & 0.25 & 4.17 & 0.46 \\
\hline & AS-18 & 32.75 & 2.44 & 3.06 & 0.77 & 6.00 & 0.99 & \multirow{8}{*}{$\begin{array}{l}\text { Pendyala et al. } \\
\text { (1994y 1996) } \\
{[106] \text { y }[107]}\end{array}$} & D1 & 33.20 & 4.61 & & 0.20 & 3.42 & 0.21 \\
\hline & AS-19 & 32.20 & 2.44 & 1.30 & 0.47 & 6.00 & 1.16 & & D2 & 32.70 & 4.61 & & 0.20 & 3.42 & 0.38 \\
\hline \multirow{4}{*}{$\begin{array}{l}\text { Bayrak O. et al. } \\
\text { (1997) [18] }\end{array}$} & ES-1HT & 72.10 & 2.58 & 3.15 & 0.50 & 6.00 & 1.15 & & D3 & 38.70 & 4.61 & & 0.17 & 3.42 & 0.51 \\
\hline & AS-2HT & 71.70 & 2.58 & 2.84 & 0.36 & 6.00 & 0.98 & & D4 & 58.10 & 4.61 & & 0.23 & 3.42 & 0.25 \\
\hline & AS-3HT & 71.80 & 2.58 & 2.84 & 0.50 & 6.00 & 0.91 & & D5 & 64.30 & 4.61 & & 0.10 & 3.42 & 0.38 \\
\hline & AS-4HT & 71.90 & 2.58 & 5.12 & 0.50 & 6.00 & 0.89 & & D6 & 64.80 & 4.61 & & 0.20 & 3.42 & 0.57 \\
\hline \multirow{4}{*}{$\begin{array}{l}\text { Bae y Bayrak } \\
\text { (2005) [12] }\end{array}$} & S24-2UT & 43.40 & 1.25 & 2.04 & 0.50 & 6.00 & 0.66 & & D7 & 62.80 & 3.84 & & 0.06 & 3.42 & 0.45 \\
\hline & S17-3UT & 43.40 & 1.25 & 1.76 & 0.50 & 6.00 & 0.91 & & D8 & 65.20 & 3.84 & & 0.11 & 3.42 & 0.38 \\
\hline & 24-4UT & 36.50 & 1.25 & 0.72 & 0.20 & 6.00 & 0.49 & & & & & & & & \\
\hline & S24-5UT & 41.40 & 1.25 & 1.30 & 0.20 & 6.00 & 0.47 & & & & & & & & \\
\hline
\end{tabular}


Estudio experimental y numérico de la capacidad de deformación de soportes esbeltos de hormigón convencional y de alta resistencia.

Tabla 6-31 Valores máximos y mínimos de los parámetros que componen la base de datos de ensayos en soportes de hormigón

\begin{tabular}{|c|c|c|}
\hline Variable & Valor Min & Valor Max \\
\hline $\mathbf{f}_{\mathbf{c}}(\mathbf{M P a})$ & 21.40 & 112.10 \\
\hline $\mathbf{\rho}_{\mathbf{I}}(\%)$ & 1.25 & 4.61 \\
\hline $\mathbf{\rho}_{\mathbf{s}}(\%)$ & 0.61 & 6.74 \\
\hline $\mathbf{N} / \mathbf{N}_{\mathbf{u}}$ & 0.06 & 0.77 \\
\hline $\boldsymbol{\lambda}$ & 2.19 & 7.35 \\
\hline $\mathbf{L}_{\mathbf{p}} / \mathbf{h}$ & 0.21 & 1.27 \\
\hline
\end{tabular}

En las Figuras 6.46a y $b$ se presentan los resultados de $L_{p \_ \text {exp2 }}$ obtenidos en el presente estudio, junto con los relacionados en la Tabla 6-30 para carga monotónica, mientras que en las Figuras $6.46 \mathrm{c}$ y d se presentan los resultados de $L_{p}$ sólo para carga cíclica. Los resultados de $L_{p}$ son comparados con respecto a los dos parámetros con los que se ha podido establecer una mayor relación, como son la esbeltez de cortante y el nivel de carga axial.

Mediante la Figura 6.46a para ensayos con carga monotónica, se indica que los ensayos con esbeltez 7.5 se encuentran dentro del rango de valores obtenidos en otras investigaciones, es decir, entre $0.5 \mathrm{~h}$ y $1.0 \mathrm{~h}$. Asimismo, se puede observar que, cuando la esbeltez aumenta hasta un valor de 10.5, la longitud de rótula plástica se incrementa significativamente, y, sólo si los soportes se encuentran en un bajo nivel de carga axial (15\%) y con una cuantía de armadura longitudinal entre el $1.43 \%$ y el $2.22 \%$, los valores de $L_{p}$ serán inferiores a $1.0 \mathrm{~h}$. Para el resto de soportes con $\lambda=10.5$, la $L_{p}$ cambia considerablemente y alcanza valores notablemente altos, superiores a $2.0 \mathrm{~h}$. En la Figura $6.46 \mathrm{c}$, para ensayos con carga cíclica, la $L_{p}$ también aumenta con el incremento de $\lambda$, tal y como señalan los estudios experimentales de la Tabla 6-29, y como se sugiere en las diferentes expresiones existentes. Sin embargo, se ha mostrado que existe un gran cambio en los valores de esbeltez superiores a 7.5, donde la comprobación experimental es nula; por lo tanto, es necesaria más experimentación en soportes esbeltos con valores de $\lambda$ superiores a 7.5 que permita una mayor comprobación de $L_{p}$ en este rango.

Como ya hemos mencionado, los ensayos relacionados en la base de datos fueron realizados, en su mayor parte, en elementos con $\lambda \leq 6$; si sólo tenemos en cuenta estos ensayos, se muestra que, para niveles de carga axil menores del $30 \%$, la longitud de rótula plástica está en torno a $0.5 \mathrm{~h}, \mathrm{y}$, para niveles de carga axil superiores al $30 \%$, la $L_{p}$ está en torno a $1.0 \mathrm{~h}$. En los ensayos realizados en este estudio, no es claro el efecto del nivel de carga axil, ya que el efecto de la esbeltez es más sobresaliente.

Respecto a los efectos de la resistencia del hormigón, la cuantía de armadura longitudinal, y la cuantía de armadura transversal, no ha sido posible obtener conclusiones que relacionen los efectos de estas variables con los resultados de la longitud de rótula plástica recopilados en este análisis. 


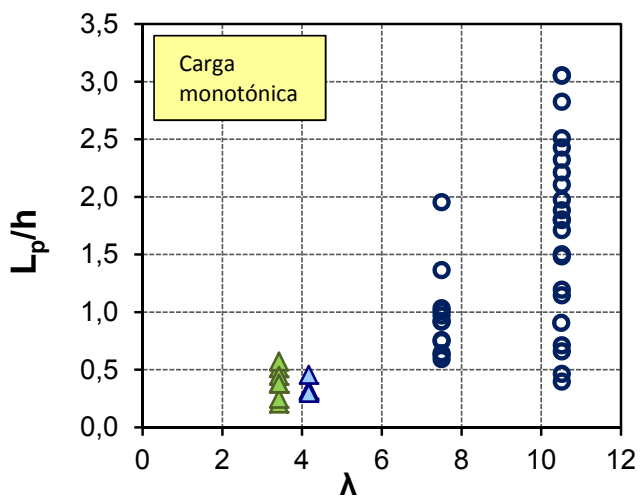

$\Delta$ Mendis P. [68] $\Delta$ Pendyala. et al. [79] OLp_exp2

(a)

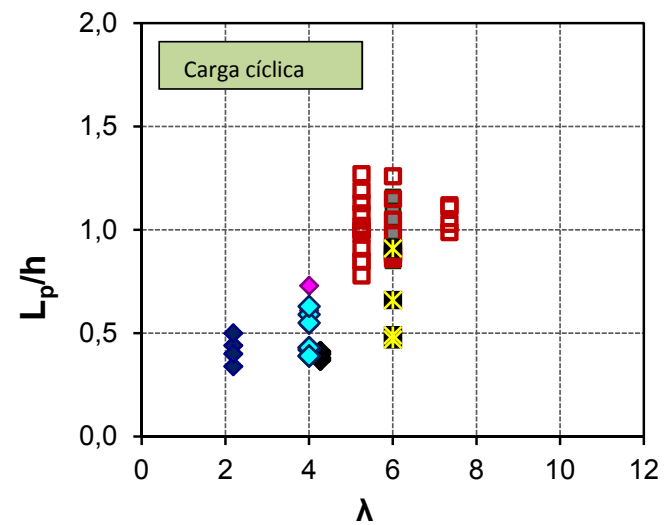

$\lambda$

\begin{tabular}{|c|c|}
\hline • Park et al. [44] & $\diamond$ Ang B. G. [1] \\
\hline • Mander J.B. [61] & $\diamond$ Zahn F. A. [101] \\
\hline 口 Sheikh S. et al. [89] & 口Bayrak O. et al. [17] \\
\hline aBae y Bayrak [4] & \\
\hline
\end{tabular}

(c)

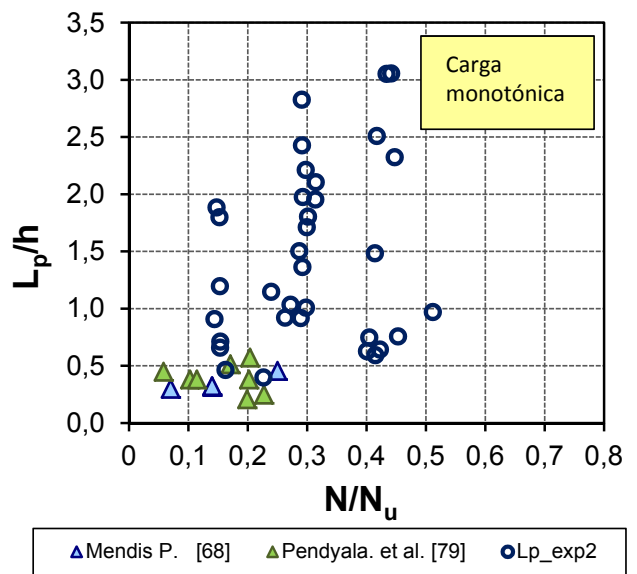

(b)

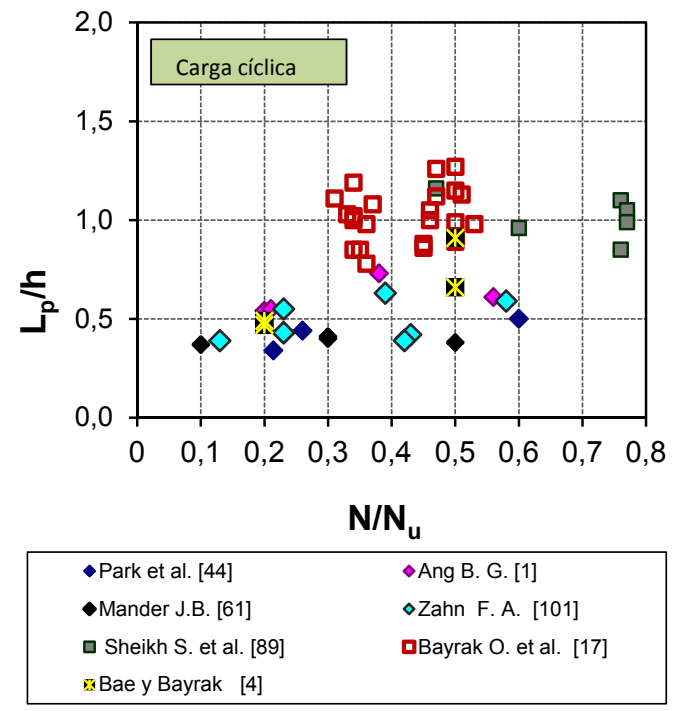

(d)

Figura 6.46 Valores de $L_{p}$ para carga monotónica en función de: (a) la esbeltez de cortante $(\lambda), y(b)$ el nivel de carga axial; $y$ valores de $L_{p}$ para carga cíclica en función de: (c) la esbeltez de cortante $(\lambda), y(d)$ el nivel de carga axial

\subsection{COMPARACIÓN DE LOS RESULTADOS EXPERIMENTALES CON LA NORMATIVA}

Las normas, en general, consideran que la ductilidad está asociada con el tipo de estructura. En el caso de la norma en España, la NCSE-02 [97] establece una clasificación de los sistemas constructivos en edificación y determina los niveles de ductilidad en desplazamientos asociados a cada tipo de estructura, (Tabla 6-32).

Por otra parte, la ductilidad de curvatura se encuentra relacionada en las normas con la cuantía de armadura transversal, la cual contribuye a garantizar el desarrollo de la ductilidad de la sección. La EHE-08 (2008) [53], en su anejo 10, se refiere a los requisitos complementarios para dotar a los elementos estructurales de una adecuada ductilidad; en el caso de soportes, la EHE-08 (2008) [53] ha adoptado la Ec. 6-34, especificada también por el Eurocódigo 8 (2004) [59], para suministrar 
Estudio experimental y numérico de la capacidad de deformación de soportes esbeltos de hormigón convencional y de alta resistencia.

una cuantía de armadura transversal en las zonas críticas en donde se puede formar una rótula plástica. La expresión incluida en la EHE-08 adopta los valores de ductilidad de curvatura de $\mu_{\varphi}=5$, en el caso de columnas que requieren una ductilidad alta, y de $\mu_{\varphi}=7$, para columnas con una demanda de ductilidad muy alta (ver Tabla 6-32).

$$
\alpha \omega_{w d} \geq 30 \mu_{\varphi} v_{d} \cdot \varepsilon_{s y} \cdot \frac{b_{c}}{b_{o}}-0.035
$$

Donde

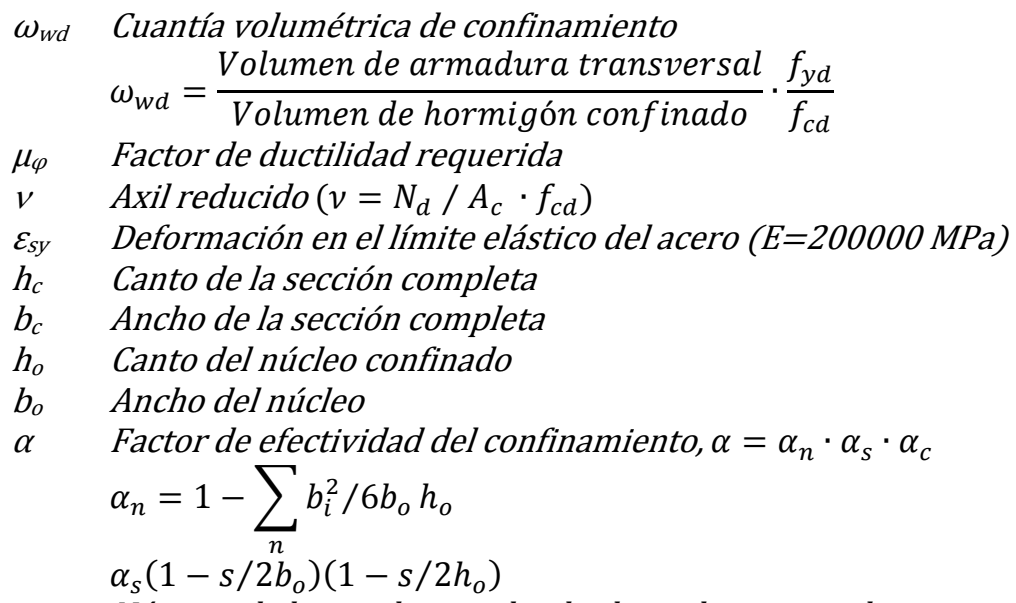

$n \quad$ Número de barras longitudinales lateralmente atadas con ganchos o cercos cerrados

$b_{i} \quad$ Distancia consecutiva entre barras atadas (en $b_{o}$ y en $h_{o}$ )

$\alpha_{c} \quad$ Factor que tiene en cuenta la resistencia del hormigón

$\alpha_{c}=1.0$ para hormigón convencional, $f_{c k} \leq 50 \mathrm{MPa}$

$\alpha_{c}=1.2-f_{c k} / 250$ para hormigón de alta resistencia, con $f_{c k}>50 M P a$

Tabla 6-32 Clasificación de los sistemas estructurales y requisitos de ductilidad de acuerdo con NCSE-02 y EHE-08

\begin{tabular}{|c|c|c|c|c|}
\hline \multicolumn{5}{|c|}{ NCSE-02 / EHE 08} \\
\hline \multicolumn{2}{|r|}{ Tipo de estructura } & Ductilidad & $\mu_{\delta}$ & $\boldsymbol{\mu}_{\varphi}$ \\
\hline 1 & $\begin{array}{l}\text { Pórticos planos o espaciales, pantallas y vigas de } \\
\text { acoplamiento, Sistemas Duales }\end{array}$ & Muy alta & 4.0 & 7.0 \\
\hline 2 & Sistemas de pantallas no acopladas de hormigón armado. & Alta & 3.0 & 5.0 \\
\hline 3 & $\begin{array}{l}\text { Estructura con soportes de acero u hormigón con núcleos, } \\
\text { muros o pantallas verticales de hormigón armado, pero no } \\
\text { satisface los requisitos anteriores en cuanto a tipo y detalles } \\
\text { estructurales. En particular se encuadran en este grupo: } \\
\text { Losas planas, forjados reticulares o unidireccionales } \\
\text { Estructuras con arriostramientos en forma de } \mathrm{V} \\
\end{array}$ & Baja & 2.0 & 3.0 \\
\hline 3.A & Estructuras de tipo péndulo invertido o similares. & & & \\
\hline 4 & $\begin{array}{l}\text { Las constituidas por muros de mampostería, ladrillo o bloques } \\
\text { de hormigón, con entramados de madera, pórticos con } \\
\text { arriostramientos en forma de K. Las estructuras de naves } \\
\text { industriales con pilares y cerchas. Las realizadas con } \\
\text { elementos prefabricados o que contengan piezas prefabricadas } \\
\text { de gran formato, en las que no se hayan adoptado disposiciones } \\
\text { especiales para dotar a los nudos de ductilidad. }\end{array}$ & $\begin{array}{c}\text { Sin } \\
\text { ductilidad }\end{array}$ & 1.0 & - \\
\hline
\end{tabular}


El Eurocódigo 8 (2004) [59] establece prácticamente la misma clasificación para los tipos de estructura; en la Tabla 6-33 se presentan los factores de ductilidad propuestos por el Eurocódigo 8, teniendo en cuenta que esta norma se basa en la expresión Ec. 6-35, que relaciona los dos factores de ductilidad, y que es normalmente una aproximación conservadora para elementos de hormigón.

$$
\mu_{\varphi}=2 \mu_{\delta}-1
$$

Tabla 6-33 Clasificación de los sistemas estructurales y requisitos de ductilidad de acuerdo con el Eurocódigo 8

\begin{tabular}{|c|c|c|c|c|c|}
\hline \multicolumn{3}{|c|}{ Eurocódigo 8 } & \multicolumn{2}{c|}{ DCM } & \multicolumn{2}{c|}{ DCH } \\
\cline { 3 - 7 } & \multirow{2}{*}{ Tipo de Estructura } & $\boldsymbol{\mu}_{\delta}$ & $\boldsymbol{\mu}_{\boldsymbol{\varphi}}$ & $\boldsymbol{\mu}_{\delta}$ & $\boldsymbol{\mu}_{\boldsymbol{\varphi}}$ \\
\hline 1 & Sistemas de pórticos; duales y pantallas acopladas & 4.0 & 7.0 & 4.5 & 8.0 \\
\hline 2 & Sistema de pantallas no acopladas & 3.0 & 5.0 & 4.0 & 7.0 \\
\hline 3 & Sistema Torsional flexible & 2.0 & 3.0 & 3.0 & 5.0 \\
\hline 3. A & Sistema de péndulo invertido (EC-8 límite inferior) & 1.5 & 2.0 & 2.0 & 3.0 \\
\hline 4 & No satisfacen los requisitos del EC-8 secc.5 & \multicolumn{5}{c|}{ DCL } \\
\hline
\end{tabular}

A diferencia de la NCSE-02 [97], el Eurocódigo 8 (2004) [59] sugiere dos niveles de ductilidad DCM y DCH para cada tipo de estructura, que se refieren a ductilidades moderadas y altas, respectivamente. Como se puede observar, la norma española NCSE-02 ha adoptado los factores de ductilidad moderada (DCM) especificados en el Eurocódigo 8, excepto en el sistema de péndulo invertido.

Las normas coinciden en que toda estructura que no disponga de los detalles y no cumpla los requisitos de las normas sísmicas, sea considerada de baja ductilidad. Dentro de esta clasificación, la NCSE-02 [97] ha incorporado las estructuras de edificación tradicionales en España, como por ejemplo estructuras de pórticos de hormigón con forjados reticulares o forjados unidireccionales con vigas planas. Por consiguiente, los valores asignados a este tipo de estructuras son los correspondientes al tipo 3 que aparecen en la Tabla 6-32.

Una pequeña diferencia entre estas dos normas consiste en el tipo de estructura de péndulo invertido, puesto que la norma NCSE-02 [97] es ligeramente más exigente en cuanto a los factores de ductilidad. Mientras que el Eurocódigo 8 (2004) [59] admite como valores límite los factores de ductilidad $\mu_{\delta}=1.5$ y $\mu_{\varphi}=2.0$, la norma NCSE-02 solicita como valores límite $\mu_{\delta}=2.0$ y $\mu_{\varphi}=3.0$.

\subsubsection{ANÁLISIS DE LOS FACTORES DE DUCTILIDAD EXPERIMENTAL RESPECTO A LA NORMATIVA}

Dadas las condiciones del ensayo, el elemento estructural puede considerarse como un péndulo invertido, pero, además, también puede representar la situación de un soporte típico de edificación que forma parte de un sistema de entramados. Por otra parte, cabe destacar que los soportes ensayados no cuentan con los detalles y requisitos del diseño sísmico en cuanto a armadura transversal. Por consiguiente, y de acuerdo con las normas NCSE-02 [97] y Eurocódigo 8 (2004) [59], los soportes sólo se evaluarán para un requerimiento de baja ductilidad. 
En las Figuras 6.47, se presenta la comparación entre los resultados experimentales y los requisitos de las normas para la ductilidad en desplazamientos. Los resultados, analizados de forma global, muestran que, en su gran mayoría, han desarrollado una ductilidad baja, y sólo 8 de los 40 ensayos han desarrollado una ductilidad superior a 3 , es decir, una alta ductilidad. Por el contrario, en 6 de los ensayos, la ductilidad ha sido inferior a 2. La ductilidad en desplazamientos presenta un aumento con el incremento de la esbeltez de cortante. Respecto a la resistencia del hormigón, esta influye desfavorablemente en la ductilidad. Las Figuras 6.47 dan cuenta de que la ductilidad en desplazamientos disminuye con el incremento de la resistencia del hormigón. Cabe destacar que, a pesar de la alta esbeltez de los soportes, cuando se utiliza hormigón convencional, estos son capaces de mantenerse dentro del rango de ductilidad requerida en estructuras tipo 3, (ver Tabla 6-32 y Tabla 6-33), como por ejemplo en soportes de edificación tradicional en España.

Todos los soportes cumplen con la ductilidad requerida en las estructuras tipo péndulo invertido. Sin embargo, al considerarse como soportes de edificación, algunos de los elementos de hormigón de alta resistencia no cumplen con la ductilidad requerida, especialmente en soportes de hormigón de $90 \mathrm{MPa}$. Esto significa que, si la utilización de hormigón de alta resistencia obedece a que el soporte se encuentre altamente comprimido, estos elementos difícilmente desarrollarán un comportamiento dúctil satisfactorio. Consecuentemente, las normas referidas a elementos altamente comprimidos deberían sugerir limitaciones en cuanto a la resistencia del hormigón, a la esbeltez, o a ambas conjuntamente.

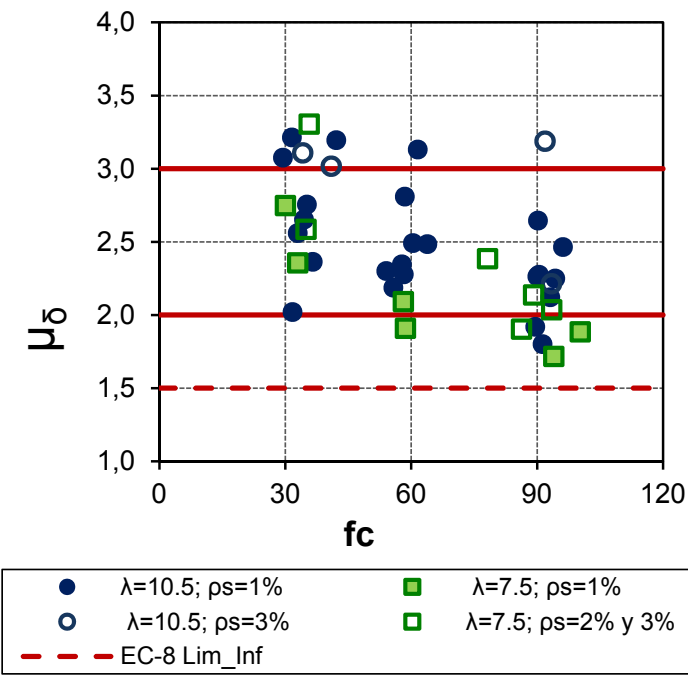

(a)

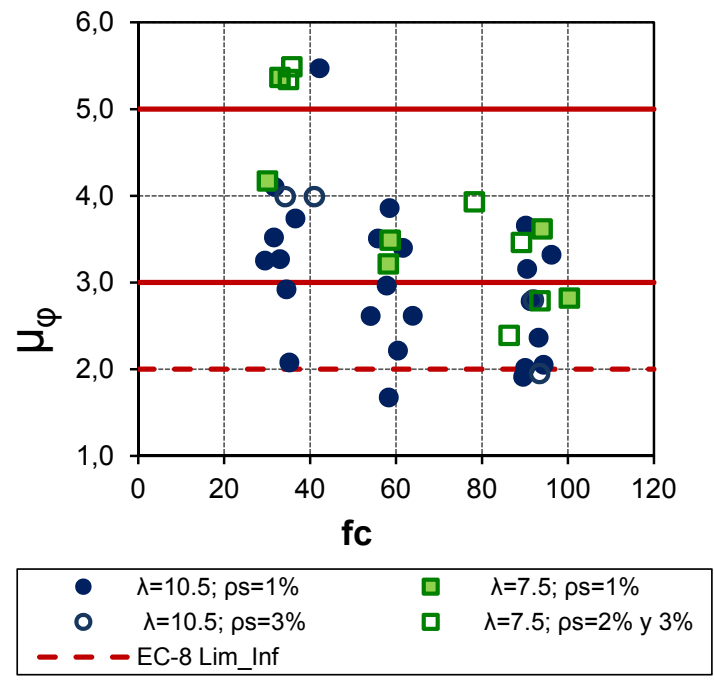

(b)

Figura 6.47 Comparación de los factores de ductilidad y las normativas: (a) ductilidad en desplazamientos, (b) ductilidad de curvatura

Respecto a la ductilidad de curvatura, ha quedado demostrado que esta disminuye conforme aumenta la esbeltez de cortante, y disminuye también con el incremento de la resistencia del hormigón. Se puede observar que, si los elementos son evaluados como soportes de edificación, la capacidad de ductilidad puede quedar seriamente comprometida, especialmente en soportes de hormigón de alta resistencia (60 MPa y $90 \mathrm{MPa}$ con esbeltez 10.5), e incluso, si los soportes se 
evalúan como estructura tipo péndulo invertido, no se alcanzan los valores de ductilidad de curvatura requerida para soportes de hormigón de alta resistencia. Las Figuras 6.47 muestran que una gran parte de los soportes en los que el factor de ductilidad de curvatura es inferior a 3 corresponden a soportes con esbeltez de cortante 10.5, especialmente si los soportes se encuentran solicitados para un nivel de carga axil superior al 30\% (como se puede ver en la Tabla 6-19 de la sección 6.5.2.2). Esto permite manifestar que es necesario revisar las limitaciones de las normas con respecto a los elementos de hormigón armado en los que se combinan los factores de esbeltez de cortante, nivel de carga axial y resistencia del hormigón, en los cuales no es posible alcanzar una adecuada capacidad de ductilidad.

\subsection{RIGIDEZ EFECTIVA}

En esta sección se lleva a cabo una comparación de la rigidez elástica efectiva obtenida en los ensayos experimentales y los modelos propuestos por Khuntia y Ghosh (2004) [70], y el modelo de Panagiotakos y Fardis (2001) [100].

Kuntia y Ghosh (2004) [70] proponen valorar la rigidez elástica efectiva $\left(E l_{\mathrm{e}}\right)$ en vigas de hormigón convencional mediante la Ec. 6-36, y, en vigas de hormigón de alta resistencia, a partir de la expresión Ec. 6-37. Para soportes de hormigón se propone la Ec. 6-38. Dichas expresiones propuestas por Kuntia y Ghosh (2004) [70] se han adoptado en el ACl 318-08 (2008) [1].

En vigas: Hormigón convencional

$$
E I_{e}=E_{c} I_{g}(0.10+25 \rho)(1.2-0.2 b / d) \leq 0.6 E_{c} I_{g}
$$

En vigas: Hormigón alta resistencia

$$
E I_{e}=E_{c} I_{g}\left(0.80+25 \rho_{g}\right)(1.2-0.2 b / d) \times\left(1.15-4 \times 10^{-5} f_{c}^{\prime}\right) \leq 0.6 E_{c} I_{g} \quad \text { Ec. } 6-37
$$

En soportes:

$$
E I_{e}=E_{c} I_{g}(0.10+25 \rho) \times\left(0.3+0.5 \frac{P_{u}}{P_{o}}\right) \leq E_{c} I_{g} \geq E_{c} I
$$

Donde:

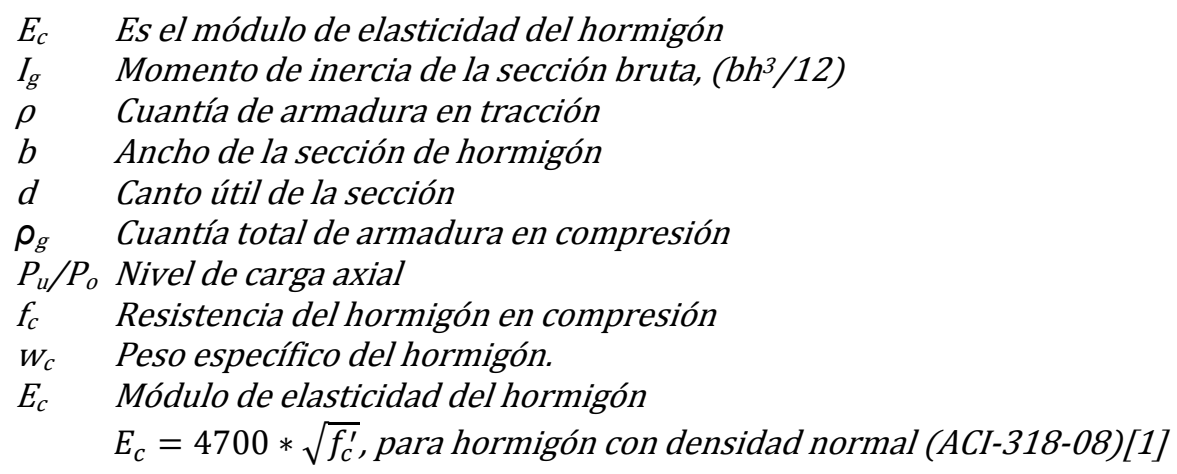

El modelo de Panagiotakos y Fardis (2001) [100] se basa en el análisis teórico de la sección en el estado de plastificación y en el estado último (el modelo completo se encuentra descrito en el capítulo 9). El modelo propone un proceso de cálculo para 
las variables de curvatura elástica teórica $\left(\varphi_{\mathrm{y}}\right)$ y momento en el punto de plastificación $\left(\mathrm{M}_{\mathrm{y}}\right)$, lo cual permite mediante la relación $\mathrm{M}_{\mathrm{y}} / \varphi_{\mathrm{y}}$ evaluar la rigidez elástica efectiva de la sección. Este modelo se ha presentado también en el CEB FIB-Bulletin 24 (2003)[34].

La rigidez elástica efectiva también suele presentarse mediante el factor de rigidez $\alpha_{e}$, que representa la relación entre la rigidez elástica efectiva y la rigidez bruta para la sección de hormigón sin fisurar $\left(\alpha_{e}=E I_{e} / E_{c} I_{g}\right)$. En la Tabla 6-35 se presentan los valores de $\alpha_{e}$, obtenidos cuando la rigidez elástica efectiva $\left(\mathrm{El}_{\mathrm{e}}\right)$ se evalúa de forma teórica ( 1 y 2 ):

1. La rigidez (EI $\left.\mathrm{I}_{\mathrm{e} A \mathrm{ACl}}\right)$ se calcula de acuerdo con Kuntia y Ghosh (2004) [70], a partir de las expresiones Ec. 6-36 a Ec. 6-38.

2. La rigidez $\left(\mathrm{El}_{\mathrm{e}_{-} \mathrm{CEB}}\right)$, se calcula con el modelo de Panagiotakos y Fardis (2001) [100], presentado en el capítulo 9.

También se presentan en la Tabla 6-35 los valores de $\alpha_{e}$ cuando la rigidez elástica efectiva se evalúa mediante la idealización del diagrama momento-curvatura experimental aplicando los siguientes métodos ( 3,4 y 5$)$ :

3. Eurocódigo 8 versión $1 \mathrm{~A},\left(\mathrm{El}_{\mathrm{e} \_\mathrm{e} \times 1 \mathrm{~A}}\right)$

4. Eurocódigo 8 versión $1 \mathrm{~B},\left(\mathrm{El}_{\mathrm{e}-\mathrm{ex} 1 \mathrm{~B}}\right)$

5. Eurocódigo 8 versión 2, $\left(\mathrm{El}_{\mathrm{e}_{-} \mathrm{e} \times 2}\right)$

Los resultados del modelo de Kuntia y Ghosh (2004) [70], número (1) de la Tabla 6-34, son comparados con los resultados experimentales obtenidos de la idealización del diagrama $\mathrm{M}-\varphi$ aplicando los métodos 1B y 3 , (resultados (4) y (5) de la Tabla 6-34). Y los resultados del modelo de Panagiotakos y Fardis (2001) [100] numeral (2), son comparados con los resultados experimentales (3) y (4). Los valores estadísticos de la comparación entre los valores calculados y experimentales se presentan en la Tabla 6-34.

Tabla 6-34 Resultados de la comparación entre los valores de rigidez efectiva calculados y los experimentales

\begin{tabular}{|c|c|c|c|c|}
\cline { 2 - 5 } \multicolumn{1}{c|}{} & $\frac{E I_{e_{-} A C I}}{E I_{e_{-} \operatorname{ex} 1 B}}$ & $\frac{E I_{e_{-} A C I}}{E I_{e_{-} \operatorname{exp3} 3}}$ & $\frac{E I_{e_{-} C E B}}{E I_{e-\operatorname{ex1A}}}$ & $\frac{E I_{e_{-} C E B}}{E I_{e-\operatorname{ex} 1 B}}$ \\
\hline $\mathrm{E}$ & 0.77 & 0.94 & 1.03 & 0.9 \\
\hline $\mathrm{CV}(\%)$ & $26 \%$ & $24 \%$ & $10 \%$ & $14 \%$ \\
\hline $\mathrm{P} 95$ & 1.05 & 1.33 & 1.18 & 1.14 \\
\hline $\mathrm{P} 5$ & 0.52 & 0.65 & 0.85 & 0.7 \\
\hline
\end{tabular}


Tabla 6-35 Resultados de la rigidez efectiva teórica y experimental

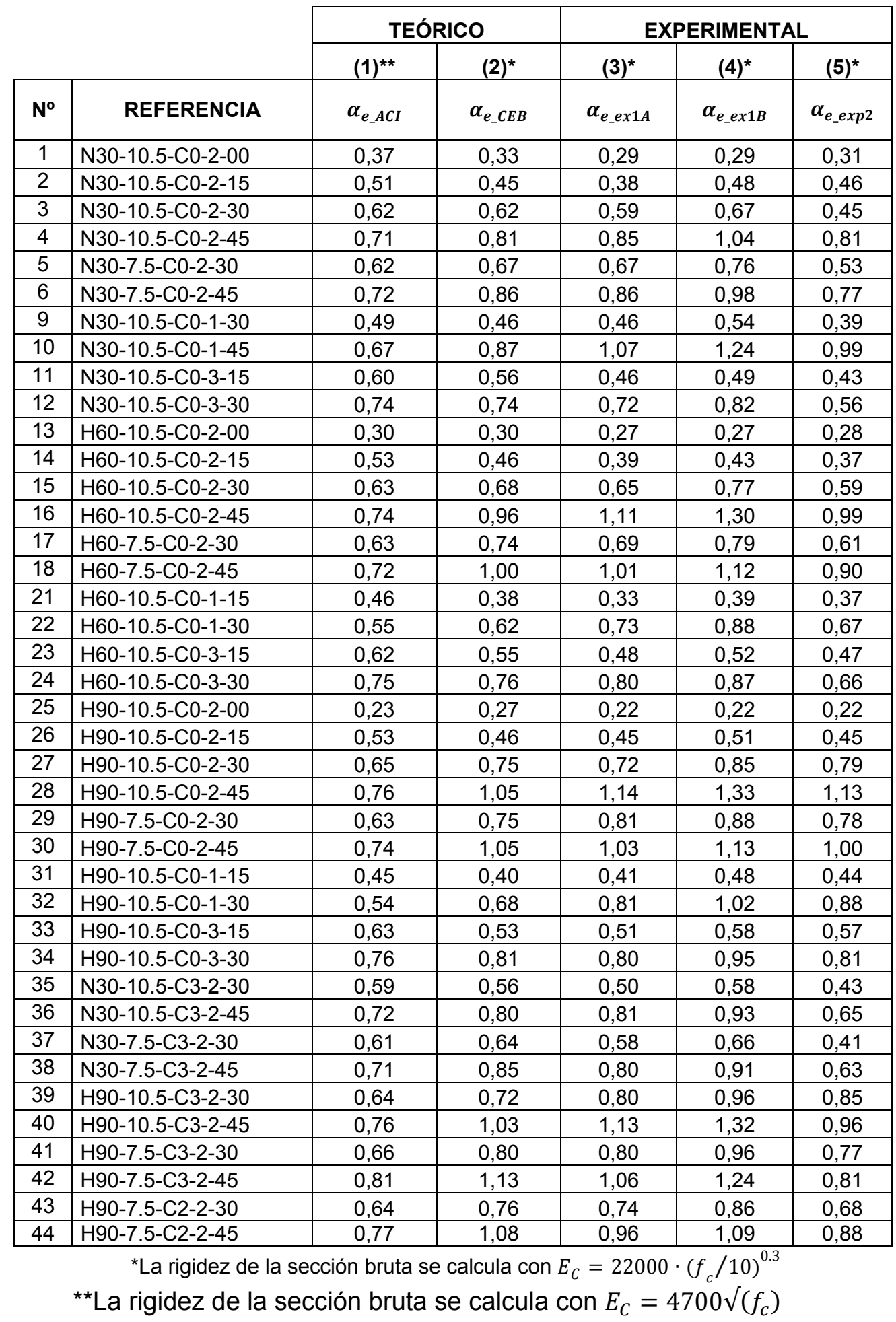

En las Figuras 6.48 se muestran gráficamente los resultados de la comparación entre el método de Kuntia y Ghosh (2004) [70] y los experimentales; los valores de la rigidez efectiva a flexión son normalizados dividiendo por la rigidez bruta $\left(E_{c} l_{g}\right)$. Los resultados de la rigidez efectiva calculados a partir de las expresiones de Kuntia y Ghosh (2004) [70], están bastante del lado de la seguridad, en especial si 
Estudio experimental y numérico de la capacidad de deformación de soportes esbeltos de hormigón convencional y de alta resistencia.

se comparan con los resultados de la idealización del diagrama $M-\varphi$ aplicando el método $1 \mathrm{~B}$, que corresponde al método que hemos adoptado a lo largo del presente capitulo.

El método simplificado de Kuntia y Ghosh (2004) [70] muestra una mejor aproximación media si se compara con los resultados experimentales de $\mathrm{E}_{\mathrm{c}} \mathrm{l}_{\mathrm{e}}$ obtenidos en la idealización de $M-\varphi$ aplicando el método aproximado (método 2); sin embargo, el método exhibe una importante dispersión de los resultados de hasta un $24 \%$. Los resultados de la idealización con el método aproximado se han utilizado en la comparación, ya que este método es comúnmente utilizado por algunas de las referencias del $\mathrm{ACl}$, por ejemplo Priestley et al. [110].

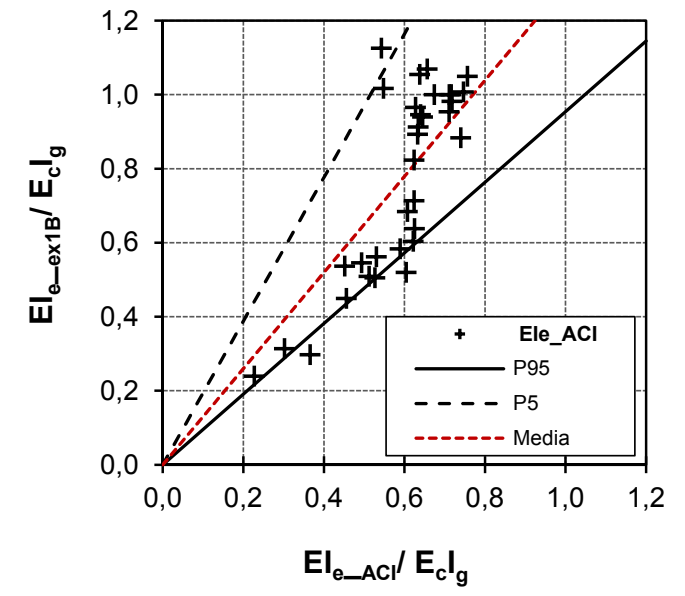

(a)

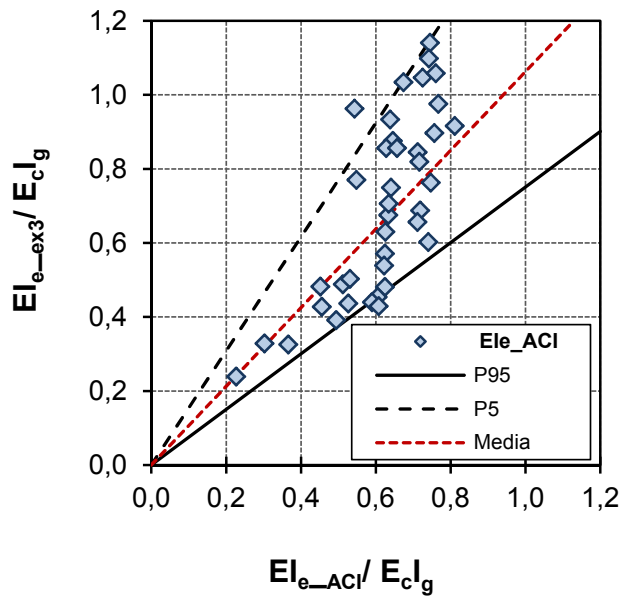

(b)

Figura 6.48 Comparación de la rigidez efectiva calculada mediante las expresiones de Kuntia y Ghosh [70] y las obtenidas experimentalmente aplicando los métodos de idealización (a) Eurocódigo 8 (versión 1B) y (b) método aproximado

En las Figuras 6.49 se muestran los valores calculados y los experimentales adimensionalizados mediante la rigidez bruta $\left(E_{c} l_{g}\right)$, respecto a la propuesta de Panagiotakos y Fardis (2001) [100]. El módulo de elasticidad del hormigón en esta comparación se calcula de acuerdo a la expresión propuesta por el EC-2 (2004) [58] $\left(E_{C}=22000\left(f_{c} / 10\right)^{0.3}\right)$.

Los resultados de Panagiotakos y Fardis (2001) [100] presentan una buena aproximación con los resultados de la idealización del diagrama $\mathrm{M}-\varphi$ utilizando el método del Eurocódigo 8 [59] versión 1a (ver Figuras 6.49 y Figura 6.50). Esto se debe a que el criterio para la determinación del punto de plastificación utilizado tanto en los ensayos experimentales como en el modelo, es el mismo. Panagiotakos y Fardis (2001) [100], en la calibración del modelo, asumieron que el punto de plastificación se localiza en la curva de respuesta de la sección $(M-\varphi)$, cuando ocurre la primera de las dos posibles situaciones, o bien porque la armadura en tracción ha plastificado, o bien porque el hormigón ha alcanzado una deformación del $0.9 \varepsilon_{\mathrm{co}}$. Naturalmente, la coincidencia en la definición de punto de plastificación facilita la aproximación de los métodos, como queda demostrado en la Figura 6.49a. 
Los resultados de la rigidez calculada mediante el modelo de Panagiotakos y Fardis (2001) [100] también se han comparado con la rigidez experimental medida en la idealización 1B, en la cual la definición para el punto de plastificación del hormigón ha cambiado a $0.75 \varepsilon_{\text {co. }}$. La Figura $6.49 \mathrm{~b}$ y la Tabla $6-34$ muestran que, en esta ocasión, el modelo de Panagiotakos et al. [100] también consigue una aproximación aceptable, aunque se encuentra un poco más del lado de la seguridad.

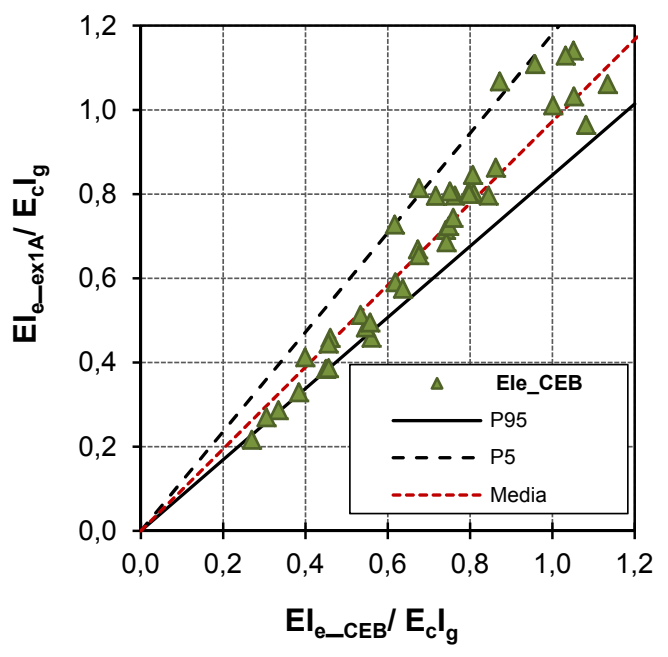

(a)

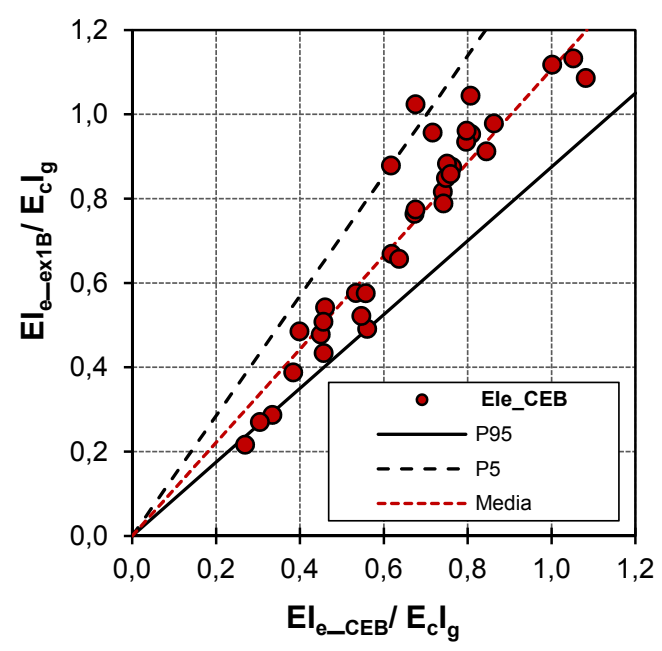

(b)

Figura 6.49 Comparación entre la rigidez efectiva calculada a partir del método de Panagiotakos y Fardis (2001) [100] y la experimental obtenida en la idealización de $M-\varphi$ aplicando el método del Eurocódigo 8 (a) versión $1 A$ y (b) versión $1 B$ 


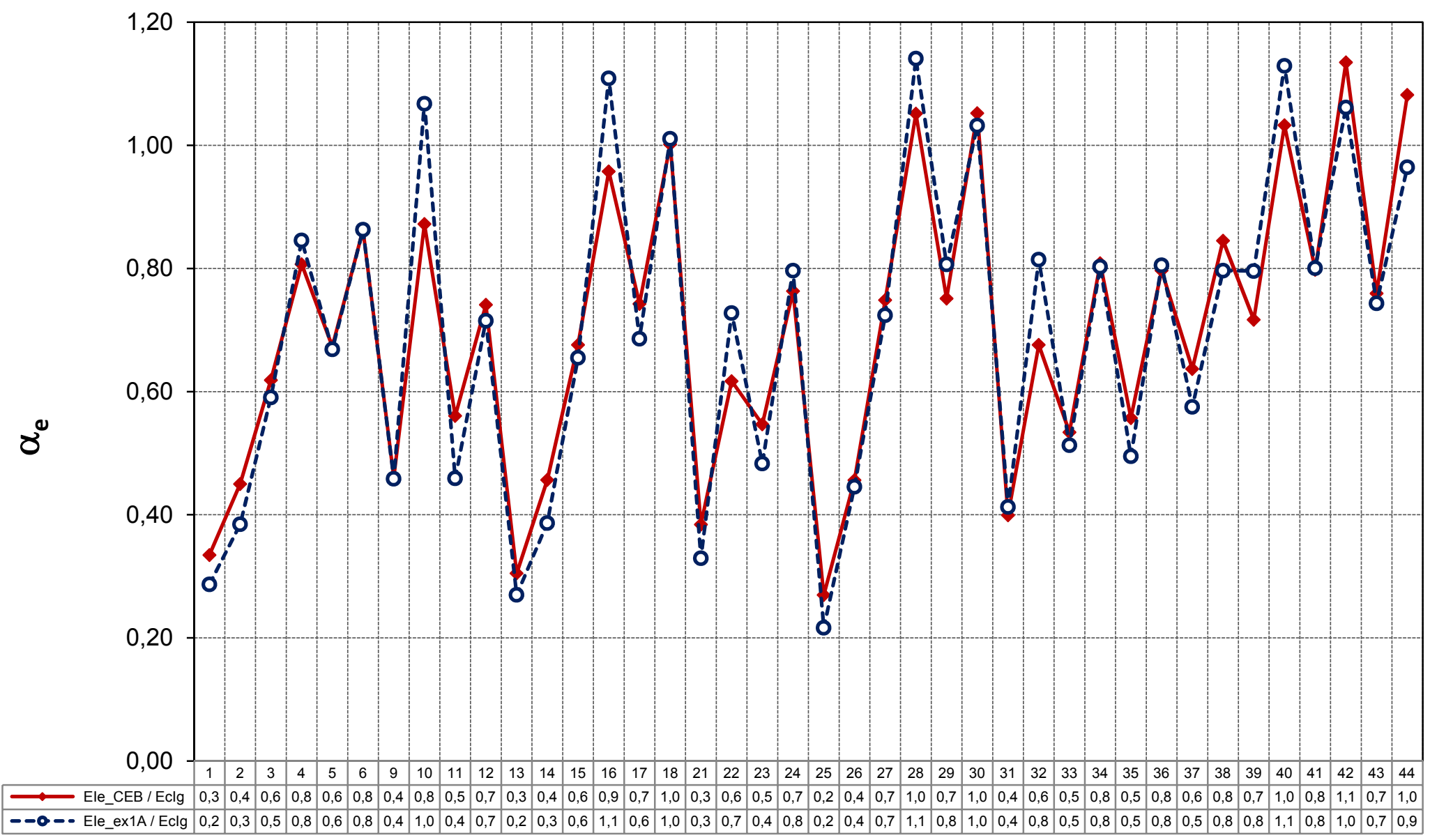

Figura 6.50 Comparación entre los valores de la rigidez efectiva calculados mediante el método de Panagiotakos et al. (2001) [100] y los valores experimentales obtenidos en la idealización del $M-\varphi$ aplicando el método $1 \mathrm{~A}$ 


\section{CAPÍTULO 7}

\section{CALIBRACIÓN DE UN MODELO NUMÉRICO PARA SIMULAR EL COMPORTAMIENTO DE SOPORTES DE HORMIGÓN ARMADO}

La simulación de elementos de hormigón armado es una metodología comúnmente usada en el estudio de su comportamiento estructural. Los modelos numéricos normalmente complementan los ensayos experimentales, y pueden resultar fundamentales a la hora de ampliar los rangos y parámetros de estudio. Sin embargo, la validez de los resultados depende de la exhaustividad en el proceso de calibración del modelo numérico.

En este capítulo se describe el proceso seguido en la calibración de un modelo numérico que permite reproducir el comportamiento estructural de soportes esbeltos de hormigón sometidos a flexo-compresión. En la simulación numérica se ha utilizado el programa de análisis no lineal "ATENA 2D", versión V3, desarrollado por CERVENKA CONSULTING.

La calibración del modelo numérico se ha realizado tomando como base los ensayos experimentales realizados dentro de esta investigación, y cuyas características y resultados ya se han presentado en los capítulos 4,5 y 6 . 
El modelo numérico se ha desarrollado con el propósito de realizar un análisis más amplio de los factores que influyen en la ductilidad de soportes de hormigón, de modo que se lleve a cabo un estudio paramétrico de dichos factores en este tipo de elementos.

\subsection{DESCRIPCIÓN DEL PROGRAMA ATENA}

El algoritmo del programa "ATENA 2D" (Červenka V. y Červenka J (2005) [39]) está formado básicamente por tres partes: técnica de elementos finitos, modelos constitutivos y métodos de solución de ecuaciones no lineales.

Los modelos constitutivos avanzados del hormigón utilizados en "ATENA 2D", versión V3, tienen en cuenta todos los aspectos importantes del comportamiento real en tracción y compresión. "ATENA 2D" implementa modelos constitutivos avanzados para el hormigón basados en mecanismos de daño, mecanismos de fractura no-lineal, y teorías de la plasticidad con un modelo de fisuración distribuida ("smeared crack model").

\subsubsection{EL MODELO CONSTITUTIVO BASADO EN UNA APROXIMACIÓN DE FISURACIÓN DISTRIBUIDA ("SMEARED CRACK MODEL")}

\subsubsection{MODELO DE FISURACIÓN}

El hormigón sin fisuración es considerado isotrópico, mientras que el hormigón fisurado se considera ortotrópico. Los ejes del hormigón fisurado puedien definirse a partir de dos posibles modelos: rotado o fijo. En el modelo de fisuración rotado, la dirección de las fisuras siempre coincide con la dirección de la deformación principal. En el modelo de fisuración fijo, la normal a la superficie de la fisura y los ejes del material están definidos por la dirección de la tensión principial en el paso de carga que determina el inicio de la fisuración. Para análisis posteriores, la dirección se mantiene fija y sin cambios. La gran diferencia entre las dos aproximaciones anteriores está en el modelo de cortante en el plano de la fisura. En el modelo de fisuración fijo, la rotación del campo de deformaciones genera un esfuerzo cortante en el plano de la fisura. Consecuentemente, el modelo de cortante empieza a ser importante. En el caso de las fisuras rotadas, en el plano de la fisura nunca aparece el esfuerzo cortante, por lo tanto el modelo de cortante no se utiliza.

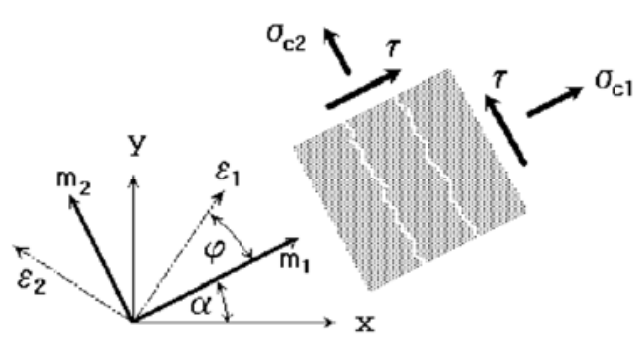

(a). Modelo fijo

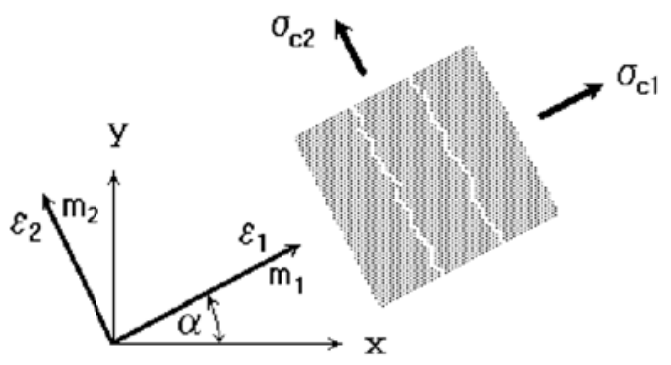

(b). Modelo rotado

Figura 7.1 Modelos de fisuración implementados en ATENA 2D, estado tensióndeformación 


\subsubsection{CURVA TENSIÓN-DEFORMACIÓN EQUIVALENTE}

Los parámetros de un modelo de fisuración distribuida ("smeared crack model") se obtienen a partir de una curva que relaciona la tensión normal a la cara de la fisura y la deformación longitudinal obtenida como el cociente entre la apertura de la fisura y la longitud característica asociada al ancho de la banda de fisuración. Esta relación se ilustra en la Figura 7.2 y en la Tabla 7-1. Los efectos del proceso de simplificación que implica la conversión de un problema unidimensional en un problema bidimensional se incluyen en la solución a través de la modificación de los límites de la relación unidimensional. Esta modificación se basa en los esfuerzos límites dados por Kupfer para las condiciones de fallo del hormigón mostrados en la Figura 7.2 y la Tabla 7-2.

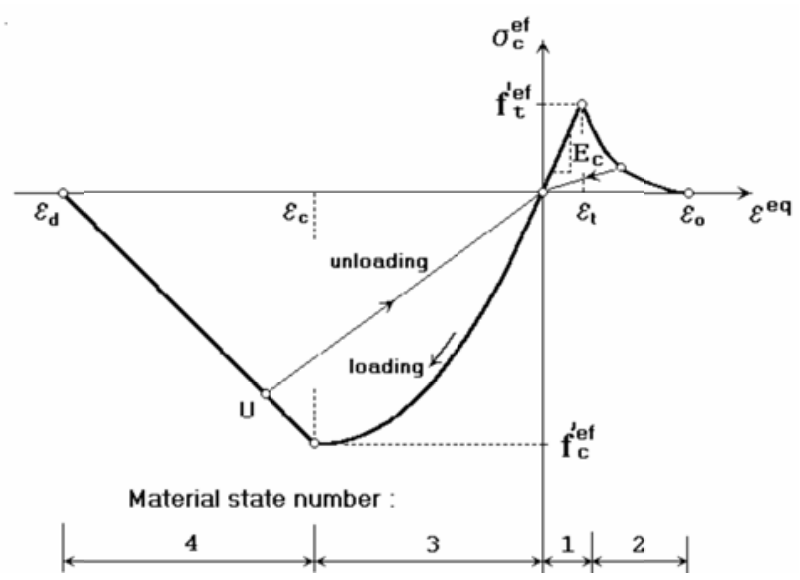

Figura 7.2 Relación tensión-deformación efectiva uniaxial del hormigón, (Tomado de ATENA Červenka V. et al. (2005) [39])

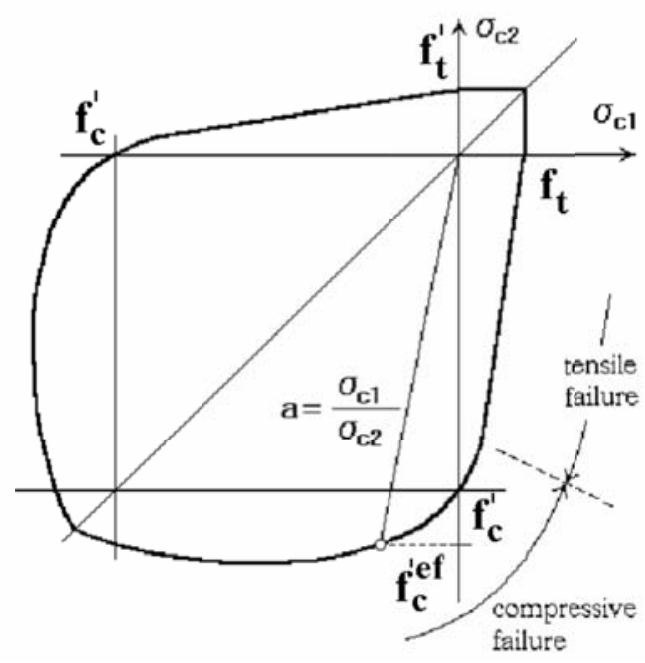

Figura 7.3 Esfuerzos límites de Kupfer para el hormigón (Tomado de ATENA Červenka V. et al. (2005) [39]) 
Estudio experimental y numérico de la capacidad de deformación de soportes esbeltos de hormigón armado

Tabla 7-1 Estados de comportamiento del hormigón

\begin{tabular}{|c|c|c|}
\hline Estado & Formulación & \\
\hline $\begin{array}{l}\text { (1) Tracción sin } \\
\text { fisuración }\end{array}$ & $\begin{array}{l}\text { Se considera elástico lineal } \\
\sigma_{c}^{e f}=E_{0} \varepsilon^{e q} \quad \text { para } \quad 0 \leq \sigma_{c}^{e f} \leq f_{t}^{\text {ef }}\end{array}$ & Ec. $7-1$ \\
\hline $\begin{array}{l}\text { (2) Tracción } \\
\text { después de la } \\
\text { fisuración }\end{array}$ & $\begin{array}{l}\text { Se introduce el modelo ficticio de fisuración de Hordijk } \\
(1991)^{1} \text { que describe la siguiente función para modelizar la } \\
\text { propagación de la fisuración en el hormigón. } \\
\frac{\sigma}{f_{t}^{\text {eff }}}=\left[1+\left(\frac{3 w}{w_{c}}\right)^{3}\right] \exp \left(-\frac{6.93 w}{w_{c}}\right)-\frac{28 w}{w_{c}} \exp (-6.93) \\
w_{c}=5.14 \frac{G_{F}}{f_{t}^{e f f}} \\
\text { El ancho de la fisura w puede ser calculado como la } \\
\text { apertura total de acuerdo con la teoría de bandas entre } \\
\text { fisuras, Bazan }(1983)^{2} \text {. }\end{array}$ & Ec. 7-2 \\
\hline $\begin{array}{l}\text { (3) Compresión } \\
\text { antes de la tensión } \\
\text { pico }\end{array}$ & $\begin{array}{l}\text { Se adopta la relación tensión-deformación recomendada por } \\
\text { el código modelo CEB-FIP 1990 [33]. } \\
\sigma_{c}^{e f}=f_{c}^{\text {eff }}\left[\frac{\left(\frac{E_{o}}{E_{c}}\right)\left(\frac{\varepsilon}{\varepsilon_{c o}}\right)-\left(\frac{\varepsilon}{\varepsilon_{c o}}\right)^{2}}{1+\left(\frac{E_{o}}{E_{c}}-2\right)\left(\frac{\varepsilon}{\varepsilon_{c o}}\right)}\right]\end{array}$ & Ec. $7-3$ \\
\hline \multirow[t]{2}{*}{$\begin{array}{l}\text { (4) Compresión } \\
\text { después de la } \\
\text { tensión pico }\end{array}$} & \multirow{2}{*}{$\begin{array}{l}\text { Van Mier }(1986)^{3} \text { ha demostrado experimentalmente que el } \\
\text { desplazamiento es independiente del tamaño de la } \\
\text { estructura. Por lo tanto, la deformación de compresión limite } \\
\varepsilon_{d} \text { puede ser expresada en términos de la deformación } \\
\text { correspondiente a la tensión pico } \varepsilon_{c o} \text {, el desplazamiento } \\
\text { plástico } w_{d} \text { y el tamaño de la banda de un elemento en } \\
\text { compresión L'd. } \\
\varepsilon_{d}=\varepsilon_{c o}+\frac{w_{d}}{L_{d}^{\prime}}\end{array}$} & \\
\hline & & Ec. 7-4 \\
\hline
\end{tabular}

Tabla 7-2 Criterios de fallo de tensión biaxial sugerido por Kupfer et al. (1969)

\begin{tabular}{|l|l|c|}
\hline \multicolumn{1}{|c|}{ Estado de tensión de fallo } & \multicolumn{2}{|c|}{ Tensión efectiva } \\
\hline (I) Compresión-Compresión & $\begin{array}{l}f_{c}^{\prime e f}=\frac{1+3.65 a}{(1+a)^{2}} f_{c}^{\prime} \\
a=\frac{\sigma_{c 1}}{\sigma_{c 2}}\end{array}$ & Ec. 7-5 \\
\hline (II) Compresión-Tracción & $\begin{array}{l}f_{c}^{\prime e f}=r_{e c} f_{c}^{\prime} \\
r_{e c}=1+5.3278 \frac{\sigma_{c 1}}{f_{c}^{\prime}}\end{array}$ & Ec. 7-6 \\
\hline (III) Tracción-Compresión & $f_{c}^{\prime e f}=\left(1-0.8 \frac{\sigma_{c 2}}{f_{c}^{\prime}}\right) f_{t}^{\prime}$ & Ec. 7-7 \\
\hline (IV) Tracción-Tracción & \multicolumn{1}{|c|}{$f_{t}^{\prime e f}=f_{t}^{\prime}$} & Ec. 7-8 \\
\hline
\end{tabular}

1,2,3,4 Citado por Červenka V. et al. (2005) [39] 
Capítulo 7. Calibración de un modelo numérico para simular el comportamiento de soportes de hormigón armado

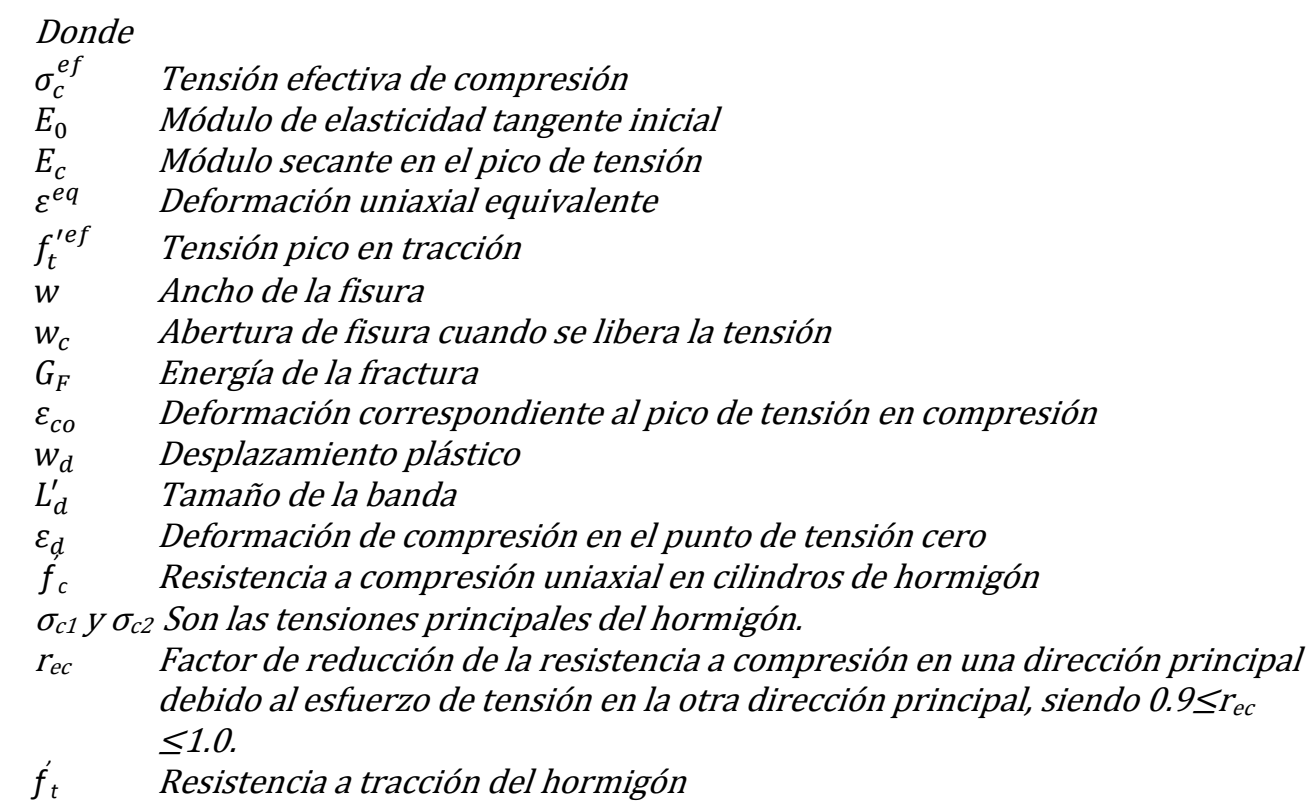

\subsubsection{PARÁMETROS DEL MODELO DEL HORMIGÓN}

El modelo constitutivo del hormigón implementado en "ATENA 2D" y utilizado en la modelización numérica es el denominado SBETA. Los parámetros necesarios para definir el modelo se resumen en la Tabla 7-3. La mayoría de los parámetros han sido utilizados por defecto, y las formulaciones se han tomado del Código Modelo CEB-FIB (1990) [33]. Sin embargo, ha sido necesario ajustar los valores de la energía de fractura $G_{F}$ y el desplazamiento de compresión crítico $W_{d}$ que define la rama post-pico del hormigón en compresión.

El modelo del hormigón "SBETA" incluye los siguientes efectos del comportamiento de este material:

- Comportamiento no lineal en compresión, incluyendo endurecimiento y ablandamiento

- Fractura del hormigón en tensión basado en la no-linealidad del mecanismo de la fractura

- Tensión biaxial en el criterio de fractura

- Reducción de la resistencia a compresión después de la fisuración

- Efecto de "tensión stiffening"

- Reducción de la rigidez de cortante después de la fisuración

- Como modelo de fisuración se utiliza el modelo rotado 
Estudio experimental y numérico de la capacidad de deformación de soportes esbeltos de hormigón armado

Tabla 7-3 Parámetros que definen el modelo constitutivo SBETA para el hormigón

\begin{tabular}{|l|ll|}
\hline \multicolumn{1}{|c|}{ Parámetro } & \multicolumn{1}{|c|}{ Fórmula } \\
\hline $\begin{array}{l}\text { Resistencia del hormigón (en probeta } \\
\text { cilíndrica) }(\mathrm{MPa})\end{array}$ & $f_{c}=-0.85 f_{c u}^{\prime}$ & Ec. 7-9 \\
\hline Módulo de elasticidad inicial (MPa) & $E_{c}=\left(6000-15.5 f^{\prime}{ }_{c u}\right) \sqrt{f_{c u}^{\prime}}$ & Ec. 7-10 \\
\hline Relación de Poisson & $v=0.2$ & Ec. 7-11 \\
\hline $\begin{array}{l}\text { Deformación del hormigón correspondiente } \\
\text { a la tensión pico } \varepsilon_{c o}\end{array}$ & $\varepsilon_{c o}=0.7\left(f_{c}^{\prime}\right)^{0.3}<2.8$ & Ec. 7-13 \\
\hline Resistencia a tracción & $f^{\prime}{ }_{t}=0.24\left(f^{\prime}{ }_{c u}\right)^{2 / 3}$ \\
\hline Tipo de rama post-pico en tracción & Exponencial \\
\hline Modelo de fisuración & Rotado \\
\hline Energía de la fractura G & $\begin{array}{l}\text { Parámetro calibrado con los ensayos } \\
\text { experimentales }\end{array}$ \\
\hline $\begin{array}{l}\text { Valor máximo de reducción de la resistencia } \\
\text { a la compresión debido a la fisuración }\end{array}$ & 0.8 \\
\hline Desplazamiento de compresión crítico & $\begin{array}{l}\text { Parámetro calibrado con losensayos } \\
\text { experimentales }\end{array}$ \\
\hline
\end{tabular}
Donde
$f_{c}^{\prime} \quad$ Resistencia del hormigón en compresión en probeta cilíndrica
$f_{c u}^{\prime} \quad$ Resistencia del hormigón en compresión en probeta cubica
$E_{c} \quad$ Modulo de elasticidad del hormigón
$v \quad$ Relación de Poisson
$\varepsilon_{c o} \quad$ Deformación del hormigón correspondiente a la tensión máxima
$f_{t}^{\prime} \quad$ Resistencia del hormigón en tracción

\subsubsection{CURVA TENSIÓN-DEFORMACIÓN DEL ACERO PARA LA ARMADURA}

En la calibración del modelo numérico se utilizó una aproximación bilineal de la curva tensión-deformación $\left(\sigma_{\mathrm{s}}-\varepsilon_{\mathrm{s}}\right)$ para el acero de la armadura. La curva real para el acero utilizado en los ensayos experimentales se obtuvo mediante ensayos de tracción, y los resultados se presentaron en el capítulo 4. En la Figura 7.4 se muestra la curva $\left(\sigma_{\mathrm{s}}-\varepsilon_{\mathrm{s}}\right)$ utilizada en la calibración de los ensayos.

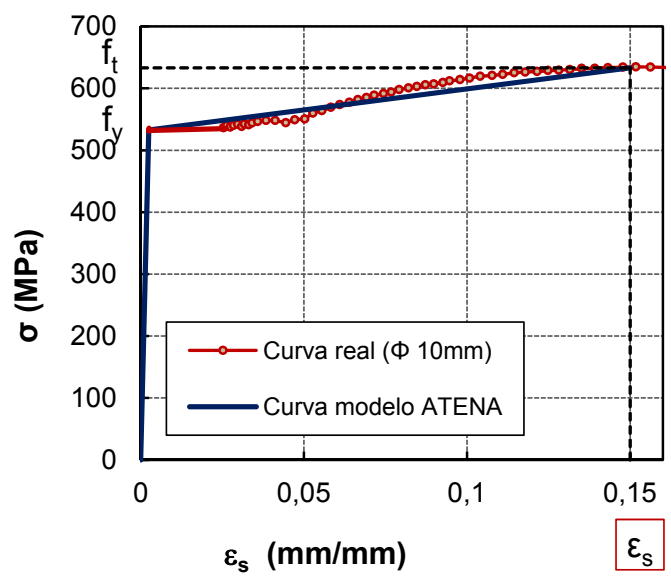

\begin{tabular}{|c|c|c|c|c|}
\hline \multicolumn{5}{|c|}{ Curva tensión-deformación del acero } \\
\hline $\begin{array}{c}\mathbf{\Phi} \\
(\mathbf{m m})\end{array}$ & $\begin{array}{c}\mathbf{f}_{\mathbf{y}} \\
(\mathbf{M P a})\end{array}$ & $\begin{array}{c}\mathbf{f}_{\mathrm{t}} \\
(\mathbf{M P a})\end{array}$ & $\begin{array}{c}\boldsymbol{\varepsilon}_{\mathbf{y}} \\
(\mathbf{\%})\end{array}$ & $\begin{array}{c}\mathbf{\varepsilon s} \\
(\mathbf{\%})\end{array}$ \\
\hline 6 & 540 & 640 & 2.70 & 15 \\
\hline 8 & 530 & 660 & 2.65 & 15 \\
\hline 10 & 530 & 640 & 2.65 & 15 \\
\hline 12 & 540 & 64 & 2.70 & 15 \\
\hline
\end{tabular}

Figura 7.4 Curva $\sigma_{s}-_{s}$ para el acero de la armadura utilizada en el modelo numérico 


\subsection{DESCRIPCIÓN DEL MODELO NUMÉRICO}

El modelo está compuesto por 4 elementos. Como se ve en la Figura 7.5, los elementos auxiliares 1 y 2 se utilizan para aplicar y transmitir la carga axial de forma uniforme. Adicionalmente, en sus extremos se definen las condiciones de apoyo del soporte. El elemento 3 funciona como un plato de carga. En el centro de su cara superior se ha definido el punto de aplicación del desplazamiento impuesto (la solución del modelo arroja los valores de carga en este punto de control). En los elementos 1,2 y 3 se ha generado un auto-mallado con elementos finitos planos triangulares de $20 \mathrm{~mm}$ de tamaño. Estos elementos tienen las propiedades de un material completamente elástico-lineal e isotrópico. El elemento 4 es el soporte real de hormigón armado. En este elemento se ha generado una malla de elementos finitos planos con cuatro nodos, utilizando un tamaño de $16 \mathrm{~mm}$ para los soportes con menor canto de la sección transversal $(140 \mathrm{~mm})$ y de $20 \mathrm{~mm}$ para los elementos de mayor canto $(200 \mathrm{~mm})$.

La carga axial se aplica en el primer paso del análisis, y luego se mantiene constante durante los demás pasos, siguiendo el mismo procedimiento que en los ensayos experimentales. En este paso inicial se utiliza el método de NewtonRaphson para resolver las ecuaciones no lineales del sistema. Posteriormente, para introducir los incrementos de carga vertical, se aplican incrementos graduales de desplazamiento en un punto específico de la placa de carga, más concretamente en el centro de su cara superior.

El método de solución numérica para resolver las ecuaciones no lineales del sistema combinado de carga axial y de flexión es el método "arc-length" junto con el método "line search". En cada uno de los pasos de carga, el incremento de desplazamiento impuesto varía entre 0.1 y $0.4 \mathrm{~mm}$ dependiendo del número de puntos necesarios para obtener la rama de descenso. En cada paso se especificó un máximo de 100 iteraciones, con errores relativos admisibles de hasta 0.001 en los resultados de desplazamiento.

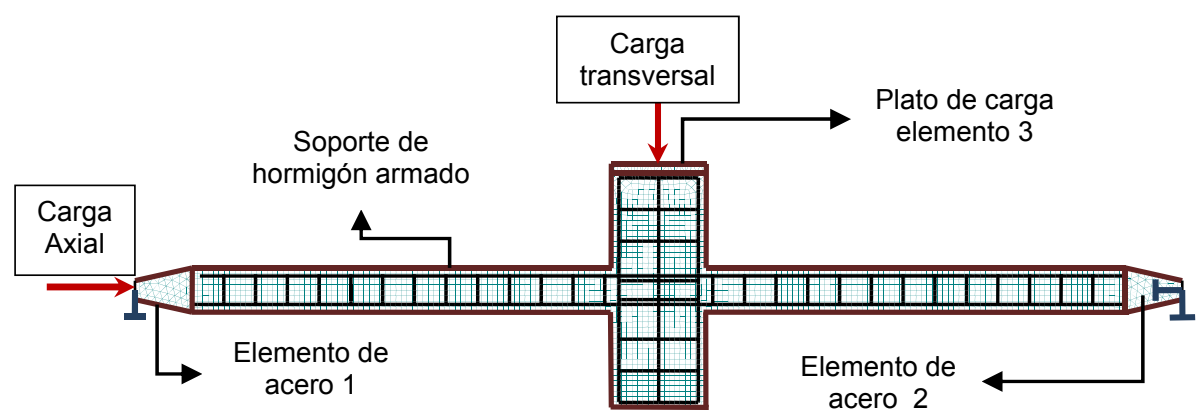

Figura 7.5 Modelo numérico

\subsubsection{RESULTADOS OBTENIDOS DEL MODELO}

El resultado más importante para la evaluación del modelo es la respuesta completa en términos del comportamiento carga-desplazamiento (V- $\delta$ ), ya que a 

hormigón armado

partir de dicha respuesta se realiza la comparación entre los resultados numéricos y los experimentales, con el propósito de validar el modelo numérico.

En la Figura 7.6, se muestran los puntos de control 1 y 2 , en los que se han obtenido los resultados de carga transversal y desplazamiento respectivamente. La deformada del soporte se obtiene a partir de los desplazamientos verticales medidos a lo largo del elemento en los nudos de control tipo 4.

Además, para verificar los resultados del modelo numérico, se han definido algunos cortes de la sección (véase Figura 7.6), con el propósito de controlar el proceso de deformación del hormigón y la deformación última alcanzada en estas secciones. Por otra parte, ATENA permite obtener las deformaciones a lo largo de la armadura longitudinal. Tanto las deformaciones del hormigón como las del acero constituyen un resultado importante para poder analizar y determinar el punto de plastificación real en la curva de respuesta $(\mathrm{V}-\delta)$.

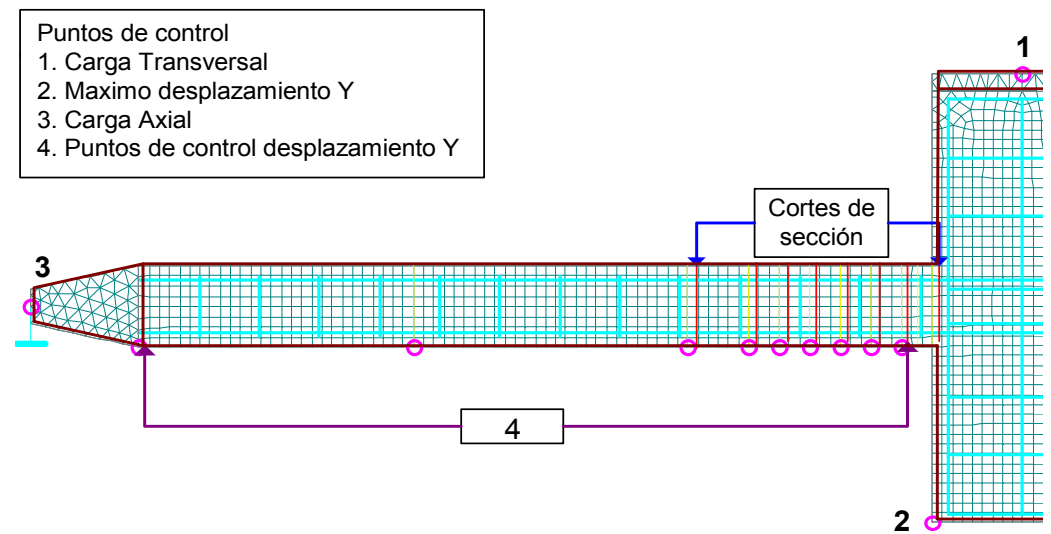

Figura 7.6 Puntos de control de carga, desplazamiento y deformaciones

\subsection{CALIBRACIÓN DEL MODELO}

En una fase anterior de la investigación, se realizó una primera calibración del modelo numérico, llevada a cabo por Bendito (2006) [23], en la cual se obtuvo una buena aproximación entre el resultado numérico y el experimental. En esta primera calibración se consiguió determinar el número y tamaño de elementos finitos que pueden ser utilizados eficientemente en el modelo numérico. Además, se encontró que, para conseguir una buena aproximación, el valor de la energía de la fractura es casi nulo. Sin embargo, para avanzar a partir de los resultados obtenidos por Bendito (2006) [23], se han revisado otros parámetros, como son: la rama de descenso de la curva constitutiva del hormigón y los efectos de adherencia y confinamiento.

En la Figura 7.7 se puede observar un ejemplo de la comparación entre la curva experimental y la obtenida numéricamente. En el anejo $\mathrm{L}$ se presenta la comparación de los resultados para todos los ensayos experimentales, a excepción de los ensayos 10,16, 18, 32 y 40, para los cuales no fue posible obtener una calibración óptima, ya que es muy posible que el efecto del pandeo de la armadura longitudinal que ha estado presente en dichos ensayos, afecte al comportamiento 
Capítulo 7. Calibración de un modelo numérico para simular el comportamiento de soportes de hormigón armado

real, mientras que, en el modelo numérico, el programa ATENA no considera dicho efecto.

En esta sección se presentan los factores más influyentes en la calibración del modelo numérico, como son:

- La energía de la fractura $G_{F}$ y el desplazamiento plástico que define la rama descendente del modelo constitutivo del hormigón $\left(\mathrm{W}_{\mathrm{d}}\right)$.

- El efecto del confinamiento del hormigón para aquellos soportes con una alta cuantía de armadura transversal. Aunque en "ATENA 2D" el efecto del confinamiento no se considera de forma directa, este se ha introducido sustituyendo los valores de resistencia del hormigón y deformación correspondiente a la tensión pico por los calculados mediante un modelo constitutivo para hormigón confinado.

- El efecto de la adherencia entre las barras longitudinales y el hormigón, para lo cual se ha implementado de forma directa uno de los modelos de adherencia disponibles en "ATENA 2D".

\subsubsection{ENERGÍA DE LA FRACTURA}

La energía de la fractura $\left(\mathrm{G}_{\mathrm{F}}\right)$ es uno de los parámetros que mayor influencia ha tenido en la calibración de los ensayos experimentales. Para conseguir un buen ajuste entre las curvas experimental y numérica, fue necesario considerar un valor casi nulo de $G_{F}$ para todos los ensayos experimentales. En la Figura 7.7 se muestra cómo, al cambiar el valor que el modelo SBETA sugiere por defecto $\left(\mathrm{G}_{\mathrm{F}}=10^{-4}\right.$ $\mathrm{MN} / \mathrm{m})$, por un valor mucho más pequeño $\left(\mathrm{G}_{\mathrm{F}}=10^{-10} \mathrm{MN} / \mathrm{m}\right)$, se logra conseguir una gran disminución en los valores de carga transversal (V) en la curva numérica, y, por consiguiente, se consigue una mayor aproximación a los valores experimentales de (V). Esto se debe a que la energía de la fractura es importante durante el proceso de fisuración por flexión, pero su importancia disminuye cuando los elementos se encuentran sujetos también a una tensión significativa de compresión constante.
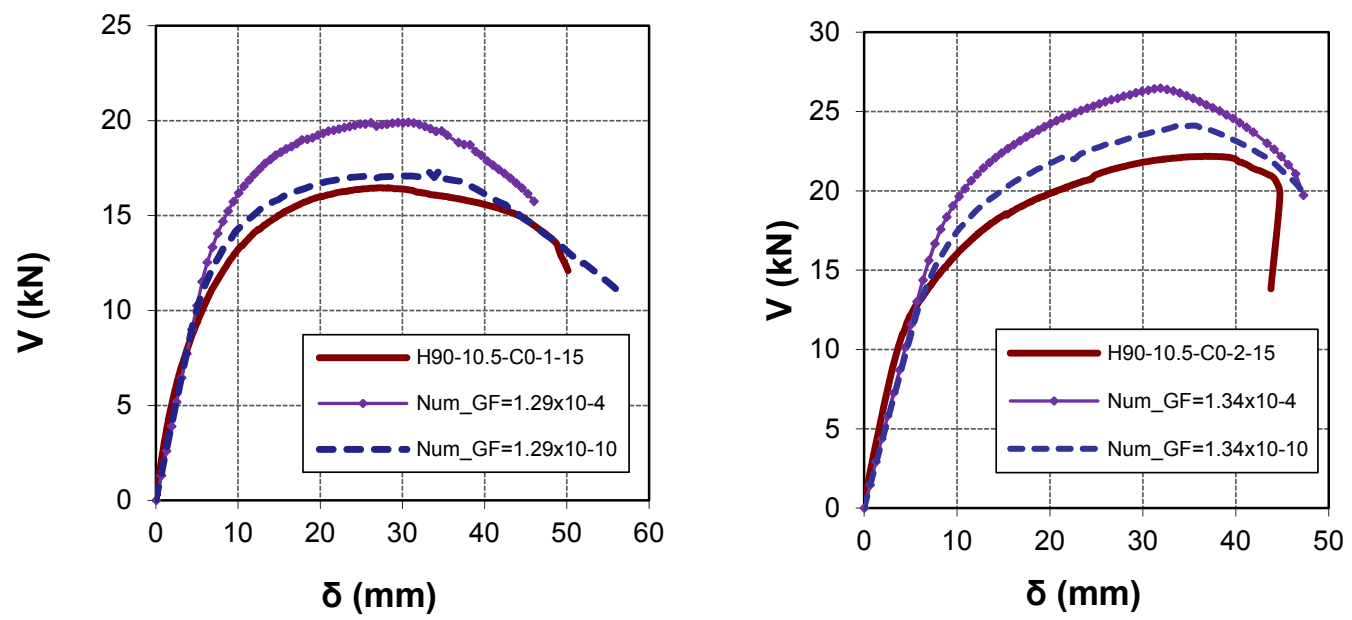

Figura 7.7 Influencia de la energía de fractura en la calibración 


\subsubsection{RAMA DE REBLANDECIMIENTO PARA EL HORMIGÓN EN COMPRESIÓN}

La rama de descenso post-pico del hormigón en compresión se define a partir del desplazamiento plástico $\left(\mathrm{W}_{\mathrm{d}}\right)$. Basándose en ensayos experimentales, Van Mier $(1982)^{5}$ sugiere que dicho desplazamiento es independiente del tamaño del elemento en compresión, siendo $\mathrm{W}_{\mathrm{d}}=0.5$ para hormigón convencional. El modelo SBETA para el hormigón asume por defecto dicho valor. Sin embargo, aún no se dispone de publicaciones que confirmen o sugieran valores de $W_{d}$ para hormigón de alta resistencia. Posteriormente, otras fuentes, como Hilleborg A. (1989) [65], consideran que la dependencia de la escala en la curva constitutiva del hormigón en compresión es la responsable de diversos factores de escala observados en el comportamiento de elementos de hormigón armado.

Teniendo en cuenta lo anterior, y, como se puede observar en la Figura 7.8, la respuesta numérica $V-\delta$ obtenida asumiendo $W_{d}=0.5$, no presenta una adecuada aproximación a la curva experimental, e incluso, en algunos casos, la curva numérica no llega a desarrollarse completamente. En consecuencia, se ha conseguido una mejor aproximación al aumentar los valores de $W_{\mathrm{d}}$. Además, se ha encontrado que el valor de $W_{d}$ no es constante para todos los valores de resistencia del hormigón, sino que este disminuye conforme aumenta la resistencia del hormigón. Esto resulta razonable, teniendo en cuenta que la pendiente de la rama de descenso aumenta con la resistencia del hormigón. Por lo tanto, los valores de $W_{d}$ con los cuales se ha obtenido una mejor aproximación entre la respuesta experimental y la numérica $\vee-\delta$ son los siguientes:

- $\mathrm{W}_{\mathrm{d}}=5 \mathrm{~mm}$ para $\mathrm{f}_{\mathrm{c}}=30 \mathrm{MPa}$

- $\mathrm{W}_{\mathrm{d}}=3.5 \mathrm{~mm}$ para $\mathrm{f}_{\mathrm{c}}=60 \mathrm{MPa}$

- $\mathrm{W}_{\mathrm{d}}=1.5 \mathrm{~mm}$ para $\mathrm{f}_{\mathrm{c}}=90 \mathrm{Mpa}$
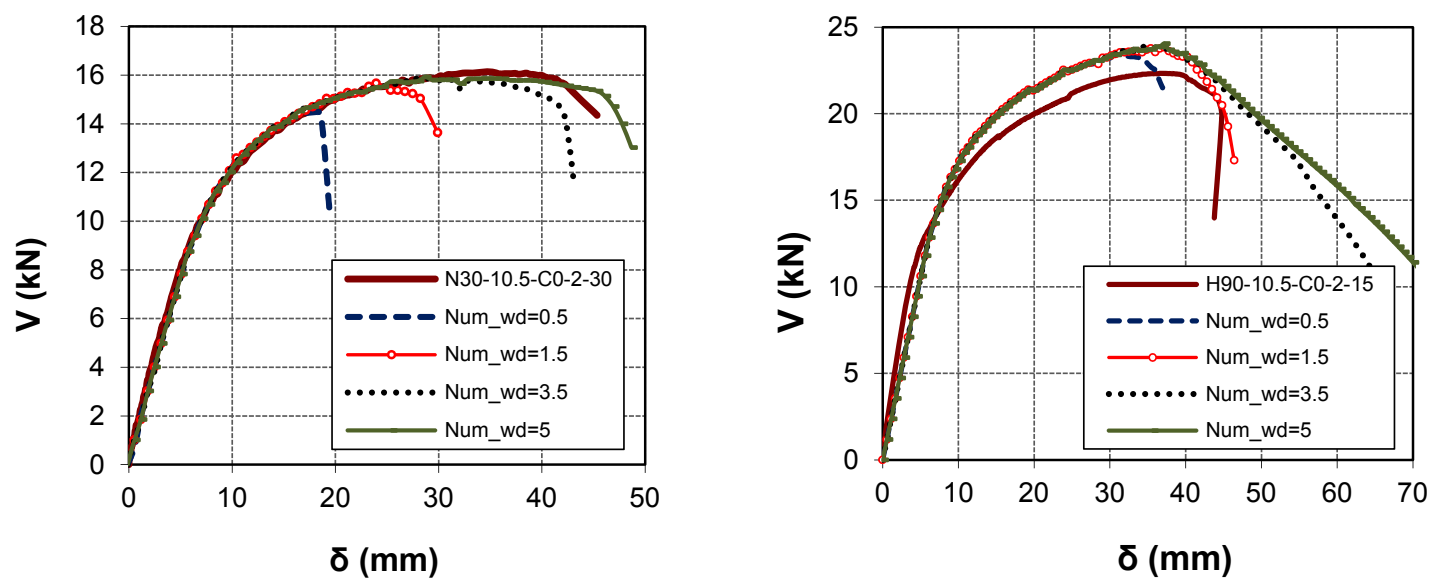

Figura 7.8 Influencia del parámetro $W_{d}$ que define la rama post-pico del hormigón en compresión

${ }^{5}$ Citado por Červenka V. et al. (2005) [39]) 


\subsubsection{MODELO DE CONFINAMIENTO}

Para tener en cuenta el efecto del confinamiento en el modelo numérico de "ATENA $2 \mathrm{D}$ ", principalmente en los soportes con cuantía de armadura transversal entre $2 \%$ y $3 \%$, el elemento completo que representa el soporte de hormigón se ha subdividido en elementos en los que se han diferenciado las propiedades del hormigón. Es decir, se han creado 2 tipos de elementos: elementos tipo 1, que representan la capa de hormigón de recubrimiento, cuyas características son las del hormigón sin confinar, y elementos tipo 2, que representan el núcleo de hormigón confinado, como se presenta en la figura 7.10. Por consiguiente, para el hormigón confinado las propiedades de resistencia y deformación en la tensión pico dadas en el modelo SBETA son modificadas por las obtenidas conforme al Código Modelo CEB FIB (1990) [33] para hormigón confinado, (véase Ec. 7-14, Ec. 7-15, Ec. 7-16). Hay que tener en cuenta que, en esta nueva composición del modelo, el tamaño del mallado que se ha generado es el mismo para todos los subelementos.

Elemento de hormigón armado compuesto por sub-elementos:

Elemento tipo 1. Capa de recubrimiento de hormigón sin confinar Elemento tipo 2. Núcleo de hormigón confinado

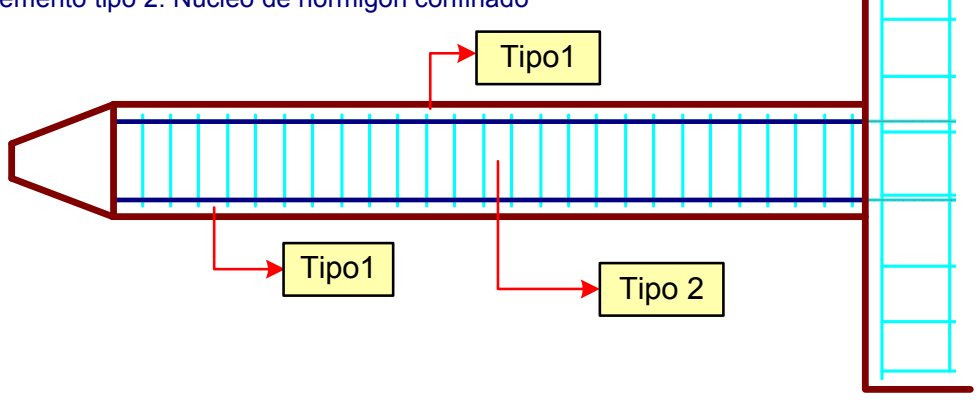

Figura 7.9 Modelo numérico para soportes confinados

$$
\begin{array}{cc}
f_{c c}^{*}=f_{c}^{\prime}\left(1.125+1.25 \alpha \varpi_{w}\right) \quad \text { for } f_{c}^{\prime} \leq 50 \mathrm{MPa} & \text { Ec. } 7-14 \\
f_{c c}^{*}=f_{c}^{\prime}\left(1+1.5 \alpha \varpi_{w}\right) \quad \text { for } f_{c}^{\prime}>50 \mathrm{MPa} & \text { Ec. } 7-15 \\
\varepsilon_{c o}^{*}=\varepsilon_{c o}+\left(f_{c c}^{*} / f_{c}^{\prime}\right)^{2} & \text { Ec. 7-16 }
\end{array}
$$

Introducir el efecto del confinamiento de esta forma ha permitido conseguir un mejor ajuste entre las curvas de respuesta experimental y numérica. En la Figura 7.10, se muestra la diferencia entre considerar el núcleo de hormigón confinado, y considerar un único modelo constitutivo del hormigón no confinado para todo el soporte. 


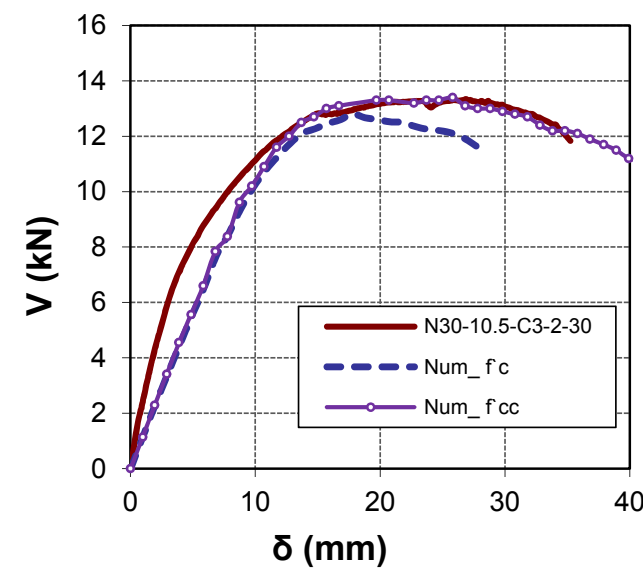

(a)

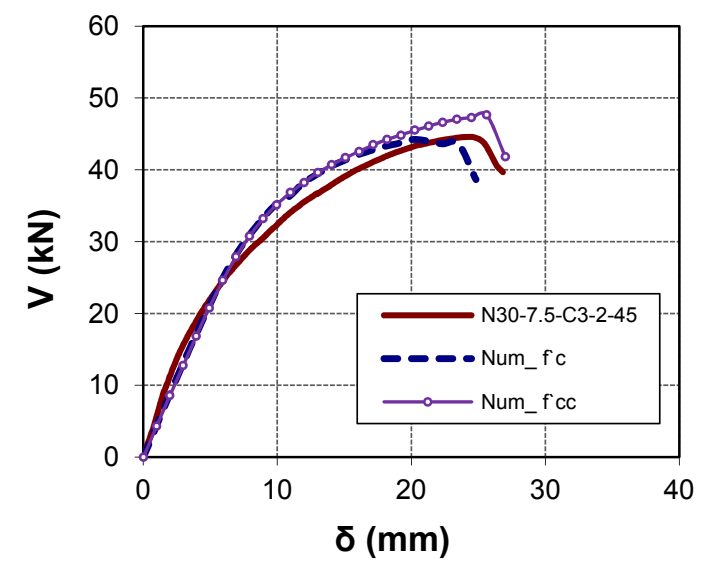

(b)

Figura 7.10 Diferencia entre considerar o no el efecto del confinamiento

\subsubsection{INCORPORACIÓN DEL MODELO DE ADHERENCIA}

En el modelo numérico se ha tenido en cuenta el efecto de la adherencia entre el hormigón y las barras de la armadura. Puesto que en los ensayos experimentales no se ha asegurado que exista una adherencia perfecta entre las barras de armadura y dado el limitado espesor del hormigón de recubrimiento, en todos los ensayos se ha incorporado el modelo de adherencia del Código modelo CEB FIB 1990 [33] disponible en "ATENA 2D" versión 3. Sistemáticamente se ha considerado que existe una escasa adherencia entre las barras y el hormigón de recubrimiento. Como se puede ver en las Figuras 7.11, el considerar el efecto de la adherencia puede en algunos casos mejorar considerablemente el ajuste entre las curvas de respuesta experimental y numérica, mientras que en otros casos puede ser ignorado.

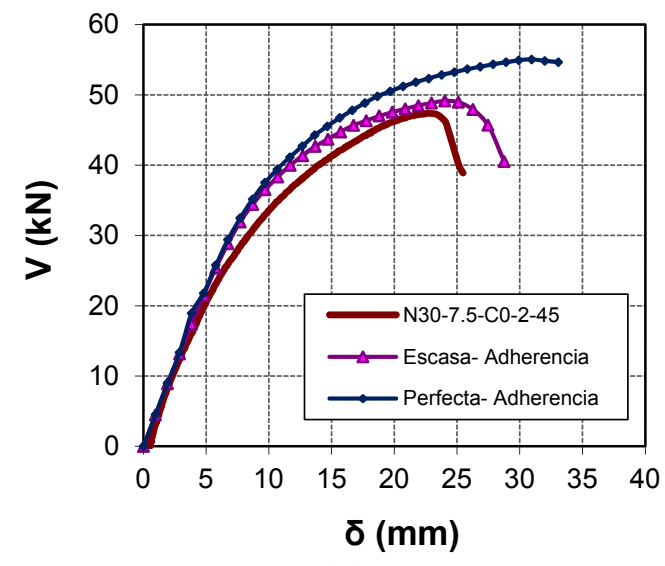

(a)

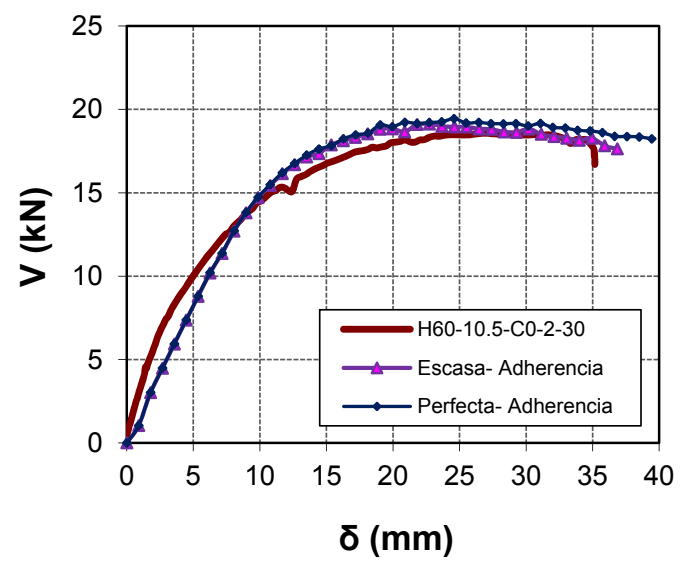

(b)

Figura 7.11 Efecto de la adherencia en el modelo numérico 


\subsection{COMPARACIÓN ENTRE LOS RESULTADOS NUMÉRICOS Y EXPERIMENTALES}

Para realizar un análisis de ajuste entre las curvas experimental y numérica, se han comparado los resultados de carga y desplazamiento para el estado de carga máxima $\left(\mathrm{V}_{\mathrm{m}}, \delta_{\mathrm{m}}\right)$, y carga ultima $\left(\mathrm{V}_{\mathrm{u}}, \delta_{\mathrm{u}}\right)$. El error se ha medido considerando la relación entre el valor numérico y el experimental para cada uno de los ensayos. $Y$ la evaluación del ajuste se determinó a partir de los parámetros estadísticos del error medio (E) y el coeficiente de variación (CV). En la Tabla 7-4 y el anejo $\mathbf{L}$ se presentan los resultados para los respectivos estados de carga máxima y carga última.

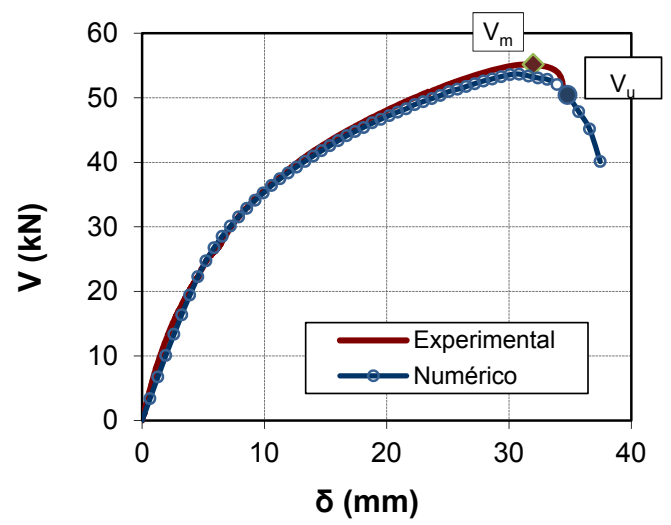

Figura 7.12 Comparación numérica y experimental para el ensayo H30-15-CO-2-30

El estado de carga última en los ensayos experimentales ocurre para una de las dos siguientes situaciones: (a) Si se consigue una importante caída de la rama de descenso, $\mathrm{V}_{\mathrm{u}}$ ocurre para el $85 \%$ de $\mathrm{V}_{\mathrm{m}}$; (b) de lo contrario, si la rama de descenso no es suficiente para conseguir el $15 \%$ de caída de $V_{m}$, entonces $V_{u}$ es el último punto de la curva $\mathrm{V}-\delta$. En consecuencia, para hacer posible la comparación entre los resultados experimentales y numéricos para el estado de carga última, tanto los valores de carga $\left(V_{u_{\text {unnum }}}\right)$ como los de desplazamiento $\left(\delta_{u_{-} \text {num }}\right)$ se obtienen en el mismo porcentaje de caída post-pico para la que ha ocurrido el fallo en la curva experimental.

Los resultados muestran una buena aproximación entre los parámetros comparados, como se muestra en la Figura 7.13, en la Figura 7.14 y en las Tablas 7-4 y 7-5. $Y$, aunque se observa una mejor aproximación de los resultados en el estado de carga máxima $\left(V_{m}\right.$ y $\left.\delta_{m}\right)$, que para la situación de carga última $V_{u}$ y $\delta_{u}$, los parámetros de error medio (E) y coeficiente de variación (CV) indican que la aproximación es bastante aceptable. La comparación muestra que el parámetro con mayor aproximación es la carga máxima $\left(\mathrm{V}_{\mathrm{m}}\right)$, y que el desplazamiento último es el que menor ajuste presenta, con un coeficiente de variación hasta del $9.1 \%$.

Tabla 7-4 Resumen de error medio y coeficiente de variación

\begin{tabular}{|l|c|c|c|c|}
\cline { 2 - 5 } \multicolumn{1}{c|}{} & \multicolumn{2}{c|}{ Estado máximo } & \multicolumn{2}{c|}{ Estado último } \\
\cline { 2 - 5 } \multicolumn{1}{c|}{} & $\mathrm{V}_{\mathrm{m} \_ \text {num }} / \mathrm{V}_{\mathrm{m} \_\exp }$ & $\delta_{\mathrm{m} \text { num }} / \delta_{\mathrm{m} \_\exp }$ & $\mathrm{V}_{\mathrm{u} \_ \text {num }} / \mathrm{V}_{\mathrm{u} \_\exp }$ & $\delta_{\mathrm{u} \_ \text {num }} / \delta_{\mathrm{u} \_\exp }$ \\
\hline$\overline{\mathrm{E}}$ & 1.038 & 1.026 & 1.041 & 1.053 \\
\hline $\mathrm{CV}$ & 0.053 & 0.080 & 0.047 & 0.091 \\
\hline
\end{tabular}


En la tabla 7.5 se presentan los resultados del error promedio ( $\overline{\mathbf{E}})$ y el coeficiente de variación (CV) respecto a los parámetros del estudio experimental: resistencia a compresión del hormigón $\left(f_{c}^{\prime}\right)$, nivel de carga axil $\left(N / N_{u}\right)$, esbeltez geométrica $(\lambda)$, cuantía longitudinal $\left(\rho_{\mathrm{I}}\right)$ y cuantía transversal $\left(\rho_{\mathrm{s}}\right)$. Se ha demostrado que existe un buen ajuste de los resultados con respecto a todos los parámetros. Por consiguiente, se concluye que el modelo numérico obtenido se puede utilizar para el estudio de un amplio rango de parámetros.

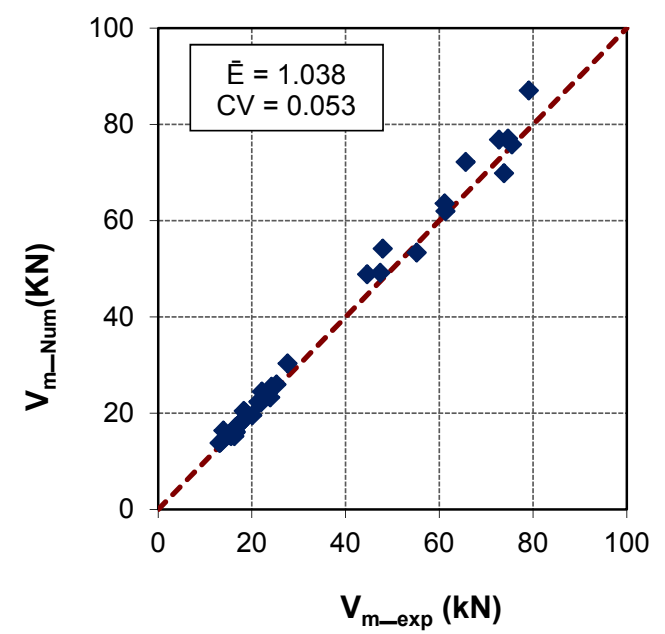

(a)

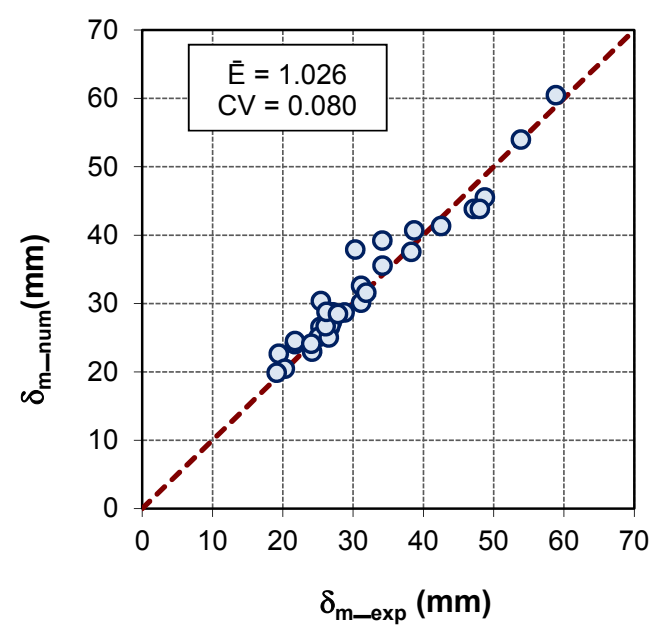

(b)

Figura 7.13 Comparación entre los resultados numéricos y experimentales de (a) carga (b) desplazamiento en el punto de carga máxima

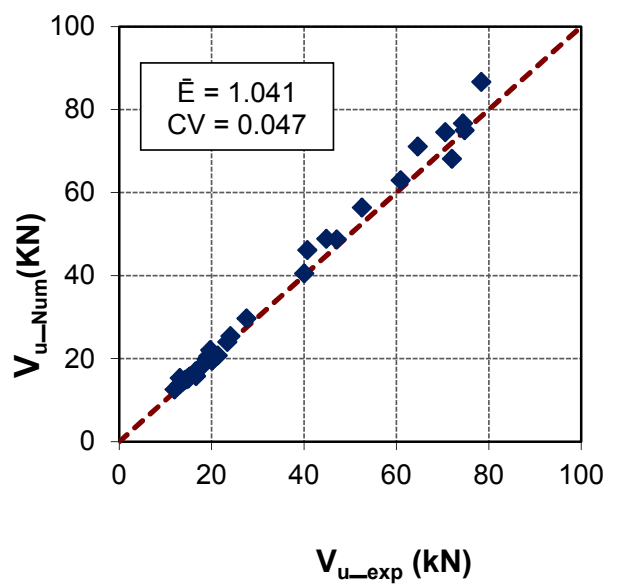

(a)

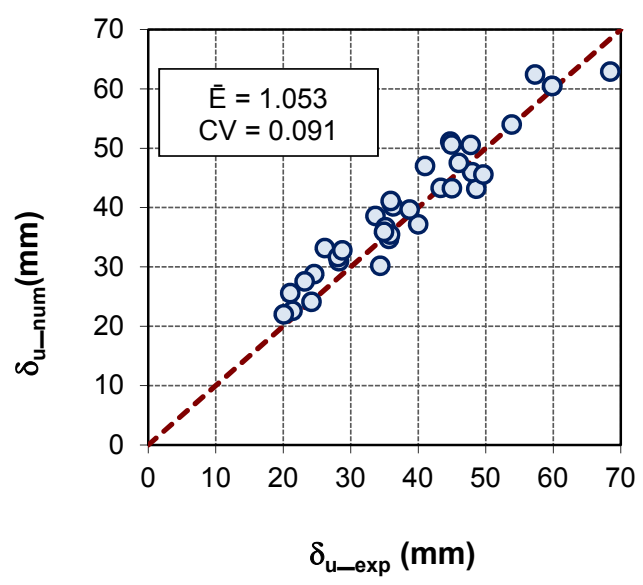

(b)

Figura 7.14 Comparación entre los resultados numéricos y experimentales de: (a) carga y (b) desplazamiento en el punto de carga última 
Capítulo 7. Calibración de un modelo numérico para simular el comportamiento de soportes de hormigón armado

Tabla 7-5 Evaluación de la calibración con respecto a los parámetros del estudio experimental

\begin{tabular}{|c|c|c|c|c|c|c|c|c|c|}
\hline & & \multicolumn{4}{|c|}{ Estado máximo } & \multicolumn{4}{|c|}{ Estado último } \\
\hline \multirow{2}{*}{\multicolumn{2}{|c|}{ Variable }} & \multicolumn{2}{|c|}{ Fuerza } & \multicolumn{2}{|c|}{ Desplazamiento } & \multicolumn{2}{|c|}{ Fuerza } & \multicolumn{2}{|c|}{ Desplazamiento } \\
\hline & & $\bar{E}$ & $\mathrm{CV}$ & $\bar{E}$ & $\mathrm{CV}$ & $\bar{E}$ & $\mathrm{CV}$ & $\bar{E}$ & $\mathrm{CV}$ \\
\hline \multirow{3}{*}{$\begin{array}{c}f_{c}^{\prime} \\
(\mathrm{MPa})\end{array}$} & 30 & 1.04 & 0.07 & 1.01 & 0.08 & 1.06 & 0.05 & 1.03 & 0.09 \\
\hline & 60 & 1.04 & 0.05 & 1.04 & 0.10 & 1.02 & 0.04 & 1.05 & 0.08 \\
\hline & 90 & 1.04 & 0.04 & 1.04 & 0.07 & 1.04 & 0.04 & 1.08 & 0.09 \\
\hline \multirow{4}{*}{$\mathrm{N} / \mathrm{Nu}$} & 0.00 & 1.02 & 0.04 & 0.96 & 0.10 & 1.02 & 0.04 & 0.98 & 0.05 \\
\hline & 0.15 & 1.06 & 0.03 & 1.03 & 0.12 & 1.06 & 0.03 & 1.05 & 0.09 \\
\hline & 0.30 & 1.04 & 0.06 & 1.02 & 0.06 & 1.04 & 0.06 & 1.06 & 0.09 \\
\hline & 0.45 & 1.02 & 0.05 & 1.05 & 0.07 & 1.04 & 0.04 & 1.08 & 0.10 \\
\hline \multirow{2}{*}{$\lambda$} & 7.5 & 1.04 & 0.05 & 1.01 & 0.08 & 1.04 & 0.05 & 1.02 & 0.08 \\
\hline & 10.7 & 1.04 & 0.05 & 1.06 & 0.07 & 1.05 & 0.05 & 1.12 & 0.08 \\
\hline \multirow{3}{*}{$\rho_{1}(\%)$} & 1.4 & 1.02 & 0.02 & 1.06 & 0.12 & 1.03 & 0.01 & 1.04 & 0.11 \\
\hline & 2.2 & 1.04 & 0.06 & 1.04 & 0.07 & 1.05 & 0.05 & 1.06 & 0.09 \\
\hline & 3.2 & 1.05 & 0.05 & 0.96 & 0.04 & 1.02 & 0.05 & 1.02 & 0.08 \\
\hline \multirow{3}{*}{$\begin{array}{l}\text { ps } \\
(\%)\end{array}$} & 1.0 & 1.03 & 0.05 & 1.03 & 0.09 & 1.03 & 0.04 & 1.05 & 0.10 \\
\hline & 2.0 & 1.05 & 0.01 & 1.03 & 0.01 & 1.04 & 0.02 & 1.12 & 0.03 \\
\hline & 3.0 & 1.06 & 0.07 & 1.02 & 0.05 & 1.07 & 0.06 & 1.05 & 0.05 \\
\hline
\end{tabular}

\subsection{CONSIDERACIONES FINALES}

Se concluye por lo tanto que la herramienta numérica se ha calibrado y puede utilizarse para modelizar estructuras de hormigón armado con comportamiento similar.

En esta sección se presenta un modelo numérico utilizando el programa "ATENA 2D" de análisis no lineal, capaz de reproducir la respuesta $V-\delta$ de soportes de hormigón sometidos a compresión y flexión monotónica. Esto ha permitido llevar a cabo una investigación posterior más amplia que incluye el estudio paramétrico de los factores que más influyen en la capacidad de deformación de soportes esbeltos de hormigón convencional y de alta resistencia.

El programa "ATENA 2D" es una importante herramienta numérica, útil en la modelización de elementos de hormigón, puesto que una vez más la comparación entre las curvas de respuesta numérica y experimental ha mostrado que la aproximación es adecuada.

Las variables utilizadas en la evaluación de la aproximación ( $\mathrm{A}$ y CV) no presentan valores demasiado altos con respecto a los parámetros evaluados en la calibración, $\mathrm{y}$, por consiguiente, se considera que el modelo es bastante fiable para ser utilizado en la modelización de elementos estructurales bajo las mismas condiciones de borde, si se quieren ampliar los rangos de los parámetros considerados en este estudio.

Las variables $G_{F}, W_{d}$, y los efectos de adherencia y el confinamiento del hormigón han sido los parámetros que han mostrado mayor sensibilidad en el ajuste entre las curvas numérica y experimental. 
En términos generales, el modelo sobrestima los resultados de carga en aproximadamente un $4 \%$ y los desplazamientos en estado de carga máxima hasta en un $2.6 \%$, mientras que para la carga última la sobrestimación es del $5.3 \%$. Aun así, estos valores son bajos y, por consiguiente, se considera que el modelo numérico es acertado y puede ser implementado para llevar a cabo un estudio paramétrico de los factores que mayor influencia tienen en la capacidad de deformación de soportes de hormigón sometidos a flexo-compresión recta. 


\section{CAPÍTULO 8}

ESTUDIO PARAMÉTRICO

Utilizando el modelo numérico implementado en el programa de análisis no lineal ATENA 2D, y en base a su calibración, se ha desarrollado un estudio paramétrico del comportamiento deformacional de elementos de hormigón convencional y de alta resistencia sometidos a flexo-compresión recta. En este estudio se pretende evaluar la influencia de los principales parámetros que afectan al comportamiento deformacional y al factor de ductilidad de desplazamiento. Los parámetros analizados se corresponden con los ya tratados en el estudio experimental, llevándose a cabo una ampliación de los rangos de estudio.

Este estudio servirá de base para definir los métodos simplificados propuestos en esta tesis (capítulo 10), con la finalidad de evaluar la capacidad de deformación en elementos de hormigón armado. 


\subsection{PARÁMETROS DE ESTUDIO}

En el estudio paramétrico se han incluido los siguientes parámetros: nivel de carga axial, esbeltez geométrica, resistencia del hormigón, cuantía de armadura longitudinal y cuantía de armadura transversal. A continuación, se abordan las razones teórico-prácticas que justifican la elección de dichos parámetros, así como algunos de los aspectos que ya han sido tratados en estudios anteriores.

\subsubsection{NIVEL DE CARGA AXIAL}

El nivel de carga axial $\left(\mathrm{N} / \mathrm{N}_{\mathrm{u}}\right)$ es uno de los parámetros clave en el estudio de la deformabilidad de elementos de hormigón armado sometidos a flexo-compresión. En primer lugar, la combinación del $N / N_{u}$ y la esbeltez de cortante $(L / h)$ da origen a los efectos de segundo orden, los cuales pueden dar lugar al fallo por inestabilidad del elemento, lo que significa una reducción en la capacidad de desplazamiento y en la ductilidad. En segundo lugar, la influencia de otros parámetros, como la resistencia del hormigón, la cuantía de armadura longitudinal y la cuantía de armadura transversal, puede estar condicionada por la interacción con el nivel de carga axial. Teóricamente, el efecto de cada uno de los parámetros puede tener una mayor o menor implicación dentro de un rango de niveles de carga axial. Por esta razón, en el estudio, los parámetros analizados son evaluados dentro de un rango de valores de carga axial, con el objeto de identificar su comportamiento conjunto.

\subsubsection{ESBELTEZ GEOMÉTRICA}

El efecto de la esbeltez en la deformabilidad de elementos de hormigón se debe esencialmente a su implicación dentro de la no linealidad geométrica, lo cual conlleva la modificación no sólo de la capacidad resistente, sino también de su capacidad de deformación. En elementos esbeltos de hormigón, el fallo se produce anticipadamente a causa de la inestabilidad del elemento, de modo que la deformación del mismo se debe más a los efectos de la no linealidad geométrica que a la no linealidad de los materiales. Esto provoca un descenso súbito de la carga en la rama post-pico, y, por lo tanto, la capacidad de deformación se ve disminuida. En la Figura 8.1 se muestra la reducción de resistencia y de ductilidad de elementos con iguales propiedades mecánicas y geométricas de la sección transversal, e igual nivel de carga axial, pero diferente esbeltez de cortante $\left(\lambda=L_{s} / H\right)$. El incremento de los efectos de segundo orden en el soporte esbelto $(\lambda=9)$, no sólo logra reducir la resistencia, sino también la energía disipada bajo la curva de respuesta $\mathrm{P}-\delta$ y, en consecuencia, la ductilidad.

Como se ha mencionado en el estado del arte (capítulo 2) y, más adelante, en la justificación del estudio (capítulo 3), la influencia del parámetro esbeltez de cortante en la capacidad de deformación y de ductilidad de elementos de hormigón armado, ha sido estudiada especialmente para valores inferiores a 6 . Este estudio comprende el análisis de un amplio rango de esbelteces, que incluye tanto elementos poco esbeltos ( $\lambda=3.5$ y $\lambda=5.0)$, como elementos esbeltos $(\lambda=7.5, \lambda=9.0$ y 10.5), sabiendo que, para estos últimos, la investigación previa ha sido escasa. En muchos casos, la utilización de hormigón de alta resistencia hace posible el uso de 
una menor sección transversal, consiguiendo de esta manera elementos más esbeltos. Esto significa que la evaluación de los efectos de la esbeltez en elementos de hormigón de alta resistencia puede ser más relevante que en elementos de hormigón convencional.

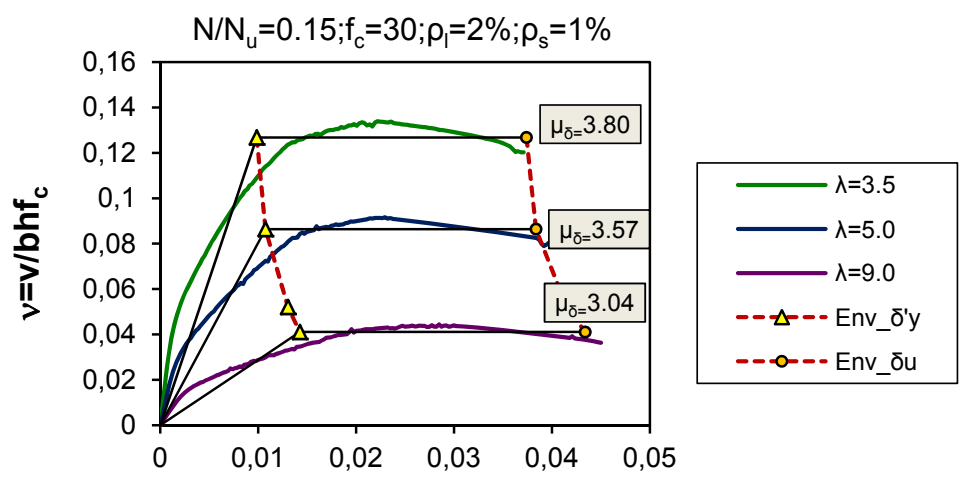

$\delta / L$

Figura 8.1 Comparación de la respuesta adimensional carga-desplazamiento, para elementos con igual sección transversal y diferente esbeltez de cortante

\subsubsection{LA RESISTENCIA DEL HORMIGÓN}

Los elementos de hormigón armado poseen un comportamiento dúctil que varía de acuerdo con las propiedades mecánicas y de deformación del hormigón. Esto implica que es necesario identificar las diferencias existentes entre el comportamiento tensión-deformación del hormigón de alta resistencia (HAR) y el del hormigón convencional $(\mathrm{HC})$, para así poder establecer su influencia en la capacidad de deformación y de ductilidad de elementos de hormigón armado. Las diferencias más significativas que se han identificado entre el hormigón convencional y el hormigón de alta resistencia, son las siguientes:

- Para el HAR, la curva tensión-deformación en compresión permanece lineal prácticamente hasta la tensión última.

- La deformación en el punto de máxima tensión aumenta con la resistencia en compresión.

- La típica deformación última de compresión disminuye cuando la resistencia aumenta.

- El modo de fallo del HAR en compresión es más frágil comparado con el HC.

- La curva post-pico empieza a tener una mayor pendiente cuando la resistencia aumenta; por consiguiente, se reduce la ductilidad.

- En el HAR no se observa el notable aumento de la ductilidad que se produce después de la tensión máxima, a causa de la propagación de microfisuras que dan lugar a una disipación de energía, como es el caso del hormigón convencional.

En base a lo anterior, los elementos de hormigón de alta resistencia pueden tener un comportamiento menos dúctil que los elementos de hormigón convencional. Sin embargo, la influencia de las características del hormigón depende de la interacción 

hormigón armado

con otras variables (cuantía de armadura, nivel de carga axial, confinamiento, etc.), lo cual definirá el tipo de fallo. Esto implica que la influencia de las propiedades mecánicas y deformacionales del hormigón está ligada principalmente al tipo de rotura del elemento, siendo más evidente en elementos en los que se presenta un fallo por rotura del hormigón en compresión, más que cuando el fallo del elemento está ligado a la rotura de la armadura de tracción.

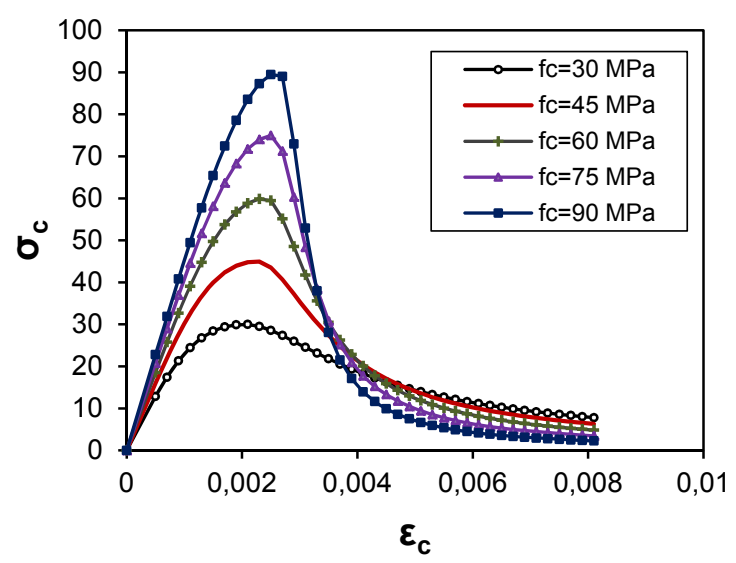

Figura 8.2 Relación tensión-deformación para diferentes resistencias del hormigón

En anteriores estudios experimentales se han identificado algunos aspectos que diferencian el comportamiento dúctil de elementos de hormigón de alta resistencia y hormigón convencional.

- Pecce y Fabbrocino (1999) [105], y Bigaj (1999) [25] sostienen que, debido a la fragilidad del hormigón de alta resistencia, pueden darse varios fenómenos de fallo local en elementos de HAR (como, por ejemplo, la pérdida prematura del recubrimiento del hormigón), lo cual conlleva una reducción de la ductilidad y de la reserva de deformación post-pico.

- Es evidente que la resistencia del hormigón tiene una influencia crucial en la ductilidad de los elementos, tanto si están sometidos a bajos como a altos niveles de carga axial; cuanto mayor es la resistencia del hormigón, menor es la ductilidad. Sin embargo, los soportes de HAR pueden llegar a comportarse de forma dúctil si cuentan con una adecuada cuantía de armadura transversal (Légeron y Paultre (2003) [79], Saatcioglu y Razvi (1992) [115], Bayrak y Sheik (1998) [16], Mendis (2001) [92]).

\subsubsection{CUANTÍA DE ARMADURA LONGITUDINAL}

En elementos sometidos a esfuerzos combinados de flexión y compresión axial, la influencia de la cuantía de armadura longitudinal no es tan evidente, y dependerá del nivel de carga axial, de la resistencia del hormigón y de la esbeltez de cortante. La combinación de los factores da lugar a que el incremento de la cuantía longitudinal origine un efecto variable para los diferentes rangos de parámetros y estados de carga (elástico y último), y, consecuentemente, el efecto sobre la ductilidad también será variable. 
Experimentalmente, lo que se conoce del efecto de la cuantía de armadura longitudinal se refiere a elementos con poca esbeltez y en estado último. Normalmente, cabe esperar que, para bajos niveles de carga axial, la ductilidad disminuya con el aumento de la cuantía de armadura longitudinal, mientras que, para altos niveles de carga axial, el efecto es inverso y la ductilidad puede aumentar con una mayor disposición de cuantía de armadura, incremento que puede no ser tan apreciable.

En realidad, el efecto de la cuantía de armadura está ligado al tipo de rotura. Por un lado, si se produce la rotura por agotamiento de la armadura en tracción, es evidente que el incremento de la cuantía de armadura provoca una disminución en el desplazamiento último. Por otra parte, en elementos con predominio de fallo del hormigón en compresión, el aumento de la cuantía de armadura longitudinal permitirá que la profundidad de la fibra neutra disminuya $y$, por consiguiente, se obtendrá un incremento en el desplazamiento último.

\subsubsection{ARMADURA TRANSVERSAL}

La armadura transversal influye en la capacidad de deformación de elementos de hormigón armado de diversas maneras; la consecuencia más importante es el confinamiento del hormigón en la zona de compresión, de modo que un aumento en la cuantía transversal contribuye favorablemente a la deformabilidad del hormigón, $y$, por lo tanto, es de esperar un aumento de la ductilidad en elementos de hormigón armado.

En elementos sometidos a flexo-compresión, el efecto de la armadura transversal en la capacidad de deformación ha sido ampliamente estudiado, tanto teórica como experimentalmente (Priestley y Park (1987) [110], Légeron y Paultre (2003) [79], Razvi y Saatcioglu (1994) [113], Sheikh et al. (1993) [121], (1994) [122]). Dichos estudios han destacado la diferencia entre el comportamiento dúctil de soportes de hormigón de alta resistencia y de hormigón convencional, manifestada en el hecho de que la presión de confinamiento lateral requerida para elementos de HAR es significativamente mayor que para soportes de HC. Por otro lado, como es sabido, la deformabilidad de soportes de hormigón disminuye con la compresión axial. Sin embargo, es posible obtener altas deformabilidades para elementos de HAR muy comprimidos, cuando la cuantía y/o resistencia de la armadura de confinamiento aumenta. En definitiva, Saatcioglu y Razvi 2002 [114] manifiestan que la ganancia en deformabilidad y resistencia debida al confinamiento es independiente de la resistencia del hormigón, aunque el porcentaje del aumento es menor en hormigón de alta resistencia. Por lo tanto, los soportes de HAR requieren proporcionalmente más confinamiento que los de hormigón convencional para obtener una deformabilidad similar.

En realidad, el comportamiento dúctil de los soportes depende de la interacción de diferentes variables, como, por ejemplo, el nivel de carga axial, la esbeltez geométrica, la resistencia del hormigón y el confinamiento transversal, entre otros. En lo que respecta a la cuantía de armadura transversal, los estudios realizados por Mendis et al. [91], [92], y Legeron y Paultre [78], [79] han destacado la necesidad de incluir el nivel de carga axial como parámetro indispensable en el cálculo de la cuantía de armadura transversal necesaria para garantizar un adecuado confinamiento del elemento y una apropiada ductilidad. Dicho parámetro ya ha sido 

hormigón armado

tenido en cuenta en algunas normas, como la EHE 08 (2008) [53], con el mismo propósito. Los estudios mencionados también han demostrado que el comportamiento de los soportes de hormigón se encuentra más afectado por el nivel de carga axial que por la propia cuantía y disposición de la armadura transversal.

Finalmente, se han identificado dentro de la bibliografía otros aspectos que influyen en el efecto del confinamiento, y, por consiguiente, en la capacidad de deformación de los soportes de hormigón armado, como por ejemplo: la disposición de la armadura transversal, la separación de los cercos, la calidad del acero y la relación entre las áreas del núcleo y de recubrimiento. Todos ellos han sido estudiados de alguna manera, pero su influencia todavía no está suficientemente clara, por lo que siguen siendo motivo de estudio.

\subsection{PROGRAMA DE ENSAYOS NUMÉRICOS}

Para llevar a cabo el estudio paramétrico se han realizado en total 216 ensayos numéricos, en elementos de hormigón convencional y de alta resistencia sometidos a flexo-compresión recta, utilizando el mismo modelo de ensayo obtenido en la calibración. Los rangos de las variables estudiadas son los siguientes:

Nivel de Carga axil (N/Nu). Este parámetro ha sido estudiado en un rango entre el $7.5 \%$ y el $60 \%$ del axil último calculado mediante la Ec. 8-1. Las normas EHE 08 (2008) [53], Eurocódigo 2 (2004) [58] y ACI 318-08 (2008) [1] especifican el 10\% del axil reducido $\left(A_{c} f_{c}\right)$, como valor límite inferior para considerar al elemento como un soporte sometido a flexo-compresión. Por otra parte, las normas EHE 08 (2008) [53] y Eurocódigo 2 (2004) [58] también consideran el valor de $0.65 \mathrm{~A}_{c} \mathrm{f}_{\mathrm{c}}$ como el límite máximo de carga axial que puede ser soportado por columnas diseñadas bajo consideraciones sismorresistentes. Por esta razón, el rango de estudio se encuentra próximo a estos dos límites.

$$
N_{u}=b \cdot h \cdot f_{c}+\sigma_{s} \cdot A_{s} \rightarrow \sigma_{s}=\varepsilon_{c 1} \cdot E_{s} \leq f_{y} \quad \text { Ec. 8-1 }
$$

$\begin{array}{ll}\text { Donde: } & \\ b & \text { Ancho de la sección transversal } \\ h & \text { Canto de la sección transversal } \\ f_{c} & \text { Resistencia del hormigón en compresión } \\ A_{s} & \text { Área de armadura longitudinal } \\ E_{S} & \text { Módulo de elasticidad del acero (200.000 MPa) } \\ f_{y} & \text { Límite elástico del acero } \\ \varepsilon_{c 1} & \text { Deformación para la tensión pico del hormigón, } \varepsilon_{c 1}(\% 0)=0.7 \cdot f_{c}^{0.31}<2.8\end{array}$

Esbeltez de cortante $(\lambda=L s / h)$. Para el estudio de este parámetro se han utilizado los valores de $3.5,5,7.5,9$ y 10.5. La sección implementada en los ensayos numéricos es de $0.15 \mathrm{~m}$ de ancho y $0.2 \mathrm{~m}$ de altura, a excepción de la esbeltez de 10.5, en la que se ha utilizado la misma sección que en los ensayos experimentales $(0.15 \mathrm{~m} \times 0.14 \mathrm{~m})$; el recubrimiento mecánico $\left(r_{\mathrm{mec}}\right)$ es de $30 \mathrm{~mm}$ para la sección de mayor área y $21 \mathrm{~mm}$ para la sección menor. De modo que, la relación $r_{\text {med }} / \mathrm{h}=0.15$ es constante para las dos secciones, siendo h el canto de la sección (Tabla 8-1). 
Tabla 8-1 Tipo de secciones utilizadas en el modelo numérico

\begin{tabular}{|c|c|c|c|c|c|}
\hline & \multicolumn{2}{|c|}{ Tipo de sección } & & $\lambda=\mathrm{Ls} / \mathrm{h}$ & Ls (m) \\
\hline & $0.15 \mathrm{~m}$ & \multirow{4}{*}{\begin{tabular}{l}
$\varepsilon$ \\
\multirow{2}{*}{}
\end{tabular}} & \multirow{4}{*}{ As" } & 3.5 & 0.7 \\
\hline & & & & 50 & 10 \\
\hline & & & & 7.5 & 1.5 \\
\hline & & & & 9.0 & 1.8 \\
\hline & $0.15 \mathrm{~m}$ & & & & \\
\hline As & & $\underset{\sigma}{\varepsilon}$ & & 10.5 & 1.5 \\
\hline & 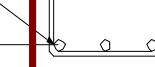 & & As" & & \\
\hline
\end{tabular}

Resistencia del hormigón. El rango de resistencias del hormigón estudiado está entre $30 \mathrm{MPa}$ y $90 \mathrm{MPa}$. En la Tabla 8-2 se muestra la relación de ensayos numéricos ejecutados con la finalidad de analizar el efecto del nivel de carga axial, esbeltez de cortante y resistencia del hormigón.

Tabla 8-2 Relación de ensayos numéricos llevados a cabo para analizar los parámetros de nivel de carga axial, esbeltez de cortante y resistencia del hormigón

\begin{tabular}{|c|c|c|c|c|c|c|c|c|c|c|}
\hline$\lambda=L / h$ & $\begin{array}{c}\rho_{1} \\
(\%)\end{array}$ & $\begin{array}{c}\rho_{\mathrm{s}} \\
(\%)\end{array}$ & $\begin{array}{c}f_{c} \\
(\mathrm{MPa})\end{array}$ & \multicolumn{6}{|c|}{$\mathrm{N} / \mathrm{N}_{\mathrm{u}}(\%)$} & $\begin{array}{c}\mathbf{N}^{\circ} \text { de } \\
\text { ensayos }\end{array}$ \\
\hline \multirow[t]{5}{*}{10.5} & \multirow[t]{5}{*}{2.2} & \multirow[t]{5}{*}{1} & 30 & 7.5 & 15 & 22.5 & 30 & 45 & 60 & 6 \\
\hline & & & 45 & 7.5 & 15 & 22.5 & 30 & 45 & 60 & 6 \\
\hline & & & 60 & 7.5 & 15 & 22.5 & 30 & 45 & 60 & 6 \\
\hline & & & 75 & & 15 & & 30 & 45 & & 3 \\
\hline & & & 90 & 7.5 & 15 & 22.5 & 30 & 45 & 60 & 6 \\
\hline \multirow[t]{3}{*}{9} & \multirow[t]{3}{*}{2.2} & \multirow[t]{3}{*}{1} & 30 & 7.5 & 15 & 22.5 & 30 & 45 & 60 & 6 \\
\hline & & & 60 & 7.5 & 15 & 22.5 & 30 & 45 & 60 & 6 \\
\hline & & & 90 & 7.5 & 15 & 22.5 & 30 & 45 & 60 & 6 \\
\hline \multirow[t]{5}{*}{7.5} & \multirow[t]{5}{*}{2.2} & \multirow[t]{5}{*}{1} & 30 & 7.5 & 15 & 22.5 & 30 & 45 & 60 & 6 \\
\hline & & & 45 & 7.5 & 15 & 22.5 & 30 & 45 & 60 & 6 \\
\hline & & & 60 & 7.5 & 15 & 22.5 & 30 & 45 & 60 & 6 \\
\hline & & & 75 & & 15 & & 30 & 45 & & 3 \\
\hline & & & 90 & 7.5 & 15 & 22.5 & 30 & 45 & 60 & 6 \\
\hline \multirow[t]{3}{*}{5} & \multirow[t]{3}{*}{2.2} & \multirow[t]{3}{*}{1} & 30 & 7.5 & 15 & 22.5 & 30 & 45 & 60 & 6 \\
\hline & & & 60 & 7.5 & 15 & 22.5 & 30 & 45 & 60 & 6 \\
\hline & & & 90 & 7.5 & 15 & 22.5 & 30 & 45 & 60 & 6 \\
\hline \multirow[t]{3}{*}{3.5} & \multirow[t]{3}{*}{2.2} & \multirow[t]{3}{*}{1} & 30 & 7.5 & 15 & 22.5 & 30 & 45 & 60 & 6 \\
\hline & & & 60 & 7.5 & 15 & 22.5 & 30 & 45 & 60 & 6 \\
\hline & & & 90 & 7.5 & 15 & 22.5 & 30 & 45 & 60 & 6 \\
\hline & & & & & tal & ensay & s nu & méri & & 108 \\
\hline
\end{tabular}

Cuantía de armadura longitudinal $\left(\rho_{I}\right)$. La cuantía de armadura longitudinal está distribuida en tres barras en la parte superior y otras tres en la inferior, tal y como aparece en la descripción del tipo de sección en la Tabla 8-1. Los valores de $\rho_{1}$ adoptados en el estudio son: $1.2 \%, 2.2 \%, 3.2 \%$ y $4.2 \%$. El valor mínimo es superior a la cuantía mínima $\left(\rho_{\text {Imin }}=0.4 \%\right)$ establecida en la norma EHE-08 [53], y en la norma $\mathrm{ACl} 318-08$ [1] $\left(\rho_{\mathrm{Imin}}=1.0 \%\right)$. La cuantía máxima especificada en la norma $\mathrm{ACl} 318$ [1] es $\rho_{\operatorname{lmax}}=4.0 \%$ obtenida a partir del área $\left(b^{*} d\right)$, siendo "d" el canto útil de la sección. Este último valor se aproxima al valor máximo considerado en el 
Estudio experimental y numérico de la capacidad de deformación de soportes esbeltos de hormigón armado

presente estudio. En la Tabla 8-3 se indica la relación de ensayos ejecutados con la finalidad de analizar este parámetro.

Tabla 8-3 Relación de ensayos numéricos llevados a cabo para analizar el parámetro de cuantía de armadura longitudinal

\begin{tabular}{|c|c|c|c|c|c|c|c|c|c|c|}
\hline$\lambda=\mathrm{L} / \mathrm{h}$ & $\begin{array}{c}\rho_{s} \\
(\%)\end{array}$ & $\begin{array}{c}\mathbf{f}_{\mathrm{c}} \\
(\mathrm{MPa})\end{array}$ & \multicolumn{3}{|c|}{$\mathrm{N} / \mathrm{N}_{\mathrm{u}}(\%)$} & \multicolumn{4}{|c|}{$\rho_{I}(\%)$} & $\begin{array}{c}\mathbf{N}^{0} \text { de } \\
\text { ensayos }\end{array}$ \\
\hline \multirow[t]{3}{*}{10.5} & \multirow[t]{3}{*}{1} & 30 & 15 & 30 & 45 & 1.2 & $2.2^{*}$ & 3.2 & 4.2 & 9 \\
\hline & & 60 & 15 & 30 & 45 & 1.2 & $2.2^{*}$ & 3.2 & 4.2 & 9 \\
\hline & & 90 & 15 & 30 & 45 & 1.2 & $2.2^{*}$ & 3.2 & 4.2 & 9 \\
\hline \multirow[t]{3}{*}{3.5} & \multirow[t]{3}{*}{1} & 30 & 15 & 30 & 45 & 1.2 & $2.2^{*}$ & 3.2 & 4.2 & 9 \\
\hline & & 60 & 15 & 30 & 45 & 1.2 & $2.2^{*}$ & 3.2 & 4.2 & 9 \\
\hline & & 90 & 15 & 30 & 45 & 1.2 & $2.2^{*}$ & 3.2 & 4.2 & 9 \\
\hline & & & & \multicolumn{6}{|c|}{ Total de ensayos numéricos } & 54 \\
\hline
\end{tabular}

Cuantía de armadura transversal $\left(\rho_{s}\right)$. Para evaluar el efecto de la cuantía de armadura transversal en la capacidad de deformación de elementos de hormigón, se han considerado los valores de $\rho_{\mathrm{s}}$ de $1 \%, 2 \%, 3 \%$ y $4 \%$. El efecto del confinamiento ha sido introducido en el modelo mediante el aumento de las variables resistencia del hormigón (Ec. 8-2) y deformación en la tensión máxima (Ec. 8-3), para el hormigón confinado en el núcleo. Dichas propiedades mecánicas han sido calculadas de acuerdo con el modelo definido en la norma EHE 08 (2008) [53]. El estudio se realiza para dos tipos de hormigón, de $30 \mathrm{MPa}$ y $90 \mathrm{MPa}$.

$$
\begin{gathered}
f_{c c}=f_{c}\left(1+\alpha \omega_{w d}\right) \\
\varepsilon_{c c o}=\varepsilon_{c o}\left[1+5\left(\frac{f_{c c}}{f_{c}}-1\right)\right]
\end{gathered}
$$

Donde

$\omega_{w d} \quad$ Cuantía mecánica volumétrica de confinamiento

$$
\omega_{w d}=\frac{W_{s c}}{W_{c}} \cdot \frac{f_{y d}}{f_{c d}}=\frac{\sum A_{s i} \cdot l_{i}}{A_{c c} S_{t}} \cdot \frac{f_{y d}}{f_{c d}}
$$

$W_{s c} \quad$ Volumen de horquillas y estribos de confinamiento

$A_{s i} \quad$ Área de cada una de las armaduras transversales de confinamiento

$l_{i} \quad$ Longitud de cada una de las armaduras transversales de confinamiento

$W_{c} \quad$ Volumen de hormigón confinado

$A_{c c} \quad$ Área del núcleo de hormigón confinado

$s_{t} \quad$ Separación longitudinal de las armaduras transversales de confinamiento

$\alpha \quad$ Factor que tiene en cuenta la separación de los cercos, el tipo de hormigón y la disposición de la armadura de confinamiento, cuyo valor es $\alpha=\alpha_{c} \cdot \alpha_{s} \cdot \alpha_{e}$

$\alpha_{c} \quad$ Factor que tiene en cuenta la resistencia del hormigón, $\alpha_{c}=1.0$ para hormigón convencional, $f_{c k} \leq 50 \mathrm{MPa}$

$\alpha_{c}=1.2-f_{c k} / 250$ para hormigón de alta resistencia, con $f_{c k}>50 \mathrm{MPa}$

$\alpha_{s} \quad$ Factor que tiene en cuenta la influencia de la separación longitudinal entre cercos, de valor:

$$
\alpha_{s}=\left(1-\frac{s_{t}}{2 b_{o}}\right) \cdot\left(1-\frac{s_{t}}{2 h_{o}}\right)
$$

$h_{o} \quad$ Canto del núcleo confinado

$b_{o} \quad$ Ancho del núcleo

$\alpha_{e} \quad$ Factor que tiene en cuenta la efectividad de la armadura transversal dispuesta en el confinamiento de la sección, de valor: 


$$
\alpha_{n}=1-\sum_{n} b_{i}^{2} / 6 b_{o} h_{o}
$$

n Número de barras longitudinales lateralmente atadas por ganchos o cercos cerrados

$b_{i} \quad$ Distancia consecutiva entre barras atadas (en $b_{o}$ y en $h_{o}$ )

En la Tabla 8-4 se muestra la relación de ensayos ejecutados para el análisis de este parámetro.

Tabla 8-4 Relación de ensayos numéricos llevados a cabo para analizar el parámetro de la cuantía de armadura transversal

\begin{tabular}{|c|c|c|c|c|c|c|c|c|c|c|}
\hline$\lambda=\mathrm{L} / \mathrm{h}$ & $\begin{array}{r}\rho_{1} \\
(\%)\end{array}$ & $\begin{array}{c}f_{c} \\
(\mathrm{MPa})\end{array}$ & \multicolumn{3}{|c|}{$\mathrm{N} / \mathrm{N}_{\mathrm{u}}(\%)$} & \multicolumn{4}{|c|}{$\rho_{\mathrm{s}}(\%)$} & $\begin{array}{c}N^{\circ} \text { de } \\
\text { ensayos }\end{array}$ \\
\hline \multirow[t]{2}{*}{10.5} & \multirow[t]{2}{*}{2.24} & 30 & 30 & 45 & 60 & $1^{*}$ & 2.0 & 3.0 & 4.0 & 9 \\
\hline & & 90 & 30 & 45 & 60 & $1^{*}$ & 2.0 & 3.0 & 4.0 & 9 \\
\hline \multirow[t]{2}{*}{7.5} & \multirow[t]{2}{*}{2.26} & 30 & 30 & 45 & 60 & $1^{*}$ & 2.0 & 3.0 & 4.0 & 9 \\
\hline & & 90 & 30 & 45 & 60 & $1^{*}$ & 2.0 & 3.0 & 4.0 & 9 \\
\hline \multirow[t]{2}{*}{3.5} & \multirow[t]{2}{*}{2.26} & 30 & 30 & 45 & 60 & $1^{*}$ & 2.0 & 3.0 & 4.0 & 9 \\
\hline & & 90 & 30 & 45 & 60 & $1^{*}$ & 2.0 & 3.0 & 4.0 & 9 \\
\hline & & & & \multicolumn{6}{|c|}{ Total de ensayos numéricos } & 54 \\
\hline
\end{tabular}

\section{Diagrama tensión-deformación de la armadura}

En todos los ensayos numéricos se ha definido una única curva tensióndeformación para la armadura longitudinal y transversal. El diagrama característico para el cálculo ha sido adoptado conforme a la norma EHE 08 [53] (Figura 8.3). El tramo elástico está definido por el módulo de elasticidad de 200.000 MPa y un límite elástico de $540 \mathrm{MPa}$. La rama plástica alcanza una tensión máxima de $650 \mathrm{MPa}$ y una deformación máxima del $10 \%$. Los valores del límite elástico y tensión máxima del acero son prácticamente iguales a los del acero utilizado en los ensayos experimentales (apartado 4.6.2 ó 7.1.2).

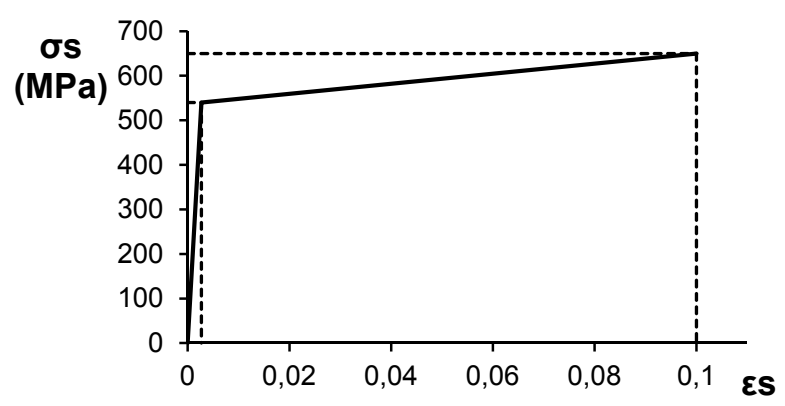

Figura 8.3 Diagrama tensión-deformación. Utilizado en los ensayos numéricos

\subsection{ANÁLISIS PARAMÉTRICO}

La evaluación de cada uno de los parámetros considerados se ha realizado sobre tres variables de deformación del elemento completo, que son el desplazamiento último $\left(\delta_{\mathrm{u}}\right)$, el desplazamiento elástico efectivo $\left(\delta_{\mathrm{y}}^{\prime}\right)$ y la relación entre estas dos variables, es decir, la ductilidad en desplazamientos $\left(\mu_{\delta}\right)$. 
Los dos desplazamientos, elástico y último, son estimados a partir de la curva de respuesta $\mathrm{P}-\delta$, obtenida a partir del modelo numérico para cada uno de los ensayos numéricos. Dicha curva ha sido idealizada mediante el método del Eurocódigo-8, versión 1B, descrito en el capítulo 6, con el propósito de obtener el desplazamiento elástico efectivo. El desplazamiento último, por otra parte, ha sido medido en el $15 \%$ de la rama post-pico. En el anejo $M$ se presentan las curvas de respuesta P- $\delta$ obtenidas para las 250 simulaciónes numéricas y su respectiva idealización.

El análisis se lleva a cabo adimensionalizando las variables de desplazamiento elástico efectivo y el desplazamiento último, mediante la longitud de cortante $\left(L_{s}\right)$.

\subsubsection{DESPLAZAMIENTO ELÁSTICO EFECTIVO}

\subsubsection{NIVEL DE CARGA AXIAL}

En las Figuras 8.4a-c, se muestra cómo varía el desplazamiento elástico efectivo $\left(\delta_{y}^{\prime}\right)$ con el nivel de carga axial $\left(N / N_{u}\right)$. En estas figuras se presentan los resultados para elementos de hormigón de $30 \mathrm{MPa}, 60 \mathrm{MPa}$, y $90 \mathrm{MPa}$. Cada una de estas figuras está compuesta por familias de curvas que hacen referencia a un valor específico de esbeltez y una serie de seis niveles de carga axial.

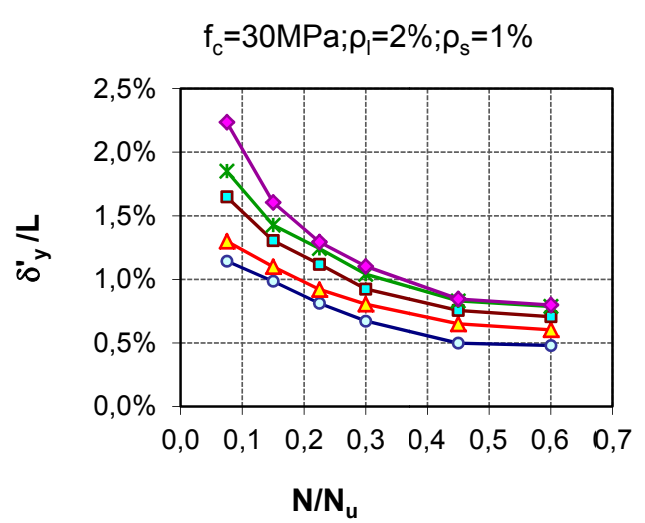

(a)

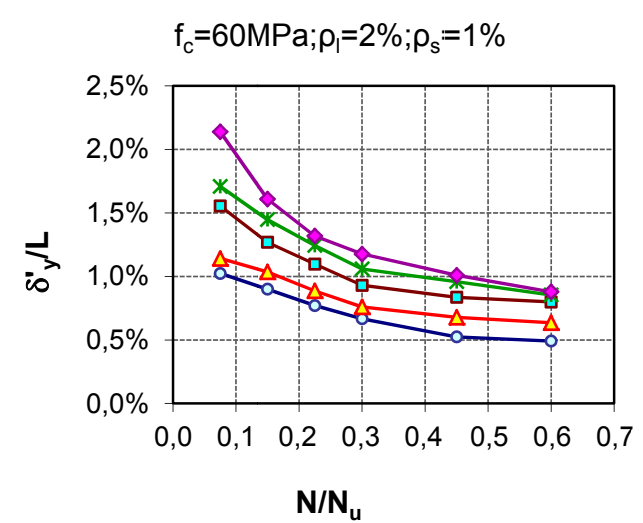

(b)

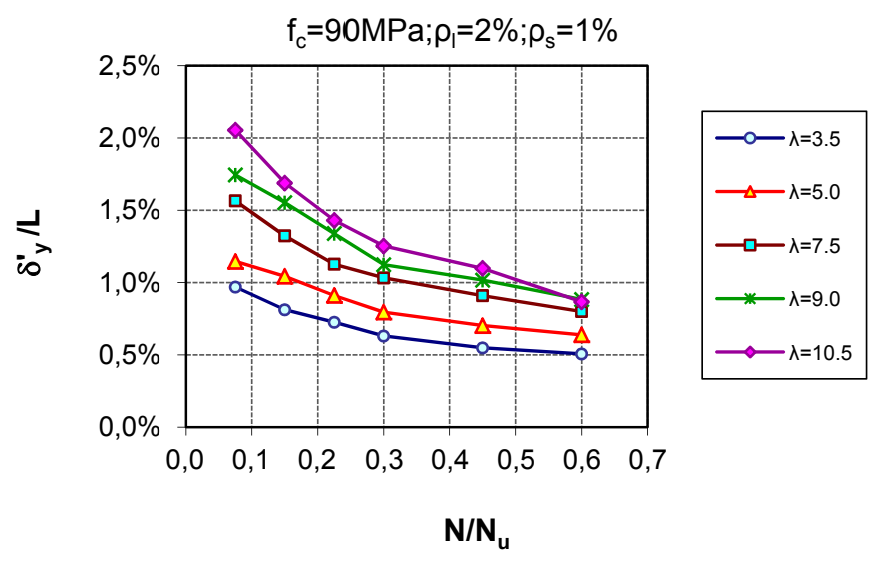

(c)

Figura 8.4 Influencia del nivel de carga axil en el desplazamiento elástico efectivo de soportes de hormigón armado con: (a) $f_{c}=30 \mathrm{MPa}$, (b) $f_{c}=60 \mathrm{MPa}$, (c) $f_{c}=90 \mathrm{MPa}$ 
El desplazamiento elástico efectivo $\left(\delta_{\mathrm{y}}^{\prime}\right)$ muestra una tendencia decreciente con el incremento del nivel de carga axial, de modo que la pendiente de la curva es mayor para bajos niveles de carga axil, y disminuye con el aumento del nivel de carga axil. Como ya es sabido, los elementos de hormigón sujetos a una mayor compresión experimentan una menor capacidad de deformación.

Las curvas del $\delta_{y}^{\prime}$ muestran la misma tendencia para todos los valores de esbeltez analizados; sin embargo, se observa que la separación entre curvas de diferente esbeltez es mayor para bajos niveles de carga axial y se hace menor conforme aumenta el nivel de carga axial. Este efecto es visible si se comparan las Figuras 8.4a-c.

\section{Efecto del nivel de a carga axial y la resistencia del hormigón.}

La Figura 8.5a muestra las curvas para las diferentes esbelteces; si el nivel de carga axial utilizado es de $7.5 \%$, las curvas son casi paralelas y la separación entre ellas es visiblemente mayor que en la Figura $8.5 \mathrm{~b}$, donde el nivel de carga axial ha aumentado a un $30 \%$. Finalmente, en la Figura $8.4 \mathrm{c}$, para un nivel alto de $\mathrm{N} / \mathrm{N}_{\mathrm{u}}$ del $60 \%$, la separación entre curvas de esbeltez se hace más pequeña, hasta el punto que no se aprecia diferencia entre las dos curvas de mayor esbeltez $(\lambda=9.0$ y $\lambda=10.5)$.

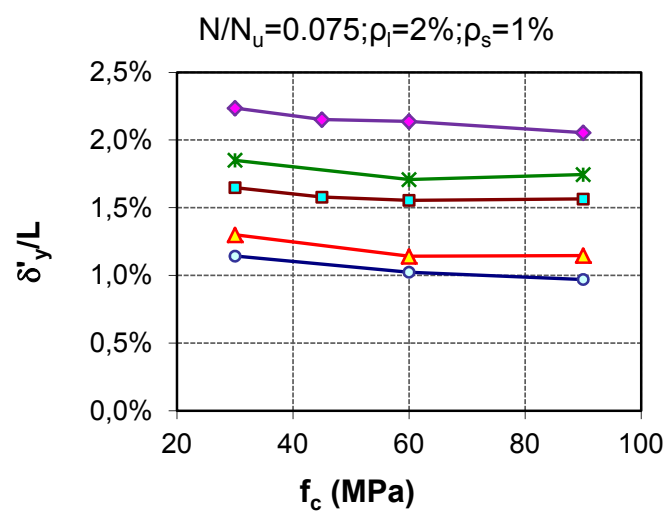

(a)

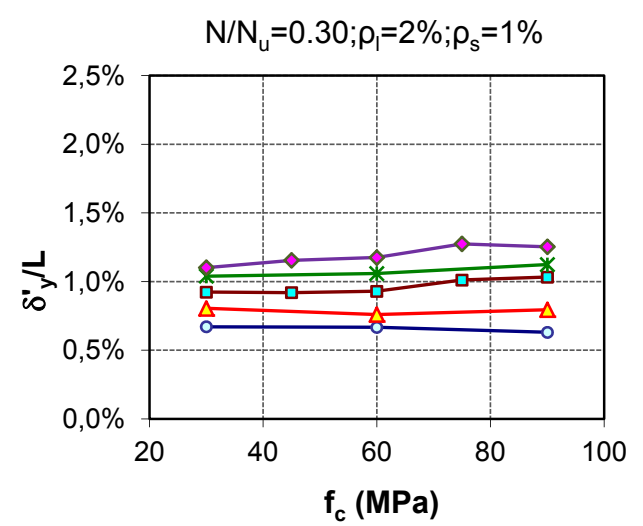

(b)

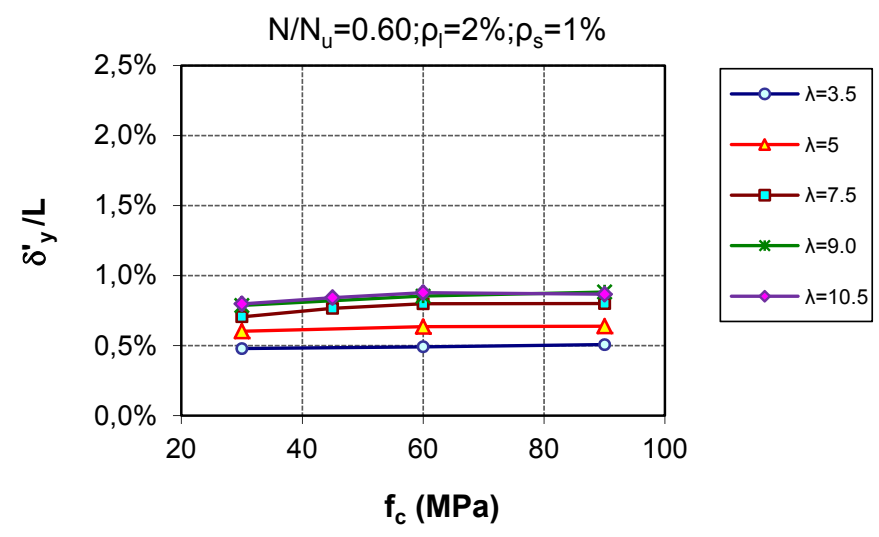

(c)

Figura 8.5 Efecto conjunto del nivel de carga axial y la resistencia del hormigón en el desplazamiento elástico de soportes de hormigón armado con: (a) bajo $\mathrm{N} / \mathrm{N}_{u}(7.5 \%)$, (b) moderado $\mathrm{N} / \mathrm{N}_{u}(30 \%)$, (c) alto $\mathrm{N} / \mathrm{N}_{u}(60 \%)$ 

hormigón armado

Como se puede apreciar en las Figuras 8.5, la influencia del nivel de carga axial es predominante sobre la influencia de la resistencia del hormigón. Las familias de curvas se muestran casi paralelas para todos los niveles de carga axial analizados. Sólo en los elementos con menor compresión (N/Nu=7.5\%) puede apenas notarse una leve inclinación de las curvas de desplazamiento elástico a medida que aumenta la resistencia del hormigón para todos los valores de esbeltez (Figura 8.5a). Sin embargo, con el aumento del nivel de carga axial, las curvas se vuelven más planas, lo cual indica que la resistencia del hormigón no afecta al desplazamiento elástico para ninguno de los tipos de esbeltez analizados.

\subsubsection{ESBELTEZ DE CORTANTE}

En las Figuras 8.6a-c se muestra la relación entre el desplazamiento elástico efectivo adimensional y la esbeltez de cortante, para elementos sujetos a flexocompresión recta y resistencias del hormigón de $30 \mathrm{MPa}, 60 \mathrm{MPa}$ y $90 \mathrm{MPa}$. Cada una de las curvas en las Figuras 8.6a-c representan el comportamiento para los diferentes niveles de carga axial.

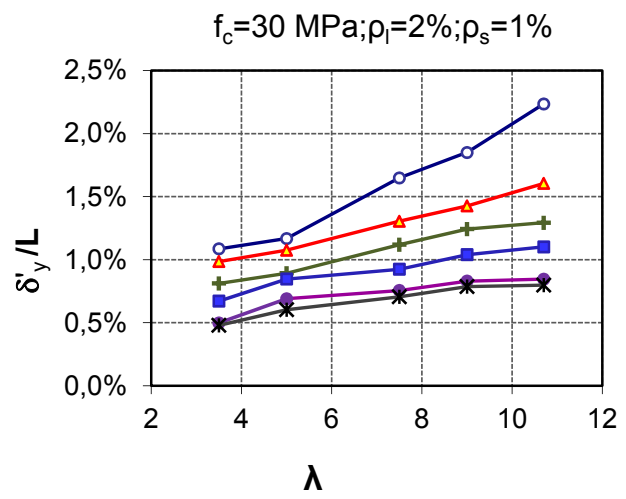

(a)

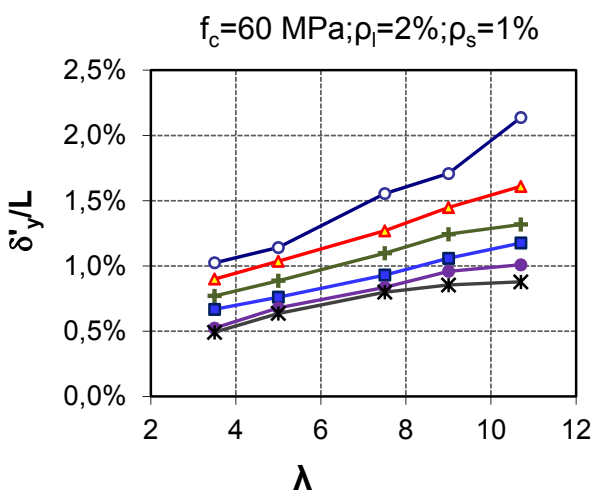

(b)

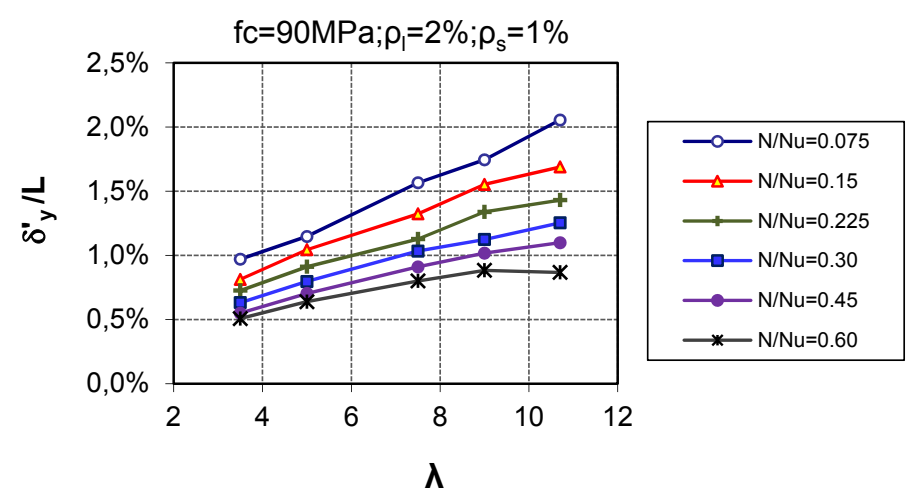

(c)

Figura 8.6 Influencia de la esbeltez de cortante en el desplazamiento elástico efectivo de elementos de hormigón armado con: $(a) f_{c}=30 \mathrm{MPa}$, (b) $f_{c}=60 \mathrm{MPa},(c) f_{c}=90 \mathrm{MPa}$

En las Figuras 8.6 se puede observar que el desplazamiento elástico se incrementa casi linealmente con el aumento de la esbeltez, notándose una mayor pendiente de las curvas para bajos niveles de carga axil, de modo que la pendiente disminuye conforme aumenta el nivel de carga axial. Esto nuevamente pone en evidencia que, 
en el estado elástico, los elementos más esbeltos y menos comprimidos son los que mayor desplazamiento elástico alcanzan.

\section{Efecto de la esbeltez de cortante y la resistencia del hormigón}

En las Figuras 8.7a-c se puede ver una leve influencia de la resistencia del hormigón para tres niveles de axil: $7.5 \%, 30 \%$ y $60 \%$. En esta secuencia es posible observar que los elementos de hormigón convencional ( $\mathrm{fc}=30 \mathrm{MPa}$ ) presentan un valor ligeramente más alto de desplazamiento elástico efectivo con bajos niveles de carga axial $(7.5 \%)$. Esta pequeña diferencia se va modificando a medida que aumenta el nivel de carga axial, de modo que, en elementos altamente comprimidos, los que presentan mayor resistencia del hormigón son los que muestran valores ligeramente más altos de desplazamiento elástico efectivo.

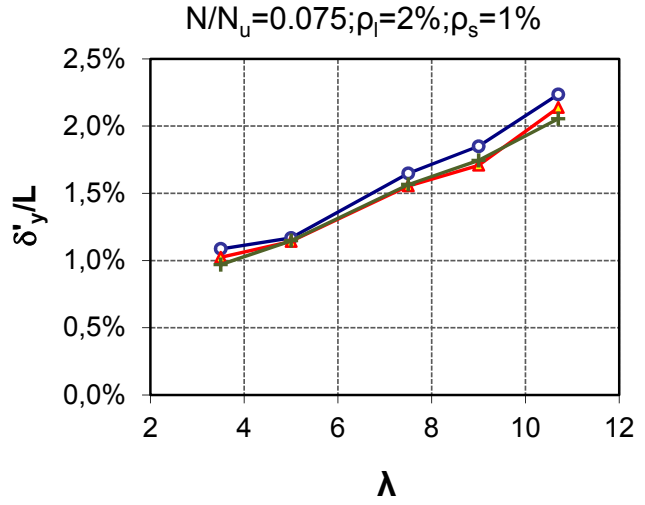

(a)

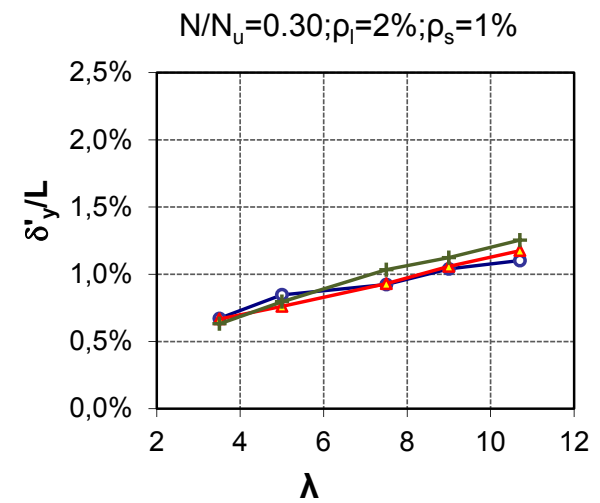

(b)

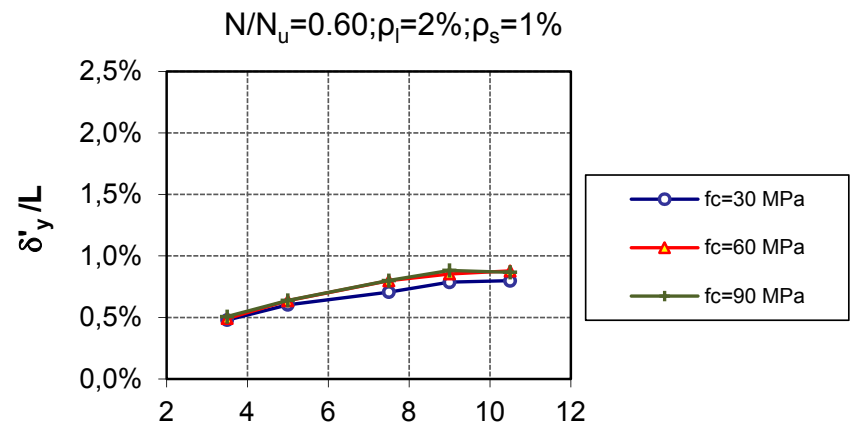

$\lambda$

(c)

Figura 8.7 Efecto conjunto de la esbeltez de cortante y la resistencia del hormigón en el desplazamiento elástico efectivo de elementos de hormigón armado con: (a) bajo $\mathrm{N} / \mathrm{N}_{u}(7.5 \%)$, (b) moderado $\mathrm{N} / \mathrm{N}_{u}(30 \%)$, (c) alto $\mathrm{N} / \mathrm{N}_{u}(60 \%)$

La pequeña influencia se explica a partir de la definición del punto de plastificación. Por un lado, en elementos con bajo nivel de carga axial (7.5\%), el punto de plastificación está marcado por el acero en tracción, de modo que, cuando se alcanza la deformación elástica del acero, la deformación del hormigón que le acompaña en este estado es menor a medida que aumenta la resistencia del hormigón. Por otro lado, cuando el punto de plastificación lo indica la deformación del $0.75 \varepsilon_{c o}$, el valor de esta deformación aumenta con la resistencia del hormigón, 

hormigón armado

permitiendo al elemento un mayor desplazamiento. Finalmente, aunque en la sección anterior y en esta se ha podido notar una leve influencia de la resistencia del hormigón en el desplazamiento elástico efectivo, este efecto es prácticamente imperceptible, y es normal que incluso se pueda ignorar.

\subsubsection{CUANTÍA DE ARMADURA LONGITUDINAL}

En las Figuras 8.8a-c se puede observar la influencia de la cuantía de armadura longitudinal $\left(\rho_{\mathrm{l}}\right)$ en el desplazamiento elástico efectivo $\left(\delta_{y}^{\prime}\right)$. Respecto al valor de esbeltez 3.5, las Figuras 8.8a-c muestran que las líneas continuas correspondientes al nivel de carga axial del $15 \%$, manifiestan un leve aumento del $\delta_{y}^{\prime}$ cuando aumenta la cuantía de armadura longitudinal. Las dos siguientes líneas continuas que representan los niveles de carga axial del $30 \%$ y del $45 \%$ no experimentan un aumento del $\delta_{\text {y }}$ cuando aumenta la cuantía longitudinal, como se puede apreciar en las respectivas Figuras 8.8a-c para resistencias del hormigón de $30 \mathrm{MPa}, 60 \mathrm{MPa}$ y $90 \mathrm{MPa}$.

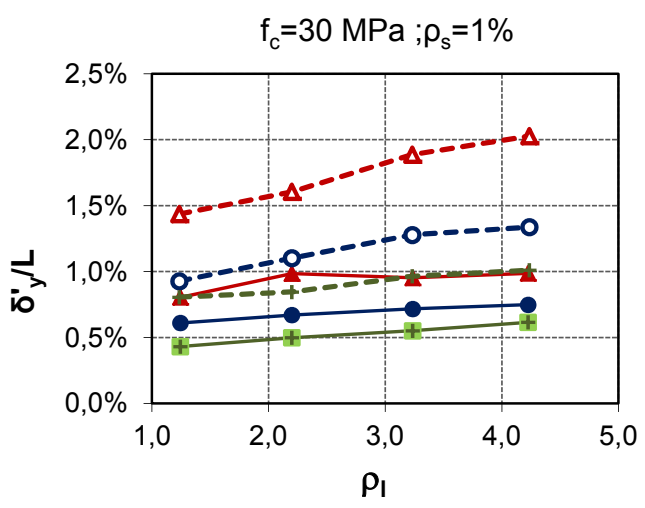

(a)

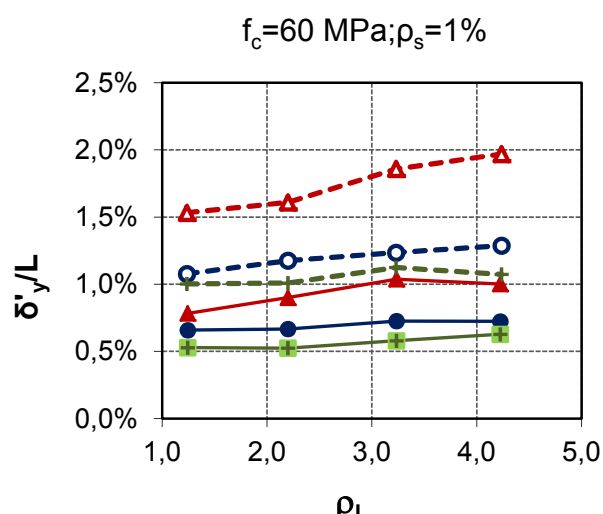

(b)

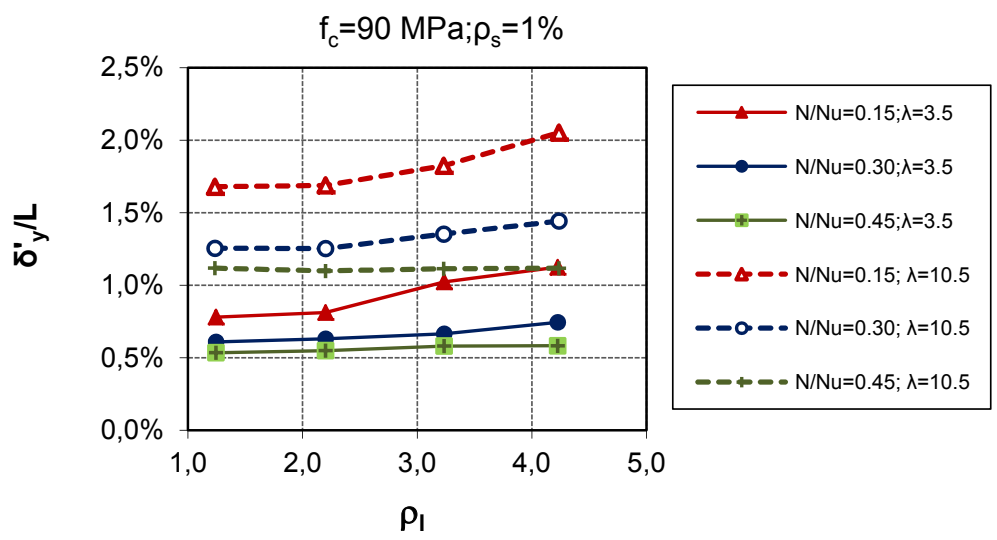

(c)

Figura 8.8 Efecto de la cuantía de armadura en el desplazamiento elástico efectivo de elementos de hormigón armado con: (a) $f_{c}=30 \mathrm{MPa}$, (b) $f_{c}=60 \mathrm{MPa}$, (c) $f_{c}=90 \mathrm{MPa}$

Las líneas discontinuas correspondientes a la esbeltez 10.5 muestran una mayor influencia de la cuantía de armadura longitudinal en el desarrollo del $\delta_{y}^{\prime}$; la pendiente de las curvas es mayor que para $\lambda=3.5$, pero esta disminuye a medida que aumenta el nivel de carga axial. Esto también es cierto para los tres valores de 
resistencia del hormigón. En este aspecto, se comprueba que el efecto de la armadura longitudinal es más efectivo en elementos con bajos niveles de carga axial, ya que la armadura en tracción puede desarrollar una mayor deformación, mientras que en elementos comprimidos el efecto del incremento de la armadura de tracción puede estar contrarrestado con el efecto del incremento de la armadura de compresión, por lo que no es visible la influencia de la cuantía de armadura longitudinal en el estado elástico.

\section{Efecto de la cuantía de la armadura longitudinal y la resistencia del hormigón}

La combinación de estos dos parámetros es más visible en elementos con esbeltez 10.5; las líneas punteadas muestran mayor separación entre las curvas de resistencia del hormigón, especialmente cuando la cuantía de armadura es baja, y a medida que aumenta la cuantía de armadura las curvas se van cerrando, lo cual es visible incluso en los tres niveles diferentes de carga axial (Figuras 8.9a-c).

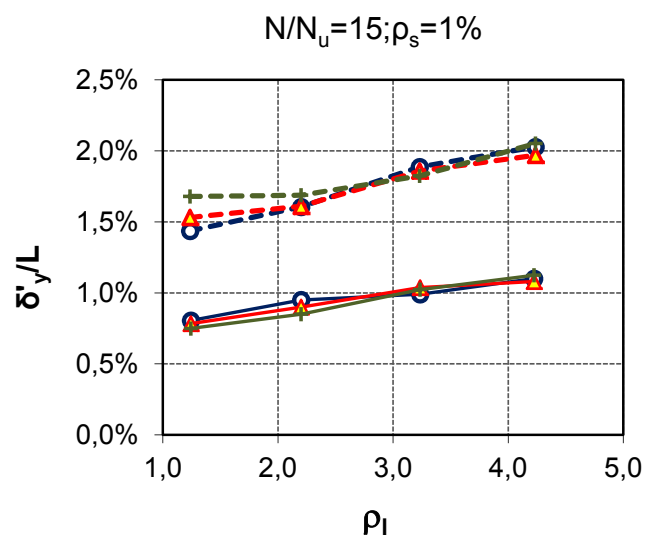

(a)

(c)

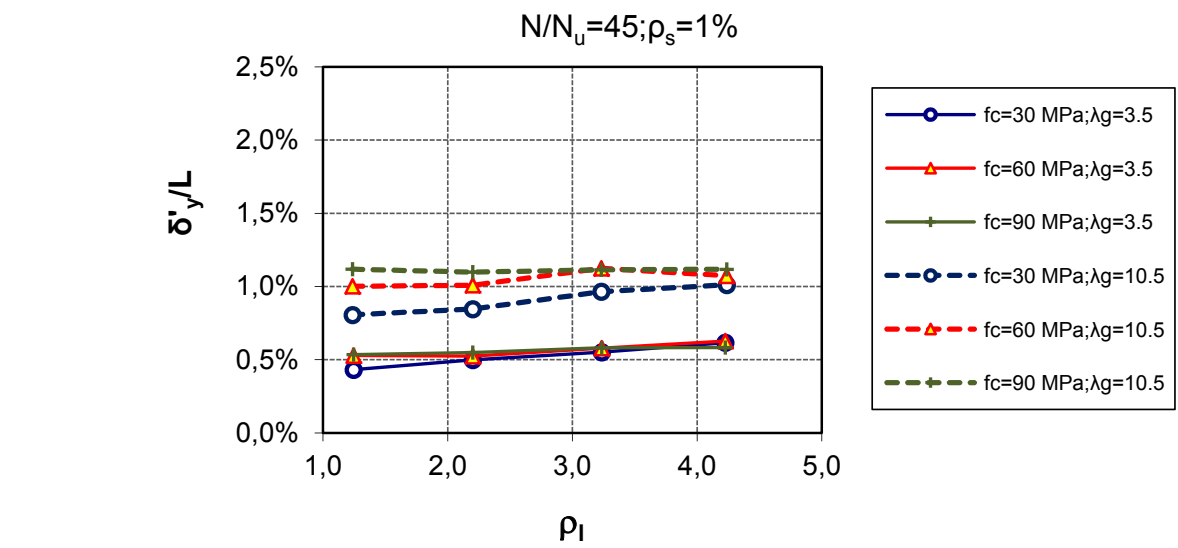

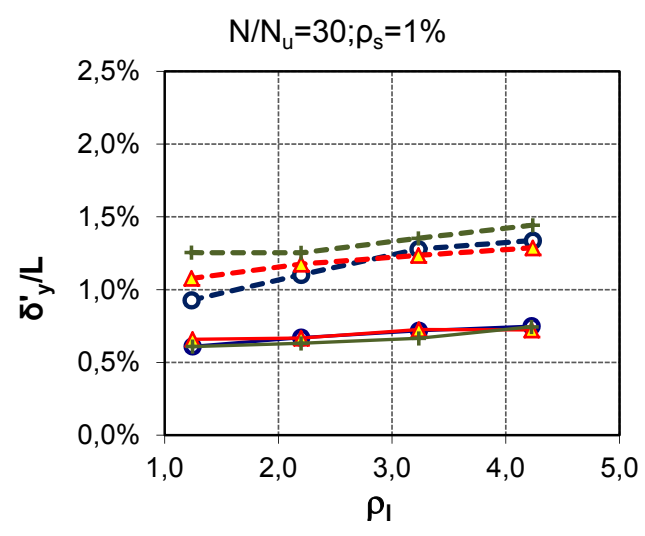

(b)

Figura 8.9 Efecto conjunto de la cuantía de armadura longitudinal y la resistencia del hormigón en el desplazamiento elástico efectivo de elementos de hormigón armado con: (a) $N / N_{u}(15 \%)$, (b) $N / N_{u}(30 \%)$, (c) $N / N_{u}(60 \%)$

Esto confirma lo explicado en la sección anterior, cuando en los elementos, como es el caso, el punto de plastificación lo indica la deformación del hormigón $\left(0.75 \varepsilon_{\mathrm{co}}\right)$, permitiendo un ligero incremento de $\delta_{y}^{\prime}$ cuando aumenta la resistencia del hormigón. En definitiva, el incremento de $\delta_{y}^{\prime}$ es tan pequeño que puede 

hormigón armado

despreciarse. Cuando la esbeltez es menor $(\lambda=3.5)$, las líneas continuas se encuentran prácticamente juntas, de modo que la influencia de la resistencia del hormigón es casi nula para el estado elástico.

\subsubsection{CUANTÍA DE ARMADURA TRANSVERSAL}

La cuantía de armadura transversal es el parámetro que presenta mayor variación cuando se analiza junto con los demás parámetros. En primer lugar, si se evalúa el efecto de la cuantía de armadura transversal de forma general, en las Figuras $8.10 a-c$ se aprecia que el $\delta_{y}^{\prime}$ no se ve influido por el aumento de la cuantía transversal. Este comportamiento tiene lugar para todos los rangos y parámetros considerados, es decir, esbelteces de 3.5, 7.5 y 10.5, niveles de carga axial del $30 \%, 45 \%$ y $60 \%$, y resistencias del hormigón de $30 \mathrm{MPa}$ y $90 \mathrm{MPa}$. Esto se debe a que la cuantía de armadura transversal actúa sobre el núcleo de hormigón, cerca de la carga máxima, en el instante en que se produce la rotura del hormigón en el recubrimiento, con su posterior desprendimiento, $\mathrm{y}$, por consiguiente, es previsible que la cuantía de armadura transversal no afecte al desplazamiento en estado elástico.

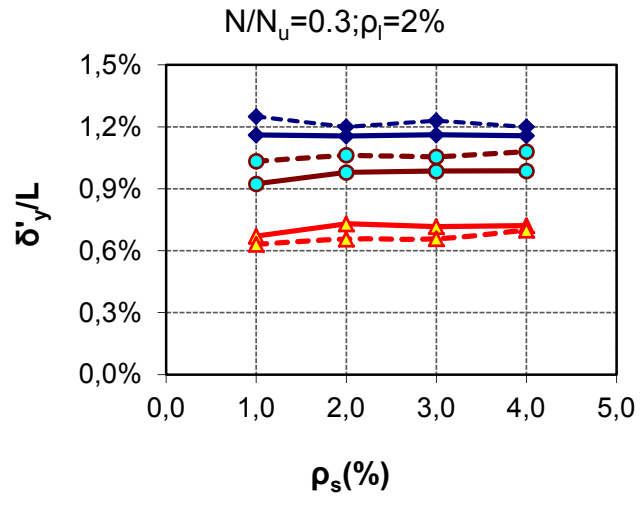

(a)

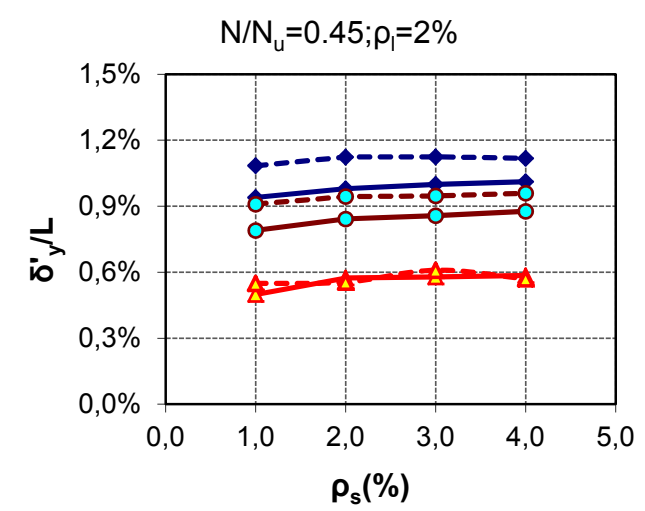

(b)

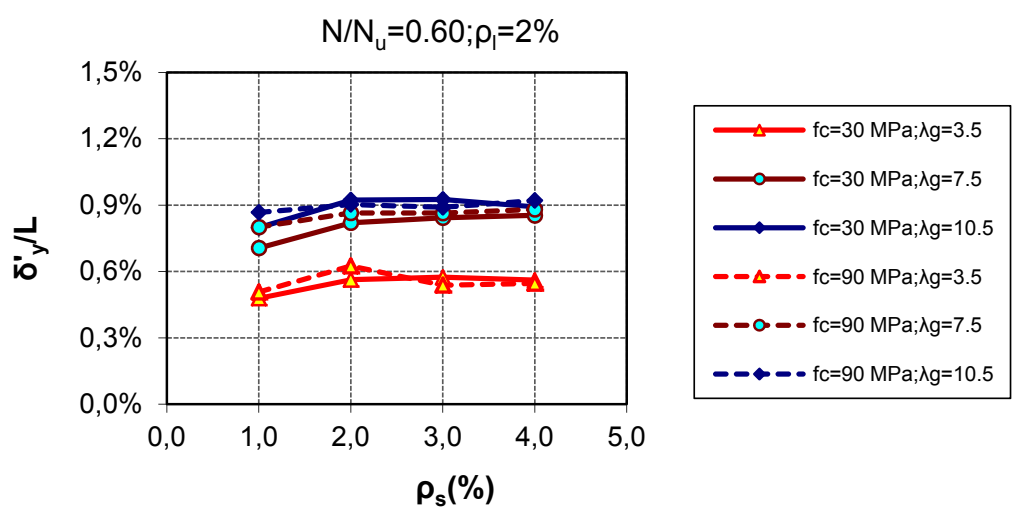

(c)

Figura 8.10 Influencia de la cuantía de armadura transversal en el desplazamiento elástico efectivo, de elementos de hormigón con N/Nu: (a) 30\%, (b) 45\%, y (c) 60\%

Nuevamente se confirma que, en elementos en los que el punto de plastificación es detectado cuando se alcanza la deformación del hormigón de $0.75 \varepsilon_{\mathrm{co}}$, el 
desplazamiento elástico es ligeramente superior en elementos de hormigón de alta resistencia, y alta esbeltez, como se puede observar en las Figuras 8.10a-b. En elementos de hormigón con niveles de carga axial elevados $(60 \%)$, el efecto de la resistencia del hormigón prácticamente desaparece, ya que el efecto de la compresión es más notable.

\subsubsection{DESPLAZAMIENTO ÚLTIMO}

\subsubsection{NIVEL DE CARGA AXIAL}

El desplazamiento último disminuye con el nivel de carga axial; las Figuras 8.11a-c muestran que las curvas poseen una mayor pendiente para bajos niveles de carga axial, hasta $\mathrm{N} / \mathrm{N}_{\mathrm{u}} \leq 30 \%$. Dicha pendiente disminuye progresiviamente con el incremento de la carga axial, hasta que la curva alcanza una forma muy plana para $\mathrm{N} / \mathrm{N}_{\mathrm{u}}=60 \%$. La explicación de esto radica en que, para altos niveles de carga axial, la profundidad de la fibra neutra es mayor y la deformación desarrollada en el acero en tracción es mínima, lo cual tiene como consecuencia el desarrollo de un menor desplazamiento último.

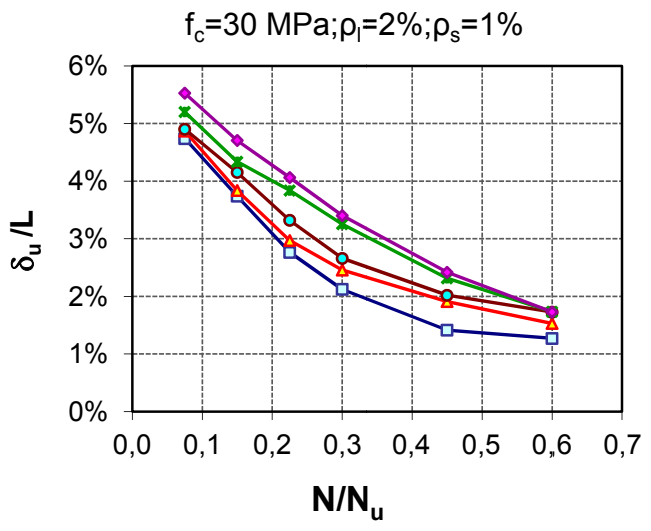

(a)

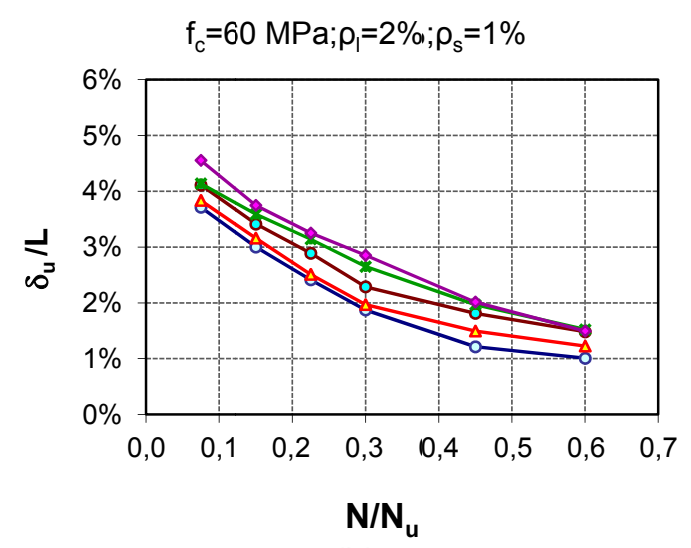

(b)

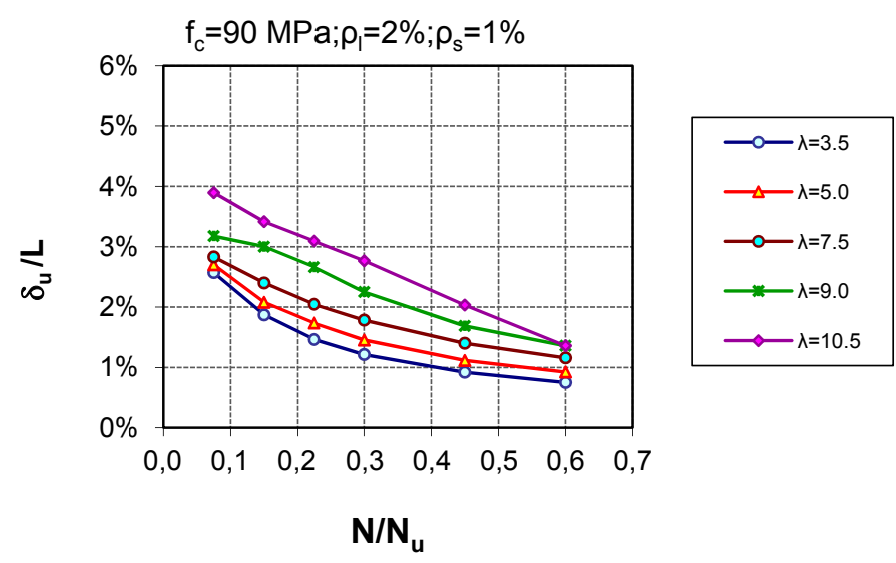

(c)

Figura 8.11 Influencia del nivel de carga axil en el desplazamiento último de elementos de hormigón armado con: (a) $f_{c}=30 \mathrm{MPa}$, (b) $f_{c}=60 \mathrm{MPa}$, (c) $f_{c}=90 \mathrm{MPa}$ 
Si comparamos la familia de curvas que representan la esbeltez, se ve un cambio en la forma de la curva. Para un valor bajo de esbeltez $(\lambda=3.5)$, la serie de curvas puede ajustarse a una función de segundo grado respecto al nivel de carga axial, y va perdiendo curvatura a medida que aumenta la esbeltez, hasta que para esbelteces mayores $(\lambda=9.0, \lambda=10.5)$, las curvas pueden ser aproximadas a una función lineal.

\subsubsection{ESBELTEZ DE CORTANTE}

En términos generales, en las Figuras $8.12 \mathrm{a}-\mathrm{c}$ se puede observar que el desplazamiento último aumenta con el incremento de la esbeltez de cortante, y disminuye con el aumento del nivel de carga axial y de la resistencia del hormigón. Estas tendencias se corresponden con el comportamiento teórico esperado.

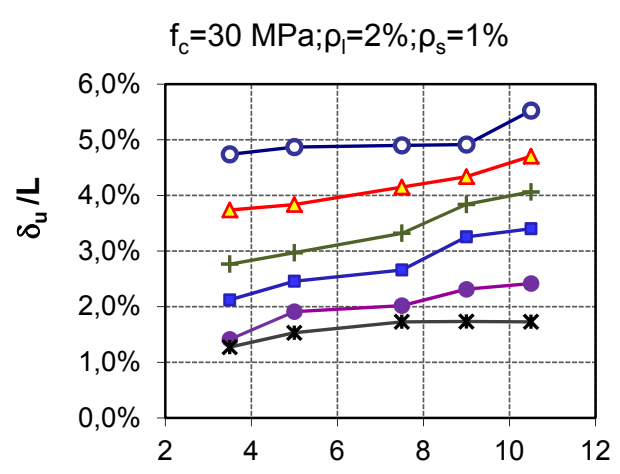

$\lambda$

(a)

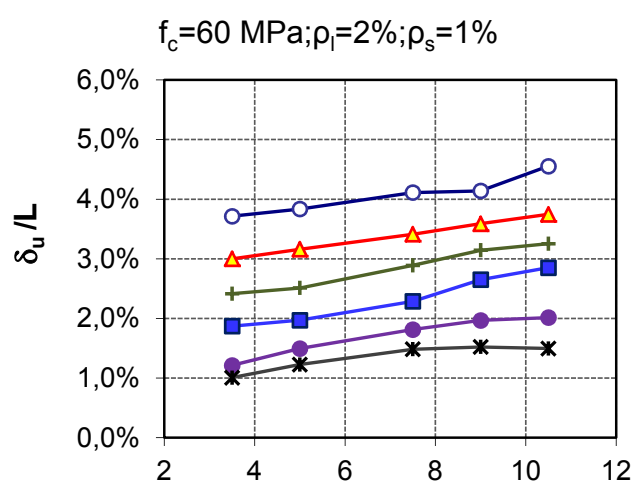

$\lambda$

(b)

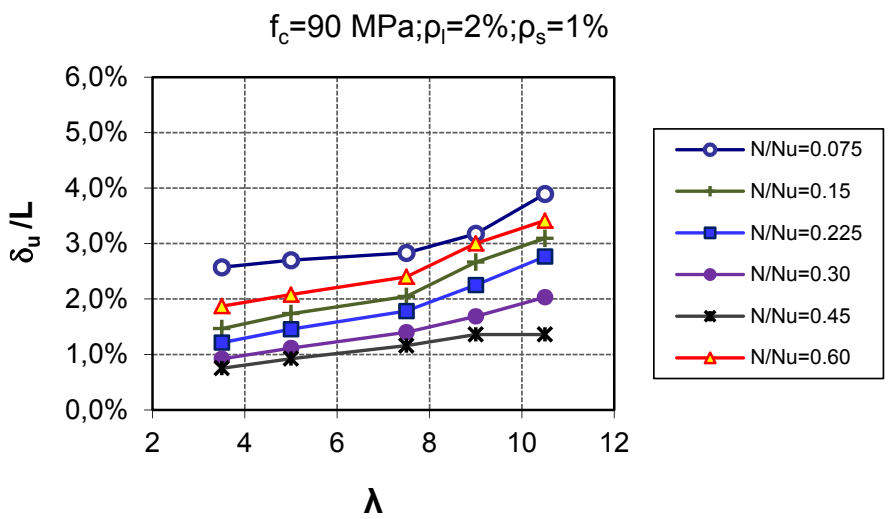

(c)

Figura 8.12 Influencia de la esbeltez de cortante en el desplazamiento último de elementos de hormigón armado con: (a) $f_{c}=30 \mathrm{MPa}$, (b) $f_{c}=60 \mathrm{MPa}$, (c) $f_{c}=90 \mathrm{MPa}$

Si se analiza el comportamiento conjunto de la esbeltez de cortante y el nivel de carga axial, a partir de las Figuras $8.12 a-c$, se ve que, para los tres valores de resistencia del hormigón, el desplazamiento último aumenta casi linealmente con la esbeltez de cortante. Además, el conjunto de curvas que identifican el nivel de carga axial muestran mayor pendiente para los niveles más bajos, de modo que las 
curvas van perdiendo inclinación conforme aumenta el nivel de carga axial. Incluso elementos muy esbeltos $(\lambda=9.0$ y $\lambda=10.5)$, con altos niveles de carga axial, experimentan desplazamientos últimos similares. Esto se debe a que, para esbelteces bastante altas, los elementos presentan un fallo por inestabilidad debido a la influencia de la no linealidad geométrica, sin que se haya desarrollado la deformabilidad correspondiente a la no linealidad del material.

Por otra parte, si se analizan conjuntamente el nivel de carga axial y la resistencia del hormigón, se aprecia, a partir de las Figuras 8.13a-b que, para todos los niveles de carga axial, el desplazamiento último disminuye con la resistencia del hormigón. La separación entre las curvas es menor conforme aumenta el nivel de carga axial.

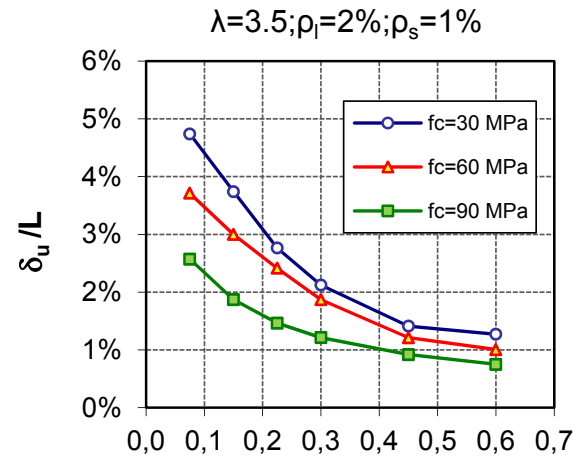

$\mathbf{N} / \mathbf{N}_{\mathbf{u}}$

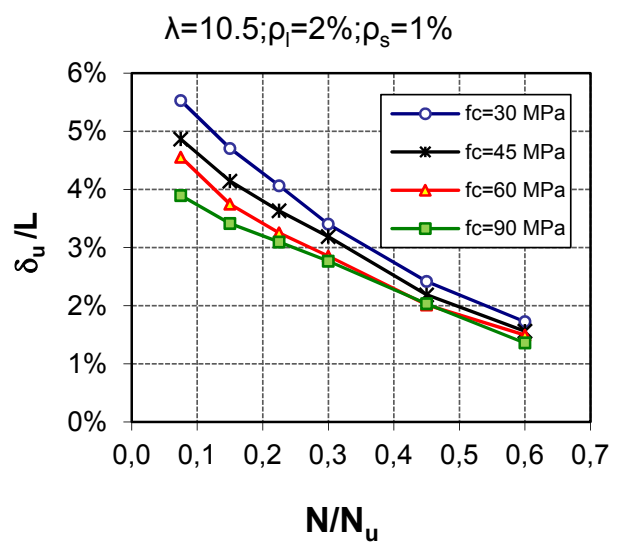

(b)

Figura 8.13 Efecto conjunto del nivel de carga axial y la resistencia del hormigón en el desplazamiento último de elementos de hormigón armado con: (a) $\lambda=3.5$ y (b) $\lambda=10.5$

Existe una gran diferencia en el desplazamiento último obtenido en elementos con diferentes resistencias del hormigón, en especial para bajos niveles de carga axial donde se produce el agotamiento de la armadura de tracción. Tal diferencia puede ser explicada a través de la Figura 8.14a, donde se presenta la respuesta del comportamiento carga-desplazamiento adimensional, para un elemento con nivel de carga axial de $7.5 \%$ y esbeltez de cortante de 3.5. En este caso, el acero es capaz de presentar grandes deformaciones en la rama post-pico, pero el proceso de fisuración se desarrolla más rápidamente a medida que aumenta la resistencia del hormigón, y, en consecuencia, el proceso de fallo se acelera, sin que se permita un desarrollo prolongado en la deformación del acero. De igual forma, cuando el nivel de carga axial provoca un predominio de deformación del hormigón, causando el fallo por agotamiento o por inestabilidad, las deformaciones últimas alcanzadas en el hormigón son inferiores a medida que disminuye la resistencia del hormigón, y en consecuencia el desplazamiento último también disminuye con la resistencia del hormigón, como se puede ver en la Figura 8.14b. 
Estudio experimental y numérico de la capacidad de deformación de soportes esbeltos de hormigón armado

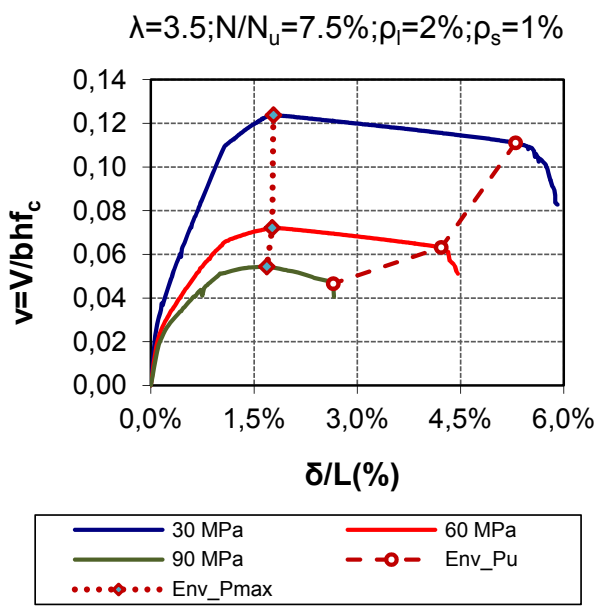

(a)

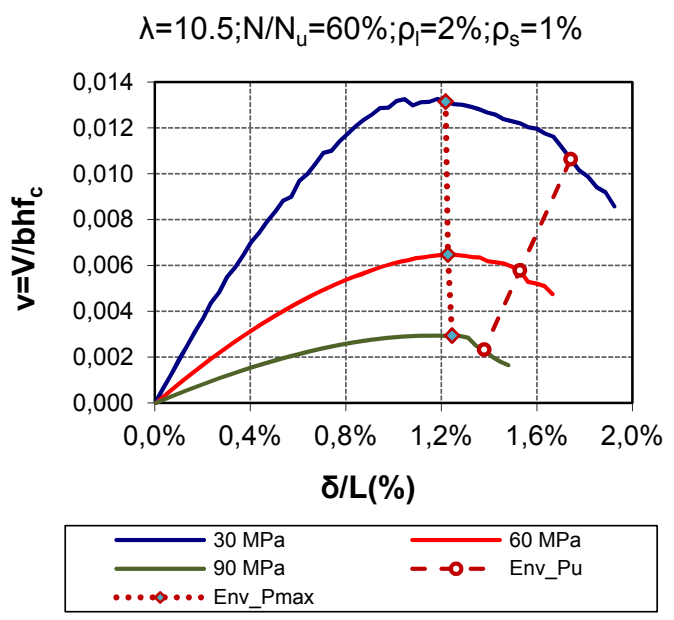

(b)

Figura 8.14 Respuesta del comportamiento carga-desplazamiento para elementos de $30 \mathrm{MPa}, 60 \mathrm{MPa}$ y $90 \mathrm{MPa}$ : (a) elementos con fallo por agotamiento en tracción, (b) elementos con fallo por inestabilidad con predominio de deformación por compresión

En las Figuras 8.15, se analiza el efecto conjunto de la esbeltez y la resistencia del hormigón, mostrándose unas curvas prácticamente paralelas que indican la disminución del desplazamiento último a causa del incremento de la resistencia del hormigón, en todo el rango de valores de esbeltez y para todos los niveles de carga axial estudiados.

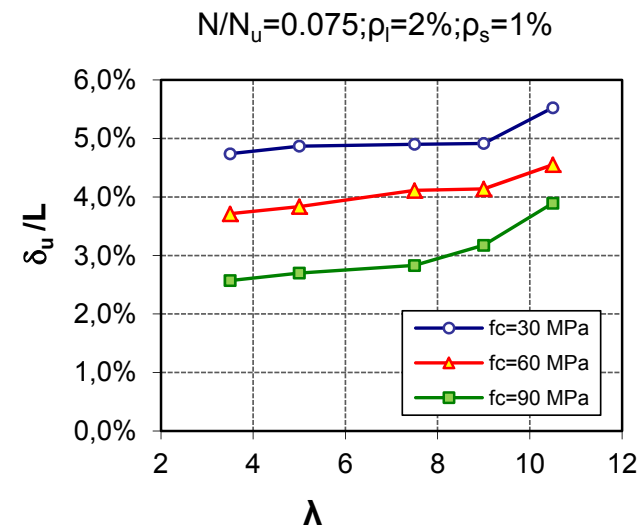

(a)

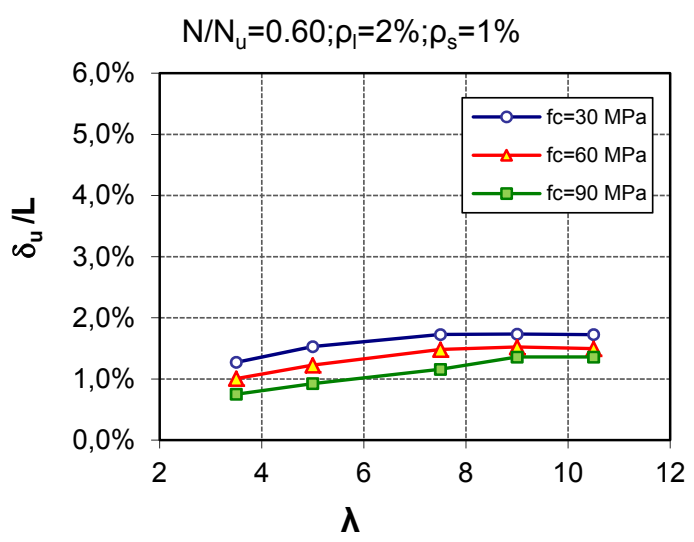

(b)

Figura 8.15 Efecto conjunto de la esbeltez de cortante y la resistencia del hormigón en el desplazamiento último de elementos de hormigón sometidos a flexo-compresión recta: (a) elementos poco comprimidos y (b) elementos altamente comprimidos

\subsubsection{CUANTÍA DE ARMADURA LONGITUDINAL}

Al igual que en el estado elástico, se ha observado que la armadura longitudinal causa un efecto notable en elementos con mayor esbeltez; por el contrario, los 
resultados muestran que, en elementos poco esbeltos, el aumento de la cuantía de armadura longitudinal no causa un aumento en la capacidad de deformación última. Esto puede observarse en las Figuras 8.16, donde se muestra la relación entre el desplazamiento último adimensional y la cuantía de armadura longitudinal, de modo que, para elementos muy esbeltos $(\lambda=10.5)$, las curvas punteadas señalan un incremento casi lineal con la cuantía de armadura longitudinal, y muestran que la pendiente de las rectas disminuye conforme aumenta el nivel de carga axial. Las líneas continuas representan el comportamiento de elementos poco esbeltos $(\lambda=3.5)$, y estas presentan un comportamiento constante conforme aumenta la cuantía de armadura longitudinal. Las líneas son prácticamente paralelas para los diferentes niveles de carga axial, comportamiento que, en general, se cumple para los tres valores de resistencia del hormigón (Figuras 8.16a-c).

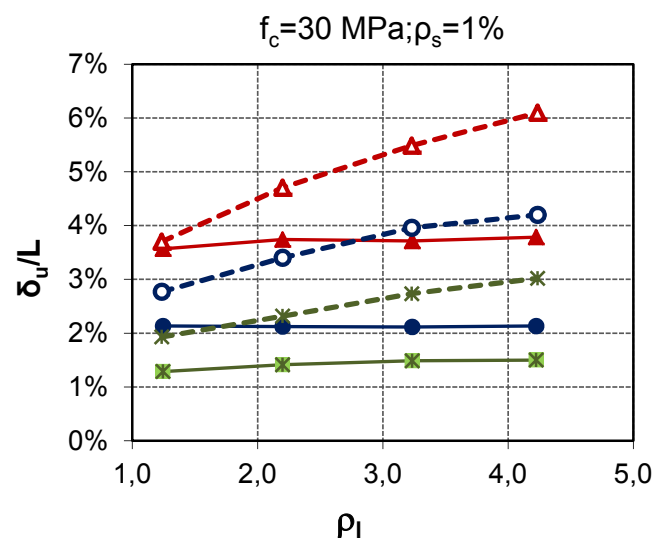

(a)

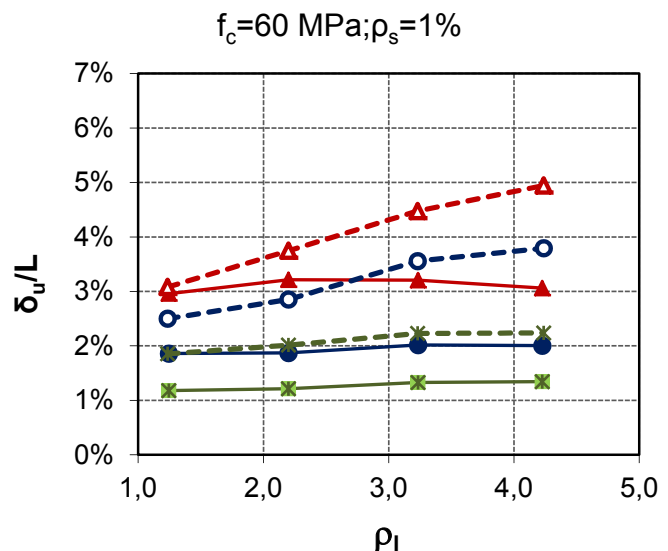

(b)

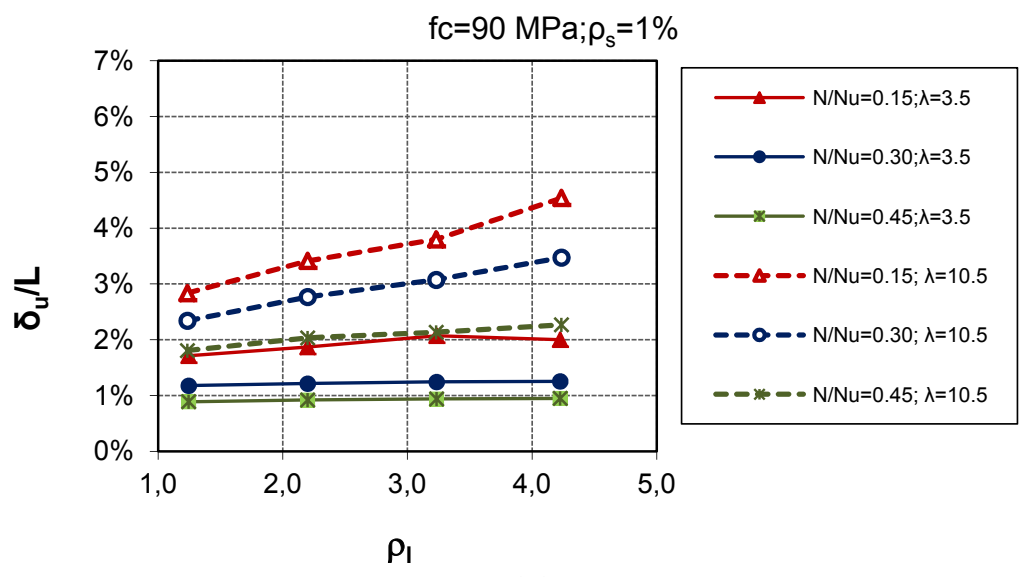

(c)

Figura 8.16 Influencia de la cuantía de armadura longitudinal en el desplazamiento último en elementos de hormigón armado sometidos a flexo-compresión recta: (a) $f_{c}$ $=30 \mathrm{MPa}$, (b) $f_{c}=60 \mathrm{MPa}$, (c) $f_{c}=90 \mathrm{MPa}$

En la Figura 8.17a nuevamente se ha comprobado que, para bajos niveles de carga axial, existe una mayor diferencia o separación entre las curvas que representan la resistencia del hormigón (30 MPa, $60 \mathrm{MPa}$ y $90 \mathrm{MPa}$ ), debido a las razones ya explicadas en la sección anterior. La separación entre curvas de diferente resistencia del hormigón continúa disminuyendo conforme aumenta el nivel de carga axial, tanto para la esbeltez de 3.5 como para la de 10.5 . 

hormigón armado

Si sólo se analizan los elementos con mayores valores de esbeltez, se comprueba una vez más que el efecto de la cuantía de armadura longitudinal desciende cuando aumenta el nivel de carga axial, hasta que el desplazamiento último permanece prácticamente invariable con el aumento de la cuantía de armadura longitudinal. Como se puede comprobar en la Figura $8.17 \mathrm{c}$, sólo los elementos con esbeltez de 10.5 y resistencia de $30 \mathrm{MPa}$ logran mostrar un leve incremento de la capacidad de deformación última aumentando la cuantía de armadura, cuando los soportes están altamente comprimidos (45\%); para hormigón de alta resistencia (60 MPa y 90 $\mathrm{MPa}$ ), la influencia de la cuantía de armadura longitudinal es mínima.

A modo de conclusión, el efecto de la armadura longitudinal es más apreciable para bajos niveles de carga axial y altas esbelteces, y su influencia disminuye con el aumento de la resistencia del hormigón.

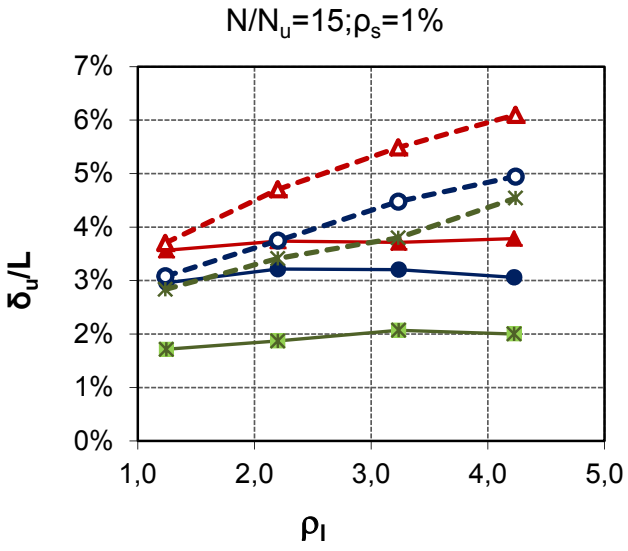

(a)

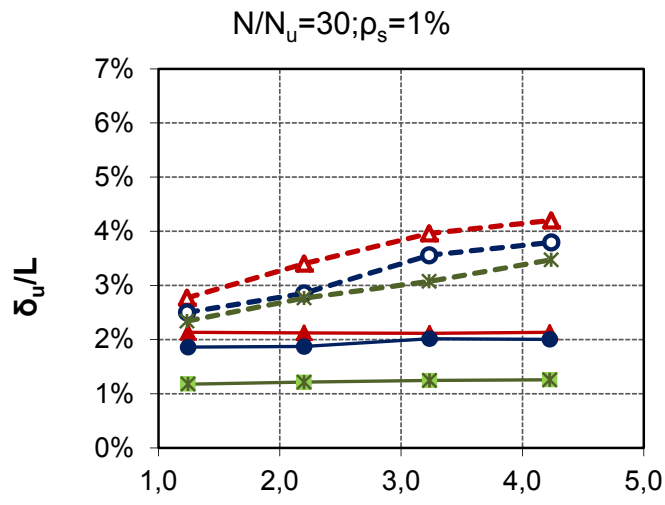

$\rho_{1}$

(b)

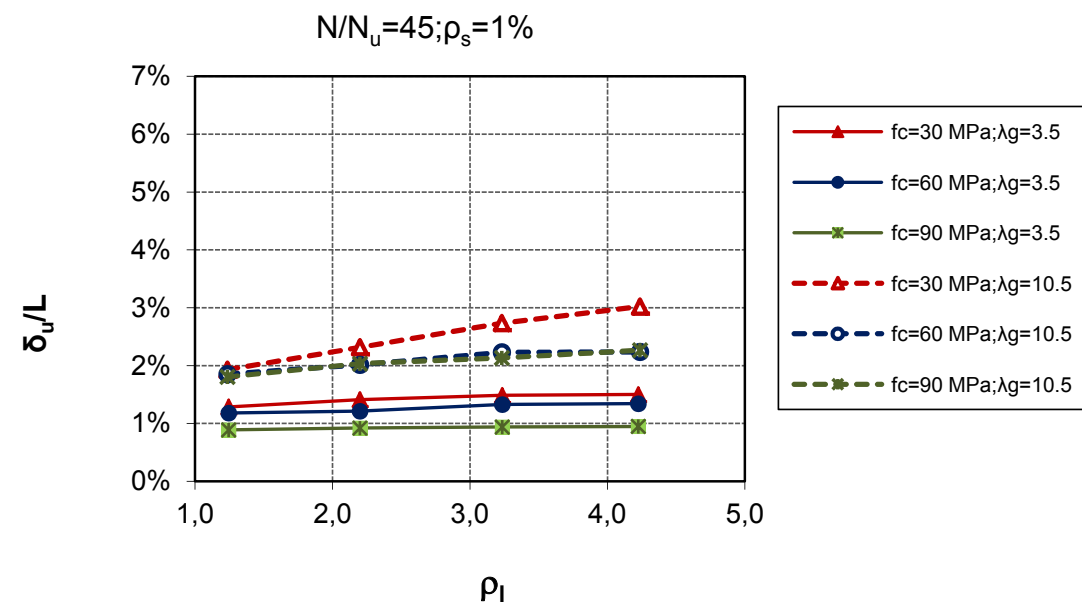

(c)

Figura 8.17 Influencia de la cuantía de armadura longitudinal en el desplazamiento último en elementos de hormigón armado sometidos a flexo-compresión recta con niveles de carga axial de: (a) 15\%, (b) 30\%, y (c) $45 \%$ 


\subsubsection{CUANTÍA DE ARMADURA TRANSVERSAL}

Las Figuras 8.18a-c muestran que el desplazamiento último aumenta ligeramente cuando se incrementa la cuantía de armadura transversal; en especial, las líneas continuas que representan el comportamiento de elementos de hormigón convencional señalan una tendencia lineal y creciente con el aumento de la cuantía de armadura transversal; sin embargo, las líneas discontinuas que representan el hormigón de alta resistencia (90 MPa), no llegan a presentar un cambio importante en el desplazamiento último. Esto se puede apreciar en las Figuras 8.18, para los tres niveles de carga axial analizados.

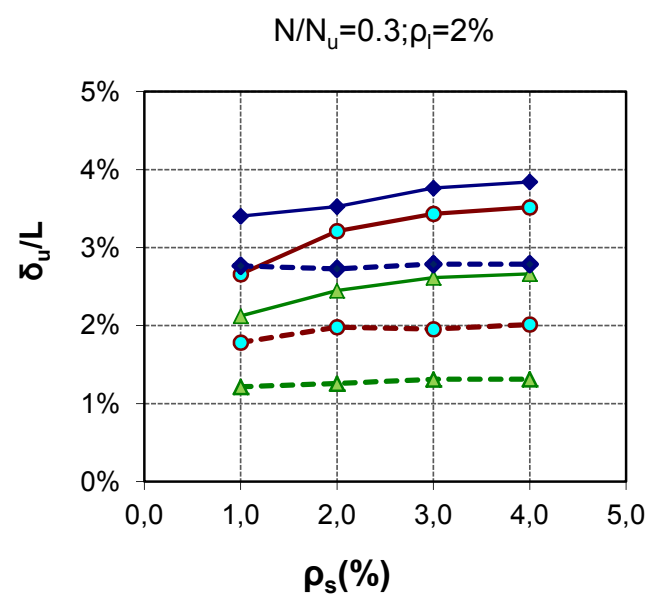

(a)

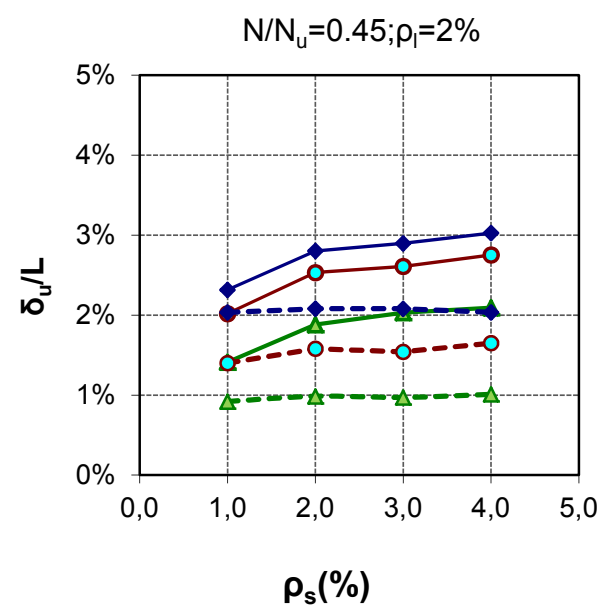

(b)

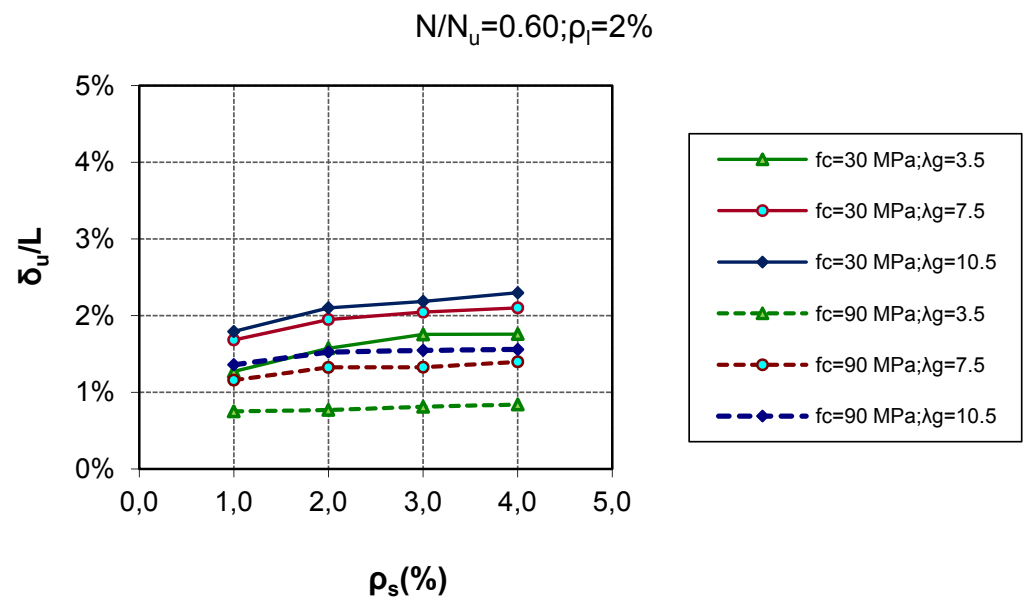

(c)

Figura 8.18 Influencia de la cuantía de armadura transversal en el desplazamiento último en elementos de hormigón armado sometidos a flexo-compresión con niveles de carga axial de: (a) $30 \%$, (b) $45 \%$, y (c) $60 \%$

El aumento de la capacidad de deformación última identificado en los elementos de hormigón de $30 \mathrm{MPa}$ es más notable cuando se da un incremento de la cuantía de armadura transversal de $1 \%$ a $2 \%$, aunque también se aprecia un menor aumento en la capacidad de deformación última para los valores de $\rho_{s}=3 \%$ y $\rho_{s}=4 \%$, como 
Estudio experimental y numérico de la capacidad de deformación de soportes esbeltos de hormigón armado

indica claramente la separación existente entre curvas de diferente cuantía (Figuras 8.19).

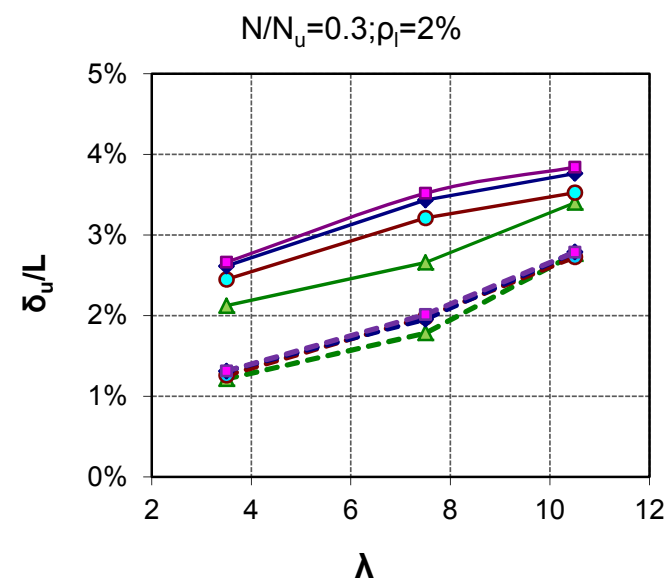

(a)

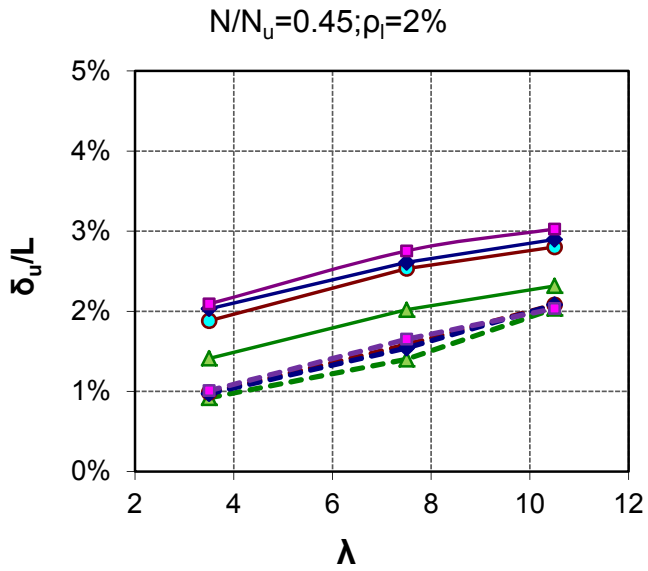

(b)

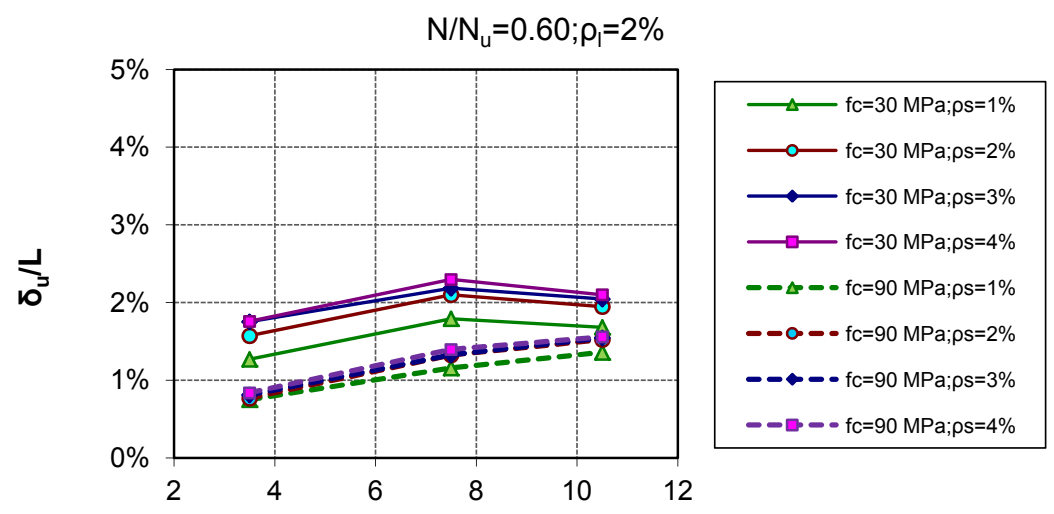

$\lambda$

(c)

Figura 8.19 Efecto conjunto de la cuantía de armadura transversal y la resistencia del hormigón en el desplazamiento último de elementos de hormigón armado sometidos a flexo-compresión con niveles de carga axial de: (a) 30\%, (b) 45\%, y (c) 60\%

Para lograr explicar la diferencia entre el efecto del confinamiento en elementos con hormigón convencional (30 MPa) y elementos con hormigón de alta resistencia (90 $\mathrm{MPa}$ ), se ha comparado la respuesta carga-desplazamiento para elementos con similares características en cuanto a sección transversal, esbeltez de cortante y nivel de carga axial, pero diferente cuantía de armadura transversal. Los resultados se presentan en la Figura 8.20a para elementos con hormigón convencional y en la Figura $8.20 \mathrm{~b}$ para elementos con hormigón de alta resistencia. A partir de las figuras, se demuestra que tales diferencias se deben a los siguientes aspectos:

- Los elementos de hormigón de $30 \mathrm{MPa}$ son capaces de desarrollar una prolongada rama de descenso, mientras que en elementos de hormigón de alta resistencia, una vez se alcanza la carga máxima, la curva cae súbitamente, debido al comportamiento frágil post-pico del HAR. En consecuencia, en elementos de HAR se produce la fractura del 
hormigón de recubrimiento prematuramente, de tal modo que el núcleo no es capaz de estabilizarse, produciéndose el fallo sin desarrollarse una prolongada rama de descenso.

- Por otra parte, como se puede ver en las Figuras 8.20, el desplazamiento último y la carga máxima llegan a aumentar ligeramente con el incremento de la cuantía de armadura transversal. Esto se debe al aumento de la resistencia y de la deformación correspondiente a la tensión máxima del hormigón confinado. Sin embargo, es sabido que tales incrementos, causados por el confinamiento, son menores para hormigón de alta resistencia que para hormigón convencional.

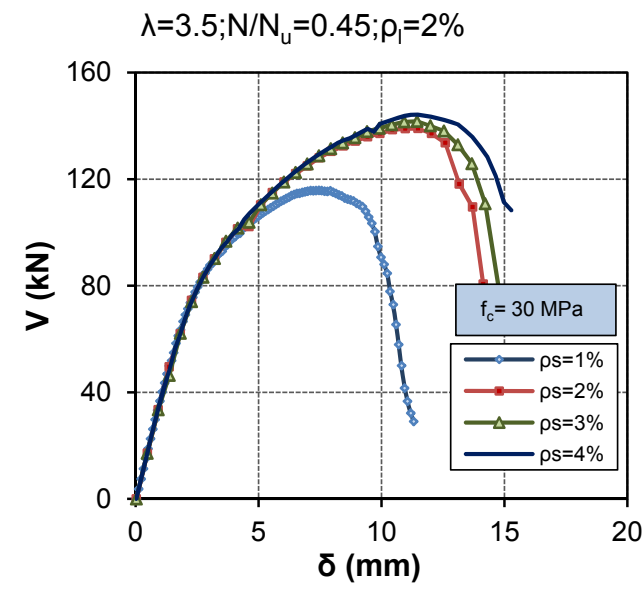

(a)

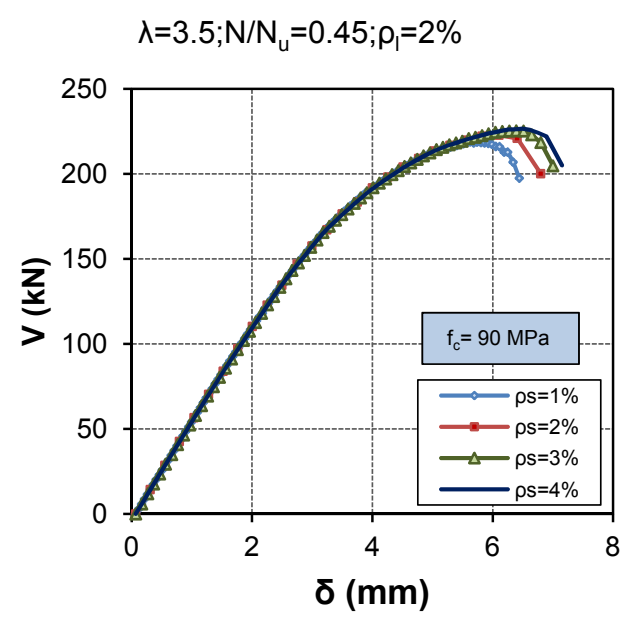

(b)

Figura 8.20 Comparación del comportamiento carga-desplazamiento para elementos de las misma sección transversal, esbeltez de cortante y nivel de carga axial, para diferentes cuantías de armadura transversal y utilizando resistencias del hormigón de (a) $30 \mathrm{MPa}$ y (b) $90 \mathrm{MPa}$

\subsubsection{DUCTILIDAD DE DESPLAZAMIENTO}

\subsubsection{NIVEL DE CARGA AXIAL}

Como se ha demostrado en las secciones anteriores, en el estudio de la influencia del parámetro del nivel de carga axial en la deformación de elementos de hormigón, para el estado elástico y último, las variables $\delta_{y}^{\prime}$ y $\delta_{u}$ disminuyen progresivamente con el aumento del nivel de carga axial, para todos los valores de esbeltez considerados en el presente estudio. Sin embargo, como se puede observar en las Figuras 8.21, el efecto del nivel de carga axial en la ductilidad de desplazamiento presenta un cambio de comportamiento al aumentar el valor de la esbeltez.

En elementos poco esbeltos (con $\lambda \leq 5$ ), se observa que la tendencia de $\mu_{\delta}$ es similar a las otras dos variables estudiadas en la deformabilidad $\left(\delta_{y}^{\prime}\right.$ y $\left.\delta_{u}\right)$. En elementos más esbeltos, dicha tendencia cambia de forma continua con el aumento de la esbeltez de cortante, especialmente para bajos niveles de carga axial. Como se puede observar en la Figura 8.21-e (donde se presentan los resultados de ductilidad de desplazamiento, para elementos con valores de esbeltez $\lambda=7.5,9.0$ y 10.5, respectivamente), las series de curvas muestran un punto de inflexión con 
respecto a la influencia del nivel de carga axial. Para valores inferiores al punto de inflexión, la ductilidad aumenta cuando se incrementa el nivel de carga axil, mientras que, para valores superiores al punto de inflexión, la ductilidad disminuye con el aumento de la carga axial.

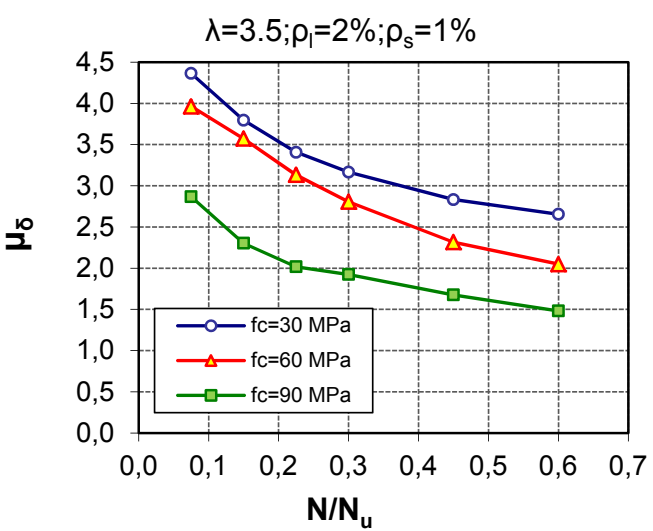

(a)

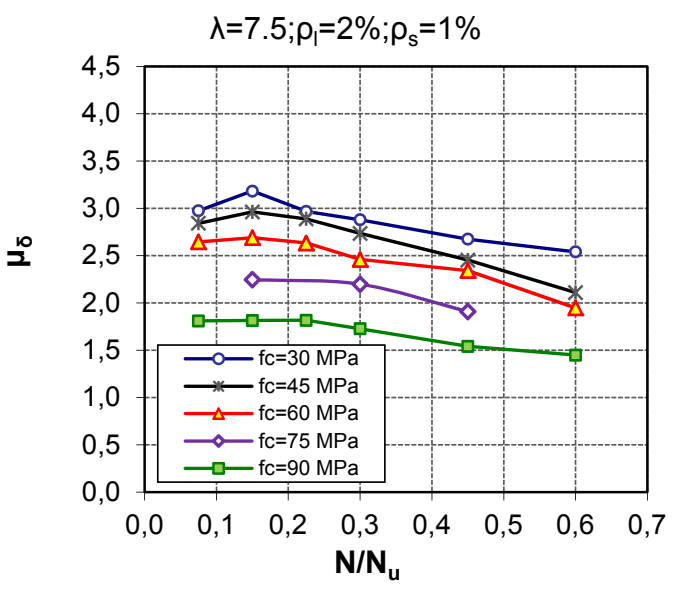

(c)

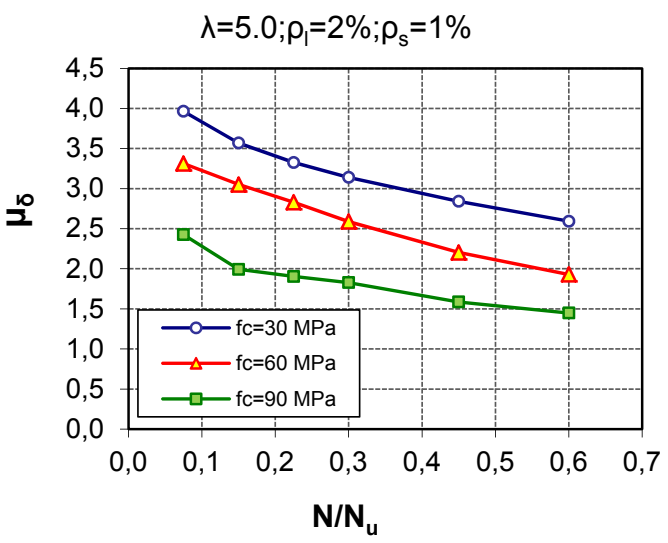

(b)

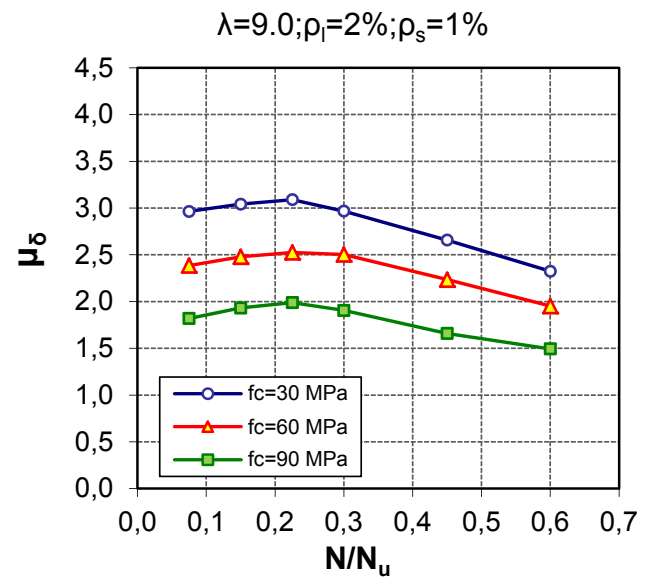

(d)

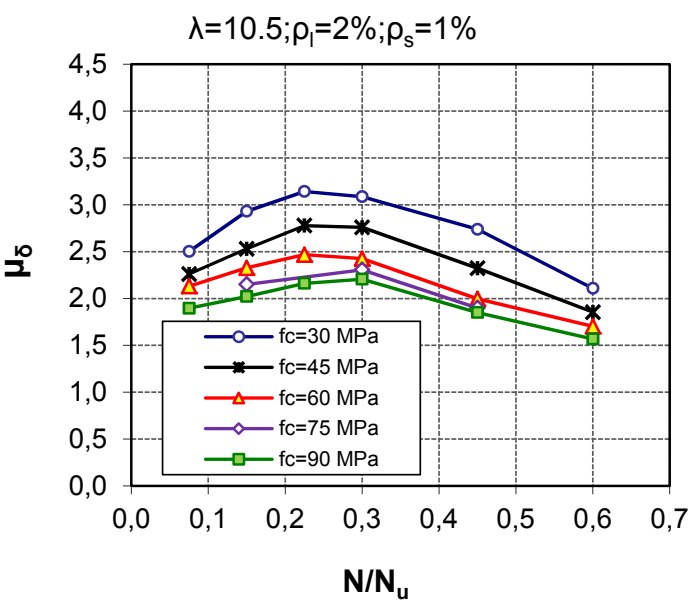

(e)

Figura 8.21 Efecto del nivel de carga axial en la ductilidad de desplazamiento para elementos de hormigón armado sometidos a flexo-compresión con valores de esbeltez de cortante de: (a) 3.5, (b) 5.0, (c) 7.5, (d) 9 y (e) 10.5 
Esto se debe a las dos razones siguientes. Por un lado, el desplazamiento elástico aumenta con la esbeltez de cortante. Por ejemplo, en las Figuras 8.22 , se muestra que el desplazamiento elástico efectivo es bastante mayor para $\lambda=10.5$ que para $\lambda=3.5$. Por otro lado, la figura muestra que la curva del desplazamiento plástico para $\lambda=3.5$ es más pronunciada para bajos niveles de carga axial, mientras que la misma curva para $\lambda=10.5$ tiende a ser más plana, para los mismos niveles de carga axial. Por consiguiente, la combinación de estos dos efectos hace que la ductilidad de desplazamiento presente un descenso claro cuando aumenta la esbeltez de cortante.

$\lambda=3.5 ; \mathrm{f}_{\mathrm{c}}=30 \mathrm{MPa} ; \mathrm{\rho}_{\mathrm{l}}=2 \% ; \rho_{\mathrm{s}}=1 \%$

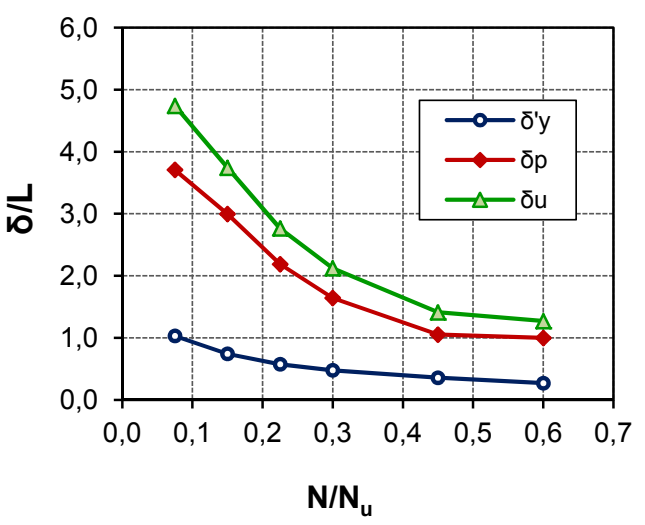

(a)

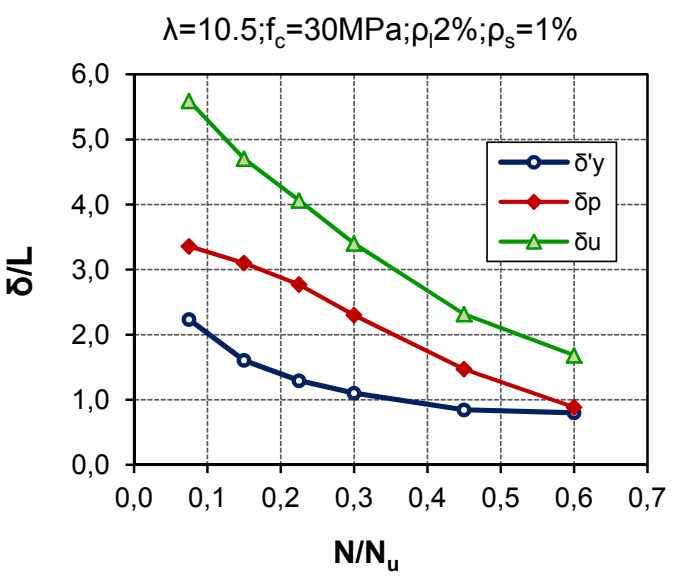

(b)

Figura 8.22 Curvas de desplazamiento elástico efectivo, desplazamiento plástico y desplazamiento último para elementos de hormigón con: (a) $\lambda=3.5,(b) \lambda=10.5$

\subsubsection{ESBELTEZ DE CORTANTE}

En las Figuras 8.23 se puede ver que la influencia de la esbeltez de cortante en la ductilidad de desplazamiento está estrechamente relacionada con el nivel de carga axial. Por una parte, para valores bajos de nivel de carga axial (entre el $7.5 \%$ y el $22.5 \%$ ), la esbeltez desempeña un importante papel en la ductilidad de desplazamiento. Por otra parte, para valores moderados y altos de nivel de carga axial (entre $22.5 \%$ y $60 \%$ ), la influencia de la esbeltez no resulta tan significativa, ya que predomina el efecto del nivel de carga axial. El análisis e interpretación de los resultados empieza a ser más complejo, ya que surge la interacción con otros parámetros, como por ejemplo la resistencia del hormigón.

Mientras que para elementos con resistencias del hormigón de $30 \mathrm{MPa}$ y $60 \mathrm{MPa}$ y bajos niveles de carga axial (menores que el $22,5 \%$ ), se observa una relación clara entre la ductilidad de desplazamiento y la esbeltez de cortante, ya que la $\mu_{\delta}$ disminuye con el aumento de la esbeltez; por el contrario, para elementos con hormigón de $90 \mathrm{MPa}$ y niveles igualmente bajos de carga axial, el aumento de la ductilidad debido al incremento de la esbeltez no resulta tan claro. Sin embargo, se puede afirmar que la combinación de una esbeltez alta $(\lambda \geq 7.5)$ con una resistencia del hormigón de $90 \mathrm{MPa}$, hace que la variación en la ductilidad se reduzca a un estrecho margen comprendido entre 1.5 y 2.0 , para todo el rango de niveles de carga axial. 


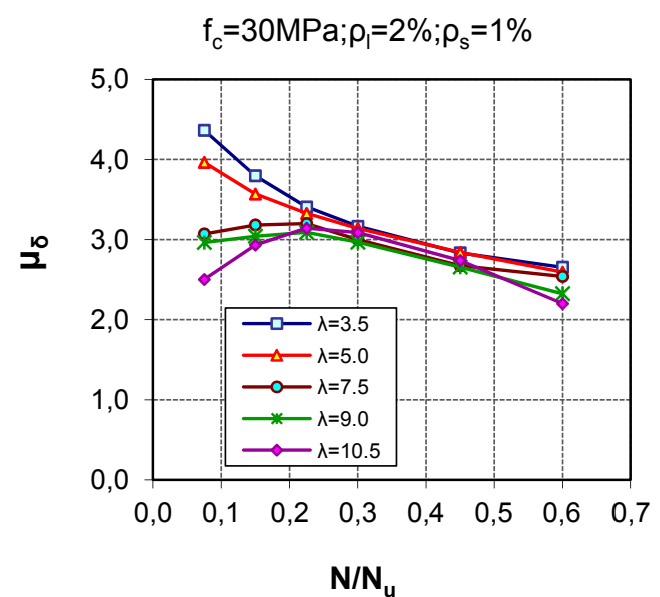

(a)

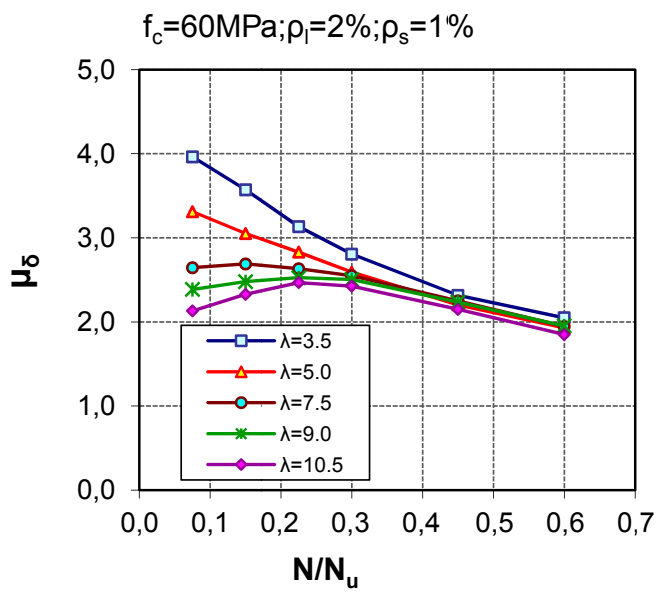

(b)

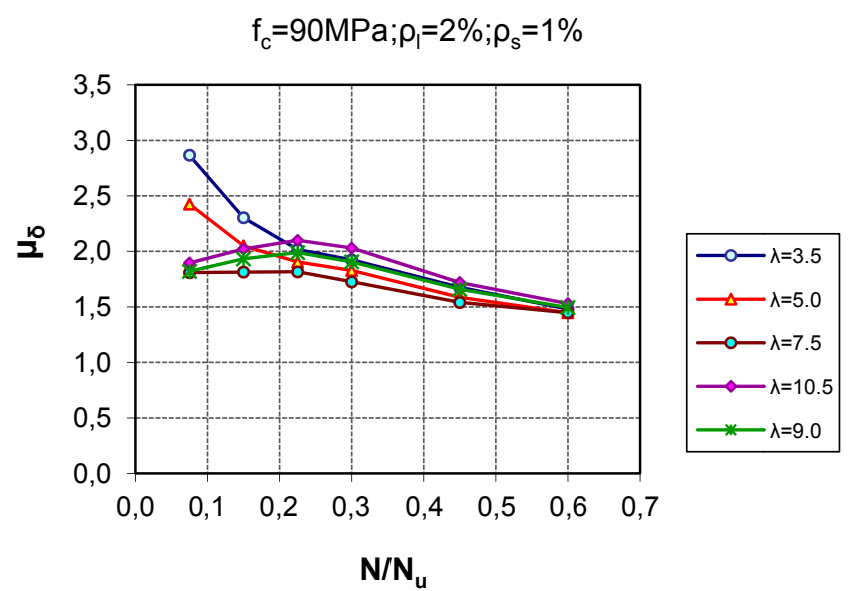

(c)

Figura 8.23 Influencia de la esbeltez de cortante en la ductilidad de desplazamiento de elementos de hormigón armado sometidos a flexo-compresión con: (a) $f_{c}=30 \mathrm{MPa}$, (b) $f_{c}=60 \mathrm{MPa}$, (c) $f_{c}=90 \mathrm{MPa}$

Al analizar las Figuras 8.24, se puede comprobar que la ductilidad disminuye de una forma aproximadamente lineal con el parámetro de la esbeltez de cortante, para los niveles de carga axial de $7.5 \%, 15 \%$ y $22.5 \%$, y para elementos de hormigón de $30 \mathrm{MPa}$, y 60MPa. Sin embargo, en elementos de $90 \mathrm{MPa}$, la ductilidad de desplazamiento no muestra variación para altos valores de esbeltez de cortante $(\lambda \geq 7.5)$.

A medida que aumenta el nivel de carga axial (Figuras 8.24), las curvas se hacen cada vez más horizontales, en especial para elementos de hormigón de $30 \mathrm{MPa}$ y $60 \mathrm{MPa}$, En elementos de hormigón de $90 \mathrm{MPa}$, la ductilidad de desplazamiento fluctúa con respecto a la esbeltez de cortante, aunque dicha variación es mínima. 


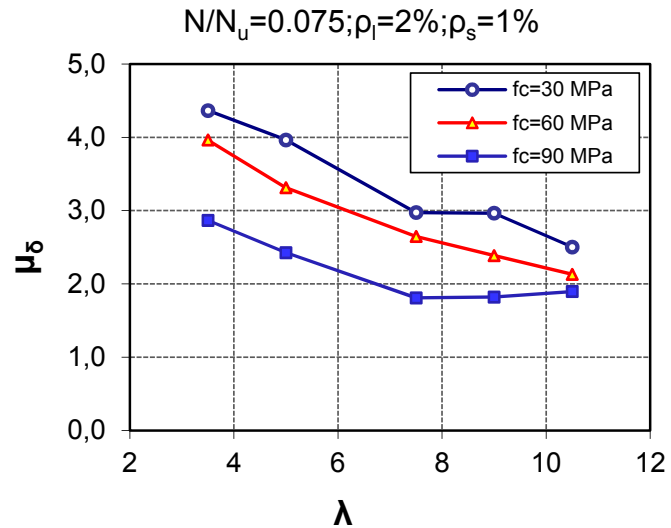

(a)

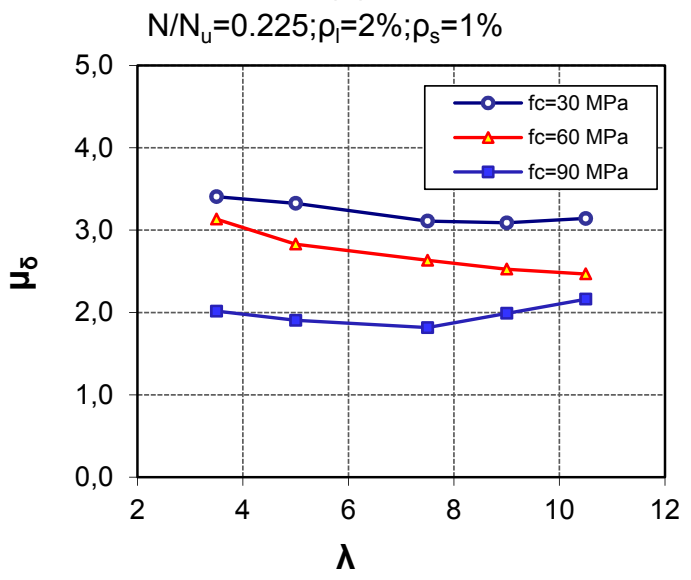

(c)

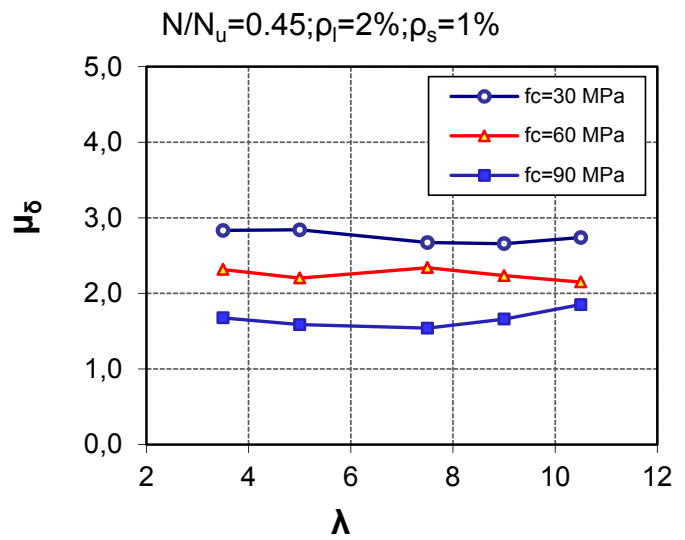

(e)

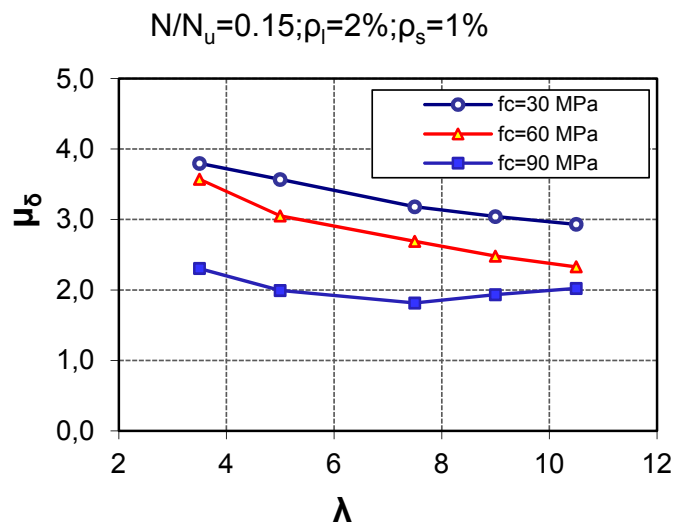

(b)

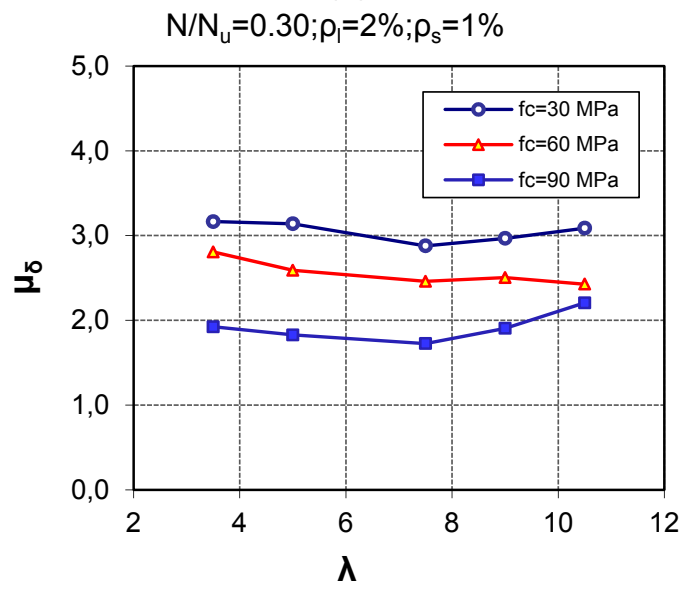

(d)

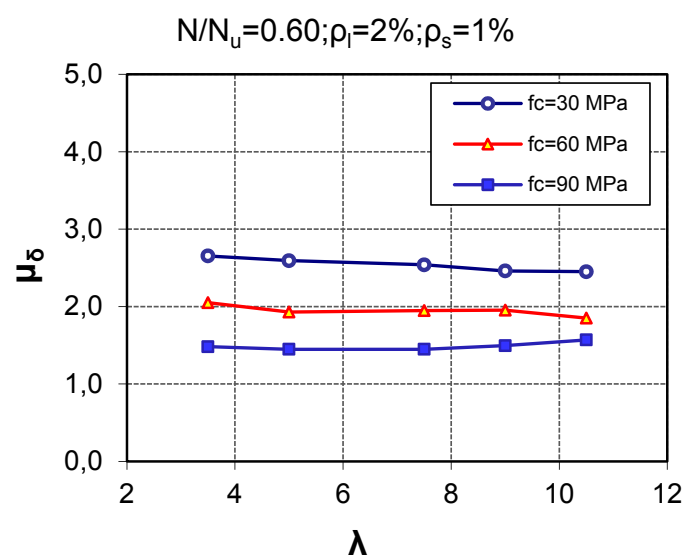

(f)

Figura 8.24 Efecto conjunto de la esbeltez de cortante y la resistencia del hormigón en la ductilidad de desplazamiento de elementos de hormigón con: (a) $N / N_{u}=7.5 \%$, (b) $N / N_{u}=15 \%$, (c) $N / N_{u}=22.5 \%$, (d) $N / N_{u}=30 \%$, (e) $N / N_{u}=45 \%$, (f) $N / N_{u}=60 \%$

En las Figura 8.24 se muestra nuevamente que la ductilidad de desplazamiento disminuye con el aumento de la resistencia del hormigón, para todo el rango de esbelteces y niveles de carga axial estudiados. En las Figuras 8.25 se comprueba que la tendencia de la pérdida de $\mu_{\delta}$ es lineal con respecto al parámetro de 
resistencia del hormigón, y la inclinación de las curvas depende en especial del nivel de carga axial.

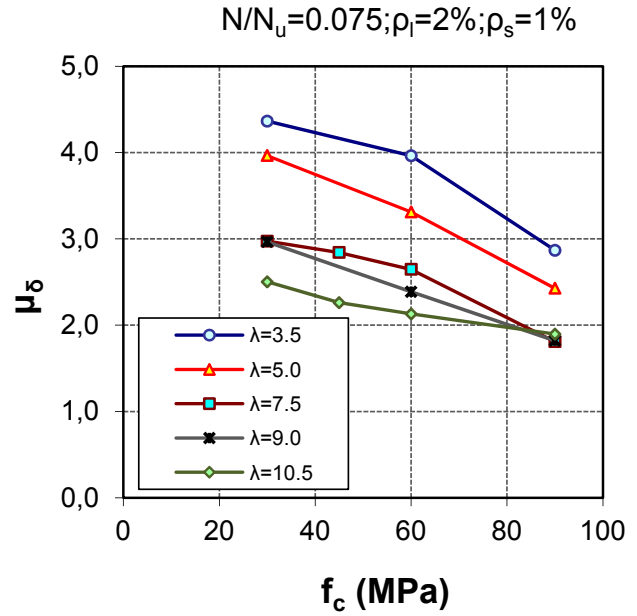

(a)

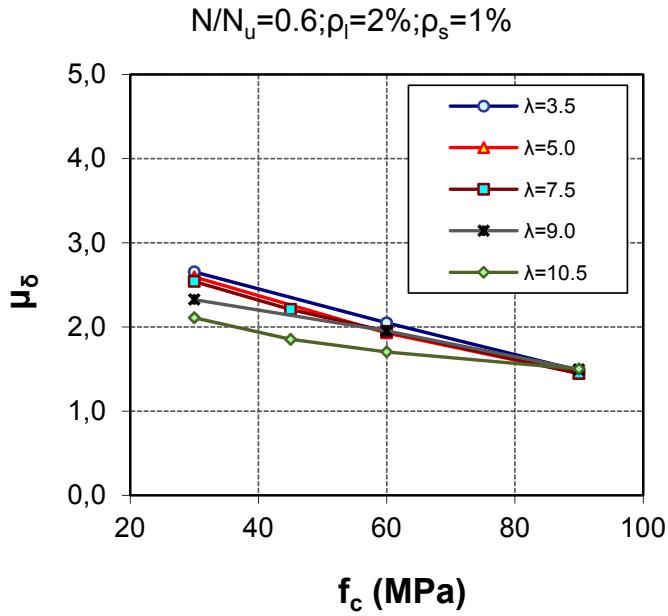

(b)

Figura 8.25 Influencia del parámetro resistencia del hormigón en la ductilidad de desplazamiento de elementos sometidos a flexo-compresión recta: (a) $N / N_{u}=7.5 \%$ y (b) $N / N_{u}=60 \%$

\subsubsection{CUANTÍA DE ARMADURA LONGITUDINAL}

Los resultados del factor de ductilidad de desplazamiento $\left(\mu_{\delta}\right)$ se presentan en las Figuras 8.26, con relación a la cuantía de armadura longitudinal $\left(\rho_{1}\right)$ para niveles de carga axial $\mathrm{N} / \mathrm{N}_{\mathrm{u}}=15 \%, 30 \%$ y $45 \%$.

Respecto a la influencia de la cuantía de armadura longitudinal en la ductilidad de desplazamiento, se ha encontrado que dicho efecto varía para las dos esbelteces analizadas en este estudio.

En primer lugar, en elementos cortos $(\lambda=3.5)$, la ductilidad disminuye con el aumento de la cuantía de armadura longitudinal. Esto obedece a la relación entre el comportamiento del desplazamiento en estado último y en estado elástico. En las secciones anteriores se ha demostrado que el desplazamiento último permanece indiferente ante el aumento de la cuantía de armadura longitudinal (para este tipo de esbeltez), mientras que el desplazamiento elástico aumenta linealmente con el incremento de $\rho_{\text {l. }}$. Por consiguiente, la relación entre el desplazamiento último y el elástico muestra una tendencia decreciente al aumentar la $\rho_{\text {I. }}$ Este efecto ha sido en principio identificado para un nivel de carga axial del 15\% (Figura 8.26a). Sin embargo, a medida que aumenta el nivel de carga axial y la resistencia del hormigón, la tendencia va disminuyendo, debido a que la influencia de estos dos últimos parámetros se hace cada vez más importante; por consiguiente, la ductilidad de desplazamiento se muestra indiferente al aumento de la $\rho_{1}$, como se observa en la Figura 8.26c. 


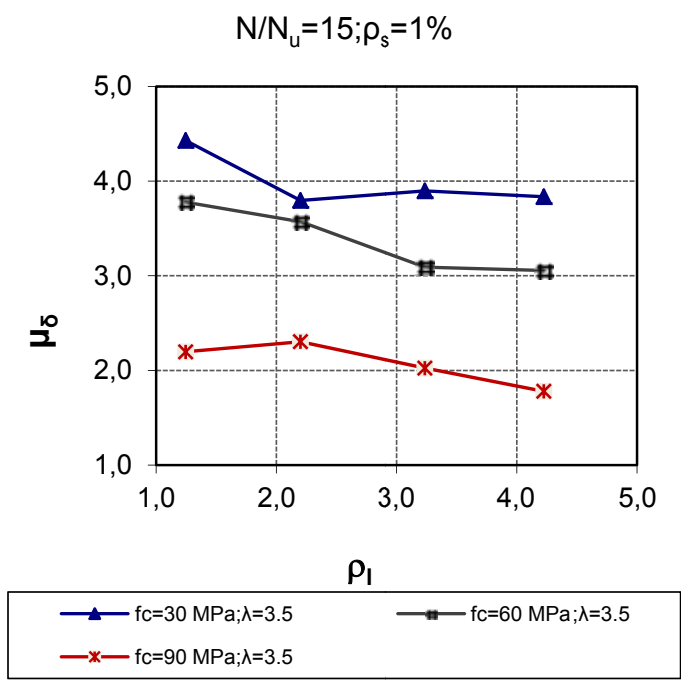

(a)

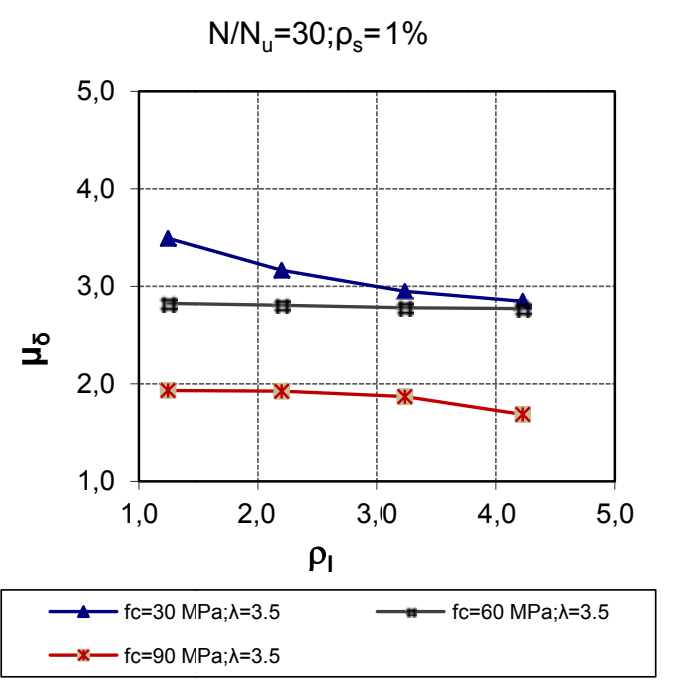

(b)

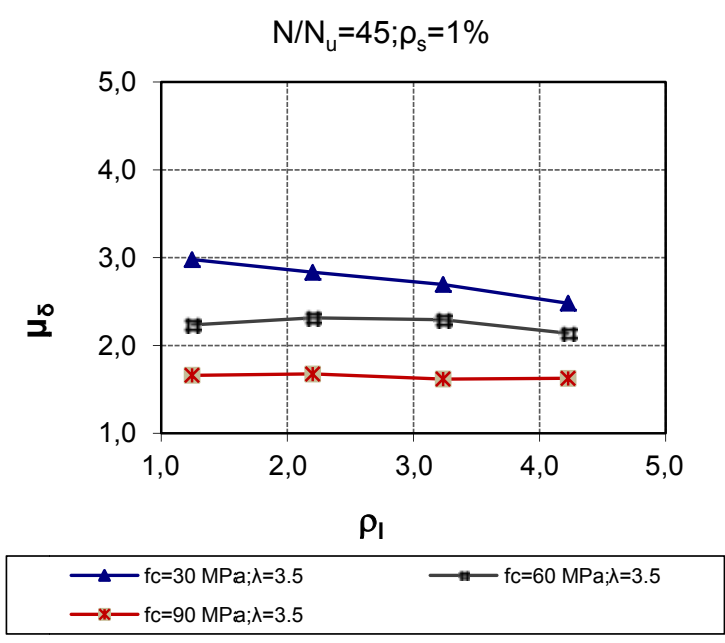

(c)

Figura 8.26 Influencia de la cuantía de armadura longitudinal en la ductilidad de desplazamiento en elementos poco esbeltos de hormigón armado sometidos a flexocompresión recta: (a) $\mathrm{N} / \mathrm{N}_{u}=15 \%$; (b) $\mathrm{N} / \mathrm{N}_{u}=30 \%$; (c) $\mathrm{N} / \mathrm{N}_{u}=45 \%$

En segundo lugar, en elementos de mayor esbeltez (Figuras 8.27), el aumento de la cuantía de armadura longitudinal provoca un ligero aumento de la ductilidad de desplazamiento, para todos los rangos estudiados de nivel de carga axial y de resistencia del hormigón. Esto se debe a que el aumento de la rigidez que proporciona la armadura longitudinal permite que el elemento aguante un poco más antes de producirse el fallo por inestabilidad (característico en elementos con este tipo de esbeltez). Por consiguiente, en estado último, es posible obtener un aumento del desplazamiento con el incremento de la cuantía de armadura longitudinal y, en consecuencia, un incremento de la ductilidad.

Se confirman nuevamente los efectos del nivel de carga axial, la esbeltez de cortante y la resistencia del hormigón, los cuales resultan ser desfavorables en términos de ductilidad. 


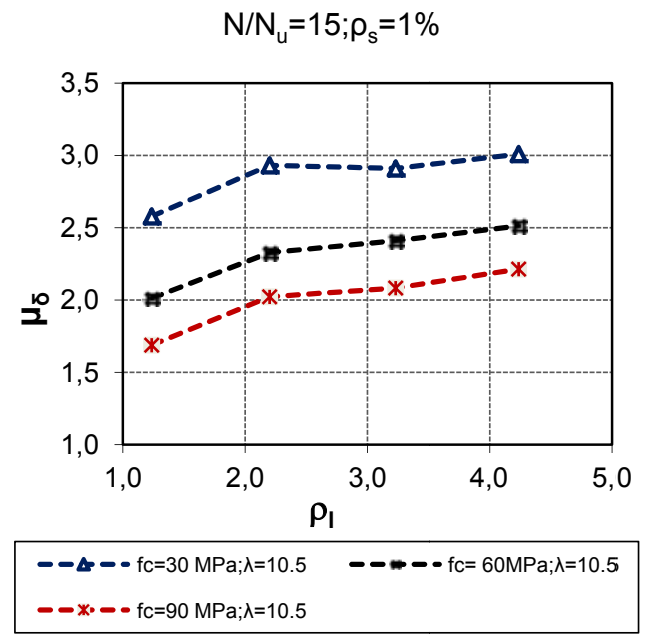

(a)

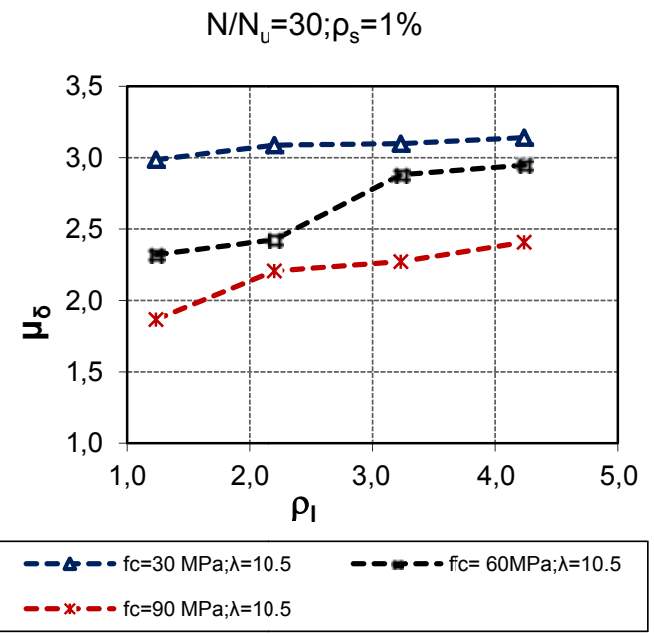

(b)

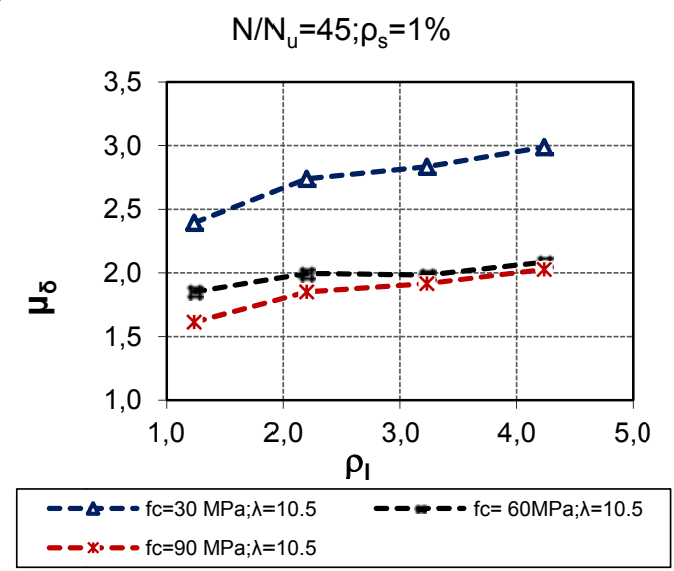

(c)

Figura 8.27 Influencia de la cuantía de armadura longitudinal en la ductilidad de desplazamiento en elementos altamente esbeltos de hormigón armado sometidos a flexo-compresión recta: (a) $\mathrm{N} / \mathrm{N}_{u}=15 \%$; (b) $\mathrm{N} / \mathrm{N}_{u}=30 \%$; (c) $\mathrm{N} / \mathrm{N}_{u}=45 \%$

\subsubsection{CUANTÍA DE ARMADURA TRANSVERSAL}

El incremento de la cuantía de armadura transversal para conseguir un mejor comportamiento dúctil en elementos de hormigón es más eficaz en hormigón de 30 $\mathrm{MPa}$ que en hormigón de $90 \mathrm{MPa}$ (como se puede ver en las Figuras 8.28). La familia de curvas continuas que identifican al hormigón de $30 \mathrm{MPa}$ muestran un incremento de ductilidad de desplazamiento a medida que aumenta la $\rho_{\mathrm{s}}$. Pero dicho aumento es menor a medida que se incrementan el nivel de carga axial y la esbeltez de cortante. Por otra parte, las curvas discontinuas que representan el hormigón de $90 \mathrm{MPa}$ se muestran indiferentes ante el aumento de la cuantía de armadura transversal. Sin embargo, los valores de ductilidad disminuyen con el aumento del nivel de carga axial, pero no muestran una tendencia clara ante la esbeltez de cortante, ya que, como se ha explicado en las secciones anteriores, para estos niveles de carga axial, el hormigón de $90 \mathrm{MPa}$ presenta una mayor variabilidad en cuanto a la ductilidad de desplazamiento para todos los valores de esbeltez de cortante. 


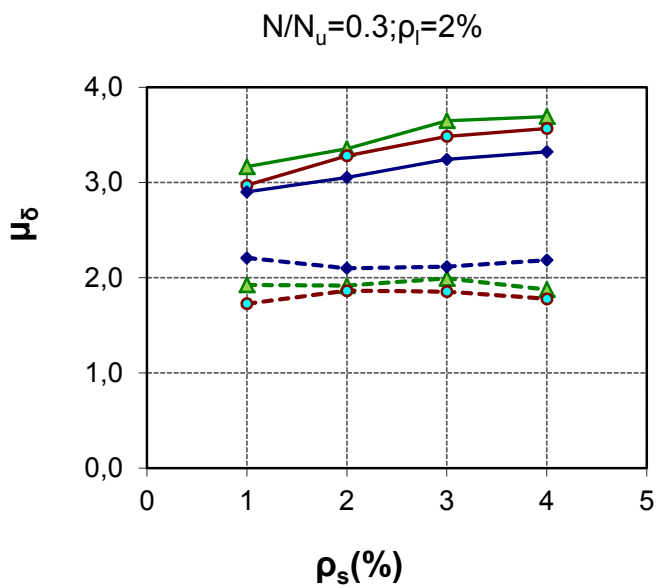

(a)

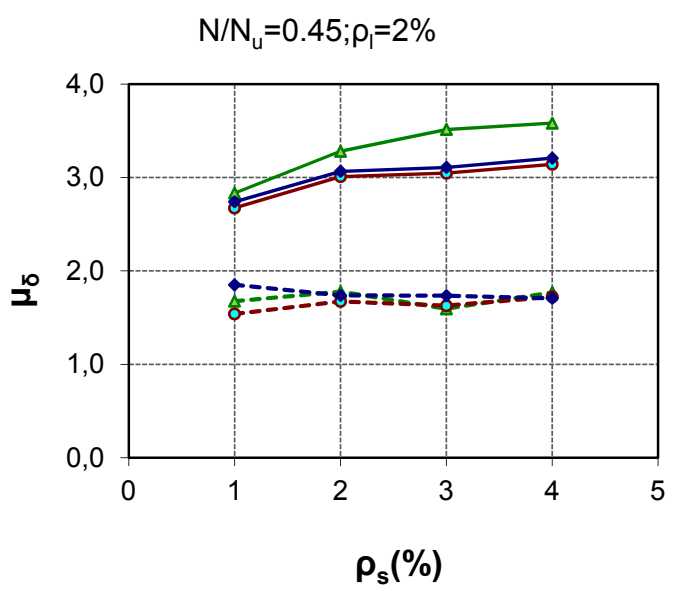

(b)

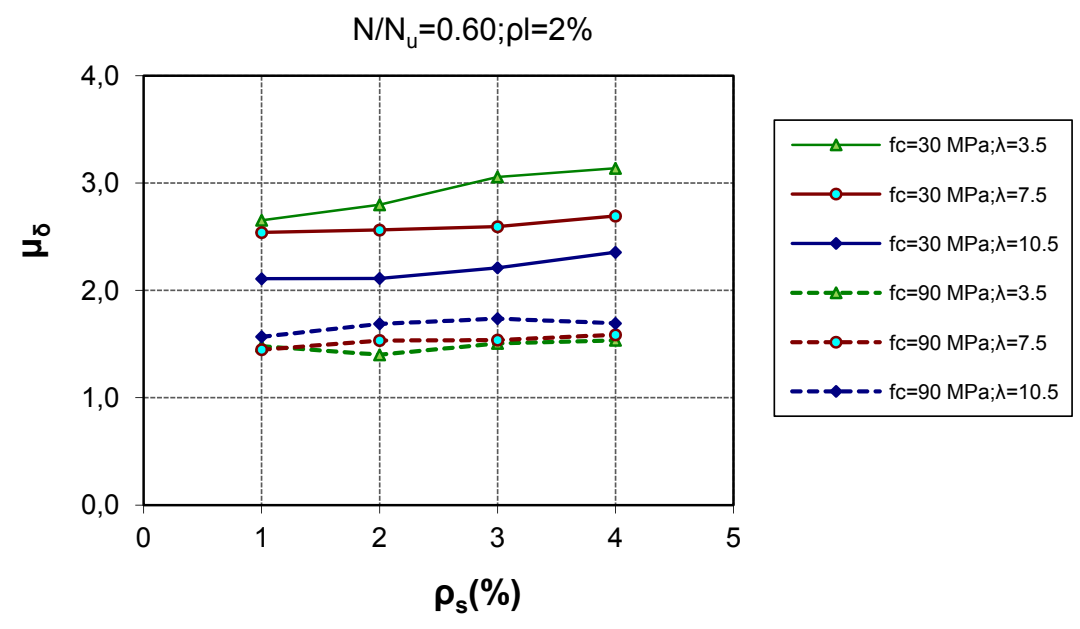

(c)

Figura 8.28 Influencia de la cuantía de armadura transversal en la ductilidad de desplazamiento en elementos de hormigón armado sometidos a flexo-compresión con niveles de carga axial de: (a) 30\%, (b) $45 \%$, y (c) $60 \%$

\subsection{RESUMEN GENERAL DEL ESTUDIO PARAMÉTRICO}

\section{Para el desplazamiento elástico}

Los principales parámetros que influyen en el estado elástico son el nivel de carga axial y la esbeltez de cortante. El desplazamiento elástico se reduce drásticamente para bajos niveles de carga axial, y disminuye más lentamente para altos valores de carga axial. El desplazamiento elástico aumenta con el incremento de la esbeltez de cortante. La tendencia puede ser lineal con el aumento de la esbeltez.

La cuantía de armadura longitudinal influye sólo cuando el nivel de carga axial es bajo, y es más sensible cuando los valores de cuantía de armadura longitudinal son bajos. 

hormigón armado

La resistencia del hormigón influye ligeramente en el desplazamiento elástico, pero el efecto es tan pequeño que puede despreciarse.

\section{Para el desplazamiento último}

La esbeltez y el nivel de carga axial son los parámetros con mayor influencia. El desplazamiento último aumenta conforme se incrementa la esbeltez, de una forma aproximadamente lineal. Mientras que el $\delta_{u}$ disminuye con el nivel de carga axial, para esbelteces bajas, la curva tiene la forma de una ecuación de segundo grado, y para esbelteces altas, la influencia es casi lineal. Este cambio en la tendencia se debe a que el aporte de la no linealidad del material presente en el desarrollo de la rama plástica de la curva de respuesta $\mathrm{P}-\delta$ disminuye conforme aumenta la esbeltez. En la Figura 8.29 se puede observar un ejemplo de la interacción de los parámetros esbeltez de cortante y nivel de carga axial.

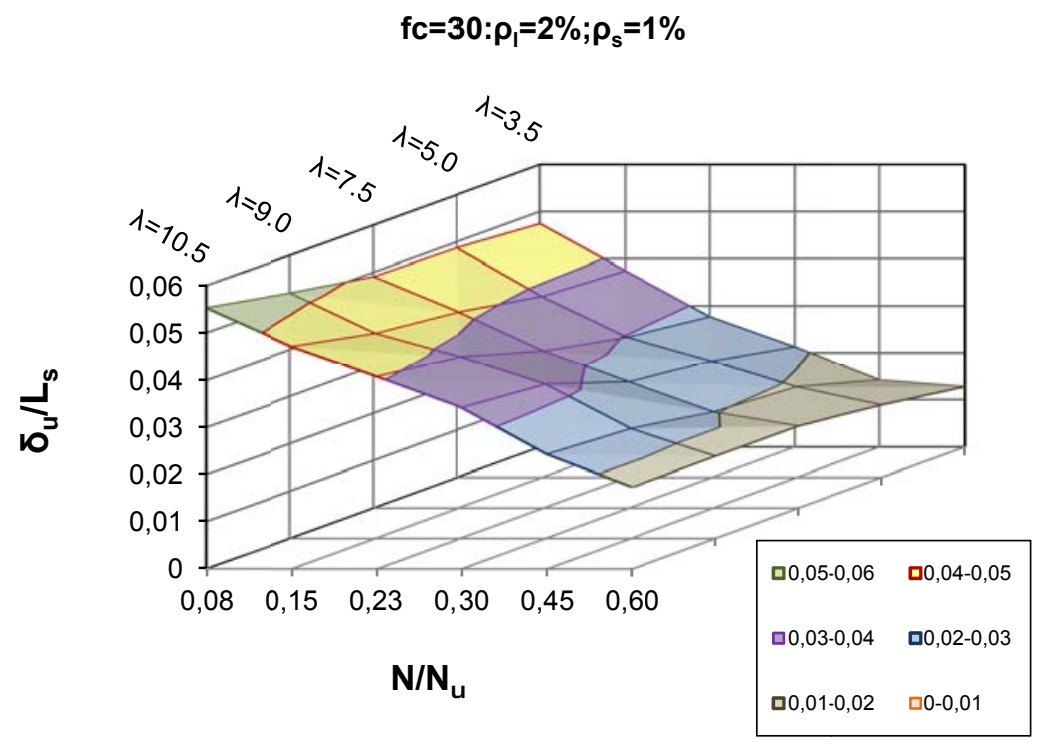

Figura 8.29 Interacción de los parámetros nivel de carga axial y esbeltez de cortante en el desplazamiento último de elementos de hormigón armado sometidos a flexocompresión recta

Respecto a la resistencia del hormigón, el análisis muestra que la capacidad de desplazamiento último disminuye con el aumento de la resistencia del hormigón.

El efecto de la cuantía de armadura longitudinal es notable para valores altos de esbeltez $(\lambda=10.5)$; el incremento de la $\rho_{\text {I }}$ provoca un aumento en el desplazamiento último, y el efecto disminuye a medida que aumenta el nivel de carga axial. En elementos poco esbeltos, el desplazamiento último permanece indiferente respecto al incremento de la $\rho_{\mathrm{l}}$.

La cuantía de armadura transversal causa un aumento en el desplazamiento último, especialmente en elementos con hormigón de $30 \mathrm{MPa}$; sin embargo, en elementos de hormigón de $90 \mathrm{MPa}$, el incremento de la capacidad de deformación es apenas visible. 


\section{Para la ductilidad de desplazamiento}

La ductilidad de desplazamiento empieza a presentar algunas dificultades para la interpretación simultánea de los parámetros nivel de carga axial y esbeltez de cortante. Tal y como se muestra en la Figura 8.30, el nivel de carga axil sigue siendo el parámetro predominante en la ductilidad. Y, en este caso, la influencia de la esbeltez depende del nivel de carga axial. De modo que la ductilidad de desplazamiento disminuye con el aumento de la esbeltez de cortante, para bajos niveles de carga axial. Sin embargo, cuando los elementos se encuentran altamente comprimidos, la influencia de la esbeltez es prácticamente insignificante.

$$
f c=30: p_{1}=2 \% ; p_{s}=1 \%
$$

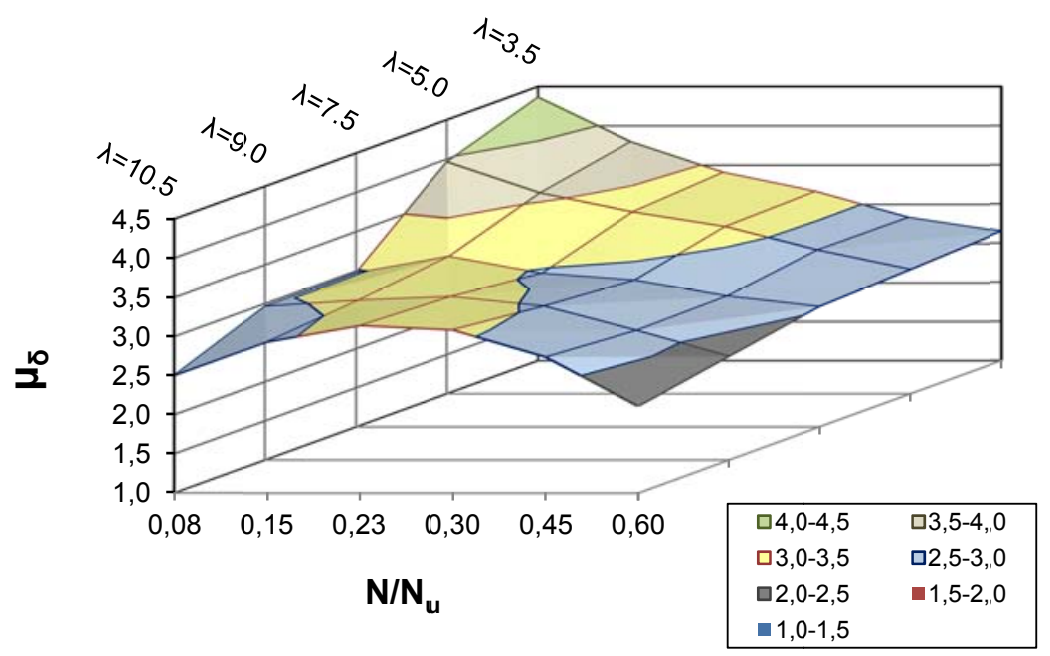

Figura 8.30 Interacción de los parámetros nivel de carga axial y esbeltez de cortante en la ductilidad de desplazamiento de elementos de hormigón sometidos a flexocompresión recta

En elementos poco esbeltos $(\lambda=3.5)$, la ductilidad disminuye con el aumento de la cuantía de armadura longitudinal. Sin embargo, a medida que aumenta el nivel de carga axial y la resistencia del hormigón, la tendencia va disminuyendo hasta mostrarse indiferente. Por otra parte, en elementos con altos valores de esbeltez, el aumento de la cuantía de armadura longitudinal provoca un ligero incremento de la ductilidad de desplazamiento, para todos los rangos estudiados de nivel de carga axial y de resistencia del hormigón.

Mediante el incremento de la cuantía de armadura transversal es posible conseguir un mejor comportamiento dúctil en elementos de hormigón de alta resistencia (90 $\mathrm{MPa}$ ) que en elementos de hormigón convencional (30 MPa).

Respecto a la resistencia del hormigón, la ductilidad de desplazamiento también disminuye conforme aumenta la resistencia del hormigón. 
Estudio experimental y numérico de la capacidad de deformación de soportes esbeltos de hormigón armado 


\section{CAPÍTULO 9}

\section{EVALUACIÓN DE LA CAPACIDAD DE DEFORMACIÓN MEDIANTE MÉTODOS EXISTENTES}

En la literatura especializada se encuentran dos tipos de métodos simplificados para evaluar la capacidad de deformación de soportes de hormigón armado. El primer tipo corresponde a modelos analíticos donde el desplazamiento máximo o deriva última $\left(\theta_{u}=\delta_{u} / L_{s}\right)$ de un elemento de hormigón armado se evalúa a partir del comportamiento de la sección crítica y de la longitud de rótula plástica $\left(L_{p}\right)$. Sin embargo, su correcta aproximación no sólo depende de una evaluación adecuada del diagrama momento-curvatura $(\mathrm{M}-\varphi)$, sino que depende especialmente de la estimación de la longitud de rótula plástica, la cual se obtiene a partir de expresiones empíricas. En este tipo de métodos analíticos se encuentra, el método descrito por Panagiotakos y Fardis (2001) [100], uno de los más conocidos y utilizados en diferentes investigaciones, que se ha presentado en diversas publicaciones, como los Boletines del CEB-FIP 24 (2003) [34] y 25 (2003) [35].

El segundo tipo comprende los métodos totalmente empíricos, obtenidos a partir de resultados de ensayos experimentales. En ellos se proponen especialmente 
expresiones para la estimación de la deriva última $\left(\theta_{\mathrm{u}}=\delta_{\mathrm{u}} / \mathrm{L}_{\mathrm{s}}\right)$. En este tipo de métodos se incluyen las expresiones de Panagiotakos y Fardis. (2001) [100] que se presentan también en los Boletines del CEB-FIP 24 (2003) [34] y 25 (2003) [35] y más adelante son modificadas por Fardis y Biskinis (2003) [60]. Dichas expresiones, con algunos ajustes, se han incluido en el Eurocódigo 8 [59].

En el presente capítulo se ha llevado a cabo, en primer lugar, una comparación de los resultados experimentales de la capacidad de deformación de elementos de hormigón armado en términos de la deriva última, con los resultados calculados mediante diferentes métodos tanto analíticos como empíricos. En segundo lugar, se ha hecho una comparación de los métodos con los resultados numéricos del modelo "ATENA 2D", lo que ha permitido realizar una revisión de los diversos métodos en un amplio rango de parámetros.

\subsection{COMPARACIÓN ENTRE LOS MÉTODOS EXISTENTES Y LOS RESULTADOS EXPERIMENTALES, PARA LA CAPACIDAD DE DEFORMACIÓN}

\subsubsection{MÉTODO ANALÍTICO DE PANAGIOTAKOS Y FARDIS}

\subsubsection{DESCRIPCIÓN DEL MÉTODO}

Como ya se ha mencionado en el capítulo 2 del estado del conocimiento, este método se basa en el modelo de soporte en voladizo, donde la distribución de curvatura inelástica se concentra en una longitud equivalente de rótula plástica $\left(L_{p}\right)$, y se asume un comportamiento elástico fuera de $L_{p}$. Por consiguiente, el desplazamiento último $\left(\delta_{\mathrm{u}}\right)$ o la deriva última $\left(\theta_{\mathrm{u}}=\delta_{\mathrm{u}} / \mathrm{L}_{\mathrm{s}}\right)$ pueden calcularse mediante la Ec. 9-1.

$$
\theta_{u}=\left(\theta_{y}+\theta_{p}\right)=\theta_{y}+\left(\varphi_{u}-\varphi_{y}\right) L_{p}\left(1-\frac{0.5 L_{p}}{L_{s}}\right)
$$

Donde

$\theta_{u} \quad$ Deriva última $\left(\delta_{u} / L_{s}\right)$

$\theta_{y} \quad$ Deriva elástica $\left(\delta_{y} / L_{s}\right)$

$\theta_{p} \quad$ Deriva plástica $\left(\delta_{p} / L_{s}\right)$

$\varphi_{u} \quad$ Curvatura última

$\varphi_{y} \quad$ Curvatura elástica

$L_{p} \quad$ Longitud de rótula plástica

$L_{s} \quad$ Distancia entre la sección de momento máximo y la sección de momento nulo.

Para aplicar la Ec. 9-1 es necesario calcular la curvatura de la sección crítica tanto en el inicio de la plastificación $\left(\varphi_{y}\right)$, como en el estado último $\left(\varphi_{u}\right)$, y definir una expresión para la longitud de rótula plástica $\left(L_{p}\right)$. Por consiguiente, la aplicación de este método consiste en tres pasos. En un primer paso, se realiza un análisis del elemento en condiciones de comportamiento elástico de los materiales, y tomando como límite el inicio de la plastificación. Esto se hace con el propósito de calcular inicialmente la curvatura elástica $\left(\varphi_{y}\right)$. Sin embargo, en el inicio de la plastificación se pueden obtener otros parámetros, fácilmente comparables con los obtenidos 
experimentalmente, como son el momento elástico $\left(M_{y}\right)$, la rigidez elástica efectiva del elemento $\left(E l_{e}\right)$ y la deriva elástica $\left(\theta_{y}=\delta_{y} / L_{s}\right)$. En el segundo paso, se lleva a cabo el cálculo de la curvatura última $\left(\varphi_{\mathrm{u}}\right)$. Finalmente, para obtener la deriva última $\left(\theta_{u}=\delta_{u} / L_{s}\right), y$, de acuerdo con la ecuación Ec. 9-1, es necesario adoptar algunas de las expresiones empíricas para la longitud de rótula plástica $\left(L_{p}\right)$, propuestas también por Panagiotakos y Fardis. (2001) [100] dentro de este método.

\title{
9.1.1.1.1 Curvatura, momento, deriva, y rigidez efectiva evaluados en el estado elástico
}

La curvatura elástica $\left(\varphi_{y}\right)$ se cuantifica en términos de los parámetros de la sección y de las propiedades del material, bajo la hipótesis de sección plana. Panagiotakos y Fardis (2001) [100] definen la curvatura elástica $\left(\varphi_{y}\right)$ considerando que la sección plastifica, o bien cuando se alcanza el límite elástico de la armadura en tracción, o bien cuando se alcanza la no-linealidad del hormigón en el extremo de la fibra mas comprimida.

Aunque normalmente la no-linealidad del hormigón ocurre en una deformación $\varepsilon_{\mathrm{c}}$ igual al $75 \%$ de la deformación correspondiente a la tensión máxima de compresión del hormigón $\left(\varepsilon_{\mathrm{co}}\right)$, el modelo de Panagiotakos y Fardis. (2001) [100] se ha ajustado considerando una deformación igual al $90 \%$ de $\varepsilon_{\mathrm{co}}$. Y por consiguiente, tanto en la aplicación práctica del modelo como en la obtención del punto de plastificación de los ensayos experimentales, se ha utilizado este criterio para la deformación que marca la no-linealidad del hormigón.

Para evaluar la deformación del hormigón correspondiente a la tensión pico, se ha utilizado el modelo constitutivo para análisis no-lineal de estructuras descrito en el Eurocódigo 2 [58].

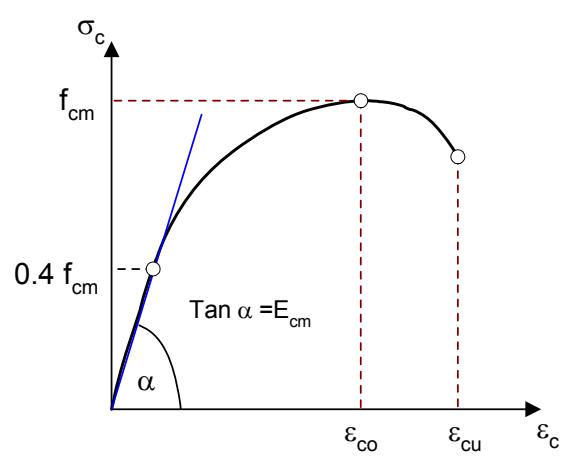

$$
\begin{aligned}
& \varepsilon_{c o}(\%)=0.7 f_{c m}^{0.31}<2.8 \\
& \text { para } f_{c m}<50 \mathrm{MPa} \\
& \varepsilon_{c u}(\%)=3.5 \\
& \text { para } f_{c m} \geq 50 \mathrm{MPa} \\
& \varepsilon_{c u}(\%)=2.8+27\left[\left(98-f_{c m}\right) / 100\right]^{4} \\
& E_{c}=22\left(f_{c m} / 10\right)^{0.3} f_{c m} \text { en } \mathrm{MPa}
\end{aligned}
$$

Figura 9.1 Modelo constitutivo del hormigón, EC-2 [58]

\author{
Donde \\ $\varepsilon_{c o} \quad$ Deformación correspondiente a la tensión pico \\ $f_{c m} \quad$ Resistencia media del hormigón en compresión en probetas cilíndricas \\ $\varepsilon_{c u} \quad$ Deformación última del hormigón en compresión \\ $E_{c} \quad$ Módulo de elasticidad del hormigón
}


Estudio experimental y numérico de la capacidad de deformación de soportes esbeltos de hormigón armado

El esquema de la Figura 9.2 muestra el proceso seguido en el cálculo de la curvatura elástica $\left(\varphi_{y}\right)$. A partir de $\varphi_{y}$ es posible calcular otras variables también relacionadas con el estado elástico, como son: (1) el momento $M_{y}$, (2) la deriva elástica $\theta_{\mathrm{y}}$ y $(3)$ la rigidez efectiva de la sección o del elemento $\left(\mathrm{El}_{\mathrm{ef}}\right)$.

\section{CÁLCULO DE LA CURVATURA ELÁSTICA}

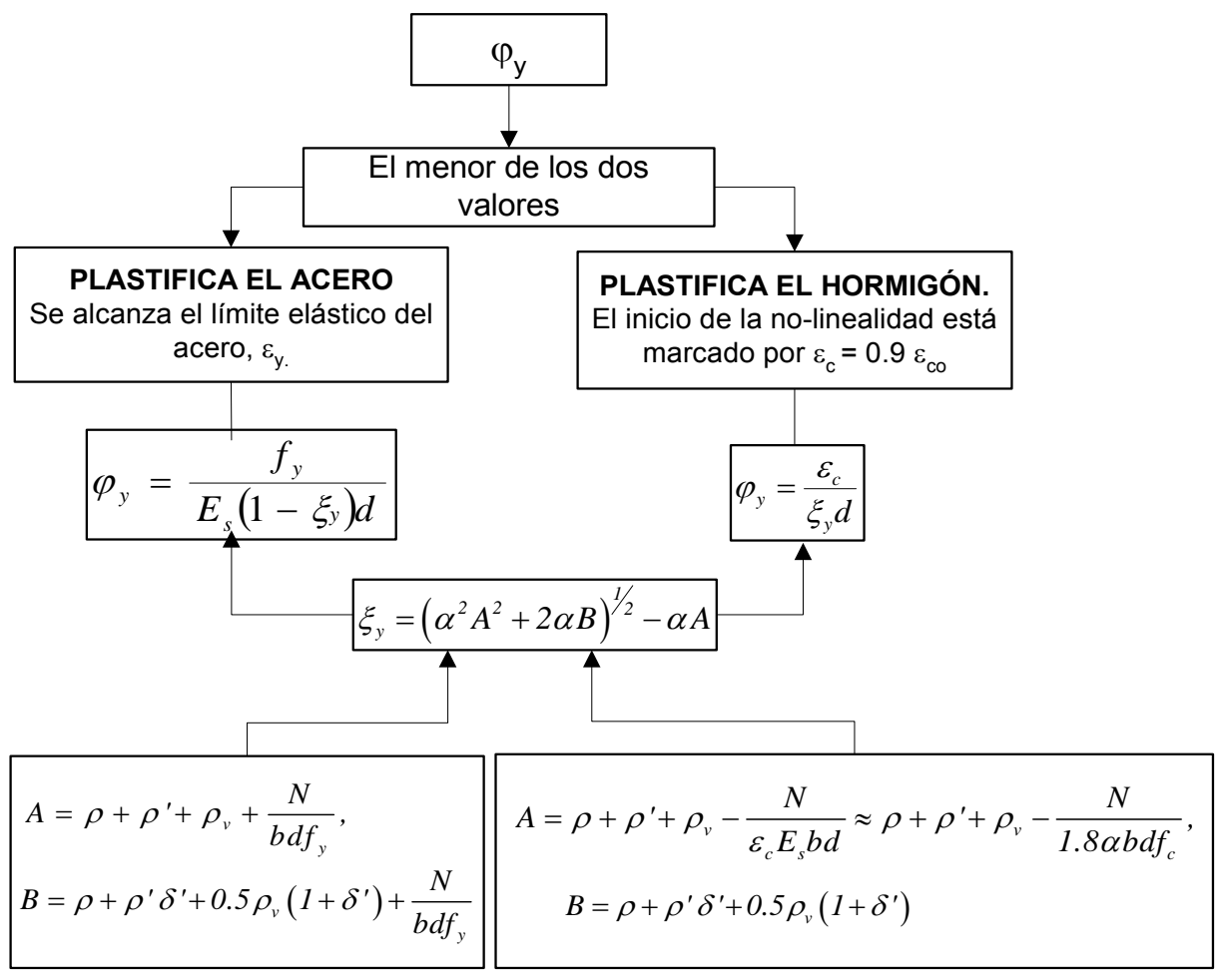

Figura 9.2 Esquema del proceso para el cálculo de la curvatura elástica, método propuesto por Panagiotakos y Fardis. (2001) [100]

Donde

b Ancho de la sección

d Canto útil de la sección transversal

$d^{\prime} \quad$ Recubrimiento mecánico de la armadura comprimida

$E_{c} \quad$ Módulo de elasticidad del hormigón

$E_{s} \quad$ Módulo de elasticidad del acero

$\varepsilon_{c} \quad$ Deformación del hormigón en compresión que marca el inicio de la no-

linealidad

$f_{c} \quad$ Resistencia del hormigón en compresión

$N \quad$ Carga axial aplicada

$\alpha \quad$ Relación entre el módulo de elasticidad del acero y del hormigón Es/Ec

$\rho \quad$ Cuantía de armadura en tracción (para toda la sección bd)

$\rho^{\prime} \quad$ Cuantía de armadura en compresión (para toda la sección bd)

$\rho_{V} \quad$ Cuantía de armadura distribuida (para toda la sección bd)

$\delta^{\prime} \quad$ Relación $d^{\prime} / d$

$\mathcal{E}_{c} \quad$ Deformación del hormigón en compresión que marca el inicio de la nolinealidad

$\varepsilon_{y} \quad$ Deformación para el límite elástico del acero $\varepsilon_{y}=f_{y} / E_{s}$

$\varphi_{y} \quad$ Curvatura elástica 
El momento elástico $\left(\mathbf{M}_{\mathbf{y}}\right)$ puede calcularse a partir de la Ec. 9-6:

$$
\frac{M_{y}}{b d^{3}}=\phi_{y}\left\{E_{c} \frac{k_{y}^{2}}{2}\left(0.5\left(1+\delta^{\prime}\right)-\frac{k_{y}}{3}\right)+\frac{E_{s}}{2}\left[\left(1-k_{y}\right) \rho+\left(\kappa_{y}-\delta^{\prime}\right) \rho^{\prime}+\frac{\rho_{v}}{6}\left(1-\delta^{\prime}\right)\right]\left(1-\delta^{\prime}\right)\right\} \quad \text { Ec. 9-6 }
$$

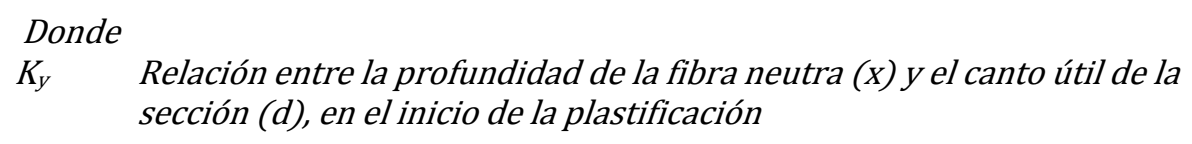
sección (d), en el inicio de la plastificación

Para predecir la deriva en estado elástico $\left(\boldsymbol{\theta}_{\mathrm{y}}\right)$, Panagiotakos y Fardis (2001) [100] proponen una expresión que se compone de tres términos independientes (Ec. 9-7). El primer término tiene que ver con la plastificación teórica debida a la flexión, $\left(\varphi_{y} L_{s} / 3\right)$; en el segundo término se considera la contribución debida a la distorsión por cortante; y el tercer término se refiere a la rotación en el extremo fijo debida al deslizamiento de la armadura, el cual depende directamente de la adherencia.

$$
\theta_{y}=\varphi_{y} \frac{L_{s}}{3}+0.0025+a_{s l} \frac{0.25 \varepsilon_{y} d_{b} f_{y}}{\left(d-d^{\prime}\right) \sqrt{f_{c}}}
$$

Donde

$d_{b} \quad$ Diámetro de la armadura longitudinal

$\alpha_{S l} \quad$ Coeficiente igual a 1 si se desliza la armadura longitudinal en la zona de anclaje en las secciones cercanas al apoyo, y 0 si esto no es posible.

Finalmente, la rigidez efectiva del elemento fisurado se puede obtener mediante la Ec. 9-8.

$$
E I_{e}=\frac{M_{y} L_{s}}{3 \theta_{y}}
$$

\subsection{Curvatura en estado último}

Definir el estado último de la sección es más complejo y requiere de un análisis más detallado en el que se tienen en cuenta la mayor parte de los parámetros que afectan la deformabilidad, como son: el nivel de carga axial $\left(\mathrm{N} / \mathrm{N}_{\mathrm{u}}\right)$, la esbeltez de cortante $(\lambda=L s / h)$, el confinamiento $\left(\rho_{s}\right)$, la cuantía de armadura longitudinal $\left(\rho_{1}\right), y$ las características de los materiales.

El procedimiento consiste en identificar la capacidad de deformación última de la sección asociada al tipo de fallo que se produce por cualquiera de las dos situaciones siguientes: o bien por la rotura de la armadura en tracción o bien cuando la zona en compresión falla y pierde su capacidad de carga. Adicionalmente, el nivel de confinamiento es otro de los parámetros que condicionan que el fallo se origine o bien a nivel de la sección completa, o bien a nivel del núcleo confinado una vez tenga lugar el desprendimiento del recubrimiento. Por lo tanto, la interacción de estos dos parámetros (nivel de carga axial y confinamiento) serán los principales condicionantes, en el método propuesto por Panagiotakos y Fardis (2001) [100], para el cálculo de la curvatura última de la sección. En la Figura 9.3 se presenta un esquema general del procedimiento de cálculo. 
Estudio experimental y numérico de la capacidad de deformación de soportes esbeltos de hormigón armado

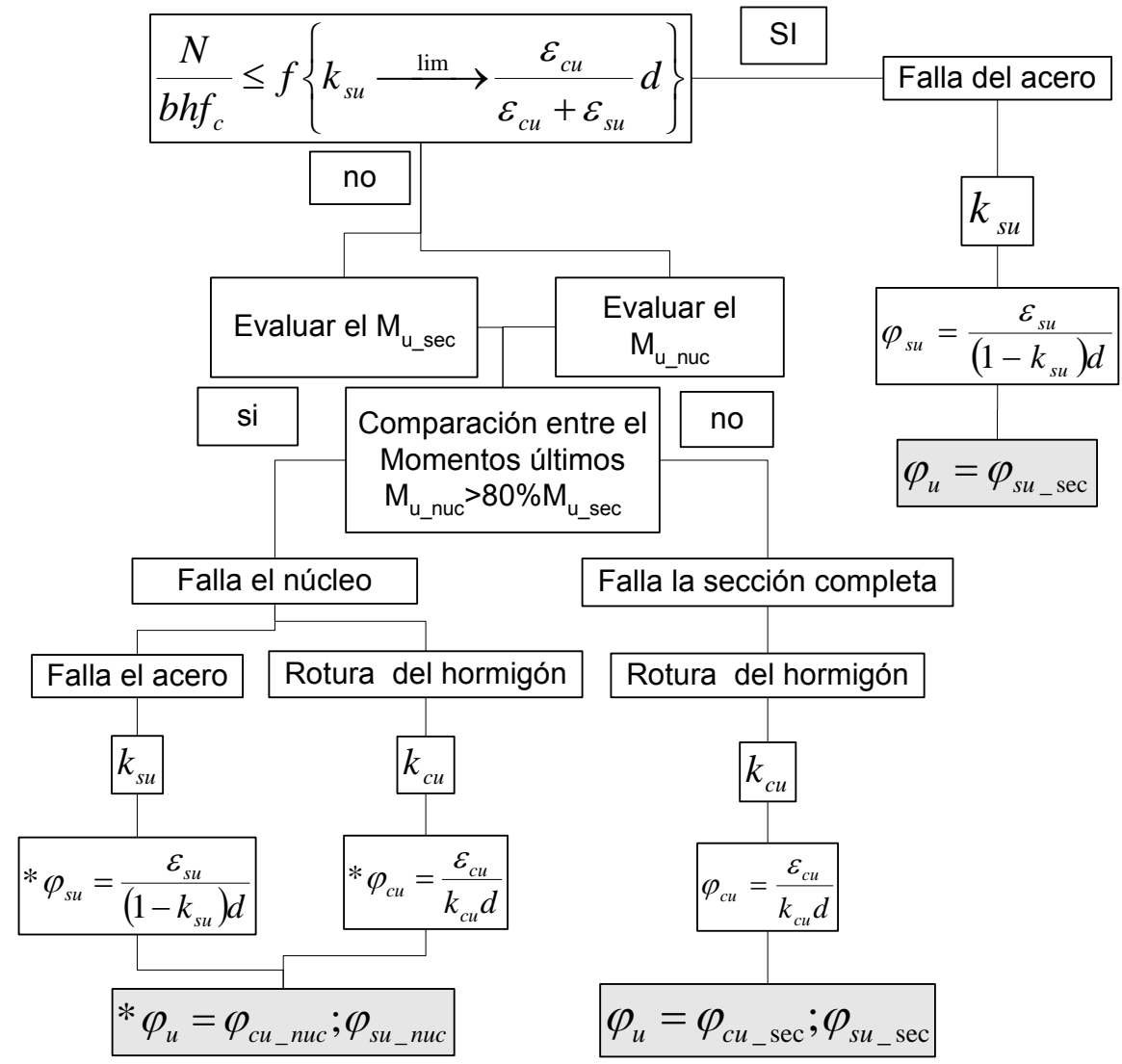

*Variables evaluadas teniendo en cuenta las propiedades y características geométricas del núcleo

Figura 9.3 Esquema del proceso para el cálculo de la curvatura última, método propuesto por Panagiotakos y Fardis (2001) [100]

El proceso de cálculo se inicia con el análisis de la sección completa. En esta situación, el fallo de la sección debido a la rotura del acero se produce cuando la armadura en tracción alcanza la deformación última, lo cual sólo se da para bajos niveles de carga axial, donde la profundidad de la fibra neutra $\left(\kappa_{\mathrm{su}}\right)$ es inferior a $\varepsilon_{\mathrm{cu}} \mathrm{d} /\left(\varepsilon_{\mathrm{su}}+\varepsilon_{\mathrm{cu}}\right)$. Esto implica la siguiente limitación en el nivel de carga axial:

$$
\frac{N}{b d f_{c}}<\frac{\varepsilon_{c u}-\frac{\varepsilon_{c o}}{3}}{\varepsilon_{c u}+\varepsilon_{s u}}+\omega^{\prime}-\frac{\rho f_{t}}{f_{c}}-\frac{\rho_{v}\left(f_{y}+f_{t}\right)}{f_{c}} \frac{\varepsilon_{\text {su }}\left(1+\delta^{\prime}\right)-\varepsilon_{c u}\left(1-\delta^{\prime}\right)}{\left(1-\delta^{\prime}\right)\left(\varepsilon_{\text {su }}+\varepsilon_{c u}\right)}
$$

Donde:
$b \quad$ Ancho de la sección transversal
d Canto útil de la sección
$d^{\prime} \quad$ Recubrimiento mecánico de la armadura de compresión
$f_{y} \quad$ Límite elástico del acero
$f_{t} \quad$ Carga última del acero longitudinal
$f_{c} \quad$ Resistencia del hormigón en compresión
$N \quad$ Carga axial aplicada
$\rho \quad$ Cuantía de armadura en tracción (para la sección bd)
$\rho^{\prime} \quad$ Cuantía de armadura en compresión (para la sección bd) 
$\rho_{V} \quad$ Cuantía de armadura de reparto en caso de muros (para la sección bd)

$\omega^{\prime} \quad$ Cuantía mecánica de armadura en compresión $=\rho f_{y} / f_{c}$

$\delta^{\prime} \quad$ Relación $d^{\prime} / d$

$\mathcal{E}_{c o} \quad$ Deformación para la tensión máxima del hormigón en compresión

$\varepsilon_{c u} \quad$ Deformación última del hormigón en compresión no confinado

$\mathcal{E}_{s u} \quad$ Deformación última del acero longitudinal

Cuando se cumple la Ec. 9-9, la curvatura última se calcula mediante las Ec. 9-10 y Ec. 9-11.

$$
\begin{gathered}
\varphi_{\text {su }}=\frac{\varepsilon_{\text {su }}}{\left(1-k_{\text {su }}\right) d} \\
k_{\text {su }}=\frac{\left(1-\delta^{\prime}\right)\left(\frac{N}{b d f_{c}^{\prime}}+\frac{\rho f_{t}}{f_{c}^{\prime}}-\frac{\rho^{\prime} f_{y}^{\prime}}{f_{c}^{\prime}}+\frac{\varepsilon_{c o}}{3 \varepsilon_{s u}}\right)+\left(\frac{1+\delta^{\prime}}{2}\right) \frac{\rho_{v}\left(f_{y}+f_{t}\right)}{f_{c}^{\prime}}}{\left(1-\delta^{\prime}\right)\left(1+\frac{\varepsilon_{c o}}{3 \varepsilon_{s u}}\right)+\frac{\rho_{v}\left(f_{y}+f_{t}\right)}{f_{c}^{\prime}}}
\end{gathered}
$$

Donde

$\varphi_{s u} \quad$ Curvatura última de la sección cuando el fallo es debido al agotamiento del acero

$k_{s u} \quad$ Relación entre la profundidad de la fibra neutra ( $x$ ) y el canto útil de la sección (d), cuando el fallo ocurre por agotamiento del acero

En caso contrario, la rotura ocurre en la zona de compresión, es decir, se alcanza la deformación última del hormigón no-confinado $\left(\varepsilon_{\mathrm{cu}}\right)$ en la fibra más comprimida, y la curvatura última se evalúa a partir de la Ec. 9-12.

$$
\varphi_{c u}=\frac{\varepsilon_{c u}}{k_{c u} d}
$$

Donde

$\varphi_{c u} \quad$ Curvatura última de la sección cuando el fallo se debe al hormigón

$k_{c u} \quad$ Relación entre la altura de la fibra neutra ( $x$ ) y la altura efectiva de la sección (d), cuando el fallo ocurre en la zona en compresión

Sin embargo, la rotura del hormigón se alcanza con la plastificación o previamente a la plastificación de la armadura de tracción. Es decir, si la armadura de tracción plastifica, la profundidad de la fibra neutra $\left(\mathrm{k}_{\mathrm{cu}}=\mathrm{x} / \mathrm{d}\right)$ será menor que $\varepsilon_{c u} d /\left(\varepsilon_{y}+\varepsilon_{c u}\right)$, lo que nos lleva a la siguiente condición (Ec. 9-13).

$$
\frac{N}{b d f_{c}^{\prime}}<\frac{\rho^{\prime} f_{y}^{\prime}}{f_{c}^{\prime}}-\frac{\rho f_{y}}{f_{c}^{\prime}}-\frac{\delta^{\prime}}{1-\delta^{\prime}} \frac{\rho_{v} f_{y}}{f_{c}^{\prime}}+\frac{\left(\varepsilon_{c u}-\frac{\varepsilon_{c o}}{3}\right)+\left(\varepsilon_{c u}-\varepsilon_{y}\right) \frac{\rho_{v} f_{y}}{\left(1-\delta^{\prime}\right) f_{c}^{\prime}}}{\varepsilon_{c u}+\varepsilon_{y}}
$$

Si la ecuación anterior se cumple, $\mathrm{K}_{\mathrm{cu}}$ se obtiene a partir de la Ec. 9-14.

$$
k_{c u}=\frac{\left(1-\delta^{\prime}\right)\left(\frac{N}{b d f_{c}^{\prime}}+\frac{\rho f_{y}}{f_{c}^{\prime}}-\frac{\rho^{\prime} f_{y}^{\prime}}{f_{c}^{\prime}}\right)+\left(1+\delta^{\prime}\right)\left(\frac{1+\delta^{\prime}}{2}\right) \frac{\rho_{v} f_{y}}{f_{c}^{\prime}}}{\left(1-\delta^{\prime}\right)\left(1-\frac{\varepsilon_{c o}}{3 \varepsilon_{c u}}\right)+2 \frac{\rho_{v} f_{y}}{f_{c}^{\prime}}}
$$


De lo contrario, $\mathrm{k}_{\mathrm{cu}}$ es la raíz positiva de la Ec. 9-15.

$$
\begin{aligned}
& {\left[1-\frac{\varepsilon_{c o}}{3 \varepsilon_{c u}}-\frac{\rho_{v} f_{y}}{2\left(1-\delta^{\prime}\right) f_{c}^{\prime}} \frac{\left(\varepsilon_{c u}-\varepsilon_{y}\right)^{2}}{\varepsilon_{c u} \varepsilon_{y}}\right] k^{2}+\left[\frac{\rho^{\prime} f_{y}^{\prime}}{f_{c}^{\prime}}+\frac{\rho f_{y} \varepsilon_{c u}}{f_{c}^{\prime} \varepsilon_{y}}-\frac{N}{b d f_{c}^{\prime}}+\frac{\rho_{v} f_{y}}{\left(1-\delta^{\prime}\right) f_{c}^{\prime}}\left(\frac{\varepsilon_{c u}}{\varepsilon_{y}}-\delta^{\prime}\right)\right] k} \\
& -\left[\frac{\rho f_{y}}{f_{c}^{\prime}}+\frac{\rho_{v} f_{y}}{2\left(1-\delta^{\prime}\right) f_{c}^{\prime}}\right] \frac{\varepsilon_{c u}}{\varepsilon_{y}}=0
\end{aligned}
$$

Aunque en este primer análisis se ha obtenido la curvatura última $\varphi_{c u}$ para la sección completa, el efecto del confinamiento puede influir en el comportamiento último de la sección. Esto se debe a que, una vez se produce la pérdida de recubrimiento, el núcleo confinado permite un incremento de la deformación sin una pérdida significativa en su capacidad. Consecuentemente, el fallo puede deberse o bien a la rotura del acero o bien a la rotura del hormigón, pero para el núcleo confinado.

Por consiguiente, se considera que, si la capacidad de momento del núcleo confinado, determinada en base a la resistencia $\left(\mathrm{f}_{\mathrm{cc}}\right)$ y la deformación última del hormigón confinado $\left(\varepsilon_{\mathrm{cc}}\right)$, es mayor que el $80 \%$ de la capacidad de momento para la sección completa sin confinar, el comportamiento post-pico de la sección será resistido por el núcleo confinado, y el fallo último ocurrirá en el menor de los dos valores de curvatura, obtenidos mediante las Ec. 9-10 y Ec. 9-11 (para la rotura del acero), y las Ec. 9-12 a Ec. 9-15 (para la rotura del hormigón), pero esta vez aplicadas de acuerdo con las características geométricas del núcleo confinado $\left(b_{c}\right.$, $d_{c}, h_{c}, d_{c}$, teniendo en cuenta que: $N, \rho, \rho$ ' son obtenidas para $b_{c} . d_{c}$ ) e incorporando un modelo constitutivo para el hormigón confinado.

El modelo del hormigón confinado adoptado inicialmente por Panagiotakos y Fardis (2001) [100] dentro de la metodología descrita, es también asumido en el presente estudio, y corresponde a una modificación del modelo de Mander et al. (1988) [85].

$$
\begin{gathered}
f_{c c}=f_{c}\left(1+3.7\left(\frac{0.5 \alpha \rho_{s} f_{y h}}{f_{c}}\right)^{0.87}\right) \\
\varepsilon_{c c}=0.004+0.6 \varepsilon_{s u} \frac{\rho_{s} f_{y h}}{f_{c c}} \\
\alpha=\left(1-\frac{s_{h}}{2 b_{c}}\right)\left(1-\frac{s_{h}}{2 h_{c}}\right)\left(1-\frac{\Sigma b_{i}^{2}}{6 b_{c} h_{c}}\right)
\end{gathered}
$$

Donde

$d_{c} \quad$ Altura efectiva de la sección del núcleo confinado

$d_{c}{ }^{\prime} \quad$ Distancia del centro de la armadura de compresión al centro del estribo

$h_{c} \quad$ Altura de la sección del núcleo confinado

$\rho_{s} \quad$ Cuantía volumétrica de armadura transversal

$f_{y h} \quad$ Límite elástico del acero transversal

$f_{c} \quad$ Resistencia del hormigón en compresión

$s_{h} \quad$ Separación entre cercos

$b_{c} \quad$ Ancho del núcleo confinado

$h_{c} \quad$ Canto del núcleo confinado

$b_{i} \quad$ Distancia entre sucesivas armaduras longitudinales atadas mediante ganchos 


\subsection{Longitud de plastificación}

La expresión utilizada para el cálculo de la longitud de rótula plástica es la propuesta por Panagiotakos y Fardis (2001) [100].

$$
L_{p l, \text { mon }, L s}=0.18 L_{s}+0.025 a_{s l} d_{b} f_{y}
$$

Donde

Ls $\quad$ Longitud del elemento de hormigón entre el punto de momento máximo y momento nulo

$a_{s l} \quad$ Coeficiente igual a 1 si se desliza la armadura longitudinal en la zona de anclaje en las secciones cercanas al apoyo, y 0 si esto no es posible

$d_{b} \quad$ Diámetro de la armadura longitudinal

fy Límite elástico de la armadura

En la expresión de $L_{p}$, el segundo término tiene que ver con el deslizamiento de la armadura anclada en el apoyo. Sin embargo, en los ensayos experimentales no se desarrolla este efecto, dada la continuidad de la armadura. Por tanto, la longitud de rótula plástica de acuerdo con la Ec. 9-19 sólo depende de la longitud del vano de cortante $\left(L_{s}\right)$.

\subsubsection{COMPARACIÓN ENTRE RESULTADOS EXPERIMENTALES Y TEÓRICOS OBTENIDOS MEDIANTE EL MÉTODO ANALÍTICO DE PANAGIOTAKOS Y FARDIS}

\subsection{Curvatura, deriva, momento y rigidez efectiva calculados en el estado elástico}

Los parámetros estimados en el estado elástico de acuerdo con el modelo analítico expuesto por Panagiotakos y Fardis (2001) [100], son comparados con los resultados experimentales, y se presentan en las Figura 9.5.

Los valores experimentales de la curvatura $\left(\varphi_{y}\right)$, el momento $\left(\mathrm{M}_{\mathrm{y}}\right)$, la deriva $\left(\theta_{\mathrm{y}}\right)$ y la rigidez efectiva del elemento $\left(\mathrm{El}_{\mathrm{e}}\right)$, son medidos sobre la curva real de los diagramas de momento-curvatura y carga-desplazamiento, conforme a los principios utilizados por Panagiotakos y Fardis (2001) [100] para definir el punto de plastificación (Figura 9.4). Dicho punto se ha identificado previamente en los ensayos experimentales, puesto que es uno de los criterios aplicados en este estudio para la idealización de los diagramas $M-\varphi$ y $P-\delta$ mediante el método $1 \mathrm{~A}$ (Eurocódigo 8) [59], explicado en la sección 6.4.
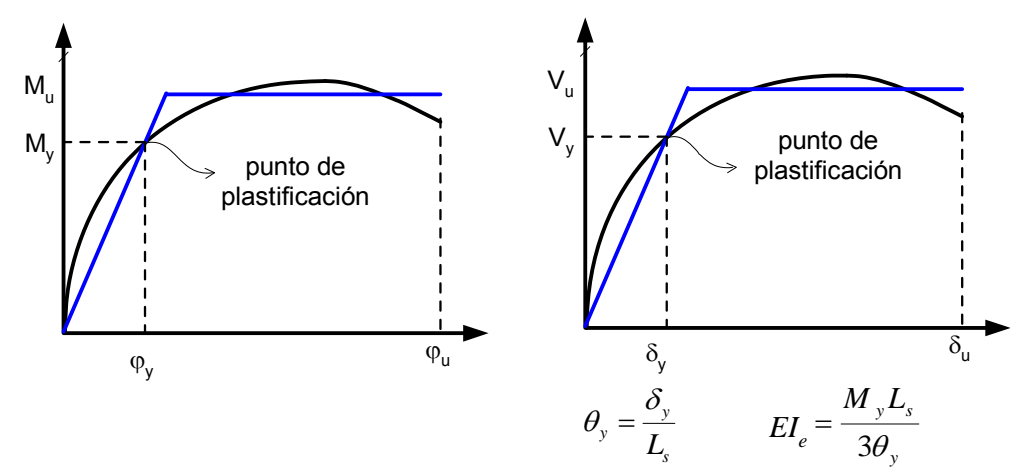

Figura 9.4 Descripción de: $\varphi_{y}, M_{y}, \theta_{y}$ y El $l_{e}$ evaluadas en la curva experimental 
Estudio experimental y numérico de la capacidad de deformación de soportes esbeltos de hormigón armado

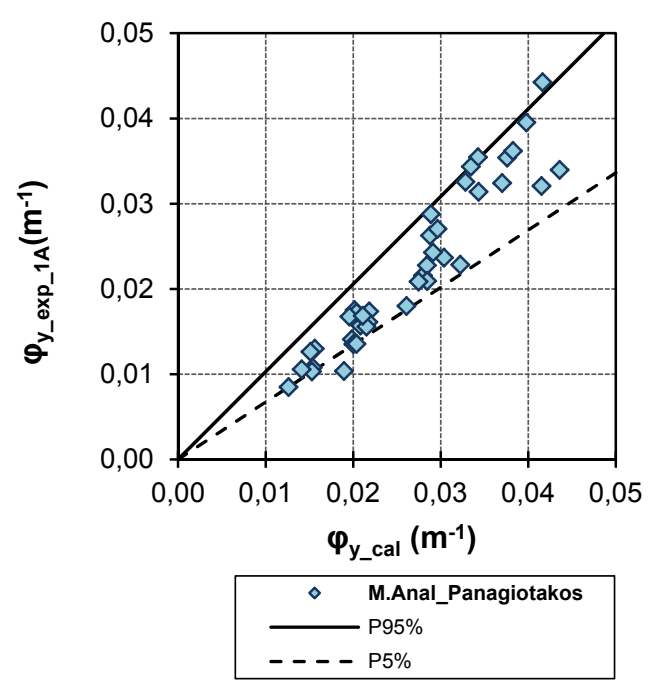

(a)

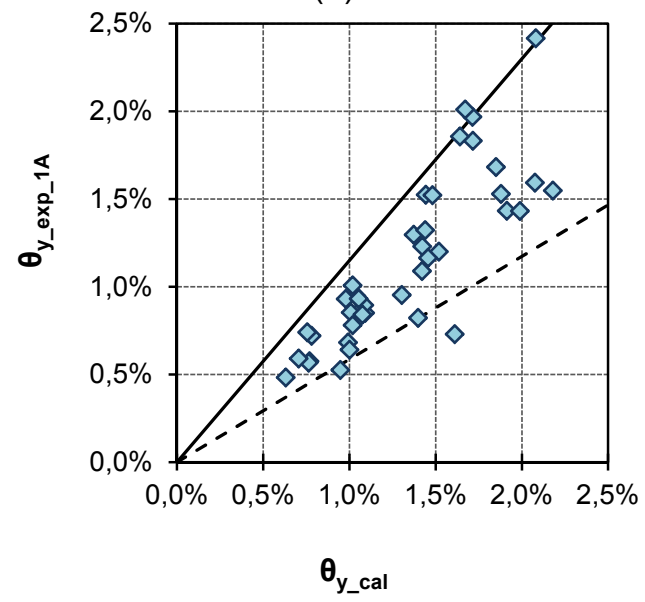

(c)

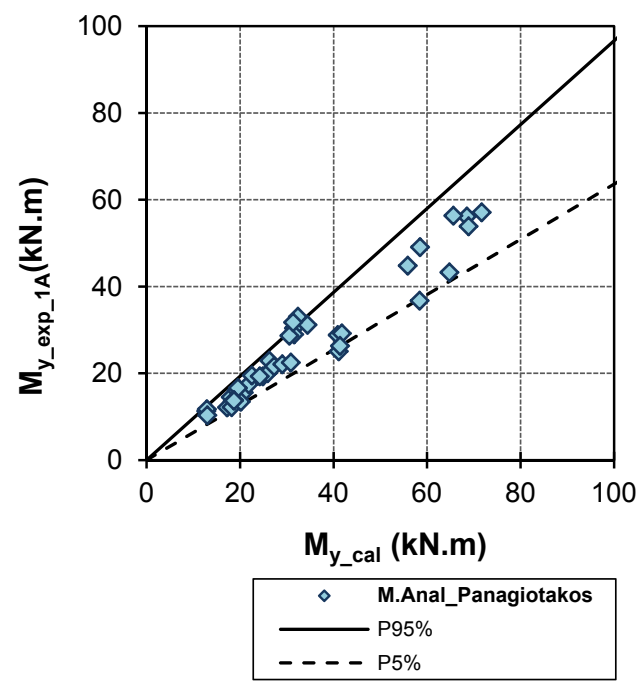

(b)

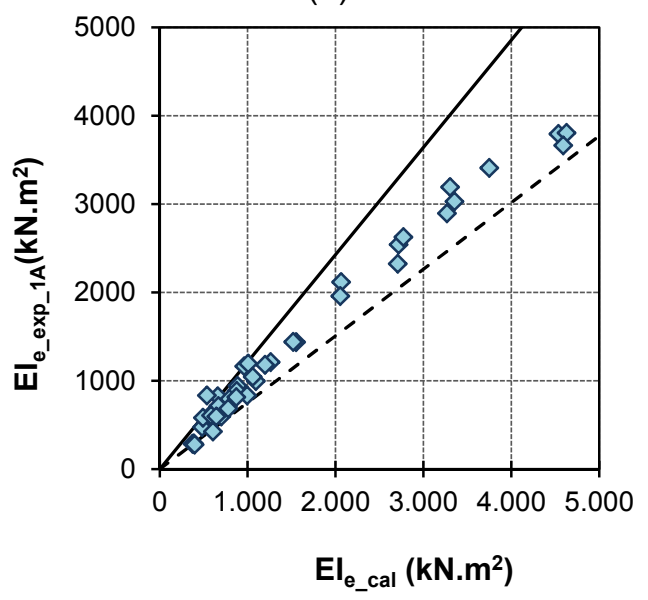

(d)

Figura 9.5 Comparación entre los valores experimentales y los calculados para $\varphi_{y}$, $M_{y}, \theta_{y}, y E I_{e}$

En la Tabla 9-1 se presentan los resultados del error (obtenido a partir de la relación entre el valor experimental y el calculado). Las variables estadísticas del error son: el valor medio $(\bar{E})$, el coeficiente de variación $(C V)$, el percentil del $95 \%$ y el percentil del $5 \%$ para cada uno de los parámetros analizados en el estado elástico $\left(\varphi_{\mathrm{y}}, \theta_{\mathrm{y}}, \mathrm{M}_{\mathrm{y}}, \mathrm{El}_{\mathrm{ef}}\right)$, y evaluados en los 40 ensayos experimentales.

Tabla 9-1 Resultados de la comparación entre los valores experimentales y calculados con el método de Panagiotakos y Fardis (2001), para las variables evaluadas en el punto de plastificación

\begin{tabular}{|c|r|r|r|r|}
\hline PARÁMETRO & $\overline{\mathbf{E}}$ & $\mathbf{C V}$ & $\mathbf{P}_{\mathbf{9 5} \%}$ & $\mathbf{P}_{\mathbf{5} \%}$ \\
\hline $\boldsymbol{\varphi}_{\mathbf{y} \_ \text {exp }} \boldsymbol{\varphi}_{\text {y-cal }}$ & 0.82 & $15 \%$ & 1.03 & 0.67 \\
\hline $\mathbf{M}_{\mathbf{y} \_ \text {exp }} \mathbf{M}_{\mathbf{y} \text {-cal }}$ & 0.80 & $13 \%$ & 0.97 & 0.64 \\
\hline $\boldsymbol{\theta}_{\text {y_exp } /} \boldsymbol{\theta}_{\text {ycal }}$ & 0.85 & $20 \%$ & 1.15 & 0.59 \\
\hline $\mathbf{E l}_{\mathbf{e}_{\text {_exp }} / \mathbf{E l}_{\text {ef-cal }}}$ & 0,98 & $10 \%$ & 1,18 & 0,85 \\
\hline
\end{tabular}


En la Tabla 9-1 se puede observar que la aproximación entre los valores calculados y los experimentales es aceptable, para todos los parámetros estudiados, ya que el valor del error medio se encuentra dentro de un rango entre 0.80 y 0.98 , siendo, en este caso, la rigidez efectiva el parámetro que muestra un error medio más cercano a la unidad, con un coeficiente de variación del 10\%. El parámetro momento elástico es el que presenta un mayor error medio (0.80), pero su coeficiente de variación es el menor de todos. Por otra parte, el parámetro de deriva elástica, aunque muestra un error medio aceptable (0.85), es el que tiene una mayor dispersión de los resultados $(C V=20 \%)$. En el caso de la curvatura elástica, la aproximación es asimismo aceptable, tanto en términos del error medio (0.82) como de la dispersión de los resultados $(\mathrm{CV}=15 \%)$.

\subsection{Curvatura y deriva últimas}

El método analítico de Panagiotakos y Fardis (2001) [100] no logra predecir con acierto los valores de curvatura última. En la Tabla 9-2 se puede ver que tanto el error medio ( $\mathrm{E}=1.34)$, como el coeficiente de variación $(\mathrm{CV}=47 \%)$ son altos.

Tabla 9-2 Resultados de la comparación entre los valores experimentales y calculados con el método de Panagiotakos y Fardis (2001) para las variables evaluadas en estado último

\begin{tabular}{|c|c|c|c|c|}
\hline Variable & $\overline{\mathbf{E}}$ & $\mathbf{C V}$ & $\mathbf{P}_{\mathbf{9 5} \%}$ & $\mathbf{P}_{\mathbf{5} \%}$ \\
\hline $\boldsymbol{\varphi}_{\text {u_exp }} / \boldsymbol{\varphi}_{\text {u_cal }}$ & 1.34 & $47 \%$ & 2.57 & 0.63 \\
\hline $\boldsymbol{\theta}_{\text {u_exp }} \boldsymbol{\theta}_{\text {u_cal }}$ & 1.14 & $30 \%$ & 1.59 & 0.63 \\
\hline
\end{tabular}

Como se puede observar en las Figura 9.6, en la mayoría de los ensayos la curvatura última calculada es inferior a la curvatura experimental. Esto puede ser debido a que el modelo teórico fundamentalmente considera las características de la sección y las propiedades teóricas de los materiales, pero en realidad las deformaciones últimas de los materiales superan las deformaciones teóricas utilizadas en los modelos.

Por otra parte, en el cálculo de la deriva última parece haber un mejor ajuste de los resultados, ya que muchos de los efectos antes mencionados son asumidos en la longitud de rotula plástica que concentra parte de los efectos no lineales, y es posible que a pesar de la falta de asertividad en el cálculo de la curvatura última, se logre mejorar la aproximación para el cálculo de la deriva última. Como se puede ver en la Tabla 9-2, el error medio que se logra con el método analítico de Panagiotakos y Fardis (2001) [100] para el cálculo de la deriva última es aceptable $(\bar{E}=1.14)$, con un coeficiente de variación del $30 \%$. 


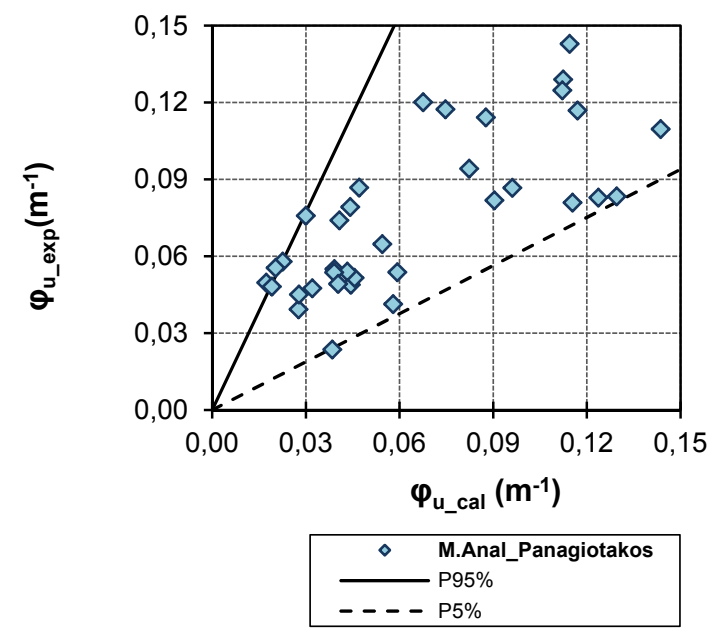

(a)

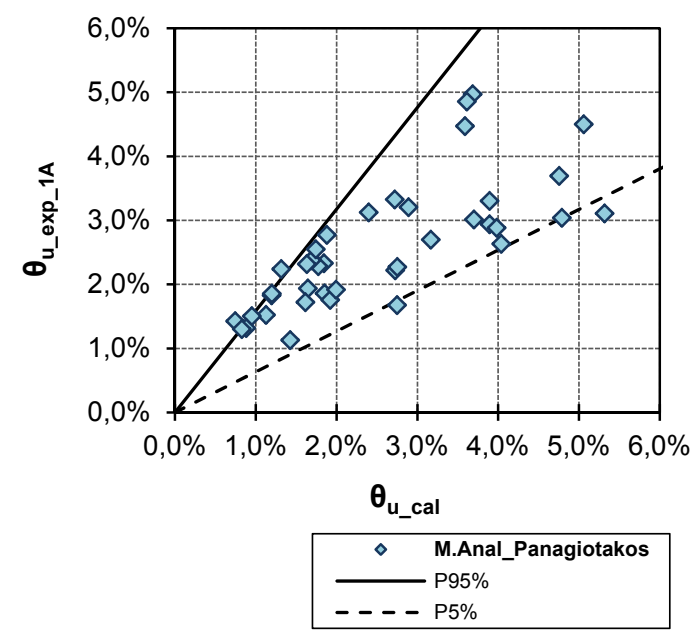

(b)

Figura 9.6 Comparación entre los valores experimentales y los calculados para $\varphi_{\omega} \theta_{u}$

\subsubsection{MÉTODO ANALÍTICO DEL EUROCÓDIGO 8}

\subsubsection{DESCRIPCIÓN DEL MÉTODO}

En el Eurocódigo 8 [59] (parte 3, Anejo A), se describe un método analítico para el cálculo de la deriva última. Al igual que el método anterior, este se basa en el desarrollo de la ecuación convencional, Ec. 9-1. A continuación, se describe el proceso seguido para evaluar cada una de las variables necesarias en el desarrollo de la Ec. 9-1.

\section{Curvatura elástica}

En el método descrito en el Anejo A del Eurocódigo 8 (parte 3) [59], no se define un criterio de plastificación de la sección. En este estudio se decidió adoptar el mismo criterio de plastificación que el utilizado en el método de Panagiotakos y Fardis (2001) [100], de modo que la curvatura elástica calculada será la misma del método anterior.

\section{Deriva elástica}

La deriva elástica se calcula conforme a las expresiones propuestas en el Eurocódigo 8 (parte 3, anejo A) [59]. La norma sugiere que puede utilizarse cualquiera de las siguientes expresiones:

$$
\begin{gathered}
\theta_{y}=\varphi_{Y} \frac{L_{V}+a_{v} z}{3}+0.00135\left(1+1.5 \frac{h}{L_{v}}\right)+\frac{\varepsilon_{y}}{d-d^{\prime}} \frac{d_{b} f_{y}}{6 \sqrt{f_{c}}} \\
\theta_{y}=\varphi_{Y} \frac{L_{V}+a_{v} z}{3}+0.0013\left(1+1.5 \frac{h}{L_{v}}\right)+0.13 \varphi_{y} \frac{d_{b} f_{y}}{\sqrt{f_{c}}}
\end{gathered}
$$




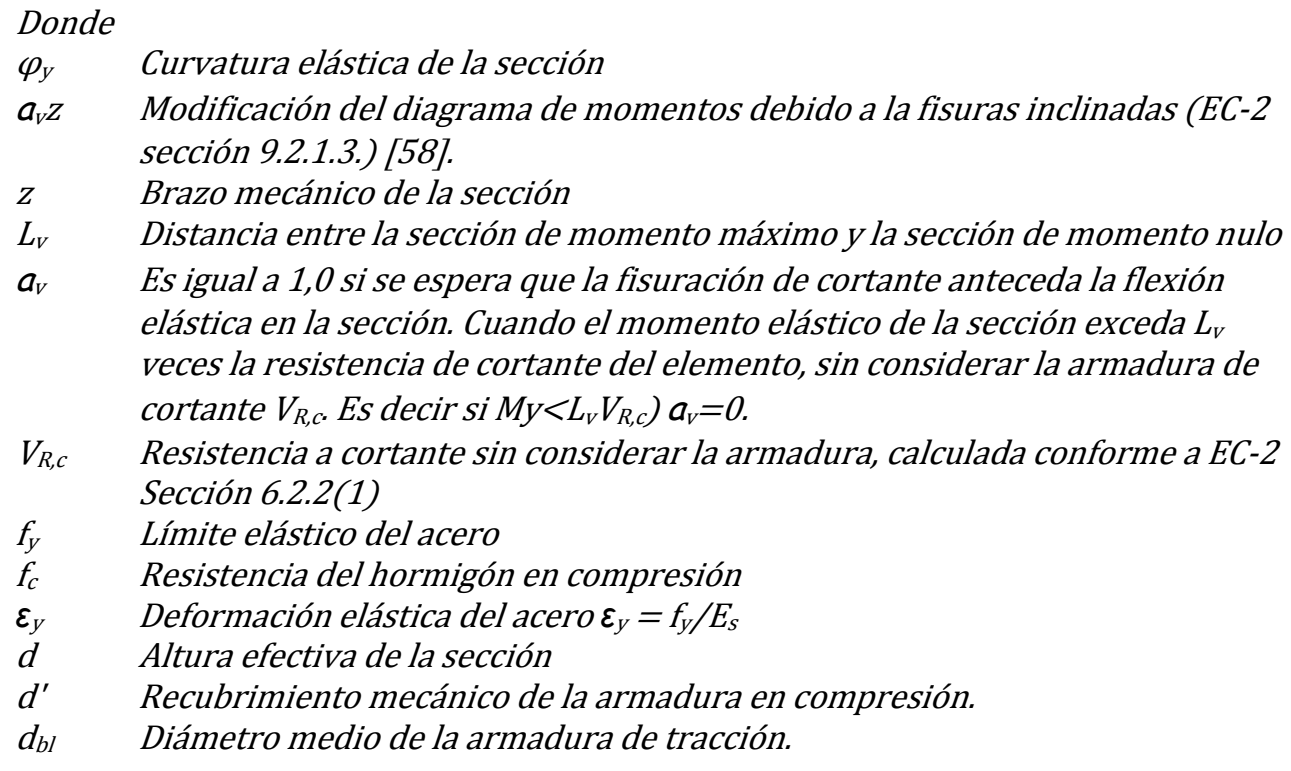

En el cálculo de la deriva elástica se han tenido en cuenta los siguientes aspectos:

- En las Ec. 9-20 y Ec. 9-21 el tercer término indica la parte de la deriva elástica debida al deslizamiento de la armadura en la zona de anclaje. En los ensayos experimentales no es posible que se desarrolle dicho efecto, de modo que se ignora el tercer término en las expresiones de $\theta_{\mathrm{y}}$.

- Este método exige realizar la comprobación de fisuración por cortante conforme al Eurocódigo 2 [58] (secciones 6.2.2 y 9.2.1.3), para poder tener en cuenta el cambio del diagrama de momentos. Sin embargo, mediante la comprobación de $\mathrm{M}_{\mathrm{y}}<\mathrm{L}_{\mathrm{v}} \cdot \mathrm{V}_{\mathrm{R}, \mathrm{c}}$ se ha confirmado que no existe fisuración por cortante, por lo que el parámetro $a_{v}$ es nulo, y el primer término en las expresiones Ec. 9-20 y Ec. 9-21 se simplifica $\left(\varphi_{y} L_{v} / 3\right)$.

\section{La curvatura última}

Para calcular la curvatura última se sigue el proceso de Panagiotakos y Fardis (2001) [100], con la única modificación de que se sustituye el modelo de hormigón confinado por los sugeridos en el Eurocódigo 8 [59]

La curvatura última se evalúa teniendo en cuenta dos posibles condiciones de fallo:

Si el acero falla, la deformación del acero para la tensión máxima $\varepsilon_{\mathrm{uk}}$ viene dada por la tabla C1 del Eurocódigo 2 [58], según el tipo de acero. En los ensayos experimentales se ha utilizado un tipo de acero B500SD, por lo que se adopta un valor para $\varepsilon_{\mathrm{uk}}=5 \%$.

Por otra parte, si el fallo se produce por el hormigón, la deformación última del hormigón $\left(\varepsilon_{\mathrm{cu}}\right)$ puede ser evaluada adoptando el modelo constitutivo para el hormigón confinado del Eurocódigo 2 (sección 3.1.9) [58], o el modelo descrito en el Eurocódigo 8 (parte 3, anejo A) [59]. Estos dos modelos han sido ya presentados en el capítulo 2. 
En este estudio se han implementado los dos modelos de confinamiento, y, por consiguiente, se han obtenido dos posibles alternativas para el cálculo de la curvatura última.

\section{Longitud de rótula plástica}

La expresión de longitud de rótula plástica utilizada en el método para el cálculo de la deriva última $\left(\theta_{\mathrm{u}}\right)$ depende también de cuál de los dos modelos de confinamiento se haya implementado en el cálculo de la curvatura última $\left(\varphi_{\mathrm{u}}\right)$.

Es decir, si la curvatura última $\left(\varphi_{\text {u-cal }}\right)$ se evalúa considerando el modelo de confinamiento del Eurocódigo 2 (sección 3.9.1) [58], la expresión para $L_{p}$ es la Ec. 9-22. De lo contrario, si $\varphi_{u-c a l}$ se evalúa teniendo en cuenta el modelo de confinamiento del Eurocódigo 8 (parte 3, anejo A) [59], la expresión para $L_{p}$ es Ec. 9-23.

$$
\begin{gathered}
L_{P 1}=0.1 L_{s}+0.17 h+0.24 \frac{d_{b l} f_{y}}{\sqrt{f_{c}}} \\
L_{P 1}=\frac{L_{s}}{30}+0.2 h+0.11 \frac{d_{b l} f_{y}}{\sqrt{f_{c}}}
\end{gathered}
$$
Donde
$L_{s} \quad$ Distancia entre la sección de momento máximo y la sección de momento nulo
h Canto de la sección transversal
$d_{b l} \quad$ Diámetro medio de la armadura en tracción
$f_{y} \quad$ Límite elástico del acero

\subsubsection{COMPARACIÓN ENTRE RESULTADOS EXPERIMENTALES Y TEÓRICOS OBTENIDOS MEDIANTE EL MÉTODO ANALÍTICO DEL EUROCÓDIGO 8}

En la primera columna de la Tabla 9-3 se hace una relación de las variables evaluadas de acuerdo con el método analítico del Eurocódigo 8 (Parte3, anejo A) [59]. En la segunda columna aparece la nomenclatura utilizada para identificar la alternativa de cálculo utilizada, y la tercera columna indica el modelo de hormigón confinado y las expresiones utilizadas en la evaluación de cada una de las variables.

Tabla 9-3 Variables calculadas aplicando el método analítico del Eurocódigo 8

\begin{tabular}{|c|l|l|}
\hline $\begin{array}{c}\text { Variable } \\
\text { calculada }\end{array}$ & $\begin{array}{c}\text { Alternativa de } \\
\text { cálculo }\end{array}$ & $\begin{array}{c}\text { Modelo para el hormigón confinado } \\
\text { y Ecuaciones utilizadas }\end{array}$ \\
\hline$\theta_{\mathrm{y} \text {-cal }}$ & $\mathrm{A} 1$ & Ec. 9-20 \\
\hline$\theta_{\mathrm{y} \text {-cal }}$ & $\mathrm{A} 2$ & Ec. 9-21 \\
\hline$\varphi_{\mathrm{u} \text {-cal }}$ & $\mathrm{A} 1$ & Eurocódigo 2 \\
\hline$\varphi_{\mathrm{u} \text {-cal }}$ & $\mathrm{A} 2$ & Eurocódigo 8 \\
\hline$\theta_{\mathrm{u} \text {-cal }}$ & $\mathrm{A} 1$ & Eurocódigo 2 + Ec. 9-22 \\
\hline$\theta_{\mathrm{u} \text {-cal }}$ & $\mathrm{A} 2$ & Eurocódigo 8 + Ec. 9-23 \\
\hline
\end{tabular}

Las variables relacionadas en la Tabla 9-3, calculadas de acuerdo con el método analítico del Eurocódigo 8 (parte 3, anejo A) [59], se comparan con los respectivos 
valores experimentales. Los resultados de la comparación permiten identificar las siguientes observaciones.

Tabla 9-4 Resultados de la comparación entre los valores experimentales y calculados con el método Eurocódigo 8, para la deriva elástica

\begin{tabular}{|c|c|c|c|c|c|}
\hline Variable & $\begin{array}{c}\text { Alternativa de } \\
\text { cálculo }\end{array}$ & $\overline{\mathbf{E}}$ & $\mathbf{C V}$ & $\mathbf{P}_{\mathbf{9 5} \%}$ & $\mathbf{P}_{\mathbf{5} \%}$ \\
\hline $\boldsymbol{\theta}_{\text {yexp }} \boldsymbol{\theta}_{\text {ycal }}$ & $\mathrm{A} 1$ & 0.752 & $21.2 \%$ & 1.056 & 0.527 \\
\hline $\boldsymbol{\theta}_{\text {yexp }} \boldsymbol{\theta}_{\text {ycal }}$ & A2 & 0.755 & $21.2 \%$ & 1.059 & 0.529 \\
\hline
\end{tabular}

Las dos expresiones (Ec. 9-20 y Ec. 9-21) utilizadas en el cálculo de la deriva elástica $\left(\theta_{y_{-} \text {cal }}\right)$ muestran prácticamente la misma aproximación. Los valores calculados, en su mayoría, resultan ser superiores a los experimentales, siendo el error medio conseguido de $\bar{E}=0.75$, y el coeficiente de variación del $21 \%$ para las dos expresiones. En realidad, existe un incremento del error con respecto al método analítico propuesto por Panagiotakos y Fardis (2001) [100] donde el error conseguido es del $\bar{E}=0.85$. Este incremento se debe a que, en las expresiones Ec. 9-20 y Ec. 9-21 se ha considerado la participación del segundo término, el cual originalmente representa las deformaciones de cortante y la fisuración inclinada, mientras que, en el método de Panagiotakos y Fardis (2001) [100], sólo se ha considerado la contribución por flexión $\left(\theta_{y}=\varphi_{y} L_{s} / 3\right)$. Esto último resulta adecuado, ya que, en elementos altamente esbeltos, como es el caso de los soportes ensayados, cabe esperar la inexistencia o poca influencia de la deformación de cortante y la fisuración inclinada.

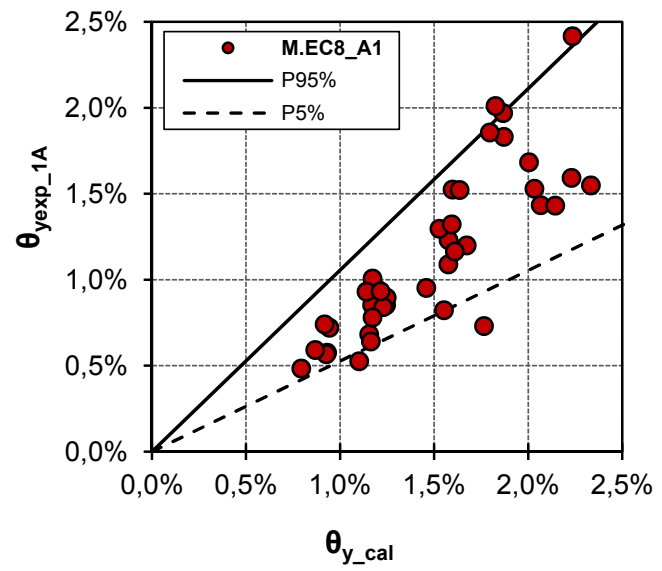

(a)

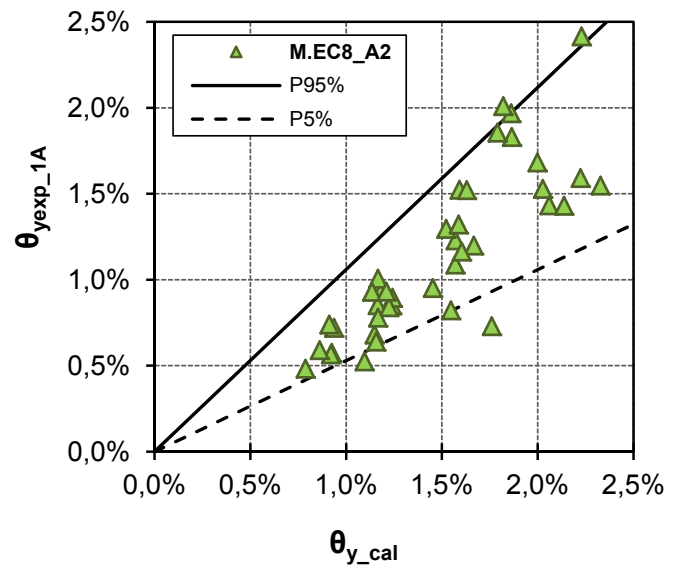

(b)

Figura 9.7 Comparación entre los valores experimentales y los calculados con el método del Eurocódigo 8, para $\theta_{y}$. (a) Ec. 9-20, (b) Ec. 9-21

Con respecto a la curvatura última $\left(\varphi_{\text {u-cal }}\right)$, se observa que, si esta se calcula teniendo en cuenta el modelo para el hormigón confinado del Eurocódigo 2 (alternativa A1) [58], el error medio evaluado es mayor ( $\bar{E}=1.46)$ que si se utiliza el modelo del hormigón confinado propuesto en el Eurocódigo 8 (alternativa A2) [59], con un error medio obtenido de $\bar{E}=1.17$. Sin embargo, la modificación en el modelo de confinamiento hace que aumente la dispersión de los resultados (CV aumenta de $51 \%$ a $70 \%)$. 
Estudio experimental y numérico de la capacidad de deformación de soportes esbeltos de hormigón armado

Tabla 9-5 Resultados de la comparación entre los valores experimentales y calculados con el método Eurocódigo 8, para la curvatura última

\begin{tabular}{|c|c|c|c|c|c|c|}
\hline Variable & $\begin{array}{c}\text { Alternativa } \\
\text { de cálculo }\end{array}$ & $\begin{array}{c}\text { Modelo del } \\
\text { hormigón } \\
\text { confinado }\end{array}$ & $\overline{\mathbf{E}}$ & $\mathbf{C V}$ & $\mathbf{P 9 5 \%}$ & $\mathbf{P 5 \%}$ \\
\hline$\phi_{\mathrm{u} \_ \text {exp }} \phi_{\mathrm{u} \_ \text {cal }}$ & $\mathrm{A} 1$ & Eurocódigo 2 & 1.462 & $50.8 \%$ & 2.920 & 0.642 \\
\hline$\phi_{\mathrm{u} \_ \text {_exp }} / \phi_{\mathrm{u} \_c a l}$ & $\mathrm{~A} 2$ & Eurocódigo 8 & 1.167 & $69.5 \%$ & 2.920 & 0.341 \\
\hline
\end{tabular}

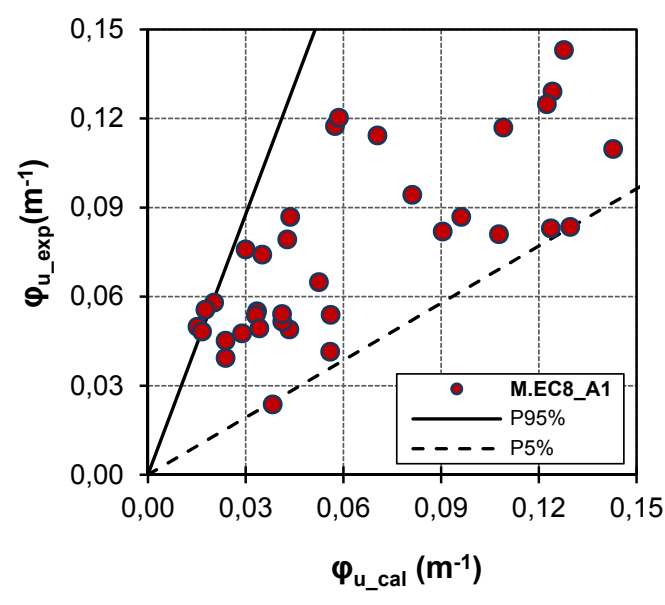

(a)

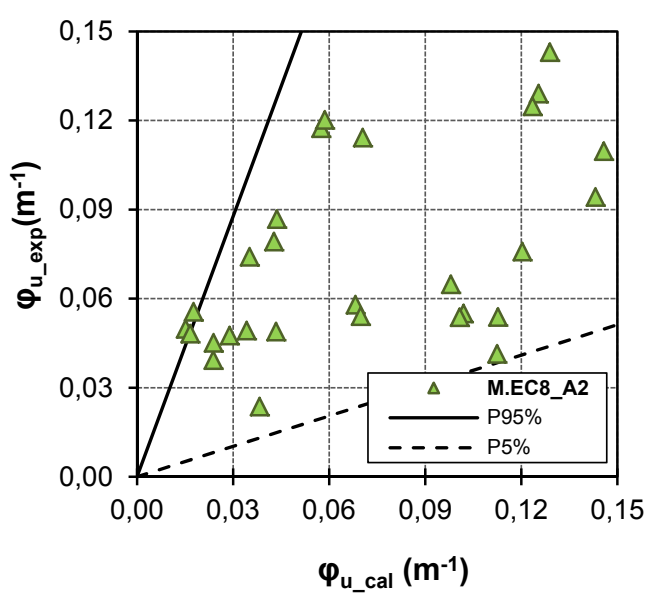

(b)

Figura 9.8 Comparación entre los valores experimentales y los calculados con el método del Eurocódigo 8, para $\varphi_{u}$. (a) Alternativa A1 (b) Alternativa A2

Por último, los resultados de la deriva última calculada a partir de las dos alternativas (que se denominarán en lo sucesivo A1 y A2) del modelo analítico indicado en el Eurocódigo 8 (parte 3, anejo A) [59], Figura 9.9, muestran que la A1 consigue una mejor aproximación para la deriva última, a pesar de que, por un lado, el error en la curvatura última es mayor que en la alternativa del método $A 2$, y de que, por otro lado, la longitud de rótula plástica de la alternativa $A 1$ es más del doble de la calculada en A2. La alternativa A1 para evaluar $\theta_{\text {u_cal }}$ ha conseguido una aproximación aceptable, ya que el error medio obtenido es de $\overline{\mathrm{E}}=1.20 \mathrm{y}$ el coeficiente de variación es del $23 \%$. Además, los valores calculados en la mayoría de los casos se encuentran del lado de la seguridad. No sucede lo mismo con la alternativa $A 2$, puesto que el error medio es bastante alto $(E=1.40), y$, aunque la dispersión de los resultados sea menor $(\mathrm{CV}=18 \%)$, esta alternativa se considera menos fiable.

Tabla 9-6 Resultados de la comparación entre los valores experimentales y calculados con el método Eurocódigo 8, para la deriva última

\begin{tabular}{|c|c|c|c|c|c|c|c|}
\hline Variable & $\begin{array}{l}\text { Alternativa } \\
\text { de cálculo }\end{array}$ & $\begin{array}{l}\text { Modelo del } \\
\text { hormigón } \\
\text { confinado }\end{array}$ & Lp & $\overline{\mathbf{E}}$ & CV & $\mathbf{P}_{95 \%}$ & $\mathbf{P}_{5 \%}$ \\
\hline 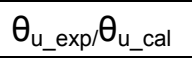 & A1 & Eurocódigo 2 & Ec. 9-22 & 1.208 & $23.2 \%$ & 1.529 & 0.758 \\
\hline$\theta_{u_{\text {_exp }}} / \theta_{\mathrm{u}_{\text {_cal }}}$ & A2 & Eurocódigo 8 & Ec. 9-23 & 1.402 & $18.5 \%$ & 1.812 & 1.027 \\
\hline
\end{tabular}




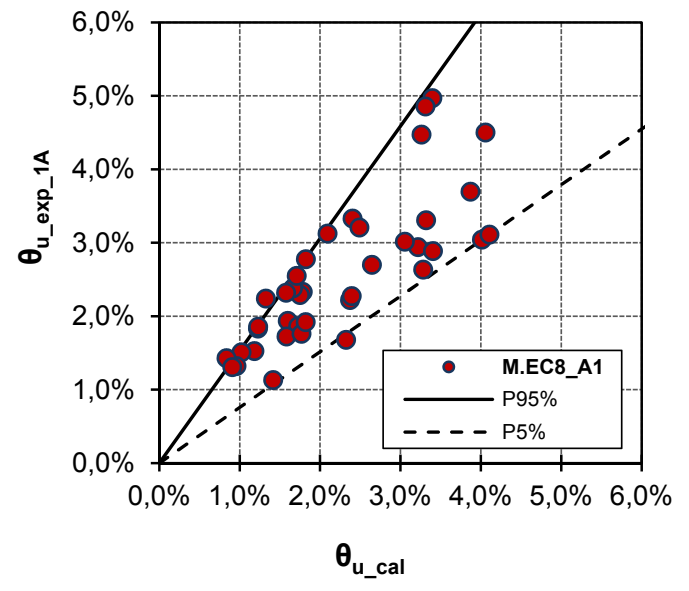

(a)

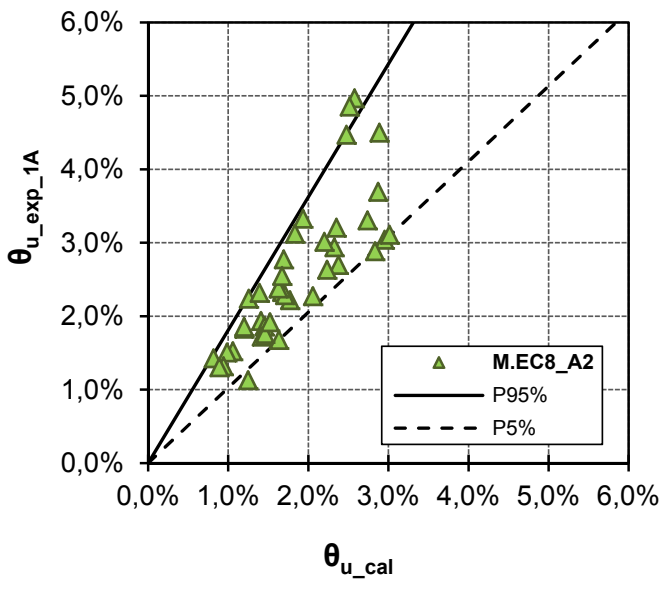

(b)

Figura 9.9 Comparación entre los valores experimentales y los calculados con el método del Eurocódigo 8, para $\theta_{u}$. (a) alternativa $A 1$ (b) alternativa $A 2$

\subsubsection{MÉTODOS EMPÍRICOS}

Los resultados experimentales de deriva última se han comparado con los cuatro modelos empíricos que se relacionan en la Tabla 9-7. Todos los modelos han sido inicialmente desarrollados a partir de un análisis estadístico sobre la base de datos realizada por Panagitakos y Fardis (2001) [100], y más tarde actualizada por Fardis y Biskinis (2003) [60].

La Ec. 9-24 corresponde a una de las primeras expresiones propuestas por Panagiotakos y Fardis (2001) [100]. Esta expresión ha sido exclusivamente obtenida en base a los resultados en ensayos experimentales bajo carga monotónica, en elementos sometidos a flexión simple y flexo-compresión.

La Ec. 9-25 aparece propuesta en el boletín CEB-FIP 25 (2003) [35], y se caracteriza por haber sido obtenida teniendo en cuenta los resultados experimentales de elementos sometidos a flexión y flexo-compresión bajo carga cíclica y monotónica, en los que se incluyen vigas, soportes y muros de cortante.

La tercera expresión utilizada, la Ec. 9-26, ha sido propuesta por Fardis y Biskinis (2003) [60]. En ésta, además de ampliarse el número de ensayos utilizados en su comprobación, se han utilizado los resultados de ensayos bajo carga cíclica y monotónica.

La cuarta expresión (Ec. 9-27), a pesar de que ha sido presentada en el Eurocódigo 8 (parte 3, anejo A) [59] para calcular la deriva última en elementos bajo carga cíclica, se ha implementado en esta comparación con ensayos bajo carga monotónica, puesto que es la única referencia de modelos empíricos propuesta en la normativa. 
Estudio experimental y numérico de la capacidad de deformación de soportes esbeltos de hormigón armado

Tabla 9-7 Relación de modelos empíricos para el cálculo de la deriva última utilizados en la comparación con los resultados experimentales

\begin{tabular}{|c|c|}
\hline$\theta_{u, \text { mon }}(\%)=\alpha_{s t}\left[1+\frac{\alpha_{s l}}{8}\right](0.15)^{v}\left[\frac{\max \left(0.01, \omega^{\prime}\right)}{\max (0.01, \omega)} \frac{L_{s}}{h} f_{c}\right]^{0.425}$ & Ec. 9-24 \\
\hline$\theta_{u}=\alpha_{s t}\left(1-0.38 \alpha_{c y c}\right)\left[1+\frac{\alpha_{s l}}{1.7}\right](0.3)^{v}\left[\frac{\max \left(0.01, \omega^{\prime}\right)}{\max (0.01, \omega)} f_{c}\right]^{0.2}\left(\frac{L_{s}}{h}\right)^{0.425} 25^{\alpha k}\left(1.45^{100 \rho_{d}}\right)$ & Ec. 9-25 \\
\hline$\theta_{u}=\alpha_{s t}\left(1-0.4 \alpha_{c y c}\right)\left[1+0.5 \alpha_{s l}\right](0.3)^{v}\left[\frac{\max \left(0.01, \omega^{\prime}\right)}{\max (0.01, \omega)} f_{c}\right]^{0.175}\left(\frac{L_{s}}{h}\right)^{0.4} 25^{\alpha k}\left(1.25^{100 \rho_{d}}\right)$ & Ec. 9-26 \\
\hline$\theta_{u m}=\alpha_{s t} \frac{1}{\gamma_{e l}} 0,016 \cdot\left(0.3^{v}\right)\left[\frac{\max \left(0,01 ; \omega^{\prime}\right)}{\max (0,01 ; \omega)} f_{c}\right]^{0,225}\left(\frac{L_{s}}{h}\right)^{0,35} 25^{(\alpha k)}\left(1,25^{100 \rho_{d}}\right)$ & Ec. 9-27 \\
\hline
\end{tabular}

Donde:

$\alpha_{s t} \quad$ Factor que tiene en cuenta el tipo de acero de la armadura (ver Tabla 9-8)

$\alpha_{s l} \quad 1$ si se desliza la armadura longitudinal en la zona de anclaje y

o si esto es imposible

$\alpha_{c y c} \quad$ Factor que tiene en cuenta el tipo de carga (Tabla 9-8)

$v \quad$ Nivel de axil reducido $\left(v=N / A_{g} f_{c}\right)$

$\omega \quad$ Cuantía mecánica de armadura en tracción $\left(\omega=\rho f_{y} / f_{c}\right)$

$\omega^{\prime} \quad$ Cuantía mecánica de armadura en compresión $\left(\omega^{\prime}=\rho^{\prime} f_{y}^{\prime} / f_{c}\right)$

$L_{s} \quad$ Distancia entre la sección de momento máximo y la sección de momento nulo

$\gamma_{e l} \quad$ En este estudio es igual a la unidad. Aunque, la norma específica 1.5 para elementos principales y 1.0 para elementos secundarios

$h \quad$ Canto de la sección transversal

$f_{y} \quad$ Límite elástico del acero transversal (MPa)

$f_{y}^{\prime} \quad$ Límite elástico del acero en compresión (MPa)

$f_{y} \quad$ Límite elástico del acero en tracción (MPa)

$f_{c} \quad$ Resistencia del hormigón (MPa)

$\rho_{d} \quad$ Cuantía de armadura diagonal si existe

$\kappa \quad$ Cuantía mecánica transversal $\left(\kappa=\rho_{S x} f_{h y} / f_{c}\right)$

$\rho_{S X} \quad$ Cuantía de acero transversal paralela a la dirección $x$ de carga $\left(\rho_{S x}=\right.$ $\left.A_{s x} / b_{w} S_{h}\right)$.

$\alpha \quad$ Factor de efectividad del confinamiento de acuerdo con Sheikh y Uzumeri (1982) [119], Ec. 9-18

Tabla 9-8 Factores de $\alpha_{s t}$ y $\alpha_{c y c}$ asignados en los modelos empíricos

\begin{tabular}{|c|c|c|c|c|c|}
\hline & \multicolumn{2}{|c|}{$\alpha_{\text {st }}$ Factor Tipo de acero } & \multicolumn{2}{c|}{$\alpha_{\text {cyc }}$} \\
\cline { 2 - 6 } Ec. & $\begin{array}{c}\text { Rodado en } \\
\text { caliente }\end{array}$ & $\begin{array}{c}\text { Tratamient } \\
\text { o térmico }\end{array}$ & $\begin{array}{c}\text { Trabajado } \\
\text { en frío }\end{array}$ & $\begin{array}{c}\text { carga } \\
\text { monotónica }\end{array}$ & $\begin{array}{c}\text { Carga } \\
\text { cíclica }\end{array}$ \\
\hline Ec. 9-24 & 1.250 & 1.00 & 0.50 & - & - \\
\hline Ec. 9-25 & 0.016 & 0.016 & 0.0105 & 0 & 1.0 \\
\hline Ec. 9-26 & 0.0194 & 0.0194 & 0.0125 & 0 & 1.0 \\
\hline Ec. 9-27 & 1.00 & 1.0 & 0.625 & - & - \\
\hline
\end{tabular}


Los resultados presentados en las Figura 9.10 y en la Tabla 9-9 indican que ninguno de los métodos muestra una aproximación aceptable para predecir la deriva última.

Si se aplican las ecuaciones Ec. 9-25 y Ec. 9-26, se obtienen prácticamente los mismos resultados, los cuales también se acercan mucho a los resultados obtenidos mediante la Ec. 9-27. Estas tres expresiones, en realidad, son muy similares, siendo la mayor diferencia entre ellas el coeficiente exponencial que afecta la esbeltez de cortante $\left(L_{s} / h\right)$. Este coeficiente, en las expresiones Ec. 9-25, Ec. 9-26 y Ec. 9-27, disminuye de 0.425 a 0.4 y a 0.35 respectivamente, y, en consecuencia, el error en el cálculo se reduce, como se muestra en la Tabla 9-9.

Tabla 9-9 Resultados de la comparación entre los valores experimentales y los calculados con los métodos empíricos, para la deriva última

\begin{tabular}{|c|c|c|c|c|c|}
\hline Variable & Ec. & $\overline{\mathbf{E}}$ & $\mathbf{C V}$ & $\mathbf{P}_{\mathbf{9 5} \%}$ & $\mathbf{P}_{5 \%}$ \\
\hline$\theta_{\mathrm{u} \text { exp }} \theta_{\mathrm{u} \text { cal }}$ & Ec. 9-24 & 0.32 & $34 \%$ & 0.52 & 0.21 \\
\hline$\theta_{\mathrm{u}}$ exp $\theta_{\mathrm{u} \text { cal }}$ & Ec. 9-25 & 0.39 & $26 \%$ & 0.57 & 0.26 \\
\hline$\theta_{\mathrm{u} \text { exp }} \theta_{\mathrm{u} \text { cal }}$ & Ec. 9-26 & 0.38 & $25 \%$ & 0.54 & 0.25 \\
\hline$\theta_{\mathrm{u} \text { exp }} \theta_{\mathrm{u} \text { cal }}$ & Ec. 9-27 & 0.42 & $27 \%$ & 0.62 & 0.27 \\
\hline
\end{tabular}

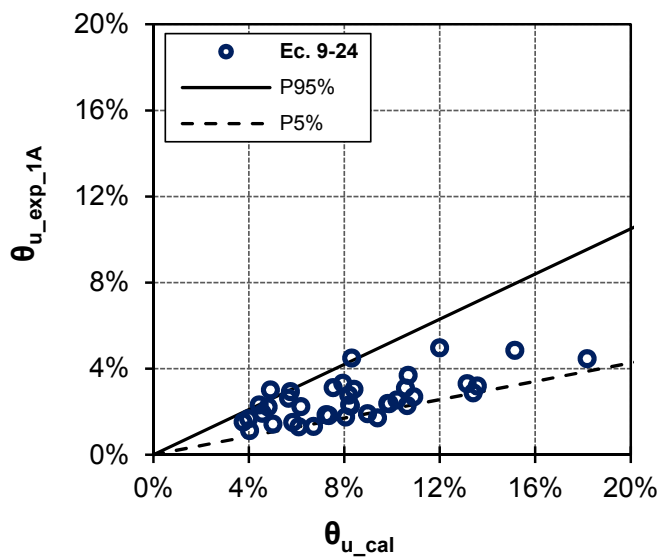

(a)

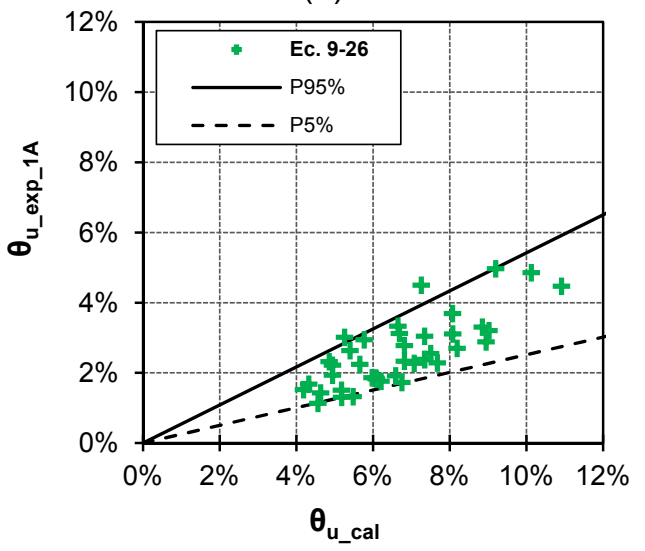

(c)

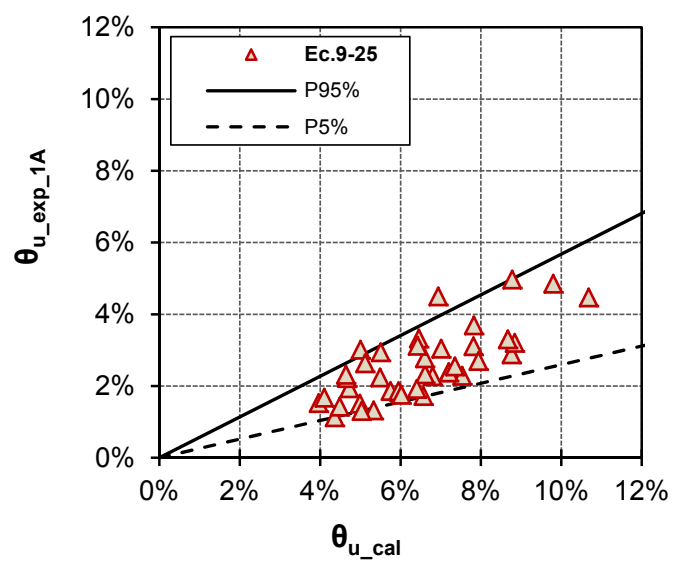

(b)

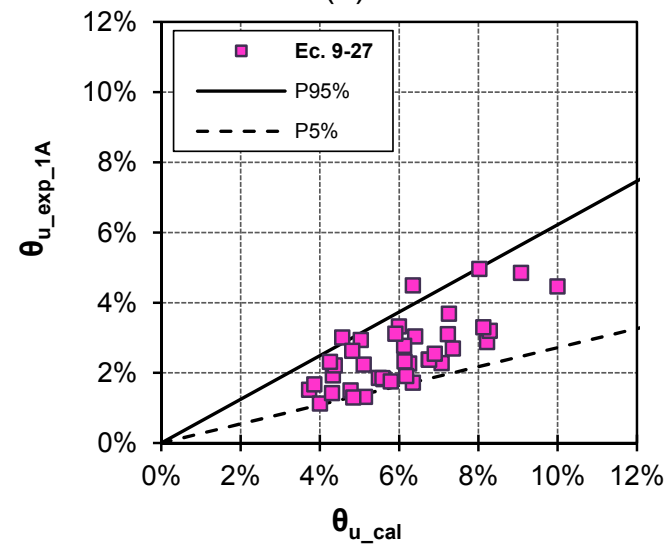

(d)

Figura 9.10 Comparación entre los valores experimentales y los calculados con los métodos empíricos de: (a) Ec. 9-24 (b) Ec. 9-25 (c) Ec. 9-26 (d) Ec. 9-27 
La peor aproximación se obtiene con la Ec. 9-24. Esto se debe a que esta expresión se ha obtenido a partir de ensayos experimentales exclusivamente bajo carga monotónica, siendo la mayoría de elementos vigas sometidas a flexión. Además, si se tiene en cuenta que en la Ec. 9-24 la deriva última es aproximadamente proporcional a la raíz cuadrada de la relación entre las cuantías mecánicas de armadura de compresión y tracción $\left(\omega^{\prime} / \omega\right)$, relación que normalmente es inferior a 1 en vigas, el resultado de la ecuación disminuye. Sin embargo, en soportes, como es el caso de los ensayos experimentales, la relación $(\omega / \omega)$ es igual a 1, lo cual no afecta al resultado de la ecuación. En definitiva la Ec. 9-24 parece estar pensada más bien para elementos con armadura asimétrica. Por otra parte, tanto el coeficiente exponencial de la esbeltez, que es el mayor de las cuatro expresiones, como el término que tiene en cuenta el nivel de carga axial, contribuyen también a un aumento en el resultado de la deriva última, lo que implica un incremento del error.

\subsubsection{CONSIDERACIONES DE LA COMPARACIÓN ENTRE LOS MÉTODOS TEÓRICOS Y LOS RESULTADOS EXPERIMENTALES}

Las variables $\varphi_{\mathrm{y}}, \mathrm{M}_{\mathrm{y}}, \theta_{\mathrm{y}}$ y $\mathrm{El}_{\mathrm{e}}$ calculadas en el punto de plastificación mediante el método de Panagiotakos y Fardis (2001) [100], tienden a ser ligeramente sobreestimadas en relación con los resultados experimentales. Sin embargo, la aproximación es bastante aceptable, ya que el error medio se encuentra dentro de un rango entre 0.80 y 0.96 , y la dispersión del error varía entre $C V=0.15$ y $C V=0.2$.

En cuanto a la deriva elástica, se ha identificado que los resultados calculados se acercan más a los resultados experimentales cuando sólo se tiene en cuenta la contribución por flexión. Además, la fisuración inclinada y la distorsión de cortante no son efectos propiamente presentes en elementos esbeltos. Y, claramente, el efecto del deslizamiento de la armadura anclada no se debe tener en cuenta en los casos en que la armadura es pasante.

La curvatura última es una variable difícil de evaluar mediante los métodos analíticos, y, aunque en la metodología general se han implementado tres modelos para el hormigón confinado, no ha sido posible obtener una aproximación razonable con los resultados experimentales. La curvatura última calculada en la mayoría de los casos es subestimada con respecto a la experimental.

Se ha podido comprobar que, aunque los métodos analíticos no son lo suficientemente capaces de medir la curvatura última, los resultados de la deriva última logran una mayor aproximación, que los métodos empíricos. Por consiguiente, está claro que la aproximación de los métodos depende en gran medida de la longitud de la rótula plástica, en la que se permite acumular parte de los efectos no lineales.

Se ha demostrado que ninguno de los métodos empíricos consigue predecir la deriva última de forma razonable, llegando a sobrestimar los valores hasta dos y tres veces. Esto se debe a que los modelos empíricos se han obtenido a partir de los resultados de una gran base de datos de ensayos experimentales, en la que existe una escasa presencia o participación de ensayos con características de esbeltez superiores a 6 y resistencias del hormigón a compresión mayores que 50 
$\mathrm{MPa}$, como es el caso de los ensayos experimentales. Por consiguiente, aunque dichos modelos pueden ser válidos en los rangos para los que han sido propuestos, queda demostrado que no son válidos para elementos de hormigón fuera de dichos rangos.

En la comparación de los métodos analíticos con los resultados experimentales para la deriva última, los métodos de Panagiotakos y Fardis (2001) [100] y la alternativa $A 1$ del método del Eurocódigo 8 [59] han conseguido una aproximación aceptable respecto al error medio (1.14 y 1.20 , respectivamente), aunque también se aprecia una notable dispersión reflejada en el coeficiente de variación (30\% y $23 \%$, respectivamente). La alternativa A2 del Eurocódigo 8 [59] presenta un mayor valor en el error (1.4) y un coeficiente de variación del 18\%. Los métodos empíricos sobrestiman ampliamente los valores experimentales, obteniéndose errores de entre 0.32 y 0.42 , con coeficientes de variación de entre el $25 \%$ y el $34 \%$, lo cual indica que los métodos empíricos resultan menos adecuados para predecir la capacidad de deformación de elementos esbeltos de hormigón armado.

\subsection{COMPARACIÓN DE LOS MÉTODOS TEÓRICOS Y LOS RESULTADOS DE LA SIMULACIÓN NUMÉRICA, PARA LA CAPACIDAD DE DEFORMACIÓN}

En el análisis se han considerado los métodos empíricos de Fardis y Biskinis (2003) [60], el Boletín del CEB-FIP 25 (2003) [35] y el Eurocódigo 8 [59], (ver Tabla 9-10). Además se han implementado los métodos analíticos de Panagiotakos y Fardis (2001) [100] y las dos versiones del método del Eurocódigo 8 [59]. Los resultados calculados con los métodos se comparan con los valores obtenidos mediante el modelo numérico de "ATENA 2D" y los resultados experimentales.

Tabla 9-10 Métodos empíricos

\begin{tabular}{|l|l|l|}
\hline \multicolumn{1}{|c|}{ Método } & \multicolumn{1}{c|}{ Ec. } & \multicolumn{1}{c|}{ Nomenclatura } \\
\hline Método del Boletín del FIB 25 (2003) & Ec. 9-25 & Ec. Fib25 \\
\hline Método de Biskinis y Fardis (2003) & Ec. 9-26 & Ec. Biskinis \\
\hline Método del Eurocódigo 8 (Part 3, Anejo A) & Ec. 9-27 & Ec. Ec8 \\
\hline
\end{tabular}

Los tres métodos analíticos utilizados en la comparación se relacionan en la Tabla 9-11. El proceso de cálculo para los dos modelos del Eurocódigo 8 [59] es similar al descrito por Panagiotakos y Fardis (Apartado 9.1.1.1) [100], sólo que, en cada método, se sustituye el modelo del hormigón confinado para el cálculo de la curvatura última, así como también cambia la expresión para la longitud de rótula plástica, tal y como se refleja en la Tabla 9-11.

Respecto a las expresiones de longitud de rótula plástica, en esta comparación no se ha tenido en cuenta el efecto del deslizamiento de la armadura en la zona de anclaje, y, por lo tanto, el último término de la expresión no se ha considerado en el cálculo. 
Estudio experimental y numérico de la capacidad de deformación de soportes esbeltos de hormigón armado

Tabla 9-11 Modelos del hormigón confinado y longitudes de rótula plástica utilizados en la comparación de métodos analíticos

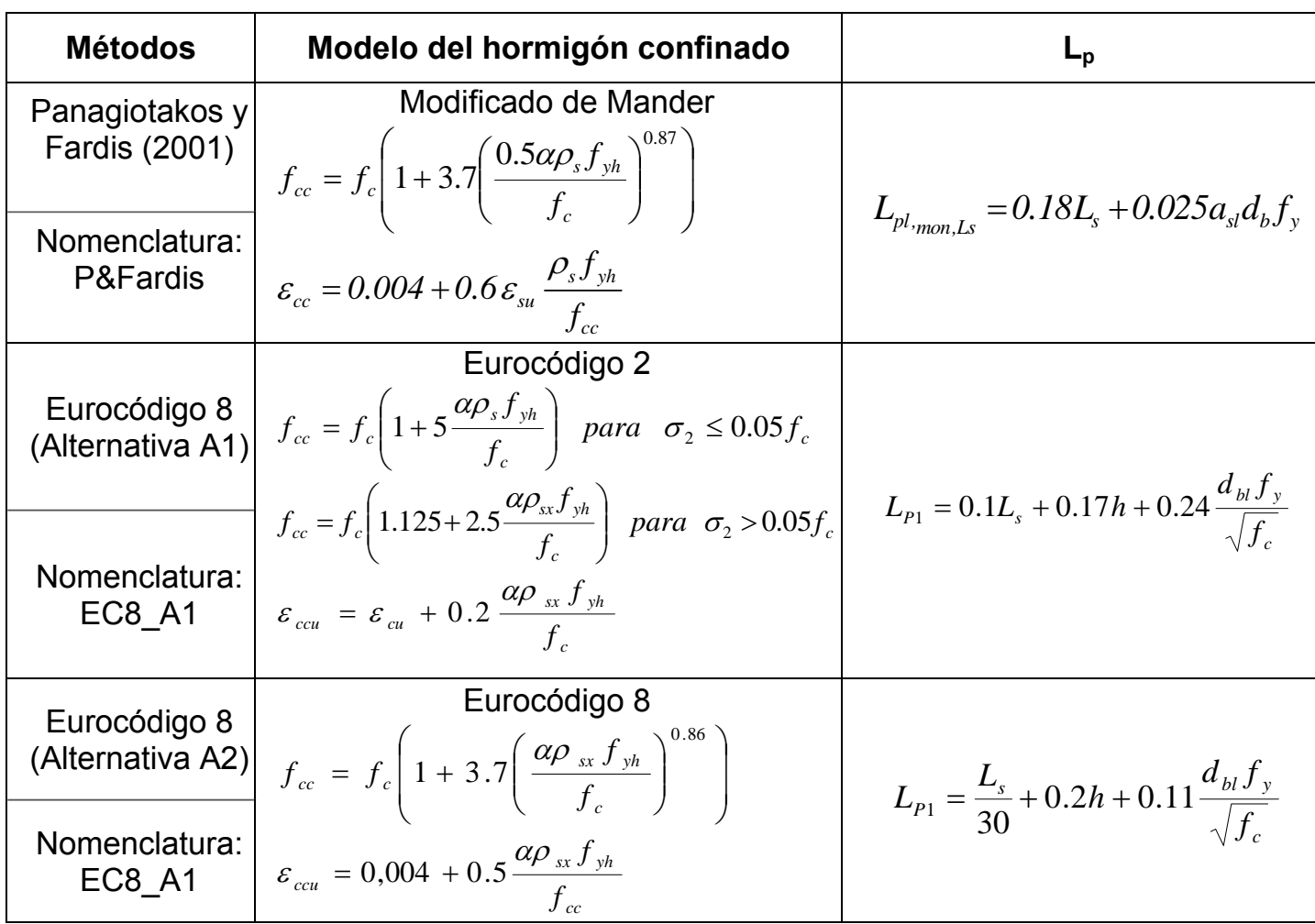

Donde

$\rho_{s x} \quad$ Cuantía de armadura transversal paralela a la dirección de la carga $\left(A_{s x} / b_{w}{ }^{*} S_{h}\right)$

$\rho_{s} \quad$ Cuantía volumétrica de armadura transversal

$f_{y h} \quad$ Límite elástico del acero transversal

$f_{c} \quad$ Resistencia del hormigón en compresión

$s_{h} \quad$ Separación entre cercos

$b_{c} \quad$ Ancho del núcleo confinado

$A_{s w} \quad$ Área de armadura transversal paralela a la dirección de la carga

$\alpha \quad$ Factor de eficiencia del confinamiento Ec. 9-18

$L_{s} \quad$ Distancia entre la sección de momento máximo y la sección de momento nulo

$h \quad$ Canto de la sección transversal

$d_{b l} \quad$ Diámetro medio de la armadura en tracción

$a_{s l} \quad$ Coeficiente igual a 1 si se desliza la armadura longitudinal en la zona de anclaje en las secciones cercanas al apoyo, y 0 si esto no es posible

$d_{b} \quad$ Diámetro de la armadura longitudinal

$f_{y} \quad$ Límite elástico de la armadura

Para comparar los resultados calculados con los diferentes métodos y los obtenidos con el modelo numérico de "ATENA 2D", se estima el error $(\bar{E})$ mediante la relación entre la deriva última calculada $\left(\theta_{u_{\text {ucal }}}\right)$ y la del modelo numérico $\left(\theta_{u_{\text {_nnm }}}\right)$. Esto permitirá evaluar si los métodos resultan acertados, y en qué medida, a la hora de predecir la deriva última respecto al modelo numérico, ya que este último se considera como una herramienta bastante adecuada para medir la deriva última, como se ha demostrado en el capítulo 7. Sin embargo, su difícil implementación y su alto costo operativo dificultan su viabilidad. 


\subsubsection{COMPARACIÓN DE LOS MÉTODOS RESPECTO A LA ESBELTEZ DE CORTANTE}

Para analizar los métodos con respecto a la influencia de la esbeltez de cortante, la deriva última se ha evaluado a partir de los diferentes métodos para una serie de ensayos con características de esbeltez entre 3.5 y 10.5 , nivel de carga axil 0.15 y 0.45 , y resistencias del hormigón de $30 \mathrm{MPa}$ y $90 \mathrm{MPa}$.

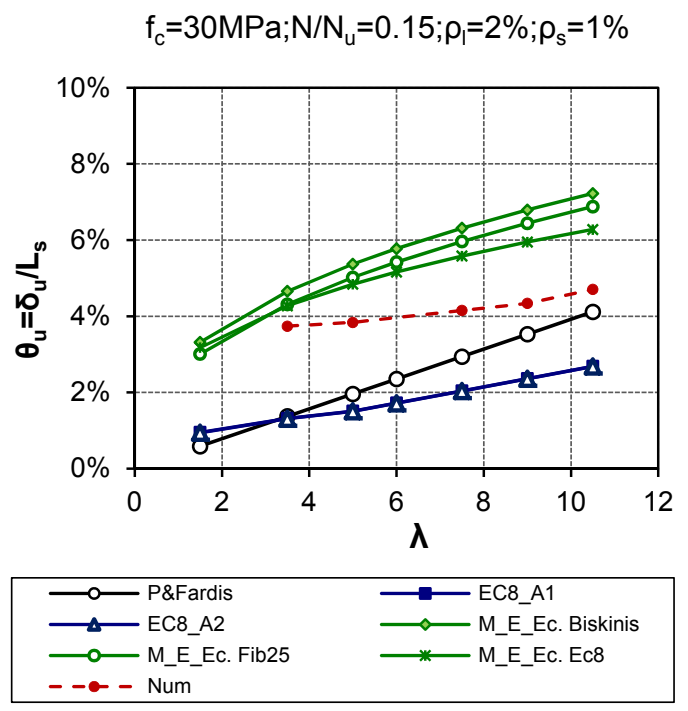

(a)

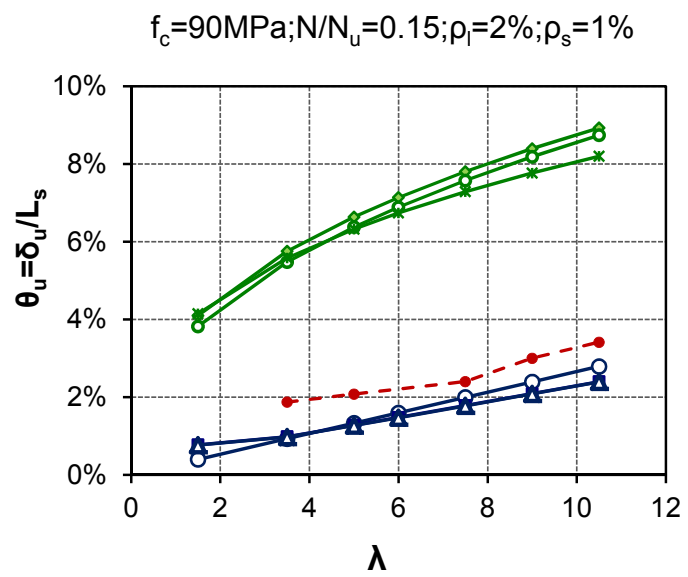

(c)

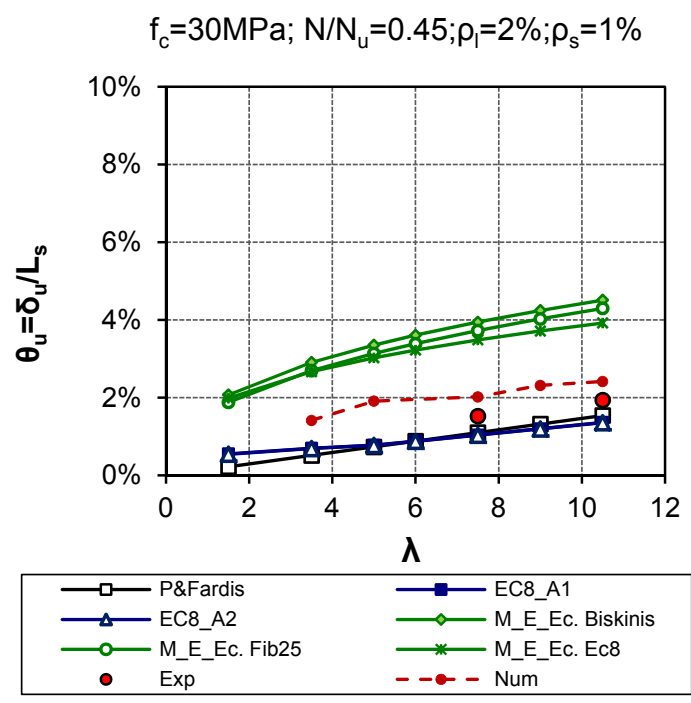

(b)

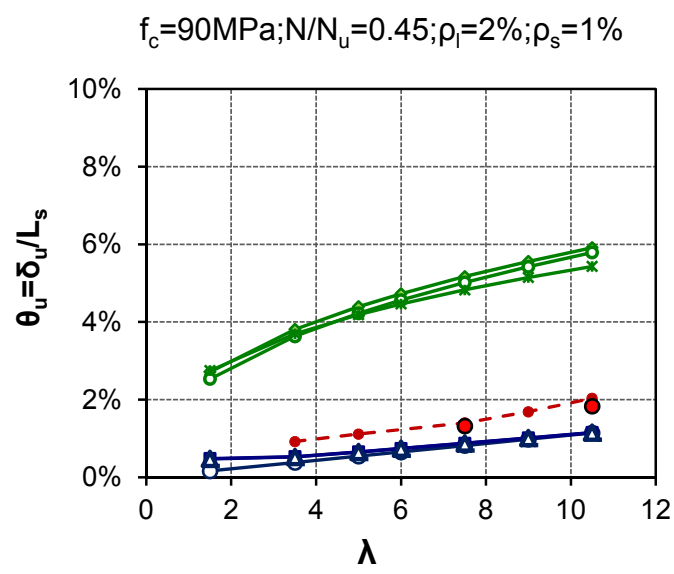

(d)

Figura 9.11 Comparación entre la deriva última calculada por diferentes métodos, la obtenida mediante el modelo numérico de "ATENA 2D", y la resultante de ensayos experimentales, respecto a la esbeltez de cortante

Todos los métodos coinciden en que la deriva última aumenta con el incremento de la esbeltez de cortante $(\lambda=\mathrm{L} / \mathrm{h})$. Sin embargo, dicho aumento en los métodos analíticos y en el modelo numérico es prácticamente lineal, mientras que, en los métodos empíricos, las expresiones asumen una relación potencial de la esbeltez que varía entre 0.425 y 0.35 . 
Se ha observado también que las dos alternativas del método analítico del Eurocódigo 8 (parte 3-Anejo A) [59] son prácticamente iguales en relación al parámetro esbeltez de cortante. Adicionalmente, los métodos del Eurocódigo se separan del método analítico de Panagiotakis y Fardis [100], cuando el nivel de carga axial es bajo, y en especial cuando la resistencia del hormigón es de $30 \mathrm{MPa}$.

En las Figura 9.12 se presenta la relación entre la deriva última calculada a partir de los diferentes modelos $\left(\theta_{u_{\text {u}} \text { cal }}\right)$ y la deriva obtenida del modelo numérico ( $\left.\theta_{\text {u_num }}\right)$, y su relación con la esbeltez de cortante. Las Figura 9.12a y b, indican que la deriva última es subestimada con los métodos analíticos para todo el rango de esbelteces. Aunque puede haber una leve recuperación de la aproximación entre los resultados de los modelos analíticos y los del modelo numérico, cuando aumenta alguno de los parámetros de resistencia del hormigón, nivel de carga axial y esbeltez, la aproximación es inadecuada para un amplio rango de parámetros. Por su parte, los métodos empíricos logran una aceptable predicción respecto a los valores del modelo numérico sólo para elementos con un valor de esbeltez de 3.5 y resistencia del hormigón de $30 \mathrm{MPa}$ (ver Figura 9.12a); pero si aumenta alguno de los parámetros de nivel de carga axial, esbeltez o resistencia del hormigón, los métodos empíricos se alejan significativamente de la solución del modelo numérico.

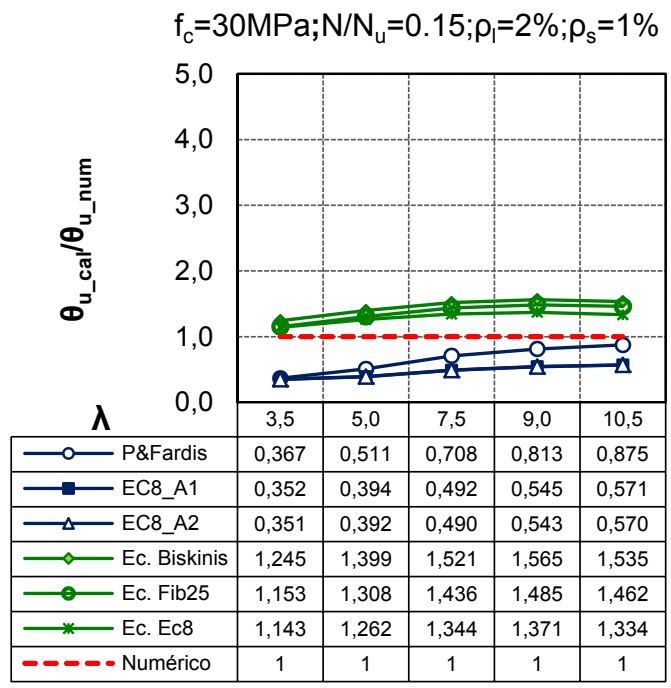

(a)

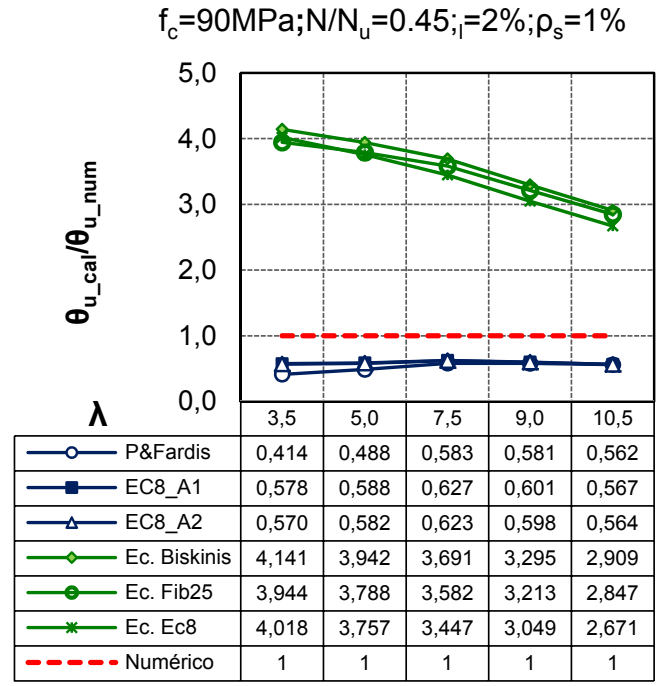

(b)

Figura 9.12 Relación $\theta_{u_{-} \text {cal }} \theta_{u_{-} \text {num }}$ para los diferentes métodos respecto a la esbeltez de cortante

\subsubsection{COMPARACIÓN DE LOS MÉTODOS RESPECTO AL NIVEL DE CARGA AXIAL}

En esta comparación se presentan los resultados de la deriva última calculada mediante los diferentes métodos, para elementos de hormigón armado con las siguientes características: nivel de carga axial entre 0 y 0.6 , esbeltez de cortante 3.5 y 10.5 , y resistencia del hormigón de $30 \mathrm{MPa}, 60 \mathrm{MPa}$, y $90 \mathrm{MPa}$. Las cuantías de armadura longitudinal $\left(\rho_{\mathrm{l}}=2 \%\right)$ y transversal $\left(\rho_{\mathrm{s}}=1 \%\right)$ se han considerado constantes en todos los cálculos. 


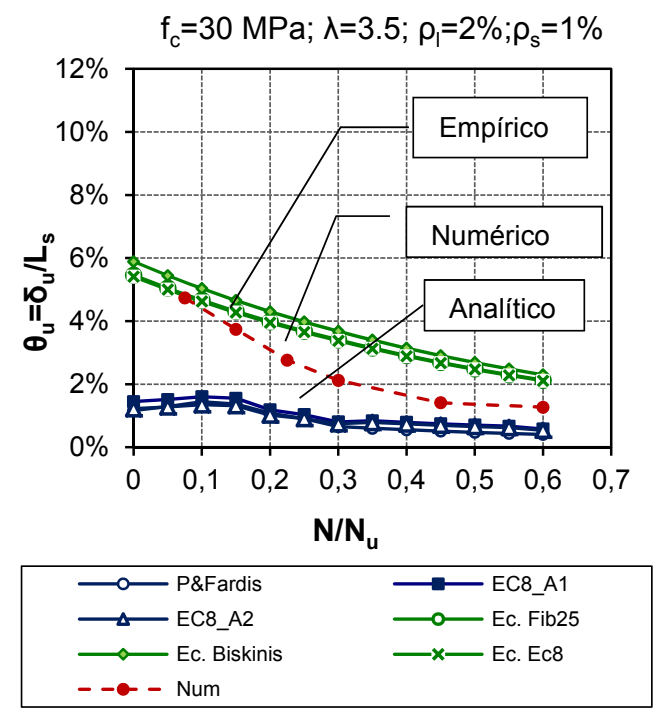

(a)

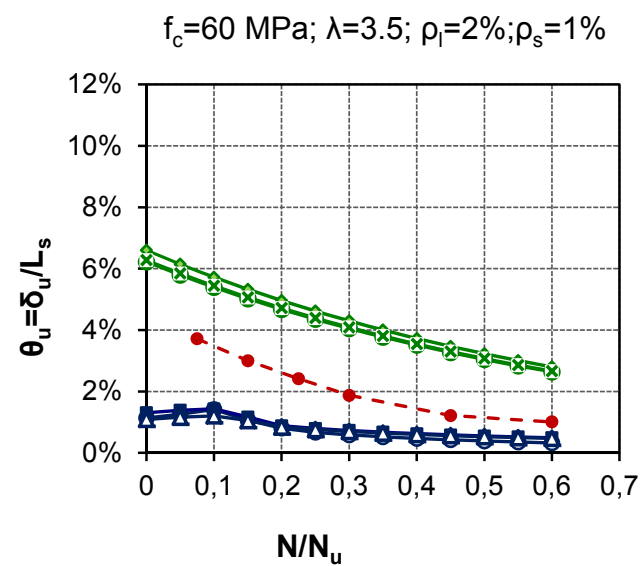

(c)

$f_{c}=90 \mathrm{MPa} ; \lambda=3.5 ; \rho_{1}=2 \% ; \rho_{\mathrm{s}}=1 \%$

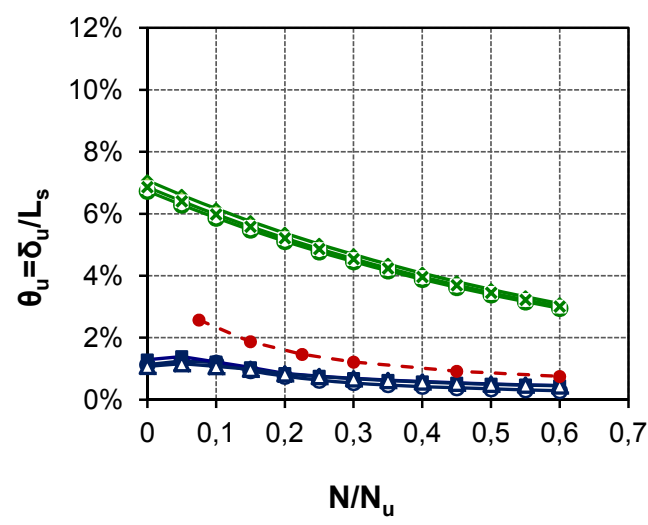

(e)

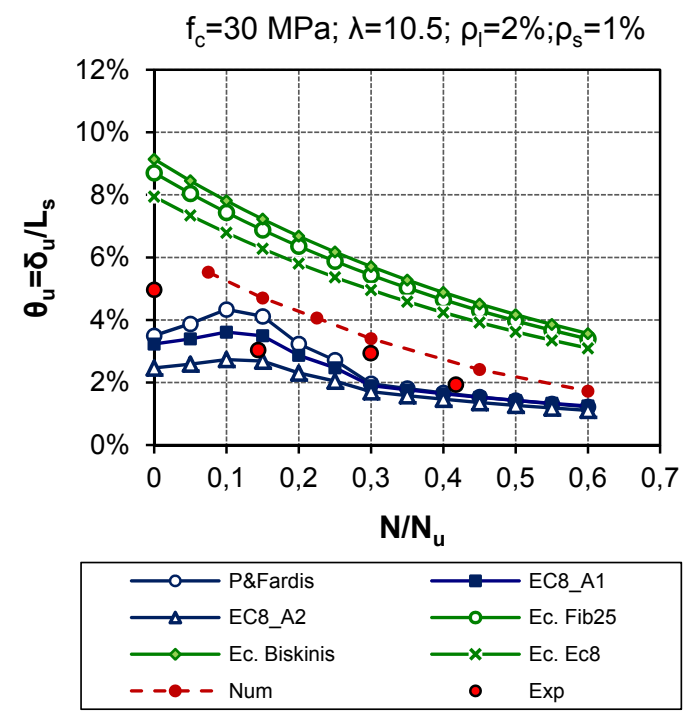

(b)

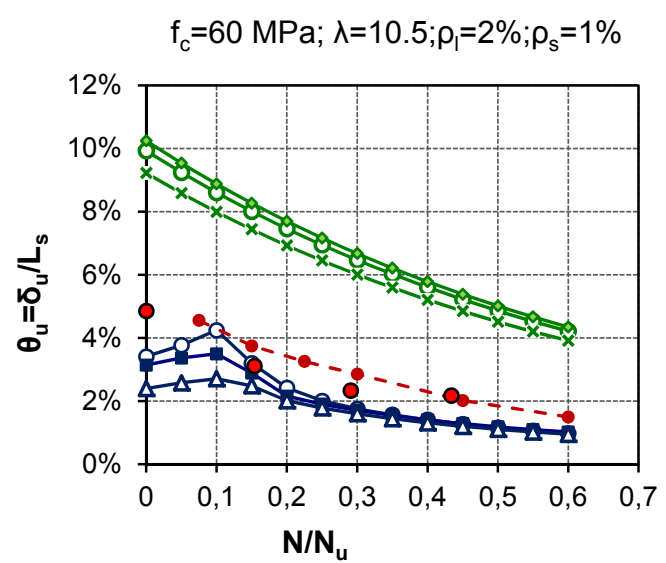

(d)

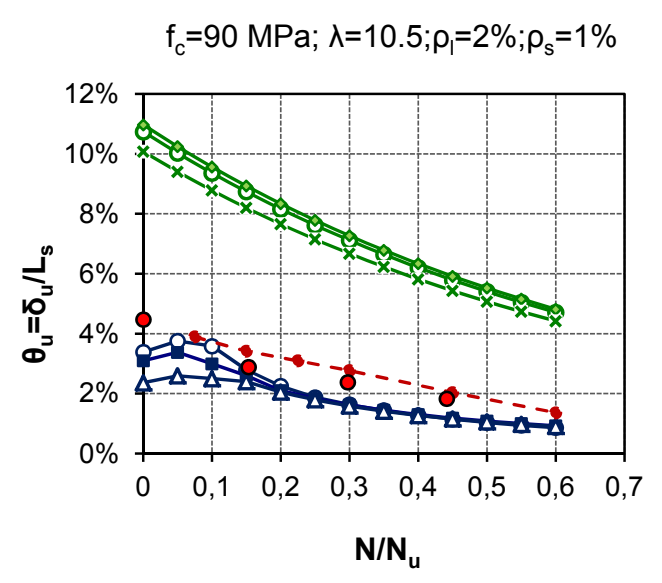

(f)

Figura 9.13 Comparación entre la deriva última calculada por diferentes métodos, la obtenida mediante el modelo numérico de "ATENA 2D", y la resultante de ensayos experimentales, respecto al nivel de carga axial 
Resulta evidente la diferencia entre los métodos empíricos y analíticos en el cálculo de la deriva última $\left(\theta_{u}\right)$. La diferencia no se encuentra únicamente en los valores, sino también en la tendencia de las curvas. Como ya se ha explicado, al analizar los métodos analíticos, las curvas de deriva última muestran prácticamente dos tramos para describir la influencia del nivel de carga axial. Por otra parte, los métodos empíricos consideran que la deriva última disminuye con el aumento del nivel de carga axial.

La curva obtenida a partir del modelo numérico muestra una tendencia similar a los métodos empíricos. Sin embargo, cuantitativamente, los métodos empíricos sobreestiman ampliamente la deriva última, en la mayoría de los casos. Los valores de $\theta_{u}$ obtenidos con el modelo numérico se encuentran entre los resultados de aplicar los métodos empíricos y analíticos, aunque se aproximan un poco más a las curvas obtenidas con los métodos analíticos. Dicha aproximación depende de la interacción de los parámetros resistencia del hormigón y nivel de carga axial.

Como se puede apreciar en las Figura 9.13b, d y f, para $\lambda=10.5$ la curva numérica se aproxima cada vez más a las curvas del método analítico a medida que aumenta la resistencia del hormigón y, en especial, si el nivel de carga axial es bajo. Si el nivel de carga axial aumenta, la separación entre las curvas es mayor. Esto se puede confirmar también en las Figura 9.14, en cuya tabla se muestra la relación $\theta_{\text {u_cal }} / \theta_{\text {u_num. }}$.

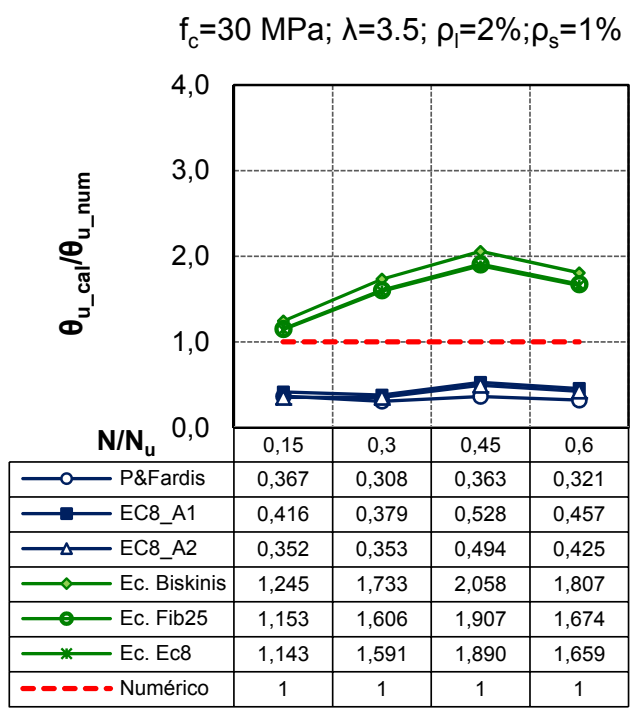

(a)

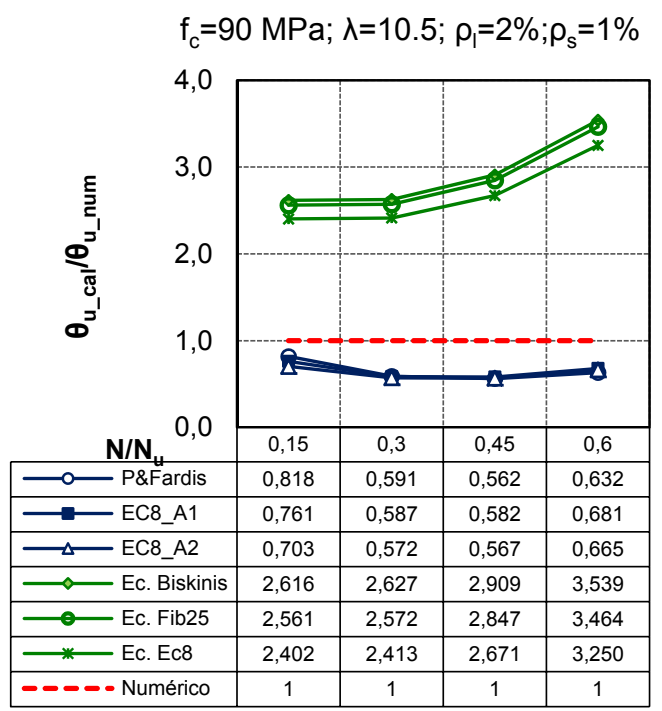

(b)

Figura 9.14 Relación $\theta_{u_{-} c a l} / \theta_{u_{\_} n u m}$ para los diferentes métodos, respecto al nivel de carga axial

En la Figura 9.14a, los parámetros de esbeltez y resistencia del hormigón son representativos dentro del rango en el que tanto los métodos analíticos como los empíricos han sido calibrados. Sin embargo, es evidente la gran diferencia cuantitativa que existe entre los tipos de métodos. Como se puede observar, la relación $\theta_{u_{\text {_cal }}} / \theta_{u_{\text {unnum }}}$ varía ligeramente entre 0.35 y 0.52 para los métodos analíticos, mientras que para los métodos empíricos varía ampliamente entre 1.14 y 2.05. Esto 
demuestra la incertidumbre de la aplicación de los métodos, incluso para elementos de hormigón dentro del rango en el que han sido validados.

Por otra parte, para elementos con características diferentes a las de la Figura 9.14a, como en el caso de la Figura 9.14b, donde se presentan los resultados de elementos altamente esbeltos $(\lambda=10.5)$, con un alto valor de resistencia del hormigón $(90 \mathrm{MPa})$, la relación $\theta_{\mathrm{u}_{-} \text {cal }} / \theta_{\mathrm{u} \_ \text {num }}$ en los métodos analíticos aumenta ligeramente, mientras que los resultados de los métodos empíricos se alejan cada vez más de la respuesta del modelo numérico, a medida que aumenta el nivel de carga axial.

\subsubsection{COMPARACIÓN DE LOS MÉTODOS RESPECTO A LA RESISTENCIA DEL HORMIGÓN}

Utilizando el parámetro de resistencia del hormigón en la comparación de los distintos métodos teóricos de capacidad de deformación, la evaluación de la deriva última se ha realizado para la estimación de la serie ensayos con las siguientes características: resistencia del hormigón en compresión entre $30 \mathrm{MPa}$ y $90 \mathrm{MPa}$, esbeltez de cortante de 7.5 y 10.5 , y nivel de carga axial de 0.15 y 0.30 . Las cuantías de armadura longitudinal $\left(\rho_{l}=2 \%\right)$ y transversal $\left(\rho_{s}=1 \%\right)$ son constantes en todos los cálculos.

Como se puede observar en las Figura 9.15, los métodos muestran contradicciones respecto a la forma en que influye la resistencia del hormigón en compresión $\left(\mathrm{f}_{\mathrm{c}}\right)$ en la variable de capacidad de deformación $\left(\theta_{\mathrm{u}}\right)$. Por una parte, los métodos empíricos consideran que el incremento de la resistencia del hormigón causa un aumento en la deriva última, y, por otra parte, el modelo numérico de "ATENA 2D" indica que $\theta_{u}$ disminuye conforme aumenta la resistencia del hormigón. Por último, los métodos analíticos muestran que la $\theta_{\mathrm{u}}$ disminuye ligeramente con el aumento de la resistencia del hormigón en compresión, siendo dicha disminución casi imperceptible.

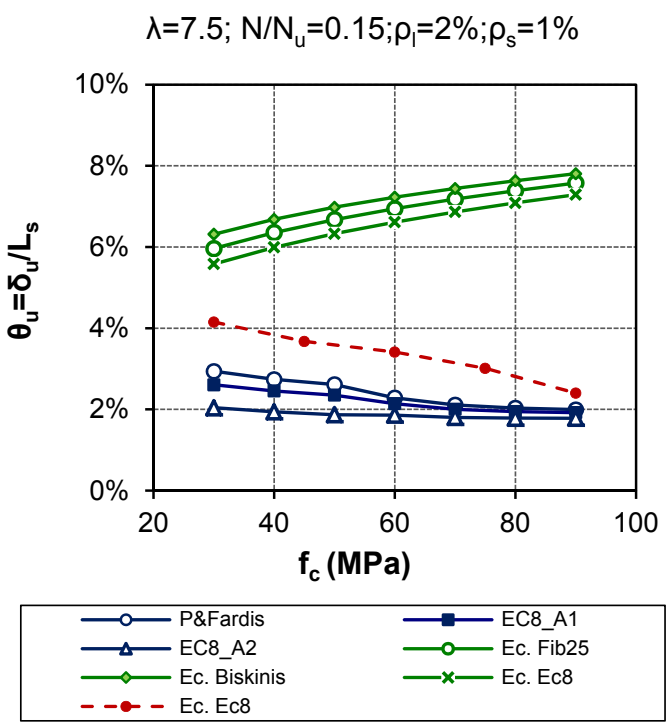

(a)

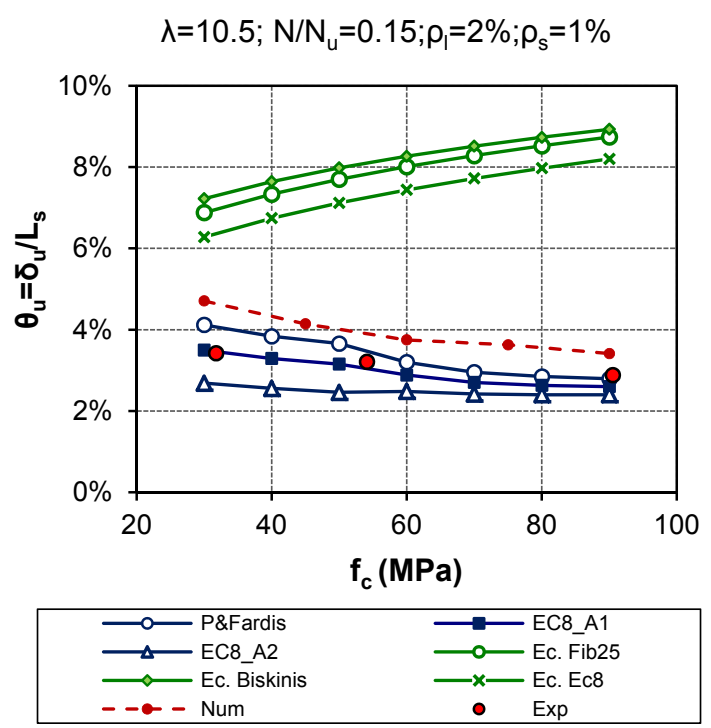

(b) 
Estudio experimental y numérico de la capacidad de deformación de soportes esbeltos de hormigón armado

$\lambda=7.5 ; \mathrm{N} / \mathrm{N}_{\mathrm{u}}=0.30 ; \rho_{1}=2 \% ; \rho_{\mathrm{s}}=1 \%$

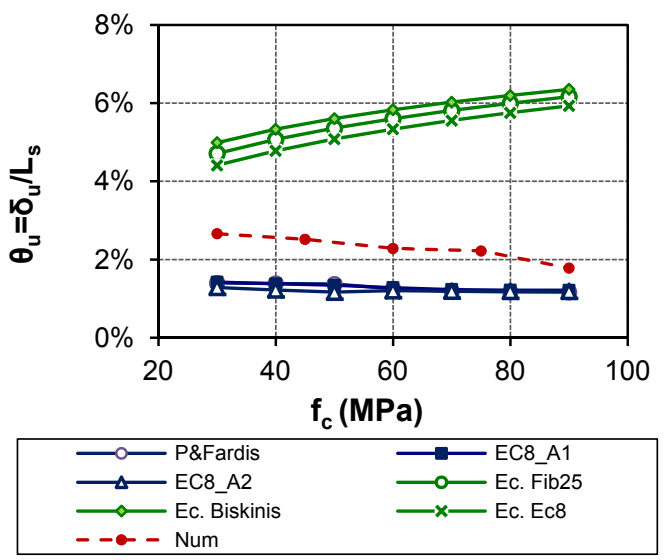

(c) $\lambda=10.5 ; \mathrm{N} / \mathrm{N}_{\mathrm{u}}=0.30 ; \rho_{1}=2 \% ; \rho_{\mathrm{s}}=1 \%$

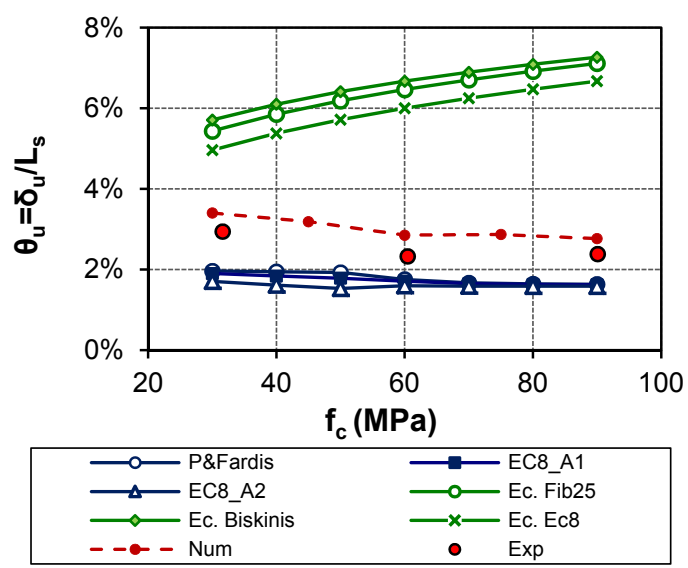

(d)

Figura 9.15 Comparación entre la deriva última calculada por diferentes métodos, la obtenida mediante el modelo numérico de "ATENA 2D", y la resultante de ensayos experimentales, respecto a la resistencia del hormigón en compresión

Al comparar la deriva última calcula a partir de los diferentes métodos y la obtenida a partir del modelo numérico "ATENA 2D" (Figura 9.16), se ha encontrado que:

La resistencia del hormigón incrementa significativamente los valores de deriva última calculada mediante los métodos empíricos. Consecuentemente, la diferencia entre los valores calculados y los obtenidos del modelo numérico se amplían con el aumento de la resistencia del hormigón.

Los métodos analíticos mantienen siempre una relación $\theta_{\mathrm{u} \_ \text {cal }} / \theta_{\mathrm{u} \_ \text {num }}$ menor a la unidad, y muestran un ligero aumento con el incremento de la resistencia del hormigón, aunque no lo suficiente para que los métodos analíticos sean considerados como apropiados.

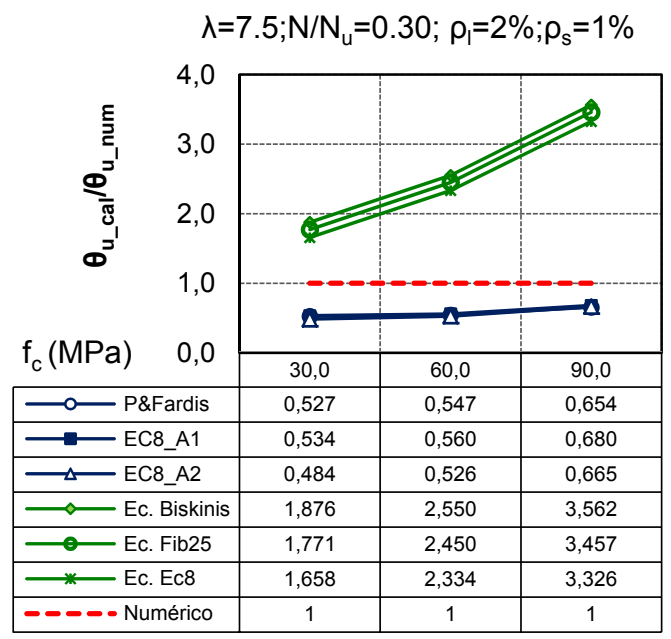

(a)

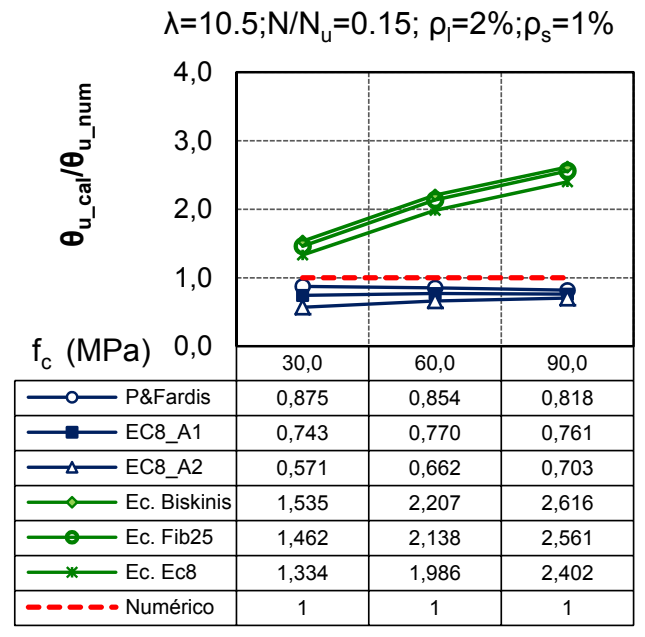

(b)

Figura 9.16 Relación $\theta_{u_{-} c a l} \theta_{u_{-} n u m}$ para los diferentes métodos respecto a la resistencia del hormigón en compresión 


\subsubsection{COMPARACIÓN DE LOS MÉTOdOS RESPECTO A LA CUANTíA DE ARMADURA LONGITUDINAL}

Para interpretar las diferencias entre los distintos métodos respecto al parámetro de cuantía de armadura longitudinal, la deriva última ha sido evaluada en una serie de ensayos con las siguientes características: cuantía de armadura longitudinal entre $1 \%$ y $5 \%$, nivel de carga axial de 0.15 y 0.30 . Se han considerado dos valores de esbeltez (3.5 y 10.5) y la resistencia del hormigón es de $30 \mathrm{MPa}$ y $90 \mathrm{MPa}$. La cuantía de confinamiento es del $1 \%$ en todos los ensayos.

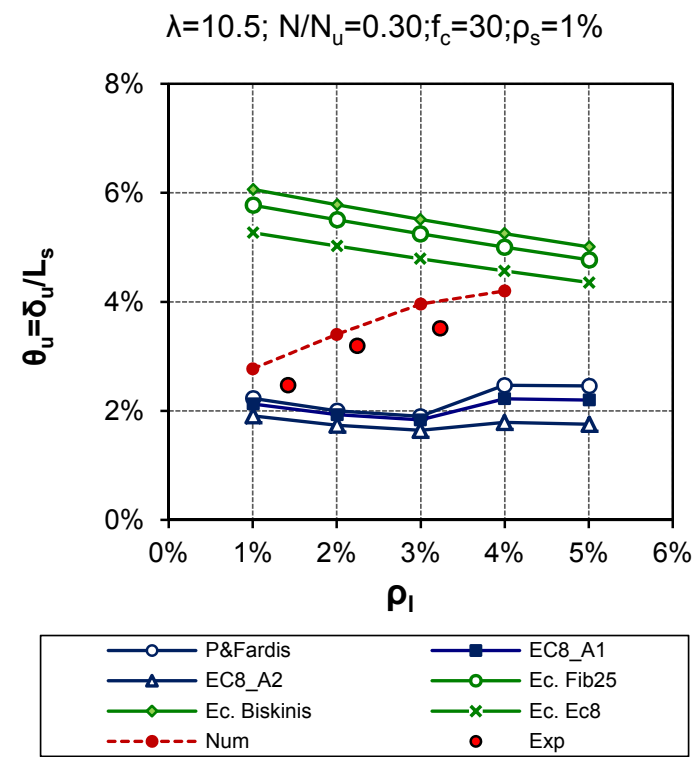

(a)

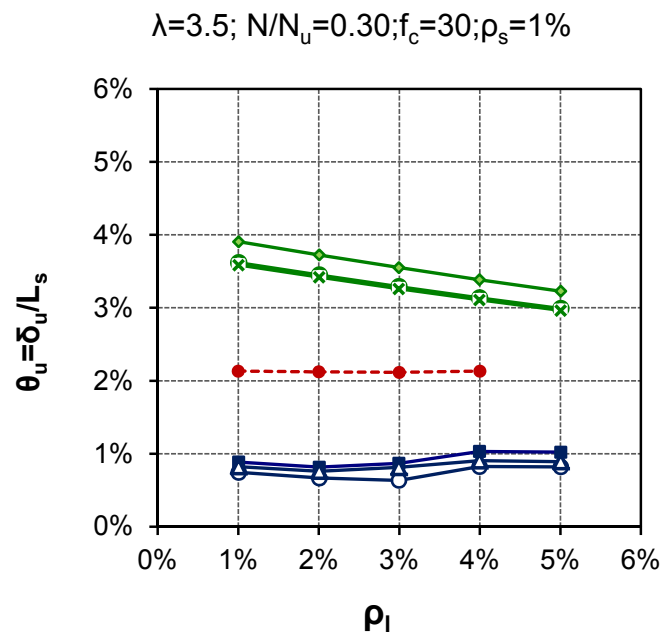

(c)

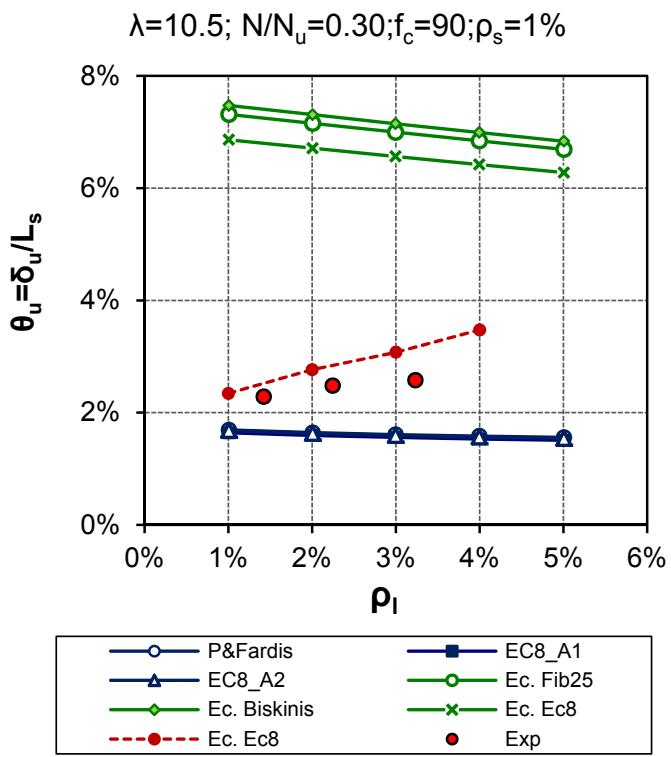

(b)

$\lambda=3.5 ; N / N_{u}=0.15 ; f_{c}=90 ; p_{s}=1 \%$

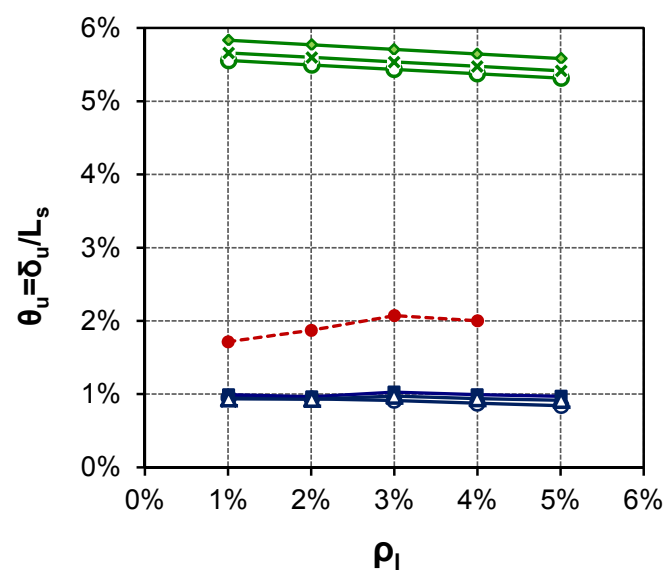

(d)

Figura 9.17 Comparación entre la deriva última calculada por diferentes métodos, la obtenida mediante el modelo numérico de "ATENA 2D", y la resultante de ensayos experimentales, respecto a la cuantía de armadura longitudinal 
La comparación entre los diferentes métodos teóricos, el modelo numérico "ATENA 2D" y algunos ensayos experimentales, muestran algunas diferencias respecto al efecto de la cuantía de armadura longitudinal. En primer lugar, los métodos empíricos muestran, en general, que la $\theta_{u}$ disminuye con el incremento de la cuantía longitudinal. En segundo lugar, los métodos analíticos indican que el efecto de la cuantía de armadura longitudinal es ligeramente variable, y puede considerarse inapreciable. Por último, el modelo numérico muestra que el efecto de la cuantía de armadura longitudinal depende directamente de la esbeltez: en elementos altamente esbeltos, como se ve en las Figura 9.17a y b, la deriva última aumenta notablemente con el incremento de la cuantía longitudinal, mientras que, en elementos poco esbeltos, la influencia de la cuantía de armadura longitudinal es mucho menor, y tiende a ser prácticamente nula a medida que aumenta el nivel de carga axial (Figura 9.17c y d).

La comparación de los resultados de los métodos teóricos y los del modelo numérico (Figura 9.18), mediante la relación $\theta_{u_{\text {u_cal }}} / \theta_{\mathrm{u}_{-} \text {num, }}$ confirma que ni los métodos analíticos ni los empíricos son capaces de interpretar el efecto de la cuantía de armadura longitudinal de forma coherente.

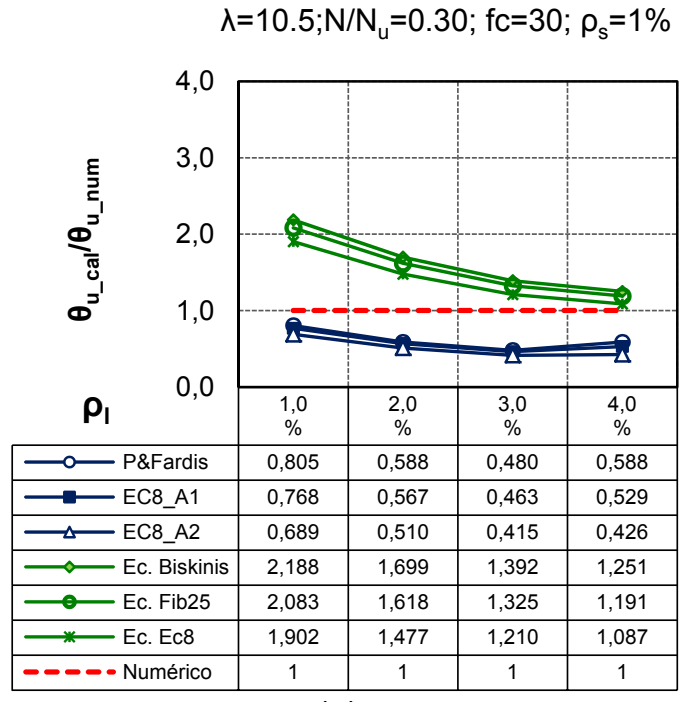

(a)

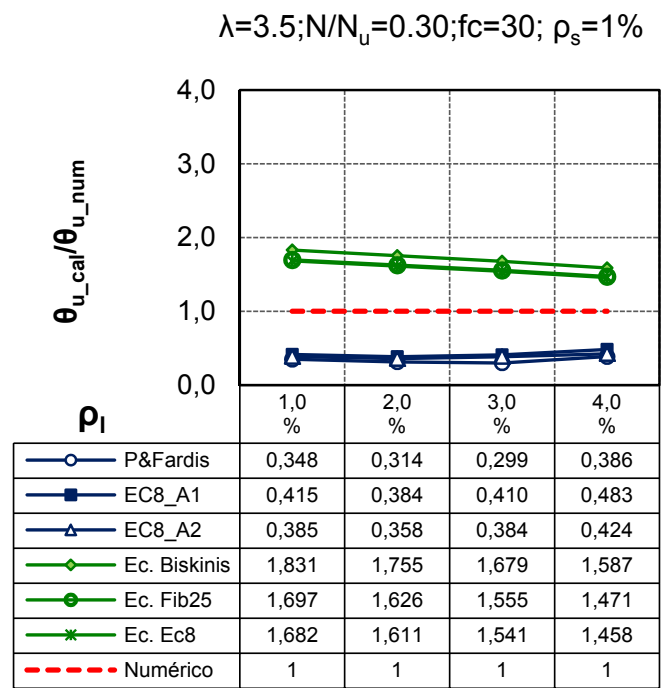

(b)

Figura 9.18 Relación $\theta_{u_{-} \text {cal }} \theta_{u_{-} \text {num }}$ para los diferentes métodos respecto a la cuantía de armadura longitudinal

\subsubsection{COMPARACIÓN DE LOS MÉTODOS RESPECTO A LA CUANTÍA DE ARMADURA TRANSVERSAL}

En el análisis llevado a cabo hasta aquí se han considerado elementos con cuantía de armadura transversal del $1 \%$, de modo que las curvas que representan los métodos analíticos siempre están por debajo de las curvas del modelo numérico y de los métodos empíricos. Sin embargo, al incluir la cuantía de armadura transversal, la respuesta de los métodos analíticos cambia significativamente y llega a alcanzar incluso, en algunos casos, valores mucho mayores que los métodos empíricos. 
Los métodos empíricos siguen sobrestimando ampliamente los resultados de deriva última obtenidos del modelo numérico "ATENA 2D" y de los ensayos experimentales. Como se puede ver en las Figura 9.19, los métodos empíricos consideran que el aumento de la cuantía transversal logra un aumento en la deformación última de los elementos de hormigón armado.

En elementos con escasa cuantía de armadura transversal $\left(\rho_{\mathrm{s}}=1 \%\right)$, se ha encontrado que las dos alternativas del método analítico descrito en el Eurocódigo 8 (parte 3-Anejo A) [59], son bastante similares, como se ha podido ver en el análisis de los otros parámetros; sin embargo, cuando los efectos del confinamiento empiezan a intervenir en los cálculos, las diferencias entre las dos alternativas del modelo analítico se amplían, llegando en algunos casos incluso a alcanzarse diferencias del $100 \%$.

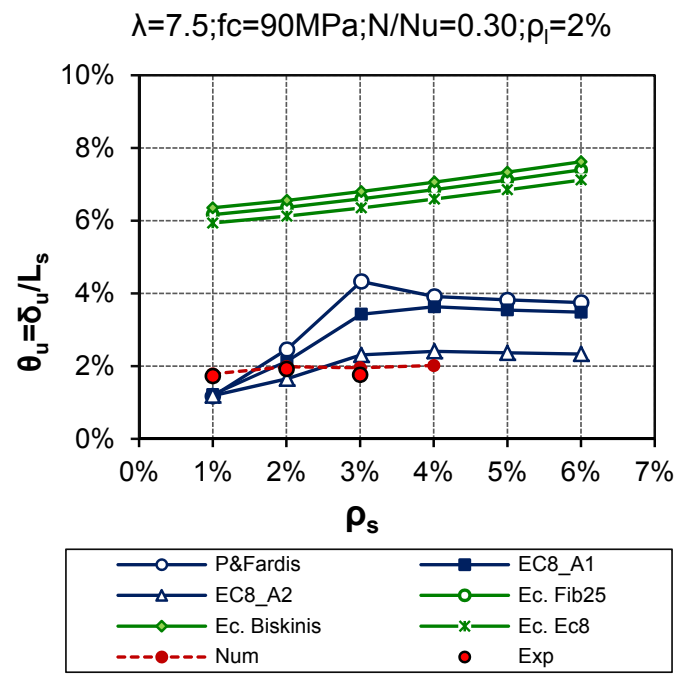

(a)

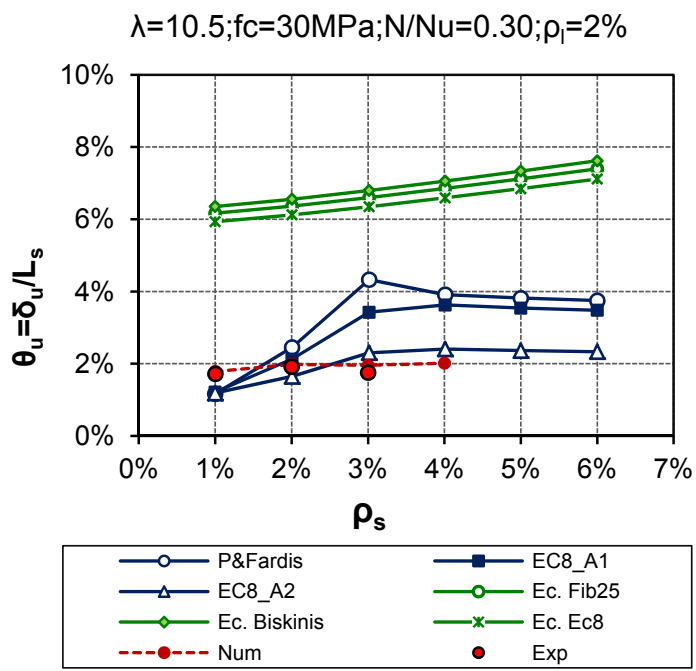

(c)

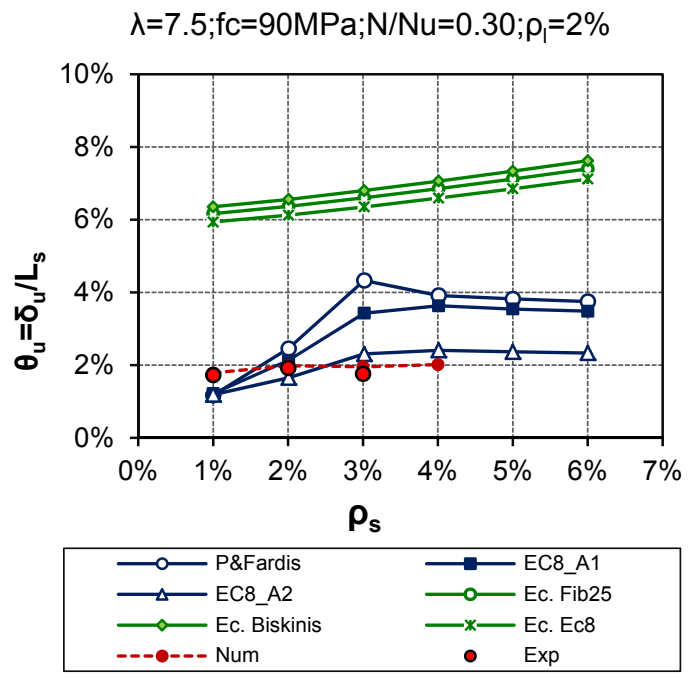

(b)

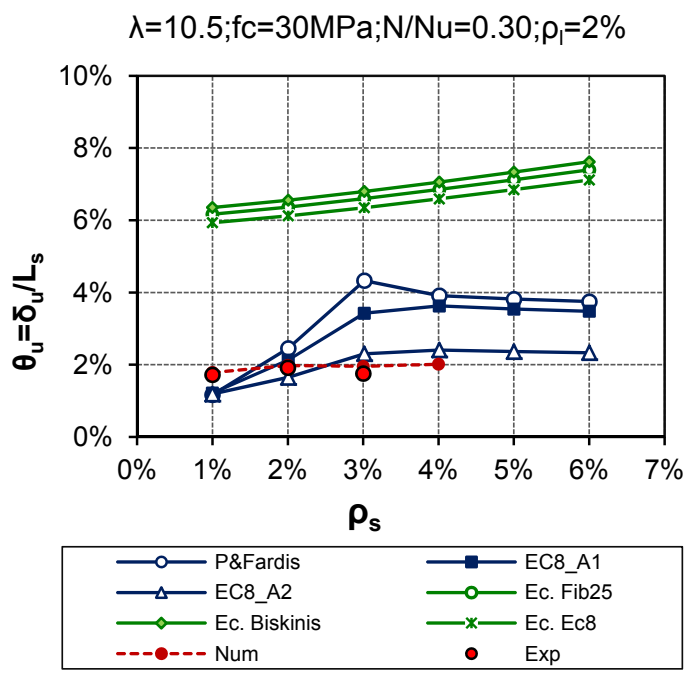

(d)

Figura 9.19 Comparación entre la deriva última calculada por diferentes métodos, la obtenida mediante el modelo numérico de "ATENA 2D", y la resultante de ensayos experimentales, respecto a la cuantía de armadura transversal 
El modelo numérico de "ATENA 2D", y los ensayos experimentales consiguen un ligero aumento en la deriva última con el incremento de la cuantía de armadura transversal. El modelo analítico EC8_A2 logra también un incremento de $\theta_{u}$ en algunos rangos de $\rho_{\mathrm{s}}$, consiguiéndose así una mejor aproximación con los resultados del modelo numérico.

La comparación de los métodos respecto al parámetro de cuantía de armadura transversal $\left(\rho_{\mathrm{s}}\right)$ muestra una importante dispersión de los resultados, especialmente en los métodos analíticos, puesto que en estos métodos la expresión de la longitud de rótula plástica asociada a cada método implica grandes variaciones, lo cual resulta ser bastante influyente en los resultado de la deriva última.

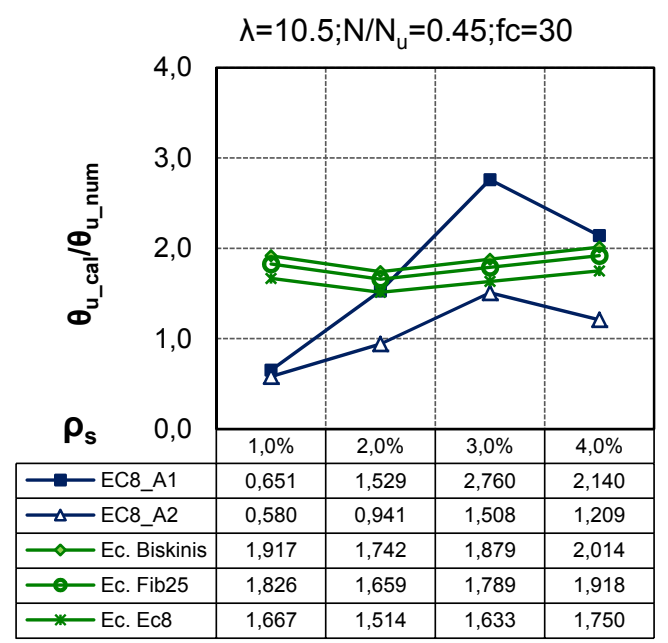

(a)

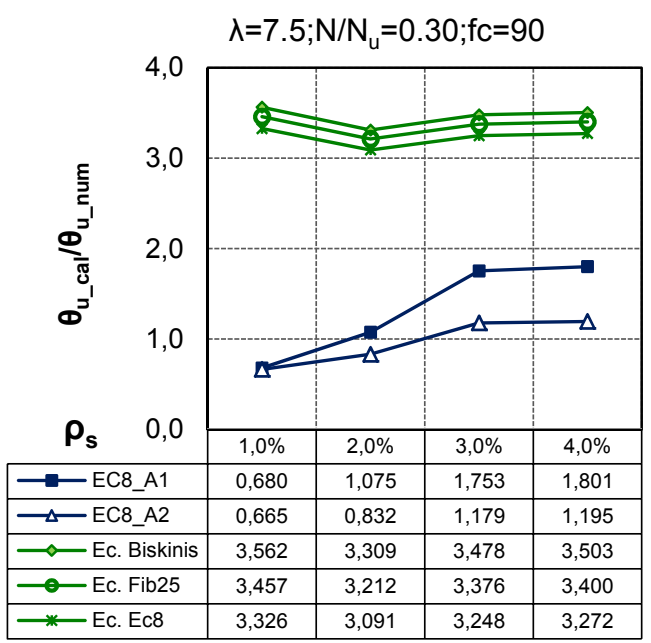

(b)

Figura 9.20 Relación $\theta_{u_{-} c a l} \theta_{u_{-} \text {num }}$ para los diferentes métodos respecto a la cuantía de armadura transversal

\subsubsection{CONSIDERACIONES DE LA COMPARACIÓN ENTRE LOS MÉTODOS TEÓRICOS Y LOS RESULTADOS NUMÉRICOS}

En este apartado se han revisado y comparado los métodos teóricos propuestos para evaluar la capacidad de deformación de elementos de hormigón armado en términos de la deriva última, con el objeto de comprobar los diversos métodos existentes. Los resultados del análisis llevado a cabo demuestran los siguientes hechos:

La respuesta obtenida mediante los métodos empíricos es bastante diferente a la obtenida en los métodos analíticos. La capacidad de deriva última $\left(\theta_{u_{-} \text {cal }}\right)$ calculada mediante los métodos empíricos es ampliamente sobrestimada en comparación con los valores de $\theta_{\text {u_num }}$ obtenidos mediante el modelo numérico de "ATENA 2D" y los medidos en los ensayos experimentales. Por otra parte, la aproximación entre los valores calculados mediante los métodos analíticos y los obtenidos a partir del modelo numérico dependen en gran medida de la interacción entre los parámetros de cuantía de armadura de confinamiento $\left(\rho_{s}\right)$, nivel de carga axial y esbeltez de 
cortante. Aun así, en este análisis se ha comprobado que para elementos poco confinados $\left(\rho_{s} \leq 1 \%\right)$, la $\theta_{u_{-} \text {cal }}$ suele ser subestimada respecto a los valores de $\theta_{u_{-} \text {num. }}$.

La respuesta de $\theta_{\mathrm{u}}$ obtenida con los métodos empíricos presentados en el Boletín del CEB-FIP 25 (2003) [35], en Fardis y Biskinis (2003) [60] y en el Eurocódigo 8 [59], muestran bastante aproximación, ya que las expresiones son similares, y sólo varían ligeramente algunos de sus coeficientes. La expresión de Panagiotakos y Fardis (2001) [100] es la más deficiente para predecir la capacidad de deriva última en elementos de hormigón armado sometidos a compresión y flexión monotónica, puesto que la expresión ha sido calibrada con resultados de $\theta_{u}$ medidos en su mayor parte en ensayos de elementos sometidos a flexión sin carga axial, y, además, no considera el efecto del confinamiento que produce la armadura transversal en soportes de hormigón.

En el análisis se han encontrado importantes contradicciones respecto a la forma en que los métodos empíricos tienen en cuenta algunos parámetros, como por ejemplo la resistencia del hormigón y la cuantía de armadura longitudinal. Por una parte, los métodos empíricos asumen que la deriva última se incrementa cuando aumenta la resistencia del hormigón en compresión, lo cual resulta contrario a lo demostrado en el estudio paramétrico llevado a cabo a partir del modelo numérico de "ATENA 2D". Por otra parte, los modelos empíricos generalizan el efecto de la cuantía de armadura longitudinal y consideran que el aumento de esta produce una disminución en la deriva última. Sin embargo, el modelo numérico muestra que el efecto de la cuantía de armadura longitudinal depende de la combinación con otros parámetros, como la esbeltez y el nivel de carga axial.

Al comparar los valores de deriva última calculada a partir de los métodos analíticos con los resultados obtenidos mediante el modelo numérico de "ATENA 2D" y los resultados de los ensayos experimentales, se ha encontrado que, en general, los métodos analíticos subestiman los valores de $\theta_{\mathrm{u}}$ especialmente cuando existe una baja cuantía de armadura de confinamiento.

Cuando la cuantía de armadura transversal aumenta $\left(\rho_{\mathrm{s}}>1 \%\right)$, los modelos analíticos interpretan que el efecto del confinamiento es tan importante que consigue un aumento considerable de la capacidad de deformación, de modo que tienden a sobrestimar la deriva última. Sin embargo, interpretar el efecto de la cuantía de armadura transversal en los métodos analíticos resulta complejo, las curvas muestran que el efecto favorable que causa un aumento de $\rho_{\mathrm{s}}$, es positivo hasta un valor límite. A partir de este valor, un aumento de $\rho_{\mathrm{s}}$ provoca un descenso de la deriva última. Esta interpretación también depende del modelo de confinamiento implementado. 
Estudio experimental y numérico de la capacidad de deformación de soportes esbeltos de hormigón armado 


\section{CAPÍTULO 10}

\section{PROPUESTA DE MÉTODO SIMPLIFICADO}

En este capítulo se presenta una propuesta de método simplificado que permite determinar la capacidad de deformación de elementos fabricados con hormigón convencional o de alta resistencia sujetos a flexo-compresión. El método propuesto ha tomado como base los resultados obtenidos de la simulación numérica realizada con el programa "ATENA 2D", los cuales se describieron y analizaron en el estudio paramétrico presentado en los capítulos 7 y 8 . En el anejo $\mathrm{N}$ se presenta la relación de las características geométricas y mecánicas para las 250 simulaciones numéricas, cuya respuesta carga-flecha se encuentra en el anejo $\mathrm{M}$.

Mediante la aplicación del método propuesto, es posible predecir las siguientes variables relacionadas con la capacidad de deformación de elementos de hormigón armado sometidos a flexo-compresión: desplazamiento elástico efectivo $\left(\delta_{y}^{\prime}\right)$, desplazamiento último $\left(\delta_{\mathrm{u}}\right)$, ductilidad de desplazamiento $\left(\mu_{\delta}\right)$, rigidez elástica efectiva $\left(E I_{e}\right)$ y rigidez última $\left(E I_{u}\right)$.

El método ha sido contrastado tanto con los resultados de la simulación numérica como con los resultados experimentales de los 40 soportes ensayados en este trabajo. De acuerdo con los rangos de los parámetros analizados en la simulación 
numérica (capítulo 8), las expresiones que se desarrollan son válidas para el siguiente rango de aplicación:

- $\quad$ Axiles reducidos $\left(N / A_{g} f_{c}\right)$ entre 0.1 y 0.6

- $\quad$ Esbeltez de cortante $(\lambda)$ entre 3.5 y 10.5

- Resistencia del hormigón $\left(\mathrm{f}_{\mathrm{c}}\right.$ ) entre 30 y $90 \mathrm{MPa}$

- Cuantías de armadura longitudinal $\left(\rho_{1}\right)$ entre $1 \%$ y $4 \%$

- Cuantías de armadura transversal $\left(\rho_{\mathrm{s}}\right)$ entre $1 \%$ y $4 \%$

\subsection{EVALUACIÓN DE LA RIGIDEZ ELÁSTICA EFECTIVA DE SOPORTES DE HORMIGÓN}

En este apartado se propone una expresión para el cálculo de la rigidez elástica efectiva $\left(E \mathrm{I}_{\mathrm{e}}\right)$ a flexión de soportes. Dicha rigidez se ha deducido a partir de resultados de la simulación numérica. Una vez conocida la rigidez $\mathrm{El}_{\mathrm{e}}$, es posible calcular el desplazamiento elástico efectivo $\left(\delta_{\mathrm{y}}\right)$.

\subsubsection{METODOLOGÍA}

Conocidas las características mecánicas y geométricas del soporte, y habiendo aplicado previamente un nivel de axil conocido, se obtiene, mediante el programa de análisis no lineal "ATENA 2D", la respuesta carga-desplazamiento (Figura 10.1). Dicha respuesta se idealiza mediante un diagrama bilineal, aplicando en dicha idealización el método propuesto en el Eurocódigo 8 (2004) [59], que realiza un balance de energía a partir del punto de plastificación que puede producirse en cualquiera de las dos situaciones siguientes: o bien la armadura de tracción alcanza el límite elástico, o bien la deformación de la fibra extrema alcanza el $0.75 \varepsilon_{\text {co }}$ (siendo $\varepsilon_{\mathrm{co}}$ la deformación correspondiente a la tensión pico del hormigón).

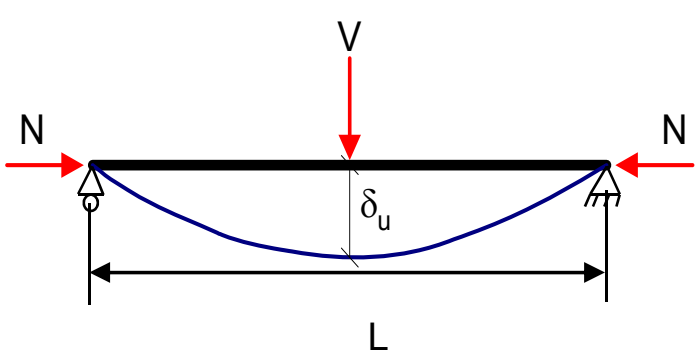

(a)

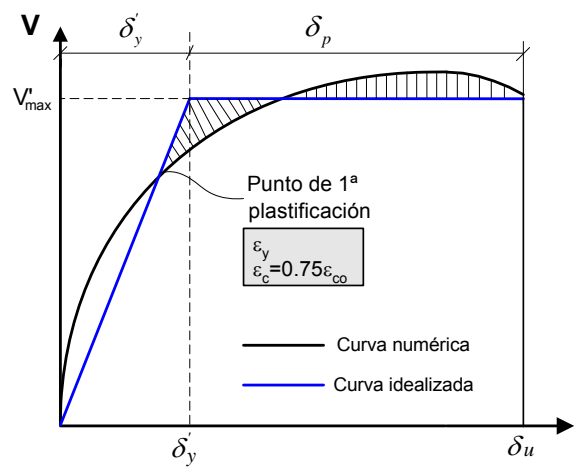

(b)

Figura 10.1 Respuesta carga lateral-desplazamiento

En consecuencia, a partir de la idealización del diagrama carga-desplazamiento ( $\mathrm{V}$ $\delta)$, se obtiene el desplazamiento elástico efectivo $\left(\delta_{\mathrm{y}}^{\prime}\right)$ y la carga lateral $\left(V^{\prime}{ }_{\max }\right)$, deduciéndose la rigidez elástica efectiva correspondiente a la rama ascendente del diagrama idealizado, mediante la Ec. 10-1: 


$$
E I_{e}=\frac{V_{\text {max }}^{\prime} L^{3}}{48 \delta_{y}^{\prime}}
$$

Si la cuantía y la distribución de la armadura se conocen, la rigidez elástica efectiva puede obtenerse a partir de la rigidez del hormigón $\left(E_{c} l_{c}\right)$ y de la rigidez del acero $\left(E_{s} I_{s}\right)$, Ec. $10-2$.

$$
E I=\alpha_{e} E_{c} I_{c}+E_{s} I_{s}
$$

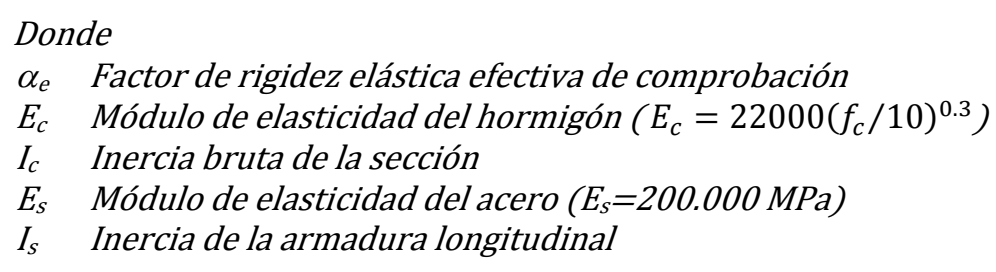

Sin embargo, en el caso de que no se conozca la cuantía y distribución de armado, la rigidez elástica efectiva puede obtenerse a partir de la rigidez del hormigón $E_{c} l_{c}$.

Donde

$$
E I_{e}=\alpha_{e}^{*} E_{c} I_{c}
$$

Ec. $10-3$

$\alpha_{e}^{*} \quad$ Factor de rigidez elástica efectiva de diseño

La aplicación de una u otra propuesta dependerá de si se realiza la comprobación del diseño de la estructura (si es conocida la distribución de la cuantía, Ec. 10-2) o si se está realizando el dimensionamiento de la misma (Ec. 10-3).

A partir de los resultados de la simulación numérica se deducirá el factor de rigidez mediante las siguientes expresiones.

$$
\begin{gathered}
\alpha_{e}^{*}=\frac{\left(E I_{e}\right)_{S N}}{E_{c} I_{c}} \\
\alpha_{e}=\frac{\left(E I_{e}\right)_{S N}-E_{s} I_{s}}{E_{c} I_{c}}
\end{gathered}
$$

Donde $\left(E I_{e}\right)_{S N}$ es la rigidez elástica efectiva obtenida mediante la simulación numérica.

\subsubsection{FACTOR DE RIGIDEZ ELÁSTICO EFECTIVO DE DISEÑO $\alpha_{\mathbf{e}}^{*}$}

El estudio del factor de rigidez $\alpha_{e}^{*}$ se desarrolla inicialmente a partir del análisis de los resultados obtenidos en una serie de ensayos numéricos con las características que se indican en la Tabla 10-1. 
Tabla 10-1 Características de los ensayos numéricos a partir de los cuales se inicia el análisis de $\alpha_{e}^{*}$

\begin{tabular}{|l|l|}
\hline Nivel de carga axial $\left(\mathrm{N} / \mathrm{N}_{\mathrm{u}}\right)$ & $0.075-0.60$ \\
\hline Axil reducido $\left(v=\mathrm{N} / \mathrm{A}_{\mathrm{g}} \mathrm{f}_{\mathrm{c}}\right)$ & $\approx 0.1-0.8$ \\
\hline Esbeltez de cortante $\left(\lambda=\mathrm{L}_{\mathrm{s}} / \mathrm{h}\right)$ & $3.5,5,7.5,9.0$ y 10.5 \\
\hline Resistencia del hormigón $\left(\mathrm{f}_{\mathrm{c}}\right)$ & 30,60 y $90 \mathrm{MPa}$ \\
\hline Cuantía de armadura longitudinal & $2.2 \%$ \\
\hline Cuantía de confinamiento $\left(\rho_{\mathrm{s}}\right)$ & $1 \%$ \\
\hline
\end{tabular}

Las Figura 10.2a-d permiten determinar la relación del factor $\alpha_{e}^{*}$ con respecto al axil reducido $\left(v=N / A_{g} f_{c}\right)$, la esbeltez de cortante $\left(\lambda=L_{s} / h\right)$, y la resistencia del hormigón $\left(f_{c}\right)$. Más adelante, se introducen en el modelo simplificado los efectos producidos por la cuantía longitudinal. Sin embargo, el modelo propuesto para $\alpha_{e}^{*}$ no considera los efectos debidos a la armadura transversal $\left(\rho_{s}\right)$, ya que, como se ha demostrado en el estudio paramétrico del capítulo 8 , la cuantía transversal no influye en la capacidad deformacional de elementos de hormigón armado durante el comportamiento en el estado elástico.

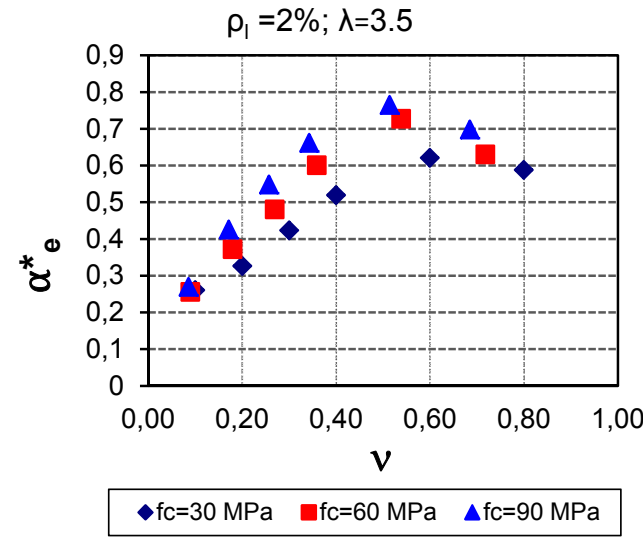

(a)

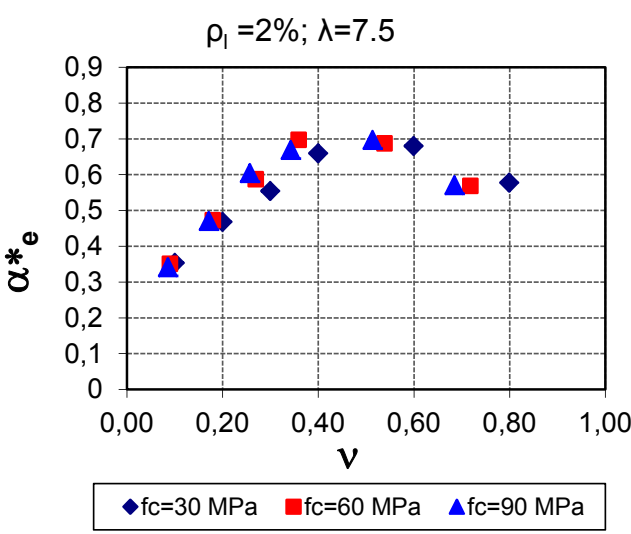

(c)

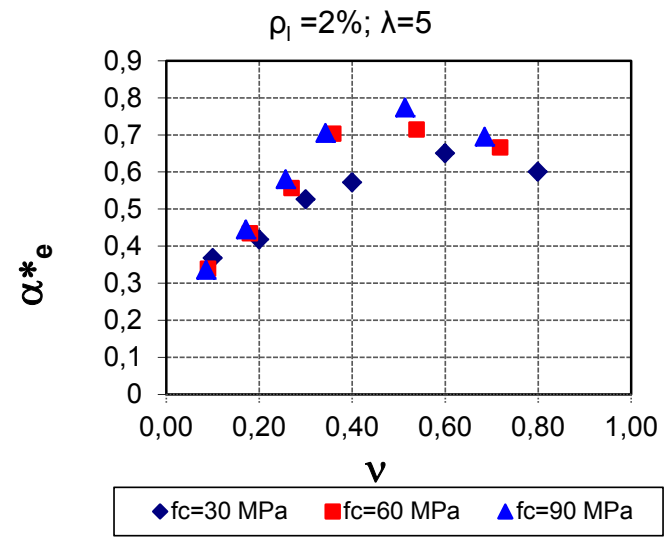

(b)

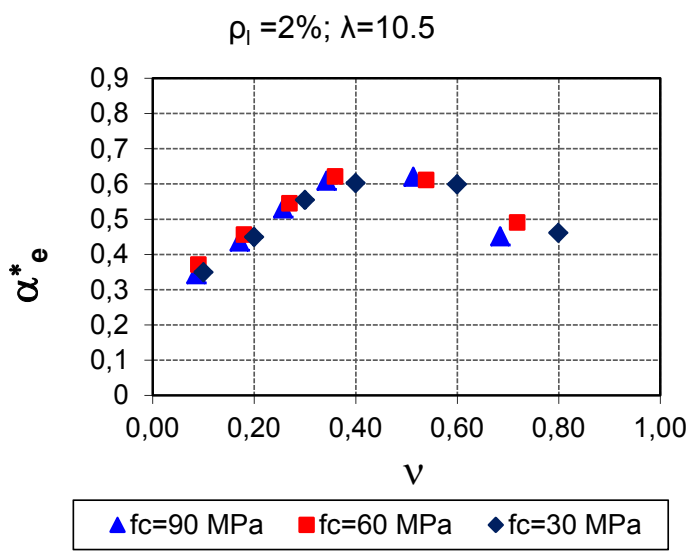

(d)

Figura 10.2 Relación entre el factor $\alpha_{e}^{*}$ y el axil reducido, para (a) $\lambda=3.5,(b) \lambda=5.0,(c)$ $\lambda=7.5$ y $(d) \lambda=10.5$ 
En las Figura 10.2a-d se muestra que el incremento del axil reducido provoca un aumento del factor de rigidez $\left(\alpha_{e}^{*}\right)$ hasta alcanzar un valor máximo, el cual se presenta cuando el axil reducido $(v)$ es aproximadamente igual a 0.6. A partir de este valor, el factor de rigidez disminuye con el aumento del axil reducido. Esto también se puede comprobar mediante las Figura 10.3a y b, en las que se presenta la curva de respuesta idealizada carga-flecha, para dos valores de esbeltez $(\lambda=5.0 \mathrm{y}$ $\lambda=9.0$ ). Como se puede observar, la pendiente de la rama elástica aumenta con el incremento del axil reducido; sin embargo, para el mayor valor de axil reducido $(v=0.68)$, la pendiente disminuye.

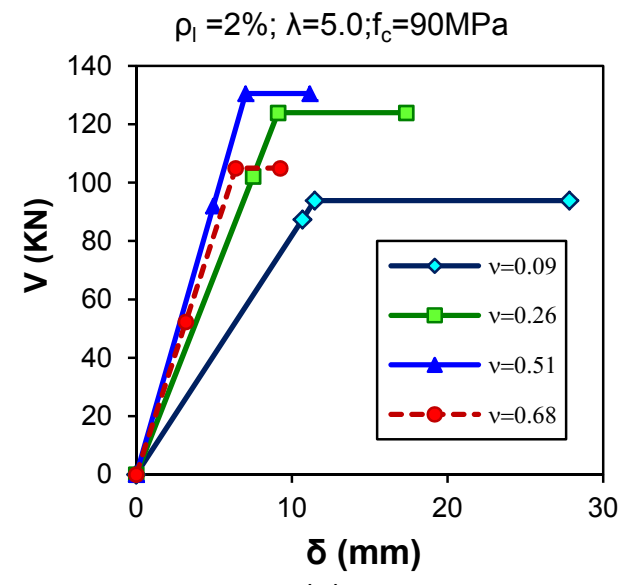

(a)

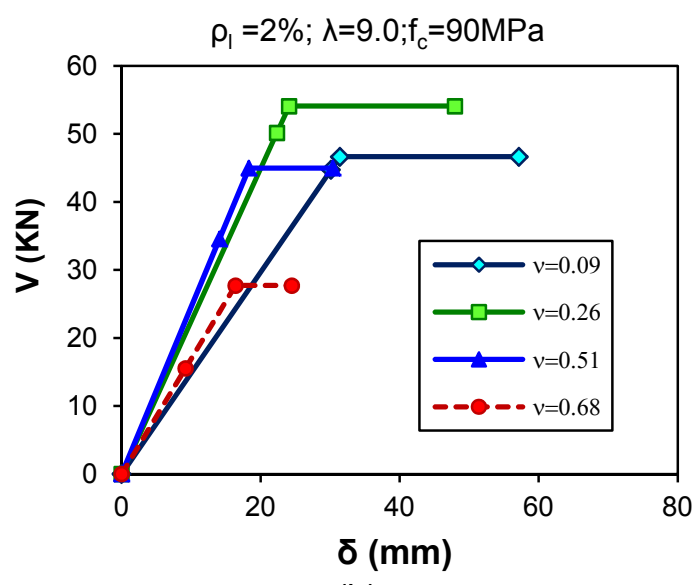

(b)

Figura 10.3 Curvas de respuesta numérica carga-desplazamiento idealizadas, para elementos con: (a) $\lambda=5.0$ y (b) $\lambda=9.0$

Por otra parte, en la Figura 10.2 también se observa que en la rama ascendente el factor de rigidez $\left(\alpha_{e}^{*}\right)$ aumenta con el incremento de la resistencia del hormigón para elementos con valores de esbeltez $\lambda \leq 5$, mientras que, para elementos con $\lambda>5$, el efecto de la resistencia del hormigón es casi imperceptible. Además, se considera que, para altos valores de axil reducido, el efecto de la resistencia del hormigón es muy pequeño, y puede ser ignorado.

\section{Formulación del método para el factor de rigidez elástica de diseño $\alpha_{e}^{*}$}

La expresión analítica correspondiente a las observaciones cualitativas mencionadas es:

$$
\begin{array}{lll}
\text { Para valores de } v \leq 0.6 & \alpha_{e}^{*}=m_{1} \cdot v+\alpha_{\rho}^{\prime} \leq \alpha_{e, \text { max }}^{*} & \text { Ec. 10-6 } \\
\text { Para valores de } v>0.6 & \alpha_{e}^{*}=\alpha_{e, \text { max }}^{*}-0.5(v-0.6) & \text { Ec. } 10-7
\end{array}
$$

Donde:

$v \quad$ Axil reducido $v=N / A_{g} f_{c}$

$N$ Carga axial aplicada

$A_{g}$ Área de la sección transversal

$f_{c} \quad$ Resistencia del hormigón a compresión 
Los coeficientes $\mathrm{m}_{1}, \alpha_{\rho}^{\prime}$ y $\alpha_{e, \max }^{*}$ se obtienen mediante un ajuste por mínimos cuadrados respecto a los resultados de la simulación numérica.

Tal y como se ha descrito, la pendiente $m_{1}$ depende principalmente de la esbeltez de cortante del soporte $(\lambda)$ y de la resistencia del hormigón $\left(f_{c}\right)$; por consiguiente:

$$
m_{1}=K_{\lambda} \cdot K_{f c}
$$

Donde:

$$
\begin{array}{crr}
\text { para } & 3.5 \leq \lambda \leq 7.5 & K_{\lambda}=1+\frac{(\lambda-3.5)}{3.75} \leq 1.4 \\
\text { para } & 7.5<\lambda \leq 10.5 & K_{\lambda}=1.40-\frac{(\lambda-7.5)}{15} \\
& K_{f c}=1+\frac{0.4-0.03 \lambda}{30}\left(f_{c}-60\right)
\end{array}
$$

El coeficiente $\alpha_{\rho}^{\prime}$ depende de la cuantía de armadura longitudinal $\left(\rho_{\mathrm{I}}\right)$ y representa el punto de corte del eje vertical en las Figura 10.2. En ellas se puede observar que, para elementos con cuantía longitudinal del $2.2 \%$, el factor $\alpha_{\rho}^{\prime}$ es aproximadamente 0.2. Para cualquier cuantía, se propone la Ec. 10-12 para evaluar el factor $\alpha_{\rho}^{\prime}$.

$$
\alpha_{\rho}^{\prime}=0.2+\frac{\left(\rho_{l}-0.02\right) * 100}{15}
$$

El factor de rigidez elástica efectiva máximo $\alpha_{e, \max }^{*}$ depende de la resistencia del hormigón para $\lambda \leq 5.0$, y depende de la esbeltez para $\lambda>5.0$.

$$
\alpha_{e, \max }^{*}=0.7-\frac{(\lambda-0.75)}{15} \leq 0.7+\frac{\left(f_{c}-60\right)}{850}
$$

\subsubsection{FACTOR DE RIGIDEZ ELÁSTICO EFECTIVO DE COMPROBACIÓN $\alpha_{\mathrm{e}}$}

En esta sección se realiza una estimación de la rigidez El de los soportes, introduciendo la armadura. En los ensayos numéricos, el factor $\alpha_{e}$ se evalúa conforme a la Ec. 10-14.

$$
\alpha_{e}=\frac{\left(E I_{e}\right)_{S N}-E_{s} I_{s}}{E_{c} I_{c}}
$$

Donde $\left(E I_{e}\right)_{S N}$ es la rigidez elástica efectiva obtenida mediante la simulación numérica.

El comportamiento del factor de rigidez elástica $\left(\alpha_{e}\right)$ con respecto al axil reducido $\left(v=N / A_{g} f_{c}\right)$, la esbeltez de cortante $\left(\lambda=L_{s} / h\right)$ y la resistencia del hormigón $\left(f_{c}\right)$, que se indica en las Figura $10-4 a-d$, ha sido analizado para llevar a cabo la propuesta para el cálculo de $\alpha_{e}$. 


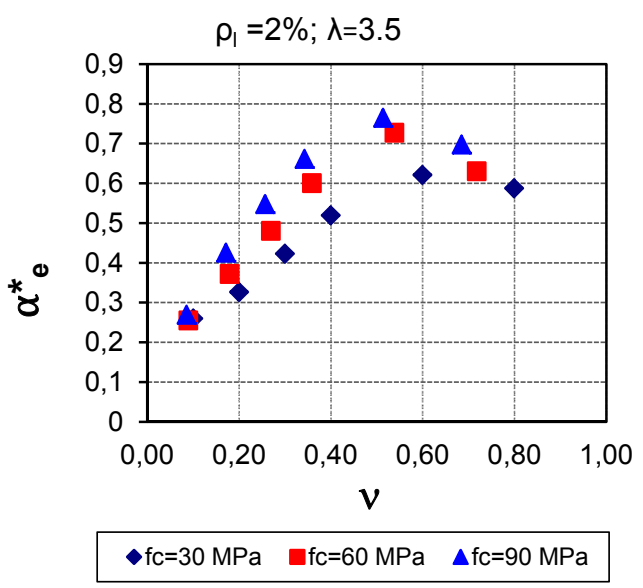

(a)

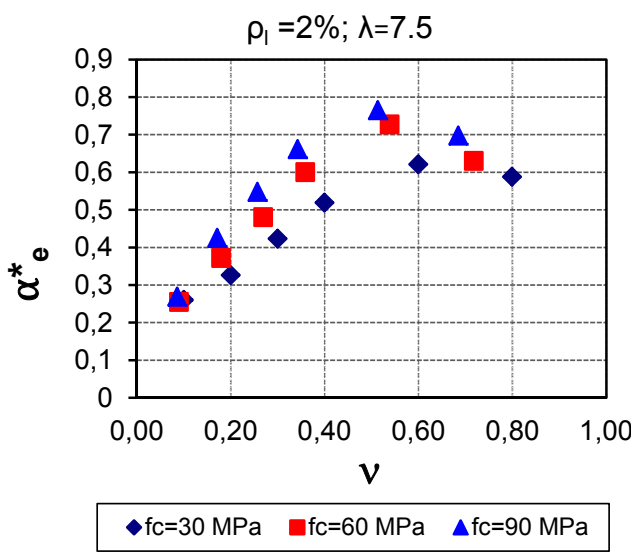

(c)

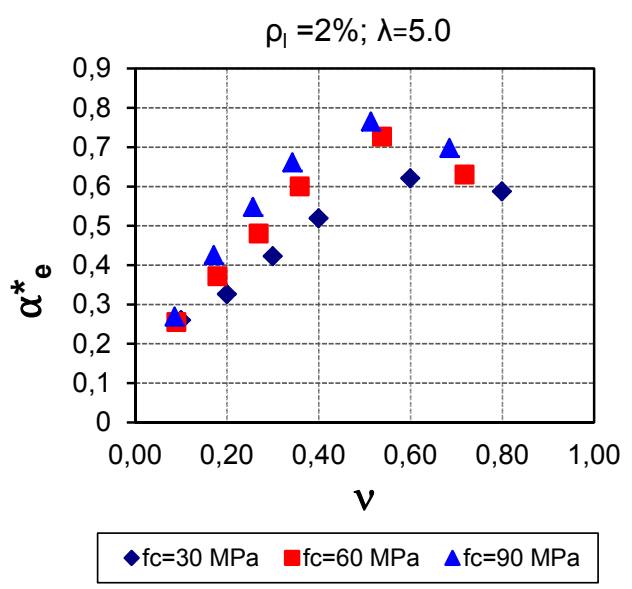

(b)

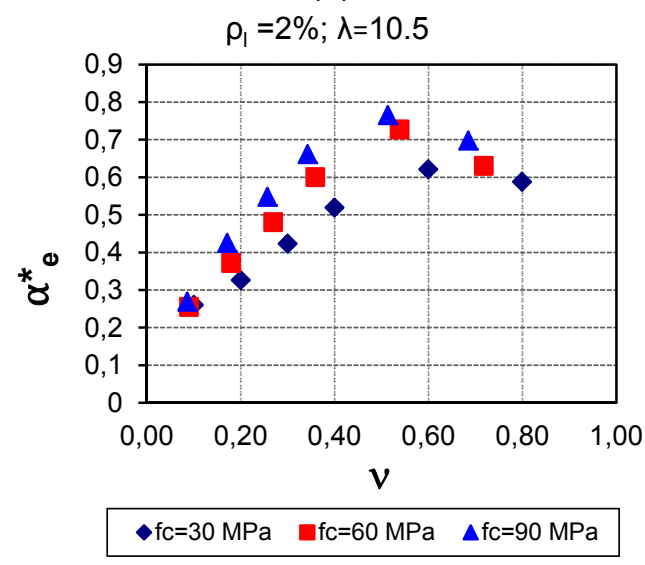

(d)

Figura 10-4 Relación entre el factor $\alpha_{e} y$ el axil reducido, para ensayos numéricos con valores de esbeltez 3.5, 57.5 y 10.5 y diferentes resistencias del hormigón

En las Figura 10-4 se muestra que el factor $\alpha_{e}$ aumenta linealmente para bajos niveles de axil reducido $(v)$, hasta alcanzar un valor máximo cuando $v$ se aproxima a 0.50 ; dicho comportamiento se observa para todos los valores de esbeltez. A partir de este valor, $\alpha_{e}$ disminuye con el aumento del nivel de axil reducido. Por consiguiente, la propuesta del modelo se desarrolla en base al análisis del comportamiento en la: (a) rama ascendente, (b) punto máximo y (c) rama descendente.

\section{Formulación del método para el factor de rigidez elástica de diseño $\alpha_{\mathrm{e}}$}

En el rango de valores de axil reducido $0<v \leq 0.50, \alpha_{e}$ presenta un comportamiento lineal con respecto al nivel de axil reducido $(v)$; la pendiente de estas rectas es función de la esbeltez y de la resistencia del hormigón. La expresión analítica correspondiente a las observaciones cualitativas mencionadas es:

$$
\begin{array}{ccc}
\text { Para valores de } v \leq 0.5 & \alpha_{e}=m_{1} \cdot v \cdot K_{\rho} \leq \alpha_{e, \max } \cdot K_{\rho} & \text { Ec. } 10-15 \\
\text { Para valores de } v>0.5 & \alpha_{e}=\left(\alpha_{e, \max }-0.1(v-0.5)\right) \cdot K_{\rho} & \text { Ec. } 10-16
\end{array}
$$


Donde:

$v \quad$ Axil reducido $v=N / A_{g} f_{c}$

$N$ Carga axial aplicada

$A_{g} \quad$ Área de la sección transversal

$f_{c} \quad$ Resistencia del hormigón a compresión

Los coeficientes $\mathrm{m}_{1}, \mathrm{~K}_{\rho}$ y $\alpha_{e, \max }$ se obtienen mediante un ajuste por mínimos cuadrados respecto a los resultados de la simulación numérica.

Tal y como se ha descrito la pendiente $m_{1}$ depende principalmente de la esbeltez de cortante del soporte $(\lambda)$ y de la resistencia del hormigón $\left(f_{c}\right)$, Ec. 10-17.

$$
m_{1}=K_{\lambda} \cdot K_{f c}
$$

Donde:

$$
\begin{aligned}
& \text { para } 3.5 \leq \lambda \leq 7.5 \\
& K_{\lambda}=1.14+0.24(\lambda-3.5) \leq 1.5 \quad \text { Ec. } 10-18 \\
& \text { para } 7.5<\lambda \leq 10.5 \\
& K_{\lambda}=1.50-0.08(\lambda-7.5) \\
& \text { Ec. } 10-19 \\
& K_{f c}=1+\frac{0.44-0.026 \lambda}{30}\left(f_{c}-60\right)
\end{aligned}
$$

El factor de rigidez elástica efectiva máximo $\alpha_{e, \max }$ depende de la resistencia del hormigón para $\lambda \leq 5.0$ y depende de la esbeltez para $\lambda>5.0$.

$$
\alpha_{e, \max }=0.6-\frac{(\lambda-5)}{18} \leq 0.4+\frac{\left(f_{c}-30\right)}{300}
$$

Dado que, en el desarrollo del modelo descrito anteriormente, sólo se han considerado ensayos numéricos con un valor de cuantía de armadura longitudinal $\left(\rho_{\mathrm{l}}=2.2 \%\right)$, se ha llevado a cabo una comprobación del error para aquellos ensayos numéricos con diferentes cuantías de armadura. Se ha podido observar que $\alpha_{e}$ depende de la cuantía de armadura, y en consecuencia se propone un factor adicional $K_{\rho}$ como se muestra en la Ec. 10-22.

$$
K_{\rho}=1-15\left(\rho_{l}-0.02\right)
$$

\subsection{EVALUACIÓN DE LA RIGIDEZ ÚLTIMA DE SOPORTES DE HORMIGÓN}

\subsubsection{METODOLOGÍA}

En esta sección, para tener en cuenta los efectos de segundo orden en el cálculo de la rigidez última de elementos de hormigón armado, se recurre al factor de amplificación descrito en la Ec. 10-23. 


$$
\delta_{N S}=\frac{1}{1-N_{d} / N_{c r}}
$$

Donde

$N_{d} \quad$ Carga axial aplicada

$N_{c r} \quad$ Axil crítico; $N_{c r}=\pi^{2} E I_{u} / l_{p}^{2}$

De modo que se ha considerado que el desplazamiento último de elementos de hormigón sometidos a esfuerzos combinados de flexión y compresión axial puede expresarse a partir de la Ec. 10-24. Siendo $\delta_{u 1}$ el desplazamiento último de primer orden.

$$
\begin{gathered}
\delta_{u}=\delta_{u 1}\left(\delta_{N S}\right) \\
\delta_{u}=\frac{V L^{3}}{48 E I_{u}}\left(\frac{N_{c r}}{N_{c r}-N}\right)
\end{gathered}
$$

Donde:

V Carga máxima

$L \quad$ Longitud total del elemento

$E I_{u} \quad$ Rigidez última del elemento

$I_{p} \quad$ Longitud de pandeo del elemento.

Además, si se considera el cambio de variable en las Ec. 10-26 y Ec. 10-27,

$$
\begin{gathered}
\eta=\frac{V L^{3}}{48} \\
x=\frac{\pi^{2}}{l_{p}^{2}}
\end{gathered}
$$

La rigidez última $\left(\mathrm{El}_{\mathrm{u}}\right)_{\mathrm{SN}}$ es evaluada para los ensayos numéricos mediante la Ec. 10-28.

$$
\left(E I_{u}\right)_{S N}=\frac{x \eta+N \delta_{u}}{x \delta_{u}}
$$

Al igual que en la sección anterior, si la cuantía y la distribución de la armadura son conocidas, el factor de rigidez último de comprobación pueden obtenerse a partir de la rigidez del hormigón $\left(E_{c} l_{c}\right)$ y de la rigidez del acero $\left(E_{s} I_{s}\right)$,Ec. 10-29.

$$
\alpha_{u}=\frac{\left(E I_{u}\right)_{S N}-E_{s} I_{s}}{E_{c} I_{c}}
$$

Donde

$\alpha_{u} \quad$ Factor de rigidez última de comprobación

$E_{c} \quad$ Módulo de elasticidad del hormigó $\left(E_{c}=22000\left(f_{c} / 10\right)^{0.3}\right)$

$I_{c} \quad$ Inercia bruta de la sección

$E_{s} \quad$ Módulo de elasticidad del acero $\left(E_{s}=200.000 \mathrm{MPa}\right)$

$I_{s} \quad$ Inercia de la armadura longitudinal 
Sin embargo, en el caso de que no se conozca la cuantía y distribución de armado, el factor de rigidez última para el dimensionamiento, puede obtenerse de a partir de la rigidez del hormigón $E_{c} I_{c}$, Ec. 10-30.

$$
\alpha_{u}^{*}=\frac{\left(E I_{u}\right)_{S N}}{E_{c} I_{c}}
$$

\subsubsection{FACTOR DE RIGIDEZ ÚLTIMO DE DISEÑO $\alpha_{u}^{*}$}

En las Figura 10-5a-d se presentan los resultados de $\alpha_{u}^{*}$ para una serie de ensayos numéricos en los que se puede analizar la influencia de los parámetros nivel de axil reducido $\left(v=N / A_{g} F_{c}\right)$, esbeltez de cortante $\left(\lambda=L_{s} / h\right)$, y resistencia del hormigón $\left(f_{c}\right)$. Otros efectos, como los de la cuantía de armadura longitudinal $\left(\rho_{\mathrm{I}}\right)$ y transversal $\left(\rho_{\mathrm{s}}\right)$, son incorporados en el modelo para elementos con cuantías de armadura diferentes al $2.2 \%$ y cuantías de armadura transversal superiores al $1 \%$.

Como se puede observar en las Figura 10-5a-d, el factor $\alpha_{u}^{*}$ es prácticamente lineal con respecto al nivel de carga axial, y aumenta conforme incrementa el axil reducido. Sin embargo, la pendiente de la recta depende de la esbeltez de cortante y de la resistencia del hormigón. Aunque la rama de ascenso muestra un comportamiento lineal. Se observa que se alcanza un valor máximo $\left(\alpha_{u \_ \text {max }}^{*}\right)$, el cual depende también de tres parámetros: axil reducido, esbeltez de cortante $\left(\lambda=L_{s} / h\right)$ y resistencia del hormigón en compresión $\left(f_{c}\right)$. Mediante una aproximación de mínimos cuadrados, y considerando siempre una relación lineal con las variables, se ha obtenido el modelo propuesto de $\alpha_{u}^{*}$ en la Ec. 10-31.

$$
\alpha_{u}^{*}=K_{1} \cdot K_{\rho s} \cdot v+K_{2} \leq \alpha_{u_{-} \max }^{*}
$$

Donde los coeficientes $\mathrm{K}_{1}, \mathrm{~K}_{2}$ y $\alpha_{e, \max }$ se obtienen mediante un ajuste por mínimos cuadrados respecto a los resultados de la simulación numérica.

$$
\begin{gathered}
K_{1}=\left(\frac{\lambda}{22}+\frac{f_{c}}{150}\left(\frac{f_{c}+55}{100}\right)+\frac{1}{250}\right) \\
K_{\rho s}=\left(1-\frac{10\left(\rho_{s}-0.01\right)}{3}\right) \\
K_{2}=\left(\frac{\lambda}{50}-0.03\right)+\frac{3}{2}\left(\rho_{l}-0.02\right) \\
\alpha_{u: \max }^{*}=\frac{f_{c}}{175}+\frac{\lambda-1}{22}
\end{gathered}
$$


Donde

$\rho_{l} \quad$ Cuantía de armadura longitudinal $\left(A_{s} / A_{g}\right)$

$\rho_{s} \quad$ Cuantía de aramadura volumétrica transversal $\left(A_{s}^{\prime \prime} /(b \cdot h \cdot s)\right)$

$A_{s} \quad$ Área total de armadura longitudinal

$A_{s}^{\prime \prime} \quad$ Volumen de armadura transversal

$b \quad$ Ancho de la sección transversal

$h \quad$ Canto de la sección transversal

$A_{g}$ Área de la sección transversal

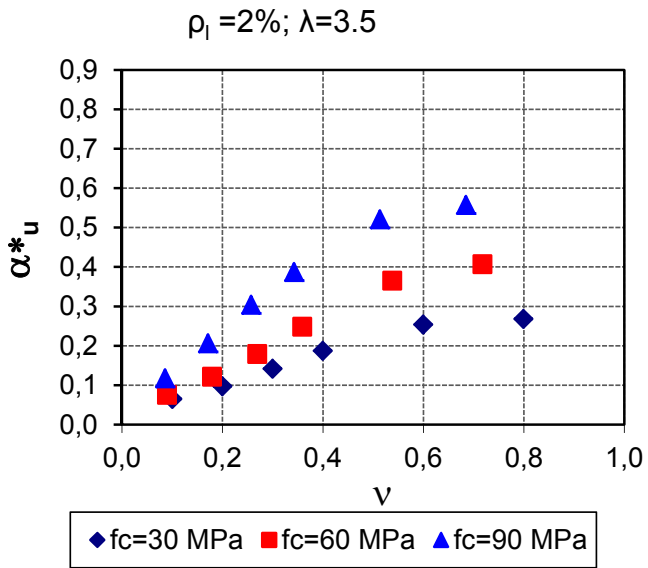

(a)

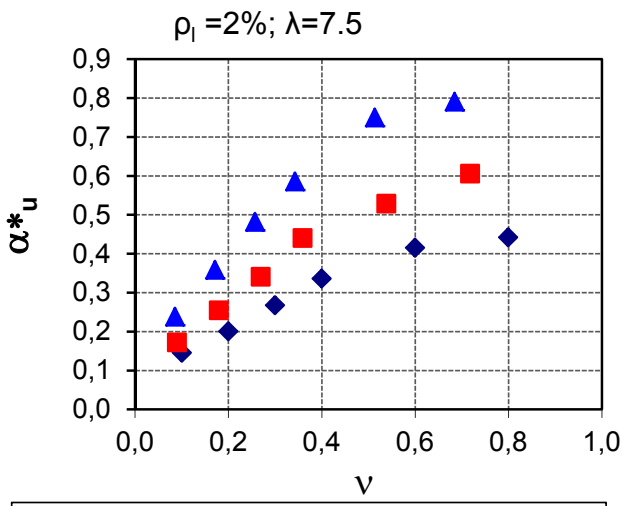

- $\mathrm{fc}=30 \mathrm{MPa} \quad \square \mathrm{fc}=60 \mathrm{MPa} \quad \Delta \mathrm{fc}=90 \mathrm{MPa}$

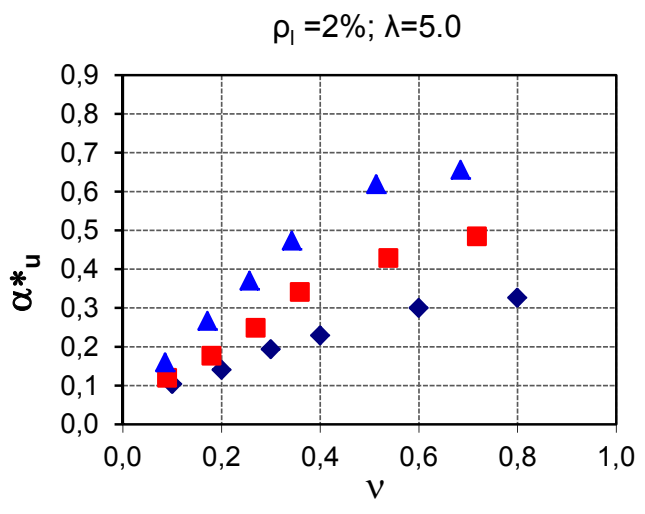

$\bullet \mathrm{fc}=30 \mathrm{MPa} \quad \mathrm{fc}=60 \mathrm{MPa} \quad \Delta \mathrm{fc}=90 \mathrm{MPa}$

(b)

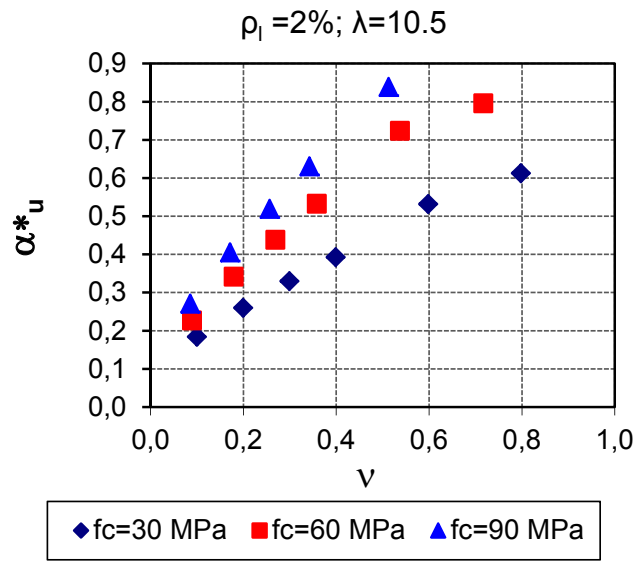

(d)

Figura 10-5 Relación entre el factor $\alpha_{u}^{*}$ y el axil reducido, para (a) $\lambda=3.5,(b) \lambda=5.0,(c)$ $\lambda=7.5,(d) \lambda=10.5$.

\subsubsection{FACTOR DE RIGIDEZ ÚLTIMO DE COMPROBACIÓN $\alpha_{u}$}

En las Figura 10-6a-d se presentan los valores del factor $\alpha_{u}$, para los ensayos con valores de esbeltez $3.5,5,7.5$ y 10.5 , con respecto al nivel de axil reducido $(v)$. Las figuras muestran que el comportamiento puede aproximarse a una línea recta, hasta alcanzar un valor máximo $\left(\alpha_{u, \max }\right)$. 


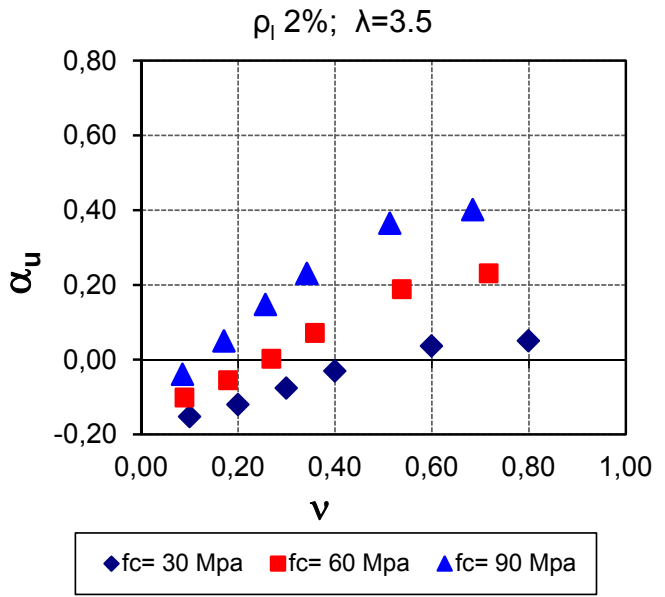

(a)

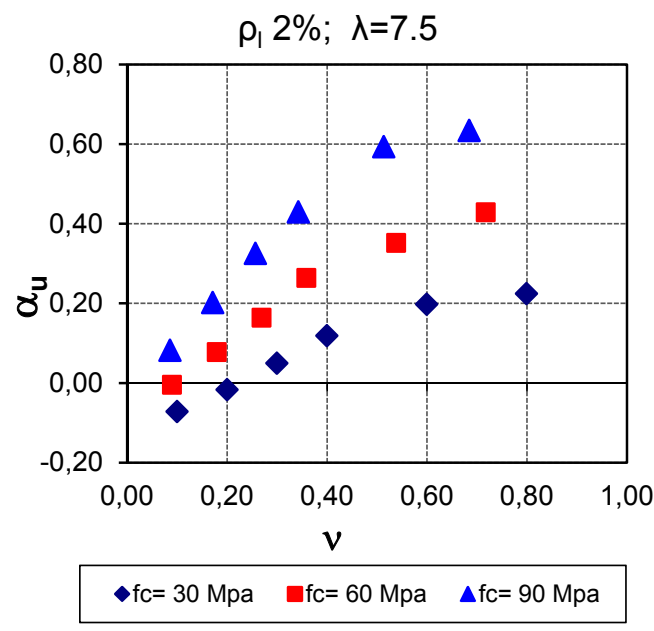

(c)

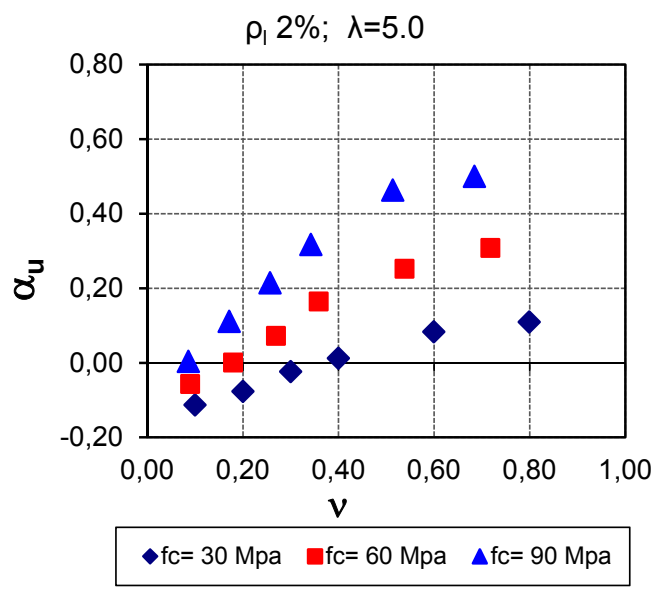

(b)

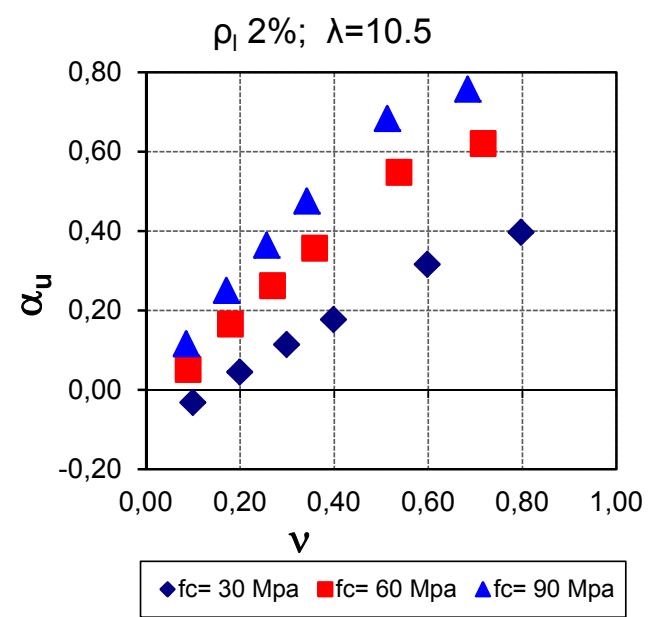

(d)

Figura 10-6 Relación entre el factor $\alpha_{u}$ y el axil reducido, para ensayos numéricos con valores de esbeltez 3.5, 5.0, 7.5 y 10.5 y diferentes resistencias del hormigón.

Por consiguiente el modelo propuesto tiene la forma de:

$$
\alpha_{u}=K_{1} \cdot K_{\rho s} v+K_{2} \leq \alpha_{u, \max }
$$

En donde los factores $K_{1}, K_{2}, K_{\rho s}$ y $\alpha_{u \text {,max }}$, se han obtenido mediante un ajuste por mínimos cuadrados.

$\mathrm{K}_{1}$ depende de los parámetros de esbeltez $(\lambda)$ y resistencia del hormigón ( $\mathrm{f}_{\mathrm{c}}$ ), y se evalúa mediante la Ec. 10-37.

$$
K_{1}=\frac{\lambda_{c}}{85}+\frac{\lambda \cdot f_{c}}{1050}-0.15
$$

Para tener en cuenta los efectos de la cuantía de armadura longitudinal $\left(\rho_{\mathrm{I}}\right)$ y transversal $\left(\rho_{s \mathrm{~s}}\right)$ en el cálculo de $\alpha_{u}$, se proponen los factores $K_{2}$ y $K_{\rho s}$ respectivamente, definidos en las Ec. 10-38 y Ec. 10-39. 


$$
\begin{gathered}
K_{2}=\frac{\lambda}{60}-7 \rho_{l}-0.08 \\
K_{\rho s}=1-\frac{10\left(\rho_{s}-0.01\right)}{3}
\end{gathered}
$$

La expresión propuesta para $\alpha_{u, \max }$, es la Ec. 10-40.

$$
\alpha_{u, \max }=\frac{f_{c}}{170}+\frac{\lambda}{20}-7 \rho_{l}-0.15
$$

\subsubsection{VARIABLES QUE PUEDEN SER EVALUADAS MEDIANTE LOS METODOS SIMPLIFICADOS PROPUESTOS}

Mediante los métodos propuestos para la evaluación de los factores de rigidez elástica efectiva y última, se podrán evaluar los índices de capacidad de deformación para elementos de hormigón armado sometidos a compresión y flexión monotónica que se relacionan en la Tabla 10-2.

Tabla 10-2 Variables de capacidad de deformación que pueden ser evaluadas mediante los métodos propuestos $\alpha_{u}$.

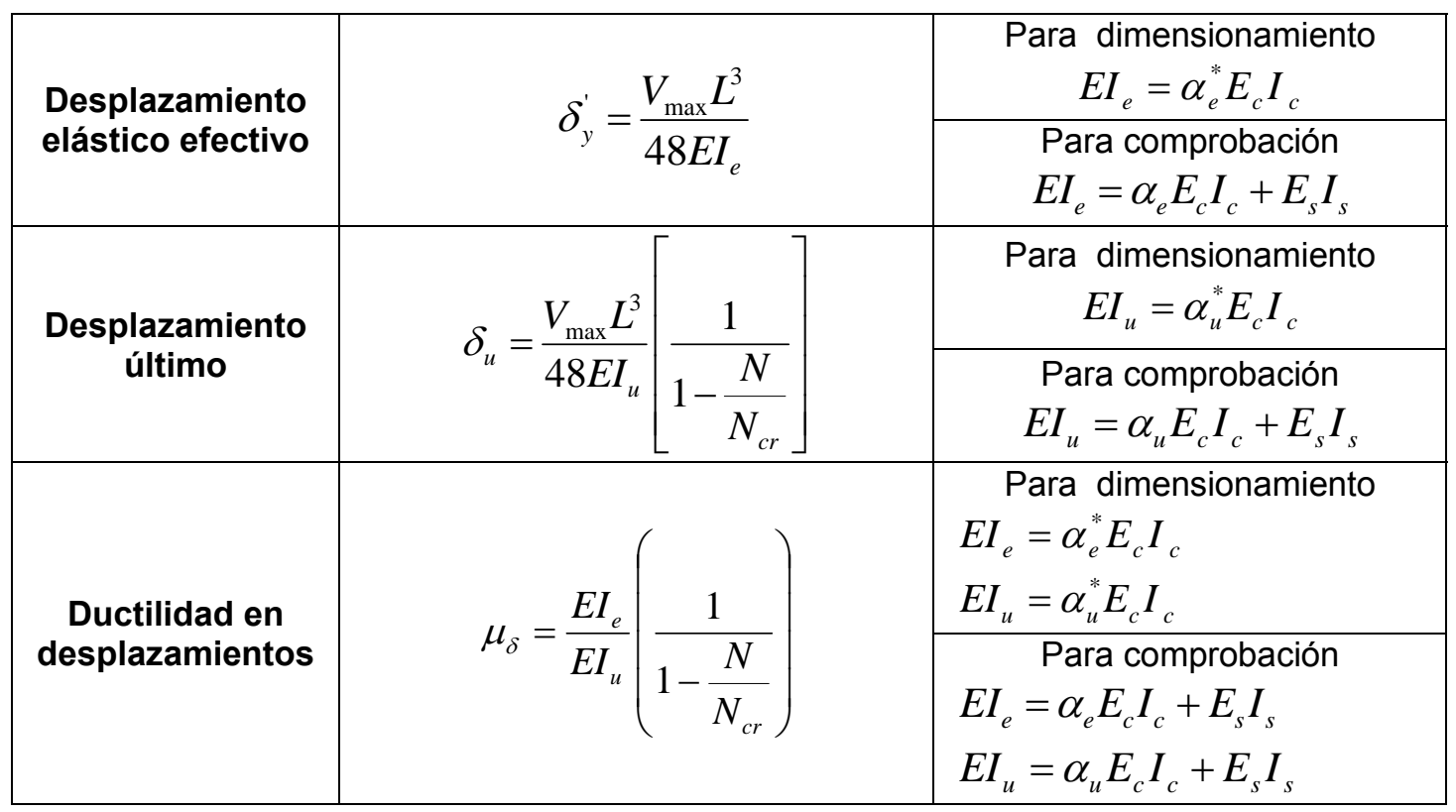

Donde

$E_{c} \quad$ Módulo de elasticidad del hormigón, $E_{c}=22000\left(f_{c} / 10\right)^{0.3}$

$I_{c} \quad$ Inercia bruta de la sección

$E_{s} \quad$ Módulo de elasticidad del acero $\left(E_{s}=200.000 \mathrm{MPa}\right)$

$I_{s} \quad$ Inercia de la armadura longitudinal

$V_{\max }$ Carga máxima perpendicular

$L \quad$ Longitud total del elemento

$N \quad$ Carga axial aplicada

$N_{c r} \quad$ Axil crítico; $N_{c r}=\pi^{2} E I_{u} / l_{p}^{2}$

$I_{p} \quad$ Longitud de pandeo del elemento 


\subsection{EVALUACIÓN DEL ERROR}

Los métodos propuestos en este estudio han sido comprobados: (a) con los resultados obtenidos a partir de las 250 simulaciones numéricas ejecutadas en el programa "ATENA 2D", y (b) con los resultados de los 40 ensayos experimentales en soportes esbeltos de hormigón convencional y de alta resistencia realizados en el presente estudio.

\subsubsection{COMPARACIÓN DE LOS MODELOS PROPUESTOS CON LOS RESULTADOS OBTENIDOS EN LA SIMULACIÓN NUMÉRICA}

En esta sección se verifican los métodos con los resultados de 250 simulaciones numéricas realizadas en el programa de análisis no lineal "ATENA 2D". En la verificación de los métodos propuestos se han comparado las variables de rigidez elástica efectiva $\left(\mathrm{El}_{\mathrm{e}}\right)$, desplazamiento elástico efectivo $\left(\delta^{\prime}{ }_{\mathrm{y}}\right)$, desplazamiento último $\left(\delta_{\mathrm{u}}\right)$, ductilidad de desplazamiento $\left(\mu_{\delta}\right)$, y rigidez última $\left(\mathrm{El}_{\mathrm{u}}\right)$.

Los métodos también se han verificado con respecto a las tres posibles formas de considerar la carga máxima. La primera situación corresponde a los valores de carga máxima obtenidos en la simulación numérica $\left(\mathrm{V}_{\max }\right)$, teniendo en cuenta que estos valores se han utilizado en el análisis llevado a cabo para desarrollar los métodos propuestos. La segunda consideración corresponde a los valores de carga máxima obtenidos en la idealización del diagrama carga-desplazamiento $\left(\mathrm{V}_{\text {max }}^{\prime}\right)$. $\mathrm{Y}$, por último, los métodos también se verifican cuando los valores de carga máxima se obtienen de forma teórica $\left(\mathrm{V}_{\mathrm{EC} 2 \text { ea }}\right)$, utilizando el método aproximado del Eurocódigo 2 (2004) [58] (descrito en el capítulo 6, apartado 6.3).

Los resultados de la comprobación de las variables obtenidas con los métodos simplificados propuestos y las obtenidas en los ensayos numéricos, son presentados mediante las siguientes variables estadísticas: error medio $(\bar{E})$, coeficiente de variación (C.V), percentil del $5 \%\left(P_{0.05}\right)$ y percentil del $95 \%\left(P_{0.95}\right)$.

La comprobación se realiza incluyendo un total de 250 simulaciones numéricas. En las Tabla $10-3,10-4,10-5$ y 10.6 se muestran los resultados obtenidos en la comprobación para las variables desplazamiento elástico efectivo $\left(\delta_{y}^{\prime}\right)$, rigidez elástica efectiva $\left(E l_{e}\right)$, desplazamiento último $\left(\delta_{\mathrm{u}}\right)$, y rigidez última $\left(\mathrm{El}_{\mathrm{u}}\right)$ respectivamente.

Tabla 10-3 Resultados del error para la variable $\delta_{y}^{\prime}$

\begin{tabular}{|c|c|c|c|c|c|c|c|c|}
\hline & \multicolumn{4}{|c|}{$\begin{array}{l}\text { CÁLCULO EN BASE AL FACTOR } \\
\text { DE RIGIDEZ DE DISEÑO } \alpha_{e}^{*}\end{array}$} & \multicolumn{4}{|c|}{$\begin{array}{l}\text { CÁLCULO EN BASE AL FACTOR DE } \\
\text { RIGIDEZ DE COMPROBACIÓN } \alpha_{e}\end{array}$} \\
\hline & \multicolumn{4}{|c|}{$\mathbf{E}=\delta_{y_{-} \text {aprox }}^{\prime} / \delta_{y_{-} \text {num }}^{\prime}$} & \multicolumn{4}{|c|}{$\mathbf{E}=\delta_{y_{-} \text {aprox }}^{\prime} / \delta_{y_{n} \text { num }}^{\prime}$} \\
\hline & $\overline{\mathrm{E}}$ & CV (\%) & $\mathrm{P}_{0.05}$ & $P_{0.95}$ & $\bar{E}$ & CV (\%) & $P_{0.05}$ & $\mathrm{P}_{0.95}$ \\
\hline$V_{\text {máx }}$ & 0,98 & 8,4 & 0,83 & 1,10 & 1,03 & 8,7 & 0,88 & 1,15 \\
\hline $\mathrm{V}_{\text {max }}^{\prime}$ & 0,93 & 8,3 & 0,78 & 1,06 & 0,98 & 9,0 & 0,81 & 1,11 \\
\hline$V_{E C 2}$ & 0,86 & 13,2 & 0,67 & 1,03 & 0,90 & 12,8 & 0,69 & 1,07 \\
\hline
\end{tabular}


Tabla 10-4 Resultados del error para la variable $\mathrm{El}_{e}$

\begin{tabular}{|c|c|c|c|c|c|c|c|c|}
\hline & \multicolumn{4}{|c|}{$\begin{array}{c}\text { CÁLCULO EN BASE AL FACTOR } \\
\text { DE RIGIDEZ DE DISEÑO } \alpha_{e}^{*}\end{array}$} & \multicolumn{4}{|c|}{$\begin{array}{l}\text { CÁLCULO EN BASE AL FACTOR DE } \\
\text { RIGIDEZ DE COMPROBACIÓN } \alpha_{e}\end{array}$} \\
\hline & \multicolumn{4}{|c|}{$\mathrm{E}=\boldsymbol{E} \boldsymbol{I}_{e_{-} \text {aprx }} / E \boldsymbol{I}_{e_{-} \text {num }}$} & \multicolumn{4}{|c|}{$\mathbf{E}=E I_{e_{-} \text {aprx }} / E I_{e_{\text {_num }}}$} \\
\hline & $\bar{E}$ & CV (\%) & $P_{0.05}$ & $P_{0.95}$ & $\bar{E}$ & CV (\%) & $P_{0.05}$ & $P_{0.95}$ \\
\hline$V_{\text {máx }}$ & 1.02 & 9. & 0.89 & 1.19 & 0.98 & 9.5 & 0.87 & 1.14 \\
\hline $\mathrm{V}_{\mathrm{ma}}^{\prime}$ & 1.06 & 7.4 & 0.93 & 1.20 & 1.02 & 9.6 & 0.901 & 1.23 \\
\hline$V_{E C 2}$ & 1.16 & $14.7 \%$ & 0.93 & 1.42 & 1.10 & 11.4 & 0.91 & 1.33 \\
\hline
\end{tabular}

Tabla 10-5 Resultados del error para la variable $\delta_{u}$

\begin{tabular}{|c|c|c|c|c|c|c|c|c|}
\hline & \multicolumn{4}{|c|}{$\begin{array}{c}\text { CÁLCULO EN BASE AL FACTOR } \\
\text { DE RIGIDEZ DE DISEÑO } \alpha_{e}^{*}\end{array}$} & \multicolumn{4}{|c|}{$\begin{array}{l}\text { CÁLCULO EN BASE AL FACTOR DE } \\
\text { RIGIDEZ DE COMPROBACIÓN } \alpha_{e}\end{array}$} \\
\hline & \multicolumn{4}{|c|}{$\mathbf{E}=\boldsymbol{\delta}_{\boldsymbol{u}_{\_} \text {aprx }} / \boldsymbol{\delta}_{\boldsymbol{u}_{\_} \text {num }}$} & \multicolumn{4}{|c|}{$\mathbf{E}=\boldsymbol{\delta}_{\boldsymbol{u}_{-} \text {aprx }} / \boldsymbol{\delta}_{\boldsymbol{u}_{-} \text {num }}$} \\
\hline & $\overline{\mathrm{E}}$ & CV (\%) & $P_{0.05}$ & $P_{0.95}$ & $\overline{\bar{E}}$ & CV (\%) & $P_{0.05}$ & $P_{0.95}$ \\
\hline$V_{\text {máx }}$ & 0,93 & 12,3 & 0,74 & 1,13 & 0,94 & 11,0 & 0,74 & 1,10 \\
\hline $\mathrm{V}_{\max }^{\prime}$ & 0,89 & 11,6 & 0,73 & 1,05 & 0,90 & 11,3 & 0,77 & 1,14 \\
\hline$V_{E C 2}$ & 0,82 & 14,3 & 0,64 & 1,03 & 0,84 & 15,3 & 0,64 & 1,06 \\
\hline
\end{tabular}

Tabla 10-6 Resultados del error para las variable $E_{u}$

\begin{tabular}{|c|c|c|c|c|c|c|c|c|}
\hline & \multicolumn{4}{|c|}{$\begin{array}{c}\text { CÁLCULO EN BASE AL FACTOR } \\
\text { DE RIGIDEZ DE DISEÑO } \alpha_{e}^{*}\end{array}$} & \multicolumn{4}{|c|}{$\begin{array}{l}\text { CÁLCULO EN BASE AL FACTOR DE } \\
\text { RIGIDEZ DE COMPROBACIÓN } \alpha_{e}\end{array}$} \\
\hline & \multicolumn{4}{|c|}{$\mathrm{E}=E I_{u \_n u m} / E I_{u \_a p r x}$} & \multicolumn{4}{|c|}{$\mathrm{E}=E I_{u \_n u m} / E I_{u \_a p r x}$} \\
\hline & $\overline{\mathrm{E}}$ & CV (\%) & $P_{0.05}$ & $P_{0.95}$ & $\overline{\mathrm{E}}$ & CV (\%) & $P_{0.05}$ & $P_{0.95}$ \\
\hline & 0,96 & 7,8 & 0,8 & 1,0 & 0,97 & 7,4 & 0,85 & 1,08 \\
\hline & 0,92 & & & & 0,94 & & & 1,05 \\
\hline$V_{E C 2}$ & 0,88 & 9,8 & 0,74 & 1,02 & 0,89 & 10,4 & 0,74 & 1,04 \\
\hline
\end{tabular}

A partir de estos resultados se pueden destacar los siguientes aspectos:

1. La comprobación de los métodos propuestos muestra, en todas las series de ensayos utilizadas en la evaluación del error, que existe una mejor aproximación cuando las variables se calculan asumiendo los valores de carga máxima $\left(\mathrm{V}_{\text {máx }}\right)$ obtenida en la respuesta numérica. El ajuste disminuye cuando las variables ( $\left.\delta_{y_{-} \text {aprox }}, \mathrm{El}_{\mathrm{e}_{\text {_aprox }},} \delta_{\mathrm{u}_{\_} \text {aprox }}, \mathrm{El}_{\mathrm{u}_{\_} \text {aprox }}\right)$ se calculan con la carga máxima $\left(\mathrm{V}_{\text {max }}\right)$, obtenida en la idealización $\mathrm{P}-\delta$. $\mathrm{Y}$ el ajuste es más desfavorable cuando dichas variables se evalúan con la carga teórica $\left(\mathrm{V}_{\mathrm{EC} 2}\right)$.

2. Si se adoptan, por una parte, los valores de carga $V_{\max }$ obtenidos en la simulación numérica $y$, por otra parte, los valores de carga teóricos $V_{E C 2}$, la diferencia entre el error obtenido en las variables $\left(\delta_{y_{\_}}^{\prime}\right.$ aprox $, E E_{e_{-} a p r o x}, \delta_{u_{-} a p r o x}$, $\mathrm{El}_{\mathrm{u} \_ \text {aprox }}$ ), se debe especialmente al error entre estas dos cargas, tal y como se puede ver en la Figura 10-7.

3. Para los dos tipos de métodos (obtenidos mediante $\alpha^{*} y \alpha$ ), la comparación entre la respuesta de los métodos propuestos y la respuesta de la simulación numérica, indica que los métodos propuestos son más exactos para la variable de desplazamiento elástico efectivo $\left(\delta_{y}^{\prime}\right)$ que para la variable de desplazamiento último $\left(\delta_{\mathrm{u}}\right)$. 


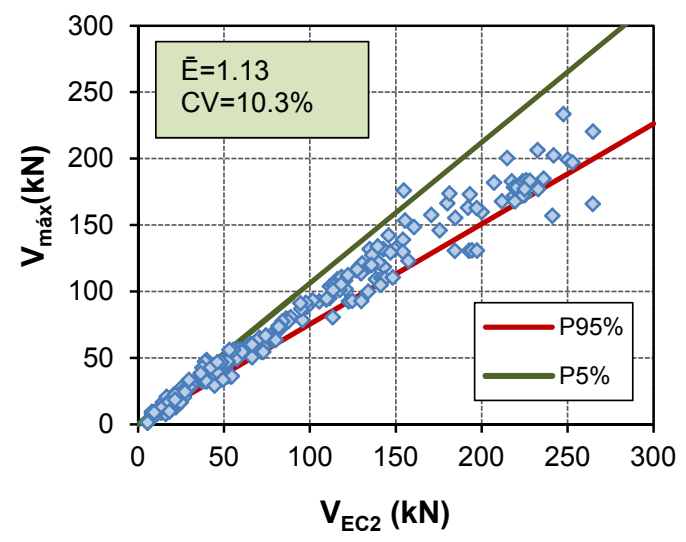

Figura 10-7 Comparación entre los valores de carga máxima obtenida en la simulación numérica $\left(V_{\text {máx }}\right)$ y los valores calculados mediante el método simplificado del Eurocódigo 2 (2004), para 250 elementos

4. Los resultados de la comprobación de los métodos para la variable de rigidez última $\left(\mathrm{El}_{\mathrm{u}}\right)$, se muestran en la Tabla 10-6. Los factores estadísticos del error indican que el ajuste es ligeramente mejor que en la variable $\delta_{u}$. Además, al igual que en las variables $\delta_{y}^{\prime}$ y $\delta_{u}$, la aproximación entre los valores calculados con el método propuesto $\left(\mathrm{El}_{\mathrm{u} \_ \text {aprx }}\right)$ y los resultados de la simulación numérica ( $\left(\mathrm{I}_{\mathrm{u} \_n u m}\right)$, depende de la carga $\mathrm{V}$ aplicada, obteniéndose un mejor ajuste cuando se utiliza $V_{\max }$, aunque la precisión disminuye ligeramente cuando se utiliza $V^{\prime}$ max. La situación más desfavorable se da cuando en el cálculo se utiliza la carga teórica $\vee_{\mathrm{EC} 2}$.

5. En la evaluación del error alcanzado para la variable rigidez última, los resultados no son muy diferentes para los dos métodos (basados en $\alpha_{\mathrm{u}}^{*}$ ó $\left.\alpha_{\mathrm{u}}\right)$.

En la Tabla 10-7 se presentan los resultados del error para la ductilidad de desplazamiento. En este análisis, los resultados no dependen del método considerado para conocer la carga máxima, ya que los métodos propuestos resultan ser independientes de esta variable.

En la variable de ductilidad de desplazamiento $\left(\mu_{\delta}\right)$, los dos tipos de métodos propuestos, alcanzan un valor del error $(\bar{E})$ mayor que la unidad, siendo los valores de $\bar{E}$ ligeramente mayores en el caso de que $\mu_{\delta}$ se evalúe aplicando el método basado en $\alpha_{e}$ y $\alpha_{u}$. Aun así, el método es bastante aproximado, lográndose para la serie completa un valor de $\bar{E}=1.06$ y $C V=12 \%$.

Tabla 10-7 Resultados de la comprobación entre los resultados numéricos y los métodos simplificados propuestos, para las variables $\mu_{\delta}$

\begin{tabular}{|c|c|c|c|c|c|c|c|}
\hline \multicolumn{4}{|c|}{$\begin{array}{l}\text { CÁLCULO EN BASE AL FACTOR } \\
\text { DE RIGIDEZ DE DISEÑO } \alpha_{e}^{*}\end{array}$} & \multicolumn{4}{|c|}{$\begin{array}{l}\text { CÁLCULO EN BASE AL FACTOR DE } \\
\text { RIGIDEZ DE COMPROBACIÓN } \alpha_{e}\end{array}$} \\
\hline \multicolumn{4}{|c|}{$\overline{\mathrm{E}}=\mu_{\delta_{-} a p r x} / \mu_{\delta_{-} n u m}$} & \multicolumn{4}{|c|}{$\overline{\mathrm{E}}=\boldsymbol{\mu}_{\boldsymbol{\delta} \boldsymbol{a} \text { aprx } \boldsymbol{x}} / \boldsymbol{\mu}_{\boldsymbol{\delta} \boldsymbol{n} \text { num }}$} \\
\hline$\overline{\mathrm{E}}$ & $\mathrm{CV}(\%)$ & & $P_{0}$ & $\overline{\mathrm{E}}$ & $\mathrm{CV}(\%)$ & $\mathrm{P}_{0.05}$ & \\
\hline 1,02 & 12,5 & 0,8 & 1,24 & 1,06 & 12,0 & 0,81 & 1,25 \\
\hline
\end{tabular}


En general, la comprobación entre los valores calculados mediante los métodos simplificados propuestos y los obtenidos de la simulación numérica, muestran que los dos tipos de métodos basados tanto en el cálculo del factor de rigidez de diseño $\alpha_{e}^{*}$ y $\alpha_{u}^{*}$, como en el cálculo del factor de rigidez de comprobación $\alpha_{e}$ y $\alpha_{u}$, alcanzan una importante aproximación para todas las variables evaluadas $\left(\mathrm{El}_{\mathrm{e}}, \delta_{\mathrm{y}}^{\prime}, \delta_{\mathrm{u}}, \mathrm{El}_{\mathrm{u}}, \mathrm{y}\right.$ $\left.\mu_{\delta}\right)$, sin que haya una diferencia significativa entre los dos métodos. Sin embargo, hay que destacar que, en términos absolutos, el método basado en $\alpha_{e}$ y $\alpha_{u}$ (comprobación) logra resultados ligeramente mejores en las variables $\left(\mathrm{El}_{\mathrm{e}}, \delta_{\mathrm{y}}^{\prime}, \delta_{\mathrm{u}}\right.$, $\mathrm{El}_{u}$,) que cuando los métodos se basan en $\alpha_{e}^{*}$ y $\alpha_{u}^{*}$ (diseño), situándose ligeramente del lado de la inseguridad en el caso de la variable de ductilidad de desplazamiento $\left(\mu_{\delta}\right)$.

\section{Comprobación de los métodos propuestos con respecto a los parámetros de estudio}

La comprobación del ajuste de los métodos propuestos con respecto a los principales parámetros implicados en el análisis de la capacidad de deformación de soportes esbeltos de hormigón, se ha llevado a cabo para todas las variables calculadas mediante los métodos propuestos (desplazamiento elástico efectivo, desplazamiento último, rigidez elástica efectiva, rigidez última y ductilidad de desplazamiento). Para ello, los resultados del error medio evaluado para los 250 ensayos numéricos son comparados gráficamente con respecto a los siguientes parámetros: axil reducido, nivel de carga axial, resistencia del hormigón, esbeltez de cortante, cuantía de armadura longitudinal y cuantía de armadura transversal.

En la comprobación se obtienen las gráficas que aparecen en la Figura 10-8. En ellas se observa que el error medio representado por la línea continua se encuentra sobre un valor cercano a la unidad, y su comportamiento es casi horizontal para todos los parámetros analizados, lo cual demuestra la escasa influencia en el error.

Las Figuras 10-8 a 10-13, en términos generales, han demostrado que los parámetros considerados en el análisis de la capacidad de deformación de soportes de hormigón no tienen especial influencia en el error. 


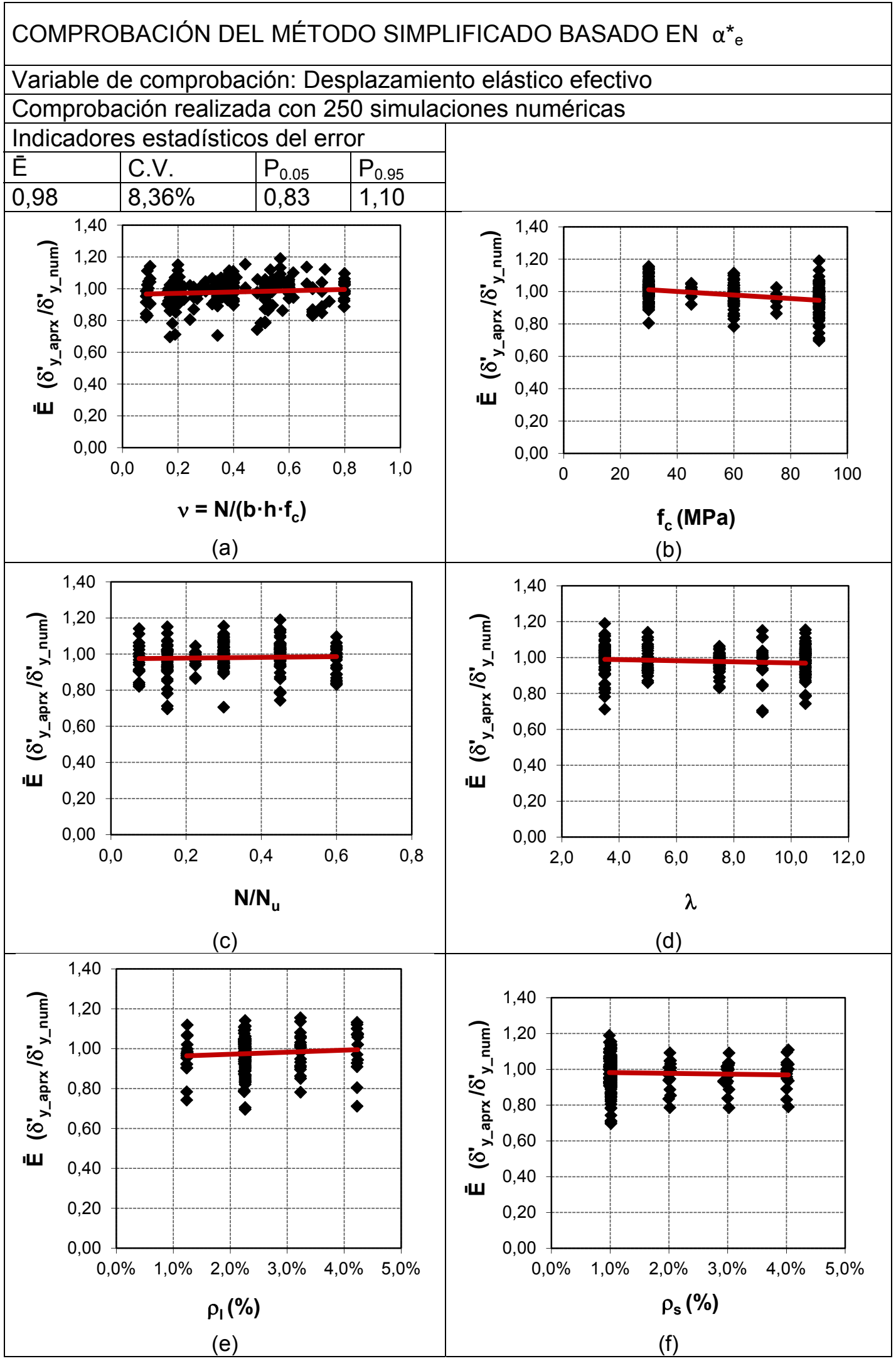

Figura 10-8 Comprobación del método simplificado basado en $\alpha^{*}$, para el desplazamiento elástico efectivo 


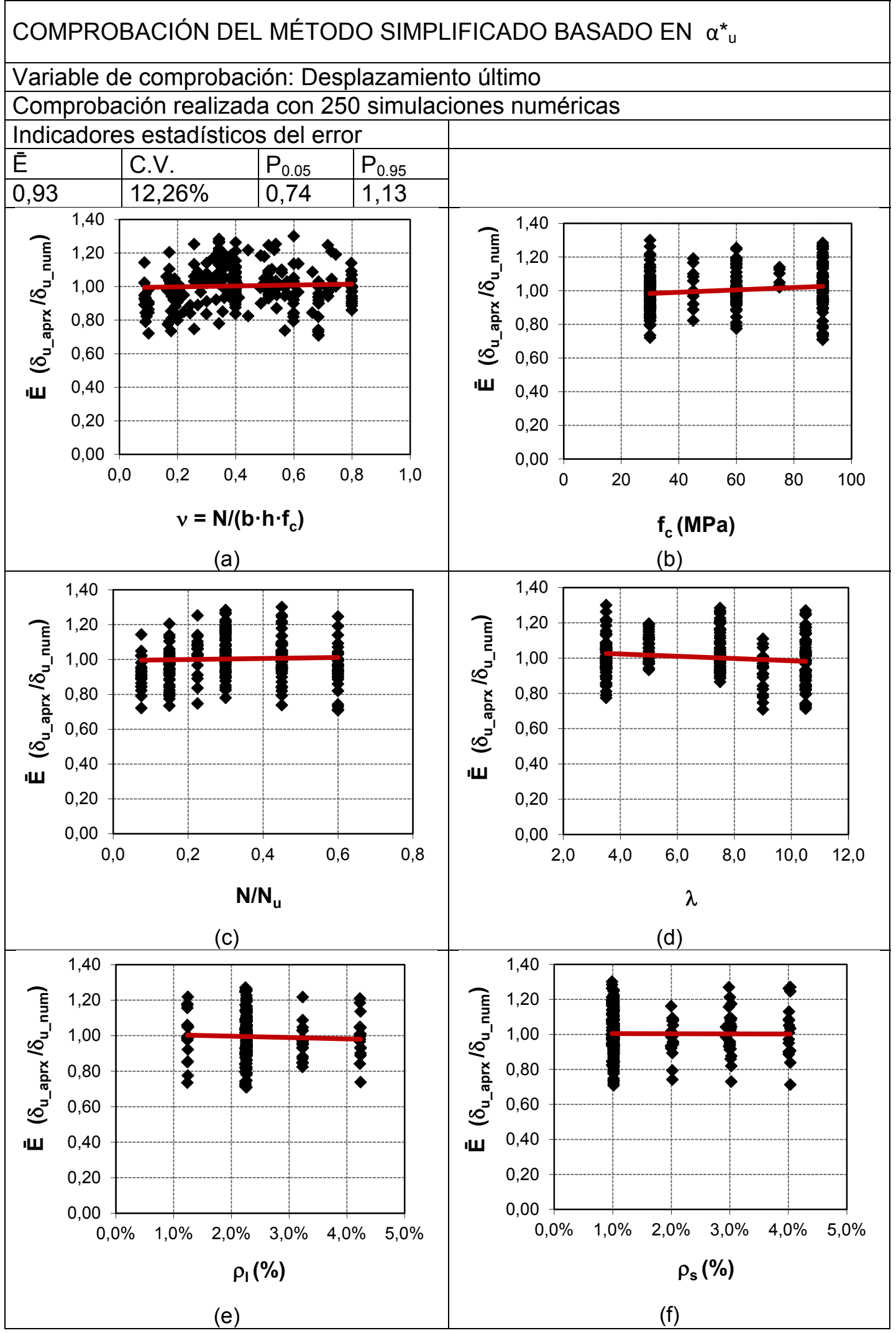

Figura 10-9 Comprobación del método simplificado basado en $\alpha^{*}{ }_{e}$ para el desplazamiento último 


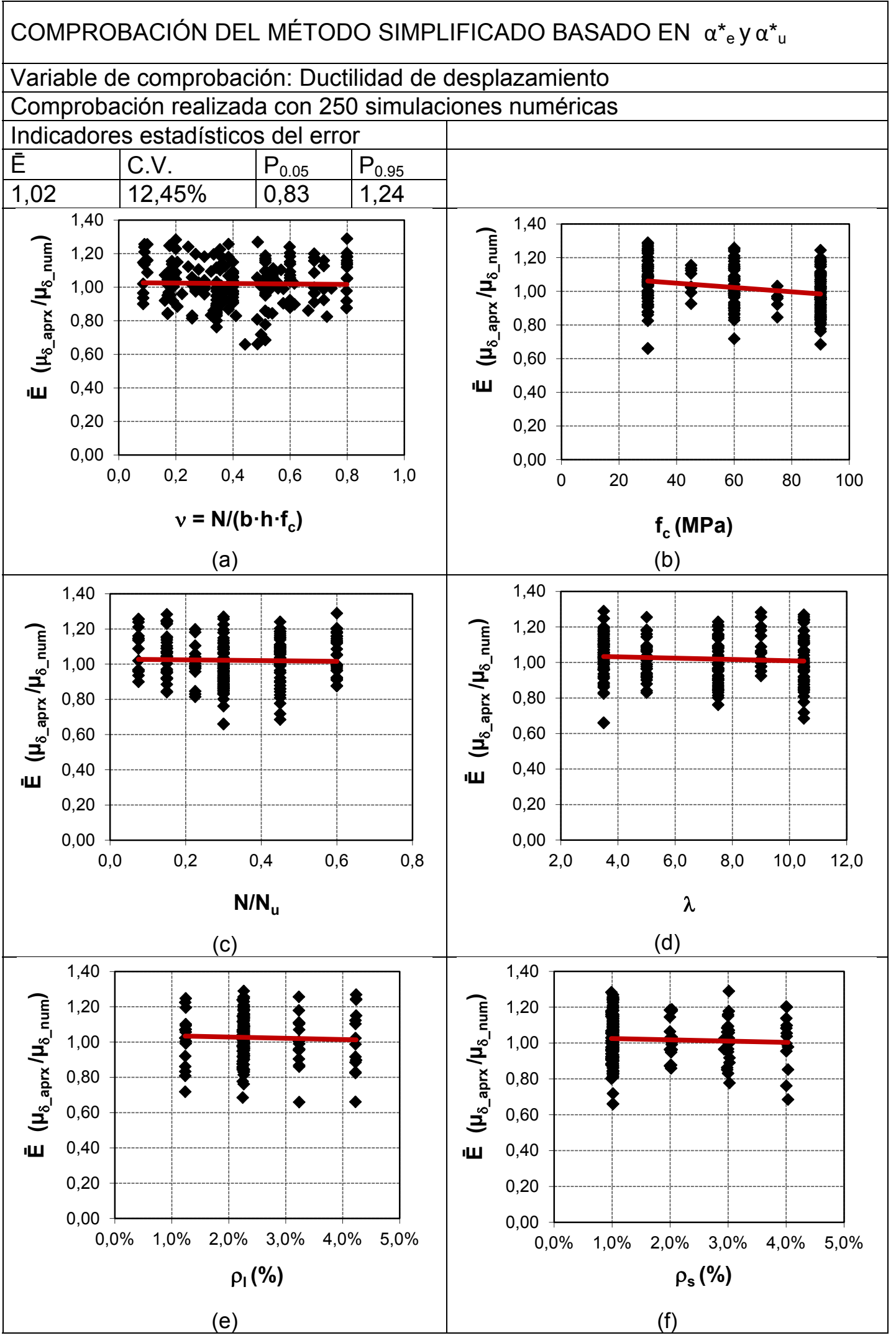

Figura 10-10 Comprobación del método simplificado basado en $\alpha^{*}{ }_{e}$ para la ductilidad en desplazamientos 


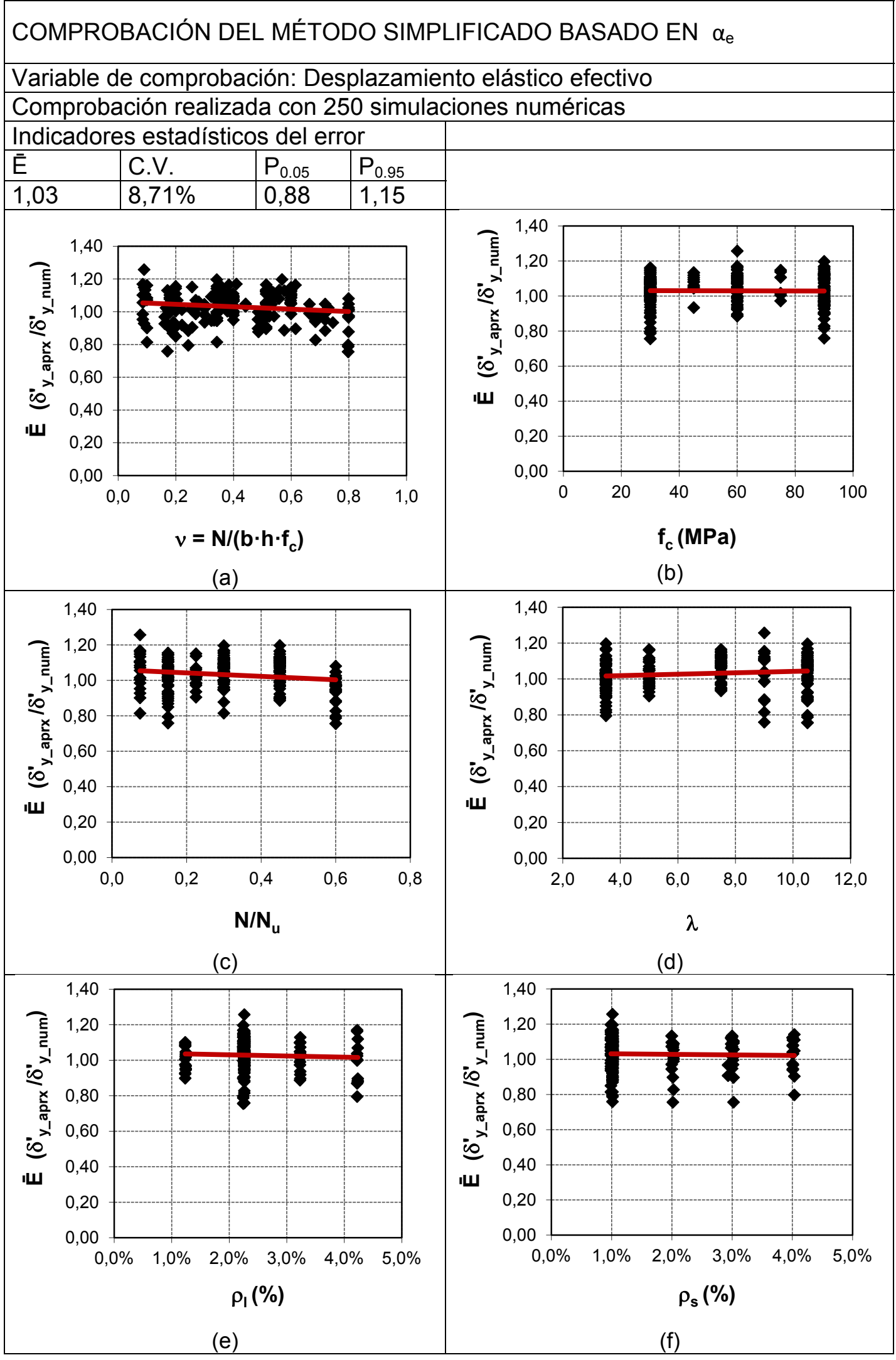

Figura 10-11 Comprobación del método simplificado basado en $\alpha_{e}$ para el desplazamiento elástico efectivo 


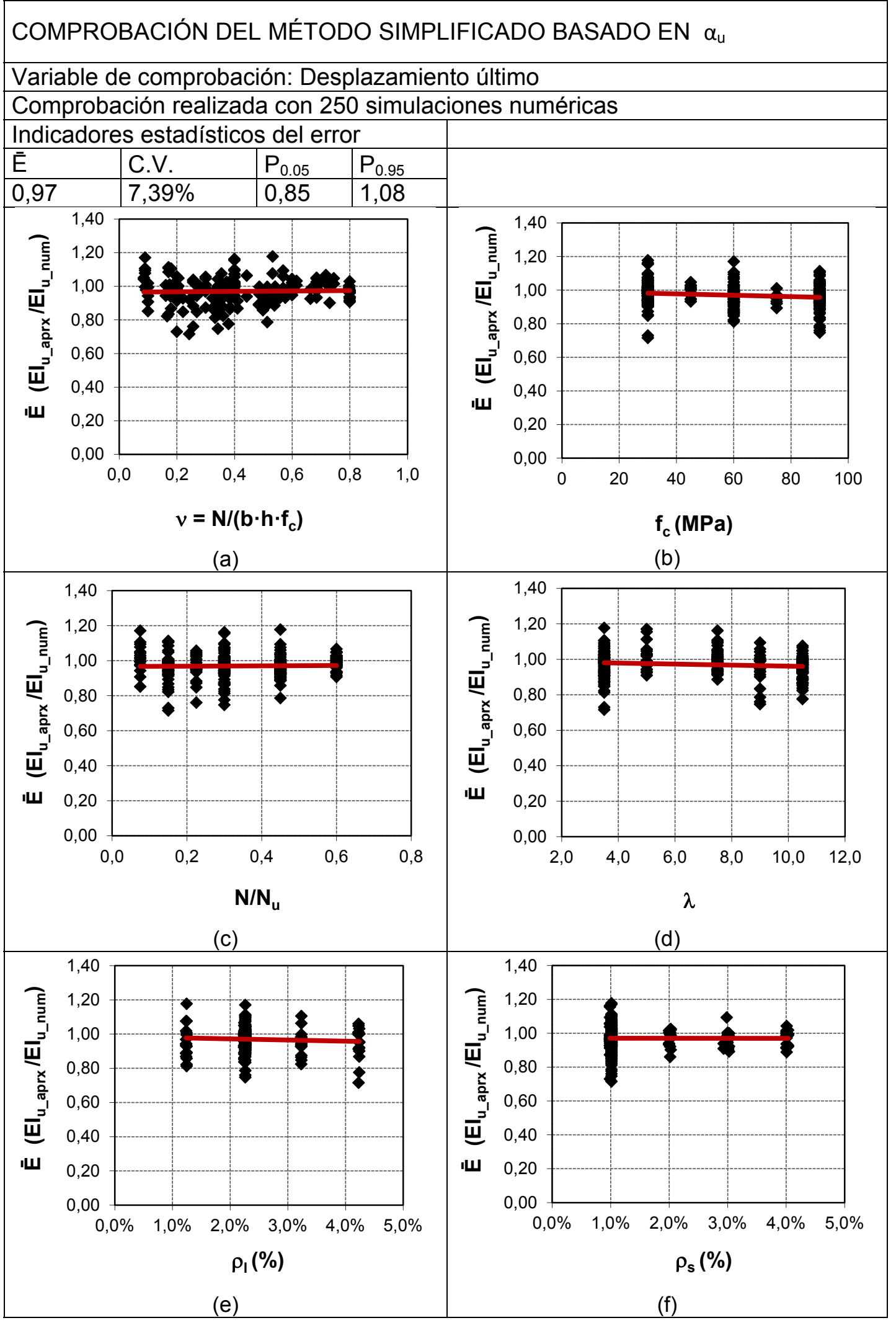

Figura 10-12 Comprobación del método simplificado basado en $\alpha_{\omega}$ para el desplazamiento último 


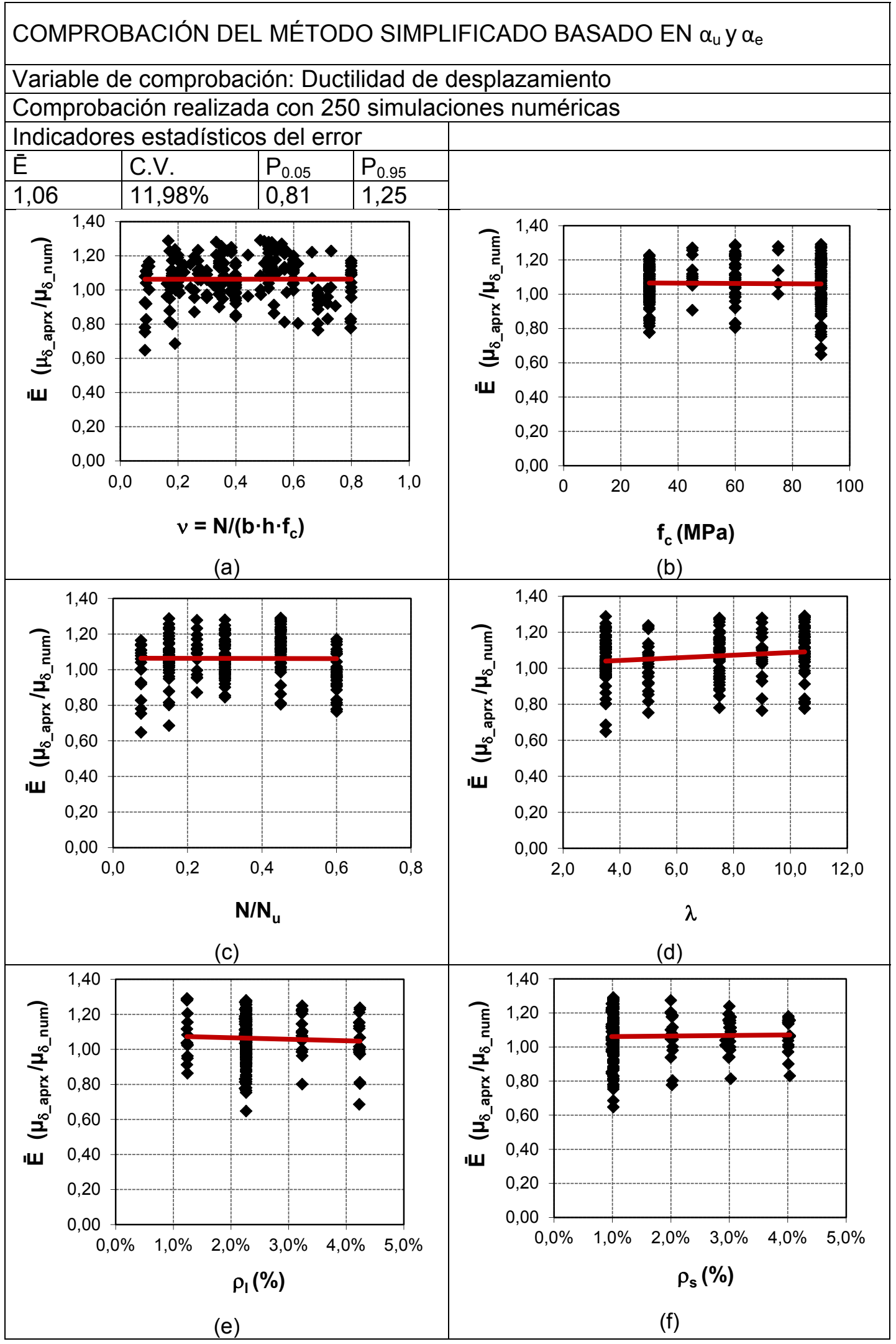

Figura 10-13 Comprobación del método simplificado basado en $\alpha_{u} y \alpha_{e}$, para la ductilidad en desplazamientos 


\subsubsection{COMPROBACIÓN DE LOS MÉTODOS PROPUESTOS Y LOS RESULTADOS EXPERIMENTALES}

Los resultados de la comparación entre los métodos simplificados propuestos y los resultados de los 40 ensayos experimentales realizados en este estudio, se muestran en la Tabla 10-13. Las variables utilizadas en la comparación son: el desplazamiento elástico efectivo $\left(\delta_{\mathrm{y}}^{\prime}\right)$, el desplazamiento último $\left(\delta_{\mathrm{u}}\right)$, y la ductilidad de desplazamiento $\left(\mu_{\delta}\right)$.

Tabla 10-8 Resultados de la comprobación entre los resultados experimentales y los métodos simplificados propuestos, para la variable $\delta_{y}^{\prime}$

\begin{tabular}{|c|c|c|c|c|c|c|c|c|}
\hline \multirow[b]{2}{*}{ Error } & \multicolumn{4}{|c|}{$\begin{array}{l}\text { MÉTODO BASADO EN EL } \\
\text { CÁLCULO DE } \alpha_{e}^{*} \text { y } \boldsymbol{\alpha}_{u}^{*}\end{array}$} & \multicolumn{4}{|c|}{$\begin{array}{l}\text { MÉTODO BASADO EN EL } \\
\text { CÁLCULO DE } \alpha_{e} \text { y } \alpha_{u}\end{array}$} \\
\hline & $\bar{E}$ & $\begin{array}{l}\text { C.V. } \\
(\%)\end{array}$ & $P_{0.05}$ & $P_{0.95}$ & $\bar{E}$ & $\begin{array}{l}\text { C.V. } \\
(\%)\end{array}$ & $P_{0.05}$ & $P_{0.95}$ \\
\hline$\delta_{y y \text { aprox }}^{\prime} / \delta_{y \text { exp }}^{\prime}$ & 1,09 & 22,8 & 0,85 & 1,32 & 1,10 & 23,9 & 0.82 & 1,44 \\
\hline$\delta_{\mathrm{u}}$ aprox $/ \delta_{\mathrm{u}} \exp$ & 1,06 & 25,9 & 0,64 & 1,49 & 1,08 & 23,4 & 0,76 & 1,51 \\
\hline$\mu_{\delta_{\delta} \text { aprx }} / \mu_{\delta_{\delta} \exp }$ & 1,06 & $25,1 \%$ & 0,78 & 1,56 & 1,14 & $25,0 \%$ & 0,76 & 1,60 \\
\hline
\end{tabular}

Los resultados del error muestran que las variables calculadas en base a los modelos propuestos tienden a sobrestimar los valores, lo cual se debe a que los valores de carga máxima en la simulación numérica son casi un $4 \%$ mayores que los valores experimentales de carga máxima. Por consiguiente, existe un aumento del error en los métodos que es proporcional al error en la carga. Por otra parte, el desplazamiento último medido experimentalmente, para una gran parte de los ensayos, es inferior al desplazamiento último alcanzado en la simulación numérica, ya que experimentalmente fue medido en el último punto de la rama de reblandecimiento antes de alcanzar una caída del $15 \%$ de la carga máxima, mientras que en la simulación numérica el desplazamiento último se midió siempre en una caída del $15 \%$ de la carga pico. Esto, naturalmente, implica un aumento del error, tanto en el desplazamiento último como en la ductilidad en desplazamientos.

Aunque el error aumenta al comparar los resultados de los métodos propuestos con los resultados experimentales, el error medio y el coeficiente de variación son bastante aceptables.

\subsection{COMPARACIÓN ENTRE LOS MÉTODOS PROPUESTOS Y LOS MÉTODOS EXISTENTES}

En esta sección se comparan los resultados de los métodos propuestos con los métodos analíticos y empíricos existentes.

\subsubsection{COMPARACIÓN EN ESTADO ELÁSTICO}

Para el estado elástico se comparan los resultados de los métodos propuestos en base a los factores de rigidez elástica de diseño $\alpha_{e}^{*}$ y de comprobación $\alpha_{e}$, con los resultados obtenidos del método analítico de Panagiotakos y Fardis (2001) [100], 
Ec. 10-41, y con las dos alternativas de cálculo prescritas en el Eurocódigo 8 (parte 3, anejo A), Ec. 10-42 y Ec. 10-43.

$$
\begin{array}{ccc}
\theta_{y}=\varphi_{y} \frac{L_{s}}{3}+0.0025+a_{s l} \frac{0.25 \varepsilon_{y} d_{b} f_{y}}{\left(d-d^{\prime}\right) \sqrt{f_{c}}} & \text { Ec. } 10-41 \\
\theta_{y}=\varphi_{Y} \frac{L_{V}+a_{v} z}{3}+0.00135\left(1+1.5 \frac{h}{L_{v}}\right)+\frac{\varepsilon_{y}}{d-d^{\prime}} \frac{d_{b} f_{y}}{6 \sqrt{f_{c}}} & \text { Ec. } 10-42 \\
\theta_{y}=\varphi_{Y} \frac{L_{V}+a_{v} z}{3}+0.0013\left(1+1.5 \frac{h}{L_{v}}\right)+0.13 \varphi_{y} \frac{d_{b} f_{y}}{\sqrt{f_{c}}} & \text { Ec. } 10-43
\end{array}
$$

La comparación se realiza en términos del desplazamiento elástico efectivo $\left(\delta_{y}^{\prime}\right)$, siendo $\delta_{y}^{\prime}=\theta_{y} L_{s}$ en las Ec. 10-42, a Ec. 10-44. En la Tabla 10-9 se presentan los resultados del error medio $\left(E=\delta_{y_{-} c a l}^{\prime} / \delta_{y_{-} n u m}^{\prime}\right)$ para cuando $\delta_{y_{-} \text {cal }}^{\prime}$ se calcula a partir de los métodos de diseño y comprobación propuestos en este estudio, o mediante los métodos existentes. La comparación se realiza para los 250 ensayos numéricos.

Tabla 10-9 Resultados de la comparación de los valores de $\delta_{y_{-} \text {cal }}$ calculados mediante los métodos propuestos y existentes con los $\delta_{y_{-} \text {nun }}$ obtenidos de la simulación numérica

\begin{tabular}{|c|c|c|c|c|c|}
\cline { 2 - 6 } \multicolumn{1}{c|}{} & $\boldsymbol{\alpha}_{\boldsymbol{e}}^{*}$ & $\boldsymbol{\alpha}_{\boldsymbol{e}}$ & Ec. 10-42 & Ec. 10-43 & EC. 10-44 \\
\hline$E=\delta_{\delta_{\_} \text {cal }}^{\prime} / \delta_{y_{\_} \text {num }}^{\prime}$ & 0.98 & 1.03 & 1,12 & 1,05 & 1,04 \\
\hline $\mathrm{CV}(\%)$ & 8.4 & 8.7 & 16 & 17 & 17 \\
\hline $\mathrm{P}_{0.95}$ & 1.10 & 1.15 & 1,42 & 1,34 & 1,34 \\
\hline $\mathrm{P}_{0.05}$ & 0.83 & 0.88 & 0,87 & 0,80 & 0,79 \\
\hline
\end{tabular}

En la Tabla 10-9 se muestra que los métodos propuestos presentan un mejor ajuste que los métodos existentes. Sin embargo, estos últimos también logran predecir el desplazamiento elástico efectivo con una buena aproximación, pero con una mayor dispersión de los resultados.

En las Figura 10-14 se presentan los valores del error medio para los métodos propuestos por Panagiotakos y Fardis (Ec. 10-41) y el método del Eurocodigo 8 (Ec. 10-42); no se representan los valores de la Ec. 10-43, ya que son muy similares a los de la Ec. 10-42.

Los métodos existentes muestran un buen ajuste con respecto a los parámetros de estudio. Sin embargo, el error medio $(\bar{E})$ aumenta con el incremento de la esbeltez (Figura 10-14b). Además, en la Figura 10-14d se observa una pequeña influencia de la cuantía de armadura longitudinal $\left(\rho_{l}\right)$ en el error medio. 


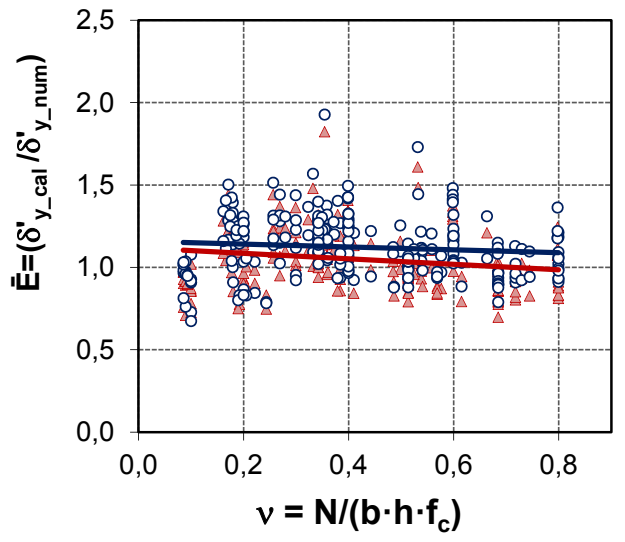

(a)

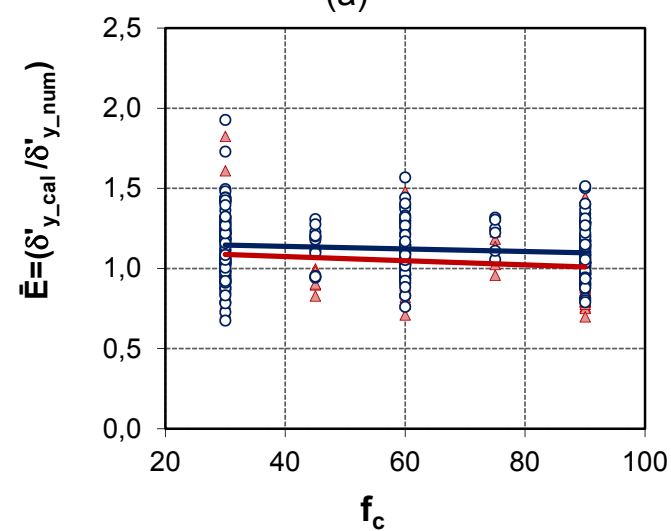

(c)

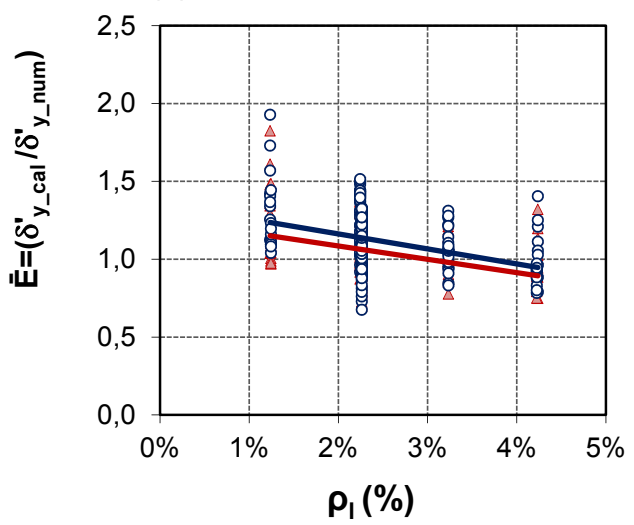

(e)

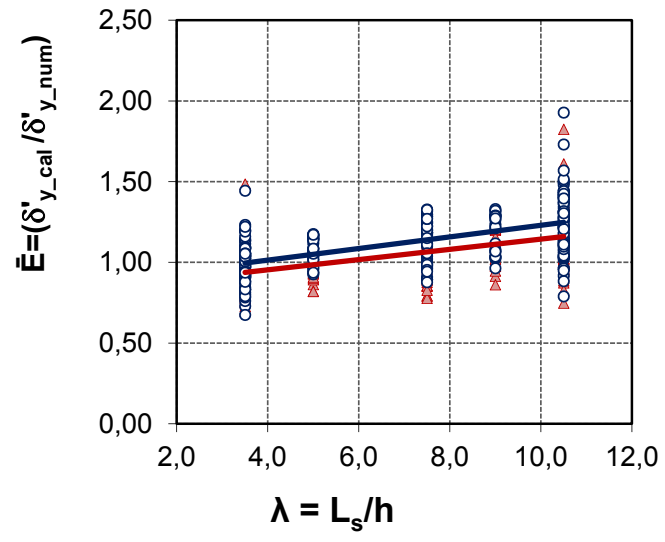

(b)

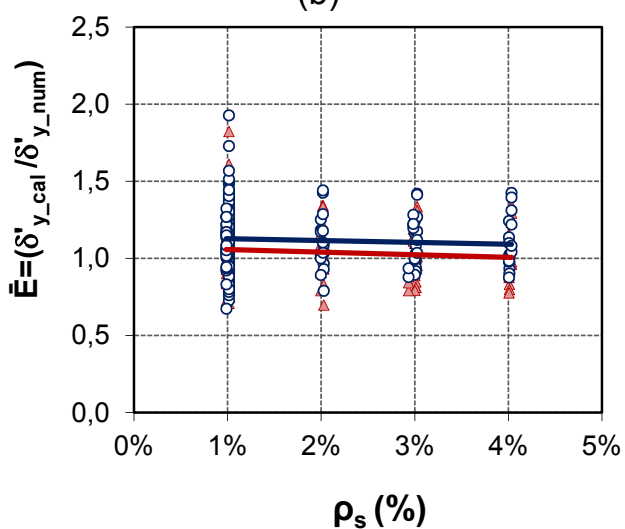

(d)

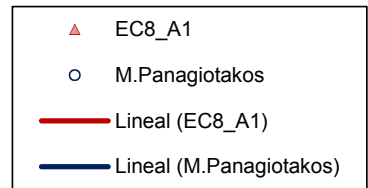

Figura 10-14 Comprobación del error medio con respecto a los parámetros de estudio para los métodos existentes, para el desplazamiento elástico

Por otra parte, en la Tabla $10-11$ se indican los resultados del error medio $(E=$ $\delta_{y_{-} \text {cal }}^{\prime} / \delta_{y_{-} \text {exp }}^{\prime}$ ) obtenido al comparar los resultados de los 40 ensayos experimentales con los resultados de $\delta_{y_{-} \text {cal }}$ evaluados mediante los métodos de diseño y comprobación propuestos en este estudio, y los calculados mediante las Ec $10-42,10-43$ y $10-44$. 
Tabla 10-10 Resultados de la comparación de los valores de $\delta_{y_{-} \text {cal }}^{\prime}$ calculados mediante los métodos propuestos y existentes con los $\delta_{y_{-} \text {exp. }}^{\prime}$

\begin{tabular}{|c|c|c|c|c|c|}
\cline { 2 - 6 } \multicolumn{1}{c|}{} & $\boldsymbol{\alpha}_{\boldsymbol{e}}^{*}$ & $\boldsymbol{\alpha}_{\boldsymbol{e}}$ & Ec. 10-42 & Ec. 10-43 & EC. 10-44 \\
\hline$\left(E=\delta_{y_{\_} \text {cal }}^{\prime} / \delta_{y_{\_} \text {exp }}^{\prime}\right)$ & 1.09 & 1.10 & 1,18 & 1,33 & 1,32 \\
\hline $\mathrm{CV}(\%)$ & 22.8 & 23.9 & 20 & 21.2 & 21.2 \\
\hline $\mathrm{P}_{0.95}$ & 1.32 & 1.44 & 1.15 & 1.06 & 1.59 \\
\hline $\mathrm{P}_{0.05}$ & 0.85 & 0.82 & 0.59 & 0.53 & 0.53 \\
\hline
\end{tabular}

Respecto a los ensayos experimentales, los métodos propuestos también muestran un mejor ajuste que los métodos existentes. Sin embargo, la Ec. 10-42 también muestra una aceptable aproximación con los resultados experimentales.

\subsubsection{COMPARACIÓN EN EL ESTADO ÚLTIMO}

En estado último se comparan los valores de desplazamiento último calculados mediante los métodos analíticos y existentes con los valores obtenidos en las simulaciones numéricas.

Los métodos analíticos utilizados en la comparación son: el propuesto por Panagitakos y Fardis (2001) [100], y las dos alternativas del modelo analítico del Eurocódigo (2004). Estos métodos se encuentran descritos en el capítulo 9.

Por otra parte, los métodos simplificados utilizados también en la comparación son: el método de Panagiotakos y Fardis (Ec. 10-79), el propuesto en el boletín CEB-FIP 25 (2003) [35], y la propuesta de Fardis y Biskinis (2003) [60].

Tabla 10-11 Relación de modelos empíricos para el cálculo de la deriva última utilizados en la comparación con los resultados experimentales

\begin{tabular}{|c|c|}
\hline$\theta_{u, \text { mon }}(\%)=\alpha_{s t}\left[1+\frac{\alpha_{s l}}{8}\right](0.15)^{v}\left[\frac{\max \left(0.01, \omega^{\prime}\right)}{\max (0.01, \omega)} \frac{L_{s}}{h} f_{c}\right]^{0.425}$ & Ec. 10-44 \\
\hline$\theta_{u}=\alpha_{s t}\left(1-0.38 \alpha_{c y c}\right)\left[1+\frac{\alpha_{s l}}{1.7}\right](0.3)^{v}\left[\frac{\max \left(0.01, \omega^{\prime}\right)}{\max (0.01, \omega)} f_{c}\right]^{0.2}\left(\frac{L_{s}}{h}\right)^{0.425} 25^{\alpha k}\left(1.45^{100 \rho_{d}}\right)$ & Ec. 10-45 \\
\hline$\theta_{u}=\alpha_{s t}\left(1-0.4 \alpha_{c y c}\right)\left[1+0.5 \alpha_{s l}\right](0.3)^{v}\left[\frac{\max \left(0.01, \omega^{\prime}\right)}{\max (0.01, \omega)} f_{c}\right]^{0.175}\left(\frac{L_{s}}{h}\right)^{0.4} 25^{\alpha k}\left(1.25^{100 \rho_{d}}\right)$ & Ec. 10-46 \\
\hline
\end{tabular}

Donde:

$\alpha_{s t}$ Factor que tiene en cuenta el tipo de acero de la armadura: 1.0 para Ec. 10-45, 0.016 para Ec. $10-46$ y 0.194 para Ec. $10-47$

$\alpha_{s l} 1$ si se desliza la armadura longitudinal en la zona de anclaje y 0 si esto es imposible

$\alpha_{c y c}$ Factor que tiene en cuenta el tipo de carga (1 para carga cíclica y 0 para carga monotónica) 


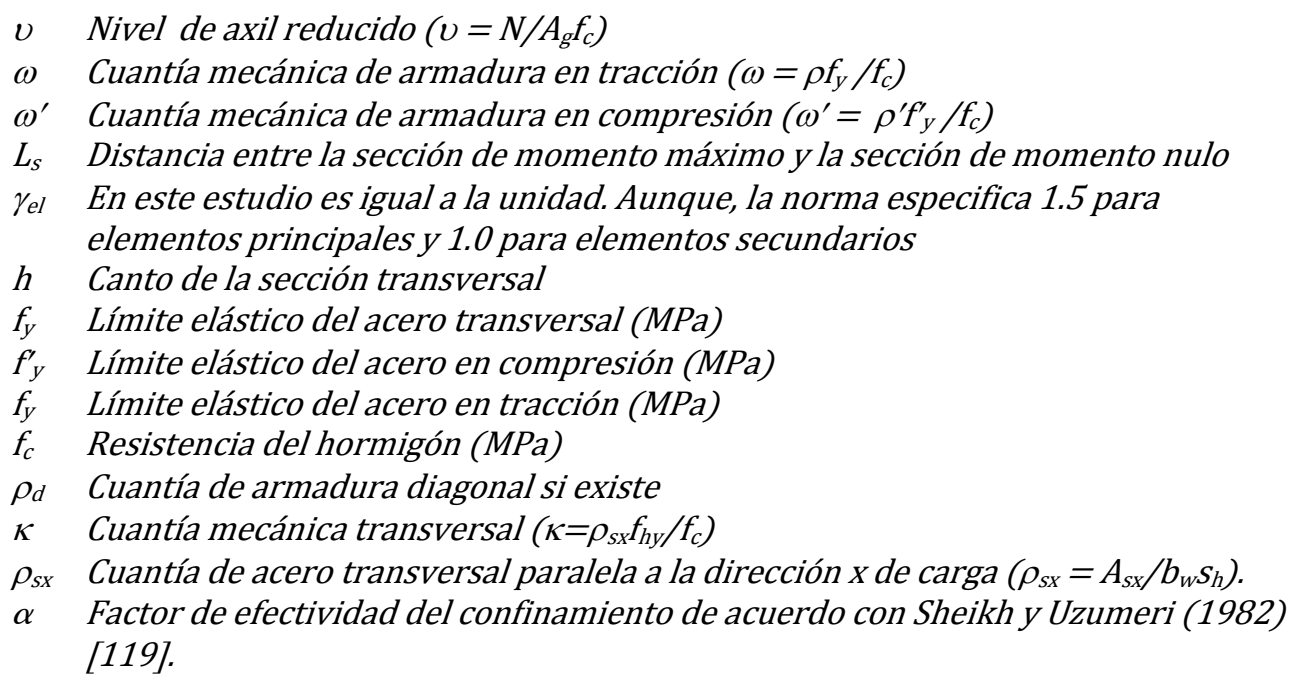

Los resultados del error medio se indican en Tabla 10-12. Como se puede observar en esta tabla, el desplazamiento último calculado en base a los métodos propuestos para el factor de rigidez última de diseño $\alpha_{u}^{*}$ y el factor de rigidez de comprobación $\alpha_{u}$, predicen con un buena aproximación los desplazamientos últimos obtenidos en la simulación numérica. El error medio $(\bar{E})$ se encuentra sobre o muy cerca de la unidad, consiguiéndose una dispersión del $\bar{E}$ bastante aceptable.

Por otra parte, los métodos analíticos de Panagiotakos y Fardis (2001) y la propuesta del Eurocódigo 8 alternativa 1, logran un mayor $\bar{E}$ que los métodos propuestos, pero también cercano a la unidad $(\bar{E}=0.96$ y $\bar{E}=0.92$, respectivamente); sin embargo, la dispersión del error es muy alta $(\mathrm{CV}=62$ y $\mathrm{CV}=56 \%$, respectivamente). La alternativa 2 del método propuesto en el Eurocódigo 2 no consigue una aproximación aceptable y el error es mucho mayor $(\overline{\mathrm{E}}=0.7)$. Por otra parte, los tres métodos empíricos son poco fiables, ya que, por un lado, sobreestiman el desplazamiento último, y, por otro, la dispersión del error medio es muy alta (superior a $35 \%$ ).

Tabla 10-12 Resultados de la comparación de los valores de $\delta_{u_{-} \text {cal }}$ calculados mediante los métodos propuestos y existentes con los $\delta_{u_{-} n u n}$ obtenidos de la simulación numérica

\begin{tabular}{|c|c|c|c|c|}
\hline Método & $\overline{\mathbf{E}}$ & $\mathbf{C V}(\%)$ & P95(\%) & P5(\%) \\
\hline Propuesto para $\boldsymbol{\alpha}_{\boldsymbol{u}}^{*}$ & 0.93 & $12.2 \%$ & 1.13 & 0.74 \\
\hline Propuesto para $\boldsymbol{\alpha}_{\boldsymbol{u}}$ & 0.97 & $7.4 \%$ & 1.08 & 0.85 \\
\hline M. Panagiotakos et al. & 0.96 & $62 \%$ & 2.19 & 0.35 \\
\hline M. EC8_A1 & 0.92 & $56 \%$ & 2.05 & 0.44 \\
\hline M. EC8_A2 & 0.70 & $43 \%$ & 1.30 & 0.39 \\
\hline EC. 79 & 2.71 & $45 \%$ & 4.77 & 1.18 \\
\hline EC. 80 & 2.26 & $36 \%$ & 3.68 & 1.20 \\
\hline EC. 81 & 2.36 & $36 \%$ & 3.85 & 1.28 \\
\hline
\end{tabular}

En las Figura 10-15 se presentan los resultados del error con respecto a los siguientes parámetros de estudio: axil reducido, esbeltez de cortante, resistencia del hormigón, y cuantías de armadura longitudinal y transversal. En el lado izquierdo de las figuras se presentan los resultados del error para los métodos analíticos, y en el lado izquierdo los resultados de $\bar{E}$ para los métodos empíricos. 

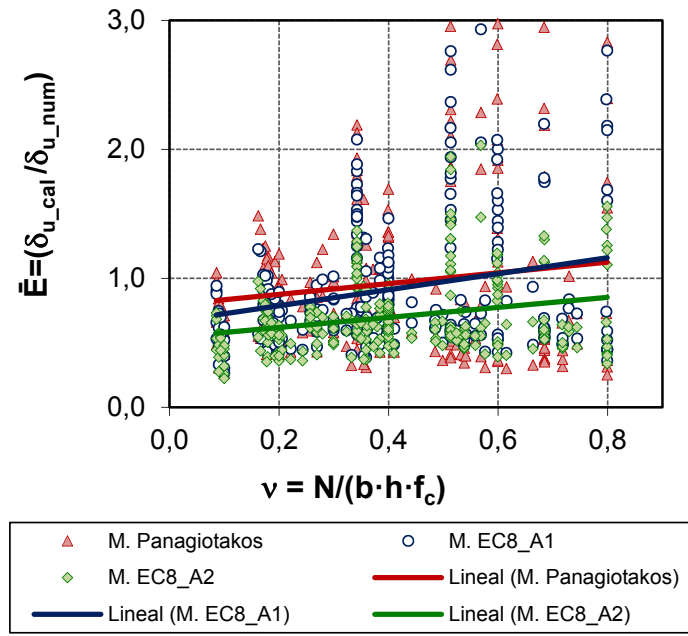

(a)
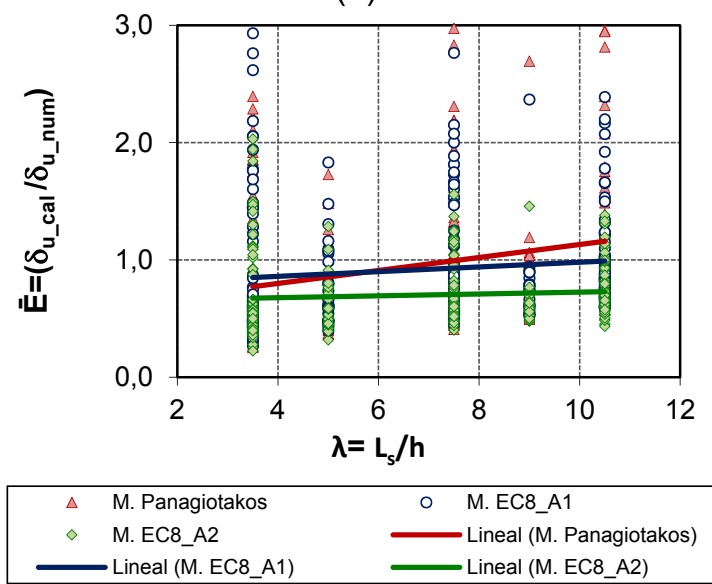

(c)
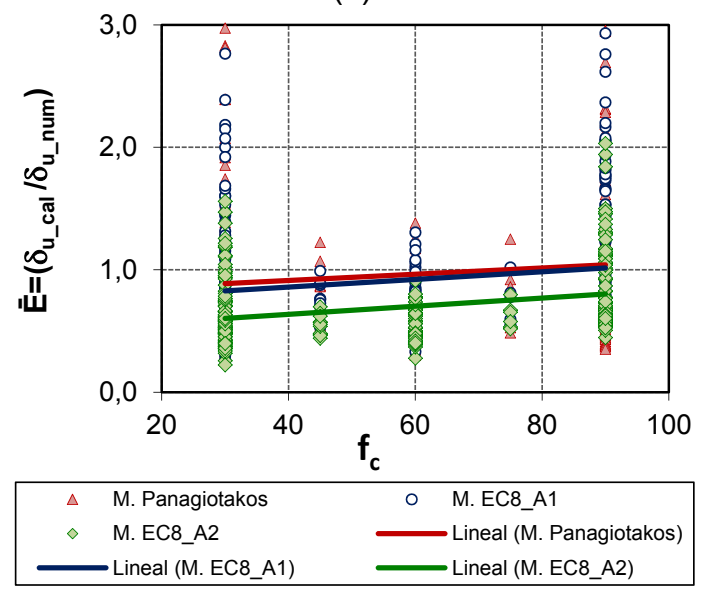

(e)
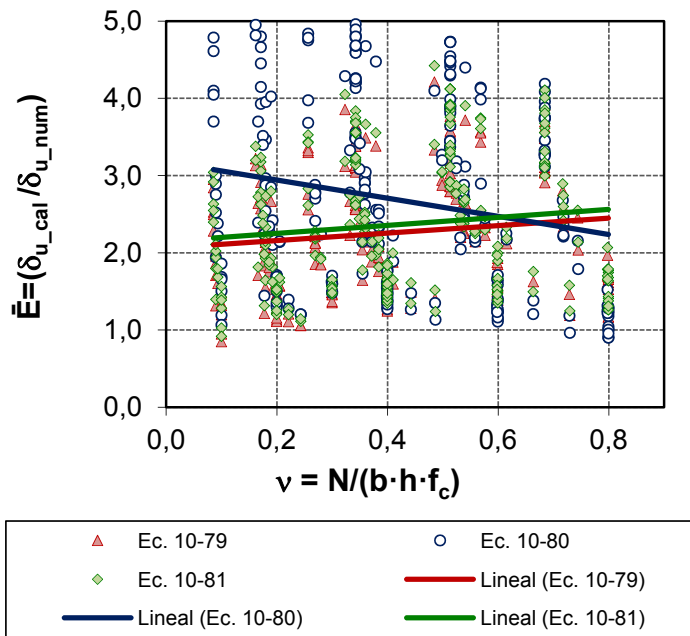

(b)

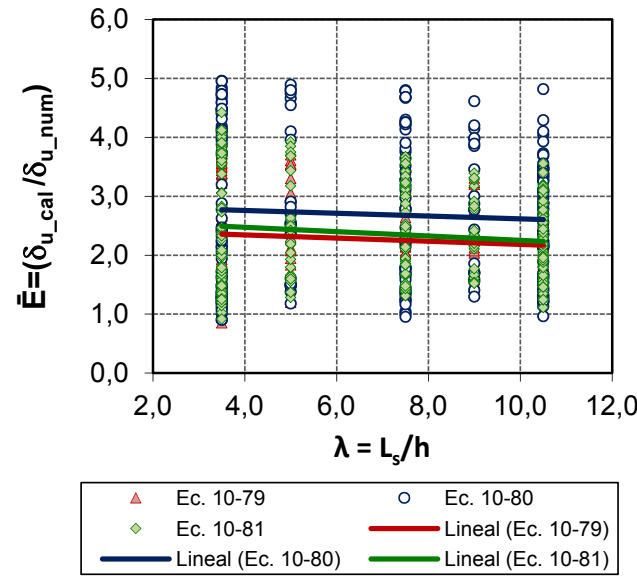

(d)

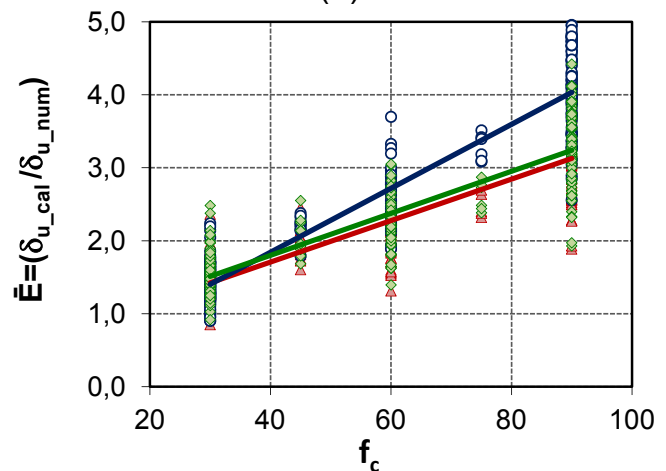

\begin{tabular}{|clr|}
\hline$\Delta$ & Ec. 10-79 & Ec. 10-80 \\
$\diamond$ & Ec. 10-81 & Lineal (Ec. 10-79) \\
& Lineal (Ec. 10-80) & Lineal (Ec. 10-81) \\
\hline
\end{tabular}

(f) 

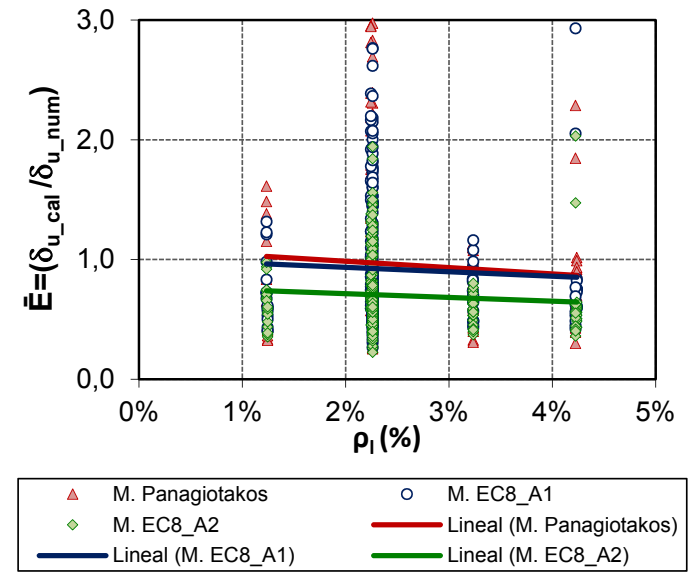

(g)

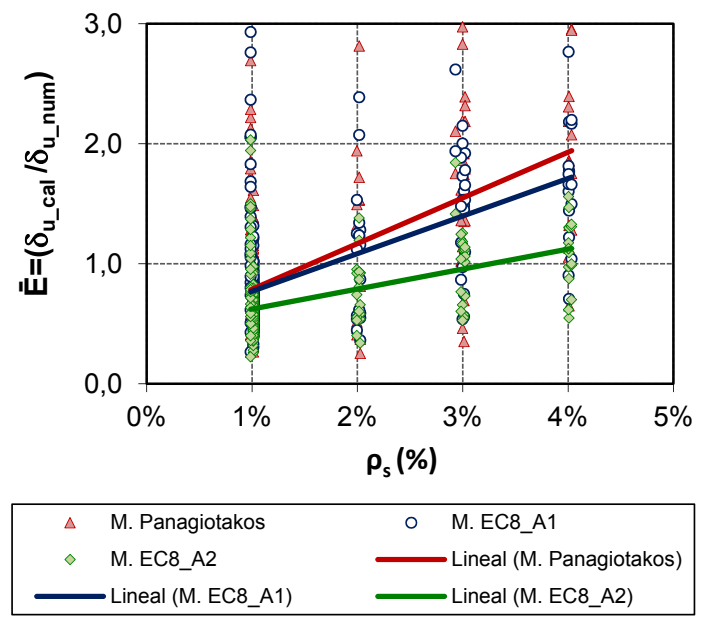

(i)
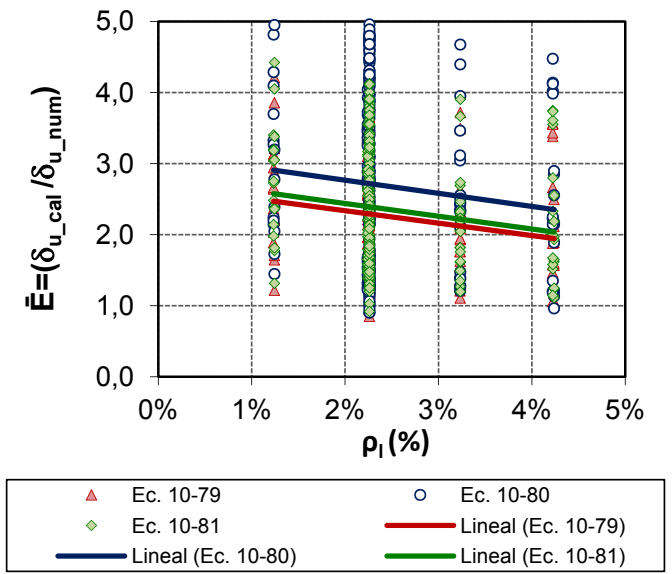

(h)
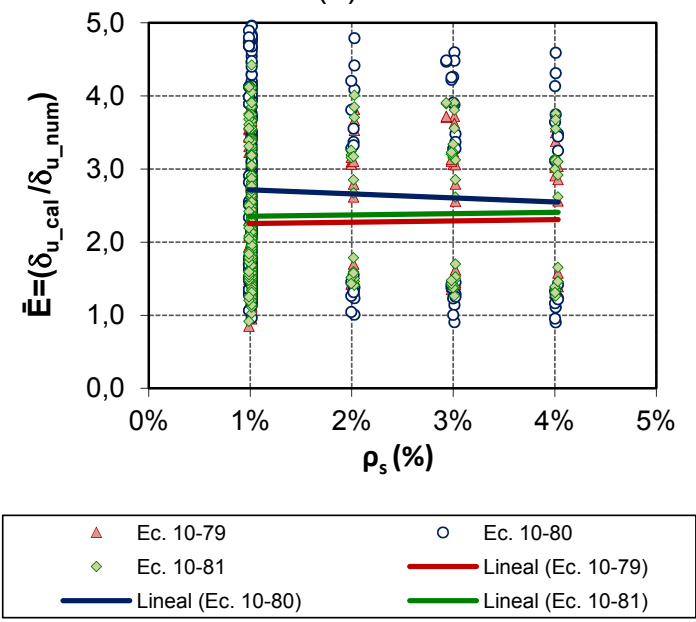

(j)

Figura 10-15 Comprobación del error medio con respecto a los parámetros de estudio para los métodos existentes, para el desplazamiento último

Como se puede observar en la Figura $10-15 i$, el parámetro que más influye en el error obtenido en los métodos analíticos, es la cuantía de armadura transversal. Esto se debe a que los métodos analíticos interpretan el aumento de la cuantía transversal como un aumento efectivo en la capacidad de deformación, mientras que, en el modelo numérico, el efecto del confinamiento no resulta ser tan significativo.

En los métodos empíricos el parámetro que más afecta al error es la resistencia del hormigón $\left(f_{c}\right)$, como se puede ver en la Figura 10-15f; el error se incrementa ampliamente con el aumento de la $f_{c}$. Otra variable que influye en el $\bar{E}$ en un menor grado es la cuantía de armadura longitudinal (ver Figura 10-15h). Por último, en el método propuesto por Panagiotakos y Fardis, Ec. 10-44, el error disminuye con el incremento del axil reducido.

En la Tabla 10-13 se muestra un resumen del error medio obtenido para el desplazamiento último, al comparar los valores $\delta_{u_{-} \text {cal }}$ calculados a partir de los diferentes métodos propuestos en este estudio y de los existentes, con los valores de $\delta_{u_{\text {_exp }}}$ para los 40 ensayos experimentales. 
Tabla 10-13 Resultados de la comparación de los valores de $\delta_{u_{-} \text {cal }}$ calculados mediante los métodos propuestos y existentes con los $\delta_{u_{-} \text {exp }}$

\begin{tabular}{|c|c|c|c|c|}
\hline Método & $\overline{\mathbf{E}}$ & $\mathbf{C V}(\%)$ & $\mathbf{P 9 5}(\%)$ & $\mathbf{P 5 ( \% )}$ \\
\hline Propuesto para $\boldsymbol{\alpha}_{\boldsymbol{u}}^{*}$ & 1.06 & 25.9 & 1.49 & 0.64 \\
\hline Propuesto para $\boldsymbol{\alpha}_{\boldsymbol{u}}$ & 1.08 & 23.4 & 1.51 & 0.76 \\
\hline M. Panagiotakos et al. & 0,88 & 30.0 & 1.59 & 0.63 \\
\hline M. EC8_A1 & 0,83 & 23.2 & 1.53 & 0.75 \\
\hline M. EC8_A2 & 0,71 & 18.5 & 1.81 & 1.03 \\
\hline EC. 79 & 3,13 & $34 \%$ & 0.52 & 0.21 \\
\hline EC. 80 & 2,56 & $26 \%$ & 0.57 & 0.26 \\
\hline EC. 81 & 2,63 & $25 \%$ & 0.54 & 0.25 \\
\hline
\end{tabular}

Como se puede observar en la Tabla 10-13, los métodos propuestos logran una mejor aproximación que los métodos existentes, cuando la comparación se hace con los resultados experimentales. Los métodos analíticos tienden a subestimar el desplazamiento último, el error puede ser aún mayor si se tiene en cuenta que los ensayos experimentales no llegaron a desarrollar una rama de reblandecimiento suficiente hasta alcanzar el $15 \%$ de caída de la carga máxima, que es el punto que define el desplazamiento último. Por otra parte, los métodos empíricos están notablemente del lado de la inseguridad.

\subsubsection{COMPARACIÓN CON LA DUCTILIDAD}

Finalmente, los resultados del factor de ductilidad $\left(\mu_{\delta_{-} c a l}=\delta_{u} / \delta_{y}^{\prime}\right)$ calculados mediante los métodos analíticos y los resultados calculados a partir de los métodos propuestos, son comparados con los valores de $\mu_{\delta_{-} \text {num }}$ medidos en los ensayos numéricos. Los resultados del error $\left(\overline{\mathrm{E}}=\mu_{\delta_{-} \text {cal }} / \mu_{\delta_{-} \text {num }}\right)$ se presentan en la Tabla $10-14$.

Tabla 10-14 Resultados de la comparación de los valores de $\mu_{\delta_{-} \text {cal }}$ calculados mediante los métodos propuestos y existentes con los $\mu_{\delta_{-} \text {num }}$ obtenidos de la simulación numérica

\begin{tabular}{|c|c|c|c|c|}
\hline Método & $\overline{\mathbf{E}}$ & $\mathbf{C V}(\%)$ & P95(\%) & P5(\%) \\
\hline Propuesto para $\boldsymbol{\alpha}_{\boldsymbol{e}}^{*} \mathbf{y} \boldsymbol{\alpha}_{\boldsymbol{u}}^{*}$ & 1,02 & $12.5 \%$ & 1,24 & 0,83 \\
\hline Propuesto para $\boldsymbol{\alpha}_{\boldsymbol{e}} \mathbf{y} \boldsymbol{\alpha}_{\boldsymbol{u}}$ & 1.06 & $12 \%$ & 1,25 & 0,81 \\
\hline M. Panagiotakos et al. & 1,14 & $66 \%$ & 3,18 & 0,54 \\
\hline M. EC8_A1 & 0,86 & $57 \%$ & 2,02 & 0,45 \\
\hline M. EC8_A2 & 0,67 & $45 \%$ & 1,36 & 0,40 \\
\hline
\end{tabular}

En la Tabla 10-14 se muestra que la ductilidad en desplazamientos calculada en base a los métodos propuestos para los factores de rigidez elástica y última, para diseño y para comprobación, presenta una buena aproximación con los resultados del modelo numérico. Por el contrario, los valores de ductilidad calculados mediante los métodos analíticos existentes no son lo suficientemente fiables. $Y$ aunque los métodos del Eurocódigo 8 pueden estar del lado de la seguridad, la dispersión de los resultados es muy alta. 
Estudio experimental y numérico de la capacidad de deformación de soportes esbeltos de hormigón armado 


\section{CAPÍTULO 11}

\section{CONCLUSIONES Y FUTURAS LÍNEAS DE INVESTIGACIÓN}

\subsection{CONCLUSIONES}

Las principales conclusiones obtenidas durante el desarrollo de este estudio, se han clasificado siguiendo los principales apartados del trabajo.

\section{Respecto al estado del conocimiento}

- A lo largo de la revisión bibliográfica llevada a cabo en este estudio, se ha podido constatar que existe una gran cantidad de estudios realizados con el propósito de proponer diferentes metodologías para la evaluación de la capacidad de deformación en elementos de hormigón. Dichas propuestas pueden ser clasificadas en métodos empíricos y analíticos (con mayor o menor grado de complejidad, dependiendo de los efectos considerados). Estos métodos muestran amplias diferencias entre ellos debido a las siguientes razones: (1) fueron desarrollados en base a la información experimental y/o numérica de elementos con determinadas características geométricas y mecánicas y su aplicabilidad está limitada a los rangos para 
los que fueron propuestos; (2) las diferencias también pueden deberse a la variedad de los efectos considerados en su formulación, como son: el deslizamiento de la armadura en la zona de anclaje, la fisuración de cortante, el pandeo local de la armadura longitudinal, el confinamiento del núcleo, etc.

- A partir de la revisión de la documentación existente, se ha conformado una base de datos de ensayos de elementos de hormigón armado, en los que se ha evaluado su capacidad de deformación. Por otra parte, existe una base de datos de ensayos en elementos de hormigón, que ha servido de fundamento para proponer métodos utilizados en la evaluación de la capacidad de deformación, los cuales incluso han sido incluidos, con pequeñas modificaciones, en las actuales normas (Eurocódigo 8, parte 3). $\mathrm{Y}$, aunque estos métodos evidentemente cuentan con una amplia comprobación experimental, se ha logrado verificar que existe una carencia de ensayos experimentales para determinados rangos de parámetros, como son la resistencia del hormigón (mayor de $50 \mathrm{MPa}$ ), altos y moderados niveles de compresión axial (superiores al $40 \%$ del axil reducido), cuantías de armadura transversal mayores que el $2 \%$ y esbeltez de cortante mayor que 6. Esto se ha comprobado tras revisar las características de los elementos que componen las dos bases de datos.

- Todo lo anterior ha permitido plantear un estudio, con el propósito de obtener métodos más generales, identificando y analizando los parámetros que más influyen en el comportamiento deformacional de soportes esbeltos de hormigón armado. Pero también, dada la complejidad de cada uno de los fenómenos que se producen, este estudio ha delimitado el análisis a los efectos de flexión y los posibles efectos debidos a la fisuración por cortante, sin tener en cuenta los efectos del deslizamiento de la armadura en la zona de anclaje, puesto que dichos efectos se han evitado mediante la disposición de la armadura longitudinal de forma continua sin solapes.

\section{Respecto al estudio experimental de soportes de hormigón armado}

- En este estudio se ha llevado a cabo la construcción de un modelo de ensayo de soportes esbeltos de hormigón armado sometidos a compresión y flexión monotónica, a partir del cual se ha obtenido información experimental sobre la capacidad resistente y deformacional, a nivel de la sección y del elemento. Utilizando este modelo, se ha desarrollado un programa experimental de 44 elementos que han sido sometidos a flexocompresión hasta la rotura. Los parámetros incluidos en el estudio experimental son los siguientes: resistencia del hormigón (30, 60 y $90 \mathrm{MPa})$, nivel de carga axial (desde 0 hasta 0.6), esbeltez de cortante $(7.5,10.5$ y $15)$, cuantía de armadura longitudinal $(1.4 \%, 2.2 \%, 3.2 \%)$ y cuantía de armadura transversal $(1 \%, 2 \%$ y $3 \%)$.

- En los ensayos experimentales se ha comprobado que se presentan algunos efectos característicos. Uno de ellos es el desarrollo de la rótula punto en elementos sometidos a flexión simple sin carga axial. Otro es el efecto del "stub", el cual se manifiesta cuando las secciones cercanas a la conexión ("stub") no presentan daño, y por lo tanto la sección con mayor 
deformación se desplaza aproximadamente $5 \mathrm{~cm}$ de la cara del "stub". Este efecto se ha observado ya en otros estudios, como Sheikh S.A. et al. (1993) [121] y (1998) [16], Légeron F. y Paultre P.(2000) [78], Bae (2005) [12], los cuales atribuyen este efecto al confinamiento producido por la mayor rigidez del "stub" en las secciones más cercanas (alrededor de $5 \mathrm{~cm}$ ).

\section{Respecto a los resultados experimentales}

- En la comparación entre los resultados experimentales y los obtenidos al aplicar los métodos teóricos para el cálculo de los momentos máximos, se ha comprobado que, en general, todos los métodos implementados en este estudio son capaces de predecir con una buena aproximación los momentos máximos obtenidos experimentalmente. El método del Eurocódigo-2 y de la EHE-08, en los que se utiliza el modelo constitutivo parábola-rectángulo para el hormigón en compresión, son los que alcanzan una mejor aproximación. Sin embargo, cabe destacar el hecho de que, en todos los métodos, el error medio aumenta con el incremento del nivel de carga axial; y en los métodos de la EHE-08 y el Eurocódigo 2 se aprecia un leve incremento del error medio cuando aumenta la resistencia del hormigón. En definitiva, esta comparación ha permitido validar los resultados experimentales en términos de la capacidad de momento resistente.

- Al llevar a cabo la comparación entre resultados experimentales de la carga máxima y los obtenidos mediante la aplicación de métodos teóricos, se comprueba que dichos métodos son más imprecisos cuando se evalúa la carga máxima teórica, ya que el proceso implica el cálculo de los efectos de segundo orden utilizando métodos aproximados, como la amplificación de momentos y la excentricidad adicional. El método con el que se ha conseguido una mejor aproximación con los resultados experimentales es el del Eurocódigo-2, evaluando los efectos de segundo orden a partir del método de la excentricidad adicional. Una aproximación algo menor, aunque igualmente aceptable, se logra también para el método del Eurocódigo 2 cuando los efectos de segundo orden son evaluados mediante el método de amplificación de momentos. Los resultados teóricos demuestran estar del lado de la seguridad a medida que aumenta la resistencia del hormigón y el nivel de carga axil se incrementa también.

- A la vista de los diferentes métodos aplicados a la idealización de los diagramas de respuesta, este estudio ha llegado a la conclusión de que el método más conveniente para la idealización de los diagramas de respuesta experimental $\mathrm{M}-\varphi$ y $\mathrm{P}-\delta$ es el método del Eurocódigo 8, por diversas razones: (1) el criterio para definir el punto de plastificación relacionado con el estado de deformación de los materiales es bastante preciso y permite valorar la rigidez efectiva, la curvatura elástica y el desplazamiento elástico para el mismo punto, tanto en el $\mathrm{M}-\varphi$ como en $\mathrm{P}-\delta$, es decir, existe un criterio de concomitancia; (2) el criterio de deformación límite para el comportamiento elástico de los materiales asegura que, por lo menos hasta este punto, los materiales se encuentran sujetos a un comportamiento elástico; y (3) la deformación $0.75 \varepsilon_{\mathrm{co}}$ representa un límite adecuado para el comienzo de la no linealidad del hormigón, tanto para hormigón convencional como de alta resistencia. 
- Los parámetros que presentan mayor influencia en los resultados de la longitud de rótula plástica $\left(L_{p}\right)$ son la esbeltez de cortante, el nivel de carga axial y la cuantía de armadura longitudinal. Los resultados experimentales han demostrado que la $L_{p}$ medida en elementos con esbeltez de cortante 7.5 , se encuentra en un rango de $0.5 \mathrm{~h}$ a $1.0 \mathrm{~h}$, independientemente del nivel de carga axial. Sin embargo, en elementos con mayor esbeltez $(\lambda=10.5)$, la $L_{p}$ depende del nivel de carga axial y la cuantía de armadura longitudinal. En los soportes con $\lambda=10.5$, por un lado, si el nivel de carga axial es superior a 0.15 , la $L_{p}$ aumenta considerablemente entre $1.5 \mathrm{~h}$ y $3 \mathrm{~h}$. Pero, por otro lado, si el nivel de carga axial está alrededor de 0.15 , los elementos con cuantías de armadura de $1.4 \%$ y $2.2 \%$ desarrollan una $L_{p}$ de entre $0.5 \mathrm{~h}$ y $1.0 \mathrm{~h}$; y si la cuantía es de $3.2 \%$, la $L_{p}$ experimenta un incremento de hasta $1.8 \mathrm{~h}$. La resistencia del hormigón y la cuantía de armadura de confinamiento no muestran efectos claros en la longitud de rótula plástica medida experimentalmente.

- Los resultados experimentales de la longitud de rótula plástica $\left(L_{p}\right)$ y las expresiones teóricas (Pristley y Park (1987) [110], Eurocódigo 8 (2004) [59], Panagiotakos y Fardis (2001) [100], Fardis y Biskinis (2003) [60], Bae (2005) [12], Ceroni et al. (2003) [36]), coinciden en el hecho de que el principal parámetro que afecta a la $L_{p}$ es la esbeltez de cortante. Sin embargo, todas las expresiones subestiman los valores de $L_{p}$ para elementos con esbeltez de 10.5 y altos niveles de carga axial (mayores que 0.15). Por consiguiente, se concluye que, para valores de esbeltez superiores al rango en el que se han concentrado los estudios experimentales y teóricos $(\lambda \leq 6)$, la $L_{p}$ depende especialmente de los efectos de segundo orden. Aunque esto ya ha sido sugerido por Bae (2005) [12], no existe suficiente evidencia al respecto, por lo que convendría una mayor comprobación experimental para elementos con $\lambda>7.5$.

- Los resultados experimentales de ductilidad en desplazamientos y curvatura se compararon con los requisitos establecidos en las normas (NCSE-02 [97], y Eurocódigo 8 (2004) [59]). Para llevar a cabo dicha comparación, hay que tener en cuenta que los soportes ensayados fueron clasificados en las normas como elementos estructurales tipo 3, ya que, de acuerdo con las condiciones del ensayo, los soportes representan la situación de un soporte típico de edificación. Además, si se tiene en cuenta que la norma NCSE-02 ha adoptado las condiciones de ductilidad moderada (DCM) especificadas en el Eurocódigo 8 para soportes de edificación, entonces se establece que los factores de ductilidad en desplazamientos y en curvaturas requeridos son mayores que 2 y 3 , respectivamente. Los resultados muestran que la mayoría de los soportes ensayados cumplen con estos requerimientos. Sin embargo, se ha detectado que soportes de alta resistencia con esbeltez de 10.5 en los que los niveles de carga axil son superiores a 0.3 , difícilmente desarrollan un comportamiento dúctil satisfactorio. Por tanto, es recomendable sugerir algunas limitaciones del nivel de carga axil en soportes esbeltos de hormigón de alta resistencia. 
- El parámetro con mayor influencia en la rigidez elástica efectiva $\left(E I_{e}\right)$ es el nivel de carga axial, de modo que, cuando este último aumenta, la rigidez $\mathrm{El}_{\mathrm{e}}$ se incrementa. Para bajos niveles de carga axial, la rigidez elástica no depende de la resistencia del hormigón, mientras que para altos niveles de carga axial, $\mathrm{El}_{\mathrm{e}}$ se incrementa con el aumento de la resistencia del hormigón. Por otra parte, la rigidez $\mathrm{El}_{\mathrm{e}}$ no se ve claramente afectada por la esbeltez de cortante y tampoco depende de las cuantías de armadura longitudinal y transversal.

- En la comparación entre los resultados experimentales de la rigidez elástica efectiva y los valores calculados mediante los métodos de Kuntia y Ghosh (2004) [70] y Panagiotakos y Fardis (2001) [100], se encontró que este último método predice la rigidez efectiva con una buena aproximación, especialmente si el punto de plastificación se define cuando el hormigón en la fibra extrema alcanza el $0.9 \varepsilon_{\mathrm{co}}$, tal y como se consideró originalmente al plantear el método. La aproximación es algo menor, pero también aceptable, para el método de Panagiotakos y Fardis cuando el criterio de plastificación del hormigón es $0.75 \varepsilon_{\mathrm{co}}$. Por otra parte, el método simple propuesto por Kuntia y Ghosh, aunque es ligeramente más impreciso (mayor dispersión de los resultados), también permite evaluar la rigidez efectiva con una aceptable aproximación a los resultados experimentales, especialmente si el criterio de punto de plastificación se define en el 0.75 del momento máximo, en la curva de respuesta momento-curvatura.

- En al análisis de los resultados experimentales de la capacidad de deformación de la sección y del elemento, para los estados elástico y último, se ha demostrado que los 5 parámetros incluidos en el estudio (nivel de carga axial, esbeltez de cortante, resistencia del hormigón, cuantía de armadura longitudinal y cuantía de armadura transversal) afectan de algún modo a las variables analizadas (curvaturas elástica y última, desplazamientos elástico y último, y ductilidad en curvaturas y en desplazamientos). Sin embargo, no se dispone de un importante número de ensayos para interpretar cada uno de los parámetros, y su interacción con los demás. Por consiguiente, para realizar un estudio más exhaustivo del efecto de cada uno de las variables, resulta necesario realizar una simulación numérica.

\section{Respecto a la simulación numérica de soportes}

- Se ha calibrado un modelo numérico utilizando el programa "ATENA 2D" de análisis no lineal, capaz de reproducir la respuesta carga-flecha de soportes de hormigón sometidos a compresión y flexión monotónica. Esto ha permitido llevar a cabo un amplio estudio paramétrico de los factores que más influyen en la capacidad de deformación de soportes esbeltos de hormigón convencional y de alta resistencia. En la calibración se han utilizado los resultados de la curva de respuesta carga-flecha de 40 de los ensayos experimentales realizados en este estudio. La comparación entre los resultados experimentales y los obtenidos en la simulación numérica muestra que los ensayos numéricos en "ATENA 2D" sobrestiman los valores de carga y desplazamiento en el punto máximo en un $3.8 \%$ y un $2.6 \%$, respectivamente, mientras que, para el estado último, la 
sobrestimación de la carga y el desplazamiento es del $4.0 \%$ y $5.3 \%$ respectivamente. Estos valores son bajos y, por consiguiente, se considera que el modelo numérico es acertado y puede ser implementado para llevar a cabo el estudio paramétrico.

\section{Respecto al estudio paramétrico}

A partir del estudio paramétrico, se ha analizado la influencia de los siguientes parámetros en el comportamiento deformacional de soportes esbeltos de hormigón armado sometidos a flexo-compresión: nivel de carga axial, esbeltez de cortante, resistencia del hormigón, cuantía de armadura longitudinal y cuantía de armadura transversal. La capacidad de deformación del elemento se evalúa en términos del desplazamiento elástico, desplazamiento último, y ductilidad en desplazamientos. Las conclusiones obtenidas a partir de este análisis son las siguientes:

- El nivel de carga axial y la esbeltez de cortante son los parámetros que más influyen en la capacidad de deformación a nivel del elemento. El desplazamiento elástico efectivo y último disminuyen cuando aumenta el nivel de carga axial, para todos los rangos de esbeltez estudiados. Sin embargo, respecto a la ductilidad en desplazamientos, por una parte, el efecto de la esbeltez disminuye conforme aumenta el nivel de carga axial, hasta que, en elementos altamente comprimidos $\left(\mathrm{N} / \mathrm{N}_{\mathrm{u}}=0.6\right)$, el efecto de la esbeltez es prácticamente despreciable. Por otra parte, si la esbeltez es mayor que 7.5, el efecto del nivel de carga axil es variable: en elementos con bajos niveles de carga axial, la ductilidad aumenta hasta un punto de inflexión, a partir del cual la ductilidad en desplazamientos disminuye con el aumento del nivel de carga axial.

- El efecto de la cuantía de armadura longitudinal $\left(\rho_{\mathrm{I}}\right)$ depende de la interacción con otros parámetros, como son la esbeltez de cortante y los niveles de carga axial. En el desplazamiento elástico, la $\rho_{1}$ influye sólo cuando el nivel de carga axial es bajo. En el desplazamiento último, el efecto de la $\rho_{l}$ es notable para valores altos de esbeltez $(\lambda=10.5)$ : el incremento de la $\rho_{\text {I }}$ provoca un aumento en el desplazamiento último, y el efecto disminuye a medida que aumenta el nivel de carga axial. En elementos poco esbeltos, el desplazamiento último permanece indiferente respecto al incremento de la $\rho_{\text {. }}$. En la ductilidad en desplazamientos, para elementos poco esbeltos $(\lambda=3.5)$, la ductilidad disminuye con el aumento de la cuantía de armadura longitudinal. Pero, a medida que aumenta el nivel de carga axial y la resistencia del hormigón, la tendencia va disminuyendo hasta mostrarse indiferente. Por otra parte, en elementos con altos valores de esbeltez $(\lambda$ $\geq 7.5$ ), el aumento de la cuantía de armadura longitudinal provoca un ligero incremento de la ductilidad de desplazamiento, para todos los rangos estudiados de nivel de carga axial y de resistencia del hormigón.

- La resistencia del hormigón influye ligeramente en el desplazamiento elástico, pero su efecto es tan pequeño que puede despreciarse. Por otra parte, la capacidad de desplazamiento último disminuye con el aumento de la resistencia del hormigón. En consecuencia, la ductilidad en desplazamientos también disminuye conforme aumenta la resistencia del hormigón. 
- La cuantía de armadura transversal no influye en el estado elástico. Sin embargo, el desplazamiento último aumenta con el incremento de la cuantía de armadura transversal, especialmente en elementos con hormigón con $f_{c}=30 \mathrm{MPa}$, aunque en elementos con $\mathrm{f}_{\mathrm{c}}=90 \mathrm{MPa}$ este efecto no es destacable. Por consiguiente, el incremento de la cuantía de armadura transversal para conseguir un mejor comportamiento dúctil en elementos de hormigón es más efectivo en hormigón de $f_{c}=30 \mathrm{MPa}$ que en hormigón de $\mathrm{f}_{\mathrm{c}}=90 \mathrm{MPa}$.

\section{Respecto a la comparación de métodos de evaluación de la capacidad de deformación}

- En este estudio se ha llevado a cabo una revisión y comparación de los métodos existentes, tanto empíricos como analíticos, utilizados para la evaluación de la capacidad de deformación de elementos de hormigón armado, en términos de la deriva última $\left(\theta_{\mathrm{u}}=\delta_{\mathrm{u}} / \mathrm{L}_{\mathrm{s}}\right)$. Los métodos se han comparado con los resultados de los ensayos experimentales realizados en este estudio y con los resultados del estudio paramétrico desarrollado mediante un programa de simulaciones numéricas utilizando el programa de análisis no lineal "ATENA 2D".

- Los métodos empíricos, que permiten una evaluación directa de la deriva última $\left(\theta_{\mathrm{u}}\right)$, presentan una respuesta bastante diferente con respecto a los métodos analíticos basados en la longitud de la rótula plástica. Los resultados obtenidos con métodos empíricos son menos aproximados que los obtenidos mediante métodos analíticos, lo cual se ha demostrado al comparar los valores calculados de deriva última con los valores experimentales y con los resultados de la simulación numérica. En general, se ha demostrado que, para todo el rango de parámetros considerados en este estudio, los métodos empíricos sobrestiman los valores de $\theta_{u}, y$, por consiguiente, resultan inseguros a la hora de predecir la capacidad última en elementos de hormigón armado sometidos a compresión y flexión monotónica.

- En el análisis también se demostró que los métodos analíticos pueden presentar dificultades en la interpretación de los efectos del confinamiento. Por un lado, cuando estos métodos se han comparado con resultados ya sea experimentales $o$ de simulaciones numéricas para elementos de hormigón armado poco confinados $\left(\rho_{s} \leq 1\right)$, la deriva última calculada es subestimada, mientras que, por otro lado, cuando se incrementa la cuantía de confinamiento $\left(\rho_{s}>1\right)$, los métodos muestran fluctuaciones en el comportamiento y los valores calculados de $\theta_{u}$ incluso pueden llegar a ser sobrestimados.

- En definitiva, los dos tipos de métodos (empíricos y analíticos) se consideran imprecisos. Además, presentan notables diferencias en la interpretación de la influencia de los distintos parámetros cuando se comparan con los resultados de las simulaciones numéricas de ATENA 2D, incluso para el rango de parámetros en que dichos métodos fueron calibrados. Las diferencias aumentan cuando se amplían los rangos de 
algunos parámetros, como la esbeltez de cortante, el nivel de carga axial, la resistencia del hormigón y las cuantías de armadura longitudinal y transversal.

- Por lo tanto, se justifica la necesidad de seguir desarrollando métodos simplificados para estimar la capacidad de deformación última en elementos de hormigón armado sometidos a flexo-compresión. Dichos métodos deben, por una parte, cubrir un amplio rango de parámetros, incluso ser válidos en rangos a los que, hasta ahora, los métodos existentes no pueden ser aplicados con fiabilidad, y, por otra parte, deben ser sencillos en su implementación.

\section{Respecto a la propuesta de modelos para la evaluación de la capacidad de deformación}

- En este estudio se han desarrollado dos tipos de métodos para evaluar la capacidad de deformación de elementos de hormigón armado sometidos a flexo-compresión. Mediante estos métodos, es posible predecir las siguientes variables: el desplazamiento elástico efectivo, la rigidez elástica efectiva, el desplazamiento último y la rigidez secante última $y$, consecuentemente, también la ductilidad en desplazamientos. Los métodos se han desarrollado en base al comportamiento obtenido de un estudio paramétrico llevado a cabo mediante la simulación numérica de soportes esbeltos de hormigón. El fundamento teórico para el desarrollo de los métodos ha sido la teoría general de la flexión. Por consiguiente, la variable a partir de la cual se ha realizado el análisis es la rigidez (EI), tanto para el estado elástico como para el estado último.

- Se han realizado dos propuestas de la rigidez $\mathrm{El}\left(\mathrm{El}_{\mathrm{e}} \mathrm{O} \mathrm{El}_{\mathrm{u}}\right)$, en función de si se conoce o no la cuantía y distribución de armaduras.

- Debido a la importancia de los efectos de segundo orden en el comportamiento deformacional de soportes esbeltos de hormigón armado, los métodos simplificados propuestos tienen en cuenta dichos efectos mediante un factor de amplificación, para obtener el desplazamiento último y la ductilidad de desplazamiento.

- El método propuesto ha mostrado una buena aproximación, tanto para la verificación con los resultados de las simulaciones numéricas como con los resultados experimentales llevados a cabo en este estudio. Estos métodos pueden ser aplicados a un amplio rango de parámetros, como niveles de carga axil de entre 0 y 0.6 , esbeltez de cortante de hasta 10.5, cuantía de armadura longitudinal de hasta un $4 \%$, cuantía de confinamiento de hasta un $4 \%$ y resistencia del hormigón de hasta $90 \mathrm{MPa}$. 


\subsection{FUTURAS LÍNEAS DE INVESTIGACIÓN}

A partir del trabajo llevado a cabo en la presente tesis doctoral se ha abierto una nueva línea de investigación dentro del Instituto de Ciencia y tecnología del Hormigón "ICITECH" de la Universidad Politécnica de Valencia, respecto al estudio de la capacidad de deformación de elementos de hormigón. Para continuar desarrollando esta línea de investigación se plantean los siguientes aspectos que pueden ser tratados en estudios posteriores.

1. En este estudio se ha demostrado que los métodos existentes, en la bibliografía y en las actuales normas, para evaluar la capacidad de deformación de elementos de hormigón sometidos a compresión y flexión monotónica o cíclica, no son válidos para cierto rango de parámetros, como son los soportes esbeltos $(\lambda>6)$, con moderados y altos niveles de carga axial, en los cuales los efectos de segundo orden no pueden ser despreciados. En el presente estudio se hace una propuesta de dichos métodos aplicados a soportes esbeltos sometidos a compresión y flexión monotónica. Por consiguiente, es conveniente también llevar a cabo un estudio centrado en elementos sometidos a compresión y flexión cíclica, con el propósito de estudiar su comportamiento deformacional y proponer nuevos métodos aplicados a soportes esbeltos. Dicho estudio también podría ser extensivo a otro tipo de materiales que carecen de comprobación experimental, como por ejemplo el hormigón con fibras.

2. Otra propuesta derivada de este trabajo es el estudio del comportamiento estructural en uniones prefabricadas, ya que en el estado del conocimiento se ha comprobado que la mayoría de los estudios se centran en el análisis del comportamiento deformacional para uniones realizadas "in situ", de modo que existe un vacio experimental, de modelos analíticos y de normativa, respecto al comportamiento de la conexión entre soportes prefabricados y la cimentación. Por consiguiente, se debería llevar a cabo un estudio teórico-experimental de este tipo de conexiones sometidas a compresión y flexión cíclica, con el objetivo de llegar a proponer modelos simplificados para predecir la capacidad de deformación en este tipo de uniones.

3. Debería llevarse a cabo un estudio experimental del detalle de los cercos en la armadura transversal, ya que, en este estudio, se ha observado que el efecto del confinamiento no ha sido tan efectivo como se describe en otros estudios (Razvi y Saatcioglu (1994, 2002 y 1992) [113][114][115], Cusson y Paultre (1994, 1995 y 1996) [46],[47][48], Sheikh y Uzumeri (1982, 1980) [119][120], Tanaka et al (1990) [125]). En los soportes ensayados en este estudio, la armadura transversal se ha dispuesto conforme a los detalles de armado típicamente utilizados en España (cercos cerrados a $90^{\circ}$ ). Sin embargo, algunas normas, como el ACl-318-08, especifican claramente que el cierre de los cercos debe realizarse doblando las barras a $135^{\circ}$; otras normas, como el Eurocódigo2, BS 8110, EHE 08, no hacen referencia al tipo de doblado en el cierre del cerco de la armadura transversal. En consecuencia, los cercos cerrados a $90^{\circ}$ aún siguen siendo usados ampliamente en zonas de bajo y moderado riesgo sísmico en todo el 
mundo, debido a su facilidad en la colocación comparada con el cierre a $135^{\circ}$. Por consiguiente, se debería evaluar la capacidad de deformación para los dos tipos de configuraciones en el cierre del cerco, con los siguientes propósitos. En primer lugar, para determinar si este detalle tiene una influencia significativa en el comportamiento deformacional; en segundo lugar, para determinar si el efecto de confinamiento garantiza un aumento de la ductilidad en soportes esbeltos; y, en tercer lugar, para evaluar la pérdida de capacidad de deformación relacionada con el uso de cercos cerrados a $90^{\circ}$.

4. Adicionalmente, existe un amplio estudio experimental de soportes de hormigón confinado que puede encontrarse en diferentes publicaciones (Park et al. (1982) [102]; Watson y Park (1994) [133]; Tanaka y Park (1990) [125]; Zahn, et al. (1986) [138]; Sheikh y Khoury (1993) [121]; Bayrak y Sheikh $(1997,1998)$ [18][16]). El principal objetivo de estos estudios experimentales fue evaluar el comportamiento de soportes diseñados de acuerdo con las recomendaciones de normas aplicables en zonas de alto riesgo sísmico. Algunos de estos trabajos han dedicado gran parte de su investigación al estudio específico de la configuración de la armadura transversal según las indicaciones de dichas normas. El presente estudio se ha centrado en un tipo especifico de configuración de armado transversal, por lo que convendría comprobar la validez de los modelos propuestos mediante ensayos en soportes con diferentes configuraciones.

5. Otra de las líneas de investigación que se plantean, a partir de este estudio, es el desarrollo y propuesta de modelos de pandeo de la armadura para su incorporación en programas de análisis no lineal concebidos para la simulación numérica del comportamiento estructural de elementos de hormigón. Dicha propuesta se basa en el hecho, de que, durante la experimentación, el efecto del pandeo de la armadura se observó especialmente en soportes con niveles de carga axial cercanos al $45 \%$, y poco confinados, es decir, en los que había una mayor separación de cercos $(10 \mathrm{~cm})$. Precisamente, estos soportes coinciden con los que mayor error presentan en la calibración del modelo numérico. Esto se debe a que, en los ensayos experimentales, el pandeo de la armadura provoca una rotura súbita del soporte, mientras que, en la simulación numérica, este efecto no es considerado, y el fallo sólo se produce con la rotura de hormigón en la capa de recubrimiento de compresión, y, en consecuencia, los resultados de carga y desplazamiento son superiores a los resultados experimentales.

6. Sería asimismo interesante realizar un estudio teórico experimental de soportes fabricados con hormigón reforzados con fibras de acero sometidos a cargas laterales cíclicas. Las fibras de acero pueden servir para sustituir la armadura transversal y mejorar la fabricación de soportes sometidos a niveles altos de axil, en donde las normas de diseño requieren de una gran cuantía de armadura transversal con el objeto de asegurar un determinado nivel de ductilidad requerida. 


\section{REFERENCIAS BIBLIOGRÁFICAS}

[1] $\quad \mathrm{ACl}$ Committee 318-08; Building Code Requeriments for Reinforced concrete and Commentary; American Concrete Institute; Detroit: 2008.

[2] ACl Committee 363R-92; State of the art on high strength concrete (Reported by ACl committee 363); American Concrete Institute; Detroit 1992, Reapproved 1997.

[3] Almeida Bernardo L. F.; "Torção em Vigas em Caixão de Betão de Alta Resistencia"; Departamento de Engenharia Civil, Faculdade de Ciências e Tecnología; Universidade da Coimbra, 2003.

[4] Almeida Bernardo, L. F.; "Ductilidade e Capacidade de Rotação em vigas de Betão de Alta Resistencia"; Trabalho aptresentado no ambito das provas de Aptidao Pedagógica e Capacidade Científica em cumprimento do n. ${ }^{\circ} 1$ do Artigo $58^{\circ}$ da lei n. ${ }^{\circ} 19 / 80$ do Estatuto da carreira Docente Universitaria. Departamento de Engenharia Civil, Universidade da Beira Interior; 1998.

[5] Ang, B. G., Priestley, M. J. N. y Park, R.; "Ductility of reinforced concrete bridge piers under seismic loading"; Department of Civil Engineering Research Report 81-3; University of Canterbury; Christchurch: 1981.

[6] Bae, S. y Bayrak, O.; "Drift capacity of reinforced concrete columns"; ACI Structural Journal, 106(4); 2009: 405-415.

[7] Bae, S. y Bayrak, O.; "Performance-based design of confining reinforcement: research and seismic design provisions"; American Concrete Institute (SP-238-3); 2006: 43-62.

[8] Bae, S. y Bayrak, O.; "Plastic hinge length of reinforced concrete columns"; ACI Structural Journal, 105(3); 2008: 290-300.

[9] Bae, S. y Bayrak, O.; "Seismic performance of full-scale reinforced concrete columns"; ACI Structural Journal, 105(2); 2008: 123-133.

[10] Bae, S. y Bayrak, O.; "Seismic performance of reinforced concrete columns: P- $\Delta$ effect”; American Concrete Institute (SP-236-4); 2006: 61-80.

[11] Bae, S. y Bayrak, O.; "Stress block parameters for high strength concrete members"; ACI Structural Journal, 100(5); 2003: 626-636.

[12] Bae, S.; "Seismic performance of full-scale reinforced concrete columns"; Tesis Doctoral; The University of Texas at Austin; diciembre de 2005.

[13] Bai, Z. Z. y Au, F. T. K.; "Ductility of symmetrically reinforced concrete columns"; Magazine of Concrete Research, 61(5); 2009: 345-357.

[14] Baker, A. L. L. y Amarakone, A. M. N.; "Inelastic Hyperstatic Frames Analysis"; Proceedings of the International Symposium on the Flexural Mechanics of Reinforced Concrete, ASCE - ACl; Miami; 1964: 85-142.

[15] Baker, A. L. L.; "Ultimate Load Theory Appied to the Design on Reinforced and Prestressed Concrete Frames"; Concrete Publications Ltd.;London UK; 1956: 1-99. 
[16] Bayrak, O. y Sheikh, S. A.; "Confinement reinforcement design considerations for ductile HSC columns"; Journal of Structural Engineering, 124(9); 1998: 999-1010.

[17] Bayrak, O. y Sheikh, S. A.; "Design of rectangular HSC columns for ductility"; American Concrete Institute (SP-213-4); 2003: 61-82.

[18] Bayrak, O. y Sheikh, S. A.; "High-strength concrete columns under simulated earthquake loading"; ACI Structural Journal, 94(6); 1997: 708-722.

[19] Bayrak, O. y Sheikh, S. A.; "Plastic Hinge Analysis"; Journal of Structural Engineering, 127(9); 2001: 1092-1100.

[20] Bayrak, O. y Sheikh, S. A.; "Response Predictions by Plastic Hinge Analysis Technique" -web-

[21] Bayrak, O.; "Seismic Performance of rectilinearly confined high strength concrete columns"; Tesis Doctoral; University of Toronto; Ontario: 1998.

[22] Beeby, A. W.;"Ductility in reinforced concrete: why is it needed and how is it achieved?"; Structural Engineer 75 (18); 1997:311-318.

[23] Bendito Torija, M. A,; "Estudio numérico de la longitud de pandeo inelástica de soportes de hormigón armado intraslacionales"; Tesis Doctoral; Universidad Jaume I de Castellón; Castellón: 2006.

[24] Berry, M.P., Parrish, M. y Eberhard, M.O.; "PEER Structural Performance Database User's Manual"; Pacific Earthquake Engineering Research Center Report; Universidad de California, Berkeley, 2004.

[25] Bigaj, A. J.; "Structural Dependence of Rotation Capacity of Plastic Hinges in RC Beams and Slabs"; Tesis Doctoral; Delft University of Technology, Delft University Press: 1999.

[26] Bonet Senach, J. L.; "Método simplificado de cálculo de soportes esbeltos de hormigón armado de sección rectangular sometidos a compresión y flexión biaxial"; Tesis Doctoral; Universidad Politécnica de Valencia; Valencia: 2001.

[27] Bosco, C. A., Debernardi, P.G.; "Experimental Investigation on the Ultimate Rotational Capacity of R.C. Beams", Atti del Dipartimento di Ingegneria Strutturale, Politecnico di Torino, N 36, 1992.

[28] Burnett, E. F. P. y Trenberth, R. J.; "Column Load Influence on Reinforced concrete Beam - Column Connection"; $\mathrm{ACl}$ Journal Proceedings, 69(2); 1972: 101-109.

[29] Burns, N. H., Siess, C. P.;" Load deformation characteristics of beamcolumn connections in reinforced concrete"; Civil Engineering studies, Structural research series $n^{\circ} 234$, University of Illinois at UrbanaChampaign, 1962.

[30] CEB; "Ductility of Reinforced Concrete Structures"; Synthesis Report and Individual Contributions; Comité Euro-Intenational du Béton (CEB); Bulletin D'Information $n^{\circ} 242$; Lausanne: 1998.

[31] CEB; "Ductility Requirements for Structural Concrete - Reinforcement"; Progress report of Task Group 2.2; Comité Euro-International du Béton (CEB); Bulletin D’Information $n^{\circ} 218$; Lausanne: 1993.

[32] CEB; "Non-linear Analysis"; Discussion Papers from the Working Party on "Non-Linear Desing Methods and Safety Concept"; Bulletin D'Information $n^{\circ} 239$, in CEB Commission 1; Comité Euro-Intenational du Béton (CEB); Lausanne: 1993. 
[33] CEB-FIP 1990, Código Modelo para hormigón estructural; Recomendaciones y Manuales Técnicos; Estructuras y Edificación (E4). Madrid, 1995.

[34] CEB-FIP Bulletin 24; "State of art report (Seismic assessment and retrofit of reinforced concrete buildings)"; Tark Group 7.1; LausanneSwitzerland, 2003.

[35] CEB-FIP Bulletin 25; "State of art report (Displacement -based seismic design of reinforced concrete buildings)"; Tark Group 7.2, LausanneSwitzerland ,2003.

[36] Ceroni, F., Manfredi, G. y Pecce, M.; "A Formulation of Plastic Hinge Length in R.C. Columns"; FIB Symposium "Concrete Structures in Seismic Regions"; Atenas; 6-9 mayo 2003.

[37] Ceroni, F., Pecce, M. R., Di Sarno, L. y Manfredi, G. "Evaluation of inelastic deformation capacity of r.c. columns", en Chiorino, M. A. y Nanni, A. (eds.); Seismic Engineering for Concrete Structures: Italian Perspective. Proceedings of the ACl Spring Convention, New York City, April 2005; Salerno: CUES; 2006: 177-188.

[38] Červenka V. y Červenka J.; "ATENA Program Documentation :Theory”; Praga, 2005.

[39] Červenka V. y Červenka J.; "ATENA Program Documentation :User's Manual for ATENA 2D"; Praga, 2003.

[40] Chan, W. W. L.; "An Investigation of the Characteristics of Plastic Hinges in Reinforced Concrete"; PhD thesis; London University; 1954: 1-136.

[41] Chan, W. W. L.; "The ultimate strength and deformation of hinges in reinforced concrete frameworks"; Magazine of concrete research, 7(21); 1955: 121-132.

[42] Chien-Hung Lin y Feng-Sheng Lee; "Ductility of High-Performance Concrete Beams with High-Strength Lateral Reinforced"; ACI Structural Journal, 98(4); 2001: 600-609.

[43] Code for Design of Concrete Structures for Buildings (CAN3-A23.3M94); Canadian Standards Association; Rexdale, Ontario, 1994.

[44] Code of Practice for the Design of Concrete Structures, (NZS 3101: 1982); Standards Association of New Zealand; Wellington, 1982.

[45] Corley, W. G.; "Rotational Capacity of Reinforced Concrete Beams"; Journal of The Structural Division, Proceedings of the ASCE; 1966: 121-146.

[46] Cusson, D. y Paultre, P.; "High-strength concrete columns confined by rectangular ties"; Journal of Structural Engineering, ASCE, 120(3); 1994: 783-804.

[47] Cusson, D. y Paultre, P.; "Stress-strain model for confined highstrength concrete"; Journal of Structural Engineering, ASCE, 121(3); 1995: 468-477.

[48] Cusson, D., De Larrard, F., Boulay, C. y Paultre, P.; "Strain localization in confined high-strength concrete columns"; Journal of Structural Engineering, ASCE, 122(9); 1996: 1365-1381.

[49] Dhakal, R. P. y Fenwick, R. C.; "Detailing of plastic hinges in seismic design of concrete structures"; ACI Structural Journal, 105(6); 2008: 740-749. 
[50] Dimova, S.L. y Negro, P.; "Seismic assessment of an industrial frame structure designed according to Eurocodes. Part 1: Experimental tests and their numerical simulation"; Engineering Structures, 27(5), 2005: 709-723.

[51] Dimova, S.L. y Negro, P.; "Seismic assessment of an industrial frame structure designed according to Eurocodes. Part 2: Capacity and vulnerability"; Engineering Structures, 27(5), 2005: 724-735.

[52] EHE, Instrucción de Hormigón Estructural, Comisión Permanente del Hormigón; edición, Ministerio de Fomento, Gobierno de España; Madrid, 1998.

[53] EHE-08, Instrucción de Hormigón Estructural; Comisión Permanente del Hormigón; edición, Ministerio de Fomento, Gobierno de España; Madrid 2008.

[54] Eligehausen, R. y Langer, P.; "Rotation capacity of plastic hinges and allowable degree of moment redistribution"; CEB Bulletin d'Information $\mathrm{n}^{\circ}$ 175; Comité Euro-International du Béton; Lausanne; 1987: pp I.7.9I.7.41.

[55] Eligehausen, R. y Li, L.; "Rotation Capacity of Prestressed Concrete Members"; Proceedings of the International Conference "Bond Concrete". Volumen 1; Riga: 1992.

[56] Elwood, K. J. y Eberhard, M. O.; "Effective stiffness of reinforced concrete columns"; ACI Structural Journal, 106(4), 2009: 476-484.

[57] Ernest, G. C.; "Plastic Hinging at the intersection of Beams and columns"; Journal Proceedings of the American Concrete Institute, 53(6); 1957: 1119-1144.

[58] Eurocode 2: Desing of concrete structures-Part 1-1: General rules and rules for buildings. European Committee for Standarization, EN 19921-1:2004(E). Brussels, 2004.

[59] European Standard, Eurocode 8: Design of structures for earthquake resistance, EN 1998-1/2/3:2004, European Committee for Standarization. Brussels, 2004.

[60] Fardis M.N., Biskinis D.E.; "Deformation capacity of RC members, as controlled by flexure or shear"; Proceedings of the International Symposium Honoring Shunsuke Otani; Tokyo, 2003: 511530.

[61] Fischinger, M., Kramar, M. y Isaković, T.; "Cyclic response of slender RC columns typical of precast industrial buildings"; Bulletin of Earthquake Engineering, 6(3), 2008: 519-534.

[62] Flexural Mechanics of Reinforced concrete. Proceedings of the international Symposium Miami, Florida, November 10-12, 1964.

[63] Ghosh, S. K. y Cohn, M. Z.; "Ductility of reinforced Concrete Sections in Combined Bending and Axial Load"; Inelasticity and Non-Linearity in Structural Concrete; University of Waterloo Press; Waterloo, Ontario; 1972: pp. 147-180.

[64] Gill, W. D., Park, R. y Priestley, M. J. N.; "Ductility of Spirally Reinforced Concrete Columns with Axial Loads"; Department of Civil Engineering Research Report 79-1; University of Canterbury; Canterbury: 1979.

[65] Hillerborg, A.; "Fracture mechanics and the concrete codes"; Fracture mechanichs: aplications to concrete; ACI-SP 118; 1989: 157-170. 
[66] Ho, J. C. M. y Pam, H. J.; "Flexural strength and ductility performance of high-strength reinforced concrete columns"; The Structural Engineer, 80(23), 2002: 26-34.

[67] Inel, M., Aschheim, M. A. y Pantazopoulou, S. J.; "Seismic deformation capacity indices for concrete columns: model estimates and experimental results"; Magazine of Concrete Research, 59(4); 2007: 297-310.

[68] Inel, M.; "Modelling ultimate deformation capacity of RC columns using artificial neural networks"; Engineering Structures, 29(3), 2007: 329335.

[69] Jendele, L. y Cervenka, J.; "Finite element modelling of reinforcement with bond", Computers \& Structures, 84(28), 2006: 1780-1791.

[70] Khuntia, M. y Ghosh, S. K.; "Flexural stiffness of reinforced concrete columns and beams: analytical approach"; ACI Structural Journal, 101(3), 2004: 351-363.

[71] Khuntia, M. y Ghosh, S. K.; "Flexural stiffness of reinforced concrete columns and beams: experimental verification"; ACI Structural Journal, 101(3); 2004: 364-374.

[72] Kim, J.K., Yoo, S.H., Han, B. S. y Shin, S.W.; "Ductility of ultra highstrength concrete tied columns under combined axial load and lateral force"; Key Engineering Materials, Vols. 348-349, 2007: 609-612.

[73] Ko, M.Y., Kim, S.W., Kim, J.K.;"Experimental study on the plastic rotation capacity of reinforced high strength concrete beams";. Materials and Structures 34, 2001,302-311.

[74] Kwak, H-G. y Kim, S-P.; "Simplified monotonic moment-curvature relation considering fixed-end rotation and axial force effect"; Engineering structures, 32(1), 2010: 69-79.

[75] Lam, J. Y. K., Ho, J. C. M. y Kwan, A. K. H.; "Flexural ductility of highstrength concrete columns with minimal confinement"; Materials and Structures, 42(7); 2009: 909-921.

[76] Lam, J. Y. K., Ho, J. C. M. y Kwan, A. K. H.; "Maximum axial load level and minimum confinement for limited ductility design of high-strength concrete columns"; Computers and Concrete, 6(5); 2009: 357-376.

[77] Lam, S. S. E., Wu, B., Wong, Y. L., Wang, Z. Y., Liu, Z. Q. y Li, C. S.; "Drift capacity of rectangular reinforced concrete columns with low lateral confinement and high-axial load"; Journal of Structural Engineering, 129(6); 2003: 733-742.

[78] Légeron, F. y Paultre, P.; "Behavior of high strength concrete columns under cyclic flexure and constant axial load"; ACI Structural Journal, 97(4); 2000: 591-601.

[79] Légeron, F. y Paultre, P.; "Uniaxial confinement model for normal and high strength concrete columns"; Journal of Structural Engineering, 129(2); 2003: 241-252.

[80] Lehman D.E., Moehle J.P.;"Seismic performance of well-confined concrete bridge columns"; PEER Report 1998/01; Pacific earthqueke engineering research center; College of Engineering University of California; Berkeley, 2000.

[81] Lehman, D. E.; "Performance-based seismic design of well confined concrete columns"; Ph.D. thesis, Univ. of Calif., Berkeley; 1998. 
[82] Lukkunaprasit, P. y Sittipunt, C.; "Ductility enhancement of moderately confined concrete tied columns with hook-clips"; ACl Structural Journal, 100(4); 2003: 422-429.

[83] Mander, J. B., Priestley, M. J. N. y Park, R.; "Observed stress-strain behavior of confined concrete"; Journal of Structural Engineering, 114(8); 1988: 1827-1849.

[84] Mander, J. B., Priestley, M. J. N. y Park, R.; "Seismic design of bridge piers"; Research Report $n^{\circ}$ 84-2; Department of Civil Engineering; University of Canterbury; Christchurch: 1984.

[85] Mander, J. B., Priestley, M. J. N. y Park, R.; "Theoretical stress-strain model for confined concrete", Journal of Structural Engineering, 114(8); 1988: 1804-1826.

[86] Matamoros, A. B. y Sozen, M. A.; "Drift limits of high-strength concrete columns subjected to load reversals"; $\mathrm{ACl}$ Journal of Structural Engineering, 129(3); 2003: 297-313.

[87] Mattock, A. H.; "Rotational Capacity of Hinging Regions in Reinforced Concrete Beams"; Proceedings of the International Symposium on the Flexural Mechanics of Reinforced Concrete; ASCE - ACl Special Publication 12; Miami; 1965: 143-181.

[88] Mattock, A. H.; "Secondary Moments and Moment Redistribution in $\mathrm{ACl}$ 318-77 Code"; Proceedings of the International Symposium Nonlinearity and Continuity in Prestressed Concrete; University of Waterloo, Ontario; 1983: 27-48.

[89] Mattock, A. H.; Discussion of "Rotation capcity of reinforced concrete beams " by W.G. Corley; Journal of Structural Division, ASCE. 93 (ST2);1967, 519-522.

[90] Mehanny, S. S. F., Kuramoto, H. y Deierlein, G. G.; "Stiffness modelling of reinforced concrete beam-columns for frame analysis"; ACI Structural Journal, 98(2), 2001: 215-225.

[91] Mendis, P. A.; "Design of High-Strength Concrete Members: State of the art", Concrete Construction, Progress in Structural Engineering and Materials, 5(1); 2003: 1-15.

[92] Mendis, P.; "Plastic Hinge Lengths of normal and high-strength concrete in flexure"; Advances in Structural Engineering, 4(4); 2001: 189-195.

[93] Meschkart, R.; "Rotation Capacity of reinforced concrete beams under various loading conditions"; Tesis Doctoral; University of Calgary, Department of civil Engineering; Calgary, Alberta: 1969.

[94] Mezzina, M. y Raffaele, D.; "Rotational Ductility of R.C. Beams: a Parametric Analysis"; Proceedings of the 2nd International Congress; Fédération Internationale du Béton; June 5-8, Naples: 2006.

[95] Mostafaei, H., Vecchio, F. J. y Kabeyasawa, T.; "Deformation capacity of reinforced concrete columns"; ACI Structural Journal, 106(2), 2009: 187-195.

[96] Nawy, E. G., Danesi, R. F., and Grosco, J. J.; "Rectangular Spiral Binders Effect on Plastic Hinge Rotation Capacity in Reinforced Concrete Beams"; ACI Journal 65(12); 1968:1001-1010.

[97] NCSR-02; "Norma de construcción sismorresistente: Parte general y edificación"; Dirección general de arquitectura y vivienda. Consejería de medio ambiente y ordenación del territorio; Madrid:2002. 
[98] NEHRP Guidelines for the seismic rehabilitation of buildings, (FEMA Publication 273); Building Seismic Safety Council; Washington, D.C., 1997.

[99] Pam, H. J. y Ho, J. C. M.; "Length of critical region for confinement steel in limited ductility high-strength reinforced concrete columns"; Engineering Structures, 31(12); 2009: 2896-2908.

[100] Panagiotakos, T. B. y Fardis, M. N.; "Deformations of reinforced concrete members at yielding and ultimate"; $\mathrm{ACI}$ Journal Structural, 98(2); 2001: 135-148.

[101] Pantazopoulou, S. J.; "Detailing for reinforcement stability in RC members"; Journal of Structural Engineering, 124(6); 1998: 623-632.

[102] Park R., Priestley M., Gill W. D.; "Ductility of Square Confined Concrete. Columns"; Journal of Structural Division, ASCE, 108 (4); 1982: 929-950.

[103] Park, R. y Paulay, T.; "Estructuras de Concreto Reforzado"; Limusa S.A.; México DC: 1975.

[104] Paulay, T. y Priestley M. J. N.; "Seismic design of reinforced concrete and masonry buildings", John Wiley and Sons Ltd; New York: 1992.

[105] Pecce, M. y Fabbrocino, G.; "Plastic rotation capacity of beams in normal and high-performance concrete"; ACI Structural Journal, 96(2); 1999: 290-296.

[106] Pendyala, R. S., Mendis, P.A. y Patnaikuni, I.; " Softening of Plastic Hinges in High Strength Concrete Structures", Transactions of the Institution of Engineers, Australia, Civil engineering, 36(1); 1994: 5155.

[107] Pendyala, R., Mendis, P. y Patnaikuni, I.; "Full-range behavior of highstrength concrete flexural members: comparison of ductility parameters of high and normal-strength concrete members"; ACl Structural Journal, 93(1); 1996: 30-35.

[108] Peruš, I., Poljanšek, K. y Fajfar, P.; "Flexural deformation capacity of rectangular RC columns determined by the CAE method"; Earthquake Engineering \& Structural Dynamics, 35(12), 2006: 1453 - 1470.

[109] Pontangaroa, R. T., Priestley, M. J. N. y Park, R.; "Ductility of spirally reinforced concrete columns under seismic loading", Research Report 79-8, Department of Civil Engineering; University of Canterbury; Christchurch: 1979.

[110] Priestley M.J.N. and Park R.; "Strength and ductility of concrete bridge columns under seismic loading"; ACI Structural Journal, 84(1); 1987: 61-76.

[111] Priestley M.J.N., Seible F., Calvi G.M.;"Seismic desing and retrofit of bridges"; John Wiley \& Sons, INC.; 1996.

[112] Qingxiang, W., Guofan, Z. y Liyan, L.; "Ductility of high strength reinforced concrete columns"; Nuclear Engineering and Design, 156(1), 1995: 75-81.

[113] Razvi, S. R. y Saatcioglu, M.; "Strength and deformability of confined high- strength concrete columns"; ACI Structural Journal, 91(6); 1994: 678-687.

[114] Saatcioglu, M. y Razvi, S. R.; "Displacement based design of reinforced concrete columns for confinement"; $\mathrm{ACl}$ Structural Journal, 99(1); 2002: 3-11. 
[115] Saatcioglu, M. y Razvi, S. R.; "Strength and ductility of confined concrete"; Journal of Structural Engineering, 118(6); 1992: 1590-1607.

[116] Sakai, K. y Sheikh, S. A.; "What do we know about confinement in reinforced concrete columns (a critical review of previous work and code provisions)"; ACI Structural Journal, 86(2); 1989: 192-207.

[117] Sawyer, H. A.; "Design of concrete frames for two failure states"; Proceedings of the international symposium on the flexural mechanics of the reinforced concrete; ASCE-ACl; Miami; 1964: 439-456.

[118] Shakir, A., Rogowsky, D.M.; Evaluation of ductility and allowable moment redistribution in reinforced concrete structures"; Canadian Journal of Civil Engineering, v.27, $n^{\circ}$ 6, 2000, 1286-1299.

[119] Sheikh, S. A. and Uzumeri, S. M.; "Analytical model for concreteconfinement in tied columns"; J.Struct. Div., ASCE, Vol. 108, No. ST12; 1982: 2703-2722.

[120] Sheikh, S. A. and Uzumeri, S. M.; "Strength and ductility of tied concrete columns”; J. Struct. Div.,ASCE, Vol. 106, No. ST5; (1980),1079-1102.

[121] Sheikh, S. A. y Khoury, S. S.; "Confined concrete columns with stubs"; ACI Structural Journal, 90(4); 1993: 414-431.

[122] Sheikh, S. A., Dharmendra, V. S. y Khoury, S. S.; "Confinement of high strength concrete columns"; ACl Structural Journal, 91(1); 1994: 100111.

[123] Shin, S-W., Ghosh, S. K. y Moreno, J.; "Flexural ductility of ultra-highstrength concrete members"; ACI Structural Journal, 86(4); 1989: 394400.

[124] Tadros Gamil S.; "Plastic Rotation of reinforced concrete members subjected to bending, Axial load and Shear"; Thesis, University of Calgary, Department of Civil Engineering, Calgary - Alberta; 1970.

[125] Tanaka, H. and Park, R.; "Effect of lateral confining reinforcement on the ductile behavior ofreinforced concrete columns"; Report 90-2, Department of Civil Engineering, University of Canterbury,Christchurch, New Zealand; 1990:1-458.

[126] Taylor, A. W., Kuo, C.,Wellenius, K., y Chung, D.; "A sumary of cyclic lateral loada tests on rectangular reinforced concrete columns"; NISTIR 5984, Building and Fire Research Laboratory, National Institute of Standars of Technology.

[127] Tholen, M. L. y Darwin, D.; "Effect of Reinforcing Bar Deformation Pattern on Flexural Ductility"; ACI Structural Journal, 95(1); 1998: 3742.

[128] Thomson, J. H. y Wallace, J. W.; "Lateral load behavior of reinforced concrete columns constructed using high strength materials"; $\mathrm{ACl}$ Structural Journal, 91(5); 1994: 605-615.

[129] Ventorini, L. A.; "Influência da Aderência na capacidade de rotação plástica de vigas de Concreto Armado"; Tese Submetida ao corpo docente da coordenação dos programas de Pós-Graduação de Engenharia da Univesidade Federal de Rio de Janeiro, para obtenção do título de Doutor em Ciências em Engenharia Civil; Rio de Janeiro, RJ-Brasil, 2003.

[130] Verderame, G. M., Fabbrocino, G. y Manfredi, G.; "Seismic response of r.c. columns with smooth reinforcement. Part I: Monotonic tests"; Engineering Structures, 30(9), 2008: 2277-2288. 
[131] Verderame, G. M., Fabbrocino, G. y Manfredi, G.; "Seismic response of r.c. columns with smooth reinforcement. Part II: Cyclic tests"; Engineering Structures, 30(9); 2008: 2289-2300.

[132] Watson S., Zahn, F. A. y Park, R.;" Confining reinforcement for concrete columns"; Journal of Structural Engineering, 120(6); 1994: 1798-1824.

[133] Watson, S. y Park, R.; "Simulated seismic load tests on reinforced concrete columns"; Journal of Structural Engineering, 120(6); 1994: 1825-1849.

[134] Wu, Y-F., Oehlers, D. J. y Griffith, M. C.; "Rotational definition of the flexural deformation capacity of RC columns sections"; Engineering structures, 26(5); 2004: 641-650.

[135] Yamashiro, R. y Siess, C. P.; "Moment-Rotation Characteristics of Reinforced Concrete Members Subjected to Bending, Shear, and Axial Load"; Civil Engineering Studies, Structural Research series No 260; University of Illinois; Urbana, Illinois: 1962.

[136] Zahn, F. A., Park, R. y Priestley, M. J. N.; "Strength and ductility of square reinforced concrete column section subjected to biaxial bending"; ACI Structural Journal, 56(2); 1989: 123-131.

[137] Zahn, F. A., Park, R. y Priestley, M. J. N.; "Strength and ductility of reinforced concrete piers - a summary report"; Research Report no 837; Department of Civil Engineering, University of Canterbury; Christchurch: 1983.

[138] Zahn, F. A.; "Design of reinforced concrete bridge columns for strength and ductility"; Research report $\mathrm{n}^{\circ}$ 86-7; Department of Civil Engineering, University of Canterbury; Christchurch: 1986. 
Estudio experimental y numérico de la capacidad de deformación de soportes esbeltos de hormigón armado 


\section{ANEJO A. RESUMEN DE LOS ESTUDIOS EXPERIMENTALES INCLUIDOS EN LA BASE DE DATOS}

\section{GENERALIDADES}

La bibliografía consultada en este estudio ha sido seleccionada siguiendo el criterio de que las referencias incluyeran el desarrollo de un programa de ensayos en el cual se midiera experimentalmente algún tipo de índice de deformación y/o la longitud de rótula plástica.

En este anejo se resume la información detallada acerca de todos los estudios experimentales que se han analizados en la fase de revisión de la bibliografía, a partir de la cual se construye la base de datos de ensayos experimentales. Estos estudios han sido seleccionados ya que, de alguna manera, han estudiado la deformabilidad en términos de ductilidad, derivas o rotación plástica en elementos sometidos a flexión simple o esfuerzos combinados de flexo-compresión. Se ha considerado conveniente plasmar esta información claramente en forma de tablas que resuman de forma sistemática lo que aportan todos y cada uno de los estudios. Esta información resulta útil para elaborar conclusiones generales, determinar vacíos de investigación y, en definitiva, comparar y utilizar los datos existentes de una manera eficaz y precisa. La información ha sido clasificada de acuerdo a los siguientes aspectos: (1) el objetivo de la investigación; (2) el número de ensayos realizados; (3) el tipo de ensayos llevados a cabo; (4) la descripción resumida del programa experimental; (5) los valores numéricos relacionados con los parámetros estudiados (resistencia del hormigón, nivel de carga axial, esbeltez geométrica, cuantía de armadura longitudinal, cuantía de armadura transversal y límite elástico del acero); y (6) las conclusiones del estudio, de forma también resumida. Encabezando esta información se encuentra la referencia bibliográfica, incluida en la bibliografía del presente trabajo. Este resumen incorpora un total de 27 estudios, cuyas fuentes son tesis doctorales, proyectos de investigación y artículos de investigación en publicaciones relevantes. A continuación se presenta el resumen de cada uno de los estudios experimentales previos. 


\section{LISTADO DE ESTUDIOS EXPERIMENTALES}

\begin{tabular}{|c|c|c|c|c|c|c|}
\hline \multicolumn{7}{|l|}{ Chan, W. W. L. (1955) [40] } \\
\hline Objetivo: & \multirow{2}{*}{\begin{tabular}{|l} 
№ Ensayos \\
Tipo de ensayo
\end{tabular}} & \multirow[t]{2}{*}{7} & \multicolumn{4}{|c|}{$\begin{array}{l}\text { Parámetros } \\
\text { estudio }\end{array}$} \\
\hline \multirow{6}{*}{$\begin{array}{l}\text { Dentro del estudio de la validez } \\
\text { de la teoría del diseño plástico, } \\
\text { Chan pretende encontrar una } \\
\text { expresión para el cálculo de la } \\
\text { capacidad de rotación } \\
\text { disponible en la rótula plástica. } \\
\text { Especialmente busca } \\
\text { demostrar la influencia del } \\
\text { efecto del confinamiento en } \\
\text { elementos de hormigón armado } \\
\text { en donde el fallo se debe } \\
\text { principalmente por el hormigón } \\
\text { en compresión. }\end{array}$} & & & \multicolumn{2}{|c|}{$\mathrm{f}_{\mathrm{c}}(\mathrm{MPa})$} & \multicolumn{2}{|c|}{27.6} \\
\hline & \multicolumn{2}{|c|}{ Programa Experimental } & \multicolumn{2}{|c|}{$\mathrm{N} / \mathrm{N}_{\mathrm{u}}$} & \multicolumn{2}{|c|}{ variable } \\
\hline & \multirow{4}{*}{\multicolumn{2}{|c|}{$\begin{array}{l}\text { La serie S de su programa experimental } \\
\text { consiste en elementos prismáticos } \\
\text { sometidos a compresión axial y carga } \\
\text { trasversal en el centro de la luz. Estudia } \\
\text { la influencia de la variación del nivel de } \\
\text { carga axial en la longitud de la zona } \\
\text { plástica y en la distribución de curvatura. } \\
\text { El nivel de carga axial fue lo } \\
\text { suficientemente alto para asegurar que } \\
\text { el elemento fallará principalmente por la } \\
\text { compresión del hormigón. }\end{array}$}} & \multicolumn{2}{|c|}{$\lambda_{g}=\mathrm{L} / \mathrm{h}$} & \multicolumn{2}{|c|}{7.5} \\
\hline & & & \multicolumn{2}{|c|}{$\rho_{\mathrm{I}}(\%)$} & \multicolumn{2}{|c|}{1.32} \\
\hline & & & \multicolumn{2}{|c|}{$\rho_{s}(\%)$} & \multicolumn{2}{|c|}{1.24 y 2.5} \\
\hline & & & \multicolumn{2}{|c|}{$\mathrm{f}_{\mathrm{y}}(\mathrm{MPa})$} & \multicolumn{2}{|c|}{275} \\
\hline \multicolumn{7}{|l|}{ Conclusiones: } \\
\hline \multicolumn{7}{|c|}{$\begin{array}{l}\text { La real rotación plástica en una rótula punto desarrollada sobre una corta longitud en la vecindad } \\
\text { de la posición asumida en la rótula. Esta longitud varía principalmente con la forma del diagrama } \\
\text { de momentos y la carga axial. En vigas continuas con carga uniforme distribuida, la longitud } \\
\text { plástica no excede L/10; en soportes con carga axial el incremento puede llegar a una longitud } \\
\text { máxima de } 0.5 \mathrm{H} \text {.En seccione poco armadas el desarrollo de una alta rotación plástica puede ser } \\
\text { incrementado utilizando un confinamiento lateral. }\end{array}$} \\
\hline \multicolumn{7}{|l|}{ Ernest, G. C. (1957) [57] } \\
\hline vo: & № Ensayos & 15 & \multicolumn{4}{|c|}{$\begin{array}{l}\text { Parámetros de } \\
\text { estudio }\end{array}$} \\
\hline \multirow{6}{*}{$\begin{array}{l}\text { El principal objetivo de su } \\
\text { investigación fue obtener } \\
\text { información de la cantidad de } \\
\text { rotación plástica que se } \\
\text { concentra en la conexión de } \\
\text { vigas y soportes. Puesto que es } \\
\text { una propiedad fundamental que } \\
\text { favorece la redistribución de } \\
\text { momentos internos en vigas } \\
\text { continúas. }\end{array}$} & Tipo de ensayo & 4 & \multicolumn{2}{|c|}{$\mathrm{f}_{\mathrm{c}}(\mathrm{MPa})$} & & $\begin{array}{l}22.7 \mathrm{a} \\
28.83^{2}\end{array}$ \\
\hline & \multicolumn{3}{|c|}{ Programa Experimental } & \multicolumn{2}{|l|}{$\mathrm{N} / \mathrm{N}_{\mathrm{u}}$} & 0 \\
\hline & \multirow{4}{*}{\multicolumn{3}{|c|}{$\begin{array}{l}\text { Consiste en una viga con un nudo rígido (de } \\
\text { diferente tamaño) en el centro que } \\
\text { representa la unión viga soporte, los } \\
\text { elementos ensayados son sometidos a } \\
\text { flexión. }\end{array}$}} & \multicolumn{2}{|c|}{$\lambda_{g}=\mathrm{L} / \mathrm{h}$} & 6 a 8.5 \\
\hline & & & & \multicolumn{2}{|c|}{$\rho_{I}(\%)$} & $\begin{array}{ll}1.4 & \mathrm{a} \\
5.3 & \end{array}$ \\
\hline & & & & \multicolumn{2}{|c|}{$\rho_{\mathrm{s}}(\%)$} & $\begin{array}{ll}1.4 & \text { a } \\
5.1 & \\
\end{array}$ \\
\hline & & & & \multicolumn{2}{|c|}{$\mathrm{f}_{\mathrm{y}}(\mathrm{MPa})$} & $\begin{array}{ll}305 & a \\
327 & \end{array}$ \\
\hline \multicolumn{7}{|l|}{ Conclusiones: } \\
\hline \multicolumn{7}{|c|}{$\begin{array}{l}\text { Durante los ensayos experimentales se identifico el orden en que aparecían los puntos críticos } \\
\text { para identificar el modo de rotura. P.e. la secuencia, plastificación del acero en tracción, rotura } \\
\text { del hormigón y carga máxima es típica de vigas que tienen una cuantía inferior a la de balanceo, } \\
\text { sin embargo la rotura del hormigón seguida de la carga máxima con ó sin plastificación del acero } \\
\text { es típica para secciones sobre-armadas. La rotación plástica en los puntos de plastificación del } \\
\text { acero y rotura del hormigón es pequeña si se compara con la obtenida para la carga máxima. }\end{array}$} \\
\hline
\end{tabular}


Yamashiro, R. y Siess, C. P. (1962) [135]

\begin{tabular}{|c|c|c|c|c|}
\hline Objetivo: & \multirow{2}{*}{\begin{tabular}{|l|} 
№ Ensayos \\
Tipo de ensayo \\
\end{tabular}} & \multirow{2}{*}{\begin{tabular}{|l|}
11 \\
6 \\
\end{tabular}} & \multicolumn{2}{|c|}{$\begin{array}{l}\text { Parámetros } \\
\text { estudio }\end{array}$} \\
\hline \multirow{6}{*}{$\begin{array}{l}\text { Este trabajo tiene el objetivo de } \\
\text { obtener información sobre la } \\
\text { resistencia y las características de } \\
\text { deformación en conexiones de } \\
\text { vigas y soportes. En una primera } \\
\text { fase se realizaron ensayos sujetos } \\
\text { sólo a flexión y fueron presentados } \\
\text { por Burns en 1962. La siguiente } \\
\text { fase consiste en el estudio de la } \\
\text { deformación en elementos tipo } \\
\text { soporte. Las principales variables } \\
\text { estudiadas fueron el nivel de carga } \\
\text { axial y la cantidad de armadura } \\
\text { longitudinal. }\end{array}$} & & & $\mathrm{f}_{\mathrm{c}}(\mathrm{MPa})$ & $\approx 30$ \\
\hline & \multicolumn{2}{|c|}{ Programa Experimental } & $\mathrm{N} / \mathrm{N}_{\mathrm{u}}$ & $\begin{array}{lll}0 & \text { a } & 20 \\
\% & & \end{array}$ \\
\hline & \multirow{4}{*}{\multicolumn{2}{|c|}{$\begin{array}{l}\text { Los elementos ensayados consisten } \\
\text { en soportes con un elemento rígido } \\
\text { en el centro del vano que representa } \\
\text { la conexión viga-soporte. }\end{array}$}} & $\lambda_{\mathrm{g}}=\mathrm{L} / \mathrm{h}$ & 12 \\
\hline & & & $\rho_{\text {I }}(\%)$ & 1 a 7 \\
\hline & & & $\rho_{s}(\%)$ & 1.6 a 2.6 \\
\hline & & & $\mathrm{f}_{\mathrm{y}}(\mathrm{MPa})$ & $\begin{array}{l}316 \\
344\end{array}$ \\
\hline
\end{tabular}

Las conclusiones más importantes de este estudio se pueden resumir como sigue: la ductilidad de elementos de hormigón armado disminuye con el incremento de la carga axial, como era de esperarse. El punto de rotura del hormigón no es un estado importante en lo que se refiere a la ductilidad del elemento. La ductilidad de elementos con fallo en compresión aumenta con la cantidad de armadura en compresión y con la cuantía de armadura transversal. Este autor es el primero en identificar los tipos de fallo en elementos tipo soporte sometidos a flexo-compresión

Mattock, A. H. (1967) [89]

\begin{tabular}{|c|c|c|c|c|}
\hline Objetivo: & № Ensayos & 37 & $\begin{array}{l}\text { Parámet } \\
\text { estudio }\end{array}$ & \\
\hline \multirow{6}{*}{$\begin{array}{l}\text { Puesto que en la teoría del diseño límite } \\
\text { en estructuras de hormigón armado } \\
\text { estáticamente indeterminadas se requiere } \\
\text { del conocimiento de la capacidad de } \\
\text { rotación plástica. Mattock realiza ensayos } \\
\text { en vigas de hormigón armado, } \\
\text { involucrando las siguientes variables: } \\
\text { resistencia del hormigón, altura de la viga, } \\
\text { distancia desde el punto de máximo } \\
\text { momento al punto de momento nulo, y por } \\
\text { último la cuantía y límite elástico de la } \\
\text { armadura. Los resultados son analizados } \\
\text { para proponer un método aplicado al } \\
\text { cálculo de la capacidad de rotación en la } \\
\text { región de la rótula plástica de vigas de } \\
\text { hormigón armado. }\end{array}$} & $\begin{array}{ll}\text { Tipo } & \text { de } \\
\text { ensayo } & \\
\end{array}$ & 1 & $\mathrm{f}_{\mathrm{c}}(\mathrm{MPa})$ & $23-43$ \\
\hline & \multicolumn{2}{|c|}{ Programa Experimental } & $\mathrm{N} / \mathrm{N}_{\mathrm{u}}$ & 0 \\
\hline & \multirow{4}{*}{\multicolumn{2}{|c|}{$\begin{array}{l}\text { Los ensayos se realizan en } \\
\text { vigas simplemente apoyadas } \\
\text { con una carga en el centro } \\
\text { del vano, puesto que esta } \\
\text { situación en realidad } \\
\text { representa la distribución de } \\
\text { momentos en el apoyo de } \\
\text { una viga continua. }\end{array}$}} & $\lambda_{g}=\mathrm{L} / \mathrm{h}$ & 5 a 20 \\
\hline & & & $\rho_{\mathrm{l}}(\%)$ & $\begin{array}{ll}0.28 \\
3.37 \%\end{array}$ \\
\hline & & & $\rho_{\mathrm{s}}(\%)$ & $\begin{array}{l}0.7 \quad a \\
2.98 \%\end{array}$ \\
\hline & & & $\mathrm{f}_{\mathrm{y}}(\mathrm{MPa})$ & $\begin{array}{l}308 \\
417\end{array}$ \\
\hline
\end{tabular}

Conclusiones:

Propone un método simplificado para el cálculo de la rotación plástica a partir de la relación de la rotación plástica desarrollada en toda la longitud y la rotación en una longitud de d/2 (d es la altura efectiva de la sección). Se considera que la máxima deformación del hormigón puede se mayor el valor de 0.003. A partir de los ensayos se encontró que la zona plástica que se desarrolla a partir de la sección de máximo momento incrementa con la esbeltez geométrica y disminuye con al tensión del acero de la armadura. De manera que está podía ser expresada en términos de la geometría del elemento y de las propiedades de la sección transversal. 
Corley, W. G. (1966) [45]

\begin{tabular}{|c|c|c|c|c|}
\hline \multirow{6}{*}{$\begin{array}{l}\text { Objetivo: } \\
\text { Los ensayos de Corley son una ampliación } \\
\text { de los realizados por Mattock. Las } \\
\text { principales variables adicionalmente } \\
\text { estudiadas son: el tamaño del elemento y } \\
\text { el confinamiento del hormigón en } \\
\text { compresión. Igualmente propone un } \\
\text { método para el calculo de la capacidad de } \\
\text { rotación de la rotula plástica en vigas de } \\
\text { hormigón armado }\end{array}$} & \multirow{2}{*}{\begin{tabular}{l|l} 
№ Ensayos & 2 \\
Tipo de & \\
ensayo
\end{tabular}} & \multirow{2}{*}{$\frac{40}{1}$} & \multicolumn{2}{|c|}{$\begin{array}{ll}\begin{array}{l}\text { Parámetros } \\
\text { estudio }\end{array} & \text { de } \\
\end{array}$} \\
\hline & & & $\mathrm{f}_{\mathrm{c}}(\mathrm{MPa})$ & $\begin{array}{l}24.7 \mathrm{a} \\
32.7\end{array}$ \\
\hline & \multicolumn{2}{|c|}{ Programa Experimental } & $\mathrm{N} / \mathrm{N}_{\mathrm{u}}$ & 0 \\
\hline & \multirow{4}{*}{\multicolumn{2}{|c|}{$\begin{array}{l}\text { Igual que Mattock. Vigas } \\
\text { simplemente apoyadas con } \\
\text { carga puntual en el centro } \\
\text { del vano. }\end{array}$}} & $\lambda_{g}=L / h$ & \begin{tabular}{|ll}
5 & $a$ \\
13.1 & \\
\end{tabular} \\
\hline & & & $\rho_{\mathrm{I}}(\%)$ & $\begin{array}{l}1.15 \mathrm{a} \\
4.40\end{array}$ \\
\hline & & & $\rho_{\mathrm{s}}(\%$ & $\begin{array}{|ll|}0.3 & a \\
8.7 & \end{array}$ \\
\hline & & & $\mathrm{f}_{\mathrm{y}}(\mathrm{MPa})$ & \begin{tabular}{|ll}
315 & $a$ \\
555 &
\end{tabular} \\
\hline
\end{tabular}

Conclusiones:

Modifica el método propuesto por Mattock, de manera que los factores fundamentales en el cálculo de la rotación plástica y en la zona plástica son; la esbeltez geométrica y altura efectiva.Considera el efecto benéfico de el confinamiento en la deformación última del hormigón, por lo tanto en la rotación plástica.

Nawy, E. G., Danesi, R. F., and Grosco, J. J.(1968) [96]

\begin{tabular}{|c|c|c|c|c|}
\hline \multirow{7}{*}{$\begin{array}{l}\text { Objetivo: } \\
\text { En esta investigación trata del estudio del } \\
\text { confinamiento en la capacidad de rotación } \\
\text { de rótulas en vigas de hormigón armado. } \\
\text { El trabajo descrito evalúa el cambio en la } \\
\text { ductilidad debido al confinamiento de vigas } \\
\text { en la zona plástica crítica con espirales } \\
\text { rectangulares continuas. Una medida del } \\
\text { incremento de la capacidad de rotación de } \\
\text { las rótulas antes de la rotura podría dar } \\
\text { una medida de la adicional ductilidad } \\
\text { mejorada en la zona plástica confinada } \\
\text { con espirales. }\end{array}$} & \multirow{2}{*}{\multicolumn{2}{|c|}{ 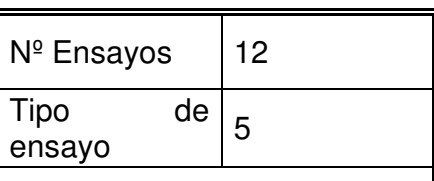 }} & \multicolumn{2}{|c|}{$\begin{array}{ll}\text { Parámetros } & \text { de } \\
\text { estudio } & \\
\end{array}$} \\
\hline & & & $\mathrm{f}_{\mathrm{c}}(\mathrm{MPa})$ & 30 \\
\hline & \multicolumn{2}{|c|}{ Programa Experimental } & $\mathrm{N} / \mathrm{N}_{\mathrm{u}}$ & \begin{tabular}{|l|} 
Sin \\
datos
\end{tabular} \\
\hline & \multirow{4}{*}{\multicolumn{2}{|c|}{$\begin{array}{l}\text { La serie B consiste en } 12 \\
\text { vigas simplemente apoyadas } \\
\text { con una longitud de } 2 \text { m. que } \\
\text { fueron sometidas a carga } \\
\text { axial y flexión, la sección } \\
\text { particularmenter fue } \\
\text { confinada con armadura en } \\
\text { espiral rectangular localizada } \\
\text { en una longitud superior a la } \\
\text { zona plástica. }\end{array}$}} & $\lambda_{g}=\mathrm{L} / \mathrm{h}$ & 7 y 10 \\
\hline & & & $\rho_{l}(\%)$ & 2,5 \\
\hline & & & $\rho_{\mathrm{s}}(\%)$ & \begin{tabular}{|l}
$0,1,2,3$ \\
, 4 \\
\end{tabular} \\
\hline & & & $\mathrm{f}_{\mathrm{y}}(\mathrm{MPa})$ & $\begin{array}{ll}342 & a \\
448 & \end{array}$ \\
\hline \multicolumn{5}{|l|}{ Conclusiones: } \\
\hline \multicolumn{5}{|c|}{$\begin{array}{l}\text { Se ha encontrado que los cercos en espiral rectangulares son bastante efectivos en el } \\
\text { incremento de la capacidad de rotación de la rótula. La investigación también indica que existe } \\
\text { un máximo efectivo de espirales rectangulares que debería ser usado, más allá del cual deja de } \\
\text { ser efectivo el confinamiento; este límite es aproximadamente un } 3 \% \text { para rótulas en las que } \\
\text { predomina la tracción y más o menos un } 2 \% \text { para rótulas donde predomina el fallo por } \\
\text { comprensión. }\end{array}$} \\
\hline
\end{tabular}


Tadros Gamil S. (1970) [124]

\begin{tabular}{|c|c|c|c|}
\hline Objetivo: & № Ensayos & $\begin{array}{l}\text { Paráme } \\
\text { estudio }\end{array}$ & \\
\hline \multirow{6}{*}{$\begin{array}{l}\text { El propósito de esta } \\
\text { investigación es el de } \\
\text { proporcionar una evaluación } \\
\text { cuantitativa de los factores } \\
\text { que afectan a la capacidad de } \\
\text { rotación plástica en } \\
\text { elementos de hormigón } \\
\text { armado. Las principales } \\
\text { variables fueron: la } \\
\text { separación de la armadura } \\
\text { transversal, la esbeltez } \\
\text { geométrica y el nivel de carga } \\
\text { axial. }\end{array}$} & Tipo de ensayo & $\mathrm{f}_{\mathrm{c}}(\mathrm{MPa})$ & 29 a 46 \\
\hline & Programa Experimental & $\mathrm{N} / \mathrm{N}_{\mathrm{u}}$ & 0 a 45 \\
\hline & \multirow{4}{*}{$\begin{array}{l}\text { Los ensayos fueron divididos en } 2 \text { series. } \\
\text { La serie M corresponde a vigas } \\
\text { simplemente apoyadas con carga en el } \\
\text { centro del vano. Aquí las variables } \\
\text { consideradas fueron la separación de la } \\
\text { armadura transversal y el tramo sometido } \\
\text { a cortante. La serie } \mathrm{N} \text { corresponde a } 14 \\
\text { vigas sujetas a carga transversal en el } \\
\text { centro de la luz y carga axial. Las } \\
\text { variables consideradas fueron el } \\
\text { confinamiento, la esbeltez geométrica y el } \\
\text { nivel de carga axial. }\end{array}$} & $\lambda_{\mathrm{g}}=\mathrm{L} / \mathrm{h}$ & 5 y 11 \\
\hline & & $\rho_{\text {I }}(\%)$ & 1.2 a 4.6 \\
\hline & & $\rho_{\mathrm{s}}(\%)$ & $\begin{array}{l}0.75 \\
1.38\end{array}$ \\
\hline & & $\mathrm{f}_{\mathrm{y}}(\mathrm{MPa})$ & 303 а 386 \\
\hline
\end{tabular}

Conclusiones:

Las conclusiones se limitan a definir la influencia de las variables estudiadas. La rotación plástica se incrementa cuando el espacio de la armadura transversal disminuye, independientemente de si actúa o no carga axial sobre el elemento. Para vigas que tienen armadura de compresión y tracción, la rotación plástica disminuye con el aumento de la esbeltez. Para vigas sujetas a carga axial y carga transversal la rotación plástica disminuye más rápidamente cuando se incrementa el nivel de carga axial.

Shin, Sung Woon, (1986) [123]

\begin{tabular}{|c|c|c|c|c|}
\hline Objetivo: & № Ensayos & 34 & \multicolumn{2}{|c|}{$\begin{array}{ll}\text { Parámetros } & \text { de } \\
\text { estudio } & \end{array}$} \\
\hline \multirow{6}{*}{$\begin{array}{l}\text { Estudiar la ductilidad de } \\
\text { elementos de hormigón de } \\
\text { alta resistencia, entre otros de } \\
\text { los objetivos también fue el } \\
\text { de observar como } \\
\text { comenzaba la fisuración, su } \\
\text { propagación, y el desarrollo } \\
\text { del patrón de fisuración en } \\
\text { vigas ensayadas bajo carga } \\
\text { monotónica. }\end{array}$} & Tipo de ensayo & 1 & $\mathrm{f}_{\mathrm{c}}(\mathrm{MPa})$ & $\begin{array}{l}30 \\
103 \\
\end{array}$ \\
\hline & \multicolumn{2}{|c|}{ Programa Experimental } & $\mathrm{N} / \mathrm{N}_{\mathrm{u}}$ & 0 \\
\hline & \multirow{4}{*}{\multicolumn{2}{|c|}{$\begin{array}{l}\text { Se desarrollaron ensayos sobre tres } \\
\text { grupos cada uno con } 12 \text { de vigas. Cada } \\
\text { grupo tenía resistencias alrededor de } 30 \\
\mathrm{MPa} 84 \mathrm{MPa} \text { y } 103 \mathrm{MPa} \text {. Las varible } \\
\text { fueron adicionalmente la cuantía de } \\
\text { armadura longitudinal y la separación de } \\
\text { la armadura transversal. }\end{array}$}} & $\lambda_{g}=\mathrm{L} / \mathrm{h}$ & 10 \\
\hline & & & $\rho_{\mathrm{I}}(\%)$ & 0.75 a 6.7 \\
\hline & & & $\rho_{\mathrm{s}}(\%)$ & 1.3 y 2.6 \\
\hline & & & $\mathrm{f}_{\mathrm{y}}(\mathrm{MPa})$ & 414 \\
\hline \multicolumn{5}{|l|}{ Conclusiones: } \\
\hline \multicolumn{5}{|c|}{$\begin{array}{l}\text { La ductilidad de vigas de hormigón armado fue generalmente mayor c } \\
\text { resistencia del hormigón, aun que la ductilidad disminuyo cuando la } \\
\text { aumento de } 84 \mathrm{MPa} \text { a } 103 \mathrm{MPa} \text {. Además aunque los ensayos en este } \\
\text { vigas sin carga axial, la ductilidad respectiva en soportes de HAR par } \\
\text { Relación entre la cuantía longitudinal y la cuantía de balanceo, es el fa } \\
\text { influye en los índices de ductilidad. La ductilidad disminuye dramátican } \\
\text { r/rb aumenta. El confinamiento en el rango estudiado no tiene un } \\
\text { ductilidad. }\end{array}$} \\
\hline
\end{tabular}




\begin{tabular}{|c|c|c|c|c|}
\hline Objetivo: & № Ensayos & 44 & \multicolumn{2}{|c|}{$\begin{array}{ll}\text { Parámetros de } \\
\text { estudio }\end{array}$} \\
\hline \multirow{6}{*}{$\begin{array}{l}\text { Estudio de la capacidad de rotación } \\
\text { plástica en vigas armadas con } \\
\text { nuevos tipos de aceros definidos en } \\
\text { los códigos europeos. En los } \\
\text { ensayos se ha variado las } \\
\text { características geométricas, el tipo } \\
\text { de acero, la cuantía de armadura y } \\
\text { la posición de la carga. Los } \\
\text { diagramas de rotación plástica son } \\
\text { dibujados como una función de x/d, y } \\
\text { son caracterizados por dos ramas } \\
\text { con pendientes de signo opuesto, } \\
\text { que representan el fallo del acero y } \\
\text { el hormigón respectivamente. }\end{array}$} & Tipo de ensayo & 1 y 3 & $\begin{array}{l}\mathrm{f}_{\mathrm{c}} \\
(\mathrm{MPa})\end{array}$ & 27.8 \\
\hline & \multicolumn{2}{|c|}{ Programa Experimental } & $\mathrm{N} / \mathrm{N}_{\mathrm{u}}$ & 0 \\
\hline & \multirow{4}{*}{\multicolumn{2}{|c|}{$\begin{array}{l}\text { Se han realizado ensayos en vigas } \\
\text { de HC con } 3 \text { tipos de tamaño, } \\
\text { sometidas a } 2 \text { diferentes } \\
\text { condiciones de carga. Una de ellas } \\
\text { es una carga puntual (P) en el } \\
\text { centro del vano, y la otra es la } \\
\text { aplicación de tres cargas }(\mathrm{P} / 3) \text { en } \\
\text { tres puntos con separación } 2 \mathrm{H} \text {. }\end{array}$}} & $\lambda_{g}=\mathrm{L} / \mathrm{h}$ & 10 \\
\hline & & & $\rho_{\mathrm{l}}(\%)$ & 0.27 a 2.5 \\
\hline & & & $\rho_{\mathrm{s}}(\%)$ & 0.2 \\
\hline & & & & $539-583$ \\
\hline \multicolumn{5}{|l|}{ Conclusiones: } \\
\hline \multicolumn{5}{|l|}{$\begin{array}{l}\text { 1) Los ensayos llevados a cabo en } \\
\text { (alta y normal ductilidad) en las } \\
\text { diagrama de rotación plástica expr } \\
\text { pendientes de signo contrario, } \\
\text { respectivamente. } 2 \text { ) Para bajos por } \\
\text { forma del diagrama de momentos } \\
\text { de alta ductilidad y condiciones de } \\
\text { armadas, cuando el valor de x/d } \\
\text { afectado por el tipo de acero, y }\end{array}$} \\
\hline
\end{tabular}

Nedim A., Scott D. B. Alexander, and James G. MacGregor. 1997 ¡Error! No se encuentra el origen de la referencia.

\begin{tabular}{|c|c|c|c|c|}
\hline Objetivo: & № Ensayos & 12 & \multicolumn{2}{|c|}{ Parámetros de estudio } \\
\hline \multirow{6}{*}{$\begin{array}{l}\text { El objetivo de esta investigación es } \\
\text { estudiar el efecto del tamaño del } \\
\text { elemento en el comportamiento del } \\
\text { hormigón en la zona de } \\
\text { compresión de la sección bajo } \\
\text { flexión simple, } \\
\text { consecuentemente, en la } \\
\text { capacidad de rotación plástica en } \\
\text { elementos de HAR sujetos a } \\
\text { flexión simple. }\end{array}$} & Tipo de ensayo & 2 & $\mathrm{f}_{\mathrm{c}}(\mathrm{MPa})$ & 43.8 a 90 \\
\hline & \multicolumn{2}{|c|}{ Programa Experimental } & $\mathrm{N} / \mathrm{N}_{\mathrm{u}}$ & 0 \\
\hline & \multirow{2}{*}{\multicolumn{2}{|c|}{$\begin{array}{l}\text { Los elementos ensayados son } \\
\text { vigas de HAR simplemente }\end{array}$}} & $\lambda_{\mathrm{g}}=\mathrm{L} / \mathrm{h}$ & 12 a 13 \\
\hline & & & $\rho_{\mathrm{I}}(\%)$ & 2.3 a 4.7 \\
\hline & \multirow{2}{*}{\multicolumn{2}{|c|}{$\begin{array}{l}\text { apoyadas, sometidas a dos } \\
\text { cargas puntuales con una } \\
\text { región de momento constante. } \\
\text { Las variables fueron: la altura } \\
\text { efectiva ( } 23,36 \text { y } 51.5 \mathrm{~cm} \text {.) y la } \\
\text { resistencia del hormigón (50 a } \\
90 \mathrm{MPa}) \text {. }\end{array}$}} & $\rho_{\mathrm{s}}(\%)$ & 0.8 a 2.1 \\
\hline & & & $\mathrm{f}_{\mathrm{y}}(\mathrm{MPa})$ & 402 a 412 \\
\hline \multicolumn{5}{|l|}{ Conclusiones: } \\
\hline \multicolumn{5}{|c|}{$\begin{array}{l}\text { El comportamiento de las vigas ensayadas no fue afectado por el tamaño de la sección. El } \\
\text { tamaño de la sección no afectó a la capacidad de deformación del hormigón en la zona de } \\
\text { compresión en vigas a flexión. De forma similar, tampoco afectó a la capacidad de rotación de } \\
\text { la rótula, ni tampoco a la gráfica tensión-deformación del hormigón en la zona de compresión } \\
\text { de vigas de HAR en flexión. }\end{array}$} \\
\hline
\end{tabular}


Ko, M. Y.; Kim, S. W.; Kim J. K. (1997) [73]

\begin{tabular}{|c|c|c|c|}
\hline Objetivo: & № Ensayos & \multicolumn{2}{|c|}{ Parámetros de estudio } \\
\hline \multirow{6}{*}{$\begin{array}{l}\text { Evaluar experimentalmente la } \\
\text { capacidad de rotación plástica, la } \\
\text { deformación última del hormigón } \\
\text { en la fibra más comprimida y la } \\
\text { longitud equivalente de la rótula } \\
\text { plástica. Los resultados } \\
\text { experimentales fueron } \\
\text { comparados con los obtenidos a } \\
\text { partir de un análisis numérico. }\end{array}$} & Tipo de ensayo & $\mathrm{f}_{\mathrm{c}}(\mathrm{MPa})$ & $60,70, y 80$ \\
\hline & Programa Experimental & $\mathrm{N} / \mathrm{N}_{\mathrm{n}}$ & 0 \\
\hline & \multirow{4}{*}{$\begin{array}{l}\text { Los ensayos consisten en } 36 \\
\text { vigas de hormigón HAR en } \\
\text { donde las principales variables } \\
\text { son las siguientes: la resistencia } \\
\text { del hormigón, la cuantía de } \\
\text { armadura en tracción y } \\
\text { compresión y el modelo de carga } \\
\text { (una y dos cargas puntuales } \\
\text { respectivamente). }\end{array}$} & $\lambda_{g}=\mathrm{L} / \mathrm{h}$ & 10 y 11 \\
\hline & & $\rho_{\mathrm{I}}(\%)$ & 0.3 a 11 \\
\hline & & $\rho_{\mathrm{s}}(\%)$ & 3 a 5 \\
\hline & & $\mathrm{f}_{\mathrm{y}}(\mathrm{MPa})$ & 385 a 443 \\
\hline
\end{tabular}

Conclusiones:

A partir de la comparación de los resultados del análisis numérico y los resultados experimentales, se ha encontrado que el cálculo de la rotación plástica teórica es más aproximado utilizando la relación Momento-curvatura considerando el efecto de tensión stiffening y del cortante, que usando la ecuación con la longitud plástica equivalente. Esta observación muestra la importancia de la resistencia a tracción del hormigón y de la deformación del cortante en la rotación plástica de vigas de HAR.

Beedy, A.W. (1997) [22]

\begin{tabular}{|c|c|c|c|}
\hline \multirow{2}{*}{\begin{tabular}{l|l} 
Objetivo: & N \\
Esta investigación tiene varios \\
objetivos, el primero consiste en \\
estudiar la influencia de la forma
\end{tabular}} & \multirow{2}{*}{$\begin{array}{l}\text { № Ensayos } \\
\text { Tipo de ensayo }\end{array}$} & \multicolumn{2}{|c|}{ Parámetros de estudio } \\
\hline & & $\mathrm{f}_{\mathrm{c}}(\mathrm{MPa})$ & 50 \\
\hline & Programa Experimental & $\mathrm{N} / \mathrm{N}_{\mathrm{u}}$ & 0 \\
\hline $\begin{array}{l}\text { en la capacidad de rotación.El } \\
\text { segundo tiene que ver con el } \\
\text { esclarecimiento de las siguientes }\end{array}$ & \multirow{4}{*}{$\begin{array}{l}\text { Las dimensiones y el número de } \\
\text { barras fueron idénticas en todas } \\
\text { las vigas, y una esbeltez } \\
\text { geométrica igual a } 6 \text {, el } \\
\text { parámetro variable fueron las } \\
\text { características del acero de la } \\
\text { armadura (10 tipos de acero), la } \\
\text { cuantía de armadura fue } \\
\text { escogida de manera que en el } \\
\text { estado último las relación x/d } \\
\text { estuviese alrededor de } 0.1 \text {. En } \\
\text { este caso el fallo se debe a la } \\
\text { rotura de la armadura más que a } \\
\text { la rotura del hormigón. Los } \\
\text { ensayos se realizaron en vigas } \\
\text { de HC con una carga en el centro } \\
\text { del vano, para cada tipo de viga } \\
\text { se ensayaron dos elementos. }\end{array}$} & $\lambda_{g}=\mathrm{L} / \mathrm{h}$ & 5 \\
\hline $\begin{array}{l}\text { ductilidad se reduce con una } \\
\text { reducción de la cuantía de }\end{array}$ & & $\rho_{\mathrm{l}}(\%)$ & 0,4 \\
\hline $\begin{array}{l}\text { armadura cuando el fallo se debe } \\
\text { a la rotura del hormigón, (2) que } \\
\text { la ductilidad está marcadamente }\end{array}$ & & $\rho_{\mathrm{s}}(\%)$ & 0 \\
\hline $\begin{array}{l}\text { afectada por las propiedades } \\
\text { dúctiles del acero de la } \\
\text { armadura, (3) que la ductilidad se } \\
\text { reduce con incremento de la } \\
\text { altura de la sección y aumenta } \\
\text { con la aumento de la esbeltez } \\
\text { geométrica. }\end{array}$ & & $\mathrm{f}_{\mathrm{y}}(\mathrm{MPa})$ & $487-600$ \\
\hline
\end{tabular}

Conclusiones:

Se ha demostrado que los factores que controlan la capacidad de rotación última de elementos de hormigón armado es más compleja que la relación implícita en la actuales normas; en donde la rotación plástica se encuentra definida solo a partir de la relación entre la altura de la fibra neutra y el canto efectivo (x/d). En realidad, la deformación última del acero de la armadura, la relación entre la carga de rotura y el límite elástico, la adherencia, la esbeltez geométrica y la altura efectiva de la sección tienen una significativa influencia. 
Tholen, M. L. y Darwin, D. (1998) [127]

\begin{tabular}{|c|c|c|c|c|}
\hline Objetivo: & № Ensayos & 4 & \multicolumn{2}{|c|}{$\begin{array}{l}\text { Parámetros } \\
\text { estudio }\end{array}$} \\
\hline \multirow{6}{*}{$\begin{array}{l}\text { Estudiar los efectos del incremento } \\
\text { del área en las corrugas de las } \\
\text { barras de acero "rib área" en la } \\
\text { respuesta Carga - Flecha y } \\
\text { Momento- rotación de vigas de } \\
\text { hormigón armado, puesto que la } \\
\text { ductilidad puede ser } \\
\text { contrariamente afectada al mejorar } \\
\text { el comportamiento de la } \\
\text { adherencia. Esto con el propósito } \\
\text { de encontrar un óptimo modelo } \\
\text { para las barras de acero y en } \\
\text { consecuencia incorporarlo en la } \\
\text { producción industrial }\end{array}$} & Tipo de ensayo & 1 & $\mathrm{f}_{\mathrm{c}}(\mathrm{MPa})$ & 33 a 36 \\
\hline & \multicolumn{2}{|c|}{ Programa Experimental } & $\mathrm{N} / \mathrm{N}_{\mathrm{u}}$ & 0 \\
\hline & \multirow{4}{*}{\multicolumn{2}{|c|}{$\begin{array}{l}\text { Las vigas fueron diseñadas para } \\
\text { determinar el posible nivel de } \\
\text { disminución de la ductilidad como } \\
\text { resultado del aumento de la "rib } \\
\text { área" en la armadura de flexión. En } \\
\text { los ensayos solo se vario la cuantía } \\
\text { longitudinal, y el tipo de barra con } \\
\text { diferente rib área. }\end{array}$}} & $\lambda_{g}=\mathrm{L} / \mathrm{h}$ & 11 \\
\hline & & & $\rho_{l}(\%)$ & \begin{tabular}{|l|}
1.19 \\
1.67 \\
\end{tabular} \\
\hline & & & $\rho_{\mathrm{s}}(\%)$ & 0.7 \\
\hline & & & $f_{y}(\mathrm{MPa})$ & 543-555 \\
\hline \multicolumn{5}{|l|}{ Conclusiones: } \\
\hline \multicolumn{5}{|c|}{$\begin{array}{l}\text { La gran similitud entre el comportamiento de las parejas (para los dos valores de cuantía) de } \\
\text { vigas ensayadas a flexión, indican la insensibilidad de la respuesta para grandes cambios en la } \\
\text { relativa "Rib área" de barras de armadura. Las conclusiones claves del estudio son: (1) Para } \\
\text { vigas con armadura continua, la relativa "rib área" de las barras no afecta la distribución de } \\
\text { fisuras de flexión para vigas en las cuales la rótula plástica se desarrolla. (2) Para armaduras } \\
\text { con armadura continua, la relativa "rib área" de las barras no afecta la flecha y la capacidad de } \\
\text { rotación de vigas en las que se desarrolla la rótula plástica. }\end{array}$} \\
\hline
\end{tabular}

Pecce, M. y Fabbrocino, G. (1999) [105]

\begin{tabular}{|c|c|c|c|c|}
\hline Objetivo: & № Ensayos & 6 & \multicolumn{2}{|c|}{$\begin{array}{l}\text { Parámetros de } \\
\text { estudio }\end{array}$} \\
\hline \multirow{6}{*}{$\begin{array}{l}\text { El desarrollo del programa experimental } \\
\text { en vigas de HC y HAR. Tiene el objetivo } \\
\text { de medir las diferencias en el } \\
\text { comportamiento de elementos de HC y } \\
\text { HAR con propósito de revisar } \\
\text { específicamente las recomendaciones } \\
\text { de las normas en relación a la } \\
\text { capacidad de rotación disponible } \\
\text { cuando de considera elementos de } \\
\text { HAR. El análisis se realiza teniendo en } \\
\text { cuenta dos definiciones para la } \\
\text { definición de la rotación última (evaluada } \\
\text { en la carga máxima o considerando la } \\
\text { rama de descenso). }\end{array}$} & Tipo de ensayo & 1 & $\begin{array}{l}\mathrm{f}_{\mathrm{c}} \\
(\mathrm{MPa})\end{array}$ & 41 a 93 \\
\hline & \multicolumn{2}{|c|}{ Programa Experimental } & $\mathrm{N} / \mathrm{N}_{\mathrm{u}}$ & 0 \\
\hline & \multirow{4}{*}{\multicolumn{2}{|c|}{$\begin{array}{l}\text { Los ensayos se realizaron en } \\
\text { vigas simplemente apoyadas con } \\
\text { una carga en el centro del vano. } \\
\text { Variables estudiadas con: } \\
\text { resistencia del hormigón, cuantía } \\
\text { mecánica, esbeltez geométrica. }\end{array}$}} & $\lambda_{g}=\mathrm{L} / \mathrm{h}$ & 18 y 10 \\
\hline & & & $\rho_{\text {I }}(\%)$ & 1,4 a 3,3 \\
\hline & & & $\rho_{\mathrm{s}}(\%)$ & 0,5 a 0,8 \\
\hline & & & $\begin{array}{l}\mathrm{f}_{\mathrm{y}} \\
(\mathrm{MPa})\end{array}$ & $\begin{array}{l}454 \\
534\end{array}$ \\
\hline
\end{tabular}

Conclusiones:

(1) La fragilidad de HAR influye en la ductilidad de las vigas pero por medio del fenómeno local como la perdida de recubrimiento. (2) La capacidad de rotación es fuertemente influenciada por la definición de rotación plástica. En particular, si el punto de fallo es referido al punto de máxima carga, la rotación plástica es pequeña en muchos casos y las vigas de HAR son calificadas como menos dúctiles que HC. Por lo tanto, este criterio parece ser también restrictivo para vigas de HAR y la rama de descenso debe ser considerada. (3) La capacidad de rotación plástica disponible que aparece en las normas es segura, aún para vigas de HAR. 
Bigaj, A. J. (1999) [25]

\begin{tabular}{|c|c|c|c|c|}
\hline Objetivo: & № Ensayos & 10 & \multicolumn{2}{|c|}{\begin{tabular}{|l}
$\begin{array}{l}\text { Parámetros de } \\
\text { estudio }\end{array}$ \\
\end{tabular}} \\
\hline \multirow{6}{*}{$\begin{array}{l}\text { Investigar el efecto del tamaño } \\
\text { en la capacidad de rotación de } \\
\text { rótulas plásticas y para investigar } \\
\text { el proceso de localización en la } \\
\text { región de la rótula, en particular } \\
\text { en la zona de compresión del } \\
\text { elemento. El estudio es limitado a } \\
\text { elementos sometidos a flexión } \\
\text { sin carga axial. En los que se han } \\
\text { investigado tres importantes } \\
\text { parámetros: el tamaño del } \\
\text { elemento, la cuantía de armadura } \\
\text { y el tipo de hormigón }\end{array}$} & Tipo de ensayo & 1 & $\mathrm{f}_{\mathrm{c}}(\mathrm{MPa})$ & 31 a 40 \\
\hline & \multicolumn{2}{|c|}{ Programa Experimental } & $\mathrm{N} / \mathrm{N}_{\mathrm{u}}$ & 0 \\
\hline & \multirow{4}{*}{\multicolumn{2}{|c|}{$\begin{array}{l}\text { Los ensayos se han realizado sobre } \\
\text { elementos tipo vigas sometidos a una } \\
\text { carga puntual en el centro del vano. } \\
\text { Las vigas tenían tres diferentes } \\
\text { tamaños con la misma relación canto- } \\
\text { ancho y longitud, las dimensiones del } \\
\text { los elementos medios y grandes se } \\
\text { obtuvieron al multiplicar por un factor } \\
\text { de } 2 \text { y de } 5 \text { respectivamente el tamaño } \\
\text { del más pequeño. }\end{array}$}} & $\lambda_{g}=\mathrm{L} / \mathrm{h}$ & 11 \\
\hline & & & $\rho_{\text {I }}(\%)$ & \begin{tabular}{|l|}
0,28 \\
1,12 \\
\end{tabular} \\
\hline & & & $\rho_{\mathrm{s}}(\%)$ & 0 \\
\hline & & & $\mathrm{f}_{\mathrm{y}}(\mathrm{MPa})$ & 573 \\
\hline
\end{tabular}

(1) Hay una clara relación entre el tamaño del elemento y su capacidad de rotación. Mientras la rotación en el inicio de la plastificación del acero es casi independiente la rotación en la carga máxima incrementa con la disminución del tamaño del elemento en el caso de elementos los cuales fallan debido a la rotura del acero, así como en el caso cuando la rotura del hormigón predomina después de la plastificación del acero. (2) Para obtener una ductilidad en estructuras de hormigón armado, se debe disponer de una distribución de armadura relacionada con el tamaño del elemento. (3) Debido al gran número de parámetros independientes que están involucrados, no se puede formular ninguna regla general de dependencia del tamaño para elementos de hormigón armado.

Ventorini, L. A. (2003) [129]

\begin{tabular}{|c|c|c|c|c|}
\hline Objetivo: & № Ensayos & & \multicolumn{2}{|c|}{\begin{tabular}{|l|}
$\begin{array}{l}\text { Parámetros } \\
\text { estudio }\end{array}$ \\
\end{tabular}} \\
\hline \multirow{6}{*}{$\begin{array}{l}\text { El objetivo de este trabajo es } \\
\text { cuantificar la influencia del diámetro de } \\
\text { las barras de armadura longitudinal en } \\
\text { tracción en la capacidad de rotación } \\
\text { plástica de de vigas de hormigón } \\
\text { armado. A partir del análisis de los } \\
\text { ensayos se propone una expresión } \\
\text { para la capacidad de rotación plástica, } \\
\text { en función de los parámetros más } \\
\text { influyentes, como el diámetro de la } \\
\text { armadura a tracción. Los resultados } \\
\text { obtenidos con la expresión son } \\
\text { comparados con los experimentales y } \\
\text { con otras expresiones propuestas en } \\
\text { normas. }\end{array}$} & \begin{tabular}{|ll} 
Tipo & de \\
ensayo & \\
\end{tabular} & 1 & $\mathrm{f}_{\mathrm{c}}(\mathrm{MPa})$ & $\begin{array}{ll}29, & 35, \\
47,76,81\end{array}$ \\
\hline & \multicolumn{2}{|c|}{ Programa Experimental } & $\mathrm{N} / \mathrm{N}_{\mathrm{u}}$ & 0 \\
\hline & \multirow{4}{*}{\multicolumn{2}{|c|}{$\begin{array}{l}\text { Vigas simplemente apoyadas } \\
\text { con un pequeño "elemento } \\
\text { rígido" solo en la parte superior, } \\
\text { localizado en el centro del } \\
\text { elemente y sobre el cual se } \\
\text { aplica una carga de flexión. Las } \\
\text { principales variables son: } \\
\text { Cuantía de armadura, la } \\
\text { resistencia del hormigón, el } \\
\text { diámetro de la barra en } \\
\text { tracción, y las características } \\
\text { del acero de las barras. }\end{array}$}} & $\lambda_{g}=\mathrm{L} / \mathrm{h}$ & 6 a 8 \\
\hline & & & $\rho_{\text {I }}(\%)$ & 1 a 2,45 \\
\hline & & & $\rho_{\mathrm{s}}(\%)$ & 1,2 a 2 \\
\hline & & & $\mathrm{f}_{\mathrm{y}}(\mathrm{MPa})$ & 540 a 630 \\
\hline \multicolumn{5}{|l|}{ Conclusiones: } \\
\hline \multicolumn{5}{|c|}{$\begin{array}{l}\text { Presenta expresiones para } L_{p} \text {, curvatura media, y por lo tanto para } \theta_{p} \text { en función del diámetro } \\
\text { de las barras longitudinales de tracción y de las propiedades mecánicas del acero de la } \\
\text { armadura. }\end{array}$} \\
\hline
\end{tabular}


Almeida Bernardo L. F. (2003) [4]

\begin{tabular}{|c|c|c|c|c|}
\hline Objetivo: & № Ensayos & 19 & \multicolumn{2}{|c|}{\begin{tabular}{|ll}
$\begin{array}{l}\text { Parámetros de } \\
\text { estudio }\end{array}$ \\
\end{tabular}} \\
\hline \multirow{6}{*}{$\begin{array}{l}\text { Estudiar la ductilidad de vigas de } \\
\text { HAR con el propósito de definir } \\
\text { un método de análisis que } \\
\text { conduzca al desarrollo de un } \\
\text { parámetro que caracterice la } \\
\text { capacidad de rotación plástica en } \\
\text { la sección de fallo. }\end{array}$} & Tipo de ensayo & 2 & $\mathrm{f}_{\mathrm{c}}(\mathrm{MPa})$ & \begin{tabular}{|l|}
62.9 \\
105 \\
\end{tabular} \\
\hline & \multicolumn{2}{|c|}{ Programa Experimental } & $\mathrm{N} / \mathrm{N}_{\mathrm{u}}$ & 0 \\
\hline & \multirow{4}{*}{\multicolumn{2}{|c|}{$\begin{array}{l}\text { Nueve vigas simplemente apoyadas } \\
\text { aplicando dos cargas concentradas } \\
\text { simétricas con una separación de un } \\
\text { tercio de la luz. Las principales } \\
\text { variables estudiadas fueron la } \\
\text { resistencia del hormigón y la cuantía } \\
\text { de armadura de tracción. }\end{array}$}} & $\lambda_{g}=\mathrm{L} / \mathrm{h}$ & 11.5 \\
\hline & & & $\rho_{\mathrm{l}}(\%)$ & 1.54 a 3.8 \\
\hline & & & $\rho_{\mathrm{s}}(\%)$ & $\begin{array}{|ll|}1.27 & \mathrm{a} \\
1.82 & \\
\end{array}$ \\
\hline & & & $\mathrm{f}_{\mathrm{y}}(\mathrm{MPa})$ & 544 a 575 \\
\hline
\end{tabular}

Dentro de su programa experimental concluye que el parámetro con mayor influencia en la ductilidad de las vigas es la cuantía de armadura longitudinal en tracción. La resistencia a compresión del hormigón parece tener una influencia bastante variable en la capacidad de rotación de las vigas. Los resultados muestran en general que para similar cuantía de armadura longitudinal, un incremento en la resistencia a la compresión del hormigón tiende a aumentar la capacidad de rotación, lo cual coincide con lo dicho por algunos autores, y contradice lo obtenido por otros autores.

Mendis, P. A. (2003) [91]

\begin{tabular}{|c|c|c|c|c|}
\hline \multirow{3}{*}{\begin{tabular}{|l|} 
Objetivo: \\
El objetivo fue el de proponer \\
una expresión para determinar \\
la longitud de rótula plástica \\
deducida a partir de la \\
experimentación. Y comparar los
\end{tabular}} & \multirow{2}{*}{$\begin{array}{l}\text { № Ensayos } \\
\text { Tipo de ensayo }\end{array}$} & \multirow{2}{*}{30} & \multicolumn{2}{|c|}{$\begin{array}{ll}\begin{array}{l}\text { Parámetros } \\
\text { estudio }\end{array} & \text { de } \\
\end{array}$} \\
\hline & & & $\mathrm{f}_{\mathrm{c}}(\mathrm{MPa})$ & 32.7 a 79 \\
\hline & \multicolumn{2}{|c|}{ Programa Experimental } & $\mathrm{N} / \mathrm{N}_{\mathrm{u}}$ & 9 a 25 \\
\hline $\begin{array}{lr}\text { valores } & \text { obtenidos } \\
\text { experimentalmente } & \text { con los } \\
\text { obtenidos a partir } & \text { de otras }\end{array}$ & \multirow{4}{*}{\multicolumn{2}{|c|}{$\begin{array}{l}\text { Los ensayos experimentales } \\
\text { reportados por Mendis corresponden } \\
\text { a vigas simplemente apoyadas con } \\
\text { carga en el centro de la luz, } \\
\text { adicionalmente realizo algunos } \\
\text { ensayos con carga axial. También } \\
\text { dentro de los reportados se } \\
\text { encuentran los realizados por } \\
\text { Pendyala, que corresponden a vigas } \\
\text { simplemente apoyadas con } 2 \text { y } 3 \\
\text { cargas puntuales, y los de Kovacic } \\
\text { que se refiere a elementos sometidos } \\
\text { a flexo-compresión. }\end{array}$}} & $\lambda_{g}=\mathrm{L} / \mathrm{h}$ & 5.4 a 10.2 \\
\hline \multirow{3}{*}{$\begin{array}{l}\text { expresiones empíricas, y con las } \\
\text { recomendaciones de la norma } \\
\mathrm{ACl}-428-1968\end{array}$} & & & $\rho_{\text {I }}(\%)$ & 5.6 \\
\hline & & & $\rho_{\mathrm{s}}(\%)$ & 1.2 a 6 \\
\hline & & & $\mathrm{f}_{\mathrm{y}}(\mathrm{MPa})$ & 420 a 438 \\
\hline \multicolumn{5}{|l|}{ Conclusiones: } \\
\hline \multicolumn{5}{|c|}{$\begin{array}{l}\text { Establecer un rango para la longitud de rótula pl } \\
\text { simple expresión. Los valores límites recomendad } \\
\text { parece ser un rango acertado para estimar la long } \\
\text { (hasta } 80 \mathrm{MPa} \text { ). Es necesario obtener mayor inf } \\
\text { observación y soportes con elevados niveles d } \\
\text { resistencia del hormigón. }\end{array}$} \\
\hline
\end{tabular}


Sakai, K. y Sheikh, S. A, (1989) [116]

\begin{tabular}{|c|c|c|c|}
\hline Objetivo: & № Ensayos & $\begin{array}{l}\text { Paráme } \\
\text { estudio }\end{array}$ & \\
\hline \multirow{2}{*}{$\begin{array}{l}\text { El objetivo general de este } \\
\text { programa de investigación es } \\
\text { relacionar los parámetros de } \\
\text { diseño tales como, la distribución } \\
\text { del acero, las combinaciones de }\end{array}$} & Tipo de ensayo & $\mathrm{f}_{\mathrm{c}}$ (Mpa) & 32 \\
\hline & Programa Experimental & $N / A_{g} f_{c}$ & $\begin{array}{l}0.47 \mathrm{a} \\
0.77\end{array}$ \\
\hline $\begin{array}{l}\text { carga, la cantidad de acero } \\
\text { lateral, la separación entre } \\
\text { cercos, y la presencia de }\end{array}$ & \multirow{4}{*}{$\begin{array}{l}\text { Se ensayaron seis soportes con } \\
\text { stub, sometidos a carga lateral } \\
\text { cíclica simultáneamente con carga } \\
\text { axial constante. El axil reducido } \\
\left(\mathrm{P} / \mathrm{A}_{\mathrm{g}} \mathrm{f}_{\mathrm{c}}\right) \text { varía entre } 0.47 \text { y } 0.77 \text {. Estos } \\
\text { altos niveles de carga axial fueron } \\
\text { utilizados en la investigación, } \\
\text { considerando que varios códigos de } \\
\text { diseño permiten altos niveles de } \\
\text { carga axial y que los efectos } \\
\text { benéficos del confinamiento son más } \\
\text { relevantes para dichos niveles. }\end{array}$} & $\lambda_{g}=\mathrm{L} / \mathrm{h}$ & 3 \\
\hline $\begin{array}{l}\text { restricciones externas en el } \\
\text { comportamiento de los }\end{array}$ & & $\rho_{\mathrm{I}}(\%)$ & 2.44 \\
\hline $\begin{array}{l}\text { ductilidad, la absorción de } \\
\text { energía, y la longitud de la rotula }\end{array}$ & & $\rho_{\mathrm{s}}(\%)$ & 1.3 a 3 \\
\hline $\begin{array}{l}\text { plástica. Con el propósito de } \\
\text { establecer líneas de guía para el } \\
\text { diseño de la armadura de } \\
\text { confinamiento. }\end{array}$ & & $\mathrm{f}_{\mathrm{y}}$ (Mpa) & 414 \\
\hline
\end{tabular}

Conclusiones:

La configuración del acero, incluyendo el tipo de soporte lateral suministrado a las barras longitudinales, tiene una importante función en el comportamiento del soporte. Los soportes con solo cuatro barras soportadas en las esquinas atadas a los cercos funcionan deficientemente, mientras la configuración en la cual las barras son soportadas apropiadamente, el funcionamiento es mejor. Un incremento en la cuantía de acero lateral mejora significativamente la resistencia, ductilidad, y la capacidad de absorción de energía de los soportes.

Bayrak, O. y Sheikh, S. A. (1997) [18]

\begin{tabular}{|c|c|c|c|c|}
\hline Objetivo: & oㅡ Ensayos & 4 & \multicolumn{2}{|c|}{$\begin{array}{l}\text { Parámetros } \\
\text { estudio }\end{array}$} \\
\hline \multirow{6}{*}{$\begin{array}{l}\text { Evaluar el comportamiento de soportes } \\
\text { de HAR en ductilidad y resistencia, así } \\
\text { como examinar críticamente las } \\
\text { recomendaciones de confinamiento } \\
\text { según el código ACl. Las variables } \\
\text { estudiadas son la resistencia del } \\
\text { hormigón, la configuración del } \\
\text { refuerzo, nivel de carga axial, y el } \\
\text { aumento en la eficacia del soporte } \\
\text { lateral suministrado a las barras } \\
\text { longitudinales. }\end{array}$} & sayo & 8 & $\mathrm{f}_{\mathrm{c}}(\mathrm{MPa})$ & 72 \\
\hline & \multicolumn{2}{|c|}{ Programa Experimental } & $N / A_{g} f_{c}$ & \\
\hline & \multicolumn{2}{|c|}{$\begin{array}{l}\text { Se ensayaron } 4 \text { soportes-stub } \\
\text { hechos con HAR de } 72 \mathrm{MPa} \text { con }\end{array}$} & $\lambda_{\mathrm{g}}=\mathrm{L} / \mathrm{h}$ & 6 \\
\hline & \multicolumn{2}{|c|}{$\begin{array}{l}\text { moderados y altos niveles de } \\
\text { carga axial y ciclos de } \\
\text { desplazamientos lateral. Los }\end{array}$} & $\rho_{\text {I }}(\%)$ & 2.58 \\
\hline & \multicolumn{2}{|c|}{$\begin{array}{l}\text { resultados fueron comparados } \\
\text { con los realizados en estudios }\end{array}$} & $\rho_{\mathrm{s}}(\%)$ & 2.8 a 5.1 \\
\hline & anteri & & $\mathrm{f}_{\mathrm{y}}(\mathrm{Mpa})$ & \\
\hline \multicolumn{5}{|l|}{ Conclusiones: } \\
\hline \multicolumn{5}{|r|}{$\begin{array}{l}\text { y carga } \\
\text { rado por } \\
\text { para las } \\
\text { cidad de } \\
\text { to de la } \\
\text { encia en } \\
\text { ıerzo de } \\
\text { gía y la } \\
\text {. }\end{array}$} \\
\hline
\end{tabular}


Bayrak, O. y Sheikh, S. A, (1998) [16]

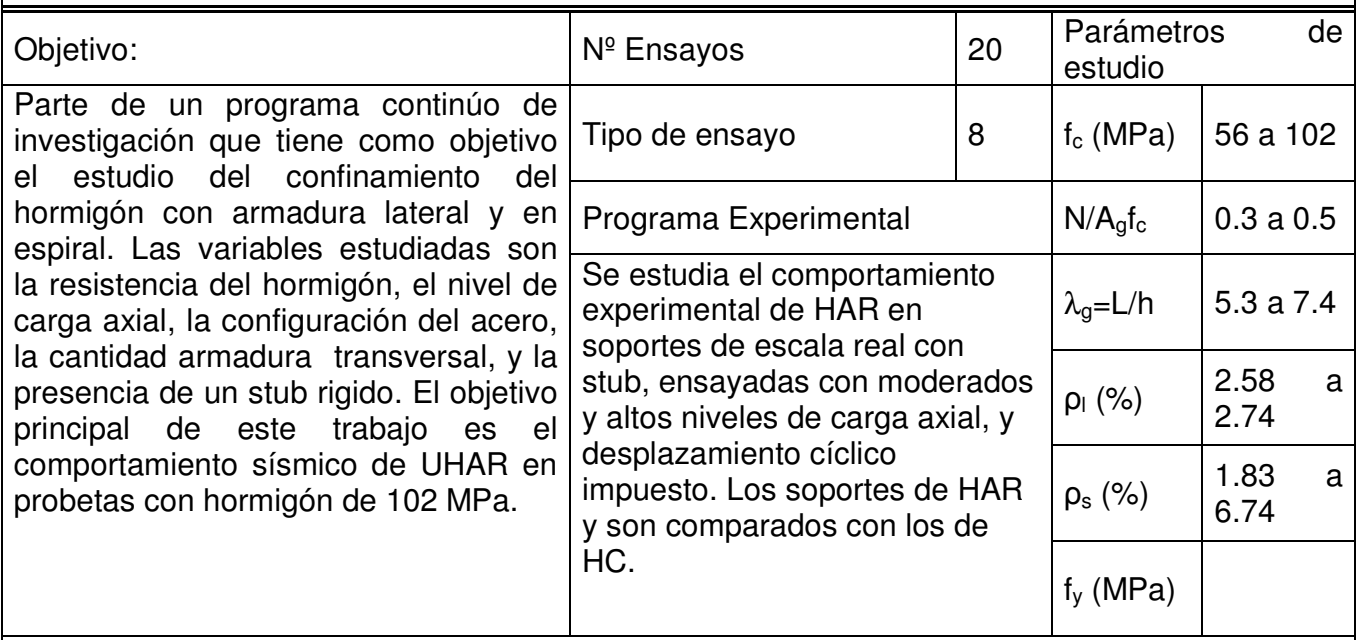

Conclusiones:

Las columnas de UHAR pueden comportarse de una manera dúctil bajo altos niveles de carga axial, proporcionando una cantidad adecuada de armadura lateral y el uso de una configuración adecuada de los cercos. Un incremento en la carga axial reduce considerablemente los parámetros de deformabilidad y ductilidad, acelerando los esfuerzos y degradando la rigidez en cada ciclo de carga. La configuración de la armadura de confinamiento y el nivel de carga axial deberían considerarse en el diseño de la armadura de confinamiento. Para altos valores de resistencia del hormigón se da una menor deformabilidad y absorción de energía y capacidad de disipación inicial, pero durante la siguiente parte del recorrido de desplazamiento, estas propiedades mejoran rápidamente y dan valores comparables a soportes con menor resistencia del hormigón.

Légeron, F. y Paultre, P. (2000) [78]

\begin{tabular}{|c|c|c|c|}
\hline Objetivo: & \multirow{2}{*}{\begin{tabular}{|l|} 
№ Ensayos \\
Tipo de ensayo
\end{tabular}} & \multicolumn{2}{|c|}{$\begin{array}{l}\text { Parámetros } \\
\text { estudio }\end{array}$} \\
\hline \multirow{6}{*}{ 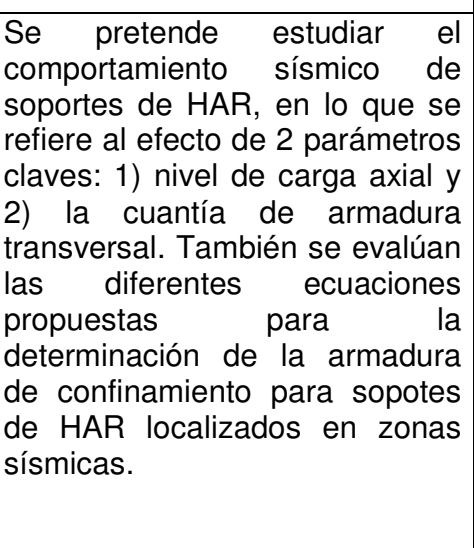 } & & $\mathrm{f}_{\mathrm{c}}(\mathrm{MPa})$ & 92 a 104 \\
\hline & Programa Experimental & $N / A_{g} f_{c}$ & $\begin{array}{l}0.14,0.30 \\
\text { y } 0.40\end{array}$ \\
\hline & \multirow{4}{*}{$\begin{array}{l}6 \text { soportes de gran escala de HAR } \\
\text { son sometidos a esfuerzos de carga } \\
\text { axial correspondientes a valores de } \\
15,25 \text { y } 40 \% \text { de la capacidad de } \\
\text { carga de compresión última y carga } \\
\text { cíclica horizontal. Las probetas } \\
\text { ensayadas están unidas } \\
\text { monolíticamente a un elemento stub. } \\
\text { La carga transversal es aplicada en el } \\
\text { extremo del elemento. }\end{array}$} & $\lambda_{g}=\mathrm{L} / \mathrm{h}$ & 7 \\
\hline & & $\rho_{\mathrm{l}}(\%)$ & 2.1 \\
\hline & & $\rho_{\mathrm{s}}(\%)$ & $\begin{array}{l}1.96 \\
4.26\end{array}$ \\
\hline & & $\mathrm{f}_{\mathrm{y}}(\mathrm{MPa})$ & $390-450$ \\
\hline \multicolumn{4}{|l|}{ Conclusiones: } \\
\hline \multicolumn{4}{|c|}{$\begin{array}{l}\text { Se demuestra que la separación entre cercos y el nivel de carga axial tienen efectos } \\
\text { significativos en el comportamiento a flexión de soportes de HAR. La necesidad de incluir los } \\
\text { efectos del nivel de carga axial son claves para los requerimientos de armadura de } \\
\text { confinamiento. Los soportes de HAR pueden comportarse de manera dúctil y por tanto usarse } \\
\text { en zonas sísmicas bajo la condición que tengan un adecuado confinamiento. }\end{array}$} \\
\hline
\end{tabular}


Ang, B. G., Priestley, M. J. N. y Park, R. (1981) [5]

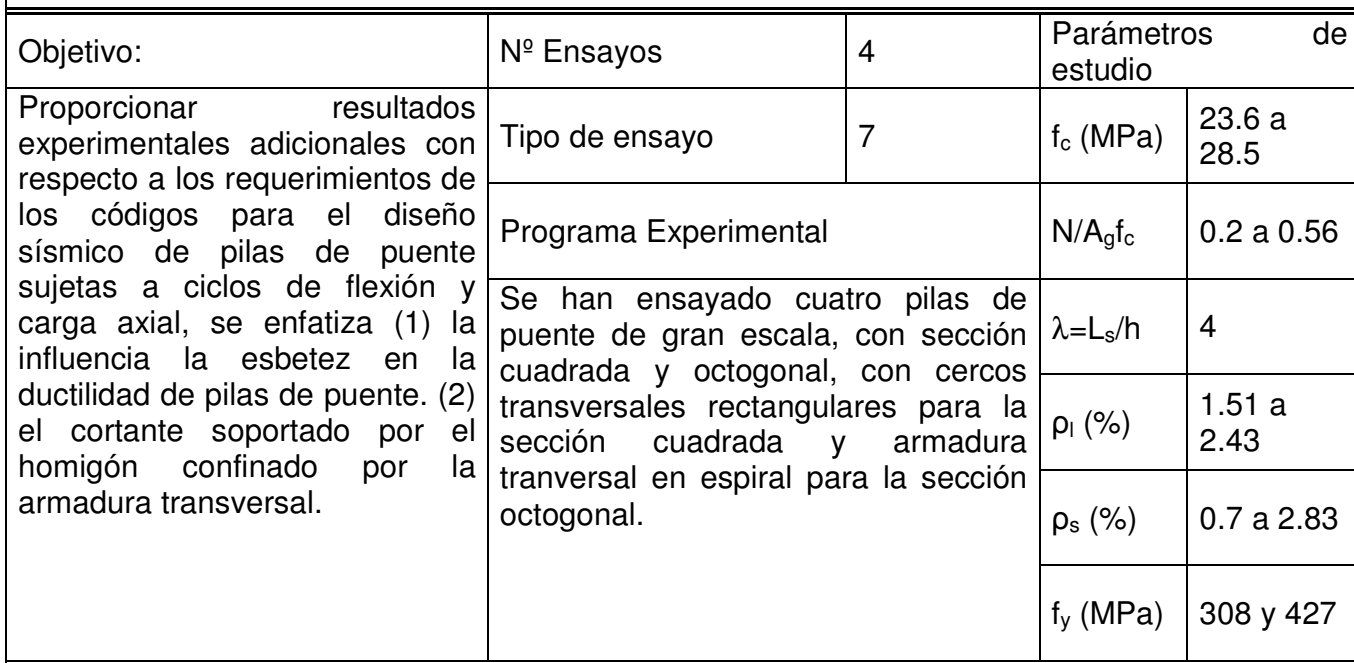

Conclusiones:

Si la región de rótula plástica está adecuadamente confinada, la influencia de la esbeltez es insignificante. $L_{p}$ no depende del factor de ductilidad de desplazamiento, ni hasta cierto punto del nivel de carga axial. $L_{p}$ se puede razonablemente establecer en aproximadamente $0.5 \mathrm{H}$, para todos los ensayos.Puede que se necesiten más ensayos en otros niveles de carga axial para investigar la influencia de la esbeltez, para confirmar mejor las cnclusiones.

\section{F. A. Zahn, 1986 [138]}

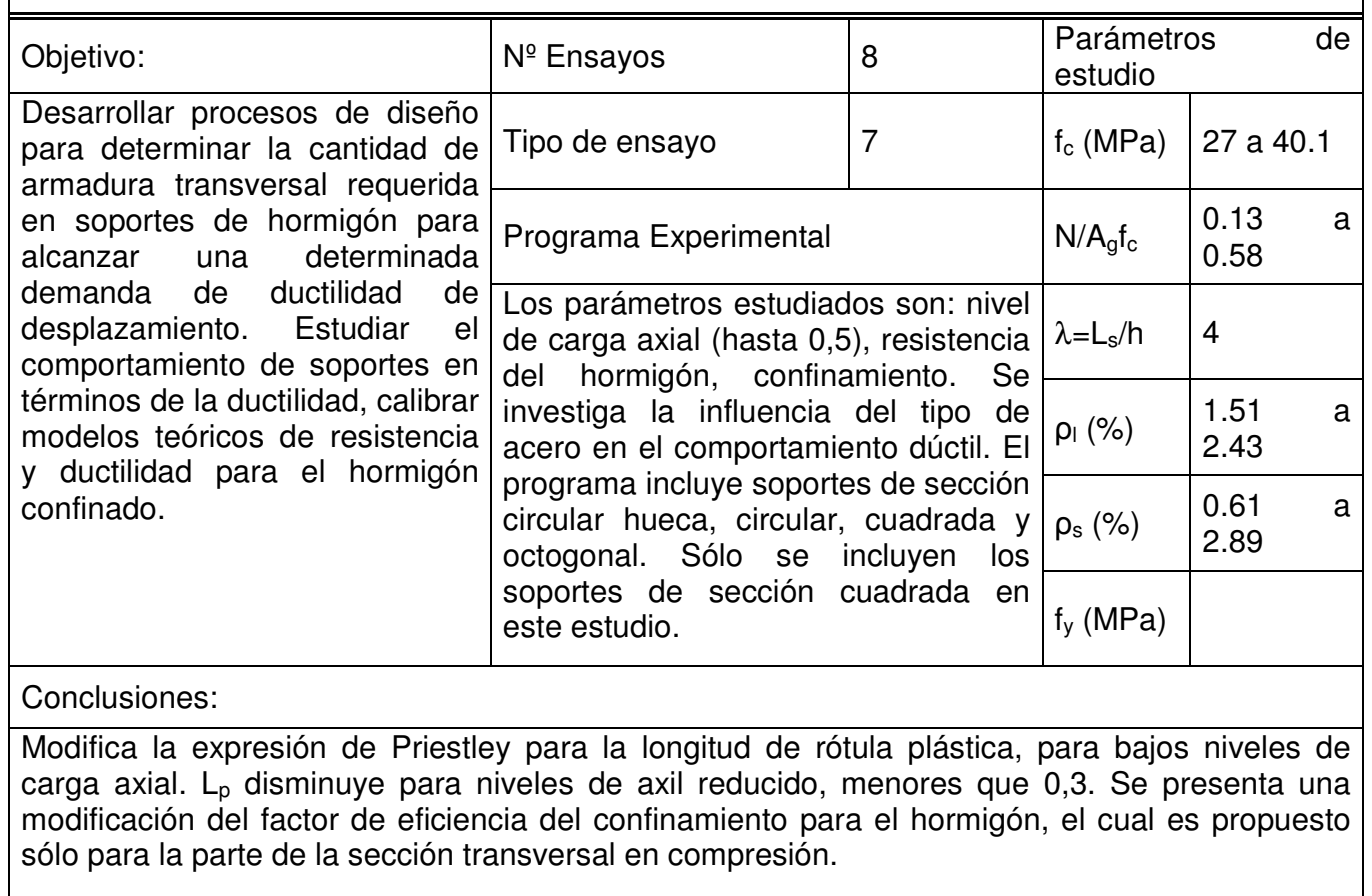


Verderame, G. M., Fabbrocino, G. y Manfredi, G. (2008) [131]

\begin{tabular}{l} 
Objetivo: \\
\hline Estudiar experimentalmente el \\
comportamiento sísmico de \\
soportes de hormigón armado \\
diseñados siguiendo códigos \\
obsoletos que datan de entre \\
los años 40 y 70 y sujetos a \\
carga axial y flexión. Se centra \\
la atención en la capacidad de \\
rotación de elementos bajo \\
carga monotónica, como parte \\
de una investigación más \\
amplia que incluye también la \\
carga cíclica. Se pretende \\
evaluar la capacidad de \\
deformación de elementos \\
dependiendo del mecanismo de \\
flexión inelástica y de \\
deslizamiento de la armadura \\
en la base (rotación en el \\
extremo fijo).
\end{tabular}

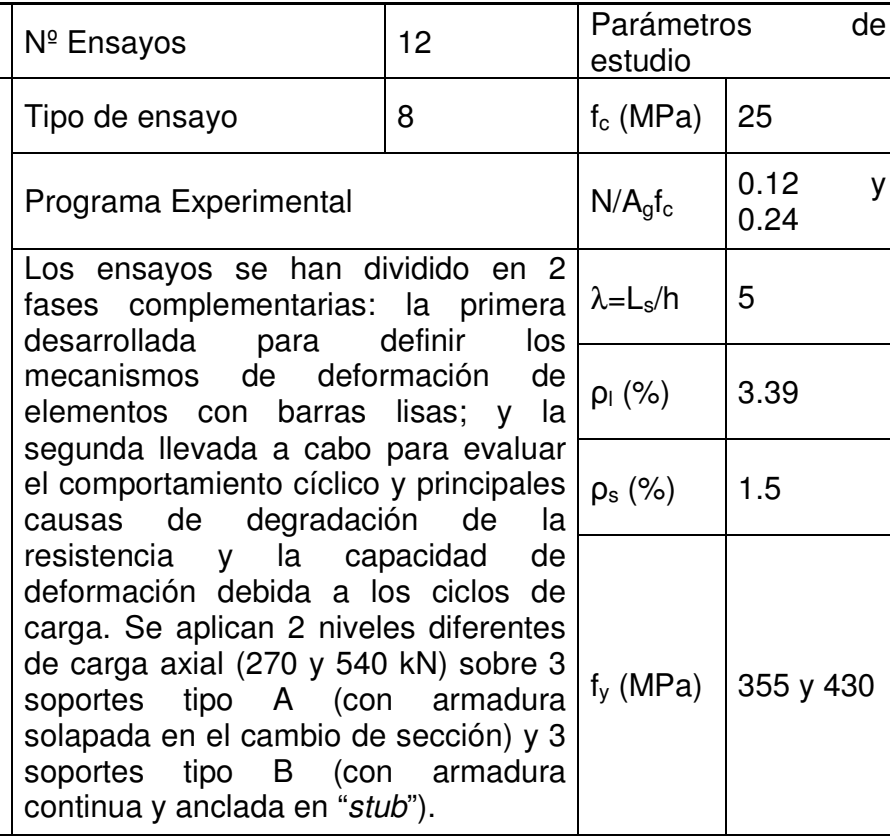

Conclusiones:

La deriva última evaluada convencionalmente en el 15\% de la caída post-pico es similar a los valores observados para elementos de hormigón con detalle sísmico. La respuesta deformacional en elementos con barras lisas es muy diferente de la respuesta en elementos con barras corrugadas. El papel significativo de la rotación en la base debida a la gran abertura de fisura en el interfaz entre el soporte y el elemento de base "stub" depende de la amplia propagación de la plastificación tanto en la base (llamada rotación en el extremo fijo) como en el soporte (llamado región plástica) y está estrictamente relacionada con el comportamiento de adherencia de las barras lisas.

Bae, Sungjin, 2005 [12]

\begin{tabular}{|c|c|c|c|c|}
\hline Objetivo: & \multirow{2}{*}{\begin{tabular}{|l} 
№ Ensayos \\
Tipo de ensayo
\end{tabular}} & \multirow[t]{2}{*}{5} & \multicolumn{2}{|c|}{$\begin{array}{ll}\text { Parámetros } & \text { de } \\
\text { estudio }\end{array}$} \\
\hline \multirow{6}{*}{$\begin{array}{l}\text { Investigar la relación entre } \\
\text { varios parámetros de ductilidad } \\
\text { considerando el efecto de la } \\
\text { esbeltez y el nivel de carga axial } \\
\text { para desarrollar métodos y } \\
\text { procesos que puedan ser } \\
\text { usados para estimar la } \\
\text { capacidad de deformación en } \\
\text { soportes de hormigón armado. }\end{array}$} & & & $\mathrm{f}_{\mathrm{c}}(\mathrm{MPa})$ & 28 y 41 \\
\hline & \multicolumn{2}{|c|}{ Programa Experimental } & $\mathrm{N} / \mathrm{N}_{\mathrm{u}}$ & 0.2 y 0.5 \\
\hline & \multirow{4}{*}{\multicolumn{2}{|c|}{$\begin{array}{l}\text { El trabajo experimental fue diseñado } \\
\text { para investigar los efectos de la } \\
\text { esbeltez, el nivel de carga axial y la } \\
\text { armadura de confinamiento en el } \\
\text { comportamiento de soportes. }\end{array}$}} & $\lambda=\mathrm{L}_{\mathrm{s}} / \mathrm{h}$ & 7 \\
\hline & & & $\rho_{\mathrm{I}}(\%)$ & $\begin{array}{l}1.25 \\
2.08\end{array}$ \\
\hline & & & $\rho_{\mathrm{s}}(\%)$ & $\begin{array}{l}0.72 \\
2.04\end{array}$ \\
\hline & & & $\mathrm{f}_{\mathrm{y}}(\mathrm{MPa})$ & 450 a 500 \\
\hline \multicolumn{5}{|l|}{ Conclusiones: } \\
\hline \multicolumn{5}{|c|}{$\begin{array}{l}\text { Se proponen dos métodos para estimar la capacidad de deformación en soportes de hormigón. } \\
\text { El primero consiste en un método analítico riguroso que tiene en cuenta los modelos } \\
\text { constitutivos del hormigón confinado, el pandeo de la armadura y las deformaciones debidas a } \\
\text { flexión, cortante y deslizamiento de la armadura. Además, considera los efectos P- } \Delta \text {. El } \\
\text { segundo método es una ecuación simple desarrollada a partir de la base de datos del } \\
\text { UW/PEER. }\end{array}$} \\
\hline
\end{tabular}


Park R., Priestley M., Gill W. D. (1982) [102]

\begin{tabular}{|c|c|c|c|c|}
\hline \multirow{7}{*}{$\begin{array}{l}\text { Objetivo: } \\
\text { Estudiar la influencia de la } \\
\text { cantidad de ganchos } \\
\text { rectangulares requeridos por } \\
\text { diversas normas de diseño } \\
\text { sísmico en la potencial zona de } \\
\text { rotula plástica de soportes de } \\
\text { hormigón armado rectangulares. }\end{array}$} & \multirow{2}{*}{$\begin{array}{l}\text { № Ensayos } \\
\text { Tipo de ensayo }\end{array}$} & \multirow[t]{2}{*}{4} & \multicolumn{2}{|c|}{$\begin{array}{l}\text { Parámetros } \\
\text { estudio }\end{array}$} \\
\hline & & & $\mathrm{f}_{\mathrm{c}}(\mathrm{MPa})$ & $\begin{array}{l}21.4 \\
41.4\end{array}$ \\
\hline & \multicolumn{2}{|c|}{ Programa Experimental } & $\mathrm{N} / \mathrm{N}_{\mathrm{u}}$ & 0.21 a 0.6 \\
\hline & \multirow{4}{*}{\multicolumn{2}{|c|}{$\begin{array}{l}\text { Se realizan ensayos en cuatro } \\
\text { soportes de hormigón armado casi a } \\
\text { escala real, con sección transversal } \\
\text { cuadrada de } 550 \text { mm, diferentes } \\
\text { niveles de carga axial y varias } \\
\text { cuantías de armadura transversal. La } \\
\text { disposición de ganchos fue diseñada } \\
\text { de acuerdo con las recomendaciones } \\
\text { de la norma de hormigón armado en } \\
\text { Nueva Zelanda (DZ 31-01:1978). }\end{array}$}} & $\lambda=L_{s} / h$ & 2.2 \\
\hline & & & $\rho_{\mathrm{I}}(\%)$ & 1.79 \\
\hline & & & $\rho_{\mathrm{s}}(\%)$ & 1.5 a 3.5 \\
\hline & & & $\mathrm{f}_{\mathrm{y}}(\mathrm{MPa})$ & \\
\hline \multicolumn{5}{|l|}{ Conclusiones: } \\
\hline \multicolumn{5}{|c|}{$\begin{array}{l}\text { Los soportes mostraron un comportamiento muy dúctil cuando se aplicaba una simulación de } \\
\text { carga sísmica hasta lograr un factor de ductilidad de desplazamiento de al menos } 6 \text {, } \\
\text { confirmando la conveniencia de las normas de diseño propuestas. Una mejora considerable de } \\
\text { la resistencia a flexión se observo con respecto a la calculada por medio de los procedimientos } \\
\text { de códigos de diseño normales, pero la mejora podría atribuirse a una mayor resistencia del } \\
\text { hormigón confinado. }\end{array}$} \\
\hline
\end{tabular}

Donde

HC Hormigón convencional

HAR Hormigón de alta resistencia

$\mathrm{f}_{\mathrm{c}} \quad$ Resistencia del hormigón en compresión

$\mathrm{N} / \mathrm{Nu} \quad$ Nivel de carga axial

$\lambda \quad$ Esbeltez de cortante $\left(L_{s} / h\right)$

$\lambda_{\mathrm{g}} \quad$ Esbeltez geométrica $(\mathrm{L} / \mathrm{h})$

h $\quad$ Canto de la sección transversal

L Longitud entre apoyos del elemento

$\mathrm{L}_{\mathrm{s}} \quad$ Distancia entre las seccines de momento máximo y el momento nulo

$\rho_{\mathrm{l}} \quad$ Cuantía de armadura longitudinal

$\rho_{s} \quad$ Cuantía de armadura transversal

$f_{y} \quad$ Límite elástico del acero

$\mathrm{N} / \mathrm{A}_{\mathrm{g}} \mathrm{f}_{\mathrm{c}} \quad$ Axil reducido

$\mathrm{A}_{\mathrm{g}} \quad$ Area de la sección transversal de hormigón

N Carga axial aplicada

$\mathrm{N}_{\mathrm{u}} \quad$ Carga axial última 
Estudio experimental y numérico de la capacidad de deformación de soportes esbeltos de hormigón armado 
Anejo B.

RESULTADOS DE LA RESISTENCIA DEL HORMIGÓN EN COMPRESIÓN EN PROBETAS CILINDRICAS

\begin{tabular}{|c|c|c|c|c|c|c|c|}
\hline \multirow{3}{*}{$\mathrm{N}^{\circ}$} & \multirow{3}{*}{ REFERENCIA } & \multicolumn{2}{|c|}{ Amasada 1} & \multicolumn{2}{|c|}{ Amasada 2} & \multirow{2}{*}{$\begin{array}{c}{ }^{*} \text { Resistencia } \\
\text { media }\end{array}$} & \multirow{2}{*}{${ }^{* *} \mathrm{C} . \mathrm{V}$} \\
\hline & & 1 & 2 & 3 & 4 & & \\
\hline & & $\mathrm{fc}(\mathrm{MPa})$ & fc (MPa) & fc (MPa) & fc (MPa) & $f^{\prime} c(\mathrm{MPa})$ & (\%) \\
\hline 1 & N30-10.5-C0-2-00 & 35,50 & 36,50 & 35,50 & 37,70 & 36,60 & $2,9 \%$ \\
\hline 2 & N30-10.5-C0-2-15 & 30,80 & 28,00 & 31,60 & 31,90 & 31,75 & $5,3 \%$ \\
\hline 3 & N30-10.5-C0-2-30 & 33,00 & 30,80 & 30,80 & 32,40 & 31,60 & $3,5 \%$ \\
\hline 4 & N30-10.5-C0-2-45 & 32,40 & 36,00 & 33,00 & 36,00 & 34,50 & $5,6 \%$ \\
\hline 5 & N30-7.5-C0-2-30 & 31,80 & 32,00 & 30,60 & 29,60 & 30,10 & $3,6 \%$ \\
\hline 6 & N30-7.5-C0-2-45 & 35,40 & 36,00 & 32,80 & 33,20 & 33,00 & $4,6 \%$ \\
\hline 7 & N30-15-C0-2-30 & 33,80 & 35,20 & 31,30 & 34,10 & 32,70 & $4,9 \%$ \\
\hline 8 & N30-15-C0-2-45 & 31,50 & 31,30 & 33,40 & 32,40 & 32,90 & $3,0 \%$ \\
\hline 9 & N30-10.5-C0-1-30 & 40,50 & 43,30 & 43,10 & 41,20 & 42,20 & $3,3 \%$ \\
\hline 10 & N30-10.5-C0-1-45 & 37,10 & 33,40 & 36,20 & 34,20 & 35,20 & $4,9 \%$ \\
\hline 11 & N30-10.5-C0-3-15 & 34,10 & 31,90 & 33,60 & 32,40 & 33,00 & $3,1 \%$ \\
\hline 12 & N30-10.5-C0-3-30 & 37,70 & 36,90 & 29,10 & 29,90 & 29,50 & $13,6 \%$ \\
\hline 13 & H60-10.5-C0-2-00 & 60,70 & 60,70 & 54,90 & 56,80 & 55,80 & $5,0 \%$ \\
\hline 14 & H60-10.5-C0-2-15 & 55,70 & 54,60 & 54,10 & 54,10 & 54,10 & $1,4 \%$ \\
\hline 15 & H60-10.5-C0-2-30 & 61,00 & 62,90 & 63,20 & 57,70 & 60,45 & $4,1 \%$ \\
\hline 16 & H60-10.5-C0-2-45 & 62,10 & 62,70 & 63,10 & 64,70 & 63,90 & $1,8 \%$ \\
\hline 17 & H60-7.5-C0-2-30 & 61,80 & 72,10 & 58,30 & 67,70 & 63,00 & $9,4 \%$ \\
\hline 18 & $\mathrm{H} 60-7.5-\mathrm{C} 0-2-45$ & 72,70 & 66,60 & 63,80 & 71,50 & 67,65 & $6,1 \%$ \\
\hline 19 & H60-15-C0-2-30 & 61,60 & 61,30 & 56,80 & 59,60 & 58,20 & $3,7 \%$ \\
\hline 20 & H60-15-C0-2-45 & 62,70 & 61,60 & 58,50 & 58,80 & 58,65 & $3,4 \%$ \\
\hline 21 & H60-10.5-C0-1-15 & 65,00 & 66,30 & 60,30 & 55,35 & 57,83 & $8,1 \%$ \\
\hline 22 & H60-10.5-C0-1-30 & 55,70 & 59,30 & 57,70 & 59,30 & 58,50 & $2,9 \%$ \\
\hline 23 & H60-10.5-C0-3-15 & 53,20 & 56,00 & 58,40 & 58,20 & 58,30 & $4,3 \%$ \\
\hline 24 & H60-10.5-C0-3-30 & 56,00 & 57,10 & 61,10 & 62,10 & 61,60 & $5,0 \%$ \\
\hline 25 & H90-10.5-C0-2-00 & 85,70 & 90,10 & 89,30 & 93,40 & 91,35 & $3,5 \%$ \\
\hline 26 & H90-10.5-C0-2-15 & 92,60 & 97,60 & 88,70 & 92,30 & 90,50 & $3,9 \%$ \\
\hline 27 & H90-10.5-C0-2-30 & 93,20 & 94,30 & 89,10 & 91,10 & 90,10 & $2,5 \%$ \\
\hline 28 & H90-10.5-C0-2-45 & 88,70 & 91,80 & 91,00 & 95,40 & 93,20 & $3,0 \%$ \\
\hline 29 & $\mathrm{H} 90-7.5-\mathrm{C} 0-2-30$ & 96,50 & 99,80 & 99,80 & 100,90 & 100,35 & $1,9 \%$ \\
\hline 30 & H90-7.5-C0-2-45 & 97,10 & 90,10 & 95,90 & 92,10 & 94,00 & $3,5 \%$ \\
\hline 31 & H90-10.5-C0-1-15 & 95,40 & 97,60 & 89,00 & 91,50 & 90,25 & $4,1 \%$ \\
\hline 32 & H90-10.5-C0-1-30 & 95,40 & 96,50 & 100,90 & 91,50 & 96,20 & $4,0 \%$ \\
\hline 33 & H90-10.5-C0-3-15 & 88,70 & 89,60 & 88,00 & 91,20 & 89,60 & $1,5 \%$ \\
\hline 34 & $-C 0-3-30$ & 88,70 & 100,10 & 97,10 & 94,30 & 94,35 & $5,1 \%$ \\
\hline 35 & N30-10.5-C3-2-30 & 39,90 & 39,90 & 41,00 & 41,00 & 41,00 & $1,6 \%$ \\
\hline 36 & N30-10.5-C3-2-45 & 37,30 & 35,80 & 37,30 & 31,10 & 34,20 & $8,3 \%$ \\
\hline 37 & N30-7.5-C3-2-30 & 37,20 & 34,40 & 34,90 & 36,60 & 35,75 & $3,7 \%$ \\
\hline 38 & N30-7.5-C3-2-45 & 34,50 & 36,80 & 34,60 & 35,40 & 35,00 & $3,0 \%$ \\
\hline 39 & H90-10.5-C3-2-30 & 91,50 & 88,70 & 94,30 & 92,60 & 93,45 & $2,6 \%$ \\
\hline 40 & H90-10.5-C3-2-45 & 95,70 & 90,70 & 89,30 & 94,60 & 91,95 & $3,3 \%$ \\
\hline 41 & H9O-7.5-C3-2-30 & 73,40 & 77,60 & 84,00 & 88,70 & 86,35 & $8,4 \%$ \\
\hline 42 & H90-7.5-C3-2-45 & 79,90 & $\overline{77,60}$ & 83,10 & 73,35 & 78,23 & $5,2 \%$ \\
\hline 43 & $\mathrm{H} 90-7.5-\mathrm{C} 2-2-30$ & 89,80 & 97,10 & 98,20 & 93,20 & 95,70 & $4,1 \%$ \\
\hline 44 & H9O-7.5-C2-2-45 & 88,80 & 89,40 & 87,40 & 91,00 & 89,20 & $1,7 \%$ \\
\hline \multicolumn{8}{|c|}{$\begin{array}{l}\text { * La resistencia característica es el promedio de las probetas de la amasada 2, que corresponde al hormigón } \\
\text { dispuesto en el brazo del soporte instrumentado }\end{array}$} \\
\hline & & & & & & & \\
\hline
\end{tabular}


Estudio experimental y numérico de la capacidad de deformación de soportes esbeltos de hormigón armado 


\section{ANEJO C.}

\section{DESCRIPCIÓN DEL PÓRTICO DE CARGA Y PROCESO CONSTRUCTIVO DE SOPORTES}

\section{DESCRIPCIÓN DEL PÓRTICO DE CARGA}

El esquema general del pórtico de carga está compuesto por cuatro sistemas cuya estructura y funcionamiento se explican a continuación.

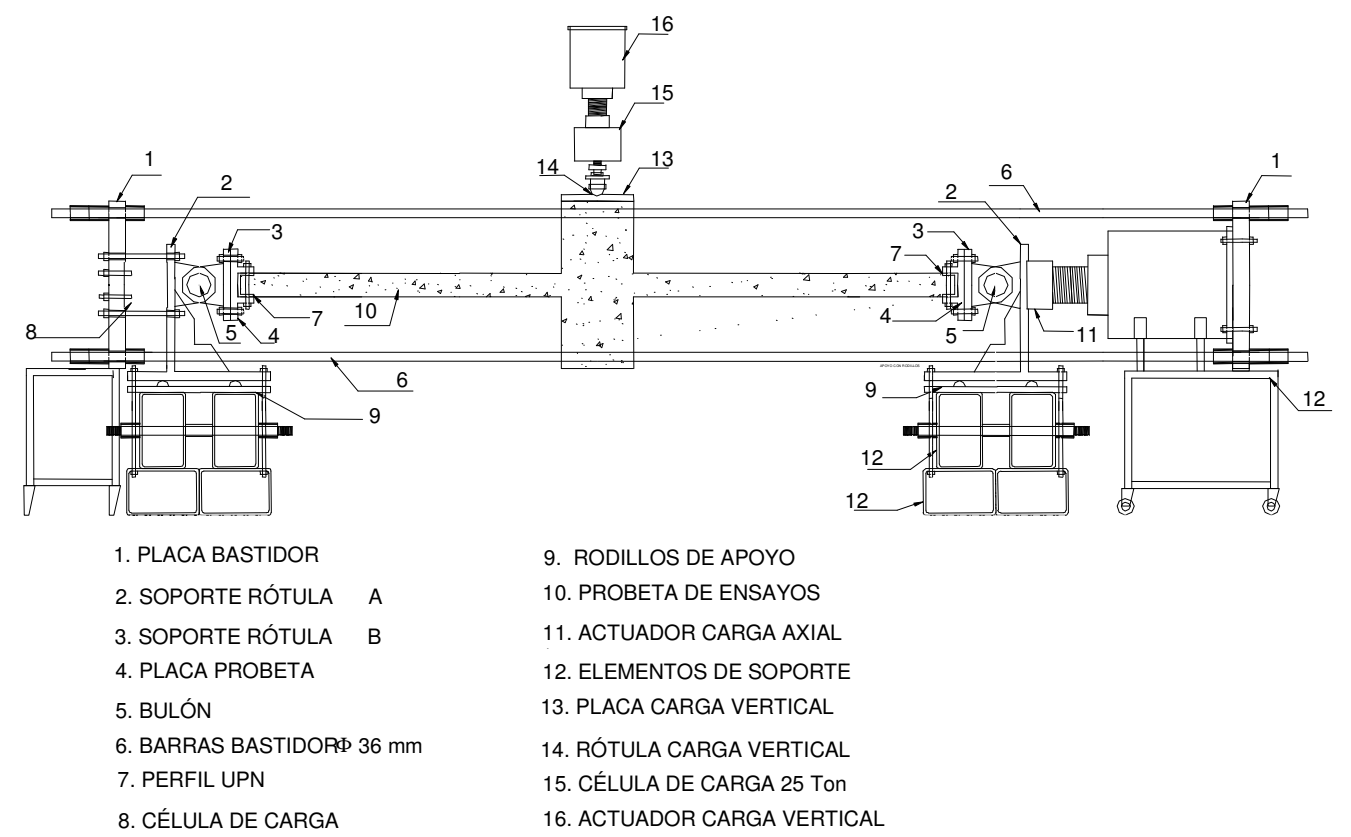

Figura 1. Esquema genera del pórtico de carga

\section{Bastidor y sistema de carga axial}

El bastidor está formado por dos placas en los extremos, unidas mediante cuatro barras de acero. Una de las placas está sujeta a un soporte fijo anclado al suelo, de la cual se sujeta la célula de carga, mediante uniones atornilladas. En la placa del otro extremo se ha dispuesto un actuador hidráulico de $250 \mathrm{~T}$. Estos elementos se apoyan sobre un soporte deslizante, con el objeto de permitir el libre movimiento horizontal debido a la posible deformación de las barras cuando se comprime el soporte. 


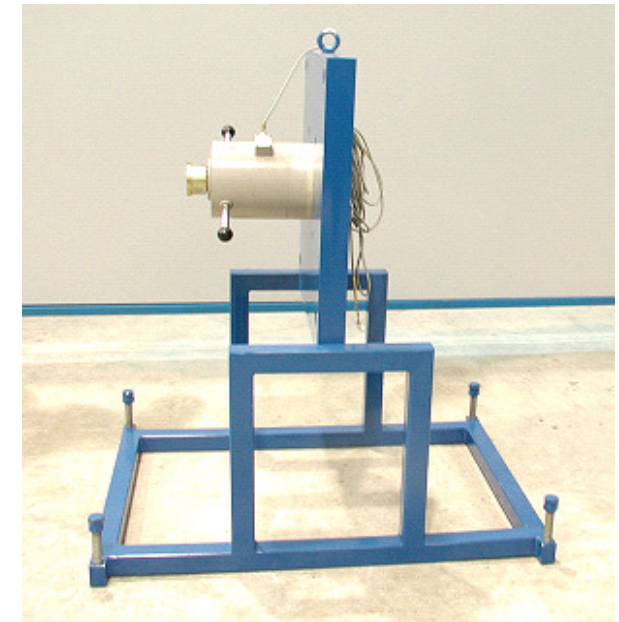

Figura 2. Extremo fijo con célula de carga

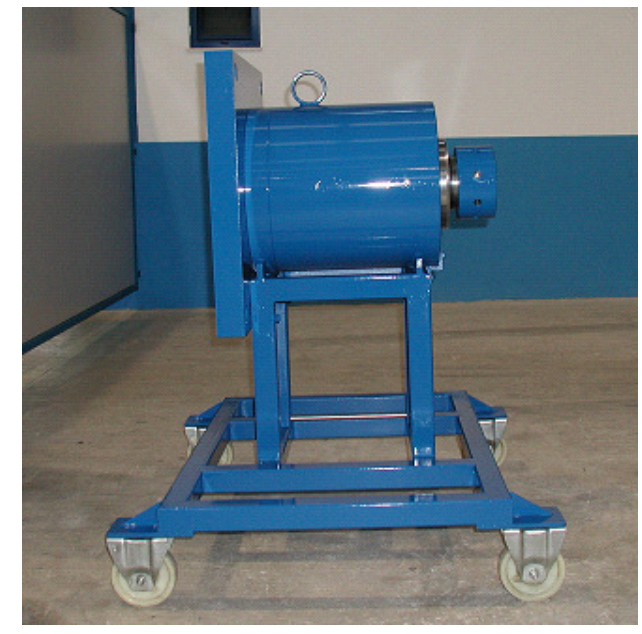

Figura 3. Extremo deslizante con actuador de carga axial de $250 \mathrm{~T}$

\section{Sistema de carga vertical}

La carga vertical es aplicada sobre el "stub". En la Figura 4 se indican los elementos utilizados en la aplicación de la carga vertical:
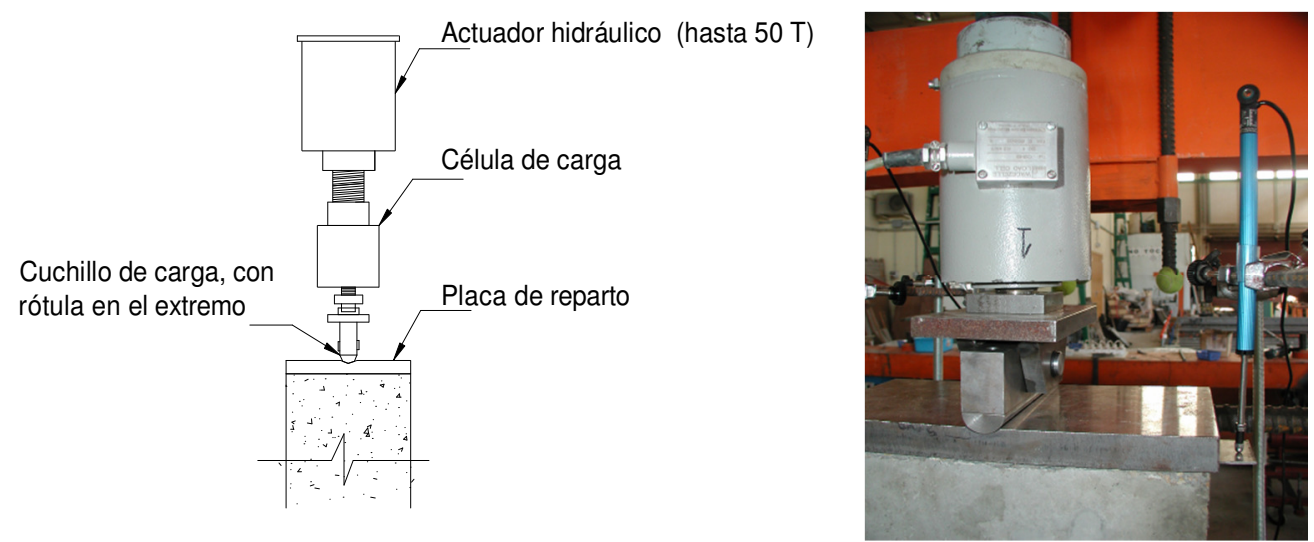

Figura 4 Disposición de elementos utilizados en el sistema de carga vertical

- Placa de reparto: permite que la carga se aplique sobre una superficie uniforme, con el fin de obtener una mejor distribución de la carga.

- Cuchillo de carga: tiene dos objetivos fundamentales: (a) amortiguar las imperfecciones en la alineación y garantizar la nivelación entre la célula de carga y el "elemento rigidizador", y (b) centrar la carga sobre el eje de la placa.

- Célula de carga de $\mathbf{5 0}$ T sobre el eje vertical: mide los valores de carga de flexión aplicados durante todo el ensayo.

- Actuador hidráulico de 50 T: aplica la carga vertical. 


\section{Condiciones de apoyo}

En la Figura 5 se presenta un esquema de los elementos dispuestos para apoyar y sujetar el soporte dentro del pórtico de carga.

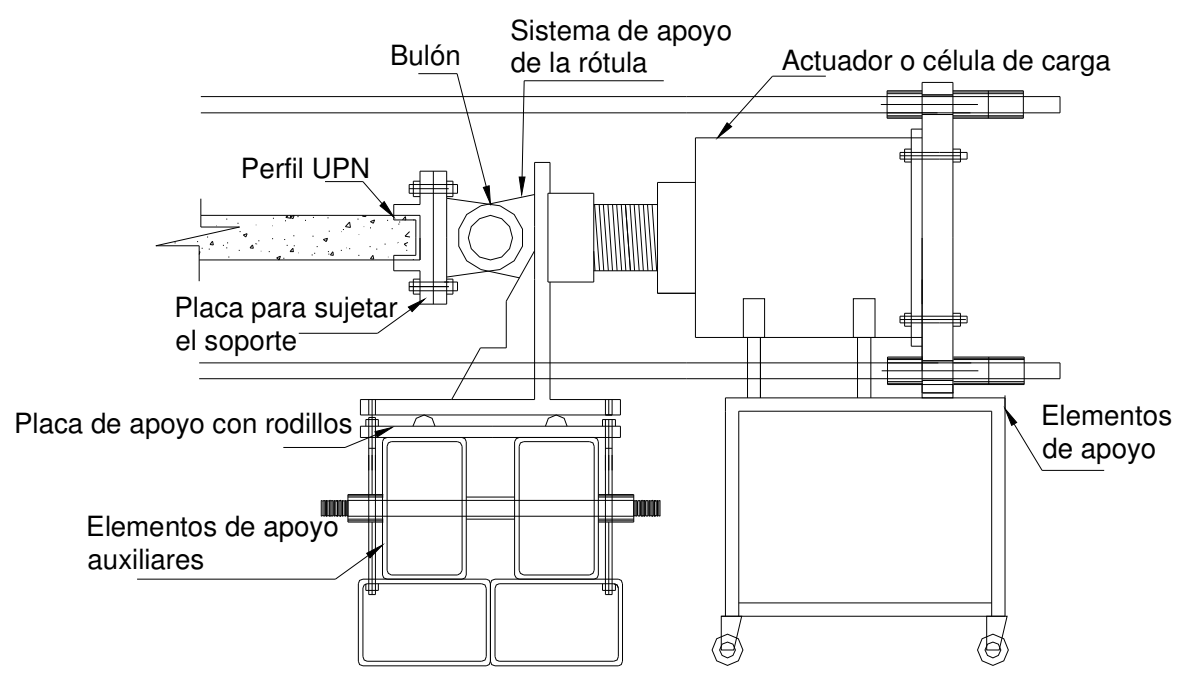

Figura 5 Disposición física de las condiciones de apoyo del soporte.

En cada uno de los extremos laterales del soporte se localizaron sistemas de rótulas para permitir el libre giro del soporte, y también para garantizar que la carga sea aplicada sobre el eje geométrico de la probeta, evitando así los efectos de excentricidad. Este sistema de rótulas está compuesto por dos elementos placa (soporte de rótula $A$ y soporte de rótula $B$ ), conectados mediante un bulón. El primero de los elementos (soporte de rótula $A$ ) se apoya sobre una placa con rodillos que representa la condición de apoyo simple del modelo propuesto. El segundo de los elementos (soporte de rótula B) se conecta, mediante uniones atornilladas, a la placa que sujeta el soporte.

\section{Atado del soporte dentro del pórtico de carga}

En los extremos del soporte se ha dispuesto de un perfil UPN soldado a las barras longitudinales (según detalle de la Figura 11). Con esta disposición, por un lado, se ha podido obtener una superficie plana en los extremos del soporte, y, por otro lado, los cuatro tornillos soldados en la parte posterior del UPN permitieron encajar y asegurar el soporte a una placa diseñada específicamente para sujetar, nivelar y centrar el soporte dentro del pórtico de carga. Las dimensiones de esta placa variaron, dependiendo de la sección transversal del soporte.

En las Figuras 6 a 10, se muestran algunos detalles del pórtico diseñado para el ensayo de soportes esbeltos de hormigón armado sometidos a flexo-compresión monótonica. 


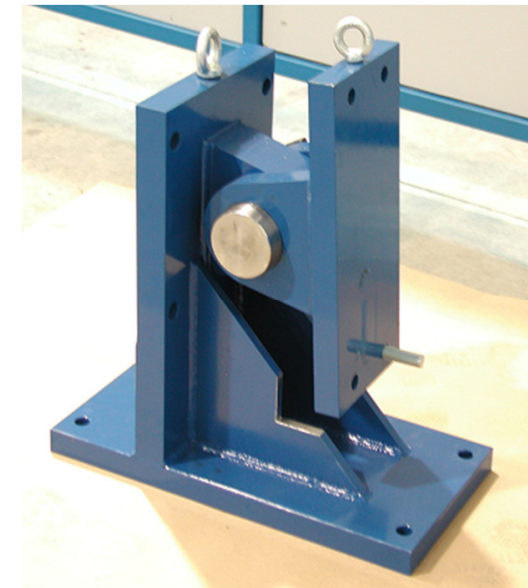

Figura 6 Sistema de acople de la rótula.

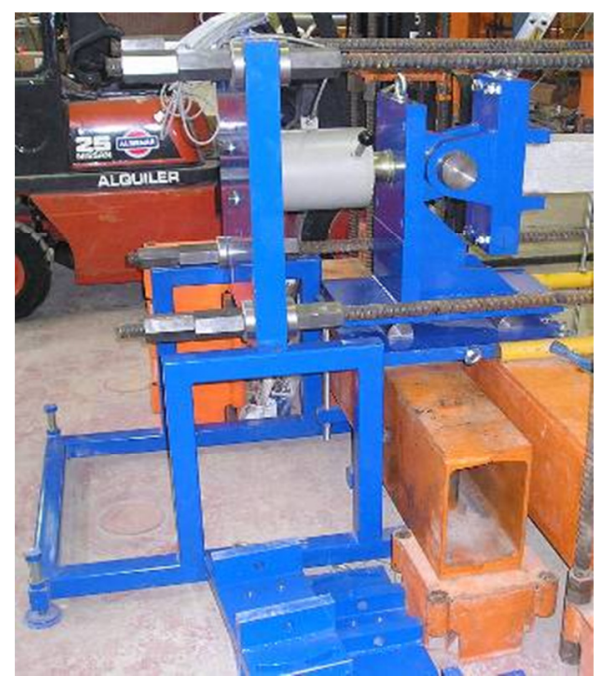

Figura 8 Vista general del extremo izquierdo del pórtico de carga.

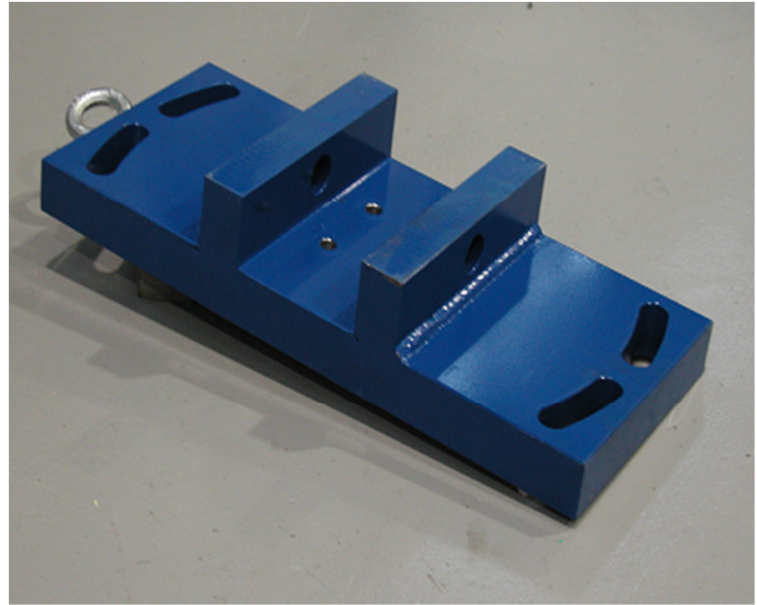

Figura 7 Placa utilizada para acoplar el soporte dentro del pórtico de carga.

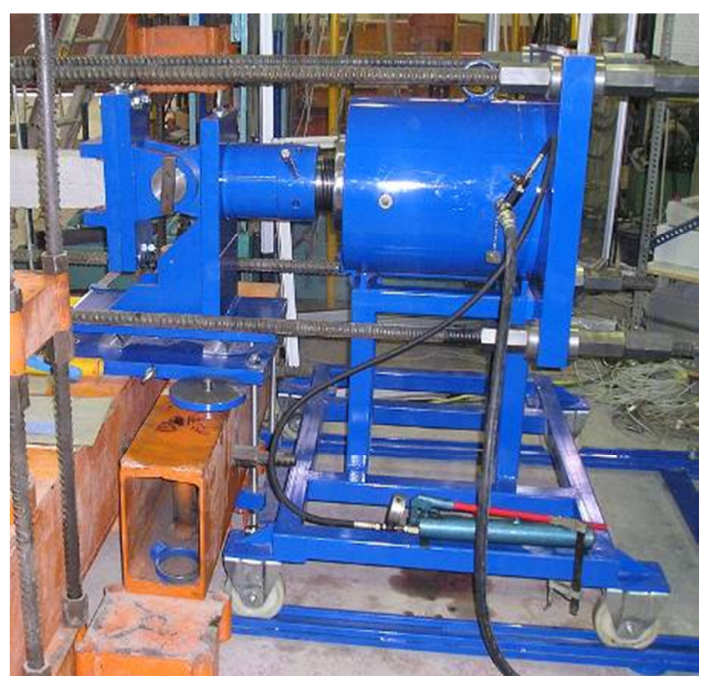

Figura 9 Vista general del extremo derecho del pórtico de carga.

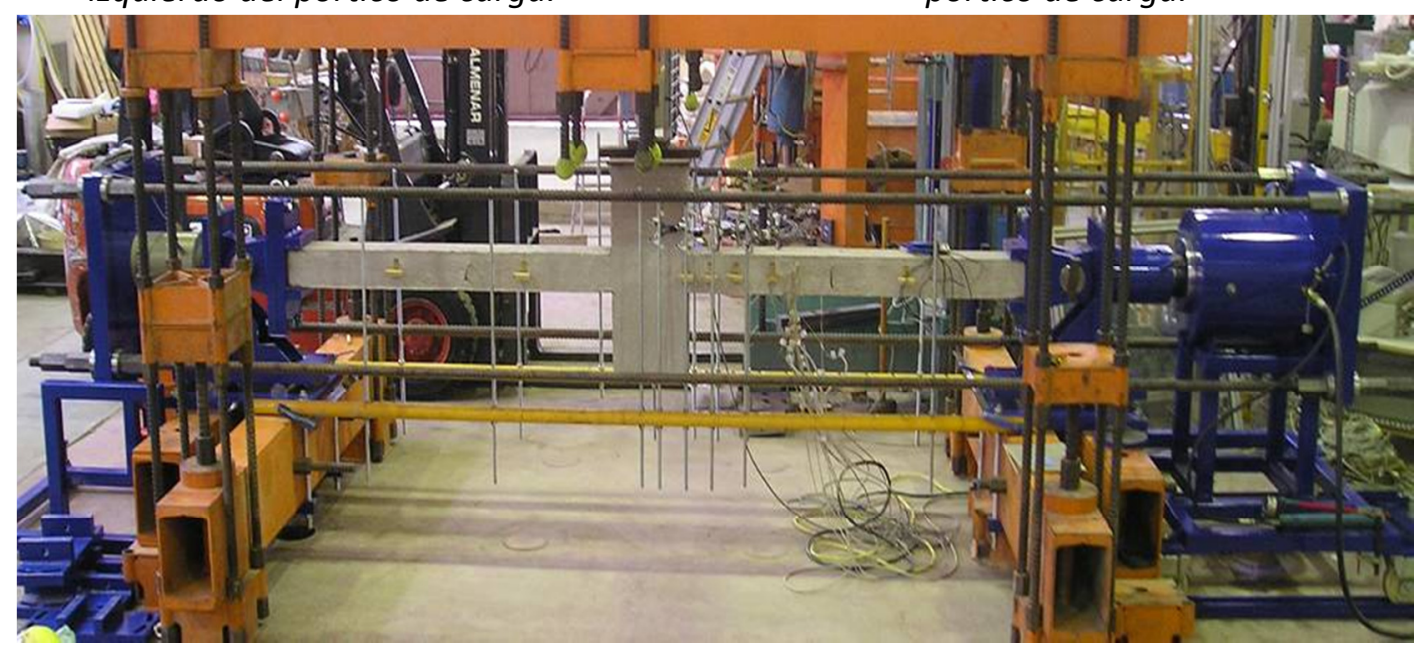

Figura 10 Disposición de los soportes ensayados dentro del pórtico de carga 


\section{PROCESO CONSTRUCTIVO DE LOS SOPORTES ENSAYADOS}

En este apartado se describe el proceso operativo seguido en la fabricación de los soportes ensayados. El proceso comprende las siguientes fases:

\section{Instrumentación de las barras de acero, que consta de las siguientes acciones:}

- Marcar sobre la barra los puntos donde se localizan las galgas

- Limar y eliminar la corruga de la armadura, evitando la pérdida de sección de la armadura

- Pegar galgas sobre la armadura

- Comprobar el funcionamiento eléctrico de las galgas

- Cubrir y proteger las galgas con una pasta aislante

- Ajustar y proteger los cables de las galgas

\section{Soldadura de perfiles UPN en los extremos del soporte}

- Los perfiles UPN han sido previamente preparados, soldando los tornillos que sobresalen en la parte posterior, con el objeto de poder sujetar la probeta al pórtico

- Centrado, alineación y nivelación de la armadura dentro del UPN

- Soldadura de la armadura al perfil UPN
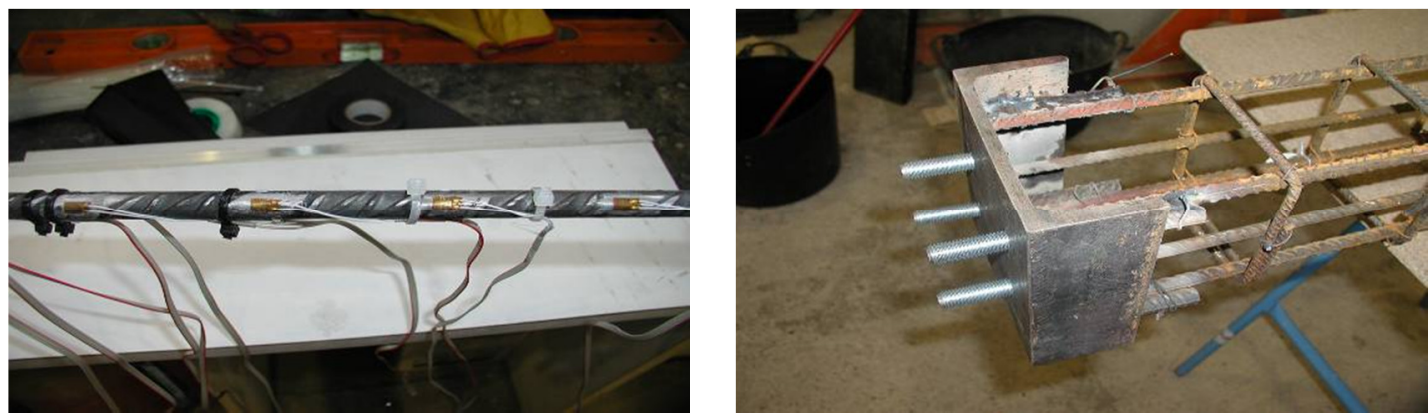

Figura 11 Instrumentación de barras y ubicación de perfiles UPN

\section{Ubicación de la armadura dentro del encofrado}

- Atado de separadores a la armadura, asegurando el recubrimiento respecto a la armadura longitudinal

- Preparación del encofrado y de sus superficies, utilizando un desencofrante

- Colocación de la armadura dentro del encofrado, controlando tanto el recubrimiento como las dimensiones del soporte

\section{Hormigonado}

La preparación del hormigón se realizó en el laboratorio de materiales, utilizando una máquina de amasado de eje horizontal de 60 litros de capacidad. De este modo, fue necesario realizar dos amasadas en la fabricación de los soportes de esbeltez 15 y 10.5 (secciones de $15 \times 10$ $\mathrm{cm}$ y $15 X 14 \mathrm{~cm}$ respectivamente), y hasta tres amasadas en los soportes 
de esbeltez 7.5 (sección de 15X20 cm). Consecuentemente, se fabricaron dos probetas estandarizadas cilíndricas (15X30), conservadas en cámara húmeda, para cada una de las amasadas. Estas probetas fueron sometidas a ensayos de compresión simple a los 28 días, para obtener la resistencia media del hormigón. Las actividades realizadas en esta fase son las siguientes:

- Preparación de moldes para probetas de control

- Medición de la humedad de los áridos

- Dosificación de materiales componentes

- Amasado

- Vertido de hormigón dentro del encofrado

- Vibrado del hormigón

- Elaboración de probetas de control

- Limpieza del material

\section{Desmoldeo y ensayo a compresión simple de las probetas de control}

- Las probetas y el soporte fueron desmoldeados dentro de los dos días posteriores al hormigonado, y debidamente almacenados.

- A los 28 días, se realizó el ensayo de compresión simple de las probetas testigo.
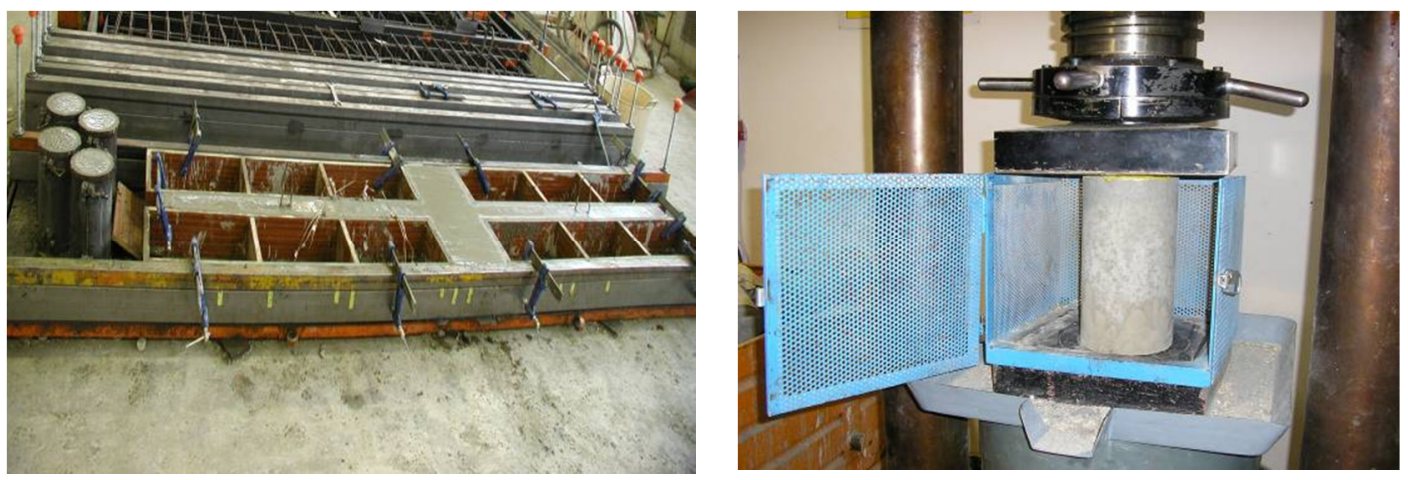

Figura 12 Hormigonado de soportes y ensayo a compresión simple de las probetas de control

\section{Colocación dentro del pórtico de carga}

- Acoplamiento de los perfiles UPN en los extremos del soporte, dentro de las placas que se conectan a las rótulas de los extremos

- El soporte fue ubicado dentro el pórtico de carga, con ayuda de un puente grúa

- Fijar y asegurar todos los elementos que sostienen el soporte dentro del pórtico de carga

- Verificar la alineación del soporte 
7. Instrumentación de los soportes mediante captadores de desplazamiento y conexión al equipo de medición

- Marcado sobre el soporte de los puntos donde deben ubicarse los captadores

- Colocación de elementos auxiliares necesarios en la ubicación de los captadores de desplazamiento (como por ejemplo los perfiles angulares en donde se apoyan algunos captadores)

- Ubicación de captadores de desplazamiento sobre el soporte

- Conexiones eléctricas de cada una de las bandas extensiométricas y de los captadores al equipo de medición
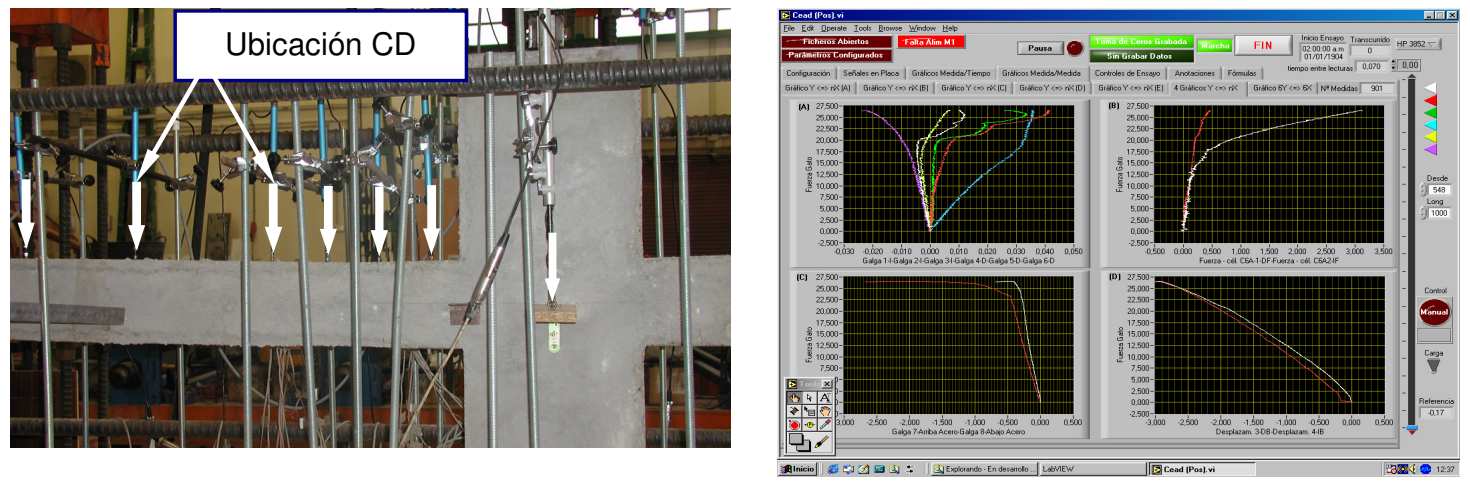

Figura 13 Localización de captadores de desplazamiento y proceso de adquisición de datos 
Estudio experimental y numérico de la capacidad de deformación de soportes esbeltos de hormigón armado 


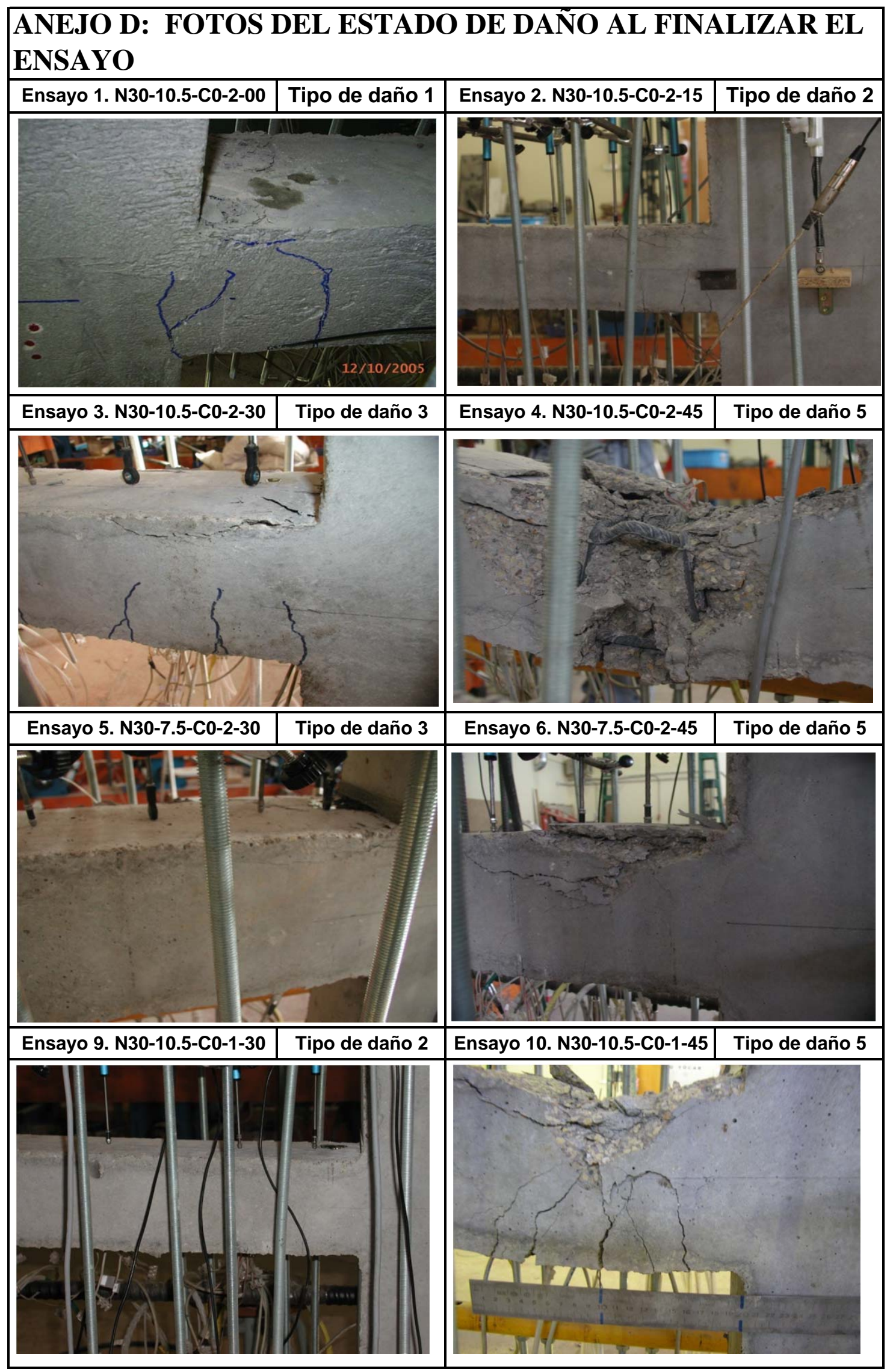


Estudio experimental y numérico de la capacidad de deformación de soportes esbeltos de hormigón armado

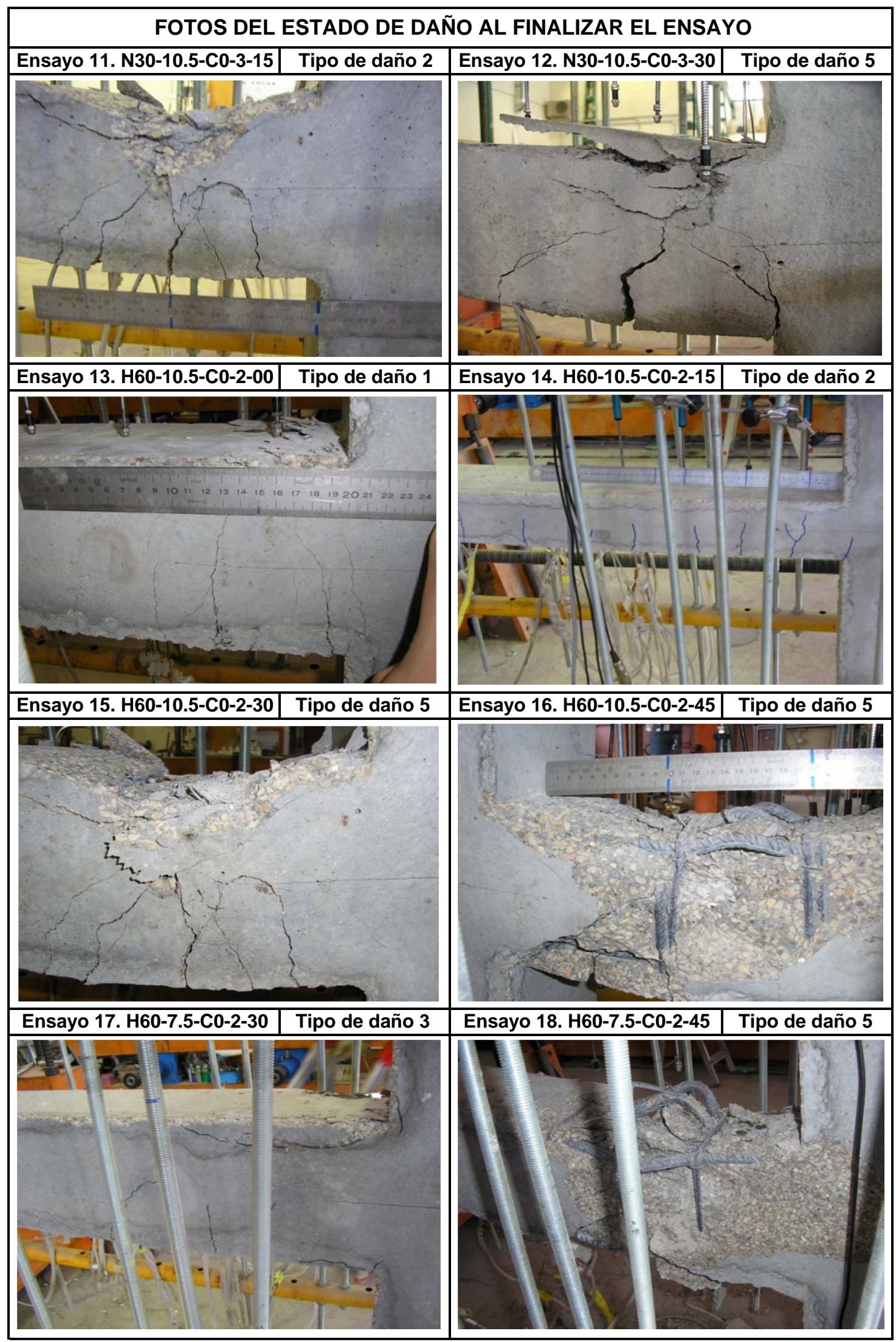




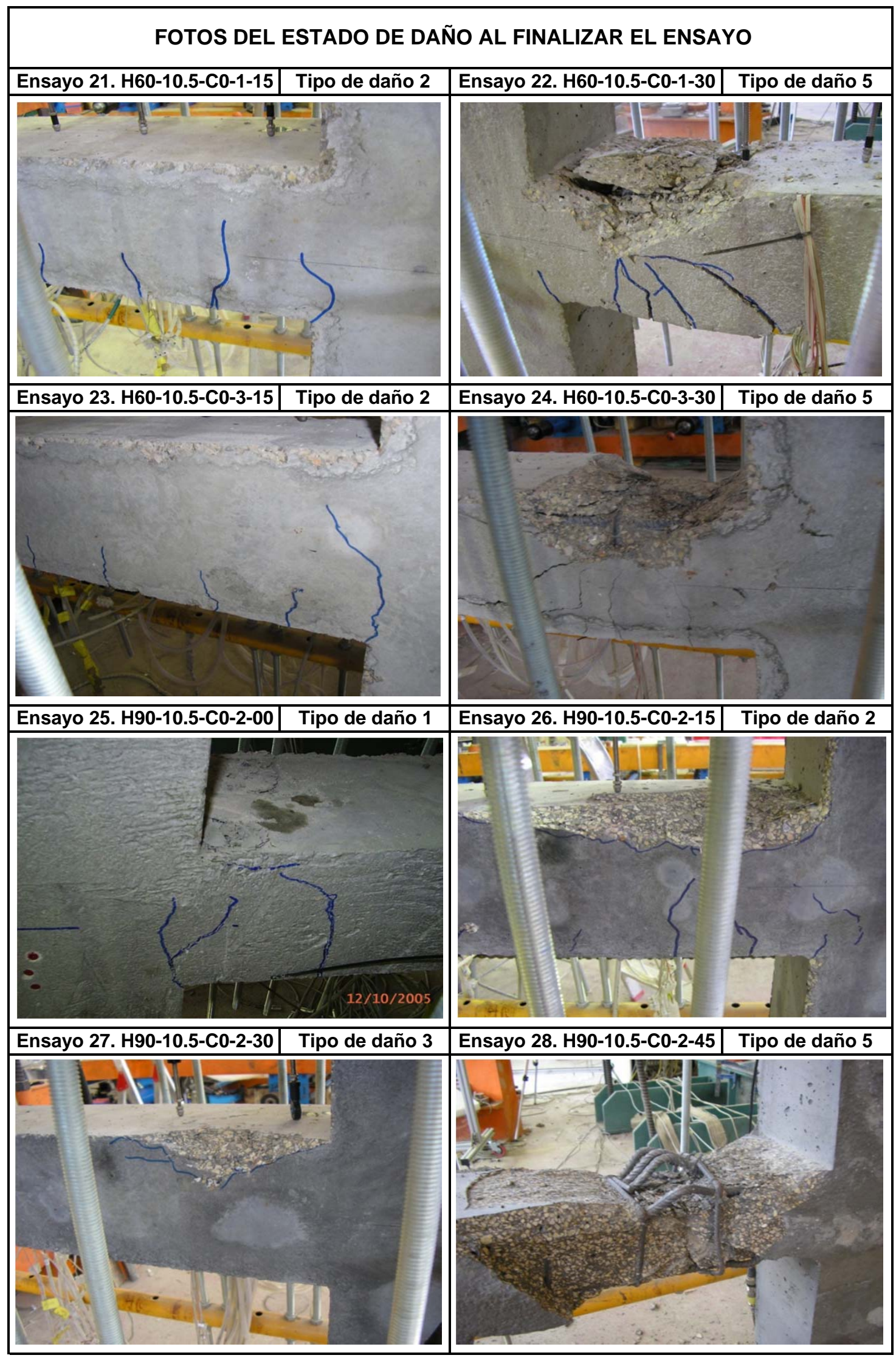


Estudio experimental y numérico de la capacidad de deformación de soportes esbeltos de hormigón armado

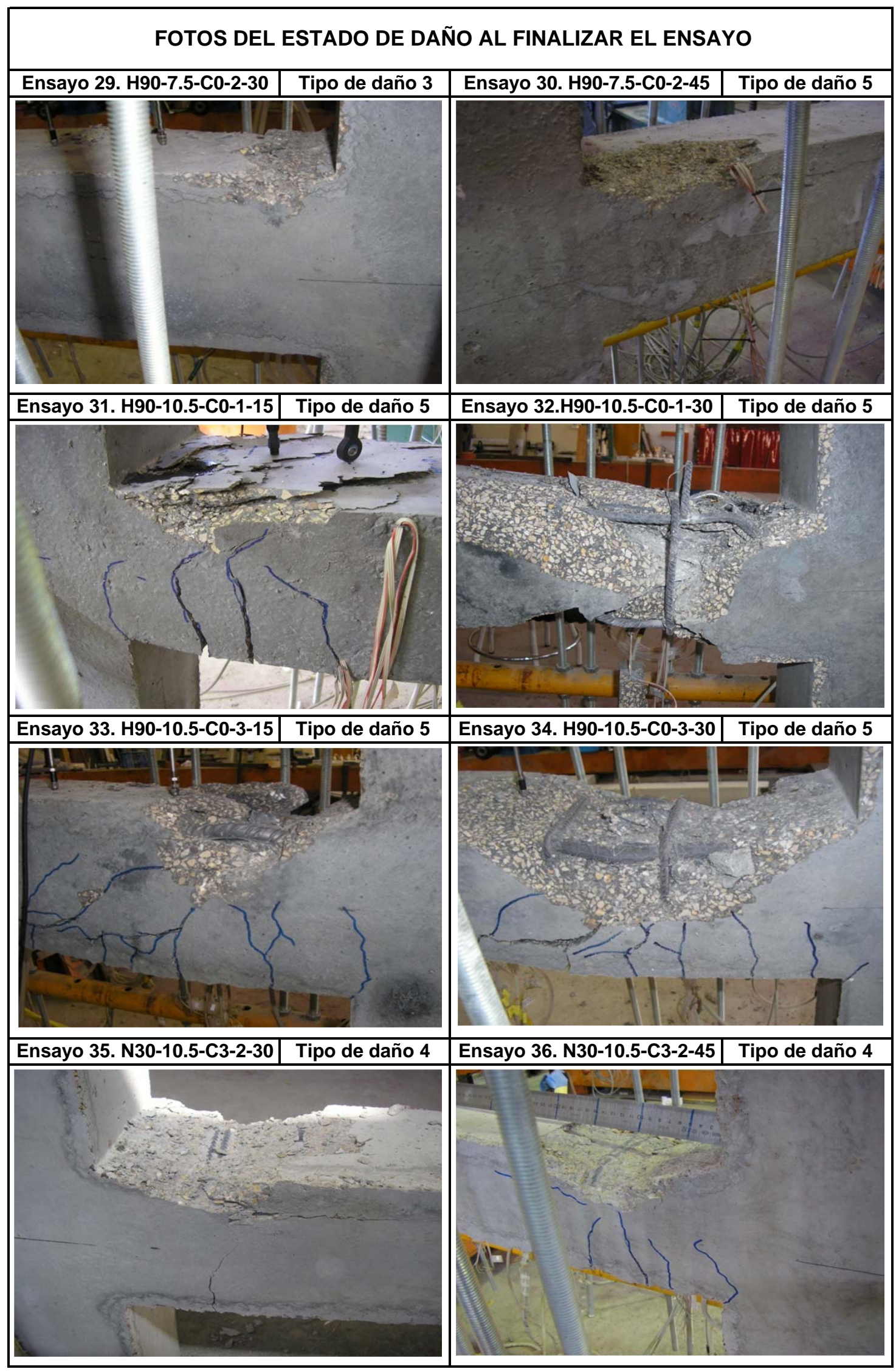




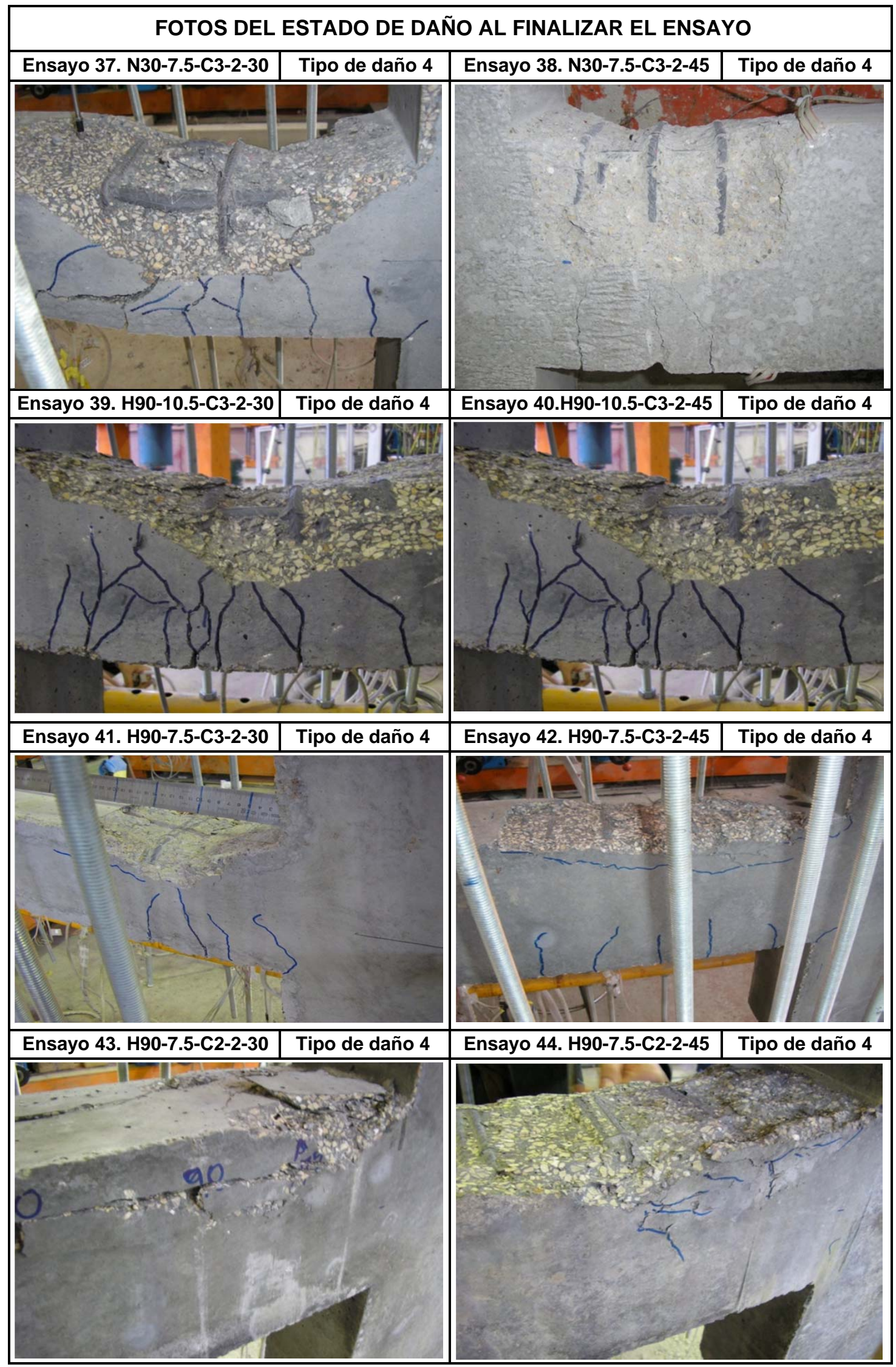


Estudio experimental y numérico de la capacidad de deformación de soportes esbeltos de hormigón armado 
ANEJO E: RESULTADOS DIRECTOS DE LOS ENSAYOS EXPERIMENTALES

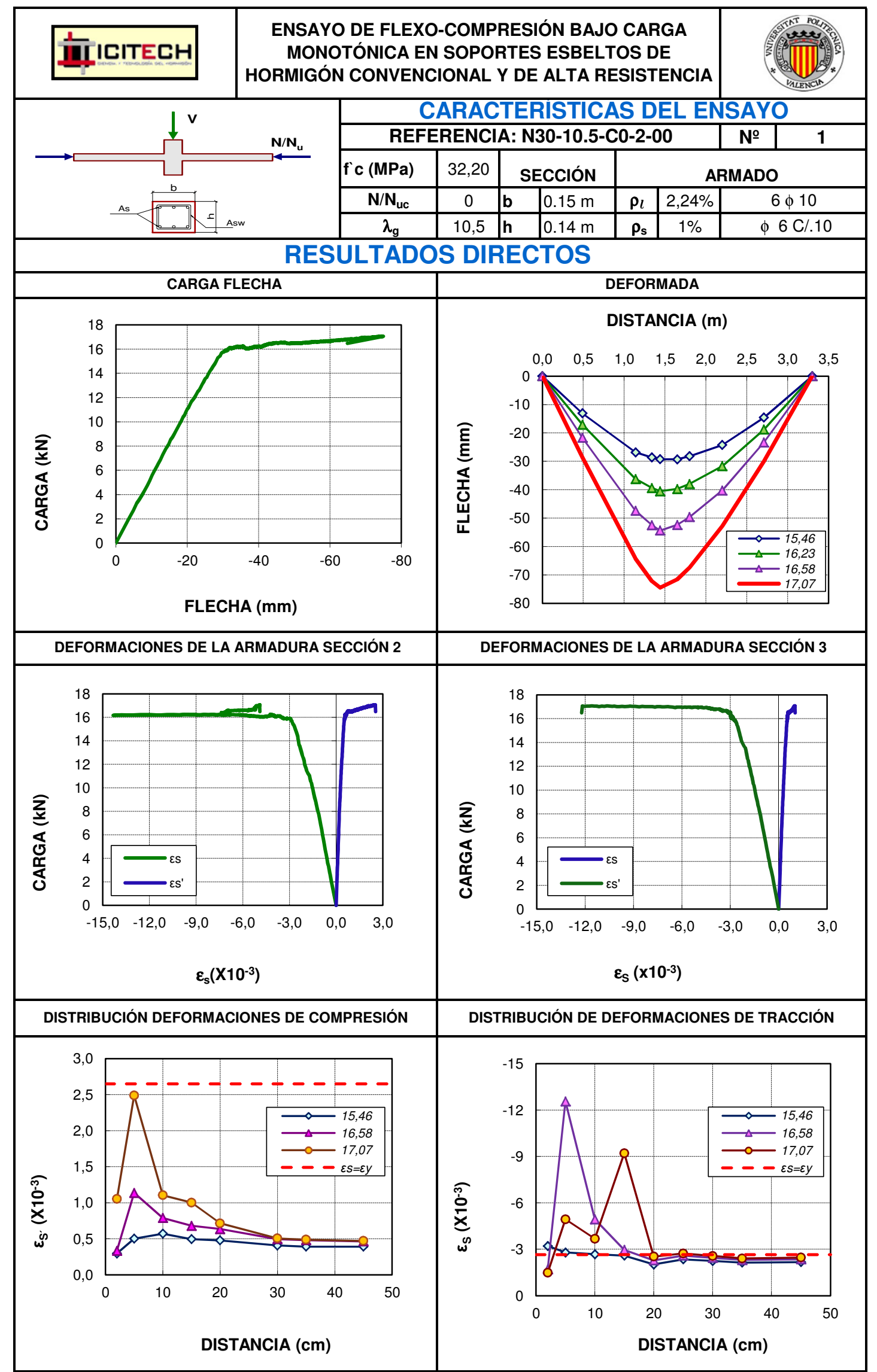


Estudio experimental y numérico de la capacidad de deformación de soportes esbeltos de hormigón armado

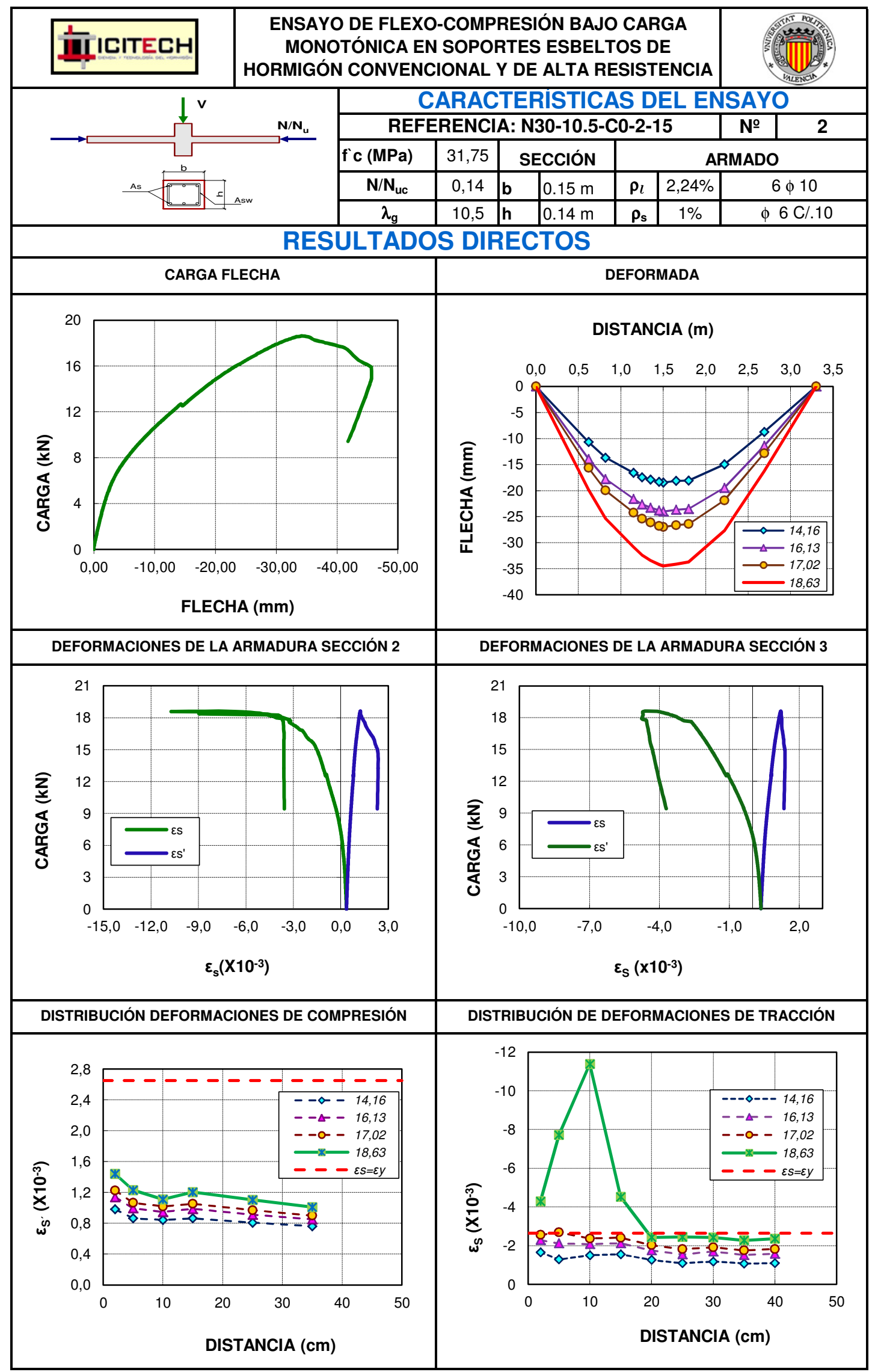


Anejo E: Resultados directos de los ensayos experimentales

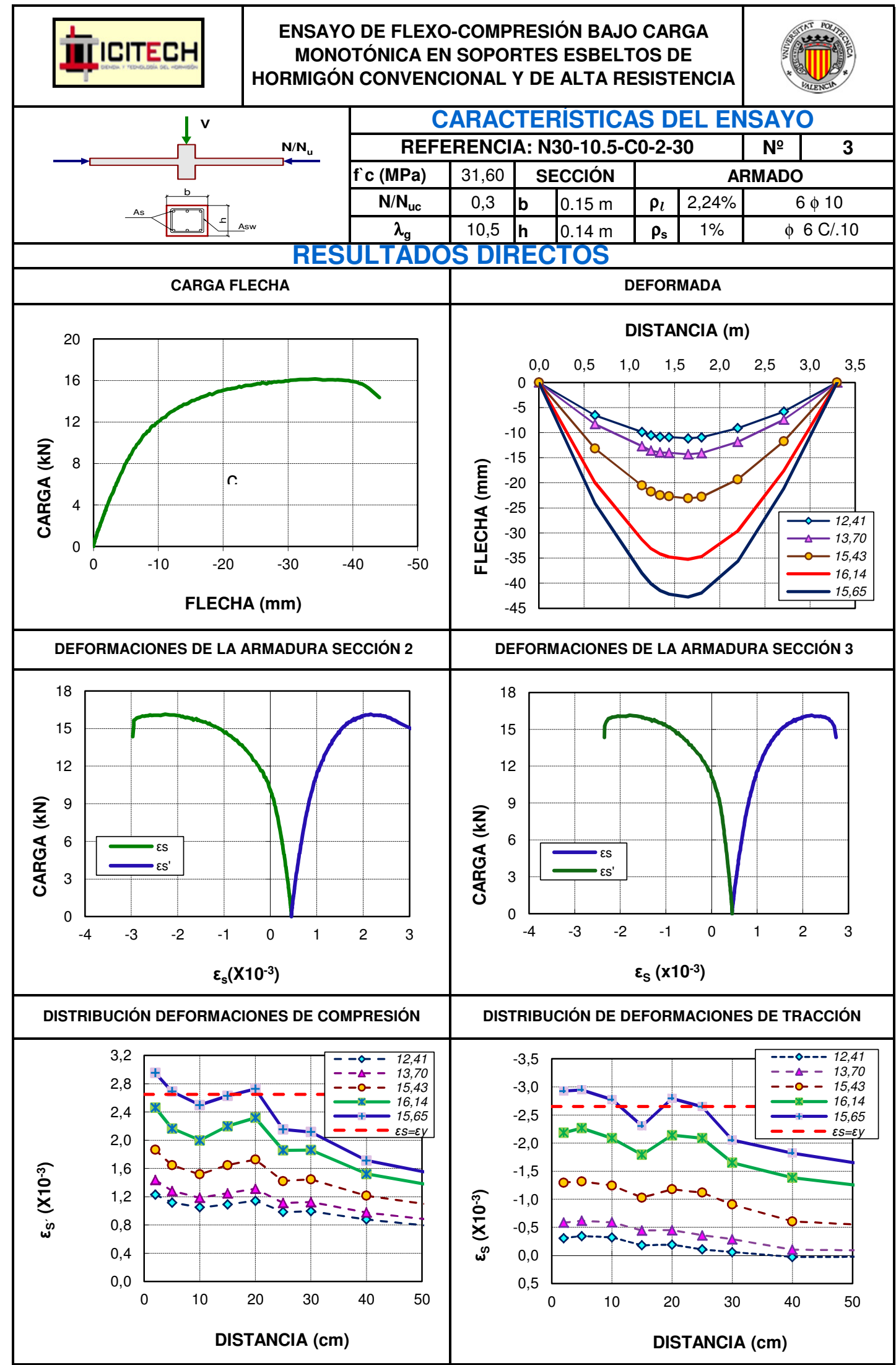


Estudio experimental y numérico de la capacidad de deformación de soportes esbeltos de hormigón armado

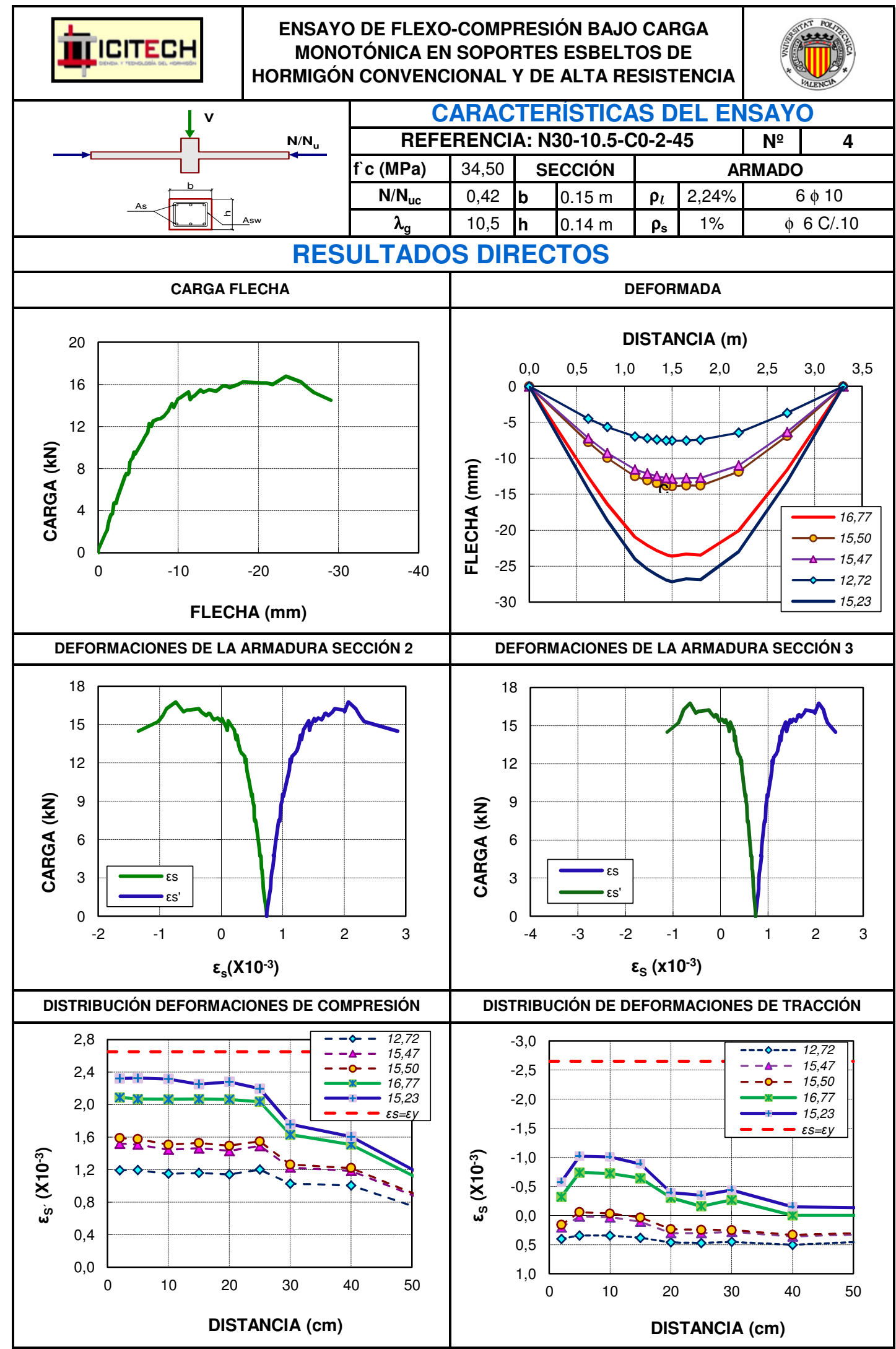


Anejo E: Resultados directos de los ensayos experimentales

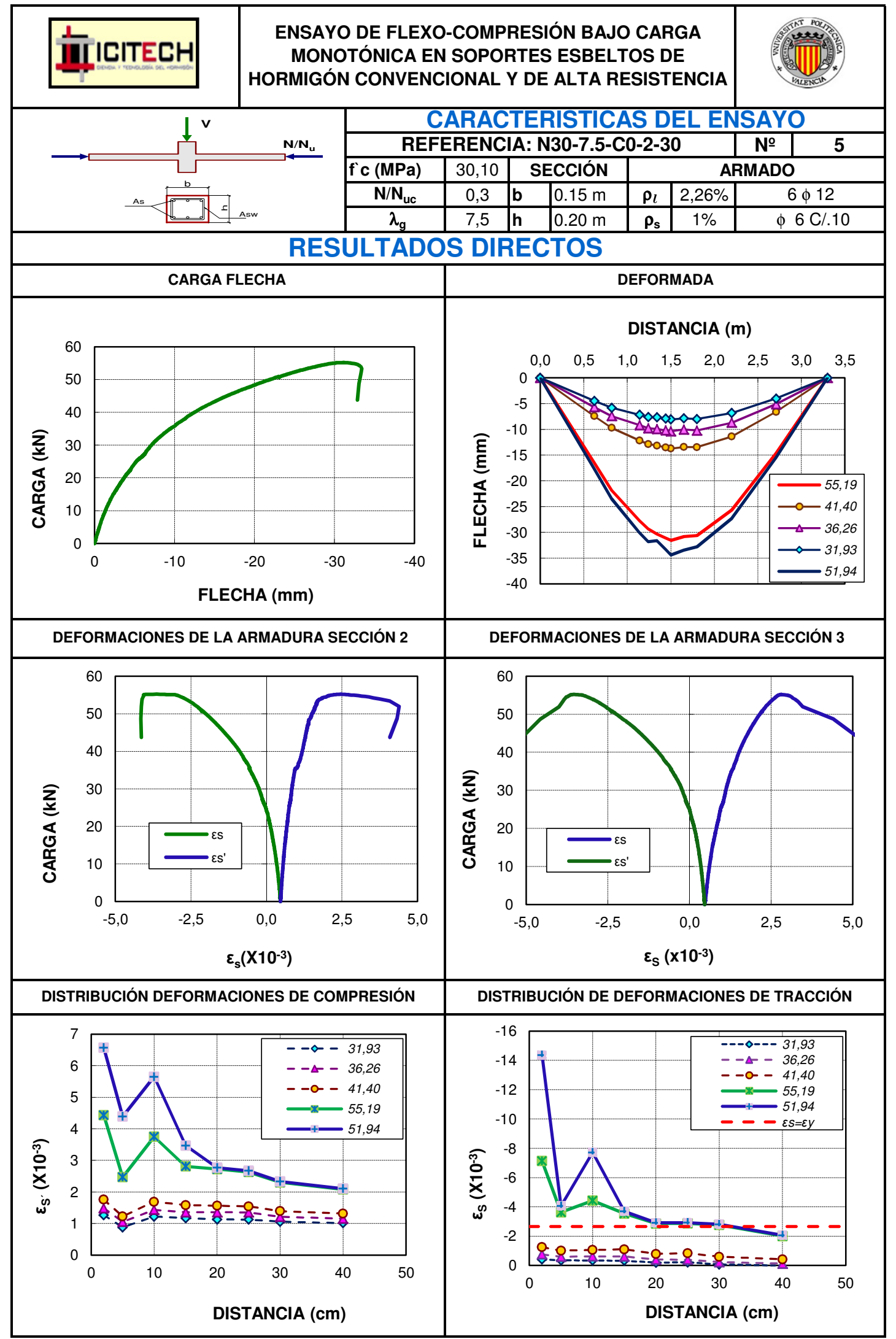


Estudio experimental y numérico de la capacidad de deformación de soportes esbeltos de hormigón armado

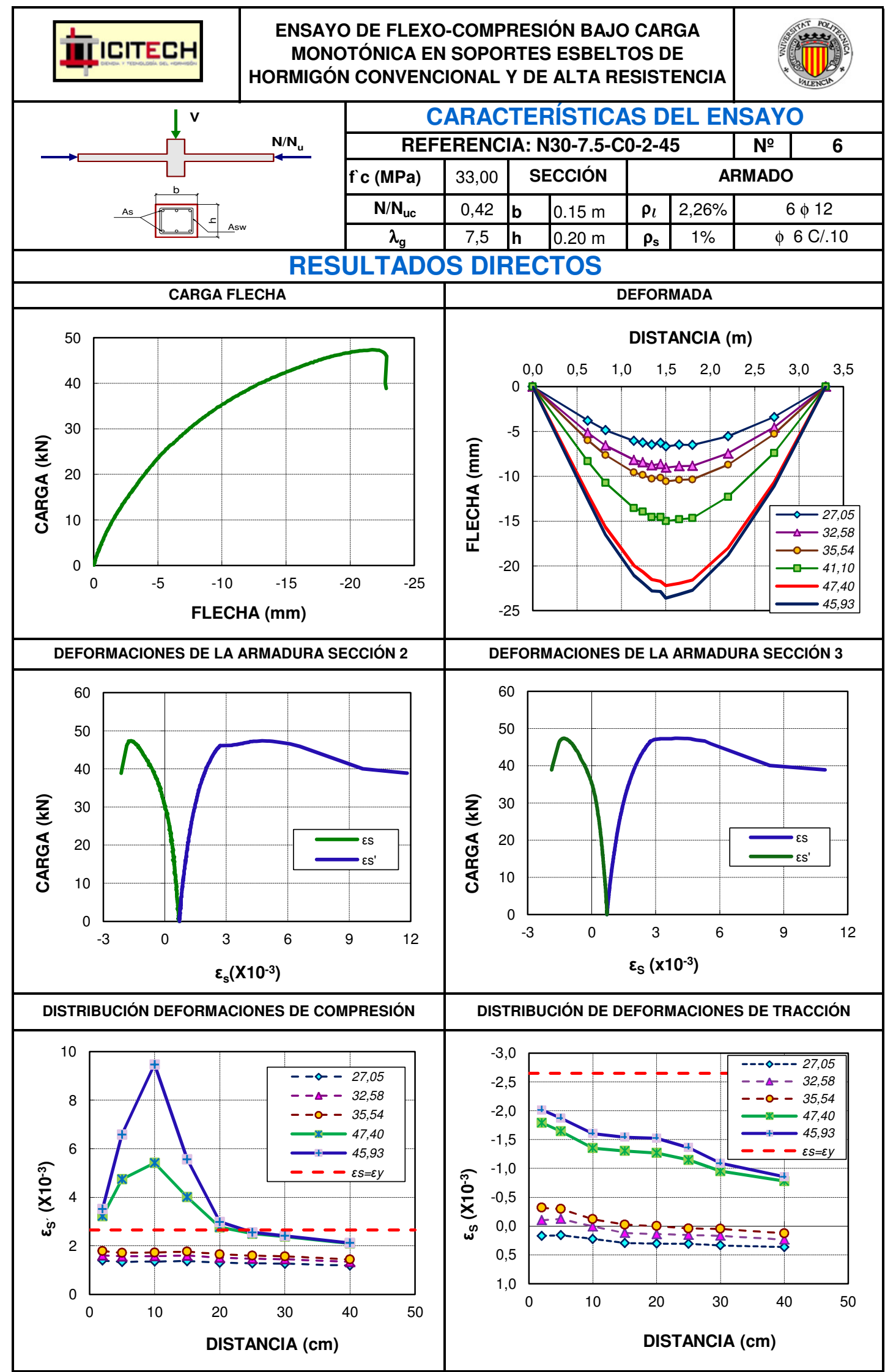


Anejo E: Resultados directos de los ensayos experimentales

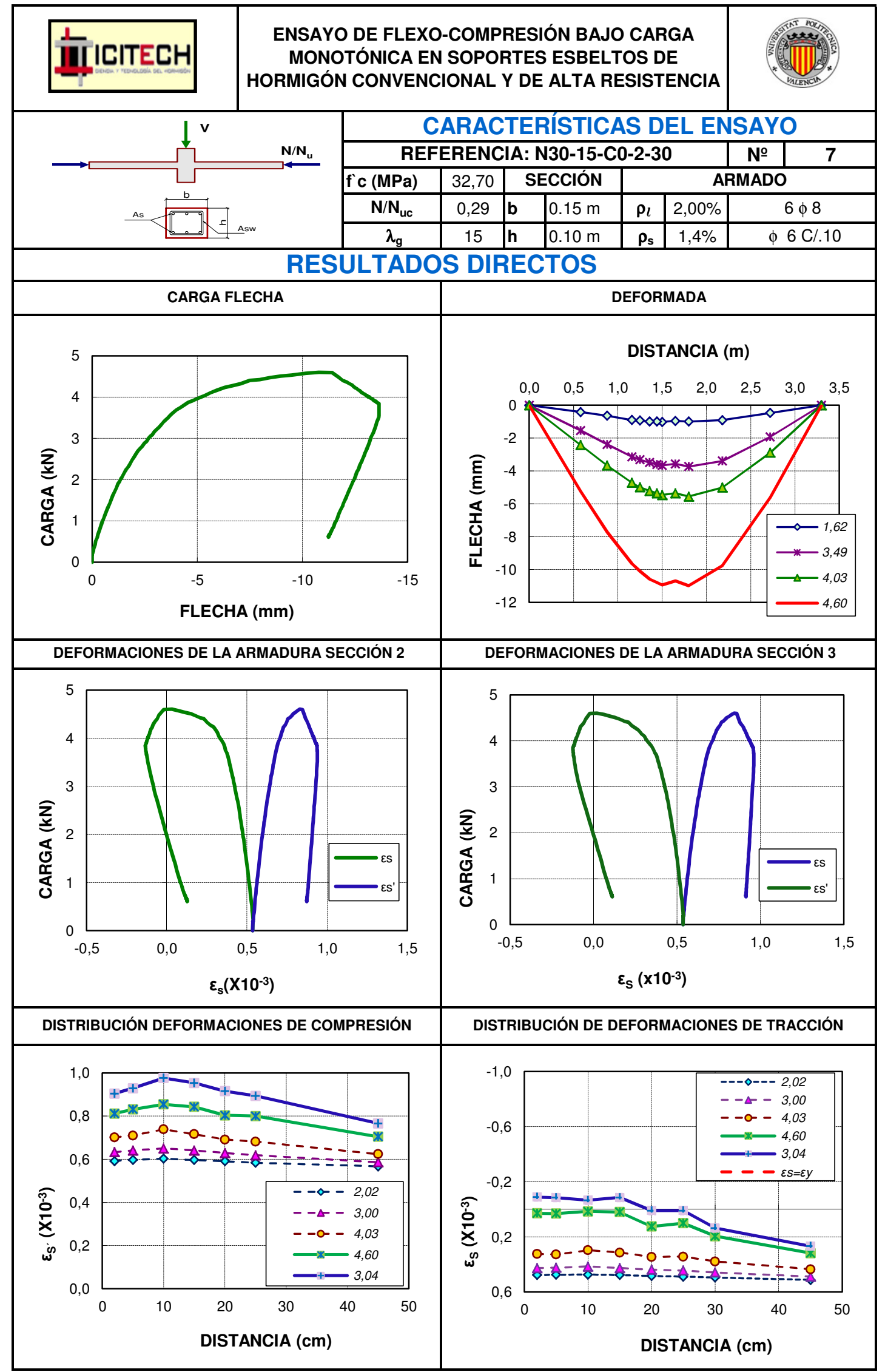


Estudio experimental y numérico de la capacidad de deformación de soportes esbeltos de hormigón armado

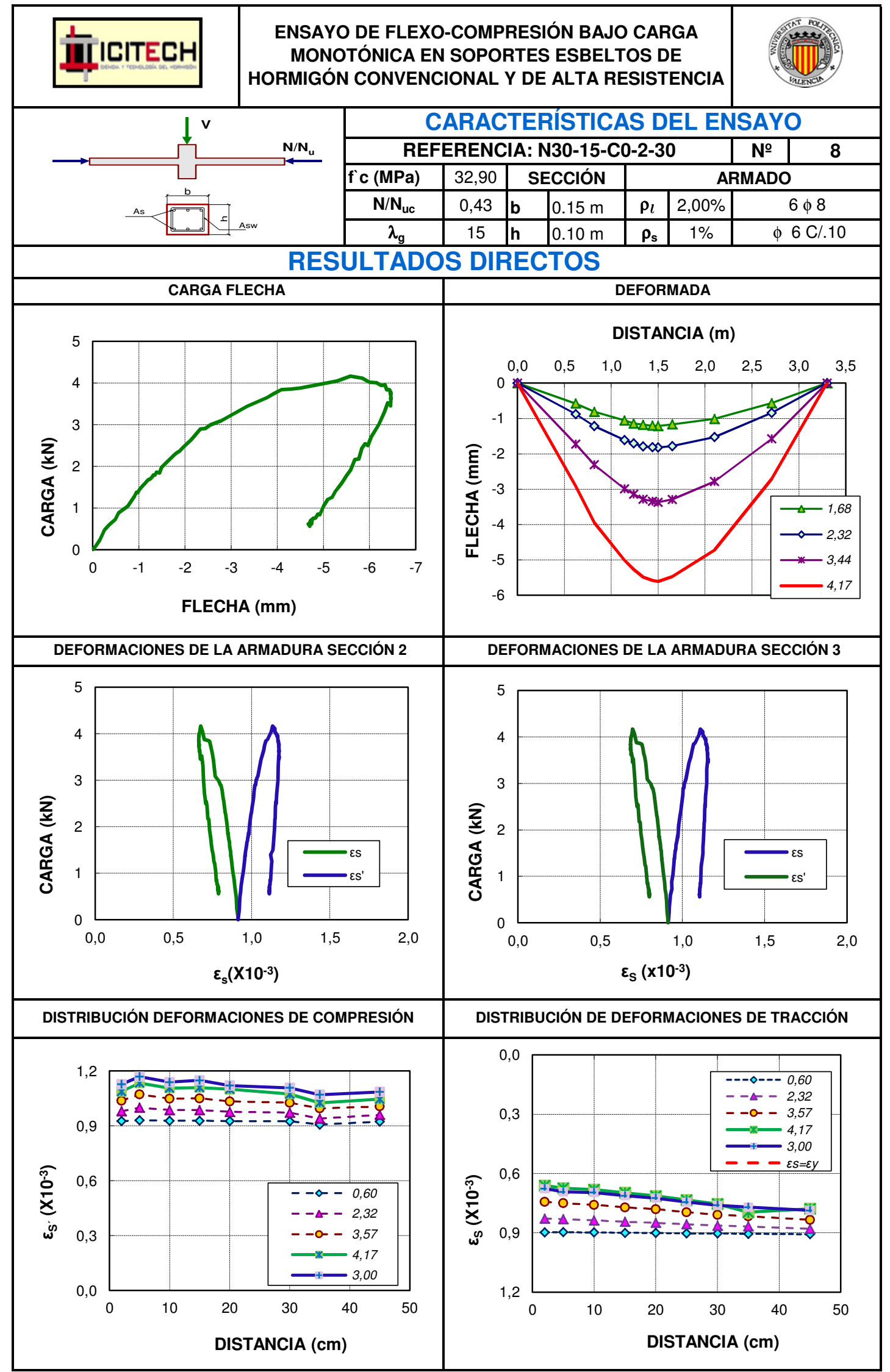


Anejo E: Resultados directos de los ensayos experimentales

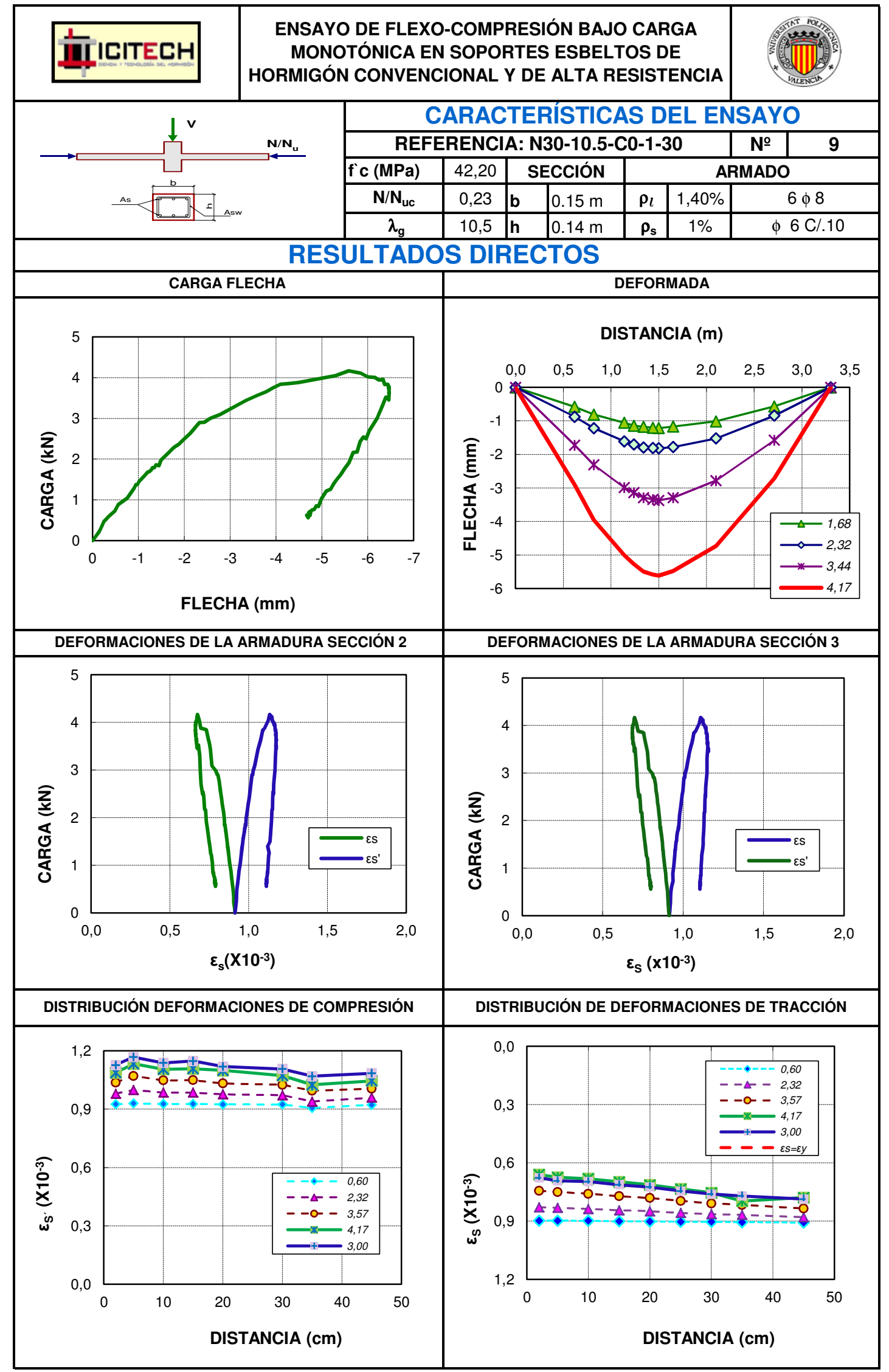


Estudio experimental y numérico de la capacidad de deformación de soportes esbeltos de hormigón armado

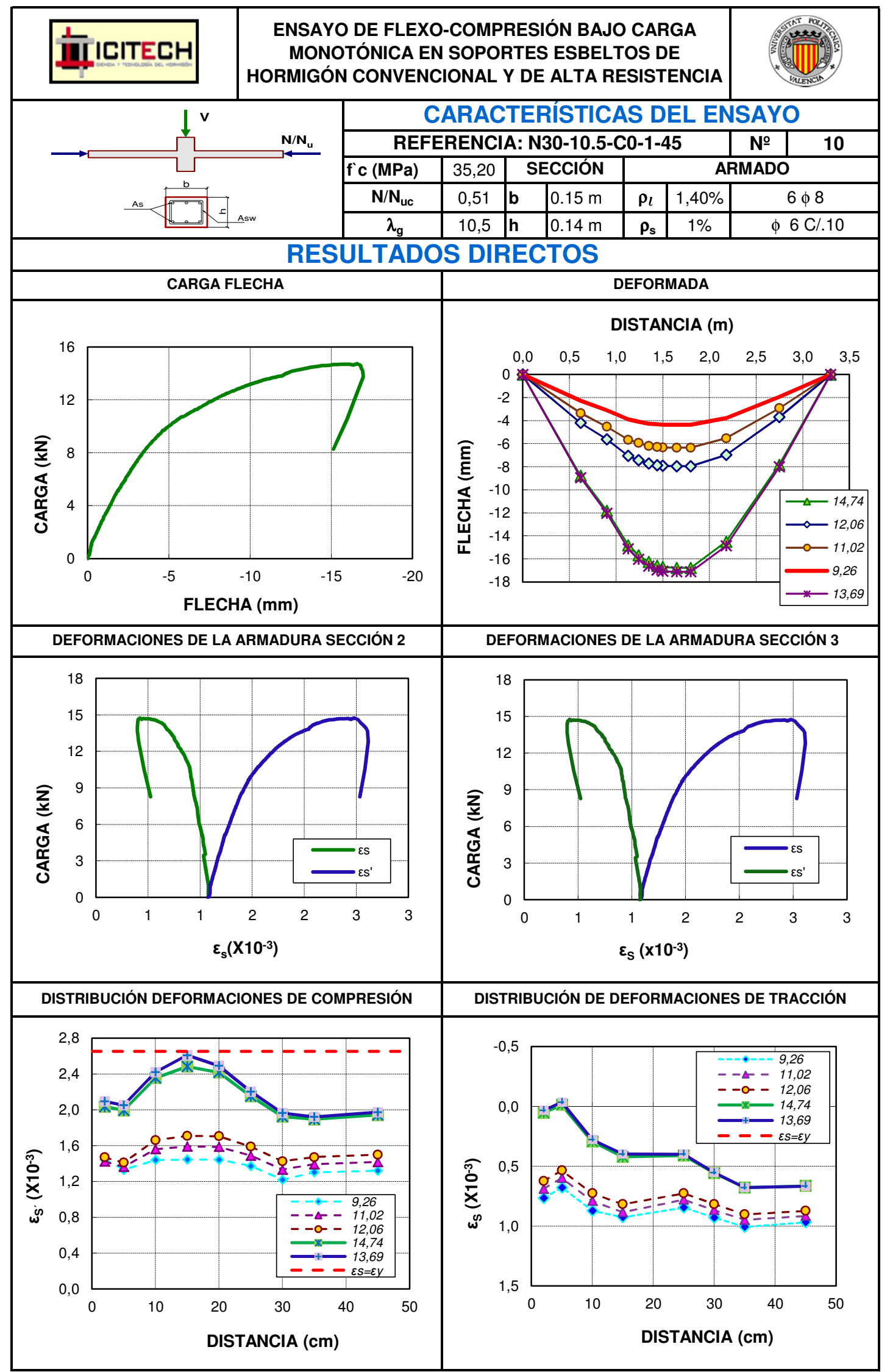


Anejo E: Resultados directos de los ensayos experimentales

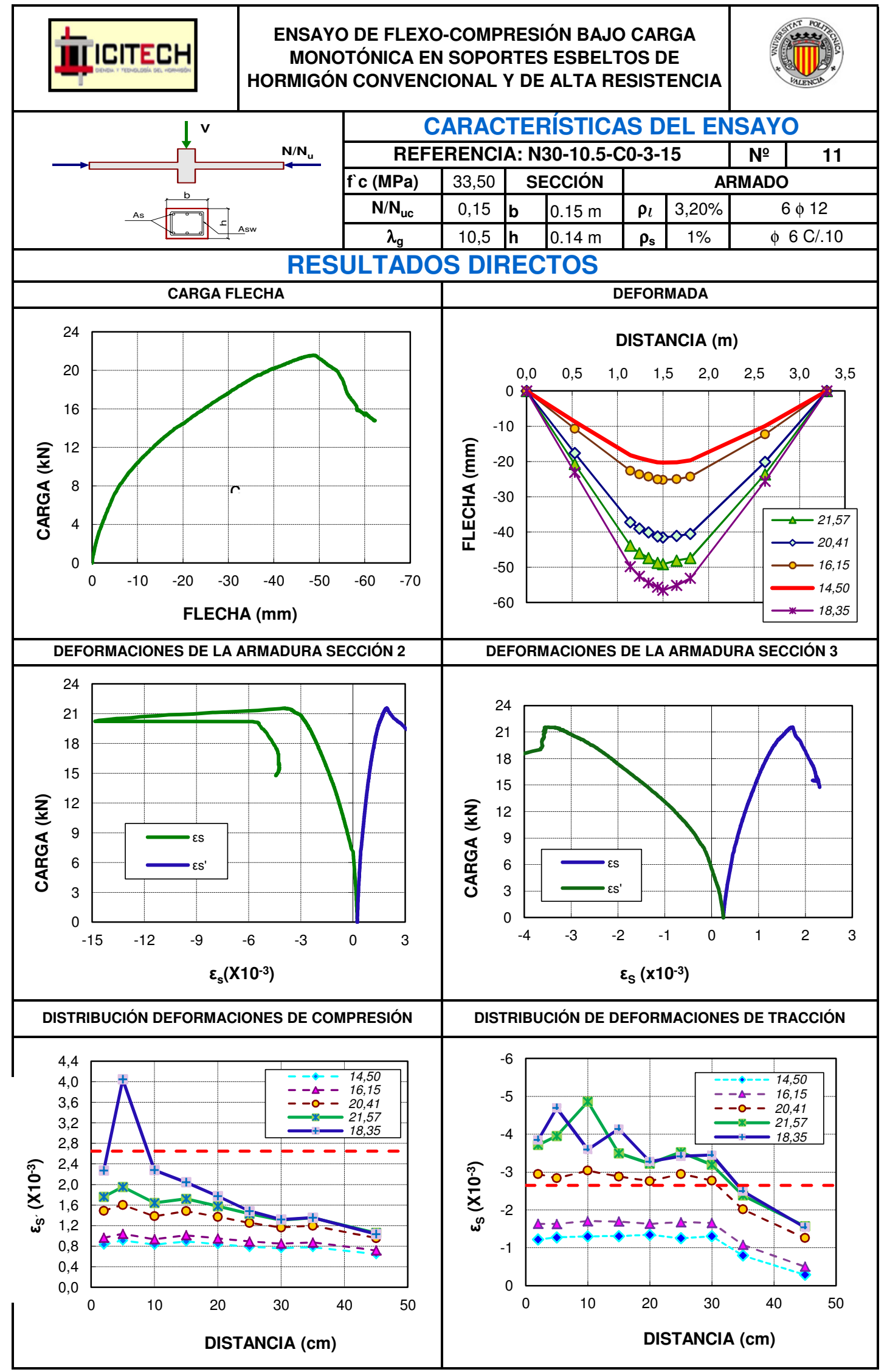


Estudio experimental y numérico de la capacidad de deformación de soportes esbeltos de hormigón armado

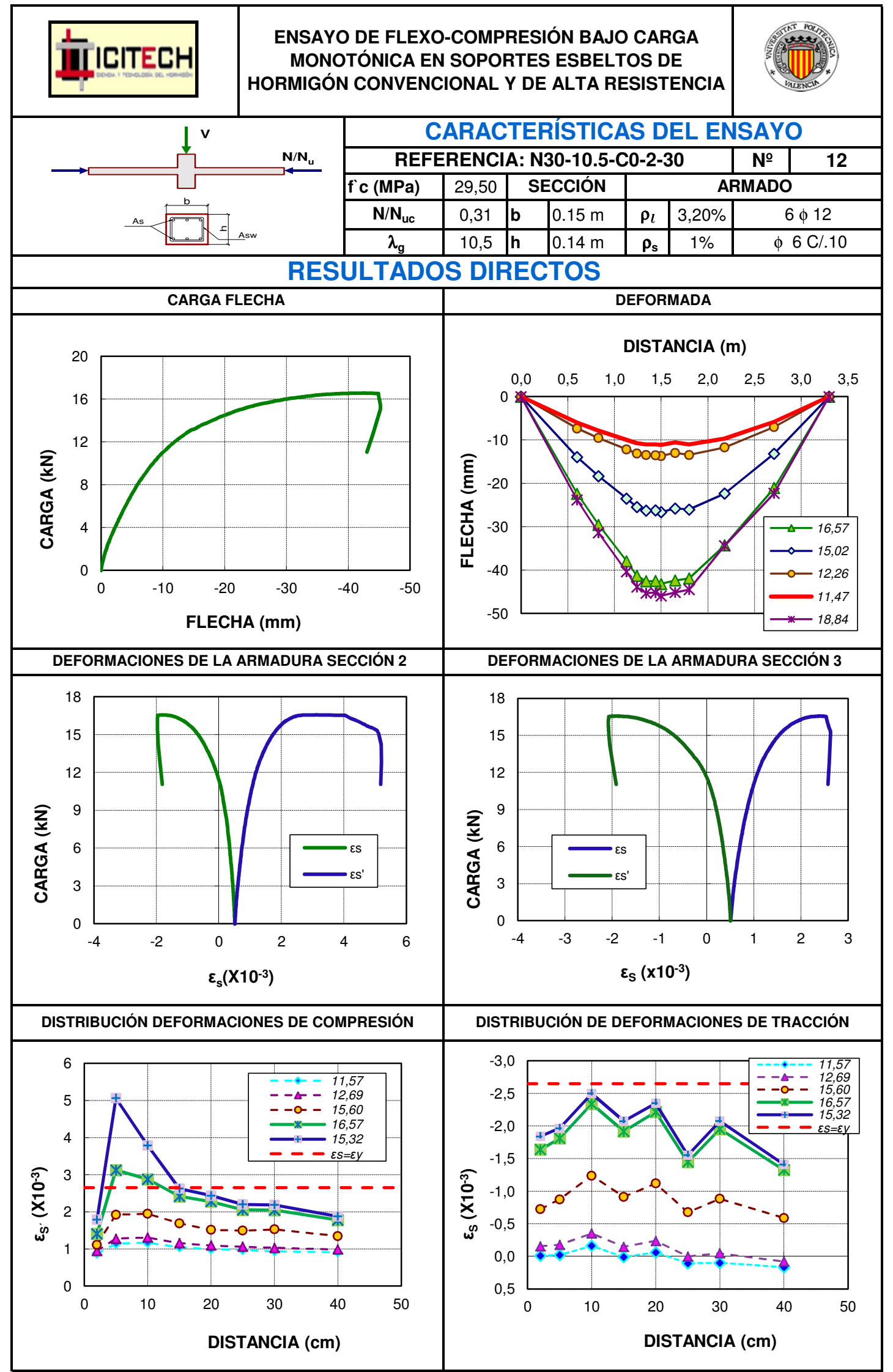


Anejo E: Resultados directos de los ensayos experimentales

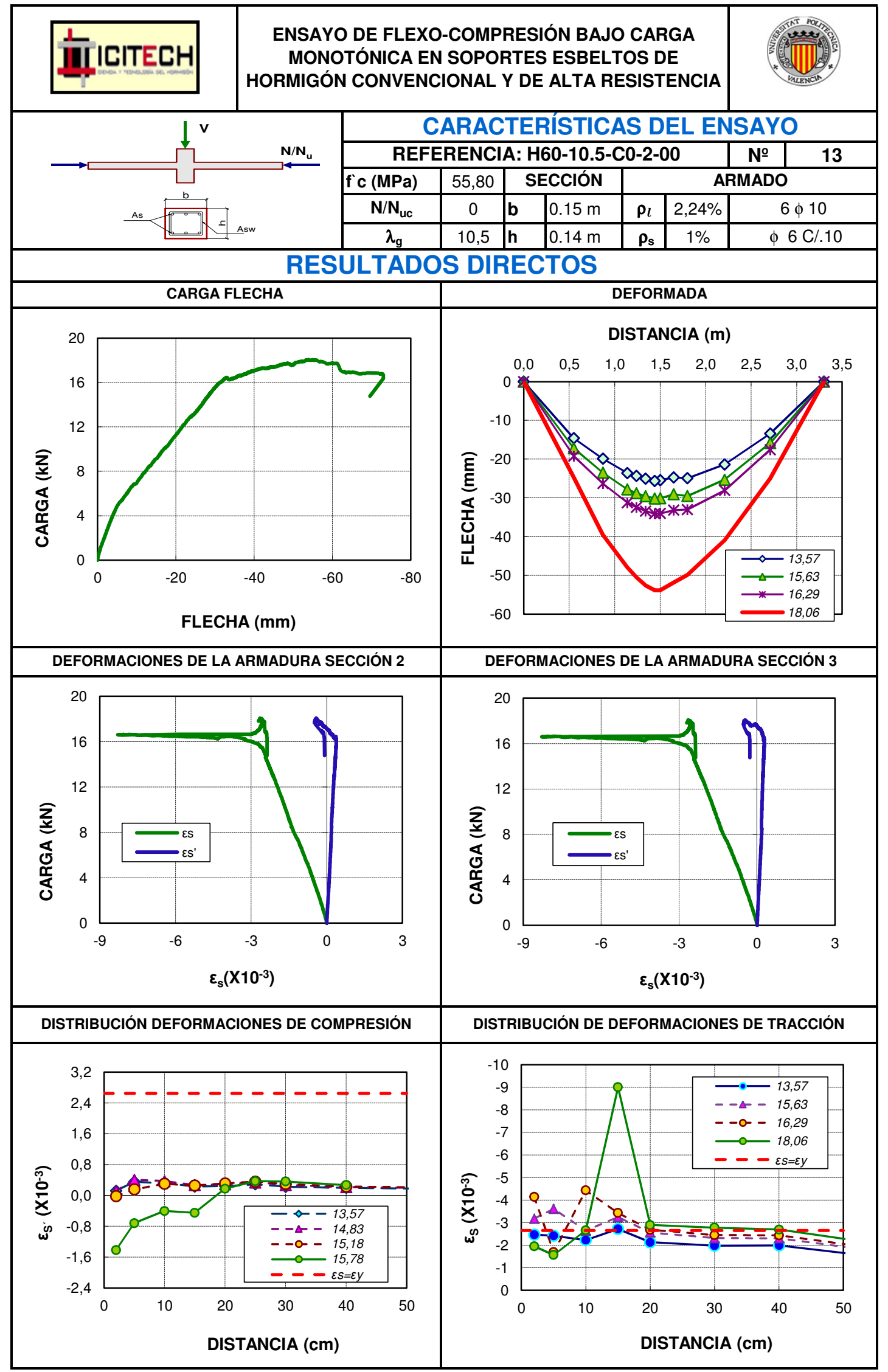


Estudio experimental y numérico de la capacidad de deformación de soportes esbeltos de hormigón armado

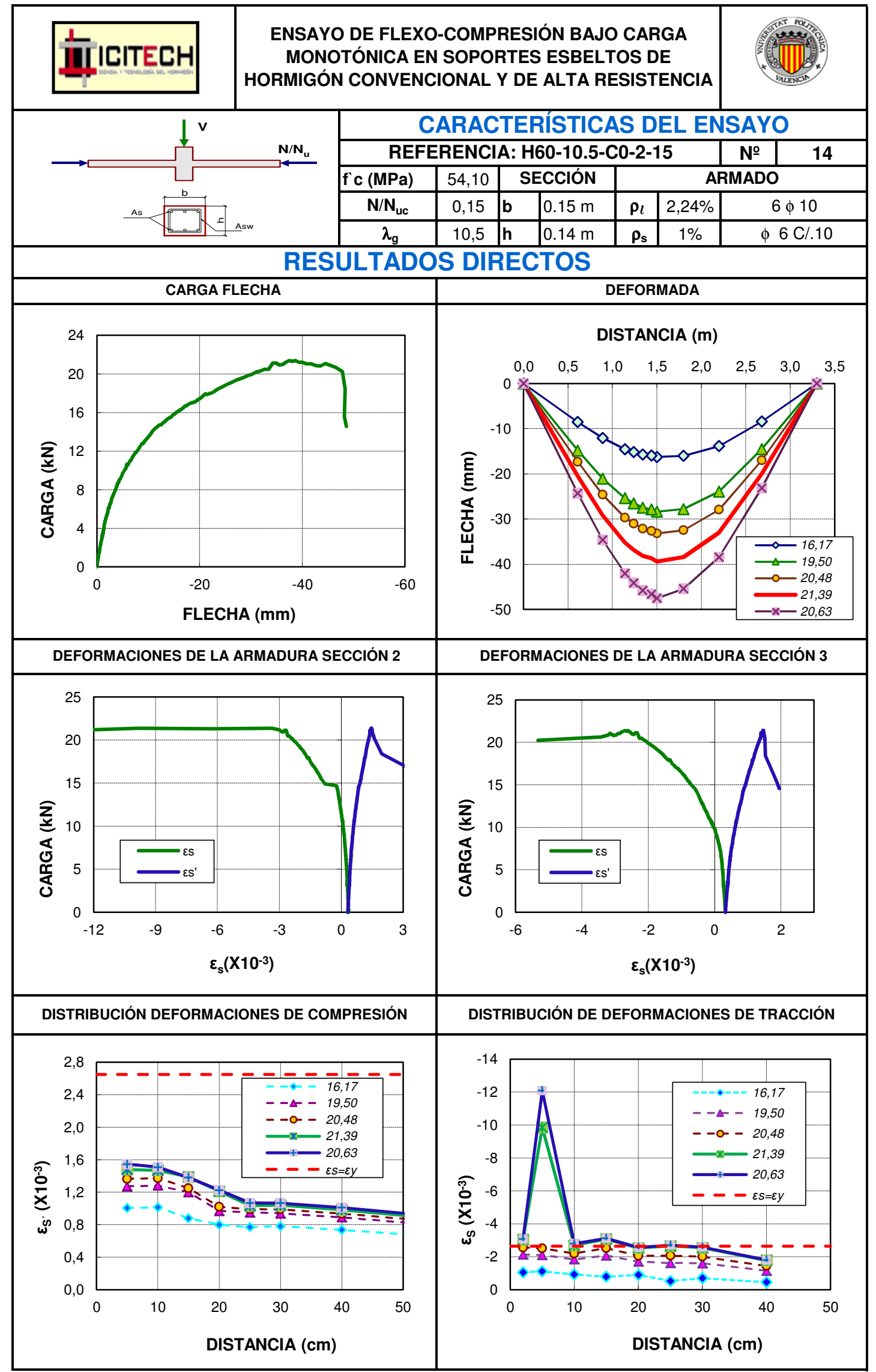


Anejo E: Resultados directos de los ensayos experimentales

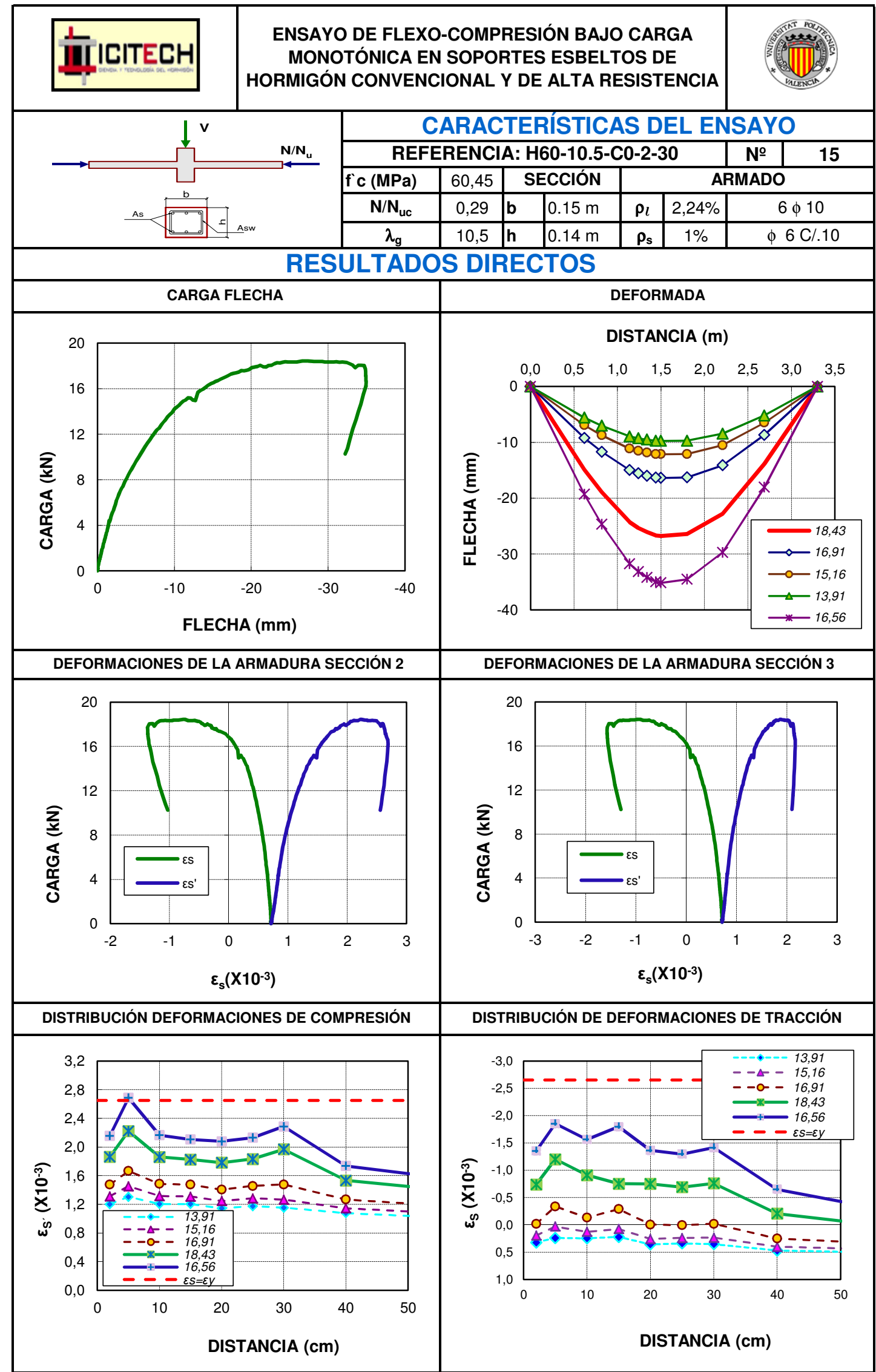


Estudio experimental y numérico de la capacidad de deformación de soportes esbeltos de hormigón armado

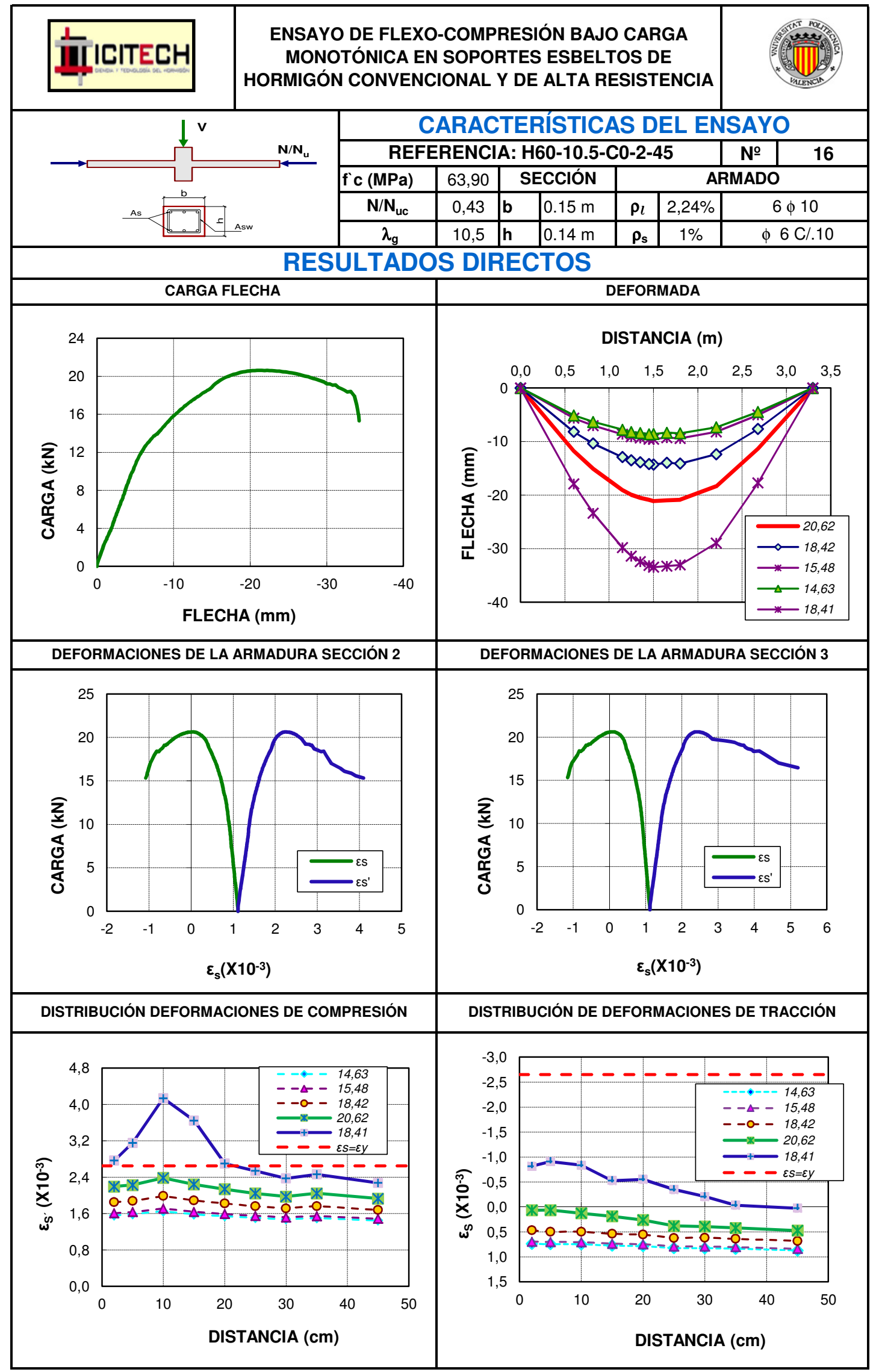


Anejo E: Resultados directos de los ensayos experimentales

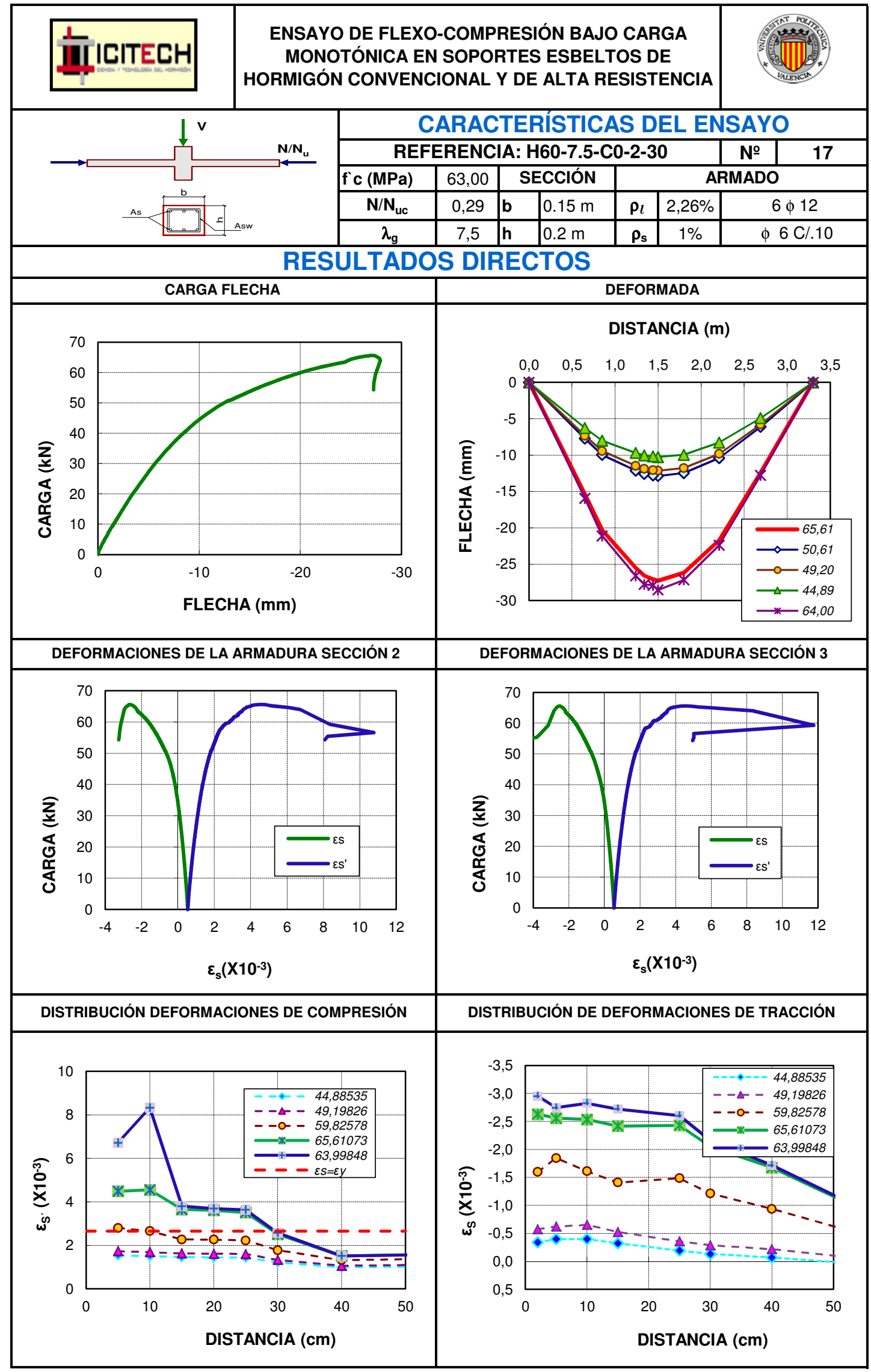


Estudio experimental y numérico de la capacidad de deformación de soportes esbeltos de hormigón armado

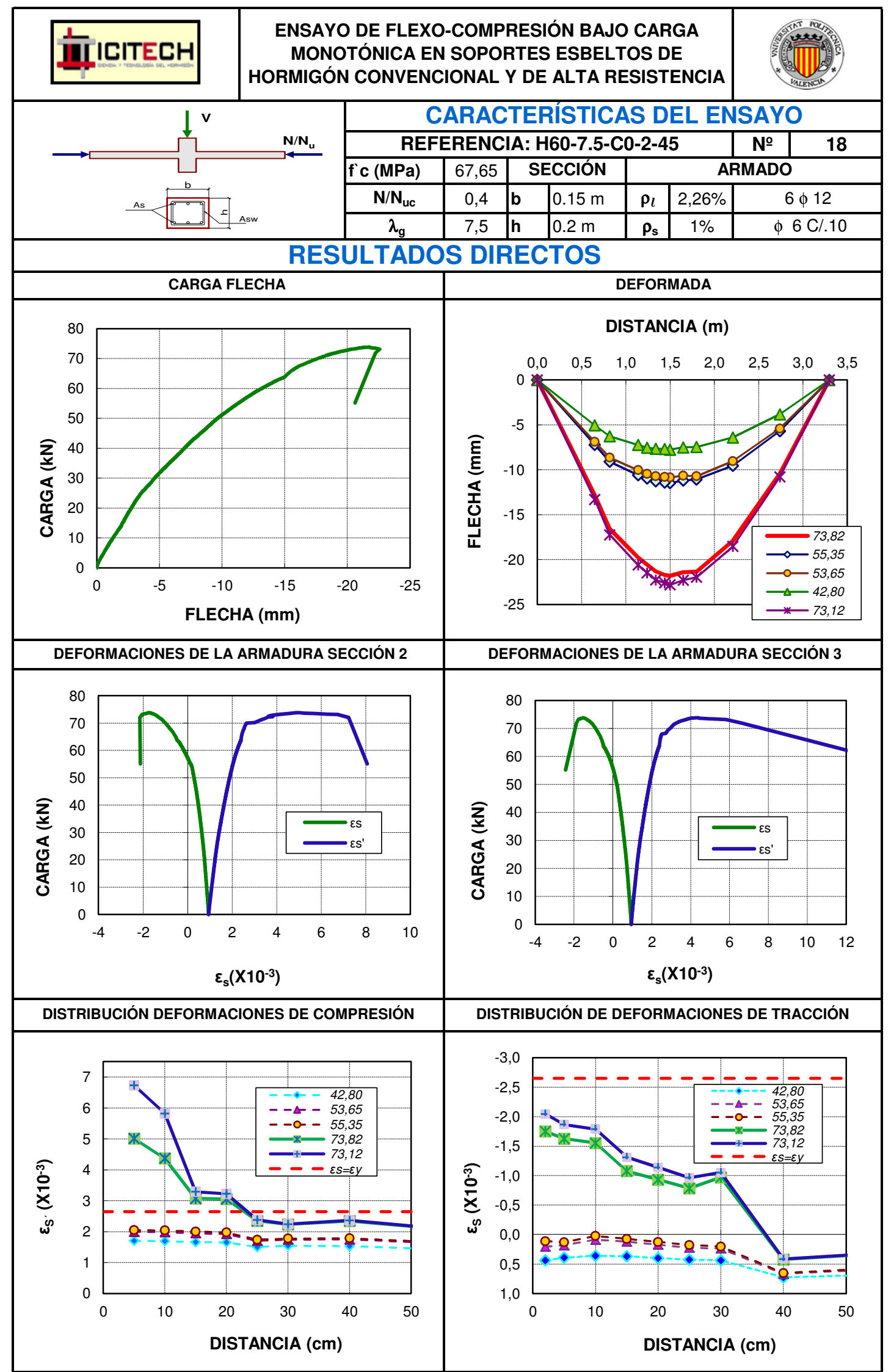


Anejo E: Resultados directos de los ensayos experimentales

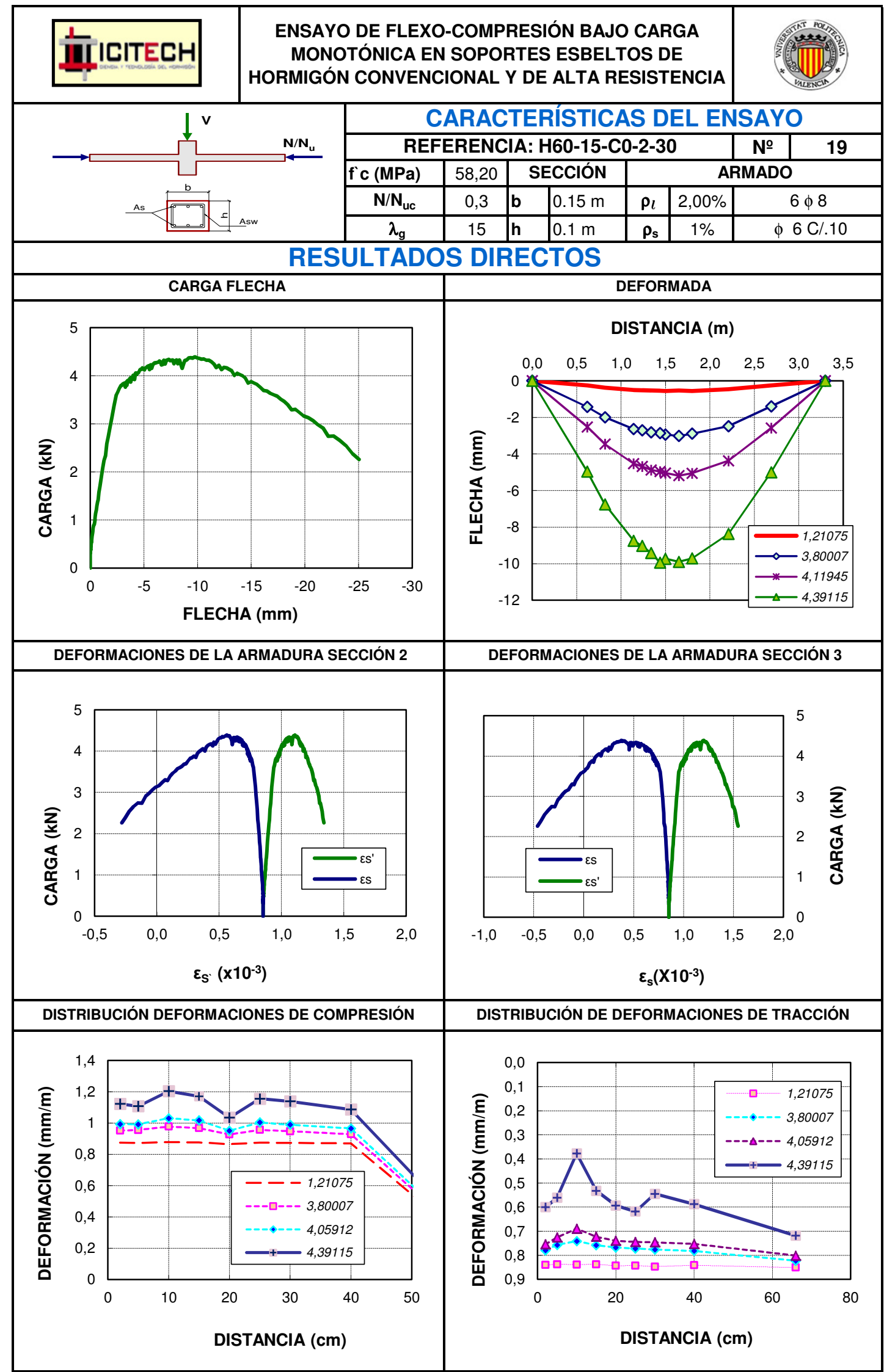


Estudio experimental y numérico de la capacidad de deformación de soportes esbeltos de hormigón armado

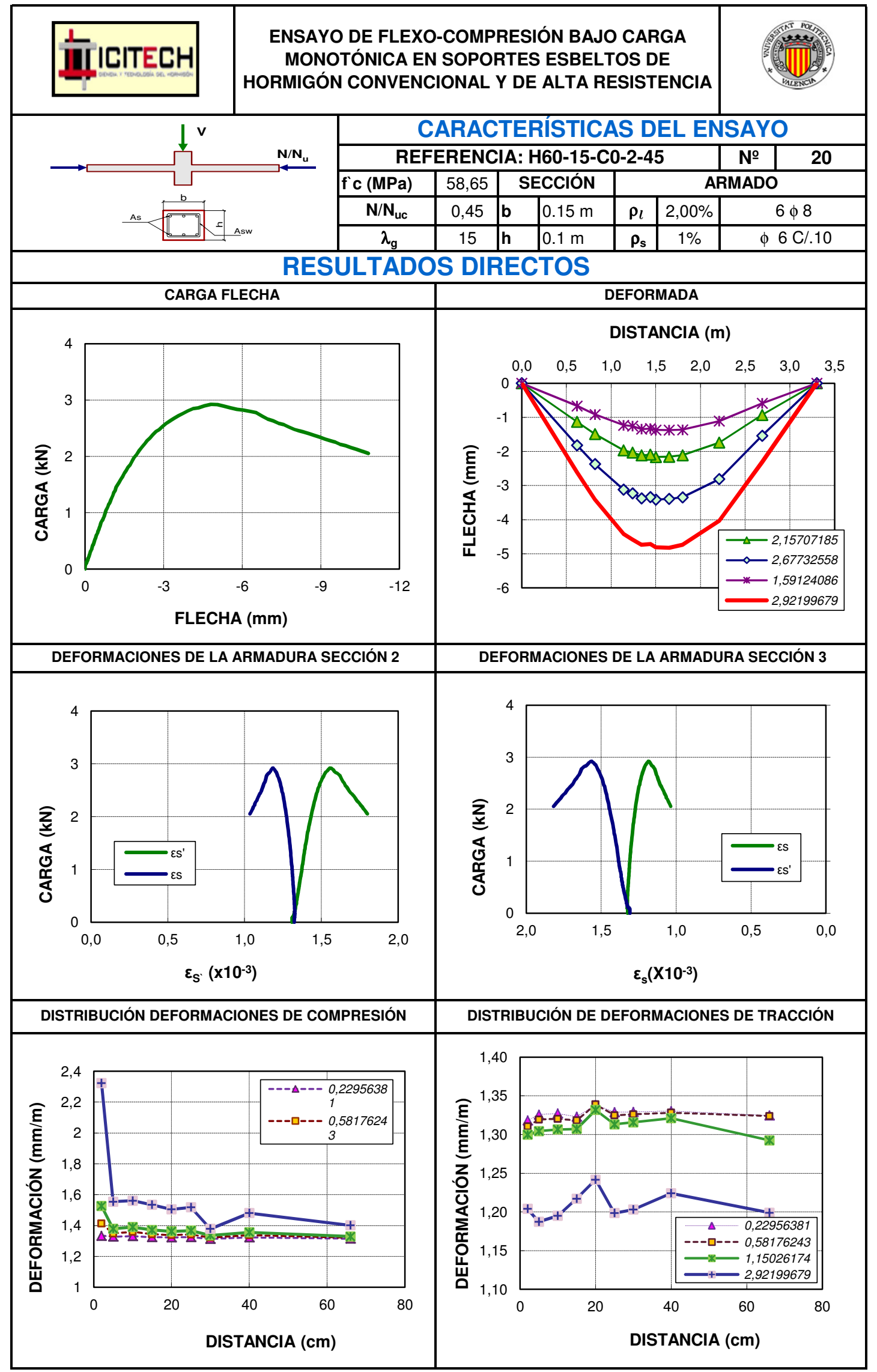


Anejo E: Resultados directos de los ensayos experimentales

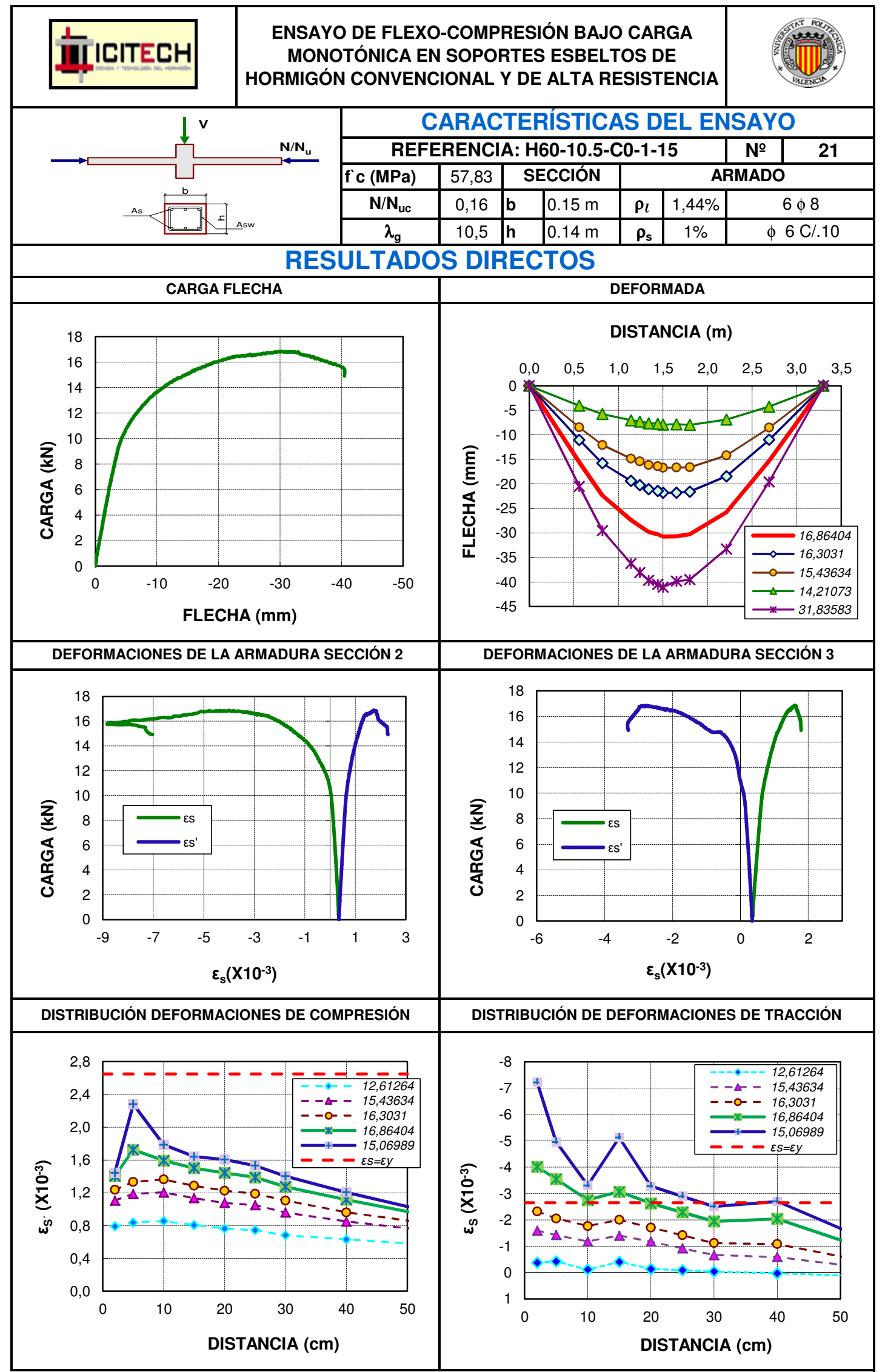


Estudio experimental y numérico de la capacidad de deformación de soportes esbeltos de hormigón armado

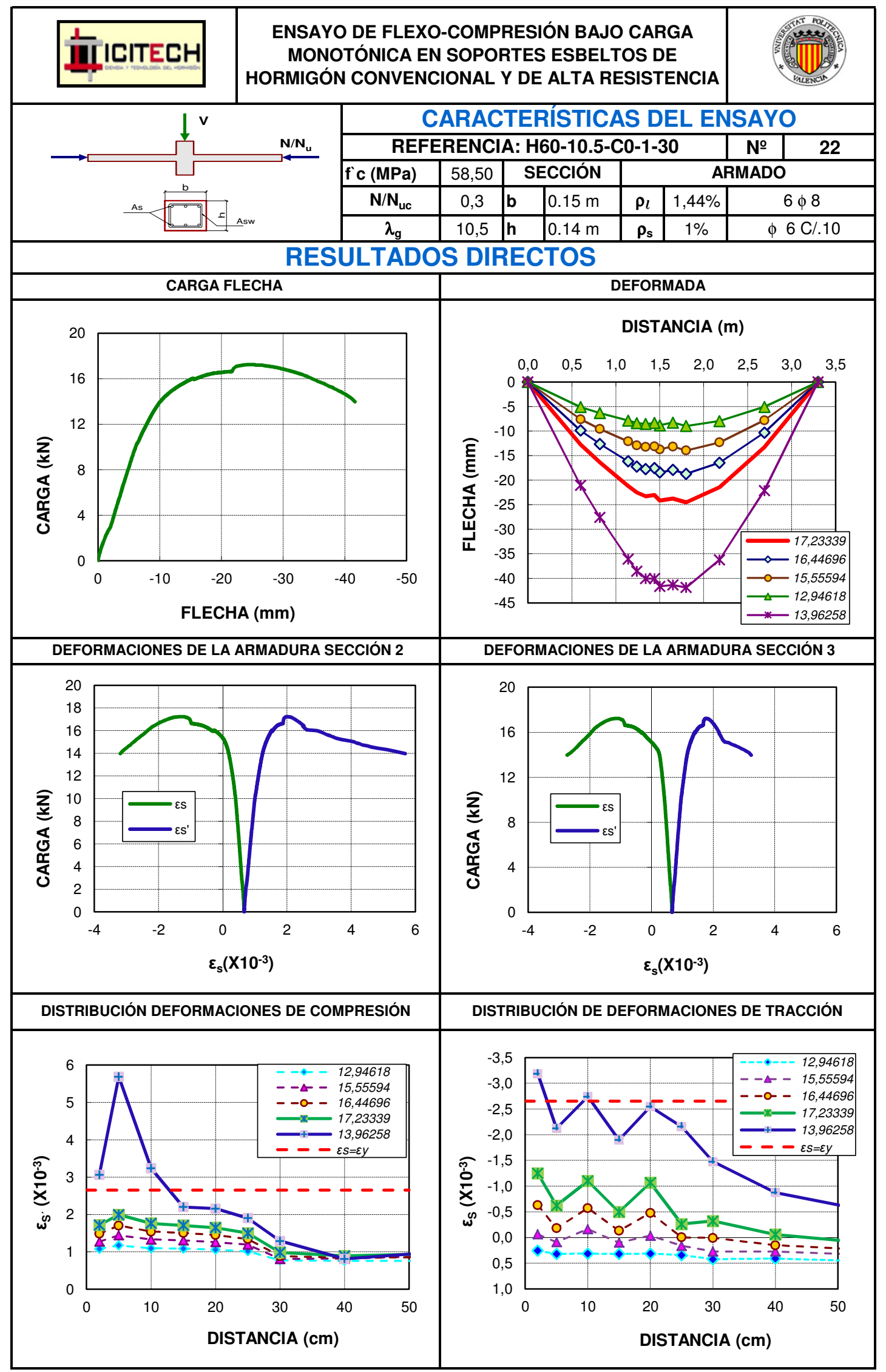


Anejo E: Resultados directos de los ensayos experimentales

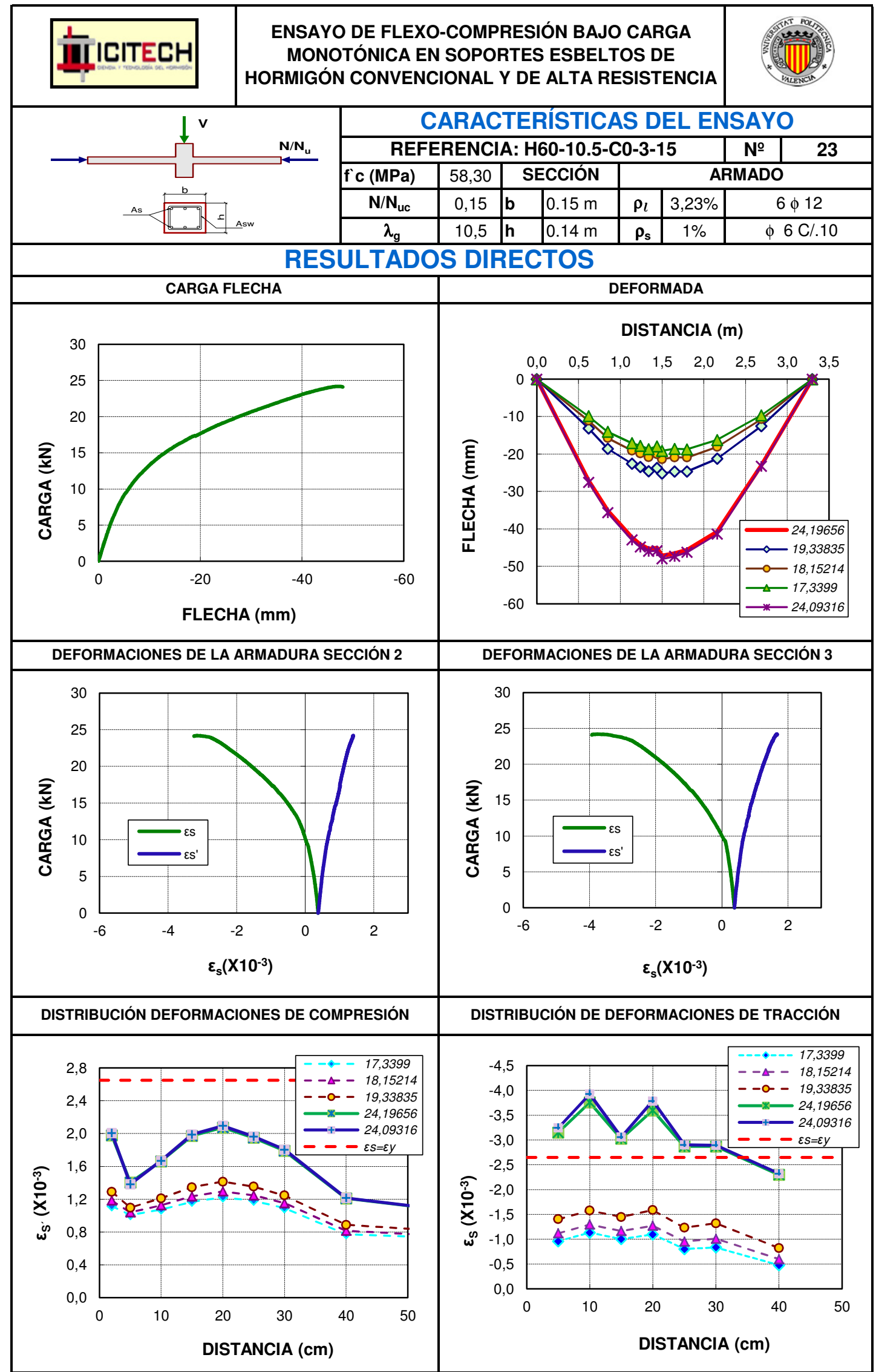


Estudio experimental y numérico de la capacidad de deformación de soportes esbeltos de hormigón armado

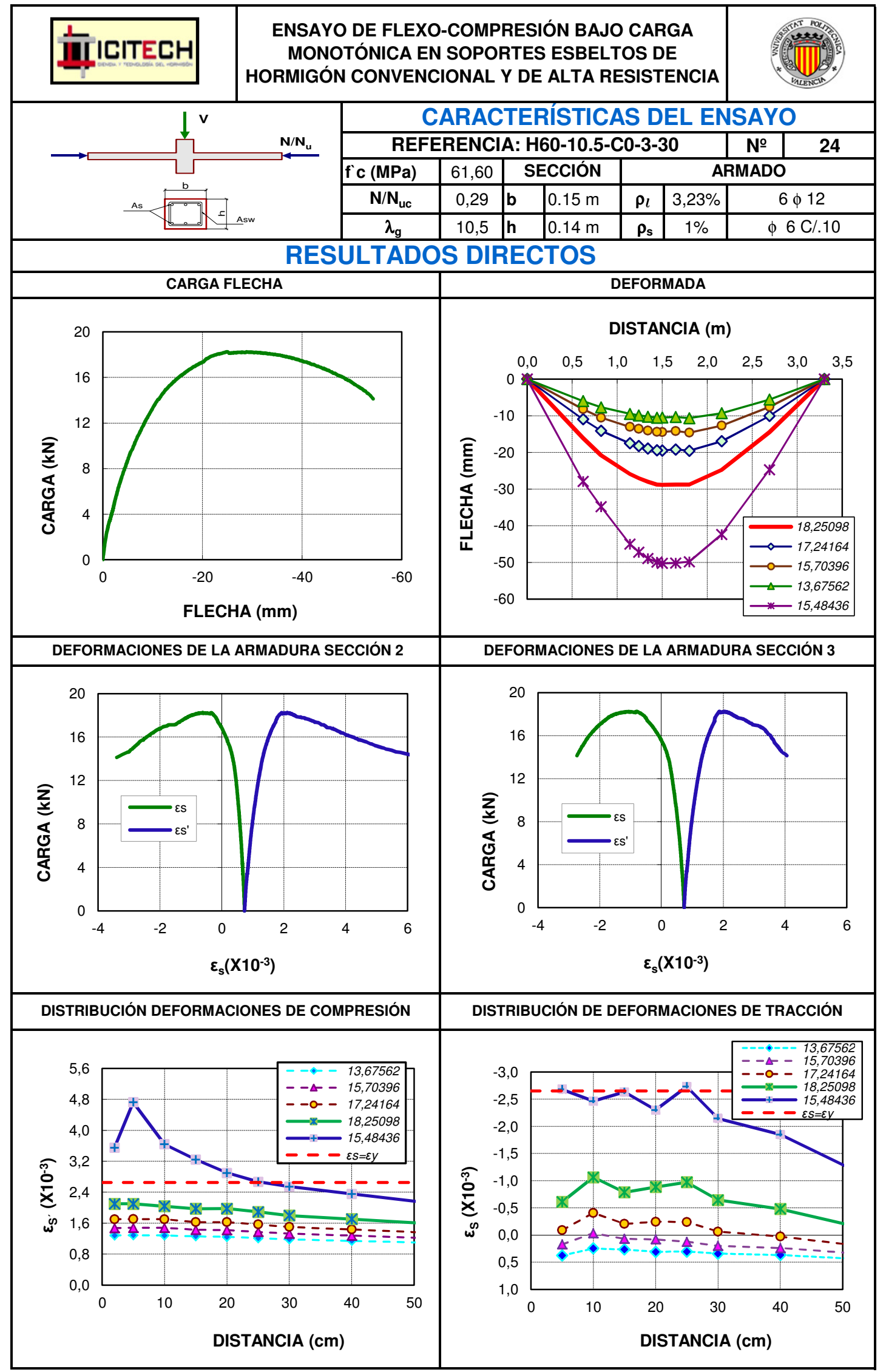


Anejo E: Resultados directos de los ensayos experimentales

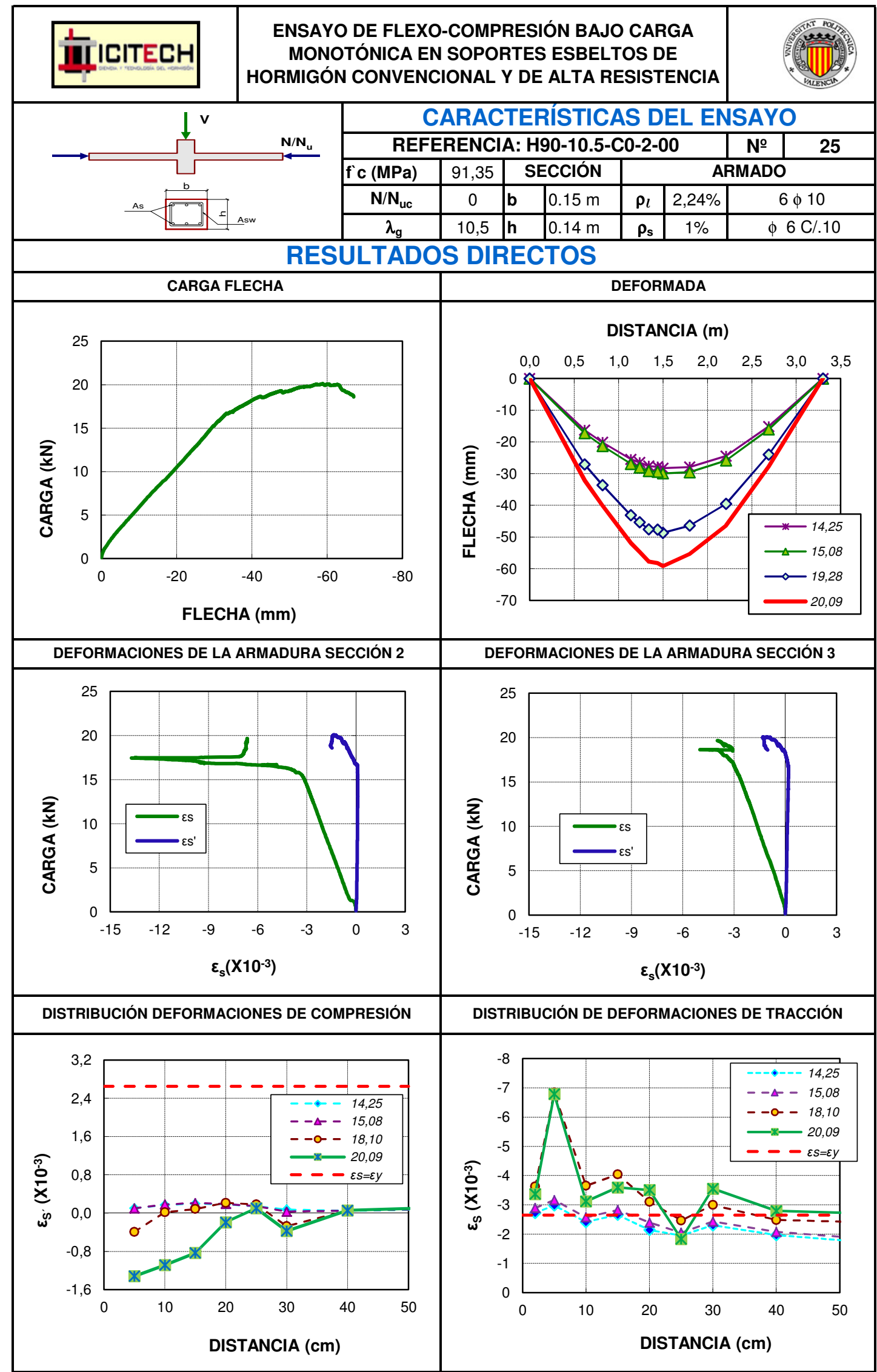


Estudio experimental y numérico de la capacidad de deformación de soportes esbeltos de hormigón armado

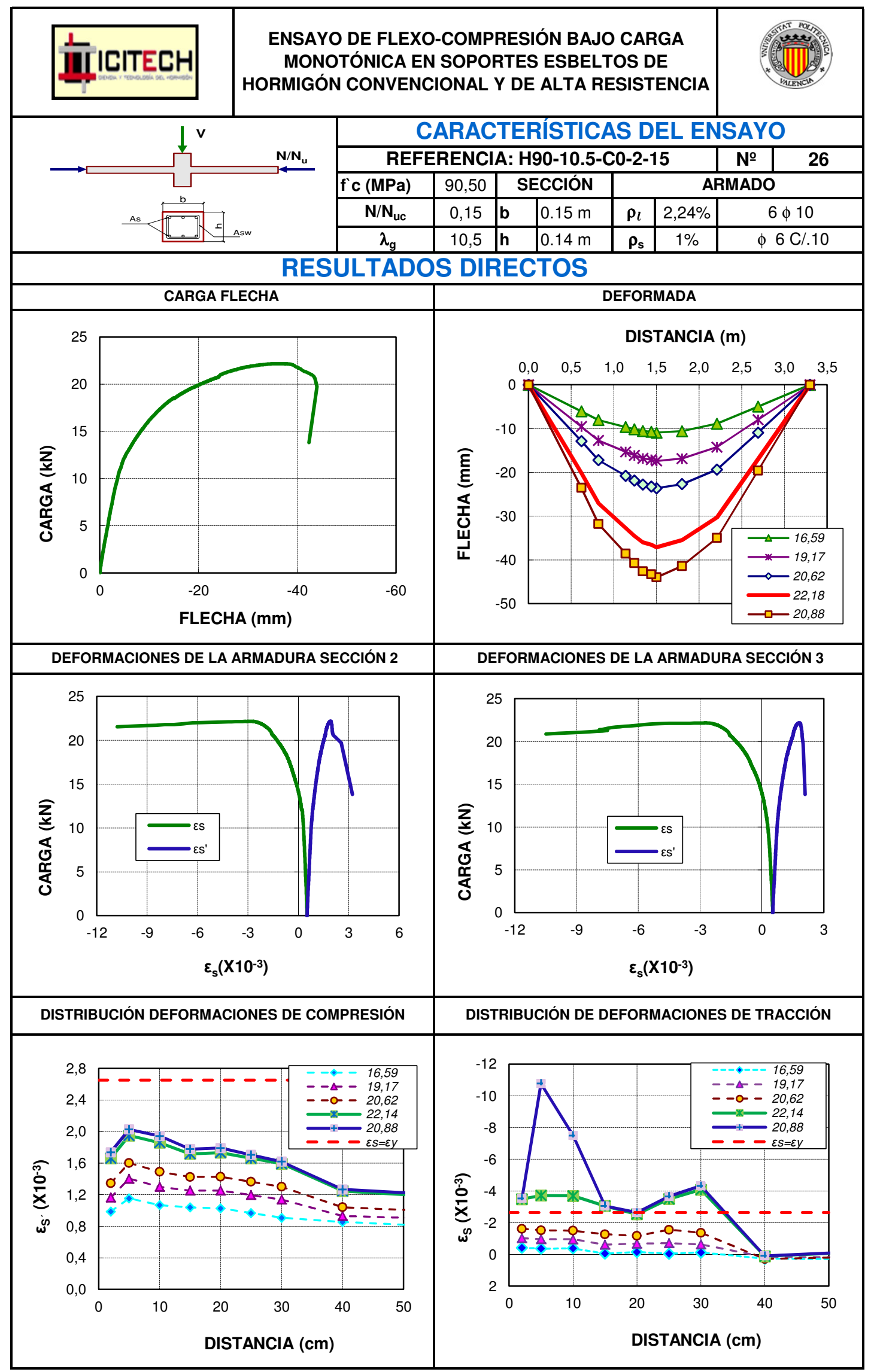


Anejo E: Resultados directos de los ensayos experimentales

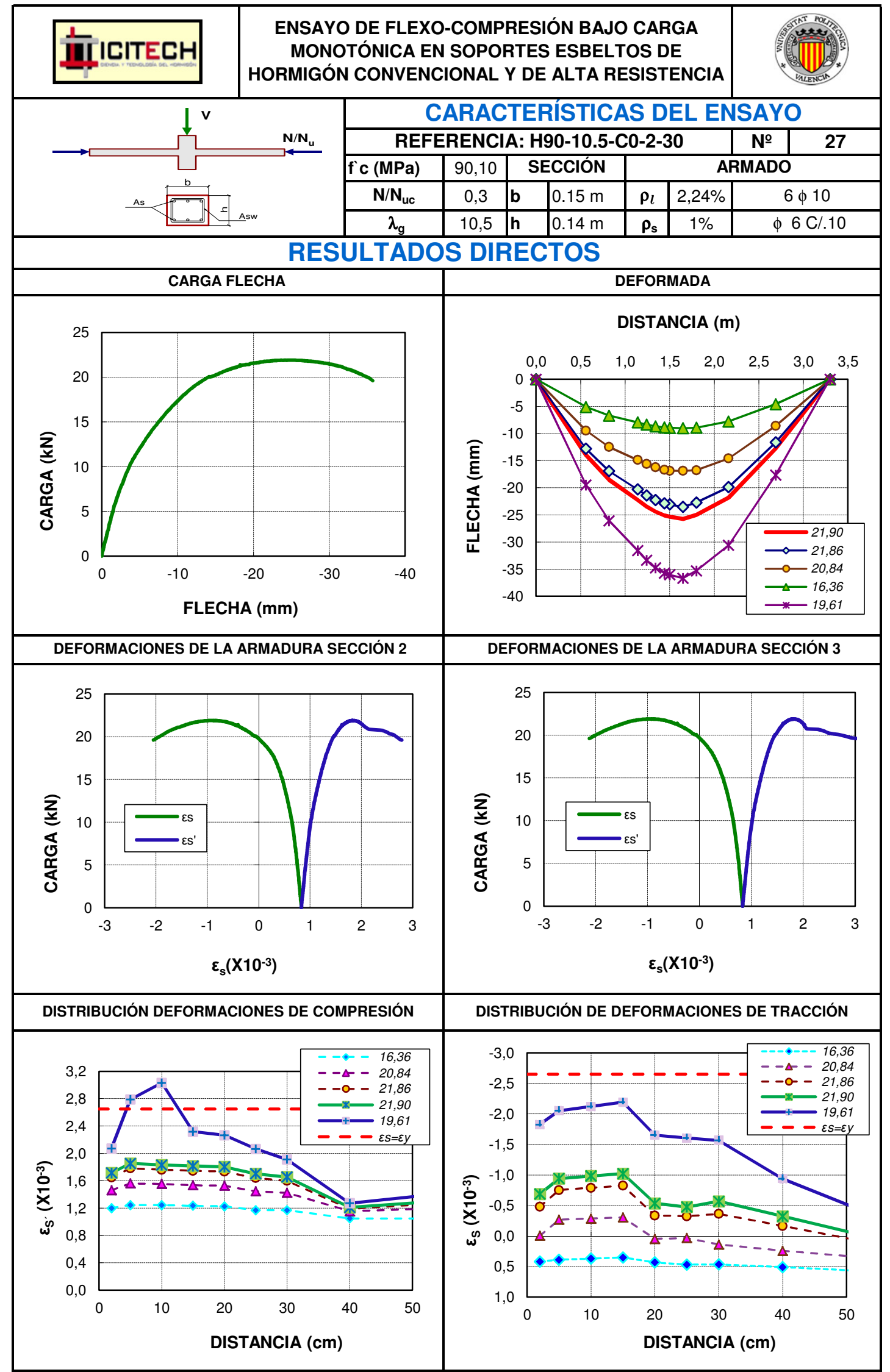


Estudio experimental y numérico de la capacidad de deformación de soportes esbeltos de hormigón armado

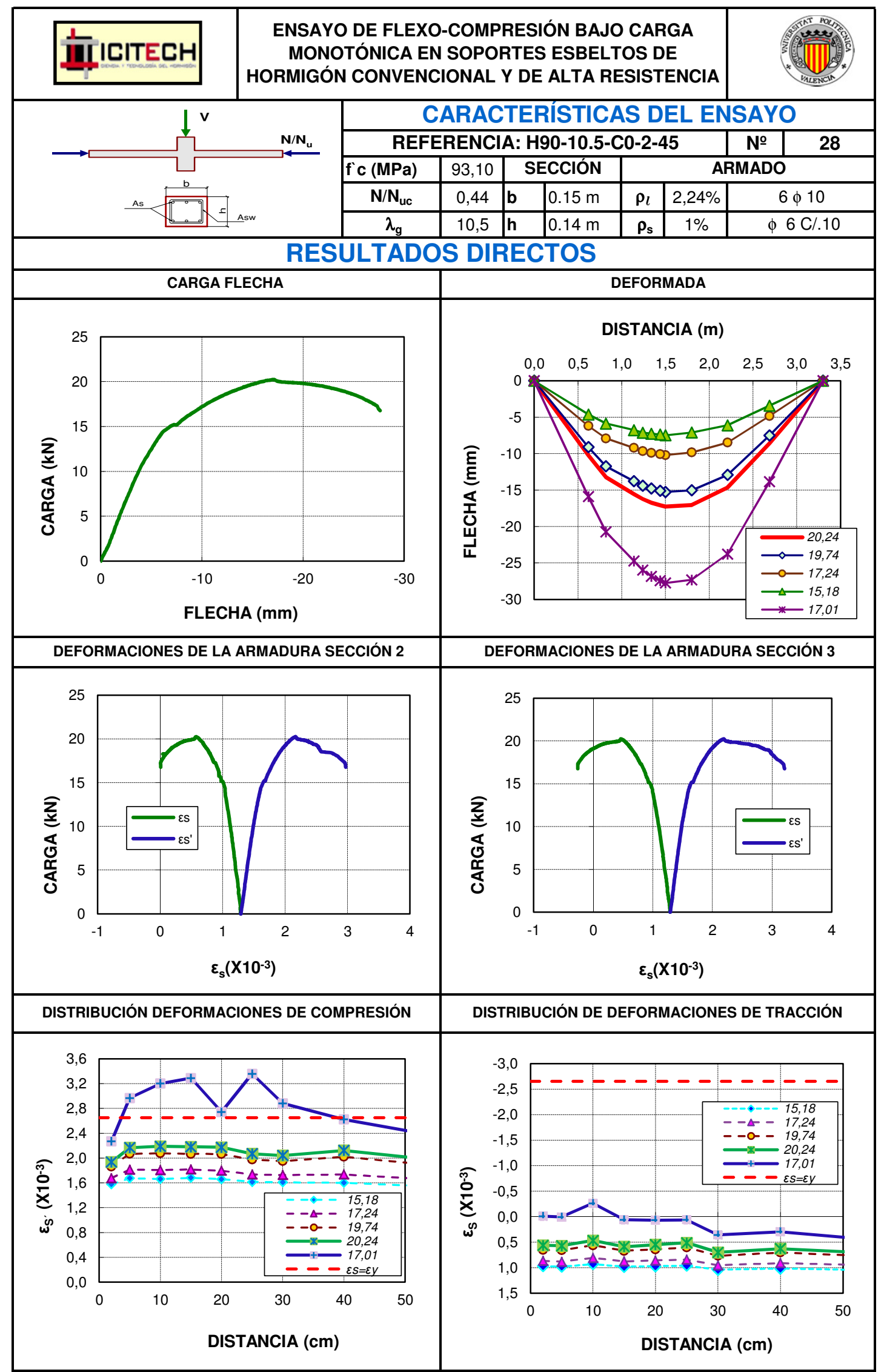


Anejo E: Resultados directos de los ensayos experimentales

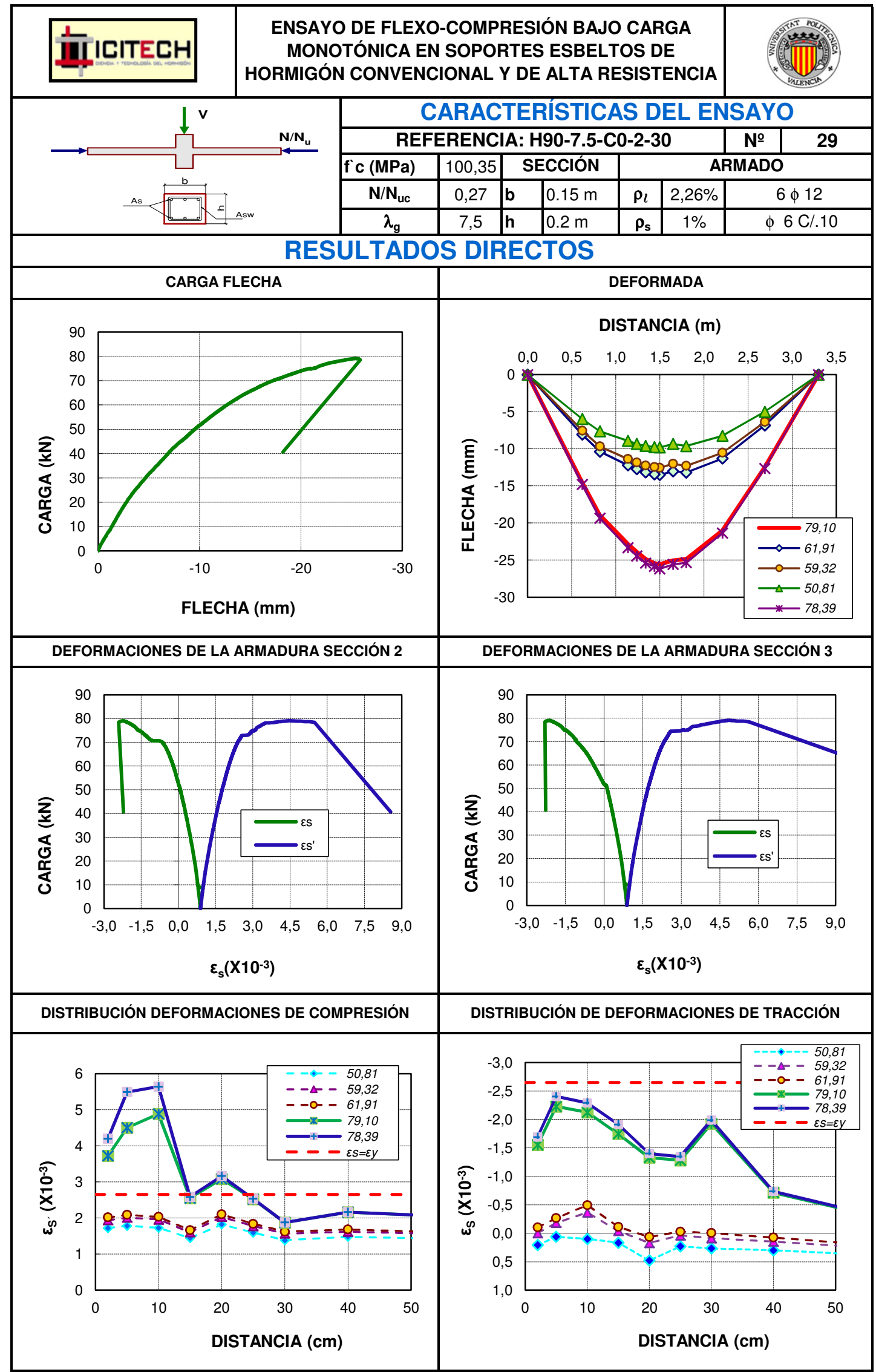


Estudio experimental y numérico de la capacidad de deformación de soportes esbeltos de hormigón armado

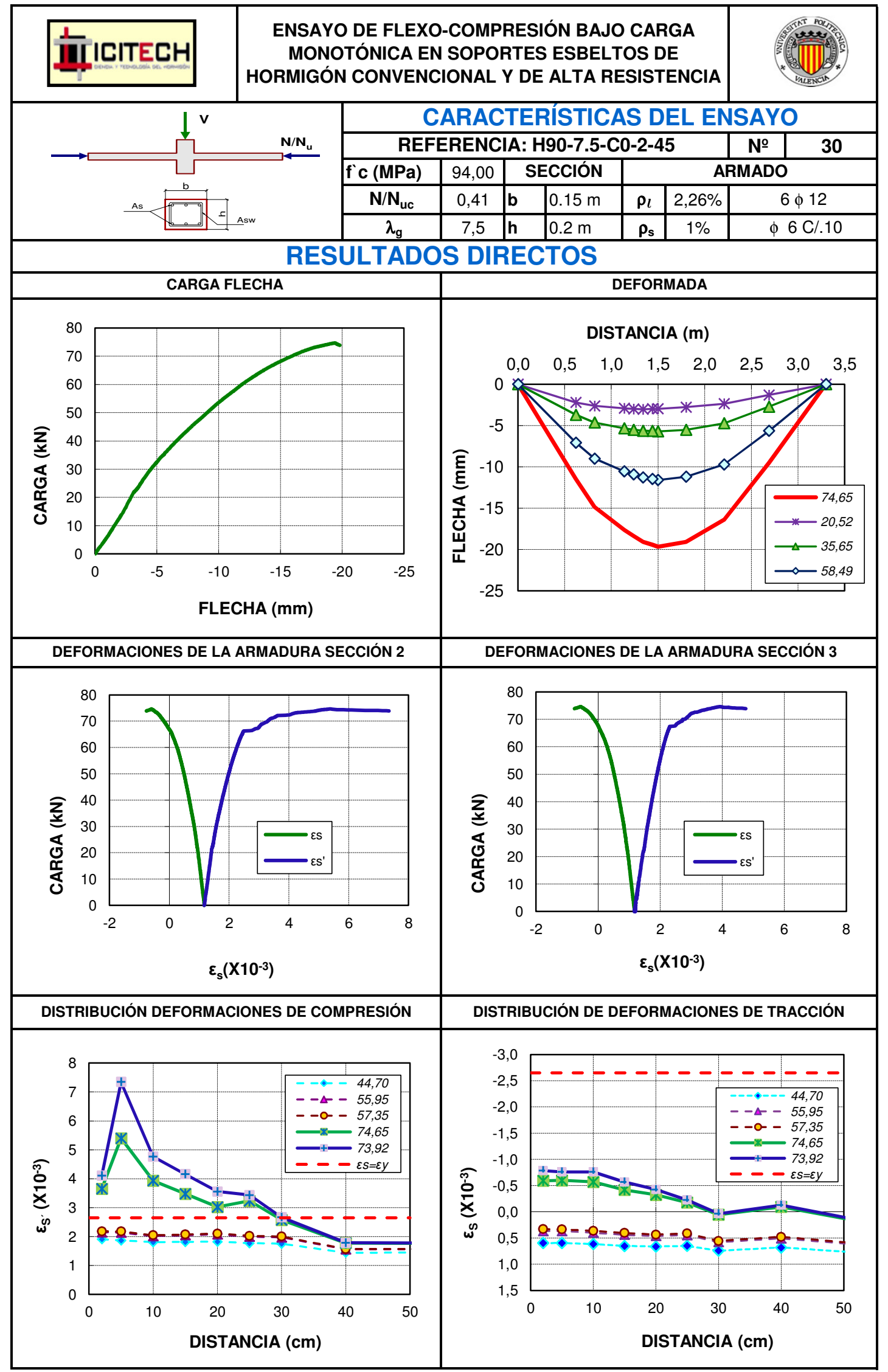


Anejo E: Resultados directos de los ensayos experimentales

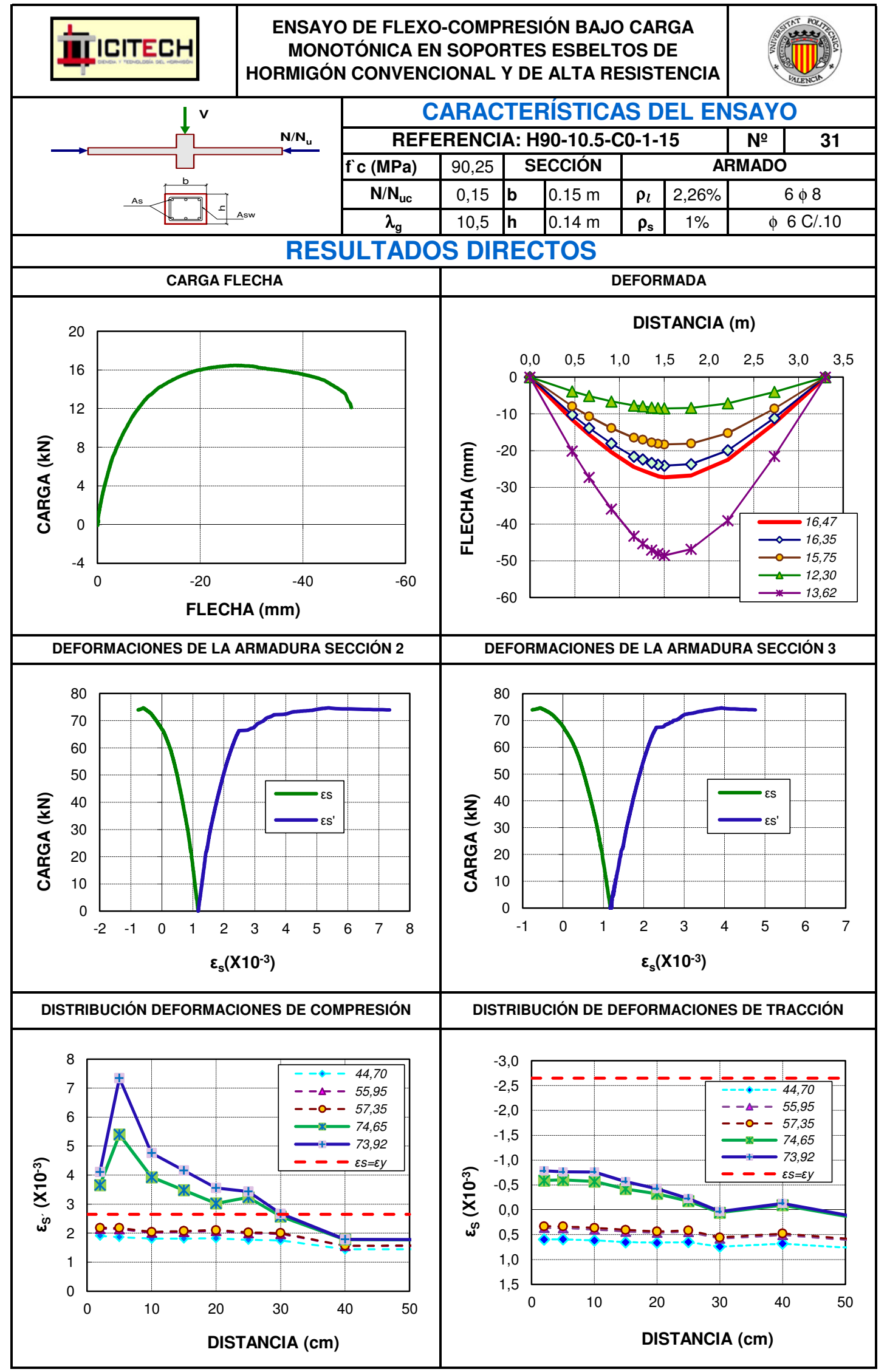


Estudio experimental y numérico de la capacidad de deformación de soportes esbeltos de hormigón armado

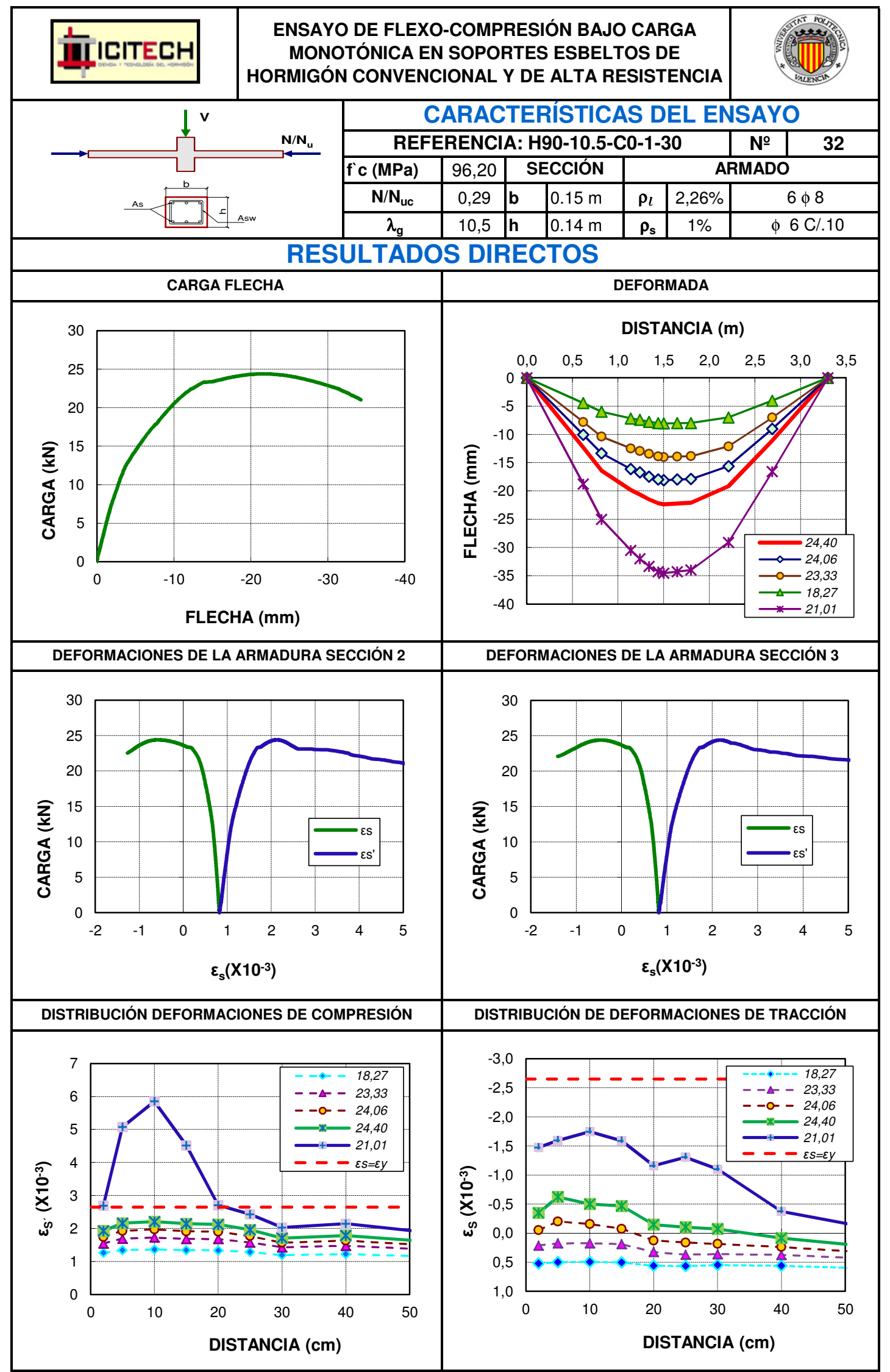


Anejo E: Resultados directos de los ensayos experimentales

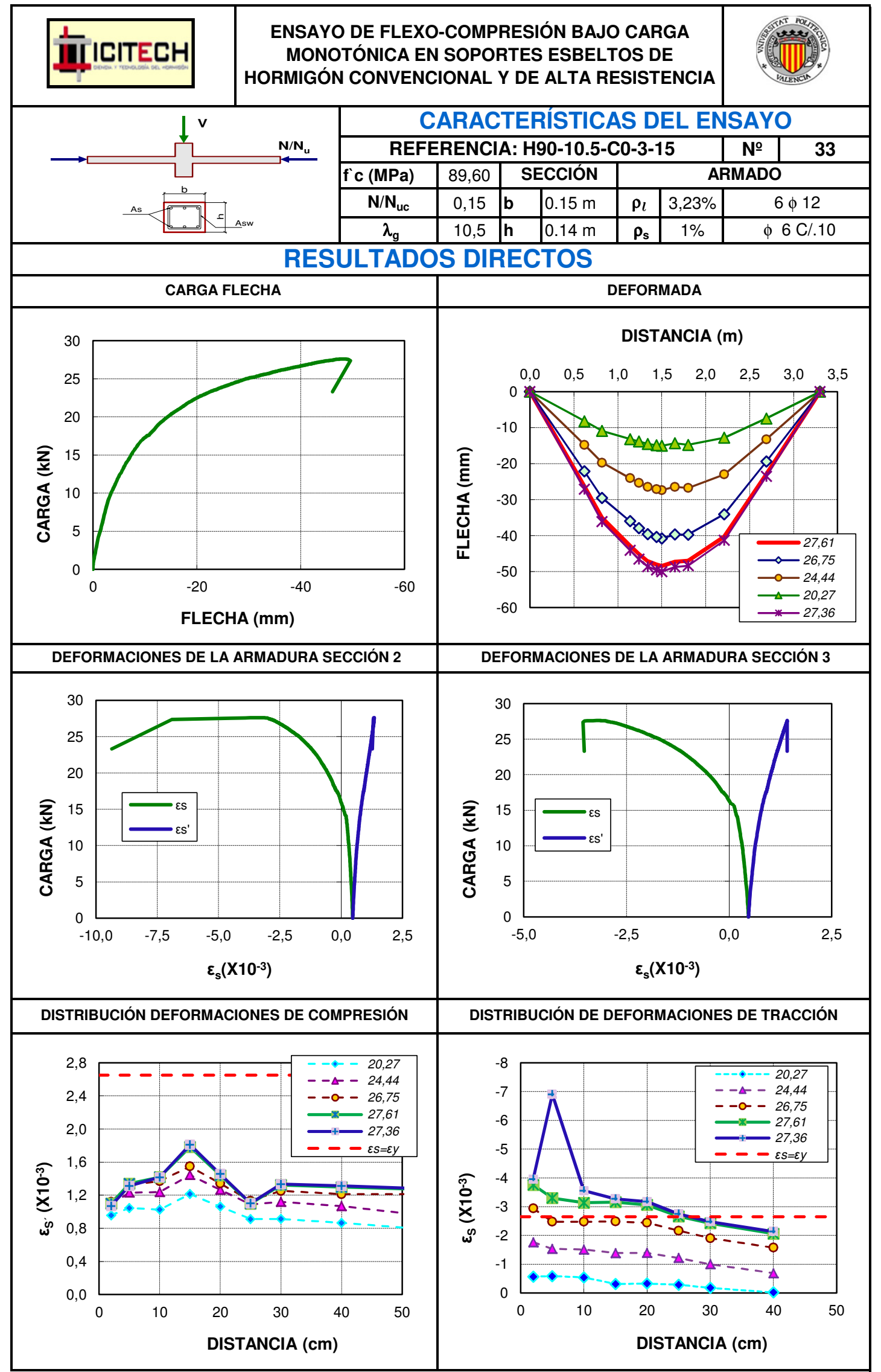


Estudio experimental y numérico de la capacidad de deformación de soportes esbeltos de hormigón armado

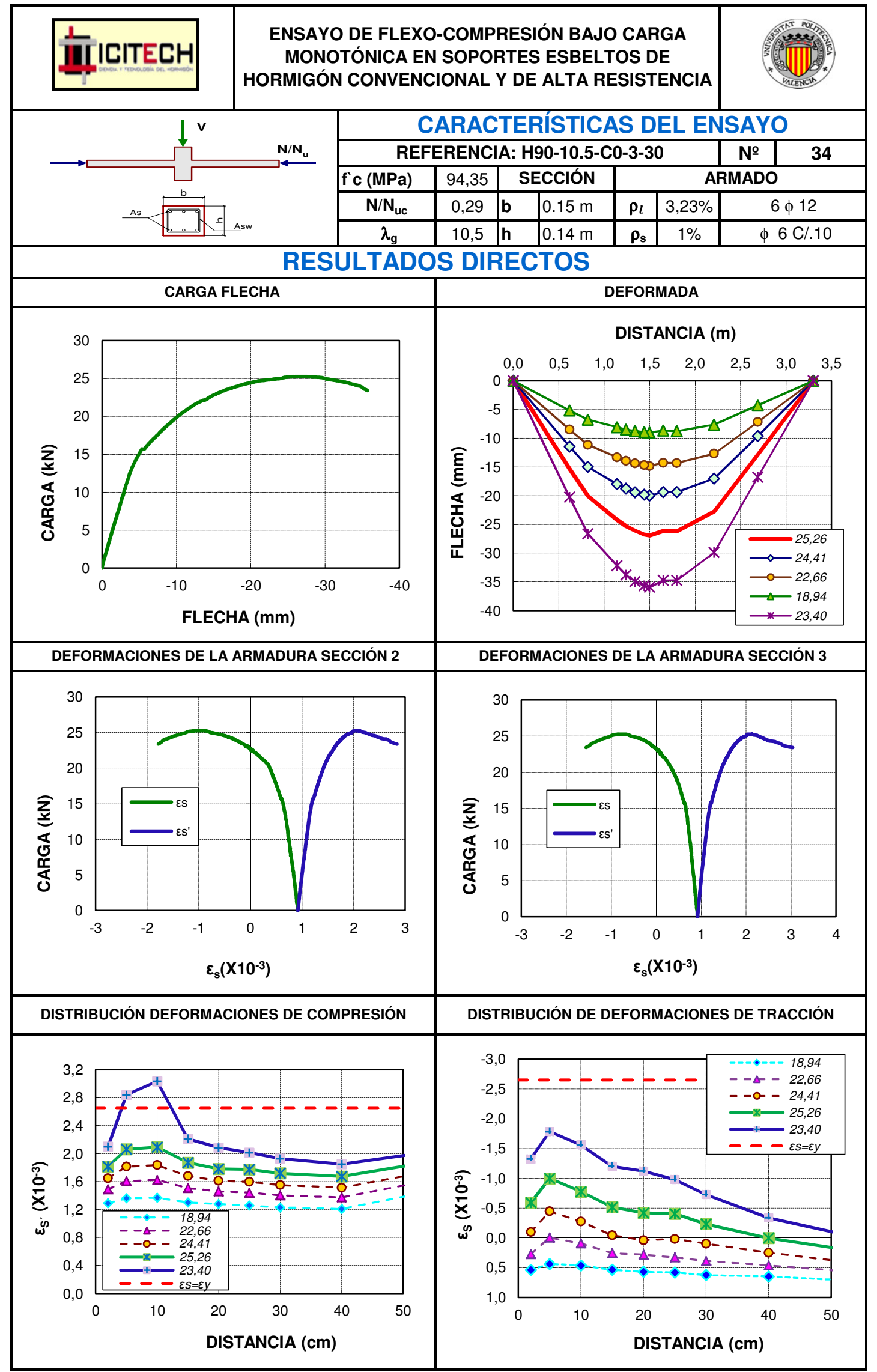


Anejo E: Resultados directos de los ensayos experimentales

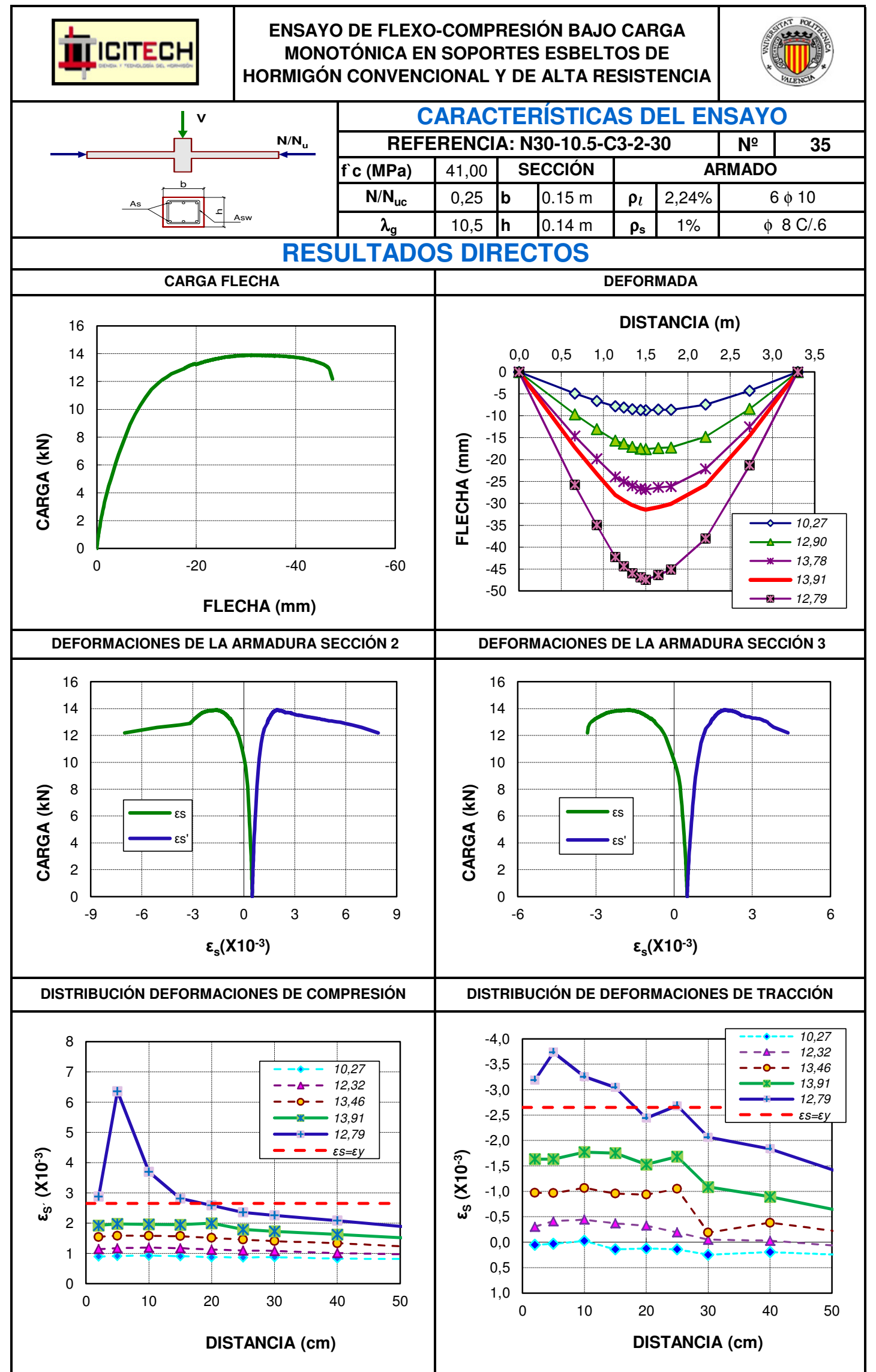


Estudio experimental y numérico de la capacidad de deformación de soportes esbeltos de hormigón armado

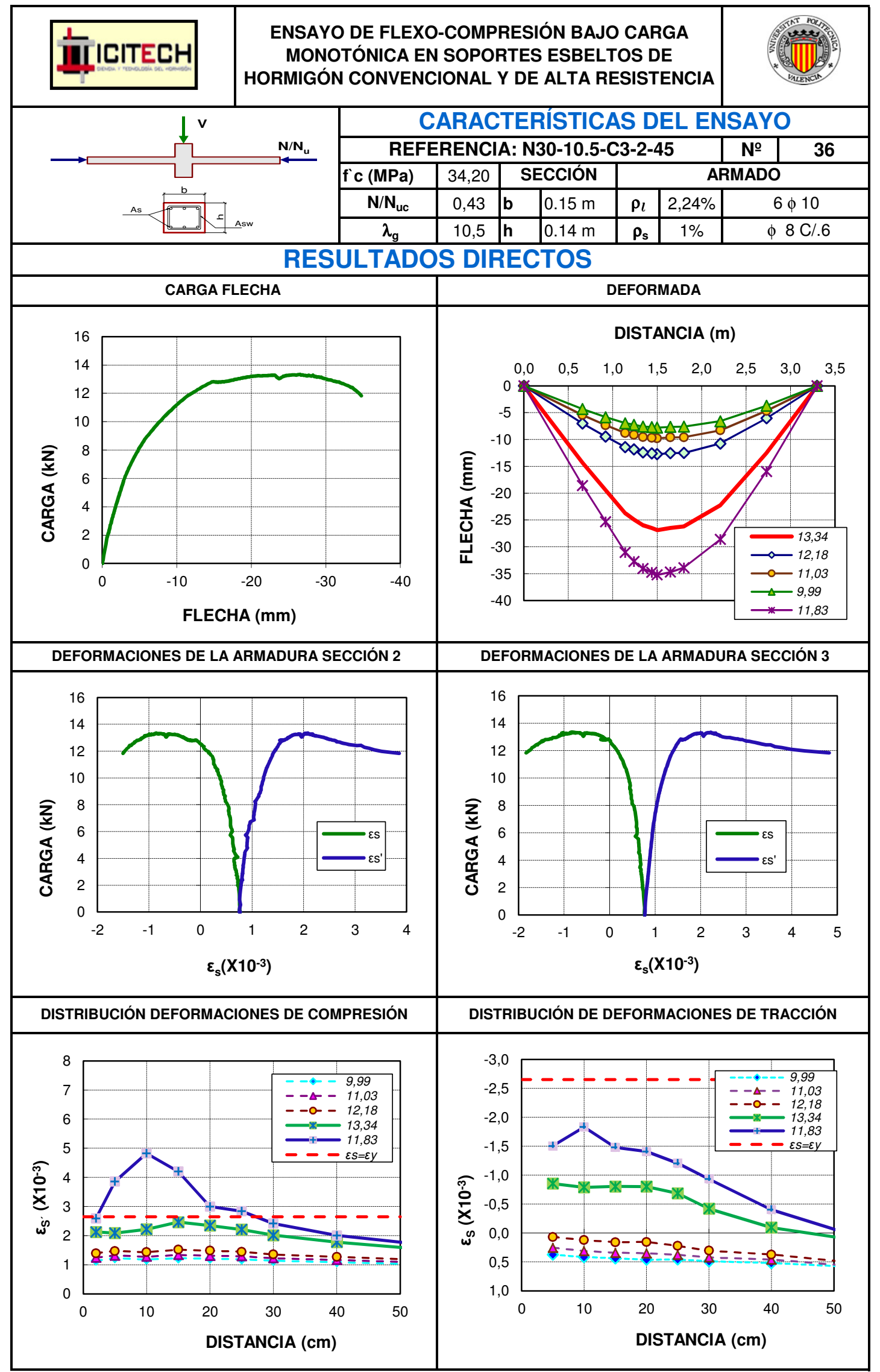


Anejo E: Resultados directos de los ensayos experimentales

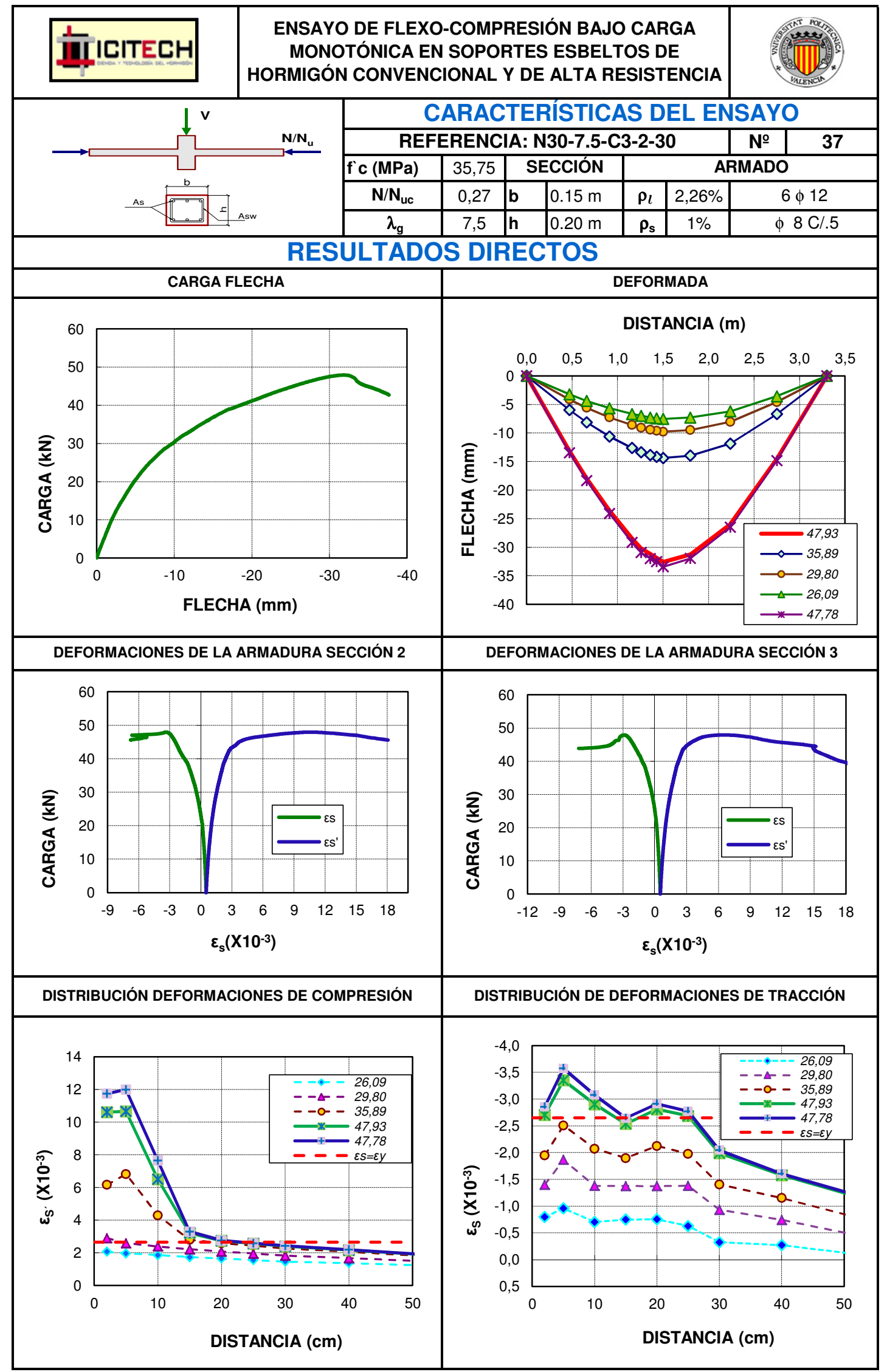


Estudio experimental y numérico de la capacidad de deformación de soportes esbeltos de hormigón armado

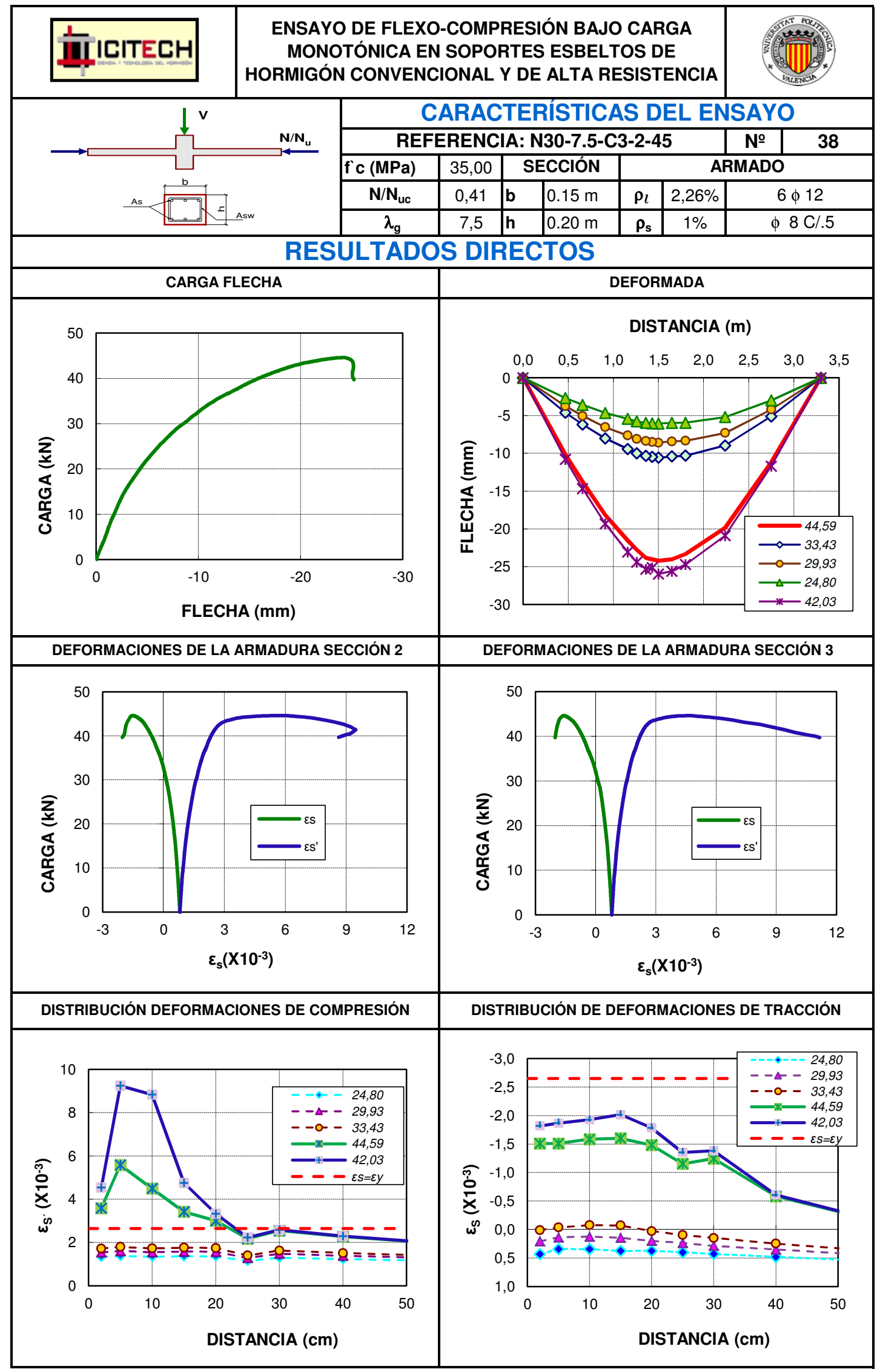


Anejo E: Resultados directos de los ensayos experimentales

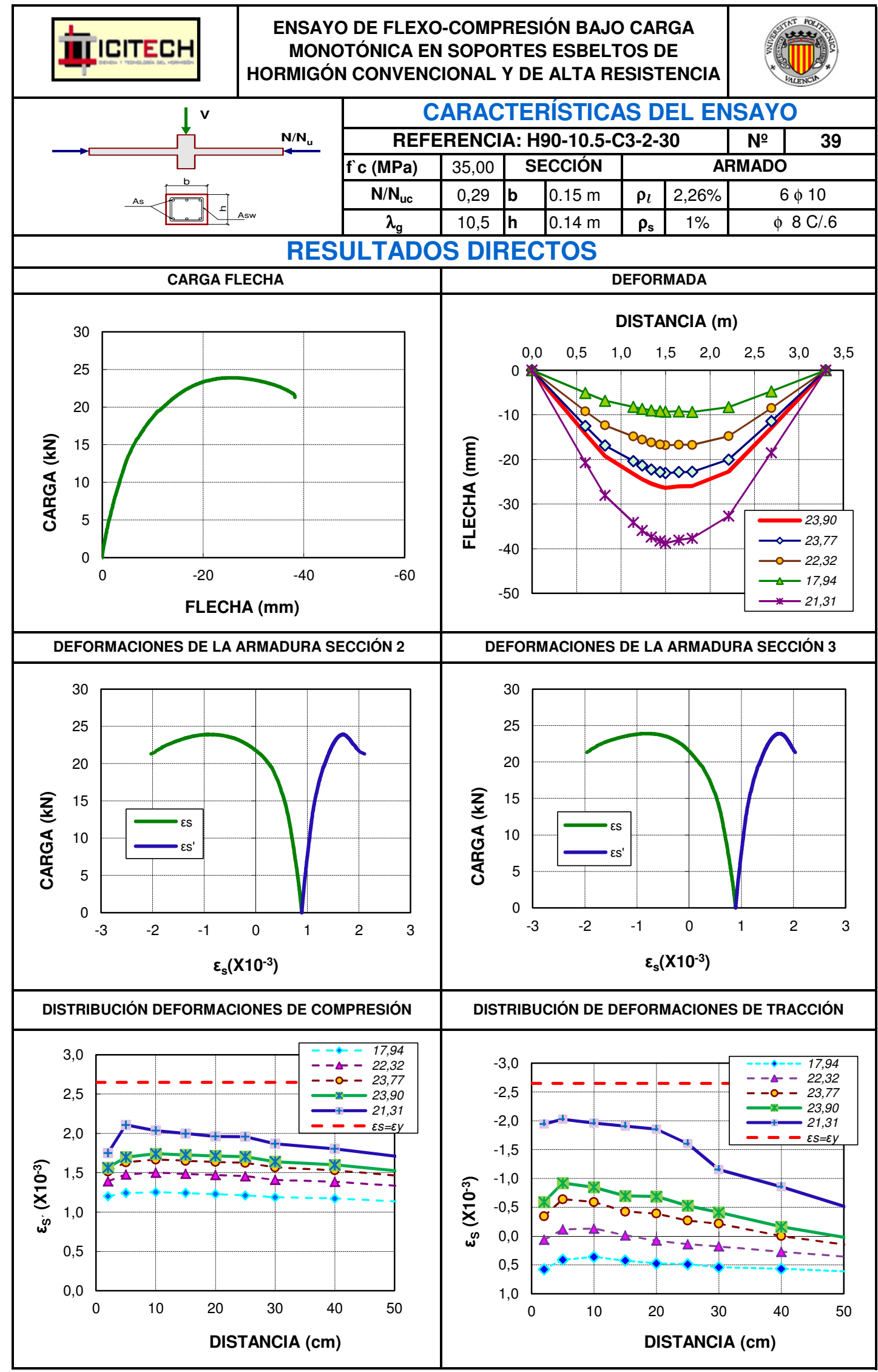


Estudio experimental y numérico de la capacidad de deformación de soportes esbeltos de hormigón armado

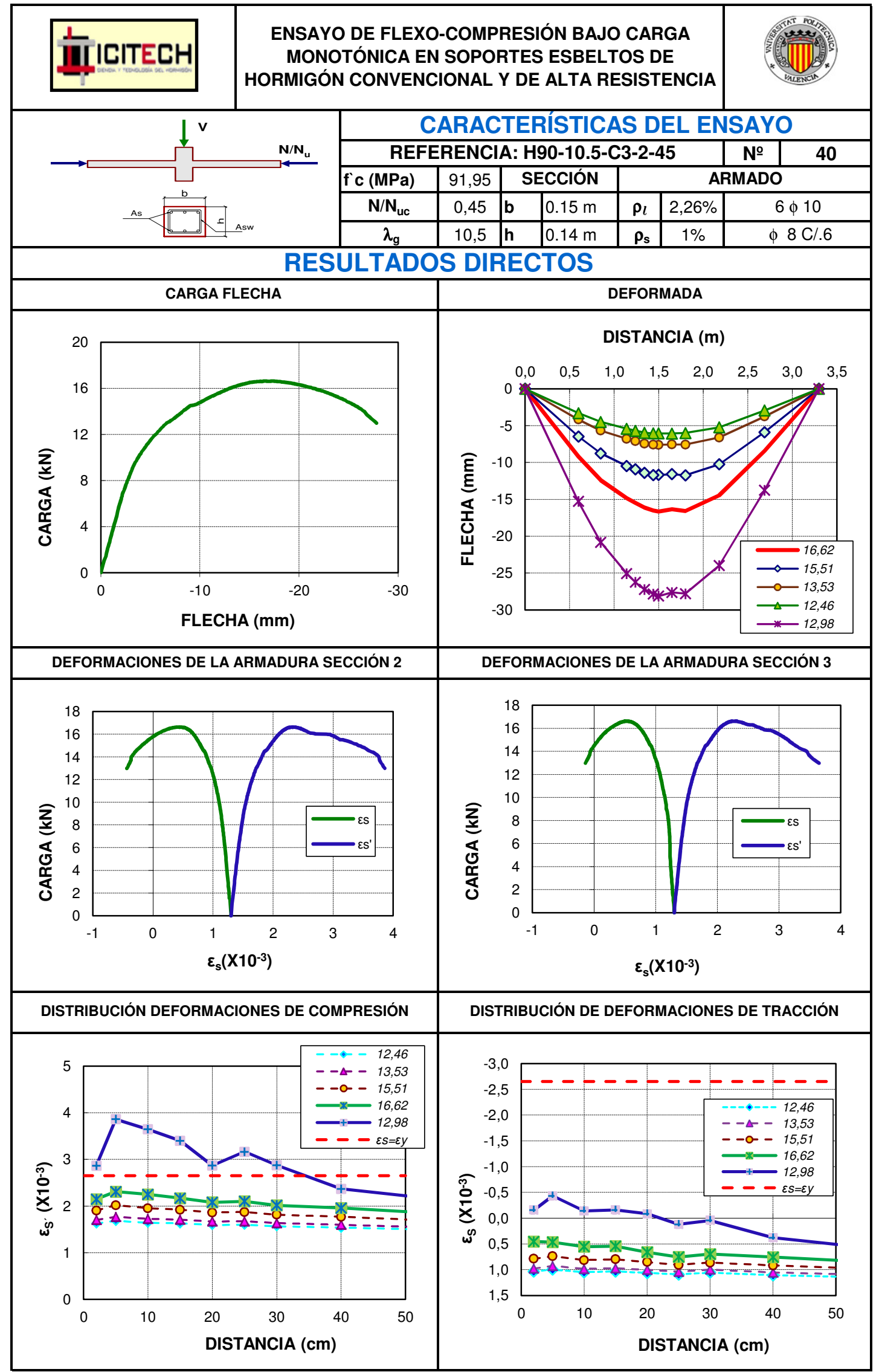


Anejo E: Resultados directos de los ensayos experimentales

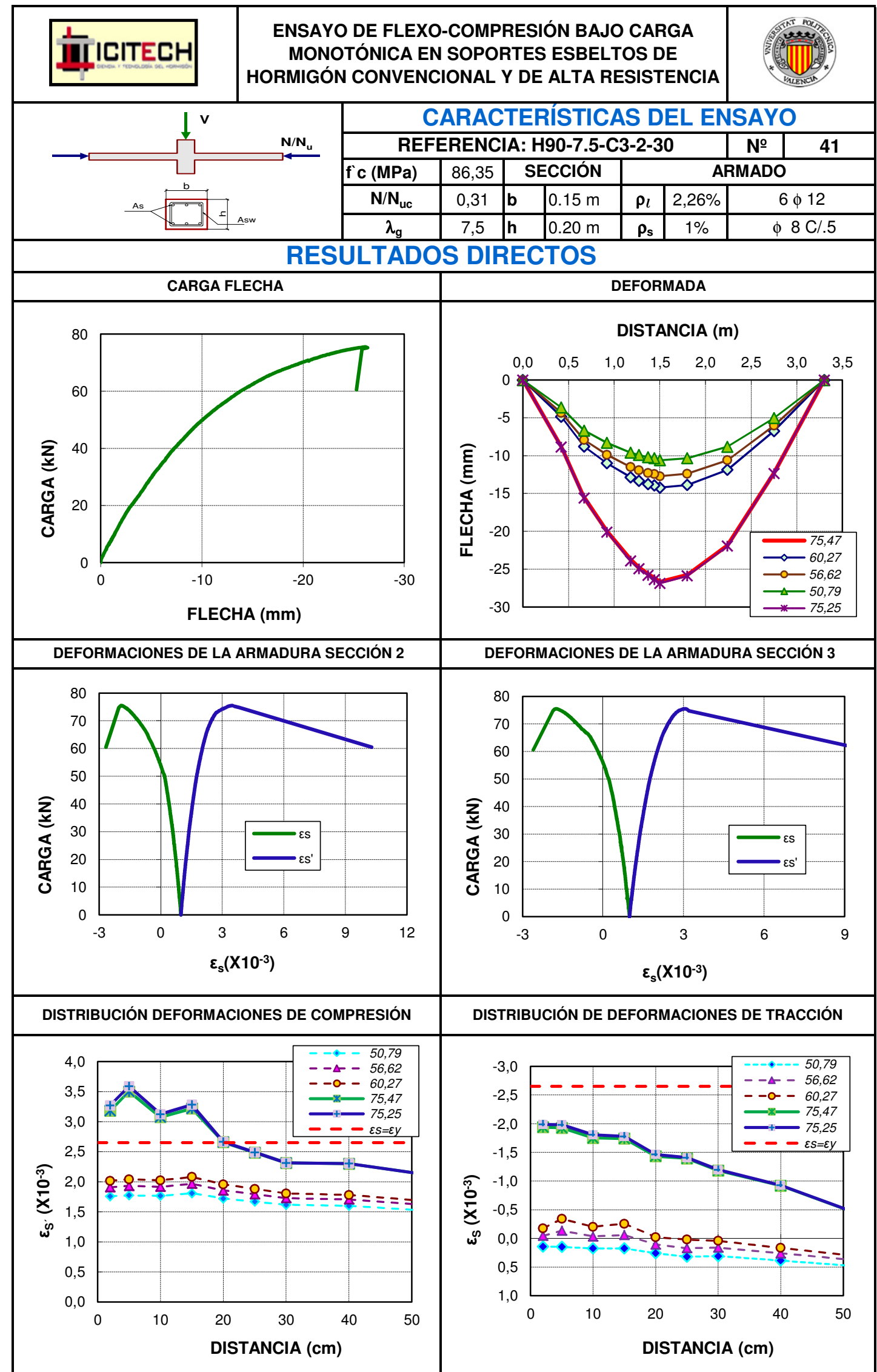


Estudio experimental y numérico de la capacidad de deformación de soportes esbeltos de hormigón armado

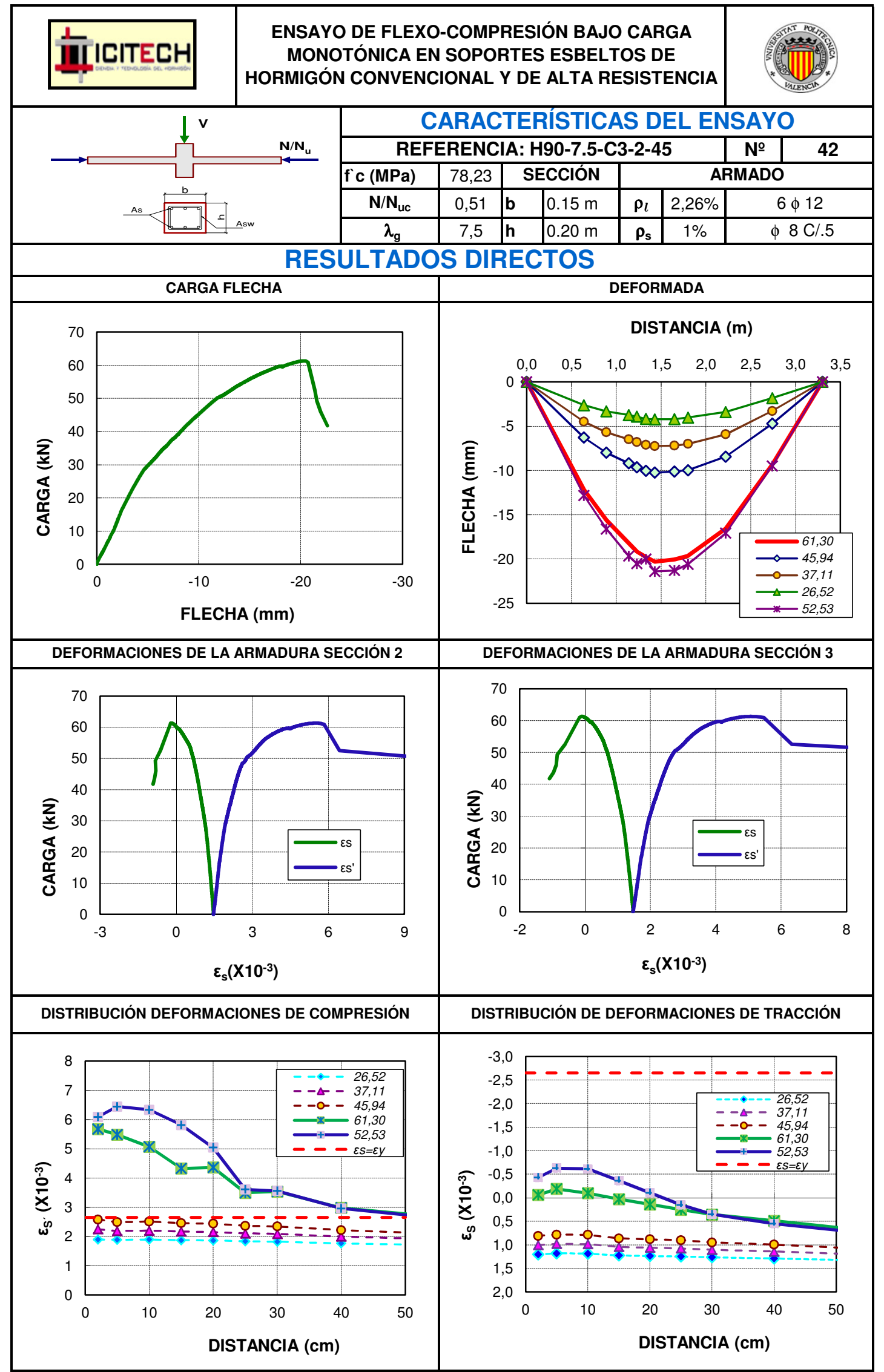


Anejo E: Resultados directos de los ensayos experimentales

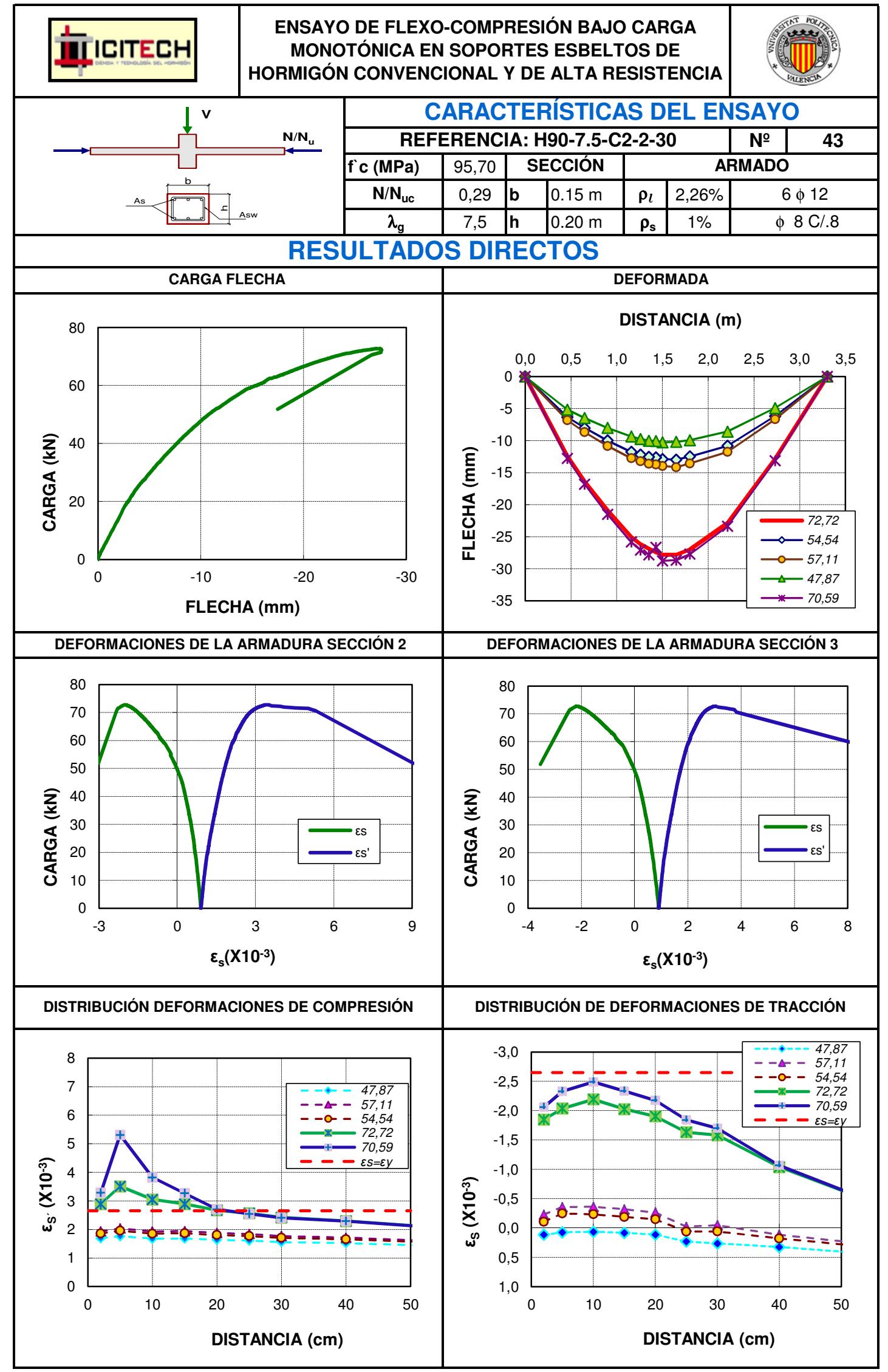


Estudio experimental y numérico de la capacidad de deformación de soportes esbeltos de hormigón armado

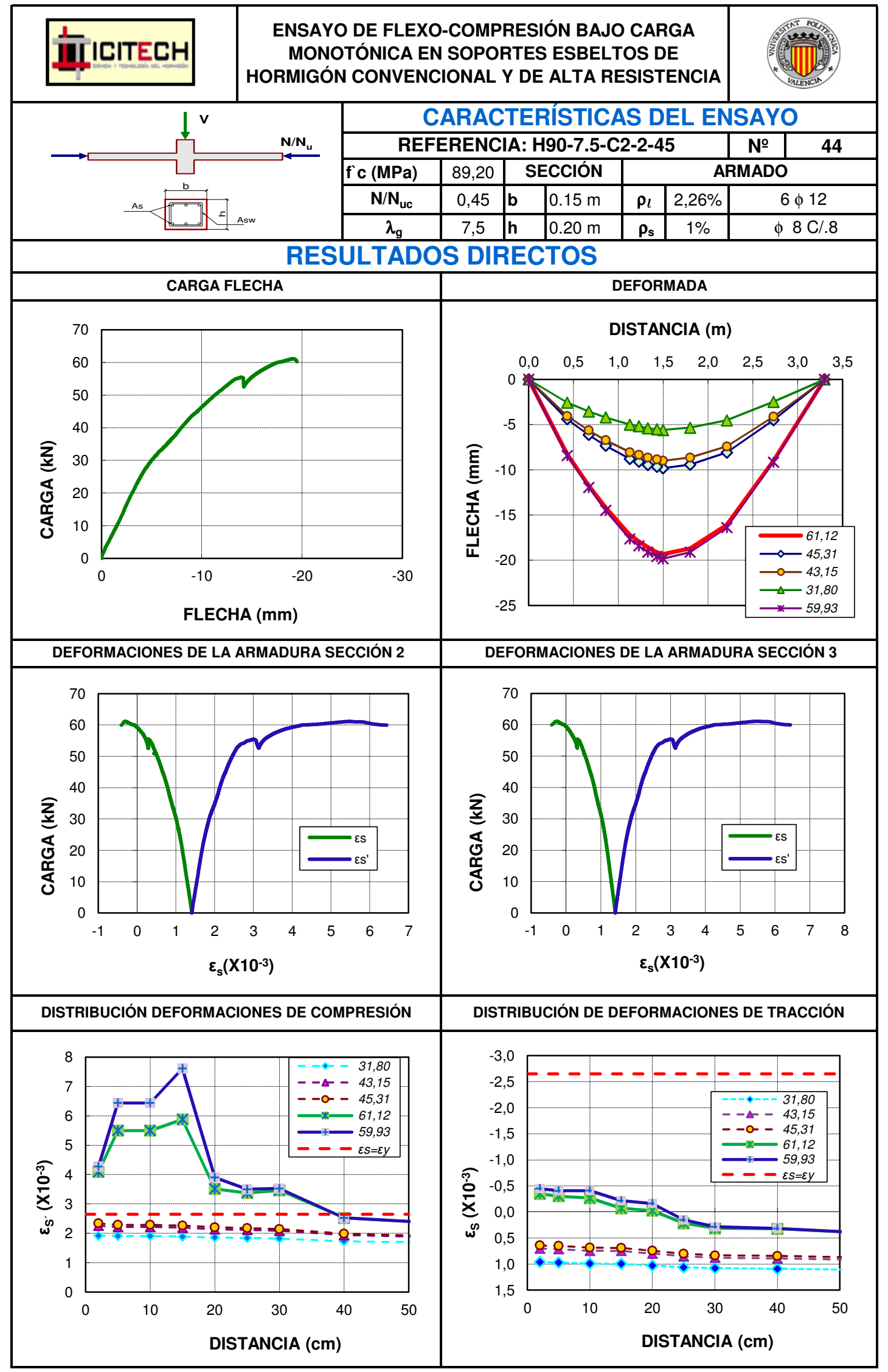




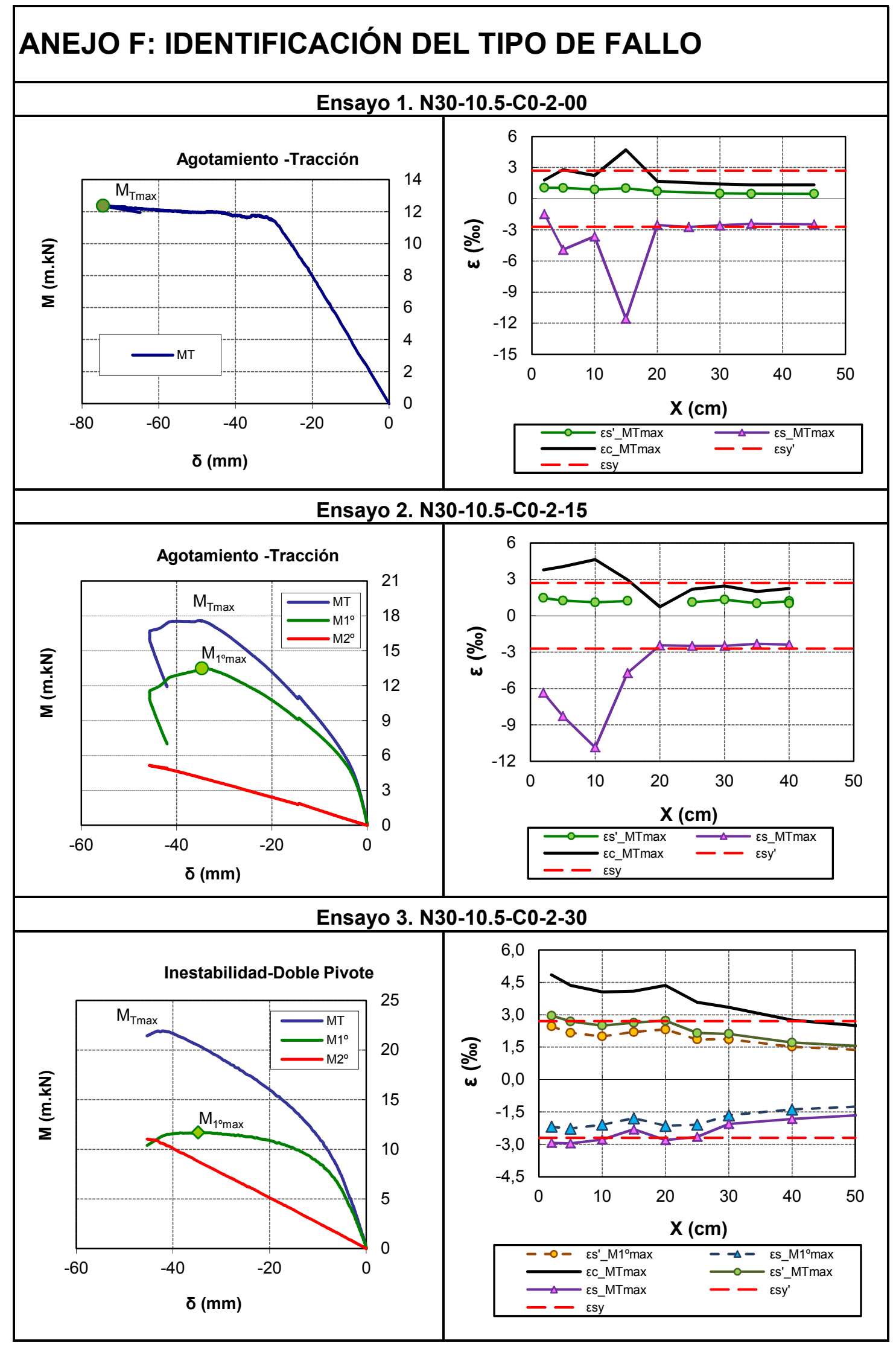


Estudio experimental y numérico de la capacidad de deformación de soportes esbeltos de hormigón armado

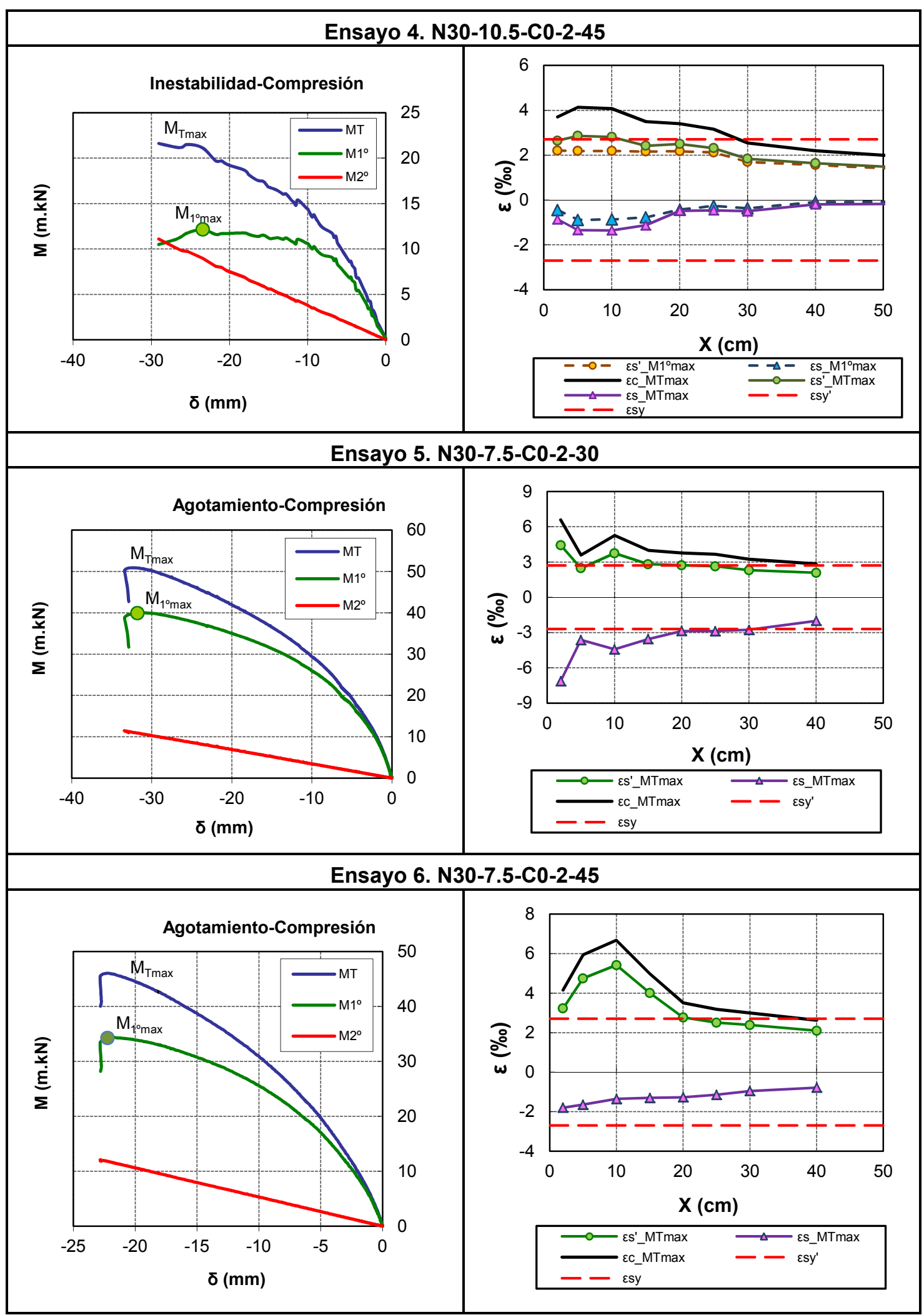




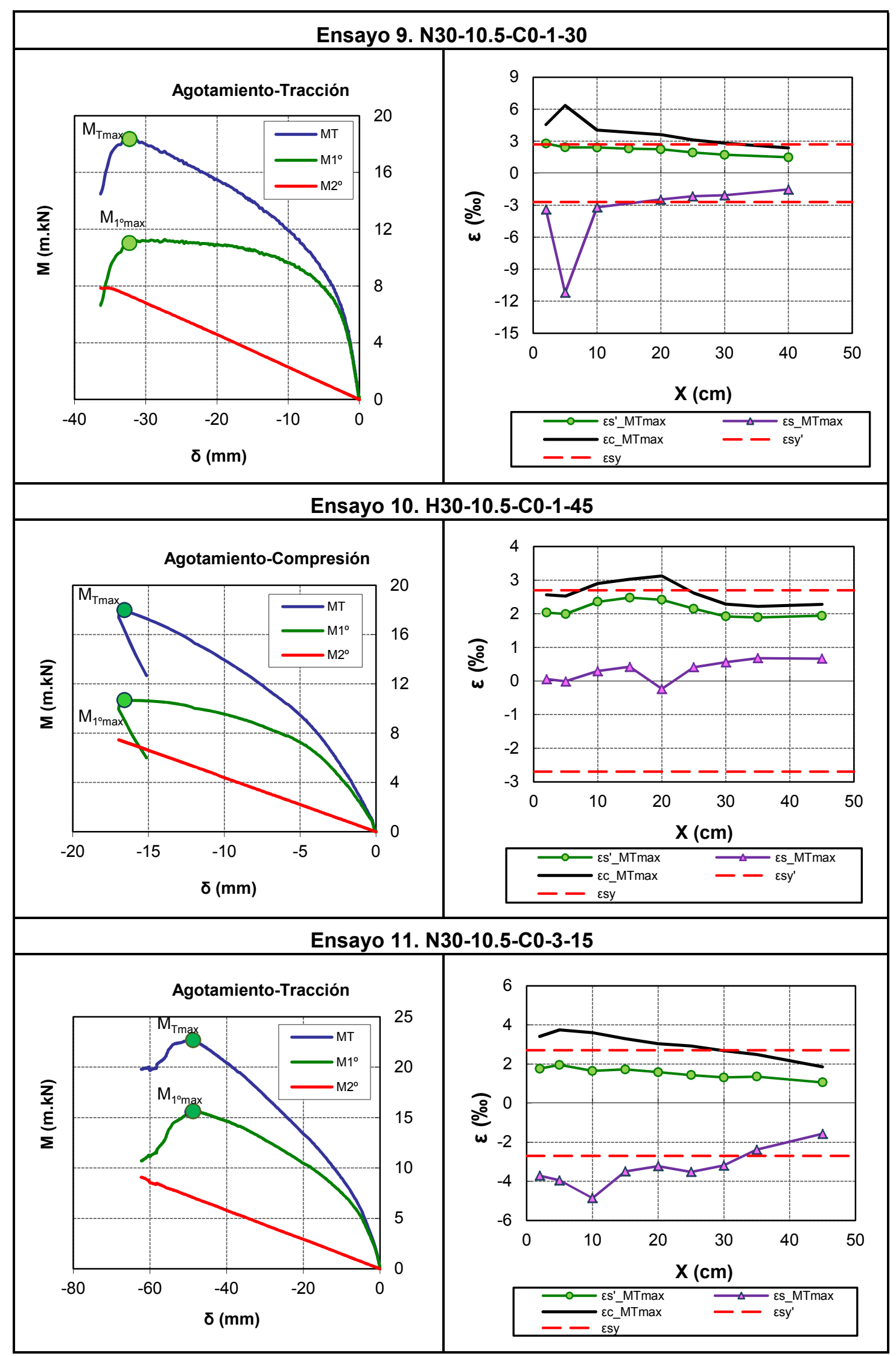


Estudio experimental y numérico de la capacidad de deformación de soportes esbeltos de hormigón armado

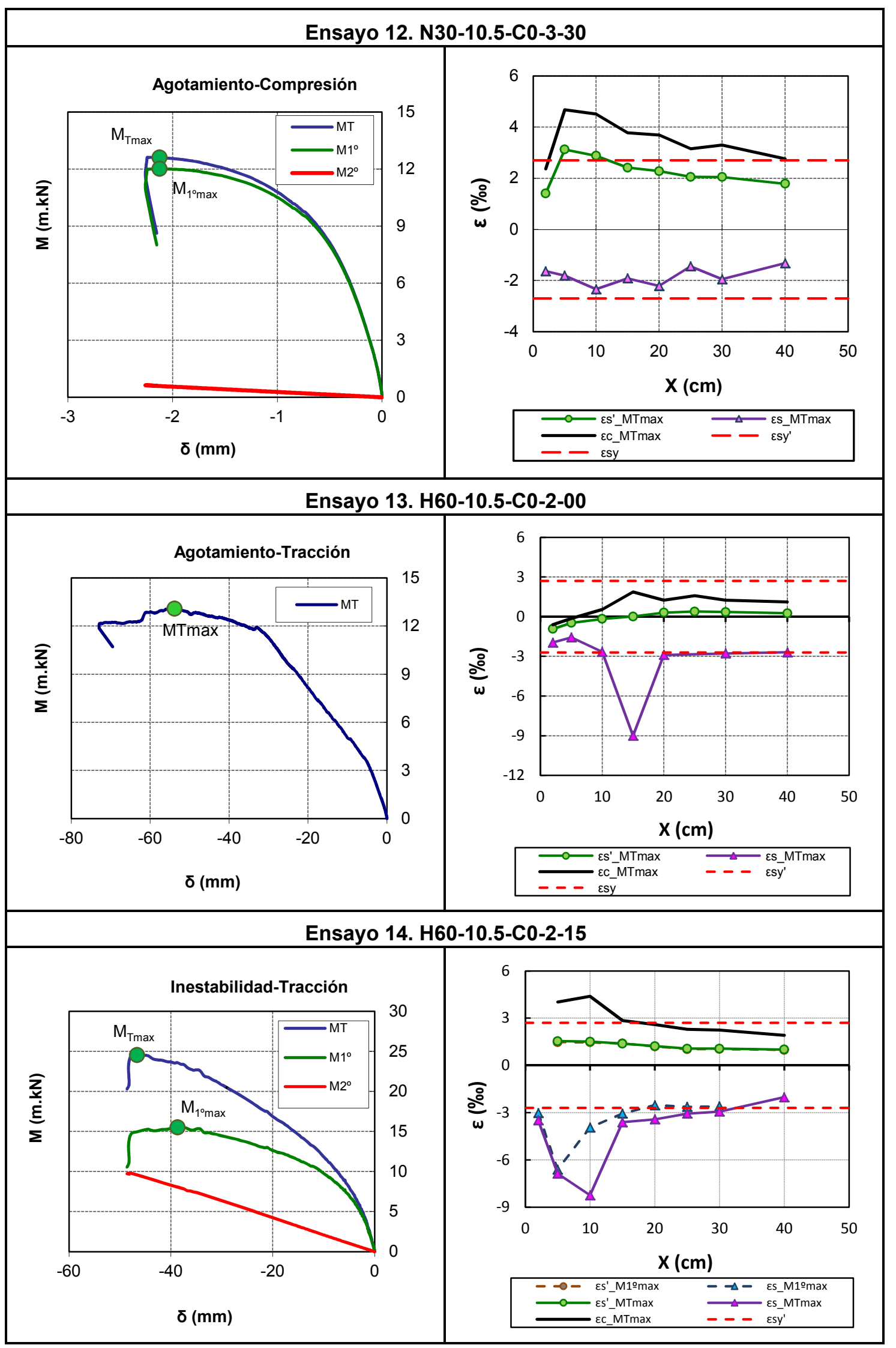




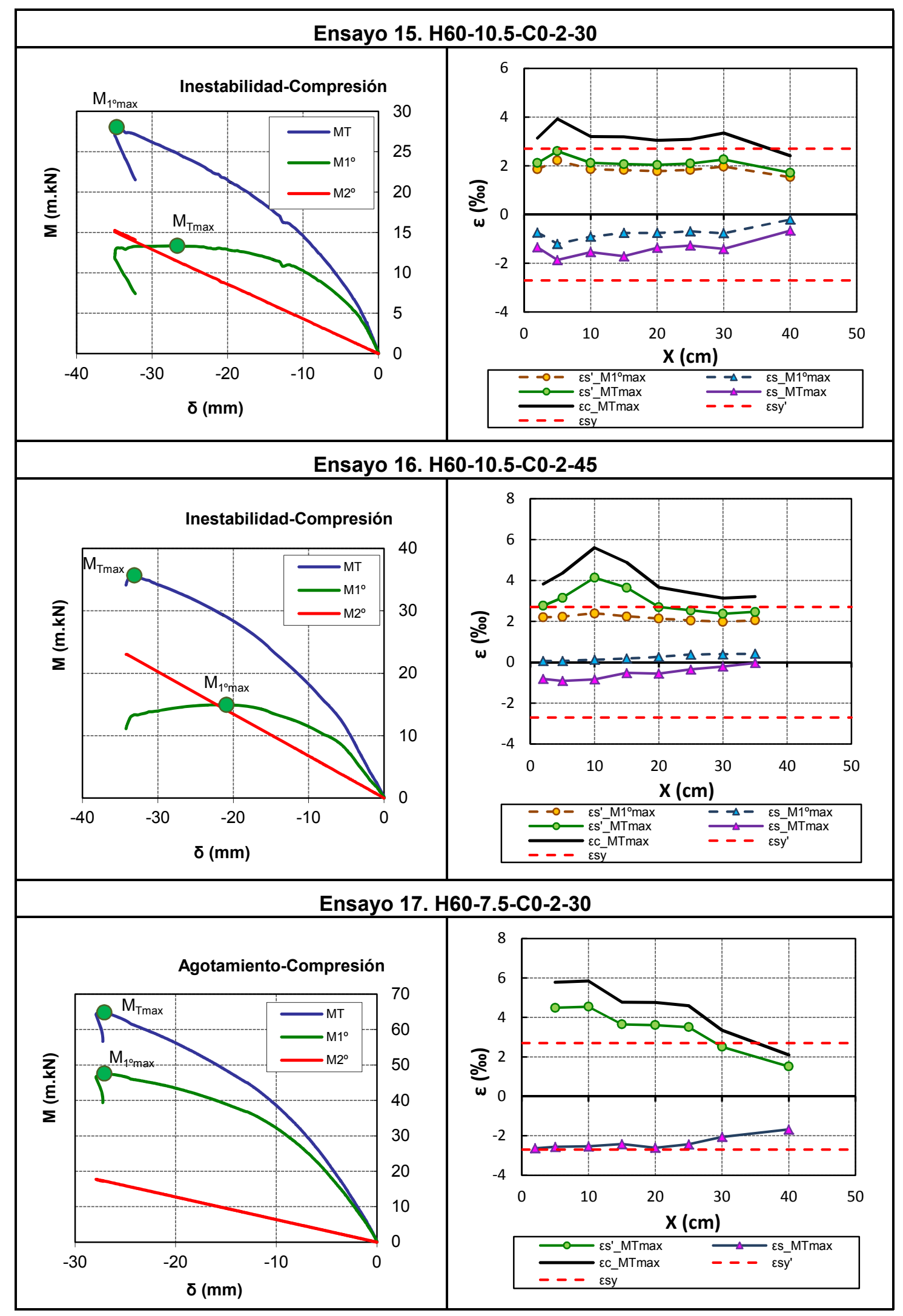


Estudio experimental y numérico de la capacidad de deformación de soportes esbeltos de hormigón armado

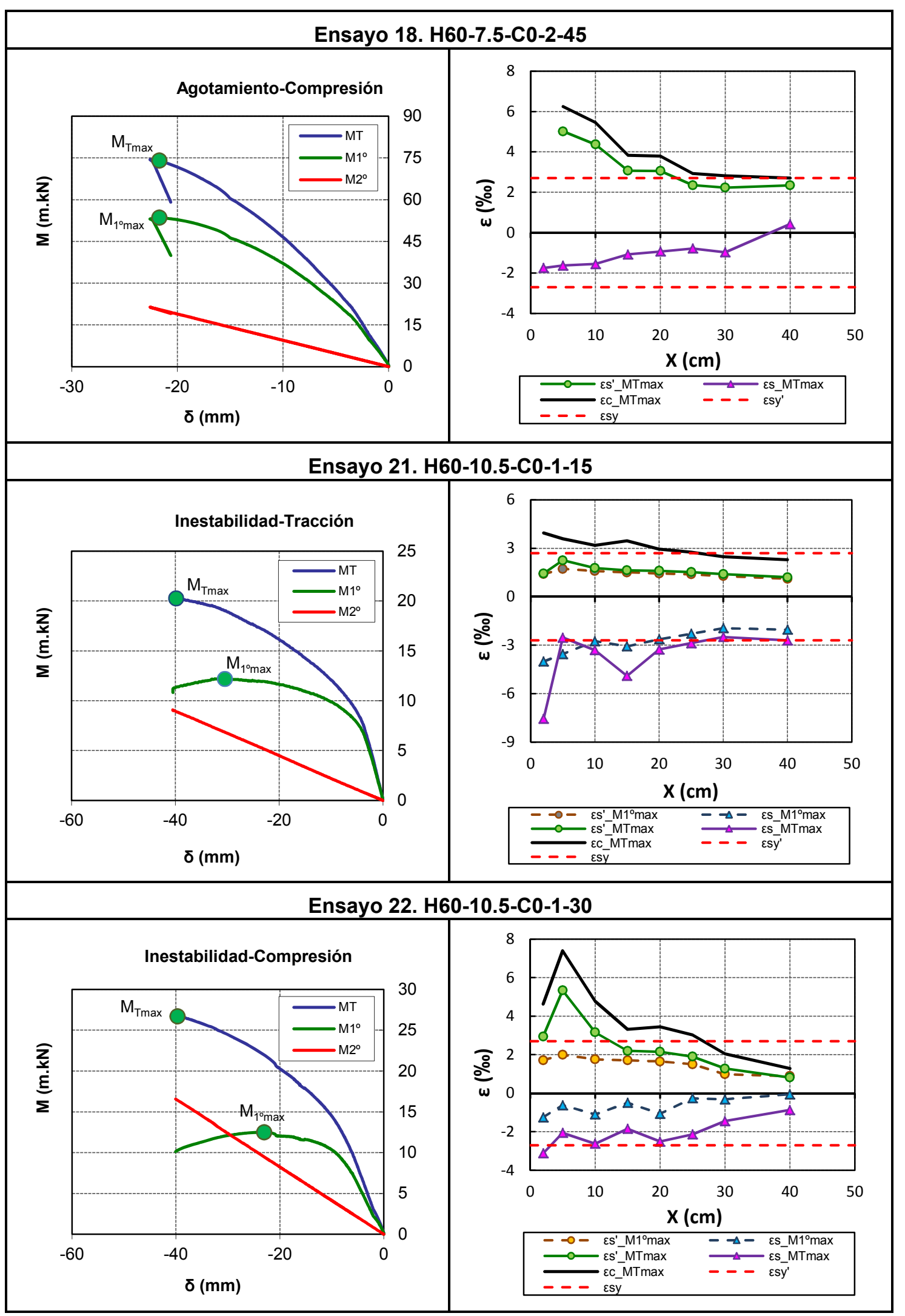




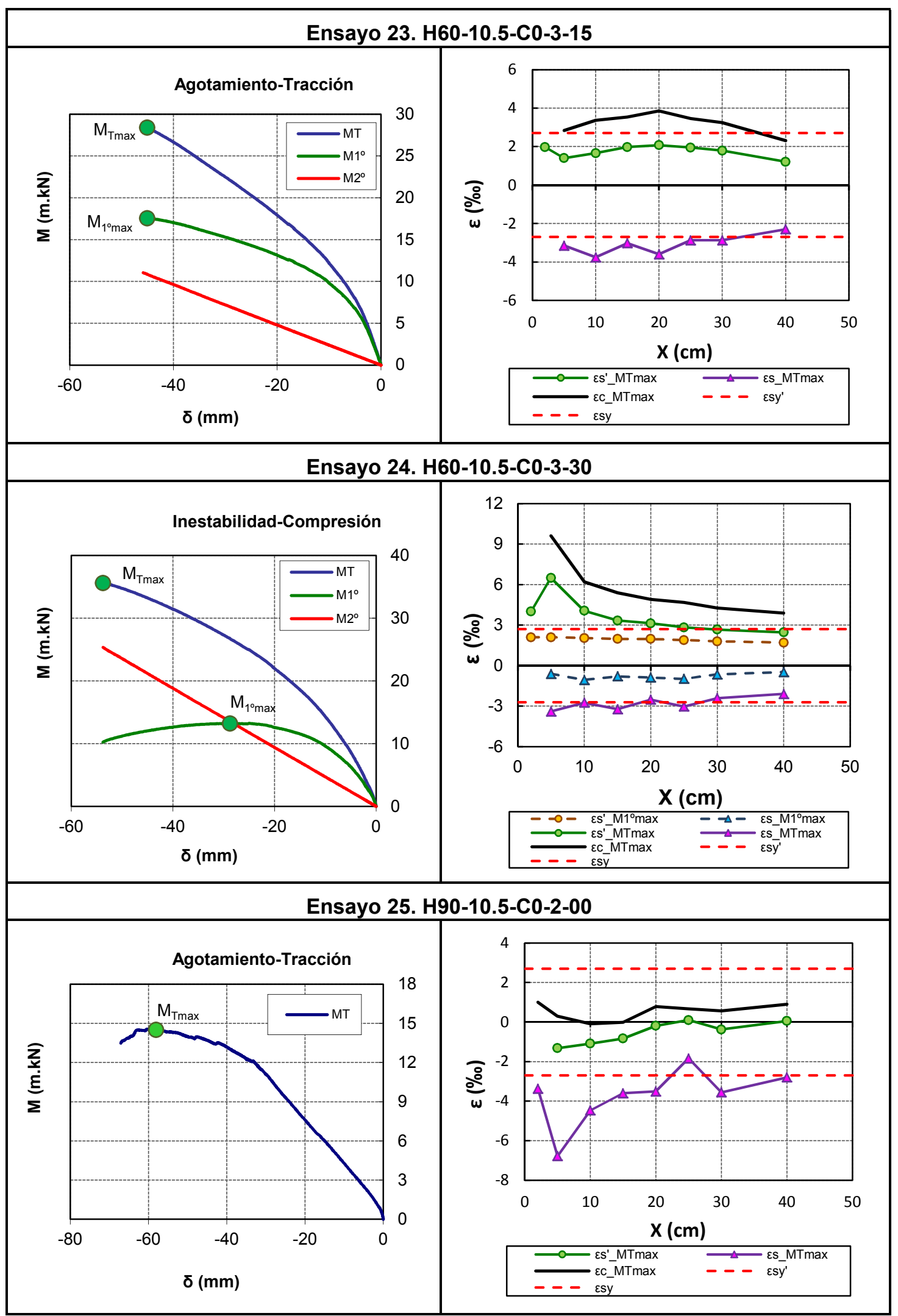


Estudio experimental y numérico de la capacidad de deformación de soportes esbeltos de hormigón armado

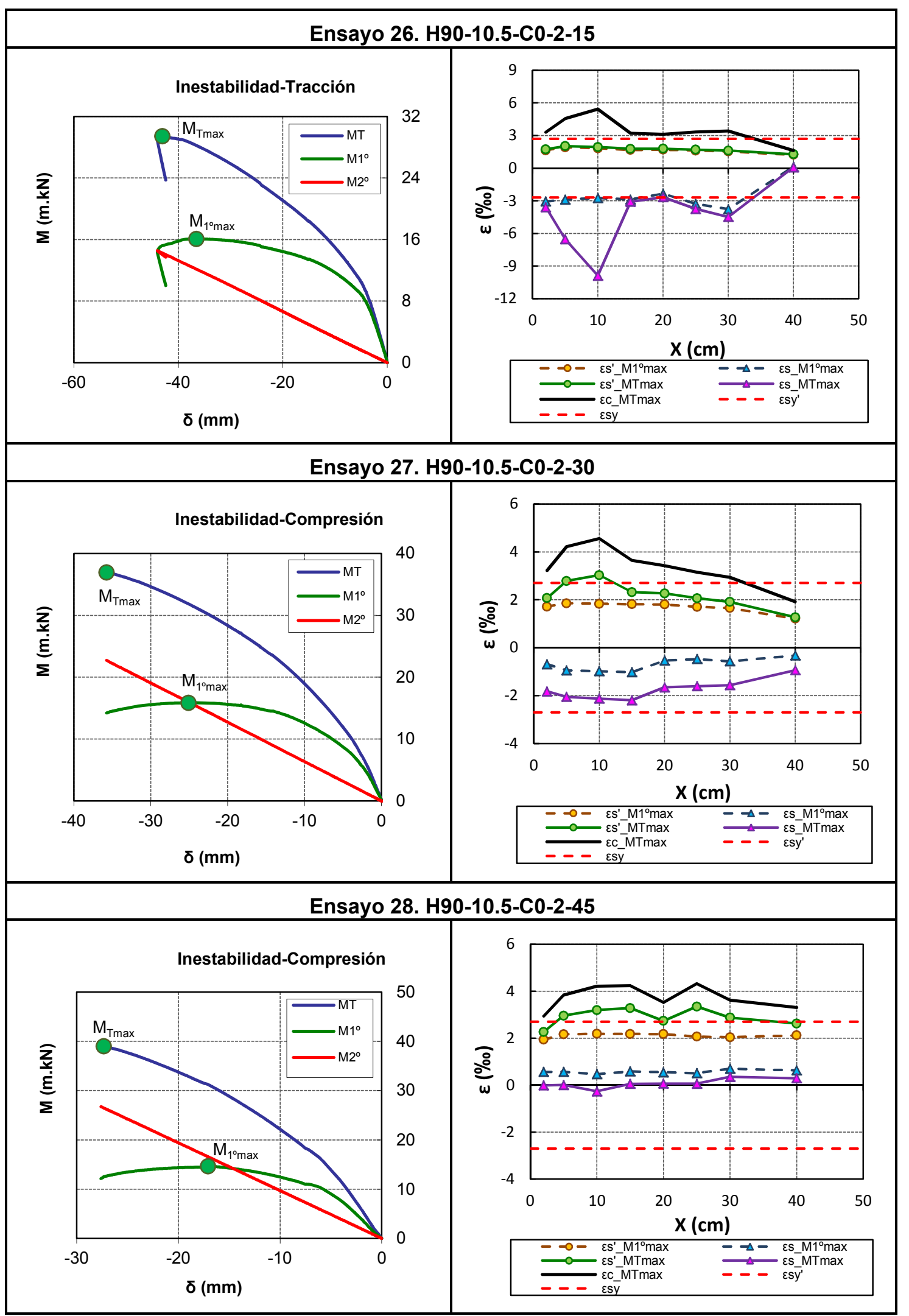




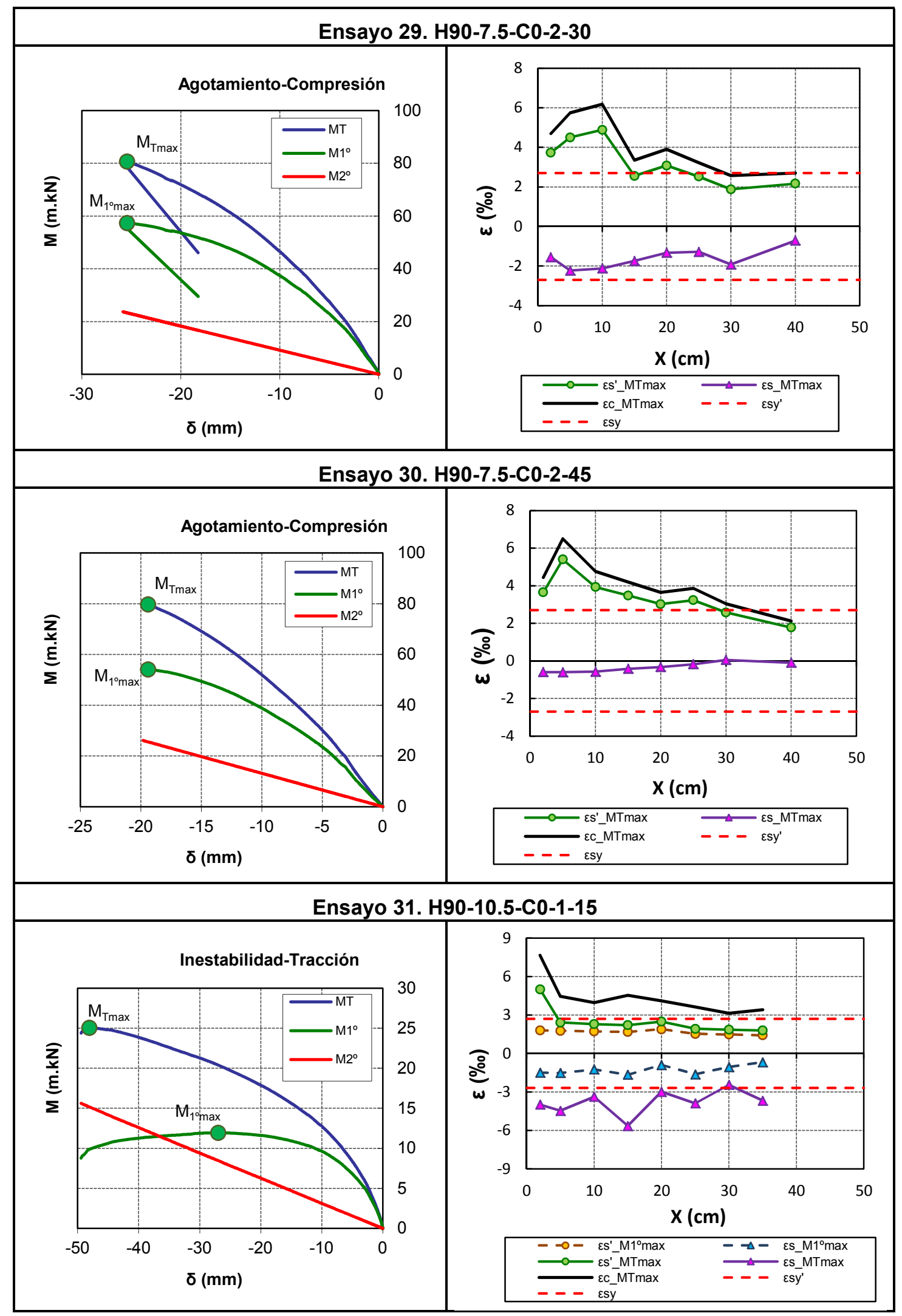


Estudio experimental y numérico de la capacidad de deformación de soportes esbeltos de hormigón armado

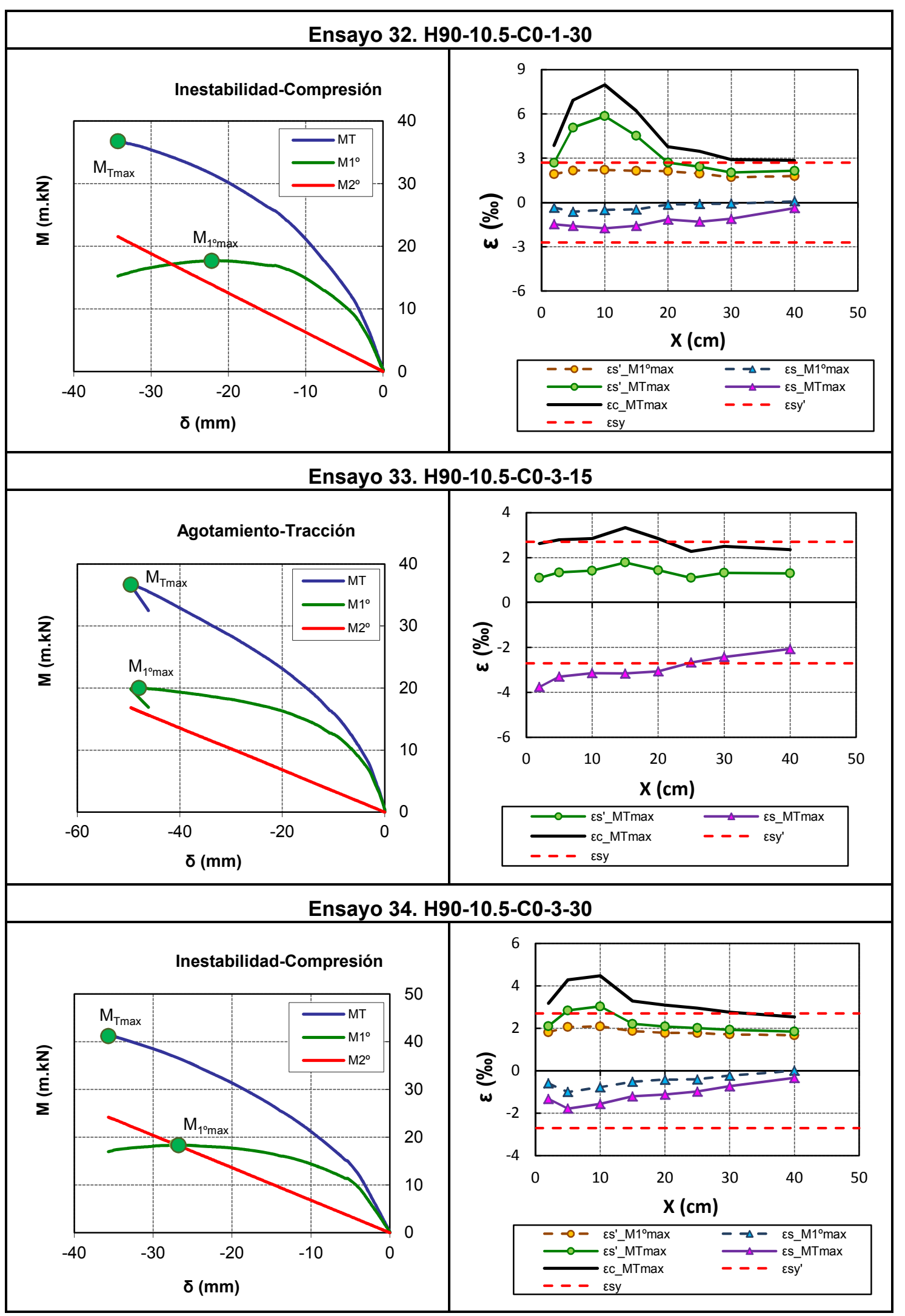




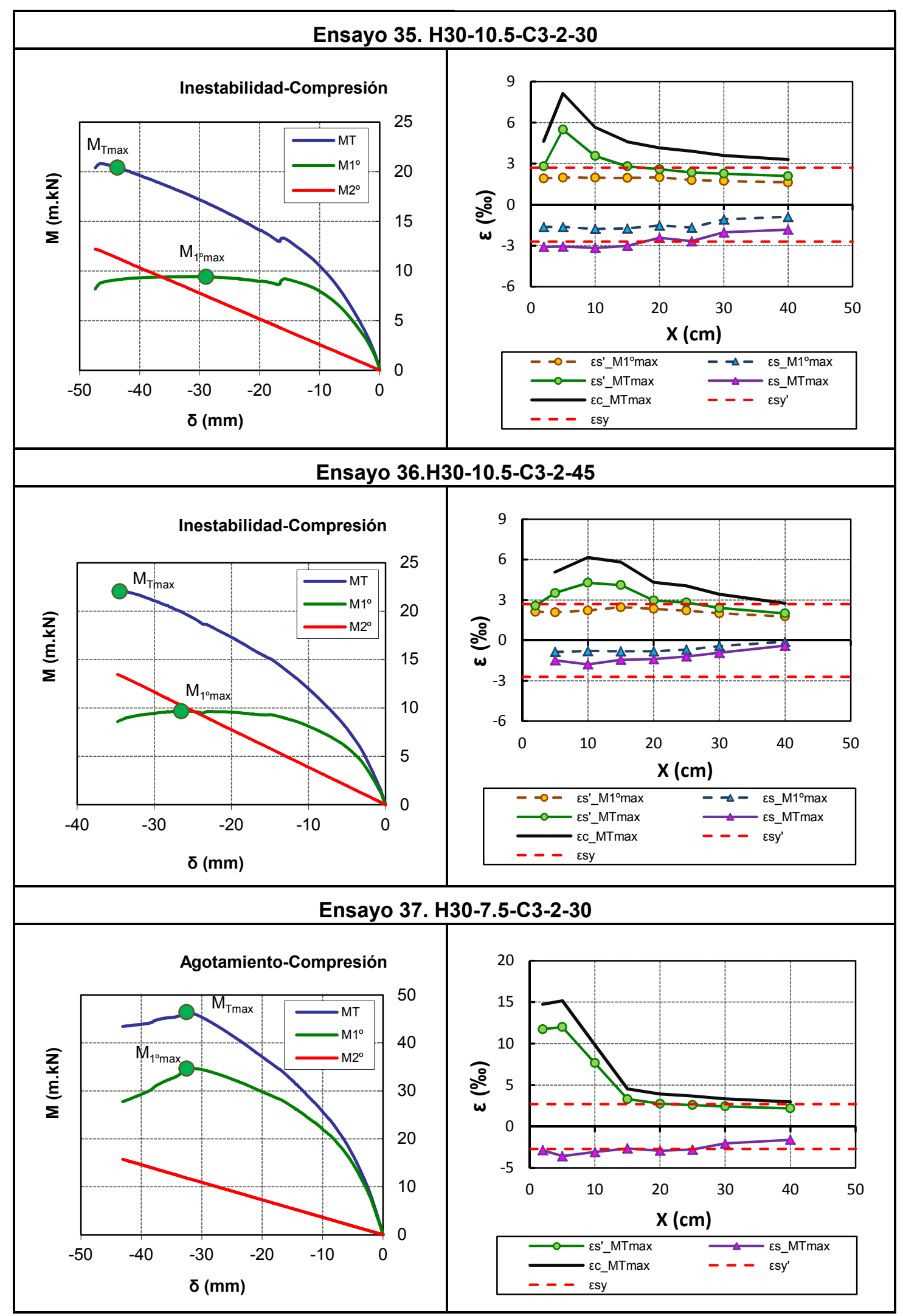


Estudio experimental y numérico de la capacidad de deformación de soportes esbeltos de hormigón armado

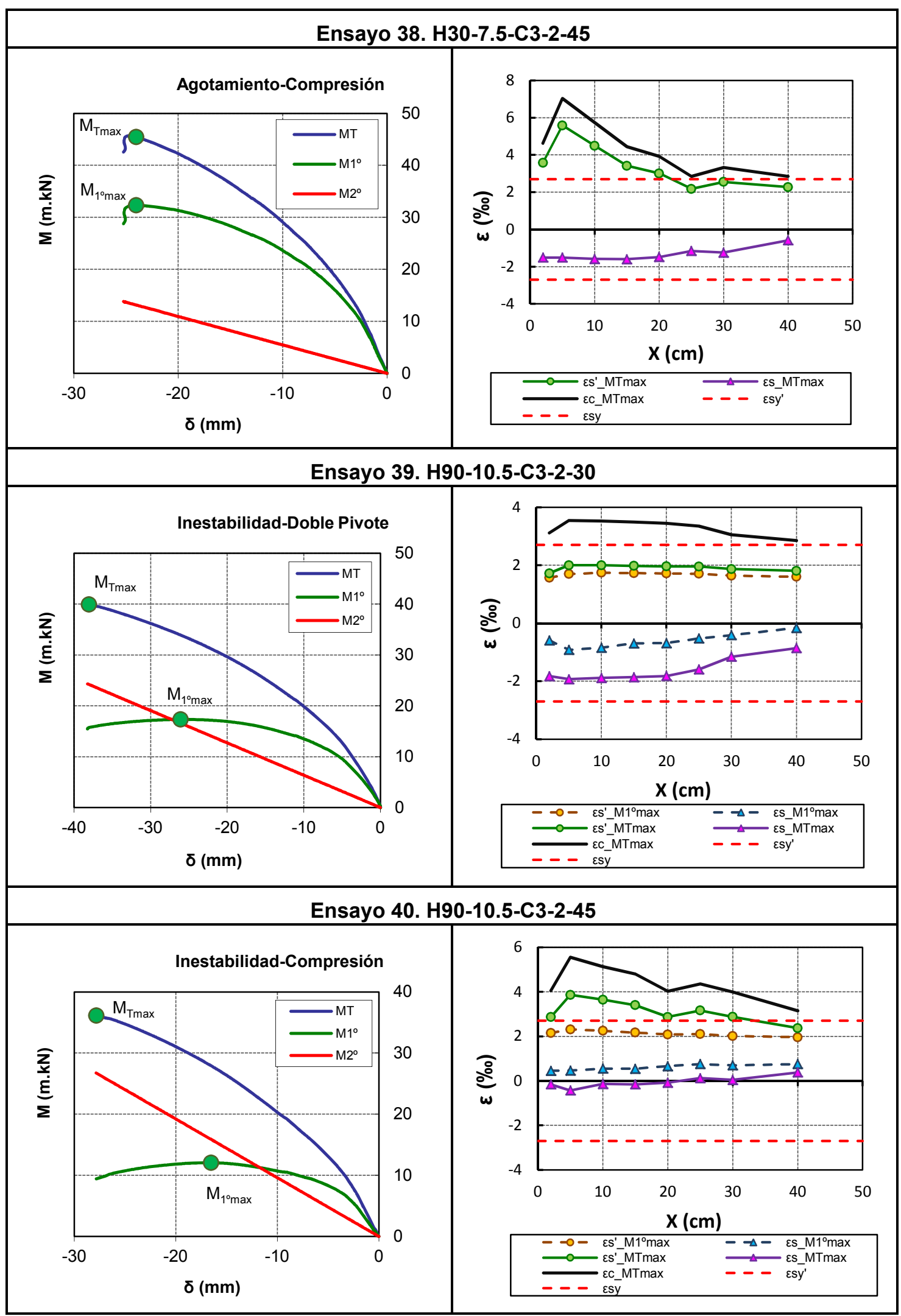




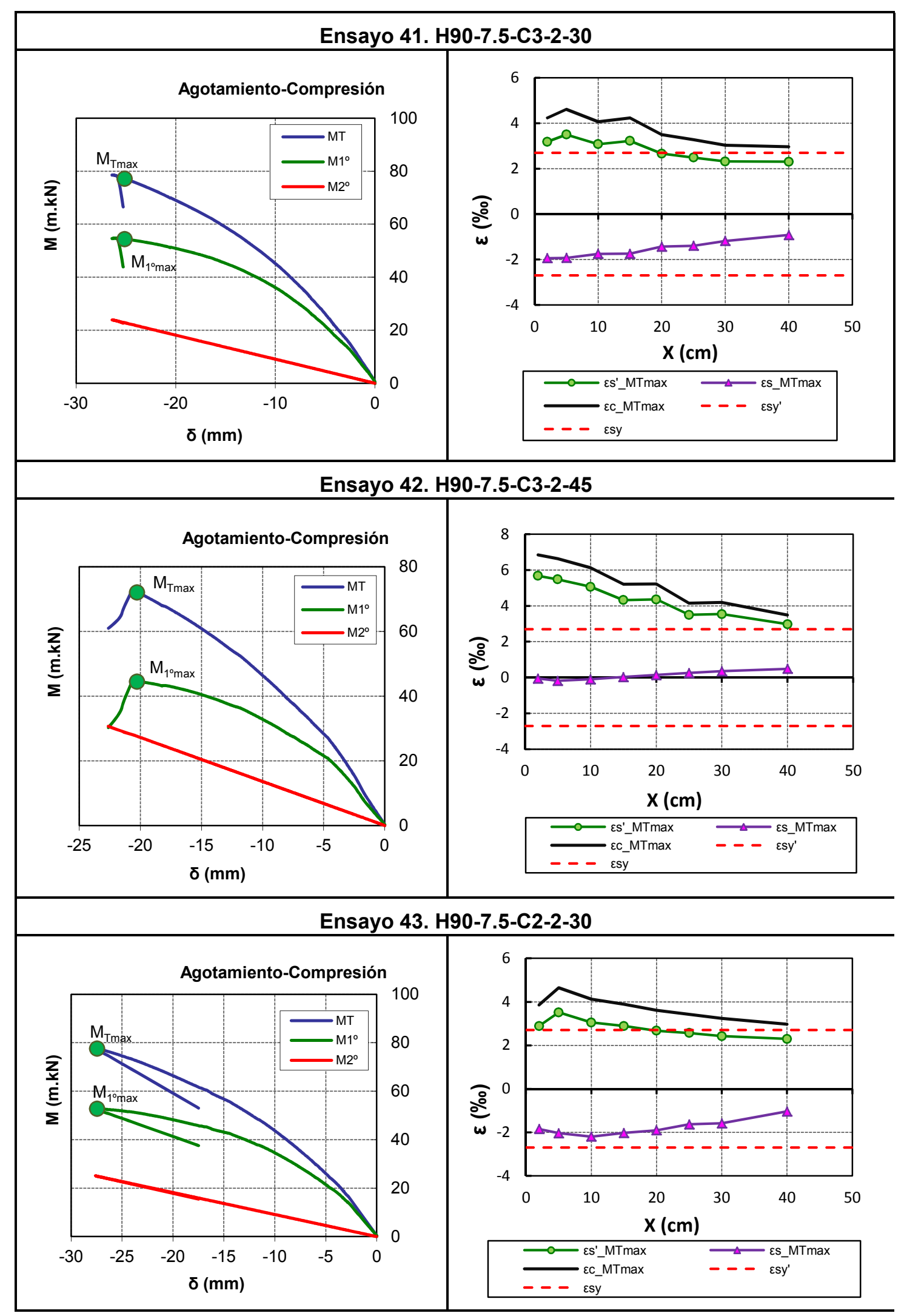


Estudio experimental y numérico de la capacidad de deformación de soportes esbeltos de hormigón armado

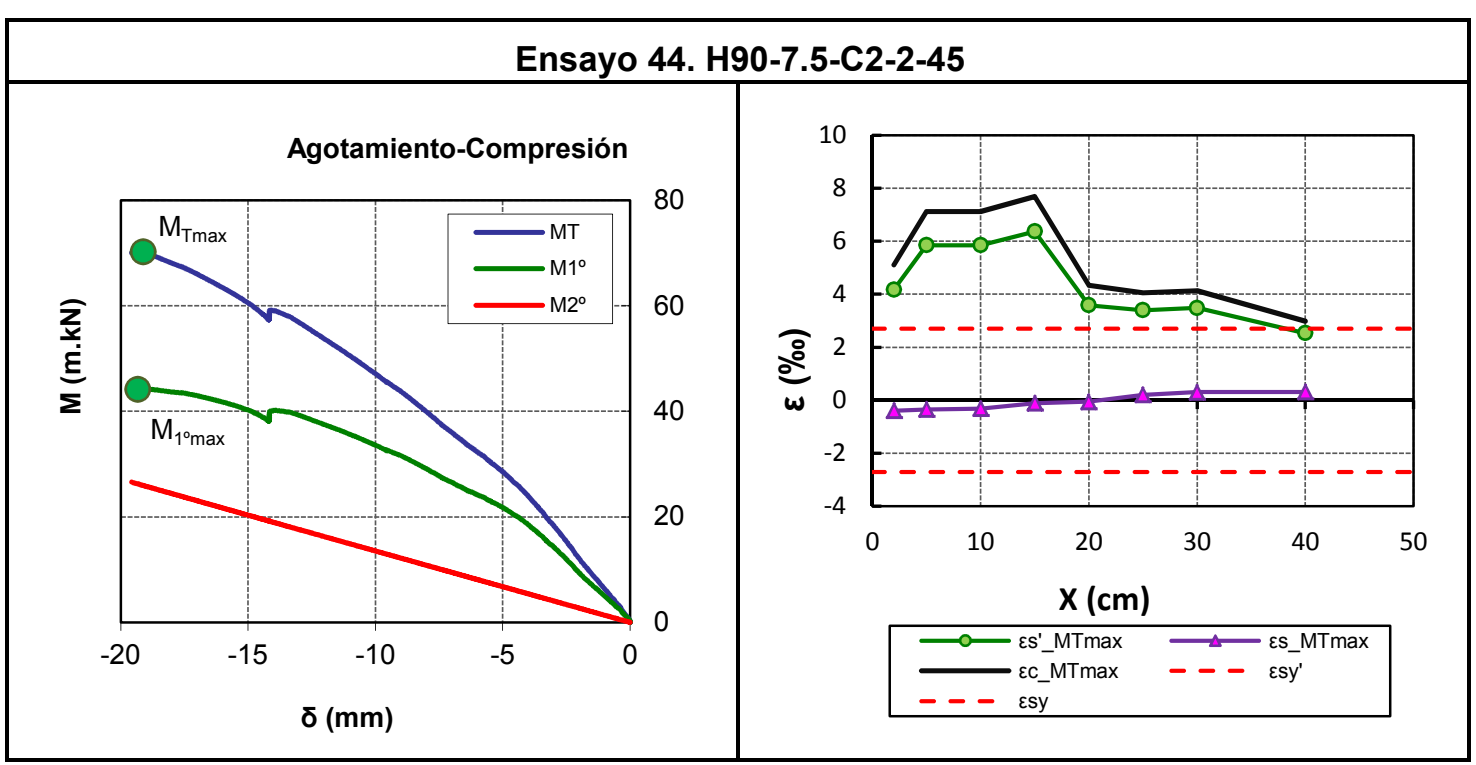


ANEJO G: DEFORMACIONES DEL ACERO Y DEL HORMIGÓN EN EL PUNTO DE PLASTIFICACIÓN APLICANDO DIFERENTES MÉTODOS

\begin{tabular}{|c|c|c|c|c|c|c|c|c|c|c|c|}
\hline \multicolumn{12}{|c|}{$\begin{array}{c}\text { Deformación del acero y del hormigón en el punto de plastificación, aplicando los métodos del } \\
\text { Eurocódigo (criterio } 1 A \text { y } 1 B \text { ) en la idealización del diagramas } P-\delta\end{array}$} \\
\hline \multirow[t]{2}{*}{$\mathbf{N}^{\circ}$} & \multirow[t]{2}{*}{ REFERENCIA } & \multirow{2}{*}{$\begin{array}{c}\mathrm{fc} \\
(\mathrm{MPa})\end{array}$} & \multirow{2}{*}{$\begin{array}{c}\varepsilon_{\mathrm{co}} \\
(\%)\end{array}$} & \multicolumn{4}{|c|}{ Método 1A } & \multicolumn{4}{|c|}{ Método 1B } \\
\hline & & & & $\varepsilon_{\mathrm{c} 1 \mathrm{~A}}$ & $\varepsilon_{\mathrm{c} 1 \mathrm{~A}} / \varepsilon_{\mathrm{co}}$ & $\varepsilon_{\mathrm{s} 1 \mathrm{~A}}$ & $\varepsilon_{\mathrm{s} 1 \mathrm{~A}} / \varepsilon_{\mathrm{sy}}$ & $\varepsilon_{\mathrm{c} 1 \mathrm{~B}}$ & $\varepsilon_{\mathrm{c} 1 \mathrm{~B}} / \varepsilon_{\mathrm{co}}$ & $\varepsilon_{\mathrm{s} 1 \mathrm{~B}}$ & $\varepsilon_{\mathrm{s} 1 \mathrm{~B}} / \varepsilon_{\mathrm{sy}}$ \\
\hline 1 & N30-10.5-C0-2-00 & 36,60 & 2,14 & $\overline{1,42}$ & 66 & $-2,62$ & $-0,99$ & 1,42 & 0,66 & $-2,62$ & $-0,99$ \\
\hline 2 & N30-10.5-C0-2-15 & 31,75 & 2,04 & 1,82 & & $-1,92$ & $-0,73$ & 1,53 & 75 & $-1,34$ & $-0,51$ \\
\hline 3 & N30-10.5-C0-2-30 & 31,60 & 2,04 & 1,86 & 91 & $-0,44$ & $-0,17$ & 1,55 & 76 & $-0,20$ & $-0,07$ \\
\hline 4 & N30-10.5-C0-2-45 & 34,50 & 2,10 & 1,84 & 0,88 & 0,10 & 0,04 & 1,58 &, 75 & 0,27 & 0,10 \\
\hline 5 & N30-7.5-C0-2-30 & 30,10 & 2,01 & 1,82 & $\overline{0,90}$ & $-0,62$ & $-0,23$ & 1,51 & 0,75 & $-0,34$ & $-0,13$ \\
\hline 6 & N30-7.5-C0-2-45 & 33,00 & 2,07 & 1,88 & 0,91 & $-0,12$ & $-0,05$ & 1,56 & 0,75 & 0,16 & 0,06 \\
\hline 9 & $\mathrm{~N} 30-10.5-\mathrm{C} 0-1-23$ & 42,20 & 2,23 & 1,91 & 0,86 & $-0,74$ & $-0,28$ & 1,59 & 0,71 & $-0,42$ & $-0,16$ \\
\hline 10 & N30-10.5-C0-1-51 & 35,20 & 2,11 & 1,91 & 90 & $\overline{0,73}$ & 0,27 & 1,59 & $\overline{75}$ & 0,87 & 0,3 \\
\hline 11 & $\mathrm{~N} 30-1 \mathrm{C}$ & 33,00 & 2,07 & 1,87 & $\overline{0}$ & $-1,91$ & $-0,72$ & 5 & 75 & $-1,42$ & \\
\hline 12 & $\mathrm{~N} 30-10.5$ & 29,50 & 2,00 & $\overline{1,81}$ & 0 & & & 50 & $\overline{75}$ & $-0,02$ & $-0,01\}$ \\
\hline 13 & $\mathrm{H} 60-$ & 55,80 & 2,44 & 1,27 & 0 & -2 & $\overline{0}$ & 27 & 52 & $-2,65$ & $-1,00$ \\
\hline 14 & $\mathrm{H} 60-1$ & 54,10 & 2,41 & 2 , & 0 & -1 & 1 & 74 & 2 & $\begin{array}{l}-1,43 \\
\end{array}$ & $-0,54$ \\
\hline 15 & $\mathrm{H} 60-1$ & 60,45 & 2,50 & 2 & 0,90 & -0 & 3 & 93 & 77 & $-0,04$ & $-0,01$ \\
\hline 16 & $\mathrm{H} 60-1$ & 63,90 & 2,54 & 2 & 0 & 0 & $\overline{9}$ & 34 &, 72 & 74 & 0,28 \\
\hline 17 & $\mathrm{H} 60-7.5$ & 63,00 & 2,53 & 2,28 & 0 & -0 & 8 & 90 &, 75 & $-0,40$ & $-0,15$ \\
\hline 18 & H60-7.5-C0-2-45 & 67,65 & 2,59 & 2,3 & 0,90 & 0,08 & 0,03 & 94 & .75 & 0,36 & $0,13 \mid$ \\
\hline 21 & H60-10.5-C0-1-15 & 57,83 & 2,46 & 2,22 & 0,90 & -2, & $-0,88$ & 1,85 & 5 & $-1,59$ & $-0,60$ \\
\hline 22 & $\mathrm{H} 60-10.5-\mathrm{C} 0-1-30$ & 58,50 & 2,47 & 2,23 & 90 & $\overline{-0,1}$ & $-0,07$ & 1,82 & $\overline{0,74}$ & 0,09 & 0,03 \\
\hline 23 & H60-10.5-C0-3-15 & 58,30 & 2,47 & 2,09 & 0,85 & $-1,58$ & $-0,60$ & 1,76 & $\overline{71}$ & $-1,12$ & $-0,42$ \\
\hline 24 & $\mathrm{H} 60-10.5-\mathrm{C} 0-3-30$ & 61,60 & 2,51 & 2,27 & 0,90 & $-0,09$ & $-0,03$ & 1,89 & 0,75 & 0,17 & 0,06 \\
\hline 25 & H90-10.5-C0-2-00 & 91,35 & 2,80 & 1,02 & 36 & -2 & $-1,02$ & 1,02 & 36 & $-2,70$ & $-1,02$ \\
\hline 26 & $\mathrm{H} 90-1$ & 90,50 & 2,80 & 2, & 0 & -1 & 7 & 97 & 70 & $\overline{6}$ & \\
\hline 27 & H90- & 90,10 & 2,80 & 2, & 0 & & 8 & 0 & 5 & 77 & \\
\hline 28 & $\mathrm{H} 90-$ & $\overline{93}$ & 2,80 & & & & 21 & 0 & 5 & 31 & \\
\hline 29 & H90-7.5 & 100,35 & $2, \varepsilon$ & & & & & & & 06 & \\
\hline 30 & H90-7.5-C0-2-45 & 94,00 & 2,8 & & 0 & 0,33 & 3 & 2,10 & & 59 & 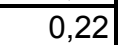 \\
\hline 31 & H90-10.5-C0-1-15 & 90,25 & 2,8 & 2 & 0,90 & -1, & $-0,46$ & 2,11 & $\overline{5}$ & $-0,71$ & $-0,27$ \\
\hline 32 & $\mathrm{H} 90-1$ & 96,20 & 2,80 & & 0 & -0 & 8 & 2,11 & & 18 & \\
\hline 33 & H90-10.5-C0-3-15 & 89,60 & 2,80 & 2,52 & 90 & $-2,48$ & $-0,93$ & 2,10 & 75 & $-1,53$ & $-0,58$ \\
\hline 34 & H90-10.5-C0-3-30 & 94,35 & 2,80 & 2,52 & $\overline{90}$ & $\overline{-0,44}$ & $-0,17$ & 2,11 & 75 & 0,00 & 0,00 \\
\hline 35 & N30-10.5-C3-2-30 & 41,00 & 2,21 & 2,02 & $\overline{91}$ & $-0,65$ & $-0,25$ & 1,67 & 75 & $-0,41$ & $-0,16$ \\
\hline 36 & N30-10.5-C3-2-45 & 34,20 & 2,09 & 1,84 & $\overline{0,88}$ & $\overline{0,12}$ & 0,05 & 1,58 & 75 & 0,31 & 0,12 \\
\hline 37 & N30-7.5-C3-2-30 & 35,75 & 2,12 & 1,91 & 0,90 & $-0,40$ & $-0,15$ & 1,59 & 75 & $-0,15$ & $-0,06$ \\
\hline 38 & N30-7.5-C3-2-45 & 35,00 & 2,11 & 1,90 & 90 & $\overline{0,14}$ & 0,05 & 1,59 & 75 & 0,34 & 0,13 \\
\hline 39 & H90-10.5-C3-2-30 & 93,45 & 2,80 & 2,53 & $\overline{90}$ & $-0,64$ & $-0,24$ & 2,10 & 75 & $-0,11$ & $-0,04$ \\
\hline 40 & H90-10.5-C3-2-45 & 91,95 & 2,80 & 2,40 & 0,86 & 0,82 & 0,31 & 2,02 & 0,72 & 0,99 & 0,37 \\
\hline 41 & H90-7.5-C3-2-30 & 86,35 & 2,79 & 2,48 & 0,89 & $-0,34$ & $-0,13$ & 2,00 & 0,72 & 0,15 & 0,06 \\
\hline 42 & H90-7.5-C3-2-45 & 78,23 & 2,70 & 2,43 & 0,90 & 0,98 & 0,37 & 2,03 & 0,75 & 1,18 & 0,45 \\
\hline 43 & H90-7.5-C2-2-30 & 93,50 & 2,80 & 2,53 & 0,90 & $-0,36$ & $-0,13$ & 2,11 & 0,75 & 0,07 & 0,03 \\
\hline 44 & H90-7.5-C2-2-45 & 89,20 & 2,80 & 2,52 & $\overline{0,90}$ & 0,71 & 0,27 & 2,20 & 0,79 & 0,83 & 0,31 \\
\hline
\end{tabular}

$\varepsilon_{\mathrm{co}}$ : Deformación del hormigón correspondiente al pico de tensión (s/n modelo constitutivo del Eurocódigo)

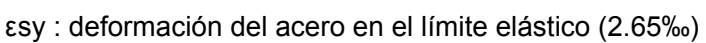

$\varepsilon S^{* *}$ : deformación de el acero en tracción obtenida experimentalmente para el punto de plastificación

$\varepsilon c^{\star *}$ : deformación del hormigón obtenida experimentalmente para el punto de plastificación 
Estudio experimental y numérico de la capacidad de deformación de soportes esbeltos de hormigón armado

\section{Deformación del acero y del hormigón en el punto de plastificación, aplicando los métodos Balance} de energía (2) y Aproximado (3) en la idealización de los diagramas $P$ - $\delta$.

\begin{tabular}{|c|c|c|c|c|c|c|c|c|c|c|c|}
\hline \multirow[t]{2}{*}{$\mathbf{N}^{\circ}$} & \multirow[t]{2}{*}{ REFERENCIA } & \multirow{2}{*}{$\begin{array}{c}\mathrm{fc} \\
(\mathrm{MPa})\end{array}$} & \multirow{2}{*}{$\begin{array}{c}\varepsilon_{\mathrm{co}} \\
(\% \circ)\end{array}$} & \multicolumn{4}{|c|}{ Método $2(\mathrm{P}-\delta)$} & \multicolumn{4}{|c|}{ Método $3(\mathrm{P}-\delta)$} \\
\hline & & & & $\varepsilon_{\mathrm{c} 2}$ & $\varepsilon_{\mathrm{c} 2} / \varepsilon_{\mathrm{co}}$ & $\varepsilon_{\mathrm{s} 2}$ & $\varepsilon_{\mathrm{s} 2} / \varepsilon_{\mathrm{sy}}$ & $\varepsilon_{\mathrm{c} 3}$ & $\varepsilon_{\mathrm{c} 3} / \varepsilon_{\mathrm{co}}$ & $\varepsilon_{\mathrm{s} 3}$ & $\varepsilon_{\mathrm{s} 3} / \varepsilon_{\mathrm{sy}}$ \\
\hline 1 & N30-10.5-C0-2-00 & 36,60 & 2,14 & 1,52 & 0,71 & $-2,81$ & $-1,06$ & 1,06 & 0,49 & $-1,93$ & $-0,73$ \\
\hline 2 & N30-10.5-C0-2-15 & 31,75 & 2,04 & 1,34 & 0,65 & $-1,02$ & $-0,38$ & 1,47 & 0,72 & 25 & $-0,47$ \\
\hline 3 & N30-10.5-C0-2-30 & 31,60 & 2,04 & 1,76 & 0,86 & $-0,36$ & $-0,14$ & 1,29 & 0,63 & 0,00 & 0,00 \\
\hline 4 & N30-10.5-C0-2-45 & 34,50 & 2,10 & 1,47 & 0,70 & 0,33 & 0,12 & 1,36 & 0,65 & 0,39 & 0,15 \\
\hline 5 & $\mathrm{~N} 30-7.5-\mathrm{C} 0-2-30$ & 30,10 & 2,01 & 2,14 & 1,06 & $-0,99$ & $-0,38$ & 2,19 & 1,09 & $-1,05$ & $-0,40$ \\
\hline 6 & N30-7.5-C0-2-45 & 33,00 & 2,07 & 2,02 & 0,98 & $-0,21$ & $-0,08$ & 2,08 & $\overline{1,01}$ & $-0,29$ & $-0,11$ \\
\hline 9 & N30-10.5-C0-1-23 & 42,20 & 2,23 & 1,54 & 0,69 & $-0,38$ & $-0,14$ & 1,36 & 0,61 & $-0,19$ & $-0,07$ \\
\hline 10 & $\mathrm{~N} 30-10.5-\mathrm{C} 0-1-51$ & 35,20 & 2,11 & 1,77 & 0,84 & 0,79 & 0,30 & 1,76 & 0,84 & 0,79 & 0,30 \\
\hline 11 & $\mathrm{~N} 30-10.5-\mathrm{C} 0-3-15$ & 33,00 & 2,07 & 1,50 & 0,73 & $-1,35$ & $-0,51$ & 1,73 & 0,84 & $-1,70$ & $-0,64$ \\
\hline 12 & $\mathrm{~N} 30-10.5-\mathrm{C} 0-3-30$ & 29,50 & 2,00 & 1,75 & 0,88 & $-0,19$ & $-0,07$ & 1,66 & 0,83 & $-0,13$ & $-0,05$ \\
\hline 13 & $\mathrm{H} 60-10.5-\mathrm{C} 0-2-00$ & 55,80 & 2,44 & 1,27 & 0,52 & $-2,67$ & $-1,01$ & 1,07 & 0,44 & $-2,23$ & $-0,84$ \\
\hline 14 & H60-10.5-C0-2-15 & 54,10 & 2,41 & 1,68 & 0,70 & $-1,35$ & $-0,51$ & 1,68 & 0,70 & $-1,35$ & $-0,51$ \\
\hline 15 & |H60-10.5-C0-2-30 & 60,45 & 2,50 & 1,65 & 0,66 & 0,22 & 0,08 & 1,59 & 0,64 & 0,26 & 0,10 \\
\hline 16 & H60-10.5-C0-2-45 & 63,90 & 2,54 & 1,89 & 0,75 & 0,72 & 0,27 & 1,90 & 0,75 & 0,71 & 0,27 \\
\hline 17 & H60-7.5-C0-2-30 & 63,00 & 2,53 & 2,27 & 0,90 & $-0,74$ & $-0,28$ & 2,17 & 0,86 & $-0,62$ & $-0,23$ \\
\hline 18 & H60-7.5-C0-2-45 & 67,65 & 2,59 & 2,34 & 0,90 & 0,08 & 0,03 & 2,41 & 0,93 & 0,02 & 0,01 \\
\hline 21 & H60-10.5-C0-1-15 & 57,83 & 2,46 & 1,21 & 0,49 & $-0,51$ & $-0,19$ & 1,11 & 0,45 & $-0,37$ & $-0,14$ \\
\hline 22 & H60-10.5-C0-1-30 & 58,50 & 2,47 & 1,56 & 0,63 & 0,25 & 0,09 & 1,41 & 0,57 & 0,32 & 0,12 \\
\hline 23 & H60-10.5-C0-3-15 & 58,30 & 2,47 & 1,79 & 0,72 & $-1,16$ & $-0,44$ & 1,88 & 0,76 & $-1,29$ & $-0,49$ \\
\hline 24 & H60-10.5-C0-3-30 & 61,60 & 2,51 & 1,59 & 0,63 & 0,37 & 0,14 & 1,57 & 0,63 & 0,38 & 0,14 \\
\hline 25 & H90-10.5-C0-2-00 & 91,35 & 2,80 & 1,14 & 0,41 & $-2,76$ & $-1,04$ & 1,08 & 0,39 & $-2,76$ & $-1,04$ \\
\hline 26 & |H90-10.5-C0-2-15 & 90,50 & 2,80 & 1,48 & 0,53 & $-0,36$ & $-0,13$ & 1,50 & 53 & $-0,37$ & $-0,14$ \\
\hline 27 & H90- & 90,10 & 2,80 & 1,46 & 0,52 & 0,42 & 0,16 & 1,50 & 3 & 99 & 0,15 \\
\hline 28 & H90- & 93,20 & 2,80 & 1,90 & 0,68 & 0,92 & 0,35 & 1,86 & 66 & 0,94 & 0,35 \\
\hline 29 & H90-7.5-C0-2-30 & 100,35 & 2,80 & 2,38 & 0,85 & $-0,15$ & $-0,06$ & 2,42 & 0,86 & $-0,18$ & $-0,07$ \\
\hline 30 & H90-7.5-C0-2-45 & 94,00 & 2,80 & 2,40 & 0,86 & 0,41 & 0,15 & 2,47 & 0,88 & 0,37 & 0,14 \\
\hline 31 & H90-10.5-C0-1-15 & 90,25 & 2,80 & 1,34 & 0,48 & 0,12 & 0,04 & 1,29 & 0,46 & 0,16 & 0,06 \\
\hline 32 & H90-10.5-C0-1-30 & 96,20 & 2,80 & 1,55 & 0,55 & 0,51 & 0,19 & 1,58 & 0,56 & 0,50 & 0,19 \\
\hline 33 & H90-10.5-C0-3-15 & 89,60 & 2,80 & 1,64 & 0,59 & $-0,72$ & $-0,27$ & 1,60 & 0,57 & $\begin{array}{ll}-0,66 \\
\end{array}$ & $-0,25$ \\
\hline 34 & H90-10.5-C0-3-30 & 94,35 & 2,80 & 1,65 & 0,59 & 0,44 & 0,17 & 1,65 & 0,59 & 0,44 & 0,17 \\
\hline 35 & N30-10.5-C3-2-30 & 441,00 & 2,21 & 1,29 & 0,58 & $-0,07$ & $-0,03$ & 1,19 & 0,54 & 0,03 & 0,01 \\
\hline 36 & N30-10.5-C3-2-45 & 34,20 & 2,09 & 1,42 & 0,68 & 0,41 & 0,16 & 1,41 & 0,67 & 0,42 & 0,16 \\
\hline 37 & N30-7.5-C3-2-30 & 35,75 & 2,12 & 2,62 & 1,23 & $-0,99$ & $-0,37$ & 2,57 & 1,21 & $-0,96$ & $-0,36$ \\
\hline 38 & N30-7.5-C3-2-45 & 35,00 & 2,11 & 2,22 & 1,06 & $-0,08$ & $-0,03$ & 2,17 & 1,03 & $-0,04$ & $-0,01$ \\
\hline 39 & H90-10.5-C3-2-30 & 93,45 & 2,80 & 1,58 & 0,56 & 0,40 & 0,15 & 1,56 & 0,56 & 0,42 & 0,16 \\
\hline 40 & H90-10.5-C3-2-45 & 91,95 & 2,80 & 1,91 & 0,68 & 1,03 & 0,39 & 1,88 & 0,67 & 1,05 & 0,40 \\
\hline 41 & H90-7.5-C3-2-30 & 86,35 & 2,79 & 1,66 & 0,60 & $-0,11$ & $-0,04$ & 1,66 & 0,60 & $-0,12$ & $-0,05$ \\
\hline 42 & H90-7.5-C3-2-45 & 78,23 & 2,70 & 2,74 & 1,01 & 0,83 & 0,31 & 2,80 & 1,03 & 0,78 & 0,30 \\
\hline 43 & H90-7.5-C2-2-30 & 93,50 & 2,80 & 2,37 & 0,85 & $-0,21$ & $-0,08$ & 2,40 & 0,86 & $-0,24$ & $-0,09$ \\
\hline 44 & H90-7.5-C2-2-45 & 89,20 & 2,80 & 2,57 & 0,92 & 0,69 & 0,26 & 2,65 & 0,94 & 0,64 & 0,24 \\
\hline
\end{tabular}

$\varepsilon_{\mathrm{co}}$ : Deformación del hormigón correspondiente al pico de tensión (s/n modelo constitutivo del Eurocódigo)

$\varepsilon s y$ : deformación del acero en el límite elástico (2.65\%o)

$\varepsilon S^{* *}$ : deformación de el acero en tracción obtenida experimentalmente para el punto de plastificación

$\varepsilon c^{\star *}$ : deformación del hormigón obtenida experimentalmente para el punto de plastificación 
Deformación del acero y del hormigón en el punto de plastificación, aplicando los métodos Balance de energía (2) y Aproximado (3) en la idealización de los diagramas $M-\varphi$

\begin{tabular}{|c|c|c|c|c|c|c|c|c|c|c|c|}
\hline \multirow[t]{2}{*}{$\mathbf{N}^{\circ}$} & \multirow[t]{2}{*}{ REFERENCIA } & \multirow{2}{*}{$\begin{array}{c}\mathrm{fc} \\
(\mathrm{MPa}) \\
\end{array}$} & \multirow{2}{*}{$\begin{array}{l}\varepsilon_{\mathrm{co}} \\
(\%)\end{array}$} & \multicolumn{4}{|c|}{ Método $2(\mathrm{M}-\varphi)$} & \multicolumn{4}{|c|}{ Método $3(M-\varphi)$} \\
\hline & & & & $\varepsilon_{\mathrm{c} 2}$ & $\varepsilon_{\mathrm{c} 2} / \varepsilon_{\mathrm{co}}$ & $\varepsilon_{\mathrm{s} 2}$ & $\varepsilon_{\mathrm{s} 2} / \varepsilon_{\mathrm{sy}}$ & $\varepsilon_{\mathrm{c} 3}$ & $\varepsilon_{\mathrm{c} 3} / \varepsilon_{\mathrm{co}}$ & $\varepsilon_{\mathrm{s} 3}$ & $\varepsilon_{\mathrm{s} 3} / \varepsilon_{\mathrm{sy}}$ \\
\hline 1 & N30-10.5-C0-2-00 & 36,60 & 2,14 & 1,27 & 0,59 & $-2,35$ & $-0,89$ & 1,07 & 0,50 & $-1,96$ & $-0,74$ \\
\hline 2 & N30-10.5-C0-2-15 & 31,75 & 2,04 & 1,72 & 0,84 & $-1,68$ & $-0,63$ & 1,60 & 0,78 & $-1,47$ & $-0,55$ \\
\hline 3 & N30-10.5-C0-2-30 & 31,60 & 2,04 & 2,46 & 1,20 & $-0,96$ & $-0,36$ & 2,74 & 1,34 & $-1,22$ & $-0,46$ \\
\hline 4 & N30-10.5-C0-2-45 & 34,50 & 2,10 & 2,16 & 1,03 & $-0,12$ & $-0,04$ & 2,16 & 1,03 & $-0,12$ & $-0,04$ \\
\hline 5 & N30-7.5-C0-2-30 & 30,10 & 2,01 & 2,31 & 1,15 & $-1,18$ & $-0,44$ & 2,53 & 1,26 & $-1,42$ & $-0,54$ \\
\hline 6 & N30-7.5-C0-2-45 & 33,00 & 2,07 & 2,26 & 1,09 & $-0,26$ & $-0,10$ & 2,22 & 1,07 & $-0,23$ & $-0,09$ \\
\hline 9 & N30-10.5-C0-1-23 & 42,20 & 2,23 & 2,10 & 0,94 & $-0,94$ & $-0,36$ & 2,34 & 1,05 & $-1,20$ & $-0,45$ \\
\hline 10 & N30-10.5-C0-1-51 & 35,20 & 2,11 & 2,03 & 0,96 & 0,68 & 0,26 & 2,08 & 0,98 & 0,66 & 0,25 \\
\hline 11 & N30-10.5-C0-3-15 & 33,00 & 2,07 & 1,71 & 0,83 & $-1,68$ & $-0,63$ & 2,01 & 0,97 & $-2,12$ & $-0,80$ \\
\hline 12 & N30-10.5-C0-3-30 & 29,50 & 2,00 & 2,47 & 1,24 & $-0,66$ & $-0,25$ & 2,74 & 1,37 & $-0,83$ & $-0,31$ \\
\hline 13 & $\mathrm{H} 60-10.5-\mathrm{C} 0-2-00$ & 55,80 & 2,44 & 1,27 & 0,52 & $-2,65$ & $-1,00$ & 0,96 & 0,40 & $-2,04$ & $-0,77$ \\
\hline 14 & $\mathrm{H} 60-10.5-\mathrm{C} 0-2-15$ & 54,10 & 2,41 & 2,02 & 0,84 & $-1,89$ & $-0,71$ & 2,23 & 0,92 & $-2,27$ & $-0,86$ \\
\hline 15 & $\mathrm{H} 60-10.5-\mathrm{C} 0-2-30$ & 60,45 & 2,50 & 2,32 & 0,93 & $-0,40$ & $-0,15$ & 2,57 & 1,03 & $-0,61$ & $-0,23$ \\
\hline 16 & $\mathrm{H} 60-10.5-\mathrm{C} 0-2-45$ & 63,90 & 2,54 & 2,59 & 1,02 & 0,30 & 0,11 & 2,62 & 1,03 & 0,27 & 0,10 \\
\hline 17 & $\mathrm{H} 60-7.5-\mathrm{CO}$ & 63,00 & 2,53 & 2,58 & 1,02 & $-1,03$ & $-0,39$ & 2,62 & 03 & 08 & $\overline{0,41}$ \\
\hline 18 & $\mathrm{H} 60-7.5-\mathrm{C} 0-2-45$ & 67,65 & 2,59 & 2,70 & 1,04 & $-0,25$ & $-0,09$ & 2,65 & 1,02 & $-0,20$ & $-0,08$ \\
\hline 21 & H60-10.5-C0-1-15 & 57,83 & 2,46 & 1,87 & 0,76 & $-1,62$ & $-0,61$ & 1,95 & 0,79 & $-1,78$ & $-0,67$ \\
\hline 22 & $\mathrm{H} 60-10.5-\mathrm{C} 0-1-30$ & 58,50 & 2,47 & 2,42 & 0,98 & & $-0,13$ & 2,42 & 98 & 34 & $-0,13$ \\
\hline 23 & $\mathrm{H} 60-10.5-\mathrm{C} 0-3-15$ & 58,30 & 2,47 & 1,90 & 0,77 & $-1,32$ & $-0,50$ & 2,28 & 0,92 & $-1,85$ & $-0,70$ \\
\hline 24 & $\mathrm{H} 60-10.5-\mathrm{C} 0-3-30$ & 61,60 & 2,51 & 2,94 & 1,17 & $-0,60$ & $-0,23$ & 2,90 & 1,16 & $-0,56$ & $-0,21$ \\
\hline 25 & $\mathrm{H} 90-10.5-\mathrm{C} 0-2-00$ & 91,35 & 2,80 & 1,13 & 0,40 & $-2,76$ & $-1,04$ & 1,04 & 37 & $-2,75$ & $-1,04$ \\
\hline 26 & $\mathrm{H} 90-10.5-\mathrm{C} 0-2-15$ & 90,50 & 2,80 & 2,11 & 0,75 & $-1,16$ & $-0,44$ & 2,30 & 0,82 & $-1,42$ & $-0,54$ \\
\hline 27 & $\mathrm{H} 90-10.5-\mathrm{C} 0-2-30$ & 90,10 & 2,80 & 2,13 & 0,76 & $-0,30$ & $-0,11$ & 2,27 & 0,81 & $-0,46$ & $-0,17$ \\
\hline 28 & H90-10.5-C0-2-45 & 93,20 & 2,80 & 2,66 & 0,95 & 0,49 & 0,18 & 2,55 & 0,91 & 0,55 & 0,21 \\
\hline 29 & H90-7.5-C0-2-30 & 100,35 & 2,80 & 2,93 & 1,05 & $-0,62$ & $-0,23$ & 2,67 & 0,95 & $-0,38$ & $-0,14$ \\
\hline 30 & H90-7.5-C0-2-45 & 94,00 & 2,80 & 2,94 & 1,05 & 0,04 & 0,02 & 2,66 & 0,95 & 0,24 & 0,09 \\
\hline 31 & $\mathrm{H} 90-10.5-\mathrm{C} 0-1-15$ & 90,25 & 2,80 & 2,25 & 0,80 & $-0,87$ & $-0,33$ & 2,38 & 0,85 & $-1,04$ & $-0,39$ \\
\hline 32 & H90-10.5-C0-1-30 & 96,20 & 2,80 & 2,44 & 0,87 & $-0,13$ & $-0,05$ & 2,38 & 0,85 & $-0,06$ & $-0,02$ \\
\hline 33 & H90-10.5-C0-3-15 & 89,60 & 2,80 & 1,81 & 0,65 & $-0,99$ & $-0,38$ & 2,14 & 0,76 & $-1,61$ & $-0,61$ \\
\hline 34 & $\mathrm{H} 90-10.5-\mathrm{C} 0-3-30$ & 94,35 & 2,80 & 2,41 & 0,86 & $-0,32$ & $-0,12$ & 2,49 & 0,89 & $-0,41$ & $-0,15$ \\
\hline 35 & N30-10.5-C3-2-30 & 41,00 & 2,21 & 2,19 & 0,99 & $-0,80$ & $-0,30$ & 2,43 & 1,10 & $-1,02$ & $-0,39$ \\
\hline 36 & N30-10.5-C3-2-45 & 34,20 & 2,09 & 2,32 & 1,11 & $-0,15$ & $-0,06$ & 2,38 & 1,14 & $-0,18$ & $-0,07$ \\
\hline 37 & N30-7.5-C3-2-30 & 35,75 & 2,12 & 3,26 & 1,54 & $-1,63$ & $-0,61$ & 3,06 & 1,44 & $-1,42$ & $-0,54$ \\
\hline 38 & N30-7.5-C3-2-45 & 35,00 & 2,11 & 2,63 & 1,25 & $-0,36$ & $-0,13$ & 2,58 & 1,23 & $-0,33$ & $-0,12$ \\
\hline 39 & H90-10.5-C3-2-30 & 93,45 & 2,80 & 2,20 & 0,79 & $-0,23$ & $-0,09$ & 2,37 & 0,85 & $-0,44$ & $-0,17$ \\
\hline 40 & H90-10.5-C3-2-45 & 91,95 & 2,80 & 2,74 & 0,98 & 0,64 & 0,24 & 2,83 & 1,01 & 0,58 & 0,22 \\
\hline 41 & H90-7.5-C3-2-30 & 86,35 & 2,79 & 1,66 & 0,60 & $-0,35$ & $-0,13$ & 1,66 & 0,60 & $-0,48$ & $-0,18$ \\
\hline 42 & H90-7.5-C3-2-45 & 78,23 & 2,70 & 2,80 & 1,03 & 0,61 & 0,23 & 2,80 & 1,03 & 0,63 & 0,24 \\
\hline 43 & H90-7.5-C2-2-30 & 93,50 & 2,80 & 2,65 & 0,95 & $-0,50$ & $-0,19$ & 2,78 & 0,99 & $-0,63$ & $-0,24$ \\
\hline 44 & H90-7.5-C2-2-45 & 89,20 & 2,80 & 3,06 & 1,09 & 0,41 & 0,16 & 2,91 & 1,04 & 0,49 & 0,18 \\
\hline
\end{tabular}

$\varepsilon_{\mathrm{co}}$ : Deformación del hormigón correspondiente al pico de tensión (s/n modelo constitutivo del Eurocódigo)

Esy : deformación del acero en el límite elástico (2.65\%o)

$\varepsilon S^{* *}$ : deformación de el acero en tracción obtenida experimentalmente para el punto de plastificación

$\varepsilon c^{* *}$ : deformación del hormigón obtenida experimentalmente para el punto de plastificación 
Estudio experimental y numérico de la capacidad de deformación de soportes esbeltos de hormigón armado 
ANEJO H: IDEALIZACIÓN DEL DIAGRAMA MOMENTO-CURVATURA EXPERIMENTAL

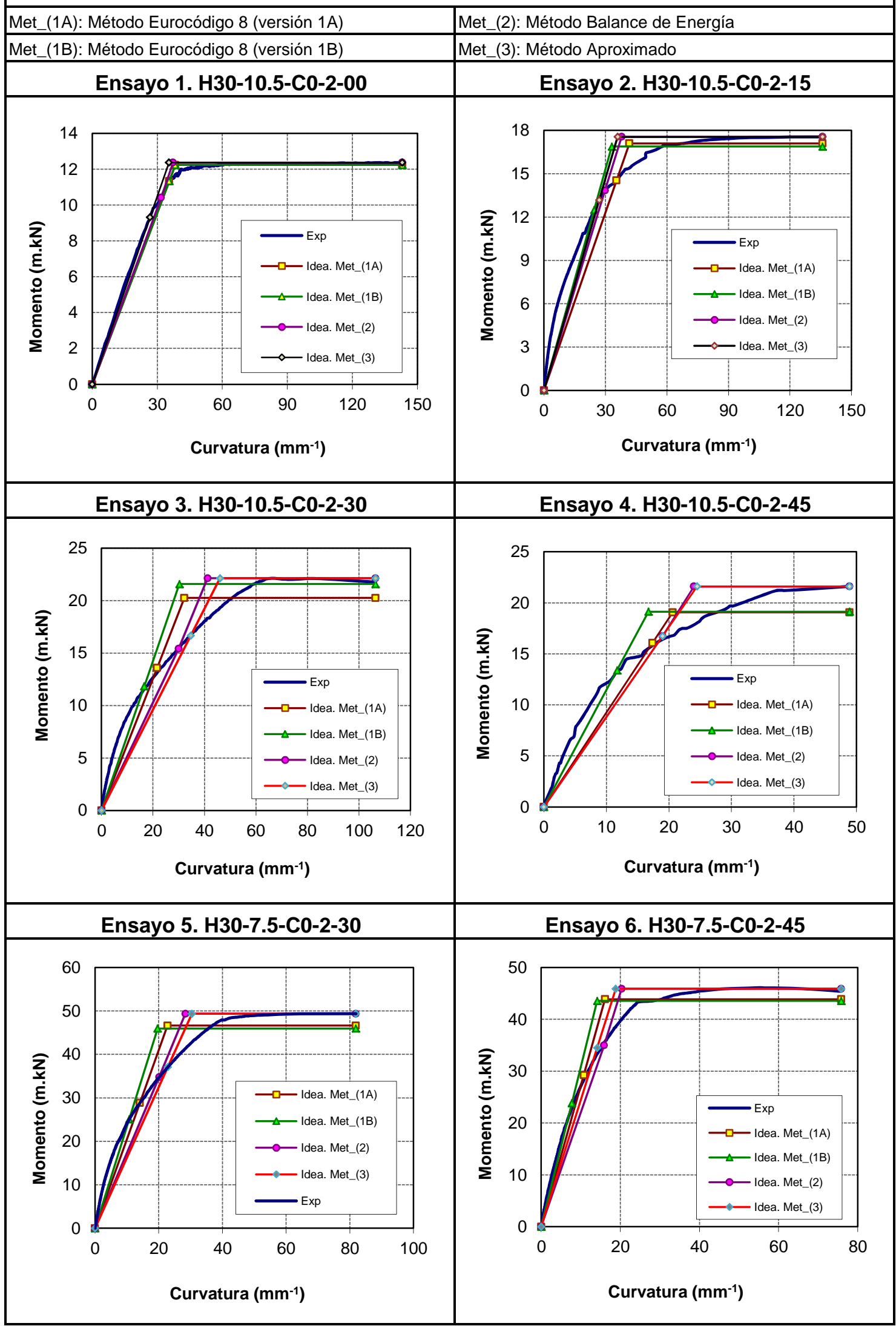


Estudio experimental y numérico de la capacidad de deformación de soportes esbeltos de hormigón armado

ANEJO H: IDEALIZACIÓN DEL DIAGRAMA MOMENTO-CURVATURA EXPERIMENTAL

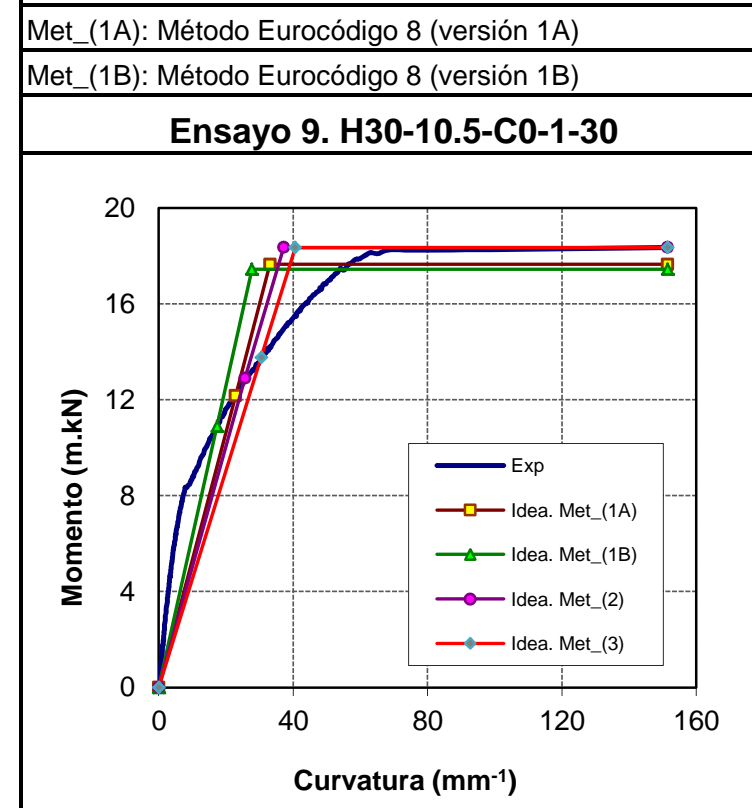

Met_(2): Método Balance de Energía Met_(3): Método Aproximado

Ensayo 10. H30-10.5-C0-1-45
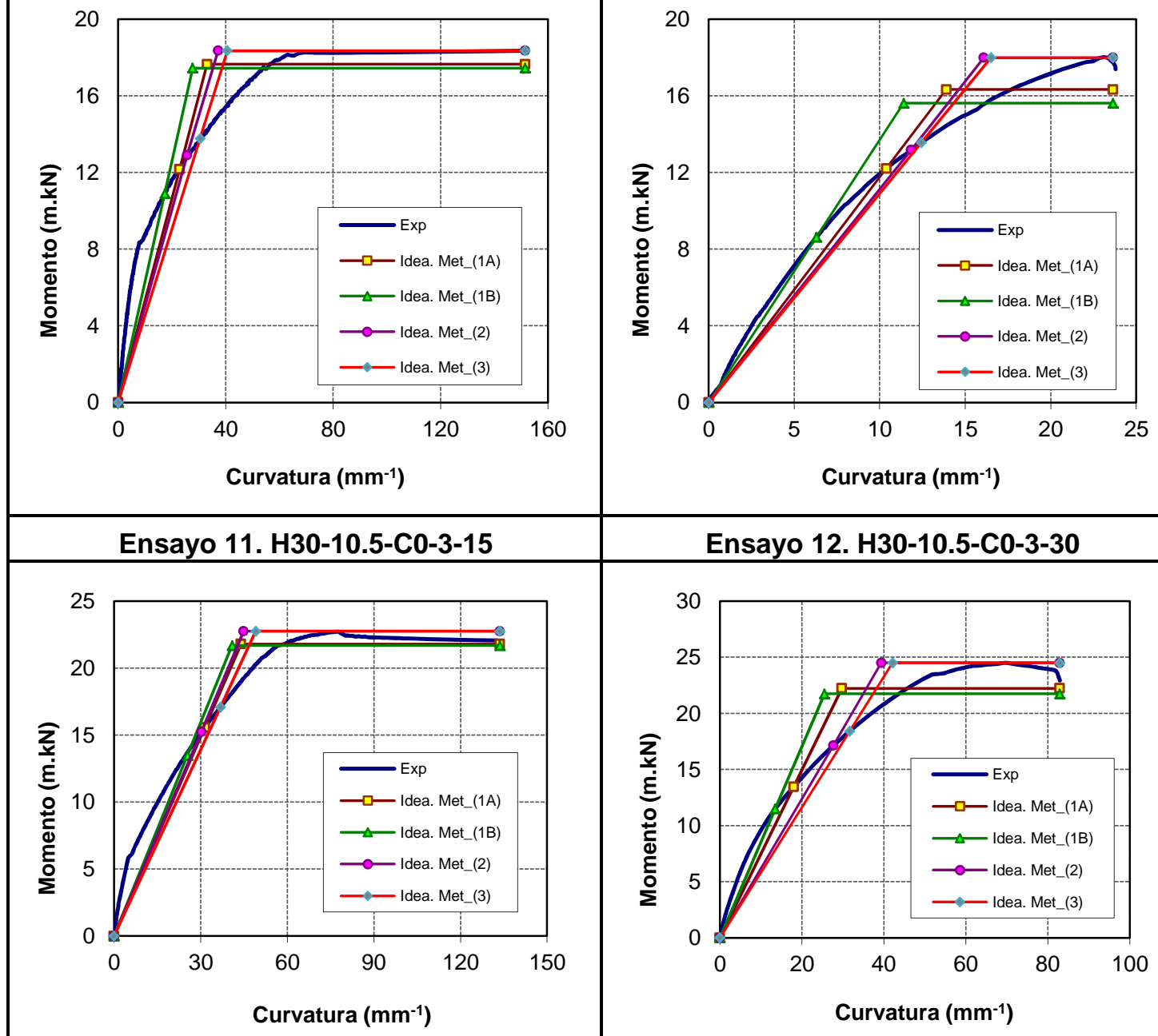

Ensayo 12. H30-10.5-C0-3-30
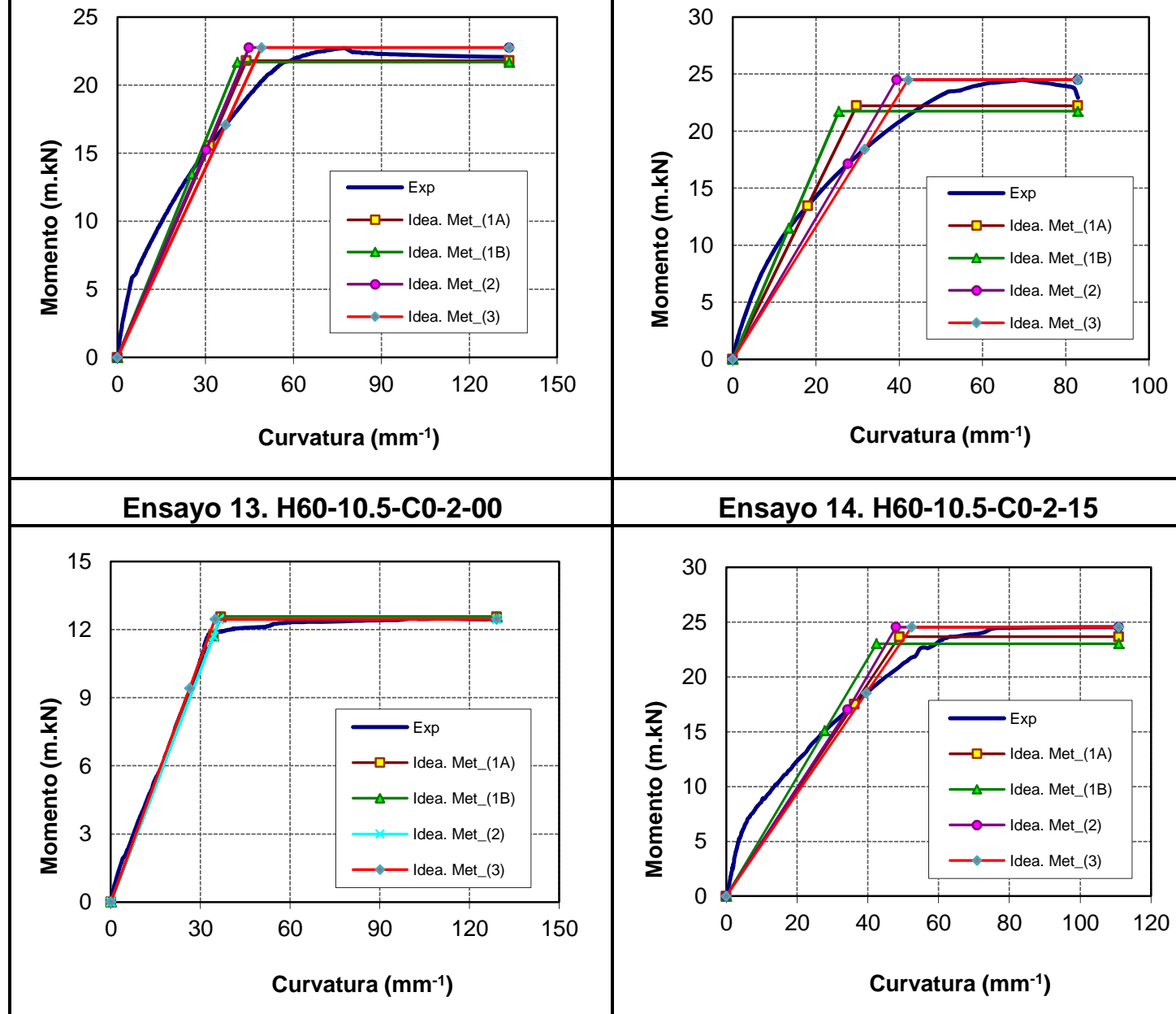

Ensayo 14. H60-10.5-C0-2-15

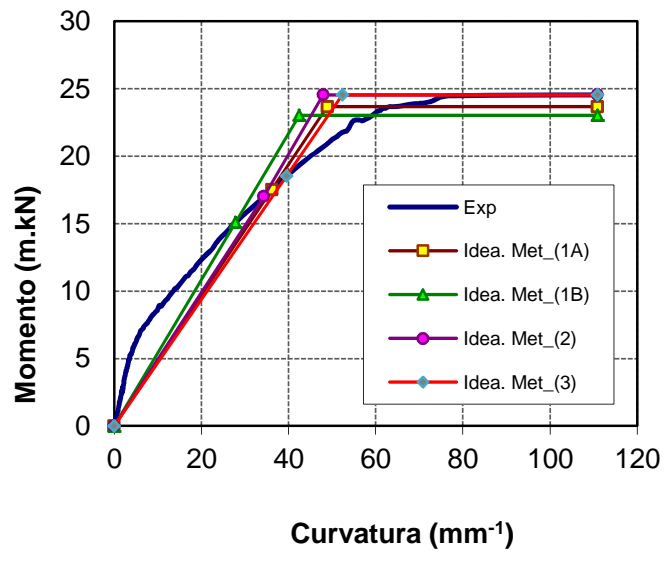


ANEJO H: IDEALIZACIÓN DEL DIAGRAMA MOMENTO-CURVATURA EXPERIMENTAL

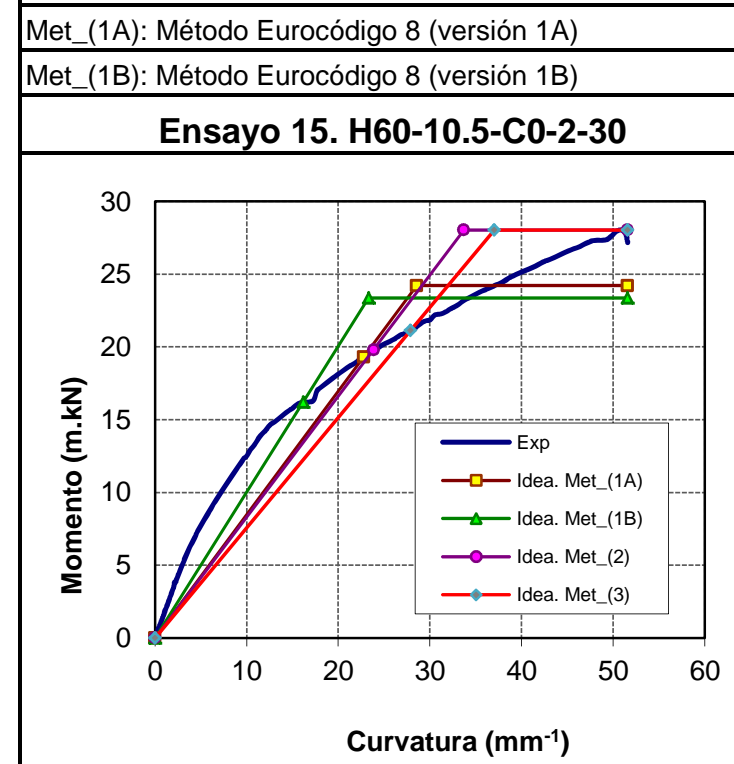

Met_(2): Método Balance de Energía Met_(3): Método Aproximado

\section{Ensayo 16. H60-10.5-C0-2-45}
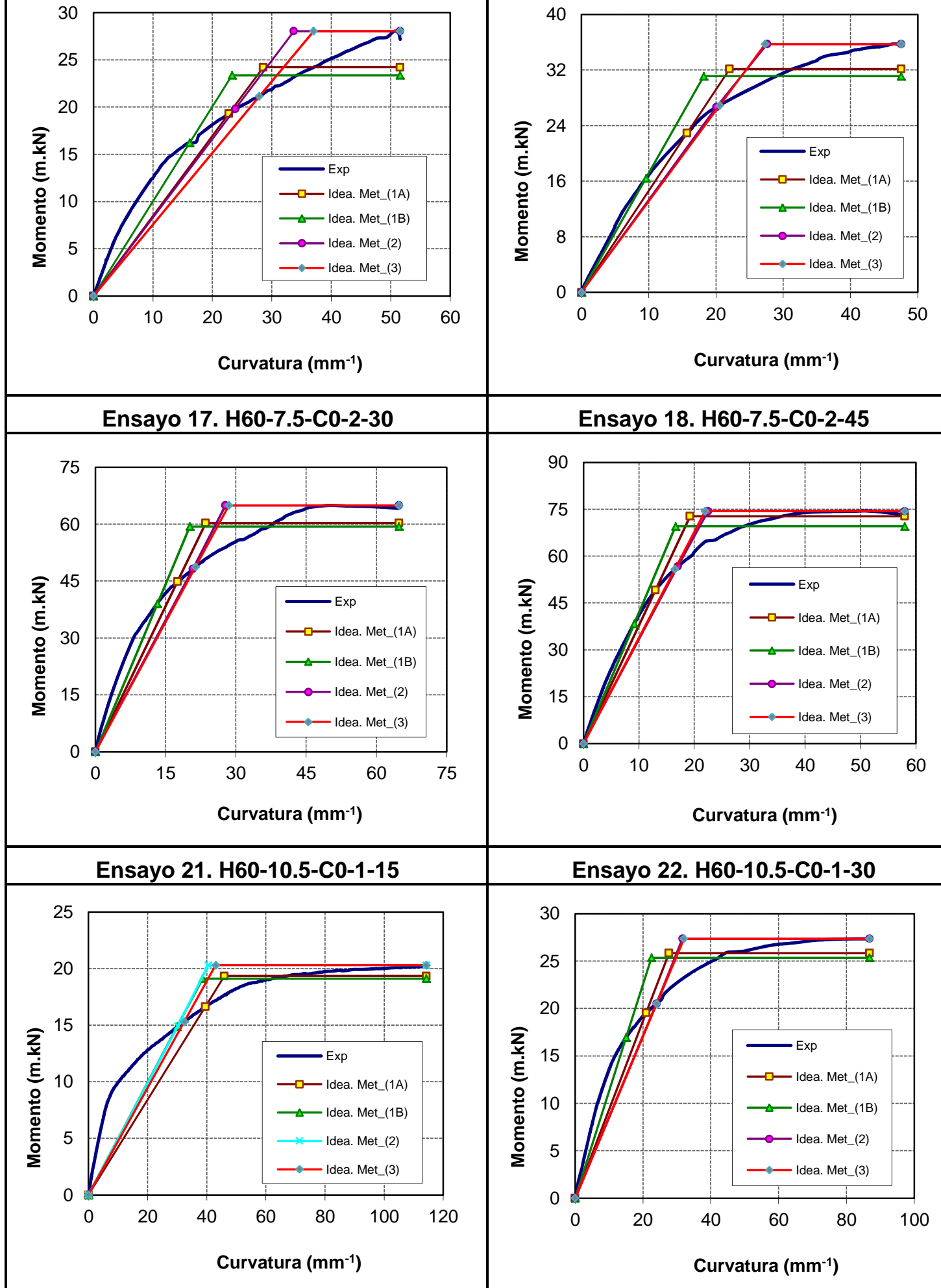
Estudio experimental y numérico de la capacidad de deformación de soportes esbeltos de hormigón armado

ANEJO H: IDEALIZACIÓN DEL DIAGRAMA MOMENTO-CURVATURA EXPERIMENTAL

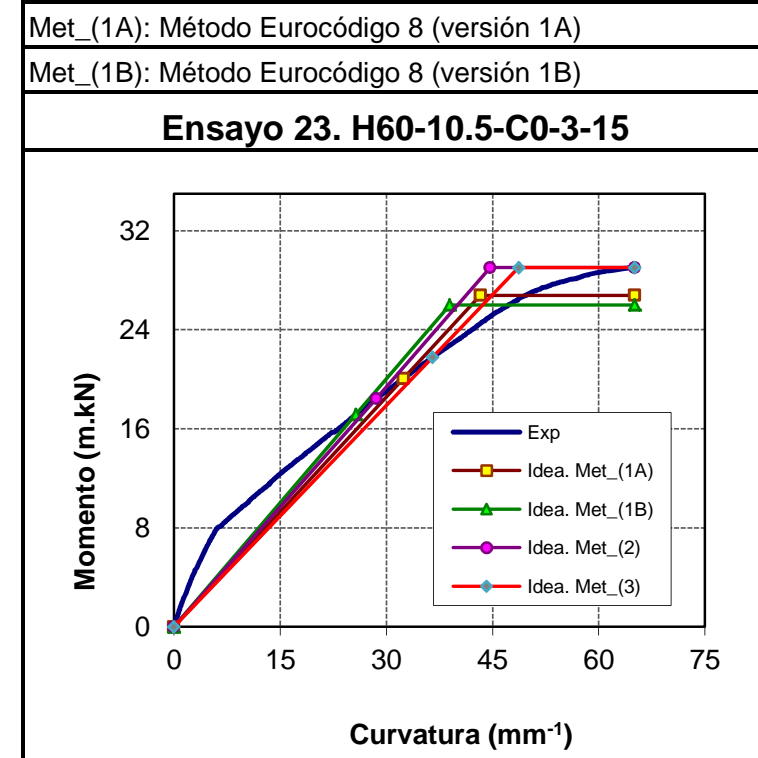

Met_(2): Método Balance de Energía Met_(3): Método Aproximado

Ensayo 24. H60-10.5-C0-3-30
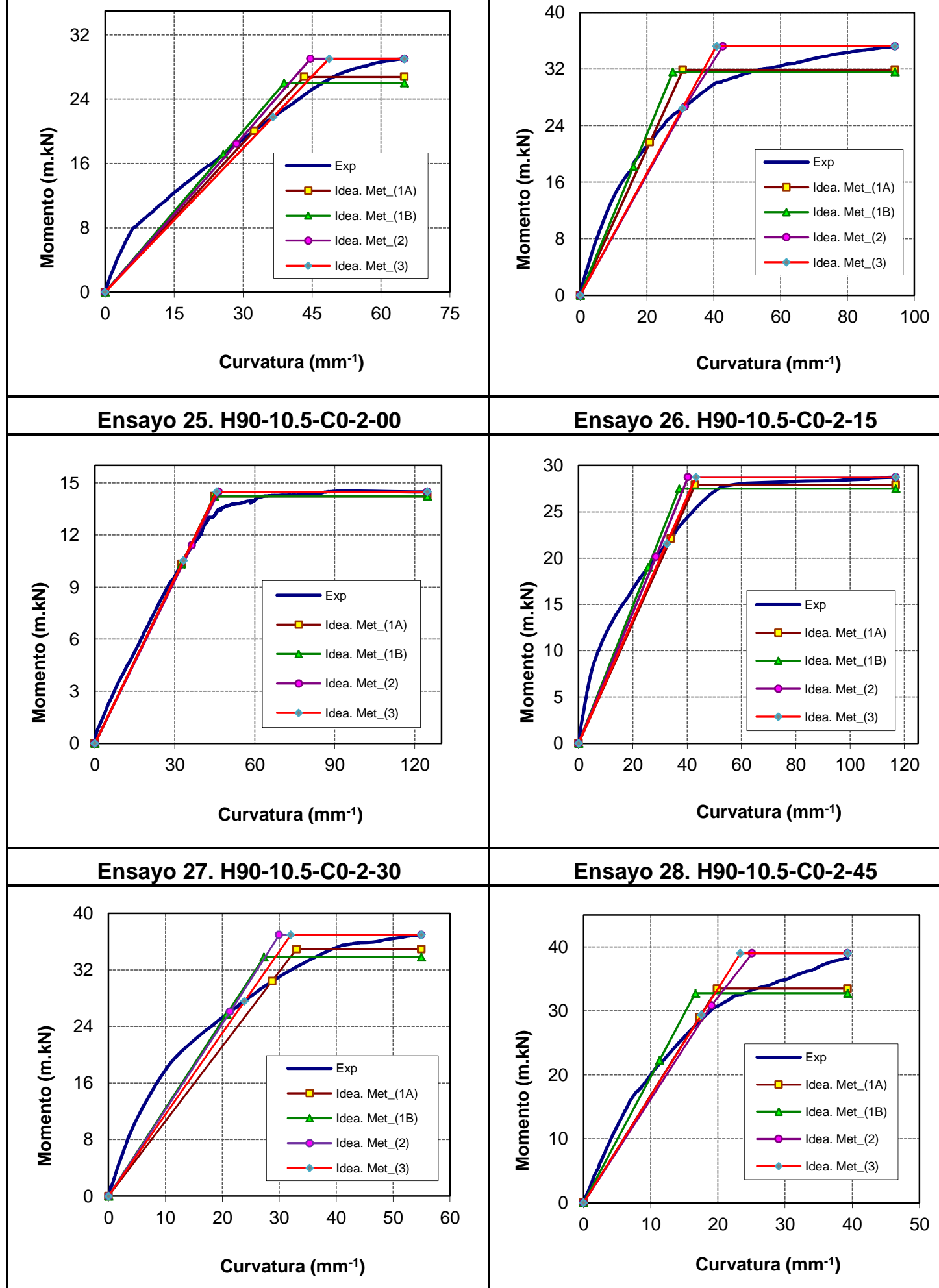

Ensayo 28. H90-10.5-C0-2-45

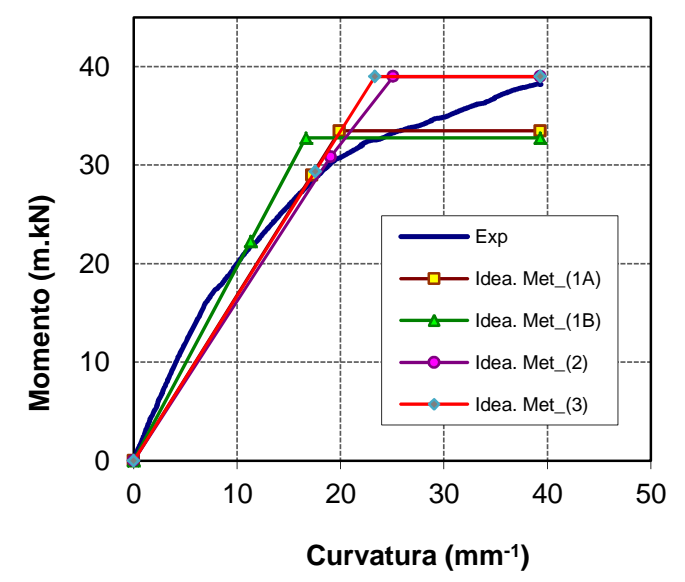


ANEJO H: IDEALIZACIÓN DEL DIAGRAMA MOMENTO-CURVATURA EXPERIMENTAL

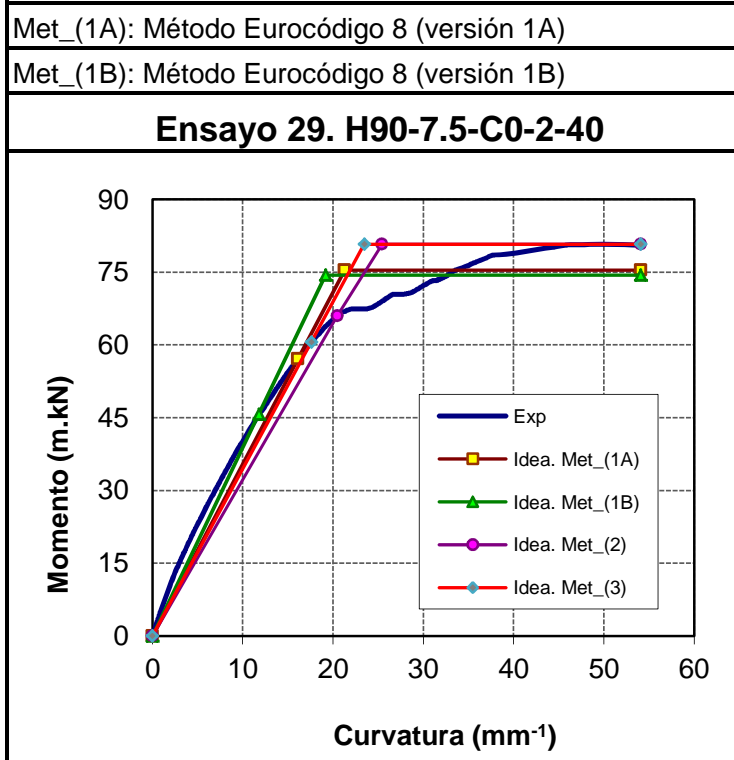

Met_(2): Método Balance de Energía

Met_(3): Método Aproximado

\section{Ensayo 30. H90-7.5-C0-2-45}
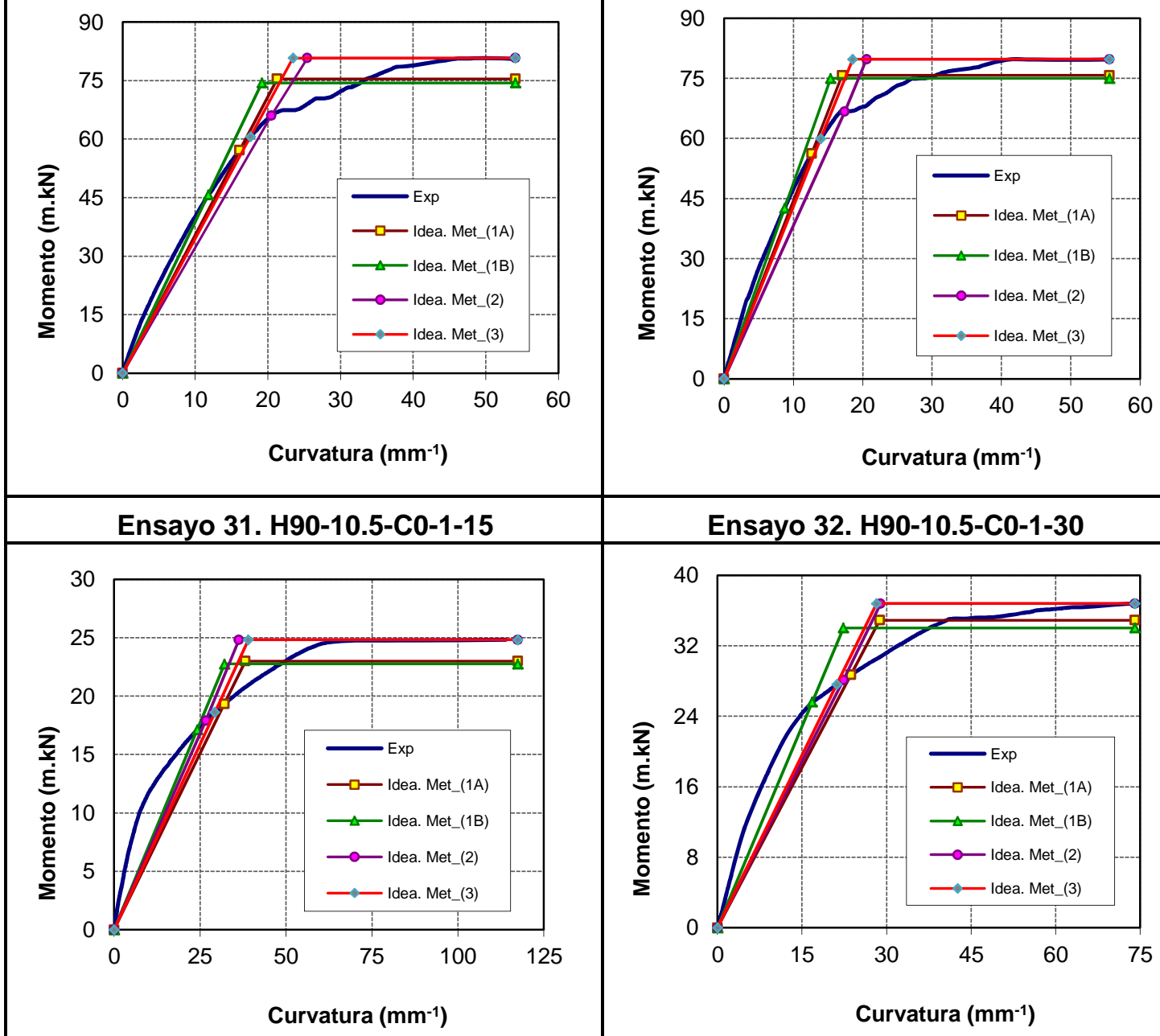

\section{Ensayo 32. H90-10.5-C0-1-30}

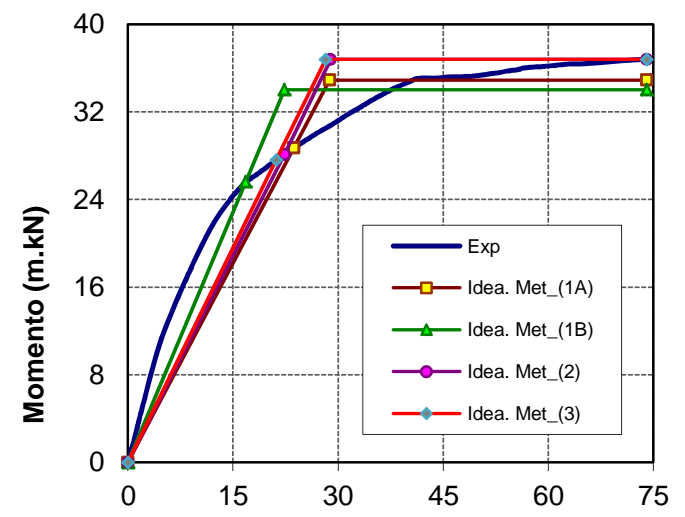

Curvatura $\left(\mathrm{mm}^{-1}\right)$

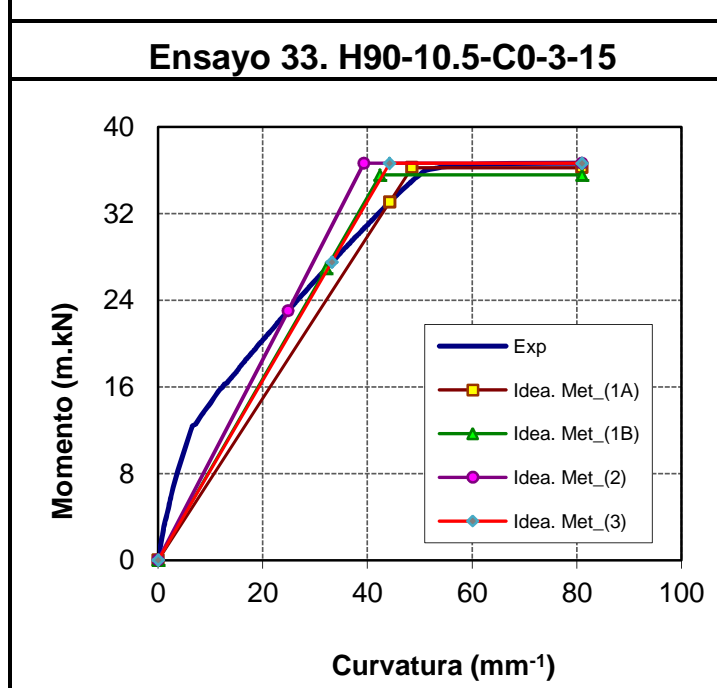

Ensayo 34. H90-10.5-C0-3-30

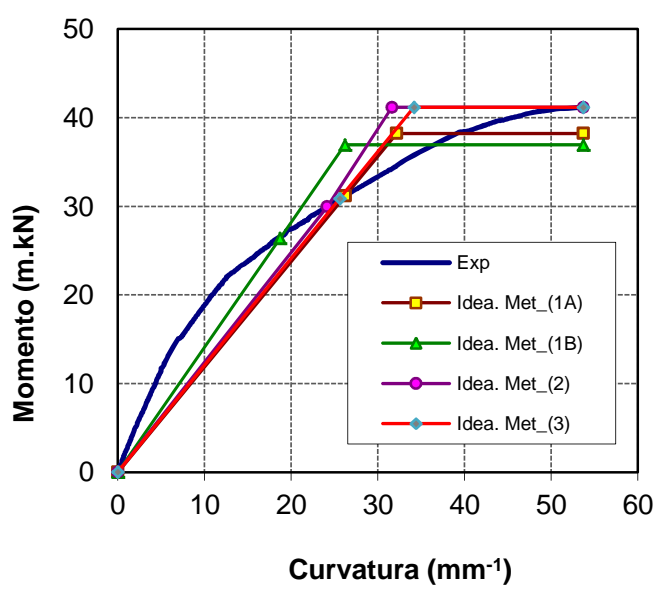


Estudio experimental y numérico de la capacidad de deformación de soportes esbeltos de hormigón armado

ANEJO H: IDEALIZACIÓN DEL DIAGRAMA MOMENTO-CURVATURA EXPERIMENTAL

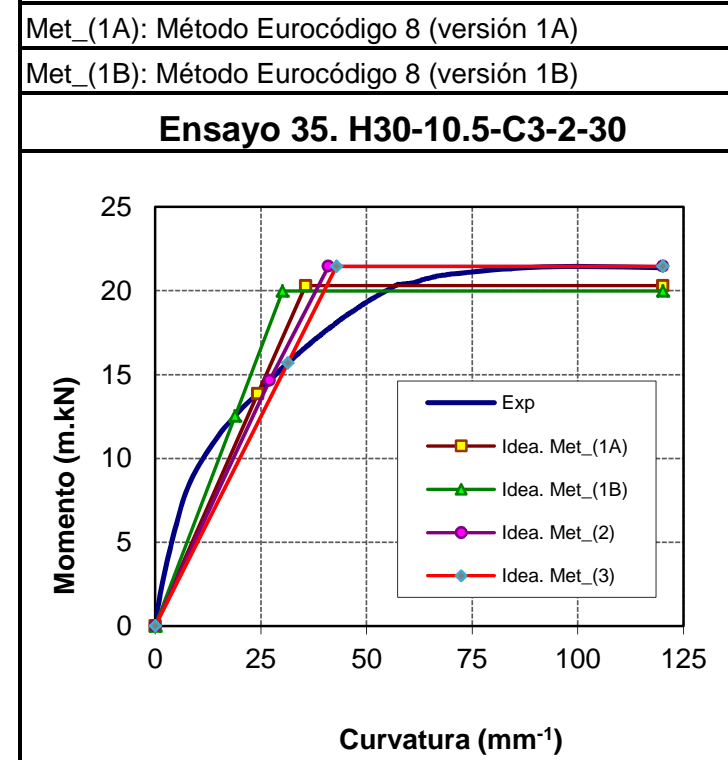

Met_(2): Método Balance de Energía

Met_(3): Método Aproximado

\section{Ensayo 36.H30-10.5-C3-2-45}
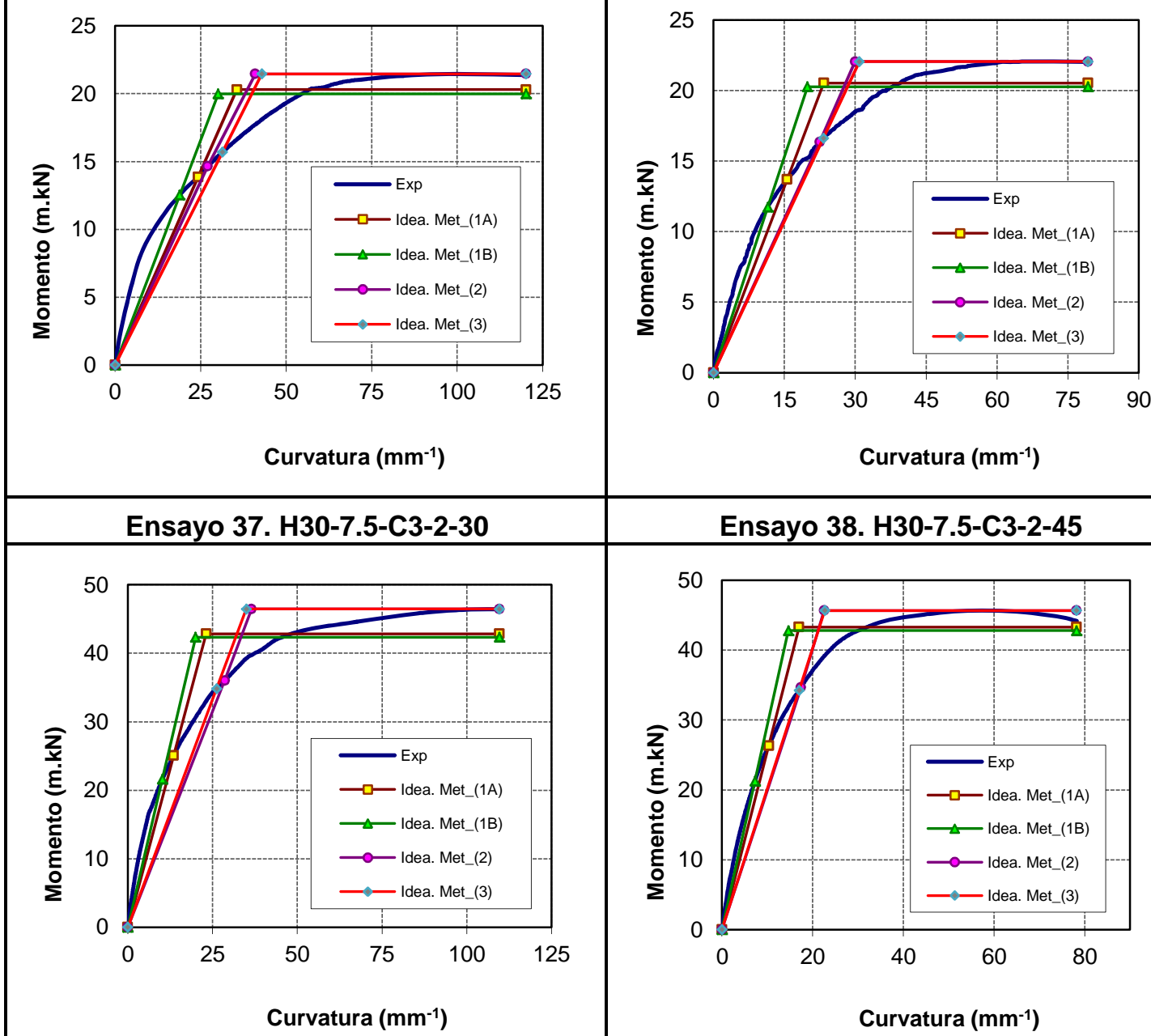

Curvatura $\left(\mathrm{mm}^{-1}\right)$

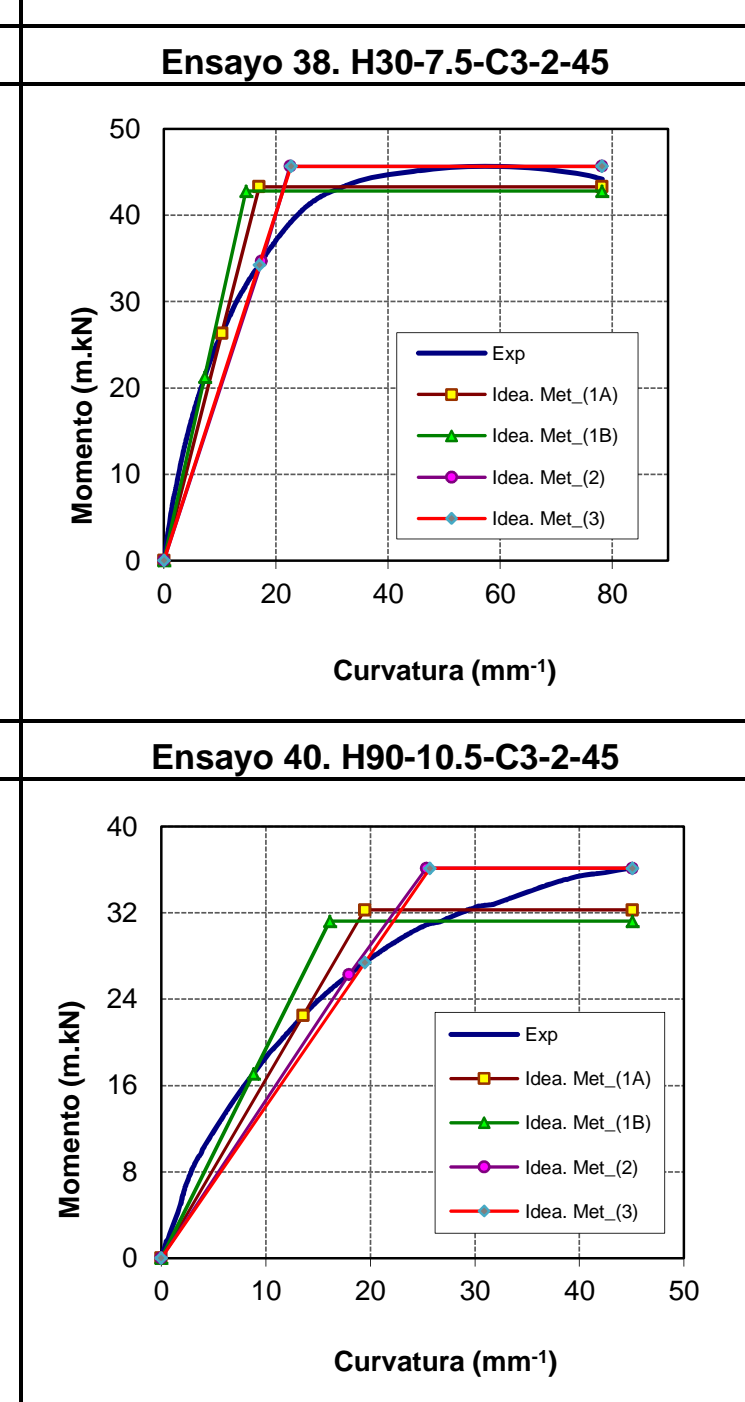


ANEJO H: IDEALIZACIÓN DEL DIAGRAMA MOMENTO-CURVATURA EXPERIMENTAL

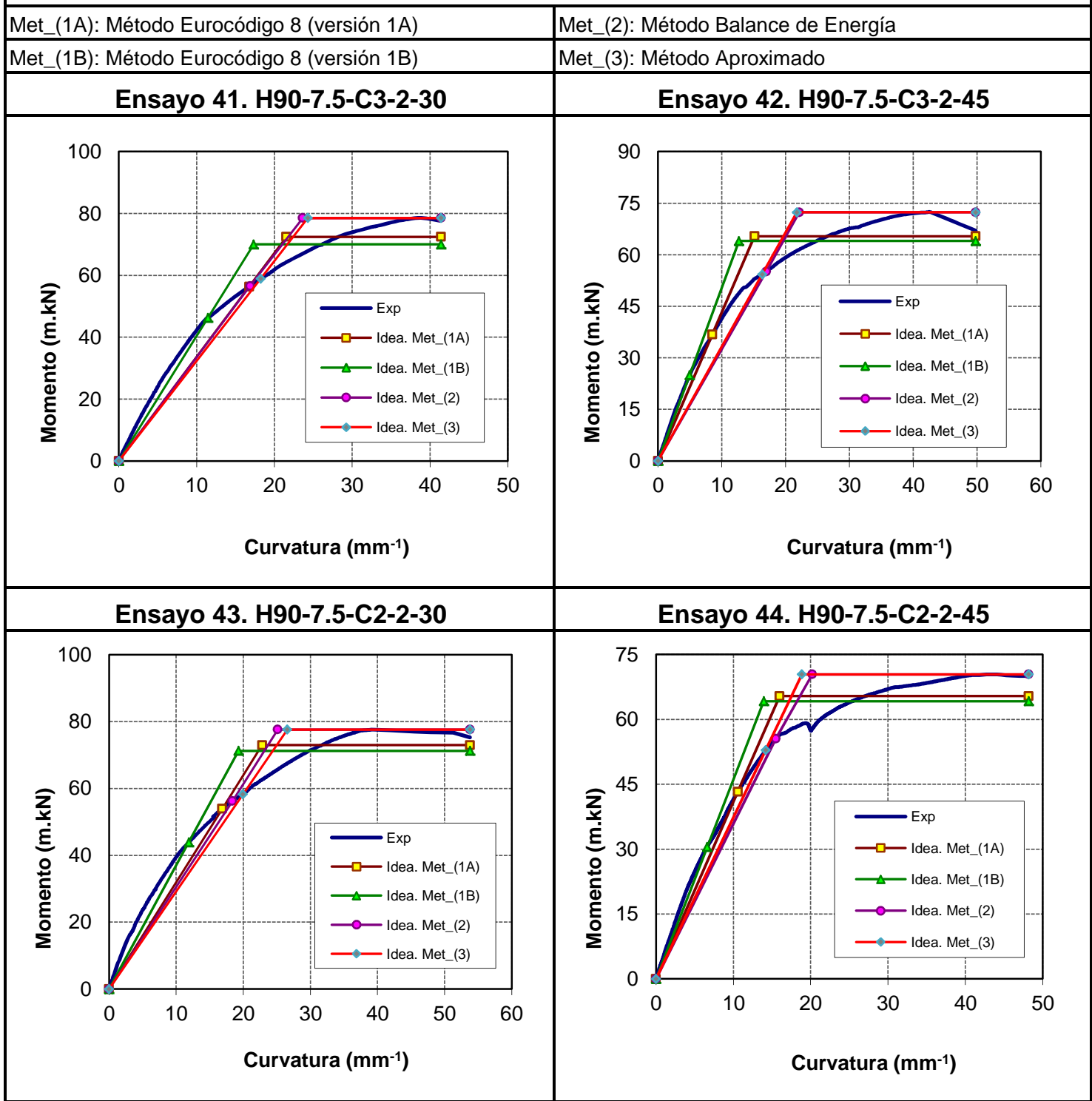


Estudio experimental y numérico de la capacidad de deformación de soportes esbeltos de hormigón armado 


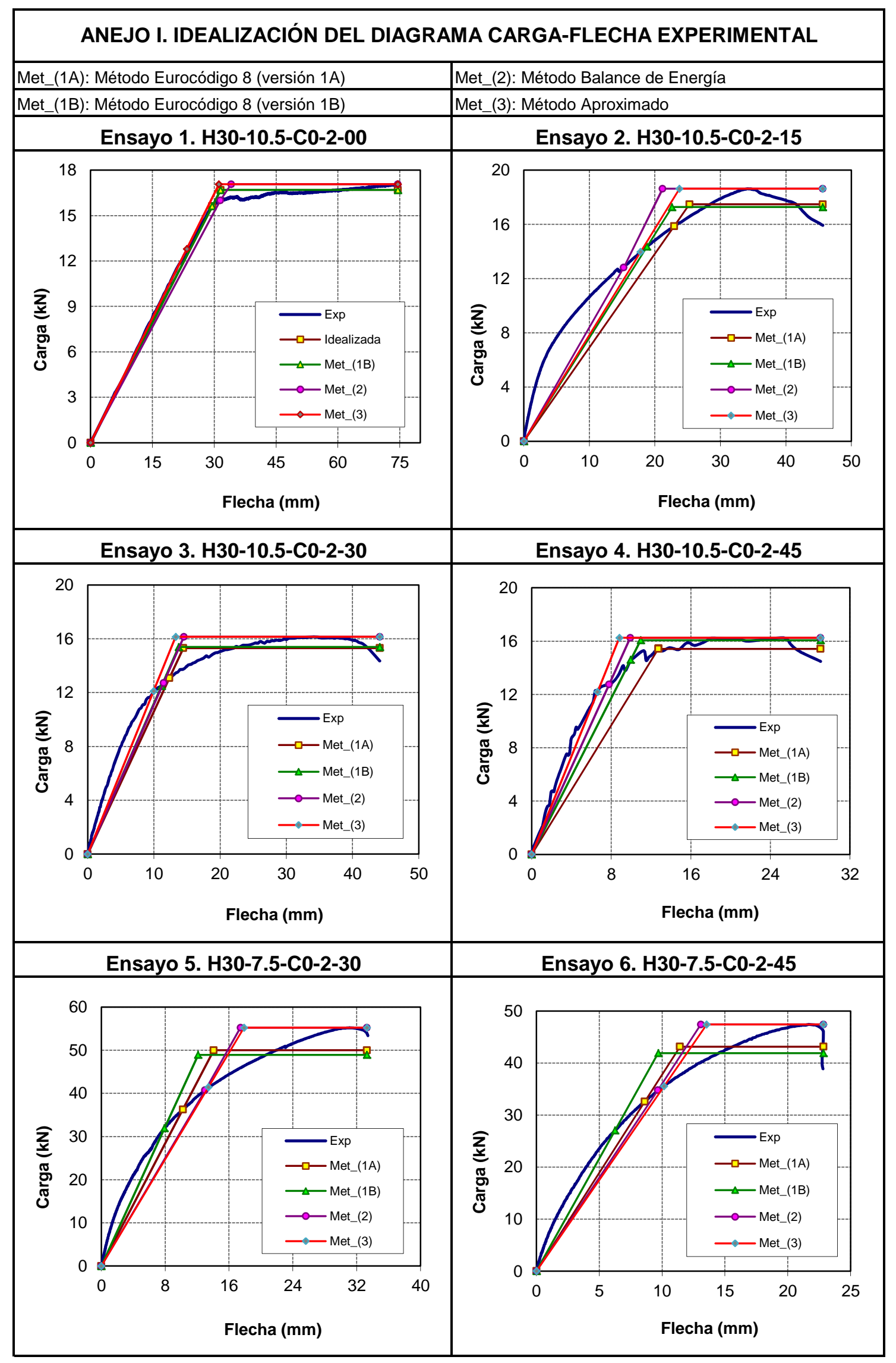


Estudio experimental y numérico de la capacidad de deformación de soportes esbeltos de hormigón armado

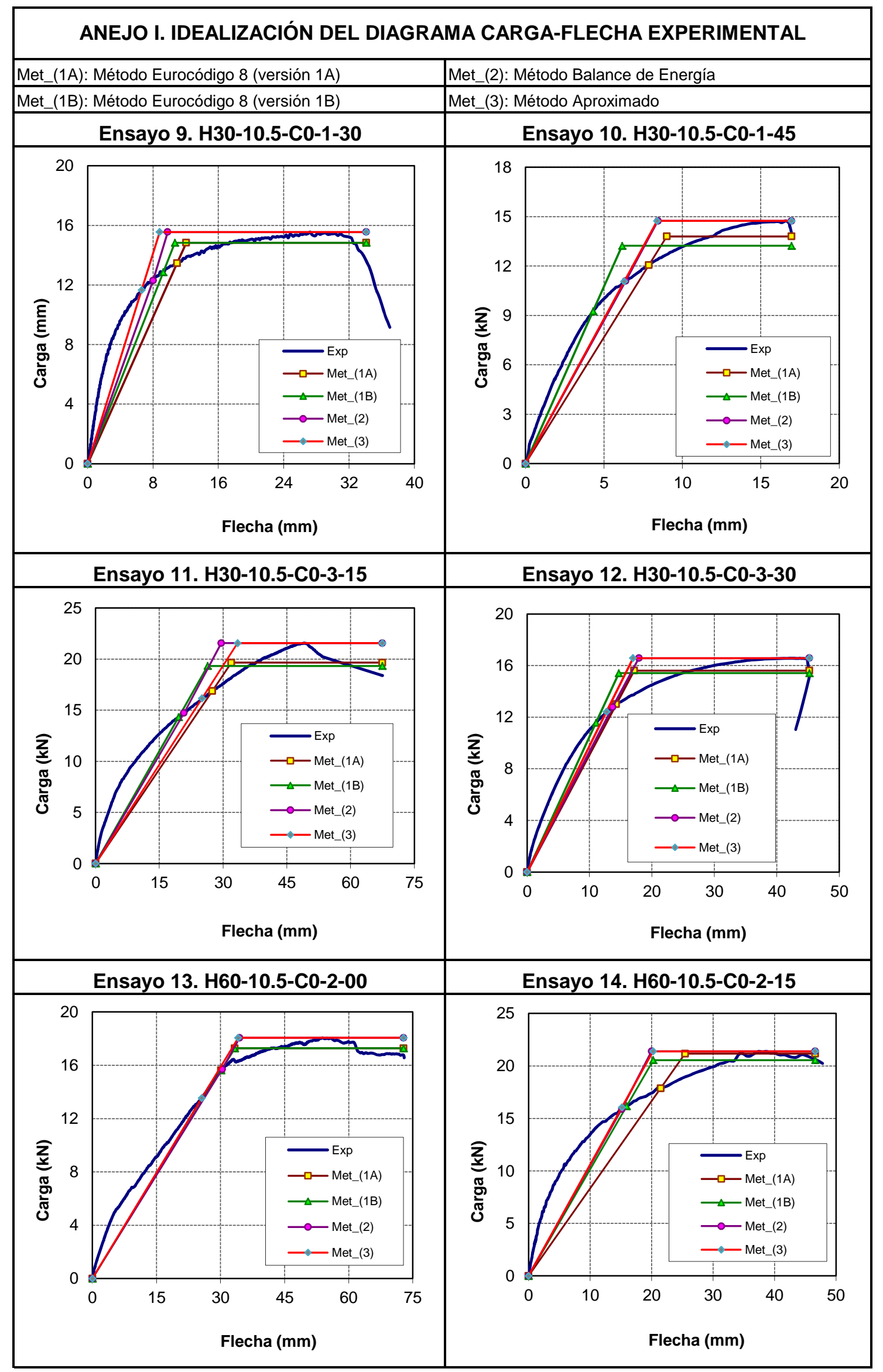


Anejo I. Idealización diagrama carga-flecha

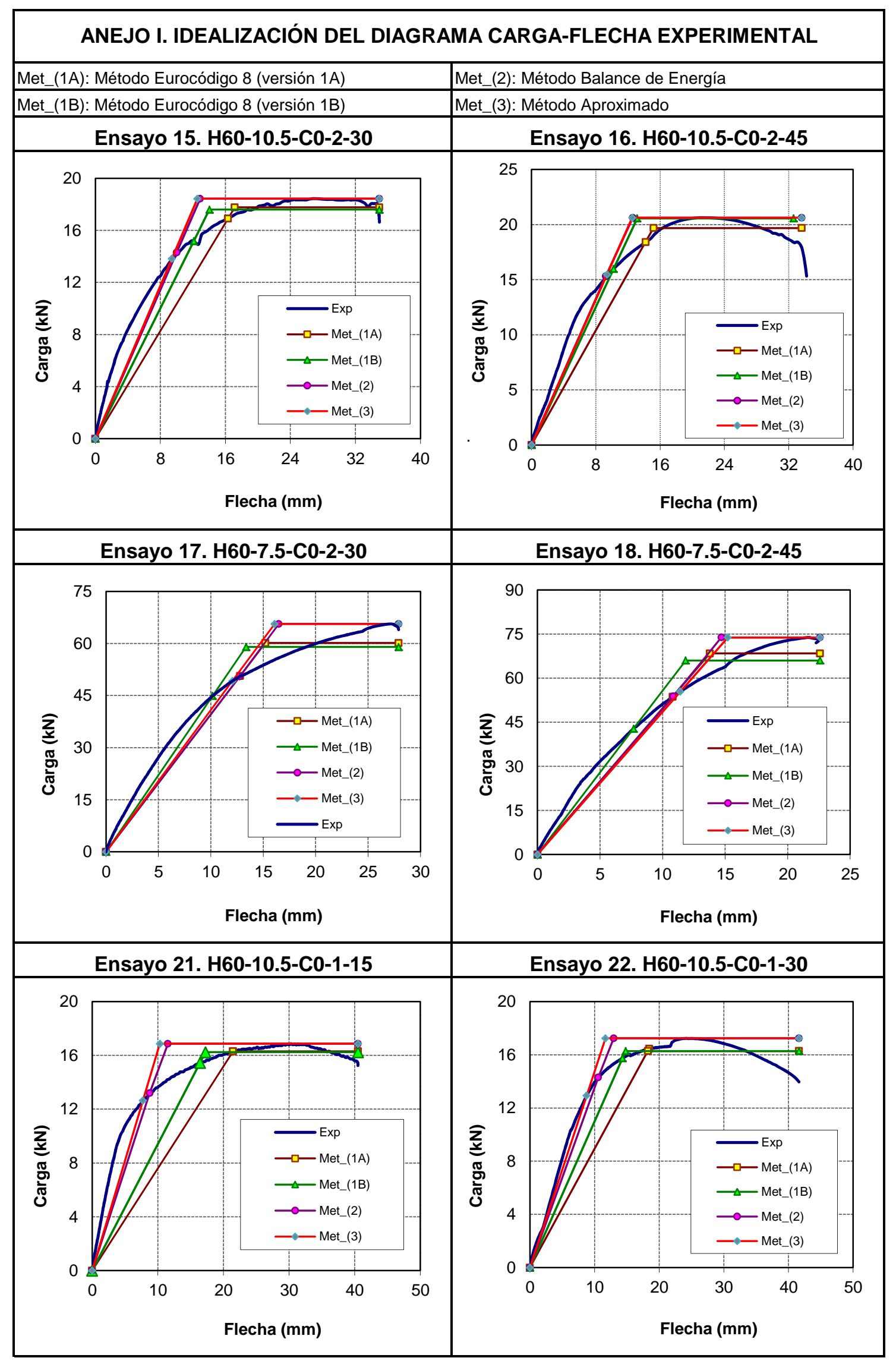


Estudio experimental y numérico de la capacidad de deformación de soportes esbeltos de hormigón armado

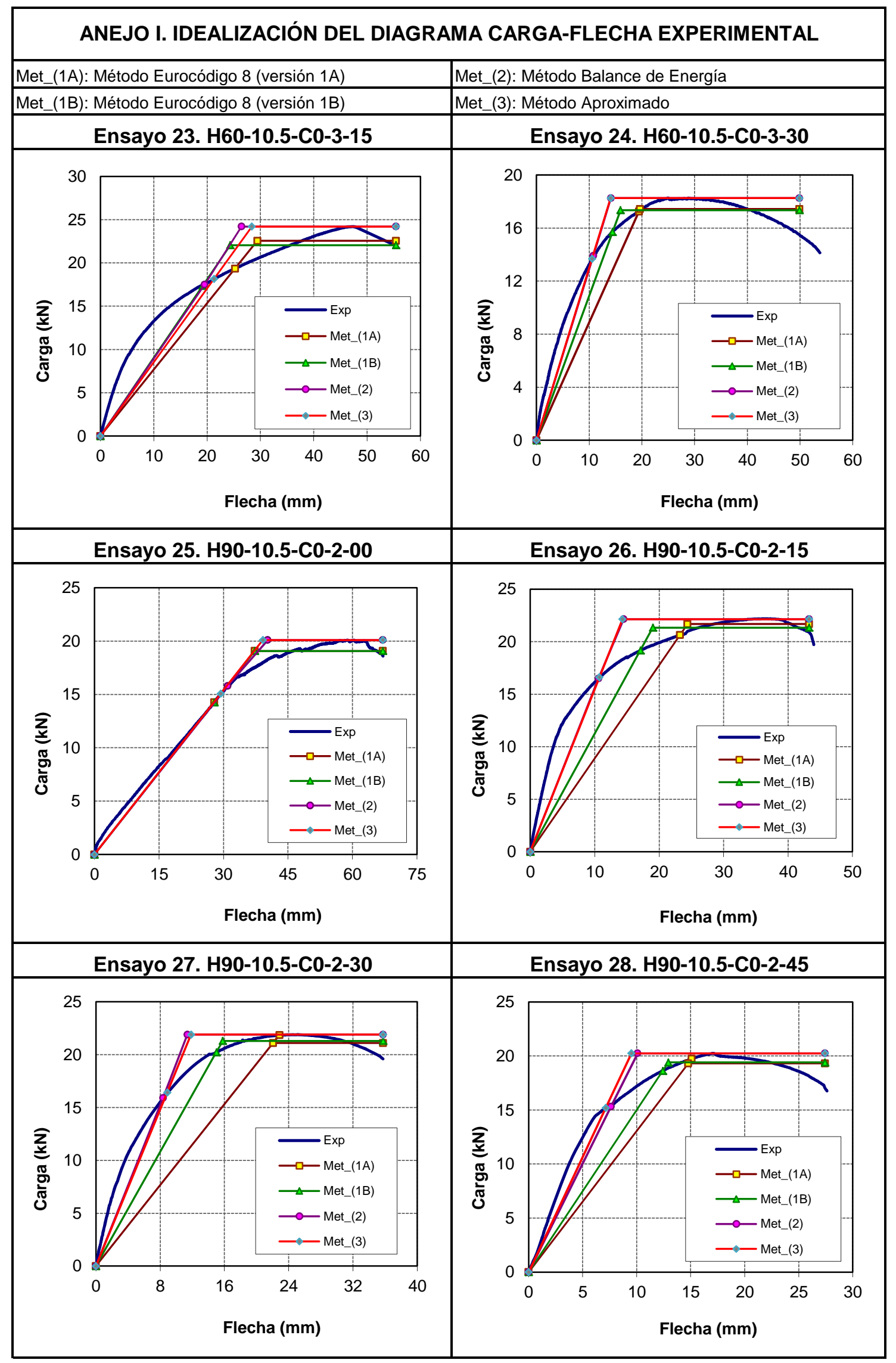


Anejo I. Idealización diagrama carga-flecha

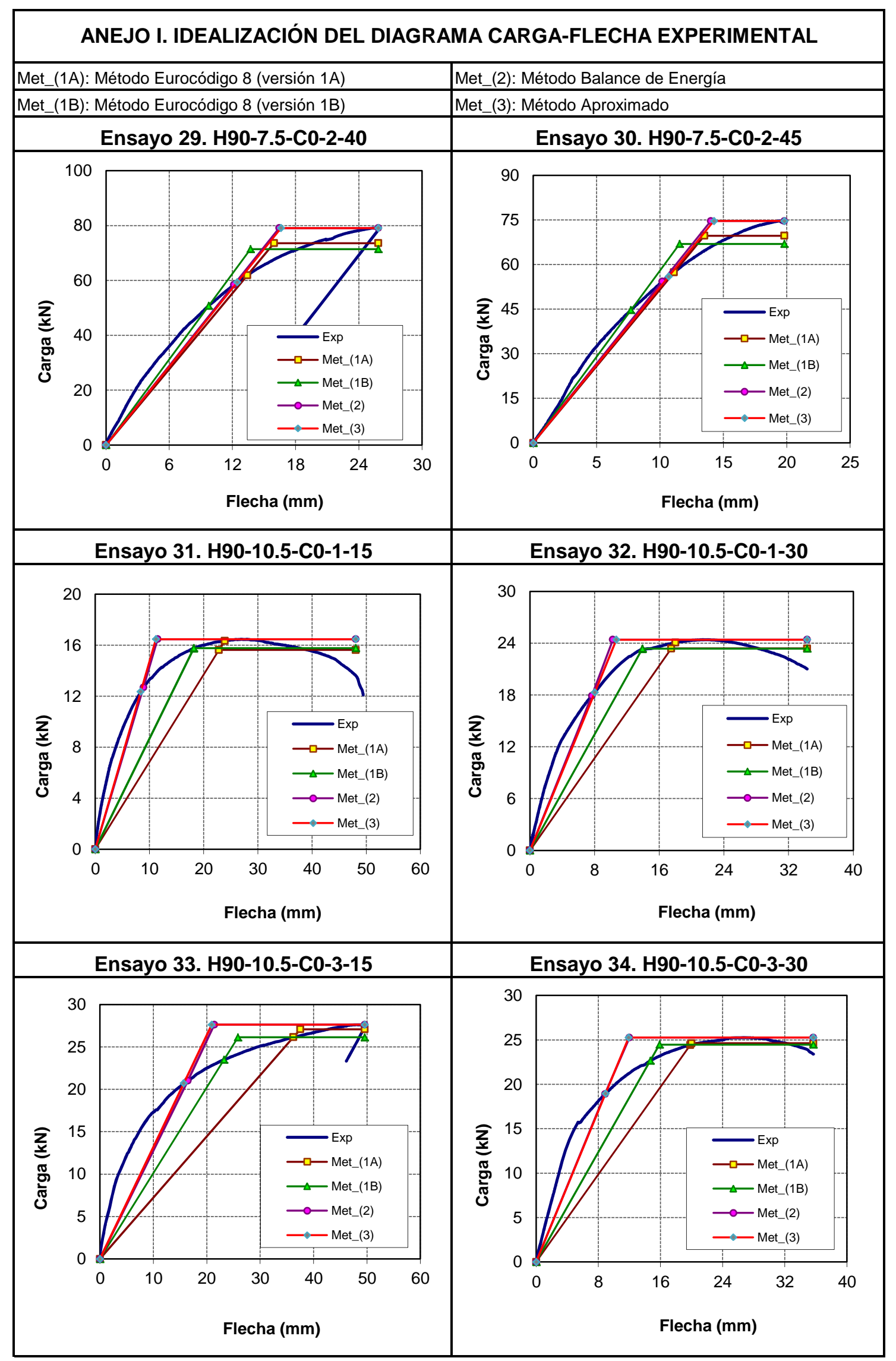


Estudio experimental y numérico de la capacidad de deformación de soportes esbeltos de hormigón armado

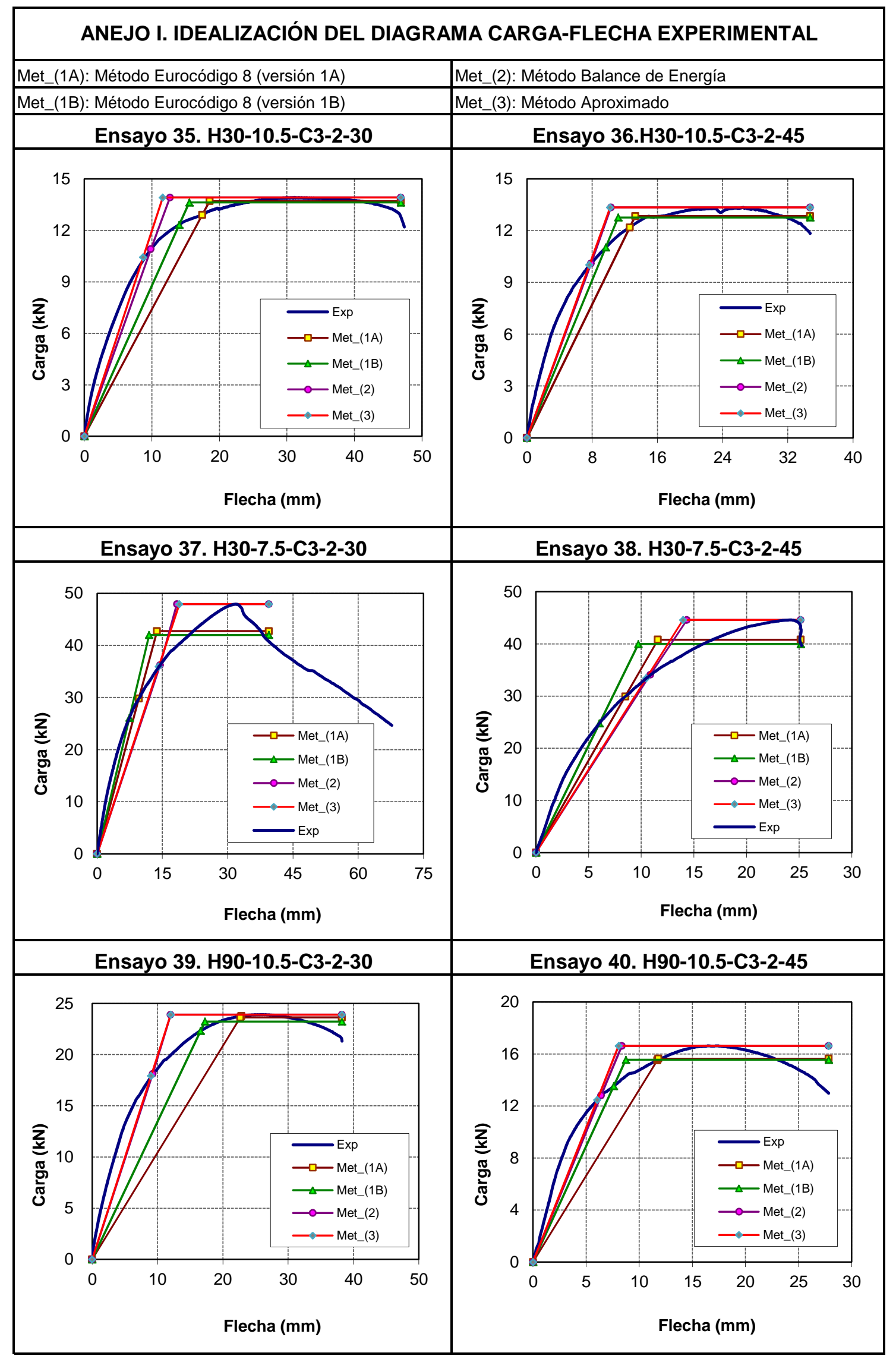




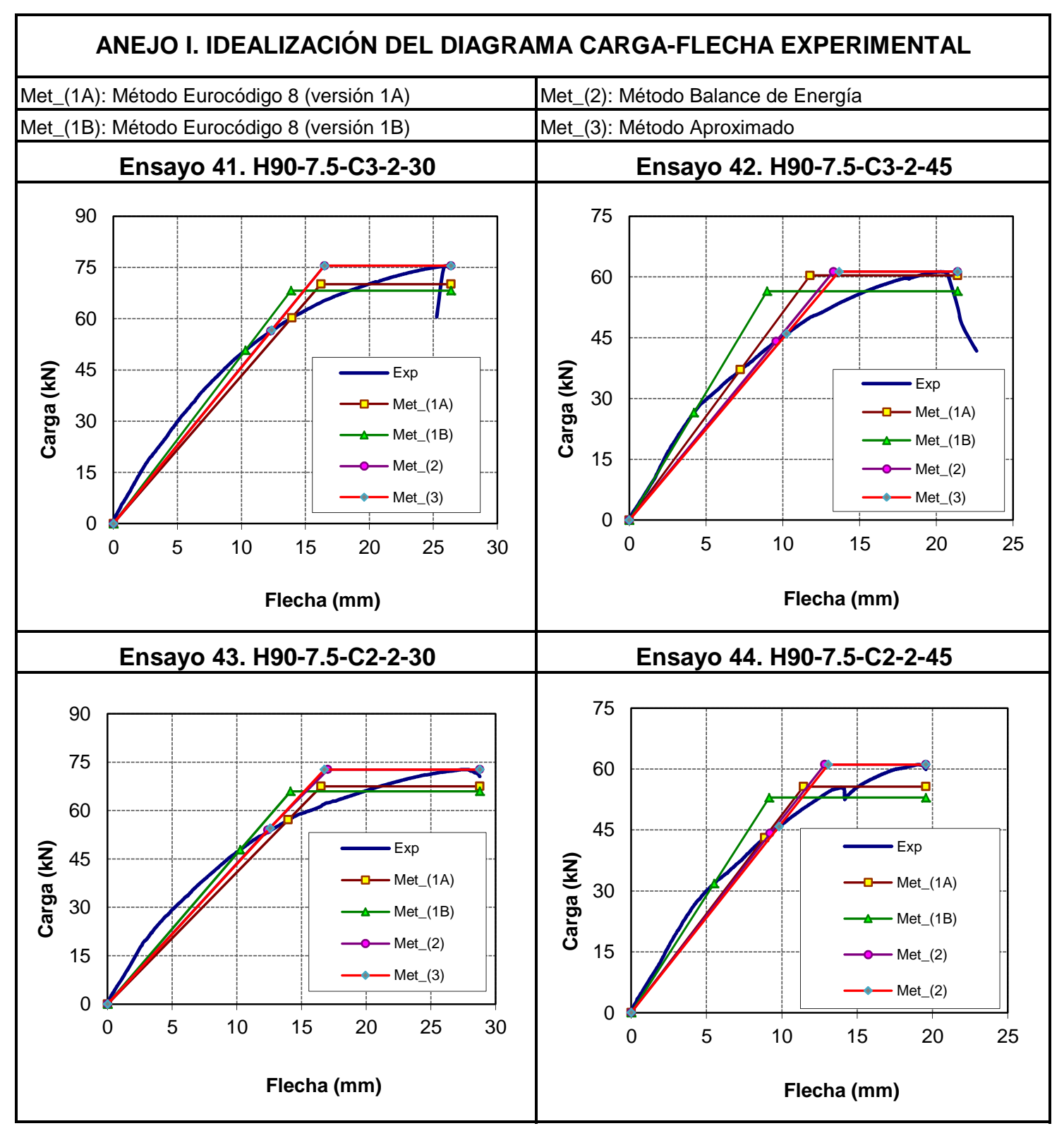


Estudio experimental y numérico de la capacidad de deformación de soportes esbeltos de hormigón armado 


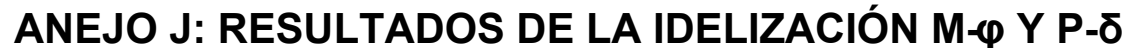

\begin{tabular}{|c|c|c|c|c|c|c|c|c|}
\hline \multicolumn{9}{|c|}{ Idealización del diagrama M- $\varphi$ aplicando el método del Eurocódigo (versión 1A) } \\
\hline $\mathbf{N}^{\circ}$ & REFERENCIA & $\begin{array}{c}\varphi_{y_{-} \exp } \\
\left(\mathrm{mm}^{-1}\right)\end{array}$ & $\begin{array}{c}\text { My } \\
\text { (m.kN) }\end{array}$ & $\begin{array}{l}\varphi_{u_{\text {_exp }}} \\
\left(\mathrm{mm}^{-1}\right)\end{array}$ & $\begin{array}{l}\text { Mmax } \\
(m . k N)\end{array}$ & $\begin{array}{c}\varphi_{y}^{\prime} \\
\left(\mathrm{mm}^{-1}\right)\end{array}$ & $\mu_{\varphi}$ & $\begin{array}{c}\text { El } \\
\left(k N \cdot m^{2}\right)\end{array}$ \\
\hline 1 & N30-10.5-C0-2-00 & 35,45 & 11,33 & 142,95 & 12,33 & 38,28 & 3,73 & 320 \\
\hline 2 & $\mathrm{~N} 30-10.5-\mathrm{C} 0-2-15$ & 35,40 & 14,53 & 135,93 & 17,56 & 41,67 & 3,26 & 410 \\
\hline 3 & N30-10.5-C0-2-30 & 21,57 & 13,58 & 106,47 & 21,75 & 32,16 & 3,31 & 629 \\
\hline 4 & N30-10.5-C0-2-45 & 17,36 & 16,06 & 48,89 & 21,61 & 20,60 & 2,37 & 925 \\
\hline 5 & N30-7.5-C0-2-30 & 14,09 & 28,85 & 81,90 & 49,34 & 22,77 & 3,60 & 2047 \\
\hline 6 & N30-7.5-C0-2-45 & 10,76 & 29,24 & 75,85 & 45,40 & 16,14 & 4,70 & 2716 \\
\hline 9 & N30-10.5-C0-1-30 & 22,84 & 12,17 & 151,48 & 18,29 & 33,11 & 4,57 & 533 \\
\hline 10 & N30-10.5-C0-1-45 & 10,39 & 12,21 & 23,65 & 16,63 & 13,89 & 1,70 & 1175 \\
\hline 11 & N30-10.5-C0-3-15 & 31,41 & 15,57 & 133,64 & 22,35 & 43,96 & 3,04 & 496 \\
\hline 12 & N30-10.5-C0-3-30 & 18,01 & 13,45 & 82,96 & 22,93 & 29,77 & 2,79 & 747 \\
\hline 13 & $\mathrm{H} 60-10.5-\mathrm{C} 0-2-00$ & 34,36 & 11,72 & 129,05 & 12,45 & 36,82 & 3,51 & 341 \\
\hline 14 & H60-10.5-C0-2-15 & 36,19 & 17,52 & 110,84 & 24,54 & 48,88 & 2,27 & 484 \\
\hline 15 & $\mathrm{H} 60-10.5-\mathrm{C} 0-2-30$ & 22,77 & 19,31 & 51,58 & 27,17 & 28,57 & 1,81 & 848 \\
\hline 16 & $\mathrm{H} 60-10.5-\mathrm{C} 0-2-45$ & 15,71 & 22,93 & 47,56 & 35,69 & 22,02 & 2,16 & 1459 \\
\hline 17 & $\mathrm{H} 60-7.5-\mathrm{C} 0-2-30$ & 17,52 & 44,84 & 64,82 & 64,13 & 23,57 & 2,75 & 2560 \\
\hline 18 & $\mathrm{H} 60-7.5-\mathrm{C} 0-2-45$ & 12,99 & 49,12 & 57,95 & 73,23 & 19,24 & 3,01 & 3780 \\
\hline 21 & H60-10.5-C0-1-15 & 39,54 & 16,64 & 114,24 & 20,21 & 45,96 & 2,49 & 421 \\
\hline 22 & H60-10.5-C0-1-30 & 20,93 & 19,53 & 86,81 & 27,34 & 27,68 & 3,14 & 933 \\
\hline 23 & H60-10.5-C0-3-15 & 32,43 & 20,07 & 65,06 & 29,02 & 43,28 & 1,50 & 619 \\
\hline 24 & $\mathrm{H} 60-10.5-\mathrm{C} 0-3-30$ & 20,86 & 21,63 & 94,19 & 34,74 & 30,74 & 3,06 & 1037 \\
\hline 25 & $\mathrm{H} 90-10.5-\mathrm{C} 0-2-00$ & 32,58 & 10,33 & 124,76 & 14,52 & 44,84 & 2,78 & 317 \\
\hline 26 & H90-10.5-C0-2-15 & 33,97 & 22,11 & 116,87 & 28,73 & 42,88 & 2,73 & 651 \\
\hline 27 & H90-10.5-C0-2-30 & 28,77 & 30,40 & 54,99 & 36,93 & 33,05 & 1,66 & 1057 \\
\hline 28 & H90-10.5-C0-2-45 & 17,22 & 28,97 & 39,31 & 38,90 & 19,91 & 1,97 & 1682 \\
\hline 29 & H90-7.5-C0-2-30 & 16,12 & 57,14 & 54,07 & 80,49 & 21,28 & 2,54 & 3544 \\
\hline 30 & H90-7.5-C0-2-45 & 12,63 & 56,18 & 55,55 & 79,66 & 17,03 & 3,26 & 4447 \\
\hline 31 & $\mathrm{H} 90-10.5-\mathrm{C} 0-1-15$ & 32,09 & 19,33 & 117,41 & 24,83 & 38,16 & 3,08 & 602 \\
\hline 32 & H90-10.5-C0-1-30 & 23,68 & 28,70 & 74,08 & 36,77 & 28,79 & 2,57 & 1212 \\
\hline 33 & H90-10.5-C0-3-15 & 44,27 & 33,08 & 80,97 & 36,66 & 48,50 & 1,67 & 747 \\
\hline 34 & H90-10.5-C0-3-30 & 26,26 & 31,20 & 53,72 & 41,17 & 32,18 & 1,67 & 1188 \\
\hline 35 & N30-10.5-C3-2-30 & 24,29 & 13,86 & 120,20 & 21,37 & 35,60 & 3,38 & 570 \\
\hline 36 & N30-10.5-C3-2-45 & 15,59 & 13,70 & 79,23 & 22,03 & 23,36 & 3,39 & 879 \\
\hline 37 & N30-7.5-C3-2-30 & 13,53 & 25,09 & 109,64 & 46,45 & 23,10 & 4,75 & 1855 \\
\hline 38 & N30-7.5-C3-2-45 & 10,32 & 26,34 & 78,23 & 44,20 & 16,97 & 4,61 & 2552 \\
\hline 39 & $\mathrm{H} 90-10.5-\mathrm{C} 3-2-30$ & 27,04 & 31,75 & 49,24 & 39,76 & 31,75 & 1,55 & 1174 \\
\hline 40 & H90-10.5-C3-2-45 & 13,56 & 22,49 & 45,08 & 36,14 & 19,47 & 2,31 & 1658 \\
\hline 41 & H90-7.5-C3-2-30 & 16,76 & 56,36 & 41,41 & 77,63 & 21,55 & 1,92 & 3363 \\
\hline 42 & H90-7.5-C3-2-45 & 8,49 & 36,75 & 49,79 & 66,99 & 15,11 & 3,30 & 4329 \\
\hline 43 & H90-7.5-C2-2-30 & 16,86 & 53,92 & 53,79 & 75,29 & 22,82 & 2,36 & 3198 \\
\hline 44 & H90-7.5-C2-2-45 & 10,58 & 43,27 & 48,21 & 70,02 & 15,99 & 3,02 & 4091 \\
\hline
\end{tabular}

$\varphi_{\text {y_exp }}\left(\mathrm{mm}^{-1}\right)$ : Curvatura elástica experimental

My (m.kN): Momento elástico experimental

$\varphi_{\text {u_exp }}\left(\mathrm{mm}^{-1}\right)$ : Curvatura última Experimental

$\operatorname{Mmax}(\mathrm{m} . \mathrm{kN})$ : Momento máximo experimental

$\varphi_{y}^{\prime}\left(\mathrm{mm}^{-1}\right)$ : Curvatura elástica efectiva

$\mu_{\varphi}$ : Ductilidad de curvatura

El $\left(k N \cdot m^{2}\right)$ : Rigidez efectiva de la sección 
Estudio experimental y numérico de la capacidad de deformación de soportes esbeltos de hormigón armado

\begin{tabular}{|c|c|c|c|c|c|c|c|c|}
\hline \multicolumn{9}{|c|}{ Idealización del diagrama $M-\varphi$ aplicando el método del Eurocódigo (versión 1B) } \\
\hline $\mathbf{N}^{\circ}$ & REFERENCIA & $\begin{array}{c}\varphi_{y_{-} \exp } \\
\left(\mathrm{mm}^{-1}\right)\end{array}$ & $\begin{array}{c}\text { My } \\
(\mathrm{m} \cdot \mathrm{kN})\end{array}$ & $\begin{array}{c}\varphi_{u_{-} \exp } \\
\left(\mathrm{mm}^{-1}\right)\end{array}$ & $\begin{array}{l}\text { Mmax } \\
(m . k N)\end{array}$ & $\begin{array}{c}\varphi_{y}^{\prime} \\
\left(\mathrm{mm}^{-1}\right)\end{array}$ & $\mu_{\varphi}$ & $\begin{array}{c}\text { El } \\
\left(k N \cdot m^{2}\right)\end{array}$ \\
\hline 1 & N30-10.5-C0-2-00 & 35,45 & 11,33 & 142,95 & 12,33 & 38,28 & 3,73 & 320 \\
\hline 2 & N30-10.5-C0-2-15 & 24,52 & 12,49 & 135,93 & 17,56 & 33,14 & 4,10 & 509 \\
\hline 3 & N30-10.5-C0-2-30 & 16,60 & 11,83 & 106,47 & 21,75 & 30,28 & 3,52 & $\overline{712}$ \\
\hline 4 & N30-10.5-C0-2-45 & 11,72 & 13,39 & 48,89 & 21,61 & 16,75 & 2,92 & 1142 \\
\hline 5 & N30-7.5-C0-2-30 & 10,71 & 25,05 & 81,90 & 49,34 & 19,65 & 4,17 & 2338 \\
\hline 6 & N30-7.5-C0-2-45 & 7,74 & 23,84 & 75,85 & 45,40 & 14,15 & 5,36 & 3079 \\
\hline 9 & N30-10.5-C0-1-30 & 17,32 & 10,91 & 151,48 & 18,29 & 27,70 & 5,47 & 630 \\
\hline 10 & N30-10.5-C0-1-45 & 6,29 & 8,62 & 23,65 & 16,63 & 11,40 & 2,08 & 1370 \\
\hline 11 & N30-10.5-C0-3-15 & 25,42 & 13,48 & 133,64 & 22,35 & 40,91 & 3,27 & 530 \\
\hline 12 & N30-10.5-C0-3-30 & 13,50 & 11,50 & 82,96 & 22,93 & 25,52 & 3,25 & 852 \\
\hline 13 & $\mathrm{H} 60-10.5-\mathrm{C} 0-2-00$ & 34,36 & 11,72 & 129,05 & 12,45 & 36,82 & 3,51 & 341 \\
\hline 14 & $\mathrm{H} 60-10.5-\mathrm{C} 0-2-15$ & 27,81 & 15,09 & 110,84 & 24,54 & 42,45 & 2,61 & 543 \\
\hline 15 & $\mathrm{H} 60-10.5-\mathrm{C} 0-2-30$ & 16,17 & 16,21 & 51,58 & 27,17 & 23,32 & 2,21 & 1002 \\
\hline 16 & H60-10.5-C0-2-45 & 9,62 & 16,44 & 47,56 & 35,69 & 18,20 & 2,61 & 1709 \\
\hline 17 & $\mathrm{H} 60-7.5-\mathrm{C} 0-2-30$ & 13,26 & 39,01 & 64,82 & 64,13 & 20,18 & 3,21 & 2943 \\
\hline 18 & H60-7.5-C0-2-45 & 9,17 & 38,31 & 57,95 & 73,23 & $\begin{array}{ll}16,63 \\
\end{array}$ & 3,49 & 4179 \\
\hline 21 & H60-10.5-C0-1-15 & 29,99 & 14,86 & 114,24 & 20,21 & 38,58 & 2,96 & 495 \\
\hline 22 & $\mathrm{H} 60-10.5-\mathrm{C} 0-1-30$ & 15,03 & 16,93 & 86,81 & 27,34 & 22,51 & 3,86 & 1126 \\
\hline 23 & H60-10.5-C0-3-15 & 25,68 & 17,15 & 65,06 & 29,02 & 38,95 & 1,67 & 668 \\
\hline 24 & H60-10.5-C0-3-30 & 15,96 & 18,17 & 94,19 & 34,74 & 27,72 & 3,40 & 1139 \\
\hline 25 & $\mathrm{H} 90-10.5-\mathrm{C} 0-2-00$ & 32,58 & 10,33 & 124,76 & 14,52 & 44,84 & 2,78 & 317 \\
\hline 26 & H90-10.5-C0-2-15 & 25,65 & 19,03 & 116,87 & 28,73 & 37,06 & 3,15 & 742 \\
\hline 27 & H90-10.5-C0-2-30 & 20,78 & 25,74 & 54,99 & 36,93 & 27,31 & 2,01 & 1239 \\
\hline 28 & H90-10.5-C0-2-45 & 11,32 & 22,26 & 39,31 & 38,90 & 16,65 & 2,36 & 1968 \\
\hline 29 & $\mathrm{H} 90-7.5-\mathrm{C} 0-2-30$ & 11,79 & 45,74 & 54,07 & 80,49 & 19,19 & 2,82 & 3879 \\
\hline 30 & H90-7.5-C0-2-45 & 8,72 & 42,55 & 55,55 & 79,66 & 15,36 & \begin{tabular}{l|l}
3,62 \\
\end{tabular} & 4880 \\
\hline 31 & H90-10.5-C0-1-15 & 24,17 & 17,11 & 117,41 & 24,83 & 32,14 & 3,65 & 708 \\
\hline 32 & H90-10.5-C0-1-30 & 16,81 & 25,61 & 74,08 & 36,77 & 22,32 & 3,32 & 1524 \\
\hline 33 & H90-10.5-C0-3-15 & 32,15 & 26,96 & 80,97 & 36,66 & 42,41 & 1,91 & 839 \\
\hline 34 & H90-10.5-C0-3-30 & 18,74 & 26,42 & 53,72 & 41,17 & 26,21 & 2,05 & 1410 \\
\hline 35 & N30-10.5-C3-2-30 & 18,90 & 12,53 & 120,20 & 21,37 & 30,14 & 3,99 & 663 \\
\hline 36 & N30-10.5-C3-2-45 & 11,51 & 11,73 & 79,23 & 22,03 & 19,87 & 3,99 & 1020 \\
\hline 37 & N30-7.5-C3-2-30 & 10,20 & 21,61 & 109,64 & 46,45 & 19,99 & 5,48 & 2119 \\
\hline 38 & N30-7.5-C3-2-45 & 7,28 & 21,28 & 78,23 & 44,20 & 14,65 & 5,34 & 2921 \\
\hline 39 & H90-10.5-C3-2-30 & 18,96 & 26,75 & 49,24 & 39,76 & 25,28 & 1,95 & 1411 \\
\hline 40 & H90-10.5-C3-2-45 & 8,83 & 17,11 & 45,08 & 36,14 & 16,12 & 2,80 & 1938 \\
\hline 41 & H90-7.5-C3-2-30 & 11,45 & 46,21 & 41,41 & 77,63 & 17,35 & 2,39 & 4036 \\
\hline 42 & H90-7.5-C3-2-45 & 4,94 & 24,97 & 49,79 & 66,99 & 12,67 & 3,93 & 5050 \\
\hline 43 & $\mathrm{H} 90-7.5-\mathrm{C} 2-2-30$ & 11,88 & 43,86 & 53,79 & 75,29 & 19,30 & 2,79 & 3691 \\
\hline 44 & H90-7.5-C2-2-45 & 6,62 & 30,49 & 48,21 & 70,02 & 13,93 & 3,46 & 4607 \\
\hline
\end{tabular}

$\varphi_{\text {y_exp }}\left(\mathrm{mm}^{-1}\right)$ : Curvatura elástica experimental

My (m.kN): Momento elástico experimental

$\varphi_{\mathrm{u} \_ \text {exp }}\left(\mathrm{mm}^{-1}\right)$ : Curvatura última Experimental

Mmax (m.kN): Momento máximo experimental

$\varphi_{y}^{\prime}\left(\mathrm{mm}^{-1}\right)$ : Curvatura elástica efectiva

$\mu_{\varphi}$ : Ductilidad de curvatura

El $\left(k N \cdot m^{2}\right)$ : Rigidez efectiva de la sección 


\begin{tabular}{|c|c|c|c|c|c|c|c|}
\hline \multicolumn{8}{|c|}{ Idealización del diagrama M- $\varphi$ aplicando el método Balance de Energía (2) } \\
\hline $\mathbf{N}^{\circ}$ & REFERENCIA & $\begin{array}{c}\varphi_{u_{-} \exp } \\
\left(\mathrm{mm}^{-1}\right)\end{array}$ & $\begin{array}{c}\varphi_{\max } \\
\left(\mathbf{m m}^{-1}\right)\end{array}$ & $\begin{array}{c}\text { Mmax } \\
(\mathrm{m} . \mathrm{kN})\end{array}$ & $\begin{array}{c}\varphi_{y}^{\prime} \\
\left(\mathrm{mm}^{-1}\right)\end{array}$ & $\mu_{\varphi}$ & $\begin{array}{c}\text { El } \\
\left(k N \cdot m^{2}\right)\end{array}$ \\
\hline 1 & N30-10.5-C0-2-00 & 35,45 & 142,95 & 12,33 & 38,28 & 3,73 & 332 \\
\hline 2 & N30-10.5-C0-2-15 & 24,52 & 135,93 & 17,56 & 33,14 & 4,10 & 463 \\
\hline 3 & N30-10.5-C0-2-30 & 16,60 & 106,47 & 21,75 & 30,28 & 3,52 & 536 \\
\hline 4 & N30-10.5-C0-2-45 & 11,72 & 48,89 & 21,61 & \begin{tabular}{|l|l|}
16,75 \\
\end{tabular} & 2,92 & 900 \\
\hline 5 & N30-7.5-C0-2-30 & 10,71 & 81,90 & 49,34 & 19,65 & 4,17 & 1739 \\
\hline 6 & N30-7.5-C0-2-45 & 7,74 & 75,85 & 45,40 & 14,15 & 5,36 & 2258 \\
\hline 9 & N30-10.5-C0-1-30 & 17,32 & 151,48 & 18,29 & 27,70 & 5,47 & 493 \\
\hline 10 & N30-10.5-C0-1-45 & 6,29 & 23,65 & 16,63 & 11,40 & 2,08 & 1118 \\
\hline 11 & N30-10.5-C0-3-15 & 25,42 & 133,64 & 22,35 & 40,91 & 3,27 & 507 \\
\hline 12 & N30-10.5-C0-3-30 & 13,50 & 82,96 & 22,93 & 25,52 & 3,25 & 622 \\
\hline 13 & $\mathrm{H} 60-10.5-\mathrm{C} 0-2-00$ & 34,36 & 129,05 & 12,45 & 36,82 & 3,51 & 343 \\
\hline 14 & H60-10.5-C0-2-15 & 27,81 & 110,84 & 24,54 & 42,45 & 2,61 & 512 \\
\hline 15 & $\mathrm{H} 60-10.5-\mathrm{C} 0-2-30$ & 16,17 & 51,58 & 27,17 & 23,32 & 2,21 & 832 \\
\hline 16 & $\mathrm{H} 60-10.5-\mathrm{C} 0-2-45$ & 9,62 & 47,56 & 35,69 & 18,20 & 2,61 & 1293 \\
\hline 17 & $\mathrm{H} 60-7.5-\mathrm{C} 0-2-30$ & 13,26 & 64,82 & 64,13 & 20,18 & 3,21 & 2337 \\
\hline 18 & H60-7.5-C0-2-45 & 9,17 & 57,95 & 73,23 & 16,63 & 3,49 & 3303 \\
\hline 21 & H60-10.5-C0-1-15 & 29,99 & 114,24 & 20,21 & 38,58 & 2,96 & 501 \\
\hline 22 & H60-10.5-C0-1-30 & 15,03 & 86,81 & 27,34 & 22,51 & 3,86 & 863 \\
\hline 23 & H60-10.5-C0-3-15 & 25,68 & 65,06 & 29,02 & 38,95 & 1,67 & 650 \\
\hline 24 & $\mathrm{H} 60-10.5-\mathrm{C} 0-3-30$ & 15,96 & 94,19 & 34,74 & 27,72 & 3,40 & 824 \\
\hline 25 & $\mathrm{H} 90-10.5-\mathrm{C} 0-2-00$ & 32,58 & 124,76 & 14,52 & 44,84 & 2,78 & 312 \\
\hline 26 & H90-10.5-C0-2-15 & 25,65 & 116,87 & 28,73 & 37,06 & 3,15 & 712 \\
\hline 27 & H90-10.5-C0-2-30 & 20,78 & 54,99 & 36,93 & 27,31 & 2,01 & 1232 \\
\hline 28 & H90-10.5-C0-2-45 & 11,32 & 39,31 & 38,90 & 16,65 & 2,36 & 1553 \\
\hline 29 & H90-7.5-C0-2-30 & 11,79 & 54,07 & 80,49 & 19,19 & 2,82 & 3174 \\
\hline 30 & H90-7.5-C0-2-45 & 8,72 & 55,55 & 79,66 & 15,36 & 3,62 & 3878 \\
\hline 31 & $\mathrm{H} 90-10.5-\mathrm{C} 0-1-15$ & 24,17 & 117,41 & 24,83 & 32,14 & 3,65 & 683 \\
\hline 32 & $\mathrm{H} 90-10.5-\mathrm{C} 0-1-30$ & 16,81 & 74,08 & 36,77 & 22,32 & 3,32 & 1271 \\
\hline 33 & H90-10.5-C0-3-15 & 32,15 & 80,97 & 36,66 & 42,41 & 1,91 & 932 \\
\hline 34 & H90-10.5-C0-3-30 & 18,74 & 53,72 & 41,17 & 26,21 & 2,05 & 1301 \\
\hline 35 & N30-10.5-C3-2-30 & 18,90 & 120,20 & 21,37 & 30,14 & 3,99 & 524 \\
\hline 36 & N30-10.5-C3-2-45 & 11,51 & 79,23 & 22,03 & 19,87 & 3,99 & 735 \\
\hline 37 & N30-7.5-C3-2-30 & 10,20 & 109,64 & 46,45 & 19,99 & 5,48 & 1272 \\
\hline 38 & N30-7.5-C3-2-45 & 7,28 & 78,23 & 44,20 & 14,65 & 5,34 & 2350 \\
\hline 39 & H90-10.5-C3-2-30 & 18,96 & 49,24 & 39,76 & 25,28 & 1,95 & 1340 \\
\hline 40 & H90-10.5-C3-2-45 & 8,83 & 45,08 & 36,14 & 16,12 & 2,80 & 1425 \\
\hline 41 & H90-7.5-C3-2-30 & 11,45 & 41,41 & 77,63 & 17,35 & 2,39 & 3320 \\
\hline 42 & H90-7.5-C3-2-45 & 4,94 & 49,79 & 66,99 & 12,67 & 3,93 & 3265 \\
\hline 43 & H90-7.5-C2-2-30 & 11,88 & 53,79 & 75,29 & 19,30 & 2,79 & 3088 \\
\hline 44 & H90-7.5-C2-2-45 & 6,62 & 48,21 & 70,02 & 13,93 & 3,46 & 3366 \\
\hline
\end{tabular}

$\varphi_{y_{-} \text {exp }}\left(\mathrm{mm}^{-1}\right)$ : Curvatura elástica experimental

My (m.kN): Momento elástico experimental

$\varphi_{\text {u_exp }}\left(\mathrm{mm}^{-1}\right)$ : Curvatura última Experimental

$\operatorname{Mmax}(\mathrm{m} . \mathrm{kN})$ : Momento máximo experimental

$\varphi_{y}^{\prime}\left(\mathrm{mm}^{-1}\right)$ : Curvatura elástica efectiva

$\mu_{\varphi}$ : Ductilidad de curvatura

El $\left(k N \cdot m^{2}\right)$ : Rigidez efectiva de la sección 
Estudio experimental y numérico de la capacidad de deformación de soportes esbeltos de hormigón armado

\begin{tabular}{|c|c|c|c|c|c|c|c|c|}
\hline \multicolumn{9}{|c|}{ Idealización del diagrama M- $\varphi$ aplicando el método Aproximado (3) } \\
\hline $\mathbf{N}^{\circ}$ & REFERENCIA & $\begin{array}{c}\varphi_{y_{-} \exp } \\
\left(\mathrm{mm}^{-1}\right)\end{array}$ & $\begin{array}{c}\text { My } \\
(\mathrm{m} \cdot \mathrm{kN})\end{array}$ & $\begin{array}{c}\text { Mmax } \\
(m . k N)\end{array}$ & $\begin{array}{c}\varphi_{y}^{\prime} \\
\left(\mathrm{mm}^{-1}\right)\end{array}$ & $\begin{array}{l}\varphi_{u_{-} \exp } \\
\left(\mathrm{mm}^{-1}\right)\end{array}$ & $\mu_{\varphi}$ & $\begin{array}{c}\text { El } \\
\left(k N \cdot m^{2}\right)\end{array}$ \\
\hline 1 & N30-10.5-C0-2-00 & 26,64 & 9,32 & 12,36 & 35,34 & 142,95 & 4,05 & 350 \\
\hline 2 & N30-10.5-C0-2-15 & 26,95 & 13,18 & 17,56 & 35,92 & 135,93 & 3,78 & 489 \\
\hline 3 & N30-10.5-C0-2-30 & 34,68 & 16,66 & 22,12 & 46,04 & 106,47 & 2,31 & 480 \\
\hline 4 & N30-10.5-C0-2-45 & 18,98 & 16,74 & 21,61 & 24,50 & 48,89 & 2,00 & 882 \\
\hline 5 & N30-7.5-C0-2-30 & 22,85 & 37,06 & 49,34 & 30,42 & 81,90 & 2,69 & 1622 \\
\hline 6 & N30-7.5-C0-2-45 & 14,16 & 34,50 & 45,89 & 18,83 & 75,85 & 4,03 & 2437 \\
\hline 9 & N30-10.5-C0-1-30 & 30,50 & 13,77 & 18,35 & 40,64 & \begin{tabular}{|l|}
151,48 \\
\end{tabular} & 3,73 & 452 \\
\hline 10 & N30-10.5-C0-1-45 & 12,43 & 13,55 & 17,99 & 16,51 & 23,65 & 1,43 & 1090 \\
\hline 11 & N30-10.5-C0-3-15 & 36,86 & 17,08 & 22,75 & 49,11 & 133,64 & 2,72 & 463 \\
\hline 12 & N30-10.5-C0-3-30 & 31,66 & 18,40 & 24,50 & 42,15 & 82,96 & 1,97 & 581 \\
\hline 13 & H60-10.5-C0-2-00 & 26,33 & 9,41 & 12,45 & 34,84 & 129,05 & 3,70 & 357 \\
\hline 14 & H60-10.5-C0-2-15 & 39,51 & 18,53 & 24,54 & 52,35 & 110,84 & 2,12 & 469 \\
\hline 15 & $\mathrm{H} 60-10.5-\mathrm{C} 0-2-30$ & 27,89 & 21,13 & 28,05 & 37,02 & 51,58 & 1,39 & 758 \\
\hline 16 & $\mathrm{H} 60-10.5-\mathrm{C} 0-2-45$ & 20,57 & 26,91 & 35,72 & 27,30 & 47,56 & 1,74 & 1308 \\
\hline 17 & $\mathrm{H} 60-7.5-\mathrm{C} 0-2-30$ & 21,39 & 48,70 & 64,93 & 28,52 & 64,82 & 2,27 & 2276 \\
\hline 18 & H60-7.5-C0-2-45 & 16,49 & 55,80 & 74,35 & 21,98 & 57,95 & 2,64 & 3383 \\
\hline 21 & H60-10.5-C0-1-15 & 32,48 & 15,31 & 20,30 & 43,09 & 114,24 & 2,65 & 471 \\
\hline 22 & $\mathrm{H} 60-10.5-\mathrm{C} 0-1-30$ & 24,05 & 20,51 & 27,34 & 32,05 & 86,81 & 2,71 & 853 \\
\hline 23 & H60-10.5-C0-3-15 & 36,53 & 21,78 & 29,02 & 48,69 & 65,06 & 1,34 & 596 \\
\hline 24 & $\mathrm{H} 60-10.5-\mathrm{C} 0-3-30$ & 30,63 & 26,41 & 35,19 & 40,81 & 94,19 & 2,31 & 862 \\
\hline 25 & $\mathrm{H} 90-10.5-\mathrm{C} 0-2-00$ & 33,24 & 10,53 & 14,49 & 45,75 & 124,76 & 2,73 & 317 \\
\hline 26 & H90-10.5-C0-2-15 & 32,49 & 21,57 & 28,73 & 43,27 & 116,87 & 2,70 & 664 \\
\hline 27 & H90-10.5-C0-2-30 & 23,90 & 27,57 & 36,93 & 32,02 & 54,99 & 1,72 & 1153 \\
\hline 28 & H90-10.5-C0-2-45 & 17,55 & 29,35 & 39,00 & 23,32 & 39,31 & 1,69 & 1672 \\
\hline 29 & H90-7.5-C0-2-30 & 17,62 & 60,58 & 80,76 & 23,48 & 54,07 & 2,30 & 3439 \\
\hline 30 & H90-7.5-C0-2-45 & 13,95 & 59,89 & 79,73 & 18,57 & 55,55 & 2,99 & 4294 \\
\hline 31 & H90-10.5-C0-1-15 & 29,28 & 18,61 & 24,81 & 39,03 & 117,41 & 3,01 & 636 \\
\hline 32 & H90-10.5-C0-1-30 & 21,18 & 27,60 & 36,77 & 28,22 & 74,08 & 2,63 & 1303 \\
\hline 33 & $\mathrm{H} 90-10.5-\mathrm{C} 0-3-15$ & 33,24 & 27,53 & 36,66 & 44,25 & 80,97 & 1,83 & 828 \\
\hline 34 & $\mathrm{H} 90-10.5-\mathrm{C} 0-3-30$ & 25,64 & 30,88 & 41,17 & 34,18 & 53,72 & 1,57 & 1204 \\
\hline 35 & N30-10.5-C3-2-30 & 31,41 & 15,71 & 21,46 & 42,91 & 120,20 & 2,80 & 500 \\
\hline 36 & N30-10.5-C3-2-45 & 23,28 & 16,62 & 22,05 & 30,88 & 79,23 & 2,57 & 714 \\
\hline 37 & N30-7.5-C3-2-30 & 26,21 & 34,85 & 46,45 & 34,94 & 109,64 & 3,14 & 1329 \\
\hline 38 & N30-7.5-C3-2-45 & 17,03 & 34,27 & 45,67 & 22,70 & 78,23 & 3,45 & 2012 \\
\hline 39 & H90-10.5-C3-2-30 & 24,01 & 29,98 & 39,92 & 31,96 & 49,24 & 1,54 & 1249 \\
\hline 40 & H90-10.5-C3-2-45 & 19,49 & 27,42 & 36,14 & 25,69 & 45,08 & 1,75 & 1407 \\
\hline 41 & H90-7.5-C3-2-30 & 18,23 & 58,91 & 78,52 & 24,29 & 41,41 & 1,70 & 3232 \\
\hline 42 & H90-7.5-C3-2-45 & 16,33 & 54,27 & 72,35 & 21,78 & 49,79 & 2,29 & 3323 \\
\hline 43 & H90-7.5-C2-2-30 & 19,94 & 58,27 & 77,63 & 26,56 & 53,79 & 2,02 & 2923 \\
\hline 44 & H90-7.5-C2-2-45 & 14,16 & 52,89 & 70,42 & 18,86 & 48,21 & 2,56 & 3734 \\
\hline
\end{tabular}

$\varphi_{y \_ \text {exp }}\left(\mathrm{mm}^{-1}\right)$ : Curvatura elástica experimental

My (m.kN): Momento elástico experimental

$\varphi_{\text {u_exp }}\left(\mathrm{mm}^{-1}\right)$ : Curvatura última Experimental

$\operatorname{Mmax}(\mathrm{m} . \mathrm{kN})$ : Momento máximo experimental

$\varphi_{y}^{\prime}\left(\mathrm{mm}^{-1}\right)$ : Curvatura elástica efectiva

$\mu_{\varphi}$ : Ductilidad de curvatura

El $\left(k N . m^{2}\right)$ : Rigidez efectiva de la sección 
Idealización del diagrama P-ס aplicando el método del Eurocódigo (versión 1A)

\begin{tabular}{|c|c|c|c|c|c|c|c|c|}
\hline $\mathbf{N}^{\circ}$ & NCIA & $\begin{array}{l}\delta_{y_{-} \exp } \\
(\mathrm{mm})\end{array}$ & $P_{y}(k N)$ & $\begin{array}{l}\delta_{\mathrm{u}_{-} \exp } \\
(\mathrm{mm})\end{array}$ & $\begin{array}{l}P_{\max } \\
(\mathrm{kN})\end{array}$ & $\begin{array}{c}\delta_{y}^{\prime} \\
(\mathrm{mm})\end{array}$ & $\mu_{\delta}$ & $\begin{array}{c}\mathrm{El}_{\mathrm{e}} \\
\left(\mathrm{kN} \cdot \mathrm{m}^{2}\right)\end{array}$ \\
\hline 1 & N30-10.5-C0-2-00 & 29,53 & 15,62 & 74,53 & 17,07 & 31,55 & 2,36 & 298 \\
\hline 2 & 330-10.5-C0-2-15 & 22,94 & 15,86 & 445,63 & 15,92 & 25,27 & 1,81 & 389 \\
\hline 3 & N30-10.5-C0-2-30 & 12,34 & 13,09 & 44,11 & 15,46 & 14,43 & 3,06 & 597 \\
\hline 4 & N30-10.5-C0-2-45 & 12,77 & 15,47 & 29,05 & 14,48 & 12,73 & 2,28 & 682 \\
\hline 5 & N30-7.5-C0-2-30 & 10,22 & 36,26 & 33,30 & 51,94 & 14,09 & 2,36 & 1995 \\
\hline 6 & N30-7.5-C0-2-45 & 8,63 & 32,58 & 22,84 & 45,93 & 11,42 & 2,00 & 2124 \\
\hline 9 & N30-10.5-C0-1-30 & 10,95 & 13,46 & 34,10 & 13,62 & 12,07 & 2,83 & 691 \\
\hline 10 & $-\mathrm{C} 0-1-45$ & 7,87 & 12,06 & 16,96 & 13,69 & 9,01 & 88 & 862 \\
\hline 11 & $\mathrm{~N} 30-1$ & 27,47 & 16,89 & 67,50 & 18,35 & 31,96 & 2,11 & 346 \\
\hline 12 & $\mathrm{~N} 30-1$ & 14,28 & 3,01 & 45,21 & 15,32 & 17,15 & 2,64 & 512 \\
\hline 13 & $\mathrm{H} 60-1$ & 30,15 & 5,63 & 72,82 & 16,78 & 33,33 & 2,18 & 292 \\
\hline 14 & H60-10.5-C0-2-15 & 21,49 & 17,87 & $\begin{array}{ll}46,63 \\
\end{array}$ & 20,63 & 25,46 & 1,83 & $\overline{46}$ \\
\hline 15 & $\mathrm{H} 60-10.5-\mathrm{C} 0-2-30$ & 16,33 & 16,91 & 34,95 & 16,56 & 17,15 & 2,04 & $\overline{582}$ \\
\hline 16 & H60-10.5-C0-2-45 & 14,20 & 18,42 & 33,60 & 17,94 & 15,18 & 2,21 & $\overline{729}$ \\
\hline 17 & H60-7.5-C0-2-30 & 12,80 & 50,61 & 27,92 & 64,00 & 15,20 & 1,84 & 2224 \\
\hline 18 & $\mathrm{H} 60-7.5-\mathrm{C} 0-2-45$ & 10,80 & 53,65 & 22,59 & 73,12 & 13,77 & 1,64 & 2793 \\
\hline 21 & $\mathrm{H} 60-10.5-\mathrm{C} 0-1-15$ & 21,46 & 16,30 & 40,49 & 15,07 & 21,46 & 1,89 & 427 \\
\hline 22 & $\mathrm{H} 60-10.5-\mathrm{C} 0-1-30$ & 18,44 & 16,45 & 41,62 & 13,96 & 18,25 & 2,28 & 502 \\
\hline 23 & $\mathrm{H} 60-1$ & 25,24 & 19,34 & 55,40 & 24,09 & 29,43 & 1,88 & 431 \\
\hline 24 & $\mathrm{H} 60-$ & 19,45 & 17,24 & 49,90 & 15,48 & 19,66 & 2,54 & 499 \\
\hline 25 & $\mathrm{H} 90$ & 27,84 & 14,25 & 67,06 & 18,60 & 37,26 & 1,80 & 288 \\
\hline 26 & $\mathrm{H} 90-$ & 23,22 & 62 & 43,28 & 20,88 & 24,41 & 1,77 & 495 \\
\hline 27 & H90- & 22,85 & 21,86 & 35,74 & 19,61 & 22,06 & 1,62 & $\overline{538}$ \\
\hline 28 & H90- & 15,10 & 19,74 & 27,44 & 17,01 & 14,78 & 1,86 & 735 \\
\hline 29 & H90-7. & 13,42 & 1,91 & 25,85 & 78,39 & 15,95 & 1,62 & 2595 \\
\hline 30 & $\mathrm{H} 90-7 . t$ & 11,11 & 57,35 & $\overline{19,81}$ & 73,92 & 13,49 & 1,47 & 2905 \\
\hline 31 & $\mathrm{H} 90-10.5-\mathrm{C} 0-1-15$ & 23,89 & 16,35 & 48,08 & 13,62 & 22,82 & 2,11 & 385 \\
\hline 32 & $\mathrm{H} 90-10.5-\mathrm{C} 0-1-30$ & 17,99 & 24,06 & 34,30 & 21,01 & 17,49 & 1,96 & 752 \\
\hline 33 & $\mathrm{H} 90-10.5-\mathrm{C} 0-3-15$ & 36,24 & 26,15 & 49,57 & 27,36 & 37,52 & 1,32 & 372 \\
\hline 34 & $\mathrm{H} 90-10.5-\mathrm{C} 0-3-30$ & 19,83 & 24,41 & 35,67 & 23,40 & 20,00 & 1,78 & 693 \\
\hline 35 & N30-10.5-C3-2-30 & 17,47 & 12,90 & 46,86 & 12,79 & 18,55 & 2,53 & 415 \\
\hline 36 & N30-10.5-C3-2-45 & 12,61 & 12,18 & 34,75 & 11,83 & 13,29 & 2,61 & 543 \\
\hline 37 & N30-7 & 9,60 & 29,80 & 39,49 & 40,74 & 13,77 & 2,87 & $\overline{1746}$ \\
\hline 38 & N30- & 8,49 & 29,93 & 25,15 & 42,03 & 11,58 & 2,17 & $\overline{1982}$ \\
\hline 39 & $\mathrm{H} 90$ & 22,83 & & 38,23 & 21,31 & 22,69 & 1,68 & 586 \\
\hline 40 & $\mathrm{H} 90-$ & 11,70 & 15,51 & 27,83 & 12,98 & 11,81 & 2,36 & 745 \\
\hline 41 & H90- & 13,95 & 0,27 & 26,38 & 75,25 & 16,22 & 1,63 & 2430 \\
\hline 42 & $\mathrm{H} 90-7$ & 7,24 &, 11 & 21,39 & 52,53 & 11,78 & 1,82 & 2884 \\
\hline 43 & H90- & 13,97 & 11 & 28,77 & 70,59 & 16,51 & 1,74 & 2300 \\
\hline 44 & H90-7.5-C2-2-45 & 8,86 & 43,15 & 19,57 & 59,93 & 11,44 & 1,71 & 2740 \\
\hline
\end{tabular}

$\delta_{y_{-} \exp }(\mathrm{mm})$ : Desplazamiento elástico experimental

$P_{\mathrm{y}}(\mathrm{kN})$ : Carga elástica experimental

$\delta_{u_{\text {_exp }}}(\mathrm{mm})$ : Desplazamiento último Experimental

$P_{\max }(\mathrm{kN})$ : Carga máxima experimental

$\delta_{y}^{\prime}\left(m^{-1}\right)$ :Desplazamiento elástico efectivo

$\mu_{\delta}$ : Ductilidad de Desplazamiento

$\mathrm{El}_{\mathrm{e}}\left(\mathrm{kN} \cdot \mathrm{m}^{2}\right)$ : Rigidez efectiva del elemento 
Estudio experimental y numérico de la capacidad de deformación de soportes esbeltos de hormigón armado

\begin{tabular}{|c|c|c|c|c|c|c|c|c|}
\hline \multicolumn{9}{|c|}{ Idealización del diagrama P-ס aplicando el método del Eurocódigo (versión 1B) } \\
\hline $\mathbf{N}^{\circ}$ & REFERENCIA & $\begin{array}{l}\delta_{y_{-} \exp } \\
(\mathrm{mm})\end{array}$ & $P_{y}(k N)$ & $\begin{array}{l}\delta_{u_{\text {}} \exp } \\
(\mathrm{mm})\end{array}$ & $\begin{array}{l}P_{\max } \\
\text { (kN) }\end{array}$ & $\begin{array}{c}\delta_{y}^{\prime} \\
(\mathrm{mm})\end{array}$ & $\mu_{\delta}$ & $\begin{array}{c}\mathrm{El}_{\mathrm{e}} \\
\left(\mathrm{kN} \cdot \mathrm{m}^{2}\right)\end{array}$ \\
\hline 1 & N30-10.5-C0-2-00 & 29,53 & $\begin{array}{ll}15,62 \\
\end{array}$ & 74,53 & \begin{tabular}{|l|}
17,07 \\
\end{tabular} & 31,55 & 2,36 & 298 \\
\hline 2 & N30-10.5-C0-2-15 & 18,81 & 14,37 & 45,63 & 15,92 & 22,61 & 2,02 & 430 \\
\hline 3 & $\mathrm{N30-10.5- \textrm {C } 0 - 2 - 3 0}$ & 11,15 & 12,49 & 44,11 & \begin{tabular}{l|}
15,46 \\
\end{tabular} & 13,73 & 3,21 & 630 \\
\hline 4 & N30-10.5-C0-2-45 & 9,96 & 14,60 & 29,05 & 14,48 & 10,96 & 2,65 & 825 \\
\hline 5 & N30-7.5-C0-2-30 & 7,92 & 31,93 & 33,30 & 51,94 & 12,13 & 2,75 & 2269 \\
\hline 6 & N30-7.5-C0-2-45 & 6,26 & 27,05 & 22,84 & 45,93 & 9,70 & 2,36 & 2431 \\
\hline 9 & N30-10.5-C0-1-30 & 9,26 & 12,86 & 34,10 & 13,62 & 10,68 & 3,19 & 841 \\
\hline 10 & N30-10.5-C0-1-45 & 4,31 & 9,26 & 16,96 & 13,69 & 6,16 & 2,75 & 1208 \\
\hline 11 & N30-10.5-C0-3-15 & 19,54 & 14,32 & 67,50 & 18,35 & 26,38 & 2,56 & 390 \\
\hline 12 & N30-10.5-C0-3-30 & 11,04 & 11,57 & 45,21 & 15,32 & 14,71 & 3,07 & 590 \\
\hline 13 & H60-10.5-C0-2-00 & 30,15 & 15,63 & 72,82 & 16,78 & 33,33 & 2,18 & 292 \\
\hline 14 & $\mathrm{H} 60-10.5-\mathrm{C} 0-2-15$ & 15,96 & 16,17 & 46,63 & 20,63 & 20,28 & 2,30 & 570 \\
\hline 15 & H60-10.5-C0-2-30 & 12,10 & \begin{tabular}{ll|}
15,16 \\
\end{tabular} & 34,95 & 16,56 & 14,04 & 2,49 & 705 \\
\hline 16 & $\mathrm{H} 60-10.5-\mathrm{C} 0-2-45$ & 10,21 & 15,98 & 32,60 & 17,94 & 13,13 & 2,48 & 881 \\
\hline 17 & $\mathrm{H} 60-7.5-\mathrm{C} 0-2-30$ & 10,16 & 44,89 & 27,92 & 64,00 & 13,35 & 2,09 & 2484 \\
\hline 18 & $\mathrm{H} 60-7.5-\mathrm{C} 0-2-45$ & 7,68 & 42,80 & 22,59 & 73,12 & 11,84 & 1,91 & 3135 \\
\hline 21 & $\mathrm{H} 60-10.5-\mathrm{C} 0-1-15$ & 16,42 & 15,44 & 40,49 & 15,07 & 17,27 & 2,34 & 529 \\
\hline 22 & $\mathrm{H} 60-10.5-\mathrm{C} 0-1-30$ & 14,33 & 15,74 & 41,62 & 13,96 & 14,82 & 2,81 & 638 \\
\hline 23 & H60-10.5-C0-3-15 & 19,14 & \begin{tabular}{ll|}
17,34 \\
\end{tabular} & 55,40 & 24,09 & 24,34 & 2,28 & 510 \\
\hline 24 & $\mathrm{H} 60-10.5-\mathrm{C} 0-3-30$ & 14,44 & 15,70 & 49,90 & 15,48 & 15,95 & 3,13 & 612 \\
\hline 25 & H90-10.5-C0-2-00 & 27,84 & 14,25 & 67,06 & 18,60 & 37,26 & 1,80 & 288 \\
\hline 26 & H90-10.5-C0-2-15 & 17,10 & $\mid 19,17$ & 43,28 & 20,88 & 19,03 & 2,27 & 630 \\
\hline 27 & $\mathrm{H} 90-10.5-\mathrm{C} 0-2-30$ & 15,00 & 20,24 & 35,74 & 19,61 & 15,80 & 2,26 & 759 \\
\hline 28 & H90-10.5-C0-2-45 & 12,42 & $\begin{array}{ll}18,62 \\
\end{array}$ & 27,44 & 17,01 & 12,94 & 2,12 & 843 \\
\hline 29 & H90-7.5-C0-2-30 & 9,76 & 50,81 & 25,85 & 78,39 & 13,72 & 1,88 & 2927 \\
\hline 30 & H90-7.5-C0-2-45 & 7,71 & 44,70 & 19,81 & 73,92 & 11,54 & 1,72 & 3261 \\
\hline 31 & H90-10.5-C0-1-15 & 18,15 & 15,75 & 48,08 & $\begin{array}{ll}13,62 \\
\end{array}$ & 18,18 & 2,64 & 488 \\
\hline 32 & $\mathrm{H} 90-10.5-\mathrm{C} 0-1-30$ & 13,91 & 23,33 & 34,30 & 21,01 & 13,92 & 2,46 & $\overline{944}$ \\
\hline 33 & H90-10.5-C0-3-15 & 23,24 & 23,49 & 49,57 & 27,36 & 25,85 & 1,92 & 508 \\
\hline 34 & $\mathrm{H} 90-10.5-\mathrm{C} 0-3-30$ & 14,69 & 22,66 & 35,67 & 23,40 & 15,87 & 2,25 & 868 \\
\hline 35 & N30-10.5-C3-2-30 & 14,05 & 12,32 & 46,86 & 12,79 & 15,54 & 3,02 & 493 \\
\hline 36 & N30-10.5-C3-2-45 & 9,67 & 11,03 & 34,75 & 11,83 & 11,19 & 3,11 & 642 \\
\hline 37 & N30-7.5-C3-2-30 & 7,43 & 26,09 & 39,49 & 40,74 & 11,95 & 3,30 & 1976 \\
\hline 38 & N30-7.5-C3-2-45 & 6,04 & 24,80 & 25,15 & 42,03 & 9,73 & 2,58 & 2311 \\
\hline 39 & H90-10.5-C3-2-30 & 16,61 & 22,32 & 38,23 & 21,31 & 17,28 & 2,21 & 756 \\
\hline 40 & H90-10.5-C3-2-45 & 7,60 & 13,53 & 27,83 & 12,98 & 8,74 & 3,19 & 1002 \\
\hline 41 & H90-7.5-C3-2-30 & 10,33 & 50,79 & 26,38 & 75,25 & 13,87 & 1,90 & 2765 \\
\hline 42 & H90-7.5-C3-2-45 & 4,22 & 26,52 & 21,39 & 52,53 & 8,98 & 2,38 & 3538 \\
\hline 43 & H90-7.5-C2-2-30 & 10,26 & 47,87 & 28,77 & 70,59 & 14,14 & 2,03 & 2624 \\
\hline 44 & $\mathrm{H} 90-7.5-\mathrm{C} 2-2-45$ & 5,50 & 31,80 & 19,57 & 59,93 & 9,16 & 2,14 & 3252 \\
\hline
\end{tabular}

$\delta_{y_{-} \exp }(\mathrm{mm})$ : Desplazamiento elástico experimental

$P_{y}(k N)$ : Carga elástica experimental

$\delta_{\mathrm{u}_{\text {exp }}}(\mathrm{mm})$ : Desplazamiento último Experimental

$P_{\max }(\mathrm{kN})$ : Carga máxima experimental

$\delta_{y}^{\prime}\left(\mathrm{m}^{-1}\right)$ :Desplazamiento elástico efectivo

$\mu_{\delta}$ : Ductilidad de Desplazamiento

$\mathrm{El}_{\mathrm{e}}\left(\mathrm{kN} \cdot \mathrm{m}^{2}\right)$ : Rigidez efectiva del elemento 


\begin{tabular}{|c|c|c|c|c|c|c|c|}
\hline \multicolumn{8}{|c|}{ Idealización del diagrama P-ס aplicando el método Balance de Energía (2) } \\
\hline No & REFERENCIA & $\begin{array}{l}\delta_{\mathrm{u}_{-} \exp } \\
(\mathrm{mm})\end{array}$ & $\begin{array}{c}\delta_{\max } \\
(\mathrm{mm})\end{array}$ & $\begin{array}{l}P_{\max } \\
(\mathrm{kN})\end{array}$ & $\begin{array}{c}\delta^{\prime}{ }_{y} \\
(\mathrm{~mm})\end{array}$ & $\mu_{\delta}$ & $\begin{array}{c}\mathrm{El}_{\mathrm{e}} \\
\left(\mathrm{kN} \cdot \mathrm{m}^{2}\right)\end{array}$ \\
\hline 1 & N30-10.5-C0-2-00 & 74,53 & \begin{tabular}{ll|}
74,53 \\
\end{tabular} & \begin{tabular}{c|}
17,07 \\
\end{tabular} & 34,10 & 2,19 & 282 \\
\hline 2 & N30-10.5-C0-2-15 & 45,63 & 34,16 & 18,63 & 21,19 & 2,15 & 495 \\
\hline 3 & N30-10.5-C0-2-30 & 44,11 & 34,18 & $\begin{array}{ll}16,14 \\
\end{array}$ & 14,52 & 3,04 & 625 \\
\hline 4 & N30-10.5-C0-2-45 & 29,05 & 25,34 & 16,25 & 9,92 & 2,93 & 921 \\
\hline 5 & N30-7.5-C0-2-30 & 33,30 & 31,13 & 55,19 & 17,45 & 1,91 & 1779 \\
\hline 6 & N30-7.5-C0-2-45 & 22,84 & 21,71 & 47,40 & 13,09 & 1,74 & 2036 \\
\hline 9 & N30-10.5-C0-1-30 & 34,10 & 27,23 & 15,55 & 9,80 & 3,48 & 893 \\
\hline 10 & N30-10.5-C0-1-45 & 16,96 & 16,59 & 14,74 & 8,45 & 2,01 & 982 \\
\hline 11 & N30-10.5-C0-3-15 & 67,50 & 48,74 & 21,57 & 29,59 & 2,28 & 403 \\
\hline 12 & N30-10.5-C0-3-30 & 45,21 & 42,52 & 16,57 & 17,92 & 2,52 & 520 \\
\hline 13 & H60-10.5-C0-2-00 & 72,82 & 72,82 & $\begin{array}{ll}18,06 \\
\end{array}$ & 34,48 & 2,52 & 295 \\
\hline 14 & H60-10.5-C0-2-15 & 46,63 & 38,70 & $\begin{array}{l}21,39 \\
\end{array}$ & 20,02 & 2,33 & 601 \\
\hline 15 & H60-10.5-C0-2-30 & 34,95 & $\begin{array}{l}26,67 \\
\end{array}$ & \begin{tabular}{ll|}
18,43 \\
\end{tabular} & 12,88 & 2,71 & 805 \\
\hline 16 & $\mathrm{H} 60-10.5-\mathrm{C} 0-2-45$ & 33,60 & 20,89 & $\begin{array}{l}20,62 \\
\end{array}$ & 12,60 & 2,67 & 921 \\
\hline 17 & $\mathrm{H} 60-7.5-\mathrm{C} 0-2-30$ & 27,92 & 27,09 & 65,61 & 16,49 & 1,69 & 2238 \\
\hline 18 & H60-7.5-C0-2-45 & 22,59 & 21,72 & $\begin{array}{ll}73,82 \\
\end{array}$ & 14,71 & 1,54 & 2824 \\
\hline 21 & $\mathrm{H} 60-10.5-\mathrm{C} 0-1-15$ & 40,49 & 30,30 & 16,86 & 11,54 & 3,51 & 822 \\
\hline 22 & H60-10.5-C0-1-30 & 41,62 & 24,16 & 17,23 & 12,97 & 3,21 & 747 \\
\hline 23 & H60-10.5-C0-3-15 & 55,40 & 47,17 & 24,20 & 26,45 & 2,09 & 515 \\
\hline 24 & H60-10.5-C0-3-30 & 49,90 & 28,79 & 18,25 & 14,13 & 3,53 & 726 \\
\hline 25 & H90-10.5-C0-2-00 & 67,06 & 58,84 & 20,09 & 40,29 & 3,53 & 281 \\
\hline 26 & H90-10.5-C0-2-15 & 43,28 & 38,26 & 22,14 & 14,49 & 2,99 & 860 \\
\hline 27 & $\mathrm{H} 90-10.5-\mathrm{C} 0-2-30$ & 35,74 & 25,10 & 21,90 & 11,39 & 3,14 & 1081 \\
\hline 28 & H90-10.5-C0-2-45 & 27,44 & 17,08 & 20,24 & 10,09 & 2,72 & 1129 \\
\hline 29 & H90-7.5-C0-2-30 & 25,85 & 25,42 & 79,10 & 16,44 & 1,57 & 2706 \\
\hline 30 & H90-7.5-C0-2-45 & 19,81 & $\begin{array}{l}19,41 \\
\end{array}$ & 74,65 & 14,02 & 1,41 & 2995 \\
\hline 31 & H90-10.5-C0-1-15 & 48,08 & 26,97 & \begin{tabular}{ll|}
16,47 \\
\end{tabular} & 11,51 & 4,18 & 805 \\
\hline 32 & $\mathrm{H} 90-10.5-\mathrm{C} 0-1-30$ & 34,30 & 22,17 & 24,40 & 10,25 & 3,34 & 1338 \\
\hline 33 & H90-10.5-C0-3-15 & 49,57 & 48,03 & 27,61 & 21,42 & 2,31 & 725 \\
\hline 34 & $\mathrm{H} 90-10.5-\mathrm{C} 0-3-30$ & 35,67 & 26,78 & 25,26 & 12,00 & 2,97 & 1184 \\
\hline 35 & N30-10.5-C3-2-30 & 46,86 & 31,13 & \begin{tabular}{ll|}
13,91 \\
\end{tabular} & 12,68 & 3,70 & 617 \\
\hline 36 & N30-10.5-C3-2-45 & 34,75 & 26,53 & 13,34 & 10,31 & 3,37 & 728 \\
\hline 37 & N30-7.5-C3-2-30 & 39,49 & 31,88 & 47,93 & 18,35 & 2,15 & 1469 \\
\hline 38 & N30-7.5-C3-2-45 & 25,15 & 24,03 & 44,59 & 14,33 & 1,75 & 1750 \\
\hline 39 & H90-10.5-C3-2-30 & 38,23 & 26,09 & 23,90 & 12,02 & 3,18 & 1119 \\
\hline 40 & H90-10.5-C3-2-45 & 27,83 & 16,53 & 16,62 & 8,37 & 3,33 & 1117 \\
\hline 41 & H90-7.5-C3-2-30 & 26,38 & 26,21 & 75,47 & 16,49 & 1,60 & 2574 \\
\hline 42 & H90-7.5-C3-2-45 & 21,39 & 20,29 & 61,30 & 13,30 & 1,61 & 2592 \\
\hline 43 & $\mathrm{H} 90-7.5-\mathrm{C} 2-2-30$ & 28,77 & 27,83 & 72,72 & 17,04 & 1,69 & 2401 \\
\hline 44 & $\mathrm{H} 90-7.5-\mathrm{C} 2-2-45$ & 19,57 & 19,11 & 61,12 & 12,86 & 1,52 & 2674 \\
\hline \multicolumn{8}{|c|}{$\delta_{y_{-} \exp }(\mathrm{mm})$ : Desplazamiento elástico experimental } \\
\hline & \multicolumn{7}{|c|}{$P_{y}(k N)$ : Carga elástica experimental } \\
\hline & \multicolumn{7}{|c|}{$\delta_{\mathrm{u} \_ \text {exp }}(\mathrm{mm})$ : Desplazamiento último Experimental } \\
\hline & \multicolumn{7}{|c|}{$P_{\max }(k N)$ : Carga máxima experimental } \\
\hline & \multicolumn{7}{|c|}{$\delta_{y}^{\prime}\left(m^{-1}\right)$ :Desplazamiento elástico efectivo } \\
\hline & \multicolumn{7}{|c|}{$\mu_{\delta}:$ Ductilidad de Desplazamiento } \\
\hline & \multicolumn{7}{|c|}{$\mathrm{El}_{\mathrm{e}}\left(\mathrm{kN} \cdot \mathrm{m}^{2}\right)$ : Rigidez efectiva del elemento } \\
\hline
\end{tabular}


Estudio experimental y numérico de la capacidad de deformación de soportes esbeltos de hormigón armado

\begin{tabular}{|c|c|c|c|c|c|c|c|c|}
\hline \multicolumn{9}{|c|}{ Idealización del diagrama P-ס aplicando el método Aproximado (3) } \\
\hline $\mathrm{N}^{\circ}$ & REFERENCIA & $\begin{array}{l}\delta_{y_{-} \exp } \\
(\mathrm{mm})\end{array}$ & $P_{y}(k N)$ & $\begin{array}{l}P_{\max } \\
(k N)\end{array}$ & $\begin{array}{c}\delta_{y}^{\prime} \\
(\mathrm{mm})\end{array}$ & $\begin{array}{l}\delta_{\mathrm{u}_{-} \exp } \\
(\mathrm{mm})\end{array}$ & $\mu_{\delta}$ & $\begin{array}{c}\mathrm{El}_{\mathrm{e}} \\
\left(\mathrm{kN} \cdot \mathrm{m}^{2}\right)\end{array}$ \\
\hline 1 & N30-10.5-C0-2-00 & 23,36 & 12,80 & 17,07 & 31,14 & 74,53 & 2,39 & 308 \\
\hline 2 & $\mathrm{~N} 30-10.5-\mathrm{C} 0-2-15$ & 17,81 & 13,97 & 18,63 & 23,75 & 45,63 & 1,92 & 441 \\
\hline 3 & N30-10.5-C0-2-30 & 9,97 & 12,11 & 16,14 & 13,29 & 44,11 & 3,32 & 683 \\
\hline 4 & N30-10.5-C0-2-45 & 6,62 & 12,18 & 16,25 & 8,82 & 29,05 & 3,29 & 1036 \\
\hline 5 & N30-7.5-C0-2-30 & 13,41 & 41,40 & 55,19 & 17,88 & 33,30 & 1,86 & 1736 \\
\hline 6 & N30-7.5-C0-2-45 & 10,16 & 35,55 & 47,40 & 13,55 & 22,84 & 1,69 & 1967 \\
\hline 9 & N30-10.5-C0-1-30 & 6,61 & 11,67 & 15,55 & 8,81 & 34,10 & 3,87 & 993 \\
\hline 10 & N30-10.5-C0-1-45 & 6,30 & 11,06 & 14,74 & 8,40 & 16,96 & 2,02 & 988 \\
\hline 11 & N30-10.5-C0-3-15 & 25,06 & \begin{tabular}{ll|}
16,17 \\
\end{tabular} & 21,57 & 33,41 & 67,50 & 2,02 & 363 \\
\hline 12 & N30-10.5-C0-3-30 & 12,72 & 12,43 & 16.57 & 16.97 & 45,21 & 2,66 & 549 \\
\hline 13 & $\mathrm{H} 60-10.5-\mathrm{C} 0-2-00$ & 25,61 & 13,55 & 18,06 & 34,15 & 72,82 & 2,13 & 298 \\
\hline 14 & H60-10.5-C0-2-15 & 15,19 & 16,04 & 21,39 & 20,25 & 46,63 & 2,30 & $\overline{594}$ \\
\hline 15 & H60-10.5-C0-2-30 & 9,41 & 13,82 & 18,43 & 12,55 & 34,95 & 2,78 & 826 \\
\hline 16 & $\mathrm{H} 60-10.5-\mathrm{C} 0-2-45$ & 9,40 & 15,47 & 20,62 & 12,53 & 33,60 & 2,68 & 925 \\
\hline 17 & H60-7.5-C0-2-30 & 12,06 & 49,21 & 65,61 & 16,09 & 27,92 & 1,74 & 2294 \\
\hline 18 & H60-7.5-C0-2-45 & 11,41 & 55,36 & 73,82 & 15,21 & 22,59 & 1,48 & 2729 \\
\hline 21 & H60-10.5-C0-1-15 & 7,74 & 12,65 & 16,86 & 10,32 & 40,49 & 3,92 & 919 \\
\hline 22 & $\mathrm{H} 60-10.5-\mathrm{C} 0-1-30$ & 8,77 & 12,93 & 17,23 & 11,70 & 41,62 & 3,56 & 829 \\
\hline 23 & H60-10.5-C0-3-15 & 21,29 & 18,15 & 24,20 & 28,39 & 55,40 & 1,95 & 479 \\
\hline 24 & $\mathrm{H} 60-10.5-\mathrm{C} 0-3-30$ & 10,56 & 13,69 & 18,25 & 14,07 & 49,90 & 3,55 & 729 \\
\hline 25 & $\mathrm{H} 90-10.5-\mathrm{C} 0-2-00$ & 29,36 & 15,07 & 20,09 & 39,15 & 67,06 & 1,71 & 289 \\
\hline 26 & H90-10.5-C0-2-15 & 10,72 & \begin{tabular}{ll|}
16,60 \\
\end{tabular} & 22,14 & 14,30 & 43,28 & 3,03 & 871 \\
\hline 27 & H90-10.5-C0-2-30 & 8,88 & \begin{tabular}{l|}
16,42 \\
\end{tabular} & 21,90 & 11,85 & 35,74 & 3,02 & 1040 \\
\hline 28 & H90-10.5-C0-2-45 & 7,14 & $\begin{array}{ll}15,18 \\
\end{array}$ & 20,24 & 9,51 & 27,44 & 2,88 & 1197 \\
\hline 29 & H90-7.5-C0-2-30 & 12,47 & $\begin{array}{l}59,33 \\
\end{array}$ & 79,10 & 16,62 & 25,85 & 1,56 & 2677 \\
\hline 30 & H90-7.5-C0-2-45 & 10,70 & 55,99 & 74,65 & 14,26 & 19,81 & 1,39 & 2944 \\
\hline 31 & H90-10.5-C0-1-15 & 8,39 & 12,35 & 16,47 & 11,19 & 48,08 & 4,30 & 828 \\
\hline 32 & $\mathrm{H} 90-10.5-\mathrm{C} 0-1-30$ & 8,02 & 18,30 & 24,40 & 10,69 & 34,30 & 3,21 & 1284 \\
\hline 33 & H90-10.5-C0-3-15 & 15,70 & 20,71 & 27,61 & 20,93 & 49,57 & 2,37 & 742 \\
\hline 34 & H90-10.5-C0-3-30 & 8,92 & $\begin{array}{ll}18,95 \\
\end{array}$ & 25,26 & 11,90 & 35,67 & 3,00 & 1194 \\
\hline 35 & N30-10.5-C3-2-30 & 8,70 & 10,43 & 13,91 & 11,60 & 46,86 & 4,04 & 674 \\
\hline 36 & N30-10.5-C3-2-45 & 7,66 & 10,01 & 13,34 & 10,21 & 34,75 & 3,40 & 735 \\
\hline 37 & N30-7.5-C3-2-30 & 14,17 & 35,94 & 47,93 & 18,89 & 39,49 & 2,09 & 1427 \\
\hline 38 & N30-7.5-C3-2-45 & 10,48 & 33,44 & 44,59 & 13,98 & 25,15 & 1,80 & 1794 \\
\hline 39 & H90-10.5-C3-2-30 & 9,03 & \begin{tabular}{c|}
17,93 \\
\end{tabular} & 23,90 & 12,03 & 38,23 & 3,18 & 1117 \\
\hline 40 & H90-10.5-C3-2-45 & 6,05 & 12,47 & \begin{tabular}{ll|}
16,62 \\
\end{tabular} & 8,07 & 27,83 & 3,45 & 1159 \\
\hline 41 & H90-7.5-C3-2-30 & 12,37 & 56,60 & 75,47 & 16,49 & 26,38 & 1,60 & 2574 \\
\hline 42 & H90-7.5-C3-2-45 & 10,25 & 45,97 & 61,30 & 13,67 & 21,39 & 1,57 & 2523 \\
\hline 43 & H90-7.5-C2-2-30 & 12,57 & 54,54 & \begin{tabular}{l|}
72,72 \\
\end{tabular} & 16,76 & 28,77 & 1,72 & 2440 \\
\hline 44 & H90-7.5-C2-2-45 & 9,82 & 45,84 & 61,12 & 13,09 & 19,57 & 1,50 & 2627 \\
\hline
\end{tabular}

$\delta_{y_{\_} \exp }(\mathrm{mm})$ : Desplazamiento elástico experimental

$P_{y}(k N)$ : Carga elástica experimental

$\delta_{\mathrm{u}_{\_} \exp }(\mathrm{mm})$ : Desplazamiento último Experimental

$P_{\max }(\mathrm{kN})$ : Carga máxima experimental

$\delta_{y}^{\prime}\left(m^{-1}\right)$ :Desplazamiento elástico efectivo

$\mu_{\delta}$ : Ductilidad de Desplazamiento

$\mathrm{El}_{\mathrm{e}}\left(\mathrm{kN} \cdot \mathrm{m}^{2}\right)$ : Rigidez efectiva del elemento 


\section{ANEJO K: Desplazamientos elásticos teóricos y longitudes de rótula plástica.}

\begin{tabular}{|c|c|c|c|c|c|c|c|c|c|}
\hline $\begin{array}{c}\mathrm{N}^{\circ} \\
\text { ensayo }\end{array}$ & $\delta u(m)$ & $\varphi_{\mathrm{u}}\left(\mathrm{m}^{-1}\right)$ & $\varphi_{y}^{\prime}\left(m^{-1}\right)$ & $\delta_{y \text {-teo1 }}(\mathrm{m})$ & $\delta_{y \text {-teo2 }(m)}$ & $L p / H_{-} \exp 1$ & Lp/H_exp2 & $\frac{\delta_{y_{t} \text { teo } 1}}{\delta_{y_{-} \text {teo2 }}}$ & $\frac{L p \_ \text {exp1 }}{L p_{-} \exp 2}$ \\
\hline 1 & 0,0745 & 0,1430 & 0,0383 & 0,0349 & 0,0287 & 1,99 & 2,34 & 1,22 & 0,85 \\
\hline 2 & 0,0456 & 0,1359 & 0,0331 & 0,0302 & 0,0269 & 0,74 & 0,91 & 1,13 & 0,81 \\
\hline 3 & 0,0441 & 0,0834 & 0,0301 & 0,0274 & 0,0265 & 1,61 & 1,71 & 1,04 & 0,94 \\
\hline 4 & 0,0291 & 0,0489 & 0,0167 & 0,0153 & 0,0141 & 2,28 & 2,51 & 1,08 & 0,91 \\
\hline 5 & 0,0333 & 0,0819 & 0,0196 & 0,0179 & 0,0157 & 0,87 & 1,01 & 1,14 & 0,87 \\
\hline 6 & 0,0228 & 0,0759 & 0,0141 & 0,0129 & 0,0114 & 0,56 & 0,64 & 1,13 & 0,87 \\
\hline 9 & 0,0341 & 0,1515 & 0,0277 & 0,0253 & 0,0239 & 0,35 & 0,40 & 1,06 & 0,87 \\
\hline 10 & 0,0170 & 0,0237 & 0,0114 & 0,0104 & 0,0099 & 2,96 & 3,26 & 1,05 & 0,91 \\
\hline 11 & 0,0675 & 0,1336 & 0,0409 & 0,0373 & 0,0340 & 1,68 & 1,88 & 1,10 & 0,89 \\
\hline 12 & 0,0452 & 0,0830 & 0,0255 & 0,0233 & 0,0223 & 2,01 & 2,11 & 1,04 & 0,95 \\
\hline 13 & 0,0728 & 0,1291 & 0,0368 & 0,0336 & 0,0276 & 2,27 & 2,67 & 1,22 & 0,85 \\
\hline 14 & 0,0466 & 0,1108 & 0,0425 & 0,0387 & 0,0367 & 0,57 & 0,71 & 1,05 & 0,80 \\
\hline 15 & 0,0349 & 0,0516 & 0,0233 & 0,0213 & 0,0204 & 2,63 & 2,83 & 1,04 & 0,93 \\
\hline 16 & 0,0326 & 0,0476 & 0,0182 & 0,0166 & 0,0165 & 3,02 & 3,05 & 1,01 & 0,99 \\
\hline 17 & 0,0279 & 0,0648 & 0,0202 & 0,0184 & 0,0164 & 0,75 & 0,92 & 1,12 & 0,81 \\
\hline 18 & 0,0226 & 0,0580 & 0,0166 & 0,0152 & 0,0138 & 0,62 & 0,75 & 1,10 & 0,83 \\
\hline 21 & 0,0405 & 0,1142 & 0,0386 & 0,0352 & 0,0333 & 0,34 & 0,46 & 1,06 & 0,73 \\
\hline 22 & 0,0416 & 0,0868 & 0,0225 & 0,0205 & 0,0193 & 1,70 & 1,81 & 1,06 & 0,94 \\
\hline 23 & 0,0554 & 0,0651 & 0,0390 & 0,0355 & 0,0333 & 4,62 & 5,38 & 1,07 & 0,86 \\
\hline 24 & 0,0499 & 0,0942 & 0,0277 & 0,0253 & 0,0249 & 1,94 & 1,98 & 1,02 & 0,98 \\
\hline 25 & 0,0671 & 0,1248 & 0,0448 & 0,0409 & 0,0336 & 1,69 & 2,22 & 1,22 & 0,76 \\
\hline 26 & 0,0433 & 0,1169 & 0,0371 & 0,0338 & 0,0326 & 0,58 & 0,66 & 1,04 & 0,88 \\
\hline 27 & 0,0357 & 0,0550 & 0,0273 & 0,0249 & 0,0242 & 2,06 & 2,21 & 1,03 & 0,93 \\
\hline 28 & 0,0274 & 0,0393 & 0,0166 & 0,0152 & 0,0150 & 2,99 & 3,06 & 1,01 & 0,98 \\
\hline 29 & 0,0258 & 0,0541 & 0,0192 & 0,0175 & 0,0158 & 0,85 & 1,03 & 1,11 & 0,82 \\
\hline 30 & 0,0198 & 0,0556 & 0,0154 & 0,0140 & 0,0129 & 0,50 & 0,59 & 1,08 & 0,84 \\
\hline 31 & 0,0481 & 0,1174 & 0,0321 & 0,0293 & 0,0278 & 1,11 & 1,20 & 1,05 & 0,92 \\
\hline 32 & 0,0343 & 0,0741 & 0,0223 & 0,0204 & 0,0191 & 1,37 & 1,50 & 1,07 & 0,91 \\
\hline 33 & 0,0496 & 0,0810 & 0,0424 & 0,0387 & 0,0362 & 1,44 & 1,80 & 1,07 & 0,80 \\
\hline 34 & 0,0357 & 0,0537 & 0,0262 & 0,0239 & 0,0232 & 2,28 & 2,43 & 1,03 & 0,94 \\
\hline 35 & 0,0469 & 0,1202 & 0,0301 & 0,0275 & 0,0263 & 1,08 & 1,15 & 1,04 & 0,94 \\
\hline 36 & 0,0348 & 0,0792 & 0,0199 & 0,0181 & 0,0175 & 1,43 & 1,49 & 1,03 & 0,96 \\
\hline 37 & 0,0395 & 0,1096 & 0,0200 & 0,0182 & 0,0162 & 0,84 & 0,92 & 1,12 & 0,91 \\
\hline 38 & 0,0252 & 0,0868 & 0,0148 & 0,0135 & 0,0121 & 0,56 & 0,63 & 1,11 & 0,89 \\
\hline 39 & 0,0382 & 0,0492 & 0,0253 & 0,0231 & 0,0220 & 3,63 & 3,97 & 1,05 & 0,92 \\
\hline 40 & 0,0278 & 0,0451 & 0,0161 & 0,0147 & 0,0152 & 2,44 & 2,32 & 0,96 & 1,05 \\
\hline 41 & 0,0264 & 0,0414 & 0,0173 & 0,0158 & 0,0141 & 1,64 & 1,96 & 1,12 & 0,84 \\
\hline 42 & 0,0214 & 0,0498 & 0,0127 & 0,0116 & 0,0113 & 0,94 & 0,97 & 1,02 & 0,97 \\
\hline 43 & 0,0288 & 0,0538 & 0,0193 & 0,0176 & 0,0159 & 1,17 & 1,37 & 1,10 & 0,86 \\
\hline 44 & 0,0196 & 0,0482 & 0,0139 & 0,0127 & 0,0122 & 0,70 & 0,76 & 1,04 & 0,92 \\
\hline & & & & & \multicolumn{3}{|c|}{ Promedio $(\bar{E})$} & 1,08 & 0,89 \\
\hline & & & & & \multicolumn{3}{|c|}{ Coeficiente de Variación (CV) } & 0,05 & 0,08 \\
\hline
\end{tabular}


Estudio experimental y numérico de la capacidad de deformación de soportes esbeltos de hormigón armado 


\section{ANEJO L: COMPARACIÓN DE LOS RESULTADOS CARGA- DESPLAZAMIENTO EXPERIMENTALES Y NUMÉRICOS}

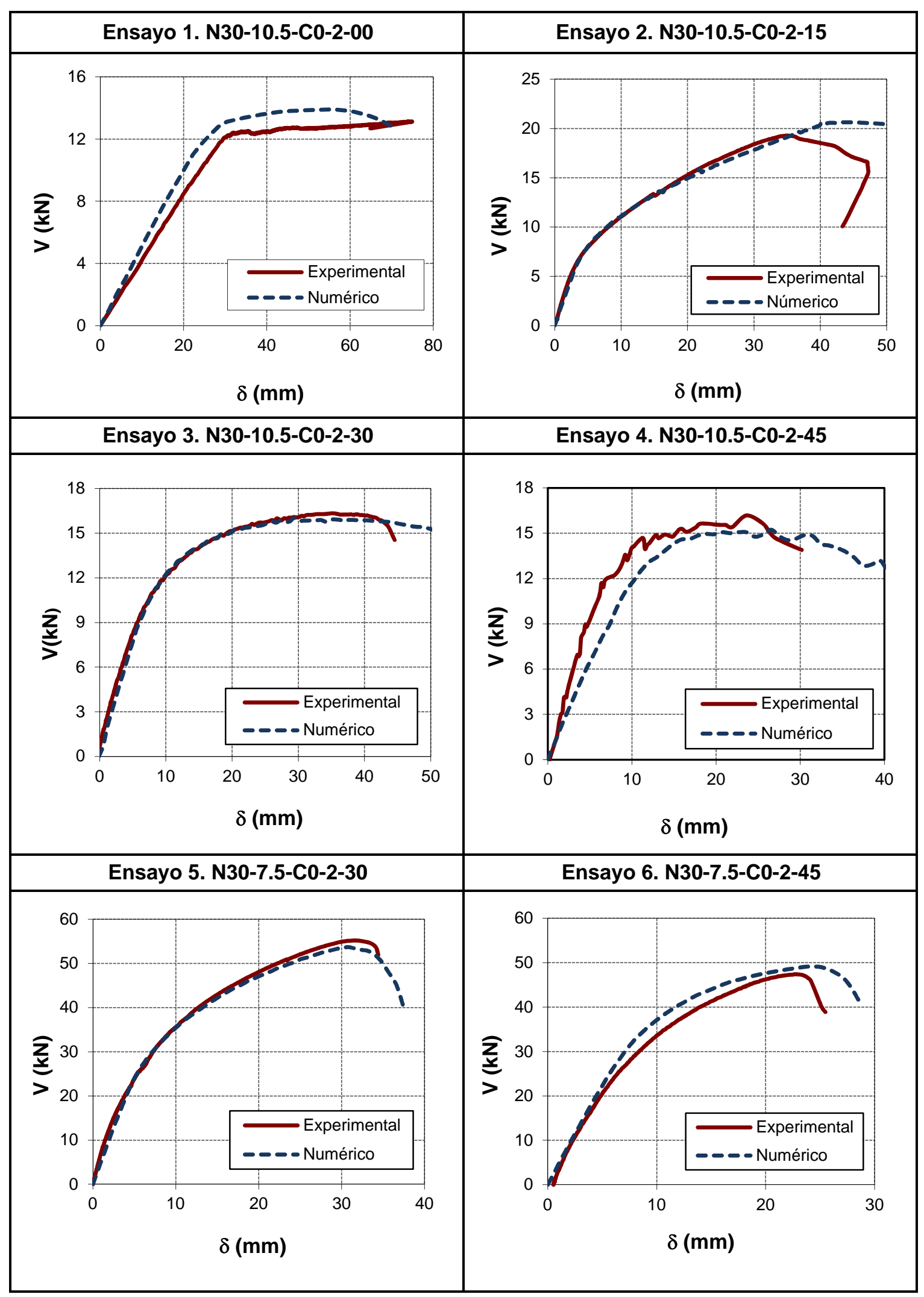


Estudio experimental y numérico de la capacidad de deformación de soportes esbeltos de hormigón armado

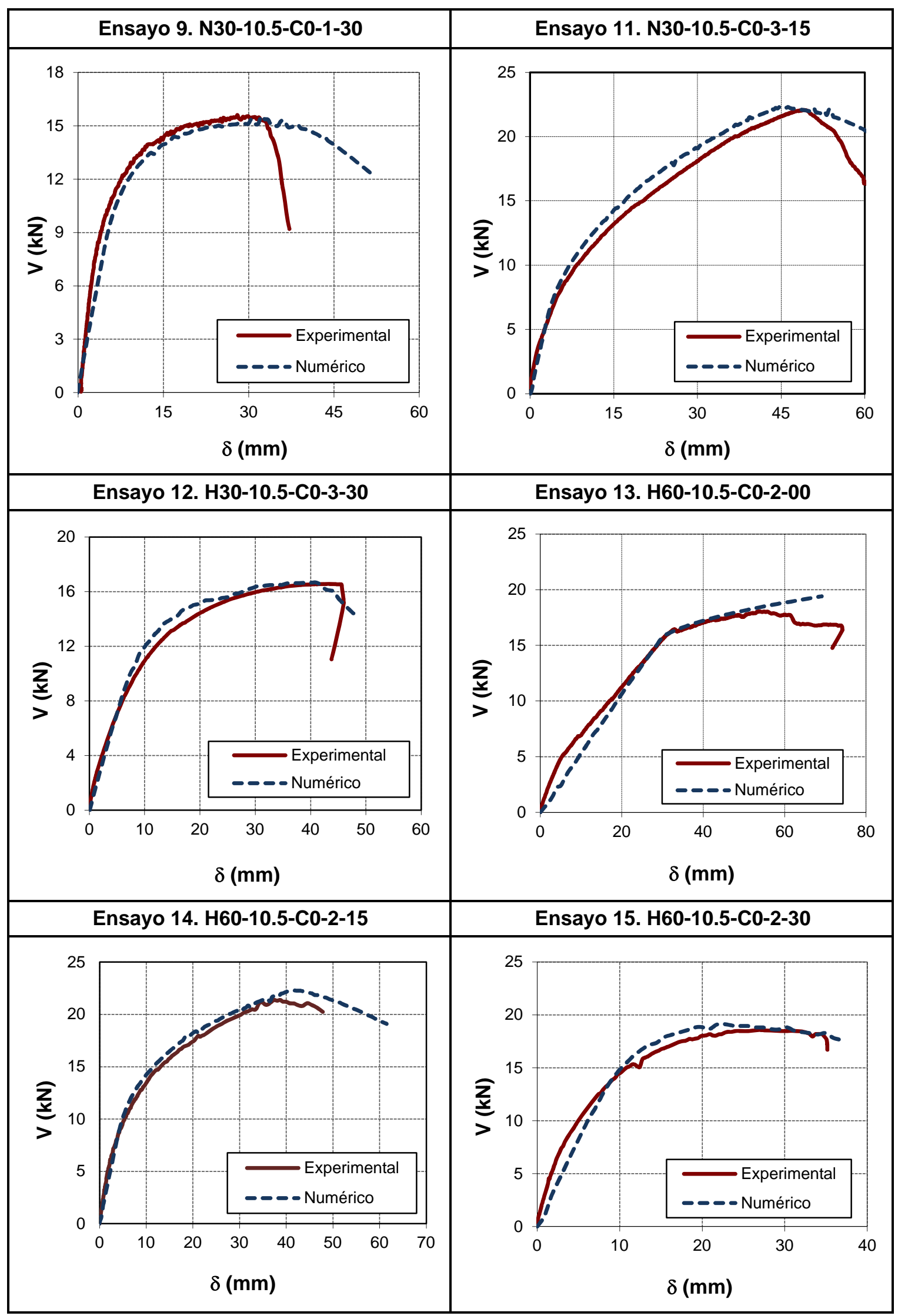




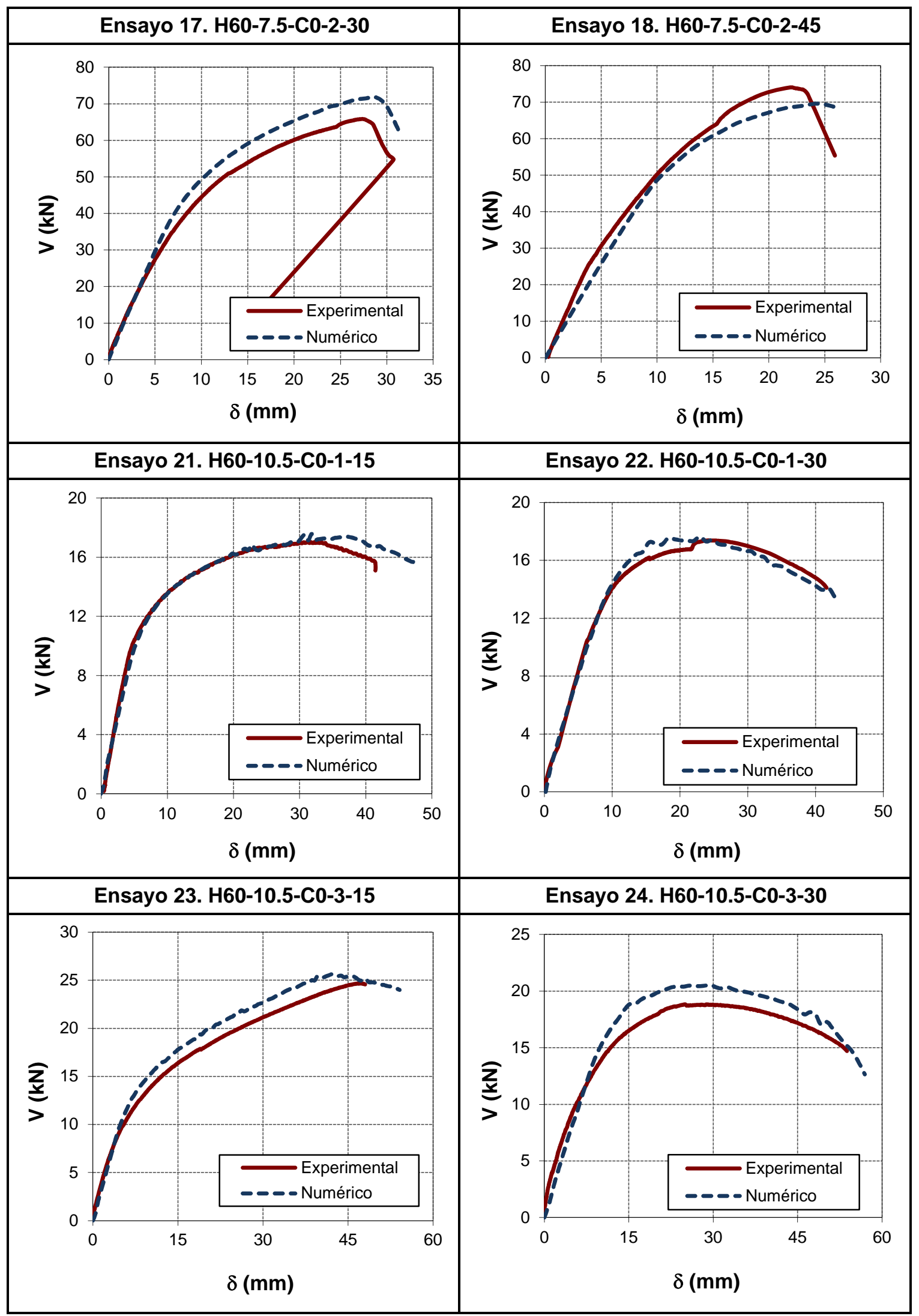


Estudio experimental y numérico de la capacidad de deformación de soportes esbeltos de hormigón armado

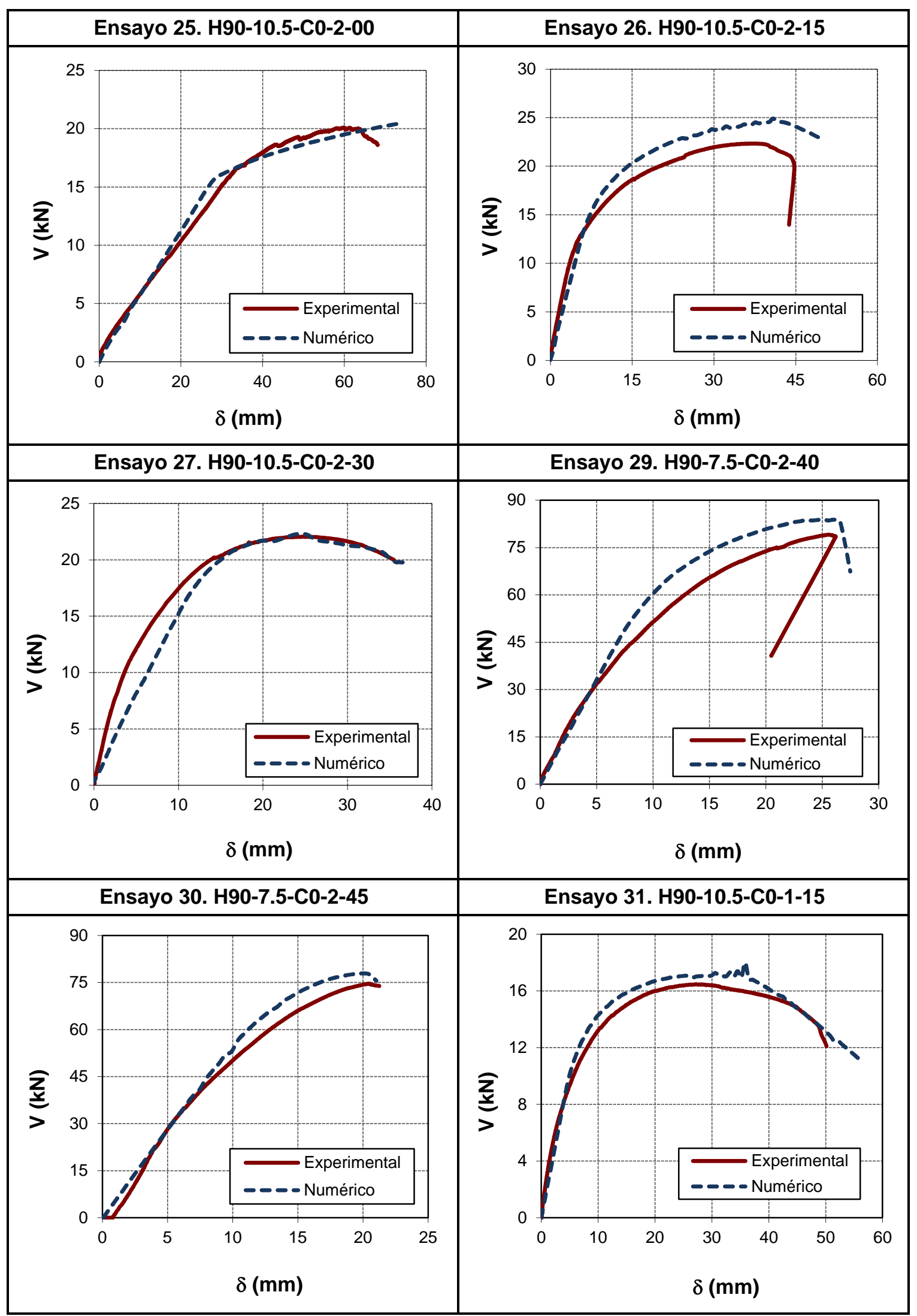




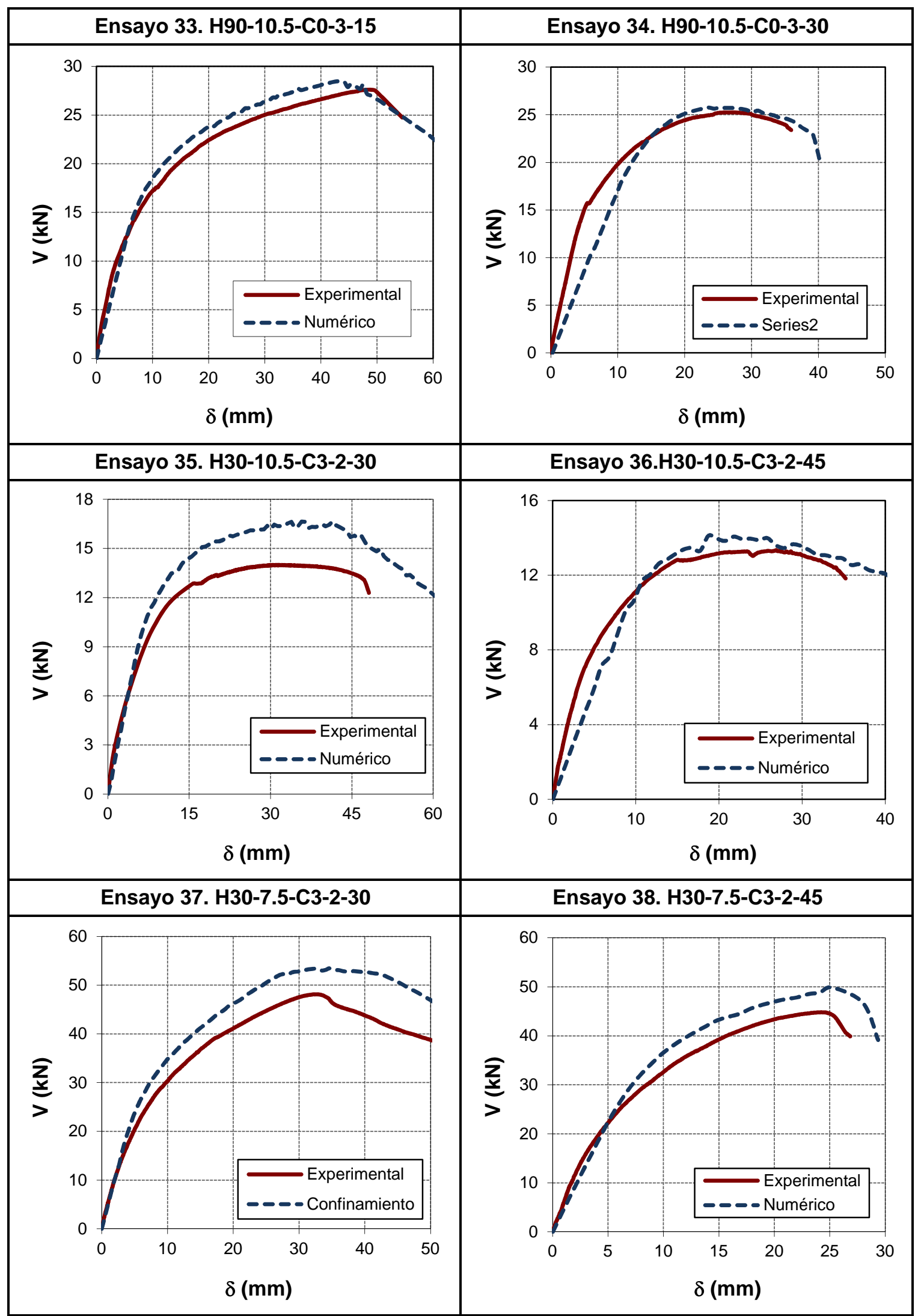


Estudio experimental y numérico de la capacidad de deformación de soportes esbeltos de hormigón armado

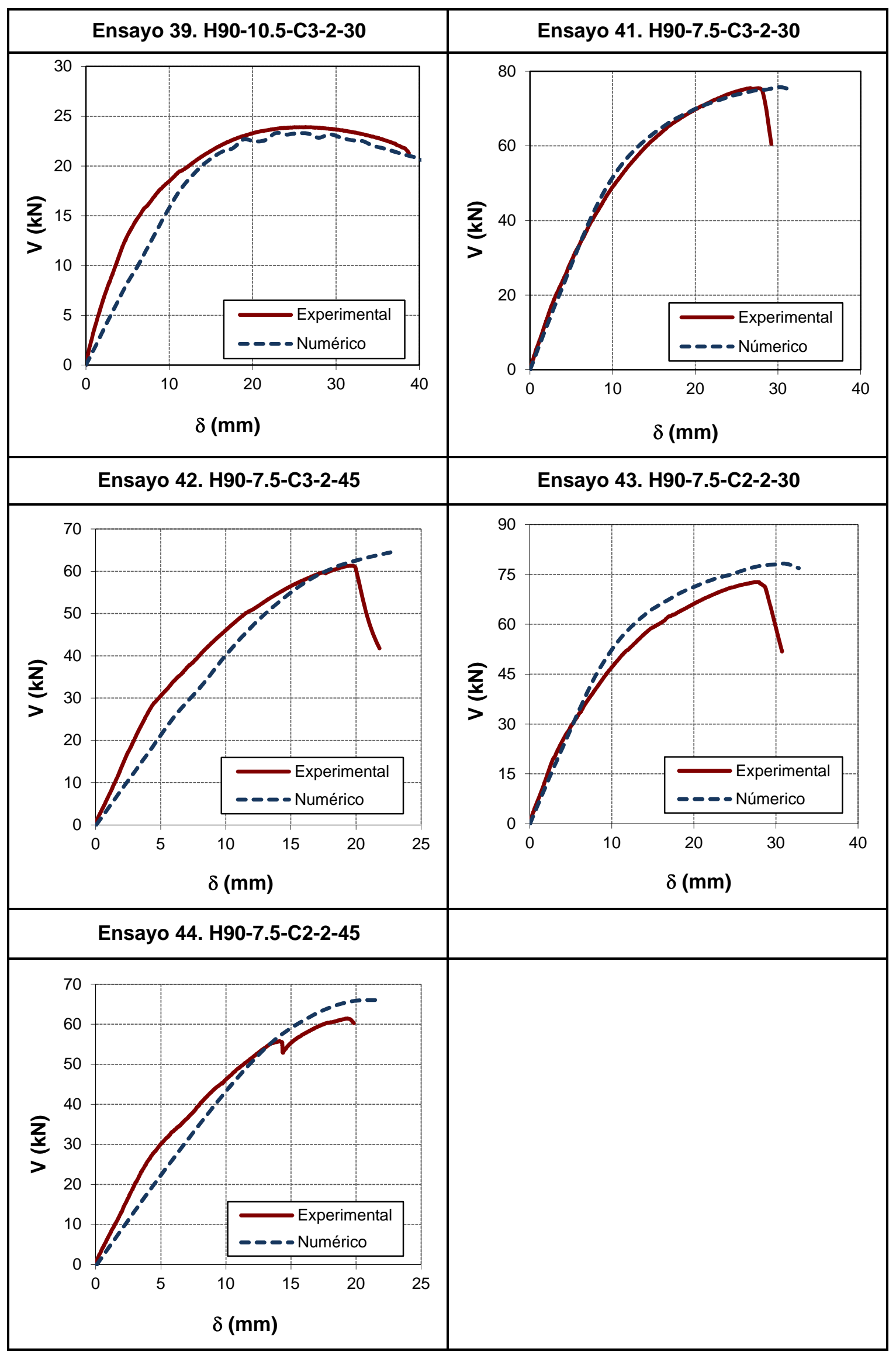


Comparación de las cargas verticales y los desplazamientos en el punto de carga máxima de la curva V- $\delta$

\begin{tabular}{|c|c|c|c|c|c|c|c|}
\hline $\begin{array}{c}\mathrm{N}^{\circ} \\
\text { Ensayo }\end{array}$ & Referencia & $\begin{array}{c}\mathbf{V}_{\mathrm{m} . \operatorname{Exp}} \\
(\mathrm{kN})\end{array}$ & $\begin{array}{c}\mathbf{V}_{\text {m.num }} \\
(\mathbf{k N})\end{array}$ & $\begin{array}{l}\delta_{\mathrm{m} . \operatorname{Exp}} \\
(\mathrm{mm})\end{array}$ & $\begin{array}{l}\delta_{\text {m.num }} \\
(\mathrm{mm})\end{array}$ & $\begin{array}{c}\text { Error } \\
\mathbf{V}_{\text {num }} / \mathbf{V}_{\text {Exp }}\end{array}$ & $\begin{array}{c}\text { Error } \\
\delta_{\text {num }} / \delta_{\text {Exp }}\end{array}$ \\
\hline 1 & N30-10.5-C0-2-00 & 13,11 & 13,8 & 74,53 & 62,9 & 1,05 & 0,84 \\
\hline 2 & N30-10.5-C0-2-15 & 18,63 & 20,14 & 34,16 & 39,19 & 1,08 & 1,15 \\
\hline 3 & N30-10.5-C0-2-30 & 16,14 & 15,92 & 34,18 & 35,53 & 0,99 & 1,04 \\
\hline 4 & N30-10.5-C0-2-45 & 16,25 & 15,23 & 25,34 & 26,55 & 0,94 & 1,05 \\
\hline 5 & N30-7.5-C0-2-30 & 55,19 & 53,36 & 31,13 & 30,09 & 0,97 & 0,97 \\
\hline 6 & N30-7.5-C0-2-45 & 47,4 & 49,14 & 21,71 & 24,02 & 1,04 & 1,11 \\
\hline 9 & N30-10.5-C0-1-30 & 15,55 & 15,23 & 27,23 & 28,19 & 0,98 & 1,04 \\
\hline 11 & N30-10.5-C0-3-15 & 21,57 & 22,23 & 48,74 & 45,49 & 1,03 & 0,93 \\
\hline 12 & N30-10.5-C0-3-30 & 16,57 & 16,1 & 42,52 & 41,3 & 0,97 & 0,97 \\
\hline 13 & H60-10.5-C0-2-00 & 18,06 & 18,42 & 53,87 & 53,97 & 1,02 & 1,00 \\
\hline 14 & H60-10.5-C0-2-15 & 21,39 & 22,38 & 38,7 & 40,68 & 1,05 & 1,05 \\
\hline 15 & $\mathrm{H} 60-10.5-\mathrm{C} 0-2-30$ & 18,43 & 18,82 & 26,67 & 26,48 & 1,02 & 0,99 \\
\hline 17 & $\mathrm{H} 60-7.5-\mathrm{C} 0-2-30$ & 65,61 & 72,18 & 27,09 & 28,7 & 1,10 & 1,06 \\
\hline 18 & $\mathrm{H} 60-7.5-\mathrm{C} 0-2-45$ & 73,82 & 69,83 & 21,72 & 24,48 & 0,95 & 1,13 \\
\hline 21 & H60-10.5-C0-1-15 & 16,86 & 17,3 & 30,3 & 37,88 & 1,03 & 1,25 \\
\hline 22 & H60-10.5-C0-1-30 & 17,23 & 17,64 & 24,16 & 22,93 & 1,02 & 0,95 \\
\hline 23 & H60-10.5-C0-3-15 & 24,2 & 25,48 & 47,17 & 43,8 & 1,05 & 0,93 \\
\hline 24 & H60-10.5-C0-3-30 & 18,25 & 20,49 & 28,79 & 28,67 & 1,12 & 1,00 \\
\hline 25 & H9O-10.5-C0-2-00 & 20,09 & 19,54 & 58,84 & 60,46 & 0,97 & 1,03 \\
\hline 26 & H9O-10.5-C0-2-15 & 22,14 & 24,51 & 38,26 & 37,54 & 1,11 & 0,98 \\
\hline 27 & $\mathrm{H} 90-10.5-\mathrm{C} 0-2-30$ & 21,9 & 22,25 & 25,1 & 25,11 & 1,02 & 1,00 \\
\hline 29 & $\mathrm{H} 90-7.5-\mathrm{C} 0-2-30$ & 79,1 & 87,04 & 25,42 & 30,35 & 1,10 & 1,19 \\
\hline 30 & H90-7.5-C0-2-45 & 74,65 & 77,01 & 19,41 & 22,63 & 1,03 & 1,17 \\
\hline 31 & H90-10.5-C0-1-15 & 16,47 & 17,05 & 26,97 & 27,28 & 1,04 & 1,01 \\
\hline 33 & H90-10.5-C0-3-15 & 27,61 & 30,33 & 48,03 & 43,8 & 1,10 & 0,91 \\
\hline 34 & H90-10.5-C0-3-30 & 25,26 & 25,98 & 26,78 & 26,76 & 1,03 & 1,00 \\
\hline 35 & N30-10.5-C3-2-30 & 13,91 & 16,4 & 31,13 & 32,57 & 1,18 & 1,05 \\
\hline 36 & N30-10.5-C3-2-45 & 13,34 & 13,99 & 26,53 & 25,02 & 1,05 & 0,94 \\
\hline 37 & N30-7.5-C3-2-30 & 47,93 & 54,17 & 31,88 & 31,57 & 1,13 & 0,99 \\
\hline 38 & N30-7.5-C3-2-45 & 44,59 & 48,86 & 24,03 & 24,1 & 1,10 & 1,00 \\
\hline 39 & H9O-10.5-C3-2-30 & 23,9 & 23,26 & 26,09 & 26,65 & 0,97 & 1,02 \\
\hline 41 & H90-7.5-C3-2-30 & 75,47 & 75,8 & 26,21 & 28,75 & 1,00 & 1,10 \\
\hline 42 & H90-7.5-C3-2-45 & 61,3 & 61,97 & 20,29 & 20,43 & 1,01 & 1,01 \\
\hline 43 & H90-7.5-C2-2-30 & 72,72 & 76,8 & 27,83 & 28,45 & 1,06 & 1,02 \\
\hline 44 & H90-7.5-C2-2-45 & 61,12 & 63,55 & 19,11 & 19,86 & 1,04 & 1,04 \\
\hline
\end{tabular}


Estudio experimental y numérico de la capacidad de deformación de soportes esbeltos de hormigón armado

\section{Comparación de las cargas verticales y los desplazamientos en el punto de carga última de la curva V-ठ}

\begin{tabular}{|c|c|c|c|c|c|c|c|}
\hline $\begin{array}{c}N^{\circ} \\
\text { Ensayo }\end{array}$ & Referencia & $\begin{array}{c}\mathbf{V}_{\text {u. Exp }} \\
(\mathbf{k N})\end{array}$ & $\begin{array}{c}\mathbf{V}_{\text {u.num }} \\
(\mathbf{k N})\end{array}$ & $\begin{array}{c}\delta_{\mathrm{u} . \operatorname{Exp}} \\
(\mathrm{mm})\end{array}$ & $\begin{array}{l}\delta_{\text {u.num }} \\
\text { (mm) }\end{array}$ & $\begin{array}{c}\text { Error } \\
\mathbf{V}_{\text {num }} / V_{\text {exp }}\end{array}$ & $\begin{array}{c}\text { Error } \\
\delta_{\text {num }} / \delta_{\text {Exp }}\end{array}$ \\
\hline 1 & N30-10.5-C0-2-00 & 13,11 & 13,8 & 68,47 & 62,9 & 1,05 & 0,92 \\
\hline 2 & N30-10.5-C0-2-15 & 19,28 & 20,61 & 36,3 & 40,19 & 1,07 & 1,11 \\
\hline 3 & N30-10.5-C0-2-30 & 15,02 & 15,23 & 48,64 & 43,17 & 1,01 & 0,89 \\
\hline 4 & N30-10.5-C0-2-45 & 13,78 & 14,48 & 34,4 & 30,16 & 1,05 & 0,88 \\
\hline 5 & N30-7.5-C0-2-30 & 47,08 & 48,7 & 35,7 & 34,7 & 1,03 & 0,97 \\
\hline 6 & N30-7.5-C0-2-45 & 40,05 & 40,53 & 24,6 & 28,76 & 1,01 & 1,17 \\
\hline 9 & N30-10.5-C0-1-30 & 14,23 & 14,87 & 33,68 & 38,57 & 1,04 & 1,15 \\
\hline 11 & N30-10.5-C0-3-15 & 18,92 & 19,89 & 57,33 & 62,39 & 1,05 & 1,09 \\
\hline 12 & N30-10.5-C0-3-30 & 16,64 & 15,8 & 43,35 & 43,31 & 0,95 & 1,00 \\
\hline 13 & H60-10.5-C0-2-00 & 18,06 & 18,42 & 53,87 & 53,97 & 1,02 & 1,00 \\
\hline 14 & H60-10.5-C0-2-15 & 20,24 & 21,24 & 47,81 & 50,53 & 1,05 & 1,06 \\
\hline 15 & H60-10.5-C0-2-30 & 16,56 & 16,91 & 35,17 & 36,65 & 1,02 & 1,04 \\
\hline 17 & $\mathrm{H} 60-7.5-\mathrm{C} 0-2-30$ & 64,62 & 71,1 & 28,28 & 30,94 & 1,10 & 1,09 \\
\hline 18 & H60-7.5-C0-2-45 & 72 & 68,12 & 23,18 & 27,53 & 0,95 & 1,19 \\
\hline 21 & H60-10.5-C0-1-15 & 15,24 & 15,69 & 41,04 & 46,97 & 1,03 & 1,14 \\
\hline 22 & H60-10.5-C0-1-30 & 14,65 & 15 & 40,01 & 37,17 & 1,02 & 0,93 \\
\hline 23 & H60-10.5-C0-3-15 & 24,09 & 25,4 & 48,01 & 45,95 & 1,05 & 0,96 \\
\hline 24 & H60-10.5-C0-3-30 & 20,09 & 19,54 & 59,87 & 60,46 & 0,97 & 1,01 \\
\hline 25 & H90-10.5-C0-2-00 & 20,09 & 19,54 & 59,87 & 60,46 & 0,97 & 1,01 \\
\hline 26 & H90-10.5-C0-2-15 & 19,72 & 22,05 & 44,76 & 51,09 & 1,12 & 1,14 \\
\hline 27 & H90-10.5-C0-2-30 & 19,7 & 19,89 & 35,84 & 35,42 & 1,01 & 0,99 \\
\hline 29 & $\mathrm{H} 90-7.5-\mathrm{CO}-2-30$ & 78,39 & 86,65 & 26,18 & 33,16 & 1,11 & 1,27 \\
\hline 30 & H90-7.5-C0-2-45 & 74,41 & 76,64 & 21,06 & 25,56 & 1,03 & 1,21 \\
\hline 31 & H90-10.5-C0-1-15 & 14,79 & 15,23 & 45,03 & 43,23 & 1,03 & 0,96 \\
\hline 33 & H90-10.5-C0-3-15 & 27,53 & 29,67 & 49,69 & 45,55 & 1,08 & 0,92 \\
\hline 34 & H90-10.5-C0-3-30 & 23,39 & 24,01 & 35,93 & 41,09 & 1,03 & 1,14 \\
\hline 35 & N30-10.5-C3-2-30 & 13,14 & 15,35 & 46,05 & 47,51 & 1,17 & 1,03 \\
\hline 36 & N30-10.5-C3-2-45 & 11,98 & 12,56 & 34,95 & 35,9 & 1,05 & 1,03 \\
\hline 37 & N30-7.5-C3-2-30 & 40,74 & 46,13 & 44,95 & 50,62 & 1,13 & 1,13 \\
\hline 38 & N30-7.5-C3-2-45 & 44,81 & 48,86 & 24,21 & 24,1 & 1,09 & 1,00 \\
\hline 39 & H90-10.5-C3-2-30 & 21,31 & 20,74 & 38,74 & 39,66 & 0,97 & 1,02 \\
\hline 41 & H90-7.5-C3-2-30 & 74,76 & 75,03 & 28,12 & 31,65 & 1,00 & 1,13 \\
\hline 42 & H90-7.5-C3-2-45 & 52,53 & 56,4 & 21,39 & 22,57 & 1,07 & 1,06 \\
\hline 43 & $\mathrm{H} 90-7.5-\mathrm{C} 2-2-30$ & 70,58 & 74,54 & 28,77 & 32,75 & 1,06 & 1,14 \\
\hline 44 & $\mathrm{H} 90-7.5-\mathrm{C} 2-2-45$ & 60,93 & 62,95 & 20,09 & 21,99 & 1,03 & 1,09 \\
\hline
\end{tabular}


ANEJO M: RESPUESTA CARGA-FLECHA E IDEALIZACIÓN DE LOS ENSAYOS NUMÉRICOS

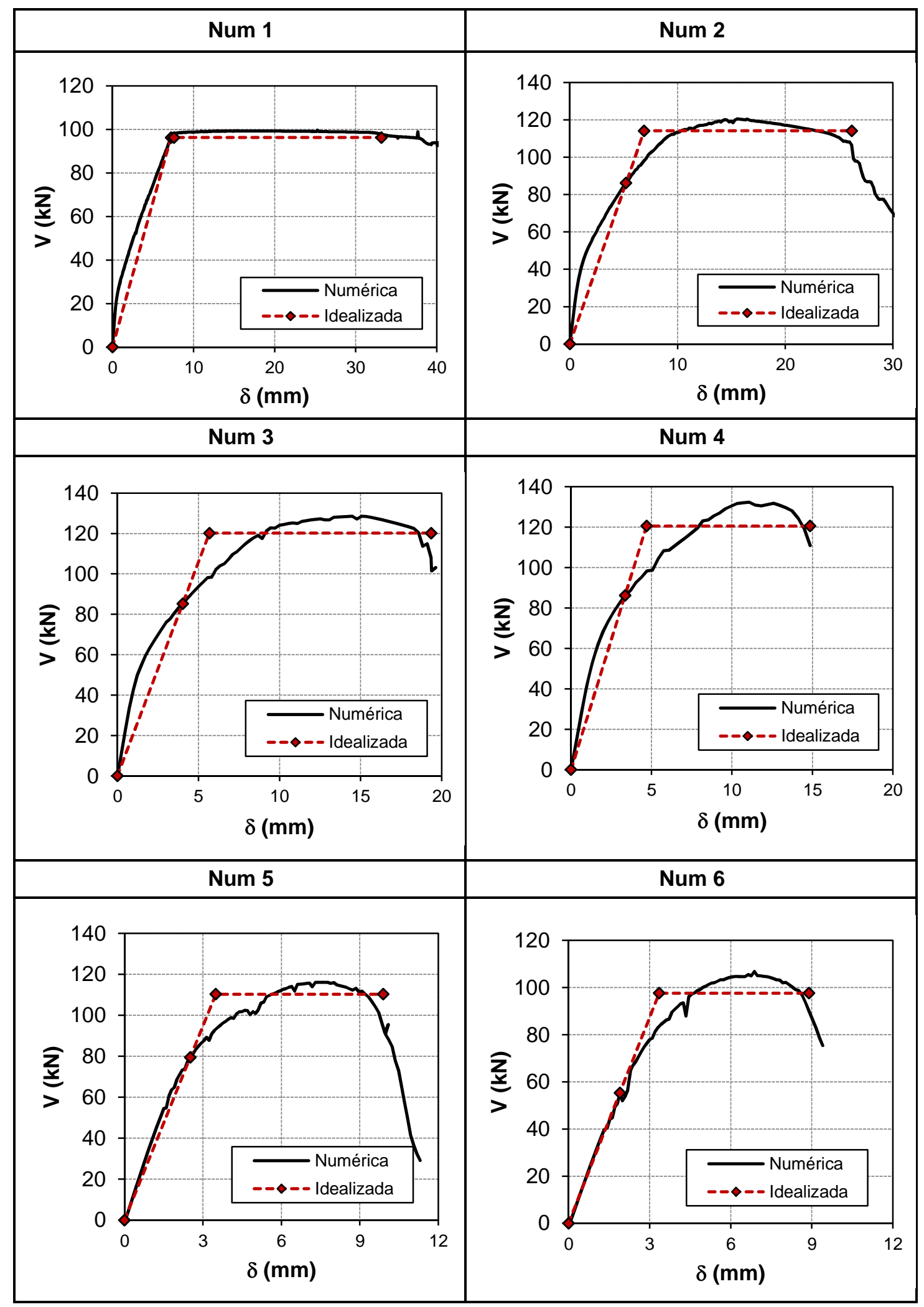


Estudio experimental y numérico de la capacidad de deformación de soportes esbeltos de hormigón armado

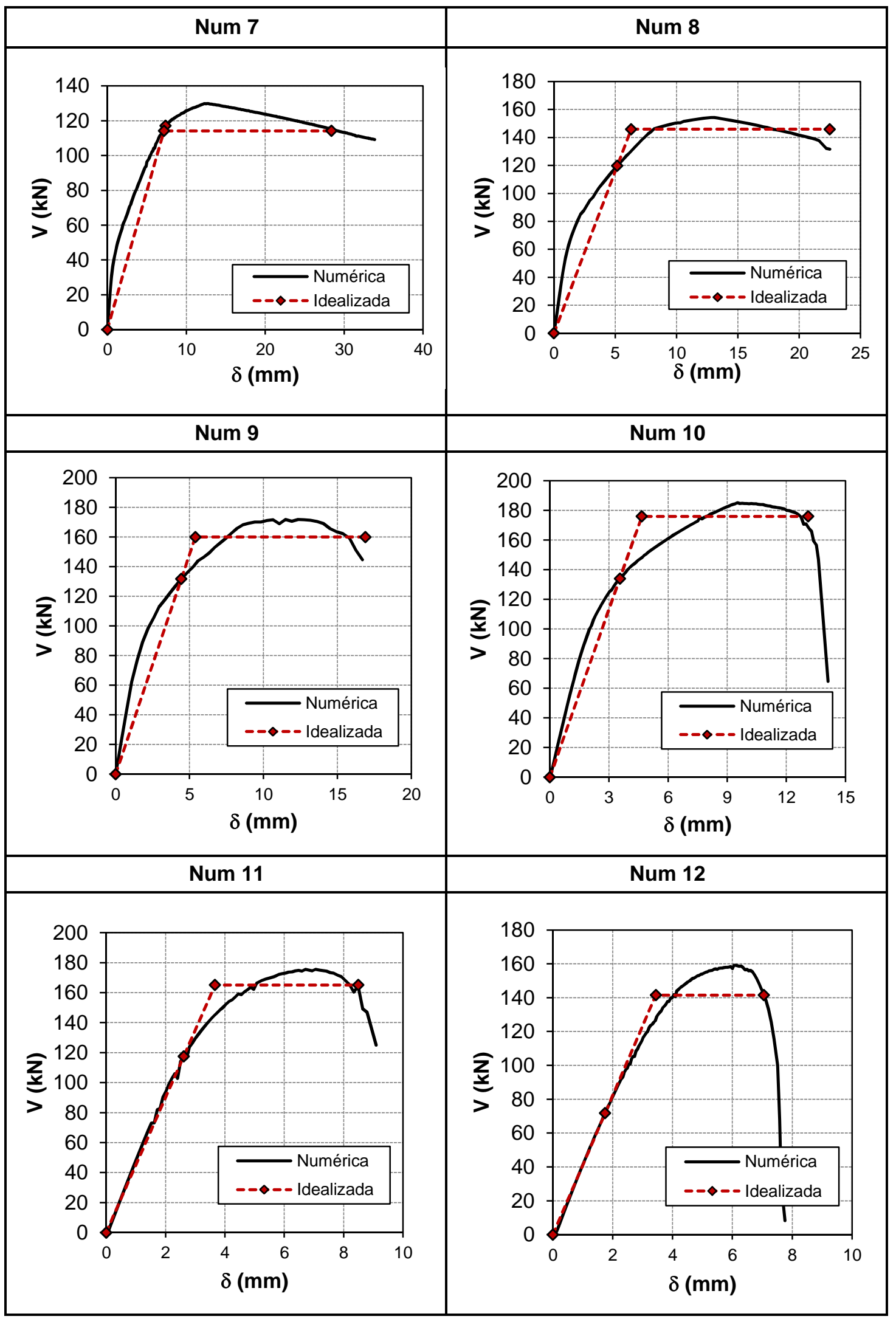




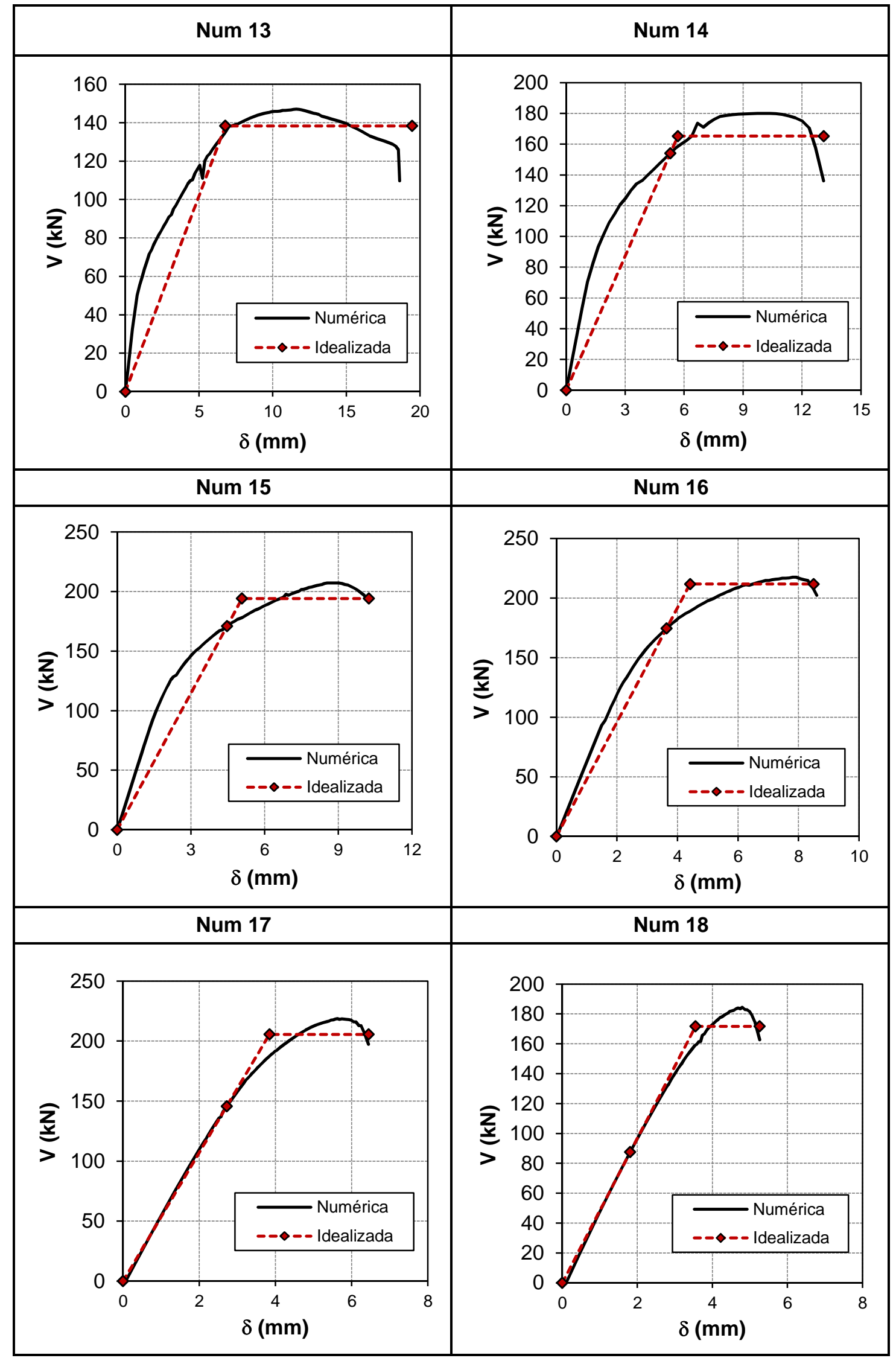


Estudio experimental y numérico de la capacidad de deformación de soportes esbeltos de hormigón armado

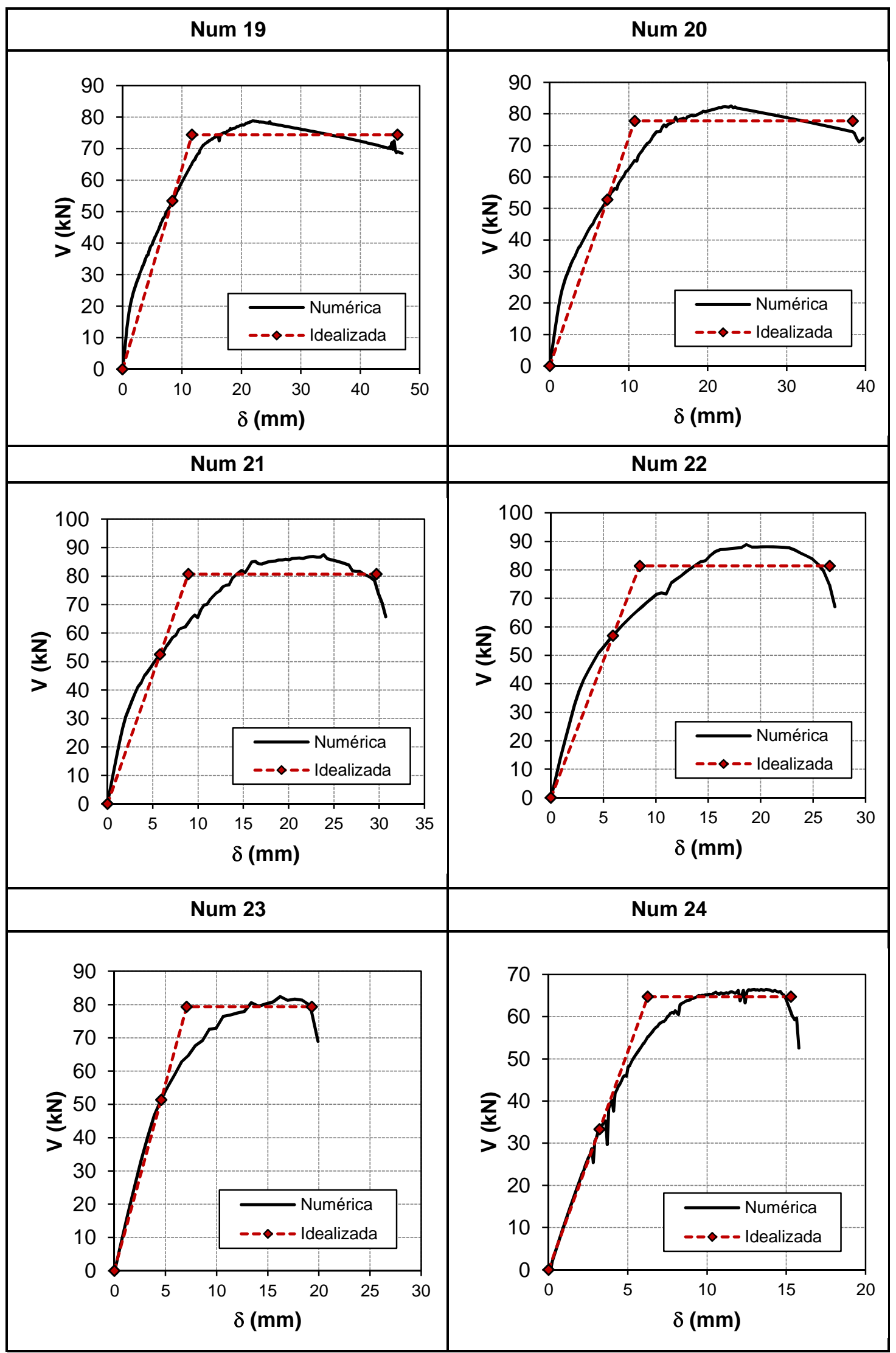


Anejo M: Respuesta Carga-Flecha e idealización de los ensayos numéricos

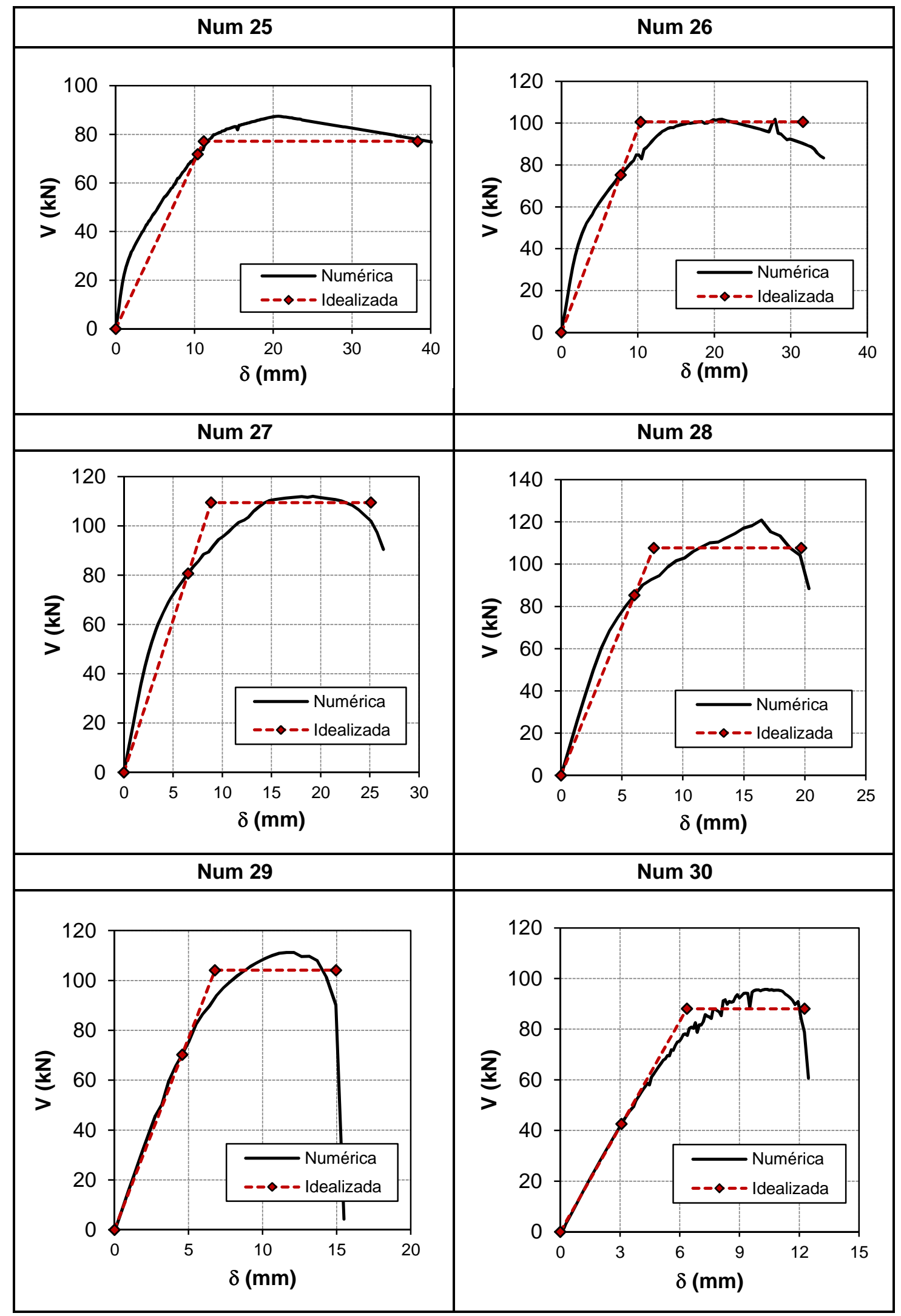


Estudio experimental y numérico de la capacidad de deformación de soportes esbeltos de hormigón armado

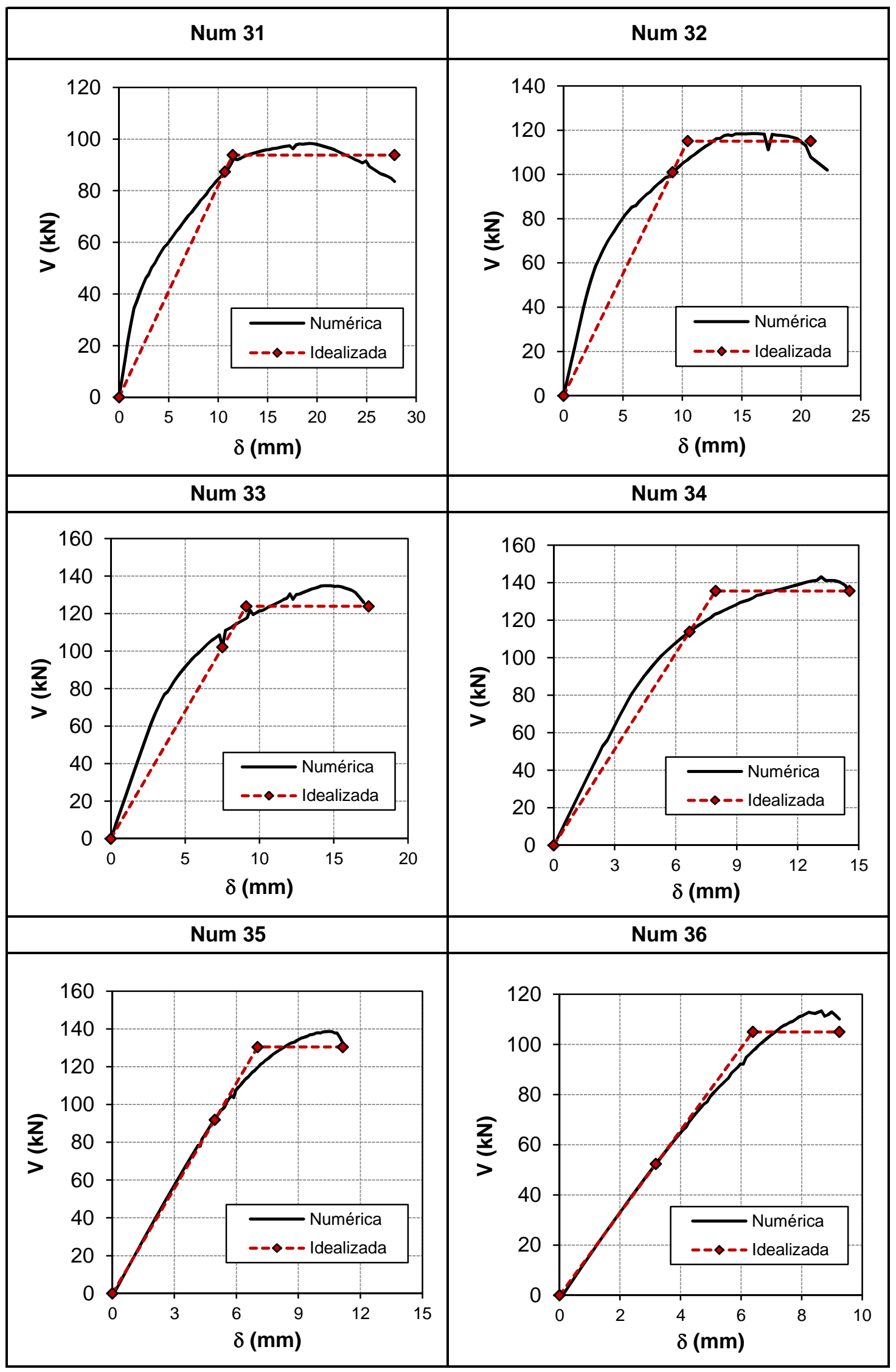



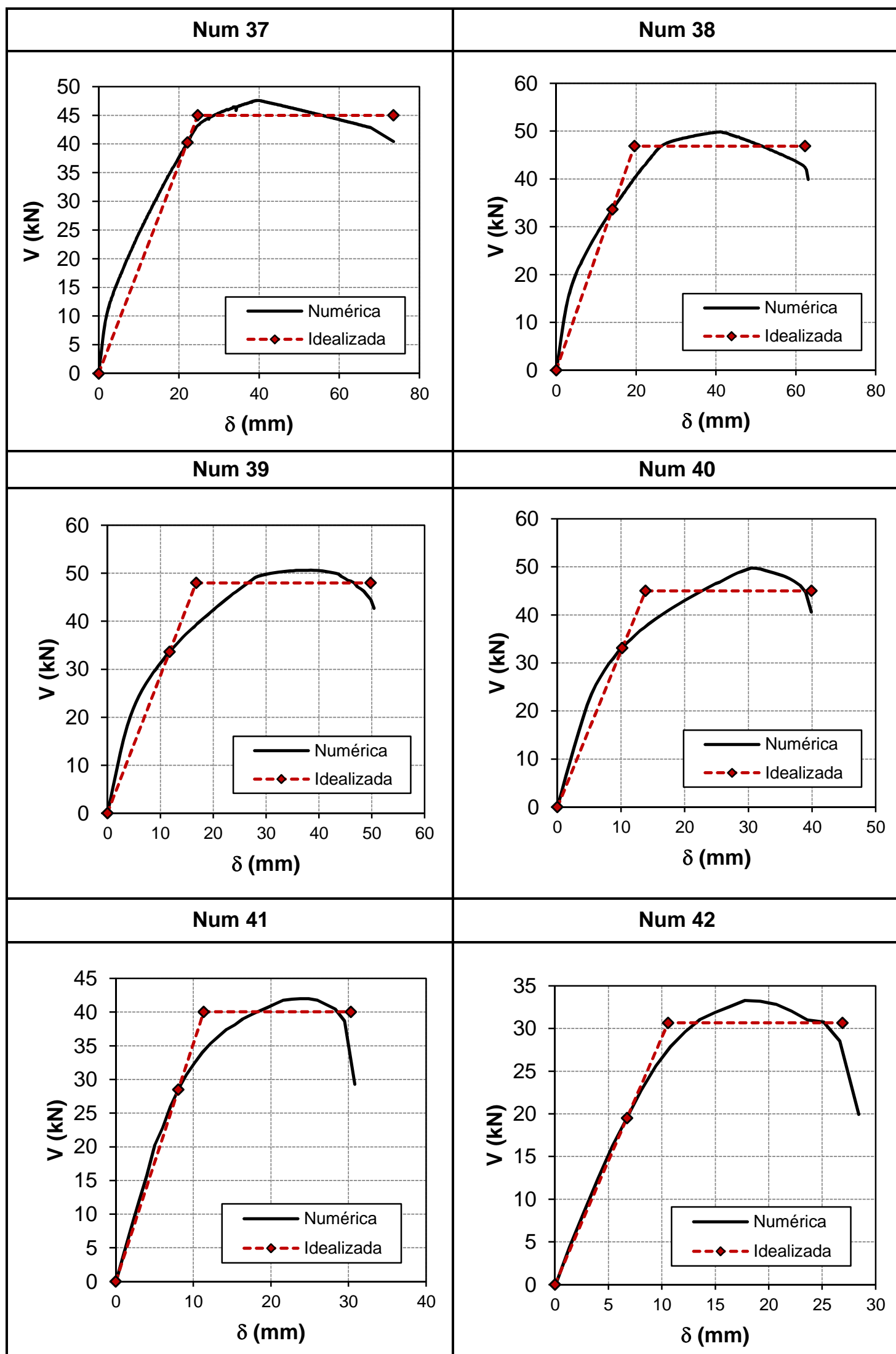

Num 42

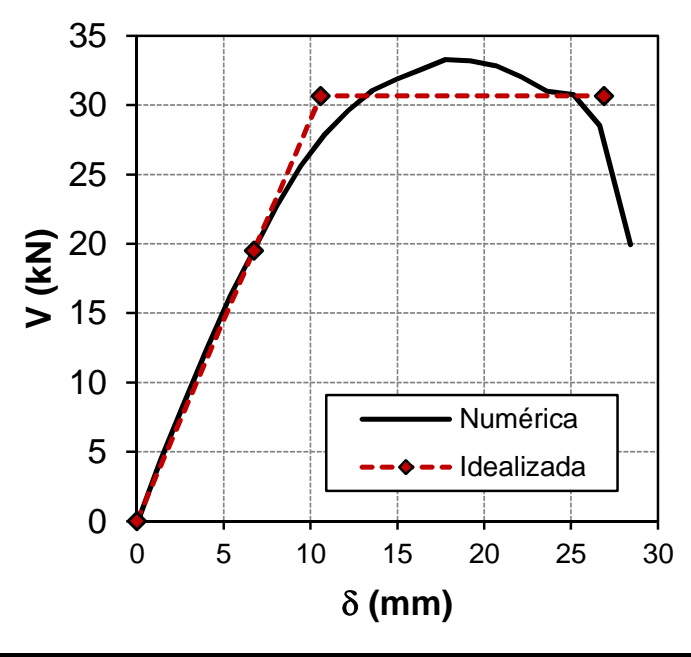


Estudio experimental y numérico de la capacidad de deformación de soportes esbeltos de hormigón armado

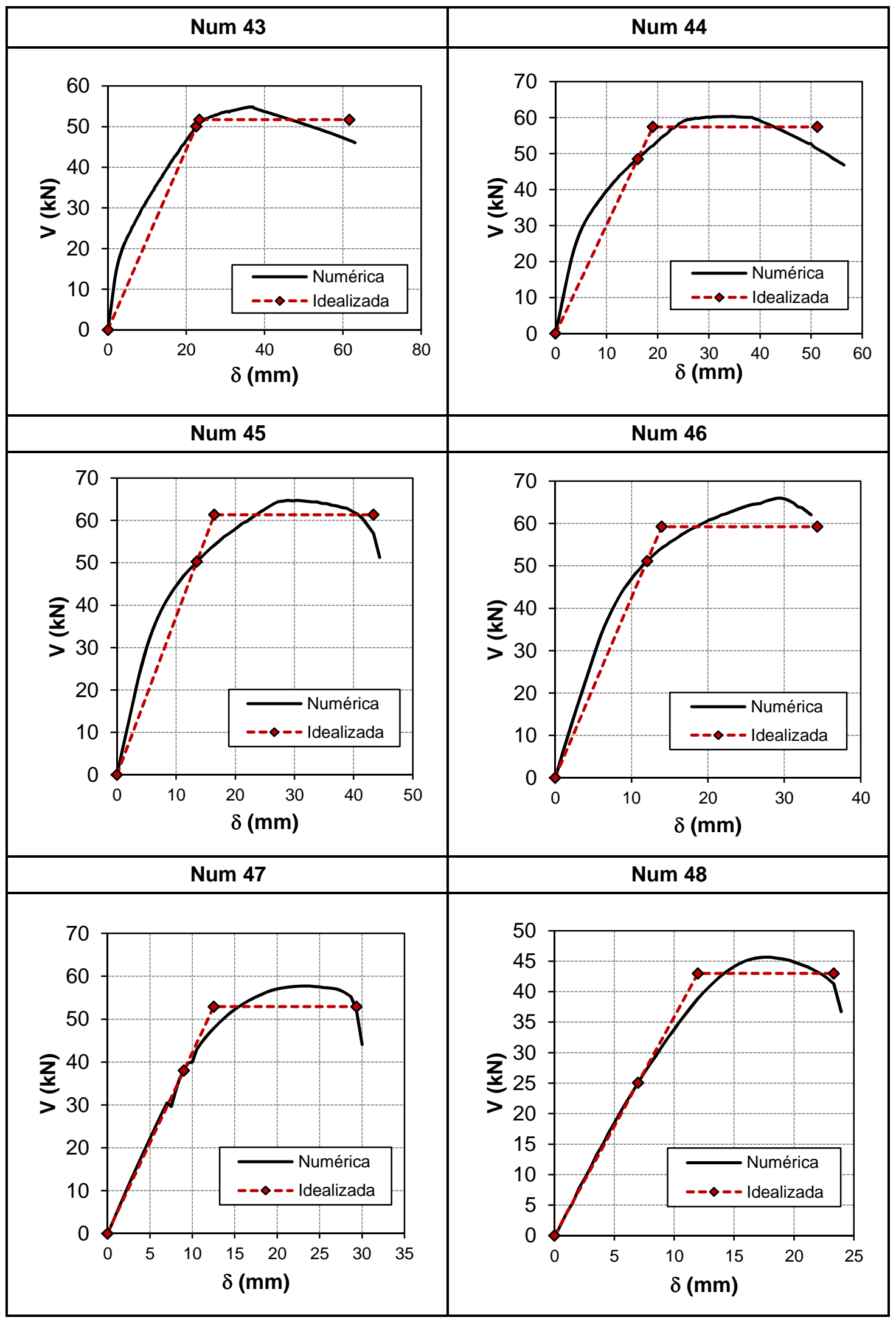


Anejo M: Respuesta Carga-Flecha e idealización de los ensayos numéricos

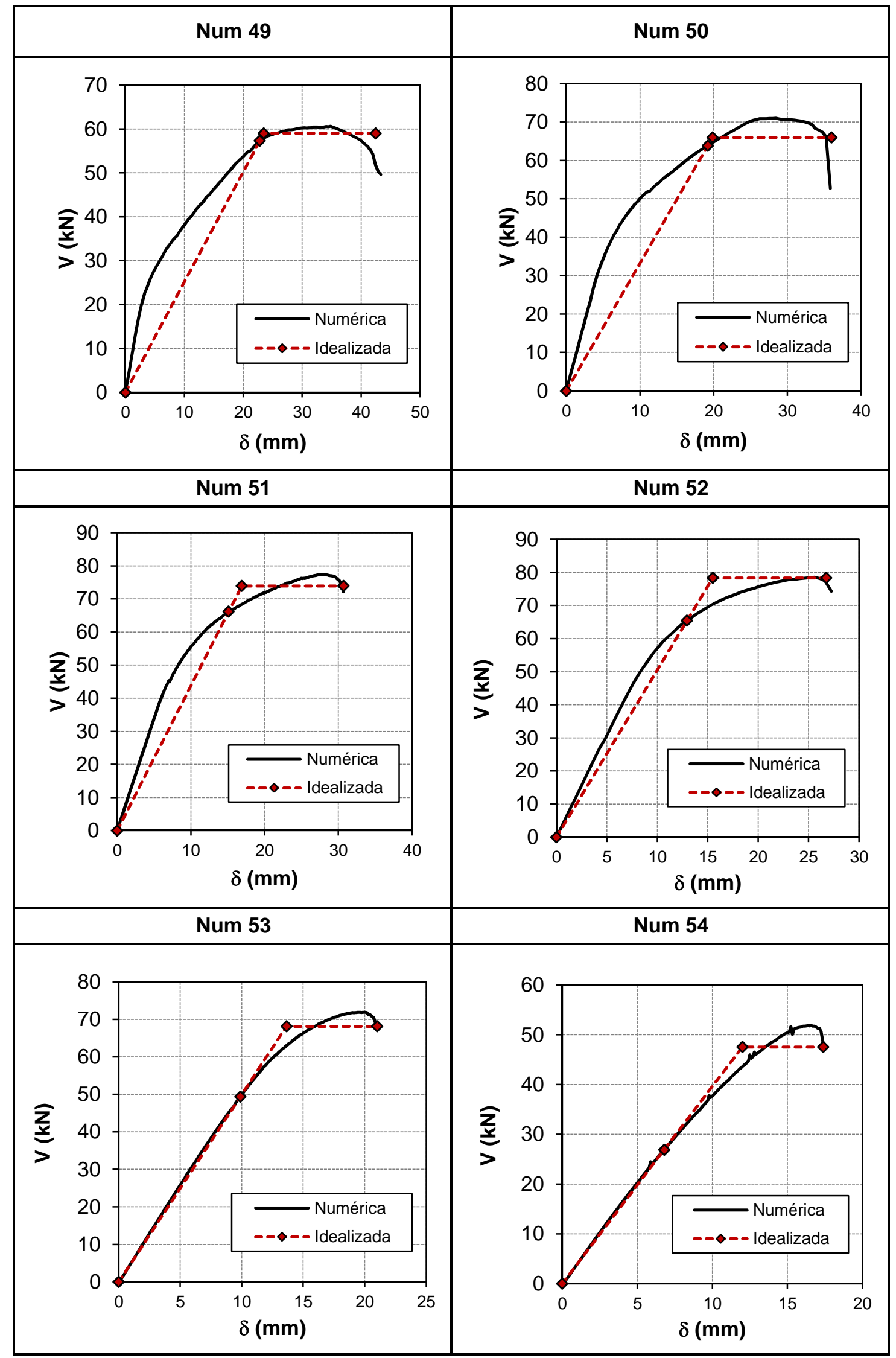


Estudio experimental y numérico de la capacidad de deformación de soportes esbeltos de hormigón armado

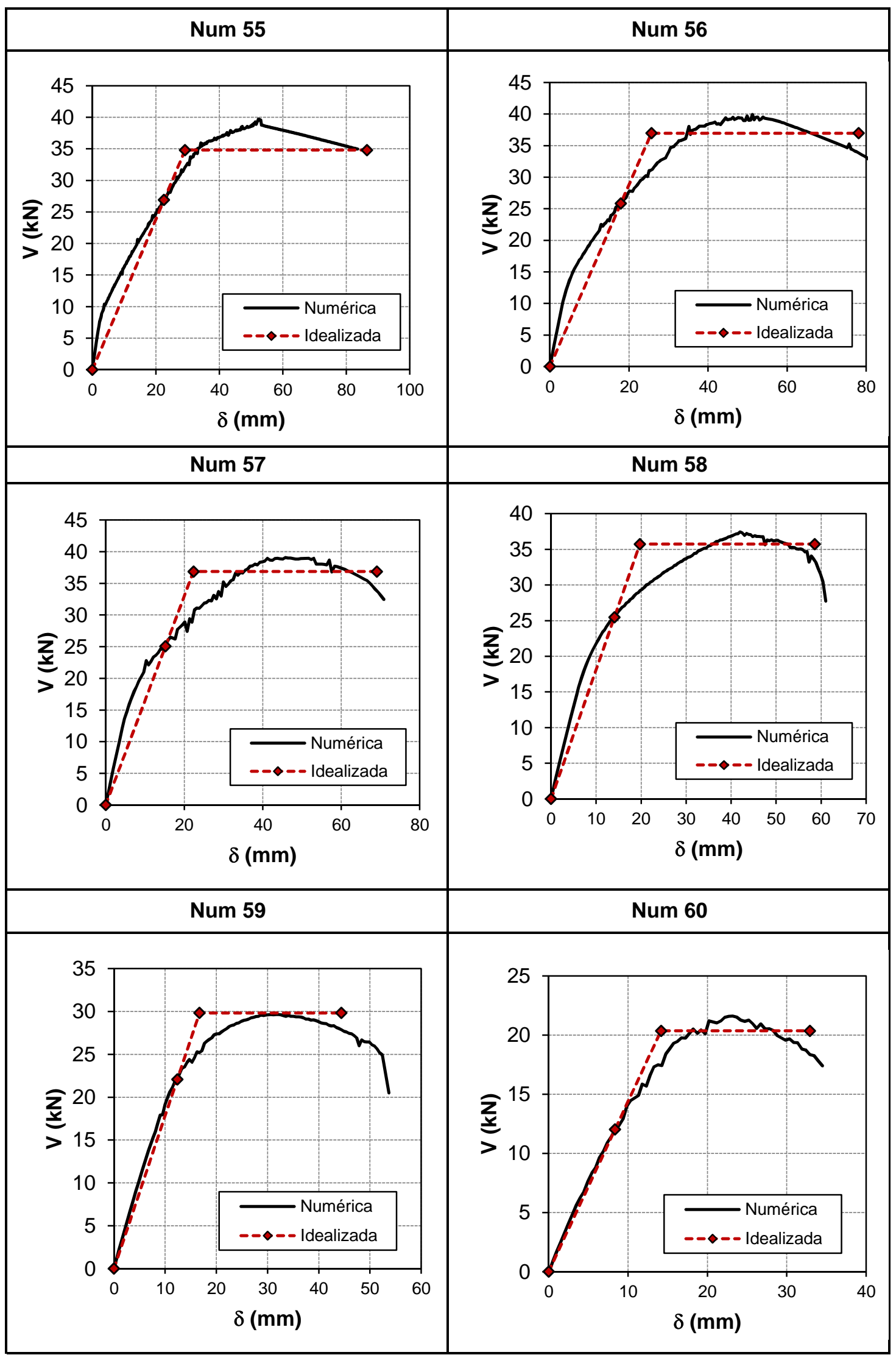


Anejo M: Respuesta Carga-Flecha e idealización de los ensayos numéricos

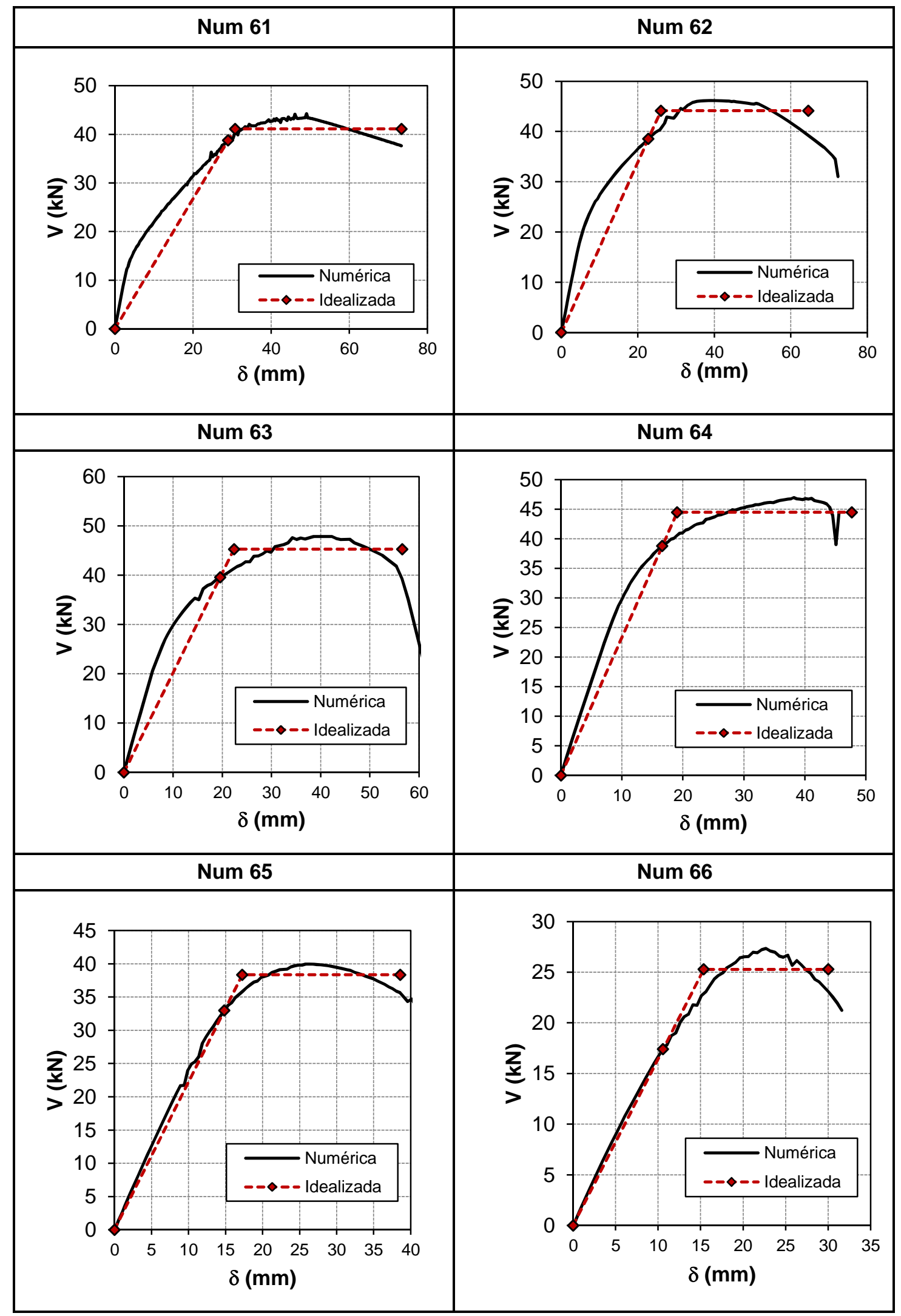


Estudio experimental y numérico de la capacidad de deformación de soportes esbeltos de hormigón armado

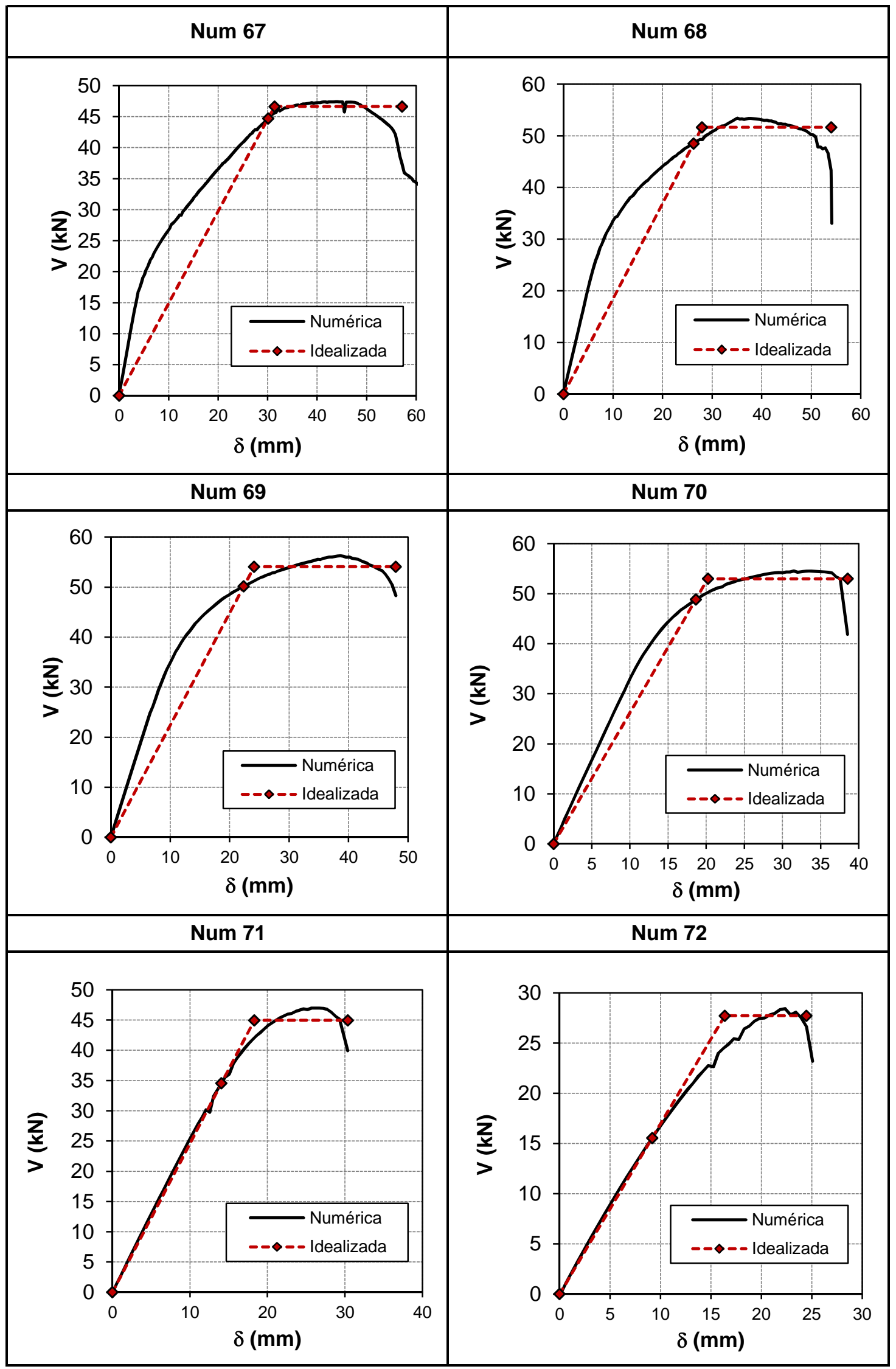




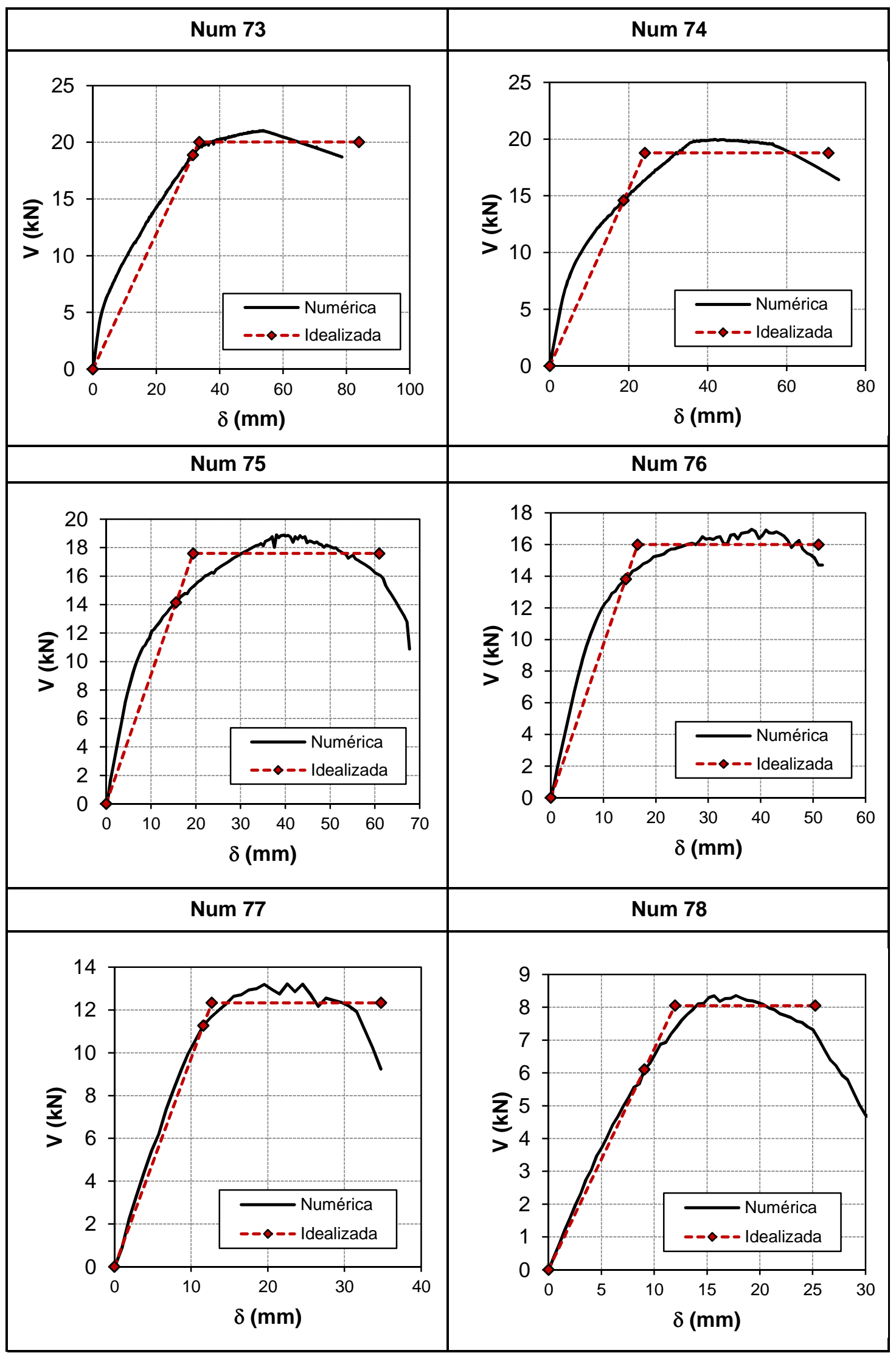


Estudio experimental y numérico de la capacidad de deformación de soportes esbeltos de hormigón armado

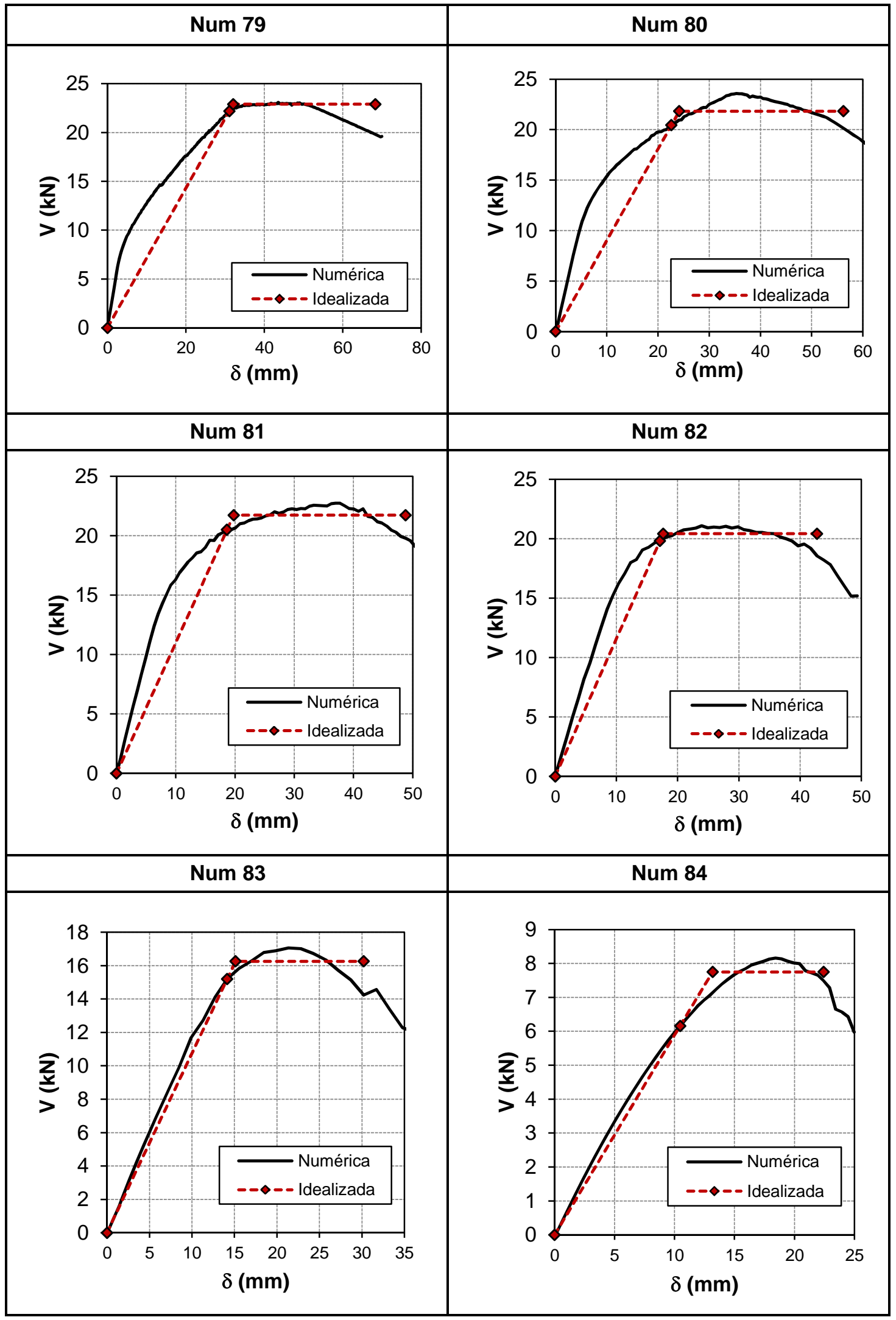


Anejo M: Respuesta Carga-Flecha e idealización de los ensayos numéricos

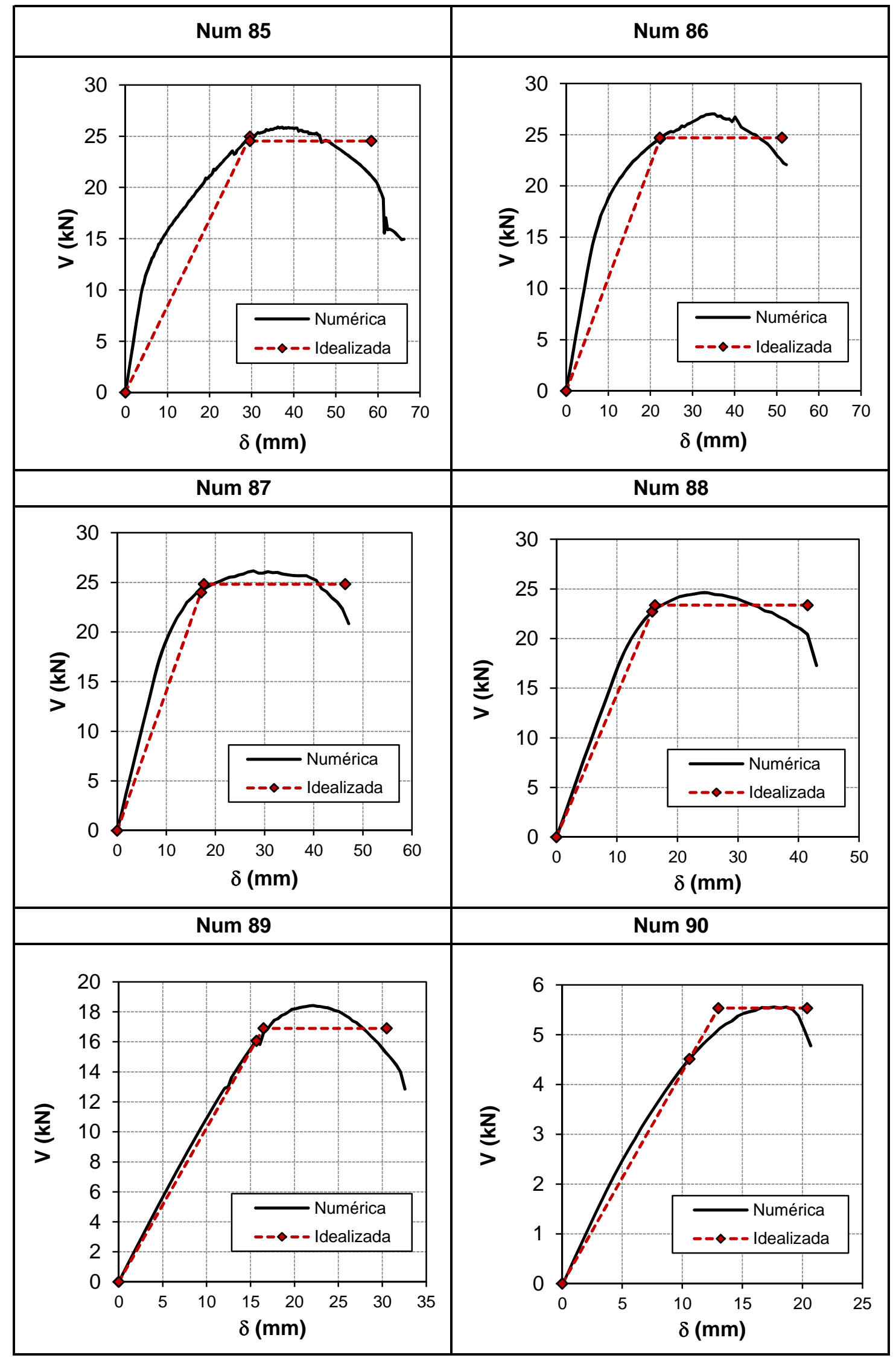


Estudio experimental y numérico de la capacidad de deformación de soportes esbeltos de hormigón armado

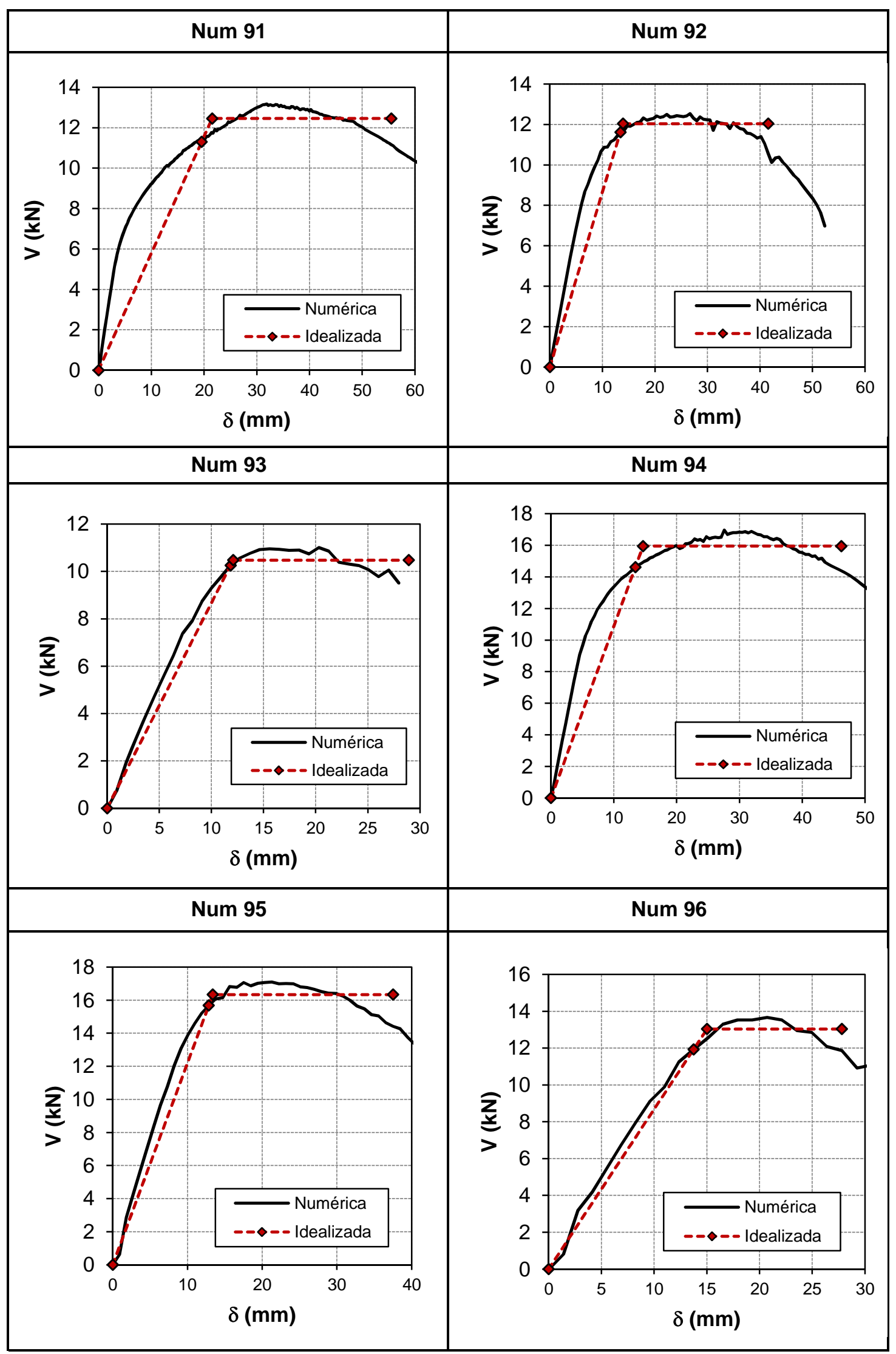


Anejo M: Respuesta Carga-Flecha e idealización de los ensayos numéricos

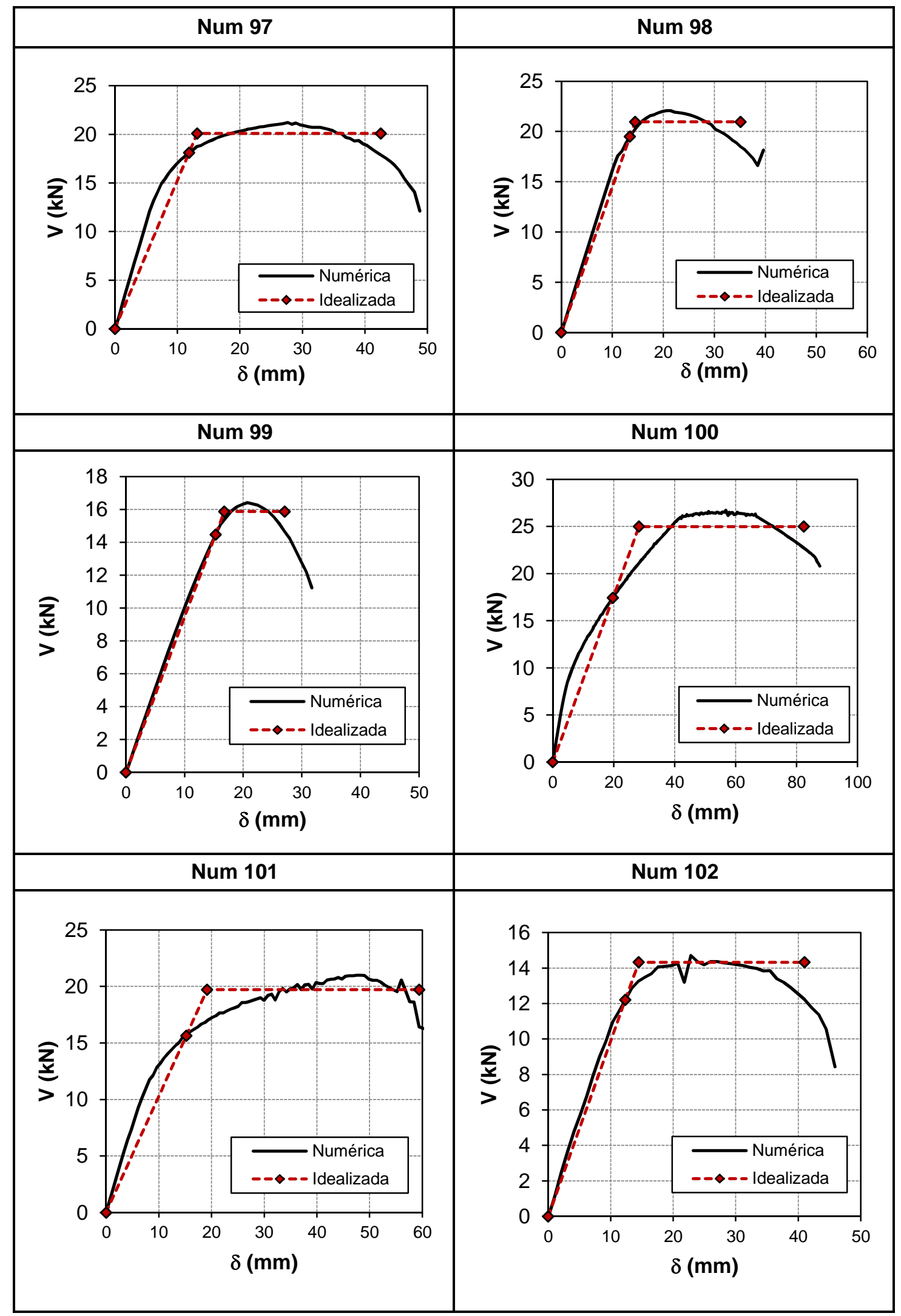


Estudio experimental y numérico de la capacidad de deformación de soportes esbeltos de hormigón armado

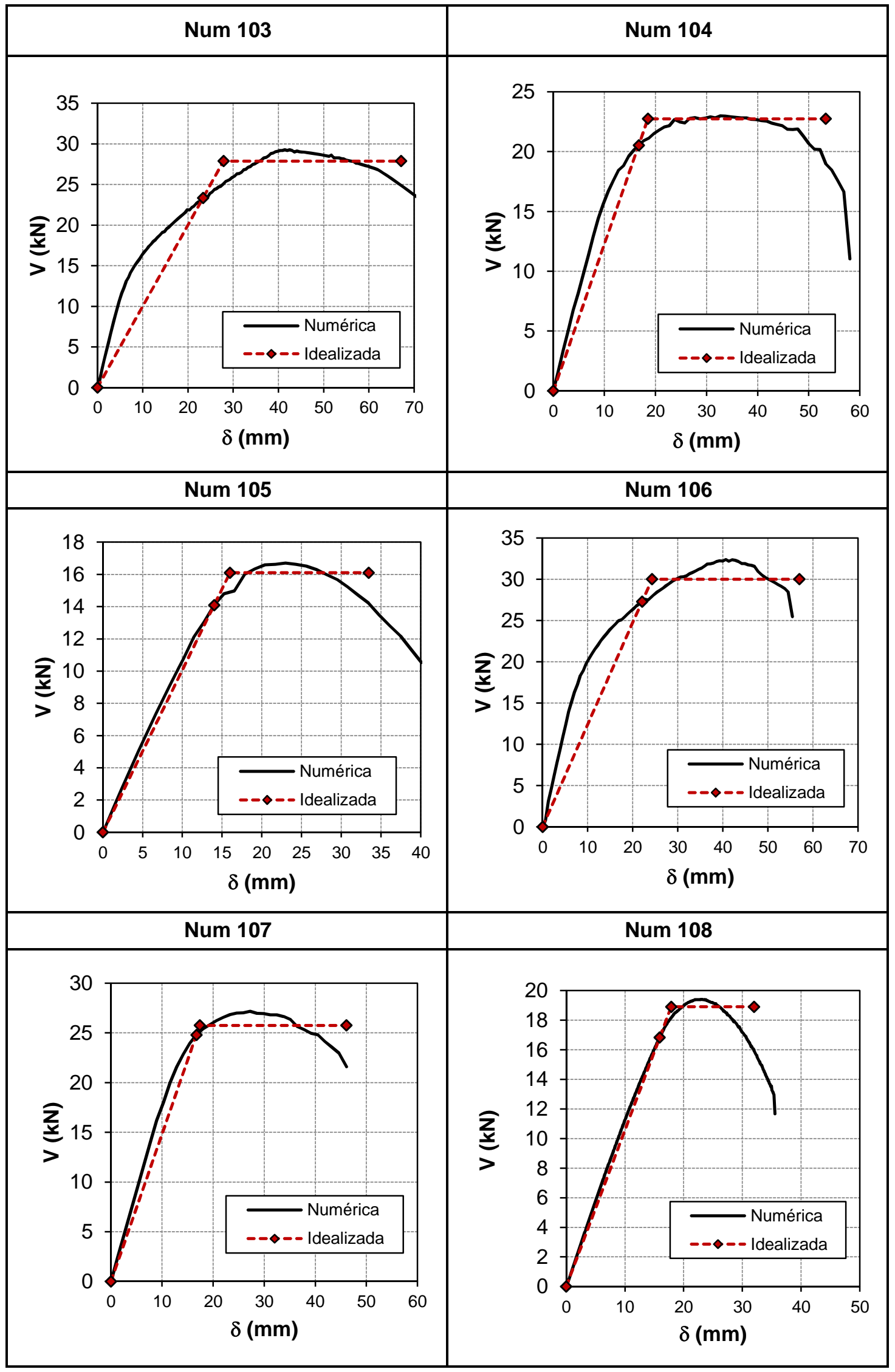




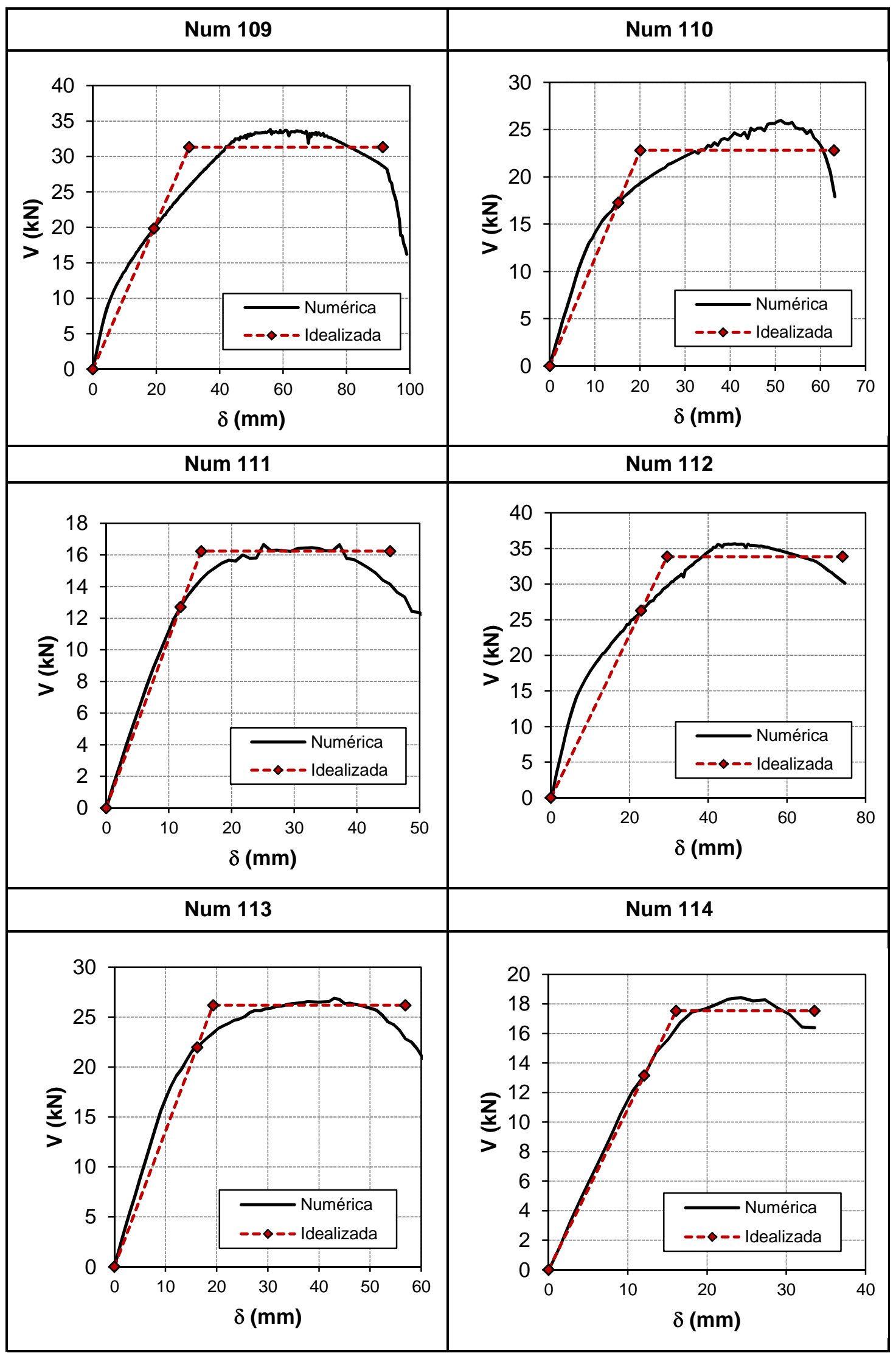


Estudio experimental y numérico de la capacidad de deformación de soportes esbeltos de hormigón armado

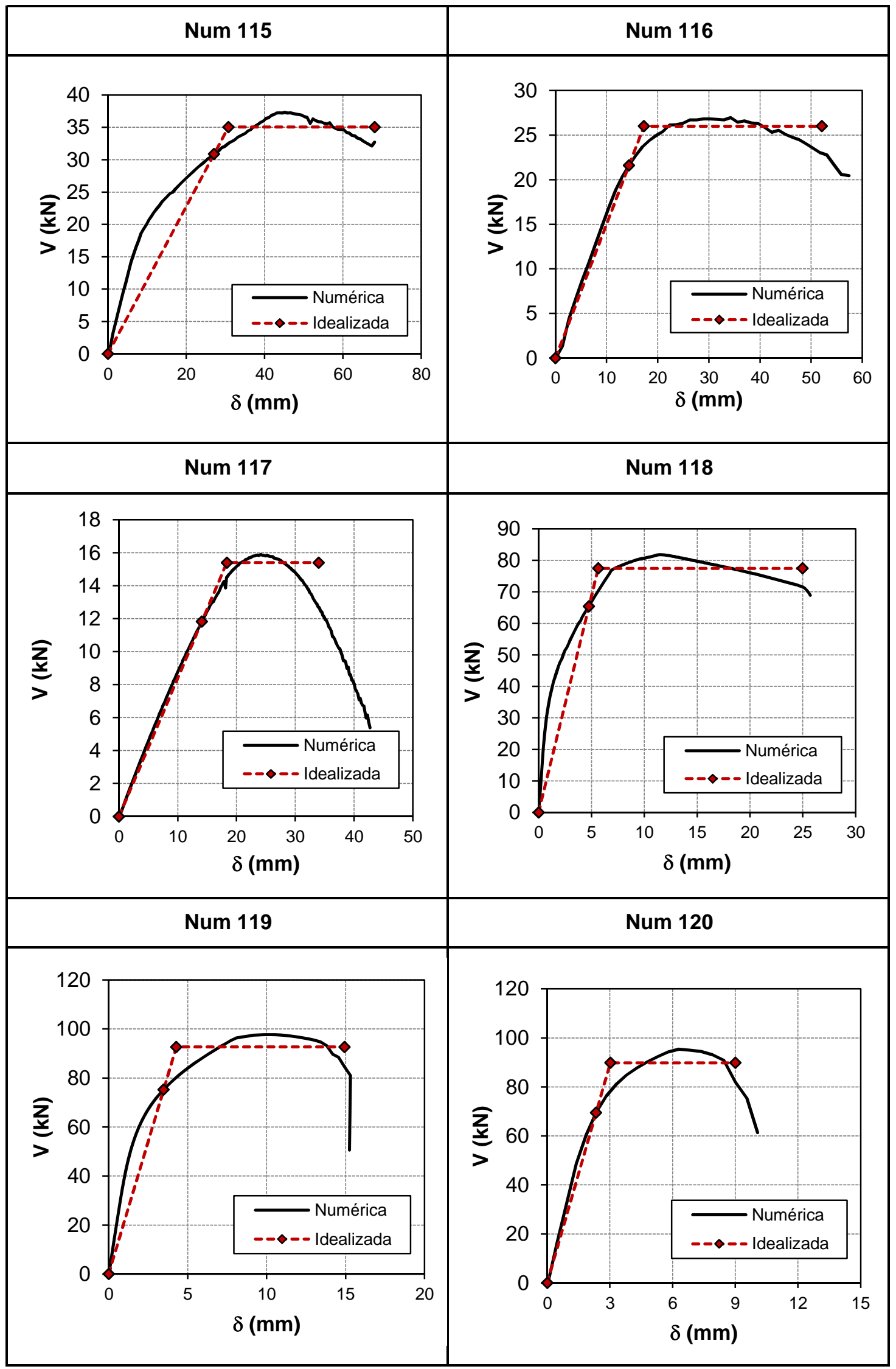


Anejo M: Respuesta Carga-Flecha e idealización de los ensayos numéricos

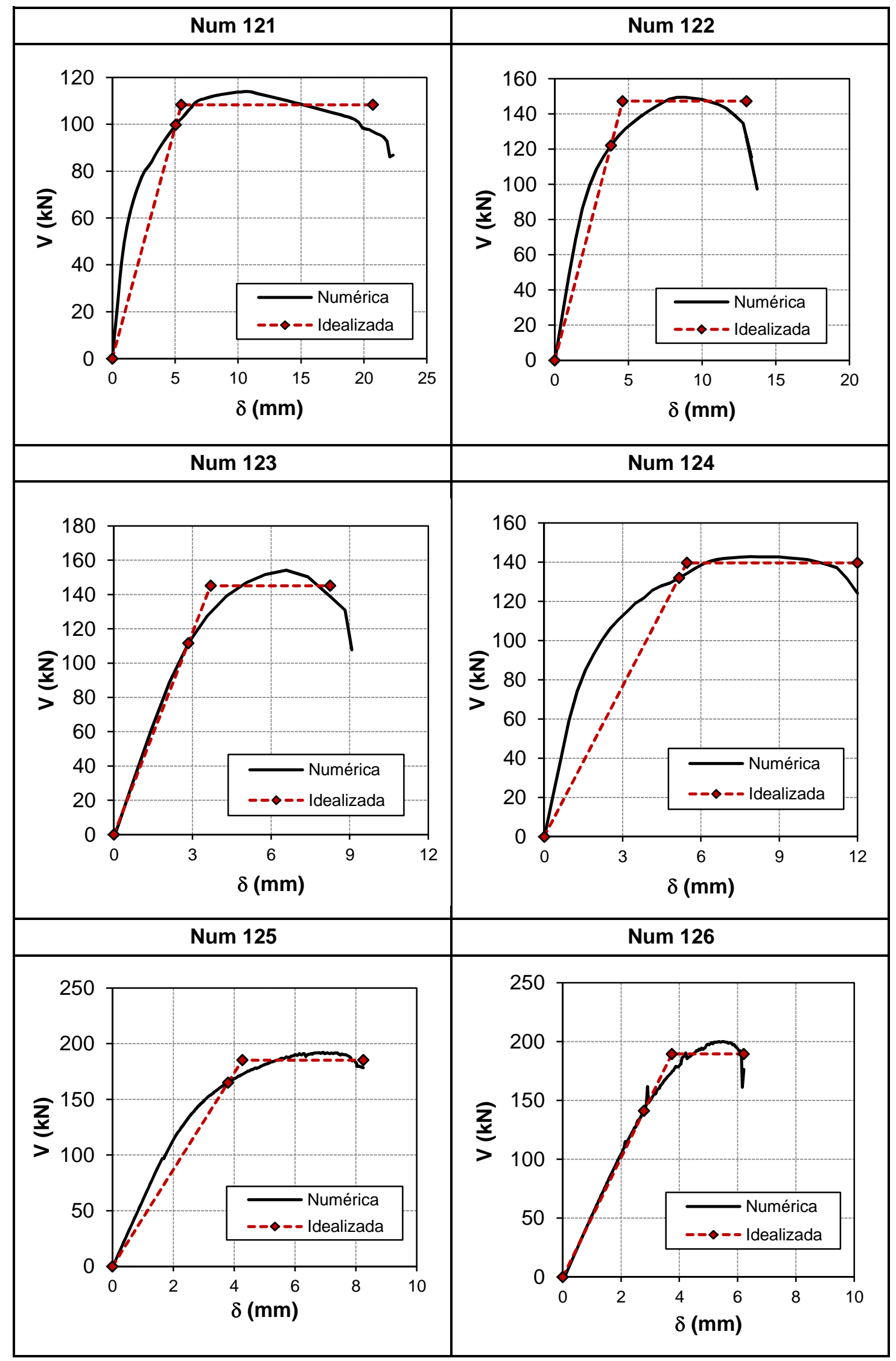


Estudio experimental y numérico de la capacidad de deformación de soportes esbeltos de hormigón armado

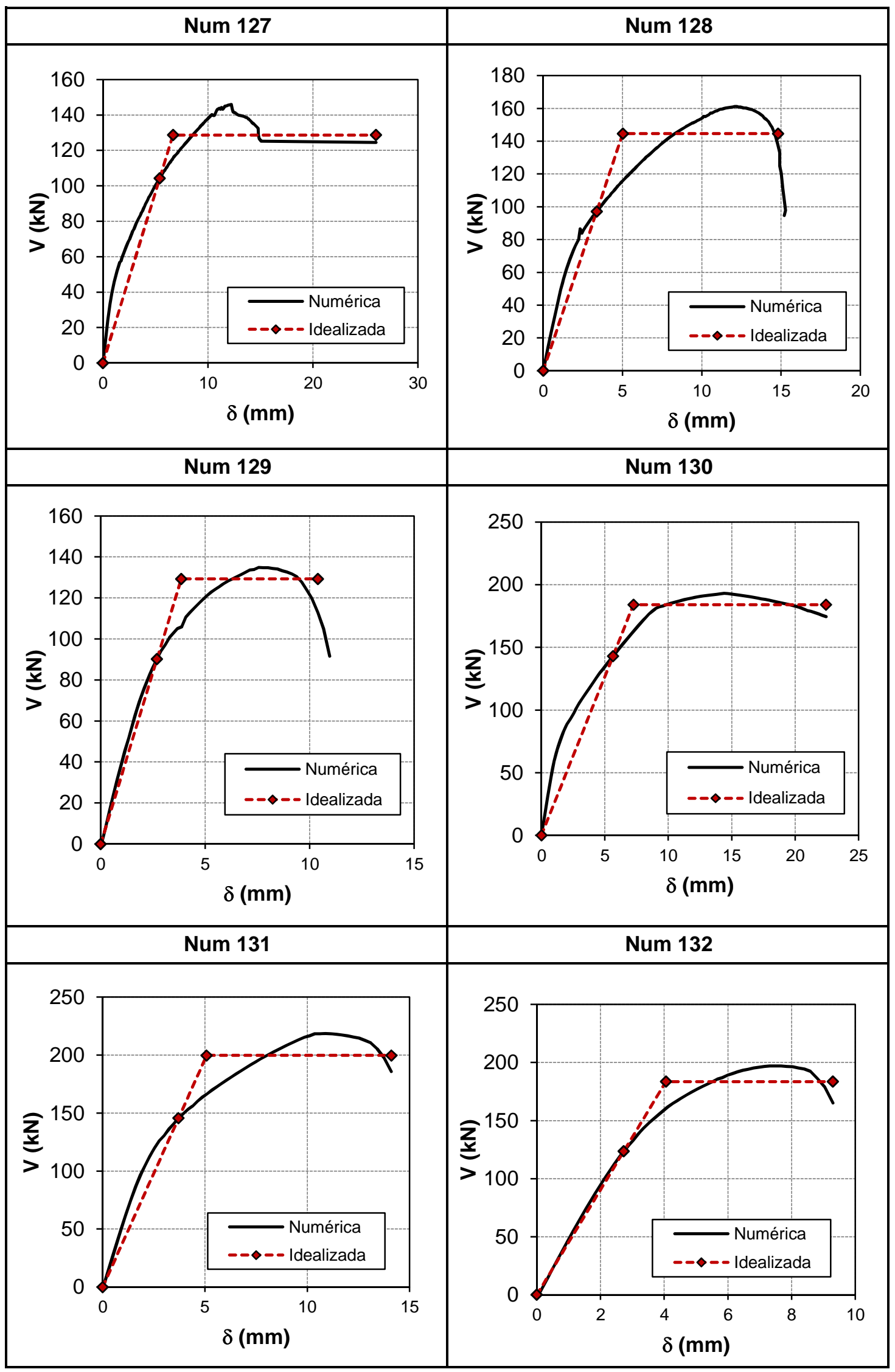


Anejo M: Respuesta Carga-Flecha e idealización de los ensayos numéricos

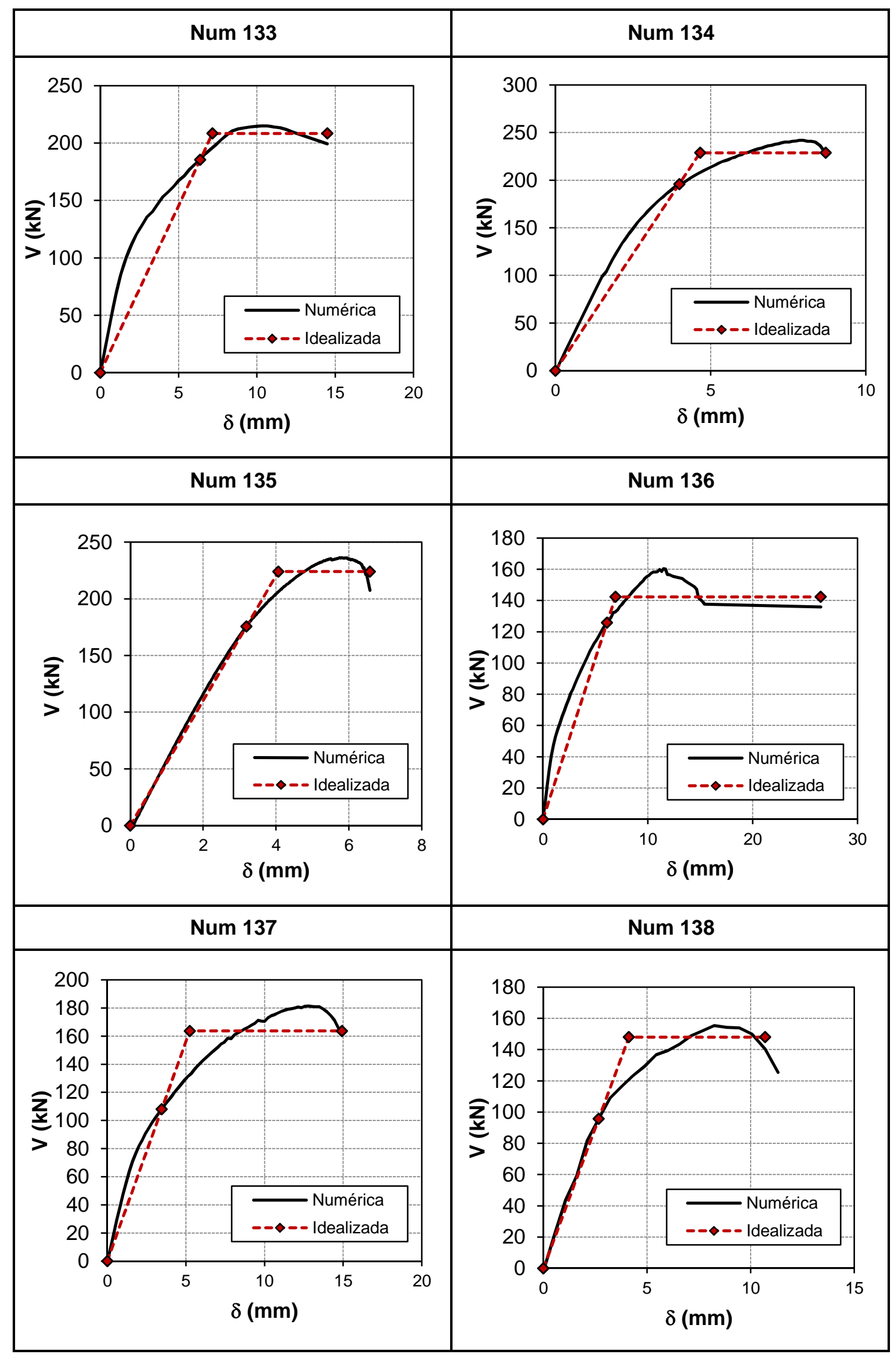


Estudio experimental y numérico de la capacidad de deformación de soportes esbeltos de hormigón armado

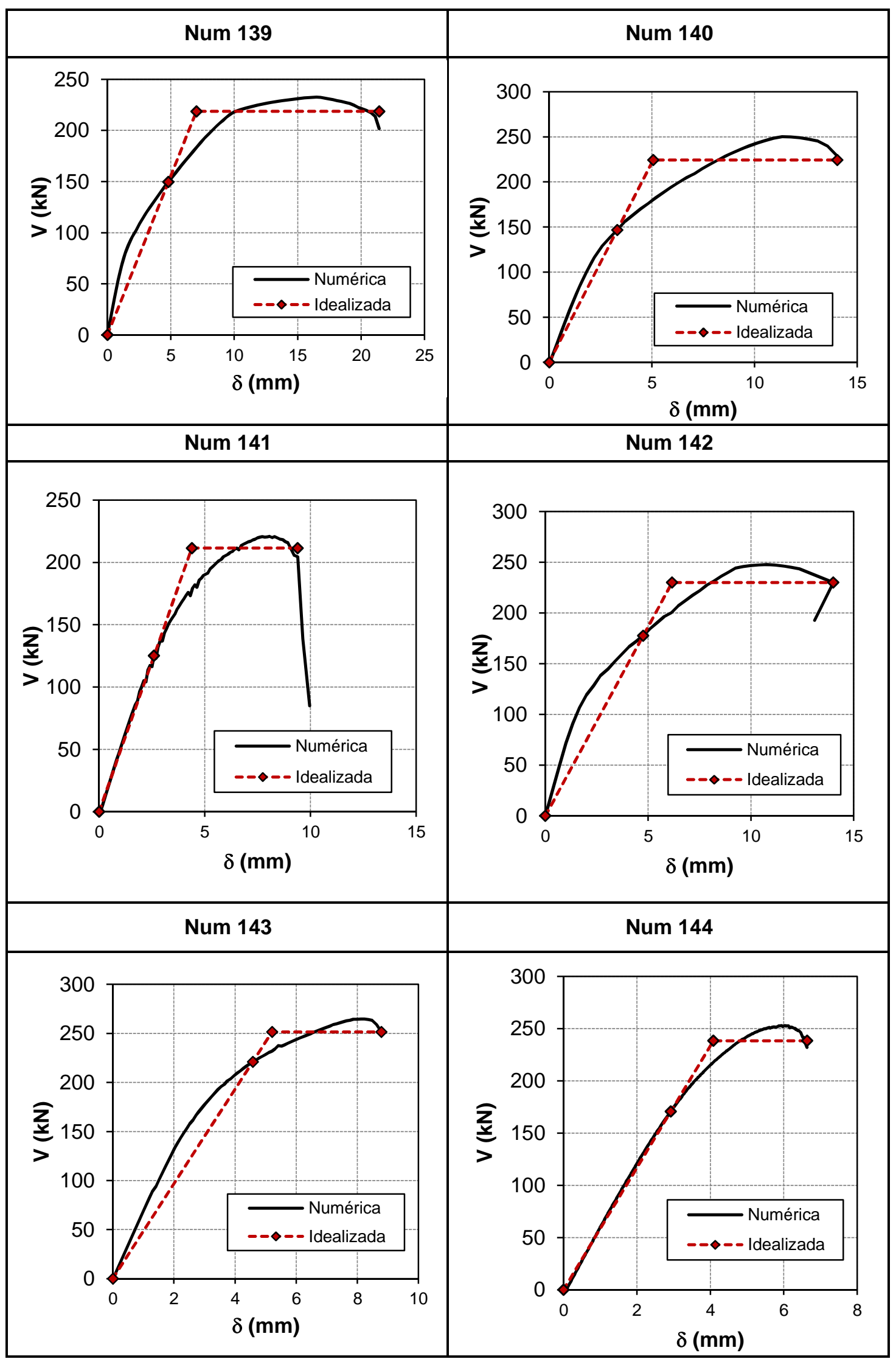


Anejo M: Respuesta Carga-Flecha e idealización de los ensayos numéricos

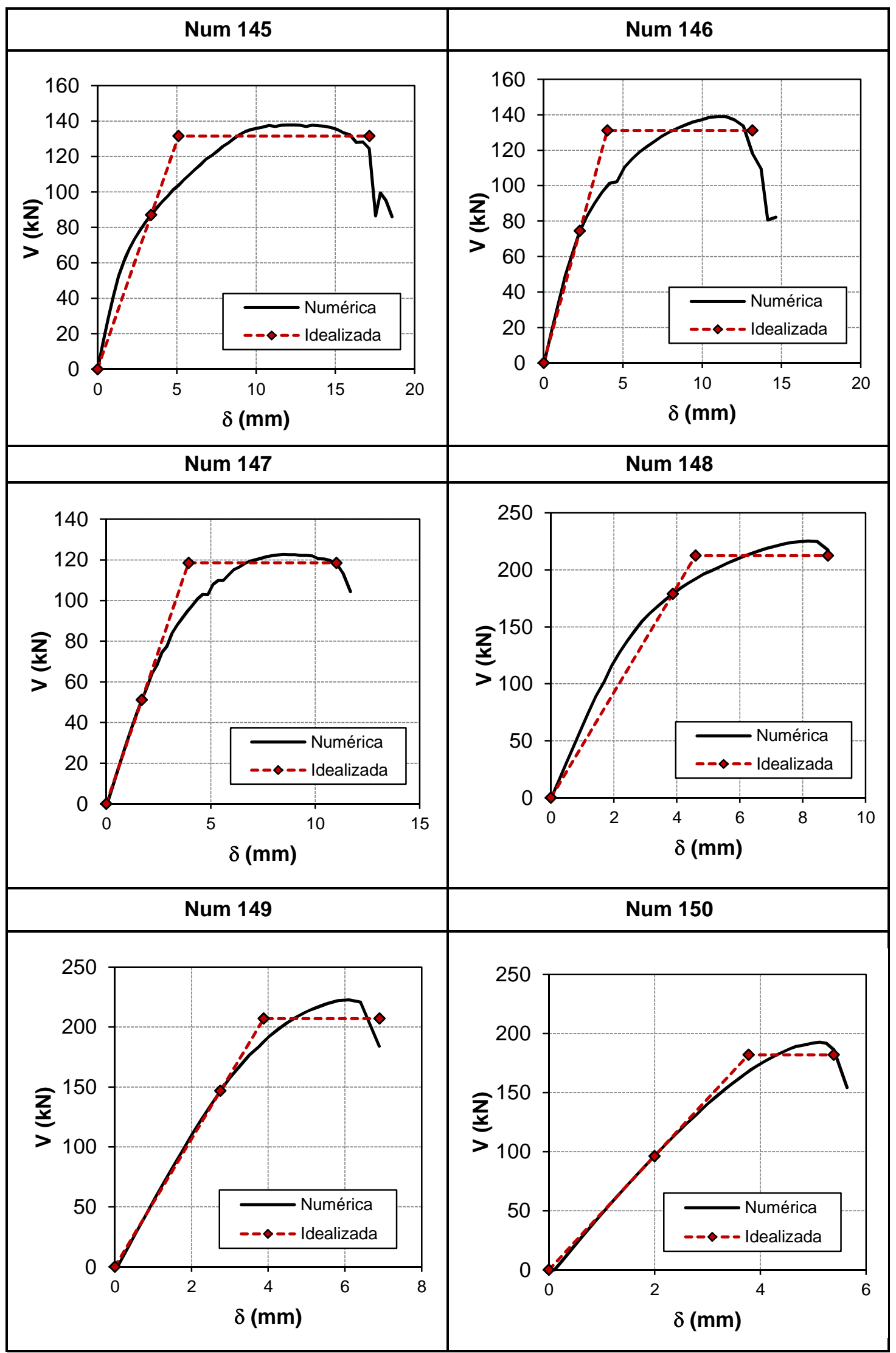


Estudio experimental y numérico de la capacidad de deformación de soportes esbeltos de hormigón armado

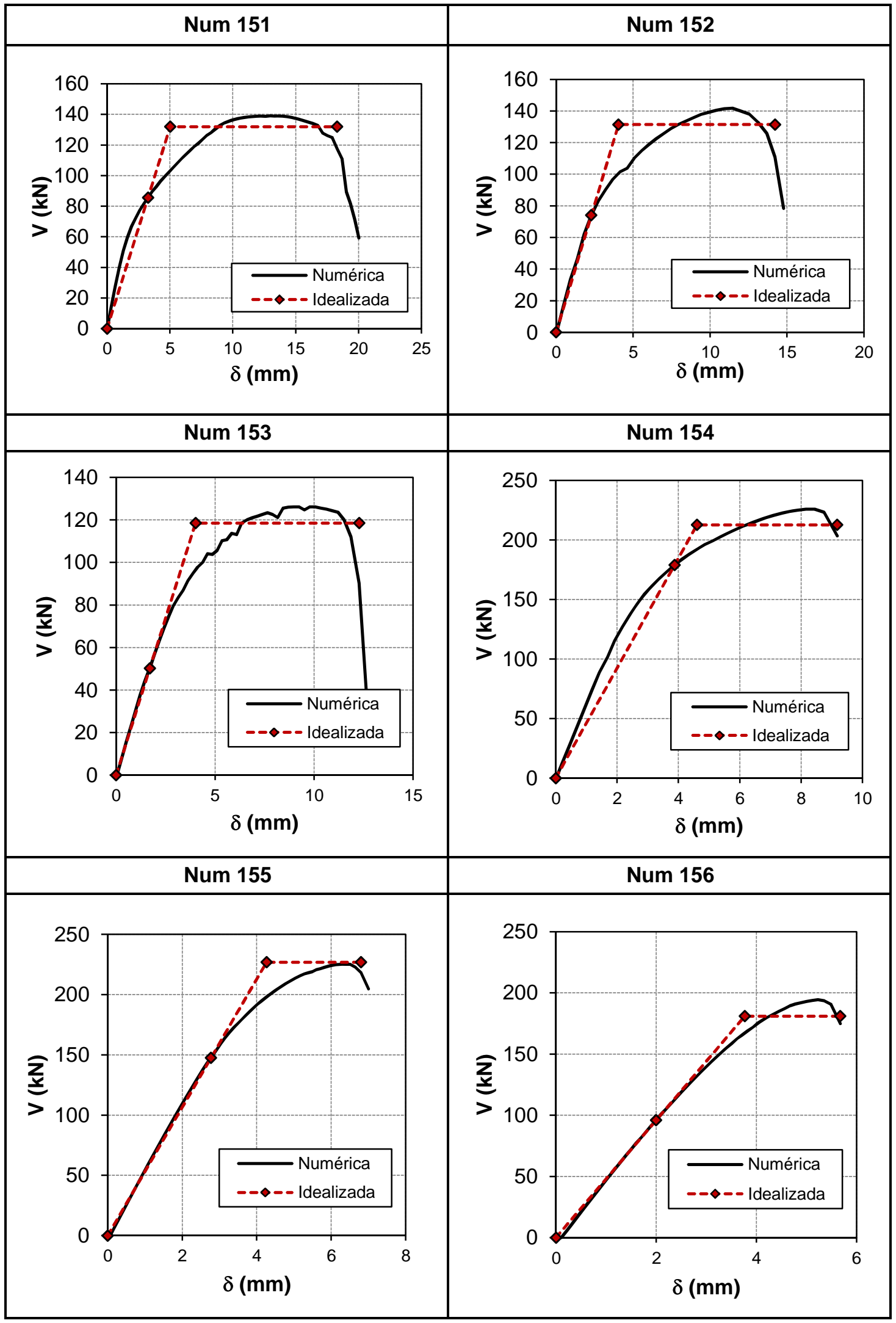


Anejo M: Respuesta Carga-Flecha e idealización de los ensayos numéricos

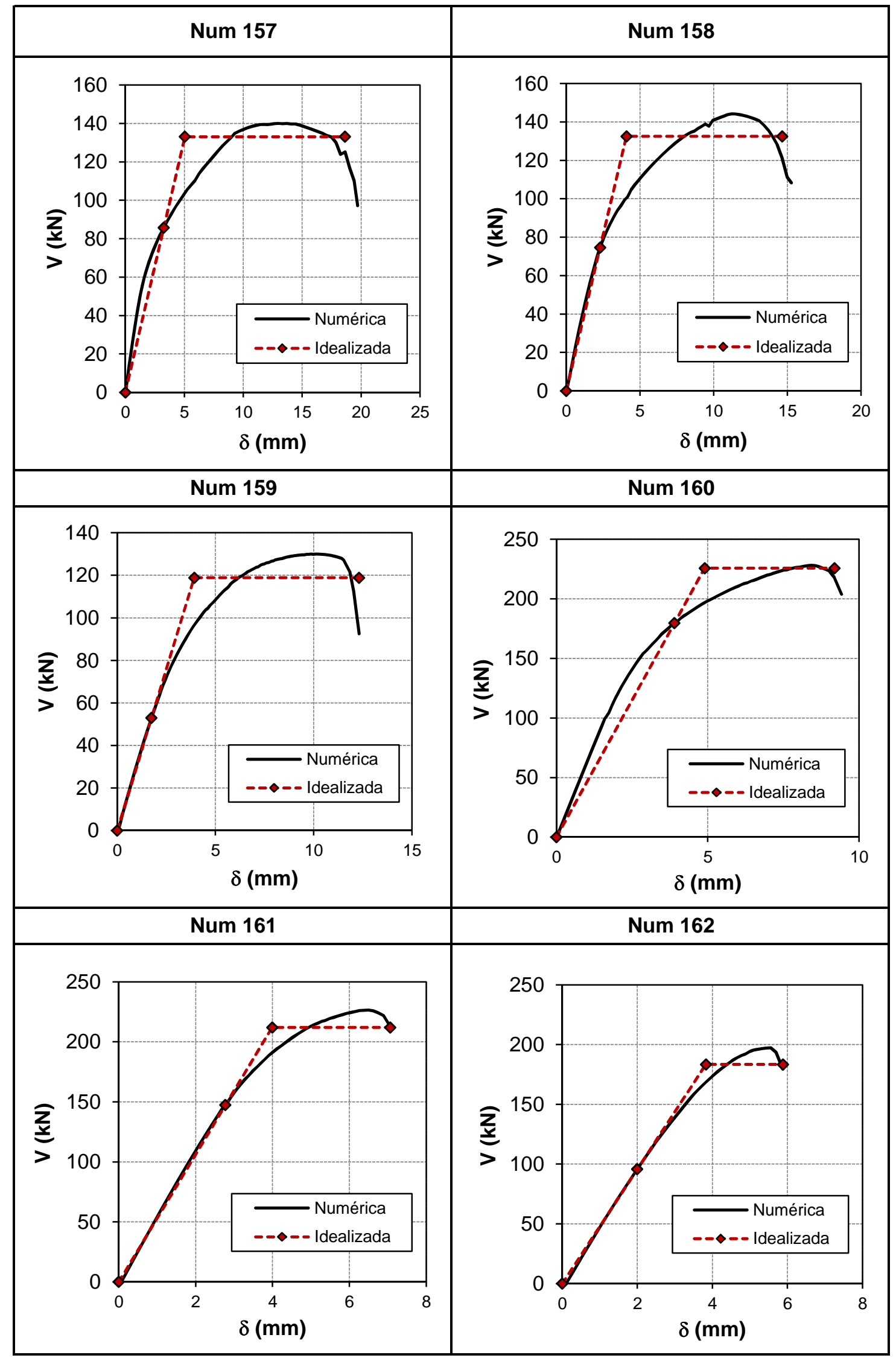


Estudio experimental y numérico de la capacidad de deformación de soportes esbeltos de hormigón armado

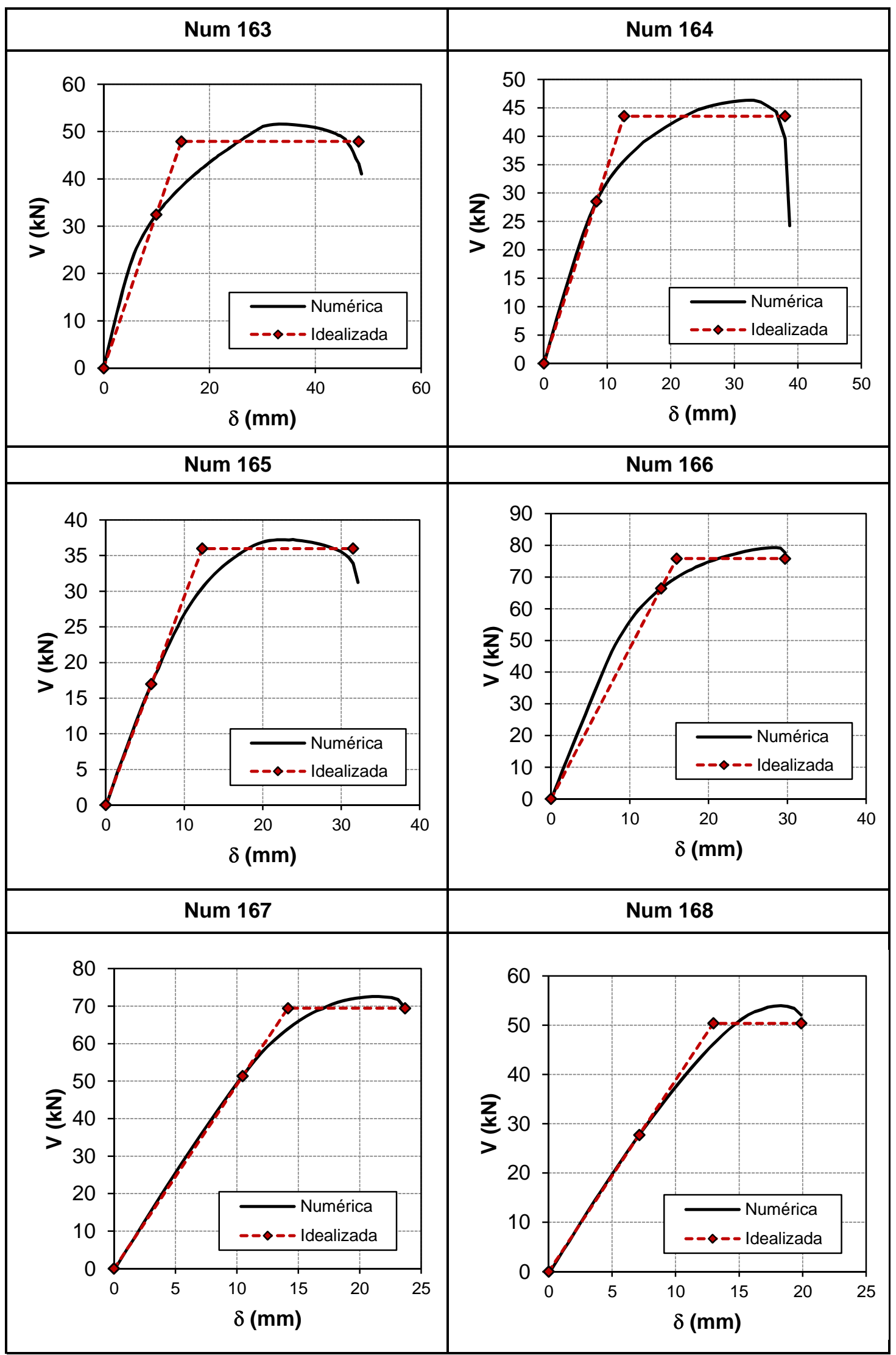




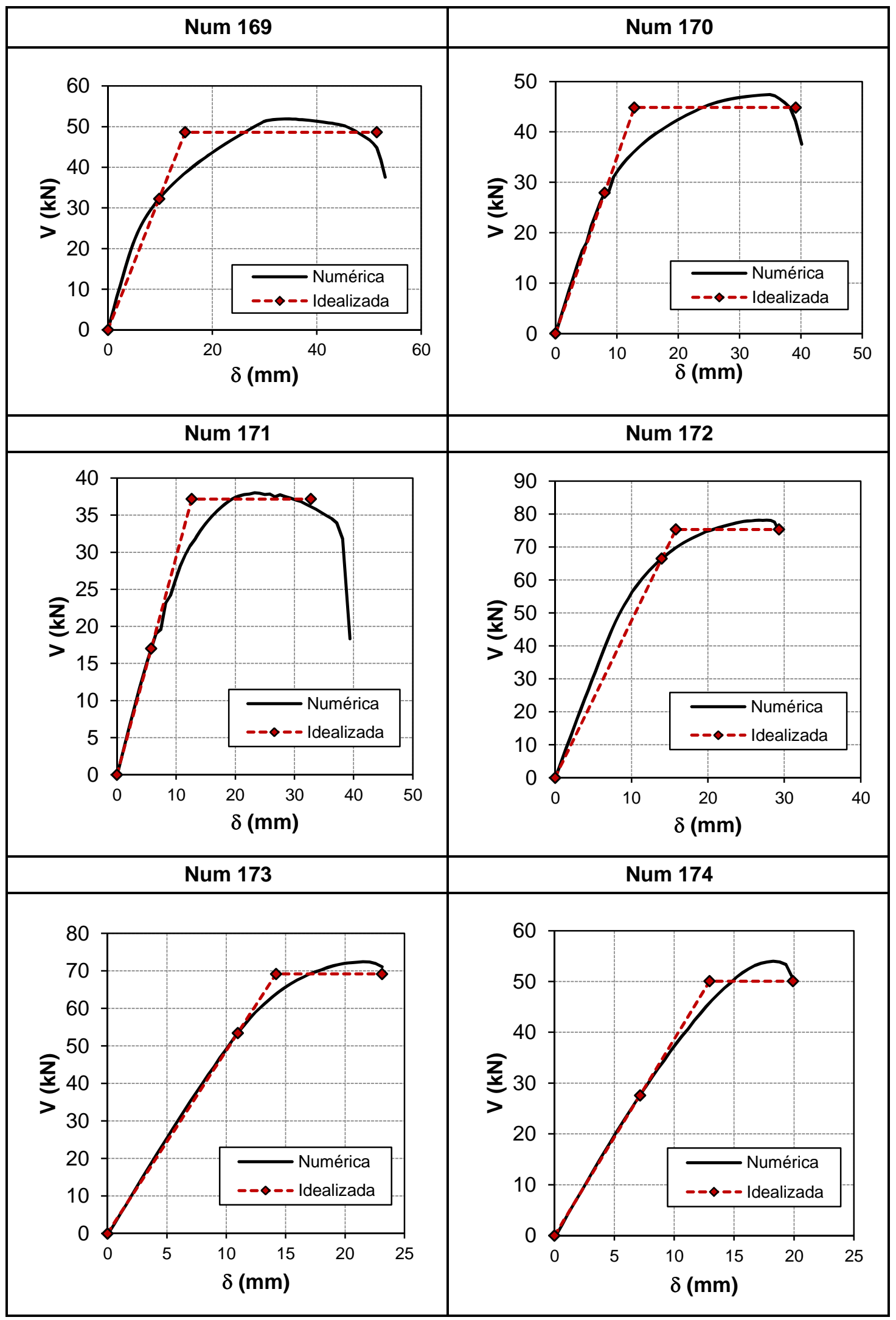


Estudio experimental y numérico de la capacidad de deformación de soportes esbeltos de hormigón armado

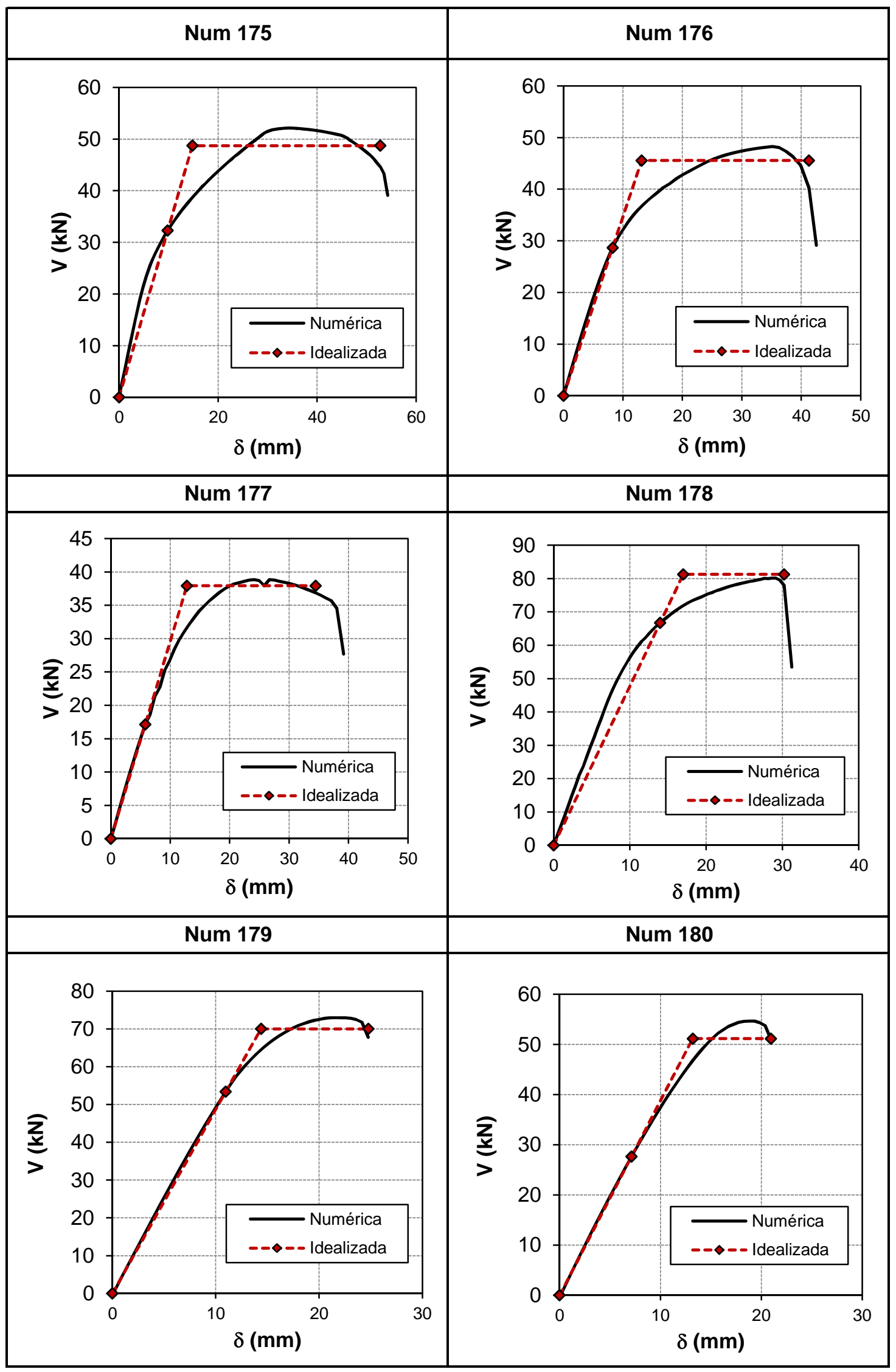




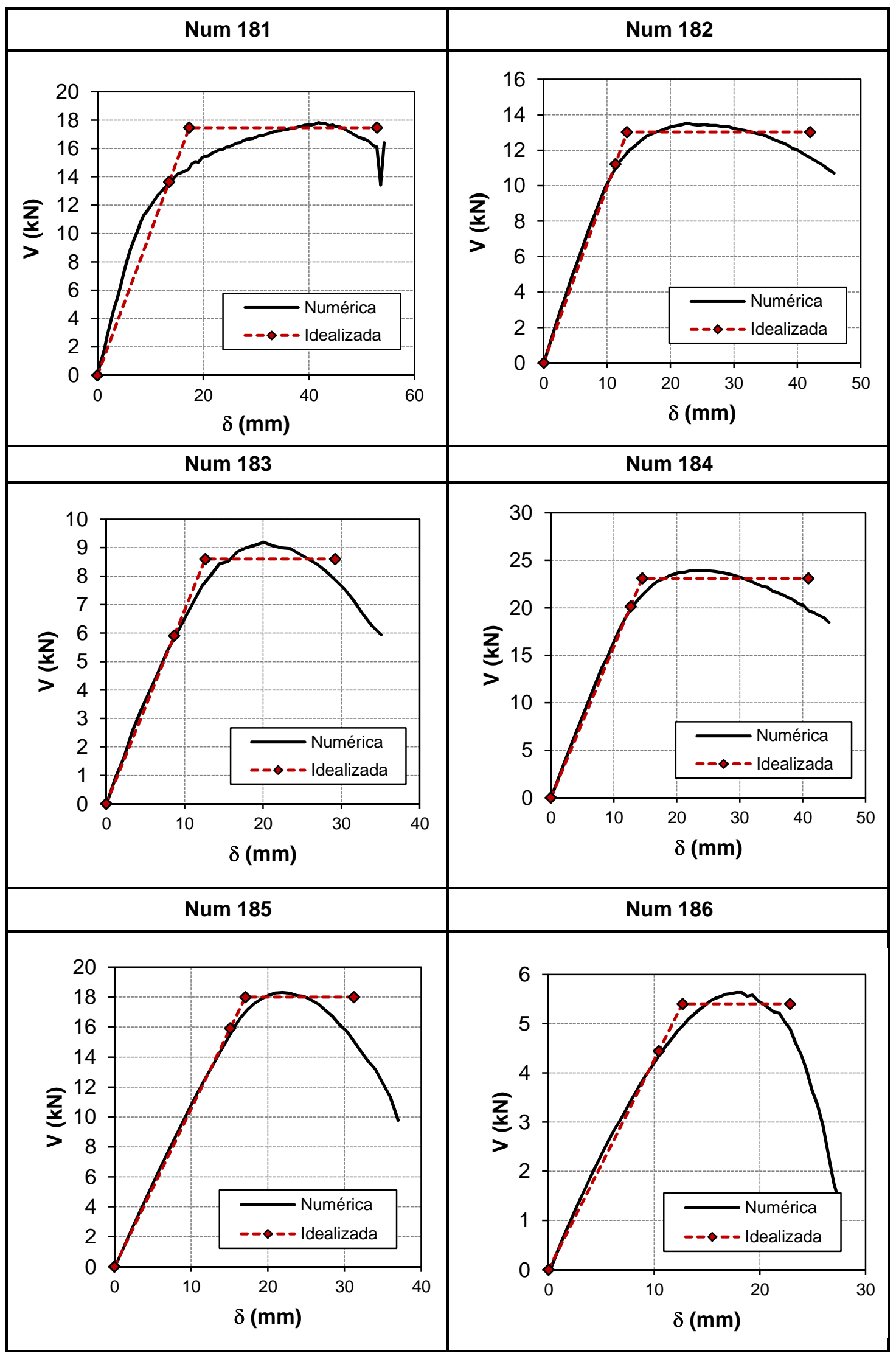


Estudio experimental y numérico de la capacidad de deformación de soportes esbeltos de hormigón armado

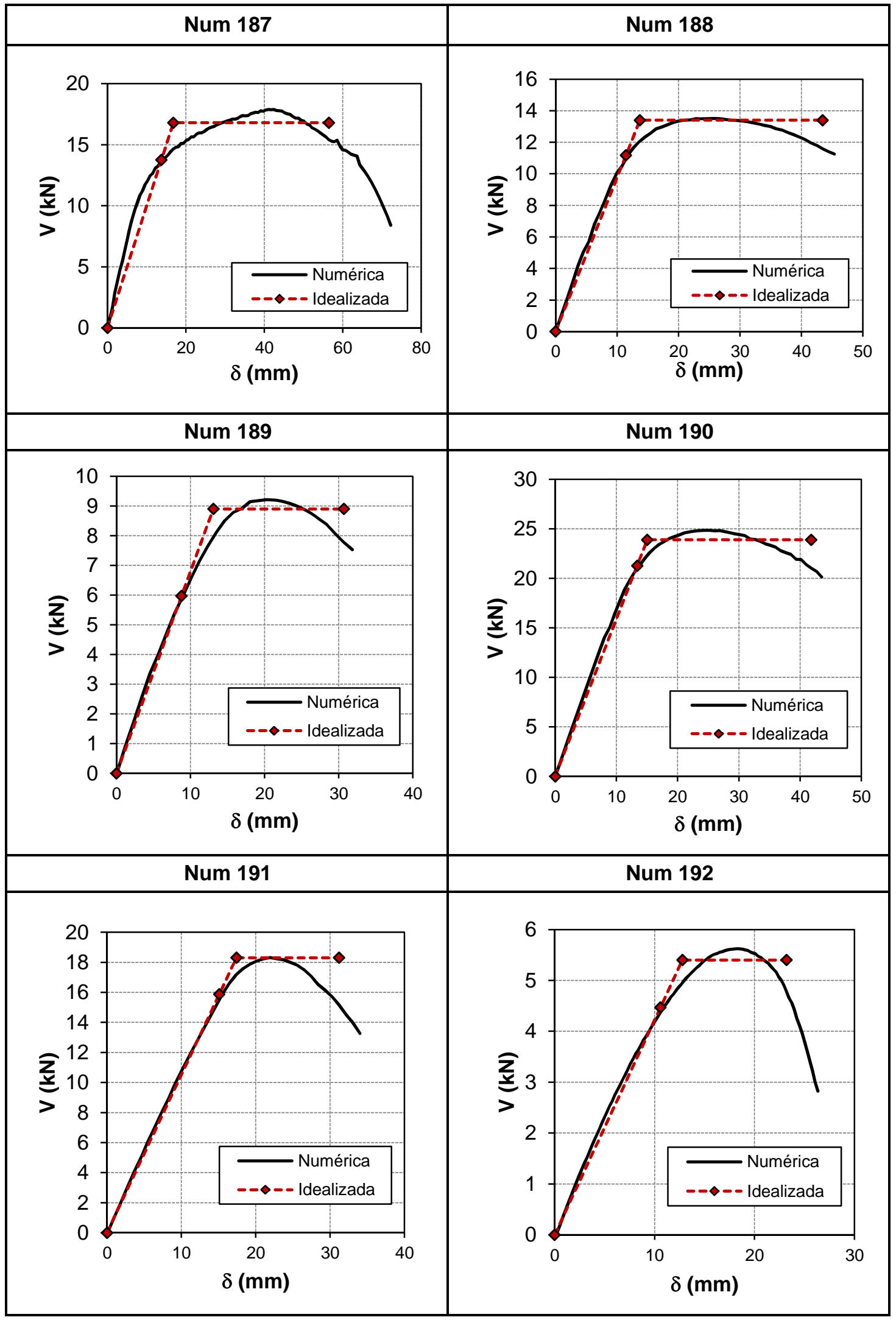


Anejo M: Respuesta Carga-Flecha e idealización de los ensayos numéricos

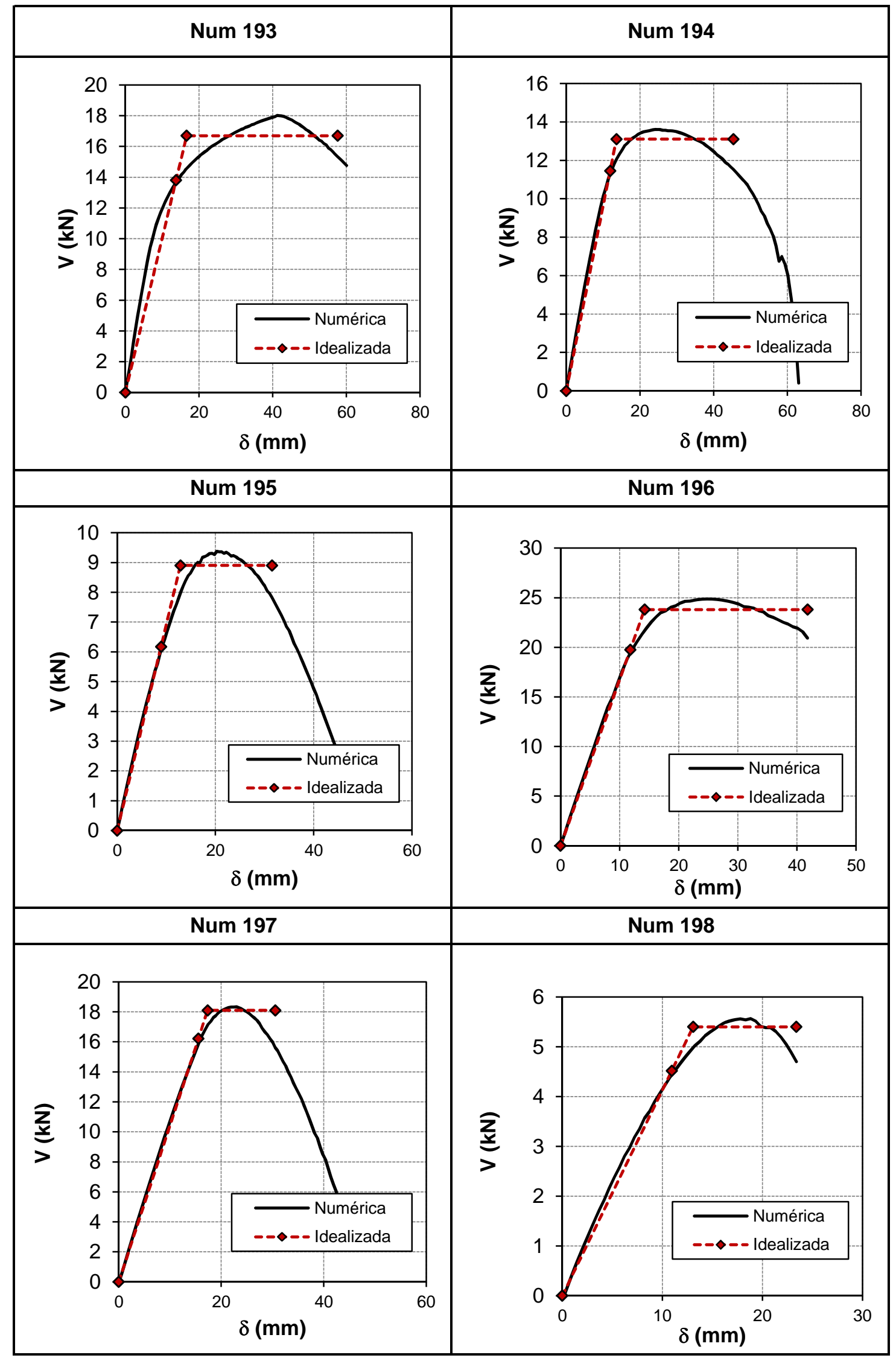


Estudio experimental y numérico de la capacidad de deformación de soportes esbeltos de hormigón armado

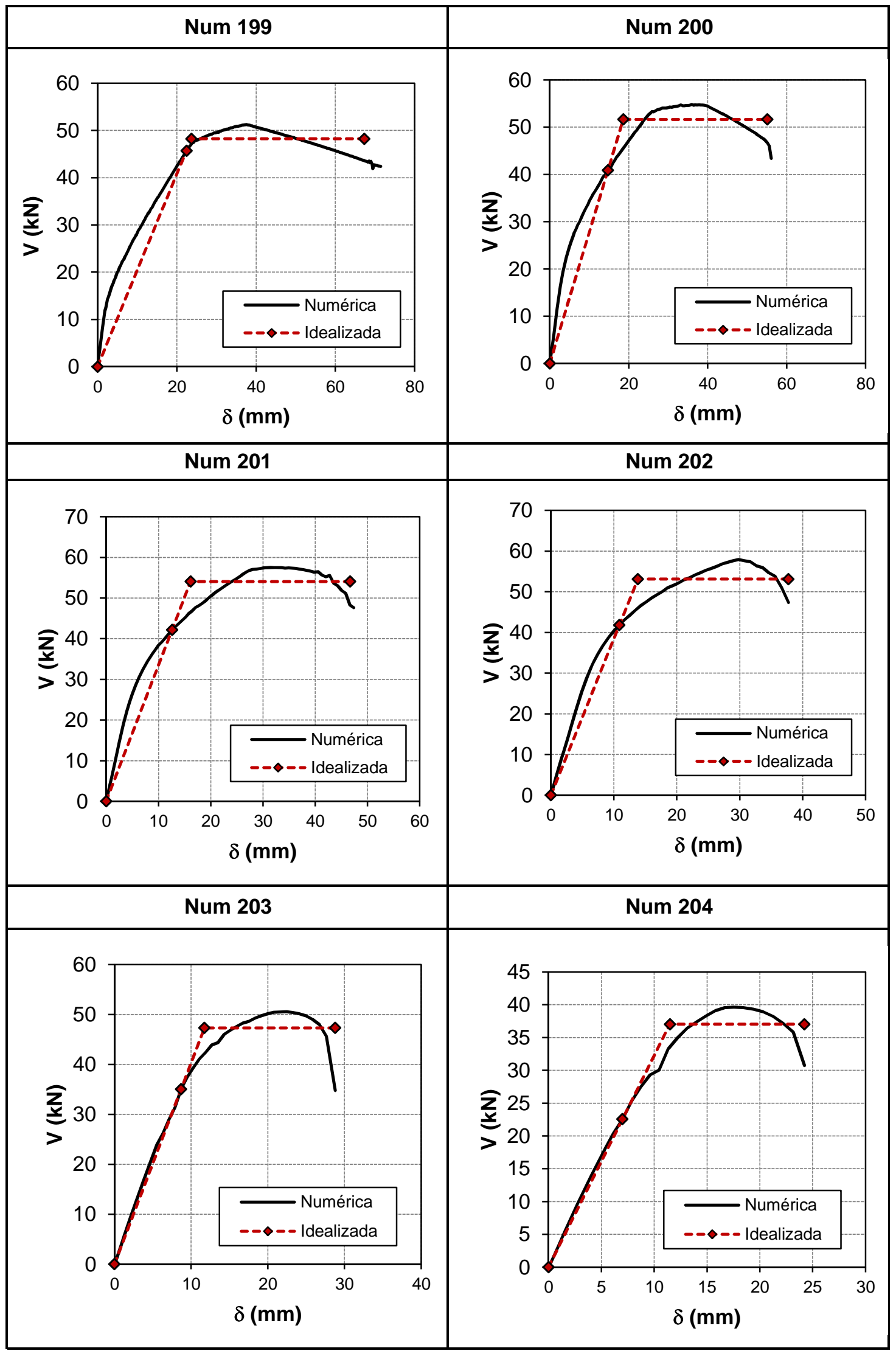


Anejo M: Respuesta Carga-Flecha e idealización de los ensayos numéricos

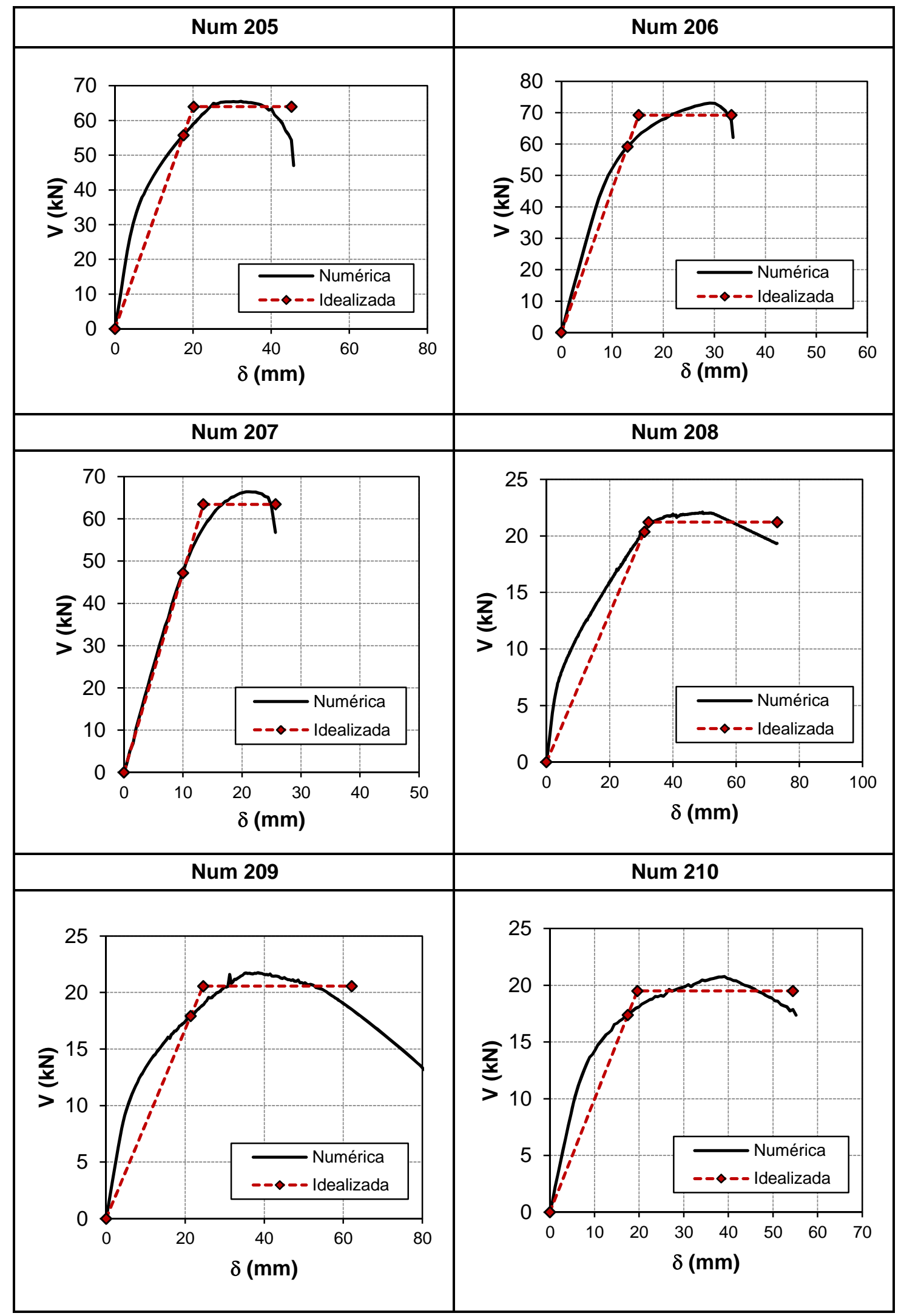


Estudio experimental y numérico de la capacidad de deformación de soportes esbeltos de hormigón armado

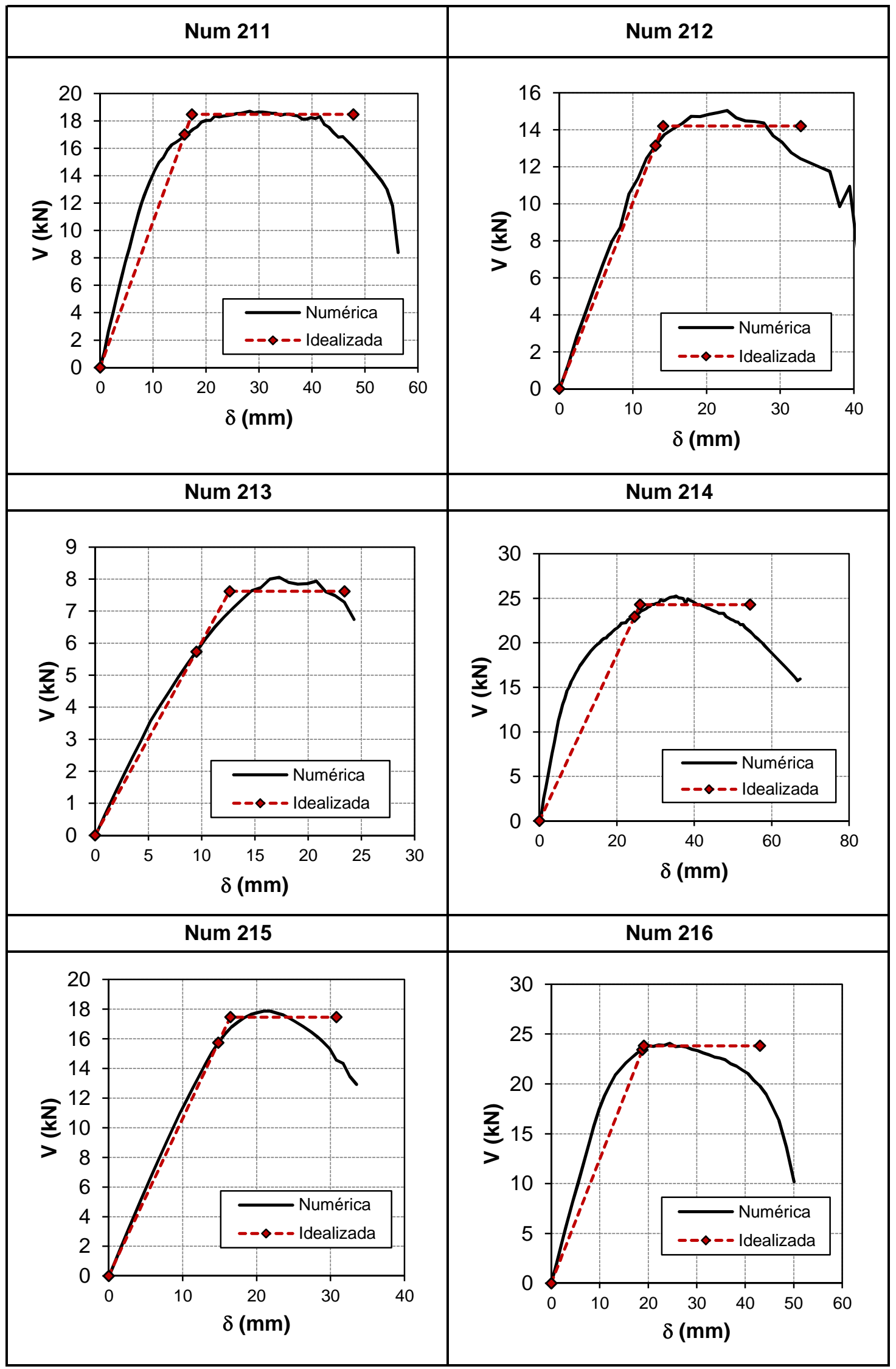


Anejo M: Respuesta Carga-Flecha e idealización de los ensayos numéricos

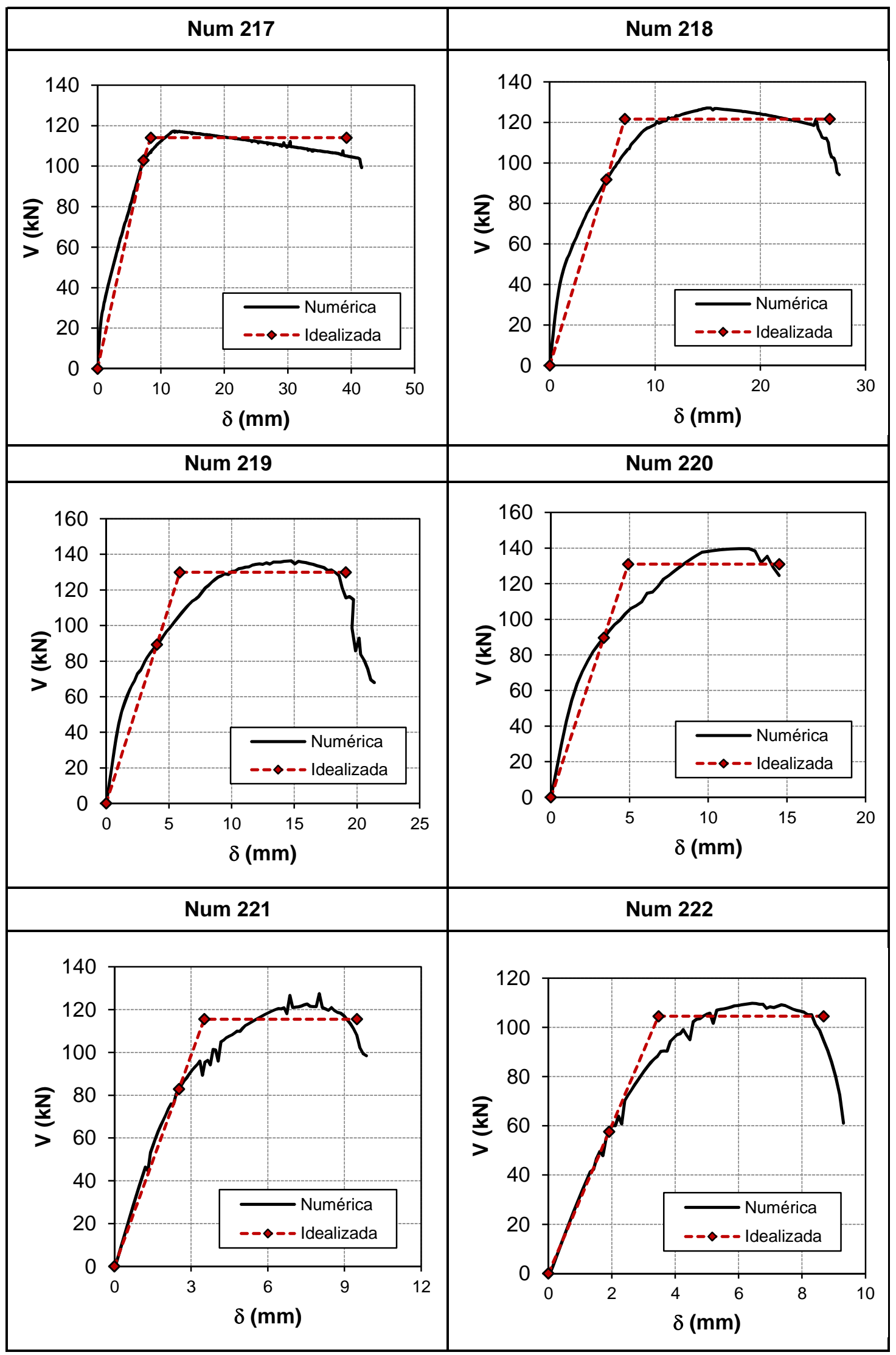


Estudio experimental y numérico de la capacidad de deformación de soportes esbeltos de hormigón armado

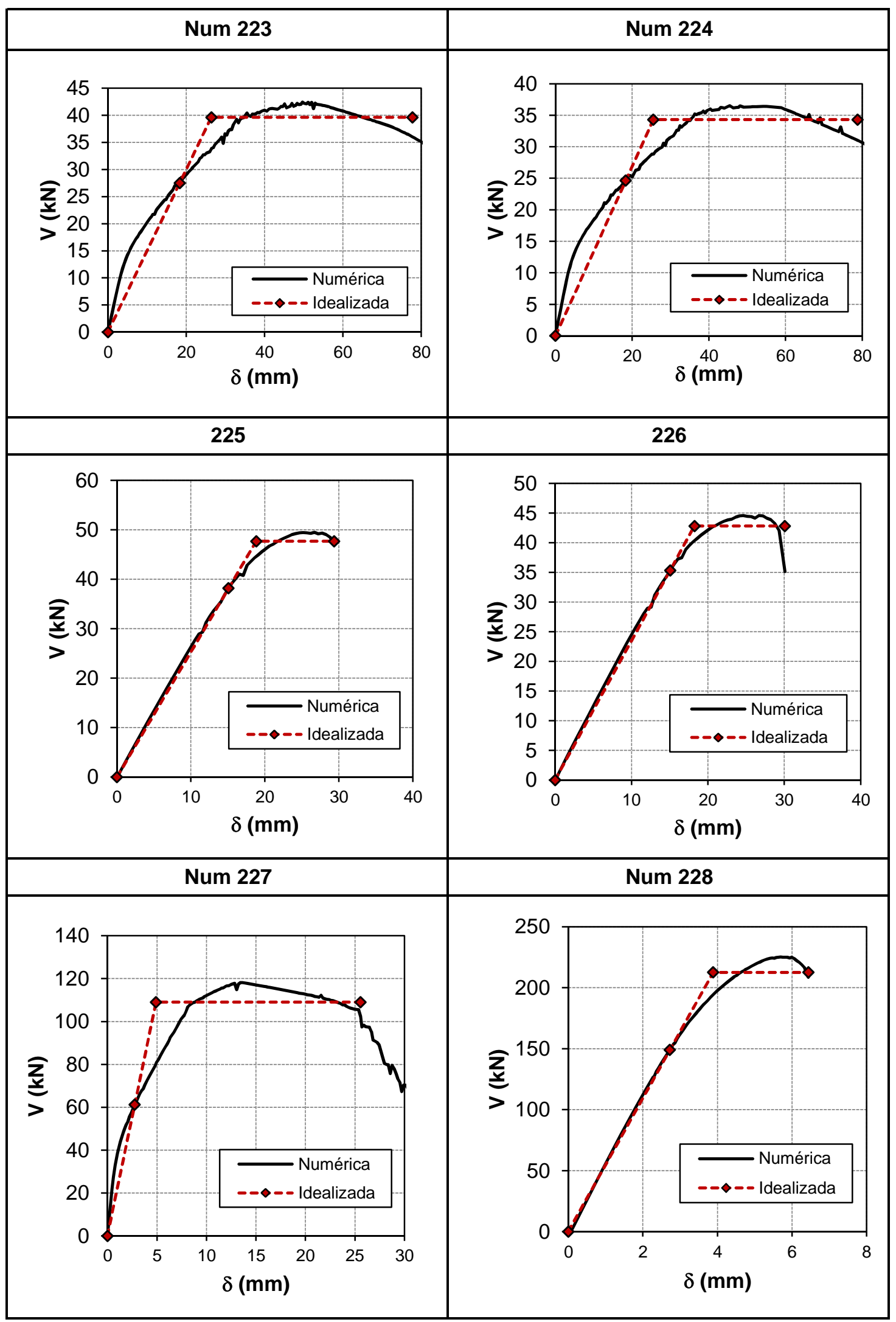


Anejo M: Respuesta Carga-Flecha e idealización de los ensayos numéricos

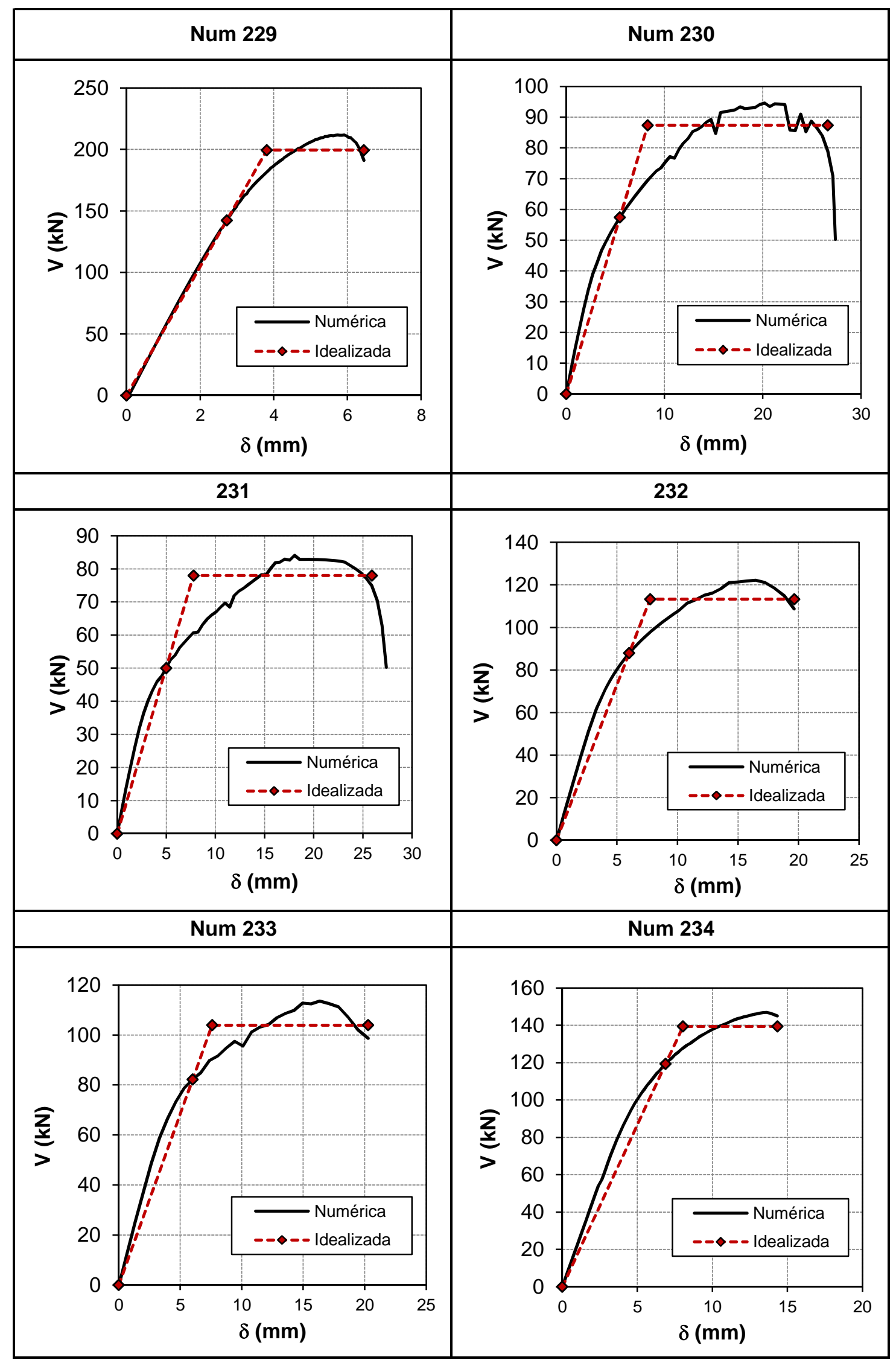


Estudio experimental y numérico de la capacidad de deformación de soportes esbeltos de hormigón armado

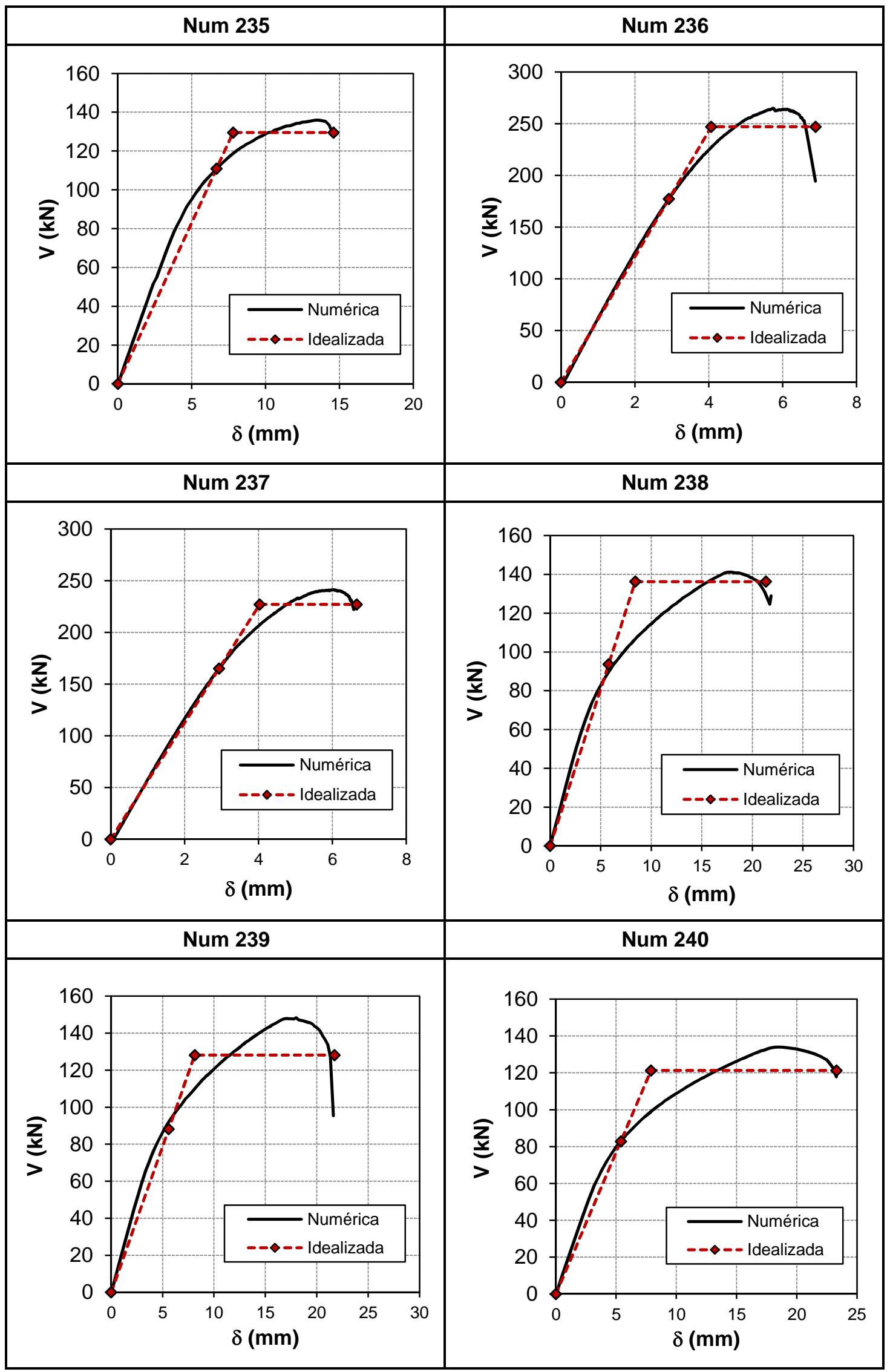


Anejo M: Respuesta Carga-Flecha e idealización de los ensayos numéricos

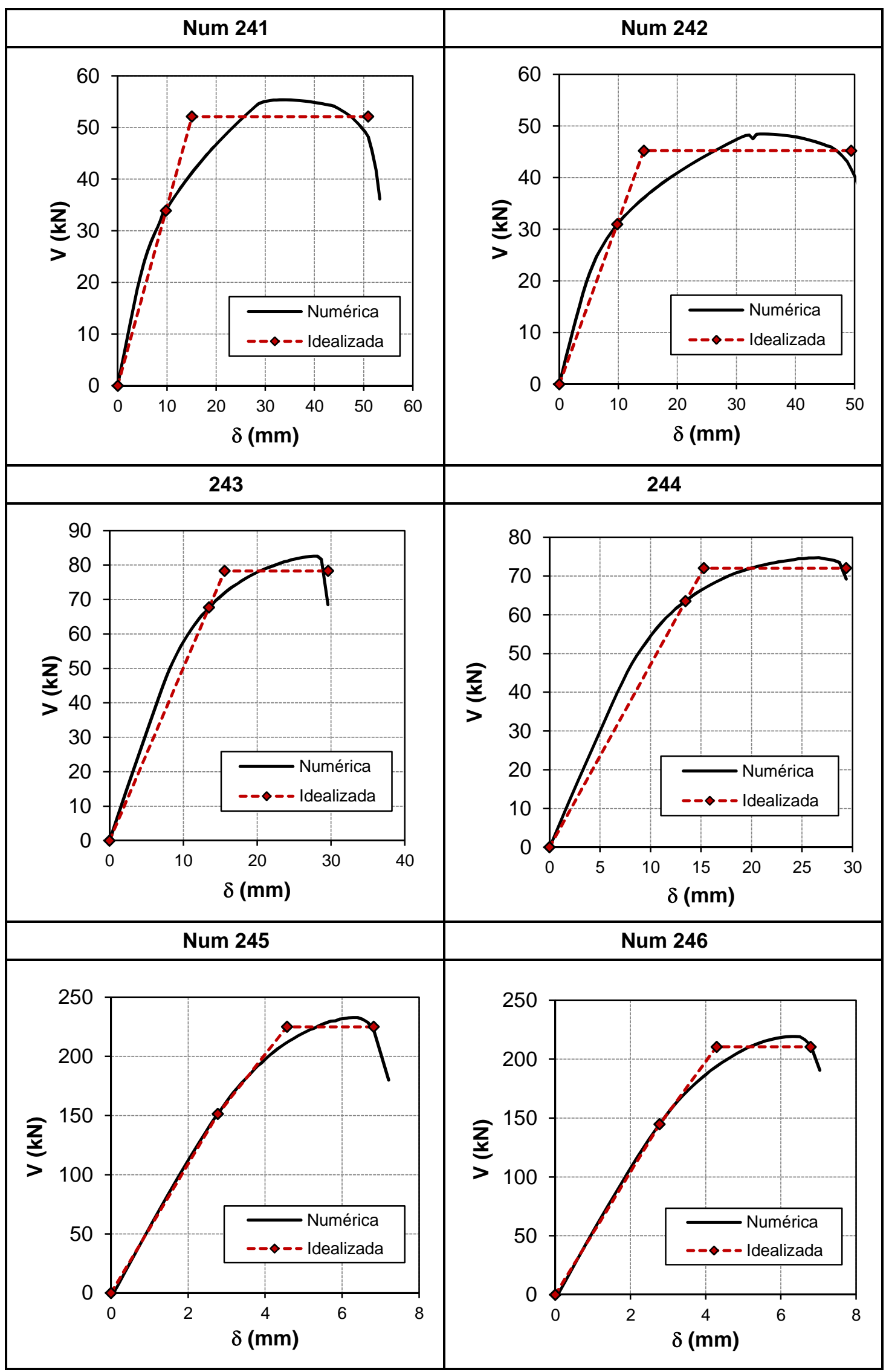


Estudio experimental y numérico de la capacidad de deformación de soportes esbeltos de hormigón armado

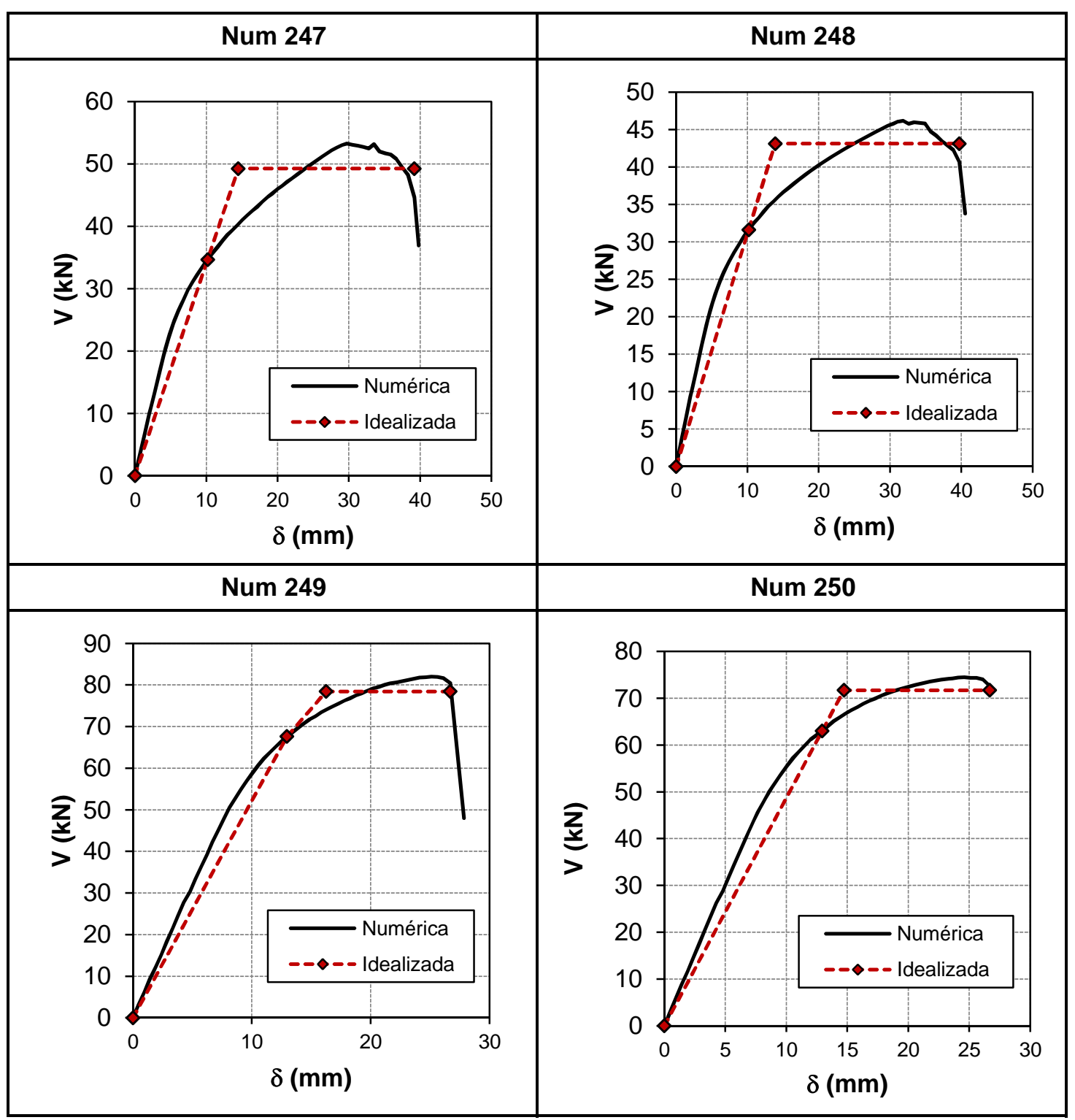




\begin{tabular}{|c|c|c|c|c|c|c|c|c|c|c|c|}
\hline \multicolumn{12}{|c|}{ LISTADO DE LAS CARACTERÍSTICAS DE LOS ENSAYOS NUMÉRICOS } \\
\hline \multirow[t]{2}{*}{$\mathrm{N}^{\circ}$} & \multirow[t]{2}{*}{ b (m) } & \multirow[t]{2}{*}{$h(m)$} & \multirow[t]{2}{*}{$\lambda$} & \multirow{2}{*}{$\begin{array}{l}\text { Recubrimiento } \\
\text { vertical }(\mathrm{m})\end{array}$} & Recubrimiento & Armad & gitudinal & Armadu & nsversal & $f^{\prime c}(\mathrm{MPa})$ & $\mathrm{N}(\mathrm{kN})$ \\
\hline & & & & & & $n^{0}$ & $\phi(\mathrm{mm})$ & $\phi(\mathrm{mm})$ & st (m) & & \\
\hline 1 & 0,15 & 0,20 & 3,5 & 0,018 & 0,018 & 6 & 12,00 & 6,00 & 0,10 & 30 & 90 \\
\hline 2 & 0,15 & 0,20 & 3,5 & 0,018 & 0,018 & 6 & 12,00 & 6,00 & 0,10 & 30 & 180 \\
\hline 3 & 0,15 & 0,20 & 3,5 & 0,018 & 0,018 & 6 & 12,00 & 6,00 & 0,10 & 30 & 270 \\
\hline 4 & 0,15 & 0,20 & 3,5 & 0,018 & 0,018 & 6 & 12,00 & 6,00 & 0,10 & 30 & 360 \\
\hline 5 & 0,15 & 0,20 & 3,5 & 0,018 & 0,018 & 6 & 12,00 & 6,00 & 0,10 & 30 & 539 \\
\hline 6 & 0,15 & 0,20 & 3,5 & 0,018 & 0,018 & 6 & 12,00 & 6,00 & 0,10 & 30 & 719 \\
\hline 7 & 0,15 & 0,20 & 3,5 & 0,018 & 0,018 & 6 & 12,00 & 6,00 & 0,10 & 60 & 161 \\
\hline 8 & 0,15 & 0,20 & 3,5 & 0,018 & 0,018 & 6 & 12,00 & 6,00 & 0,10 & 60 & 323 \\
\hline 9 & 0,15 & 0,20 & 3,5 & 0,018 & 0,018 & 6 & 12,00 & 6,00 & 0,10 & 60 & 484 \\
\hline 10 & 0,15 & 0,20 & 3,5 & 0,018 & 0,018 & 6 & 12,00 & 6,00 & 0,10 & 60 & 646 \\
\hline 11 & 0,15 & 0,20 & 3,5 & 0,018 & 0,018 & 6 & 12,00 & 6,00 & 0,10 & 60 & 969 \\
\hline 12 & 0,15 & 0,20 & 3,5 & 0,018 & 0,018 & 6 & 12,00 & 6,00 & 0,10 & 60 & 1292 \\
\hline 13 & 0,15 & 0,20 & 3,5 & 0,018 & 0,018 & 6 & 12,00 & 6,00 & 0,10 & 90 & 231 \\
\hline 14 & 0,15 & 0,20 & 3,5 & 0,018 & 0,018 & 6 & 12,00 & 6,00 & 0,10 & 90 & 462 \\
\hline 15 & 0,15 & 0,20 & 3,5 & 0,018 & 0,018 & 6 & 12,00 & 6,00 & 0,10 & 90 & 693 \\
\hline 16 & 0,15 & 0,20 & 3,5 & 0,018 & 0,018 & 6 & 12,00 & 6,00 & 0,10 & 90 & 924 \\
\hline 17 & 0,15 & 0,20 & 3,5 & 0,018 & 0,018 & 6 & 12,00 & 6,00 & 0,10 & 90 & 1386 \\
\hline 18 & 0,15 & 0,20 & 3,5 & 0,018 & 0,018 & 6 & 12,00 & 6,00 & 0,10 & 90 & 1848 \\
\hline 19 & 0,15 & 0,20 & 5,0 & 0,018 & 0,018 & 6 & 12,00 & 6,00 & 0,10 & 30 & 90 \\
\hline 20 & 0,15 & 0,20 & 5,0 & 0,018 & 0,018 & 6 & 12,00 & 6,00 & 0,10 & 30 & 180 \\
\hline 21 & 0,15 & 0,20 & 5,0 & 0,018 & 0,018 & 6 & 12,00 & 6,00 & 0,10 & 30 & 270 \\
\hline 22 & 0,15 & 0,20 & 5,0 & 0,018 & 0,018 & 6 & 12,00 & 6,00 & 0,10 & 30 & 360 \\
\hline 23 & 0,15 & 0,20 & 5,0 & 0,018 & 0,018 & 6 & 12,00 & 6,00 & 0,10 & 30 & 539 \\
\hline 24 & 0,15 & 0,20 & 5,0 & 0,018 & 0,018 & 6 & 12,00 & 6,00 & 0,10 & 30 & 719 \\
\hline 25 & 0,15 & 0,20 & 5,0 & 0,018 & 0,018 & 6 & 12,00 & 6,00 & 0,10 & 60 & 161 \\
\hline 26 & 0,15 & 0,20 & 5,0 & 0,018 & 0,018 & 6 & 12,00 & 6,00 & 0,10 & 60 & 323 \\
\hline 27 & 0,15 & 0,20 & 5,0 & 0,018 & 0,018 & 6 & 12,00 & 6,00 & 0,10 & 60 & 484 \\
\hline 28 & 0,15 & 0,20 & 5,0 & 0,018 & 0,018 & 6 & 12,00 & 6,00 & 0,10 & 60 & 646 \\
\hline 29 & 0,15 & 0,20 & 5,0 & 0,018 & 0,018 & 6 & 12,00 & 6,00 & 0,10 & 60 & 969 \\
\hline 30 & 0,15 & 0,20 & 5,0 & 0,018 & 0,018 & 6 & 12,00 & 6,00 & 0,10 & 60 & 1292 \\
\hline 31 & 0,15 & 0,20 & 5,0 & 0,018 & 0,018 & 6 & 12,00 & 6,00 & 0,10 & 90 & 231 \\
\hline 32 & 0,15 & 0,20 & 5,0 & 0,018 & 0,018 & 6 & 12,00 & 6,00 & 0,10 & 90 & 462 \\
\hline 33 & 0,15 & 0,20 & 5,0 & 0,018 & 0,018 & 6 & 12,00 & 6,00 & 0,10 & 90 & 693 \\
\hline 34 & 0,15 & 0,20 & 5,0 & 0,018 & 0,018 & 6 & 12,00 & 6,00 & 0,10 & 90 & 924 \\
\hline 35 & 0,15 & 0,20 & 5,0 & 0,018 & 0,018 & 6 & 12,00 & 6,00 & 0,10 & 90 & 1386 \\
\hline 36 & 0,15 & 0,20 & 5,0 & 0,018 & 0,018 & 6 & 12,00 & 6,00 & 0,10 & 90 & 1848 \\
\hline 37 & 0,15 & 0,20 & 7,5 & 0,018 & 0,018 & (26 & 12,00 & $\begin{array}{ll}6,00 \\
\end{array}$ & 0,10 & 30 & 90 \\
\hline 38 & 0,15 & 0,20 & 7,5 & 0,018 & 0,018 & 6 & 12,00 & 6,00 & 0,10 & 30 & 180 \\
\hline 39 & 0,15 & 0,20 & 7,5 & 0,018 & 0,018 & 6 & 12,00 & 6,00 & 0,10 & 30 & 270 \\
\hline 40 & 0,15 & 0,20 & 7,5 & 0,018 & 0,018 & 6 & 12,00 & 6,00 & 0,10 & 30 & 360 \\
\hline 41 & 0,15 & 0,20 & 7,5 & 0,018 & 0,018 & 6 & 12,00 & 6,00 & 0,10 & 30 & 539 \\
\hline 42 & 0,15 & 0,20 & 7,5 & 0,018 & 0,018 & 6 & 12,00 & 6,00 & 0,10 & 30 & 719 \\
\hline 43 & 0,15 & 0,20 & 7,5 & 0,018 & 0,018 & 6 & 12,00 & 6,00 & 0,10 & 60 & 161 \\
\hline 44 & 0,15 & 0,20 & 7,5 & 0,018 & 0,018 & 6 & 12,00 & 6,00 & 0,10 & 60 & 323 \\
\hline 45 & 0,15 & 0,20 & 7,5 & 0,018 & 0,018 & 6 & 12,00 & 6,00 & 0,10 & 60 & 484 \\
\hline 46 & 0,15 & 0,20 & 7,5 & 0,018 & 0,018 & 6 & 12,00 & 6,00 & 0,10 & 60 & 646 \\
\hline 47 & 0,15 & 0,20 & 7,5 & 0,018 & 0,018 & 6 & 12,00 & 6,00 & 0,10 & 60 & 969 \\
\hline 48 & 0,15 & 0,20 & 7,5 & 0,018 & 0,018 & 6 & 12,00 & 6,00 & 0,10 & 60 & 1292 \\
\hline 49 & 0,15 & 0,20 & 7,5 & 0,018 & 0,018 & 6 & 12,00 & 6,00 & 0,10 & 90 & 231 \\
\hline 50 & 0,15 & 0,20 & 7,5 & 0,018 & 0,018 & 6 & 12,00 & 6,00 & 0,10 & 90 & 462 \\
\hline 51 & 0,15 & 0,20 & 7,5 & 0,018 & 0,018 & 6 & 12,00 & 6,00 & 0,10 & 90 & 693 \\
\hline 52 & 0,15 & 0,20 & 7,5 & 0,018 & 0,018 & 6 & 12,00 & 6,00 & 0,10 & 90 & 924 \\
\hline 53 & 0,15 & 0,20 & 7,5 & 0,018 & 0,018 & 6 & 12,00 & 6,00 & 0,10 & 90 & 1386 \\
\hline 54 & 0,15 & 0,20 & 7,5 & 0,018 & 0,018 & 6 & 12,00 & 6,00 & 0,10 & 90 & 1848 \\
\hline 55 & 0,15 & 0,20 & 9,0 & 0,018 & 0,018 & $\bar{~} 6$ & 12,00 & $6,0,00$ & 0,10 & 30 & 90 \\
\hline 56 & 0,15 & 0,20 & 9,0 & 0,018 & 0,018 & 6 & 12,00 & 6,00 & 0,10 & 30 & 180 \\
\hline 57 & 0,15 & 0,20 & 9,0 & 0,018 & 0,018 & 6 & 12,00 & 6,00 & 0,10 & 30 & 270 \\
\hline 58 & 0,15 & 0,20 & 9,0 & 0,018 & 0,018 & 6 & 12,00 & 6,00 & 0,10 & 30 & 360 \\
\hline 59 & 0,15 & 0,20 & 9,0 & 0,018 & 0,018 & 6 & 12,00 & 6,00 & 0,10 & 30 & 539 \\
\hline 60 & 0,15 & 0,20 & 9,0 & 0,018 & 0,018 & 6 & 12,00 & 6,00 & 0,10 & 30 & 719 \\
\hline 61 & 0,15 & 0,20 & 9,0 & 0,018 & 0,018 & 6 & 12,00 & 6,00 & 0,10 & 60 & 161 \\
\hline 62 & 0,15 & 0,20 & 9,0 & 0,018 & 0,018 & 6 & 12,00 & 6,00 & 0,10 & 60 & 323 \\
\hline 63 & 0,15 & 0,20 & 9,0 & 0,018 & 0,018 & 6 & 12,00 & 6,00 & 0,10 & 60 & 484 \\
\hline 64 & 0,15 & 0,20 & 9,0 & 0,018 & 0,018 & 6 & 12,00 & 6,00 & 0,10 & 60 & 646 \\
\hline 65 & 0,15 & 0,20 & 9,0 & 0,018 & 0,018 & 6 & 12,00 & 6,00 & 0,10 & 60 & 969 \\
\hline 66 & 0,15 & 0,20 & 9,0 & 0,018 & 0,018 & 6 & 12,00 & 6,00 & 0,10 & 60 & 1292 \\
\hline 67 & 0,15 & 0,20 & 9,0 & 0,018 & 0,018 & 6 & 12,00 & 6,00 & 0,10 & 90 & 231 \\
\hline 68 & 0,15 & 0,20 & 9,0 & 0,018 & 0,018 & 6 & 12,00 & 6,00 & 0,10 & 90 & 462 \\
\hline 69 & 0,15 & 0,20 & 9,0 & 0,018 & 0,018 & 6 & 12,00 & 6,00 & 0,10 & 90 & 693 \\
\hline 70 & 0,15 & 0,20 & 9,0 & 0,018 & 0,018 & 6 & 12,00 & 6,00 & 0,10 & 90 & 924 \\
\hline 71 & 0,15 & 0,20 & 9,0 & 0,018 & 0,018 & 6 & 12,00 & 6,00 & 0,10 & 90 & 1386 \\
\hline 72 & 0,15 & 0,20 & 9,0 & 0,018 & 0,018 & 6 & 12,00 & 6,00 & 0,10 & 90 & 1848 \\
\hline
\end{tabular}




\begin{tabular}{|c|c|c|c|c|c|c|c|c|c|c|c|}
\hline \multicolumn{12}{|c|}{ LISTADO DE LAS CARACTERÍSTICAS DE LOS ENSAYOS NUMÉRICOS } \\
\hline \multirow[t]{2}{*}{$\mathbf{N}^{\circ}$} & \multirow[t]{2}{*}{$b(m)$} & \multirow{2}{*}{$h(m)$} & \multirow[t]{2}{*}{$\lambda$} & \multirow{2}{*}{$\begin{array}{l}\text { Recubrimiento } \\
\text { vertical }(m)\end{array}$} & Recubrimiento & Armad & gitudinal & Armadur & nsversal & fc (MPa) & $N(\mathrm{kN})$ \\
\hline & & & & & & $n^{\circ}$ & $\phi(\mathrm{mm})$ & $\phi(\mathrm{mm})$ & st (m) & & \\
\hline 73 & 0,15 & 0,14 & 10,5 & 0,010 & 0,010 & 6 & 10,00 & 6,00 & 0,10 & 30 & 63 \\
\hline 74 & 0,15 & 0,14 & 10,5 & 0,010 & 0,010 & 6 & 10,00 & 6,00 & 0,10 & 30 & 126 \\
\hline 75 & 0,15 & 0,14 & 10,5 & 0,010 & 0,010 & 6 & 10,00 & 6,00 & 0,10 & 30 & 188 \\
\hline 76 & 0,15 & 0,14 & 10,5 & 0,010 & 0,010 & 6 & 10,00 & 6,00 & 0,10 & 30 & 251 \\
\hline 77 & 0,15 & 0,14 & 10,5 & 0,010 & 0,010 & 6 & 10,00 & 6,00 & 0,10 & 30 & 377 \\
\hline 78 & 0,15 & 0,14 & 10,5 & 0,010 & 0,010 & 6 & 10,00 & 6,00 & 0,10 & 30 & 502 \\
\hline 79 & 0,15 & 0,14 & 10,5 & 0,010 & 0,010 & 6 & 10,00 & 6,00 & 0,10 & 60 & 113 \\
\hline 80 & 0,15 & 0,14 & 10,5 & 0,010 & 0,010 & 6 & 10,00 & 6,00 & 0,10 & 60 & 226 \\
\hline 81 & 0,15 & 0,14 & 10,5 & 0,010 & 0,010 & 6 & 10,00 & 6,00 & 0,10 & 60 & 339 \\
\hline 82 & 0,15 & 0,14 & 10,5 & 0,010 & 0,010 & 6 & 10,00 & 6,00 & 0,10 & 60 & 452 \\
\hline 83 & 0,15 & 0,14 & 10,5 & 0,010 & 0,010 & 6 & 10,00 & 6,00 & 0,10 & 60 & 677 \\
\hline 84 & 0,15 & 0,14 & 10,5 & 0,010 & 0,010 & 6 & 10,00 & 6,00 & 0,10 & 60 & 903 \\
\hline 85 & 0,15 & 0,14 & 10,5 & 0,010 & 0,010 & 6 & 10,00 & 6,00 & 0,10 & 90 & 162 \\
\hline 86 & 0,15 & 0,14 & 10,5 & 0,010 & 0,010 & 6 & 10,00 & 6,00 & 0,10 & 90 & 323 \\
\hline 87 & 0,15 & 0,14 & 10,5 & 0,010 & 0,010 & 6 & 10,00 & 6,00 & 0,10 & 90 & 485 \\
\hline 88 & 0,15 & 0,14 & 10,5 & 0,010 & 0,010 & 6 & 10,00 & 6,00 & 0,10 & 90 & 646 \\
\hline 89 & 0,15 & 0,14 & 10,5 & 0,010 & 0,010 & 6 & 10,00 & 6,00 & 0,10 & 90 & 969 \\
\hline 90 & 0,15 & 0,14 & 10,5 & 0,010 & 0,010 & 6 & 10,00 & 6,00 & 0,10 & 90 & 1292 \\
\hline 91 & 0,15 & 0,14 & $\bar{~} 10,5$ & 0,011 & 0,011 & 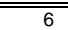 & $7,7,42$ & 6,00 & 0,10 & 30 & 1112 \\
\hline 92 & 0,15 & 0,14 & 10,5 & 0,011 & 0,011 & 6 & 7,42 & 6,00 & 0,10 & 30 & 223 \\
\hline 93 & 0,15 & 0,14 & 10,5 & 0,011 & 0,011 & 6 & 7,42 & 6,00 & 0,10 & 30 & 335 \\
\hline 94 & 0,15 & 0,14 & 10,5 & 0,011 & 0,011 & 6 & 7,42 & 6,00 & 0,10 & 60 & 209 \\
\hline 95 & 0,15 & 0,14 & 10,5 & 0,011 & 0,011 & 6 & 7,42 & 6,00 & 0,10 & 60 & 418 \\
\hline 96 & 0,15 & 0,14 & 10,5 & 0,011 & 0,011 & 6 & 7,42 & 6,00 & 0,10 & 60 & 628 \\
\hline 97 & 0,15 & 0,14 & 10,5 & 0,011 & 0,011 & 6 & 7,42 & 6,00 & 0,10 & 90 & 305 \\
\hline 98 & 0,15 & 0,14 & 10,5 & 0,011 & 0,011 & 6 & 7,42 & 6,00 & 0,10 & 90 & 611 \\
\hline 99 & 0,15 & 0,14 & 10,5 & 0,011 & 0,011 & 6 & 7,42 & 6,00 & 0,10 & 90 & 916 \\
\hline 100 & 0,15 & 0,14 & 10,5 & 0,009 & 0,009 & 6 & 12,00 & 6,00 & 0,10 & 30 & 139 \\
\hline 101 & 0,15 & 0,14 & 10,5 & 0,009 & 0,009 & 6 & 12,00 & 6,00 & 0,10 & 30 & 279 \\
\hline 102 & 0,15 & 0,14 & 10,5 & 0,009 & 0,009 & 6 & 12,00 & 6,00 & 0,10 & 30 & 418 \\
\hline 103 & 0,15 & 0,14 & 10,5 & 0,009 & 0,009 & 6 & 12,00 & 6,00 & 0,10 & 60 & 242 \\
\hline 104 & 0,15 & 0,14 & 10,5 & 0,009 & 0,009 & 6 & 12,00 & 6,00 & 0,10 & 60 & 484 \\
\hline 105 & 0,15 & 0,14 & 10,5 & 0,009 & 0,009 & 6 & 12,00 & 6,00 & 0,10 & 60 & 726 \\
\hline 106 & 0,15 & 0,14 & 10,5 & 0,009 & 0,009 & 6 & 12,00 & 6,00 & 0,10 & 90 & 341 \\
\hline 107 & 0,15 & 0,14 & 10,5 & 0,009 & 0,009 & 6 & 12,00 & 6,00 & 0,10 & 90 & 681 \\
\hline 108 & 0,15 & 0,14 & 10,5 & 0,009 & 0,009 & 6 & 12,00 & 6,00 & 0,10 & 90 & 1022 \\
\hline 109 & 0,15 & 0,14 & 10,5 & 0,008 & 0,008 & 6 & 13,74 & 6,00 & 0,10 & 30 & 153 \\
\hline 110 & 0,15 & 0,14 & 10,5 & 0,008 & 0,008 & 6 & 13,74 & 6,00 & 0,10 & 30 & 306 \\
\hline 111 & 0,15 & 0,14 & 10,5 & 0,008 & 0,008 & 6 & 13,74 & 6,00 & 0,10 & 30 & 460 \\
\hline 112 & 0,15 & 0,14 & 10,5 & 0,008 & 0,008 & 6 & 13,74 & 6,00 & 0,10 & 60 & 258 \\
\hline 113 & 0,15 & $\begin{array}{l}0,14 \\
0,14\end{array}$ & 10,5 & $\begin{array}{l}, 000 \\
0,008\end{array}$ & 0,008 & 6 & $\begin{array}{l}13,14 \\
13,74\end{array}$ & 6,00 & 0,10 & 60 & \begin{tabular}{|l|l}
517 \\
\end{tabular} \\
\hline 114 & $\begin{array}{l}0,15 \\
0,15 \\
\end{array}$ & $\begin{array}{l}0,14 \\
0,14 \\
\end{array}$ & 10,5 & 0,008 & 0,008 & 6 & 13,74 & 6,00 & 0,10 & 60 & $\begin{array}{l}771 \\
775 \\
\end{array}$ \\
\hline 115 & 0,15 & 0,14 & 10,5 & 0,008 & 0,008 & 6 & 13,74 & 6,00 & 0,10 & 90 & 358 \\
\hline 116 & 0,15 & 0,14 & 10,5 & 0,008 & 0,008 & 6 & 13,74 & 6,00 & 0,10 & 90 & 716 \\
\hline 117 & 0,15 & 0,14 & 10,5 & 0,008 & 0,008 & 6 & 13,74 & 6,00 & 0,10 & 90 & 1075 \\
\hline 118 & 0,15 & 0,20 & 3,5 & 0,019 & 0,019 & 6 & 8,90 & 6,40 & 0,10 & 30 & 160 \\
\hline 119 & 0,15 & 0,20 & 3,5 & 0,019 & 0,019 & 6 & 8,90 & 6,40 & 0,10 & 30 & 319 \\
\hline 120 & 0,15 & 0,20 & 3,5 & 0,019 & 0,019 & 6 & 8,90 & 6,40 & 0,10 & 30 & 479 \\
\hline 121 & 0,15 & 0,20 & 3,5 & 0,019 & 0,019 & 6 & 8,90 & 6,40 & 0,10 & 60 & 299 \\
\hline 122 & 0,15 & 0,20 & 3,5 & 0,019 & 0,019 & 6 & 8,90 & 6,40 & 0,10 & 60 & 598 \\
\hline 123 & 0,15 & 0,20 & 3,5 & 0,019 & 0,019 & 6 & 8,90 & 6,40 & 0,10 & 60 & 897 \\
\hline 124 & 0,15 & 0,20 & 3,5 & 0,019 & 0,019 & 6 & 8,90 & 6,40 & 0,10 & 90 & 436 \\
\hline 125 & 0,15 & 0,20 & 3,5 & 0,019 & 0,019 & 6 & 8,90 & 6,40 & 0,10 & 90 & 873 \\
\hline 126 & 0,15 & 0,20 & 3,5 & 0,019 & 0,019 & 6 & 8,90 & 6,40 & 0,10 & 90 & 1309 \\
\hline 127 & 0,15 & 0,20 & 3,5 & 0,016 & 0,016 & 6 & 14,35 & 6,40 & 0,10 & 30 & 199 \\
\hline 128 & 0,15 & 0,20 & 3,5 & 0,016 & 0,016 & 6 & 14,35 & 6,40 & 0,10 & 30 & 398 \\
\hline 129 & 0,15 & 0,20 & 3,5 & 0,016 & 0,016 & 6 & 14,35 & 6,40 & 0,10 & 30 & 597 \\
\hline 130 & 0,15 & 0,20 & 3,5 & 0,016 & 0,016 & 6 & 14,35 & 6,40 & 0,10 & 60 & 346 \\
\hline 131 & 0,15 & $\begin{array}{l}0,20 \\
0,20\end{array}$ & 3,5 & 0,016 & 0,016 & 6 & 14,35 & 6,40 & 0,10 & 60 & 691 \\
\hline 132 & 0,15 & 0,20 & 3,5 & 0,016 & 0,016 & 6 & 14,35 & 6,40 & 0,10 & 60 & 1037 \\
\hline 133 & 0,15 & 0,20 & 3,5 & 0,016 & 0,016 & 6 & 14,35 & 6,40 & 0,10 & 90 & 487 \\
\hline 134 & 0,15 & 0,20 & 3,5 & 0,016 & 0,016 & 6 & 14,35 & 6,40 & 0,10 & 90 & 973 \\
\hline 135 & 0,15 & 0,20 & 3,5 & 0,016 & 0,016 & 6 & 14,35 & 6,40 & 0,10 & 90 & 1460 \\
\hline 136 & 0,15 & 0,20 & 3,5 & $\begin{array}{l}0,010 \\
0,015\end{array}$ & 0,015 & 6 & $\begin{array}{l}14,05 \\
16,40\end{array}$ & 6,40 & 0,10 & 30 & 219 \\
\hline 137 & 0,15 & 0,20 & 3,5 & 0,015 & 0,015 & 6 & 16,40 & 6,40 & 0,10 & 30 & 437 \\
\hline 138 & 0,15 & 0,20 & 3,5 & 0,015 & 0,015 & 6 & 16,40 & 6,40 & 0,10 & 30 & 656 \\
\hline 139 & 0,15 & 0,20 & 3,5 & 0,015 & 0,015 & 6 & 16,40 & 6,40 & 0,10 & 60 & 369 \\
\hline 140 & 0,15 & 0,20 & 3,5 & 0,015 & 0,015 & 6 & 16,40 & 6,40 & 0,10 & 60 & 738 \\
\hline 141 & 0,15 & 0,20 & 3,5 & 0,015 & 0,015 & 6 & 16,40 & 6,40 & 0,10 & 60 & 1107 \\
\hline 142 & 0,15 & 0,20 & 3,5 & 0,015 & 0,015 & 6 & 16,40 & 6,40 & 0,10 & 90 & 511 \\
\hline 143 & 0,15 & 0,20 & 3,5 & 0,015 & 0,015 & 6 & 16,40 & 6,40 & 0,10 & 90 & 1023 \\
\hline 144 & 0,15 & 0,20 & 3,5 & 0,015 & 0,015 & 6 & 16,40 & 6,40 & 0,10 & 90 & 1534 \\
\hline
\end{tabular}




\begin{tabular}{|c|c|c|c|c|c|c|c|c|c|c|c|}
\hline \multicolumn{12}{|c|}{ LISTADO DE LAS CARACTERÍSTICAS DE LOS ENSAYOS NUMÉRICOS } \\
\hline \multirow{2}{*}{$\mathbf{N}^{\circ}$} & \multirow{2}{*}{$b(m)$} & \multirow{2}{*}{$h(m)$} & \multirow[t]{2}{*}{$\lambda$} & \multirow{2}{*}{$\begin{array}{l}\text { Recubrimiento } \\
\text { vertical }(\mathrm{m})\end{array}$} & Recubrimiento & Armad & gitudinal & Armadur & nsversal & fc (MPa) & $\mathrm{N}(\mathrm{kN})$ \\
\hline & & & & & & $n^{\circ}$ & $\phi(\mathrm{mm})$ & $\phi(\mathrm{mm})$ & $\mathrm{st}(\mathrm{m})$ & & \\
\hline 145 & 0,15 & 0,20 & 3,5 & 0,018 & 0,018 & 6 & 12,00 & 6,40 & 0,05 & 30 & 360 \\
\hline 146 & 0,15 & 0,20 & 3,5 & 0,018 & 0,018 & 6 & 12,00 & 6,40 & 0,05 & 30 & 539 \\
\hline 147 & 0,15 & 0,20 & 3,5 & 0,018 & 0,018 & 6 & 12,00 & 6,40 & 0,05 & 30 & 719 \\
\hline 148 & 0,15 & 0,20 & 3,5 & 0,018 & 0,018 & 6 & 12,00 & 6,40 & 0,05 & 90 & 924 \\
\hline 149 & 0,15 & 0,20 & 3,5 & 0,018 & 0,018 & 6 & 12,00 & 6,40 & 0,05 & 90 & 1386 \\
\hline 150 & 0,15 & 0,20 & 3,5 & 0,018 & 0,018 & 6 & 12,00 & 6,40 & 0,05 & 90 & 1848 \\
\hline 151 & 0,15 & 0,20 & 3,5 & 0,016 & 0,016 & 6 & 12,00 & 7,80 & 0,05 & 30 & 360 \\
\hline 152 & 0,15 & 0,20 & 3,5 & 0,016 & 0,016 & 6 & 12,00 & 7,80 & 0,05 & 30 & 539 \\
\hline 153 & 0,15 & 0,20 & 3,5 & 0,016 & 0,016 & 6 & 12,00 & 7,80 & 0,05 & 30 & 719 \\
\hline 154 & 0,15 & 0,20 & 3,5 & 0,016 & 0,016 & 6 & 12,00 & 7,80 & 0,05 & 90 & 924 \\
\hline 155 & 0,15 & 0,20 & 3,5 & 0,016 & 0,016 & 6 & 12,00 & 7,80 & 0,05 & 90 & 1386 \\
\hline 156 & 0,15 & 0,20 & 3,5 & 0,016 & 0,016 & 6 & 12,00 & 7,80 & 0,05 & 90 & 1848 \\
\hline 157 & 0,15 & 0,20 & 3,5 & 0,015 & 0,015 & 6 & 12,00 & 9,00 & 0,05 & 30 & 360 \\
\hline 158 & 0,15 & 0,20 & 3,5 & 0,015 & 0,015 & 6 & 12,00 & 9,00 & 0,05 & 30 & 539 \\
\hline 159 & 0,15 & 0,20 & 3,5 & 0,015 & 0,015 & 6 & 12,00 & 9,00 & 0,05 & 30 & 719 \\
\hline 160 & 0,15 & 0,20 & 3,5 & 0,015 & 0,015 & 6 & 12,00 & 9,00 & 0,05 & 90 & 924 \\
\hline 161 & 0,15 & 0,20 & 3,5 & 0,015 & 0,015 & 6 & 12,00 & 9,00 & 0,05 & 90 & 1386 \\
\hline 162 & 0,15 & 0,20 & 3,5 & 0,015 & 0,015 & 6 & 12,00 & 9,00 & 0,05 & 90 & 1848 \\
\hline 163 & 0,15 & 0,20 & 7,5 & 0,017 & 0,017 & 6 & 12,00 & 7,05 & 0,06 & 30 & 360 \\
\hline 164 & 0,15 & 0,20 & 7,5 & 0,017 & 0,017 & 6 & 12,00 & 7,05 & 0,06 & 30 & 539 \\
\hline 165 & 0,15 & 0,20 & 7,5 & 0,017 & 0,017 & 6 & 12,00 & 7,05 & 0,06 & 30 & 719 \\
\hline 166 & 0,15 & 0,20 & 7,5 & 0,017 & 0,017 & 6 & 12,00 & 7,05 & 0,06 & 90 & 924 \\
\hline 167 & 0,15 & 0,20 & 7,5 & 0,017 & 0,017 & 6 & 12,00 & 7,05 & 0,06 & 90 & 1386 \\
\hline 168 & 0,15 & 0,20 & 7,5 & 0,017 & 0,017 & 6 & 12,00 & 7,05 & 0,06 & 90 & 1848 \\
\hline 169 & 0,15 & 0,20 & 7,5 & 0,0154 & 0,0154 & 6 & 12,00 & 8,62 & 0,06 & 30 & 360 \\
\hline 170 & 0,15 & 0,20 & 7,5 & 0,0154 & 0,0154 & 6 & 12,00 & 8,62 & 0,06 & 30 & 539 \\
\hline 171 & 0,15 & 0,20 & 7,5 & 0,0154 & 0,0154 & 6 & 12,00 & 8,62 & 0,06 & 30 & 719 \\
\hline 172 & 0,15 & 0,20 & 7,5 & 0,0154 & 0,0154 & 6 & 12,00 & 8,62 & 0,06 & 90 & 924 \\
\hline 173 & 0,15 & 0,20 & 7,5 & 0,0154 & 0,0154 & 6 & 12,00 & 8,62 & 0,06 & 90 & 1386 \\
\hline 174 & 0,15 & 0,20 & 7,5 & 0,0154 & 0,0154 & 6 & 12,00 & 8,62 & 0,06 & 90 & 1848 \\
\hline 175 & 0,15 & 0,20 & 7,5 & 0,0140 & 0,0140 & 6 & 12,00 & 9,96 & 0,06 & 30 & 360 \\
\hline 176 & 0,15 & 0,20 & 7,5 & 0,0140 & 0,0140 & 6 & 12,00 & 9,96 & 0,06 & 30 & 539 \\
\hline 177 & 0,15 & 0,20 & 7,5 & 0,0140 & 0,0140 & 6 & 12,00 & 9,96 & 0,06 & 30 & 719 \\
\hline 178 & 0,15 & 0,20 & 7,5 & 0,0140 & 0,0140 & 6 & 12,00 & 9,96 & 0,06 & 90 & 924 \\
\hline 179 & 0,15 & 0,20 & 7,5 & 0,0140 & 0,0140 & 6 & 12,00 & 9,96 & 0,06 & 90 & 1386 \\
\hline 180 & 0,15 & 0,20 & 7,5 & 0,0140 & 0,0140 & 6 & 12,00 & 9,96 & 0,06 & 90 & 1848 \\
\hline 181 & 0,15 & 0,14 & 10,5 & 0,0102 & 0,0102 & 6 & 10,00 & 5,80 & 0,05 & 30 & 251 \\
\hline 182 & 0,15 & 0,14 & 10,5 & 0,0102 & 0,0102 & 6 & 10,00 & 5,80 & 0,05 & 30 & 377 \\
\hline 183 & 0,15 & 0,14 & 10,5 & 0,0102 & 0,0102 & 6 & 10,00 & 5,80 & 0,05 & 30 & 502 \\
\hline 184 & 0,15 & 0,14 & 10,5 & 0,0102 & 0,0102 & 6 & 10,00 & 5,80 & 0,05 & 90 & 646 \\
\hline 185 & 0,15 & 0,14 & 10,5 & 0,0102 & 0,0102 & 6 & 10,00 & 5,80 & 0,05 & 90 & 969 \\
\hline 186 & 0,15 & 0,14 & 10,5 & 0,0102 & 0,0102 & 6 & 10,00 & 5,80 & 0,05 & 90 & 1292 \\
\hline 187 & 0,15 & 0,14 & 10,5 & 0,0089 & 0,0089 & 6 & 10,00 & 7,10 & 0,05 & 30 & 251 \\
\hline 188 & 0,15 & 0,14 & 10,5 & 0,0089 & 0,0089 & 6 & 10,00 & 7,10 & 0,05 & 30 & 377 \\
\hline 189 & 0,15 & 0,14 & 10,5 & 0,0089 & 0,0089 & 6 & 10,00 & 7,10 & 0,05 & 30 & 502 \\
\hline 190 & 0,15 & 0,14 & 10,5 & 0,0089 & 0,0089 & 6 & 10,00 & 7,10 & 0,05 & 90 & 646 \\
\hline 191 & 0,15 & 0,14 & 10,5 & 0,0089 & 0,0089 & 6 & 10,00 & 7,10 & 0,05 & 90 & 969 \\
\hline 192 & 0,15 & 0,14 & 10,5 & 0,0089 & 0,0089 & 6 & 10,00 & 7,10 & 0,05 & 90 & 1292 \\
\hline 193 & 0,15 & 0,14 & 10,5 & 0,0078 & 0,0078 & 6 & 10,00 & 8,20 & 0,05 & 30 & 251 \\
\hline 194 & 0,15 & 0,14 & 10,5 & 0,0078 & 0,0078 & 6 & 10,00 & 8,20 & 0,05 & 30 & 377 \\
\hline 195 & 0,15 & 0,14 & 10,5 & 0,0078 & 0,0078 & 6 & 10,00 & 8,20 & 0,05 & 30 & 502 \\
\hline 196 & 0,15 & 0,14 & 10,5 & 0,0078 & 0,0078 & 6 & 10,00 & 8,20 & 0,05 & 90 & 646 \\
\hline 197 & 0,15 & 0,14 & 10,5 & 0,0078 & 0,0078 & 6 & 10,00 & 8,20 & 0,05 & 90 & 969 \\
\hline 198 & 0,15 & 0,14 & 10,5 & 0,0078 & 0,0078 & 6 & 10,00 & 8,20 & 0,05 & 90 & 1292 \\
\hline 199 & 0,15 & 0,20 & $7 \overline{7,5}$ & 0,018 & 0,018 & $\bar{~} 6$ & 12,00 & $6,6,00$ & 0,10 & 45 & 126 \\
\hline 200 & 0,15 & 0,20 & 7,5 & 0,018 & 0,018 & 6 & 12,00 & 6,00 & 0,10 & 45 & 251 \\
\hline 201 & 0,15 & 0,20 & 7,5 & 0,018 & 0,018 & 6 & 12,00 & 6,00 & 0,10 & 45 & 377 \\
\hline 202 & 0,15 & 0,20 & 7,5 & 0,018 & 0,018 & 6 & 12,00 & 6,00 & 0,10 & 45 & 503 \\
\hline 203 & 0,15 & 0,20 & 7,5 & 0,018 & 0,018 & 6 & 12,00 & 6,00 & 0,10 & 45 & 754 \\
\hline 204 & 0,15 & 0,20 & 7,5 & 0,018 & 0,018 & 6 & 12,00 & 6,00 & 0,10 & 45 & 1005 \\
\hline 205 & 0,15 & 0,20 & 7,5 & 0,018 & 0,018 & 6 & 12,00 & 6,00 & 0,10 & 75 & 393 \\
\hline 206 & 0,15 & 0,20 & 7,5 & 0,018 & 0,018 & 6 & 12,00 & 6,00 & 0,10 & 75 & 787 \\
\hline 207 & 0,15 & 0,20 & 7,5 & 0,018 & 0,018 & 6 & 12,00 & 6,00 & 0,10 & 75 & 1180 \\
\hline 208 & 0,15 & 0,14 & 10,5 & 0,010 & 0,010 & 6 & 10,00 & 6,00 & 0,10 & 45 & 88 \\
\hline 209 & 0,15 & 0,14 & 10,5 & 0,010 & 0,010 & 6 & 10,00 & 6,00 & 0,10 & 45 & 176 \\
\hline 210 & 0,15 & 0,14 & 10,5 & 0,010 & 0,010 & 6 & 10,00 & 6,00 & 0,10 & 45 & 264 \\
\hline 211 & 0,15 & 0,14 & 10,5 & 0,010 & 0,010 & 6 & 10,00 & 6,00 & 0,10 & 45 & 351 \\
\hline 212 & 0,15 & 0,14 & 10,5 & 0,010 & 0,010 & 6 & 10,00 & 6,00 & 0,10 & 45 & 527 \\
\hline 213 & 0,15 & 0,14 & 10,5 & 0,010 & 0,010 & 6 & 10,00 & 6,00 & 0,10 & 45 & 703 \\
\hline 214 & 0,15 & 0,14 & 10,5 & 0,010 & 0,010 & 6 & 10,00 & 6,00 & 0,10 & 75 & 275 \\
\hline 215 & 0,15 & 0,14 & 10,5 & 0,010 & 0,010 & 6 & 10,00 & 6,00 & 0,10 & 75 & 550 \\
\hline 216 & 0,15 & 0,14 & 10,5 & 0,010 & 0,010 & 6 & 10,00 & 6,00 & 0,10 & 75 & 825 \\
\hline
\end{tabular}


Estudio experimental y numérico de la capacidad de deformación de soportes esbeltos de hormigón armado

\begin{tabular}{|c|c|c|c|c|c|c|c|c|c|c|c|}
\hline \multicolumn{12}{|c|}{ LISTADO DE LAS CARACTERÍSTICAS DE LOS ENSAYOS NUMÉRICOS } \\
\hline \multirow{2}{*}{$\mathbf{N}^{\circ}$} & \multirow{2}{*}{$b(m)$} & \multirow{2}{*}{$h(m)$} & \multirow[t]{2}{*}{$\lambda$} & \multirow{2}{*}{$\begin{array}{l}\text { Recubrimiento } \\
\text { vertical }(\mathrm{m})\end{array}$} & \multirow{2}{*}{$\begin{array}{l}\text { Recubrimiento } \\
\text { lateral }(\mathrm{m})\end{array}$} & \multicolumn{2}{|c|}{$\begin{array}{l}\text { Armadura longitudinal } \\
\text { (total) }\end{array}$} & \multicolumn{2}{|c|}{$\begin{array}{l}\text { Armadura transversal } \\
\text { (total) }\end{array}$} & \multirow{2}{*}{$\left.\mathrm{f}^{\prime} \mathrm{(MPa}\right)$} & \multirow{2}{*}{$\mathrm{N}(\mathrm{kN})$} \\
\hline & & & & & & $n^{0}$ & $\phi(\mathrm{mm})$ & $\phi(\mathrm{mm})$ & st (m) & & \\
\hline 217 & 0,15 & 0,2 & 3,5 & 0,0130 & 0,0130 & 6 & 12,00 & 6,00 & 10,00 & 30 & 90 \\
\hline 218 & 0,15 & 0,2 & 3,5 & 0,0130 & 0,0130 & 6 & 12,00 & 6,00 & 10,00 & 30 & 180 \\
\hline 219 & 0,15 & 0,2 & 3,5 & 0,0130 & 0,0130 & 6 & 12,00 & 6,00 & 10,00 & 30 & 270 \\
\hline 220 & 0,15 & 0,2 & 3,5 & 0,0130 & 0,0130 & 6 & 12,00 & 6,00 & 10,00 & 30 & 360 \\
\hline 221 & 0,15 & 0,2 & 3,5 & 0,0130 & 0,0130 & 6 & 12,00 & 6,00 & 10,00 & 30 & 539 \\
\hline 222 & 0,15 & 0,2 & 3,5 & 0,0130 & 0,0130 & 6 & 12,00 & 6,00 & 10,00 & 30 & 719 \\
\hline 223 & 0,15 & 0,2 & 9,0 & 0,0130 & 0,0130 & 6 & 12,00 & 6,00 & 10,00 & 30 & 180 \\
\hline 224 & 0,15 & 0,2 & 9,0 & 0,0230 & 0,0230 & 6 & 12,00 & 6,00 & 10,00 & 30 & 180 \\
\hline 225 & 0,15 & 0,2 & 9,0 & 0,0130 & 0,0130 & 6 & 12,00 & 6,00 & 10,00 & 90 & 1386 \\
\hline 226 & 0,15 & 0,2 & 9,0 & 0,0230 & 0,0230 & 6 & 12,00 & 6,00 & 10,00 & 90 & 1386 \\
\hline 227 & 0,15 & 0,2 & 3,5 & 0,0230 & 0,0230 & 6 & 12,00 & 6,00 & 10,00 & 30 & 180 \\
\hline 228 & 0,15 & 0,2 & 3,5 & 0,0130 & 0,0130 & 6 & 12,00 & 6,00 & 10,00 & 90 & 1386 \\
\hline 229 & 0,15 & 0,2 & 3,5 & 0,0230 & 0,0230 & 6 & 12,00 & 6,00 & 10,00 & 90 & 1386 \\
\hline 230 & 0,15 & 0,2 & 5,0 & 0,0130 & 0,0130 & 6 & 12,00 & 6,00 & 10,00 & 30 & 360 \\
\hline 231 & 0,15 & 0,2 & 5,0 & 0,0230 & 0,0230 & 6 & 12,00 & 6,00 & 10,00 & 30 & 360 \\
\hline 232 & 0,15 & 0,2 & 5,0 & 0,0130 & 0,0130 & 6 & 12,00 & 6,00 & 10,00 & 60 & 646 \\
\hline 233 & 0,15 & 0,2 & 5,0 & 0,0230 & 0,0230 & 6 & 12,00 & 6,00 & 10,00 & 60 & 646 \\
\hline 234 & 0,15 & 0,2 & 5,0 & 0,0130 & 0,0130 & 6 & 12,00 & 6,00 & 10,00 & 90 & 924 \\
\hline 235 & 0,15 & 0,2 & 5,0 & 0,0230 & 0,0230 & 6 & 12,00 & 6,00 & 10,00 & 90 & 924 \\
\hline 236 & 0,15 & 0,2 & 3,5 & 0,0130 & 0,0130 & 6 & 12,00 & 6,00 & 10,00 & 90 & 1534 \\
\hline 237 & 0,15 & 0,2 & 3,5 & 0,0230 & 0,0230 & 6 & 12,00 & 6,00 & 10,00 & 90 & 1534 \\
\hline 238 & 0,15 & 0,2 & 5,0 & 0,0130 & 0,0130 & 6 & 12,00 & 6,00 & 10,00 & 60 & 691 \\
\hline 239 & 0,15 & 0,2 & 5,0 & 0,0180 & 0,0180 & 6 & 12,00 & 6,00 & 10,00 & 60 & 691 \\
\hline 240 & 0,15 & 0,2 & 5,0 & 0,0230 & 0,0230 & 6 & 12,00 & 6,00 & 10,00 & 60 & 691 \\
\hline 241 & 0,15 & 0,2 & 7,5 & 0,0130 & 0,0130 & 6 & 12,00 & 6,00 & 10,00 & 30 & 360 \\
\hline 242 & 0,15 & 0,2 & 7,5 & 0,0230 & 0,0230 & 6 & 12,00 & 6,00 & 10,00 & 30 & 360 \\
\hline 243 & 0,15 & 0,2 & 7,5 & 0,0130 & 0,0130 & 6 & 12,00 & 6,00 & 10,00 & 90 & 924 \\
\hline 244 & 0,15 & 0,2 & 7,5 & 0,0230 & 0,0230 & 6 & 12,00 & 6,00 & 10,00 & 90 & 924 \\
\hline 245 & 0,15 & 0,2 & 3,5 & 0,0130 & 0,0130 & 6 & 12,00 & 6,00 & 10,00 & 90 & 1386 \\
\hline 246 & 0,15 & 0,2 & 3,5 & 0,0230 & 0,0230 & 6 & 12,00 & 6,00 & 10,00 & 90 & 1386 \\
\hline 247 & 0,15 & 0,2 & 7,5 & 0,0130 & 0,0130 & 6 & 12,00 & 6,00 & 10,00 & 30 & 360 \\
\hline 248 & 0,15 & 0,2 & 7,5 & 0,0230 & 0,0230 & 6 & 12,00 & 6,00 & 10,00 & 30 & 360 \\
\hline 249 & 0,15 & 0,2 & 7,5 & 0,0130 & 0,0130 & 6 & 12,00 & 6,00 & 10,00 & 90 & 924 \\
\hline 250 & 0,15 & 0,2 & 7,5 & 0,0230 & 0,0230 & 6 & 12,00 & 6,00 & 10,00 & 90 & 924 \\
\hline
\end{tabular}

